\section{OAK RIDGE \\ NATIONAL LABORATORY} ROANE AND ANDERSON COUNTIES, TENNESSEE

\section{HISTORIC ARCHITECTURAL RESOURCE SURVEY} JANUARY 2018

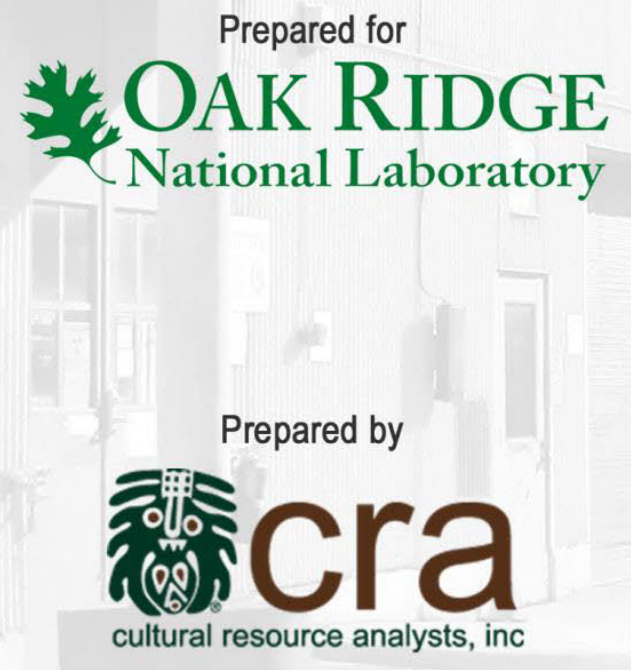

Approved for Public Release. Distribution is unlimited.
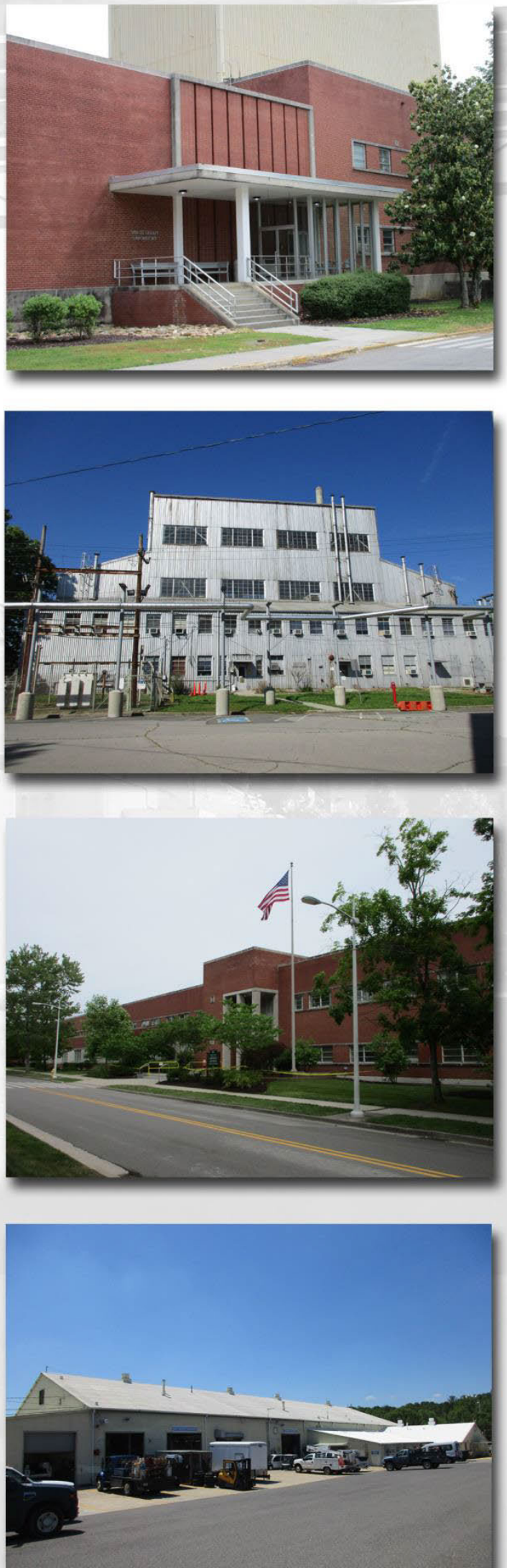
This page intentionally left blank 


\section{HISTORIC ARCHITECTURAL RESOURCE SURVEY OAK RIDGE NATIONAL LABORATORY ROANE AND ANDERSON COUNTIES, TENNESSEE}

by

Hallie Hearnes, MA; Elizabeth Heavrin, MHP; Jennifer Leeds, MHP; and Sarah Reynolds, MHP

Prepared for

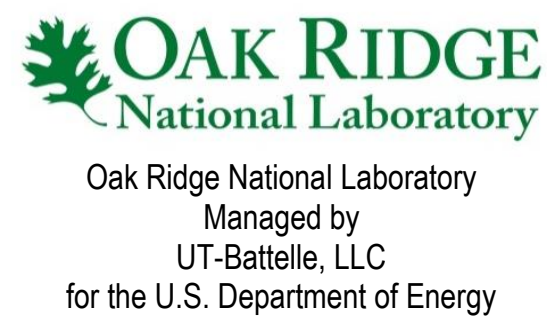

Prepared by

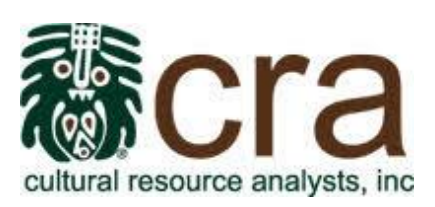

Cultural Resource Analysts, Inc. 119 West Summit Hill Drive, $2^{\text {nd }}$ Floor

Knoxville, TN 37902

Phone: (865) 249-6035

Email: cmniquette@crai-ky.com

CRA Project No.: T17U003

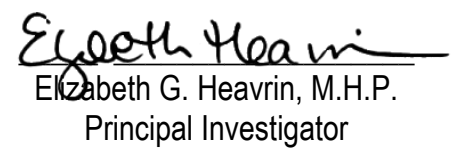

January 2018 
This page intentionally left blank 


\section{ABSTRACT}

From February through September 2017, Cultural Resource Analysts, Inc. personnel completed a historic architectural resource survey of the Oak Ridge National Laboratory in Roane and Anderson Counties, Tennessee. The survey was completed at the request of UT-Battelle, LLC, the private not-for-profit company that manages and operates Oak Ridge National Laboratory for the U.S. Department of Energy. The purpose of the survey was to assist the Department of Energy in complying with the National Historic Preservation Act of 1966, as amended, by providing updated recommendations regarding the National Register of Historic Places eligibility of historic architectural resources at Oak Ridge National Laboratory.

The survey included the entirety of Oak Ridge National Laboratory's main campus that occupies approximately 1,100 acres in Bethel and Melton Valleys and on Chestnut Ridge. Based on Facilities Information Management System data and guidance provided by UT-Battelle, LLC, preservation and modernization staff, the survey team developed a list of resources for inclusion in the survey. The list included all substantial buildings constructed in or before 1980 in order to provide sufficient coverage of buildings that will turn 50 years of age within the next decade. Only those buildings with recorded area over $100 \mathrm{sq} f \mathrm{ft}$ were included in the survey. Additionally, the UT-Battelle team identified 15 buildings for more intensive survey because such buildings are central to Oak Ridge National Laboratory's future mission needs and are expected to undergo renovations in the foreseeable future. These building were subject to both exterior and interior documentation with particular focus on identifying character-defining features, and thus were subject to more detailed analysis than the other resources included in the survey.

The findings of this historic resource survey build on the conclusions of the 1994 survey by DuVall \& Associates, Inc., as well as the survey updates completed by Thomason and Associates in 2004 and 2015 in support of the Oak Ridge National Laboratory Historic Preservation Plan. Within 12 distinct areas of Oak Ridge National Laboratory, as well as outlying areas, the survey recorded 195 buildings and structures constructed in or before 1980. In consideration of the role and significance of each area and each individual resource within the context of Oak Ridge National Laboratory, and in light of their current integrity and condition, each recorded resource was evaluated to determine if it is eligible for listing in the National Register of Historic Places.

Cultural Resource Analysts, Inc., recommends that the Graphite Reactor, Building 3001, retains integrity for continued designation as a National Historic Landmark, and the New Bethel Baptist Church, Building 0903, and Freels Cabin and its associated outbuilding, Buildings XG1401 and XG1414, retain integrity for continued listing in the National Register of Historic Places under the Historic and Architectural Resources in Oak Ridge Multiple Property Listing.

Cultural Resource Analysts, Inc., finds that the previously-recommended Oak Ridge National Laboratory Historic District, including portions of the 3000,4000 , and 5000 Areas, remains eligible for listing in the National Register as the original hub of the Manhattan Project's X-10 facility and its subsequent development as the central core of the Oak Ridge National Laboratory, a government-owned, contractor-operated, leading scientific research facility that made significant contributions in advancing both defensive and peacetime applications of nuclear science, as well as other fields of scientific inquiry, during the Cold War era. The boundaries of the proposed Oak Ridge National Laboratory Historic District have not been modified since the initial determination 
of eligibility in 1994; however, Cultural Resource Analysts, Inc. recommends that a slightly-modified boundary is needed to account for demolitions completed following consultation with the State Historic Preservation Office and current conditions recorded as a part of this survey. The recommended boundary would add five additional contributing resources (Buildings 3525, 3517, 3542, 4500S, and 4508) and would no longer include four resources (Buildings 2003, 2624, 3000, and 3518) previously determined as contributing to the district. These modifications will create a clear, concise boundary without projections or protrusions around individual resources, more appropriately capturing the concentration of significant resources within the current landscape of Oak Ridge National Laboratory. Cultural Resource Analysts, Inc., further recommends that the Low Intensity Reactor Facility, Building 3005, and Central Research \& Administration North, Building 4500N, which are located within the original and recommended boundaries of the Oak Ridge National Laboratory Historic District, also rise to the level of significance needed for individual listing.

In addition, Cultural Resource Analysts, Inc., concurs with previous determinations that the Garage and Iron Working Shop, Building 7002; and White Oak Creek Dam and Lake, Buildings 7813 and 7846 are individually eligible for listing in the National Register of Historic Places. Cultural Resource Analysts, Inc. also recommends that the Airway Beacon Lighthouse, Building 0969; the Molten Salt Reactor Experiment facility, including Building 7503 and associated Buildings 7507, 7509, 7516, and 7555; and the High Flux Isotope Reactor/Radiochemical Engineering Development Center facility, including Building 7900 and associated Buildings 7901, 7911, 7920, and 7930, are individually eligible for listing in the National Register of Historic Places.

Finally, the Tower Shielding Facility, including Buildings 7700, 7701, 7702, 7703, and 7704; the Health Physics Research Reactor, Building 7709; and the Dosimetry Applications Research Facility, Building 7710, were previously recommended eligible for listing in the National Register; however, the facilities were inaccessible at the time of the current survey, thus until reevaluated these structures should continue to be treated as eligible resources. 


\section{CONTENTS}

I. INTRODUCTION

Previous Studies 1

$\begin{array}{ll}\text { Methodology } & 7\end{array}$

Summary of Results 9

II. HISTORIC CONTEXT 11

Overview 11

The Emergence of Atomic Energy 11

The Manhattan Project $\quad 13$

The Oak Ridge Reservation (Clinton Engineer Works) 15

X-10 (Clinton Laboratories) $\quad 17$

The Manhattan Project and End of World War II 23

National Laboratory Development 25

The Cold War Era 27

Diversified Research in the 1960s 33

Expanded Mission in the 1970s 35

Post-Cold War Missions 36

$\begin{array}{ll}\text { III. RESULTS } & 39\end{array}$

$\begin{array}{lr}\text { Outlying Areas } & 49\end{array}$

1500 Area $\quad 75$

2000 Area $\quad 89$

3000 Area $\quad 123$

4000 Area $\quad 267$

5000 Area 331

6000 Area $\quad 355$

7000 Area $\quad 377$

7500 Area 433

7600 Area $\quad 453$

7700 Area $\quad 479$

7800 Area $\quad 499$

7900 Area $\quad 509$

Oak Ridge Historic District 565

IV. RECOMMENDATIONS AND CONCLUSIONS

$\begin{array}{ll}\text { REFERENCES } & 585\end{array}$

APPENDIX A

APPENDIX B 
This page intentionally left blank 


\section{FIGURES}

Figure 1. ORNL and other DOE facilities depicted on a topographic map 3

Figure 2. Aerial photograph depicting the NRHP-listed resources at ORNL 5

Figure 3. Construction of the X-10 site, including the Graphite Reactor, in October 1943

Figure 4. Construction of the concrete hot cells of the chemical separations building (Building 20 3019) in November 1943

Figure 5. Remote controls for the plutonium process in the adjacent hot cells in 1944

Figure 6. The concrete shield of the Graphite Reactor contains hundreds of tubes through 21 which the uranium slugs were inserted

Figure 7. Clinton Laboratories after the war 23

Figure 8. The Isotope "Alley" at ORNL 28

Figure 9. ORNL in the early 1950s 29

Figure 10. ORNL scientists Ernest Wolland and Clifford Shull conducted some of the world's first 30 neutron scattering experiments using this diffractometer built at ORNL and installed at the Graphite Reactor in 1950

Figure 11. The TSF was completed in 1954

Figure 12. ORNL's ORACLE was the largest and fastest computer in the world in the mid 1950s 32

Figure 13. Aerial photograph depicting the locations of NRHP-listed and eligible historic 41 resources

Figure 14. Site plan depicting the limits of each area of ORNL within the main campus 43

Figure 15. Overview of south and east elevations of Building 0903

Figure 16. Overview of north and west elevations of Building 0907

Figure 17. Overview of west elevation of the tower (Building 0970) associated with Building $0907 \quad 54$

Figure 18. Overview of north and west elevations of Building 0969

Figure 19. Overview of west and south elevations of Building 0969

Figure 20. Overview of north and east elevations of Building XF1301 complex 57

Figure 21. Overview of north and east elevations of Building XF1301 complex 58

Figure 22. Overview of north and west elevations of Building XF1302 59

Figure 23. A detail of the steel frame supporting Building XF1302 60

Figure 24. Overview of all of the buildings associated with Building XF1303 61

Figure 25. Overview of west and north elevations of one of the buildings associated with 62 Building XF1303

Figure 26. Overview of west elevation of the silo and open shed associated with 62 Building XF1303

Figure 27. Overview of north and east elevations of Building XG1401, the Freels Bend 63 Log Cabin

Figure 28. Overview of west and south elevations of Building XG1401, the Freels Bend 64 Log Cabin

Figure 29. Overview of west and south elevations of Building XG1402 
Figure 31. Overview of Building XG1404

Figure 32. Overview of façade of Building XG1404 68

Figure 33. Overview of the interior of Building XG1410 69

Figure 34. Overview of the interior of Building XG1410 70

Figure 35. Overview of north and west elevations of Building XG1414 71

Figure 36. Overview of west and south elevations of Building XG1414 72

Figure 37. Overview of Building XG1416 73

Figure 38. Plan View of 1500 Area $\quad 75$

Figure 39. Overview of 1500 Area, looking along White Oak Avenue 77

Figure 40. Overview of north elevation and partial east elevation of Building $1503 \quad 79$

Figure 41. Overview of west elevation and partial north elevation of Building 1503

Figure 42. View of culvert bridge (Building 1503-CV1) looking towards Building 1520

Figure 43. View of the pipe culverts comprising Building 1503-CV1 82

Figure 44. Overview of north and east elevations of Building 1504

Figure 45. Overview of south elevation and partial west elevation of Building 1504

Figure 46. Overview of south elevation and partial east elevation of Building 1505

Figure 47. Overview of west elevation and partial north elevation of Building 1505

Figure 48. Overview of east elevation and partial south elevation of Building 1506

Figure 49. Overview of north elevation and partial east elevation of Building 1506

Figure 50. Plan View of 2000 Area $\quad 89$

Figure 51. View of 2000 Area looking west towards First Street 91

Figure 52. View of 2000 Area facing in a southern direction towards Central Avenue 92

Figure 53. Overview of south and east elevations of Building 2003

Figure 54. Overview of west elevation and partial north elevation of Building 2007, showing 94 concrete tower addition

Figure 55. Overview of west elevation and partial south elevation of Building $2007 \quad 95$

Figure 56. Overview of north and east elevations of Building $2008 \quad 96$

Figure 57. Overview of north and south elevations of Building $2008 \quad 97$

Figure 58. View of a small section of the west elevation of Building 2026

Figure 59. View of a small section of the west elevation of Building 2026, showing an exterior 99 stairwell

Figure 60. Overview of north and east elevations of Building 2500, showing brick masonry wing 100

Figure 61. Overview of north and west elevations of Building 2500, showing large open bays for 101 the fire trucks

Figure 62. Overview of north and west elevations of Building 2518, showing decorative features 102 above openings

Figure 63. Overview of east and south elevations of Building $2518 \quad 103$

Figure 64. Overview of north elevation of Building 2519, showing the multiple modern additions 104 attached to the original building

Figure 65. Overview of north and east elevations of Building 2519

Figure 66. Overview of east elevation and partial south elevation of Building 2523

Figure 67. Overview of north and west elevations of Building 2523 
Figure 68. Overview of north elevation and partial east elevation of Building 2525

Figure 69. Overview of west elevation and partial south elevation of Building $2525 \quad 109$

Figure 70. Overview of north and west elevations of Building 2528

Figure 71. Overview of south elevation and partial west elevation of Building 2528

Figure 72. Overview of west elevation and partial south elevation of Building 2531

Figure 73. Overview of north elevation and partial east elevation of Building 2531

Figure 74. Overview of north and west elevations of Building 2532

Figure 75. Overview of east and south elevations of Building $2532 \quad 115$

Figure 76. Overview of west elevation of Building 2536 seen through the adjacent open shed 116

Figure 77. Overview of north and east elevations of Building $2536 \quad 117$

Figure 78. Overview of west elevation and partial north elevation of Building 2621

Figure 79. Overview of south and east elevations of Building 2621

Figure 80. Overview of Solid Waste Storage Area Burial Ground (Building 2624) looking from 120

Third Avenue towards the south direction

Figure 81. Overview of the south and east elevations of Building 2628

Figure 82. Overview of west and south elevations of Building 2628

Figure 83. Plan View of 3000 Area 123

Figure 84. View of the 3000 Area looking in the western direction from Fifth Street towards 125 Buildings 3010, 3042, and 3104

Figure 85. View of the 3000 Area looking in an eastern direction towards buildings located in the 126 Isotope Circle.

Figure 86. Overview of south and west elevations of Building 3000

Figure 87. Overview of west and north elevations of Building $3000 \quad 128$

Figure 88. Overview of west and north elevations of Building 3001

Figure 89. Overview of south and west elevations of Building 3001

Figure 90. Overview of north elevation and partial west elevation of Building 3002

Figure 91. Overview of partial west elevation of Building 3003, with Building 3002 in foreground 132

Figure 92. Overview of south and west elevations of Building 3005

Figure 93. Overview of east and north elevations of Building 3005

Figure 94. Overview of west elevation of Building $3009 \quad 137$

Figure 95. Overview of south elevation of Building $3010 \quad 138$

Figure 96. Overview of south and west elevations of Building 3010

Figure 97. Overview of north and west elevations of Building 3010A, which is attached to the 140 north elevation of Building 3010

Figure 98. Overview of west elevation and partial south elevation of Building $3017 \quad 142$

Figure 99. Overview of north elevation and partial east elevation of Building 3017

Figure 100. Window detail on the south elevation of Building 3025E 150

Figure 101. Enclosed walkway on south elevation of Building 3025E and Building 3025M 152

Figure 102. Hot cells on the second floor of Building 3025E and robotic arms used to operate 152 within them

Figure 103. Replacement exterior and interior doors on the second floor of Building 3025E 153

Figure 104. Interlocking dividing walls and original doors on second floor of Building 3025E 153 
Figure 105. Renovated office on the second floor of Building 3025E 154

Figure 106. Storage room on the second floor of Building 3025E 154

Figure 107. Original interior steel door and floor on the first floor of Building 3025E 155

Figure 108. Cabinetry and equipment in a lab on the first floor of Building 3025E 155

Figure 109. An empty lab space on the first floor of Building 3025E 156

Figure 110. Window located on the south elevation of Building 3025M

Figure 111. Overview of west and south elevations of Building 3027

Figure 112. Overview of north and west elevations of Building 3027

Figure 113. Overview of south elevation of Building 3028

Figure 114. Overview of south elevation and partial west elevation of Building 3028

Figure 115. Overview of west elevation and partial south elevation of Building 3029

Figure 116. Overview of north and west elevations of Building 3029

Figure 117. Overview of south elevation of Building 3030

Figure 118. Overview of north and west elevations of Building $3030 \quad 167$

Figure 119. Overview of south elevation of Building $3031 \quad 168$

Figure 120. Overview of west and south elevations of Building 3031

Figure 121. Overview of east and south elevations of Building 3032

Figure 122. Overview of west and south elevations of Building 3032

Figure 123. Overview of south elevation of Building $3033 \quad 172$

Figure 124. Overview of west and south elevations of Building $3033 \quad 173$

Figure 125. Overview of south elevation of Building 3033A 174

Figure 126. Overview of north elevation of Building 3033A 175

Figure 127. Overview of south elevation of Building 3034

Figure 128. Overview of north and west elevations of Building 3034

$\begin{array}{ll}\text { Figure 129. Overview of west and south elevations of Building } 3036 & 178\end{array}$

Figure 130. Overview of north and west elevations of Building $3036 \quad 179$

Figure 131. East and north elevations of Building $3037 \quad 180$

Figure 132. West and south elevations of Building $3037 \quad 182$

Figure 133. Detail of windows on second story of Building 3037

Figure 134. Door and window detail on north elevation of Building 3037

Figure 135. Hallway on first floor of Building $3037 \quad 184$

Figure 136. Renovated break room on first floor of Building $3037 \quad 184$

Figure 137. Original door on Women's Change Room on first floor of Building 3037

Figure 138. Men's Change Room on first floor of Building 3037

Figure 139. Showers in Men's Change Room on first floor of Building 3037

Figure 140. Stairwell and rail to second floor of Building 3037

Figure 141. Hallway on second floor of Building $3037 \quad 187$

Figure 142. Classroom/Briefing Room on second floor of Building 3037

Figure 143. Renovated office on second floor of Building $3037 \quad 188$

Figure 144. Office on second floor of Building $3037 \quad 188$

Figure 145. Overview of east and south elevations of Building $3038 \quad 189$

Figure 146. Overview of north and west elevations of Building 3038 
Figure 147. Overview of east elevation of Building 3039

Figure 148. Overview of east elevation of Building 3039

Figure 149. Overview of west and south elevations of Building 3042

Figure 150. Overview of west elevation and partial north elevation of Building 3042

Figure 151. Overview of east elevation of Building $3047 \quad 196$

Figure 152. Overview of partial north elevation of Building $3047 \quad 197$

Figure 153. Overview of partial south elevation of Building 3047

Figure 154. Overview of north and west elevations of Building 3080

Figure 155. Overview of south elevation and partial west elevation of Building 3080

Figure 156. Overview of north and east elevations of Building 3092

Figure 157. Overview of east and south elevations of Building 3092

Figure 158. Overview of south elevation of Building 3093

Figure 159. Overview of east and south elevations of Building 3104

Figure 160. Overview of north elevation and partial west elevation of Building 3104

Figure 161. Overview of west and south elevations of Building 3107

Figure 162. Overview of west and north elevations of Building 3107

Figure 163. Overview of west and north elevations of Building 3114

Figure 164. Overview of east elevation and partial north elevation of Building 3114

Figure 165. Overview of south elevation of Building 3118

Figure 166. Overview of north and east elevations of Building 3127

Figure 167. Overview of north and west elevations of Building 3127

Figure 168. Overview of south and east elevations of Building 3129

Figure 169. Overview of west and south elevations of Building 3129

Figure 170. Overview of the façade of both sections of Building $3500 \quad 219$

Figure 171. Overview of the façade of the 1-story section of Building 3500

Figure 172. Façade entry with replacement doors on the 1-story section of Building $3500 \quad 222$

Figure 173. Detail of windows on north (façade) elevation of the 1-story section of Building 3500223

Figure 174. East elevation of the 1-story section of Building 3500

Figure 175. South (rear) elevation of the 1-story section of Building 3500

Figure 176. Window detail on south (rear) elevation of the 1-story section of Building $3500 \quad 224$

Figure 177. Lobby projection of the 2-story section of Building 3500

Figure 178. West elevation of the 2-story section of Building 3500

Figure 179. South (rear) elevation of the high bay on the 2-story section of Building $3500 \quad 226$

Figure 180. South elevation of the high bay on the 2-story section of Building 3500

Figure 181. Interlocking metal dividers in 1-story section of Building 3500

Figure 182. Renovated shop/laboratory space in 1-story section of Building 3500

Figure 183. Hallway with fire door connecting original and addition sections of Building $3500 \quad 228$

Figure 184. Renovated lab space on second floor of Building $3500 \quad 228$

Figure 185. Original door in hallway of 2-story section of Building 3500

Figure 186. Freight elevator in 2-story section of Building $3500 \quad 229$

Figure 187. A two-story space for storage within Building 3500

Figure 188. Second floor of lobby of Building 3500 
Figure 189. First floor of lobby of Building 3500

Figure 190. Overview of north and east elevations of Building 3501

Figure 191. Overview of west and south elevations of Building 3501

Figure 192. Overview of west elevation and partial south elevation of Building 3502

Figure 193. Overview of partial south elevation of Building 3502, showing Building 3502 attached 235 to this elevation

Figure 194. Overview of north and east elevations of Building 3502

Figure 195. Overview of west and south elevations of Building 3515

Figure 196. Overview of north and east elevations of Building 3515

Figure 197. Overview of west and south elevations of Building $3517 \quad 244$

Figure 198. Overview of east and south elevations of Building $3517 \quad 245$

Figure 199. Overview of south and west elevations of Building 3518

Figure 200. Overview of north and west elevations of Building 3518

Figure 201. Overview of south and west elevations of Building 3523

Figure 202. Overview of east and south elevations of Building 3523

Figure 203. Detail of manufacturing plate found on the corrugated metal siding of Building $3523 \quad 249$

Figure 204. Overview of north elevation of Building 3525

Figure 205. Overview of east and north elevations of Building 3525

Figure 206. Overview of south and west elevations of Building 3525

Figure 207. Overview of east and south elevations of Building 3542

Figure 208. Overview of north and west elevations of Building 3542

Figure 209. Overview of north and west elevations of Building 3544

Figure 210. Overview of south and west elevations of Building 3544

Figure 211. Overview of Building 3544-VB1, a vehicular bridge, looking south along Third Street 258

Figure 212. View of vehicular bridge (Building 3544-VB1) and its structure supporting the 259 roadway

Figure 213. Overview of east and south elevations of Building 3587

Figure 214. Overview of south and west elevations of Building 3587

Figure 215. Overview of east and south elevations of Building 3594

Figure 216. Overview of north and west elevations of Building 3594

Figure 217. Overview of south and east elevations of Building 3618

Figure 218. Overview of north and west elevations of Building 3618

Figure 219. Plan View of 4000 Area 267

Figure 220. View of the 4000 Area looking in the western direction along White Oak Avenue 269 towards Buildings 4500N (right) and 4500S (left)

Figure 221. View of the 4000 Area looking in the eastern direction along Central Avenue towards 270 Buildings $4500 \mathrm{~N}$ (right) and 4100 (left)

Figure 222. North (façade) elevation of Building 4500N 271

Figure 223. Windows on north (façade) elevation of Building 4500N 275

Figure 224. "Flag Lobby" entrance on north elevation of Building 4500N 276

Figure 225. Secondary entry on north elevation of Building 4500N 276

Figure 226. West elevation of Building 4500N 277 
Figure 227. Loading dock at southwest corner of 4500N, at the "Canyon" between Buildings $4500 \mathrm{~N}$ and $4500 \mathrm{~S}$

Figure 228. Entry at southern end of Corridor "B" of Building 4500N 278

Figure 229. One of four courtyards of Building 4500N 278

Figure 230. West elevation of Wing Three of Building 4500N 279

Figure 231. Southern elevation of Wing Three of Building 4500N 279

Figure 232. West elevation of Wing Five of Building 4500N 280

Figure 233. Primary entry on the east elevation of Building 4500N 280

Figure 234. Interior of Wigner Auditorium on the second floor of Building 4500N 281

Figure 235. Original laboratory space in Wing 1 of Building 4500N 281

Figure 236. Metal acoustic tiles in a laboratory in Building 4500N 282

Figure 237. Interlocking metal wall and original door in laboratory wing of Building 4500N 282

Figure 238. Terrazzo floor and glazed block walls in restroom in Building 4500N 283

Figure 239. ORNL's Glass Shop is located in Building 4500N 283

Figure 240. Work Station within the Glass Shop in Building 4500N 284

Figure 241. Concrete bridges over the "Canyon" between Buildings 4500N and 4500S 285

Figure 242. South elevation of Building 4500S 288

Figure 243. South elevation of Building 4500S 288

Figure 244. East elevation of Building 4500S 289

Figure 245. West elevation of Building 4500S 289

Figure 246. Courtyard between Wing Three and Wing Four of Building 4500S 290

Figure 247. North and west elevations of Building 4500S 290

Figure 248. Window detail on west elevation of Building 4500S 291

Figure 249. Corridor $E$ on the second floor of Building 4500S 291

Figure 250. Original door to an office on the first floor of Building 4500S 292

Figure 251. The CREEP lab is located on the ground floor of Building 4500S 292

Figure 252. Laboratory space on the second floor of Building 4500S 293

Figure 253. Renovated office space on the first floor of Building 4500S 293

Figure 254. Tiled restroom in Building 4500S 294

Figure 255. Renovated office space on the ground floor of Building 4500S 294

Figure 256. Original staircase in Building 4500S 295

Figure 257. West elevation of Building 4501

Figure 258. Original doors to high bay entry on west elevation of Building 4501

Figure 259. Secondary entry on the north elevation of Building 4501

Figure 260. Bank of original windows on north elevation of Building 4501

Figure 261. North elevation of Building 4501

Figure 262. Primary entry on east elevation of Building 4501

Figure 263. Corridor on first floor of Building 4501.

Figure 264. Metal ceiling tile in corridor on first floor of Building 4501

Figure 265. Interlocking metal panel dividing walls on first floor of Building 4501

Figure 266. Original doors to a laboratory space on the second floor of Building 4501

Figure 267. Operational hot cell in laboratory on first floor of Building 4501 
Figure 268. Interior of laboratory space on the second floor of Building 4501

Figure 269. Corridor on second floor of Building 4501

Figure 270. Restroom entry on first floor of Building 4501

Figure 271. Stairwell of Building 4501 with glazed tile walls and original hand rails. 305

Figure 272. West and south elevation of Building 4505

Figure 273. South elevation of Building 4505

Figure 274. High bay entries on south elevation of Building 4505

Figure 275. Windows on the south elevation of Building 4505

Figure 276. East elevation of Building 4505

Figure 277. First floor corridor in Building 4505

Figure 278. Original door to Bioengineering Research Laboratory on second floor of Building 310 4505

Figure 279. Stairwell in Building 4505

Figure 280. Renovated conference room in Building 4505

Figure 281. Restroom in Building 4505

Figure 282. Renovated Bioengineering Research Laboratory on second floor of Building $4505 \quad 312$

Figure 283. High bay area on third floor of Building 4505. 313

Figure 284. Overview of west and south elevations of Building 4507

Figure 285. Overview of west and south elevations of Building 4507

Figure 286. South elevation of Building $4508 \quad 316$

Figure 287. Primary entry on south elevation of Building 4508

Figure 288. Secondary entry on south elevation of Building 4508

Figure 289. East elevation of Building 4508 and the corridor connecting it to Building $4500 S \quad 318$

Figure 290. Loading dock and entries of the east elevation of Building 4508

Figure 291. North elevation of Building 4508

Figure 292. West elevation of Building 4508

Figure 293. Original door on the second floor of Building 4508

Figure 294. Original doors on the second floor of Building 4508

Figure 295. Original doors to the Materials Irradiation Engineering Lab on the second floor of 322

Building 4508

Figure 296. Renovated office space on the second floor of Building 4508

Figure 297. Original casework in a laboratory on the second floor of Building 4508

Figure 298. Recently replaced casework in laboratory space on the second floor of Building 4508323

Figure 299. Corridor on the first floor of Building $4508 \quad 324$

Figure 300. High bay area of Building 4508

Figure 301. Corridor and freight elevator on second floor of Building 4508

Figure 302. Stairwell in Building 4508

Figure 303. Interior corridor on second floor of Building 4508

Figure 304. Original built-in casework on the second floor of Building 4508

Figure 305. Men's restroom on second floor of Building 4508

Figure 306. Women's restroom on second floor of Building 4508 
Figure 307. Overview of Building 4509-VB1, a vehicular bridge, looking from Southside Avenue to the south

Figure 308. Looking east, a view of the west elevation of vehicular bridge, Building 4509-VB1

Figure 309. Plan View of 5000 Area

Figure 310. View of the 5000 Area looking towards Building 5500 from the road leading to Building 5507

Figure 311. View of the 5000 Area looking towards Buildings 5505 and $5510 \mathrm{~A}$ from near the entrance of 5505-VB1

Figure 312. Façade (north) elevation of Building 5500

333

Figure 313. Façade entry on north elevation of Building 5500

Figure 314. Window detail on north, façade, elevation of Building 5500

Figure 315. Façade (north) and west elevations of Building 5500

Figure 316. West elevation of Building 5500

Figure 317. West and south elevations of Buildings 5500 and 5500A

Figure 318. Window detail on south elevation of Building $5500 \mathrm{~A}$

Figure 319. South and east elevations of Buildings 5500 and $5500 \mathrm{~A}$

Figure 320. South elevation of c.1962 east end of Building 5500

Figure 321. Loading dock on south elevation of Building 5500

Figure 322. Original interlocking metal panels on the first floor corridor of the c. 1952 section of Building 5500

Figure 323. Original interior doors to c. 1976 section of Building 5500

Figure 325. Interior of high bay area in c. 1976 section of Building 5500

Figure 326. Corridor on first floor of c. 1962 section of Building 5500

Figure 327. Corridor on second floor of c. 1962 section of Building 5500

Figure 328. Original interior door to laboratory on second floor of c. 1952 section of Building 5500

Figure 329. Restroom on second floor of the c. 1952 section of Building 5500

Figure 330. High bay area on third floor of the c. 1952 section of Building 5500

Figure 331. Original interior door in basement of the c. 1962 section of Building 5500

Figure 332. Thick doors to Valve Test Shop in the basement of the c. 1962 section of Building 5500

Figure 333. Overview of north and west elevations of Building 5505

Figure 334. Overview of south elevation of Building 5505

Figure 335. Overview of west elevation of Building 5505

Figure 336. Overview of Building 5505-VB1, a vehicular bridge, looking north towards Southside

\section{Avenue}

Figure 337. Looking in an eastern direction, a view of the west elevation of vehicular bridge, Building 5505-VB1

Figure 338. Overview of north and west elevations of Building 5507 
Figure 341. View of the 6000 Area looking towards Building 6000 from Bethel Valley Road

Figure 342. View of the 6000 Area looking towards Building 6010

Figure 343. North (façade) elevation of Building 6000

Figure 344. Façade entry on north elevation of original section of Building 6000363

Figure 345. Window detail on the north (façade) elevation of the original section of Building 6000363

Figure 346. North (façade) and east wing of Building $6000 \quad 364$

Figure 347. East elevation of the east wing of Building $6000 \quad 364$

Figure 348. West corner of wing at the south corner of Building $6000 \quad 365$

Figure 349. East elevation of the 1979 wings of Building $6000 \quad 365$

Figure 350. South elevation of the east wing of Building $6000 \quad 366$

Figure 351. South (rear) elevation of rear additions of Building $6000 \quad 366$

Figure 352. South (rear) elevation of South Annex and 1994 wing of Building 6000367

Figure 353. West elevation of Building $6000 \quad 367$

Figure 354. South elevation of concrete tower for accelerator of Building 6000368

Figure 355. Second floor corridor in original 1960 block of Building 6000368

Figure 356. Corridor in South Annex of Building $6000 \quad 369$

Figure 357. Renovated lobby in original section of Building 6000

Figure 358. Thick walls in portion of original Building 6000

Figure 359. Shielded door on second floor of Building 6000 at the base of the accelerator in 370 Building 6000

Figure 360. Restroom on second floor of the original section of Building 6000

Figure 361. North elevation of Building 6010

Figure 362. Primary and secondary entries on the east elevation of Building 6010374

Figure 363. East elevation of Building 6010

Figure 364. South elevation of Building 6010

Figure 365. West elevation of the rear additions to Building 6010.

Figure 366. West elevation of the main block of Building 6010

Figure 367. Plan View of 7000 Area 377

Figure 368. View of the 7000 Area looking toward Buildings 7013 and 7120.

Figure 369. View of the 7000 Area looking toward Buildings 7021, 7031, and 7057

Figure 370. Overview of west and south elevations of Building 7000A 381

Figure 371. Overview of west and south elevations of Building 7000A, showing concrete 382 foundation

Figure 372. Overview of north and west elevations of Building 7001

Figure 373. Overview of east and north elevations of Building 7001

Figure 374. Overview of north and west elevations of Building 7002

Figure 375. Overview of south and east elevations of Building 7002

Figure 376. Overview of east and north elevations of Building 7003

Figure 377. Overview of north and west elevations of Building 7003

Figure 378. Overview of west and south elevations of Building 7006

Figure 379. Overview of north and west elevations of Building $7006 \quad 390$

Figure 380. Overview of south and west elevations of Building $7007 \quad 391$ 
Figure 381. Overview of west and north elevations of Building 7007

Figure 382. Overview of east and north elevations of Building 7009

Figure 383. Overview of south and east elevations of Building 7009

Figure 384. Overview of south and east elevations of Building 7012

Figure 385. Overview of north and west elevations of Building 7012

Figure 386. Overview of north and west elevations of Building 7013

Figure 387. Overview of south and east elevations of Building 7013

Figure 388. Overview of west and south elevations of Building 7015

Figure 389. Overview of south and east elevations of Building 7015

Figure 394. Overview of east and north elevations of Building 7022

Figure 395. Overview of west and south elevations of Building 7022

Figure 396. Overview of west and south elevations of Building 7025

Figure 397. Overview of north elevation of Building 7025

Figure 398. Overview of the north and west elevations of Building 7026

Figure 399. Overview of west elevation of Building 7026

Figure 400. Overview of east and north elevations of Building 7031

Figure 401. Overview of north and west elevations of Building 7031

Figure 402. Overview of east and south elevations of Building 7033

Figure 403. Overview of north and west elevations of Building 7033

Figure 404. Overview of west and south elevations of Building 7035A, 7035B, and 7035C 415

Figure 405. Overview of south and east elevations of Buildings 7035A, 7035B, and 7035C 416

Figure 406. Overview of north and west elevations of standalone Building 703

Figure 407. Overview of east and south elevations of Building 7057, the steel exhaust tower 417

Figure 408. Overview of north and west elevations of Building 7057, the steel exhaust tower 418

Figure 409. Overview of west elevation of Building 7058, a Quonset Hut 419

Figure 410. Overview of south and east elevations of Building 7058, a Quonset Hut 420

Figure 411. Overview of south and east elevations of Building 7061

Figure 412. Overview of north and west elevations of Building 7061

Figure 413. Overview of north and west elevations of Building 7062

Figure 414. Overview of south and east elevations of Building 7062

Figure 415. Overview of north and west elevations of Building 7065, a Quonset hut 425

Figure 416. Overview of north and west elevations of Building 7066, a Quonset hut 426

Figure 417. Overview of south and east elevations of Building 7066, a Quonset hut 427

Figure 418. Overview of west and south elevations of Building 7067

Figure 419. Overview of east and north elevations of Building 7067

Figure 420. Overview of north and west elevations of Building 7070

Figure 421. Overview of south and east of Building 7070

Figure 422. Plan View of 7500 Area 433 
Figure 423. View of 7500 Area towards Buildings 7503, 7516, 7555, and 7507 from Melton Valley Drive

Figure 424. View of 7500 Area in a western direction towards Buildings 7500 from Melton Valley 436 Drive

Figure 425. Overview of north elevation of Building 7500

Figure 426. Overview of north and east elevations of Building $7500 \quad 438$

Figure 427. Overview of east and south elevations of Building $7503 \quad 439$

Figure 428. Overview of north and west elevations of Building $7503 \quad 440$

Figure 429. ORNL site plan depicting the recommended NRHP boundary of the ARE/MSRE 441 Facility

Figure 430. Aerial photographs depicting the recommended NRHP boundary of the ARE/MSRE Facility

Figure 431. Overview of north and east elevations of Building 7506

Figure 432. Overview of north and west elevations of Building 7506

Figure 433. Overview of east and south elevations of Building 7509

Figure 434. Overview of east elevation of Building 7509

Figure 435. Overview of north and east elevations of Building 7516

Figure 436. Overview of north and west elevations of Building 7516

Figure 437. Overview of north and west elevations of Building 7555

Figure 438. Overview of north elevation of Building 7555

450

Figure 439. Plan View of 7600 Area

Figure 440. View of the 7600 Area towards Buildings 7600 and 7601 from EGCR Access Road

Figure 441. View of the 7600 Area looking towards Buildings 7600, 7602, and 7603

Figure 442. Overview of west elevation of Building 7600

Figure 443. Overview of east elevation of Building 7600

Figure 444. Overview of west and south elevations of Building 7601

Figure 445. Overview of east elevation and partial south elevation of Building 7601

Figure 446. Overview of east elevation and partial north elevation of Building 7602

Figure 447. Overview of north elevation and partial west elevation of Building 7602

Figure 448. Overview of west elevation of Building 7603

Figure 449. Overview of east elevation of Building 7603

Figure 450. Overview of north and west elevations of Building 7604

Figure 451. Overview of west elevation and partial south elevation of Building 7604

Figure 452. Overview of east elevation of Building 7605

Figure 453. Overview of north and west elevations of Building 7605

Figure 454. Overview of west elevation and partial east elevation of Building $7606 \mathrm{~A}$

Figure 455. Overview of north and east elevations of Building 7606A

Figure 456. Overview of west elevation of Building 7606B, showing the entrance to the building 
Figure 461. Overview of west and south elevations of Building 7610

Figure 462. Overview of west and south elevations of Building 7615

Figure 463. Overview of east and south elevations of Building 7615

Figure 464. Plan View of 7700 Area 479

Figure 465. Plan View of 7800 Area $\quad 499$

Figure 466. Overview of west elevation of Building 7813, which is White Oak Creek Dam 502

Figure 467. Overview of west and south elevations of Building 7813, which is White Oak Creek 504 Dam

Figure 468. Overview of Building 7846, White Oak Lake, looking south 504

Figure 469. Overview of Building 7824

Figure 470. Overview of north and east elevations of Building 7824

Figure 471. Overview of Building 7831

Figure 472. Overview of north and west elevations of Building 7831

Figure 473. Plan View of 7900 Area $\quad 509$

Figure 474. View of the 7900 Area looking towards Buildings 7902, 7903, and 7916

Figure 475. View of the 7900 Area towards Buildings 7900 and 7901

Figure 476. Facade, or west elevation, of Building 7900

Figure 477. Façade entry on west elevation of Building $7900 \quad 516$

Figure 478. Garage bay on west elevation of Building 7900

Figure 479. North elevation of Building $7900 \quad 517$

Figure 480. North and east elevations of Building 7900

Figure 481. East elevation of Building $7900 \quad 518$

Figure 482. Cryogenics Laboratory addition to Building 7900

Figure 483. Buildings 7970 and 7972 and the south elevation of Building $7900 \quad 519$

Figure 484. Pools for reactor on first floor of Building $7900 \quad 519$

Figure 485. Crane above pools for reactor on first floor of Building 7900

Figure 486. Hot cells on the first floor of Building 7900

Figure 487. Corridor in Cryogenics Laboratory addition to Building 7900

Figure 488. Stairwell in Building 7900

Figure 489. Freight elevator in Building 7900

Figure 490. Auxiliary Control Room on second floor of Building 7900

Figure 491. Corridor on second floor of Building 7900

Figure 492. Control room on third floor of Building $7900 \quad 523$

Figure 493. Restroom on second floor of Building 7900

Figure 494. ORNL site plan depicting the recommended NRHP boundary of the HFIR/REDC 525 Facility

Figure 495. Aerial photographs depicting the recommended NRHP boundary of the HFIR/REDC 526 Facility

Figure 496. Overview of Buildings 7901 and 7900

Figure 497. South and east elevations of Building 7901

Figure 498. North and west elevations of Building 7901

Figure 499. West elevation of Building 7901 
Figure 500. Room 1 of Building 7901

Figure 501. Room 1 of Building 7901

Figure 502. Room 2 of Building 7901

Figure 503. Room 3 of Building 7901

Figure 504. Overview of Building 7903

Figure 505. Overview of north and east elevations of Building 7903

Figure 506. Overview of south elevation and partial east elevation of Building $7910 \quad 534$

Figure 507. Overview of southwest elevation and partial north elevation of Building $7910 \quad 535$

Figure 508. Overview of Building 7911, the exhaust stack for 7900 . 536

Figure 509. Overview of south elevation of Building 7914

Figure 510. Overview of north of Building 7914, 7914A, and 7915

Figure 511. Overview of south elevation of Building 7914A 539

Figure 512. Overview of southeast elevation and partial east elevation of Building 7915

Figure 513. Overview of north elevation of Building 7915

Figure 514. Overview of north and west elevations of Building $7916 \quad 542$

Figure 515. Overview of west and south elevations of Building 7916

Figure 516. Façade (west) elevation of Building $7920 \quad 544$

Figure 517. Façade entry of Building 7920

Figure 518. West elevation of Building 7920

Figure 519. North elevation of Building 7920

Figure 520. Loading dock on north elevation of Building 7920

Figure 521. East elevation of Building 7920

Figure 522. East and southeast elevations of Building 7920

Figure 523. Entry on south elevation of Building $7920 \quad 549$

Figure 524. Corridor in one-story section of Building 7920

Figure 525. Original wood door with louvered vent on first floor of Building 7920

Figure 526. Restroom in one-story section of Building 7920

Figure 527. Corridor on first floor of Building 7920

Figure 528. Laboratory space and hot cells on first floor of Building 7920

Figure 529. Stairwell in Building 7920

Figure 530. Freight elevator in Building 7920

Figure 531. Corridor on second floor of Building 7920

Figure 532. Renovated office space on second floor of Building 7920

Figure 533. Laboratory space on second floor of Building 7920

Figure 534. Laboratory space on second floor of Building 7920

Figure 535. East elevation of Building $7930 \quad 556$

Figure 536. Façade entry of Building 7930

Figure 537. North elevation of Building 7930

Figure 538. North elevation of Building $7930 \quad 559$

Figure 539. West elevation of Building 7930

Figure 540. Entry detail on the west elevation of Building $7930 \quad 560$

Figure 541. South elevation of Building 7930 
Figure 542. First floor corridor of Building 7930

Figure 543. Hot cells on first floor of Building 7930

Figure 544. Fuel transfer pool in Building 7930

Figure 545. Stairwell in Building 7930

Figure 546. Freight elevator in Building 7930

Figure 547. High bay area from second floor of Building 7930

Figure 548. Offices on second floor of Building 7930

Figure 549. Renovated laboratory space in the basement of Building 7930

Figure 550. Overview of Isotope Circle within the ORNL Historic District 567

Figure 551. Overview of the 3000 Area within the ORNL Historic District 570

Figure 552. Overview of Fifth Street within the ORNL Historic District 571

Figure 553. Overview of Central Avenue at the northern boundary of the ORNL Historic District 571 within the 4000 Area

Figure 554. Overview of Building 4500N and Central Avenue within the ORNL Historic District 572

Figure 555. ORNL site plan depicting the recommended NRHP boundary of the ORNL Historic 573 District

Figure 556. Aerial photographs depicting the recommended NRHP boundary of the ORNL $\quad 575$ Historic District. 
This page intentionally left blank 


\section{ACRONYMS}

$\begin{array}{ll}\text { ACT } & \text { Agreement to Commercialize Technology } \\ \text { AEC } & \text { Atomic Energy Commission } \\ \text { ANP } & \text { Aircraft Nuclear Propulsion } \\ \text { ANS } & \text { American Nuclear Society } \\ \text { APS } & \text { American Physical Society } \\ \text { ARE } & \text { Aircraft Reactor Experiment } \\ \text { BSR } & \text { Bulk Shielding Reactor } \\ \text { C\&CC } & \text { Carbide and Carbon Chemicals Corporation, later renamed Union Carbide Corporation } \\ \text { CEW } & \text { Clinton Engineer Works } \\ \text { Corps } & \text { U.S. Army Corps of Engineers } \\ \text { Council } & \text { Advisory Council on Historic Preservation } \\ \text { CRA } & \text { Cultural Resource Analysts, Inc. } \\ \text { DOE } & \text { U.S. Department of Energy } \\ \text { DOE-ORO } & \text { DOE Oak Ridge Operations Office } \\ \text { DOE-OSO } & \text { DOE Oak Ridge National Laboratory Site Office } \\ \text { DOI } & \text { Department of the Interior } \\ \text { DOS } & \text { Department of State } \\ \text { DSM } & \text { Laboratory for the Development of Substitute Materials } \\ \text { EGCR } & \text { Experimental Gas-Cooled Reactor } \\ \text { EM } & \text { DOE Office of Environmental Management } \\ \text { ERDA } & \text { Energy Research and Development Administration } \\ \text { FBI } & \text { Federal Bureau of Investigation } \\ \text { FIMS } & \text { Facilities Information Management System } \\ \text { HFIR } & \text { High Flux Isotope Reactor } \\ \text { HHIRF } & \text { Holifield Heavy lon Research Facility } \\ \text { HPP } & \text { Historic Preservation Plan } \\ \text { HPRR } & \text { Health Physics Research Reactor } \\ \text { HPTL } & \text { High Power Target Laboratory } \\ \text { HRIBF } & \text { Holifield Radioactive lon Beam Facility } \\ \text { HUD } & \text { Department of Housing and Urban Development } \\ \text { IMET } & \text { Irradiated Materials Examination and Testing Facility } \\ \text { LITR } & \text { Low Intensity Test Reactor } \\ \text { MED } & \text { Manhattan Engineer District } \\ \text { MMES } & \text { Martin Marietta Energy Systems, later known as Lockheed-Martin } \\ \text { MPL } & \text { Multiple Property Listing } \\ \text { MSRE } & \text { Molten Salt Reactor Experiment } \\ \text { NASA } & \text { National Aeronautics and Space Administration } \\ \text { NE } & \text { DOE Office of Nuclear Energy } \\ \text { NEPA } & \text { National Environmental Policy Act } \\ & \end{array}$




$\begin{array}{ll}\text { NHL } & \text { National Historic Landmark } \\ \text { NHPA } & \text { National Historic Preservation Act of 1966, as amended } \\ \text { NPS } & \text { National Park Service } \\ \text { NRC } & \text { Nuclear Regulatory Commission } \\ \text { NRHP } & \text { National Register of Historic Places } \\ \text { NSF } & \text { National Science Foundation } \\ \text { ORACLE } & \text { Oak Ridge Automatic Computer and Logical Engine } \\ \text { ORAU } & \text { Oak Ridge Associated Universities } \\ \text { ORELA } & \text { Oak Ridge Electron Linear Accelerator } \\ \text { ORIC } & \text { Oak Ridge Isochronous Cyclotron } \\ \text { ORINS } & \text { Oak Ridge Institute of Nuclear Studies } \\ \text { ORNL } & \text { Oak Ridge National Laboratory } \\ \text { ORR } & \text { Oak Ridge Reservation } \\ \text { ORSORT } & \text { Oak Ridge School of Reactor Technology } \\ \text { REDC } & \text { Radiochemical Engineering Development Center } \\ \text { RMS } & \text { Recoil Mass Spectrometer } \\ \text { SANS } & \text { Small-Angle Scattering Research } \\ \text { SC } & \text { DOE Office of Science } \\ \text { SHPO } & \text { State Historic Preservation Office } \\ \text { SNS } & \text { Spallation Neutron Source } \\ \text { THC } & \text { Tennessee Historical Commission } \\ \text { TSF } & \text { Tower Shielding Facility } \\ \text { TVA } & \text { Tennessee Valley Authority } \\ \text { UCOR } & \text { URS|CH2M Oak Ridge LLC } \\ \text { UT-B } & \text { UT-Battelle, LLC } \\ & \end{array}$




\section{INTRODUCTION}

From February through September 2017, Cultural Resource Analysts, Inc. (CRA), personnel completed a historic architectural resource survey of the Oak Ridge National Laboratory (ORNL) in Roane and Anderson Counties, Tennessee. The survey was completed at the request of UT-Battelle, LLC (UT-B), the private not-forprofit company that manages and operates ORNL for the U.S. Department of Energy (DOE). The purpose of the survey was to assist DOE in complying with the National Historic Preservation Act (NHPA) of 1966, as amended, by providing updated recommendations regarding the National Register of Historic Places (NRHP) eligibility of historic architectural resources at ORNL.

ORNL is one of three DOE facilities that compose the 33,316-acre Oak Ridge Reservation (ORR) in Anderson and Roane Counties, Tennessee. The main ORNL campus occupies approximately 1,100 acres in Bethel and Melton Valleys and on Chestnut Ridge (Figure 1). The ORR was first developed in the early 1940s as part of the Manhattan Project, the U.S. government's top secret effort to build the first atomic bomb. The ridges and valleys of East Tennessee provided an ideal location for the construction of the nuclear research and production facilities since the area offered extensive transportation, water, and power resources, and the topography would confine the impacts of an explosion in the event of an accident. The ORR included three production facilities and the Townsite where workers lived. The area known as Y-12 contained the electromagnetic plant, and the area known as K-25 contained the gaseous diffusion plant. The facility that would become ORNL was codenamed X-10. Centered on the Graphite Reactor, now a National Historic Landmark (NHL), X-10's primary function was the production of plutonium. Following World War II, the X-10 site became Oak Ridge National Laboratory, with a new mission focused on the peaceful applications of nuclear science. This mission has evolved over time, and today ORNL is the largest DOE science and energy laboratory pursuing advanced research in a wide variety of disciplines conducting science in 23 of DOE's 24 core capabilities. ORNL's mission is to deliver scientific discoveries and technical breakthroughs that will accelerate the development and deployment of solutions in clean energy and global security.

\section{PREVIOUS STUDIES}

The historic significance of ORNL's Manhattan Project resources has been long recognized. The National Park Service (NPS) designated the Graphite Reactor a NHL in 1966, just over 20 years after it was constructed and 3 years after it ceased to operate. This designation marked the Graphite Reactor as a site of exceptional national significance for producing the world's first gram quantities of plutonium during World War II and later producing important radioisotopes for medical and biological research. The first comprehensive survey of ORNL's historic resources occurred in 1993 when the buildings constructed for the Manhattan Project turned 50 years old. Martin Marietta Energy Systems, Inc., the company that managed ORNL for DOE at that time, hired DuVall \& Associates, Inc., to document and evaluate all buildings at ORNL, regardless of their age (Carver and Slater 1994). The final report, completed in 1994, recommended boundaries for the ORNL Historic District, consisting of 127 buildings, of which 54 were considered contributing. It also established the period of significance for the district as 1943 (the beginning of the Manhattan Project at ORNL) through 1957, a date which, at that time, exceeded the typical 50-year threshold but "reflects the ending of the initial development of ORNL, the closure of the Aircraft Nuclear Propulsion Project, a significant research program at ORNL, and the end of certain 
national trends in scientific research" (Thomason and Associates 2004:11). The survey recommended that the ORNL Historic District possessed exceptional significance, meeting the requirements of NRHP Criteria Consideration $\mathrm{G}$ for properties less than 50 years of age. Eleven buildings located outside of the district boundaries also were recommended eligible, including Building 3001, the Graphite Reactor; Buildings 7001 and 7002 in the East Support Area; Building 7503, the Aircraft Reactor Experiment Building also known as the Molten Salt Reactor Experiment Facility; Buildings 7700-7704 and 7751 comprising the Tower Shielding Facility; and White Oak Lake and Dam. The Tennessee State Historic Preservation Office (SHPO) concurred with these findings.

Two additional buildings at ORNL are listed in the NRHP; both predate use of this land by the federal government (Figure 2). The New Bethel Baptist Church was listed in the NRHP in 1992 as part of the Historic and Architectural Resources in Oak Ridge Multiple Property Listing (MPL) for its role in the social history of Oak Ridge. Freels Cabin also was listed in 1992 as part of the MPL as an example of settlement era architecture in Anderson County.

In 2004, Thomason and Associates Preservation Planners of Nashville, Tennessee prepared the National Historic Preservation Act Historic Preservation Plan (HPP) for UT-B and the Environmental Protection and Waste Services Division, Environmental Protection Services, ORNL. As stated in the Management Summary of the $2004 \mathrm{HPP}$ :

The ORNL Historic Preservation Plan (HPP) defines the preservation strategy for the ORNL and will direct efficient compliance with the NHPA and federal archaeological protection legislation at ORNL as DOE continues mission activities of the site. The HPP is directed at all historic properties at the ORNL installation... The HPP seeks to find a rational approach to balance ORNL obligations for historic and archeological protection while completing site mission activities, including removal of obsolete or contaminated facilities, adaptive reuse of existing facilities whenever feasible, and construction of new facilities in order to meet site mission needs (Thomason and Associates 2004:1).

To these ends, the HPP included a historical overview of ORNL, an inventory of historic properties and archaeological resources at ORNL, a discussion of historic property stewardship and its relationship to ORNL's mission and comprehensive planning efforts, guidance for building management and archaeological site management, recommendations for training staff responsible for historic preservation, requirements for historic property management and procedural review, and an action plan. While the HPP included an inventory of historic resources, it largely relied on the findings of the 1994 survey report, which provided coverage of all historic resources that were 50 years of age in 2004.

Building upon the $2004 \mathrm{HPP}$, in 2005, the DOE Oak Ridge Operations Office (DOE-ORO; the Tennessee State Historic Preservation Office (SHPO); and the Advisory Council on Historic Preservation (Council) entered into a programmatic agreement $(\mathrm{PA})$ concerning the management of historical and cultural properties at ORNL. The PA identified DOE-ORO as the single point of contact between DOE and the SHPO/Council, representing DOE Office of Science, DOE Office of Nuclear Energy (NE), and the DOE Office of Environmental Management (EM). The document outlined requirements agreed to by all parties in order to ensure that DOE ORO satisfies 


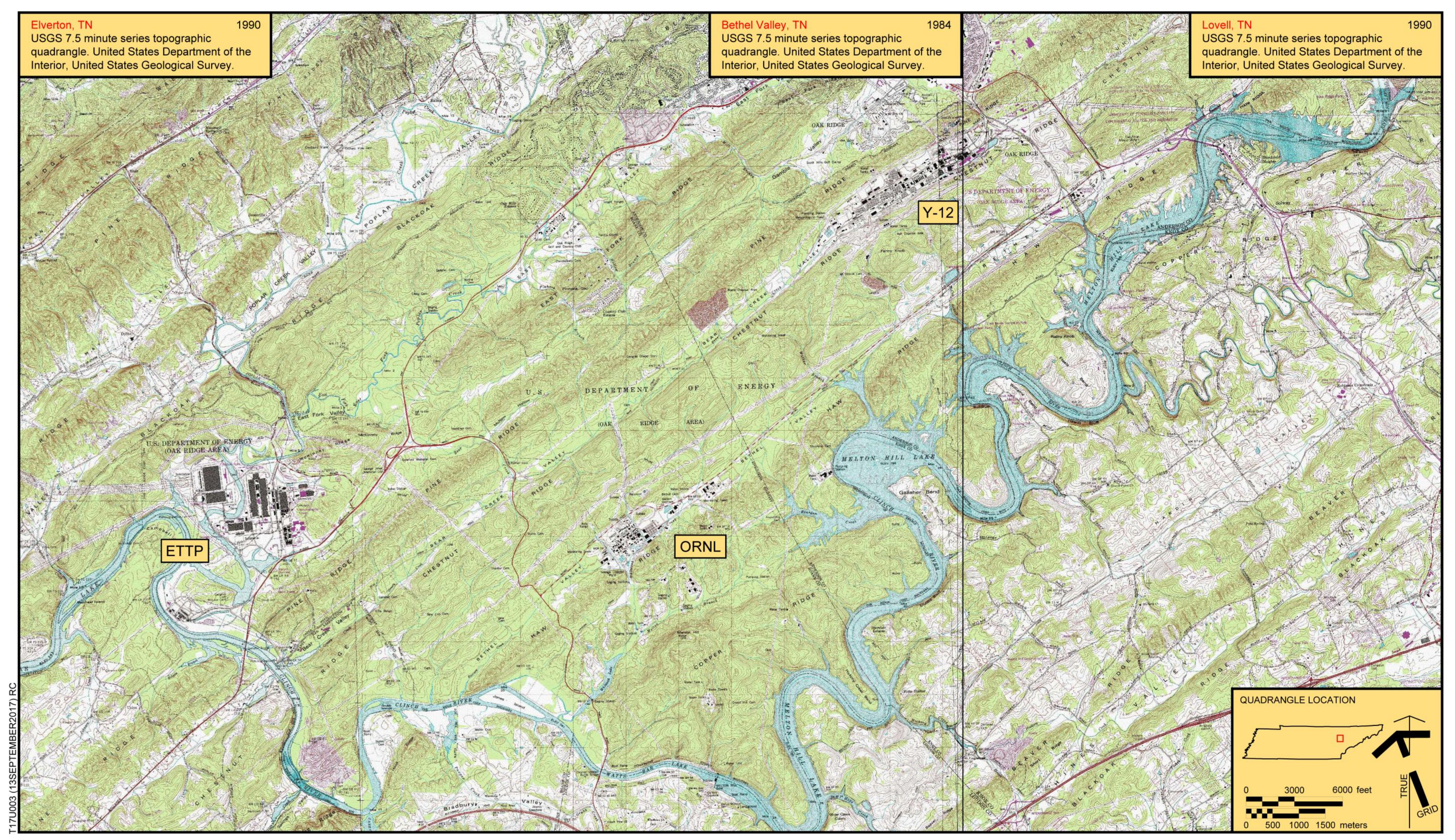

Figure 1. ORNL and other DOE facilities depicted on a topographic map. 
This page intentionally left blank 


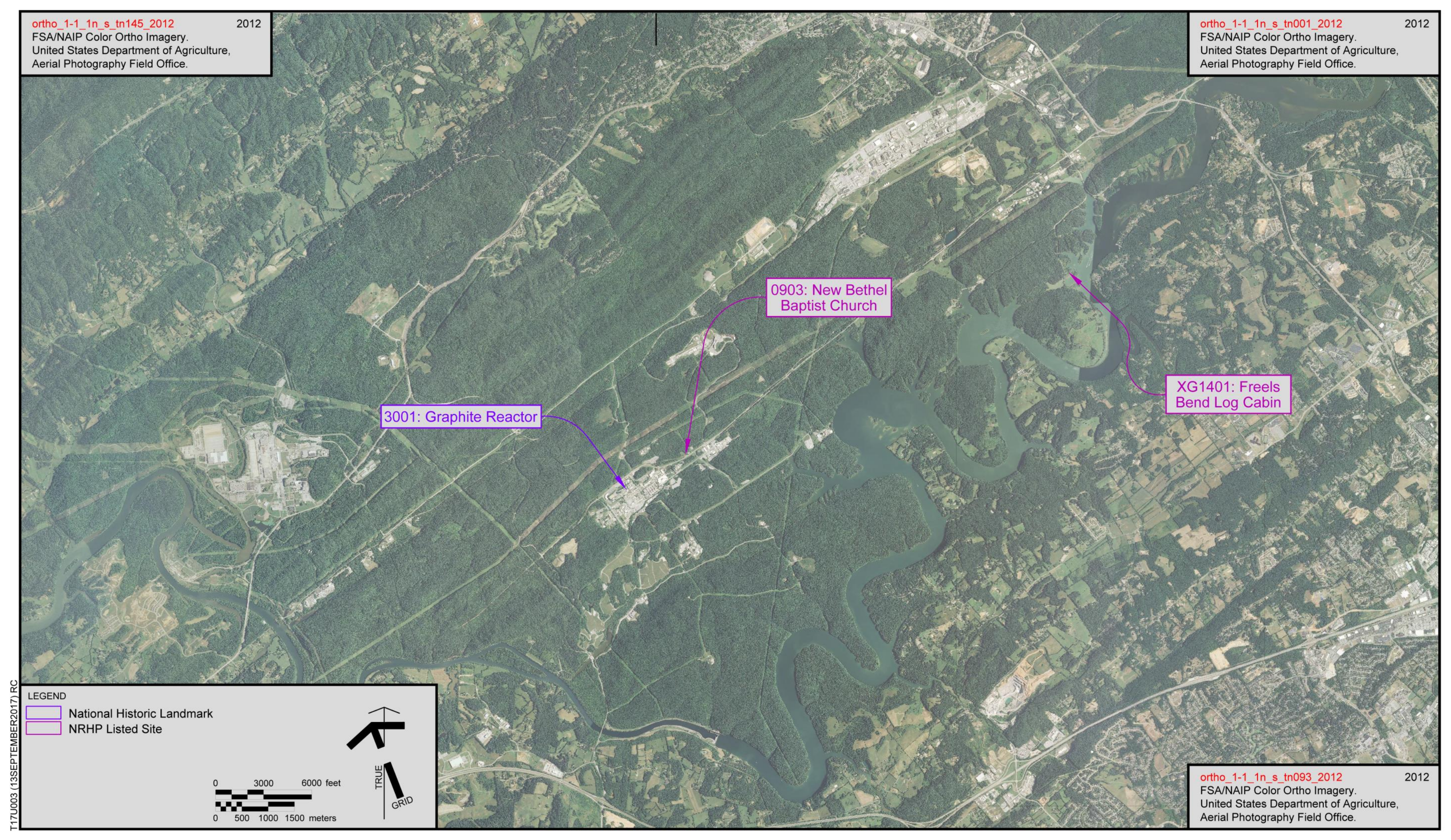

Figure 2. Aerial photograph depicting the NRHP-listed resources at ORNL. 
This page intentionally left blank 
its responsibility for compliance with Sections 106 and 110 of the NHPA, as amended, for proposed ORO activities-including the continued operation, maintenance, research, development, waste management, decontamination, decommissioning, and restorations - at ORNL that have been determined to have the potential to affect buildings that are eligible for inclusion in the NRHP. ORNL's PA was designed to be used in tandem with the ORNL HPP. The HPP identified historic properties at ORNL, categorized them in terms of future mission need, and ranked their significance (minor, moderate, or major) within the ORNL Historic District. These categories were referenced throughout the PA to stipulate the appropriate treatment of historic properties.

The PA addressed the demolition of several historic properties at ORNL and stipulated standard recordation measures, based on the building's significance ranking, for creating a permanent archival record of these buildings prior to demolition. Over 20 such recordation packages have been completed to date, comprising a significant body of work on ORNL's Manhattan Project and Cold War-era research and support facilities. Other important studies completed in accordance with the PA include an interpretive plan for ORNL, 34 oral histories with former and current ORNL employees, and a machinery and equipment survey.

By 2015, the HPP and PA required updating to better address current mission needs and modernization efforts at ORNL. UT-B hired Thomason and Associates to update the HPP, including completion of an updated facilitywide survey of ORNL (Thomason and Associates 2015). While that study provided valuable information regarding the status of ORNL's historic properties, the HPP was not finalized or reviewed by SHPO. The current survey builds on its findings to create a comprehensive, stand-alone survey report reflecting the current condition and NRHP status of ORNL's historic architectural resources. UT-B and DOE plan to update the HPP and PA in the coming year, in consultation with SHPO, based on the survey's findings.

Additional information regarding ORNL's historic resources is found in Section 106 documentation created for specific undertakings at ORNL. Documentation prepared for Buildings 3025E, 4501, 4505, 4500N, 4500S, 6000, 7002 , and many others provide in-depth histories and descriptions of facilities.

The majority of the above-referenced documents are maintained by UT-B staff responsible for NHPA and National Environmental Policy Act (NEPA) compliance at ORNL. A review of all documents related to ORNL at the Tennessee Historical Commission (THC; SHPO) was completed on April 4, 2017. Many additional documentation reports, including those prepared for buildings 3506 and 3515; 3074, 3136, 3026C and 3026D; $3008,3012,3044,3504,3509$, and 3592; 7001; and 7002, were identified during that review. In addition to those documents created specifically for cultural resource management purposes, DOE has sponsored several studies of the history of ORNL and its individual divisions, which are available online at www.ornl.gov.

\section{METHODOLOGY}

The survey was conducted in accordance with Archaeology and Historic Preservation: Secretary of the Interior's Standards and Guidelines (NPS 1983). In addition, the survey followed guidelines offered in National Register Bulletin 24: Guidelines for Local Surveys: A Basis for Preservation Planning (NPS 1985), National Register

Bulletin 15: How to Apply the National Register Criteria for Evaluation (NPS 1997a), and National Register Bulletin 22: Guidelines for Evaluating and Nominating Properties that Have Achieved Significance Within the 
Past Fifty Years (NPS 1998). All CRA staff responsible for the field survey, analysis, and report writing meet or exceed the Secretary of the Interior's Professional Qualifications for Architectural History and/or History.

CRA's architectural historians worked with ORNL historic preservation and modernization staff to develop a list of buildings for inclusion in the survey. The team determined that the survey would include buildings constructed through 1980. This date was selected to ensure that the survey provided coverage of buildings that would turn 50 years of age within the next 10 years. A review of building data indicated that 1980 , more so than 1977 , represented a break in development at ORNL, so it was selected as a more appropriate cutoff date. It also very nearly marked the end of Union Carbide's development of the laboratory, as they ceased to manage ORNL in 1982 and did not add any major buildings to the property between 1980 and 1982. Facilities Information Management System (FIMS) data provided the basis for dating buildings and generating the list for survey. Only those buildings with recorded area over $100 \mathrm{sq} f \mathrm{ft}$ were included. The survey did not account for every piece of infrastructure included in FIMS. In total 195 buildings were included in the survey.

The field survey was conducted by CRA architectural historians Hallie Hearnes, M.A., and Sarah Reynolds, M.H.P., during the weeks of May 15 and June 5, 2017. During fieldwork, all buildings included in the survey were subject to exterior photographic documentation, to the extent permitted by security regulations at the laboratory. Generally, CRA attempted to capture views of all elevations, exterior building materials, and key architectural details. Previous survey efforts used grid north, with northwest indicated as north, to describe locations and elevations. CRA utilized the same approach in this updated documentation for ORNL, using grid north, or administrative north, instead of true north. For those buildings where photography and/or visual access was not permitted, CRA has included information from previous surveys, but the buildings' integrity and condition are unknown, thus their current NRHP status is undetermined.

The UT-B team identified 15 buildings for more intensive survey because such buildings are central to ORNL's future mission needs and are expected to undergo renovations in the foreseeable future. These buildings (Buildings 3025E, 3037, 3500, 4500N, 4500S, 4501, 4505, 4508, 5500, 6000, 6010, 7900, 7901, 7920, and 7930) were subject to both exterior and interior documentation with particular focus on identifying characterdefining features.

CRA utilized field data; information from the 1993 survey report, 2004 HPP, and 2015 draft updated HPP; other cultural resource management reports; and ORNL histories to describe each recorded building and evaluate it for listing in the NRHP. In general, in order for a property to be eligible for listing in the NRHP, it must be at least 50 years old and possess both historic significance and integrity. Significance may be found in four aspects of American history recognized by these National Register Criteria:
A. Association with historic events or activities;
B. Association with important persons;
C. Distinctive design or physical characteristics; and/or
D. Information potential. 
A property must meet at least one of the criteria for listing and retain the appropriate aspects of integrity: location, design, setting, materials, workmanship, feeling, and association. NRHP eligibility under Criterion D, which is typically used to assess archaeological sites, was not applied to architectural resources for this project.

The NRHP typically requires that properties are 50 years of age or older in order to achieve the perspective needed to evaluate the lasting historic importance of a resource. However, it recognizes that such passage of time is not always necessary to recognize a property's significance. Properties less than 50 years of age may be considered for NRHP listing under Criteria Consideration G if they are of "exceptional importance." They also qualify for NRHP listing if they are integral parts of districts that are eligible for listing.

In evaluating the recorded resources, CRA found it useful to categorize them by property type according to their role and function within the national laboratory. Using an approach inspired by the NRHP multiple property listing model, CRA considered what physical and associative qualities would make individual examples of each property type eligible for listing in the NRHP. Such discussion is included at the beginning of the Results section and provided the basis for the evaluations found throughout that section.

\section{SUMMARY OF RESULTS}

The findings of this historic resource survey build on the conclusions of the 1994 survey by DuVall \& Associates, Inc., as well as the survey updates completed by Thomason and Associates in 2004 and 2015 in support of the ORNL HPP. Within 12 distinct areas of ORNL, as well as outlying areas, the survey recorded 195 buildings and structures constructed in or before 1980. In consideration of the role and significance of each area and each individual resource within the context of ORNL, and in light of their current integrity and condition, each recorded resource was evaluated to determine if it is eligible for listing in the NRHP. Resources recommended eligible for listing in the NRHP are summarized in Table 1. A table summarizing the full results of the survey, including all contributing resources to the proposed ORNL Historic District, is included as Appendix A. 
TABLE 1. NRHP-LISTED AND -ELIGIBLE HISTORIC RESOURCES AT ORNL

\begin{tabular}{|c|c|c|}
\hline BUILDING \# & BUILDING/FACILITY NAME & NRHP RECOMMENDATION \\
\hline Multiple & ORNL Historic District & Eligible District \\
\hline 0903 & New Bethel Baptist Church and Cemetery & NRHP-Listed \\
\hline 0969 & Airway Beacon Lighthouse & Individually Eligible \\
\hline XG1401, XG 1414 & Freels Bend Log Cabin and Outbuilding & NRHP-Listed \\
\hline 3001 & Graphite Reactor Building & $\begin{array}{l}\text { National Historic Landmark; } \\
\text { Contributing to ORNL Historic District }\end{array}$ \\
\hline 3005 & Low Intensity Test Reactor Facility & $\begin{array}{l}\text { Individually Eligible; } \\
\text { Contributing to ORNL Historic District }\end{array}$ \\
\hline $4500 \mathrm{~N}$ & Central Research \& Administration North & $\begin{array}{l}\text { Individually Eligible; } \\
\text { Contributing to ORNL Historic District }\end{array}$ \\
\hline 7002 & Garage and Iron Working Shop & Individually Eligible \\
\hline $\begin{array}{l}7503,7507,7509 \\
\quad 7516,7555\end{array}$ & Molten Salt Reactor Experiment Building & Individually Eligible Facility \\
\hline $\begin{array}{c}7700,7701,7702 \\
7703,7704\end{array}$ & Tower Shielding Facility (TSF) & $\begin{array}{l}\text { Previously-recommended as NRHP-Eligible; } \\
\text { Not Accessible }\end{array}$ \\
\hline 7709 & Health Physics Research Reactor (HPRR) & $\begin{array}{l}\text { Previously-recommended as NRHP-Eligible; } \\
\text { Not Accessible }\end{array}$ \\
\hline 7710 & $\begin{array}{l}\text { Dosimetry Applications Research } \\
\text { (DOSAR) Facility }\end{array}$ & $\begin{array}{l}\text { Previously-recommended as NRHP-Eligible; } \\
\text { Not Accessible }\end{array}$ \\
\hline 7813,7846 & White Oak Creek Dam/White Oak Lake & Individually Eligible \\
\hline $\begin{array}{c}7900,7901,7911 \\
7920,7930\end{array}$ & $\begin{array}{c}\text { Hi Flux Isotope Reactor } \\
\text { (HFIR)/Radiochemical Engineering and } \\
\text { Development Center (REDC) Facility }\end{array}$ & Individually Eligible Facility \\
\hline
\end{tabular}




\section{HISTORIC CONTEXT}

The history of ORNL, from its Manhattan Project roots through its development as a national laboratory, has been well documented in a number of government and scholarly publications. Such works were wellsummarized in the historic context included in the 1994 survey report, which was edited and expanded for use in the 2004 HPP and 2015 draft HPP. The following historic context is derived from the version included in the 2015 draft HPP, edited and expanded by CRA, as appropriate, to serve the needs of the current project (Thomason and Associates 2015).

\section{OVERVIEW}

What is now Oak Ridge National Laboratory (ORNL) originally developed in the early 1940s as part of the World War II Manhattan Project, the U.S. government's top secret effort to build the world's first atomic bomb. Code named $X-10$, the site's original mission was the production and separation of plutonium for the development of nuclear weapons. X-10 contained the prototype graphite reactor that produced the world's first gram quantities of plutonium. The plant and its mission were top secret and worked in concert with two other facilities, K-25 and Y-12, the three of which comprised the Oak Ridge Reservation (ORR). The nation's top physicists worked at the ORR facilities. The nearby town of Oak Ridge was built to house employees of the facilities, which numbered in the thousands. The plutonium produced at X-10 was used for research on the production of the world's first atomic bomb. After dropping the uranium gun-type atomic bomb "Little Boy" on the city of Hiroshima, Japan on August 6, 1945, the U.S. dropped the plutonium implosion-type atomic bomb "Fat Man" on Nagasaki on August 9,1945 . The bombing led to Japan's surrender and the subsequent end of World War II.

Following World War II, the Atomic Energy Commission (AEC) was formed and management of the ORR, including the X-10 installation, was contracted to private companies. Monsanto Chemical Company assumed management of the X-10 site in 1945 as a research center. Carbide and Carbon Chemicals Corporation (C\&CC), later renamed Union Carbide Corporation, operated the plant beginning March 1, 1948, and the site name was changed to ORNL. Research focus at the site included reactor development, the production of radioactive isotopes for experimental purposes, the recovery of large amounts of uranium from the extraction wastes being held in storage, and the investigation of the effects of radiation on animals.

Management of ORNL was transferred to Martin Marietta Energy Systems, Inc. (MMES, later known as Lockheed-Martin), in 1984. Ongoing missions at ORNL include energy production and conservation technologies, physical and life sciences, scientific and technological user facilities, environmental protection and waste management, science and technology transfer, and education. UT-B assumed management of ORNL facilities in April 2000.

\section{THE EMERGENCE OF ATOMIC ENERGY}

The development of atomic energy emerged from various scientific discoveries of the 1930s. During the early years of that decade, scientists discovered that the nucleus of an atom contains neutrons, particles with no charge, and electrons and protons, particles with negative and positive charges, respectively. Further research revealed that atoms of the same element can have different weights depending on the number of neutrons in a 
particular atom's nucleus. These "different classes of atoms of the same element but with varying numbers of neutrons were designated isotopes" (Gosling 1994:1).

There are three isotopes of uranium, a naturally occurring element found in the earth. All three of these isotopes have 92 protons and 92 electrons, but each has a different number of neutrons and thus a different atomic weight. Uranium-238 (U-238) has 146 neutrons and is the heaviest of the three isotopes. It accounts for over 99 percent of natural uranium. Uranium-235 (U-235) has 143 neutrons in its nucleus and makes up only 0.7 percent of natural uranium. The third isotope, uranium-234 (U-234), has 142 neutrons and is found only in traces of the element (Gosling 1994:1). This slight difference in the atomic weights of uranium isotopes played a key role in the development of nuclear energy.

Additional advancements in the field of physics during the 1930s led to the discovery of fission. In the early 1930s it was known that bombarding elements with protons could split atoms. In 1934, Italian scientist Enrico Fermi bombarded elements with neutrons instead. In 1939, Berlin radiochemists Fritz Strassman and Otto Hahn used this method with uranium and realized that "while the nuclei of most elements changed somewhat during neutron bombardment, uranium nuclei changed greatly and broke into two roughly equal pieces" (Gosling 1994:2). The end products weighed less than the original uranium; therefore, as demonstrated by Einstein's $E=m c^{2}$ equation, the loss of mass was converted into a form of kinetic energy, which in turn was converted into heat in a process called fission.

During the fission process neutrons are released. If they collide with other atoms, additional neutrons are released and in turn smash into more atoms, which release more neutrons to smash into more atoms, and so on. This chain reaction produces a continuous release of energy. Once discovered, scientists realized that "a controlled self-sustaining reaction could make it possible to generate a large amount of energy for heat and power, while an unchecked reaction could create an explosion of huge force" (Gosling 1994:2). The binding energy of the nucleus so released would be tremendous, ten million times larger than the energy released by chemical reactions (Logan 1996:264).

In the first week of January 1939, Strassman and Hahn announced that the nucleus of the uranium atom could be caused to split or fission by bombardment with neutrons. This discovery was confirmed by laboratories around the world, including four in the United States (Smyth 1945:25). As these scientific discoveries emerged, war was mounting in Europe. Scientists realized uranium fission made possible the creation of a new weapon, one with a potential for mass destruction, and the race to build the first atomic bomb began.

By spring of 1939 , scientists at Columbia University made advances toward creating a chain reaction. As scientists grasped possibilities, they began to seek a practical demonstration, an experiment far too costly for any team then researching the topic. Enrico Fermi, Leo Szilard and other leading scientists worked feverishly to stir interest from the United States government. Although they were successful in generating interest they received no funding.

Szilard sought advice, and solace, from Eugene P. Wigner, a physicist then teaching at Princeton. Finding themselves in complete agreement, Wigner and Szilard decided President Franklin D. Roosevelt should be contacted without further delay. Through mutual friends, they involved Alexander Sachs, a financier who 
grasped the issue at hand and could speak with confidence to the President. The men enlisted the help of Albert Einstein, who prepared a letter to the president regarding the implications of this scientific development.

Before this document could be composed, war broke out in Europe. Sachs finally met with Roosevelt on October 11, 1939. Sachs, who thoroughly understood theoretical science, read Einstein's letter to Roosevelt. Sachs and Roosevelt knew one another well, and Roosevelt was impressed not only with his friend's dedication but also with Einstein's endorsement. Roosevelt readily understood the letter's urgent tone and ordered Major General Edwin M. "Pa" Watson to look into the matter (Allardice and Trapnell 1974:6-7). In October 1940, Roosevelt organized a committee charged with managing theoretical scientific experimentation, which approved $\$ 6,000$ for uranium fission research. The Japanese attack on Pearl Harbor in December 1941 brought the United States into World War II, and the urgency to develop atomic power intensified.

\section{THE MANHATTAN PROJECT}

In 1942, recognizing the urgent need for atomic research, the United States government initiated the Manhattan Project, originally known as the Laboratory for the Development of Substitute Materials (DSM), a top secret effort to develop nuclear weapons. Security demands placed the atomic research program within military perimeters, and construction requirements positioned the program within the bounds of the U.S. Army Corps of Engineers (Corps). The Army initially appointed Colonel James C. Marshall as construction and administrative head of the project, but in September Colonel Leslie R. Groves replaced Marshall, who was reassigned as District Engineer. The Corps was responsible for site selection, plant design, construction, and management of project facilities. Commanded by the army, an oversight committee comprised of scientists, named S-1, would govern research and experimental work. Ordinarily, Corps districts were named for their host city. Groves and Marshall followed this course, naming the effort "Manhattan" for the city in which Marshall originally had established headquarters. The Manhattan Engineer District (MED) was formed on August 16, 1942. In very real terms, the MED was a nationally based district whose offices were scattered throughout the United States (Groves 1962:13).

Before the MED was officially created, the Corps set to work to identify sites for the separation of U-235 and the production of plutonium-239, which also had the ability to create an explosion. A remote inland site with abundant water and electrical power was required. Army guidelines for location of munitions facilities were specific stipulating they be located beyond reach of enemy aircraft, between the Rockies and Appalachians, and within 200 miles from U.S., Canadian, and Mexican borders.

To deal with the stringent construction and security requirements, the Army initially planned that all manufacturing facilities would be built in a single installation. The need for acquiring thousands of acres became readily apparent. Site requirements involved constructing a town for the thousands of workers needed for the project's construction and plant production phases. Requirements for the installation were specific. The site had to be isolated and located in a moderate climate permitting year-round construction. A steady supply of workers was vital as was access to both motor and railroad transportation systems. The terrain had to be composed of an interlocking ridge and valley system confining the devastating results of an explosion should one accidentally occur. In the best of all possible worlds, the Corps sought a remote location comprised for four isolated areas within a single, larger boundary (Jones 1985:46). 
In April 1942, officials traveled to East Tennessee and identified a possible site between the rural communities of Clinton and Kingston. The area met transportation, water, and electrical criteria as this region of Tennessee bordered the Clinch River, was served by two railroads, and was within easy reach of the Tennessee Valley Authority's (TVA) electrical power. Compton perused the site, approved all he saw, and visited TVA chairman David Lilienthal. Lilienthal was frankly dismayed. "We didn't want them to take over such vast areas of land of such fertility, and tried to get them to consider western Kentucky" (Lilienthal 1964:1). Compton steadfastly refused to consider Lilienthal's recommendations and suggested land could be acquired through the courts. Lilienthal's was discouraged from pressing his case, and the military ultimately had its way. Within forty-eight hours of his appointment, Groves moved to acquire land in East Tennessee and obtained AAA priority ranking (Jones 1985:603; Gosling 1990:12-14; Robinson, 1950:42).

The installation eventually formed by the Corps in East Tennessee was but one component of a multi-faceted "team." Research moved at a feverish pace at universities, laboratories, and plants across the country. Universities as diverse as Columbia, the University of California at Berkeley, and the University of Chicago were key players. More than twenty firms were involved in research design and in resolving production problems for the Tennessee based plants. Competition accelerated as scientists and engineers sought to prove their methodology the most beneficial (Gosling 1990:14). Two routes to producing the bomb were undertaken, the uranium route and plutonium route. Neither approach had ever been tried before; both were full of tremendous uncertainties, but each offered some possibility of success. It was felt certain the Germans were working on one or both approaches and might have a head start.

It was discovered early on that fission in uranium was occurring primarily in uranium atoms of the light isotope, the form of the uranium atom in nature that has an atomic weight of 235 rather than 238 . Unfortunately, only 7 atoms out of 1,000 in nature are the U-235 form ( 0.7115 percent) and they behave identically in chemical reactions so separation can only be effected by physical means taking advantage of the very small differences in mass or in the average behavior of molecules. Scientific studies revealed various possible approaches for separating the uranium isotopes: gas centrifuge, gaseous diffusion, thermal diffusion, photochemical, and electromagnetic. Scientists and engineers debated which process ultimately would be successful and did not hesitate to request changes to process methodology or plant construction. The choice was narrowed in late 1942 to two methods, the electromagnetic process and the gaseous diffusion process. No one had ever separated uranium isotopes in any but micro-lab-scale quantities.

Ultimately, the Manhattan Project's core sites came to consist of three separate installations: the Clinton Engineer Works (CEW or ORR, Oak Ridge, Tennessee), code named "Site X"; the Hanford Site (Hanford, Washington), code named "Site W"; and the Los Alamos Laboratory (Los Alamos, New Mexico), code named "Site Y." The three sites developed simultaneously. The CEW focused on uranium enrichment and the Hanford Site produced plutonium. "Site Y," the Los Alamos Laboratory, was responsible for the design and assembling of nuclear weapons. This isolated site was the most secret of the three installations. Many of the nation's premier scientists came to live and work at Los Alamos, where the uranium based implosion device "Little Boy" and the plutonium based "Fat Man," the world's first atomic weapons, were developed. 


\section{THE OAK RIDGE RESERVATION (CLINTON ENGINEER WORKS)}

The proposed ORR site was located 35 mi west of Knoxville, Tennessee, in an area bordered by the Clinch River and a craggy mountain range known as Black Oak Ridge. The region was roughly rectangular and almost divided in half by the Roane-Anderson County line. Three distinct valleys, fixed on a northeast course, were located here. Each valley was bisected by a road running through the valley floor and connected to its neighbors by narrow roads running across the mountains (Robinson 1950:62). The reservation was first known through the code name "Kingston Demolition Range" after Kingston, Tennessee, the town located south of the reservation. The reservation was soon renamed "Clinton Engineer Works" after Clinton, Tennessee, the town located to the reservation's north. The site is now known as the ORR. The ORR had four components: the graphite pile (reactor), code named X-10 (present day ORNL); the electromagnetic plant, code named Y-12; the gaseous diffusion plant, code named K-25; and the Townsite or residential portion along Black Oak Ridge, named Oak Ridge.

From the early settlement period of the late eighteenth century through the Depression era, the residents of East Tennessee tended to be "subsistence farmers" who survived by producing crops and livestock for their own consumption. Most farmers resided within narrow valleys along the more fertile bottom lands of streams and rivers. The adjoining mountainous terrain prevented the large scale farming of cash crops such as tobacco or cotton.

Although the project would not be officially authorized by President Franklin D. Roosevelt until December 28, 1942, on October 7th of that year, the U.S. Army filed a declaration of taking in Federal Court in Knoxville. Through the War Powers Act the Corps was originally authorized to obtain 56,200 acres in Roane and Anderson Counties, and later permitted ten additional parcels bringing total acreage to 58,900 (Jones 1985:320). The region contained four primary communities, Elza, Robertsville, Wheat, and Scarboro, each consisting of homes, schools, farms, and churches. The valleys were inhabited by those whose families had owned and farmed the same land for generations and by families who had been previously evicted from their homes due to the development of the Great Smoky Mountains National Park in 1934 and the construction of Norris Dam in 1939 (Young n.d.:6).

Smaller communities existed among the primary communities, often named after a nearby church or school. During site preparation for X-10, some cemeteries were transferred off the ORR and added to existing cemeteries in nearby communities. But in most cases, roads were rerouted or buildings were moved to new sites in order to avoid local cemeteries, which saved construction time. The New Bethel Baptist Church and Cemetery near the X-10 site is one example. Church services continued in the building until the late 1940 s. The frame building and associated cemetery have been maintained over the years and remain extant just northeast of the present-day ORNL main facilities complex. Virtually unchanged from its early twentieth century appearance, it remains a testament to life in Bethel Valley prior to the era of the Manhattan Project.

Roughly 1,000 families (approximately 3,000 people) were affected by the establishment of the ORR (Overholt 1987:102). The majority believed they were substantially underpaid for their farms and addressed grievances in federal court (Jones 1985:324). Although local opposition was sometimes intense, residents found little outside support. A real estate office, opened to purchase land through condemnation, secured clear title. 
Crops were ripening in the fields, and hay was freshly stored when federal agents covered the region. Pounding on doors they noted the War Powers Act, notifying farming families that the government was acquiring property. Landowners were told they had 30 days to vacate, and that the price of land-an average of $\$ 56$ an acre-was non-negotiable. Finding no one at home, notices were nailed directly on the dwellings. In some instances, farming families were given two weeks' notice. There were cases of families who were packing household goods while crews began tearing at the roof of their homes. The Army's eviction and relocation practices did not include relocation costs and required that property owners not be paid until the family vacated the premises. There were instances of compensation arriving six months after property condemnation (Young n.d.:6). Residents began leaving by the end of November. Numbered among them were those who hoped their loss would contribute to winning the war.

Land was quickly accrued. The Army lost no time in clearing the site and demolished many farm-related buildings. When possible, existing buildings were utilized with approximately 180 pre-Manhattan era dwellings incorporated in the Corps' overall scheme. Laboratory and processing spaces were desperately needed. At the $\mathrm{X}-10$ site, a functioning model of the Chicago graphite pile (reactor) was erected to provide design criteria for Hanford's production plant (see discussion in the following section). In addition, the MED erected the following at Oak Ridge:

- $\quad$ An electromagnetic plant, costing $\$ 300$ million to construct and $\$ 177$ million to operate (Y12). This plant would generate the first weapons grade uranium provided to the laboratory at Los Alamos

- A thermal diffusion plant, costing $\$ 10$ million in construction expense and $\$ 5$ million to operate (S-50). This facility provided feed material for another plant and made successful tandem operations possible

- A gaseous diffusion plant, costing $\$ 460$ million to construct (K-25). The plant proved the most successful of the three plants despite scientific advice to the contrary (Allardice and Trapnell 1974:17).

Security was tight at Oak Ridge, and, with the exception of a handful of select officials, employees worked on a "need to know" basis. Information was compartmentalized within each department. Employees knew only what was necessary to complete their assigned portion of the work. While many workers held slight notions about the type work they were doing, the vast majority learned of their role from radio broadcasts following the bombing of Hiroshima (Overholt 1987:91-92, 149).

The $92 \mathrm{sq}$ mi reservation was fenced with barbed wire salvaged from existing homesteads (Johnson and Jackson 1981:10). Security also included mounted guards who patrolled the boundary's perimeter. Seven gates allowed monitored entry to the reservation. The gates effectively separated the outside world from the world of the reservation. Once within reservation boundaries, checking stations provided additional security marking established limits between the town and each individual plant.

Beginning in early 1942, the Boston-based architectural firm of Skidmore, Owings, and Merrill prepared detailed plans for the town of Oak Ridge. The community would occupy the northern edge of hilly Black Oak Ridge. Originally intended to house approximately 13,000 workers, Oak Ridge's population peaked at 75,000 (Overholt 
1987:105). In time the Townsite came to contain a post office, supermarkets, drugstores, shops, churches, nurseries, movie theaters, cafeterias, laundries, a guest house/hotel, schools, a hospital, recreational facilities, trailers, hutments, barracks, dormitories, and houses. (For more information on the buildings at the Townsite, see the NRHP nomination prepared in 1991 by Thomason and Associates.)

Materials and equipment were procured through purchase orders, contracts, subcontracts, and formal modifications. Material provision involved thousands of manufacturers and vendors. These came to include DuPont, General Electric, Allis-Chalmers, and Westinghouse, as well as a number of construction subcontractors.

Contracts for design and construction were awarded, but restricted to select companies. Upon the awarding of a contract, contractors were required to isolate that portion of their plant dedicated to Manhattan Project business. No less than 119 field inspector-expediters, 26 schedulers, 9 "priority men," and 85 field stenographers/clerks were employed to inspect and move material. In addition, 11 branch offices were opened in principal manufacturing regions across the country. Originally located in Boston, the expediting office was eventually closed and moved to Oak Ridge (Engineering News-Record, 13 December 1945: 125-127).

\section{X-10 (CLINTON LABORATORIES)}

The graphite reactor at $\mathrm{X}-10$ was the prototype for the huge plutonium processing plant that was later built at Hanford, Washington. X-10 was the location of the first plutonium-producing graphite reactor in the world, becoming operational November 5, 1943. The plant was originally composed of over 150 buildings, including three chemistry buildings, a technical laboratory, a pile building, a physics lab, a power house, an electrical instrument development building, machine shop and research development shops, a lead shop, a medical building, and several administration buildings and warehouses. Construction of the plant cost $\$ 13,000,000$. In April 1943, the X-10 site was officially named the Clinton Laboratories (Figure 3).

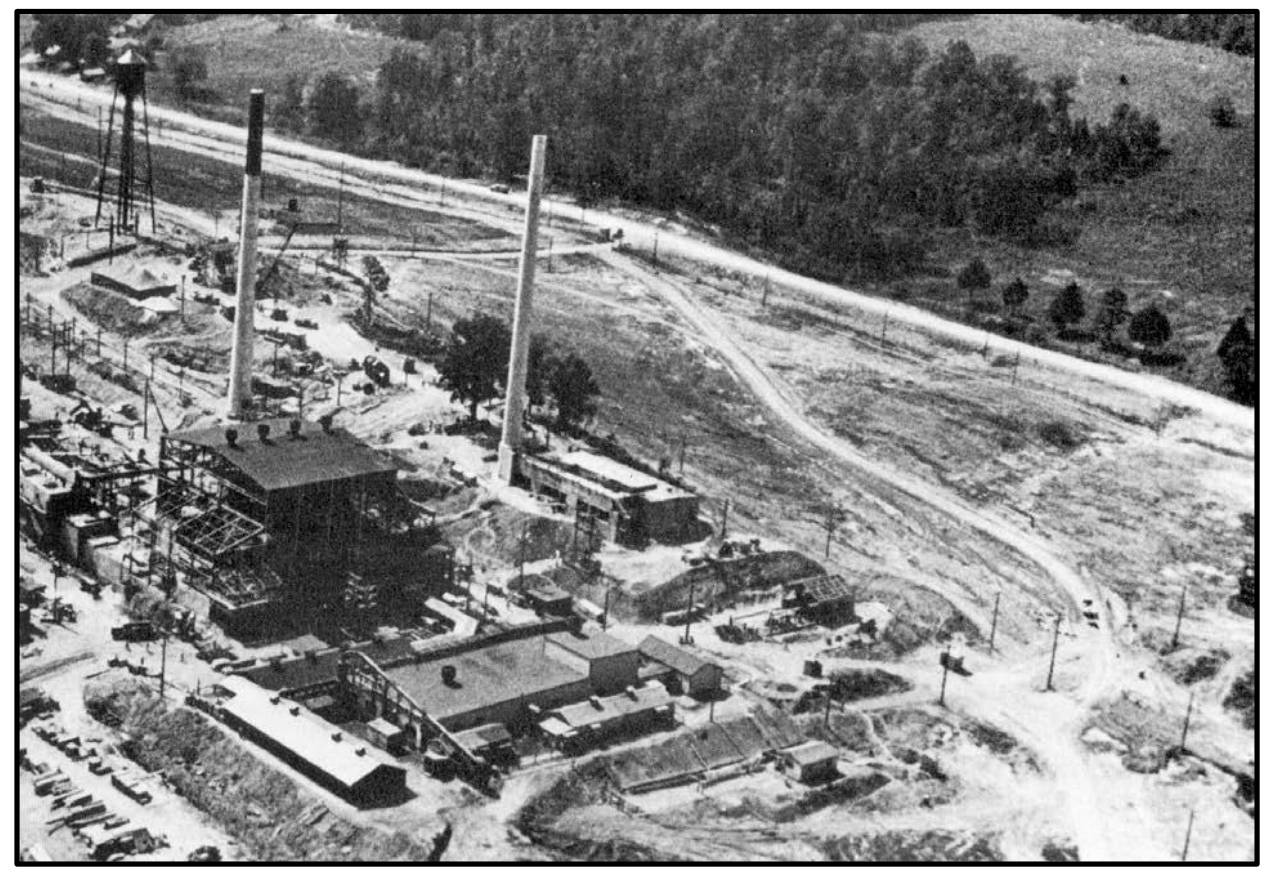

Figure 3.

Construction of the X10 site, including the Graphite Reactor, in October 1943. 
Of all the possibilities available in 1942 as a source of atomic energy, the pile (graphite reactor) appeared to be the smallest gamble. From a military perspective, the pile would produce fissionable material and radioactive materials that might be used in chemical warfare. Scientists hoped the pile could be a potential power source in the years following the war. Given the range of choices, the Military Policy Committee decided that the Manhattan Project should pursue pile production (Jones 1985:184-185).

Unlike the gaseous diffusion (K-25) and electromagnetic (Y-12) research efforts, the pile did not focus on isotope separation. Instead, this method employed a "transmutation-chemical separation" process to manufacture plutonium. Feed material, comprised of uranium slugs (a natural element), is altered into the manmade element plutonium by permitting carbon moderators to slow neutrons. This slowing allows neutrons to escape absorption by U-238 and remain free to "penetrate" U-235. The new element, plutonium, is then divided, or separated, from the uranium slug through a chemical separation process (Robinson 1950:44-45). As the pile generated plutonium, the process established criteria for a nuclear weapon vastly different from the weapon utilizing U-235.

The transmutation occurs in a "pile" that is a solid mass of graphite pierced at intervals by tubes that run from one side to the other. The uranium slugs are placed in these tubes in certain geometric designs. Fission in the form of a chain reaction then occurs and transmutes a small portion of the uranium into plutonium. The structure for this process was called a "pile" throughout World War II, because the structure was composed of graphite and uranium stacked or piled on top of one another in a lattice arrangement. But during the early 1950s, the term "reactor" commonly replaced the term "pile" (Johnson and Schaffer 1992:11).

The type of coolant used in the pile became a critical issue by 1942. "Heavy water," composed of one atom of oxygen and two atoms of an isotope of hydrogen called deuterium, was a choice preferred by Compton since this form of cooling would meet moderator and cooling demands. As heavy water was not available in large quantities, scientists felt research in that direction could prove futile. However, Compton's desire for a "heavy water pile" prompted General Groves to promote the construction of a heavy water plant in Trail, British Columbia. DuPont, too, encouraged Groves in this direction. At DuPont's urging, General Groves complied in modifying plants for the production of heavy water. Facilities were then established at Morgantown, West Virginia, the Alabama Ordnance Works, and Wabash River, Indiana. Interest in heavy water research continued, and in 1942 the Army decided all heavy water research would be conducted at the University of Chicago. In August 1943, Groves organized a committee that reviewed the role heavy water would play in the Manhattan Project. Committee members concurred with the present course and advised continuing heavy water pile research in the event the graphite piles failed (Jones 1985:72, 190-197; Hewlett and Anderson 1962:193).

By late 1942, the issue of coolant remained strongly undecided. Taking direction from General Groves, who was anxious to reach a decision, Compton charged Fermi with building a low-powered graphite pile. Compton hoped the pile's construction would provide badly needed data regarding the " $K$ " factor (the minimum number of neutrons needed to maintain fission) and demonstrate the probability of a chain reaction. Fermi began construction and located the pile beneath the West Stands of Stagg Field. On December 2, 1942, Fermi's "massive lattice pile of 400 tons of graphite, 6 tons of uranium metal, and 50 tons of uranium oxide, achieved the first self-sustaining chain reaction" in the world (Gosling 1990:10). Fermi's original pile had been so modest that coolant had not been needed. The information gained regarding the "K" factor proved scientists had more latitude in selecting coolant than previously known. It was possible that water or even air could be employed. 
Design work on an air-cooled pile located at Oak Ridge was advanced, and DuPont encouraged its use rather than changing to water-a process some scientists considered more promising than air (Jones 1985:190).

Because scientists at the University of Chicago were most closely associated with the pile process, they strongly supported locating the proposed pile production facility near Chicago at Argonne. General Groves and S-1, however, decided that while Argonne could accommodate Fermi's smaller plant, the site was too small to permit construction of the pilot facility, and Oak Ridge was selected instead. After this decision was made, Groves realized the ORR was too small to base all production facilities there. Thus, the full-scale plutonium plant was scheduled for Hanford, Washington. Consequently, the pilot-scale plutonium-producing pile, with its associated chemical separation buildings, became the primary focus of the X-10 site. Once plans for the ORR pile were finalized, Fermi's pile was moved from the University of Chicago to Argonne (Jones 1985:72).

The experiment conducted by Fermi in 1942 had only tested the physics of the pile. The pile based at X-10 was designed for small-scale production, and intended to reveal mistakes in design. The X-10 pile was not an exact miniature of the Hanford plant. X-10's pile functioned as more a "working model" from which scientists drew data for planning the Hanford development. As a result, there were at least two fundamental differences between the piles (reactors) found at Hanford and X-10. The X-10 pile was air-cooled. The Hanford pile, over DuPont's objections but at the direction of the University of Chicago, used a water-cooled approach. The second difference lay with the ORR's insistence in using bismuth phosphate in the chemical separation process. Problems resulted with this choice and prompted Hanford researchers to select lanthanum fluoride as the chemical used for Hanford's chemical separation (Gosling 1990:30-35; U.S. Department of the Interior 1965).

The University of Chicago had assumed the pile would be located at Argonne and that their scientists would direct the facility. Groves, however, was persuaded that each facility should be directed by a proven commercial leader. He selected DuPont to design and develop the separations pilot plant at Oak Ridge. DuPont, in its turn, was reluctant having earned the name "Merchants of Death" for supplying munitions during World War I. Capitulating to Groves' appeals, DuPont signed on with its participation hinging on two points-DuPont would not earn a profit and their income would be limited to costs. Secondly, the company's employment would end with the close of World War II (Hewlett and Anderson 1962:91; Hacker 1987:46-47).

Once the University of Chicago learned that DuPont would not only design but manage the X-10 site, the staff decided to stay in Chicago and develop a water-cooled pile. However, General Groves and DuPont officials knew University of Chicago staff were indispensable to X-10 development and requested that University scientists operate the site. Without question, Compton and his staff were angry over "losing" the pile, but they concluded that patriotism demanded they accept this offer (Hewlett and Anderson 1962:190-193). Even with this measure of participation, the University of Chicago's influence decreased and its involvement became increasingly less important in the overall scheme of the Manhattan Project (Gosling 1990:30).

Compton restructured his staff early in 1943, basing his decision on establishing individual laboratories of equal stature. Compton named himself director and appointed three associate directors, Robert Stone, Associate Director for Health Matters; Norman Hilberry, Associate Director for Research; and Wilbur Munnecke, Associate Director for Administration (Jones 1985:200). Associated research facilities included the University of Chicago's original Metallurgical Laboratory, lowa State College in Ames, Chicago's Argonne, and the X-10 Site at Oak Ridge directed by Martin Whitaker. In April 1943, the X-10 Site was officially recognized as Clinton Laboratories. 
Staff grew from sixty-four employees in July 1943, to almost 1,000 by December (Hewlett and Anderson 1962:210).

Construction of the X-10 site began in February 1943 with initial temporary buildings and utility installations completed by the end of March. Early in March of 1943, DuPont began construction of the foundations for the six large underground cells for plutonium and fission product separation. These "hot cells" had thick concrete walls with removable slab tops for equipment replacement (Johnson and Schaffer 1992:17-18). The first cell was linked to the pile building via an underground canal. Along one side of the row of cells, a one-story, frame building was erected to house the operating gallery and offices.

Construction on the pile building itself began on April 27, 1943. Difficulties soon arose, however, when workers struck a large bed of soft clay, which required more foundation work than had been anticipated. It was June before construction of the walls to the building began, and summer before they were completed (Jones 1985:205). The front face of the pile was composed of $7 \mathrm{ft}$ of high-density concrete, and the shield was pierced by hundreds of tubes through which the uranium slugs would be inserted. While the four-story pile building was being constructed, workers also built its auxiliary facilities, which included a control room, a small "hot" laboratory to handle radioactive materials, and a core removal area (Figures 4 and 5) (Jones 1985:205-206). In order to expedite the production of graphite bars to be used in the pile, DuPont constructed its own graphite fabrication plant adjacent to the pile building. The semiworks for the bismuthphosphate plant at the University of Chicago was disassembled and shipped to the East Tennessee site where it was reassembled and operating by

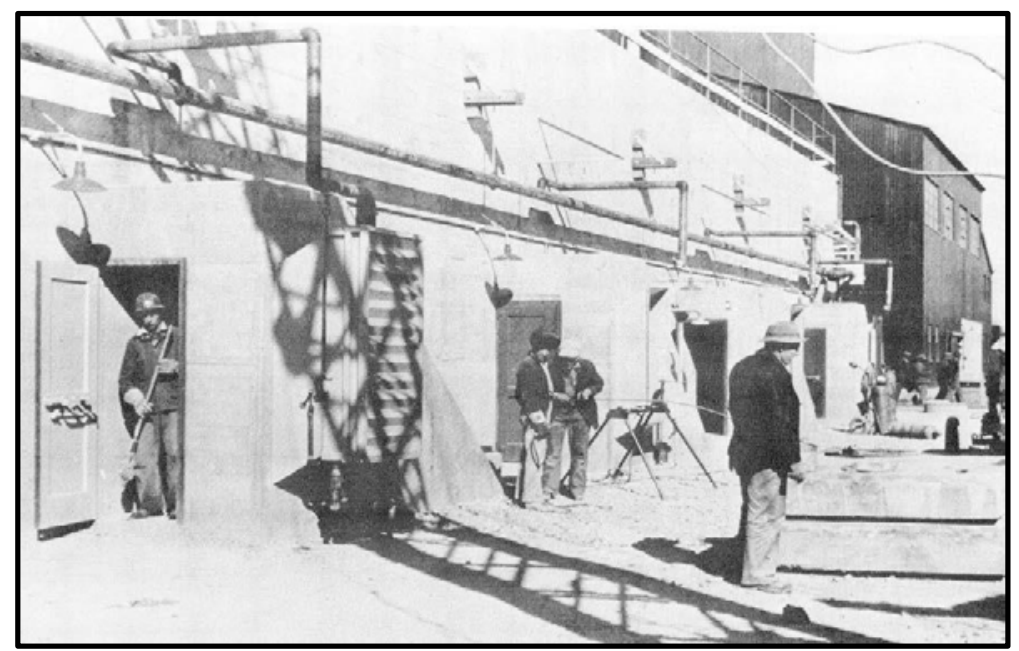

Figure 4. Construction of the concrete hot cells of the chemical separations building (Building 3019) in November 1943.

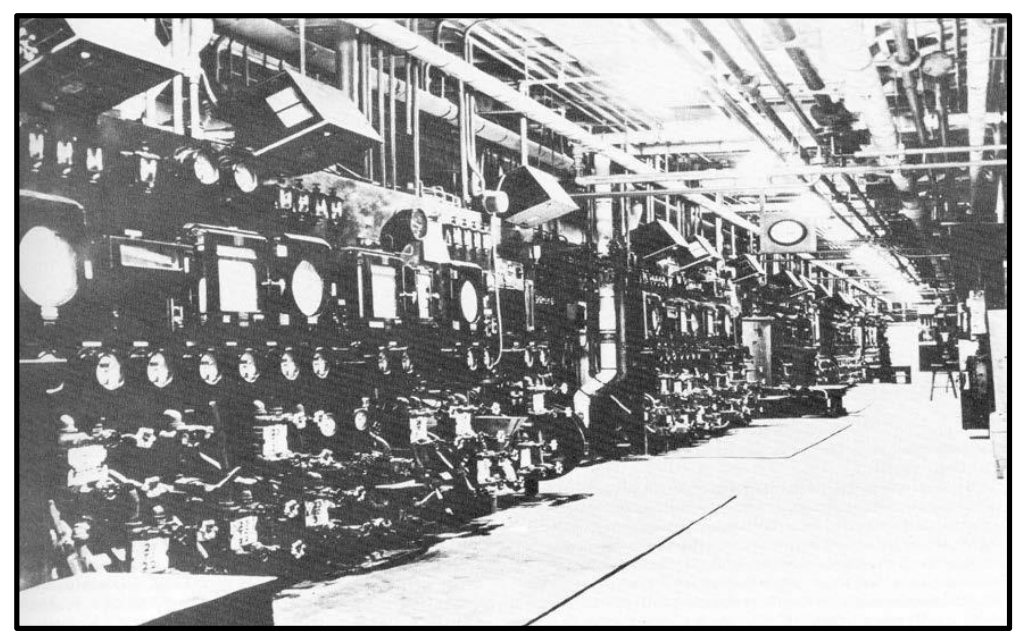

Figure 5. Remote controls for the plutonium process in the adjacent hot cells in 1944.

September 1943 (Hewlett and Anderson 1962:210). 
Overall, construction at the X-10 site proceeded slower than expected. Due to the isolation of the site, DuPont had to provide the pile with its own machine shops, water supply and treatment installations, steam plant storage areas, and classrooms and laboratories for training. The amount of construction eventually doubled from that in initial plans. The concurrent construction of the Y-12 and K-25 plants created a labor shortage, and DuPont dispatched recruiters throughout the region to find a sufficient amount of workers (Johnson and Schaffer 1992:18). Upon completion, the 112-acre X-10 site (eventually 150 acres) contained around 150 buildings that included the air-cooled experimental pile, the chemical separations pilot plant, underwater storage, an underground canal, a series of cells for chemical separation, and supporting laboratory facilities such as machine and instrument shops, warehouses, and subterranean tanks for radioactive waste (Johnson and Schaffer 1992:18; Jones 1985:204-205). The four-story pile building, which was painted black and nicknamed the "black barn," was a prominent visual feature at the site. In a building next to the pile, two of the world's largest fans were mounted that sucked outside air through the pile and then up a stack (Johnson and Schaffer 1992:18).

Scientists at the X-10 site continued to research the various separation processes on the chance that some aspect might contribute to the plutonium process. As important as the research was, the implementation of the pile was crucial to the primary purpose of the facility. By the end of October 1943, DuPont had completed the final engineering of the pile, and in early November workers began to insert thousands of U-235 slugs into the reactor (Figure 6). This process involved loading a ton or two of uranium slugs, withdrawing control rods to measure the increase in neutron flux, then reinserting the rods into the pile, loading more uranium, and continuing to stop and assess the neutron activity to determine when the pile would become "critical" or produce a self-sustaining chain reaction. The tedious procedure continued day and night with the day shift loading nearly 10 tons of uranium slugs, and the night shift loading an additional 20 tons (Johnson and Schaffer 1992:20).

At 5:00 a.m. on November 4, 1943, the pile reached its goal of criticality and became the world's first power-producing pile. By early 1944, only weeks later than estimated, the semiworks was largely completed and was fully operational by March. From the first, the pile was a success and produced plutonium in significant quantities for research

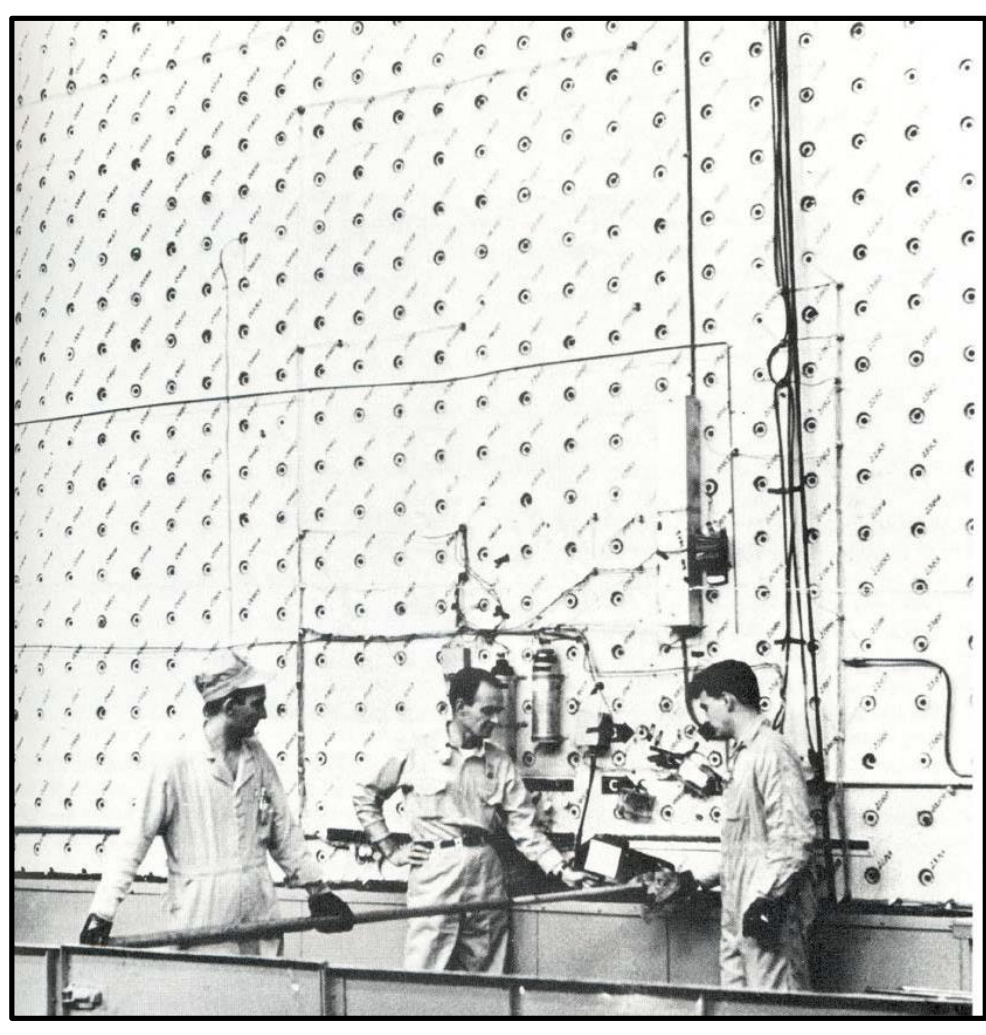

Figure 6. The concrete shield of the Graphite Reactor contains hundreds of tubes through which the uranium slugs were inserted. Workers used a long rod to push the slugs into the shield.

purposes. The quantities grew larger, and 
in the spring of 1944, the ORR began shipping samples to Los Alamos. That summer, the first samples of pileproduced plutonium resulted in revolutionary changes in weapon development (Hewlett and Anderson 1962:211-212; Jones 1985:208).

By May 1944, the pile was operating at near double the power level its designers had anticipated, and by July of that same year it had doubled again. The chemical separation plant, which had not previously been tested, operated well on its first run. The staff made modifications that eventually increased the efficiency of the plant from 40 to over 90 percent. The separation plant was in operation until January 1945, at which time enough plutonium had been produced to meet the project needs. The staff then began to use the pile for experiments with other irradiated materials as fissionable fuel. The pile was also used to test materials such as aluminum, graphite, brass, neoprene, Bakelite, concrete, and Masonite, which were used at Hanford (Johnson and Schaffer 1992: 24; Jones 1985:209).

In addition to being a pilot plant, $\mathrm{X}-10$ served as a training school for workers at the Hanford site. All of the experimental work and training of operators was performed at either the X-10 site or the University of Chicago. The X-10 site organized and conducted a training school for approximately 260 DuPont employees who later worked at Hanford.

The number of employees at the Clinton Laboratories was far less than those at the other ORR sites. Between March 1944 and January 1945, an average of approximately 1,300 people was employed at X-10, compared to 12,000 at K-25 and 22,000 at Y-12. The majority of the staff at Clinton Laboratories worked on product studies to aid the Hanford operation, and only around 12 percent were involved in product production.

In early 1945, Robert Oppenheimer, director of the Los Alamos site, urged that Los Alamos be supplied with large amounts of "RaLa", pure radioactive lanthanum, the decay product of radioactive barium-140. To provide the required amount, Clinton Laboratories erected a facility designed to produce the substance. This may well have been the first large scale production of a radioisotope (Johnson and Schaffer 1992:23-24). Through experimentation such as this, Clinton Laboratories evolved from prototype research (Hanford technology) into an institution focused on nuclear research.

The pile, an impossibly complex and expensive research instrument, became the heart of the nuclear laboratory (Figure 7). The pile provided an ample supply of neutrons and radioactive isotopes which promised countless applications in industry and science. As a radiation source, the pile opened innumerable opportunities for medical and biological research. And always, the pile held the promise of the controlled power through a controlled chain reaction. Devised in the crisis of war, the pile promised a powerful instrument for peacetime applications (Hewlett and Anderson 1962:212). Though the bomb had not been completed by June 1945, Clinton Laboratories wartime goals had been met. With University of Chicago staff anxious to be done with its responsibility, General Groves agreed Monsanto Chemical Company would assume management by July 1 , 1945. Martin Whitaker continued as director with the site assigned a new mission - conducting radiation research and producing "experimental materials" (radioactive isotopes) (Jones 1985:210; Thompson 1963:42). 


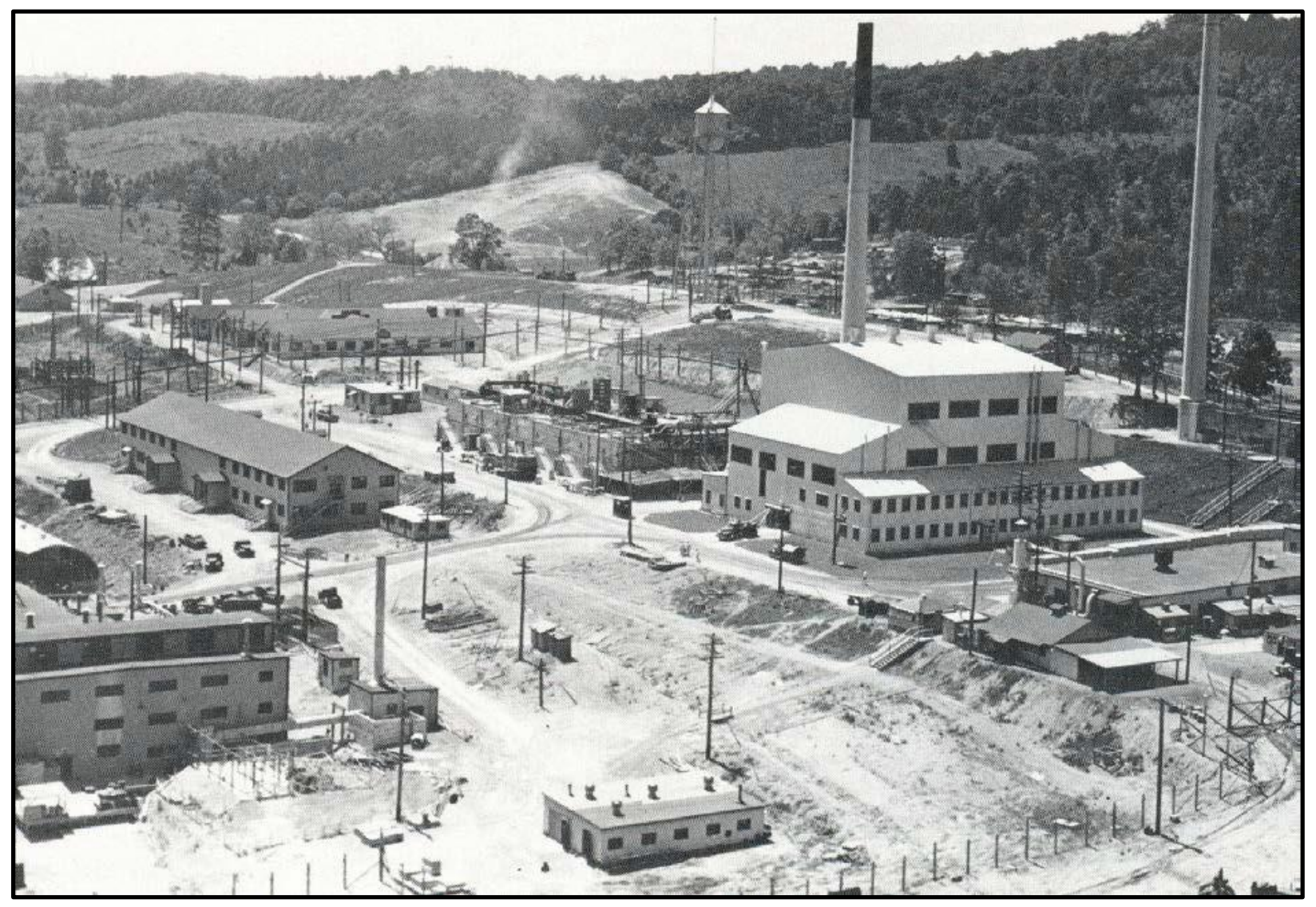

Figure 7. Clinton Laboratories after the war. Just right of center is the Graphite Reactor (Building 3001), and adjacent to it is the long, concrete separations building (Building 3019).

\section{THE MANHATTAN PROJECT AND END OF WORLD WAR II}

Following President Roosevelt's death on April 12, 1945, Harry S. Truman assumed the presidency and thus ultimate control of the Manhattan Project. Truman had little prior knowledge of the Manhattan Project. In the 82 days Truman served as Vice President, he had met Roosevelt privately on two occasions. Nothing of importance had been mentioned either time. Beyond a memorandum President Roosevelt had signed, the Manhattan Project had no policy statement. A portion of the document read that once the weapon was prepared, "It might perhaps, after mature consideration, be used against the Japanese, who should be warned that this bombardment will be repeated until they surrender" (McCullogh 1992:379). In the moments after Truman's inauguration, Henry Stimson, Roosevelt's Secretary of War, broached the topic of the Manhattan Project. Stimson explained "a matter of the utmost urgency" must be explained and that it involved "a new explosive of unbelievable power" (McCullough 1992:348). Twelve days into his presidency, Truman learned fully of the Manhattan Project. Stimson had prepared a memorandum: "Within four months we shall in all probability have completed the most terrible weapon ever known in human history, one bomb of which could destroy a whole city" (McCullough 1992:377).

The Manhattan Project had assumed "a life of its own." The project had effectively weathered the death of President Roosevelt and was functioning well as the Truman administration assumed control. Scientists now believed there were two possibilities for producing an atomic weapon. The first option lay with the plutonium 
generated at Hanford. The second option lay in using fissionable material from Oak Ridge in a gun-based device.

Meanwhile, Los Alamos scientists were not certain the "Fat Man" device, the implosion weapon designed with Hanford's plutonium, would work. A test of the device was conducted on July 16, 1945, and proved successful (Gosling 1990: 40). There was less uncertainly surrounding Oak Ridge's uranium bomb, and "Little Boy" was not tested. The Manhattan Project had achieved its goals and produced not one but two atomic weapons (Hewlett and Anderson 1962:301-302). As bomb development neared its end, decision makers realized these atomic weapons could be ready by August 1945. Scientists began to debate whether the weapons should ever be used. Moral and ethical questions were raised, and a petition drive began urging the weapons not be employed (Johnson and Jackson 1981:159).

S-1 met on Wednesday, May 9, 1945, to discuss the deployment of the U.S. atomic weapons. Chaired by Secretary of War Henry Stimson, the Interim Committee on the Manhattan Project included eight other members: Karl T. Compton, president of the Massachusetts Institute of Technology (MIT); Ralph A. Bard, Under Secretary of the Navy; James Bryan Conant, president of Harvard; Vannevar Bush, president of the Carnegie Institute; William L. Clayton, Assistant Secretary of State for Economic Affairs; and George L. Harrison, president of the New York Life Insurance Company (McCullough 1992:390). Further meetings scheduled for the 14th and 18th of May followed the initial May 9th session. A meeting, spanning two days, began on May 31st. Following long and often heated arguments, committee members and their advisors hammered out three conclusions:

1) The bomb should be used against Japan as soon as possible.

2) It should be used against war plants surrounded by worker's homes or other buildings susceptible to damage, in order "to make a profound psychological impression on as many inhabitants as possible."

3) It should be used without warning (McCullough 1992:391).

These recommendations were reported to the President by Stimson who stressed S-1's role was entirely advisory. Truman later wrote:

The conclusions of the Committee were similar to my own, although I reached mine independently. I felt that to extract a genuine surrender from the Emperor and his military advisers, there must be administered a tremendous shock which could carry convincing proof of our power to destroy the Empire. Such an effective shock would save many times the number of lives, both American and Japanese, than it would cost (McCullough 1992:394).

Motivated by a desire to end the war in the fastest way possible, the Truman administration began to ponder a Japanese invasion. Given Japan's refusal to surrender, the United States forged ahead with plans to drop the bomb.

The Enola Gay departed the Marianas on August 6, 1945. On board was the "Little Boy" bomb, the uranium-gun weapon produced in the Oak Ridge plants. The bomb was dropped on the city of Hiroshima immediately killing 
almost 100,000 people and fatally injuring 100,000 others. Hiroshima's destruction was felt for $5 \mathrm{sq}$ mi (Gosling 1990:51). Truman's statement followed immediately:

Sixteen hours ago an American airplane dropped one bomb on Hiroshima . . . It is an atomic bomb. It is a harnessing of the basic power of the universe . . . We are now prepared to obliterate more rapidly and completely every productive enterprise the Japanese have above ground in any city. We shall destroy their docks, their factories, and their communications. Let there be no mistake; we shall completely destroy Japan's power to make war ... If they do not now accept our terms they may expect a rain from the air, the like of which has never been seen on this earth ... (McCullough 1992:455).

Within hours of the bombing President Truman released a second statement warning Japan bombing would continue if unconditional surrender did not result. On August 9, 1945, the American's second atomic weapon, the "Fat Man" device made with Hanford's plutonium, was dropped on Nagasaki (Gosling 1990:53). While casualties were similar to Hiroshima, physical damage was limited due to the hills surrounding the city. Japan surrendered to American forces on Tuesday, August 14, 1945.

\section{NATIONAL LABORATORY DEVELOPMENT}

Within weeks of Japan's surrender, Congress decided to make the Oak Ridge plants permanent facilities with a focus on peacetime applications. In August 1946, the Atomic Energy Act became law transferring management of America's nuclear research program from military to civilian direction. The act established the AEC, which assumed leadership of the Oak Ridge facilities on January 1, 1947.

At the X-10 site, as previously noted, the University of Chicago had resigned as operator in 1945 and Monsanto Chemical Company had become the operating contractor. Drastic staff reductions were the norm for the entire ORR. In 1945, 82,000 people were employed on the reservation. In the three months following the bombing of Hiroshima, 51,000 workers remained on the reservation. By June 1946, reservation employment had dwindled to 34,000 .

In the years leading to World War II, the United States had not pursued science as a national interest. But to achieve an Allied victory, the federal government had funded scientific research. Federal funding, in the years following the war, was continued. Indeed, science was seen as the doorway to power and success. Research centered on a wide range of topics. Among them numbered spy planes, atomic weapons, advanced computers, improved radar systems, and long range missiles. During this period, the National Science Board, the National Science Foundation, and the Science Advisory Committee were organized. The U.S. Army and U.S. Navy also continued their individual research efforts.

General Groves also recognized the importance of research and in early 1946 began to develop a research budget for fiscal year 1947. Groves appointed an Advisory Committee on Research and Development to generate research ideas. The committee supported the expansion of further research and development in the production of fissionable materials and advanced training in nuclear studies, and suggested that national laboratories be established to conduct such research. Although neither the committee nor the AEC ever truly defined "national laboratory," it was generally understood that such facilities would serve the primary purpose of pursing unclassified fundamental research that required equipment too expensive for a private laboratory or 
university to underwrite. The Advisory Committee on Research and Development and later the AEC viewed such national laboratories as channels through which federal funds would flow to support nuclear research. Each laboratory would be assigned individual research responsibilities and have a board of directors chosen from participating universities.

General Groves also supported the establishment of national laboratories and strongly urged the formation of one at Oak Ridge. However, the Advisory Committee on Research and Development viewed the ORR more as an industrial site or an installation associated with commercial exploitation rather than as a university-affiliated laboratory, and did not originally recommend that it become a national laboratory. Instead, the committee proposed that national laboratories be established at Argonne near Chicago and at Brookhaven on Long Island (Hewlett and Anderson 1962:633-645).

After the ORR was not selected as a national laboratory site, William G. Pollard, a University of Tennessee physics professor who had work on the gaseous diffusion process at Columbia University during World War II, led a movement to form the Oak Ridge Institute of Nuclear Studies (ORINS). ORINS consisted of 14 universities from the southeast region and its purpose was to assist Monsanto Chemical Company in scientific staffing, to gain federal support, and to use the Clinton Laboratories for academic research. The project was approved, and the AEC provided space in existing buildings at the Townsite for ORINS (Hewlett and Anderson 1962:636). In 1949, the AEC gave ORINS the responsibility of managing the Museum of Atomic Energy, and in 1965, the organization changed its name to Oak Ridge Associated Universities (ORAU).

Immediately following World War II, the research focus at the Clinton Laboratories included reactor development, the production of radioactive isotopes for experimental purposes, the recovery of large amounts of uranium from the extraction wastes being held in storage, and the investigation of the effects of radiation on animals (Hewlett and Anderson 1962:627). Research on animals was coordinated through the Agricultural Research Laboratory, which was established in 1948 as a joint project between the AEC and the University of Tennessee; in 1981, ORAU acquired responsibility for this facility.

In 1946, Whitaker resigned as director of Clinton Laboratories, and James H. Lum and Eugene Wigner replaced him as co-directors. The site then turned its research focus on the development of new piles or reactors. However, in the interim between World War II and the transfer of the facility to the AEC in 1947, clear and longterm goals for the Clinton Laboratories were slow to emerge. Many leading advisors recommended that the site be closed and merged with the facility at Brookhaven, reasoning that the site's isolation and separation from a large university community would make it ineffective. However, the Clinton Laboratories was an established and working industrial site that the AEC could not easily abandon. Thus, during its first year of existence, the AEC, while not closing the Clinton Laboratories, did not clarify the site's mission. Problems developed with Monsanto as operator of the site, and in December 1947, AEC terminated its contract with the company and hired C\&CC effective March 1948. At the same time, the AEC designated Clinton Laboratories a national laboratory. Initially the site was named Clinton National Laboratory, but in 1948, the AEC changed the name to Oak Ridge National Laboratory (ORNL) (Pollard 28; Overholt 1987:358).

The third national laboratory created in the United States, ORNL was the only one located on its World War II site. These first national laboratories were intended to be regional centers where university scientists could pursue scientific research. Of the three, Brookhaven National Laboratory came the closest to being a true 
regional research center, while ORNL evolved into more of an industrial complex than an academic one. As an alternative, the AEC supported ORINS as a regional research center, and in combination with ORNL facilities, the two produced a program in research, training, and education that fulfilled its mission as a national laboratory (Hewlett and Hol 1989:253-254).

\section{THE COLD WAR ERA}

The successful creation of the atomic bombs dropped on Japan not only ended World War II; it thrust the United States to the forefront of nuclear science and weapons development in the context of Cold War with former ally, the U.S.S.R. The Cold War climate directed national policies and ideology, as well as an important future for Clinton Laboratories. As one of three major nuclear research facilities in the U.S. at the time, Clinton Laboratories would become, in the words of Eugene Wigner, "important in the life of the whole nation" (Johnson and Schaffer 1992:32).

During the race to build the first atomic bomb, uranium was the primary element sought for this purpose. Uranium also was required in the production of plutonium. During World War II, foreign sources, such as the Belgian Congo and Canada, supplied most of the Manhattan Project's uranium. However, uranium was a common by-product from vanadium mines in the American Southwest that operated before development of the atomic bomb. Manhattan Project personnel identified the availability of a small amount of uranium in the old radium-vanadium dumps and secretly ordered hundreds of Corps geologists to mine and mill these tailings for uranium oxide. In the post-war years, as the United States came to prioritize its nuclear weapons program, the federal government expanded its efforts sourcing domestic uranium. Under the Atomic Energy Act of 1946, the AEC had the authority to impose eminent domain on private properties for potential uranium mining, and in the late 1940s, the AEC established itself as the only legal buyer of uranium in the U.S. The AEC set and guaranteed artificially high prices for ten years and added a $\$ 10,000$ bonus for each individual discovery. The AEC enhanced these incentives by allowing prospectors to stake a uranium claim on public land for one dollar. The fervor for uranium was fueled through various media outlets in both scientific circles and popular culture. For example, the December 1949 issue of The Engineering and Mining Journal publicized the United States federal government's incentives for domestic uranium prospectors, in the article "Can Uranium Mining Pay?" (Ringholtz 1990). In an intensifying climate of Cold War with Russia, these actions created a mining rush in the Four Corners region.

In the immediate postwar years, the uranium industry consisted of individual prospectors and geologists in search of a large deposit to mine for themselves or on behalf of a large company (such as Union Carbide Corporation, which managed ORNL at the time). Small traces of ore were discovered, which would be transported from the mine to the uranium mill where it was converted into yellowcake. The 1951 discovery of pitchblende, a uranium-rich mineral, in the Chinle formation in southeastern Utah's Big Indian District changed the course of the U.S. uranium industry. Although the area had been condemned as unprofitable by the AEC and the U.S. Geological Survey, prospector-geologist Charles A. Steen staked several claims where low-grade uranium occurrences in the Cutler formation had been found. At a depth of $70 \mathrm{ft}$, the drill cored through $14 \mathrm{ft}$ of sandstone to reach the first commercial discovery of uraninite ore in the United States. It was the first of more than 10 million tons of uranium ore, worth more than $\$ 1$ billion, produced from the Big Indian District over the next 30 years (National Mining Hall of Fame and Museum n.d.). 
The resulting Uranium Boom of the 1950s was manifested in popular culture and the news media, fueled by a patriotic drive for U.S. nuclear advancement to outpace that of the Russians. Science during the 1950s was the ultimate tool of foreign policy, both in the context of Cold War weapons development and in peaceful applications of nuclear fission reactors and fusion energy devices. The facilities at ORR advanced both nuclear goals. Increasing Cold War tensions and the outbreak of the Korean War sparked rapid expansion of nuclear weapons production, increasing the workload at ORR's Y-12 and K-25 plants. At the same time, the AEC directed the ORNL to concentrate in three fields: basic research, chemical technology, and isotope production and research. ORNL's Cold War mission was further refined when in 1953, in the midst of Cold War tensions, President Dwight Eisenhower called for international cooperation in peaceful applications of atomic energy. His "Atoms for Peace" speech, praised world-wide, reenergized and refocused ORNL's research mission as a multifaceted research facility. Following this address, Eisenhower signed the 1954 Atomic Energy Act, which opened the door on partnerships between the AEC and private industry. AEC initiated a massive declassification of nuclear scientific data for private-user access and developed a five-year plan to construct five new demonstration nuclear reactors, including an aqueous homogeneous-fuel reactor at ORNL. ORNL Director Clarence Larson stated, "1954 has witnessed the transition that many of us have hoped for since the war. The increasing emphasis on peacetime applications of atomic energy" (Johnson and Schaffer 1992:63, 79-80).

To address ORNL's evolving missions in the Cold War era, in 1949, the AEC budgeted $\$ 20$ million for new construction, and Union Carbide initiated a building program named "Program H" at ORNL to replace many of the wooden wartime buildings with more permanent brick buildings. The program also included landscaping the grounds, paving streets, and renovating some older buildings. Approximately $250,000 \mathrm{sq} f \mathrm{ft}$ of new laboratory and office space was constructed east of or near the Graphite Reactor. The expansion included the construction of the Central Research and Administration Building North (Building 4500N), which became the center for a wide variety of research activities. Ten buildings were constructed to house research activities of the isotope program. Once scattered throughout the campus, the isotope program was now concentrated on what became known as Isotope "Alley" or Isotope Circle (Figures 8 and 9).

Throughout the period, education and training remained a key focus of ORNL. In 1946, Monsanto established the Clinton Training School on the site for training technical

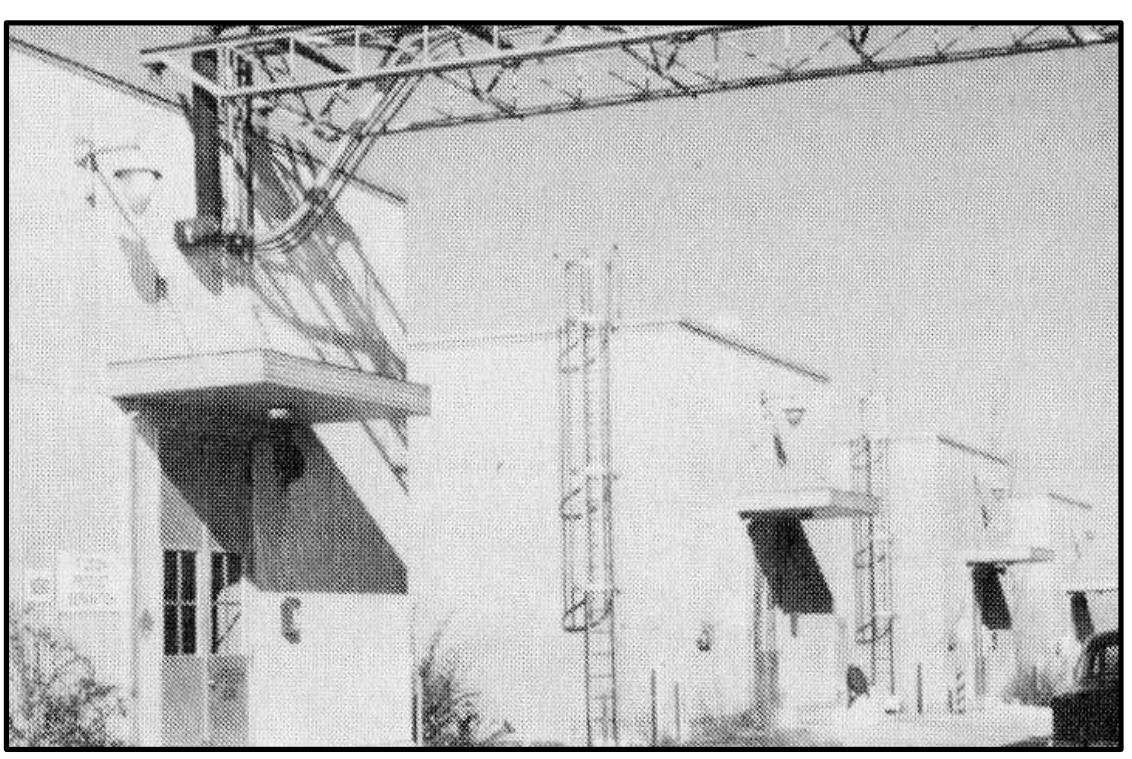

Figure 8. The Isotope "Alley" at ORNL. personnel in the various fields of nuclear science. Although it lasted only one year, several prominent scientists graduated from the program. An advanced training program known as the Oak Ridge School of Reactor 


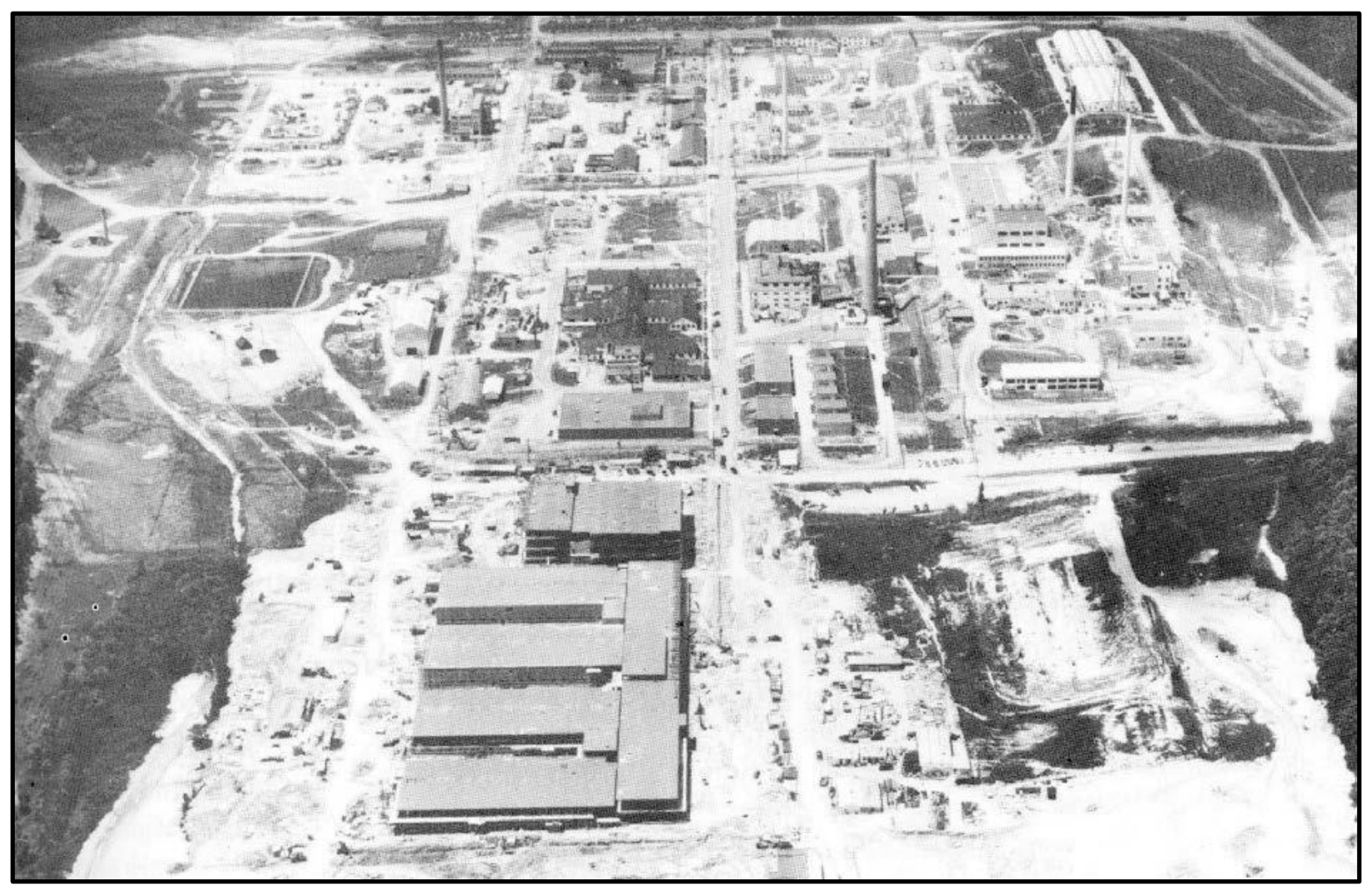

Figure 9. ORNL in the early 1950s. Building 4500N, the Central Research and Administration Facility, is in the foreground, and the Graphite Reactor (Building 3001) is in the upper right corner.

Technology (ORSORT) began on the site in 1950 and continued into 1957. A variation of the program continued until 1965. These programs were crucial in the dissemination of information about nuclear reactors and nuclear power (Johnson and Schafer 1992:43-46).

The following programs in operation at ORNL from the immediate post-war period through the 1950s made significant contributions to both the defensive and peaceful applications of nuclear energy:

Metallic Alloy and Ceramics Research: In 1946, the Clinton Laboratories had established a Metallurgical Division, which conducted intensive research into metallic elements under high temperatures and radiation stress in reactors. In 1952 a Ceramics Laboratory was also established on the site and conducted ceramics research; fabricated crucibles, insulators, and fuel elements; and customized parts for reactors. The Ceramics Laboratory became a world center for metallic alloy and ceramics research (Johnson and Schafer 1992:38-41).

Chemical Processing: Chemical processing also was a major mission of ORNL beginning in the late 1940s. This research involved the process of extracting desired materials from spent natural uranium fuel. The Chemical Technology Division was formed in 1950 and experimented with a wide variety of processing methods including the Redox and Purex processes. Much of this work was carried out in the pilot-plant stage in Building 3019. A number of reprocessing facilities worldwide currently use the Purex process developed at ORNL. In 1977, a new nuclear policy of the Carter administration resulted in less emphasis on 
nuclear fuel reprocessing. The Chemical Technology Division then began to focus on other areas of research such as waste management and environmental studies (Genung 1994:2-17, 2-27, 4-20, 4-64; Carver and Slater 1994:105).

Reactor Research: Due to the escalating hostilities with Russia and that nation's nuclear test in 1949, as well as mounting hostilities in Korea, the AEC increased its emphasis on reactor research. Argonne National Laboratory had been designated the main reactor laboratory, but its workload increased to such a degree that the site was not capable of handling all of the reactor research. As a result, AEC chose ORNL to do the overflow designs, which were some of the more unusual reactor concepts. ORNL's Reactor Experimental Engineering Division pursued various reactor designs in the 1940s and 1950s. These included an experimental homogeneous reactor that operated from 1951 to 1954, and a second such reactor developed in 1957 as part of the AEC's Power Demonstration Reactor Program, which researched the use of nuclear energy as a power source. The Oak Ridge Research Reactor (Building 3042) was completed in 1958 and operated until 1987. This high-performance reactor supported several scientific advances in physics and materials research, irradiations, and neutron beam studies (Johnson and Schaffer 1992:100-101).

Isotope Production: In the post-World War II period, the Graphite Reactor was used extensively to produce radioactive isotopes for research (Figure 10). The Isotopes Section, established in 1947, expanded into the Isotopes Division. Isotopes were distributed at cost for research in the fundamental sciences, for therapeutic research for humans, and for education and training research. In addition, the isotopes were used for valuable research in the study of effects of radiation on matter. By the early 1950s, ORNL had become the prime producer for the world's supply of radioisotopes, bringing much prestige to the laboratory and the AEC. The number of monthly shipments increased from 60 to 630 between August 1946 and January 1950 (Carver and Slater 1993).

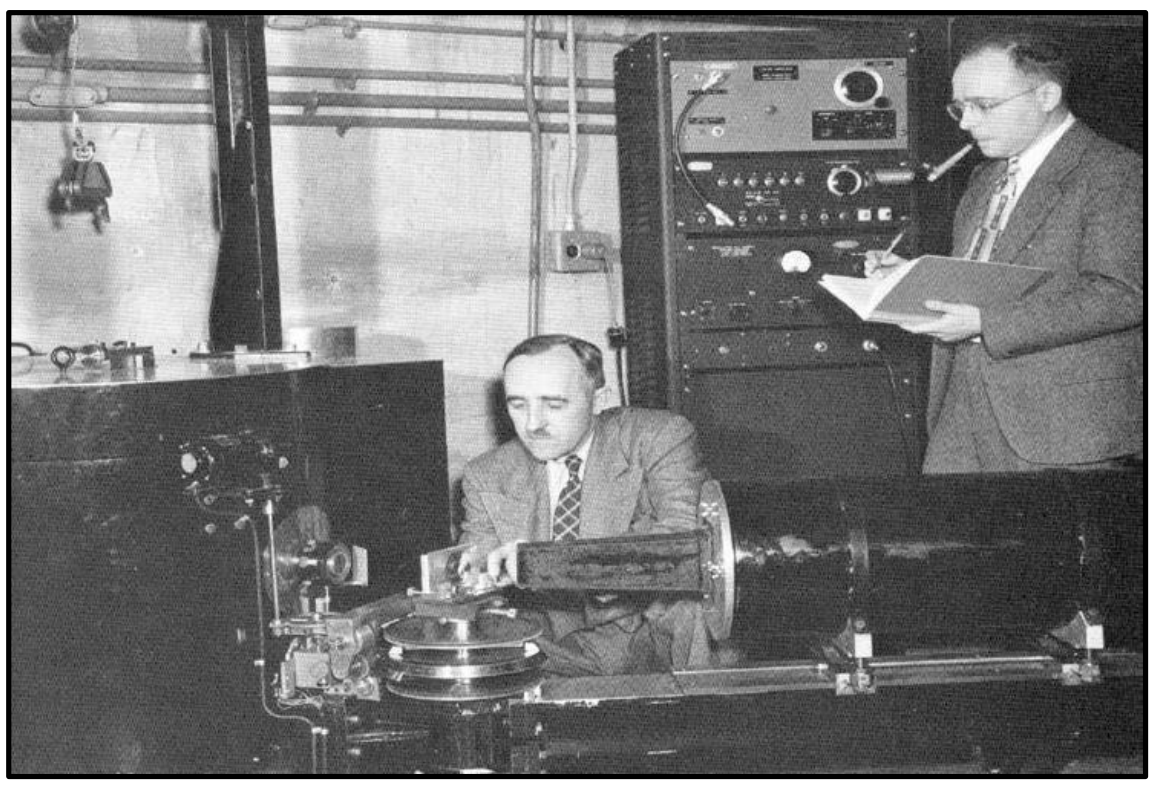

Figure 10.

ORNL scientists Ernest Wolland and Clifford Shull conducted some of the world's first neutron scattering experiments using this diffractometer built at ORNL and installed at the Graphite Reactor in 1950. This work laid the foundation for a number of programs in solid state physics and materials science at ORNL and, later, throughout the world. 
Nuclear Energy for Propulsion of Aircraft Project: A centerpiece of ORNL's research in the Cold War era was the application of atomic power for nuclear-powered submarines, aircraft, and ships. The U.S. Air Force established the Nuclear Energy for Propulsion of Aircraft Project in 1946 and began research in this field. Increasing hostilities of the Cold War convinced government officials to fund the project, and in 1949 the AEC ordered ORNL to pursue the research, which became known as the Aircraft Nuclear Propulsion (ANP) Program (Thompson 1963:90). At the time this was the only nuclear-powered aircraft research program in the United States. The U.S. Air Force closed out its own research program and jointly funded ORNL's research with the AEC. The ANP Program (later named the Aircraft Reactor Engineering Division) was a pivotal feature of ORNL's existence throughout the 1950s. ORNL constructed three unique reactors for the ANP Program, including the 2-MW Bulk Shielding Reactor (BSR, Building 3010), which was completed in December 1950. This reactor was used to study a variety of materials in bulk as shielding materials for use in aircraft. The design was relatively inexpensive, safe, and stable, and became a prototype for many research reactors around the world. It was significant in research of radiation damage processes in solids (Thompson 1963:68).

The second reactor constructed for the program was the Tower Shielding Facility (TSF, 7700 Area) (Figure 11). Completed in 1954 in an isolated area 2 mi south of the ORNL main campus, the TSF consists of four 315 -ft towers that stand on the corners of a $100 \times 200 \mathrm{ft}$ concrete pad. The towers support a reactor core that can be suspended in the air in a spherical container. It is the only reactor facility in the United States designed and built for radiation shielding studies in which both the reactor source and shield samples are raised into the air. The research conducted at the TSF addressed

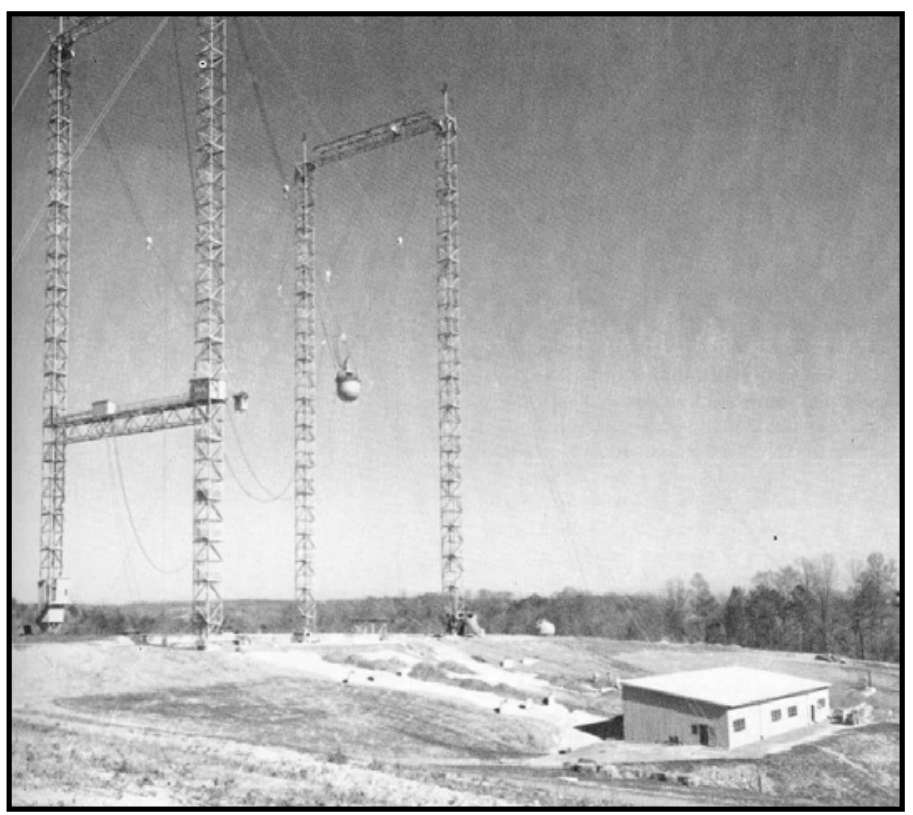

Figure 11. The TSF was completed in 1954. questions regarding the effects of radiation from a reactor flying overhead as well as the type and amount of shielding needed for a nuclear aircraft (Johnson and Schaffer 1992:66-70).

The third reactor developed for the ANP Program was an experimental liquid-fueled aircraft reactor known as the Aircraft Reactor Experiment or ARE. The ARE used molten (fused) uranium fluorides (salt) as its fuel. ORNL constructed Building 7503 to house the reactor approximately .5 mi south of the ORNL main campus. The reactor began operation in 1954. 
In 1957, Congress cancelled the ANP Program due to its high cost and advances made in supersonic aircraft and ballistic missile development. Although the project never resulted in a nuclear-powered aircraft it did generate valuable research in numerous areas including work with nuclear particle accelerators and studies of radiation damage. An outgrowth of the project was the development of the Physics of Solids Institute, which was established in 1950 to study radiation damage and related solid-state investigations. Another consequence of the project was the development of computers large enough to handle the vast quantities of scientific data the project generated. In the early 1950s, ORNL and Argonne scientists designed and fabricated the Oak Ridge Automatic Computer and Logical Engine (ORACLE) (Figure 12). When it became operational in 1954, this digital computer had the largest data storage and fastest speed of any in the world (Johnson and Schaffer 1992:71, 80-82; Thompson 1963:147148).

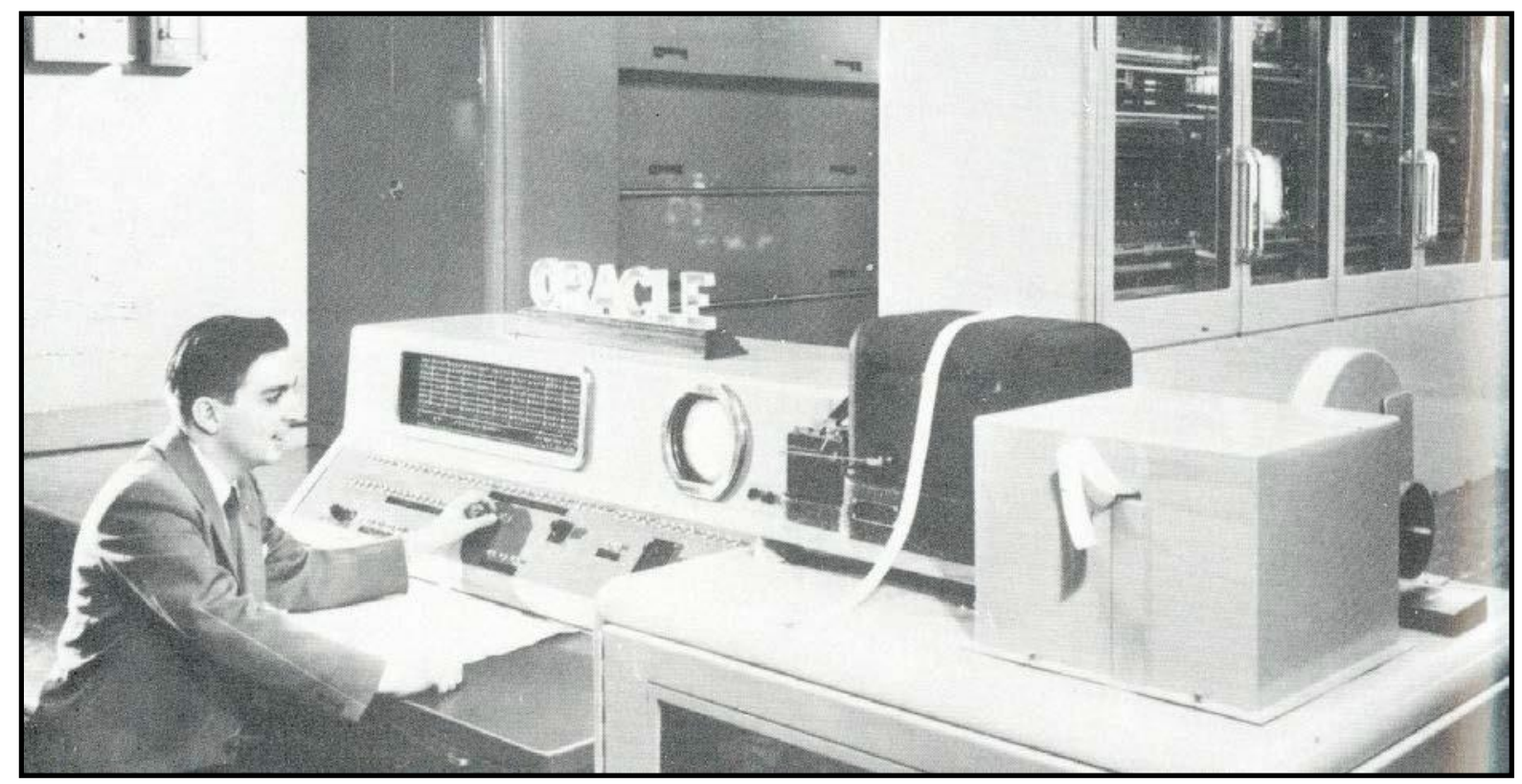

Figure 12. ORNL's ORACLE was the largest and fastest computer in the world in the mid 1950s.

Maritime Ship Reactor Program: ORNL scientists also were involved in the construction of nuclear-powered ships in the late 1950s and early 1960s through the Maritime Ship Reactor Program. The national laboratory provided technical support for the design and development of the N.S. Savannah. ORNL also provided support work such as obtaining port clearances until the ship was decommissioned in 1971 and the reactor removed (Greenstreet 1992:32-44).

Work with Y-12: In February 1950, ORNL and Y-12's research divisions merged, placing Y12 's calutrons within easy reach of ORNL staff. Research activities by ORNL were conducted at both the X-10 site and the Y-12 Plant (Johnson and Schaffer 1992:59-60, 78). Between the late 1940s and early 1950s, physicists constructed three cyclotrons (later synchrotrons) to examine properties of compound nuclei and heavy particle reactions. In 1951, engineering divisions from ORNL, the Reactor Experimental Engineering Division and the ANP Division, 
occupied buildings at Y-12. Y-12 housed ORNL scientists who came to fill the Biology, Chemical Technology, Engineering Technology, and Fusion Energy Divisions. Y-12 support of ORNL research involved parts fabrication for the High Flux Isotope Reactor (HFIR), the Molten Salt Reactor Experiment (MSRE), the Oak Ridge Isochronous Cyclotron (ORIC), and the DCX fusion experiment (ORNL 1992:2). ORNL personnel staffed in Y-12 buildings pursued diverse initiatives ranging from plant and experimental grafting studies to cancer research (Business Week 1965:54).

Project Sherwood: ORNL also played an important role in Project Sherwood, which researched whether or not the detonation of a thermonuclear weapon would touch off a chain reaction destroying the earth and its atmosphere. The AEC directed ORNL to construct a cyclotron to determine if this theory were indeed fact. Housing the new unit in Beta-3 (Building 9204-3) at the Y-12 Plant, ORNL erected and tested the unit within 18 months of the original request. Testing began in 1952 and was led by Dan Scott and Harry Reynolds. The team soon discovered a hydrogen bomb would not initiate a chain reaction immolating the earth. Their focus then turned to the unit's capability to basic research. The cyclotron became the world's first source of energetic heavy ions, creating "the interactions of complex nuclei in a new field of scientific investigation," an endeavor which allowed ORNL to pursue heavy ion nuclear science (Thompson 1963:145-146; Overholt 1987:362).

Health Physics Division: Health and safety issues were another important field of research at ORNL in the 1950s and 1960s. Physicists in ORNL's Health Physics Division initiated and refined safety features such as the remote handling of radioactive material, controlled access to "hot" areas, use of protective clothing, decontamination procedures, requirements for personnel monitoring, and the development of radiation surveys of buildings and the environment. The measurement of internal levels of radiation, known as internal dosimetry, became a study focus, and in 1960, the Internal Dosimetry Section was formed at ORNL, which conducted research for a variety of agencies (Johnson and Schaffer 1992:44-50, 120).

\section{DIVERSIFIED RESEARCH IN THE 1960s}

By the late 1950s, space exploration and the work of the National Aeronautics Space Administration (NASA) had come to overshadow nuclear research, and many were beginning to question the role of national laboratories. In response, ORNL elected to diversify its programs and developed missions outside the field of nuclear energy. During the 1960s, the large nuclear programs of the 1950s were replaced with projects or programs that were smaller in size but larger in number (Greenstreet 1992:51). The nature of the research also changed. For example, the Reactor Division had focused on the design, development, and construction of reactors in the 1950s, but in the 1960s it primarily worked on reactor operation and safety.

The change in direction led ORNL into a variety of new research fields. In the 1960s, ORNL began doing research projects for agencies other than the AEC, including NASA, the Department of Housing and Urban Development (HUD), the Department of the Interior (DOI), and the Department of State (DOS), although each project required AEC approval. By 1969, 14 percent of ORNL's programs were related to non-nuclear work for agencies other than the AEC. ORNL was the first national laboratory to diversify its programs in such a way, 
and after other national laboratories followed suit, ORNL led in the amount of non-nuclear research conducted. Research included a desalination project that worked on a process to remove salt from seawater and various civil defense programs. Nuclear research continued as well and included the development of a Molten Salt Reactor and an Experimental Gas-Cooled Reactor (Carver and Slater 1994:121-123).

President Lyndon Johnson favored and sought to incorporate desalination projects into foreign policy, reasoning that nuclear desalination centers in the arid Middle East could reduce competition for natural resources. The idea was well-received at the 1964 United Nations Conference on Peaceful Uses of Atomic Energy in Geneva, attended by both Johnson and Soviet Premier Nikita Khrushchev. That same year, ORNL staff traveled to Israel, India, Puerto Rico, Pakistan, Mexico, and the Soviet Union to assist with plans for desalination plants. However, despite Johnson's "Water for Peace" initiative, desalination projects proved cost-prohibitive, and no such facilities were ever constructed (Johnson and Schaffer 1992:110).

During the same period, tensions surrounding Berlin and Cuba strained U.S.-Soviet relations, spurring major civil defense funding. The escalating nuclear capabilities of both super powers during these Cold War years permeated American life. Schools practiced air-raid drills, and homeowners built fallout shelters in their backyards. ORNL's civil defense research explored the use of underground tunnels to protect urban populations. This research was both scientific (e.g., how to provide utilities and protect against blasts) and socio-psychological (e.g., how would population masses behave in the event of nuclear fall-out) (Johnson and Shaffer 1992:116-117).

The early 1960s began a period of major transition for ORNL, as it evolved into a premier international center for producing and separating transuranic elements. In support of the AEC reactor program, the ORNL pursued development of a molten salt reactor. An experimental molten salt reactor was designed and constructed in Building 7503, which formerly housed the ANP program, discontinued in 1957. Operation of the Molten Salt Reactor Experiment (MSRE) using U-235 fuel began in June 1965, followed by the use of U-233. The success of the MSRE prompted ORNL officials to seek approval for a molten salt breeder plant. Despite the success of the experimental concept, Congress decline to fund the pilot plant, instead prioritizing the Argonne breeder plant (Johnson and Schaffer 1992:137).

ORNL's Graphite Reactor was shut down on November 4, 1963 after 20 years of operation. The Oak Ridge Research Reactor (Building 3042), completed in 1958, then produced the majority of ORNL's radioisotopes. The High Flux Isotope Reactor (HFIR), which began operation in 1965, later served as a major source of radioisotopes for medical and industrial uses (Johnson and Schaffer 1992:36).

As knowledge of nuclear structure and nuclear reaction properties developed, there became an increasing interest in exploring the behavior of the nuclear force when nuclei were stressed beyond conditions generally present in nature. These studies involved producing new nuclear species beyond those present in nature, both those greater in atomic number than uranium, and those either proton-rich or neutron-rich far beyond existing stable nuclei. These studies also involved stressing nuclear material to high angular momentum and to high compression. More recently, there has been an emphasis on studying reactions induced by short-lived nuclei that exist only in extreme conditions such as stellar or supernova atmospheres. All of these advanced studies required development of new accelerator capabilities and advanced experimental detection devices. This led to the building of the Oak Ridge Isochronous Cyclotron (ORIC) and later the Holifield Heavy lon Research Facility 
(HHIRF). The ORIC was a variable energy, multi- particle accelerator with a constant orbit frequency of circulating ions. The concept of an Isochronous Cyclotron was first introduced in 1938; ORIC, which opened in 1962, was one of the first produced. At the time, ORIC's design was a major feat of technology (Johnson and Schaffer 1992:138).

\section{EXPANDED MISSION IN THE 1970s}

ORNL expanded its missions again in the 1970s. By this time, the AEC had significantly reduced ORNL's budget and staff. Funding for reactor research became unavailable and private companies were securing contracts for radioisotope and other research analysis. The number of staff at the site fell from 5,500 in 1968 to 3,800 in 1973. Research focuses at ORNL also began to shift as many scientists from the Manhattan Project era began to retire and the laboratory hired new employees with different research goals (Johnson and Schaffer 1992:124). A growing concern about nuclear waste disposal, the environmental effects of radiation, and the possibility of accidents at nuclear power plants led to criticism of the AEC and an increasing lack of confidence in nuclear power among the general public. To address these concerns, the AEC was reorganized as the Energy Research and Development Administration (ERDA) and the Nuclear Regulatory Commission (NRC) in 1974.

During the 1970s, ORNL broadened its missions to encompass all forms of energy research. In 1974 it formed an Energy Division that included economists, geographers, sociologists, and other social scientists. ORNL also expanded its environmental programs and non-nuclear research areas including energy conservation, materials resources, recycling, environmental analysis, and regional modeling (Johnson and Schaffer 1992:143-144, 164). As a result of the NEPA of 1971 , ORNL also began doing contract work on environmental impact statements.

In 1974, the Arab oil embargo brought national attention to energy issues, and ORNL became a leader in developing technical solutions to the energy crisis. At the time, ORNL was the only national laboratory to have a multi-program mission beyond nuclear science, and it received increased funding to engage in a broad range of energy-related research in conservation, coal, and nuclear energy (Genung 1994:4-74). This research led to an increase in the number of employees at ORNL, which reached 5,000 by the late 1970 s.

In 1977, the Department of Energy Act unified federal government energy programs, including the ERDA, under the newly-created DOE, and the nature of ORNL's work changed once more. This was in part due to President Carter's emphasis on energy conservation and "soft" energy such as solar programs as opposed to nuclear energy. The Carter administration's new focus for the national laboratories was as centers of excellence in specialized fields. DOE designated ORNL as the lead laboratory for coal technology and fuel reprocessing.

Union Carbide ended its tenure as facilities operator in 1982, and DOE awarded the operating contract to Martin Marietta Energy Systems (MMES) in 1983, which assumed control the following year. Energy Systems, Inc., a subsidiary organization, was established to administer the reservation and associated facilities (Johnson and Schaffer 1992:207). During the 1980s, ORNL expanded partnerships with industries and universities, and technology transfer of the institute's scientific and technological advances to the private sector increased its competitiveness in an international market. 


\section{POST-COLD WAR MISSIONS}

Although it continued to conduct nuclear research during the Cold War era, ORNL also expanded during that period to diversify in a wide range of research fields. As it entered the 1990s, the institute had become one of the top research centers in the world and "had emerged as a premier global research center for issues related to energy, environment, and basic science and technology" (Johnson and Schaffer 1992:vi-vii). As part of the effort to make U.S. companies more competitive, ORNL and Y-12 have been involved in technology transfer since 1984, when MMES began managing both facilities for DOE. Technology transfer was identified in the company's contract as a primary mission. As a result, both organizations offer a wide range of technology transfer options for licensing intellectual property and bringing new technologies to the marketplace.

In a publication celebrating 60 years of science at ORNL, the diversity of the laboratory's contributions to scientific knowledge, and more broadly to quality of life in the United States, is striking. Impacts range from improved nuclear power production to construction of energy-efficient buildings; from production of radioisotopes for the treatment of cancer to the creation of ion-implanted materials for more durable artificial joints; from improved understanding of supernovas to development of geographic information systems technology; and from development of desalinization technology to use of bacteria for bioremediation of industrial wastes. While celebrating past accomplishments, the publication also looked forward to the planned opening of the Spallation Neutron Source (SNS) in 2006, which would establish ORNL as "the world's foremost center of neutron science research" (ORNL 2003:1).

Indeed, SNS demonstrates ORNL's commitment to innovation in neutron science and, over 10 years after the facility went active, it continues to be the most powerful neutron source in the world, attracting hundreds of domestic and international researchers every year. As described on its website:

SNS is a one-of-a-kind research facility that provides the most intense pulsed neutron beams in the world for scientific research and industrial development. SNS produces neutrons with an accelerator-based system that delivers short (microsecond) proton pulses to a target/moderator system, where neutrons are produced by a process called spallation. Stateof-the-art experiment stations provide a variety of capabilities for researchers across a broad range of disciplines, such as physics, chemistry, materials science, and biology.

With its more intense, brighter source of neutrons and world-class instrumentation, SNS provides the neutron scattering community with unprecedented research opportunities. SNS allows for measurements of greater sensitivity, higher speed, higher resolution, and in more complex sample environments than have been possible at existing neutron facilities (ORNL 2017).

HFIR, constructed in the 1960s, also provides world-class capabilities in neutron scattering research.

Today, ORNL remains one of DOE's most diverse multi-purpose research laboratories and provides research and development for both government agencies and private industries. Its primary mission continues to be centered on energy research. Areas of ongoing research include neutron scattering; high-performance computing and data analytics; advanced materials; nuclear science and engineering; biological, environmental, and earth system science; sustainability; and science and technology for national security (ORNL 2017). 
Appearing before the Subcommittee on Energy of the U.S. House of Representatives in 2013, Director Thomas E. Mason stated that ORNL became one of eight national labs piloting the DOE's Agreement to Commercialize Technology (ACT) program, augmenting ORNL's accessibility to private technological research. Mason lauded the co-location of multiple superlative research facilities at ORNL, including the SNS, the world's most powerful source of pulsed neutrons for research; the HFIR, one of the world's most capable research reactors; and the world's second most powerful supercomputer, a Cray XK7, called Titan, the flagship system at the Oak Ridge Leadership Computing Facility.

The ORNL remains committed to the goal of ensuring that the national labs remain effective and continue to deliver national benefits to the taxpayers. The public funding that comes to the labs is based on the promise of a return to society in the form of discovery and innovation leading to clean and affordable energy, improved standards of living, a more secure future, and a vibrant economy. Today ORNL's programs include: expanding ACT agreements, implementing flexible pricing for user facilities, allowing labs autonomy in nonfederal fundingpartnership agreements to streamline the approval process; adding weight to technology transfer for those labs whose R\&D portfolios intersect the commercial world; and executing consistent guidelines on conflicts of interest through appropriate mechanisms for fostering an entrepreneurial culture and developing productive industry collaborations (Mason 2013). 
This page intentionally left blank 


\section{RESULTS}

The results of the field survey are presented in the following section. Based on the previously-described survey methods and the survey list generated in coordination with UT-B staff, a total of 195 buildings were included in the survey. Of these, 16 resources, all located in the 7700 Area, were completely inaccessible at the time of the field survey, thus the information presented is based on previous studies, and the current NRHP status of the 7700 sites is undetermined. The UT-B team identified 15 buildings (Buildings 3025E, 3037, 3500, 4500N, $4500 S, 4501,4505,4508,5500,6000,6010,7900,7901,7920$, and 7930) for more intensive survey because such buildings are central to ORNL's future mission needs and are expected to undergo renovations in the foreseeable future. These building were subject to both exterior and interior documentation with particular focus on identifying character-defining features, thus their descriptions and evaluations are more detailed than most other resources. A summary of the survey results, including a NRHP recommendation for each resource, is presented in Appendix A. A site plan for ORNL depicting NRHP-listed and eligible resources is included as Appendix $B$, an oversized map provided in the pocket at the back of this report. Figure 13 depicts NRHP-listed and eligible resources on aerial photographs.

The following discussion of survey results is divided by geographic area of ORNL. There are 12 distinct areas containing resources built prior to 1980 at ORNL, in addition to several such resources located in outlying areas (Figure 14). The 1500, 2000, 3000, 4000, 5000, 6000, and 7000 Areas are located south of Bethel Valley Road. Areas progress numerically from west to east. The 3000 Area was the original heart of the X-10 facility, including the Graphite Reactor. Development extended to the east and west of this area in post-World War II period, with support facilities located in the 2000 Area, several key processing and research facilities in the 3000 Area, additional laboratories in the 4000 Area, and the building housing the national laboratory's first accelerator in the 5000 Area . During the same period the 7000 Area was established as an outlying maintenance area, slightly separated from the central campus. The 6000 Area was first developed in the 1960s to house the Oak Ridge Isochronous Cyclotron (ORIC), and the 1500 area did not begin to reflect its current form as the home of the Environmental Science Division until the 1970s. The 7500, 7600, 7700, 7800, and 7900 Areas are located south of Melton Valley Drive, south of the main section of the campus. While the areas of the main campus are adjacent to one another, these southern areas are geographically distinct, each featuring a unique processing facility and related research facilities. These facilities were added to ORNL in the 1950s and 1960s. The Spallation Neutron Source (SNS), ORNL's newest research facility, is located north of Bethel Valley Road, at the end of Spallation Drive. Constructed in the 2000s, SNS was not included in the current survey.

Since the buildings within a given area are geographically related and generally serve a common research program, set of programs, or related function within ORNL, the area represents an appropriate unit for evaluation as a potential historic district. Thus, the individual building descriptions for each area are preceded by a description and NRHP district evaluation of the area as a whole. An evaluation of the previouslyrecommended ORNL Historic District, which includes portions of the 3000, 4000, and 5000 areas, is included at the end of the results section.

In addition to utilizing district-level analysis, CRA found it useful to analyze the survey results in terms of building types. Based on field observations and the building typology presented in Thomason and Associates' 2004 HPP, CRA identified five key building types at ORNL: research/laboratory facilities, processing facilities, offices, 
storage facilities, and utilities/maintenance facilities (Thomason and Associates 2004:56-61). While there are sometimes physical similarities among the recorded examples of each given building type, such physical characteristics are secondary to their common associative characteristics and their place within the historic context of ORNL. A discussion of building types, including characteristics that would qualify individual examples for listing in the NRHP, is included below. Historic districts are presented as an additional property type to explain the reasoning that guided district-level evaluations. A small handful of resources on ORNL property do not fall within any of the established property types; generally these resources predate the establishment of the $\mathrm{ORR}$, or they are facility infrastructure such as bridges and culverts.

Research/laboratory facilities $(n=46)$ may be significant for their association with research and development at ORNL during the Cold War era. The most significant group of such facilities is known as Isotope Circle, a concentration of buildings constructed during the early history of the national laboratory for research regarding the production and use of various radioisotopes. Most research/laboratory facilities are one to four stories tall with rectangular or rectilinear flat-roof forms and exhibit steel frame construction with brick veneer or corrugated metal siding. While some contain simple embellishments at their entrances, windows, and rooflines, including, for example, rows of soldier course brick or panels of concrete, they generally display minimal evidence of stylistic influences on their design apart from a very simple modern institutional aesthetic.

While very important work occurred in ORNL's research and laboratory facilities, it is difficult to quantify the individual significance of any one building. Although each was the location of significant scientific achievements made by notable researchers within their respective fields, the significance of these laboratories to American history more broadly lies in the role that they played in advancing the overall mission of ORNL during the Cold War era. Such significance is derived from their location within the larger research facility; much of the work that occurred in these buildings, for example, relied on the radioisotopes produced in ORNL's processing facilities. Thus, most research and laboratory facilities will qualify for listing in the NRHP as part of a historic district in order to reflect the significant role that they played in the advancement of ORNL's mission in nuclear science, isotope research, or other key fields of study during the Cold War era. Unless such a facility is the one building most closely associated with a scientific breakthrough or a scientist of truly exceptional importance, the building's significance will be most appropriately recognized as a component part of the larger laboratory, thus it will not qualify for individual listing in the NRHP under Criterion A or B. Most research and laboratory buildings exhibit the simple institutional design that characterizes ORNL's Cold War era facilities, lacking notable stylistic elements, thus they generally will not qualify for listing in the NRHP under Criterion C, although buildings could be considered for listing under Criterion $C$ if they exhibited innovative engineering related to the state-of-the-art research facilities housed within the building.

Processing facilities $(n=16)$ are associated with Manhattan Project and Cold War-era achievements in nuclear science and energy. They include the buildings that housed ORNL's reactors, accelerators, and chemical processing plants used for production of plutonium, radioisotopes, other transuranic elements, and subatomic particles for a wide variety of experimental and practical applications, and for experiments in nuclear power production. The NHL Graphite Reactor (Building 3001) is the most prominent of such facilities, serving as the anchor of the ORNL Historic District that also includes other processing facilities associated with Manhattan Project plutonium production and Cold War-era isotope production. Other significant processing facilities 


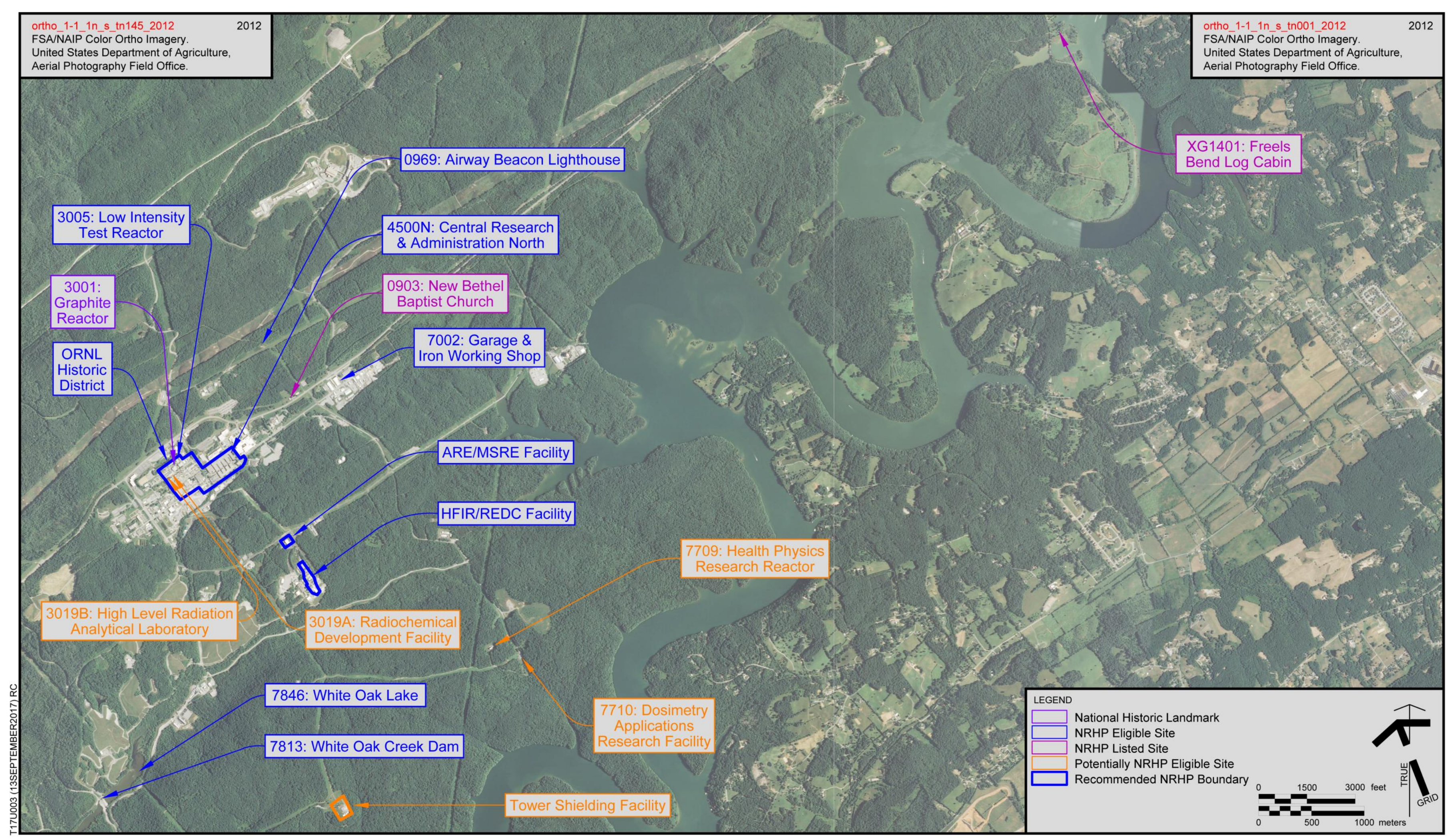

Figure 13. Aerial photograph depicting the locations of NRHP-listed and eligible historic resources 
This page intentionally left blank 


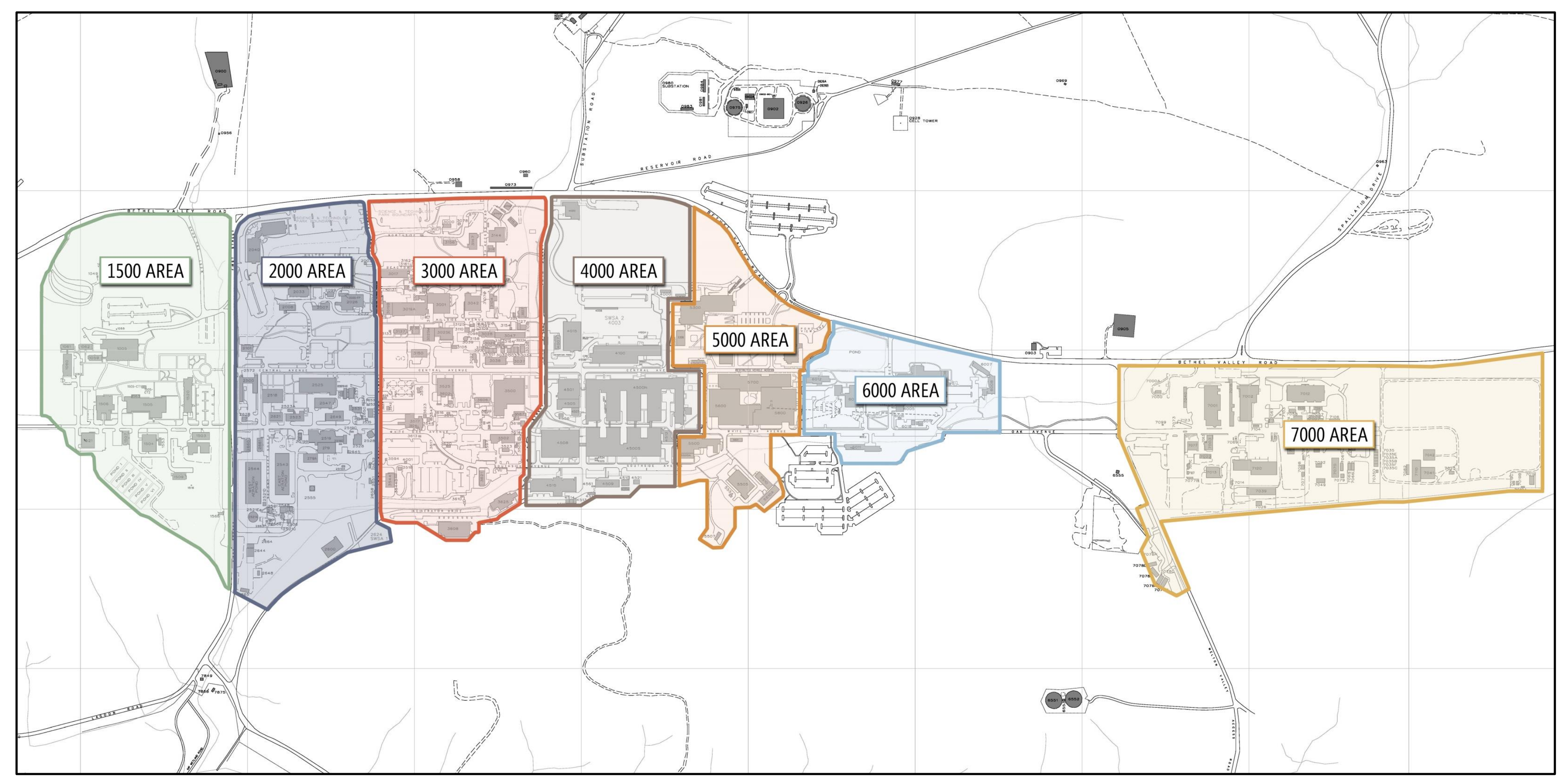

Figure 14. Site plan depicting the limits of each area of ORNL within the main campus. 
This page intentionally left blank 
constructed in the Cold War era likewise serve as the centerpieces of their respective areas at ORNL - for example ORELA in the 6000 Area, MSRE in the 7500 Area, TSF in the 7700 Area, and HFIR in the 7900 Area. While some of the processing facilities are simple rectilinear buildings with corrugated metal or concrete block exteriors, others exhibit distinctive and innovative designs reflecting their specific use and purpose, most notably the TSF.

ORNL's reactors and accelerators are its premier facilities that make much of the research that occurs here possible and continue to attract researchers from around the world. They allowed X-10 to achieve its Manhattan Project mission and have contributed to major advancements in many fields of science since then. Such facilities that offer one-of-a-kind capabilities, were the prototype for similar facilities built elsewhere, or that made scientific contributions of widely-recognized importance to the broad patterns of American history may be eligible for listing in the NRHP under Criterion A. Processing facilities are most appropriately considered for NRHP listing as part of a larger facility or historic district that includes associated laboratories and support facilities in order to fully illustrate how these buildings operated in concert to make notable advancements in science. They are, however, the lynchpins of such districts, and may be considered for individual listing in cases when an intact district does not exist and the facility exhibits exceptional significance within the context of ORNL and nuclear scientific advancement in the twentieth century. Such processing facilities also may be individually eligible for listing in the NRHP under Criterion $\mathrm{C}$ if the form and design of the building results from significant innovations needed to house the significant equipment inside.

Several of ORNL's processing facilities have been designated landmarks by various scientific organizations. HFIR, for example, has been designated a Nuclear Historic Landmark by the American Nuclear Society. While such designation does not automatically connote NRHP eligibility, it certainly suggests a level of significance worthy of careful consideration.

Offices $(n=11)$ include those buildings that provide office space for administrative and supportive functions relative to the laboratory and processing facilities and overall operation of ORNL. Laboratory buildings also often contain office space but are more appropriately evaluated as labs. Office buildings typically exhibit rectangular, flat-roof forms with brick exteriors and simple detailing, not unlike some laboratories. They may have more windows since they do not require the same environmental control as the research facilities. Overall offices exhibit simple, modern institutional design.

Since offices are not the primary sites associated with scientific achievements at ORNL, they are unlikely to rise to the level of significance needed for individual listing in the NRHP under Criterion A or B. If located within an intact grouping of associated laboratory and processing facilities, however, they could be considered contributing elements within an eligible district for their association with the work of the national laboratory during its period of significance. Since office buildings exhibit the simple institutional design that characterizes ORNL's Cold War era facilities, lacking notable stylistic elements or innovative design features, they generally will not qualify for listing in the NRHP under Criterion C.

Storage Facilities $(n=33)$ are warehouses and other related buildings used for material storage, shipping, and receiving. Generally they are simple rectangular buildings with metal-clad, steel-frame construction; some are constructed of concrete. These utilitarian buildings display few if any notable architectural details. 
Like offices, storage facilities are not the primary sites associated with scientific achievements at ORNL, thus they are unlikely to rise to the level of significance needed for individual listing in the NRHP under Criterion A or B. Two exceptions have been identified, however, that are considered to have particular significance to the history of the national laboratory. Buildings 7001 and 7002, located outside of the ORNL Historic District, were previously determined individually eligible based on the significant role that they played in Program $\mathrm{H}$, the major building program at the new national laboratory in the years following World War II. Most storage facilities, however, will only qualify for listing in the NRHP if they are located within an intact grouping of associated laboratory and processing facilities and thus could be considered contributing elements within an eligible district for their association with the work of the national laboratory during its period of significance. Since storage facilities exhibit simple utilitarian designs, lacking notable stylistic elements or innovative design features, they generally will not qualify for listing in the NRHP under Criterion C.

Utilities and Maintenance Facilities $(n=69)$ include a wide range of building types such as pump houses, exhaust stacks, filter houses, power and generator buildings, machine shops, sewage pumping stations, and waste disposal facilities. Their forms and construction vary based on their function, but they generally are purely utilitarian in character with little if any architectural detailing.

Like offices and storage facilities, utilities and maintenance facilities are not the primary sites associated with scientific achievements at ORNL, thus they are unlikely to rise to the level of significance needed for individual listing in the NRHP under Criterion A or B. Utilities and maintenance facilities are integral to the functioning of the research and processing facilities at ORNL, however, thus they will qualify for listing in the NRHP if they are located within an intact grouping of associated laboratory and processing facilities and thus could be considered contributing elements within an eligible district for their association with the work of the national laboratory during its period of significance. Since utilities and maintenance facilities generally exhibit simple utilitarian designs, lacking notable stylistic elements or innovative design features, they typically will not qualify for listing in the NRHP under Criterion C.

Historic Districts, as indicated by the above-discussion, are an important property type for understanding the interrelatedness of the buildings that comprise ORNL. Since ORNL has undergone extensive changes over the past several decades, including both demolitions and new construction, the national laboratory does not retain integrity to consider the entire property as a historic district. Instead, district-level analysis is most appropriately considered at the level of the individual area at ORNL, consisting of groups of buildings related to common research missions or other common functions within the national laboratory, although buildings within adjacent areas may contribute to a single district, as is the case in the central ORNL Historic District. If an entire area lacks integrity as a historic district, district boundaries may be drawn to encompass the most significant and intact portion of the area.

Districts should display clear associations to the central areas of significance of ORNL, namely its origins as the Manhattan Project's X-10 facility that pioneered the production of plutonium and thus contributed to the creation of the world's first atomic bombs that ended the war with Japan, and its subsequent development as Oak Ridge National Laboratory, a government-owned, contractor-operated, leading scientific research facility that made significant contributions in advancing both defensive and peacetime applications of nuclear science, as well as other fields of scientific inquiry, during the Cold War era. A district may be broadly associated with one or both of these areas of significance as the site of a wide range of scientific research and discovery throughout the mid to 
late twentieth century, as is the case for the central ORNL Historic District, or it may have more specific associations with an individual program of particular significance within these broad contexts, as is the case for potential districts located in outlying areas.

An eligible historic district at ORNL will retain its core research and processing facilities where key scientific advancements occurred. Most frequently this will include at least one major reactor or accelerator building of particular importance to the research mission(s) being pursued in that area. The loss of such a pivotal facility generally will preclude consideration of an area as a historic district. All other laboratory, office, storage, and utility/maintenance facilities located in the area and directly related to the functioning of the area as a research center during the period of significance will contribute to the district.

When evaluating both historic districts and individual buildings and structures at ORNL, CRA considered NRHP guidance regarding how resource age should be considered in significance evaluations. While the NRHP generally requires that resources are at least 50 years old to qualify for listing to help ensure adequate historic perspective for understanding its lasting historic importance, Criteria Consideration $\mathrm{G}$ allows for listing resources less than 50 years old if they possess extraordinary significance in local, state, or national history. When first evaluated in 1993, ORNL's Manhattan Project-era resources were 50 years old, but its Cold War-era resources were not. Criteria Consideration G was found to apply to the ORNL Historic District, Buildings 7001 and 7002 in the East Support Area, the Aircraft Reactor Experiment Building (Molten Salt Reactor, 7503), the Tower Shielding Facility (7700), and White Oak Lake and Dam (7813 and 7846) as resources of exceptional importance to the establishment and early Cold War missions of ORNL in the years following World War II. Today, all of these resources are over 50 years old, so Criteria Consideration $\mathrm{G}$ no longer applies.

While the current survey accounted for buildings constructed through 1980, in consideration of the historic context, CRA finds that, in general, the 50-year cutoff marks an appropriate end to the period of significance for the historic resources of ORNL. As discussed in the historic context, by the end of the 1960s, almost all of ORNL's key processing facilities were constructed. Many of the Manhattan Project scientists and early pioneers in nuclear research were retiring. The 1970s brought increased public concern regarding environmental issues, the effects of nuclear waste, and the potential impacts of nuclear power. Consequently NEPA was passed in 1971, and the AEC was reorganized as the ERDA and the NRC in 1974. The oil embargo and the priorities of the Carter Administration also encouraged new directions in energy research. Such changes led to an expanded mission for ORNL to include all forms of energy research and new programs in environmental science and other areas of non-nuclear scientific research. While much significant scientific work continued at the national laboratory throughout the period, it is not clear that such work, in a broad sense, rises to the level of significance to merit considering associated resources for listing in the NRHP under Criteria Consideration G.

Some of ORNL's individual processing facilities and immediately associated resources (particularly HRIBF and ORELA in the 6000 Area and HFIR in the 7900 Area) were constructed or expanded from the mid-1960s through 1980. The scientific work that occurred at the facilities during this period should be evaluated for its individual significance beyond the overall context of the national laboratory. While such facilities have been previously identified for their significance within their respective fields of science, CRA recommends that to qualify for listing in the NRHP under Criteria Consideration $G$ the facilities' significance should be recognized beyond the scientific community. That is, it should be clear how the important scientific work that occurred at these facilities has had significant impact on society more broadly. 
This page intentionally left blank 


\title{
OUTLYING AREAS
}

\author{
NRHP-LISTED \\ Building 0903 \\ Building XG1401 \\ Building XG1414 \\ ELIGIBLE \\ Building 0969 \\ NOT ELIGIBLE \\ Building 0907/0970 \\ Building XF1301 \\ Building XF1302 \\ Building XF1303 \\ Building XG1402 \\ Building XG1404 \\ Building XG1410 \\ Building XG1416
}


This page intentionally left blank 


\section{OUTLYING AREAS}

\section{DISTRICT NAME}

N/A

\section{DATE OF CONSTRUCTION}

1844-1968

NRHP ELIGIBILITY

N/A

\section{DESCRIPTION}

Several resources, scattered beyond the main campus of ORNL, are best described as ORNL's outlying properties. These properties, identified by $09, \mathrm{XF}$, and XG numbers, are not directly associated with the historic missions of ORNL, however they are currently associated with the facility. Four of these outlying propertiesNew Bethel Valley Baptist Church and Cemetery (Building 0903), the Airway Beacon Light House (Building 0909), Freels Bend Log Cabin (Building XG1401), and Freels Bend Outhouse/Smokehouse (Building XG1404)-pre-date the development of the Oak Ridge Reservation (ORR) and represent life in Bethel Valley and Freels Bend prior to the creation of the city of Oak Ridge and its associated facilities. 


\section{BUILDING NAME}

New Bethel Baptist Church and Cemetery

DATE OF CONSTRUCTION

1924

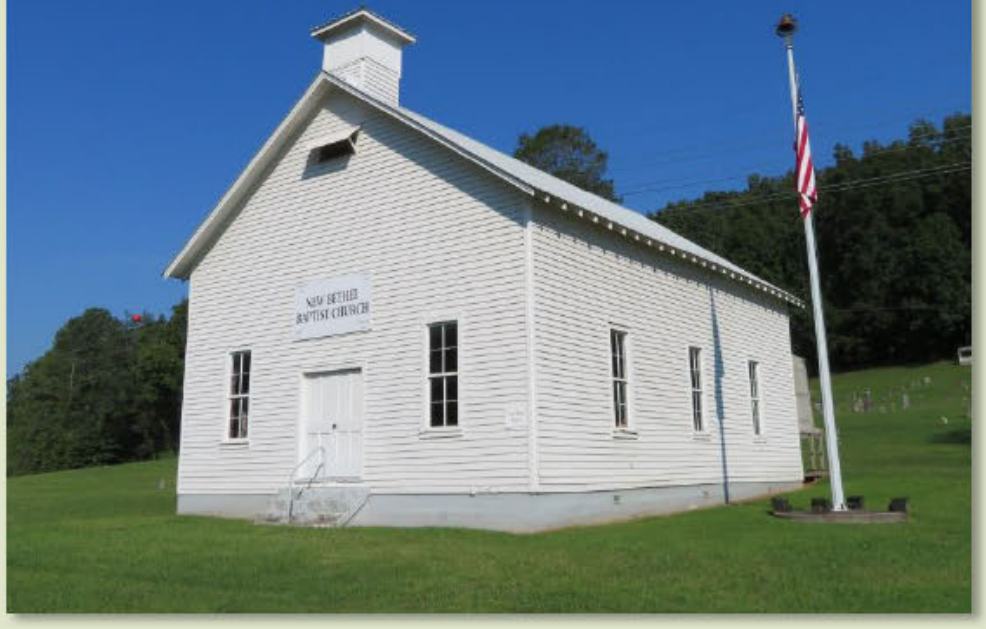

EM

Figure 15. Overview of south and east elevations of Building 0903.

NRHP ELIGIBILITY

NRHP-listed

\section{DESCRIPTION}

New Bethel Baptist Church, Building 0903, is a one-story, front-gable church (Figure 15). It features frame construction clad in wood weatherboard siding and is sheltered by a metal-clad, front-gable roof with exposed rafter tails and pierced by an enclosed bell tower with a metal pyramidal roof. Windows throughout feature fourover-four-light, double-hung wood sashes. The facade entry is comprised of a set of double-leaf wood panel doors that open to concrete steps.

A cemetery and memorial are also associated with New Bethel Church. The cemetery, which contains 323 interments dating as early as the 1860s, also includes two unique grave houses (FindAGrave 2017). Each of the grave houses features a gable roof supported by square posts sheltering multiple graves outlined by a picket fence. A memorial, comprised of a large stone marker, is located behind the church. Erected in 1949, the marker's inscription reads, "The church having been left in extended session from 1942, this monument was dedicated and the final church session closed at Memorial Day services May 29, 1949."

\section{NATIONAL REGISTER EVALUATION}

Constructed in 1924, the New Bethel Baptist Church replaced an earlier circa 1851 church and served the residents of Scarboro during the early twentieth century before the development of ORR and ORNL. New Bethel Baptist Church, (Building 0903) the cemetery, and the marker were listed in the NRHP in 1992 as part of the Historic and Architectural Resources in Oak Ridge MPL. They are significant under Criterion A for their role in the social history of Oak Ridge both before and during the Manhattan Project and under Criterion $C$ for their architectural significance. The church and grave houses met Criteria Consideration A because they are architecturally and historically significant religious properties. The marker also met Criteria Consideration $\mathrm{F}$ as a commemorative property due to the significance associated with its closure and use through 1949. The church also met Criteria Consideration $\mathrm{G}$, due to its use as a meeting room by scientists during the Manhattan Project (Murphy and Thomason 1991). CRA finds that the New Bethel Church retains a high degree of integrity for continued NRHP listing under Criteria $A$ and $C$ and Criteria Considerations $A$ and $F$. Criteria Consideration $G$ is no longer needed given the passage of time since the nomination in 1991. 


\section{$0907 / 0970$}

\section{BUILDING NAME}

Walker Branch Watershed Lab; previously Known as "Installation Dog" and later, as "Katy's Kitchen"

\section{DATE OF CONSTRUCTION}

1948

DOE OFFICE RESPONSIBLE

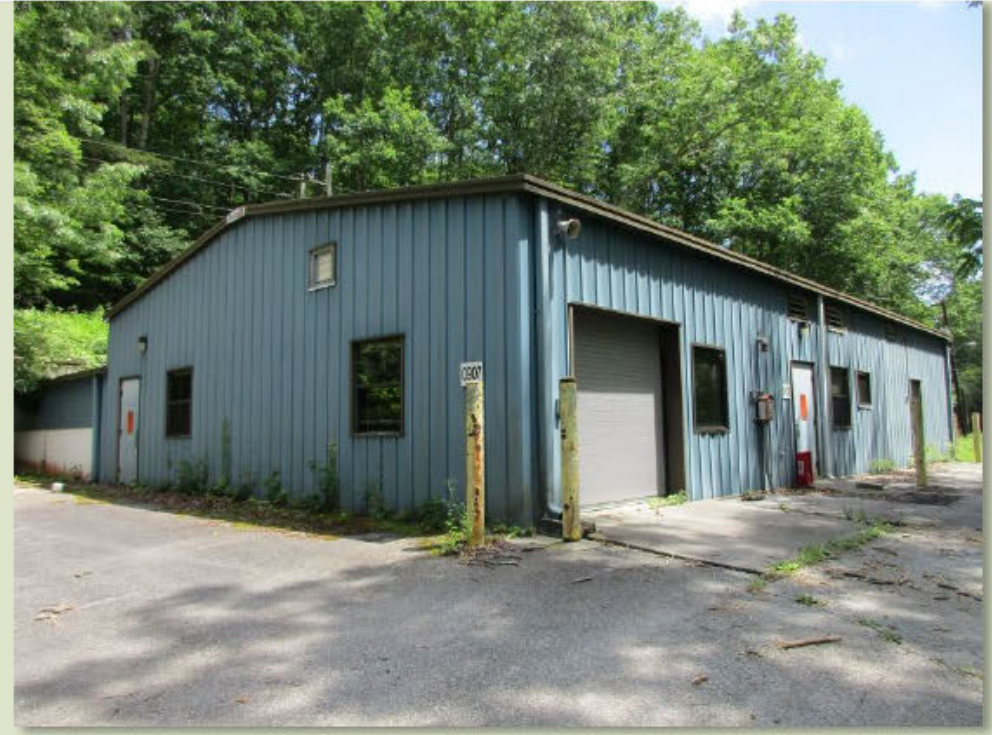

Figure 16. Overview of north and west elevations of Building 0907.

SC

NRHP ELIGIBILITY

Not Eligible

\section{DESCRIPTION}

The core of the Walker Branch Watershed Lab is currently comprised of a one-story side-gabled modern Kirby metal building and concrete bunker, Building 0907, and a "silo" guard tower, Building 0970 (Figures 16 and 17). The pre-fabricated metal building, constructed in 1988, features one-light fixed and one-over-one-light, doublehung vinyl windows, a modern overhead garage bay, and single-leaf metal doors. A cross-gable concrete block extension connects the metal building to the entrance of the bunker. The slope into which it is set is covered in overgrown vegetation. According to Thomason's 2015 survey, the bunker features reinforced concrete walls that are 12 in thick and a vault with walls that are 18 in thick (Thomason and Associates 2015:239). The "silo" guard tower, Building 0970 , which is comprised of seven pre-cast concrete culverts stacked together and topped by an eight-sided metal roof, features a row of single-light open windows under the eaves of the roof.

\section{NATIONAL REGISTER EVALUATION}

In 1994 this complex, the Walker Branch Watershed Lab was recommended as not eligible for listing in the NRHP. While the complex once served as a top-secret storage facility for U-235 known as "Installation Dog" and later "Katy's Kitchen," it no longer serves that purpose. In fact, it only served as a storage facility for one year before it sat vacant between 1949 and 1957. In 1957 the complex became part of the Analytical Chemistry Division at ORNL and it was used as a low-level radiation counting laboratory. The name Katy's Kitchen comes from the name of the Director of the Analytical Chemistry Division, Katherine Odom. In 2017 the building sits vacant following its shutdown on August 22, 2016 (Thomason and Associates 2015:239).

In 1994, Duvall and Associates determined that the facility was not eligible for listing in the NRHP due to a lack of integrity. The interior of the bunker remained relatively intact; however, the integrity of the complex had been minimized by the removal of the barn and wood staves and metal bands on the silo that served as camouflage for the top secret facility. Furthermore, the installation of the modern metal building further disrupted the setting of the complex (Carver and Slater 1994). In 2015, Thomason and Associates concurred with the 1994 assessment of the Walker Branch Watershed Lab (Thomason and Associates 2015). CRA concurs with the 
previous assessments that despite significant historical associations under Criterion $A$ for nuclear research activities at ORNL, alterations to the site have diminished the integrity of setting, materials, workmanship, feeling, and association to such a degree that it cannot convey its significant associations. Furthermore, research did not reveal significant associations to people (Criterion B) or design or architecture (Criterion $\mathrm{C}$ ) to warrant listing in the NRHP. Thus, CRA recommends that Buildings 0907 and 0970, the Walker Branch Watershed Lab, is not eligible for listing in the NRHP under Criterion A, B, or C.

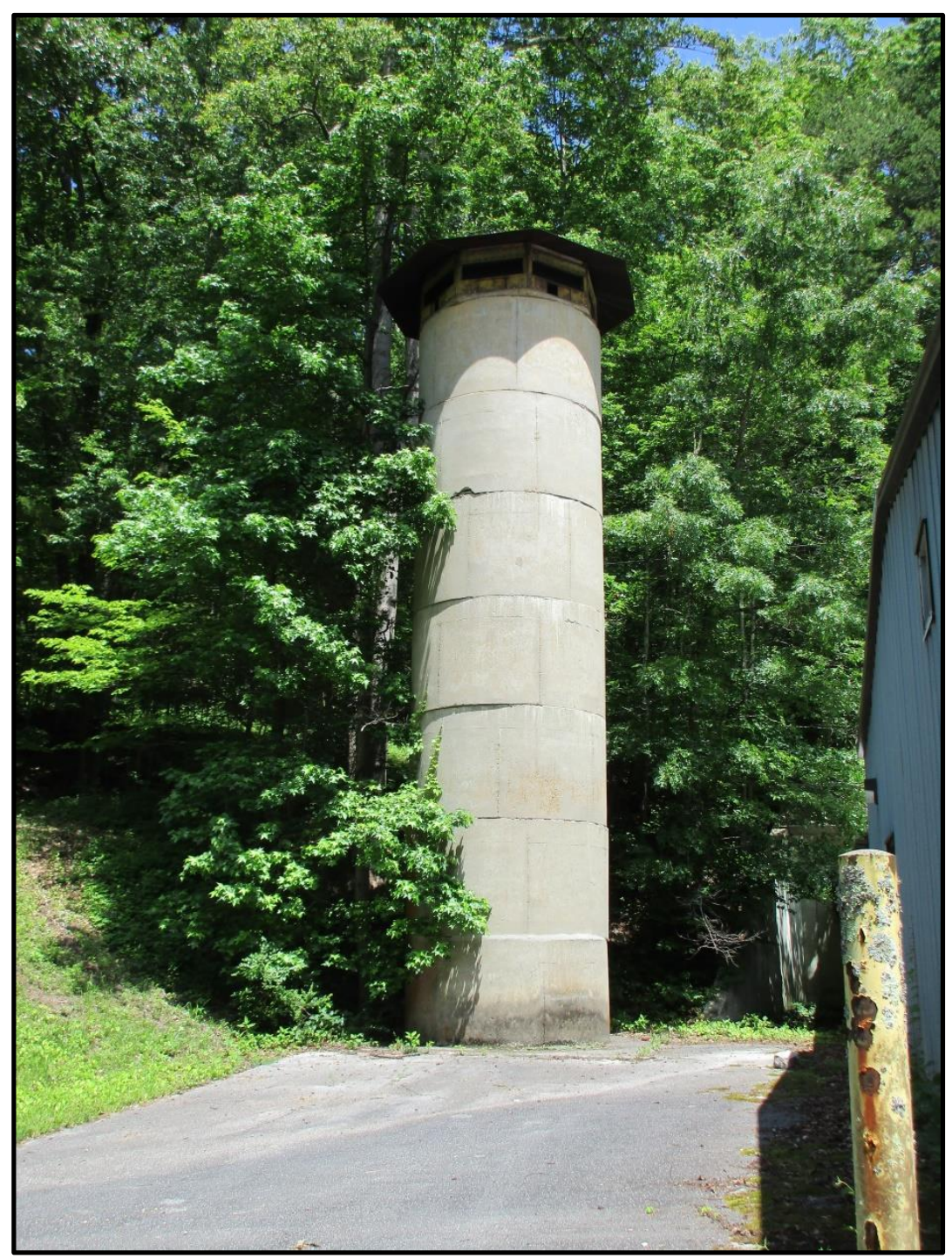

Figure 17. Overview of west elevation of the tower (Building 0970) associated with Building 0907. 


\section{BUILDING NAME}

Airway Beacon Light House

\section{DATE OF CONSTRUCTION}

1920

DOE OFFICE RESPONSIBLE

SC

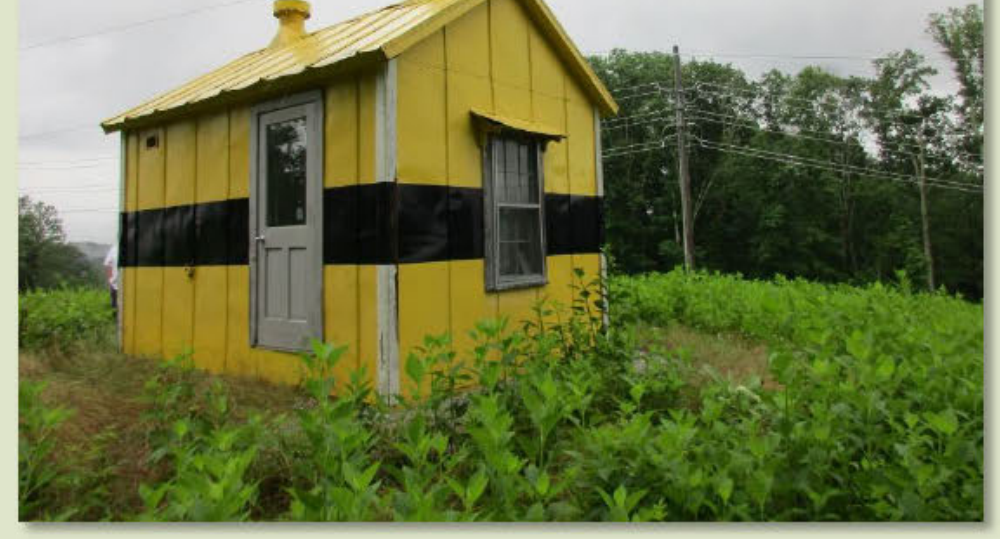

NRHP ELIGIBILITY

Figure 18. Overview of north and west elevations of Building 0969.

Eligible

\section{DESCRIPTION}

The Airway Beacon Light House is a circa 1925 one-story metal-clad frame building. Situated on a continuous poured concrete foundation, the building is sheltered by gable roof clad in corrugated metal that is pierced by two round metal roof vents at the ridgeline (Figures 18 and 19). It features frame construction clad in metal panel siding. The north elevation features a circa 2010 replacement single-light metal door; the east, west, and south elevations each feature a single window with six-over-six-light, double-hung wood sashes with a metal storm topped by a small metal awning supported by decorative brackets. The remnants of a concrete arrow are located to the east of the building.

\section{NATIONAL REGISTER EVALUATION}

The Airway Beacon Light House, Building 0969, was designed to house the diesel-powered generators that lit an adjacent aircraft beacon. The associated beacon is no longer extant. According to Thomason and Associates' assessment in 2015, beacons like these were constructed by the U.S. Post Office and Department of Commerce between 1923 and 1933 and complexes typically were comprised of generators, a beacon tower, diesel tanks, and large concrete arrows guiding pilots delivering mail to the next beacon. This visual system was replaced by the Low Frequency Radio Range system beginning in 1929. The beacon, which rotated, features a 24-in thick parabolic mirror and a 110-volt 1 kilowatt lamp that spun at six rotations per minute that created a quick flash every ten seconds, allowing them to be seen up to $40 \mathrm{mi}$ away on a clear day (Thomason and Associates 2015:239).

This structure was abandoned by the 1940s when it became associated with the X-10 site and later ORNL. The building was discovered between 2004 and 2015 and has been recently restored to its current condition. Building 0969 was first mentioned in a report by Charles Tichy and James Hall in 2007 that concluded that the structure was significant because of its associations with the U.S. Transcontinental Air Mail Route program of the early 1920s (Tichy and Hall 2007).

In 2015, Thomason and Associates recommended that because the structure is the only one of its kind located on the ORR and one of very few of these that remain extant across America, the property appeared to meet the 
NRHP criteria for association with the Transcontinental Air Mail Route program (Thomason and Associates 2015). CRA concurs with Thomason's previous assessment and recommends that Building 0969 is eligible for listing in the NRHP under Criterion A for significant associations to the Transcontinental Air Mail Route. Research revealed no significant associations between Building 0969 and people of significance under Criterion $\mathrm{B}$, and it does not exhibit noteworthy design or architecture to qualify for listing under Criterion $\mathrm{C}$. While alterations to the complex, including the deterioration of the concrete arrow to such a degree it is no longer clear from aerial imagery, and the loss of the beacon, beacon tower, and generator, have diminished the integrity of design, materials, and workmanship, research revealed that there are few intact airway beacon sites extant throughout the country. Among the remaining examples, this beacon retains a moderate degree of integrity to convey its significance under Criterion A. Therefore, CRA recommends that Building 0969 is eligible for listing in the NRHP under Criterion A.

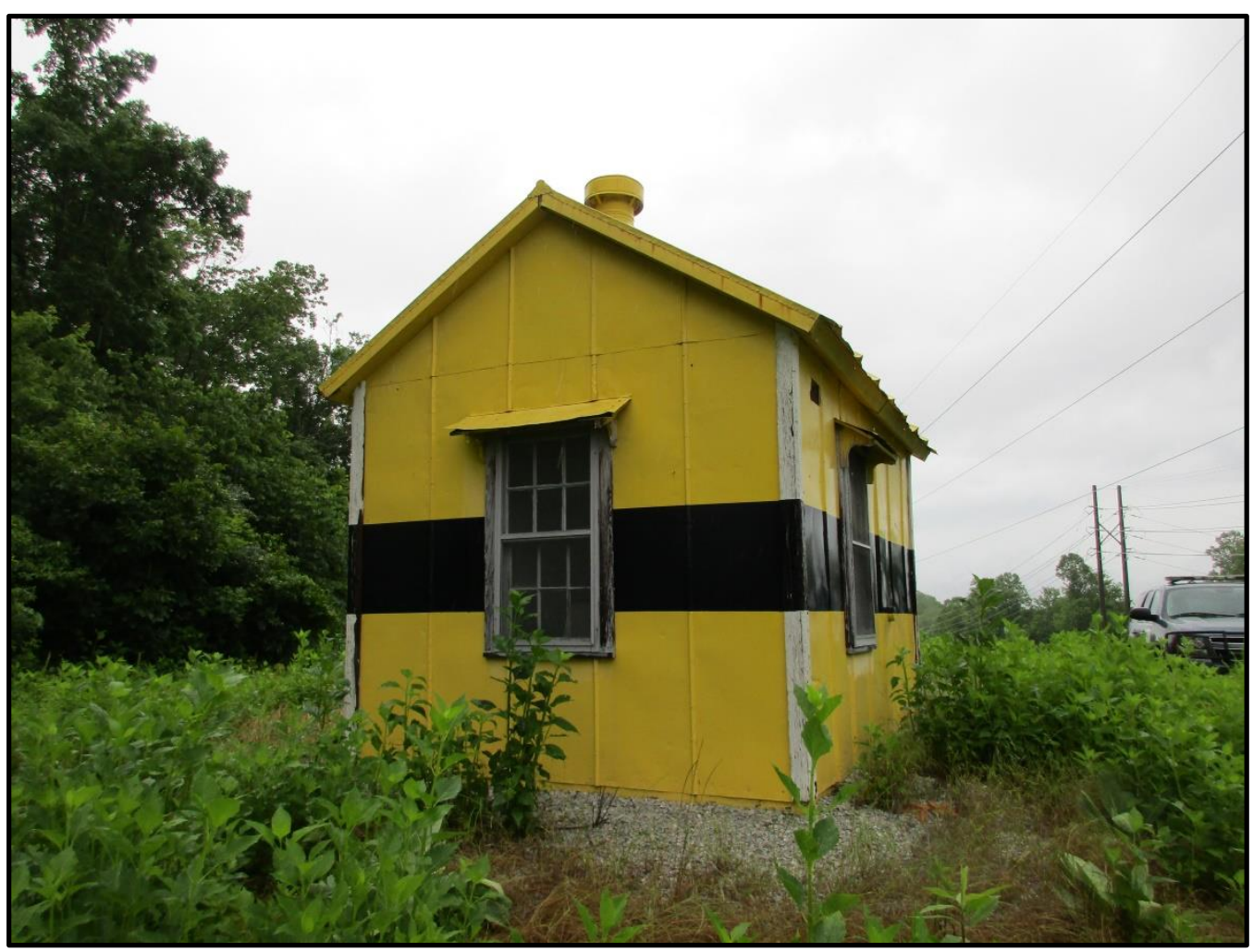

Figure 19. Overview of west and south elevations of Building 0969. 


\section{XF1301}

\section{BUILDING NAME}

Barn D

DATE OF CONSTRUCTION

1965

DOE OFFICE RESPONSIBLE

SC

NRHP ELIGIBILITY

Figure 20. Overview of north and east elevations of Building XF1301 complex.

Not Eligible

\section{DESCRIPTION}

Building XF1301 is a building complex comprised of three metal sheds aligned parallel to one another located north of Bethel Valley Road on a side road near the entrance to ORNL (Figures 20 and 21). All three buildings are supported by concrete foundations. The west and east buildings are similar wood frame structures with corrugated metal covering their exterior walls and gable roofs. Open bays are located on the east elevation of the west structure, which features a rear addition also clad with corrugated metal siding. The east shed also includes open bays, which open to the west, towards the center of the complex. A narrow, one-story, gable-roof shed is located in the center of the XF1301 complex, between the west and east buildings. This central, wood frame structure has open sides and its gable roof is clad in corrugated metal.

\section{NATIONAL REGISTER EVALUATION}

Building XF1301 was built as equipment storage in 1965. Although unconfirmed, it is likely that Building XF1301, like XF1303, which exhibits similar construction and is located on the opposite side of Bethel Valley Road, was associated with the University of Tennessee - Atomic Energy Commission (UT-AEC) Animal Research Laboratory, which was created in 1948 to study the effects of radiation on animals and agricultural products (Thomason and Associates 2015:228). Although operating in tandem with ORNL, this program did not fall under the direct jurisdiction of the national laboratory, and the majority of the UT-AEC Animal Research Laboratory facilities are outside the current boundaries of ORNL. Building XF1301 was not included in the 1994 survey report or 2004 survey update. In 2015 Thomason and Associates recorded the building complex and recommended it ineligible for listing in the NRHP (Thomason and Associates 2015:223). Building XF1301 may be associated with the UT-AEC Animal Research Laboratory, but it is distant from the program's main campus. As a storage facility, it is not a primary resource associated with scientific achievements at ORNL or the UT$\mathrm{AEC}$, nor is it known to be individually associated with any other events or persons of historic significance, thus it does not qualify for listing in the NRHP under Criterion A or B. Further, the complex is composed of simple utilitarian structures that lack architectural significance for listing in the NRHP under Criterion $\mathrm{C}$. The buildings are located in an outlying area and are not located in a NRHP-eligible historic district. Thus, CRA recommends that Building XF1301 is not eligible for listing in the NRHP under Criterion A, B, or C. 


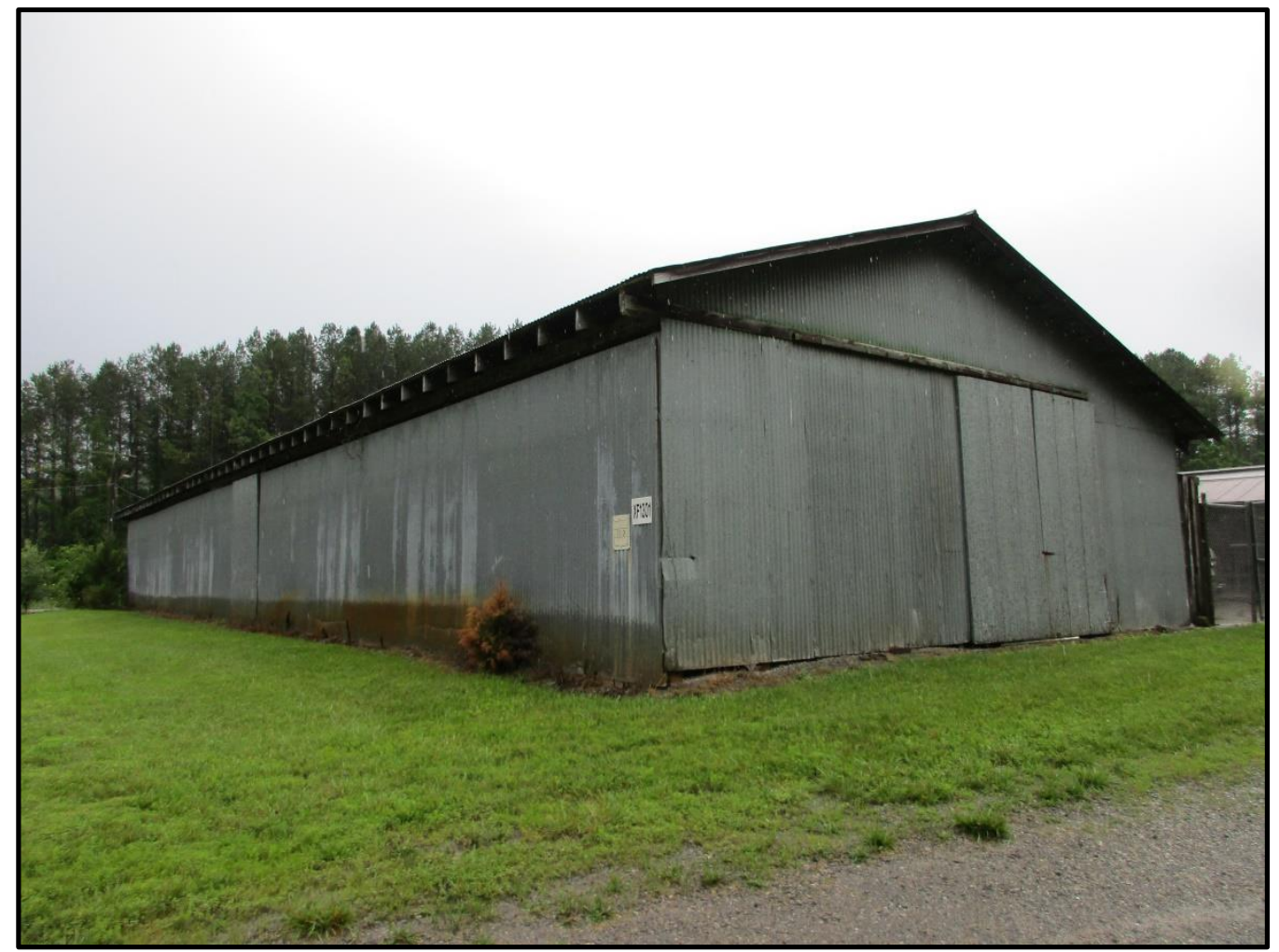

Figure 21. Overview of north and east elevations of Building XF1301 complex. 


\section{XF1302}

\section{BUILDING NAME}

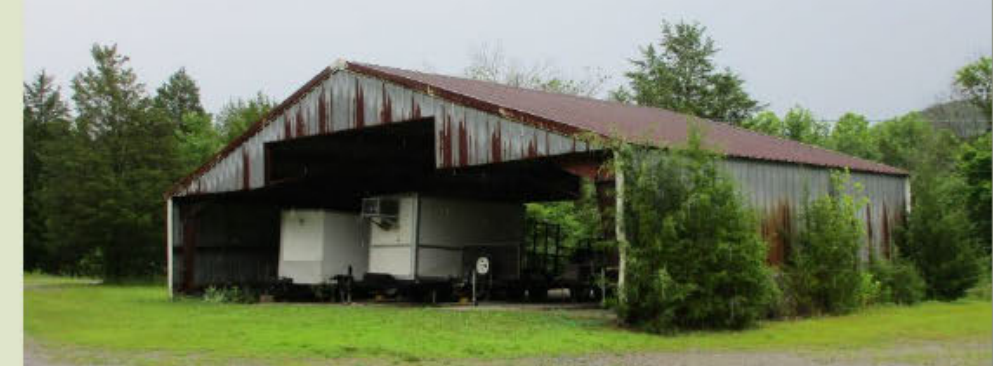

Shed D Butler

DATE OF CONSTRUCTION

1965

DOE OFFICE RESPONSIBLE

SC

Figure 22. Overview of north and west elevations of Building XF1302.

NRHP ELIGIBILITY

Not Eligible

\section{DESCRIPTION}

Building XF1302 is located near Building XF1301's complex, north of Bethel Valley Road on a side road near the entrance to ORNL. The structure is a one-story, front-gable, steel frame building clad in metal panels (Figure 22). The roof is also clad with similar metal panels. The steel structure's design features steel vertical supports that are thicker at the top and taper to a point at the bottom (Figure 23). The building has a concrete slab foundation with some of the vertical supports resting on poured concrete piers. The gable ends on the north and south elevations are open. The side walls are devoid of fenestration.

\section{NATIONAL REGISTER EVALUATION}

Building XF1302 was built as equipment storage in 1965. Although unconfirmed, it is likely that Building XF1301, like XF1303, which exhibits similar construction and is located on the opposite side of Bethel Valley Road, was associated with the UT-AEC Animal Research Laboratory, which was created in 1948 to study the effects of radiation on animals and agricultural products (Thomason and Associates 2015:228). Although operating in tandem with ORNL, this program did not fall under the direct jurisdiction of the national laboratory, and the majority of the UT-AEC Animal Research Laboratory facilities are outside the current boundaries of ORNL. It was not included in the 1994 survey report or 2004 survey update. In 2015 Thomason and Associates recorded the building and recommended it ineligible for listing in the NRHP (Thomason and Associates 2015:226). Building XF1302 may be associated with the UT-AEC Animal Research Laboratory, but it is distant from the program's main campus. As a storage facility, it is not a primary resource associated with scientific achievements at ORNL or the UT-AEC, nor is it known to be individually associated with any other events or persons of historic significance, thus it does not qualify for listing in the NRHP under Criterion A or B. Further, the building is a simple utilitarian structure that lacks architectural significance for listing in the NRHP under Criterion $\mathrm{C}$. The building is located in an outlying area and is not located in a NRHP-eligible historic district. Thus, CRA recommends that Building XF1302 is not eligible for listing in the NRHP under Criterion A, B, or C. 


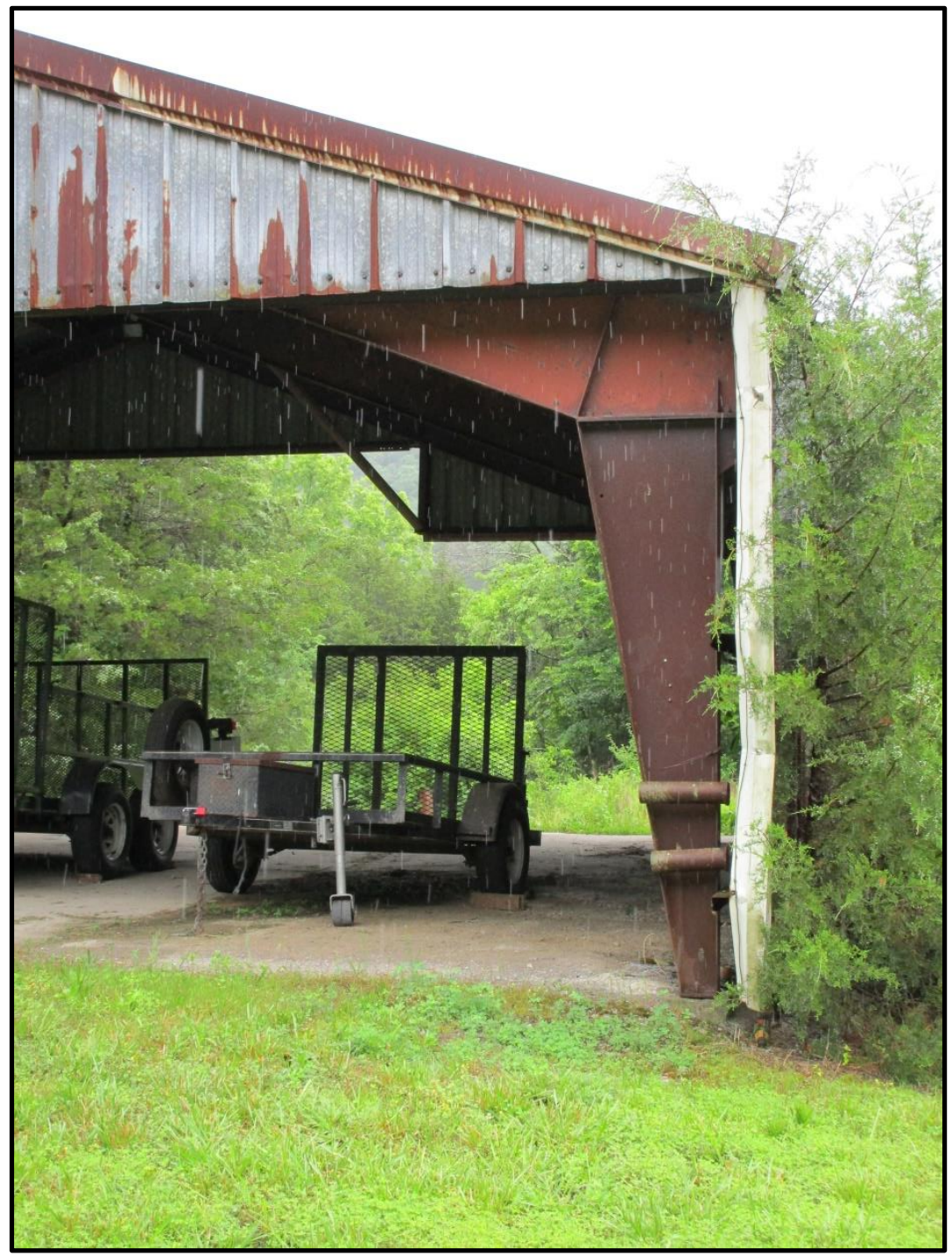

Figure 23. A detail of the steel frame supporting Building XF1302. 


\section{XF1303}

\section{BUILDING NAME}

Barn E - Deer Checking Station

DATE OF CONSTRUCTION

1964

DOE OFFICE RESPONSIBLE

SC

NRHP ELIGIBILITY

Figure 24. Overview of all of the buildings associated with Building XF1303.

Not Eligible

\section{DESCRIPTION}

Building XF1303 is a complex of buildings located south of Bethel Valley Road, near the main entrance of ORNL. The complex is comprised of three structures parallel to one another, similar to XF1301 (Figures 24 and 25). The two outer buildings are single-story, gable-roof, wood frame structures similar in construction and situated on concrete foundations. The exterior and roof of the buildings are clad in corrugated metal. The east building has large sliding track doors clad in corrugated metal on the north gable end and its west side elevation is open. The west building has open bays on its east elevation; therefore the two outer buildings have open bays towards the center of the complex. A narrow, one-story, open-sided, frame shed and a concrete silo with metal bands are located in between the two outer two buildings (Figure 26).

\section{NATIONAL REGISTER EVALUATION}

The complex known as Building XF1303 was constructed in 1965 as part of the UT-AEC Animal Research Laboratory, which was created in 1948 to study the effects of radiation on animals and agricultural products (Thomason and Associates 2015:228). Although operating in tandem with ORNL, this program did not fall under the direct jurisdiction of the national laboratory, and the majority of the UT-AEC Animal Research Laboratory facilities are outside the current boundaries of ORNL. Building XF1303 was not included in the 1994 survey report or 2004 survey update. In 2015 Thomason and Associates recorded the building complex and recommended it ineligible for listing in the NRHP (Thomason and Associates 2015:226). Although associated with the Animal Research Laboratory, it appears that Building XF1303 primarily functioned as a storage facility. As such, Building XF1303 is not a primary resource associated with scientific achievements at ORNL or the UTAEC Animal Research Laboratory, nor is it known to be individually associated with any other events or persons of historic significance, thus it does not qualify for listing in the NRHP under Criterion A or B. Further, the building complex is composed of simple utilitarian structures that lack architectural significance for listing in the NRHP under Criterion C. The buildings are located in an outlying area and are not located in a NRHP-eligible historic district. Thus, CRA recommends that Building XF1303 is not eligible for listing in the NRHP under Criterion $\mathrm{A}, \mathrm{B}$, or $\mathrm{C}$. 


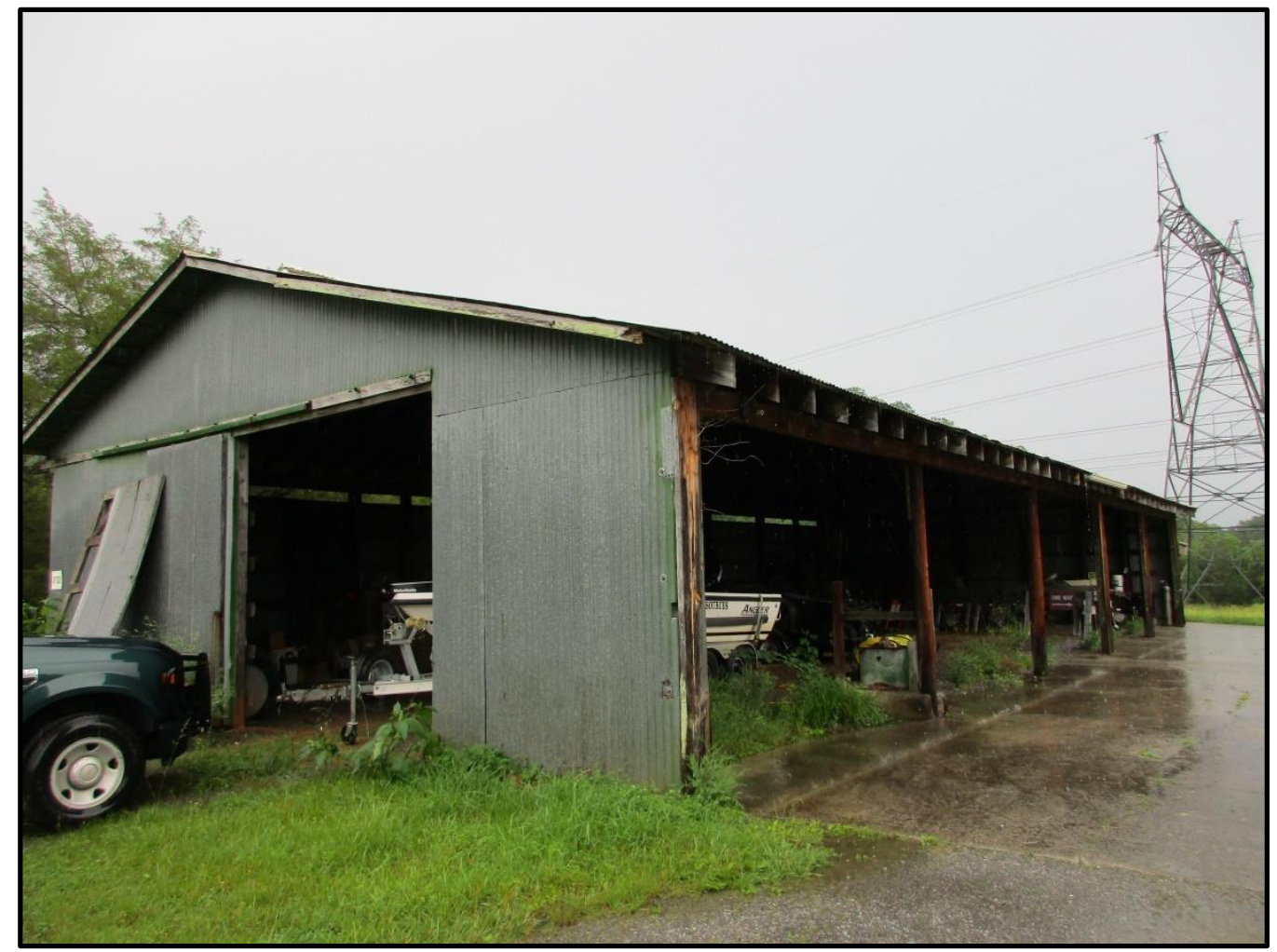

Figure 25. Overview of west and north elevations of one of the buildings associated with Building XF1303.

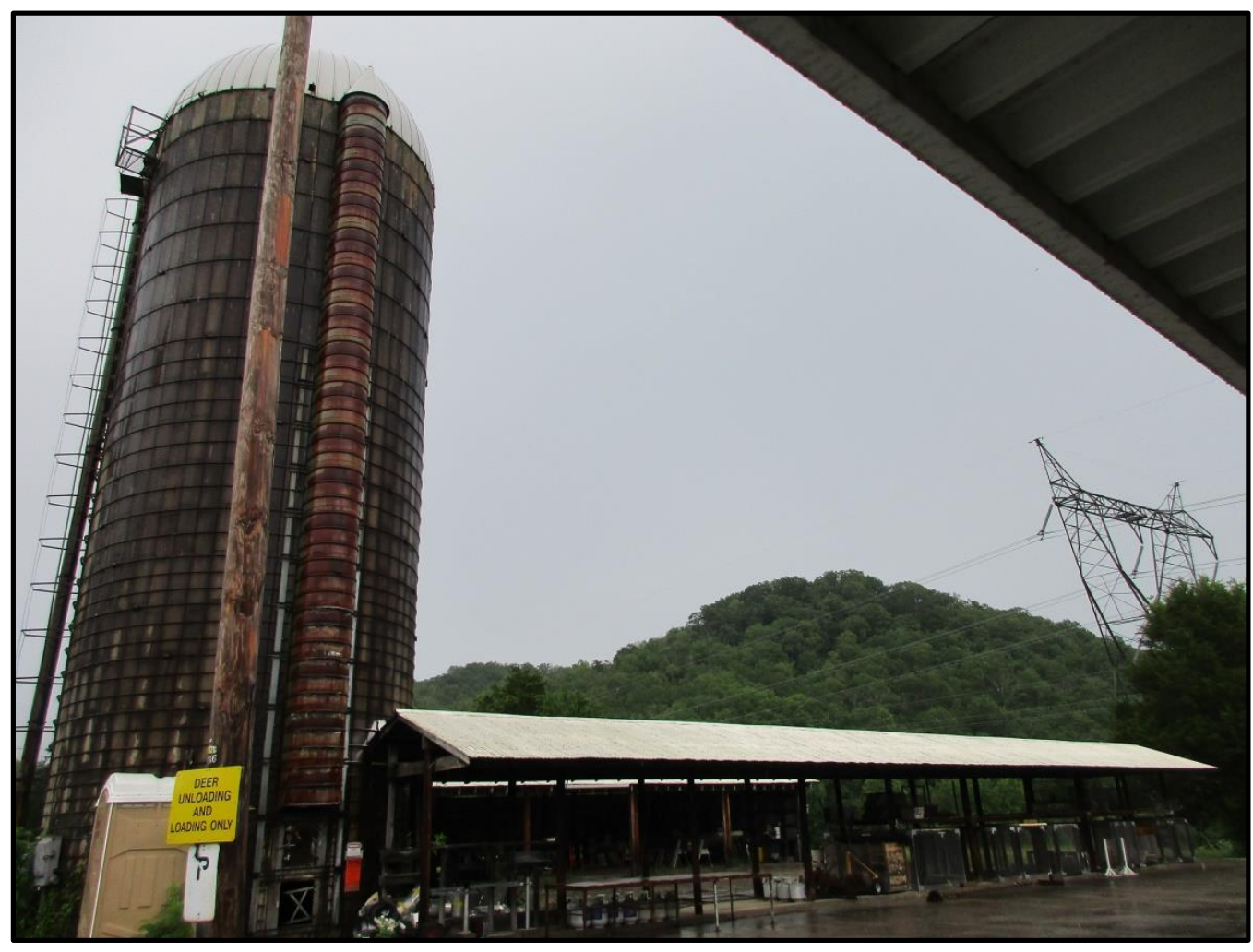

Figure 26. Overview of west elevation of the silo and open shed associated with Building XF1303. 


\section{XG1401}

\section{BUILDING NAME}

Freels Bend, Log Cabin

DATE OF CONSTRUCTION

$1810 ; 1844$

DOE OFFICE RESPONSIBLE

SC

NRHP ELIGIBILITY

Figure 27. Overview of north and east elevations of Building XG1401, the Freels Bend Log Cabin.

NRHP-listed

\section{DESCRIPTION}

Building 1401 is a one story double-pen log cabin on a stone foundation and is situated approximately $200 \mathrm{ft}$ east of Freels Bend Road (Figures 27 and 28). Oriented to the north and south, the west pen exhibits V-notched joinery and the east pen displays half dovetails. The gable roof is clad with wood shingles. A central stone chimney is located between the two pens. The west pen has a higher roof line then the east pen, demonstrating the different periods of construction for each of the pens. A wraparound hip-roof porch comprised of wood posts and decking and resting on concrete block piers surrounds the entire log cabin.

\section{NATIONAL REGISTER EVALUATION}

The Freels Cabin was constructed in two phases, both well before the development of ORR and ORNL. According to the NRHP nomination, the west pen was built circa 1810 and the east pen was constructed in 1844. Freels Cabin was listed in the NRHP in 1992 as part of the Historic and Architectural Resources in Oak Ridge MPL. The property is significant under Criteria $A$ and $C$ for its associations with early settlement patterns and architecture in Anderson County. The cabin also met Criteria Consideration $G$ due to its use as a picnic area for employees during the Manhattan Project (Murphy and Thomason 1991). CRA finds that the Freels Cabin retains a high degree of integrity for continued NRHP listing under Criteria $A$ and $C$. Criteria Consideration $\mathrm{G}$ is no longer needed given the passage of time since the nomination in 1991. 


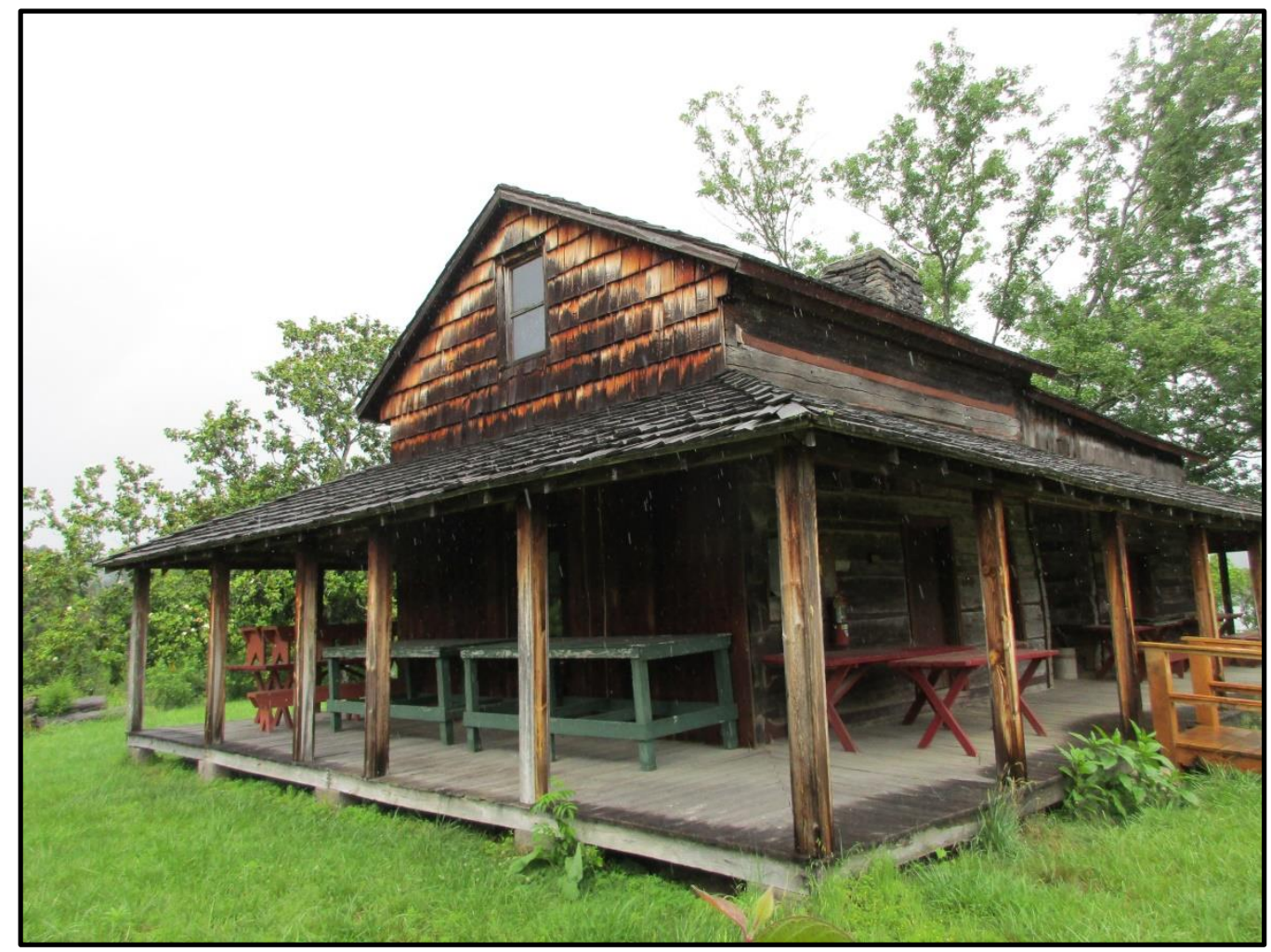

Figure 28. Overview of west and south elevations of Building XG1401, the Freels Bend Log Cabin. 


\section{XG1402}

\section{BUILDING NAME}

Freels Bend, Machine Storage Shed

\section{DATE OF CONSTRUCTION}

1966

\section{DOE OFFICE RESPONSIBLE}

SC

Figure 29. Overview of west and south elevations of Building XG1402.

\section{NRHP ELIGIBILITY}

Not Eligible

\section{DESCRIPTION}

Building XG 1402 is located approximately $200 \mathrm{ft}$ east of Freels Bend Road, south of the intersection of Freels Bend Road and Bull Bluff Road. This is a one-story, front-gable, steel frame building with a rectangular footprint (Figures 29 and 30). The building's roof and side elevations are clad in corrugated metal panels and it rests on a concrete slab foundation. Oriented to the east and west, the gable ends are open. Similar to Building XF1302, the steel framing features vertical supports that are thicker at the top and taper to a point at the foundation. The side elevations of the building are blank.

\section{NATIONAL REGISTER EVALUATION}

Building XG1402 was built as an equipment storage shed in 1966. It was not included in the 1994 survey report or 2004 survey update. In 2015 Thomason and Associates recorded the building and recommended it ineligible for listing in the NRHP (Thomason and Associates 2015:234). As a storage facility, Building XG1402 is not a primary resource associated with scientific achievements at ORNL, nor is it known to be individually associated with any other events or persons of historic significance, thus it does not qualify for listing in the NRHP under Criterion A or B. Further, the building is a simple utilitarian structure that lacks architectural significance for listing in the NRHP under Criterion C. The building is located in an outlying area and is not located in a NRHPeligible historic district. Thus, CRA recommends that Building XG1402 is not eligible for listing in the NRHP under Criterion $\mathrm{A}, \mathrm{B}$, or $\mathrm{C}$. 


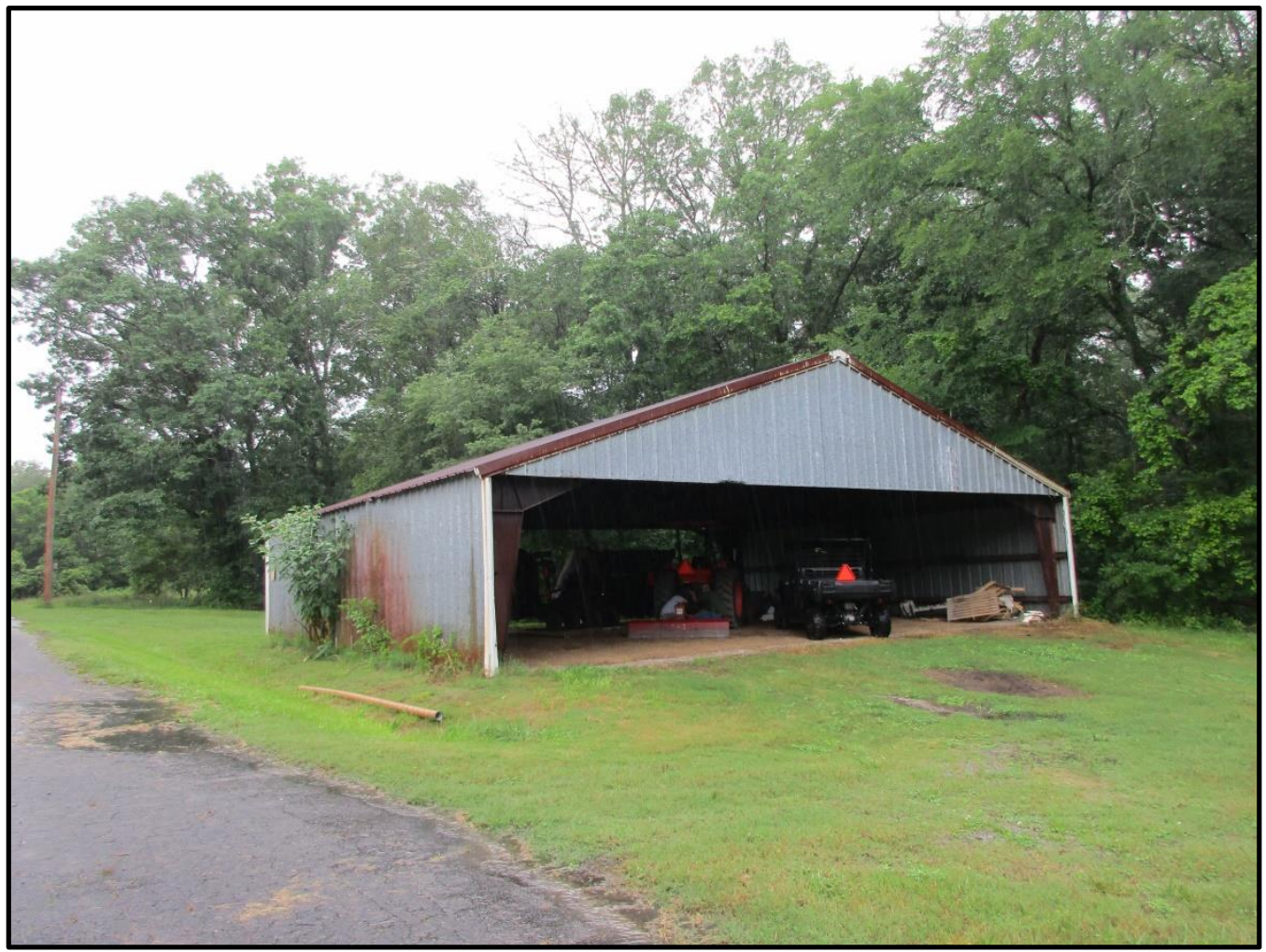

Figure 30. Overview of south and east elevations of Building XG1402. 


\section{XG1404}

\section{BUILDING NAME}

Freels Bend, Var Dose Irradiation Facility

DATE OF CONSTRUCTION

1968

\section{DOE OFFICE RESPONSIBLE}

SC

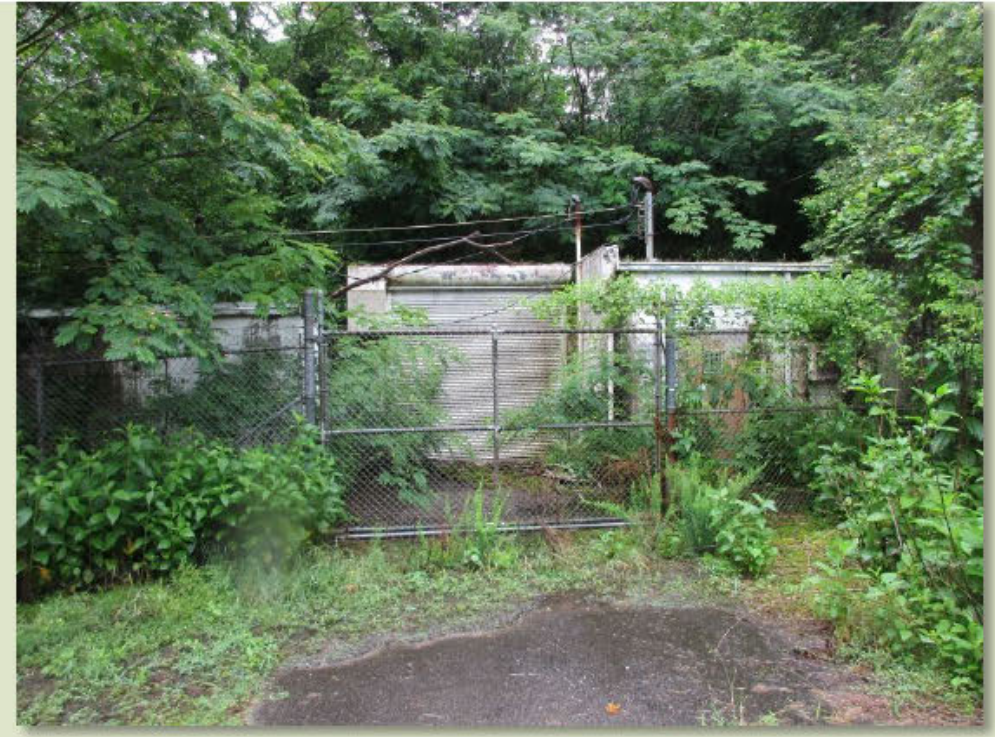

NRHP ELIGIBILITY

Figure 31. Overview of Building XG1404.

Not Eligible

\section{DESCRIPTION}

Building 1404, the Var Dose Irradiation Facility, is located approximately $330 \mathrm{ft}$ east of Freels Bend Road, south of the intersection of Freels Bend Road and Bull Bluff Road. The building is a one story concrete block masonry structure with a flat roof (Figures 31 and 32). The building features a vehicular entry filled with a rollup metal garage door and a single-leaf pedestrian entry filled with a single-light metal door on its façade. Visibility was minimal during the survey due to vegetation and a metal fence enclosing the structure.

\section{NATIONAL REGISTER EVALUATION}

Building XG1404 was constructed in 1968 as an irradiation facility for the study of the biological effects of radiation on animals and plants. It was part of the UT-AEC Animal Research Laboratory, which was created in 1948 to study the effects of radiation on animals and agricultural products (Thomason and Associates 2015:228). Although operating in tandem with ORNL, this program did not fall under the direct jurisdiction of the national laboratory. Building XG1404 was not included in the 1994 survey report or 2004 survey update. In 2015 Thomason and Associates recorded the building complex and recommended it ineligible for listing in the NRHP. It should be noted that Thomason and Associates refers to the facility as a complex, which included the Generator House (XG1416) and the Shielding Wall Donkey Area (XG1410) (Thomason and Associates 2015:226). In that report, the authors reference a 1995 study of the UT-AEC Animal Research Laboratory that recommended the core group of associated buildings (located outside the boundaries of ORNL) eligible for listing in the NRHP as a historic district, but found that outlying support structures such as Building XG1404 did not contribute to the district due to their physical separation. Such support structures were found to lack the significance for individual NRHP listing. THC concurred with that evaluation. CRA concurs that, as an outlying research/laboratory facility associated with the UT-AEC Animal Research Laboratory, Building XG1404 is not individually associated with any scientific accomplishments or other events or persons of historic significance to qualify for listing in the NRHP under Criterion A or B. Further, the building complex is composed of simple utilitarian structures that lack architectural significance for listing in the NRHP under Criterion $\mathrm{C}$. The buildings are located in an outlying area and are not located in a NRHP-eligible historic district. Thus, CRA recommends that Building XG1404 is not eligible for listing in the NRHP under Criterion A, B, or C. 


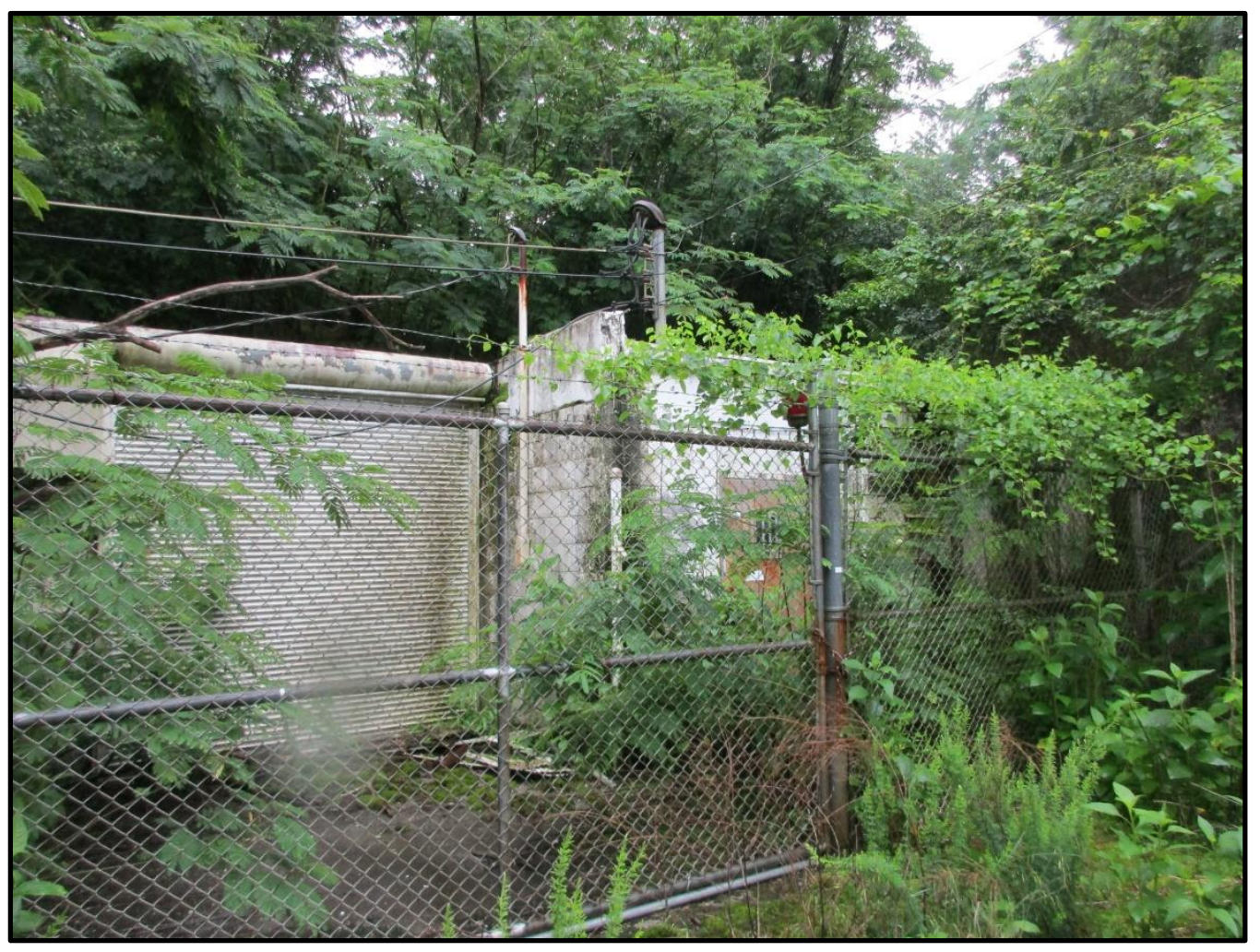

Figure 32. Overview of façade of Building XG1404. 


\section{XG1410}

\section{BUILDING NAME}

Freels Bend, Shielding Wall Donkey Area

DATE OF CONSTRUCTION

\section{DOE OFFICE RESPONSIBLE}

SC

\section{NRHP ELIGIBILITY}

Figure 33. Overview of the interior of Building XG1410.

Not Eligible

\section{DESCRIPTION}

Building XG1410 is located approximately $800 \mathrm{ft}$ east of Buildings XG1402, XG1404, and XG1416 and east of Freels Bend Road. The structure is circular in form and is composed of a concrete foundation and concrete walls (Figures 33 and 34). A large opening is located on the west side. No other fenestration exists on the concrete structure. A metal chain link fence extends along the inside of the concrete walls.

\section{NATIONAL REGISTER EVALUATION}

Building XG1410 was constructed as a testing facility for the study of the biological effects of radiation on animals, in particular donkeys. The construction date of this facility is unknown. This building, along with Buildings XG1404 and XG 1416, was a part of the UT-AEC Animal Research Laboratory, which was created in 1948 to study the effects of radiation on animals and agricultural products (Thomason and Associates 2015:228). Although operating in tandem with ORNL, this program did not fall under the direct jurisdiction of the national laboratory, and the majority of the UT-AEC Animal Research Laboratory facilities are outside the current boundaries of ORNL. Building XG1410 was not included in the 1994 survey report or 2004 survey update. In 2015 Thomason and Associates recorded the building as a part of Building's 1404 complex, thus it was not individually surveyed. Thomason considered the building complex and recommended it ineligible for listing in the NRHP (Thomason and Associates 2015:226). In that report, the authors reference a 1995 study of the UT-AEC Animal Research Laboratory that recommended the core group of associated buildings (located outside the boundaries of ORNL) eligible for listing in the NRHP as a historic district, but found that outlying support structures such as Building XG1410 did not contribute to the district due to their physical separation. Such support structures were found to lack the significance for individual NRHP listing. THC concurred with that evaluation. CRA concurs that, as an outlying research/laboratory facility associated with the UT-AEC Animal Research Laboratory, Building XG1410 is not individually associated with any scientific accomplishments or other events or persons of historic significance to qualify for listing in the NRHP under Criterion A or B. Further, the building complex is composed of simple utilitarian structures that lack architectural significance for listing in the NRHP under Criterion C. The buildings are located in an outlying area and are not located in a NRHP- 
eligible historic district. Thus, CRA recommends that Building XG1410 is not eligible for listing in the NRHP under Criterion $\mathrm{A}, \mathrm{B}$, or $\mathrm{C}$.

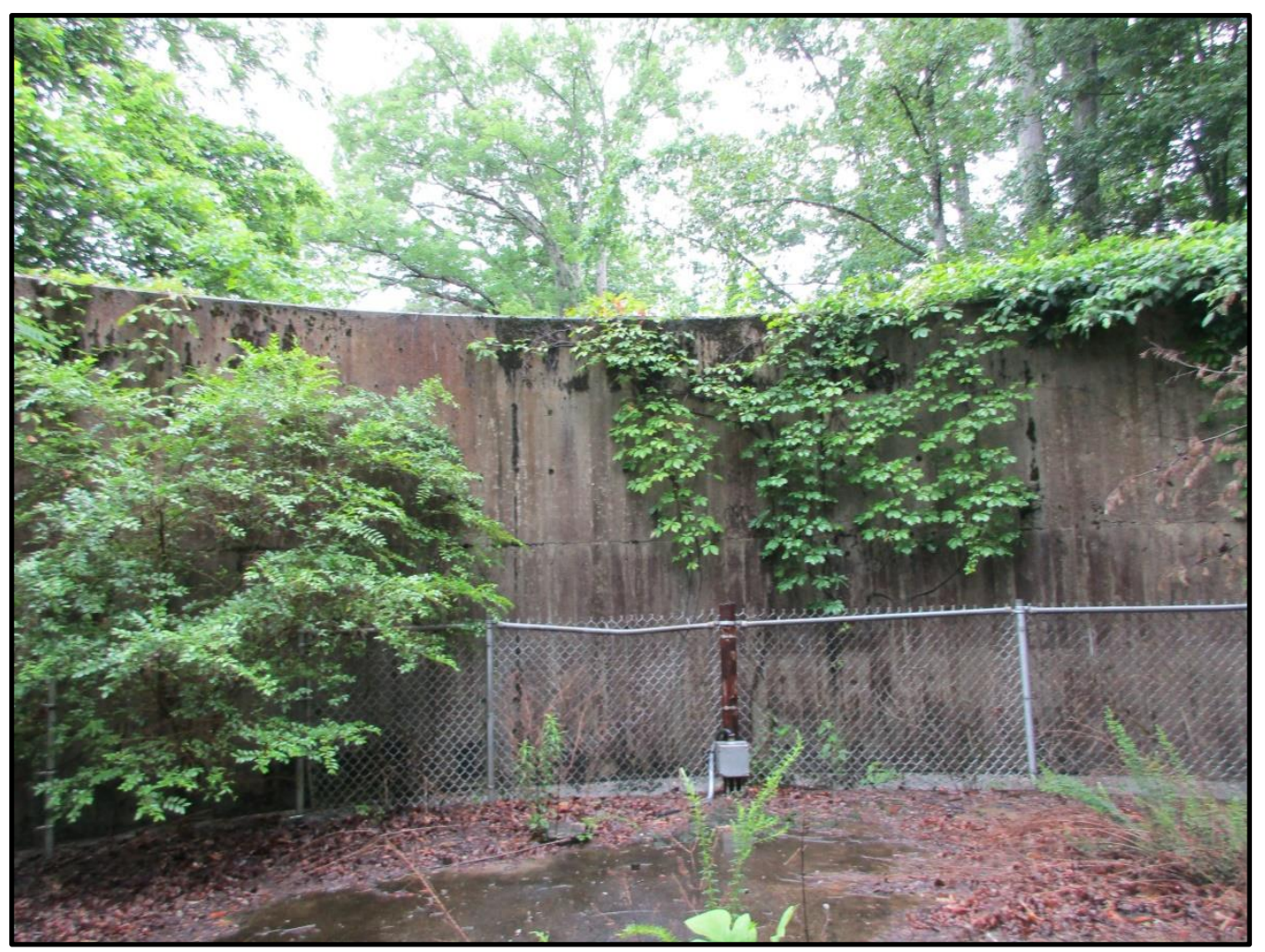

Figure 34. Overview of interior of Building XG1410. 


\section{XG1414}

\section{BUILDING NAME}

Freels Bend, Outbuilding

DATE OF CONSTRUCTION

1844

DOE OFFICE RESPONSIBLE

SC

Figure 35. Overview of north and west elevations of Building XG1414.

\section{NRHP ELIGIBILITY}

NRHP-listed as secondary resource for XG1401

\section{DESCRIPTION}

Building XG1414 is located approximately $25 \mathrm{ft}$ south-southeast of Building XG1401, east of Freels Bend Road. This outbuilding is associated with the log cabin (XG1401). The one-story, front-gable log structure features half-dovetail notching and is sheltered by a metal panel roof (Figures 35 and 36). The facade (north) elevation was altered when restrooms were installed, including the removal of logs.

\section{NATIONAL REGISTER EVALUATION}

Building XG1414 is associated with the Freels Cabin. The outbuilding dates to the nineteenth century, well before the development of ORR and ORNL. Freels Cabin and this associated outbuilding were listed in the NRHP in 1992 as part of the Historic and Architectural Resources in Oak Ridge MPL. The property is significant under Criteria $A$ and $C$ for its associations with early settlement patterns and architecture in Anderson County. The cabin also met Criteria Consideration $G$ due to its use as a picnic area for employees during the Manhattan Project (Murphy and Thomason 1991). CRA finds that Building XG1414 retains of integrity for continued NRHP listing as a contributing resource to the Freels Cabin property with significance under Criteria $A$ and $C$. Criteria Consideration $\mathrm{G}$ is no longer needed given the passage of time since the nomination in 1991. 


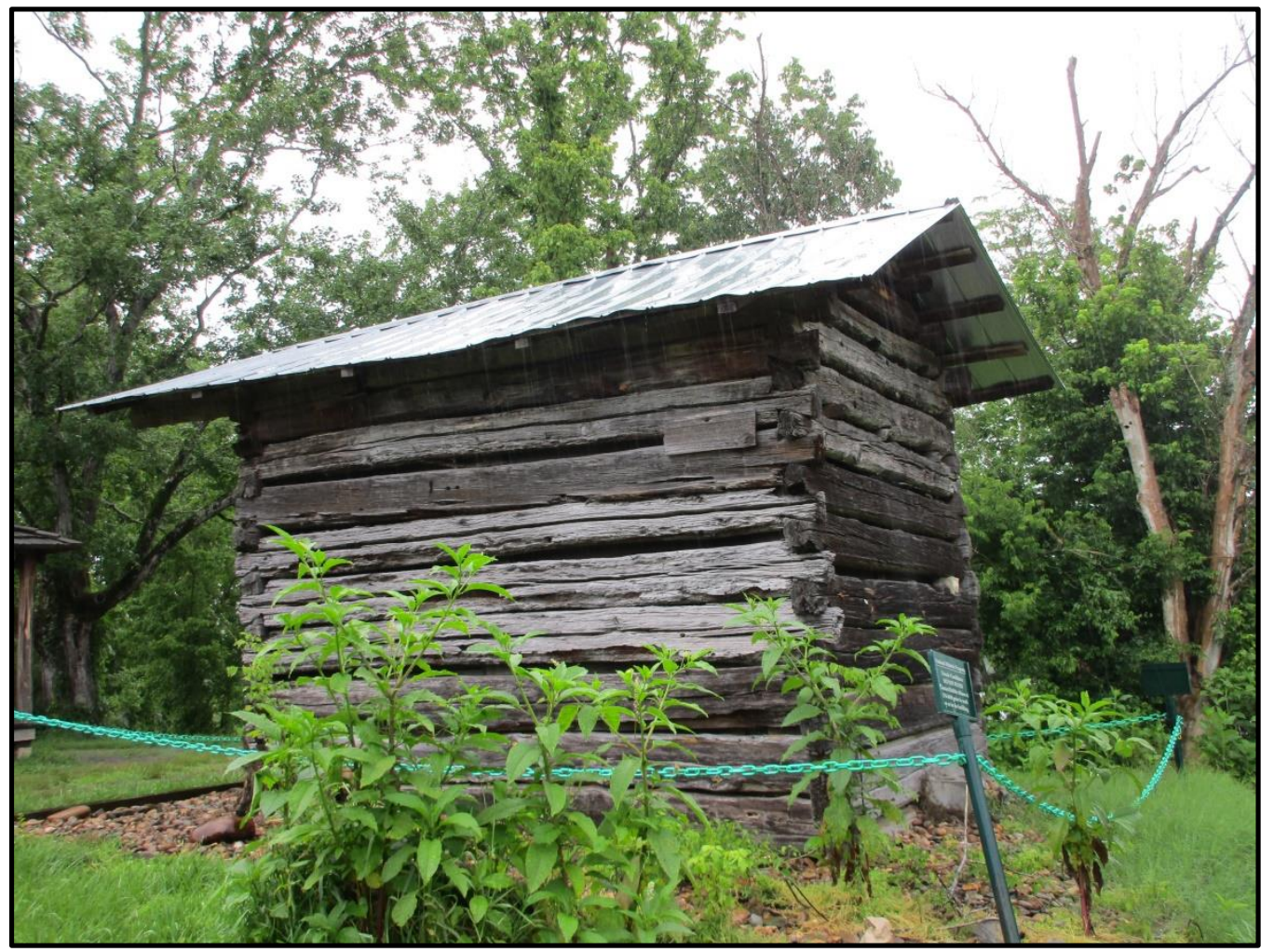

Figure 36. Overview of west and south elevations of Building XG1414. 


\section{XG1416}

\section{BUILDING NAME}

Freels Bend, Generator House

DATE OF CONSTRUCTION

Unknown

DOE OFFICE RESPONSIBLE

SC

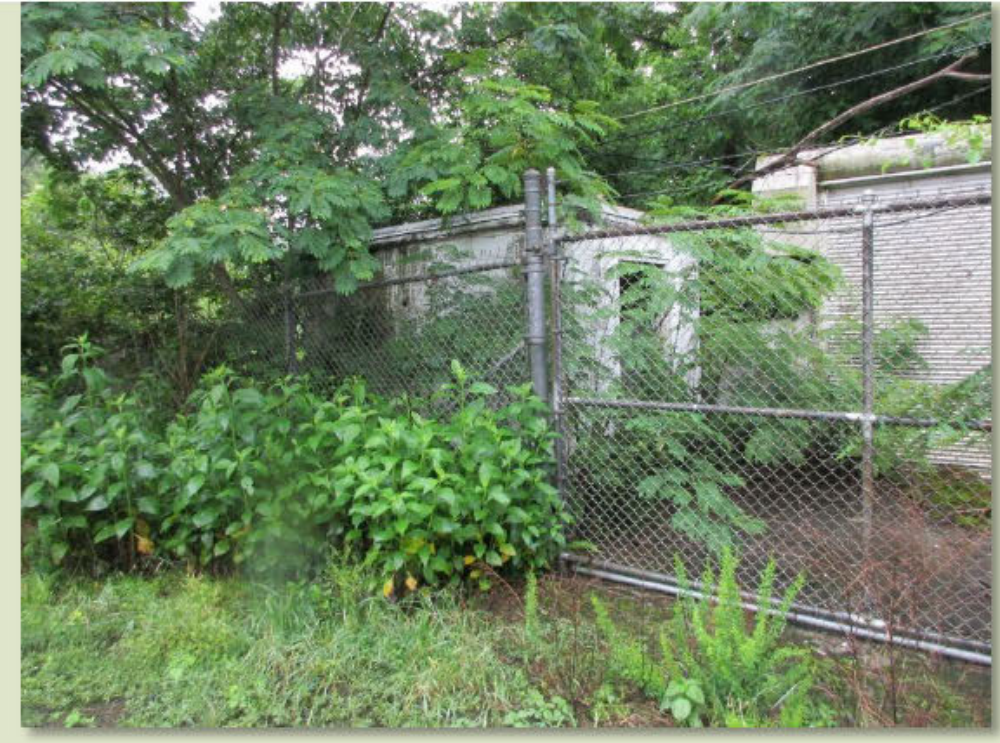

NRHP ELIGIBILITY

Figure 37. Overview of Building XG1416.

Not Eligible

\section{DESCRIPTION}

Building XG1416 is located adjacent to Building XG1404, the Variable Dose Irradiation Facility, behind a metal chain link fence. The Generator House (XG1416) is a one-story, flat-roof, concrete block building (Figure 37). The Generator House is smaller in size in comparison to Building XG1404. The building features a single-leaf entry on its façade filled with a metal door. Visibility was minimal during the survey due to vegetation and the metal fence enclosing the structure.

\section{NATIONAL REGISTER EVALUATION}

Building XG1416 was constructed as an electrical building for the Variable Dose Irradiation Facility. The construction date of this facility is unknown. This building, along with Buildings XG1404 and XG 1410, was a part of the UT-AEC Animal Research Laboratory, which was created in 1948 to study the effects of radiation on animals and agricultural products (Thomason and Associates 2015:228). Although operating in tandem with ORNL, this program did not fall under the direct jurisdiction of the national laboratory, and the majority of the UT-AEC Animal Research Laboratory facilities are outside the current boundaries of ORNL. Building XG1416 was not included in the 1994 survey report or 2004 survey update. In 2015 Thomason and Associates recorded the building as a part of Building's 1404 complex and was not individually surveyed. Thomason considered the building complex and recommended it ineligible for listing in the NRHP (Thomason and Associates 2015:226). In that report, the authors reference a 1995 study of the UT-AEC Animal Research Laboratory that recommended the core group of associated buildings (located outside the boundaries of ORNL) eligible for listing in the NRHP as a historic district, but found that outlying support structures such as Building XG1416 did not contribute to the district due to their physical separation. Such support structures were found to lack the significance for individual NRHP listing. THC concurred with that evaluation. CRA concurs that, as an outlying utility/maintenance facility associated with the UT-AEC Animal Research Laboratory, Building XG1416 is not individually associated with any scientific accomplishments or other events or persons of historic significance to qualify for listing in the NRHP under Criterion A or B. Further, the building complex is composed of simple utilitarian structures that lack architectural significance for listing in the NRHP under Criterion $\mathrm{C}$. The buildings 
are located in an outlying area and are not located in a NRHP-eligible historic district. Thus, CRA recommends that Building XG1416 is not eligible for listing in the NRHP under Criterion A, B, or C. 


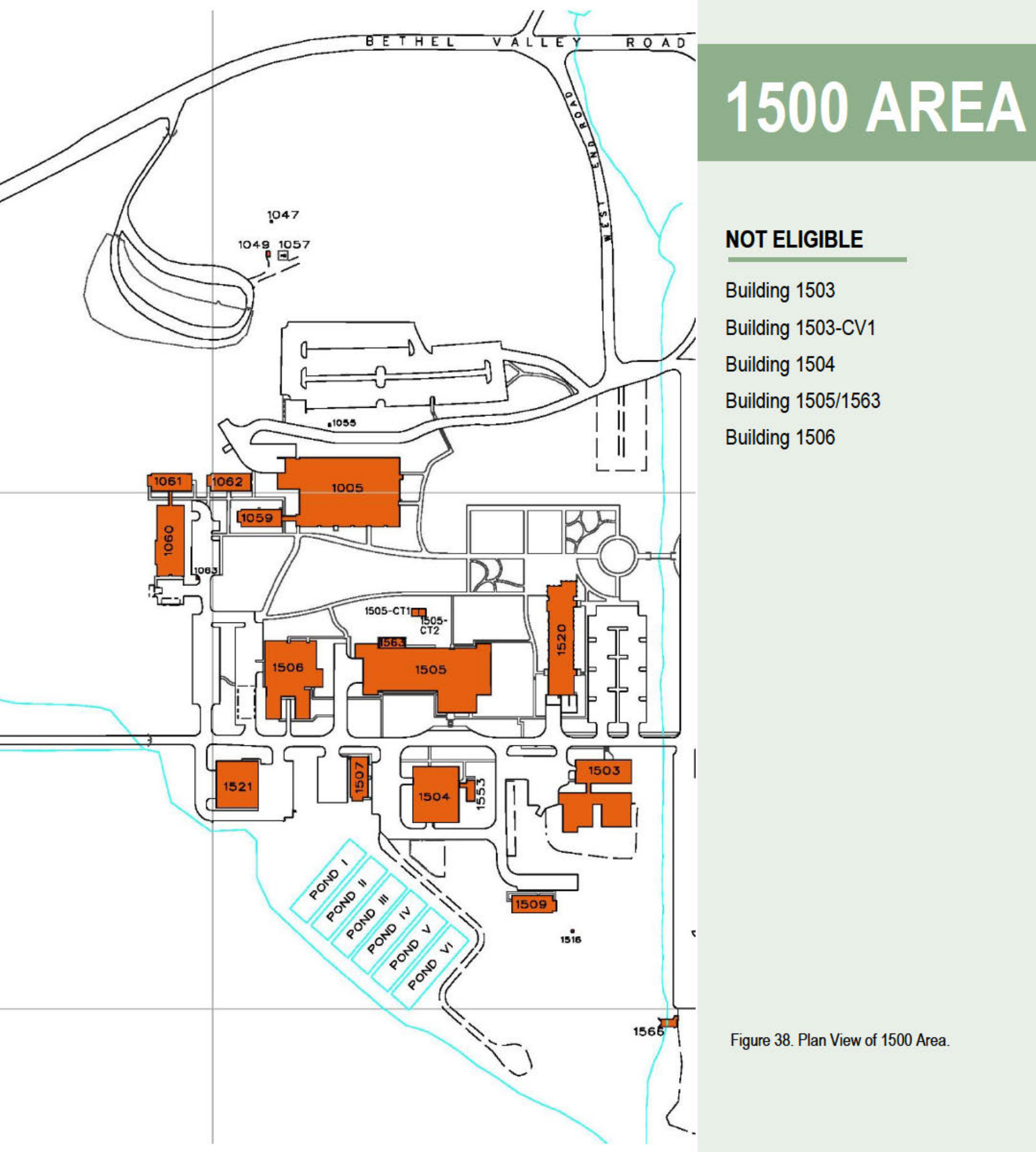


This page intentionally left blank 
DISTRICT NAME

1500 Area of ORNL

\section{DATE OF CONSTRUCTION}

1962-2008

NRHP ELIGIBILITY

Not Eligible

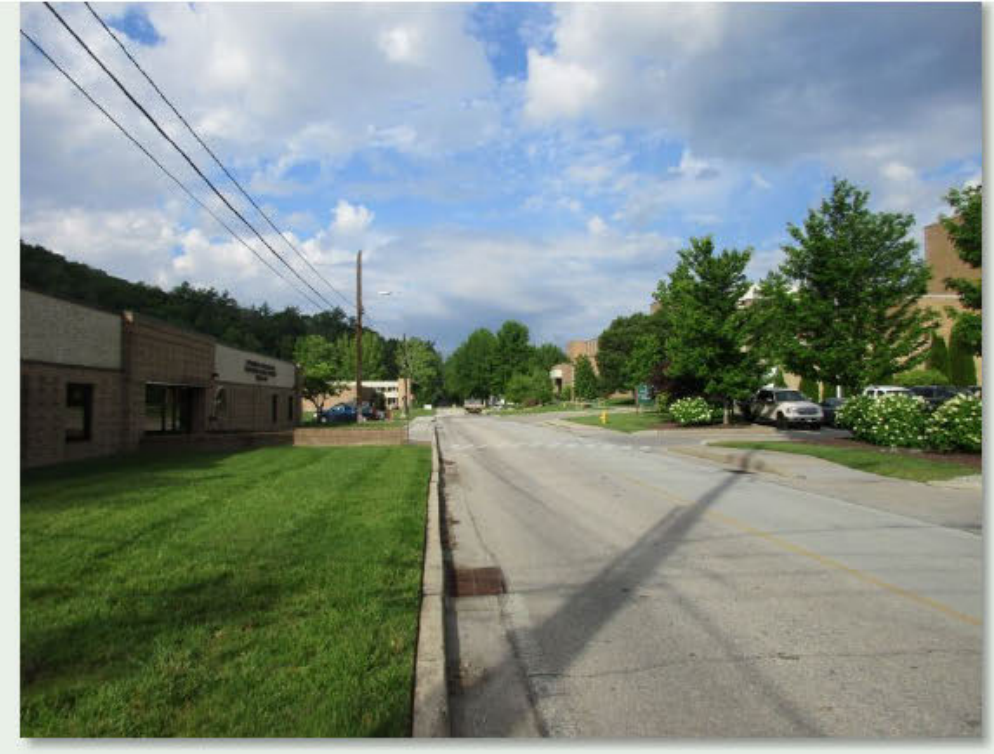

Figure 39. Overview of 1500 Area, looking along White Oak Avenue.

\section{DESCRIPTION}

The 1500 Area is located in the West Campus, to the west of First Street and of First Creek. White Oak Avenue is the primary route through the 1500 Area (Figure 39). A total of nine buildings and a culvert are located within the 1500 Area. Of these nine resources, only four buildings $(1503,1504,1505 / 1563$, and 1506) and one culvert (1503-CV1) were constructed in or before 1980 and were individually assessed as a part of this survey. The remaining four buildings were constructed between 1993 and 2008 . The buildings within the 1500 Area house the research/laboratory facilities of the Environmental Science Division. The 1500 area is situated on a relatively flat, level portion of the ORNL campus. Key landscape features associated with this area include a series of six long, narrow ponds, identified as Pond I-Pond VI, located behind Building 1504, the Aquatic Ecology Laboratory, and a recently-constructed, formally-designed garden space to the north of Building 1520, the Joint Institute for Biological Sciences. Although the majority of the buildings within this area were built and modified over 46 years between 1962 and 2008, the construction and alterations were done in such a way using similar materials and aesthetics that the resources of the 1500 area reflect a cohesive design.

\section{NATIONAL REGISTER EVALUATION}

The Environmental Sciences Division was established at ORNL in 1972, replacing the Ecological Sciences Division, established in 1970. The Health Physics Division had conducted environmental research at ORNL since the laboratory's establishment in 1943, but by the 1970s environmental science was an increasingly significant part of ORNL's mission, with research in the areas of ecology, radioecology, environmental engineering, sanitary engineering, geological studies for the disposal of radioactive waste, and radiological hazard assessment (Auerbach 1993:1).

When previously surveyed in 1994, all of the fourteen buildings within the 1500 Area-1503, 1504, 1505, 1506, $1508,1553,1556,1557,1559,1560,1561,1563,1564$, and 1565-were not yet 50 years old. The previous recommendation suggested that although the research conducted in this area is important, it does not rise to the level of significance to meet Criteria Consideration G. The survey suggested taking another look at these resources once they reached the 50 year mark. Only one resource, Building 1503 , has reached the 50 year mark since the survey in 1994; it predates the establishment of the Environmental Sciences Division in this area and was not fully utilized by the Division until the early 1980s. The Aquatic Ecology Laboratory (Building 1504) 
was constructed here in 1972, and the Environmental Science Laboratory (Building 1505), was not opened until 1978. Thus, given the age of these resources, they still must be evaluated under Criteria Consideration G. CRA concurs with the previous finding and recommends that these resources do not individually or collectively possess significant associations of exceptional importance to qualify for listing in the NRHP. As the Environmental Sciences Division and these associated buildings near 50 years of age, additional research is merited to better situate the Division within the history of the field of environmental science, which flourished in the 1970s. Such research may reveal areas of significance to merit listing once the buildings turn 50 years old. 


\section{3}

\section{BUILDING NAME}

Plant Sciences Lab

\section{DATE OF CONSTRUCTION}

1962

\section{DOE OFFICE RESPONSIBLE}

$\mathrm{SC}$

NRHP ELIGIBILITY

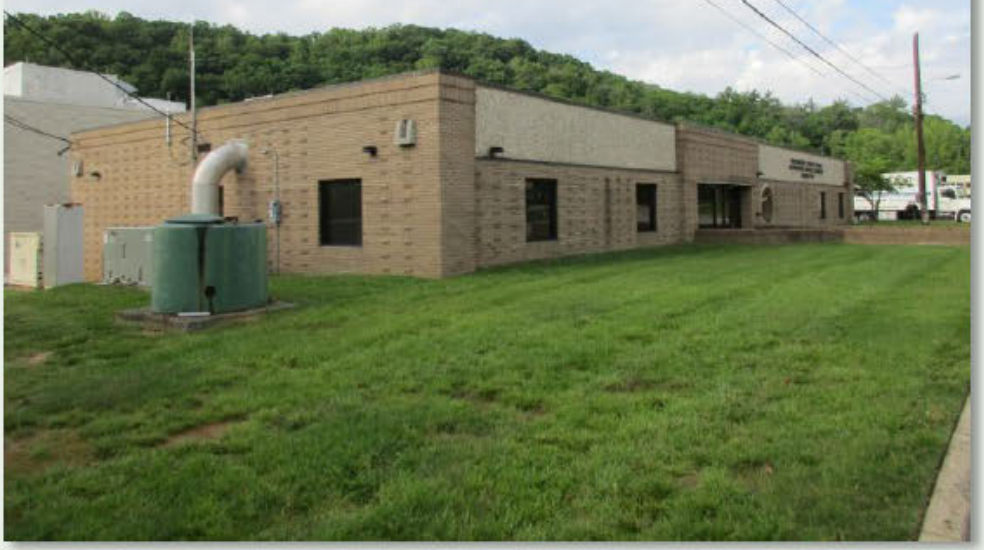

Not Eligible

Figure 40. Overview of north elevation and partial east elevation of Building 1503.

\section{DESCRIPTION}

Building 1503 is a one-story, 9,578 sq ft, rectangular building. Set upon a continuous concrete foundation, the building is sheltered by a shallow-pitched, side-gable, membrane-clad roof obscured from view at ground level by a parapet that features two soldier brick courses capped with metal flashing. The façade and side elevations and a large portion of the rear elevation are clad in stretcher bond brick veneer with every fourth row featuring projecting bricks (Figures 40 and 41). The central portion of the façade projects slightly and is flanked by sections that each feature concrete aggregate on the upper third of the façade. The façade entry features a recessed glass entrance that opens to a concrete apron. A circular masonry panel with decorative elements depicting flora and fauna is located to the right of the façade entry. Throughout the building, windows feature one-light fixed sashes with vertical brick sills. A portion of the rear elevation is clad in metal siding and features a connection to a circa 2000 rear greenhouse addition connected by a concrete block annex.

In addition to the construction of the annex and greenhouses that more than doubled the footprint of the building, alterations to Building 1503 include the enclosure with brick of an entry to the right of the façade at the end of a sidewalk, the enclosure of a garage bay on the north (side) elevation with vinyl siding, and the installation of circa 2000 replacement steel and glass doors.

\section{NATIONAL REGISTER EVALUATION}

Building 1503, the Plant Sciences Lab, is the oldest structure in the West Campus, dating before the Environmental Science Division occupied this area. The building's current appearance dates to the early 1980s when the building, "which had been nothing more than a large metal shed that had housed the on-site construction facilities, was remodeled in a style that matched Building 1505; this office and laboratory facility would house other divisional units" including the Biomass (Short Rotation Woody Crops) Program and the Forest Management Program (Auerbach 1993:124). In 1994 Building 1503 was determined to be not eligible due to age, as it was not yet 50 years old. In 2015 it was recommended to lack the significance for listing in the NRHP. As indicated in the 1993 history of the Environmental Sciences Division, prior to the 1980s Building 1503 served as a minor support structure. As a former utility and maintenance facility that served as a research/laboratory facility beginning in the 1980 s, Building 1503 is not the primary site associated with 
scientific achievements at ORNL during the historic period, thus it does not rise to the level of significance needed for individual listing in the NRHP under Criterion A or B. Additionally, Building 1503 exhibits simple institutional design features with its current appearance dating to the 1980s, with circa 2000 alterations, and thus lacks the significance and integrity to the historic period to merit evaluation for listing in the NRHP under Criterion C. Furthermore, Building 1503 is not located in a NRHP-eligible historic district. Therefore, CRA recommends that Building 1503 is not eligible for listing in the NRHP under Criterion $A, B$, or C.

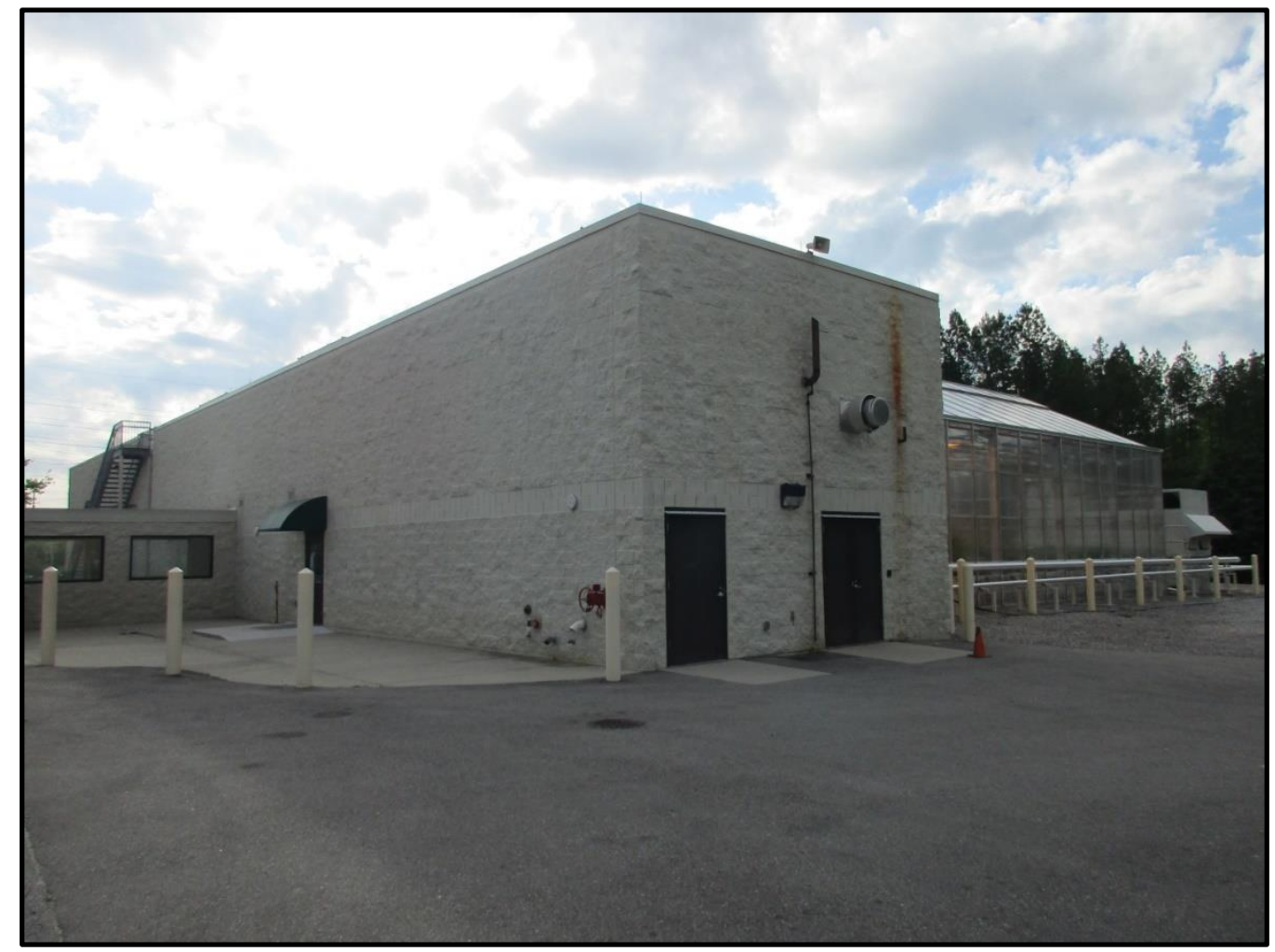

Figure 41. Overview of west elevation and partial north elevation of Building 1503. 


\section{$1503-C V 1$}

\section{BUILDING NAME}

First Creek Concrete Culvert Bridge

DATE OF CONSTRUCTION

1970

DOE OFFICE RESPONSIBLE

SC

NRHP ELIGIBILITY

Figure 42. View of culvert bridge (Building 1503-CV1) looking towards Building 1520 .

Not Eligible

\section{DESCRIPTION}

Building 1503-CV1 is a cast concrete culvert that carries First Creek under White Oak Avenue as the road enters the 1500 area, or West Campus (Figure 42). It is located immediately west of the intersection of White Oak Avenue and First Street. The concrete culvert is comprised of two precast concrete pipe culverts that extend from a poured concrete headwall with angled wing walls (Figure 43). Thin metal rails extend from the top of the headwall, flanking the road surface, which is an asphalt road on an earthen embankment.

\section{NATIONAL REGISTER EVALUATION}

Building 1503-CV1, First Creek Concrete Culvert Bridge, has not been previously recorded or surveyed. The culvert is not the primary site associated with scientific achievements at ORNL, nor is it associated with any other events or people of historic significance to qualify for individual listing in the NHRP under Criterion A or B. Furthermore, Building 1503-CV1 exhibits simple utilitarian design features, and therefore, does not qualify for listing in the NRHP under Criterion $C$. The culvert is not located in a NRHP-eligible historic district. Thus, CRA recommends that Building 1503-CV1 is not eligible for listing in the NRHP under Criterion A, B, or C. 


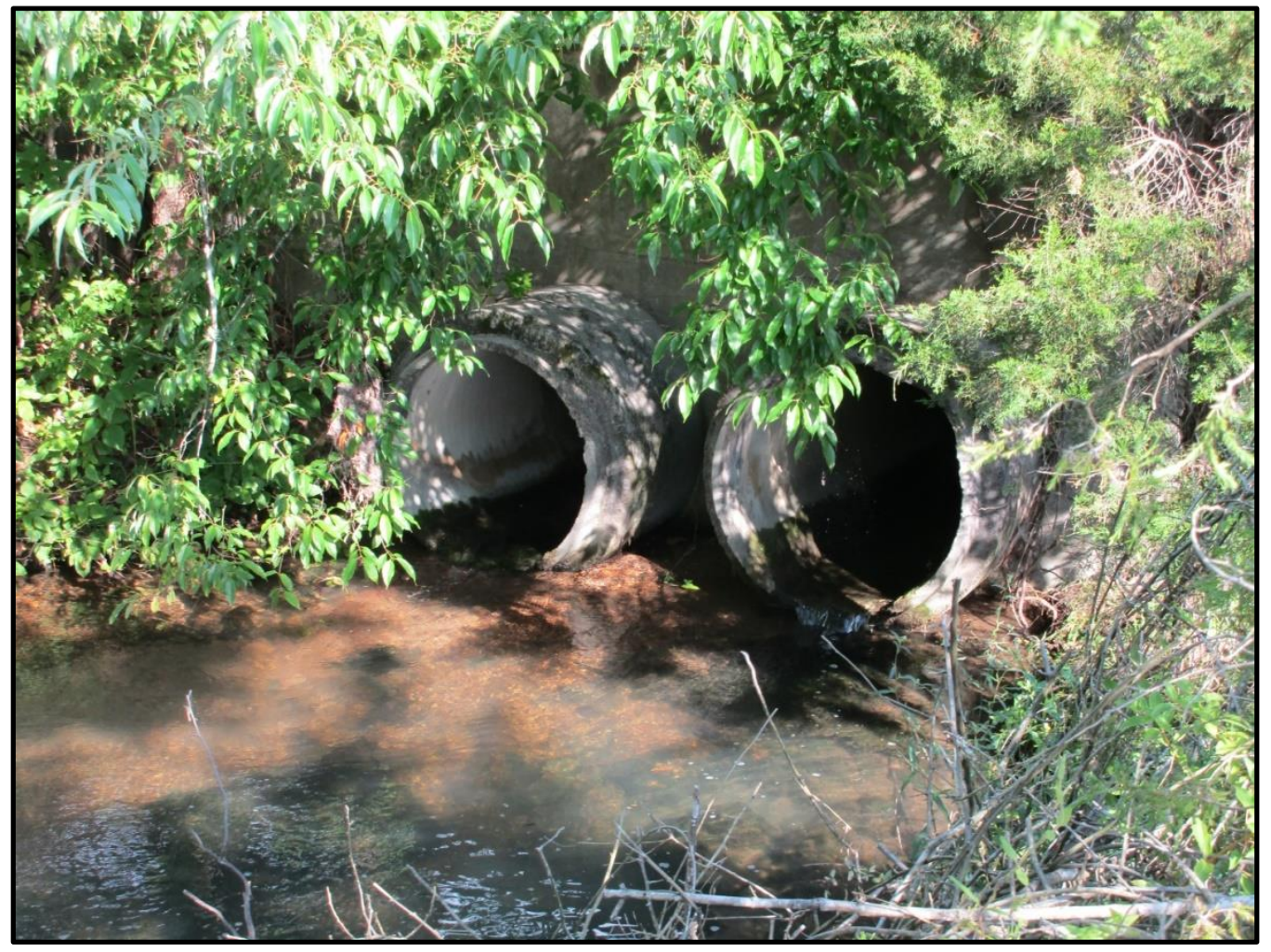

Figure 43. View of the pipe culverts comprising Building 1503-CV1. 


\section{BUILDING NAME}

Aquatic Ecology Laboratory

\section{DATE OF CONSTRUCTION}

1972

\section{DOE OFFICE RESPONSIBLE}

SC

\section{NRHP ELIGIBILITY}

Figure 44. Overview of north and east elevations of Building 1504.

Not Eligible

\section{DESCRIPTION}

Building 1504 is a one-story, 12,174 sq ft, rectangular building. Set upon a continuous concrete foundation, the building is sheltered by a flat roof with a parapet that features two rows of soldier brick capped with metal flashing. The building features masonry construction clad in stretcher bond brick veneer with every fourth row featuring projecting bricks. Windows throughout feature fixed single-light sashes. The façade entry features a full-light metal door that opens to a concrete apron sheltered by a one-bay, flat-roof, brick projection (Figure 44). A circular masonry panel with decorative elements depicting flora and fauna is located to the far left of the façade entry. The side and rear elevations feature both garage bays and single-leaf entries (Figure 45). A raised concrete tank with a raised metal rack and walkway, Building 1553 , is located to the east of the building.

\section{NATIONAL REGISTER EVALUATION}

Building 1504, the Aquatic Ecology Laboratory, was constructed in 1972 as an environmental science laboratory. As part of an expanded program of environmental research at ORNL in the 1970s, research conducted in Building 1504 under the direction of Charles (Chuck) C. Coutant studied thermal effects on aquatic organisms in order to establish biological limitations for design criteria for the siting, construction, and operation of nuclear power plants (Auerbach 1993:84). In 1994 Building 1504 was determined to be not eligible due to age, as it was not yet 50 years old. It was not included in the 2004 or 2015 surveys. As a research/laboratory facility, Building 1504 is associated with the expanded role of environmental science research at ORNL in the 1970s; however, it is not closely associated with a scientific breakthrough or a scientist of truly exceptional importance, thus it does not qualify for individual listing in the NRHP under Criterion A or B or Criteria Consideration G. Building 1504 exhibits the simple institutional design that characterizes the circa 1970-2000 style of the buildings within the 1500 Area, and does not exhibit significant design qualities to qualify for listing in the NRHP under Criterion C. Furthermore, Building 1504 is not located in a NRHP-eligible historic district. Therefore, CRA recommends that Building 1504 is not eligible for listing in the NRHP under Criterion A, B, or C. 


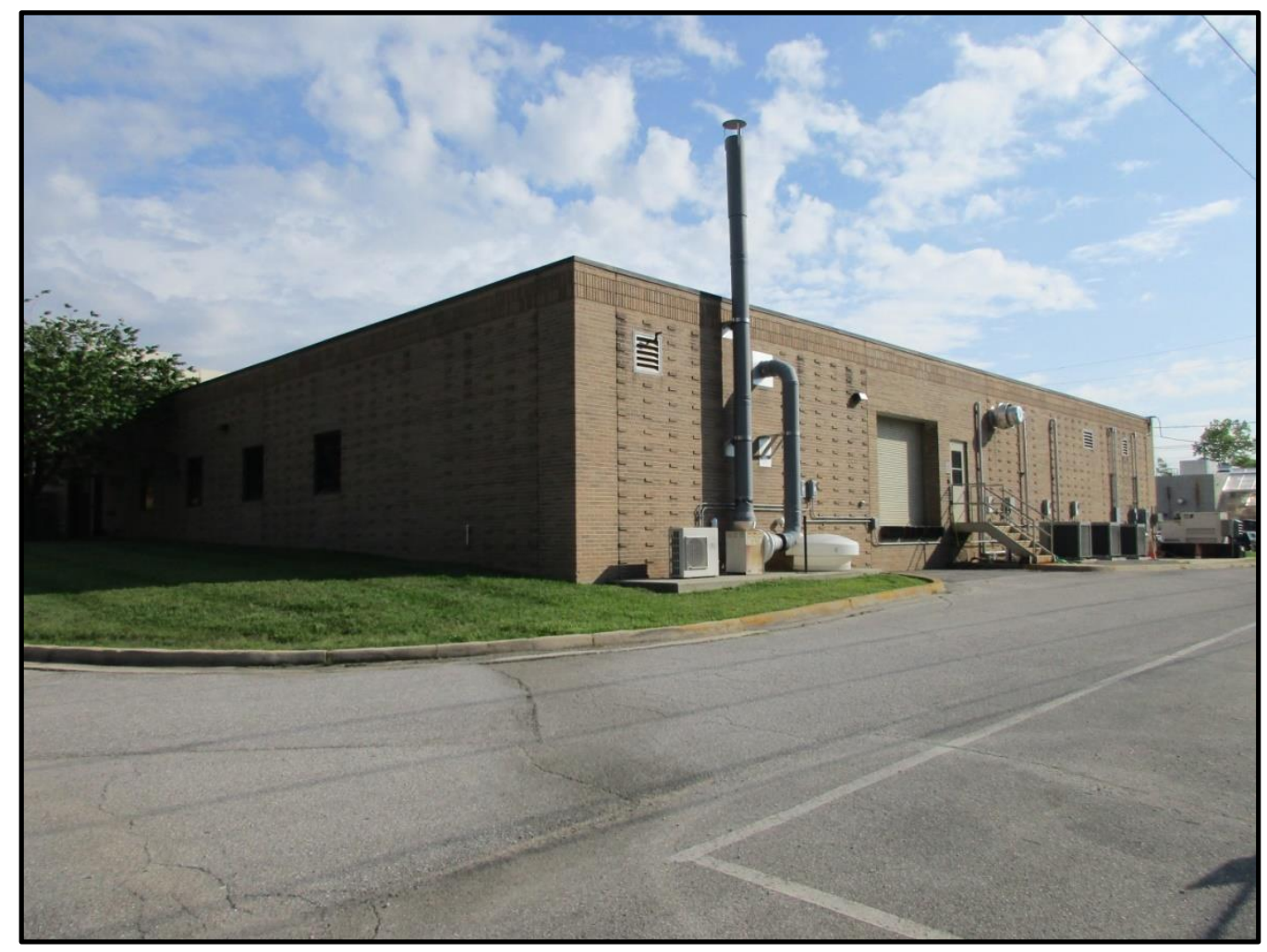

Figure 45. Overview of south elevation and partial west elevation of Building 1504. 


\section{BUILDING NAME}

Environmental Science Laboratory

\section{DATE OF CONSTRUCTION}

1978

\section{DOE OFFICE RESPONSIBLE}

SC

NRHP ELIGIBILITY

Figure 46. Overview of south elevation and partial east elevation of Building 1505.

Not Eligible

\section{DESCRIPTION}

Building 1505, the Environmental Science Laboratory, is the most prominent building within the 1500 Area. This three-story, $88,843 \mathrm{sq} \mathrm{ft}$ masonry building is clad in brick veneer and is sheltered by a flat roof. The exterior is characterized by single-light fixed windows set into slightly-recessed vertical bands of concrete aggregate that extend from the foundation to the roof (Figures 46 and 47). The façade entry is located on a one-story, irregular projection that extends from the three-story block of the building. A circular masonry panel with decorative elements depicting flora and fauna is located to the far right of the façade entry on the main block of the building. Building 1563, Substation \#234-4, extends from the north elevation of Building 1505.

\section{NATIONAL REGISTER EVALUATION}

Building 1505 was constructed in 1978 as the Environmental Science Laboratory. First proposed in 1964, the building provided much-needed space for the growing Environmental Science Division (Auerbach 1993:89). When it was finally built in 1978, it was the first major new building constructed at ORNL in over a decade and the first Energy Research and Development Association (ERDA, formerly the AEC) building to incorporate energy conservation features (Auerbach 1993:93). In 1994 Building 1505 was determined to be not eligible due to age, as it was not yet 50 years old. It was not included in the 2004 or 2015 surveys. As a research/laboratory facility, Building 1505 is associated with the expanded role of environmental science research at ORNL in the 1970s; however it is not closely associated with a scientific breakthrough or a scientist of truly exceptional importance that would rise to the level of significance needed for individual listing in the NRHP under Criterion A or B and Criteria Consideration G. Building 1505 exhibits the simple institutional design that characterizes the circa 1970-2000 style of the buildings within the 1500 Area, and does not exhibit significant design qualities to qualify for listing in the NRHP under Criterion C. Furthermore, Building 1505 is not located in a NRHP-eligible historic district. Therefore, CRA recommends that Building 1505 is not eligible for listing in the NRHP under Criterion $\mathrm{A}, \mathrm{B}$, or $\mathrm{C}$. 


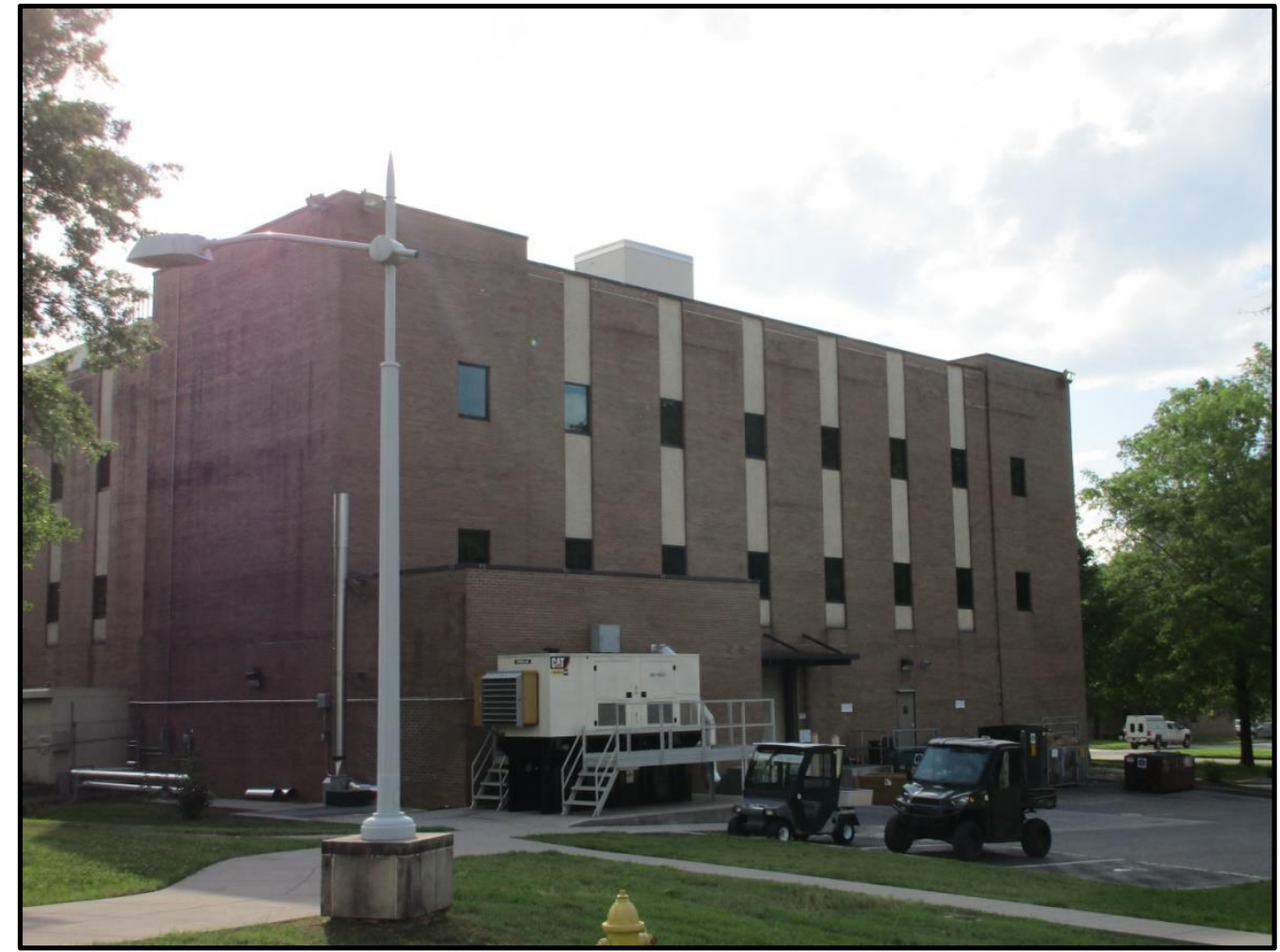

Figure 47. Overview of west elevation and partial north elevation of Building 1505. 


\section{BUILDING NAME}

Controlled Environment \& Animal Building

DATE OF CONSTRUCTION

1978

\section{DOE OFFICE RESPONSIBLE}

SC

NRHP ELIGIBILITY

Not Eligible

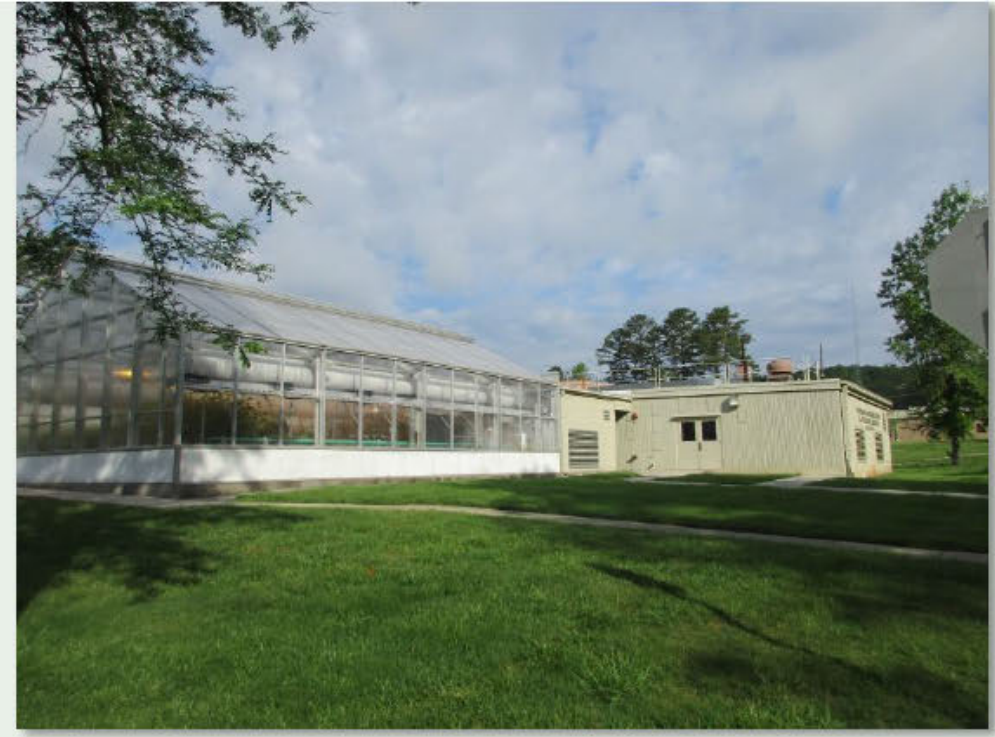

Figure 48. Overview of east elevation and partial south elevation of Building 1506.

\section{DESCRIPTION}

Building 1506, the Controlled Environment \& Animal Building, is a one-story, 16,785 sq ft masonry building. The exterior of the building is constructed of poured concrete with vertical grooves and the core of the building is sheltered by a multi-level roof with a simple metal cornice (Figures 48 and 49 ). The roof is flat and largely covered in mechanical equipment, except for a rectangular section near the western corner of the building, which features a low-pitch shed roof. Building 1506 features single-light steel doors and fixed windows comprised of a single light topped by a smaller fixed light, reminiscent of awning windows found elsewhere on campus. Two gable-roof, steel and glass greenhouses connected to a rectangular masonry addition clad in ashlar-faced stone, extend from the south elevation.

\section{NATIONAL REGISTER EVALUATION}

Building 1506, the Controlled Environment \& Animal Building, was constructed in 1978 as a part of the environmental science laboratory. In 1994 Building 1506 was determined to be not eligible due to age, as it was not yet 50 years old. It was not included in the 2004 or 2015 surveys. As a research/laboratory facility, Building 1506 is associated with the expanded role of environmental science research at ORNL in the 1970s; however, it is not closely associated to a scientific breakthrough or a scientist of truly exceptional importance, thus it does not qualify for individual listing in the NRHP under Criterion A or B and Criteria Consideration G. Building 1506 exhibits the simple institutional design that characterizes the circa 1970-2000 style of the buildings within the 1500 Area, and it features a large rear addition, thus it does not exhibit significant design qualities or adequate integrity to qualify for listing in the NRHP under Criterion C. Furthermore, Building 1506 is not located in a NRHP-eligible historic district. Therefore, CRA recommends that Building 1506 is not eligible for listing in the NRHP under Criterion A, B, or C 


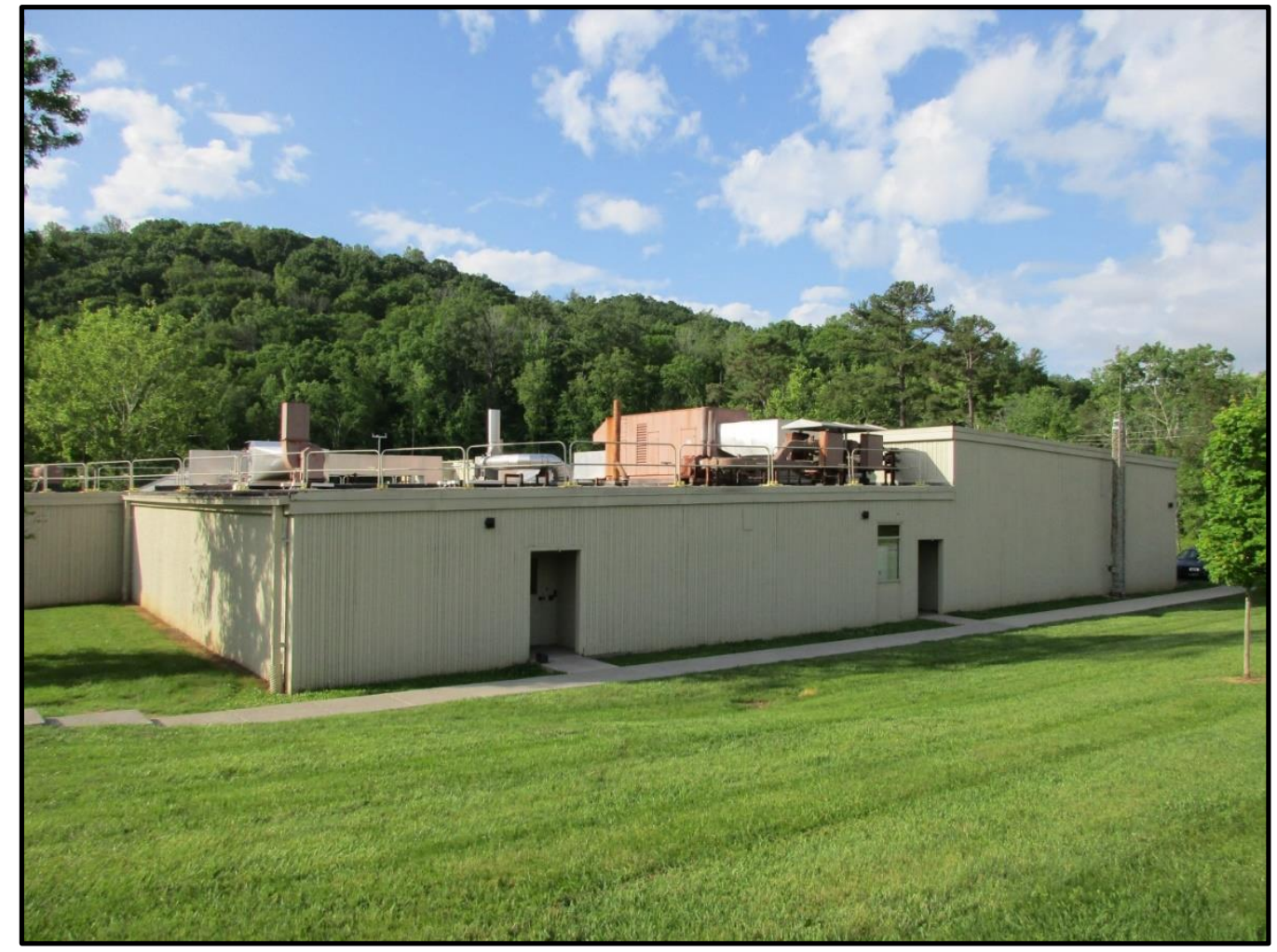

Figure 49. Overview of north elevation and partial east elevation of Building 1506. 
This page intentionally left blank 


\section{AREA}

\section{DISTRICT NAME}

2000 Area of ORNL

\section{DATE OF CONSTRUCTION}

1946-2010

NRHP ELIGIBILITY

Not Eligible

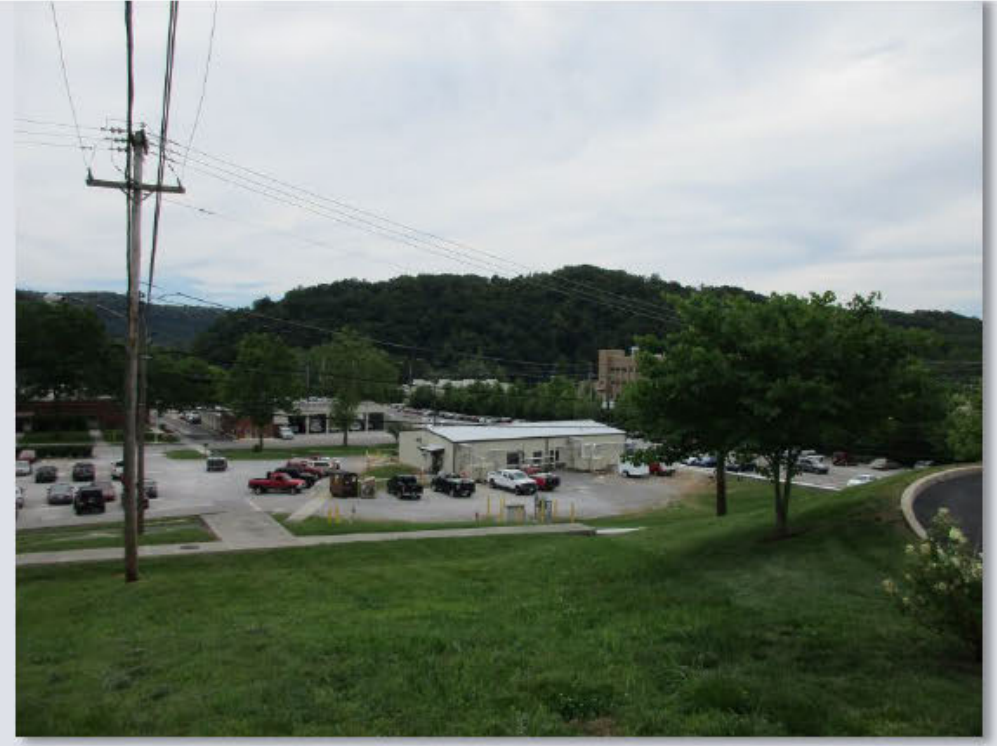

Figure 51. View of 2000 Area looking west towards First Street.

\section{DESCRIPTION}

The 2000 Area is located in the western portion of ORNL's main campus. It is roughly bounded by First Street on the west, Bethel Valley Road on the north, and Third Street on the east and south. A total of 56 buildings are located in the 2000 Area. Of these 56 buildings, 16 buildings were constructed prior to 1980 and thus were included in the present survey. These buildings were used as support facilities for ORNL's main campus and include the Fire and Patrol Station and Steam Plant. The 2000 Area is located on a gradual slope with the northern section situated at the highest point (Figures 51 and 52). Several buildings have been demolished, and large parking lots occupy much of the open space left by demolitions. A few of the buildings included in the survey are located within a secure barricaded area. Therefore, photographs of these particular buildings were limited.

\section{NATIONAL REGISTER EVALUATION}

The 2000 Area first developed in the 1940s as a support area for the X-10 plant and other resources within the 3000 Area. This area has not been individually evaluated as a district through past surveys. The 1994 assessment conducted by Duvall \& Associates determined that a small section of the 2000 Area was a part of the ORNL Historic District (Carver and Slater 1994). The 2015 survey completed by Thomason and Associates recommended the exclusion of 2000 Area from the district (Thomason and Associates 2004 and 2015). Recent demolitions of historic resources, the addition of parking areas, alteration of individual resources, and the addition of Building 2040 in 2010 has diminished the collective integrity of the 2000 Area. The 2000 Area is not a significant hub of scientific research at ORNL, containing just four historic research/laboratory facilities and no processing facilities. Furthermore, the 2000 Area reflects buildings with diverse functions and associations; the entire 2000 Area has never collectively supported a single program or division of ORNL. Therefore, CRA recommends that the 2000 Area does not represent a historic district, nor do any portions of the 2000 Area contribute to the adjacent NRHP-eligible ORNL Historic District. 


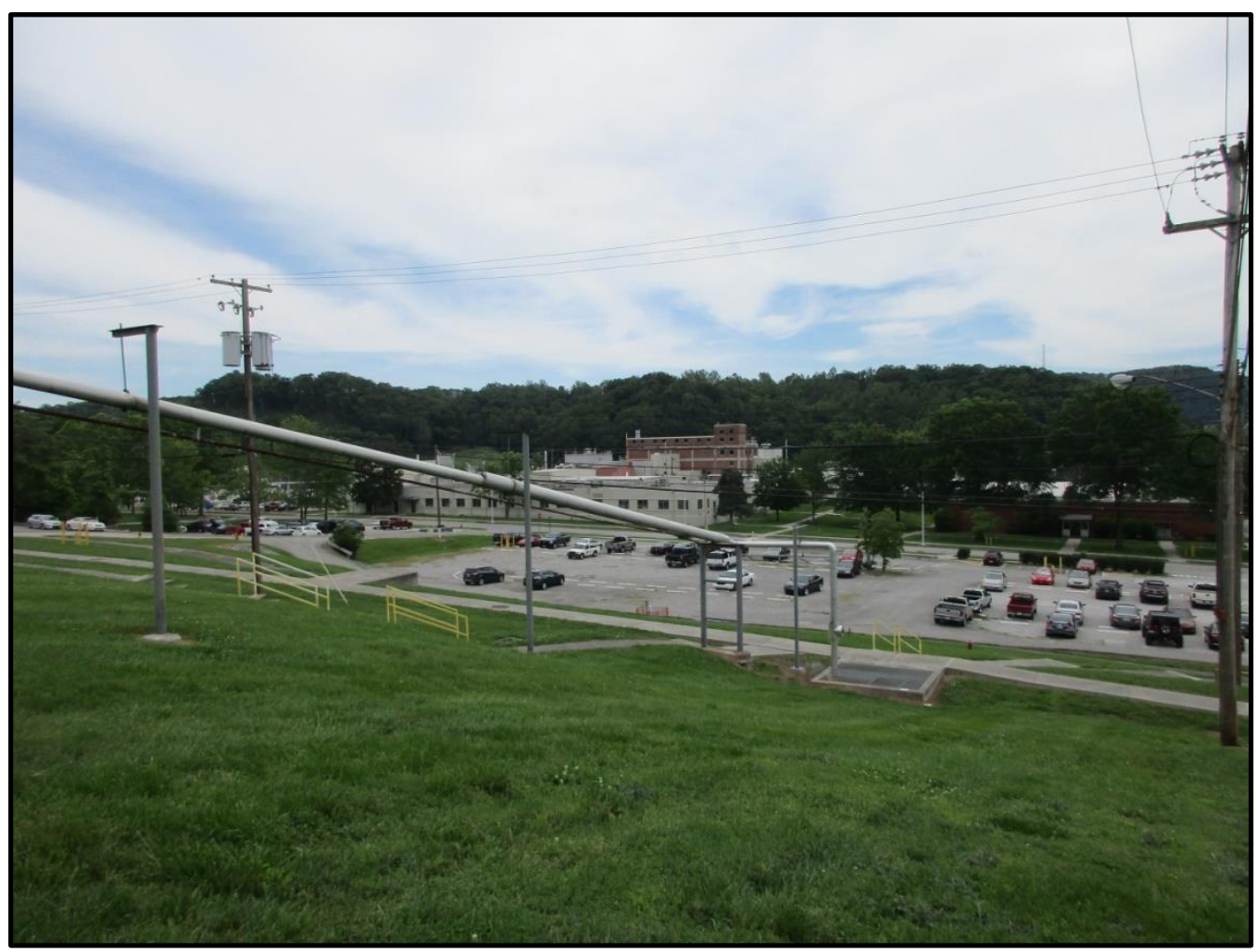

Figure 52. View of 2000 Area facing in a southern direction towards Central Avenue. 


\section{7}

BUILDING NAME

Calibration Lab

DATE OF CONSTRUCTION

1951

DOE OFFICE RESPONSIBLE

SC

NRHP ELIGIBILITY

Figure 54. Overview of west elevation and partial north elevation of Building 2007, showing concrete tower addition.

Not Eligible

\section{DESCRIPTION}

Located along Second Street, Building 2007 is one story building with an irregular floorplan (Figures 54 and 55). The building is sheltered by a flat roof. The original, single-story portion of the building has a brick exterior. Concrete coping lines the brick parapet walls along the roof. The original portion of the structure features windows filled with single and paired four-light metal sashes and smaller windows with single-light sashes along with concrete sills. Several metal awnings, in various sizes, cover entries filled with single-light metal pedestrian doors. The building has been modified since its initial construction including the addition of several new sections. A tall hexagonal concrete addition is located in the eastern corner of the building.

\section{NATIONAL REGISTER EVALUATION}

Building 2007 was constructed in 1951 for the development of test radiation monitoring systems and was a part of ORNL's Program H expansion. Today, it serves as a calibration laboratory and is associated with the Health Physics Division (Thomason and Associates 2015). Building 2007 was first surveyed by Duvall \& Associates in 1994. However, it was not identified as a building of historic significance (Carver and Slater 1994). In the 2004 assessment completed by Thomason and Associates, the building was not surveyed. In 2015 Thomason and Associates concurred with the 1994 assessment of the structure (Thomason and Associates 2015). As a research/laboratory facility, Building 2007 housed work that furthered ORNL's mission in nuclear science during the Cold War era. However, the building is not associated with a scientific achievement, scientist, or other event or person of historic significance to merit individual listing in the NRHP under Criterion A or B. Furthermore, the building lacks notable architectural elements that would warrant individual listing in the NRHP under Criterion C, and multiple additions to the building, including a large hexagonal concrete tower, have diminished its integrity. The building is not located in a NRHP-eligible historic district. Thus, CRA recommends that Building 2007 is not eligible for listing in the NRHP under Criterion A, B, or C. 


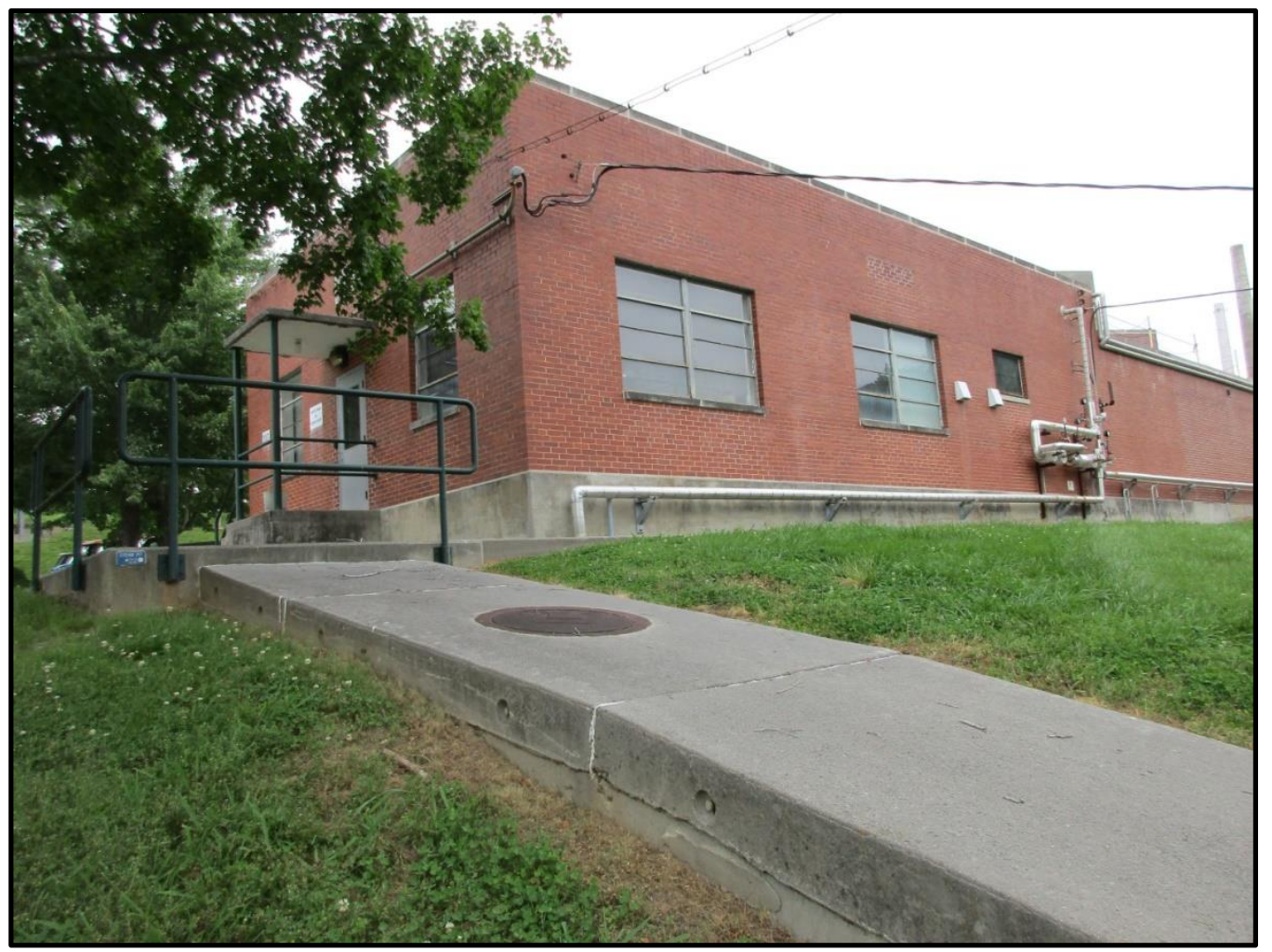

Figure 55. Overview of west elevation and partial south elevation of Building 2007. 


\section{8}

\section{BUILDING NAME}

Whole Body Counter

\section{DATE OF CONSTRUCTION}

1946

\section{DOE OFFICE RESPONSIBLE}

SC

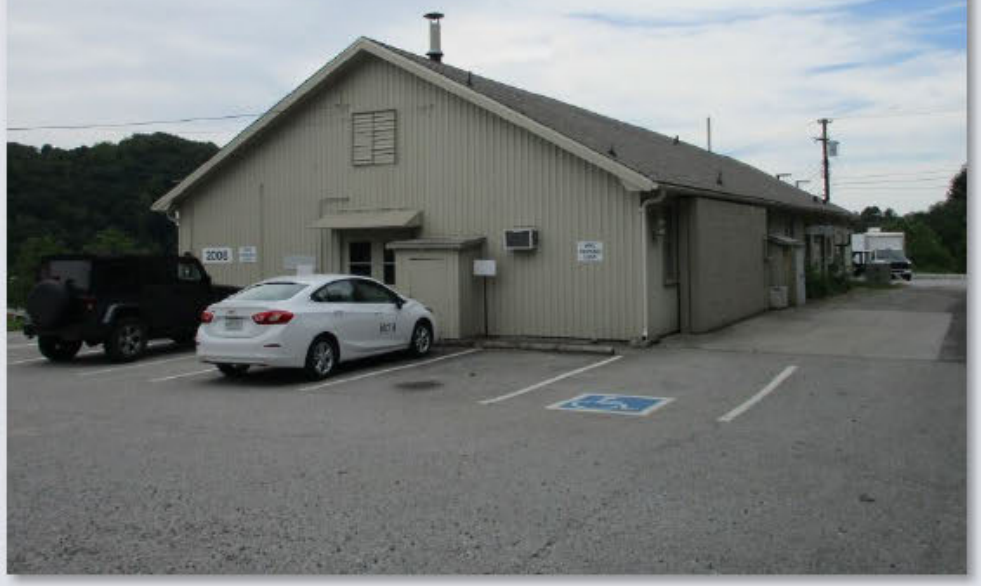

NRHP ELIGIBILITY

Figure 56. Overview of north and east elevations of Building 2008.

Not Eligible

\section{DESCRIPTION}

Located along Second Street, Building 2008 is a one-story frame structure with its gable roof clad in asphalt shingles (Figure 56 and 57). The exterior of the building is clad with corrugated metal panels. Windows with one-over-one sashes, several in pairs, are located on the north and south elevations of the building. Single and paired entries filled with two-light metal pedestrian doors, several with metal shed awnings, are located on all elevations of the building. An addition is located on the south elevation of the building and is sheathed in corrugated metal. This addition is sheltered by a flat roof. Small shed additions for storage are located on several elevations of the building.

\section{NATIONAL REGISTER EVALUATION}

Building 2008, constructed in 1946, was initially used for the Health and Physics Division of Clinton Laboratories. A Whole Body Counting Room was located within the building, which helped in the research efforts of accident dosimetry (Carver and Slater 1994). Building 2008 was first surveyed by Duvall \& Associates in 1994. However, it was not identified as a building of historic significance (Carver and Slater 1994). In the 2004 assessment completed by Thomason and Associates, the building was not surveyed. In 2015 Thomason and Associates concurred with the 1994 assessment of the structure (Thomason and Associates 2015). As a research/laboratory facility, Building 2008 housed work that furthered ORNL's mission in nuclear science during the immediate post-World War II and Cold War eras. However, the building is not associated with a scientific achievement, scientist, or other event or person of historic significance to merit individual listing in the NRHP under Criterion $\mathrm{A}$ or $\mathrm{B}$. Furthermore, the building lacks notable architectural elements that would warrant individual listing in the NRHP under Criterion C. The building is not located in a NRHP-eligible historic district. Thus, CRA recommends that Building 2008 is not eligible for listing in the NRHP under Criterion A, B, or C. 


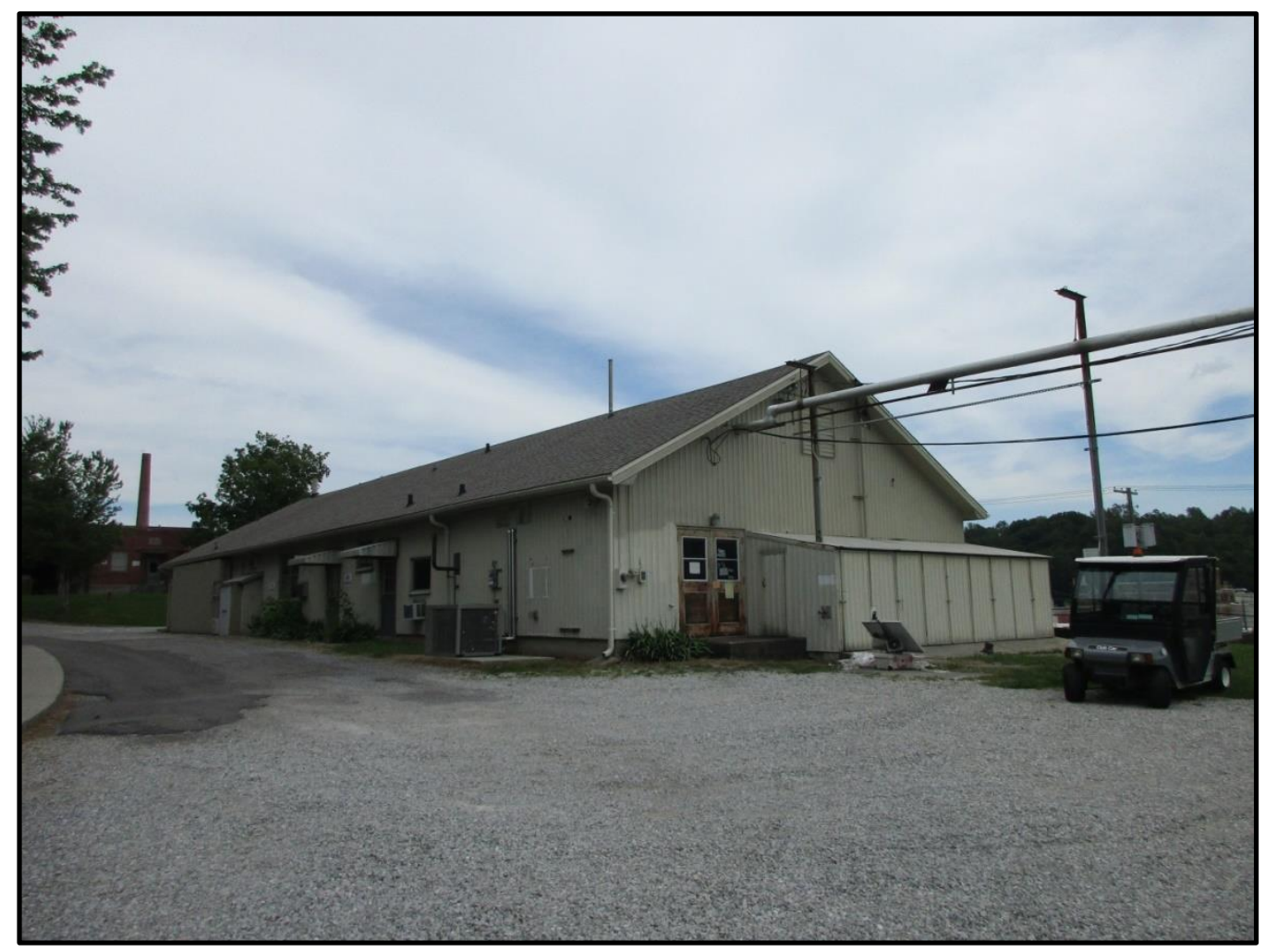

Figure 57. Overview of north and south elevations of Building 2008. 


\section{6}

\section{BUILDING NAME}

Radioactive Materials Analytical Lab

\section{DATE OF CONSTRUCTION}

1964

\section{DOE OFFICE RESPONSIBLE}

SC

NRHP ELIGIBILITY

Not Eligible

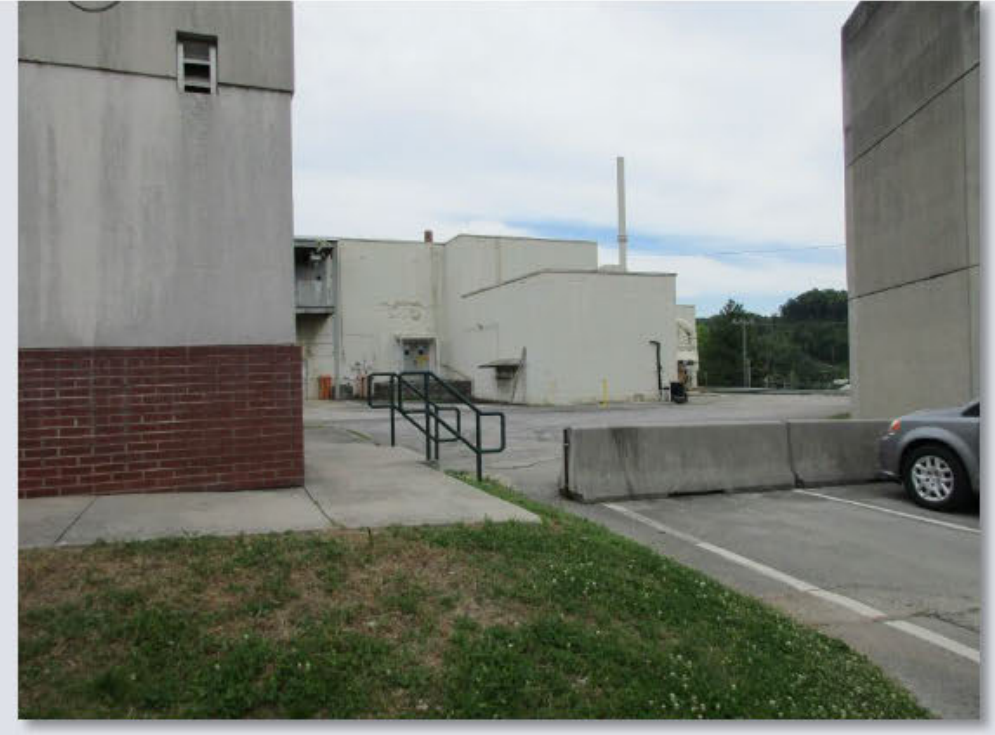

Figure 58. View of a small section of the west elevation of Building 2026.

\section{DESCRIPTION}

Building 2026 is located within a secure barricaded area that encompasses parts of the 2000 Area and 3000 Area. Access to this high security area is limited; therefore, photographs of the building's exterior were limited. The building is a $22,600 \mathrm{sq} \mathrm{ft}$, multi-story, concrete block masonry structure with an irregular plan (Figures 58 and 59). The structure is situated on a concrete foundation and is sheltered by a flat roof. The building features paired entries filled with single-light metal pedestrian doors and solid metal doors. Other openings include windows filled with two-light and four-light fixed sashes with concrete sills.

\section{NATIONAL REGISTER EVALUATION}

Building 2026 was constructed in 1964 as a Radioactive Materials Analytic Laboratory. The building is equipped with special containment areas and ventilation systems to study the general analytic chemistry of radioactive materials. This includes hot cells and a glovebox system (Thomason and Associates 2015). Building 2026 was initially surveyed by Thomason and Associates in 2015 and recommended ineligible for listing in the NRHP (Thomason and Associates 2015;95). The building was not referenced in the 1994 and 2004 assessments. As a research/laboratory facility, Building 2026 housed work that furthered ORNL's mission in nuclear science during the Cold War era. However, the building is not associated with a scientific achievement, scientist, or other event or person of historic significance to merit individual listing in the NRHP under Criterion A or B. Furthermore, the building lacks notable architectural elements that would warrant individual listing in the NRHP under Criterion $\mathrm{C}$. The building is not located in a NRHP-eligible historic district. Thus, CRA recommends that Building 2026 is not eligible for listing in the NRHP under Criterion A, B, or C. 


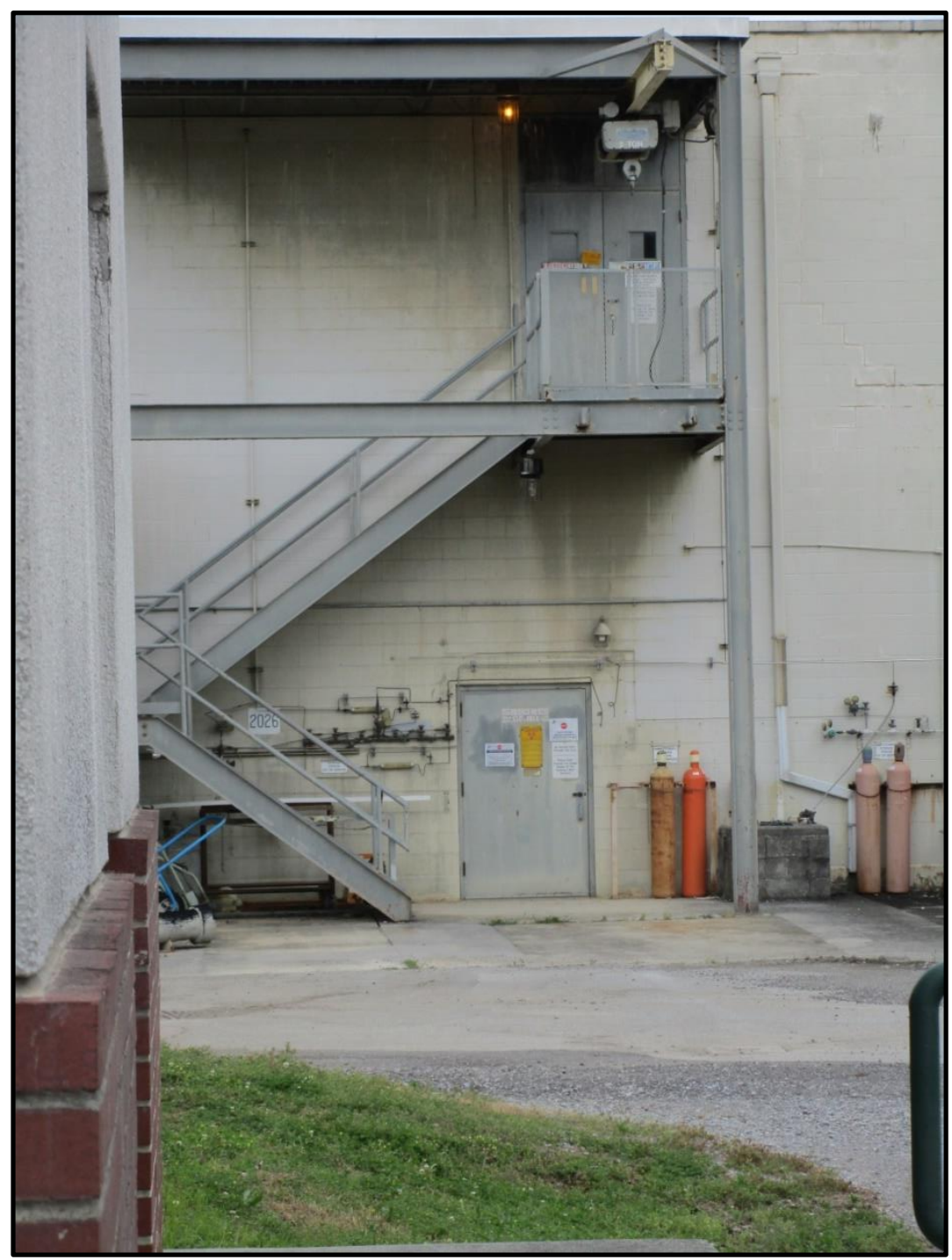

Figure 59. View of a small section of the west elevation of Building 2026, showing an exterior stairwell. 


\section{0}

\section{BUILDING NAME}

Fire Department Headquarters

\section{DATE OF CONSTRUCTION}

1967

\section{DOE OFFICE RESPONSIBLE}

SC

NRHP ELIGIBILITY

Figure 60. Overview of north and east elevations of Building 2500, showing brick masonry wing.

Not Eligible

\section{DESCRIPTION}

The building is located south of Central Avenue and east of First Street. Building 2500 is a one-story concrete block masonry building situated on a concrete foundation with two additional wings to the west and east. The west wing is also constructed of concrete block masonry and extends along First Street. The east wing is constructed with an exterior of brick laid in a five course common bond (Figure 60 ). The building is sheltered by a flat roof with a brick parapet surrounding the east wing. The central portion of the building features large bays filled by sectional overhead garage doors for the fire trucks (Figure 61). The concrete block sections of the building feature windows with concrete sills and filled with three-light sashes with horizontal panes and small windows with single light sashes. The brick-exterior wing contains windows with two-light vertical panes. The building also features entries with single-light pedestrian doors.

\section{NATIONAL REGISTER EVALUATION}

Building 2500 was constructed in 1967 as a Patrol and Fire Building and continues to house the ORNL Fire Department. This building was constructed on the site of a previous Patrol and Fire Building constructed in 1943 (Thomason and Associates 2015). Building 2500 was initially surveyed by Thomason and Associates in 2015 and recommended ineligible for listing in the NRHP (Thomason and Associates 2015). The building was not referenced in the 1994 and 2004 assessments. As an office and headquarters for the fire department, Building 2500 contributed to the safe functioning of ORNL during the Cold War era. However, the building is not directly associated with the scientific work that occurred at ORNL or any other event or person of historic significance to merit individual listing in the NRHP under Criterion A or B. Furthermore, the building lacks notable architectural elements that would warrant individual listing in the NRHP under Criterion $\mathrm{C}$. The building is not located in a NRHP-eligible historic district. Thus, CRA recommends that Building 2500 is not eligible for listing in the NRHP under Criterion $\mathrm{A}, \mathrm{B}$, or $\mathrm{C}$. 


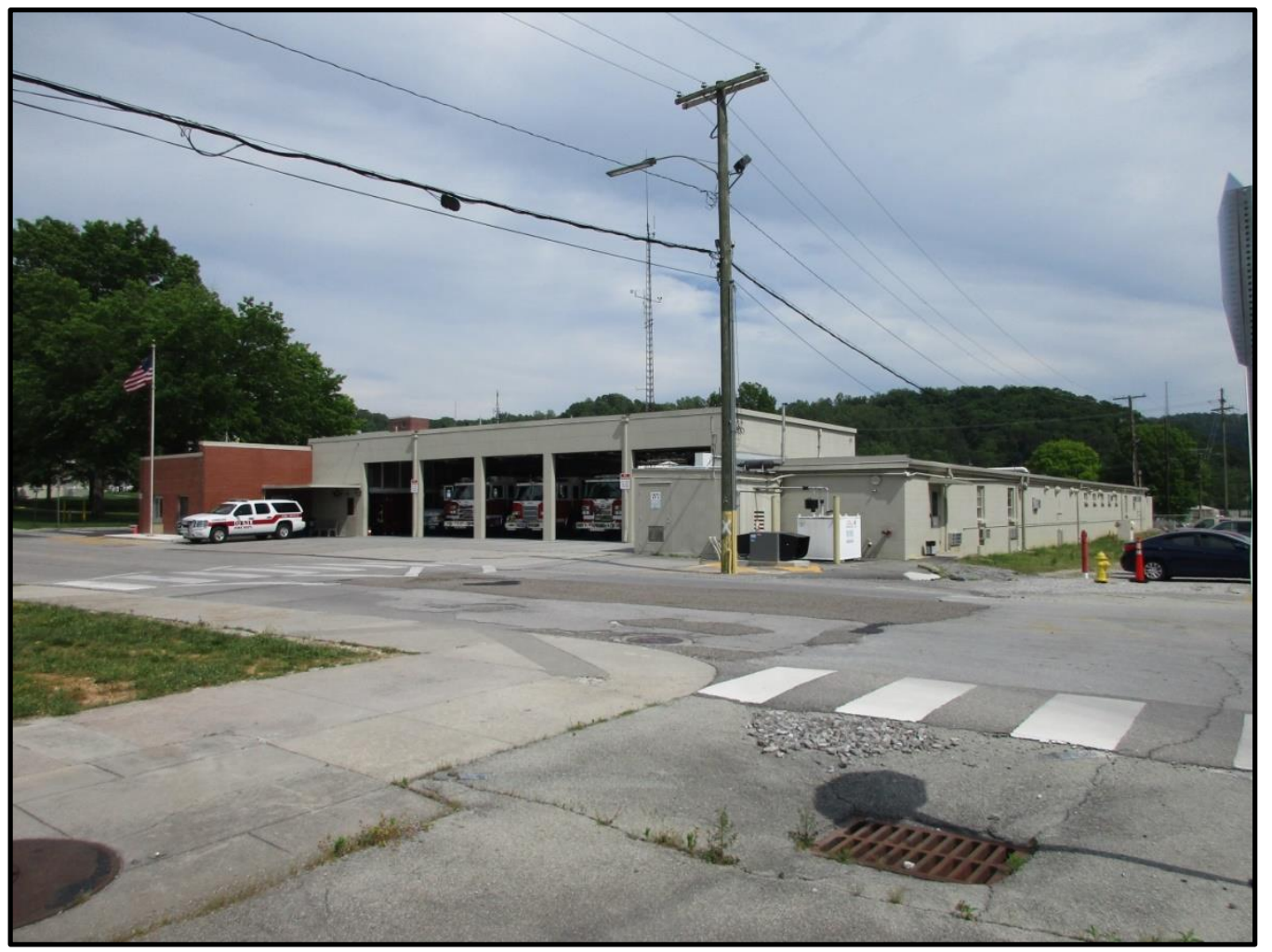

Figure 61. Overview of north and west elevations of Building 2500, showing large open bays for the fire trucks. 


\section{8}

\section{BUILDING NAME}

Support Services Building

DATE OF CONSTRUCTION

1951

DOE OFFICE RESPONSIBLE

SC

NRHP ELIGIBILITY

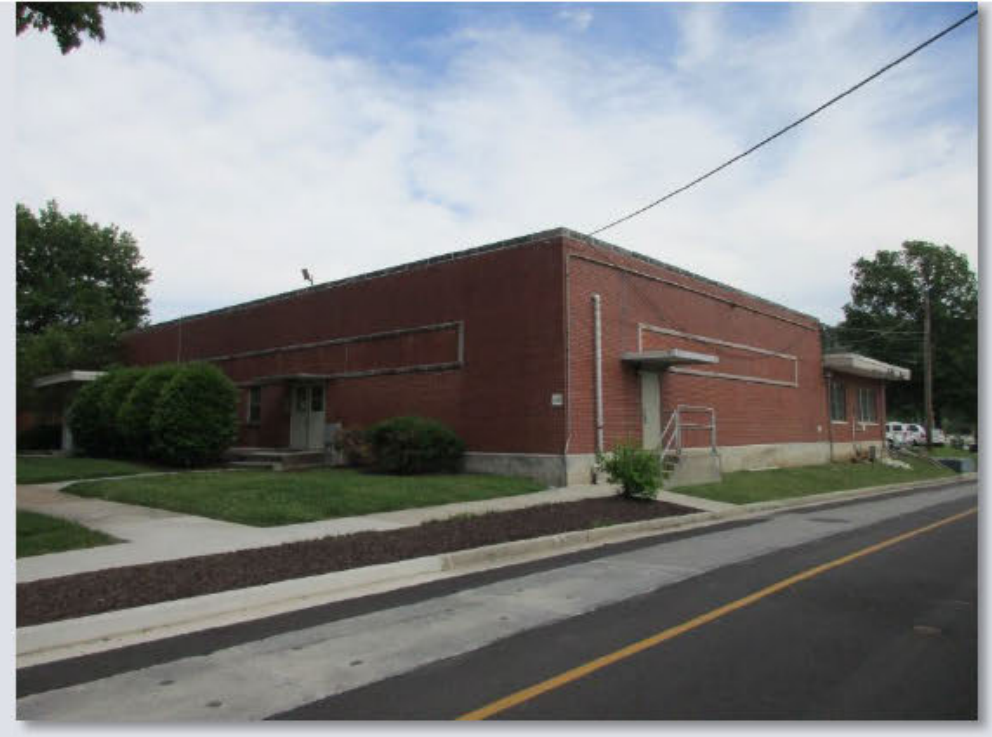

Figure 62. Overview of north and west elevations of Building 2518, showing decorative features above openings.

Not Eligible

\section{DESCRIPTION}

Building 2518 is located south of Central Avenue and east of First Street. Building 2518 is a one-story building with a brick exterior situated on a concrete foundation. The brick pattern is a modified six course common bond of stretchers with an alternating stretcher and header course. The building is sheltered by a flat roof with parapets and concrete coping. Simple, decorative stone or concrete rectangular frames are located above the windows and doors on the west, north and east elevations (Figure 62). The building features pairs of four-light windows with horizontal panes and concrete sills (Figure 63). The metal, single-light doors are sheltered by flat metal awnings.

\section{NATIONAL REGISTER EVALUATION}

Building 2518 was constructed in 1951 to serve as a change house. It has also provided classroom space for the Oak Ridge School of Reactor Technology and office space for the Plant and Equipment Division. The building is associated with the Program $\mathrm{H}$ building expansion (Carver and Slater 1994). Building 2518 was initially surveyed by Duvall \& Associates in 1994. However, it was not identified as a building of historic significance (Carver and Slater 1994). The building was not referenced in the 2004 assessment completed by Thomas and Associates. In 2015 Thomason and Associates concurred with the 1994 assessment of the structure (Thomason and Associates 2015). As a change house and office building, Building 2518 supported operations at ORNL during the Cold War era. However, the building is not associated with a scientific achievement, scientist, or other event or person of historic significance to merit individual listing in the NRHP under Criterion $\mathrm{A}$ or $\mathrm{B}$. Furthermore, the building lacks notable architectural elements that would warrant individual listing in the NRHP under Criterion $C$. The building is not located in a NRHP-eligible historic district. Thus, CRA recommends that Building 2518 is not eligible for listing in the NRHP under Criterion A, B, or C. 


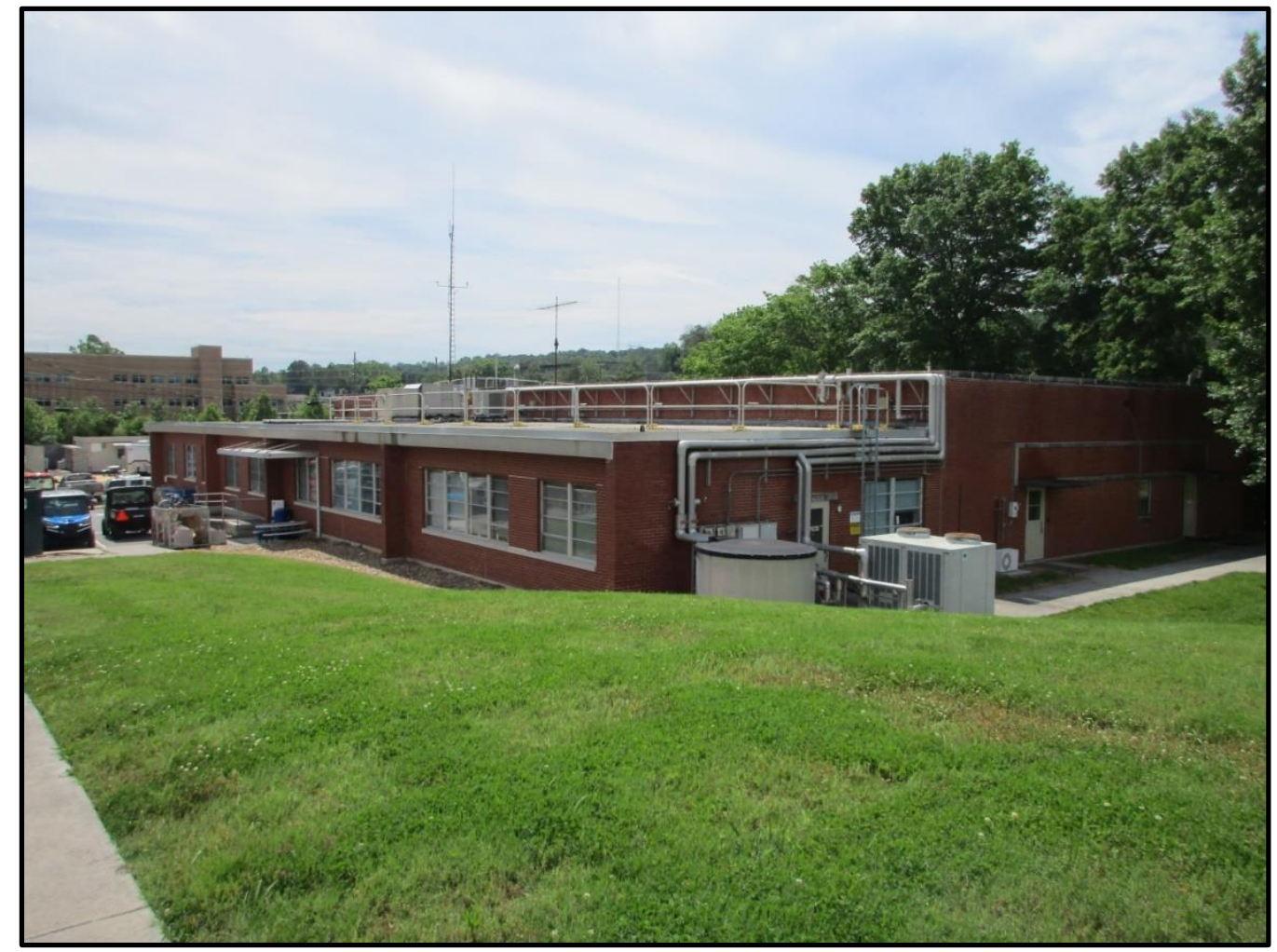

Figure 63. Overview of east and south elevations of Building 2518. 


\section{9}

\section{BUILDING NAME}

Steam Distribution Plant

DATE OF CONSTRUCTION

1948

\section{DOE OFFICE RESPONSIBLE}

SC

NRHP ELIGIBILITY

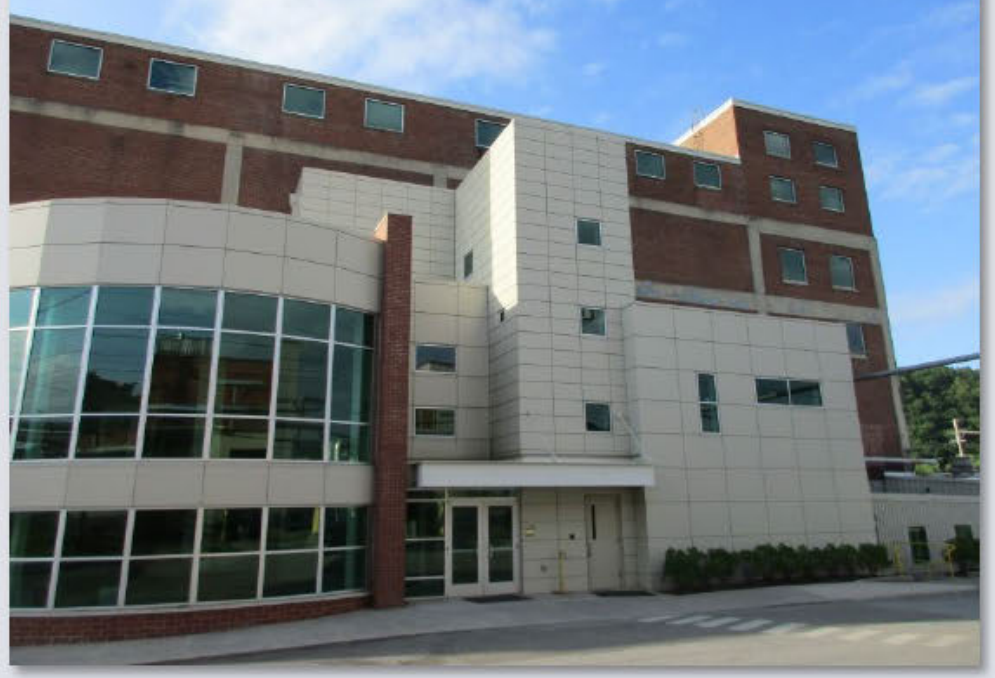

Figure 64 . Overview of north elevation of Building 2519 , showing the multiple modern additions attached to the original building.

Not Eligible

\section{DESCRIPTION}

The building is located south of White Oak Avenue and near Third Street. Building 2519 is a multi-story complex building with many additions surrounding the building's original footprint (Figures 64 and 65). The original building is a five-story structure with a brick exterior and concrete foundation. Multiple additions are located on the north, east and south elevations. The brick pattern is five course common bond and features horizontal and vertical bands of concrete to decorate the exterior and possibly define the location of interior floors. The entire complex is sheltered by a flat roof. The materials of the modern additions differ from the original building. A semicircular addition and prominent entrance is located on the north elevation that features brick accents, large glass panes, and metal panels. Single-light and two-light fixed windows are found throughout of the building. The doorways are filled with single-light metal pedestrian doors. A portion of the building clad with corrugated metal siding is located to the east and connects to a larger metal-clad steel structure. The only fenestration on this part of the building is sliding metal doors and large vents. The building sits adjacent to Building 2519D and Building 2719.

\section{NATIONAL REGISTER EVALUATION}

Building 2519 was constructed in 1948 as a steam plant, which replaced the original steam plant (Building 2011) (Carver and Slater 1994). The building was initially surveyed by Duvall \& Associates in 1994. At that time, Building 2519 was recommended as not eligible for listing in the NRHP (Carver and Slater 1994). The structure was not included in the 2004 and 2015 surveys of ORNL. As a utility building, Building 2519 is not a primary building associated with scientific achievements at ORNL, nor is it known to be associated with any other events or persons of historic significance, thus it does not qualify for individual listing in the NRHP under Criterion A or B. Further, it is a simple utilitarian structure that has been modified numerous times over the course of its history including multiple additions to the front of the building and thus lacks architectural significance and integrity for listing in the NRHP under Criterion $C$. The building is not located in a NRHP-eligible historic district. Thus, CRA recommends that Building 2519 is not eligible for listing in the NRHP under Criterion A, B, or C. 


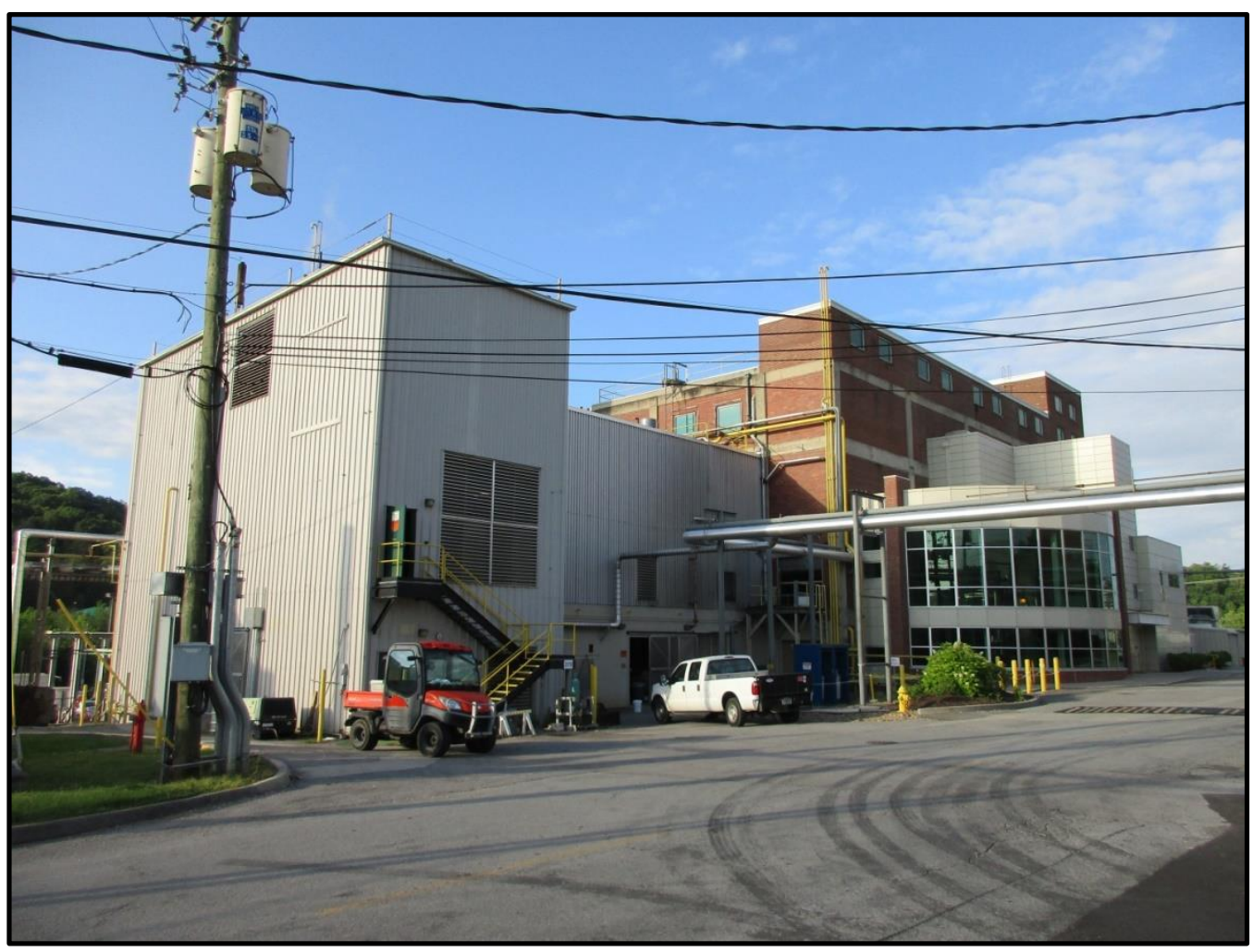

Figure 65. Overview of north and east elevations of Building 2519. 


\section{3}

\section{BUILDING NAME}

Decontamination Laundry

DATE OF CONSTRUCTION

1955

DOE OFFICE RESPONSIBLE

SC

NRHP ELIGIBILITY

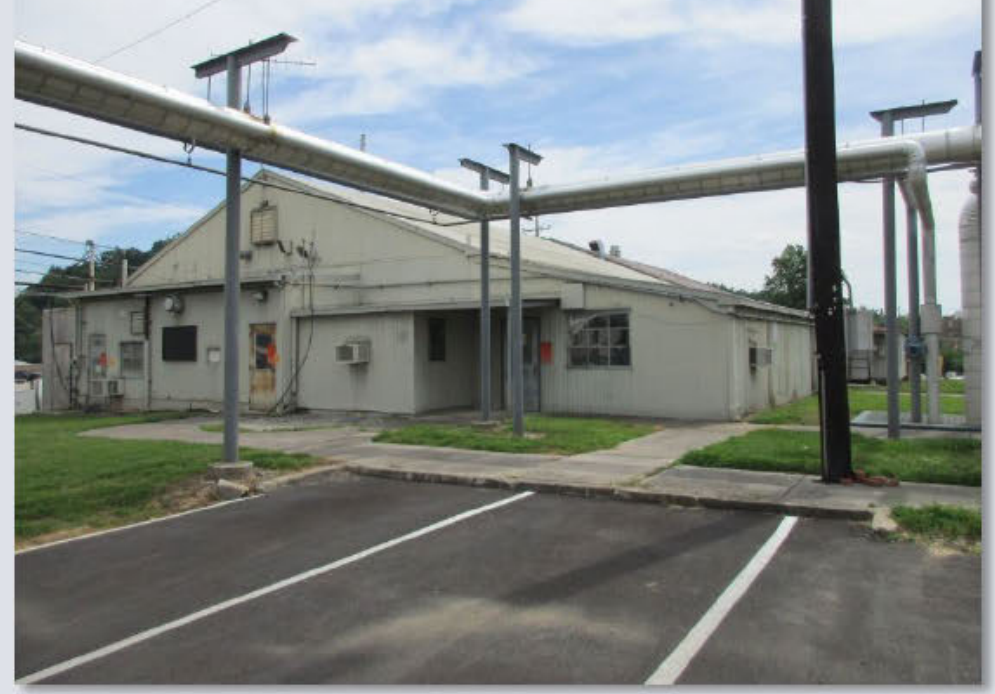

Not Eligible

Figure 66. Overview of east elevation and partial south elevation of Building 2523.

\section{DESCRIPTION}

The building is located north of White Oak Avenue, between First and Third Streets. Building 2523 is a onestory, gable-roof building situated on a concrete foundation (Figures 66 and 67). The exterior of the building is clad with corrugated metal siding including the roof. Several additions are located on the north elevation including a shed-roof addition. Another front-gabled addition is accessed by covered walkways. The additions are similar in material as the main block of the building. The building features four-light, nine-light, and fifteenlight metal awning windows. Entries filled with single-light, two-light, and four-light metal pedestrian doors are located on several elevations. Roll-up garage doors are located in an open loading dock on the south elevation.

\section{NATIONAL REGISTER EVALUATION}

Building 2523 was constructed in 1955 for the purpose of a decontamination laundry (Carver and Slater 1994). Building 2523 was initially surveyed by Duvall \& Associates in 1994. However, it was not identified as a building of historic significance (Carver and Slater 1994). The building was not referenced in the 2004 assessment completed by Thomas and Associates. In 2015 Thomason and Associates concurred with the 1994 assessment of the structure (Thomason and Associates 2015;101). As a utility/maintenance facility, Building 2523 is not a primary building associated with scientific achievements at ORNL, nor is it known to be associated with any other events or persons of historic significance, thus it does not qualify for individual listing in the NRHP under Criterion A or B. Further, it is a simple utilitarian structure that lacks architectural significance for listing in the NRHP under Criterion $C$. The building is not located in a NRHP-eligible historic district. Thus, CRA recommends that Building 2523 is not eligible for listing in the NRHP under Criterion A, B, or C. 


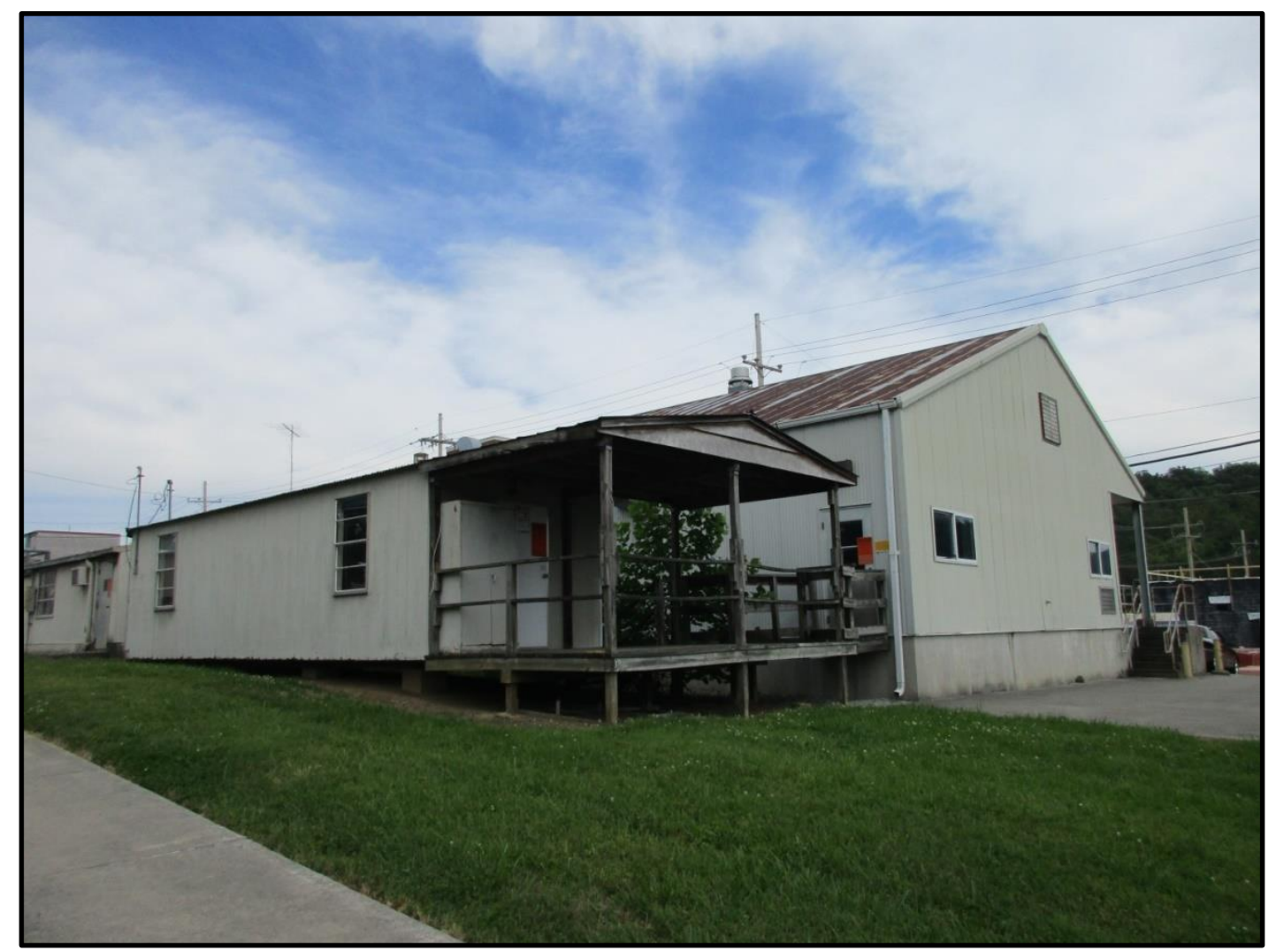

Figure 67. Overview of north and west elevations of Building 2523. 


\section{5}

\section{BUILDING NAME}

Fabrication Department Shop A

DATE OF CONSTRUCTION

1957

DOE OFFICE RESPONSIBLE

SC

NRHP ELIGIBILITY

Figure 68. Overview of north elevation and partial east elevation of Building 2525.

Not Eligible

\section{DESCRIPTION}

Building 2525 is a one-story concrete block masonry structure situated on a concrete foundation located on the south side of Central Avenue. The building is sheltered by a flat roof. The building totals to $27,622 \mathrm{sq} f t$. The main entrance located on the north façade features four-light metal doors sheltered by a concrete canopy supported by two cylindrical metal posts. The windows located on the north façade contain single-light fixed sashes with concrete sills. Multi-pane fixed sashes with concrete sills are located on all elevations. Other entrances located on all elevations include single-light and four-light metal doors, several with shed awnings or concrete canopies, similar to the main entrance. Large garage bays are located on the south elevation.

\section{NATIONAL REGISTER EVALUATION}

Building 2525 was constructed in 1957 as a research shop (Carver and Slater 1994). It is now designated a fabrication shop. Building 2525 was first surveyed by Duvall \& Associates in 1994 . However, it was not identified as a building of historic significance (Carver and Slater 1994). In the 2004 assessment completed by Thomason and Associates, the building was not surveyed. In 2015 Thomason and Associates concurred with the 1994 assessment of the structure (Thomason and Associates 2015). The integrity of the building still remains intact including its massing and materials. As a utility/maintenance building, Building 2525 housed work that supported ORNL's mission in nuclear science during the Cold War era. However, the building is not associated with a scientific achievement, scientist, or other event or person of historic significance to merit individual listing in the NRHP under Criterion A or B. Further, it is a simple utilitarian structure that lacks architectural significance for listing in the NRHP under Criterion $\mathrm{C}$. The building is not located in a NRHP-eligible historic district. Thus, CRA recommends that Building 2525 is not eligible for listing in the NRHP under Criterion A, B, or C. 


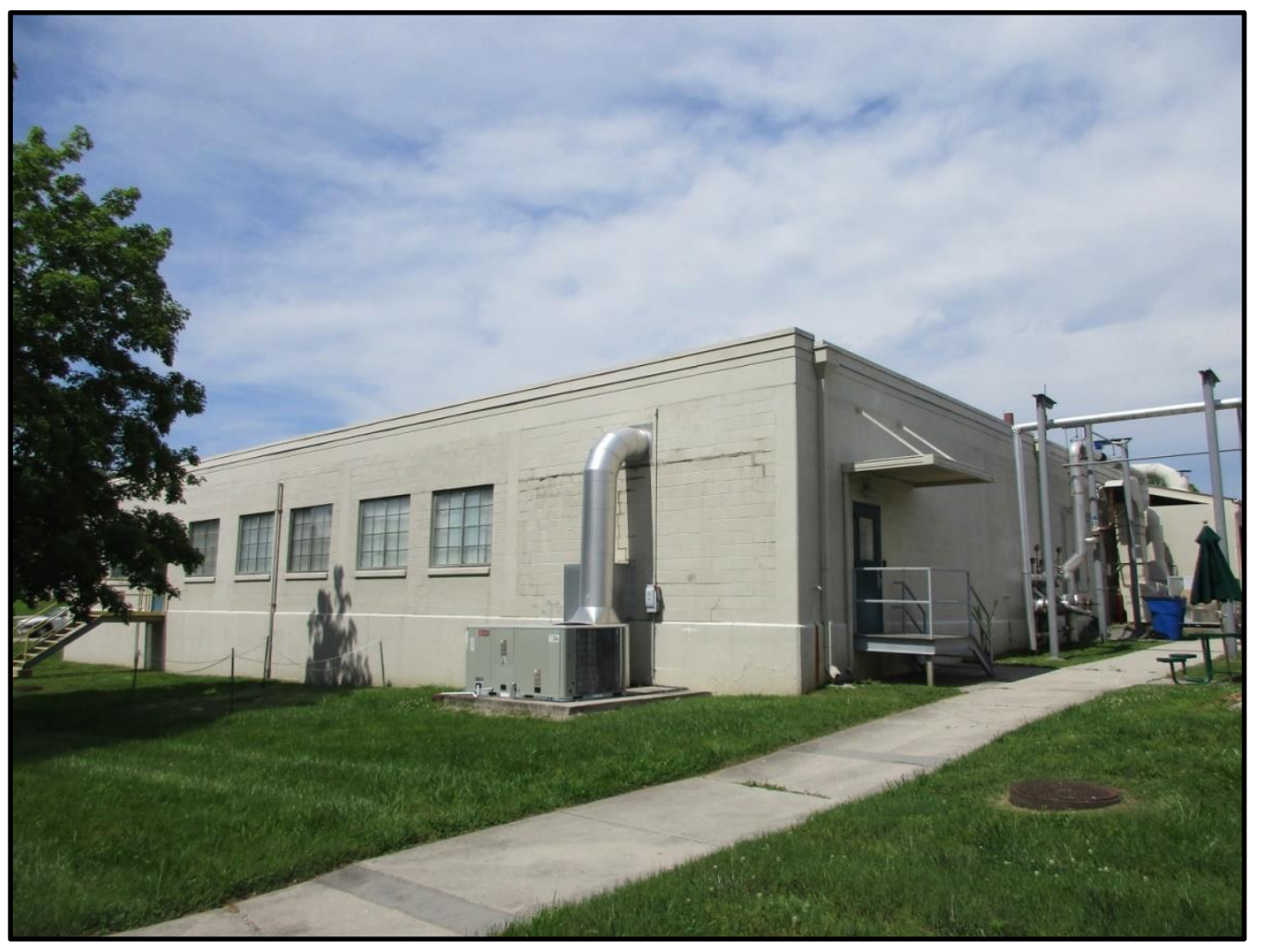

Figure 69. Overview of west elevation and partial south elevation of Building 2525. 


\section{8}

BUILDING NAME

Coal Research Lab

DATE OF CONSTRUCTION

1959

DOE OFFICE RESPONSIBLE

SC

Figure 70. Overview of north and west elevations of Building 2528.

NRHP ELIGIBILITY

Not Eligible

\section{DESCRIPTION}

The building is located south of White Oak Avenue, near Third Street. Building 2528 is composed of two sections: a one-story, gable-roof portion clad in corrugated metal; and a two-story, flat-roof section (Figures 70 and 71). The building sits on a concrete foundation. Three roof vents are located along the ridgeline of the gable roof section. Two roof vents pierce the flat roof section. The building features two-light and six-light awning windows. A shorter gable-roof section projects from the north elevation and demarks the entrance of the building filled by a single-light metal door. A large vehicular entry filled by a roll-up metal door is located on the west elevation of the flat-roof section.

\section{NATIONAL REGISTER EVALUATION}

Building 2528 was constructed in 1959 and served as a coal research laboratory (Thomason and Associates 2015). The building was initially surveyed by Thomason and Associates in 2015 and recommended ineligible for listing in the NRHP (Thomason and Associates 2015). The building was not referenced in the 1994 and 2004 assessments. As a research/laboratory facility, Building 2028 housed work that furthered ORNL's mission in energy research during the Cold War era. However, the building is not associated with a scientific achievement, scientist, or other event or person of historic significance to merit individual listing in the NRHP under Criterion A or B. Furthermore, the building lacks notable architectural elements that would warrant individual listing in the NRHP under Criterion $C$. The building is not located in a NRHP-eligible historic district. Thus, CRA recommends that Building 2528 is not eligible for listing in the NRHP under Criterion A, B, or C. 


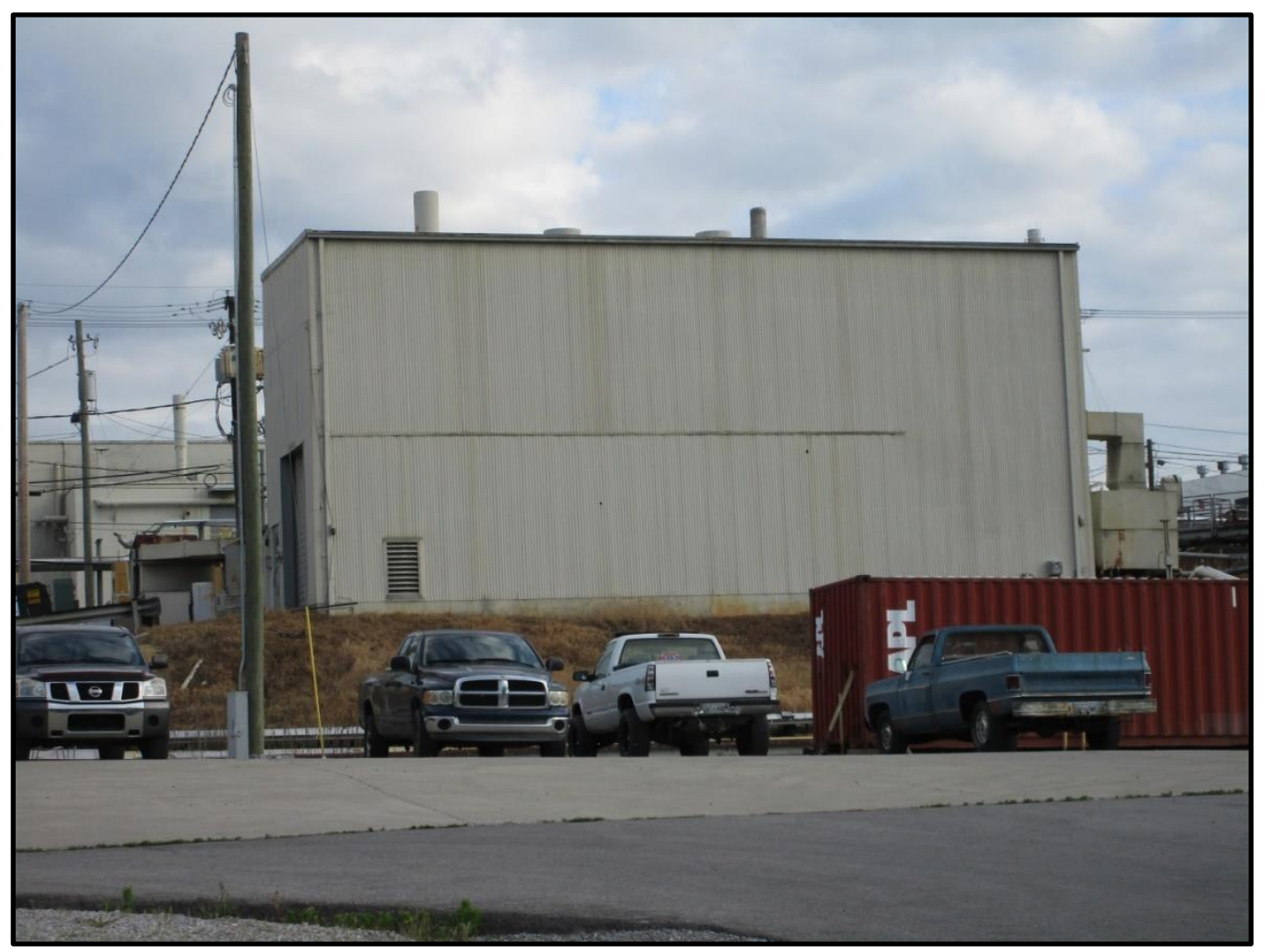

Figure 71. Overview of south elevation and partial west elevation of Building 2528. 


\section{1}

\section{BUILDING NAME}

Radioactive Waste Evaporator

DATE OF CONSTRUCTION

1966

DOE OFFICE RESPONSIBLE

EM (UCOR)

NRHP ELIGIBILITY

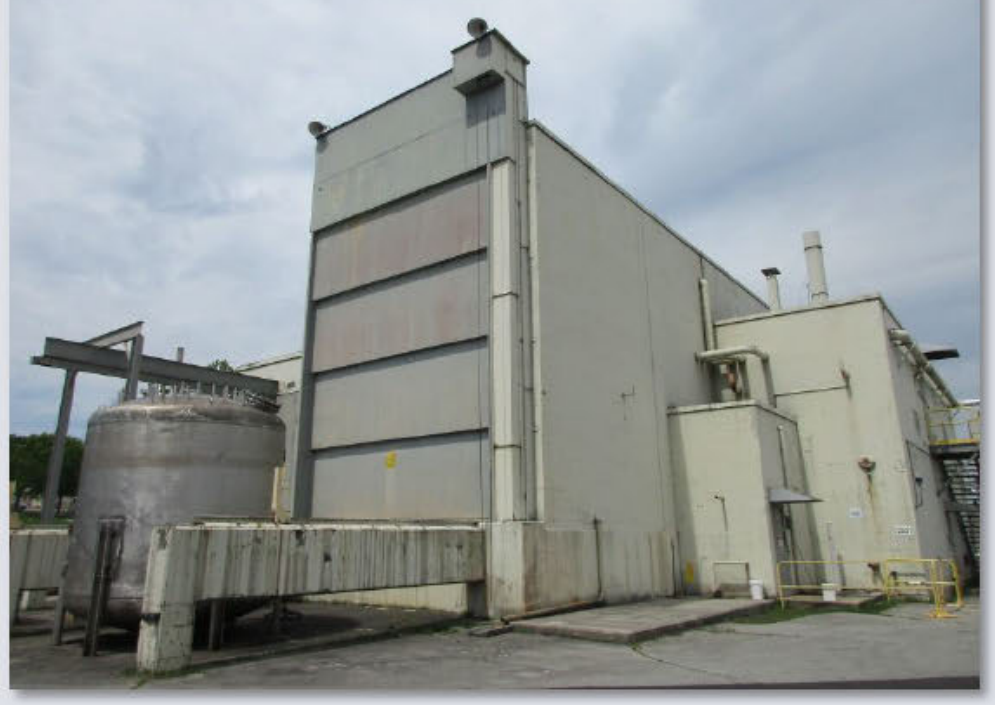

Figures 72. Overview of west elevation and partial south elevation of Building 2531.

Not Eligible

\section{DESCRIPTION}

The building is located near the intersection of White Oak Avenue and Third Street. Building 2531 is a large, flat-roof, concrete block masonry structure situated on a concrete basement foundation (Figures 72 and 73). A flat-roof wing, lower in elevation than the main block, is located on the north elevation. The building's entries are filled with single-light metal pedestrian doors with metal shed-roof awnings. However, the building lacks any other fenestration or openings. An exterior stairwell is located on the south elevation.

\section{NATIONAL REGISTER EVALUATION}

The 1994 assessment conducted by Duvall and Associates references the construction date for Building 2531 as 1954 (Carver and Slater 1994). However, FIMS data indicates that Building 2531 was constructed in 1966 as Waste Evaporator Facility to replace Building 3506. The facility continues to serve this purpose. The building was initially surveyed in 1994 by Duvall \&Associates. At that time, Building 2531 was recommended as not eligible for listing in the NRHP (Carver and Slater 1994). The structure was not included in the 2004 and 2015 surveys of ORNL. As a utility/maintenance facility, Building 2531 is not a primary building associated with scientific achievements at ORNL, nor is it known to be associated with any other events or persons of historic significance, thus it does not qualify for individual listing in the NRHP under Criterion A or B. Further, it is a simple utilitarian structure that lacks architectural significance for listing in the NRHP under Criterion C. The building is not located in a NRHP-eligible historic district. Thus, CRA recommends that Building 2531 is not eligible for listing in the NRHP under Criterion A, B, or C. 


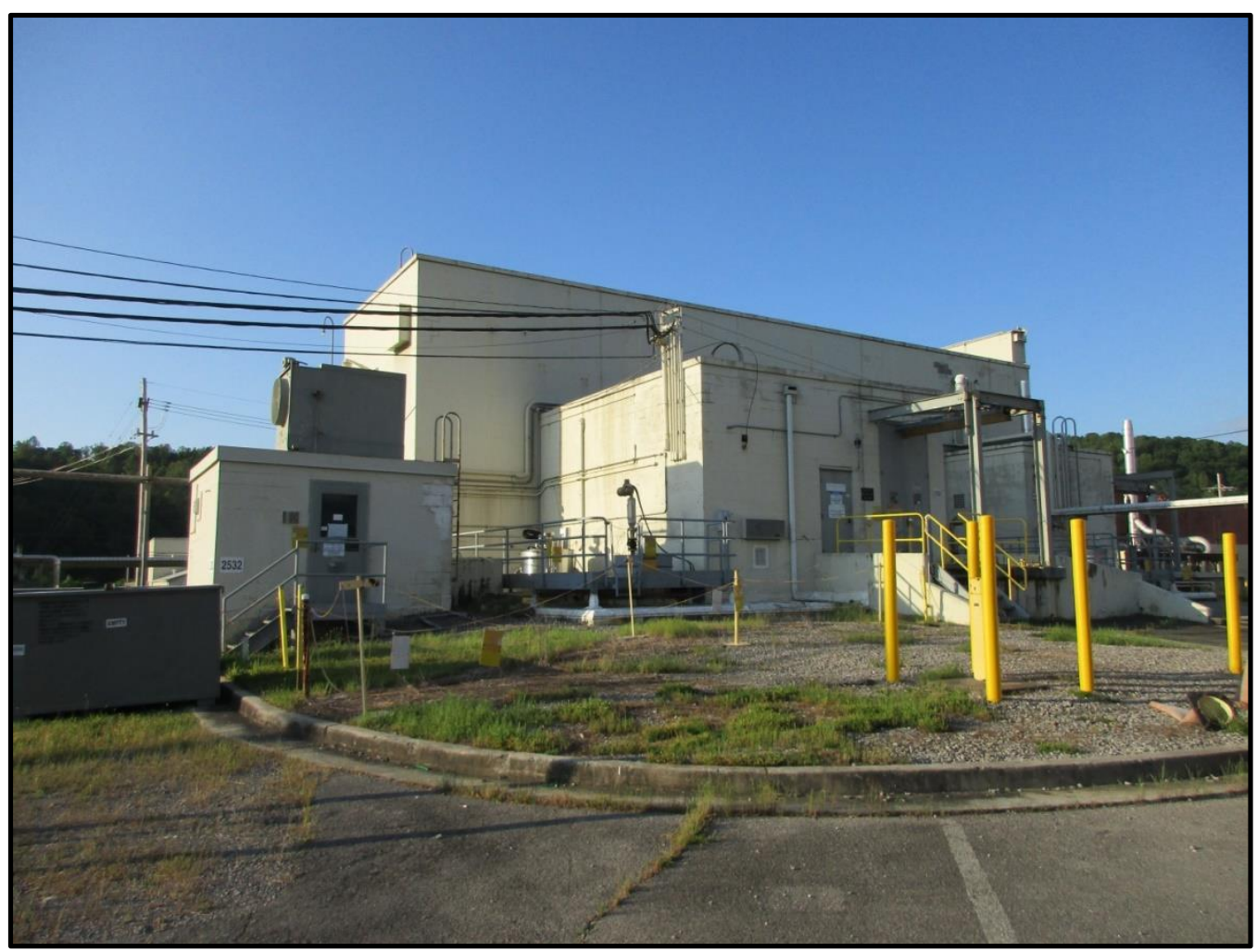

Figure 73. Overview of north elevation and partial east elevation of Building 2531. 


\section{2}

\section{BUILDING NAME}

High Level Waste Storage Cooling Pumphouse

DATE OF CONSTRUCTION

1978

DOE OFFICE RESPONSIBLE

EM (UCOR)

\section{NRHP ELIGIBILITY}

Not Eligible

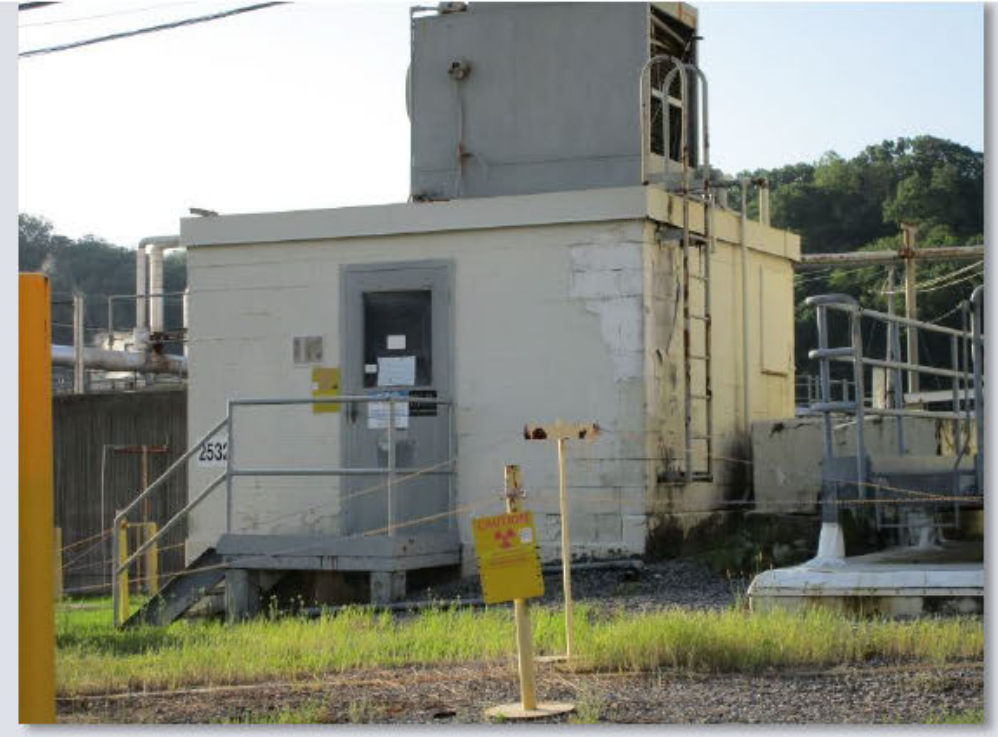

Figure 74. Overview of north and west elevations of Building 2532.

\section{DESCRIPTION}

Building 2532 is located adjacent to Building 2531 and is a small, one-story, concrete block masonry structure with a square footprint (Figures 74 and 75 ). The building is situated on a concrete foundation and is sheltered by a flat roof. Building 2532 features a single-leaf entry filled with a single-light metal door on the north elevation. No other fenestration is present on the building.

\section{NATIONAL REGISTER EVALUATION}

Building 2532 was constructed in 1978 as a High Level Waste Storage Cooling Pumphouse and was eventually shutdown in 2000. The structure was not included in the 1994, 2004, and 2015 surveys of ORNL. As a utility/maintenance facility, Building 2532 is not a primary building associated with scientific achievements at ORNL, nor is it known to be associated with any other events or persons of historic significance, thus it does not qualify for individual listing in the NRHP under Criterion A or B. Further, it is a simple utilitarian structure that lacks architectural significance for listing in the NRHP under Criterion C. The building is not located in a NRHPeligible historic district. Thus, CRA recommends that Building 2532 is not eligible for listing in the NRHP under Criterion $\mathrm{A}, \mathrm{B}$, or $\mathrm{C}$. 


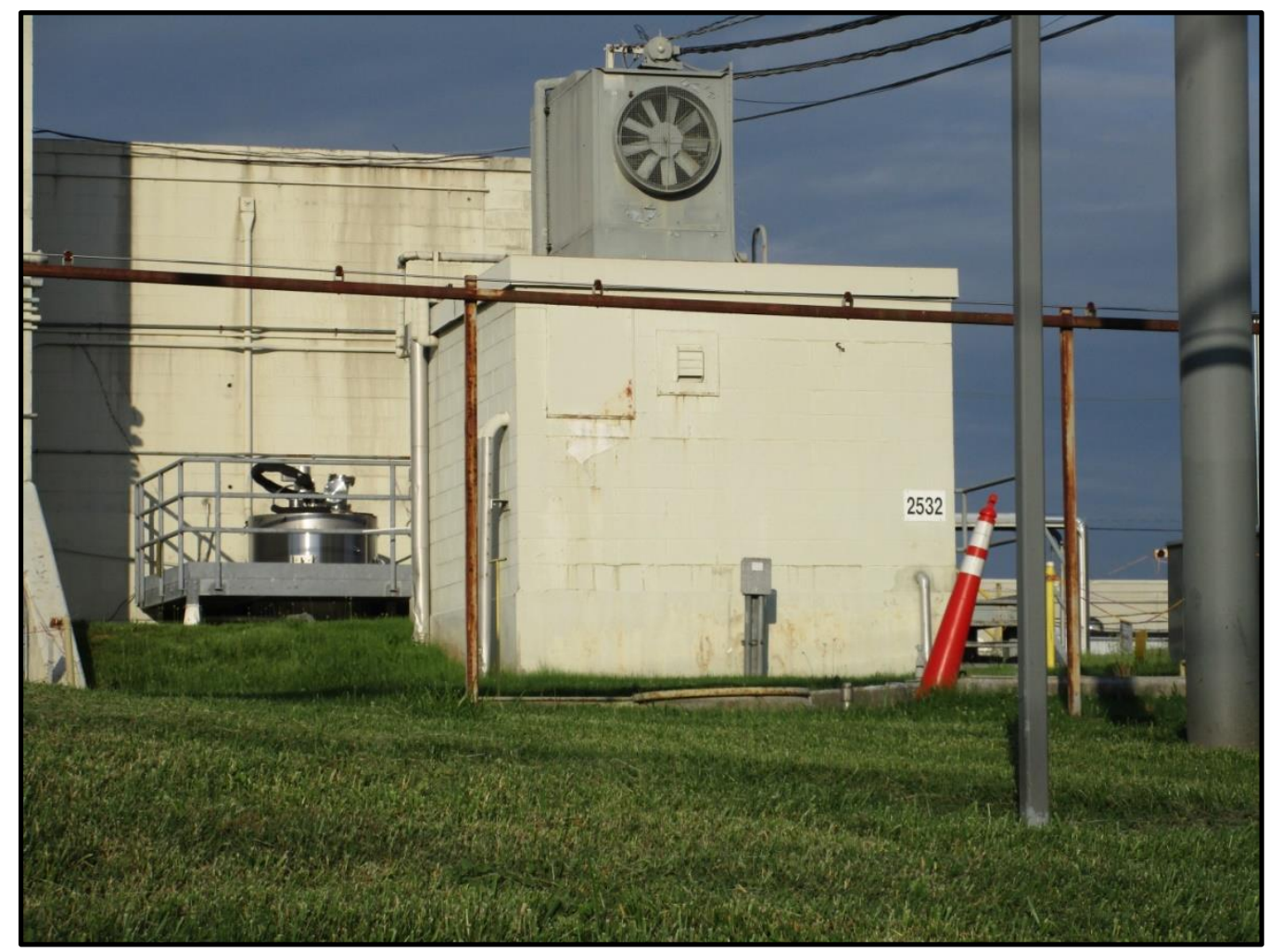

Figure 75. Overview of east and south elevations of Building 2532. 


\section{6}

\section{BUILDING NAME}

Sanitary Sewer Preparation Building

DATE OF CONSTRUCTION

1974

DOE OFFICE RESPONSIBLE

SC

NRHP ELIGIBILITY

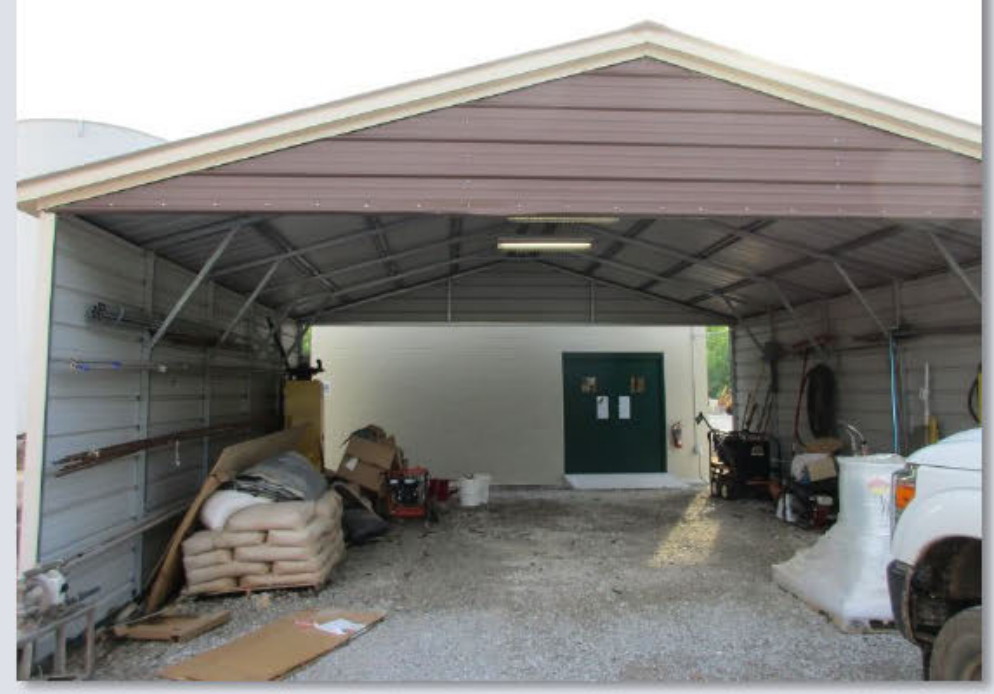

Figure 76. Overview of west elevation of Building 2536 seen through the adjacent open shed.

Not Eligible

\section{DESCRIPTION}

The building is located south of White Oak Avenue and situated between First Street and Second Street South. Building 2536 is a one-story, front-gable, concrete block masonry structure situated on a concrete foundation (Figures 76 and 77). The gables and roof are clad with corrugated metal panels. The double-leaf entry on the west elevation is filled by a pair of single-light pedestrian doors. There are no window openings present in this building. A gable-roof shed with open gable ends is located adjacent to the building on the west elevation.

\section{NATIONAL REGISTER EVALUATION}

Building 2536 was constructed as a Sanitary Sewer Preparation Building in 1974. The structure was not included in the 1994, 2004, and 2015 surveys of ORNL. As a utility/maintenance facility, Building 2536 is not a primary building associated with scientific achievements at ORNL, nor is it known to be associated with any other events or persons of historic significance, thus it does not qualify for individual listing in the NRHP under Criterion A or B. Further, it is a simple utilitarian structure that lacks architectural significance for listing in the NRHP under Criterion $C$. The building is not located in a NRHP-eligible historic district. Thus, CRA recommends that Building 2536 is not eligible for listing in the NRHP under Criterion A, B, or C. 


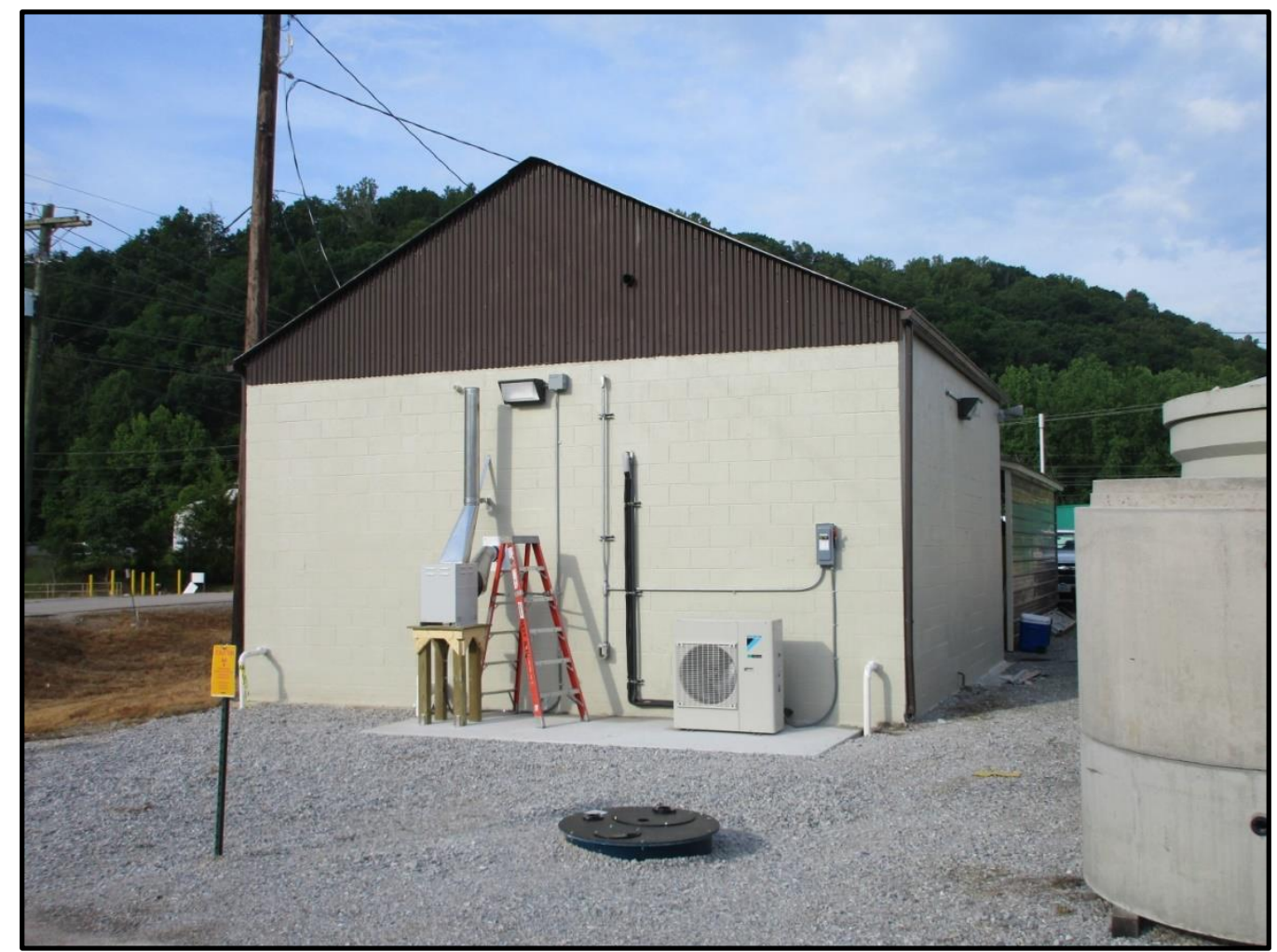

Figure 77. Overview of north and east elevations of Building 2536. 


\section{1}

\section{BUILDING NAME}

Electrical Utilities Shop

\section{DATE OF CONSTRUCTION}

1961

DOE OFFICE RESPONSIBLE

SC

NRHP ELIGIBILITY

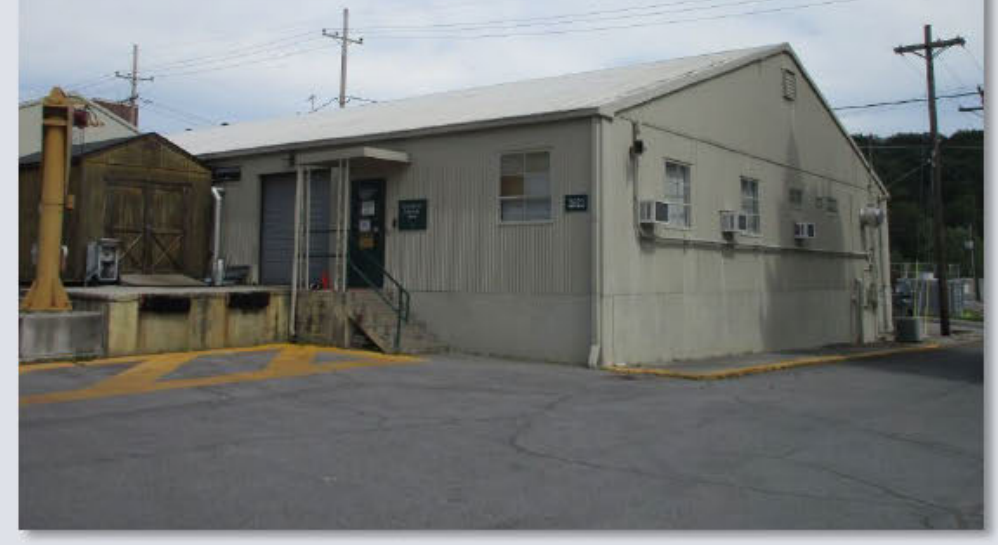

Figure 78. Overview of west elevation and partial north elevation of Building 2621.

Not Eligible

\section{DESCRIPTION}

The building is located north of White Oak Avenue. Building 2621 is a one-story, side-gabled structure clad with corrugated metal siding and supported by a concrete foundation (Figures 78 and 79). The main entrance, on the south elevation, has a pair of three-light doors sheltered by a flat metal awning. Entries filled with single-light and two-light metal doors are also featured along the façade (south) and north elevations. A loading dock with an entry filled with a roll-up metal garage door is located on the north elevation. The building features six-light awning or hopper windows and pairs of single-light windows, some of which have been painted over.

\section{NATIONAL REGISTER EVALUATION}

Building 2621 was constructed in 1961 as an Electrical Utilities Shop. The building also was referenced to be used for waste operations support shop. Building 2621 was initially surveyed by Thomason and Associates in 2015 and recommended ineligible for listing in the NRHP (Thomason and Associates 2015). The structure was not included in the 1994 and 2004 surveys of ORNL. As a utility/maintenance facility, Building 2621 is not a primary building associated with scientific achievements at ORNL, nor is it known to be associated with any other events or persons of historic significance, thus it does not qualify for individual listing in the NRHP under Criterion A or B. Further, it is a simple utilitarian structure that lacks architectural significance for listing in the NRHP under Criterion $C$. The building is not located in a NRHP-eligible historic district. Thus, CRA recommends that Building 2621 is not eligible for listing in the NRHP under Criterion $A, B$, or C. 


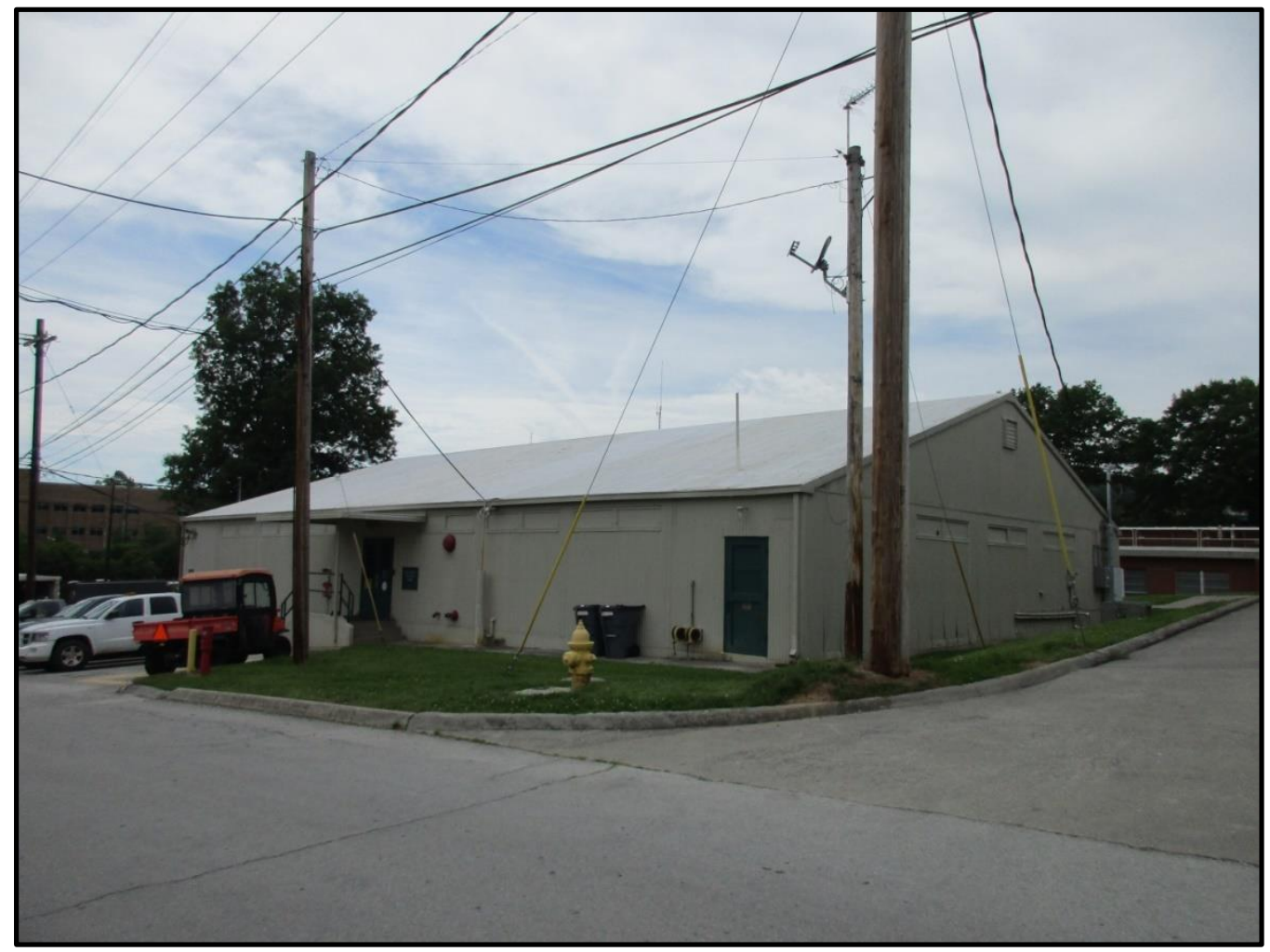

Figure 79. Overview of south and east elevations of Building 2621. 


\section{4}

\section{BUILDING NAME}

Solid Waste Storage Area Burial Ground

DATE OF CONSTRUCTION

1942

DOE OFFICE RESPONSIBLE

EM (UCOR)

NRHP ELIGIBILITY

Figure 80. Overview of Solid Waste Storage Area Burial Ground (Building 2624) looking from Third Avenue towards the south direction.

Not Eligible

\section{DESCRIPTION}

Building 2624 is an underground waste burial storage area located on both sides of Third Street as the street extends through the middle of the resource. (Figure 80 ). The area is trapezoidal in shape and is approximately one acre in size. The area is currently covered by grass.

\section{NATIONAL REGISTER EVALUATION}

Building 2624 was used as a burial ground for solid radioactive wastes from 1943 to 1944. CRA did not have access to records indicating the contents of the burial within the area (Carver and Slater 1994; Thomason and Associates 2015). The resource was initially surveyed by Duvall \& Associates in 1994. At that time, Duvall \& Associates recommended the radioactive burial ground Building 2624 as eligible for listing in the NRHP as a contributing element of the ORNL Historic District (Carver and Slater 1994). The resource was also surveyed in 2004 and 2015 by Thomason and Associates, in which they concurred with the previous 1994 assessment (Thomason and Associates 2004 and 2015). They notated Building 2624 as of minor significance to the ORNL Historic District. As a storage facility, Building 2624 is not a primary building associated with scientific achievements at ORNL, nor is it known to be individually associated with any other events or persons of historic significance, thus it does not qualify for individual listing in the NRHP under Criterion A or B. Further, it is a simple utilitarian structure that lacks architectural significance for listing in the NRHP under Criterion $\mathrm{C}$. While Building 2624 did play a supporting role in the operation of ORNL's research facilities in the World War II and Cold War eras, it is located outside of the presently-recommended boundaries of the ORNL Historic District, which have been adjusted to account for demolitions in the vicinity. Thus, CRA recommends that Building 2624 is not eligible for listing in the NRHP under Criterion $A, B$, or $C$. 


\section{8}

\section{BUILDING NAME}

Fire Protect Main \& Storage

\section{DATE OF CONSTRUCTION}

1965

DOE OFFICE RESPONSIBLE

SC

Figure 81. Overview of the south and east elevations of Building 2628.

NRHP ELIGIBILITY

Not Eligible

\section{DESCRIPTION}

The building is located at the intersection of First Street and White Oak Avenue. Building 2628 is a one-story, front-gable structure with a shed-roof addition on the north elevation (Figures 81 and 82). The sides and roof of the building area clad in metal panels. Oriented to the east, the façade features a double-leaf entry filled by paired two-light metal pedestrian doors. A similar entry is located on the rear (west) elevation. The shed-roof addition features an open façade bay.

\section{NATIONAL REGISTER EVALUATION}

Building 2628 was constructed as a maintenance and storage building for the ORNL Fire Department in 1965. The building was initially surveyed by Thomason and Associates in 2015 and recommended ineligible for the NRHP (Thomason and Associates 2015). As a storage facility, Building 2628 is not a primary building associated with scientific achievements at ORNL, nor is it known to be individually associated with any other events or persons of historic significance, thus it does not qualify for individual listing in the NRHP under Criterion A or B. Further, it is a simple utilitarian structure that lacks architectural significance for listing in the NRHP under Criterion $C$. The building is not located in a NRHP-eligible historic district. Thus, CRA recommends that Building 2628 is not eligible for listing in the NRHP under Criterion A, B, or C. 


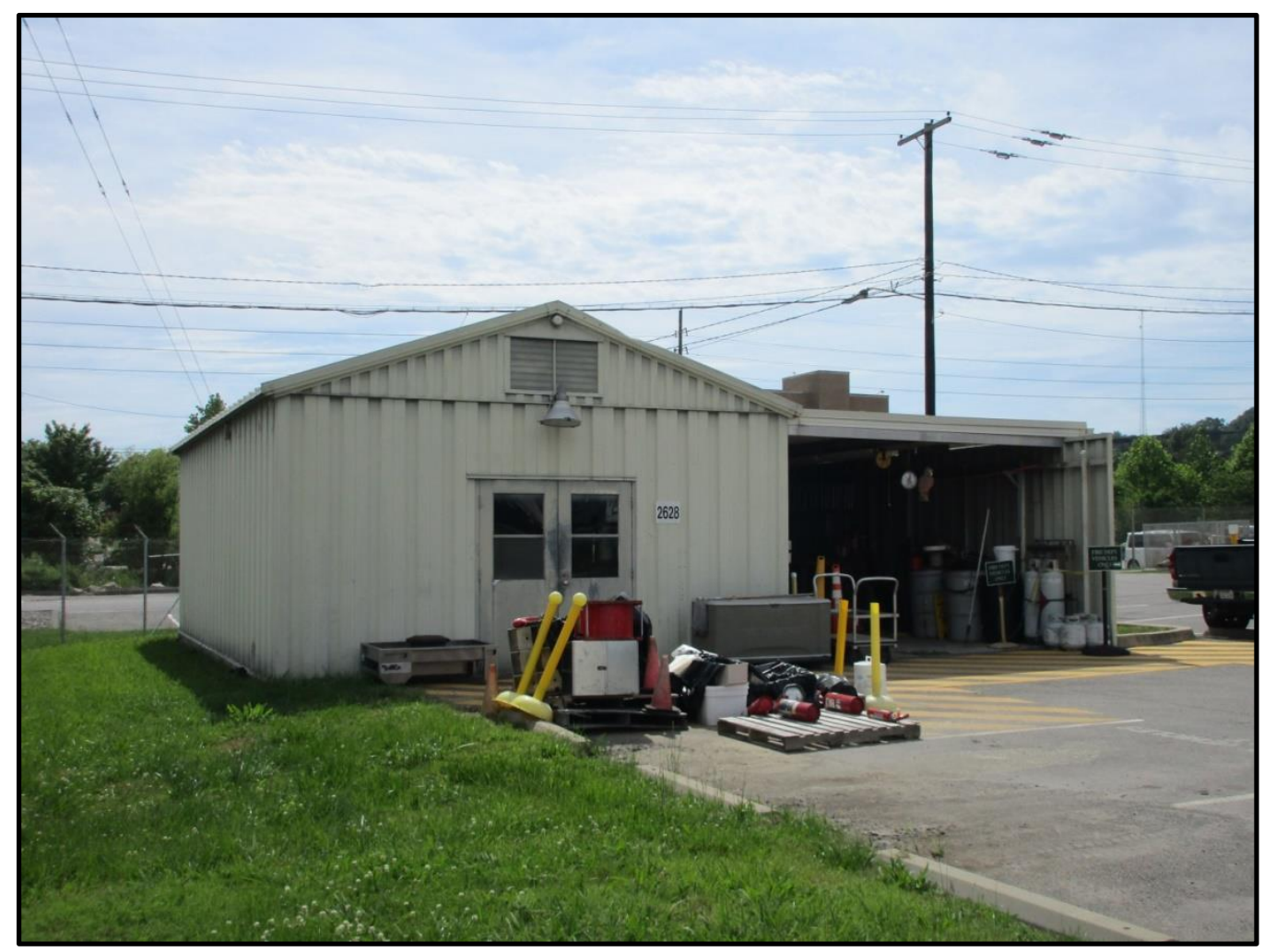

Figure 82. Overview of west and south elevations of Building 2628. 

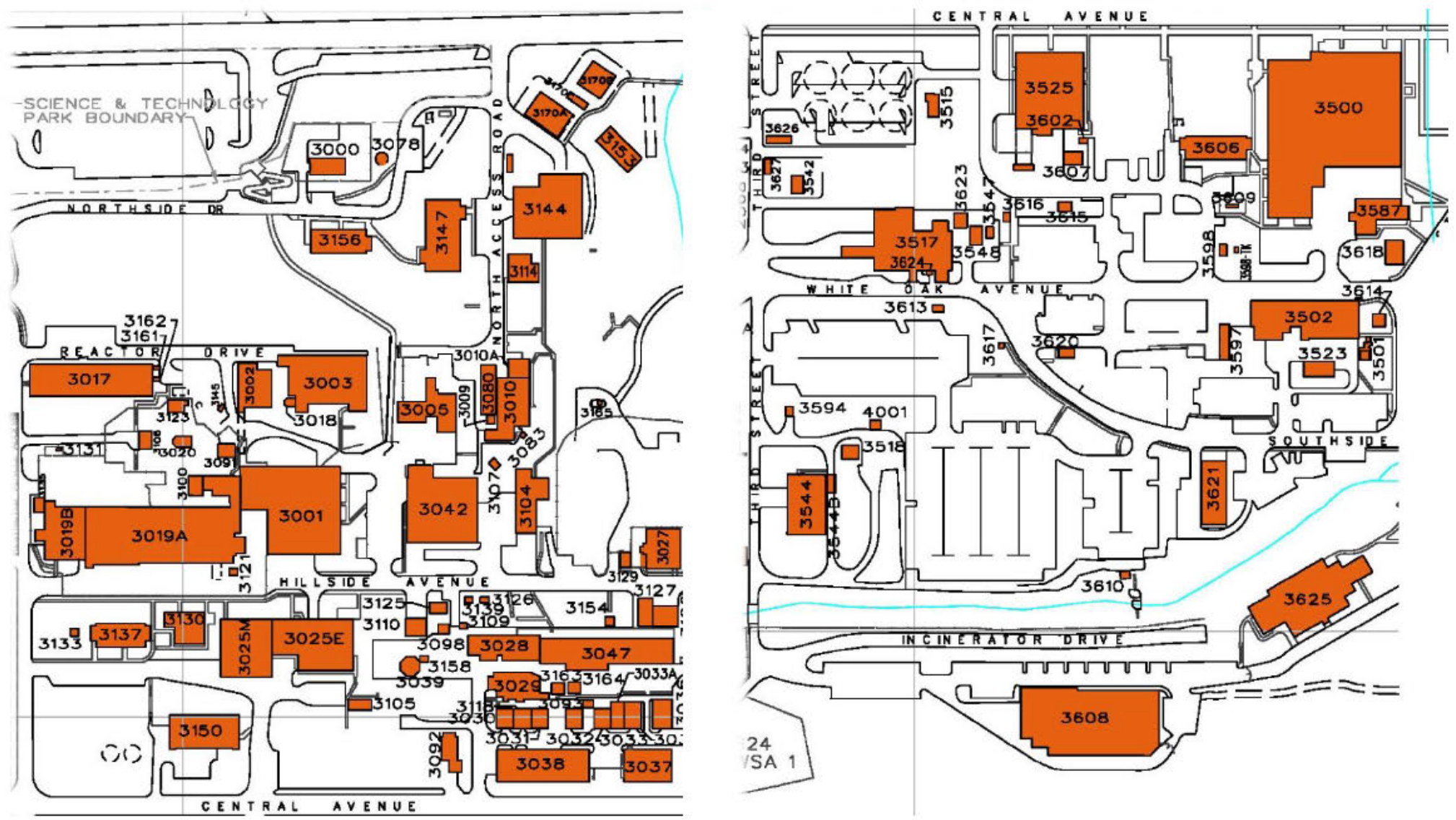

3000 AREA

Figure 83. Plan View of 3000 Area.

CONTRIBUTING TO ORNL HISTORIC DISTRICT

Building $3001^{*} \quad$ Building 3027 Building 3047 Building 3523

Building 3002 Building 3028 Building 3080 Building 3525

Building 3003 Building 3029 Building 3091 Building 3542

Building 3005* Building 3030 Building 3092 Building 3587

Building 3009 Building 3031 Building 3100

Building 3010 Building 3032 Building 3104

Building 3010A Building 3033 Building 3107

Building 3017 Building 3033A Building 3118

Building 3018 Building 3034 Building 3500

Building 3019A Building 3036 Building 3501

Building 3019B Building 3037 Building 3502

Building 3020 Building 3038 Building 3502B

Building 3025E Building 3039 Building 3515

Building 3025M Building 3042 Building 3517

\section{NOT ELIGIBLE DEMOLISHED}

Building 3000

Building 3008

Building 3021

Building 3012

Building 3023

Building 3026C

Building 3093

Building 3114

Building 3127

Building 3129

Building 3135

Building 3507

Building 3518

Building 3544

Building 3544-VB1 Building 3592

Building 3026D

Building 3044

Building 3074

Building 3503

Building 3504

Building 3508

Building 3513

Building 3524

\section{Building 3594 \\ Building 3618}


This page intentionally left blank 


\section{AREA}

\section{DISTRICT NAME}

3000 Area of ORNL

\section{DATE OF CONSTRUCTION}

1943-2004

NRHP ELIGIBILITY

Part Contributes to ORNL Historic District

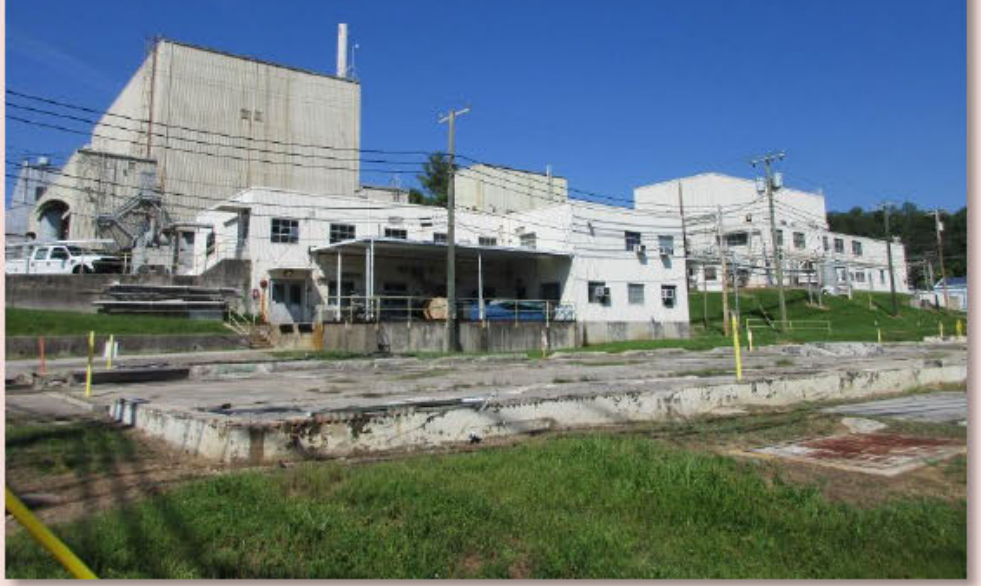

Figure 84. View of the 3000 Area looking in a western direction from Fifth Street towards Buildings 3010,3042 , and 3104.

\section{DESCRIPTION}

The 3000 Area is located in the western portion of the ORNL Historic District and is bound by Third Street to the west, Fifth Street to the east, Bethel Valley Road to the north, and White Oak Creek to the south (Figure 83). Hillside Avenue, Central Avenue, White Oak Avenue, and Southside Avenue all run through the 3000 Area. Several of the buildings are located within a secure barricaded area and were inaccessible to the survey team. Therefore, photographs of these particular buildings were limited. The 3000 Area includes all of the building types found at ORNL, including processing facilities, utilities and maintenance facilities, research/laboratories facilities, storage facilities, and office buildings. Seventy-one buildings and one bridge, Building 3544-VB1, are located within the 3000 Area. Fifty-eight of these were constructed before 1980, and were thus included in this survey. An additional 13 resources constructed before 1980 were also confirmed to be no longer extant during survey. The 3000 Area contains both the Graphite Reactor, the heart of operations during the Manhattan Project, and Isotope Circle, the grouping of research/laboratory facilities that supported ORNL's key isotope production mission, as well as many other research/laboratory facilities constructed in the 1950s under the Program $\mathrm{H}$ expansion of ORNL (Figure 84). Additionally, the 3000 Area contains the highest concentration of processing facilities in any area of ORNL's campus, with five reactors located within its boundaries.

\section{NATIONAL REGISTER EVALUATION}

The 3000 Area was previously evaluated in 1994 and 2004 and recommended as part of the ORNL Historic District (Carver and Slater 1994; Thomason and Associates 2004); the majority of the 3000 Area was included within the ORNL Historic District boundary. In 2015, the northernmost portion of the area, which included buildings situated south of Bethel Valley Road, was recommended excluded from the district due to demolitions (Thomason and Associates 2015). Currently, the majority of the 3000 Area contributes to the ORNL Historic District; buildings located in the northernmost and southernmost portions of the area are not included within the recommended district boundary adjustment due to demolition of historic resources in these areas. The remaining buildings located within the 3000 Area contribute to the ORNL Historic District as it displays clear associations to the central areas of significance of ORNL, namely its origins, which includes the Manhattan Project's X-10 facility that pioneered the production of plutonium, and thus contributed to the creation of the world's first atomic bomb that ended the war with Japan, and its subsequent development as Oak Ridge National Laboratory, a government-owned, contractor-operated, leading scientific research facility that made 
significant contributions in advancing both defensive and peacetime applications of nuclear science, as well as other fields of scientific inquiry during the Cold War era. CRA recommends that the 3000 Area retains integrity, and therefore continues to convey its meaning as an important component of the Manhattan Project, and as the historic hub of the national laboratory. Contributing resources to the ORNL Historic District located in the 3000 Area include the following buildings: 3001, 3002, 3003, 3005, 3010, 3010A, 3017, 3018, 3019A, 3019B, 3020, 3025E, 3025M, 3027, 3028, 3029, 3030, 3031, 3032, 3033, 3033A, 3034, 3036, 3037, 3038, 3039, 3042, 3047, 3080, 3091, 3092, 3100, 3104, 3107, 3118, 3500, 3501, 3502, 3515, 3517, 3523, 3525, 3542, and 3587. Additional discussion of the ORNL Historic District and proposed district boundaries are found at the end of the Results section.

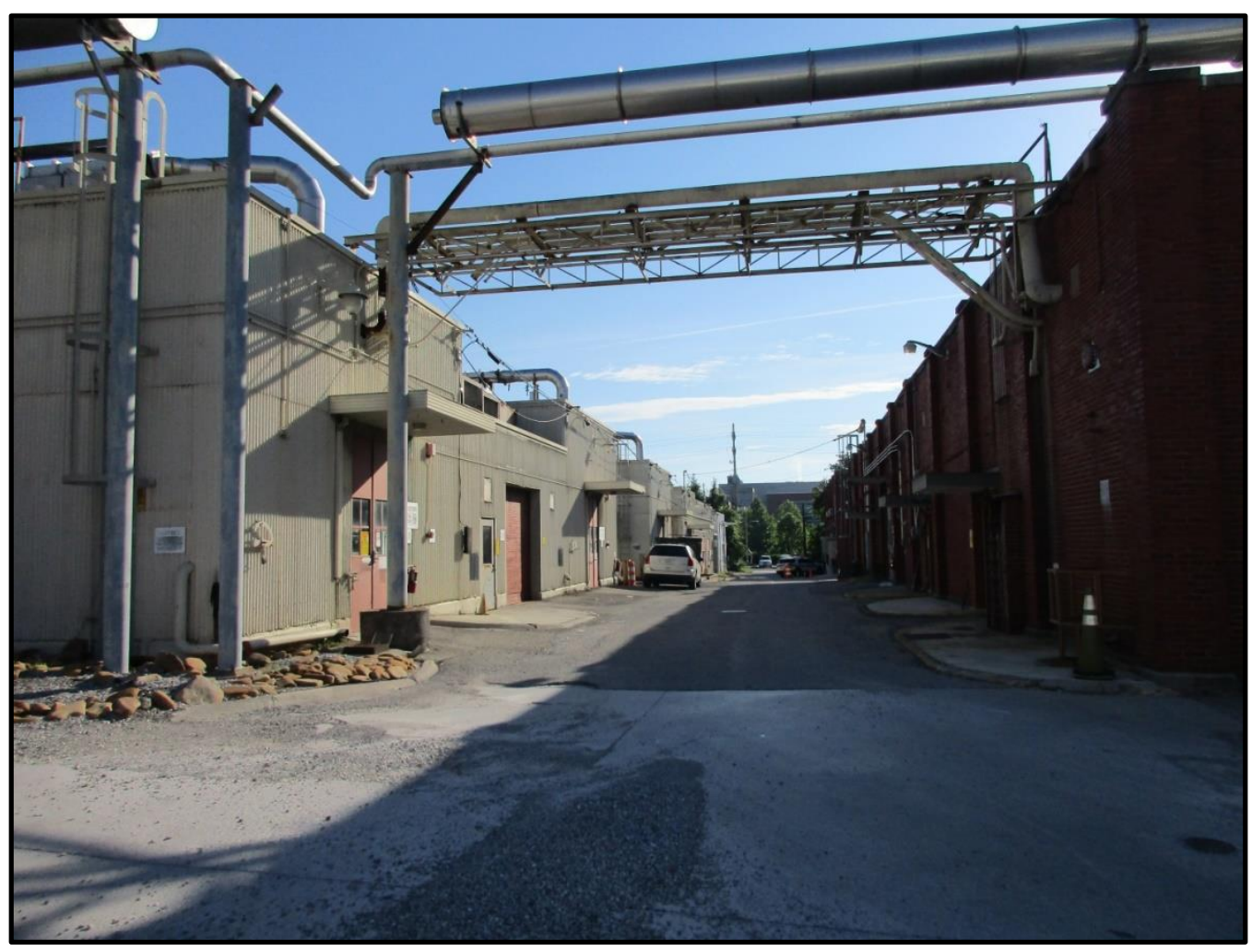

Figure 85 . View of the 3000 Area looking in an eastern direction towards buildings located in the Isotope Circle. 


\section{0}

\section{BUILDING NAME}

13.8-kV Substation

\section{DATE OF CONSTRUCTION}

1952

\section{DOE OFFICE RESPONSIBLE}

SC

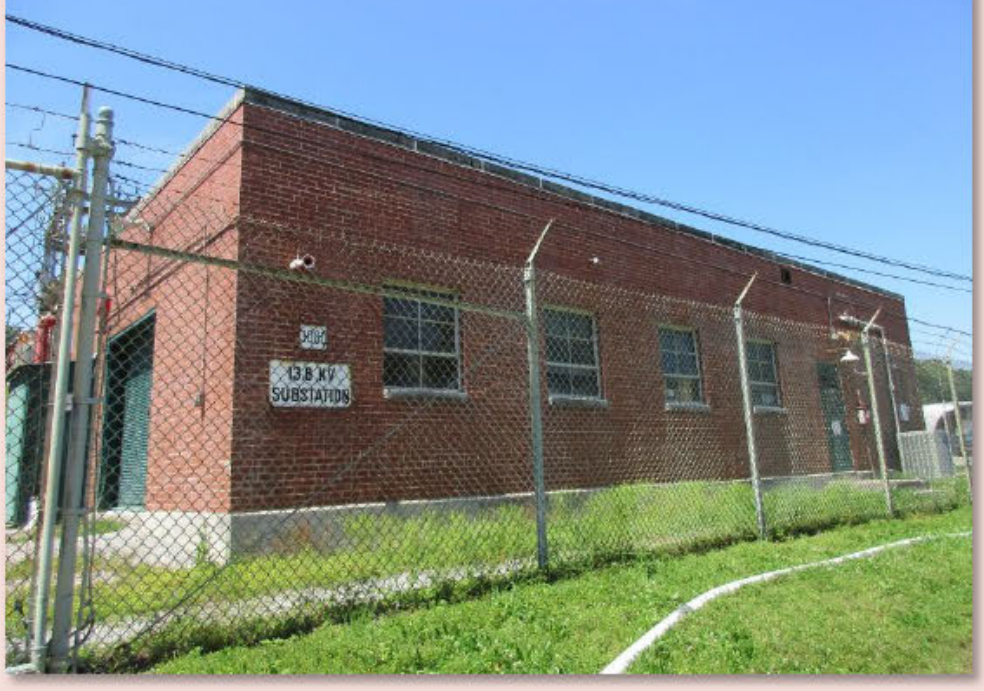

NRHP ELIGIBILITY

Figure 86. Overview of south and west elevations of Building 3000 .

Not Eligible

\section{DESCRIPTION}

The building is located north of Northside Drive and situated between Third Street and North Access Road. Building 3000 is a one-story, flat-roof building with a brick exterior resting on a concrete foundation (Figures 86 and 87 ). The brick pattern is a modified five course common bond. The building exhibits a parapet with the edges capped by concrete coping. The building features pedestrian entries filled with single-light metal doors and a larger entry on the west elevation filled by a roll-up garage door. The windows are filled with four-light and six-light metal sashes. The building is surrounded by a metal chain link fence.

\section{NATIONAL REGISTER EVALUATION}

Building 3000 was constructed in 1952 as a substation for the ORNL campus. An earlier electrical substation was located adjacent to this building and dated to the World War II era. The building was initially surveyed by Duvall \& Associates in 1994 and was recommended eligible as a contributing resource to the ORNL Historic District (Carver and Slater 1994:193). The 2004 survey conducted by Thomason and Associates also notated it as a contributing resource to the district even though it had minor significance (Thomason and Associates 2004). The building was recorded again in 2012 and noted as having minor significance (Thomason and Associates 2012). In the 2015 survey the building status was recorded "demolished" (Thomason and Associates 2015:310). However, the building is still present within the ORNL landscape. Building 3000 retains a majority of its historic materials, form, and massing. It is located outside the current recommended ORNL Historic District boundary. As a utility/maintenance facility, Building 3000 provided utilitarian support services for work that furthered ORNL's mission in nuclear science during the Cold War era. However, the building is not the single location most importantly associated with a scientific achievement, scientist, or other events or persons of historic significance to merit individual listing in the NRHP under Criterion A or B. Furthermore, the building lacks notable architectural elements that would warrant individual listing in the NRHP under Criterion C. As such, Building 3000 does not warrant individual listing in the NRHP under Criterion A, B, or C. In addition, Building 3000 is located outside of the recommended district boundary thus CRA recommends it is no longer eligible as a contributing resource to the ORNL Historic District. 


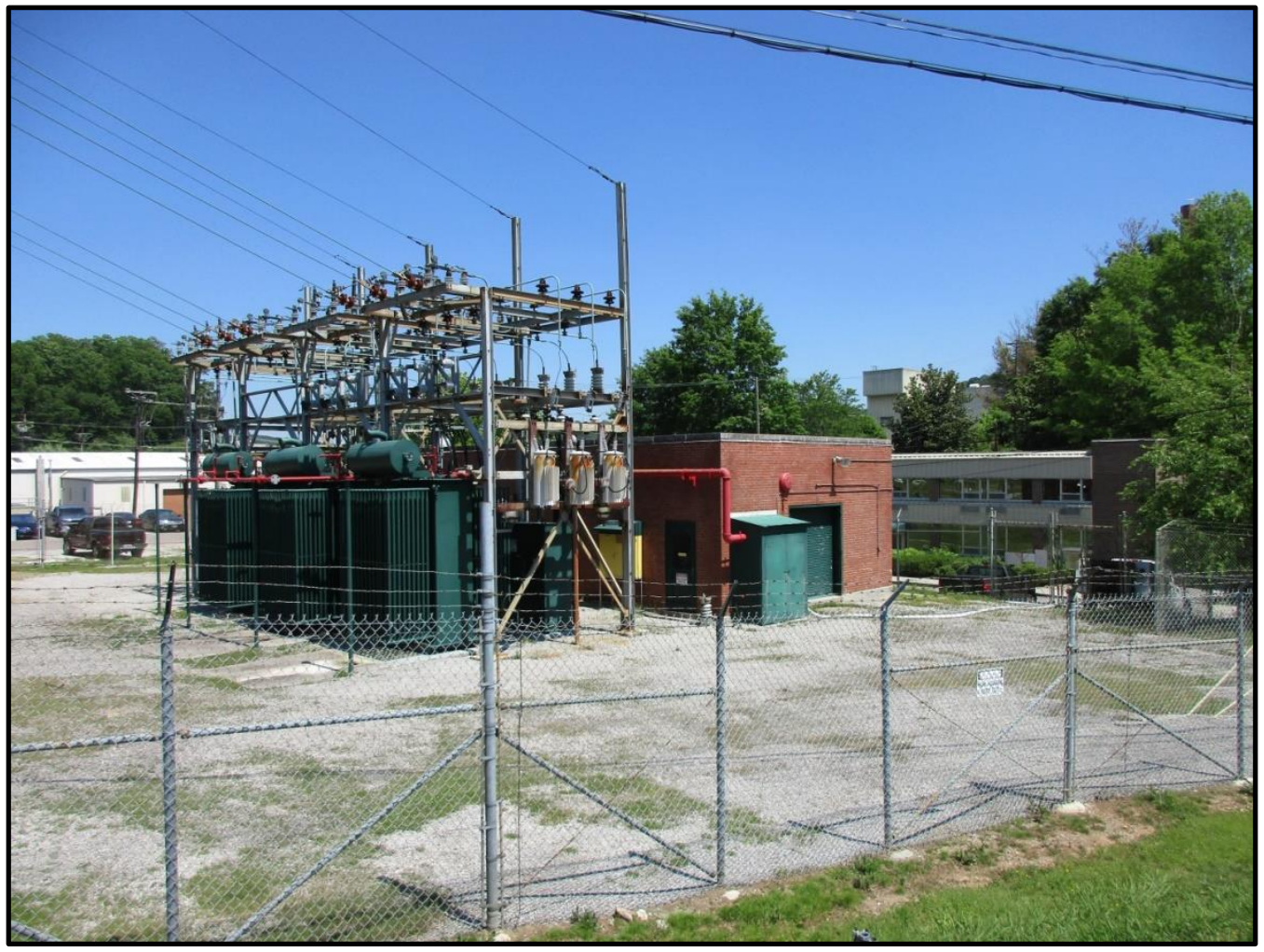

Figure 87. Overview of west and north elevations of Building 3000. 


\section{1}

\section{BUILDING NAME}

Graphite Reactor Building

DATE OF CONSTRUCTION

1943

DOE OFFICE RESPONSIBLE

EM (UCOR)

NRHP ELIGIBILITY

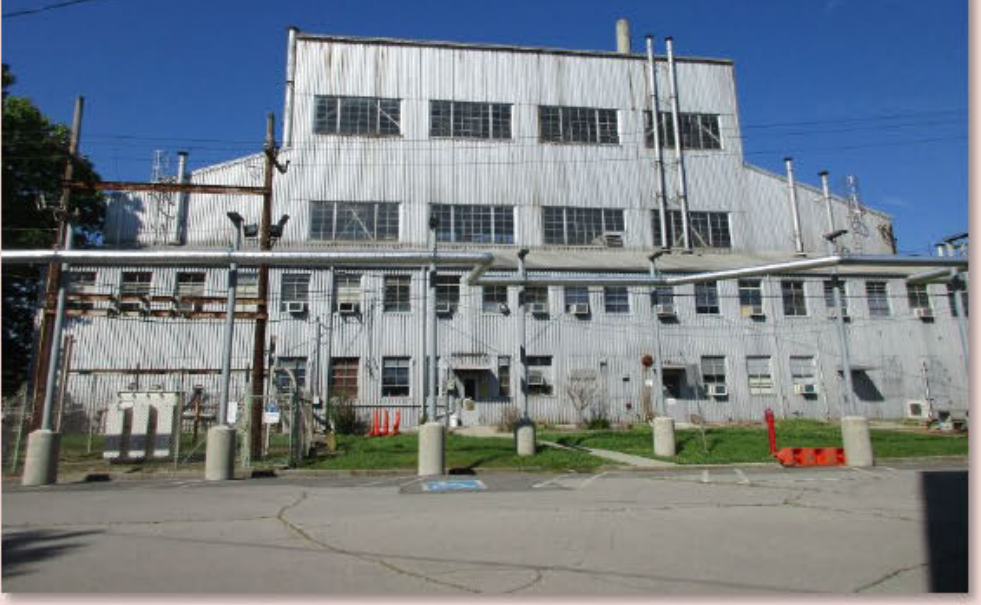

NHL; Contributing to ORNL Historic District

Figure 88. Overview of west and north elevations of Building 3001.

\section{DESCRIPTION}

The building is located along Hillside Avenue. Building 3001 is a three-story, gabled-roof steel structure supported by a concrete foundation (Figures 88 and 89 ). The building is comprised of 29,746 sq ft. Building 3001 is sheltered by a metal gable roof with several roof vents along the ridgeline. Shed-roof additions are located on the north and south elevations. Large multi-pane awning windows are located on the upper portions of the building's four elevations. Windows filled with four-light and eight-light metal sashes are located on the lower floors of the building.

\section{NATIONAL REGISTER EVALUATION}

Constructed in 1943 and in operation from 1943 until 1963, the Graphite Reactor (Building 3001) was used for research for the first atomic bomb as part of the Manhattan Project. During peacetime, the building was used to produce radioactive isotopes. The Graphite Reactor (Building 3001) was designated a National Historic Landmark (NHL) in 1966 for its role in the development of nuclear science. In all previous surveys, the Graphite Reactor also was recommended eligible for listing in the NRHP as a contributing resource to the ORNL Historic District (Carver and Slater 1994; Thomason and Associates 2004; Thomason Associates 2015). Further recognizing the building's significance, the Graphite Reactor recently was designated part of the Manhattan Project National Historical Park. Building 3001 is the most prominent of ORNL's historic processing facilities and serves as an anchor of the ORNL Historic District. It is significant as the original hub of the Manhattan Project's $\mathrm{X}-10$ facility that pioneered production of plutonium, and which later developed into the core of the Oak Ridge National Laboratory, a government-owned, contractor-operated, leading scientific research facility that made significant contributions in advancing both defensive and peacetime applications of nuclear science during the Cold War era. The building retains those key features of its original form, massing, and exterior materials, in addition to the reactor within, and thus exhibits the integrity needed for continued designation as a NHL and continued eligibility under Criteria $A$ and $C$ for its historical and engineering significance within the ORNL Historic District. 


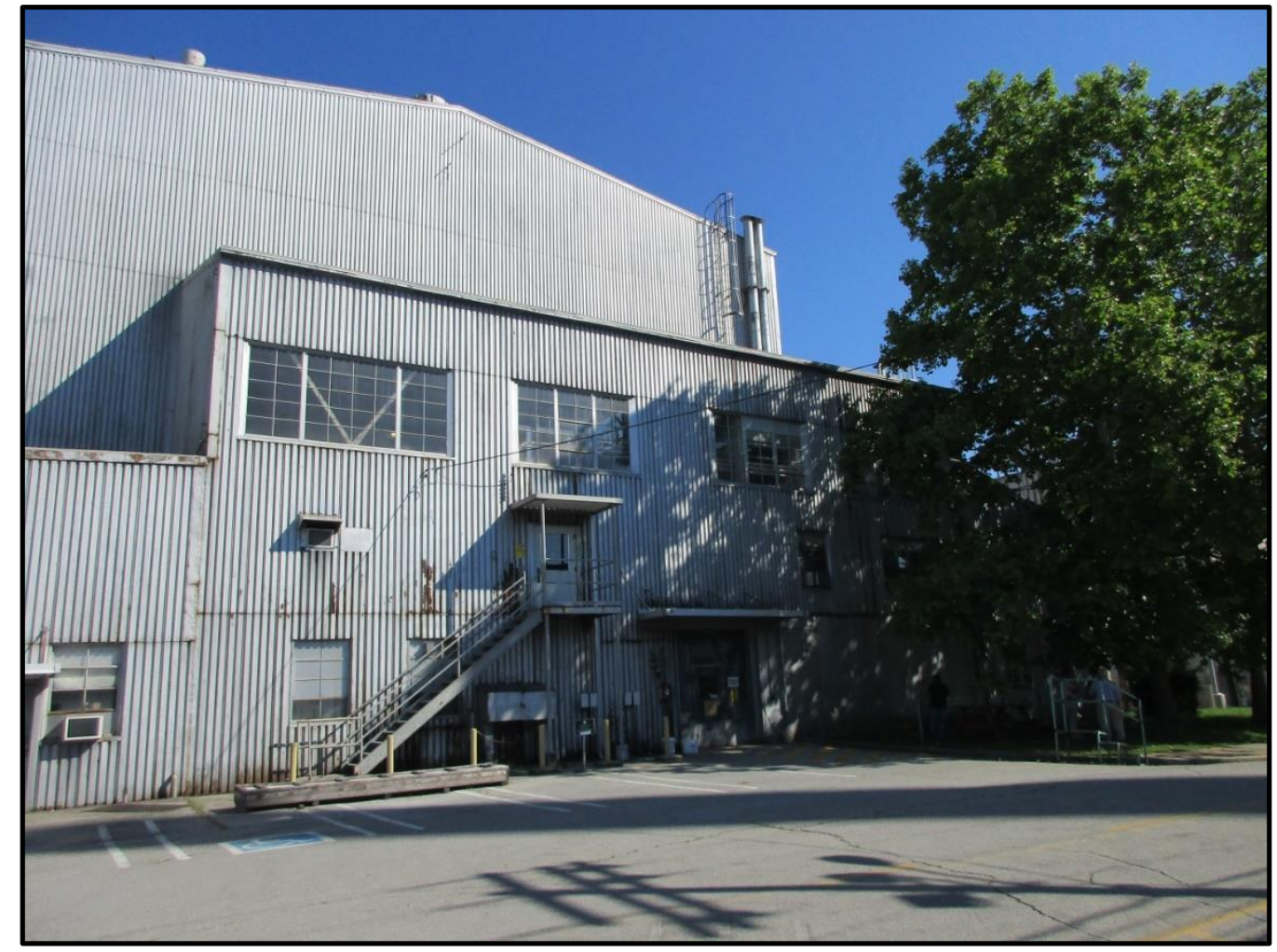

Figure 89. Overview of south and west elevations of Building 3001. 


\section{BUILDING NAME}

Filter House for Graphite Reactor

DATE OF CONSTRUCTION

1948

DOE OFFICE RESPONSIBLE

EM (UCOR)

NRHP ELIGIBILITY

Figure 90. Overview of north elevation and partial west elevation of Building 3002.

Contributing to ORNL Historic District

\section{DESCRIPTION}

Building 3002 is located along Reactor Drive and within the barricaded portion of the 3000 Area. Access to this high security area of the 3000 Area is restricted; therefore, photographs of the building's exterior were limited. Building 3002 is a concrete structure with a flat roof (Figure 90). A metal railing encompasses the roof. A small projection with a flat roof is located on the building's north elevation. No fenestration pattern was visible with the limited view of the building.

\section{NATIONAL REGISTER EVALUATION}

Building 3002 was constructed in 1948 as a Filter House for the Graphite Reactor (Building 3001). The resource was previously surveyed in 1994 and recommended contributing to the ORNL Historic District (Carver and Slater 1994). In 2004 it was again recommended contributing to the ORNL Historic District (Thomason and Associates 2004); in 2015 it was recorded as demolished (Thomason and Associates 2015). During the 2017 survey, the resource was identified as extant and in operation. Although the survey team had limited access to the facility, enough information was gathered to complete an evaluation. The building retains the majority of its historic materials, as well as its form and massing. As a utility/maintenance facility, Building 3002 provided utilitarian support services for work that furthered ORNL's mission in nuclear science during the Cold War era. However, the building is not the single location most importantly associated with a scientific achievement, scientist, or other events or persons of historic significance to merit individual listing in the NRHP under Criterion A or B. Furthermore, the building lacks notable architectural elements that would warrant individual listing in the NRHP under Criterion C. Instead, the significance of Building 3002 is best understood as an integral support resource necessary to the functioning of research and processing facilities in the ORNL Historic District during the Cold War era. As such, Building 3002 does not warrant individual listing in the NRHP under Criterion A, B, or C; however, the building is a contributing resource to the ORNL Historic District. 


\section{3}

\section{BUILDING NAME}

Solid State Accelerator Facility

DATE OF CONSTRUCTION

1943

DOE OFFICE RESPONSIBLE

SC

NRHP ELIGIBILITY

Figure 91. Overview of partial west elevation of Building 3003, with Building 3002 in foreground.

Contributing to ORNL Historic District

\section{DESCRIPTION}

Building 3003 is located along Reactor Drive and within the barricaded portion of the 3000 Area. Access to this high-security area of the 3000 Area is restricted; therefore, photographs of the building's exterior were limited. The building, irregular in plan, is comprised of metal frame and concrete block sections (Figure 91). The building is sheltered by a flat roof. A two-story section is located in the north corner of the building. The remainder of the building is one-story in height. The metal frame portions are clad with corrugated metal siding. Paired entries filled with single-light metal pedestrian doors are located on the west elevation.

\section{NATIONAL REGISTER EVALUATION}

Building 3003 was constructed in 1943 as a fan house for the Graphite Reactor (Building 3001). The fan house drew air from the reactor through underground ducts and released it through an adjacent exhaust stack (Building 3018). Once the filter house (Building 3002) was completed in 1948, the air was filtered prior to release through the exhaust stack. The building no longer served a purpose when the Graphite Reactor closed down in 1963. In 1969, the building was modified to hold laboratories and office space for the Solid State Division and became the Solid State Accelerator Facility (Carter and Slater 1994: 198).

The building was initially surveyed by Duvall \& Associates in 1994 and determined noncontributing to the ORNL historic district due to its many alterations (Carver and Slater 1994). According to surveys completed by Thomason and Associates, the building was recommended contributing under Criterion A for its association with the Manhattan Project and early post-World War II nuclear development (Thomason and Associates 2004 and 2015). While the building has undergone some modifications to alter its use from a fan house to an accelerator facility, its integrity of location, feeling, and association, those aspects most essential to conveying its identity with nuclear science, are intact. The resource is still set in close proximity to the Graphite Reactor and as such, the association between the two structures and the sense of the relationship between the buildings is still conveyed even though Building 3003 no longer performs its historic function. As a utility/maintenance facility, Building 3003 provided utilitarian support services for work that furthered ORNL's mission in nuclear science during the Manhattan Project and the Cold War era. However, the building is not the single location most 
importantly associated with a scientific achievement, scientist, or other events or persons of historic significance to merit individual listing in the NRHP under Criterion A or B. Furthermore, the building lacks notable architectural elements that would warrant individual listing in the NRHP under Criterion C. Instead, the significance of Building 3003 is best understood as an integral support resource necessary to the functioning of research and processing facilities in the ORNL Historic District during the Manhattan Project and Cold War era. As such, Building 3003 does not warrant individual listing in the NRHP under Criterion A, B, or C; however, the building is a contributing resource to the ORNL Historic District. 


\section{BUILDING NAME}

Low Intensity Test Reactor Facility

DATE OF CONSTRUCTION

1948

\section{DOE OFFICE RESPONSIBLE}

EM (UCOR)

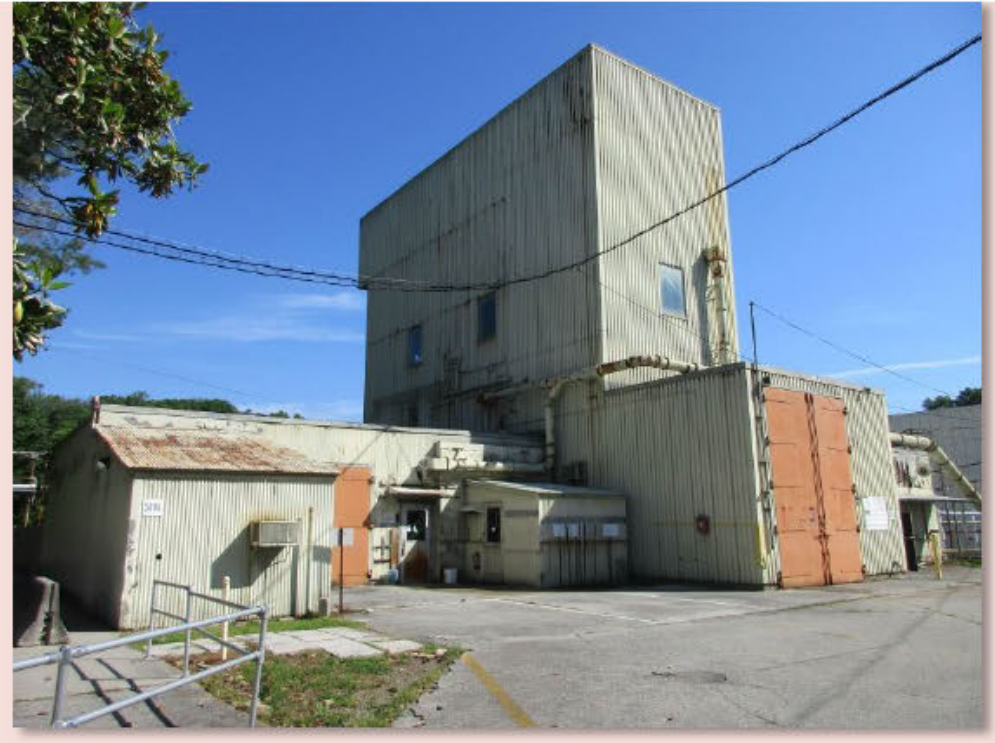

\section{NRHP ELIGIBILITY}

Figure 92. Overview of south and west elevations of Building 3005.

Eligible/Contributing to ORNL Historic District

\section{DESCRIPTION}

Building 3005 is located near the southern terminus of North Access Road. The building is an asymmetrical multi-story concrete and steel frame structure with a concrete foundation (Figures 92 and 93). The structure was built in several different phases. The north and south elevations of the building are oriented to paved parking areas or drives. The central three-story steel tower and other steel framed additions are clad in corrugated metal siding. Shed-roof additions are located on the south elevation. A concrete masonry block addition is located in the eastern corner of the building. Two double-leaf entries are located on the south elevation, including one large entry filled with hinged steel doors. Single-leaf entries filled with one-light metal pedestrian doors are also found on the south and east elevations of the building. Window openings within the tower are large single-light sashes. Other window openings are filled with eight- and sixteen-light metal awning windows.

\section{NATIONAL REGISTER EVALUATION}

Building 3005 was constructed in 1948 and historically functioned as a Low Intensity Test Reactor (LITR) Facility and is among several processing facilities located in the 3000 Area. The building began operating as a LITR facility in 1951 and played a significant role in ORNL's experimental reactor program during the Cold War era. In addition, the facility's successful design served as a prototype for commercial and military use, including commercial power plants and reactor propelled naval craft (Thomason and Associates 2015: 249). Building 3005 was previously surveyed in 1994, 2004, and 2015 and recommended as a contributing resource to the ORNL Historic District in all previous surveys (Carver and Slater 1994; Thomason and Associates 2004 and 2015). Although the building exhibits some single-story additions, most are historic, and its general form remains distinguishable. As such, its integrity of location, design, feeling, and association, those aspects most important to conveying the building's identity with nuclear science, are intact. As a processing facility, Building 3005 served as a prototype for structures built elsewhere and contributed to major achievements in many fields of science during the Cold War era. As such, the building is the single location most importantly associated with scientific achievement of widespread importance, and therefore, merits listing in the NRHP under Criterion A for its associations with nuclear science advancement during the Cold War era. In addition, Building 3005 is individually eligible for listing in the NRHP under Criterion $C$ under engineering as its design served as a 
prototype for subsequent commercial and military use. The building also contributes to the ORNL Historic District.

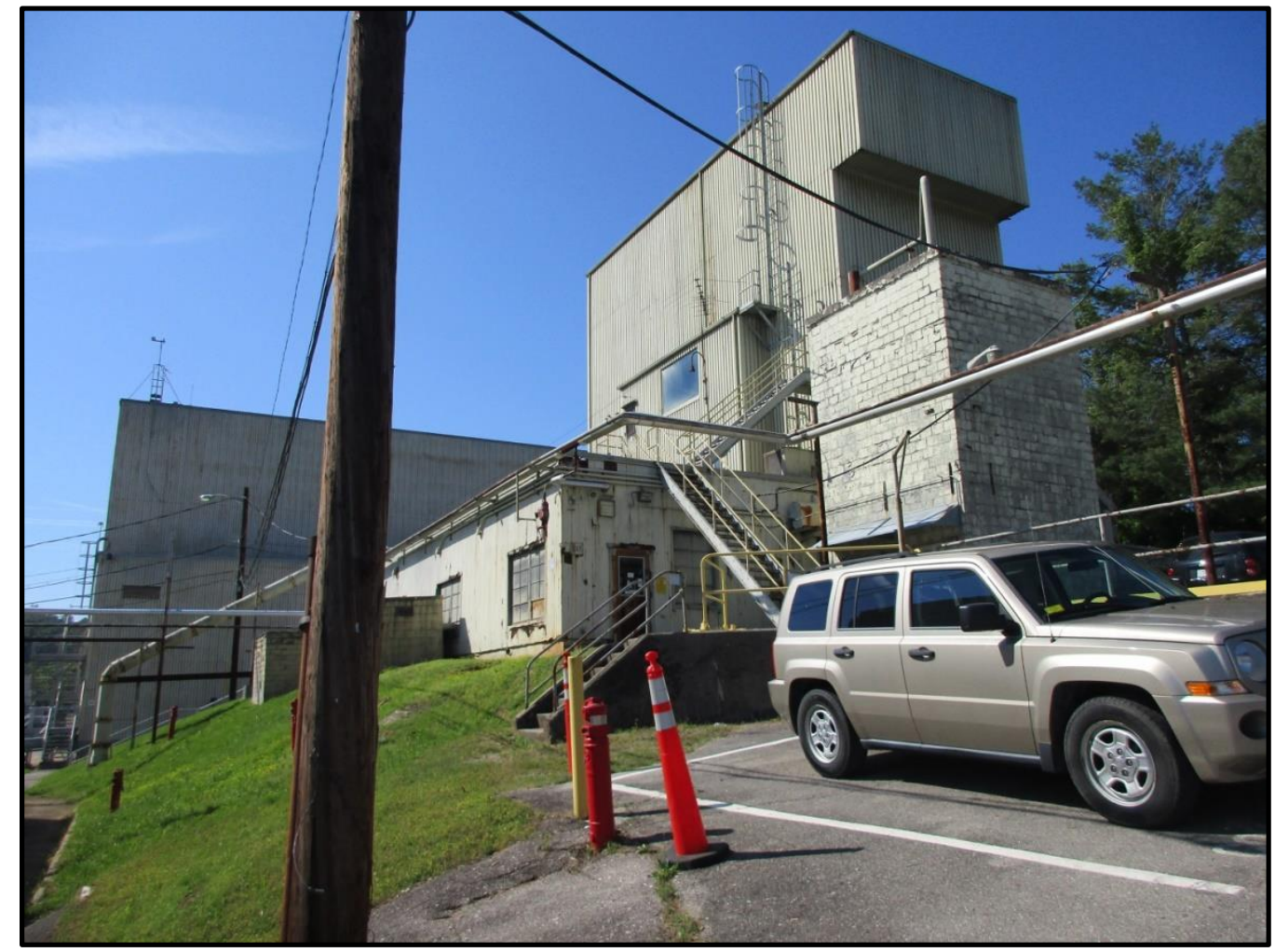

Figure 93. Overview of east and north elevations of Building 3005. 


\section{8}

\section{BUILDING NAME}

Source \& Special Material Vault

\section{DATE OF CONSTRUCTION}

1943

DOE OFFICE RESPONSIBLE

SC

NRHP ELIGIBILITY

Demolished - N/A

\section{DESCRIPTION}

Field survey confirmed Building 3008 is no longer extant.

\section{NATIONAL REGISTER EVALUATION}

Building 3008 was constructed in 1943 as a storage facility. According to data provided in the Non-Reactor General Maintenance Facilities PCCR, Building 3008 was constructed immediately adjacent to the Graphite Reactor (Building 3001) in 1943. As one of the original buildings on the site, it served as a storage vault for the Graphite Reactor and supported World War II missions and plutonium production during the post-war era of ORNL. The small, $563 \mathrm{sq}$ ft building was a one-story concrete block building clad in brick veneer with a flat roof. The building was previously surveyed in 1994 and 2004 and recommended contributing to the ORNL Historic District (Carver and Slater 1994; Thomason and Associates 2004); however, it was demolished by the time it was surveyed again in 2015 (Thomason and Associates 2015). Prior to its demolition, in 2009 DOE submitted documentation of Building 3008 to the SHPO, as required by the PA, along with documentation for several other facilities (UTB 2009). SHPO accepted the documentation and offered no objection to the proposed demolition (McIntyre 2009). During the current survey, CRA confirmed that Building 3008 is no longer extant. Thus, the integrity of location, design, setting, materials, workmanship, feeling, and association of the former Source \& Special Material Vault (Building 3008) has been destroyed, so it no longer contributes to the ORNL Historic District. 


\section{9}

\section{BUILDING NAME}

Pump House for Building 3010

DATE OF CONSTRUCTION

1950

DOE OFFICE RESPONSIBLE

EM (UCOR)

\section{NRHP ELIGIBILITY}

Non-Contributing to ORNL Historic District

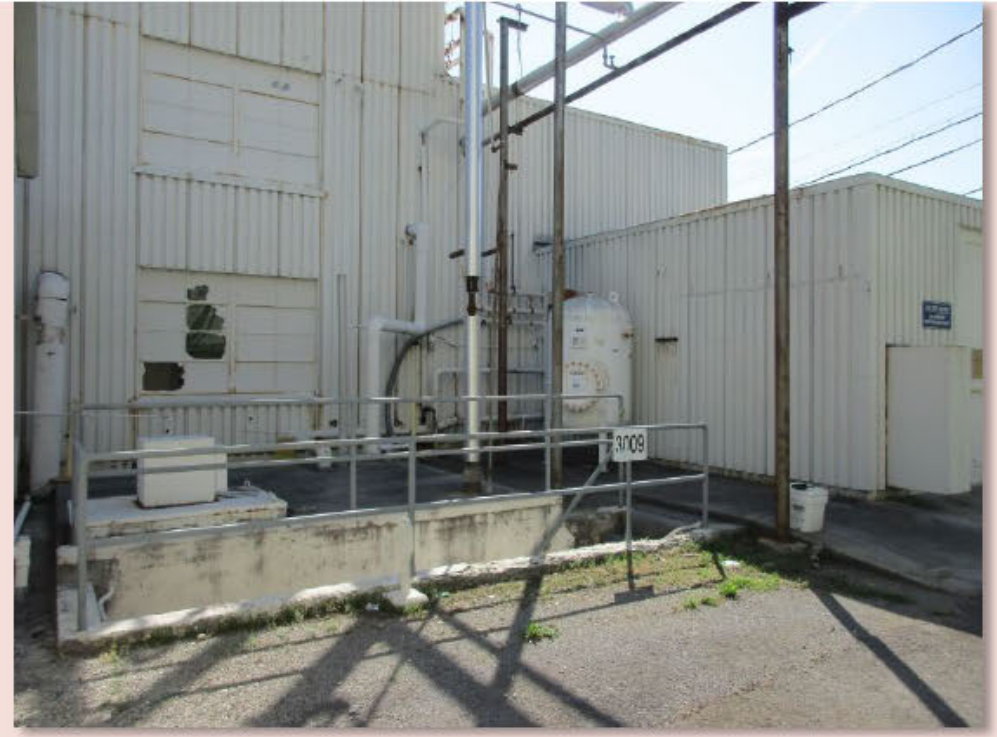

Figure 94. Overview of west elevation of Building 3009.

\section{DESCRIPTION}

Building 3009 is located near the southern terminus of North Access Road. According to Thomason and Associates, the building resource was demolished. Field survey confirmed it has not been demolished and remains extant. Building 3009 is a single-story, below-ground concrete pump house accessed by a recessed concrete stairwell with steel railing. Previous documentation from the original survey of ORNL in 1994 confirms that the building is not a foundation remnant but, rather, is a $180 \mathrm{sq} \mathrm{ft}$ underground pump house adjacent to Building 3010 (Figure 94). A pumping apparatus was once a part of the resource. Building 3009 is considered a support building for Building 3010.

\section{NATIONAL REGISTER EVALUATION}

Building 3009 was constructed in 1950 and operated as a pump house until its shutdown in April 1998. During its operation, it served as a utilities/maintenance facility that was an ancillary resource for Building 3010 . The building was previously surveyed in 1994 and 2004 and recommended as a contributing resource to the ORNL Historic District (Carver and Slater 1994; Thomason and Associates 2004). The building was surveyed again in 2015 when it was noted as demolished (Thomason and Associates 2015). During the current survey, CRA confirmed that the building is extant. The building retains a majority of its historic materials, as well as its form and massing. As a utility/maintenance facility, Building 3009 provided utilitarian support services for work that furthered ORNL's mission in nuclear science during the Cold War era. However, the building is not the single location most importantly associated with a scientific achievement, scientist, or other event or person of historic significance to merit individual listing in the NRHP under Criterion A or B. Furthermore, the building lacks notable architectural elements that would warrant individual listing in the NRHP under Criterion C. Instead, the significance of Building 3009 is best understood as an integral support resource necessary to the functioning of research and processing facilities in the ORNL Historic District during the Cold War era. As such, Building 3009 does not warrant individual listing in the NRHP under Criterion A, B, or C; however, the building is a contributing resource to the ORNL Historic District. 


\section{0}

\section{BUILDING NAME}

Bulk Shielding Reactor (BSR) Facility

DATE OF CONSTRUCTION

1950

DOE OFFICE RESPONSIBLE

EM (UCOR)

NRHP ELIGIBILITY

Figure 95. Overview of south elevation of Building 3010.

Contributing to ORNL Historic District

\section{DESCRIPTION}

Building 3010 is located near the southern terminus of North Access Road. The building is a multi-story, asymmetrical steel-frame structure with a concrete foundation and a flat roof (Figures 95 and 96). The tallest section is located at the core of the building with smaller one- and two-story flat-roof wings attached to the main block. Building $3010 \mathrm{~A}$ is attached to the north elevation of Building 3010 . The exterior of the building is clad with corrugated metal siding. A large opening filled with a set of paired, hinged metal doors is found on the building's north elevation. In various places throughout the building are single- and double-leaf entries filled with singlelight metal pedestrian doors. Window openings are filled with eight-light metal awning sashes.

\section{NATIONAL REGISTER EVALUATION}

The Bulk Shielding Reactor (BSR) Facility (Building 3010) was constructed in 1950. It operated as a processing facility as part of the ANP program and functioned as such until 1960 when a new BSR facility was built. During its active operation, radiation shielding studies were performed in the building; these studies mainly were used to test materials for possible use on nuclear-powered aircraft. Important research was produced at the BSR facility (Building 3010) regarding radiation damage processes on solids. Building 3010 was previously surveyed in 1994, 2004, and 2015 and recommended a contributing resource to the ORNL Historic District (Carver and Slater 1994; Thomason and Associates 2004 and2015). Building 3010 retains a majority of its historic materials, as well as its form and massing. Although Building 3010 was an important processing facility, it is not the single location most importantly associated with a scientific achievement, scientist, or other event or person of historic significance to merit individual listing in the NRHP under Criterion A or B. Furthermore, the building lacks notable architectural elements that would warrant individual listing in the NRHP under Criterion C. Instead, the significance of Building 3010 is best understood within the broader context of the body of work advanced by researchers in the ORNL Historic District during the Cold War era. As such, Building 3010 does not warrant individual listing in the NRHP under Criterion A, B, or C; however, the building is a contributing resource to the ORNL Historic District. 


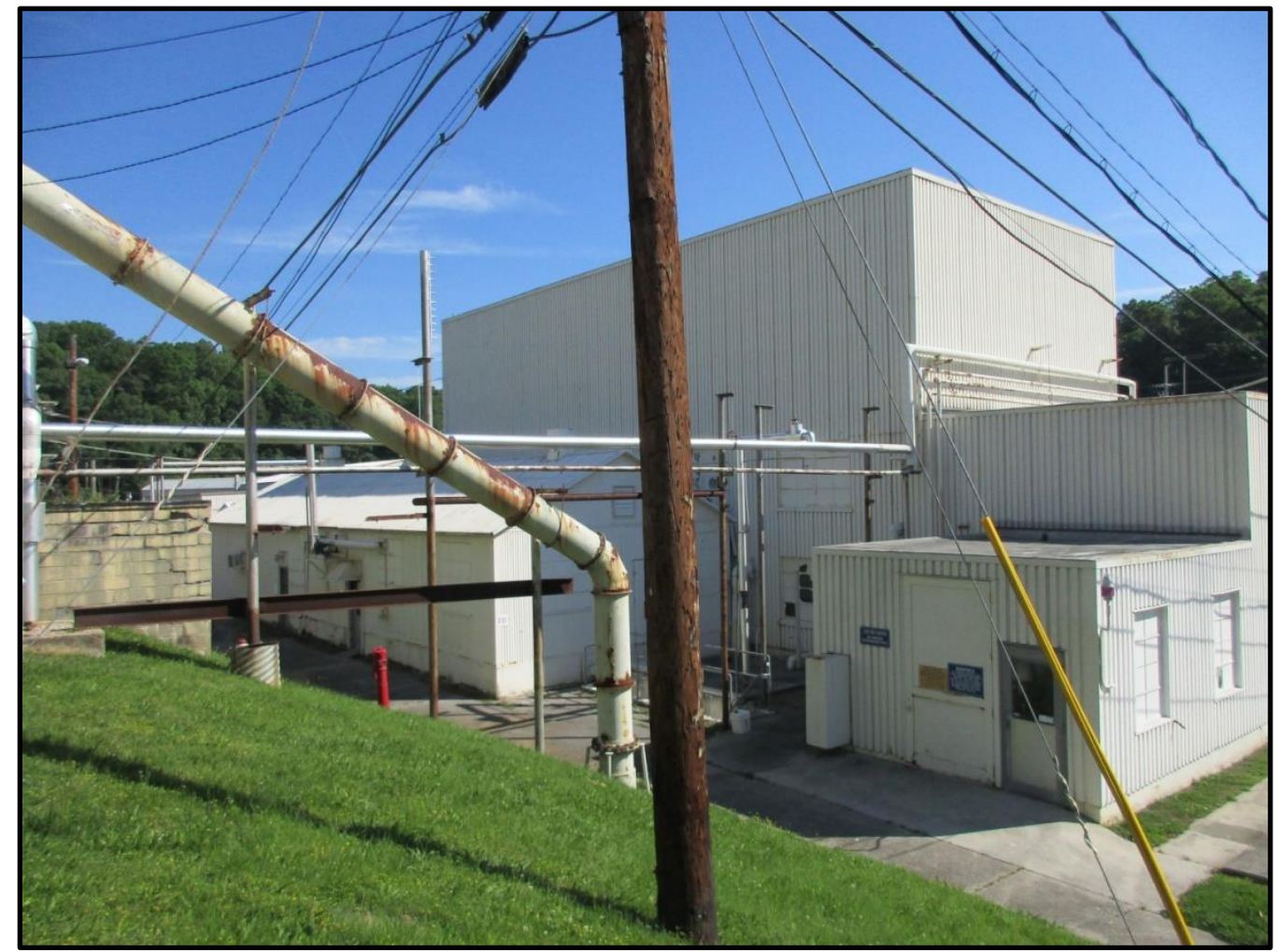

Figure 96. Overview of south and west elevations of Building 3010. 


\section{$3010 \mathrm{~A}$}

\section{BUILDING NAME}

Bulk Shielding Reactor (BSR) Annex

\section{DATE OF CONSTRUCTION}

1950

DOE OFFICE RESPONSIBLE

SC

NRHP ELIGIBILITY

Figure 97. Overview of north and west elevations of Building 3010A, which is attached to the north elevation of Building 3010 .

Contributing to ORNL Historic District

\section{DESCRIPTION}

Building $3010 \mathrm{~A}$ is attached to the north elevation of Building 3010 . This section is similar in construction and materials as Building 3010 . Building $3010 \mathrm{~A}$ is a two-story steel structure clad in corrugated metal siding and situated on a concrete foundation (Figure 97). An exterior metal staircase is located on the north elevation. Single and paired entries filled by single-light and two-light metal pedestrian doors are found on the building. The building features single and paired eight-light metal awning windows. A few metal awnings protrude from the building sheltering the entries.

\section{NATIONAL REGISTER EVALUATION}

The building was constructed in 1954 as an annex to the Bulk Shielding Reactor (BSR), which was in operation as part of the ANP program until 1960 when a new BSR facility was constructed. The processing facility aided in radiation shielding studies, which were used to test materials for possible use on nuclear-powered aircraft. Building 3010A was previously unrecorded. Building 3010A retains a majority of its historic materials, as well as its form and massing. As a processing facility, Building 3010A served in a support role to Building 3010 and is not the single location most importantly associated with a scientific achievement, scientist, or other event or person of historic significance to merit individual listing in the NRHP under Criterion A or B. Furthermore, the building lacks notable architectural elements that would warrant individual listing in the NRHP under Criterion C. Instead, the significance of Building $3010 \mathrm{~A}$ is best understood within the broader context of the body of work advanced by researchers in the ORNL Historic District during the Cold War era. As such, Building 3010A does not warrant individual listing in the NRHP under Criterion A, B, or C; however, the building is a contributing resource to the ORNL Historic District. 


\section{2}

\section{BUILDING NAME}

Rolling Mill

\section{DATE OF CONSTRUCTION}

1947

DOE OFFICE RESPONSIBLE

SC

NRHP ELIGIBILITY

Demolished - N/A

\section{DESCRIPTION}

Field survey confirmed Building 3012 is no longer extant.

\section{NATIONAL REGISTER EVALUATION}

Building 3012 was constructed in 1947 and historically functioned as a Rolling Mill. It was previously recorded in 1994 and 2004 and recommended as a contributing resource to the ORNL Historic District (Carver and Slater 1994; Thomason and Associates 2004). Prior to its demolition, in 2009 DOE submitted documentation of Building 3012 to the SHPO, as required by the PA, along with documentation for several other facilities (UTB 2009). SHPO accepted the documentation and offered no objection to the proposed demolition (Mclntyre 2009). The building was identified as demolished in 2015 (Thomason and Associates 2015). CRA confirmed the building's demolition during the current survey. Thus, the non-extant building no longer retains integrity of location, design, setting, materials, workmanship, feeling, or association and therefore is not individually eligible for listing in the NRHP nor is it a contributing resource to the ORNL Historic District. 


\section{7}

\section{BUILDING NAME}

Quality Services Division Building

DATE OF CONSTRUCTION

1952

DOE OFFICE RESPONSIBLE

EM (Isotek)

NRHP ELIGIBILITY

Figure 98. Overview of west elevation and partial south elevation of Building 3017.

Contributing to ORNL Historic District

\section{DESCRIPTION}

Building 3017 is located at the intersection of Third Street and Reactor Drive and within the barricaded portion of the 3000 Area. Access to this high-security area of the 3000 Area is restricted; therefore, photographs of the building's exterior were limited. Building 3017 is a one-story, flat-roof, concrete block structure supported by a concrete foundation (Figures 98 and 99). Metal coping encompasses the roof's edge. Single-leaf entries filled with single-light doors are located on the north and west elevations of the building. Windows filled with six-light metal hopper sashes and exhibiting concrete sills are located primarily on the north and south elevations. Some windows are filled with paired replacement single-light sashes with faux muntins.

\section{NATIONAL REGISTER EVALUATION}

Building 3017 was constructed in 1952 and historically housed laboratories for students associated with the ORSORT. The building now houses offices. It was previously surveyed in 1994, 2004, and 2015 and was recommended as a contributing resource to the ORNL Historic District (Carver and Slater 1994; Thomason and Associates 2004and 2015). The building retains a majority of its historic materials as well as its form and massing. As a research/laboratory facility, Building 3017 housed work that furthered ORNL's mission in nuclear science during the Cold War era. However, the building is not the single location most importantly associated with a scientific achievement, scientist, or other event or person of historic significance to merit individual listing in the NRHP under Criterion A or B. Furthermore, the building lacks notable architectural elements that would warrant individual listing in the NRHP under Criterion C. Instead, the significance of Building 3017 is best understood within the broader context of the body of work advanced by researchers in the ORNL Historic District during the Cold War era. As such, Building 3017 does not warrant individual listing in the NRHP under Criterion $\mathrm{A}, \mathrm{B}$, or $\mathrm{C}$; however, the building is a contributing resource to the ORNL Historic District. 


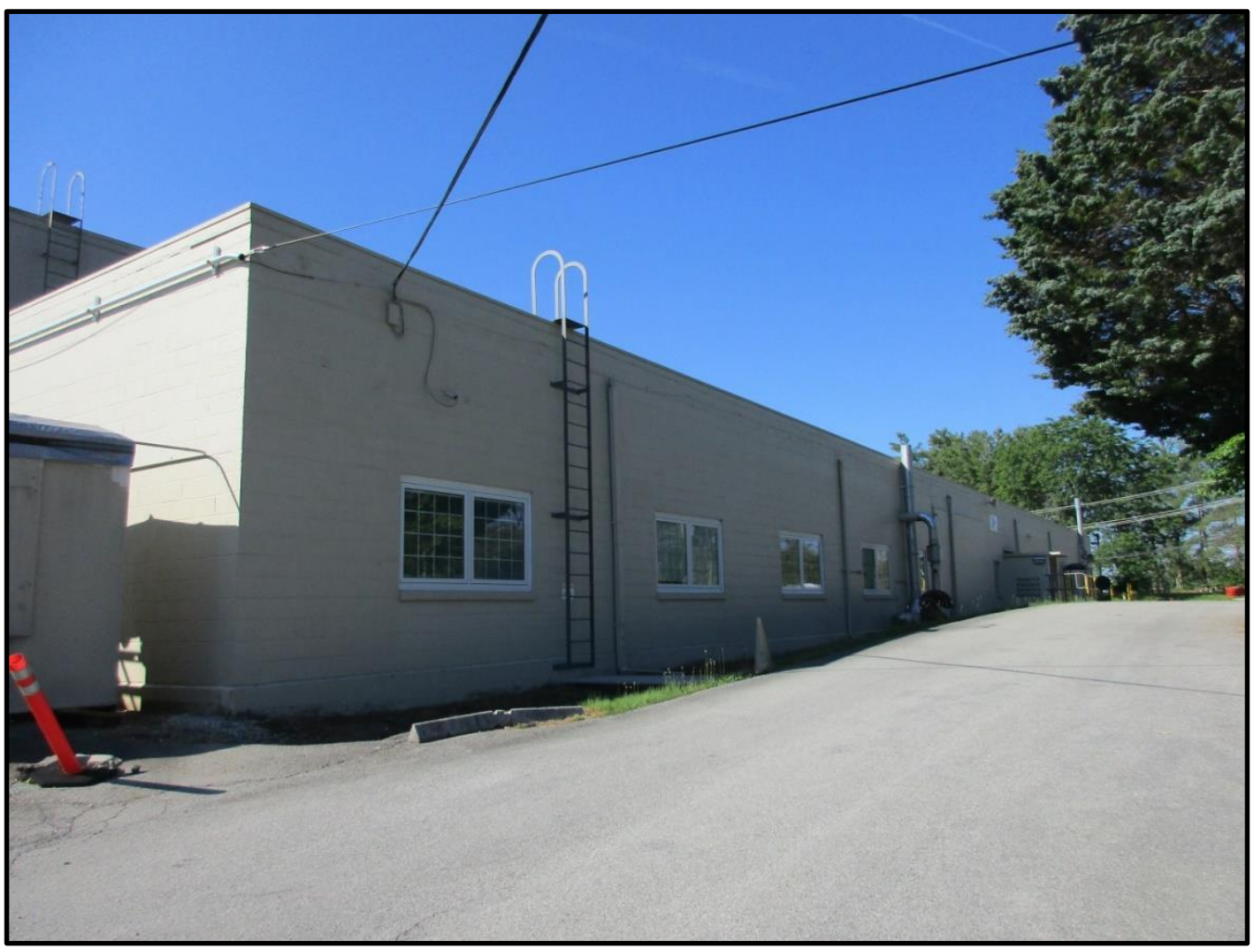

Figure 99. Overview of north elevation and partial east elevation of Building 3017. 


\section{8}

\section{BUILDING NAME}

Cv \& Og Exhaust Stack

\section{DATE OF CONSTRUCTION}

1943

\section{DOE OFFICE RESPONSIBLE}

EM (UCOR)

\section{NRHP ELIGIBILITY}

Contributing to ORNL Historic District

\section{DESCRIPTION}

Building 3018 serves as an exhaust stack for Building 3003 and is located adjacent to the south corner of Building 3003 . The exhaust stack is of concrete construction and encompassed by metal bands.

\section{NATIONAL REGISTER EVALUATION}

Building 3018 was constructed in 1943 as an exhaust stack for Building 3003. The resource was previously surveyed in 1994 and 2004 and recommended contributing to the ORNL Historic District (Carver and Slater 1994; Thomason and Associates 2004). In 2015, the resource was recorded as demolished (Thomason and Associates 2015). During the 2017 survey, the resource was identified as extant and in operation. Although the survey team had limited access to the facility, enough information was gathered to determine an evaluation. The structure retains a majority of its historic materials, form, and massing. As a utility/maintenance facility, Building 3018 provided utilitarian support services for work that furthered ORNL's mission in nuclear science during the Cold War era. However, the building is not the single location most importantly associated with a scientific achievement, scientist, or other event or person of historic significance to merit individual listing in the NRHP under Criterion $\mathrm{A}$ or $\mathrm{B}$. Furthermore, the building lacks notable architectural elements that would warrant individual listing in the NRHP under Criterion C. Instead, the significance of Building 3018 is best understood as an integral support resource necessary to the functioning of research and processing facilities in the ORNL Historic District during the Cold War era. As such, Building 3018 does not warrant individual listing in the NRHP under Criterion A, B, or C; however, the building is a contributing resource to the ORNL Historic District. 


\section{A}

\section{BUILDING NAME}

Radiochemical Development Facility

\section{DATE OF CONSTRUCTION}

1944

\section{DOE OFFICE RESPONSIBLE}

EM (Isotek)

NRHP ELIGIBILITY

Contributing to ORNL Historic District

\section{DESCRIPTION}

Building $3019 \mathrm{~A}$ is located within the barricaded portion of the 3000 Area. Access to this high-security area of the 3000 Area is restricted; therefore, no photographs of the building were taken at this time. The building is a threestory, flat-roof, steel frame and concrete building comprising $29,537 \mathrm{sq}$ ft. The building exhibits an irregular in plan.

\section{NATIONAL REGISTER EVALUATION}

Building 3019A, also known as the Radiochemical Processing Pilot Plant, was constructed in 1944. It functioned as a pilot plant for the development of chemical separation processes, which have been used in government and commercial facilities on a global scale. It was previously surveyed in 1994, 2004, and 2015, and recommended contributing to the ORNL Historic District (Carver and Slater 1994; Thomason and Associates 2004 and 2015). In addition, Building 3019A has been designated a Nuclear Historic Landmark by the American Nuclear Society. The building retains a majority of its historic materials, as well as its form and massing. As a processing facility, Building 3019A housed work that contributed to major fields of science during the Manhattan Project and Cold War era. Building 3019A is of major significance within the ORNL Historic District; an interior evaluation of the building may reveal information such as intact research and laboratory facilities that would elevate the building's significance and warrant individual listing in the NRHP under Criterion A for its association with the advancement of nuclear science and energy during the Manhattan Project and Cold War era. However, since the survey team was unable to access the high-security area surrounding the building or its interior, an interior evaluation could not be made and thus, the individual eligibility of the resource remains undetermined at this time. The building's lack of notable architectural elements precludes it from individual listing in the NRHP under Criterion C. Overall, based on current information, the significance of Building 3019A is best understood within the broader context of the body of work advanced by researchers in the ORNL Historic District during the Manhattan Project and Cold War era, and therefore it is a contributing resource to the ORNL Historic District. 


\section{B}

\section{BUILDING NAME}

High Level Radiation Analytical Laboratory

\section{DATE OF CONSTRUCTION}

1944

\section{DOE OFFICE RESPONSIBLE}

EM (Isotek)

NRHP ELIGIBILITY

Contributing to ORNL Historic District

\section{DESCRIPTION}

Building $3019 \mathrm{~B}$ is located within the barricaded portion of the 3000 Area. Access to this high-security portion of the 3000 Area is limited; therefore, no photographs of the building were taken at this time. Building $3019 \mathrm{~B}$ is attached to the west elevation of Building 3019A. The building is a one-story, flat-roof, concrete block structure with a concrete foundation. A small cubical section of concrete block is located on the west elevation. A doubleleaf entry filled by a pair of solid metal doors is located within this section.

\section{NATIONAL REGISTER EVALUATION}

Building 3019B, also known as the High Level Radiation Analytical Laboratory, was constructed in 1944 and historically functioned as a pilot plant for the development of chemical separation processes, which have been used in government and commercial facilities on a global scale. It was previously surveyed in 1994, 2004, and 2015, and recommended contributing to the ORNL Historic District (Carver and Slater 1994; Thomason and Associates 2004 and 2015). The building is part of 3019A and thus, was designated a Nuclear Historic Landmark by the American Nuclear Society. The building retains a majority of its historic materials, as well as its form and massing. As a research/laboratory facility, Building 3019B housed work that furthered ORNL's mission in nuclear science during the Manhattan Project and Cold War era. Like Building 3019A, an interior evaluation of the building may reveal information such as intact research and laboratory facilities that would elevate the building's significance and warrant individual listing in the NRHP under Criterion A for its association with the advancement of nuclear science and energy during the Manhattan Project and Cold War era. However, since the survey team was unable to access the interior of the building, an interior evaluation could not be made and thus, the individual eligibility of the resource remains undetermined at this time. The building's lack of notable architectural elements precludes it from individual listing in the NRHP under Criterion C. Overall, the significance of Building 3019B is best understood within the broader context of the body of work advanced by researchers in the ORNL Historic District during the Manhattan Project and Cold War era and therefore, is a contributing resource to the ORNL Historic District. 


\section{0}

\section{BUILDING NAME}

Cv \& Og Exhaust Stack

\section{DATE OF CONSTRUCTION}

1943

\section{DOE OFFICE RESPONSIBLE}

EM (Isotek)

\section{NRHP ELIGIBILITY}

Contributing to ORNL Historic District

\section{DESCRIPTION}

Similar to Building 3018, Building 3020 is an exhaust stack of concrete construction and is $200 \mathrm{ft}$ in height. Access to this high-security portion of the 3000 Area is limited; therefore, no photographs of the structure were taken at this time. The architectural resource is located near Building 3019A.

\section{NATIONAL REGISTER EVALUATION}

Building 3020 was constructed in 1943 as an exhaust stack for Building 3019 . The resource was previously surveyed in 1994 and 2004 and recommended contributing to the ORNL Historic District (Carver and Slater 1994; Thomason and Associates 2004). In 2015, the resource was recorded as demolished (Thomason and Associates 2015). During the 2017 survey, the resource was identified as extant and in operation; however, the survey team was unable to photographic the resource due to security restrictions. Although the survey team had limited access to the facility, enough information was gathered to determine an evaluation. The structure's integrity remains intact as it retains a majority of its historic materials, form, and massing. As a utility/maintenance facility, Building 3020 provided utilitarian support services for work that furthered ORNL's mission in nuclear science during the Manhattan Project and Cold War era. However, the building is not the single location most importantly associated with a scientific achievement, scientist, or other event or person of historic significance to merit listing in the NRHP under Criterion A or B. Furthermore, the building lacks notable architectural elements that would warrant individual listing in the NRHP under Criterion C. Instead, the significance of Building 3020 is best understood as an integral support resource necessary to the functioning of research and processing facilities in the ORNL Historic District during the Manhattan Project and Cold War era. As such, Building 3020 does not warrant individual listing in the NRHP under Criterion A, B, or C; however, the building is a contributing resource to the ORNL Historic District. 


\section{1}

\section{BUILDING NAME}

Turbine House for 3019

\section{DATE OF CONSTRUCTION}

1943

DOE OFFICE RESPONSIBLE

EM (Isotek)

NRHP ELIGIBILITY

Undetermined

\section{DESCRIPTION}

Building 3021 is not notated on the directory and no pictures were taken of this resource during the survey. In previous surveys, the building is described as a "100 square-foot, steel-frame building" that is attached to the base of Stack 3020. In Thomason and Associate's 2015 survey, the building is notated as "demolished."

\section{NATIONAL REGISTER EVALUATION}

Building 3021 was constructed in 1943 as a turbine house for Building 3019; however, it was inaccessible due to its location in a high security area. The survey team was unable to document the building and therefore, no assessment can be made. The building was previously surveyed in 1994 and 2004, and recommended contributing to the ORNL Historic District (Carver and Slater 1994; Thomason and Associates 2004). In 2015, the resource was recorded as demolished (Thomason and Associates 2015). CRA was unable to confirm if the building is non-extant and therefore its NRHP evaluation recommendation is undetermined at this time. 


\section{3}

\section{BUILDING NAME}

North Tank Farm

\section{DATE OF CONSTRUCTION}

1947

\section{DOE OFFICE RESPONSIBLE}

EM

NRHP ELIGIBILITY

Non-Contributing to ORNL Historic District

\section{DESCRIPTION}

The North Tank Farm is a collection of field constructed, steel-reinforced concrete underground tanks that were remediated and closed in-situ, rather than demolished. In the 1990s, a DOE-EM contractor constructed temporary aboveground steel platforms which allowed safe access to the highly contaminated tanks through ground-level hatchways using remotely-operated equipment. The tanks were pumped empty and rinsed, and then closed in place by filling with cement. Field survey confirmed that the tanks have been closed and that a layer on concrete and gravel covers the entire surface of the North Tank Farm.

\section{NATIONAL REGISTER EVALUATION}

Building 3023 was constructed in 1943 and historically served as an underground tank farm used for the collection and storage of liquid waste. The resource was previously surveyed in 1994 and 2004 and recommended as contributing to the ORNL Historic District (Carver and Slater 1994; Thomason and Associates 2004). In 2015, the resource was recorded as demolished (Thomason and Associates 2015). During the current survey, CRA discovered that rather than being demolished, the resource was remediated and closed in-situ. As a storage facility, Building 3023 provided support for work that furthered ORNL's mission in nuclear science during the Manhattan Project and Cold War era. However, the building is not the single location most importantly associated with a scientific achievement, scientist, or other event or person of historic significance to merit individual listing in the NRHP under Criterion A or B. Furthermore, the building lacks notable architectural elements that would warrant individual listing in the NRHP under Criterion C. While a minor support structure, Building 3023 was utilized in support of the overall mission of ORNL during the Manhattan Project and Cold War era; however, CRA recommends that alterations, including the closure and filling of the entire resource with concrete and the topping of the entire site with gravel and concrete have diminished the integrity of setting, design, and materials to such a degree that it no longer contributes to the ORNL Historic District. 


\section{$3025 E$}

\section{BUILDING NAME}

Irradiated Materials Examination and Testing

\section{DATE OF CONSTRUCTION}

1950

\section{DOE OFFICE RESPONSIBLE}

SC

\section{NRHP ELIGIBILITY}

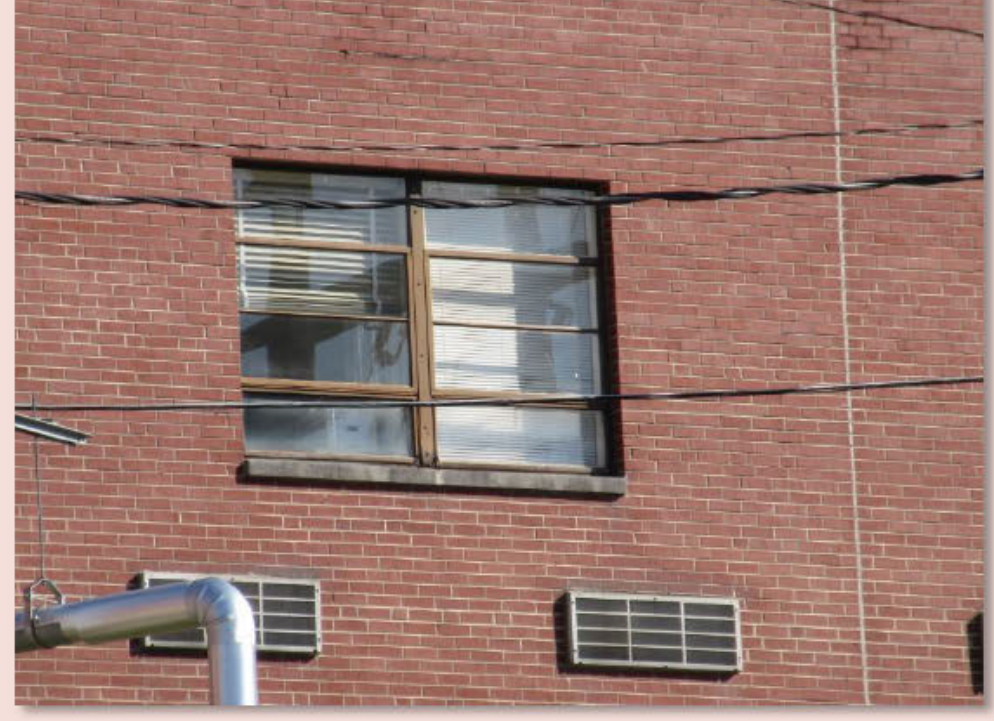

Contributing to ORNL Historic District

\section{DESCRIPTION}

Building 3025E was one of 15 resources selected for intensive survey by UT-B as a part of survey planning. Buildings $3025 \mathrm{E}$ and $3025 \mathrm{M}$ are adjoining buildings located within the barricaded portion of the 3000 Area of the main campus of ORNL. Access to this high-security area of the 3000 Area is limited; therefore, photographs of the exterior of this building were limited.

Exterior: The two-story building features two full floors and a mezzanine level, a continuous poured concrete foundation, brick exterior with a variant of common bond with five courses of stretchers followed by a course of alternating headers and stretchers, similar to Flemish bond, and a flat gravel and tar roof. Building 3025E features four-light horizontal steel windows throughout with fixed lights set above and below a two-light awning window with concrete sills (Figure 100). Exterior entrances originally featured two-light steel doors, although, from the limited views of the exterior available during the survey, the majority of exterior doors appear to have been replaced with modern single-light metal doors. The western elevation features a loading dock bay with a concrete platform and an enclosed exterior corridor with steel panels connecting the two-story Building 3025E building to the three-story Building 3025M (Figure 101). An elevated walkway, originally constructed of standard structural steel and steel-reinforced concrete, extends along the entire length of the eastern elevation. In 2016, the original elevated walkway was demolished and replaced with a structural steel walkway with galvanized steel grating, following concurrence by THC (SHPO) (Vasquez 2016).

Interior: The interior of Building $3025 \mathrm{E}$ has been renovated since its original construction; however, it retains operational hot cells, or shielded nuclear radiation chambers that protect researchers and provide containment during experiments with radioactive isotopes. The six operational hot cells are located on the second floor of the building (Figure 102). The remaining interior of the second floor is divided into offices, a conference room, and storage, and features standard $1 \mathrm{ft}$ square commercial grade tile, ceilings that are either open to the mezzanine level or that feature standard rectangular drop ceilings with acoustic tile, and original single-light metal doors (Figures 103, 104, and 105). Interior walls are comprised of concrete block, brick, or interlocking metal dividing walls, portions of which are clad in small, interlocking acoustic tiles (Figure 106). The mezzanine level is partially open to the second floor below, and is comprised of a work platform. The first floor, which is divided into offices and laboratory space, features sections of original and replacement commercial floor tile, original interior metal 
doors, interlocking metal interior dividing walls, modern cubicles, and laboratory spaces with replacement cabinetry and counters (Figures 107, 108, and 109).

\section{NATIONAL REGISTER EVALUATION}

According to the 1994 survey of ORNL, Building 3025E was constructed in 1951 as the Irradiated Materials Examination and Testing (IMET) Facility, as a part of the $\$ 878,000$ Solid State Laboratory. Solid state research, an outgrowth of the Aircraft Reactor Experiment at ORNL, involved the fundamental physics of solids and sought to understand the effects of radiation on solids (Carver and Slater 1994: 219). The six hot cells within Building 3025E remain in place and in active use. Robotic arms allow researchers to manipulate objects within the hot cells without the risk of exposure to radiation.

Building 3025E has been previously evaluated in 1994 and in 2015. In 1994 it was recommended as a contributing resource to the ORNL Historic District. In 2015, it was evaluated collectively with $3025 \mathrm{M}$ (incorrectly identified as $3025 \mathrm{~W}$ in the report), and recommended as eligible for inclusion in the NRHP under Criterion A as a part of the ORNL Historic District, for its historical association with the post-World War II governmentsponsored scientific movement, ORNL's evolution as a national laboratory, and early nuclear development.

As a research/laboratory facility, Building 3025E housed work important to the advancement of ORNL's mission in the Cold War era. However, the building is not the single site most importantly associated with a significant scientific achievement or other event or person of historic significance to merit individual listing in the NRHP under Criterion A or B. Additionally, it does not possess significant associations for its architectural or engineering design that would warrant individual listing under Criterion $C$. Thus, CRA recommends that Building 3025E is not individually eligible for listing in the NRHP under Criterion A, B, or C. Instead, the significance of Building 3025E is best understood within the context of the ORNL Historic District as a whole for its role in the advancement of nuclear science at ORNL during the Cold War era and as part of a collection of purposedesigned scientific processing and research facilities engineered to meet the specific needs of the advanced research occurring within their walls. Despite minor interior and exterior alterations and updates, Building 3025E retains integrity to support its inclusion within the ORNL Historic District. Therefore, CRA concurs with Thomason's 2015 recommendation that Building 3025E is a contributing resource of the ORNL Historic District under Criterion A for its association with the post-World War II development of government-sponsored scientific laboratories, ORNL's evolution as a national laboratory, and early nuclear development and under Criterion $\mathrm{C}$ as a purpose-designed scientific research facility within the district. 


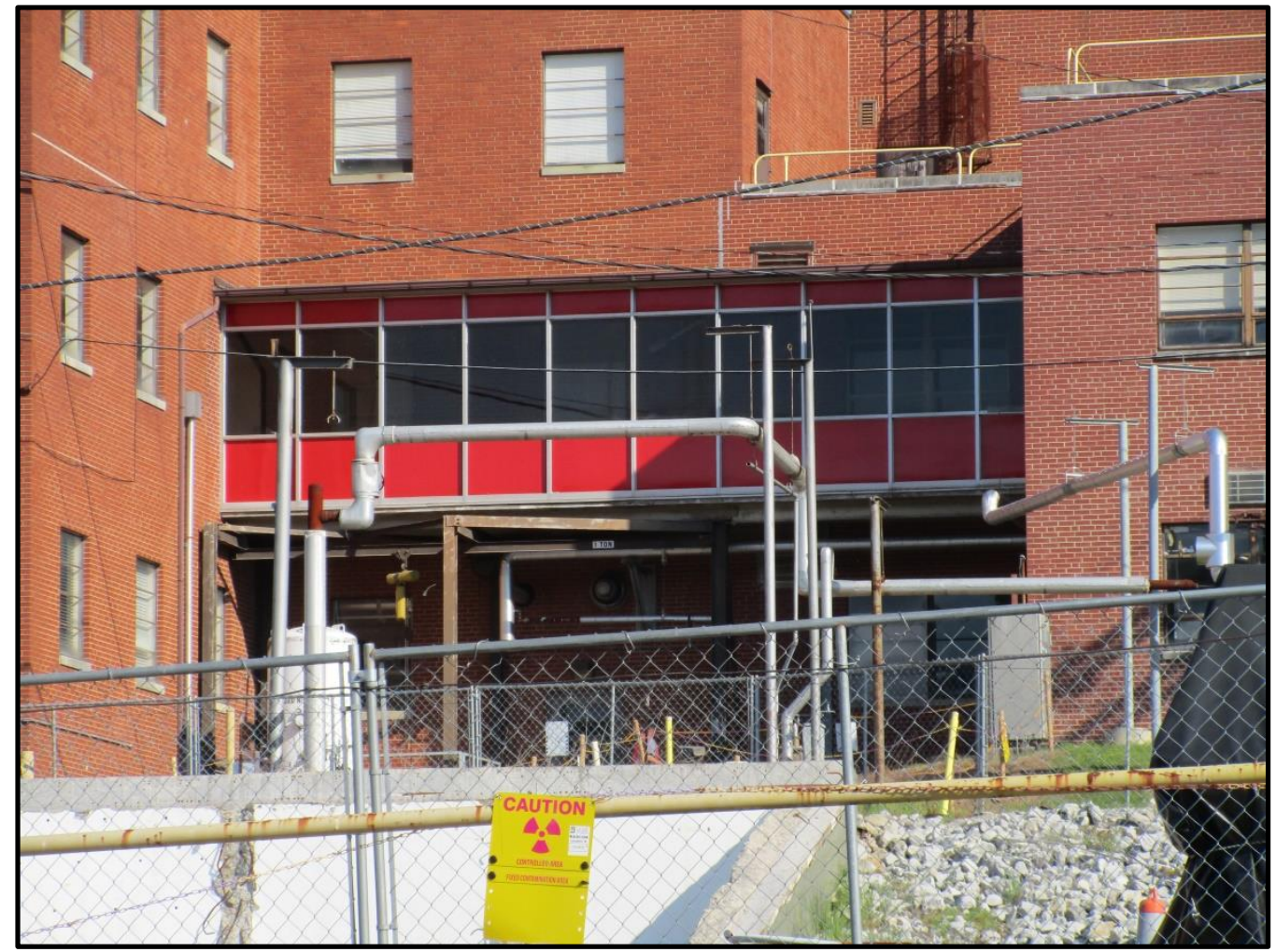

Figure 101. Enclosed walkway on south elevation of Building 3025E and Building 3025M.

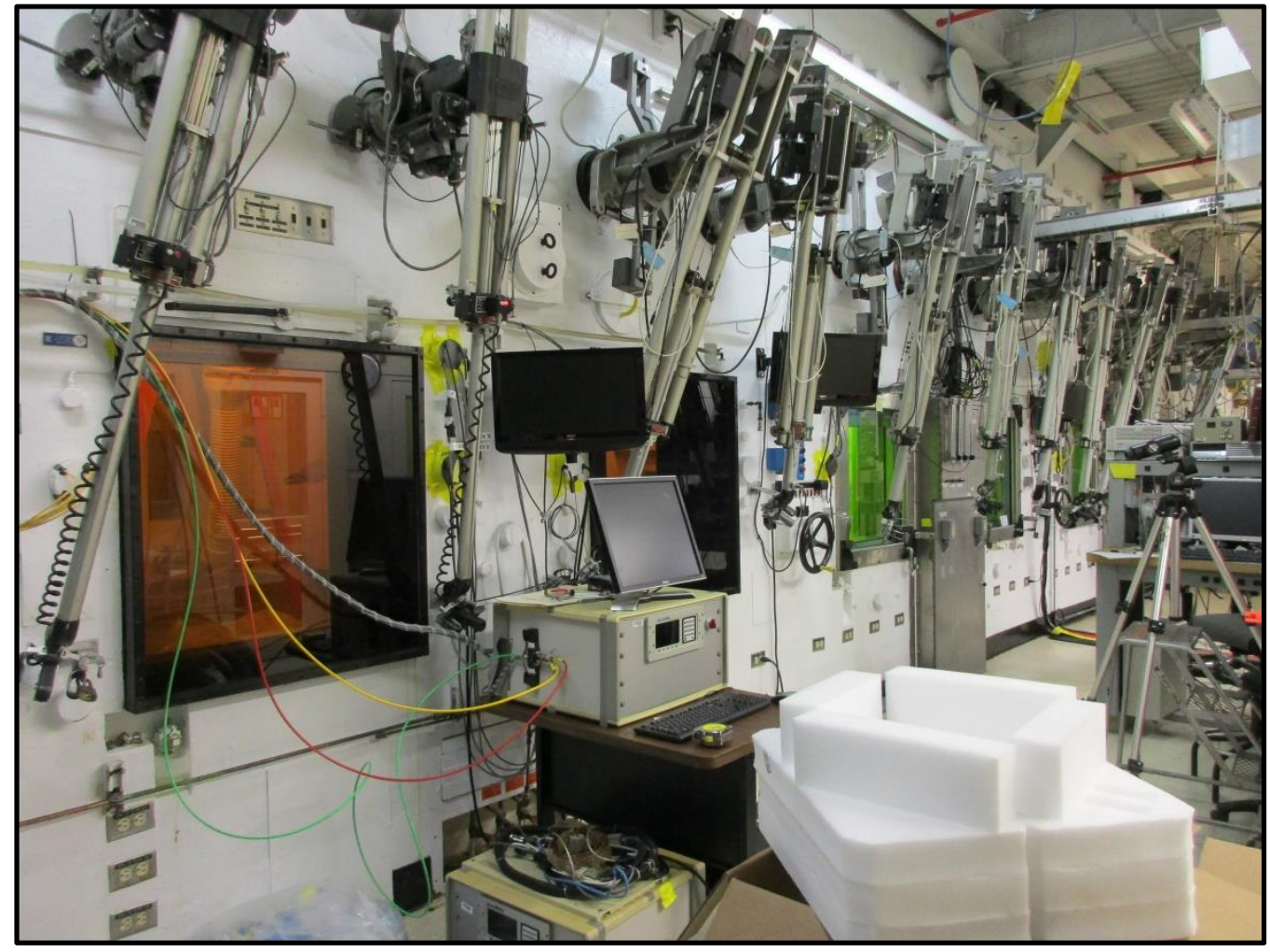

Figure 102. Hot cells on the second floor of Building 3025E and robotic arms used to operate within them. 


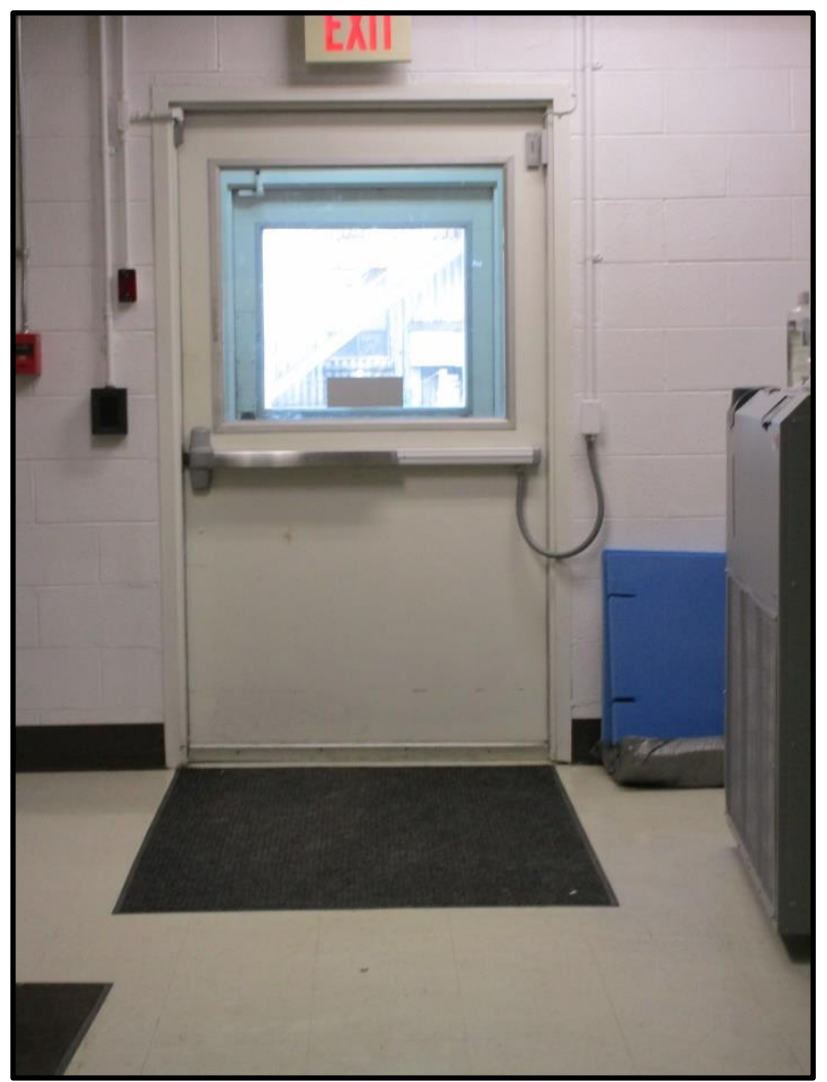

Figure 103. Replacement exterior and interior doors on the second floor of Building 3025E.

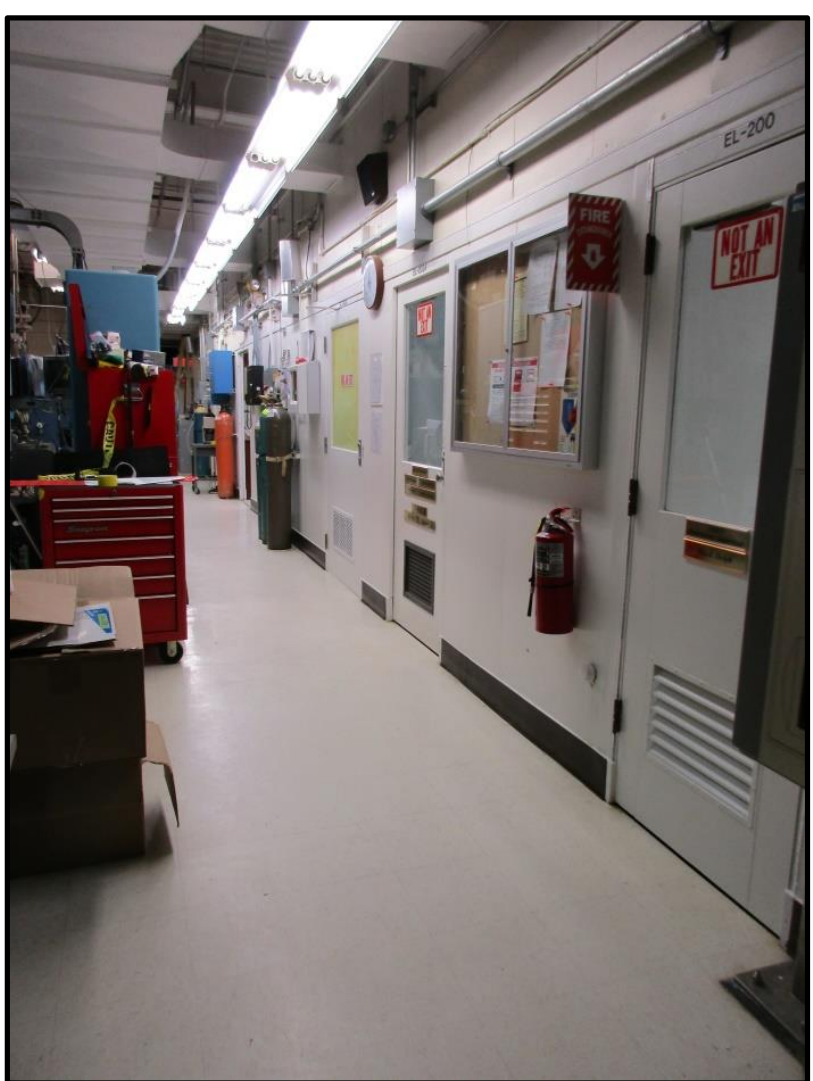

Figure 104. Interlocking dividing walls and original doors on second floor of Building 3025E. 


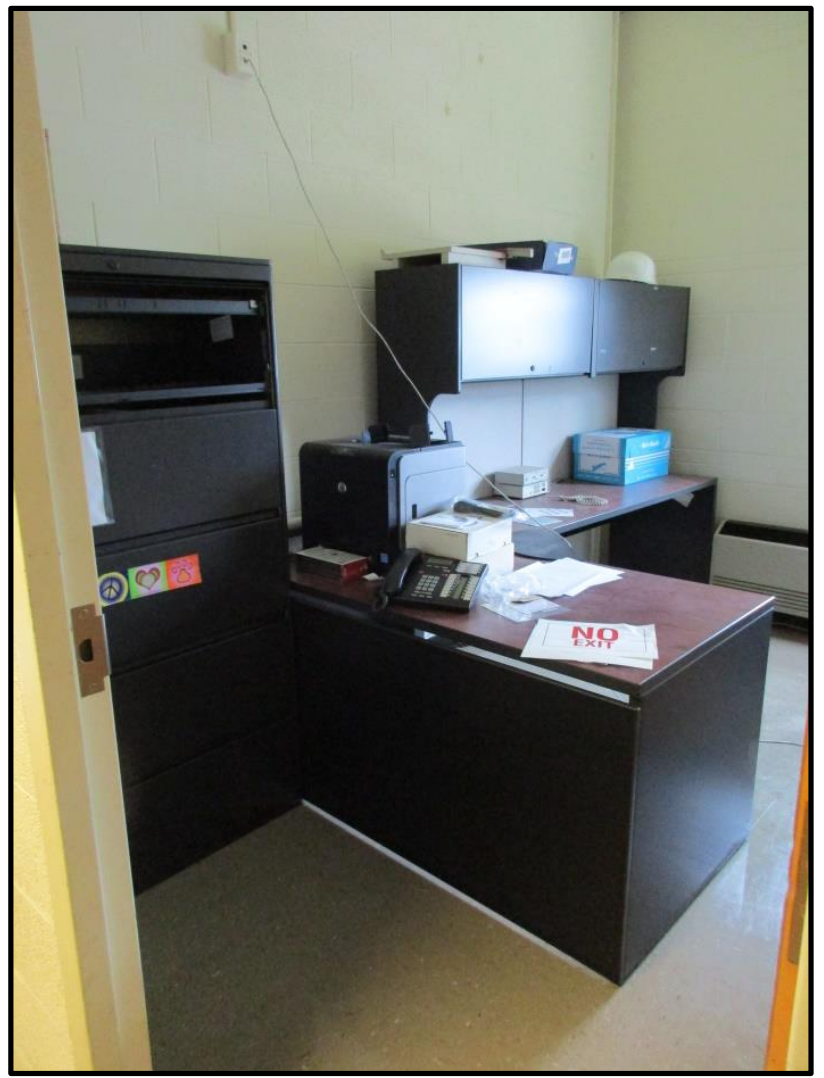

Figure 105. Renovated office on the second floor of Building 3025E.

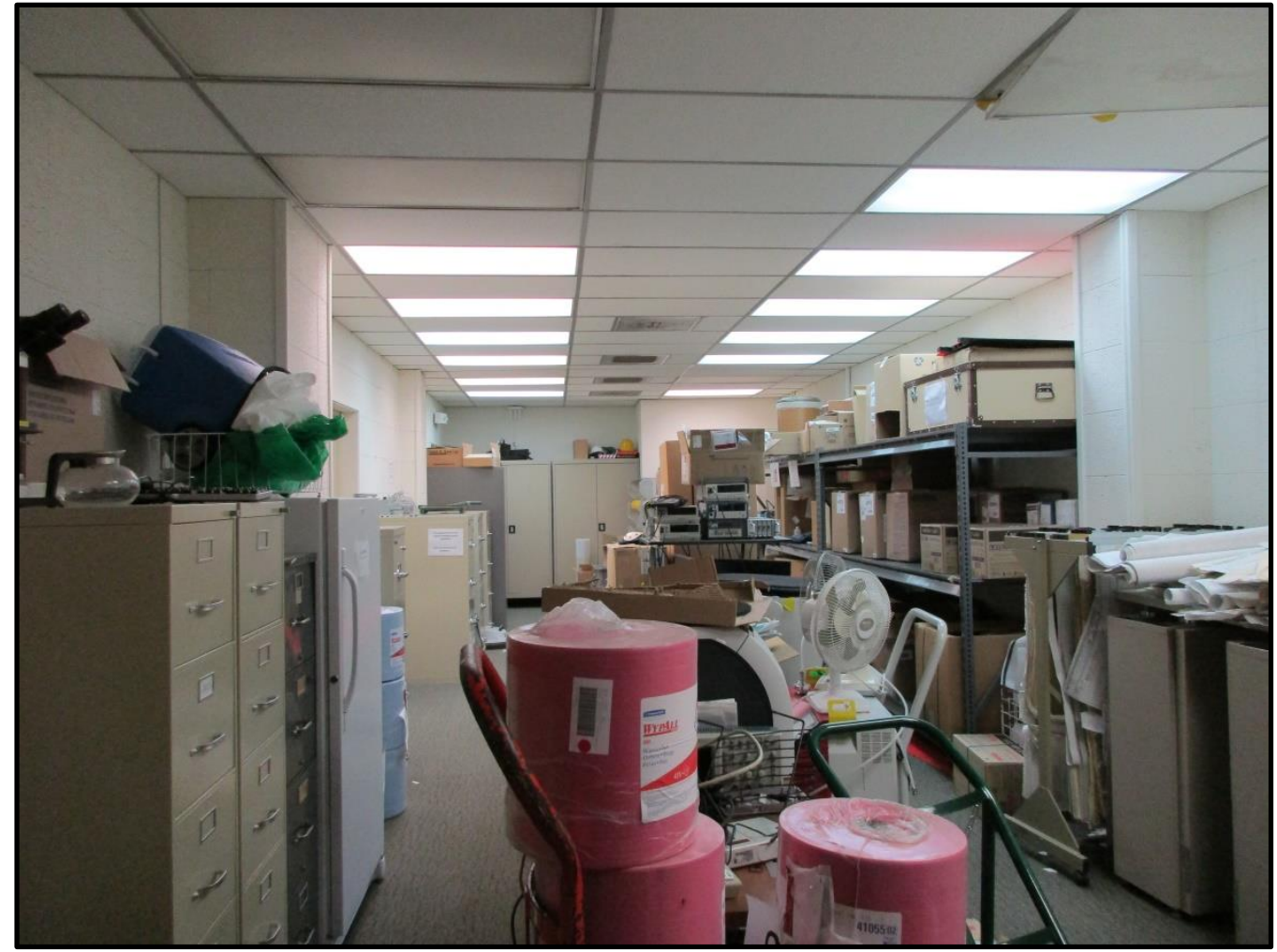

Figure 106. Storage room on the second floor of Building 3025E. 


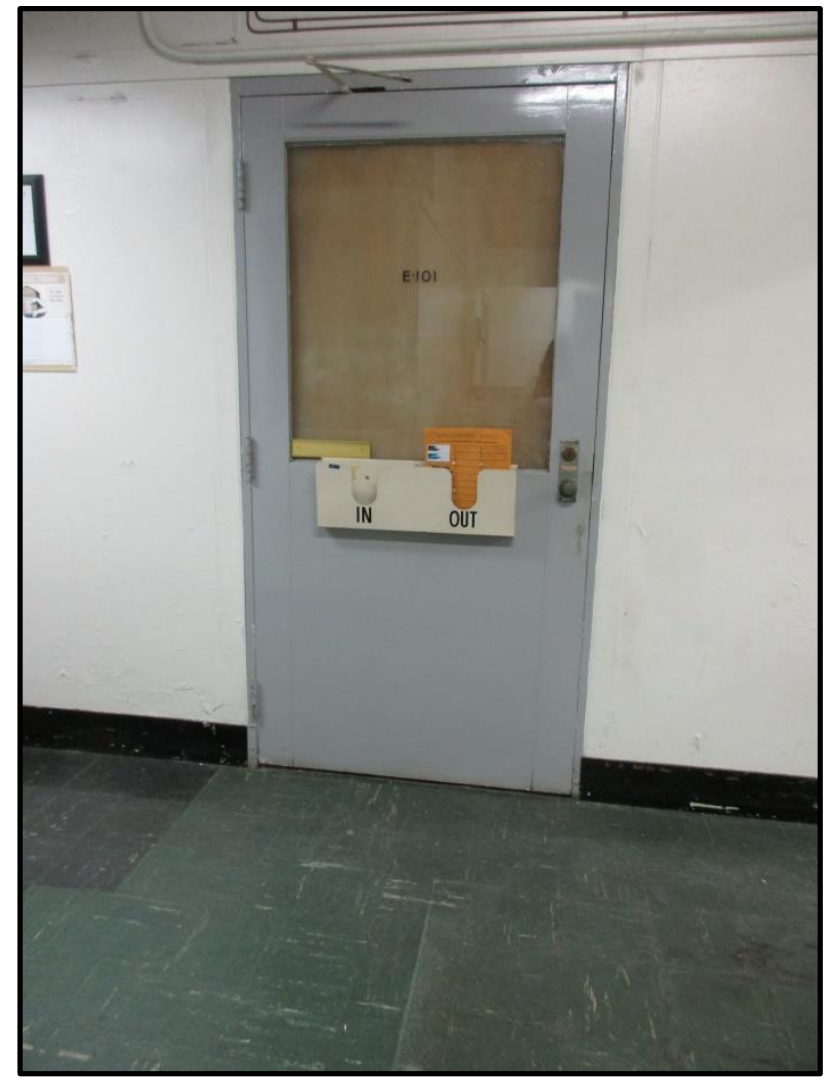

Figure 107. Original interior steel door and floor on the first floor of Building 3025E.

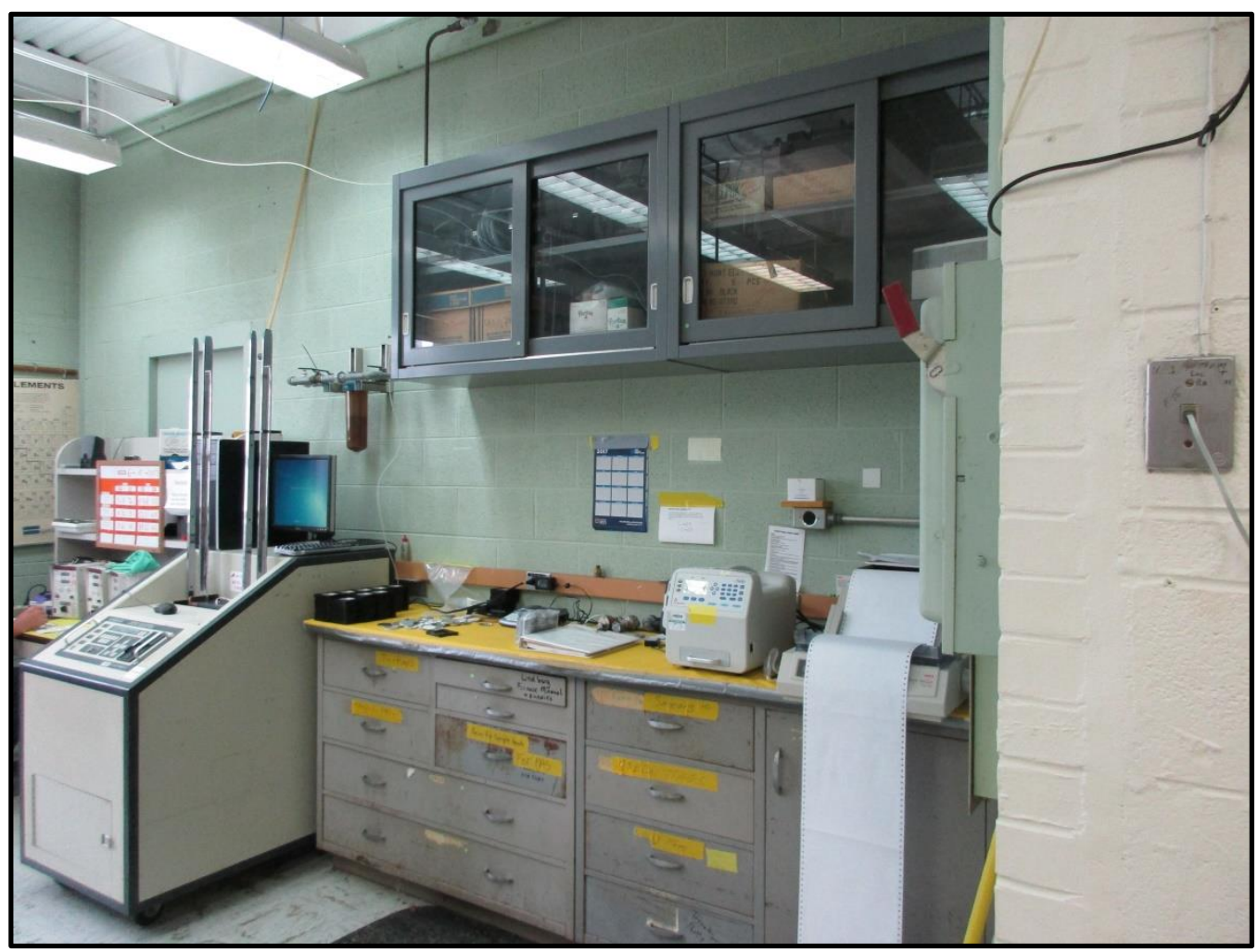

Figure 108. Cabinetry and equipment in a lab on the first floor of Building 3025E. 


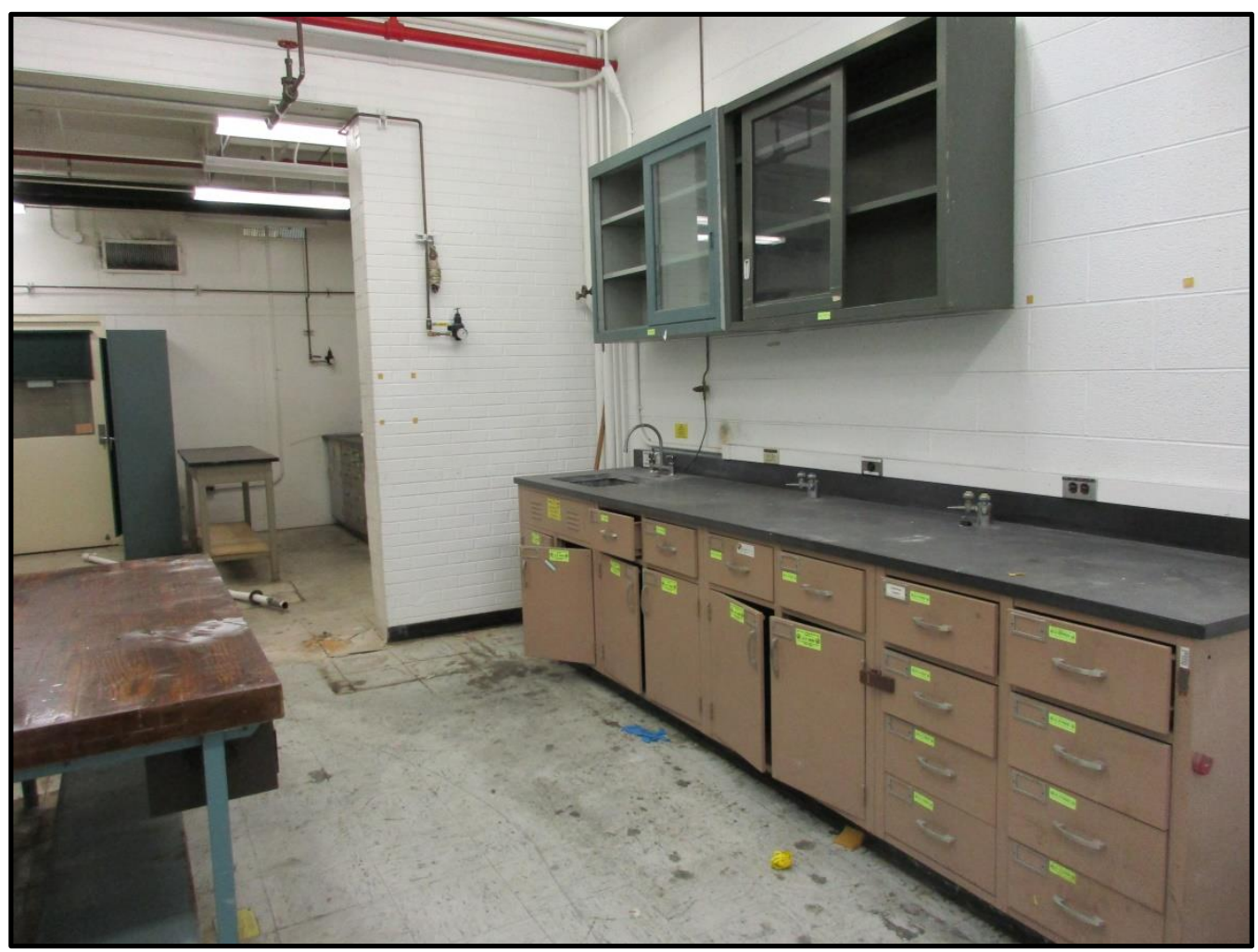

Figure 109. An empty lab space on the first floor of Building 3025E. 


\section{$3025 \mathrm{M}$}

\section{BUILDING NAME}

Solid State Office \& Laboratory Building

DATE OF CONSTRUCTION

1950

DOE OFFICE RESPONSIBLE

SC

Figure 110. Window located on the south elevation of Building 3025M.

NRHP ELIGIBILITY

Contributing to ORNL Historic District

\section{DESCRIPTION}

This building is located along Hillside Avenue. Building $3025 \mathrm{M}$ is adjoined to Building $3025 \mathrm{E}$ and both are located within the barricaded portion of the 3000 Area. Access to this high-security area of the 3000 Area is restricted; therefore, there are no photographs of the exterior of this building. The adjoining buildings (Buildings $3025 \mathrm{E}$ and $3025 \mathrm{M}$ ) are similar in materials and design. Building $3025 \mathrm{M}$ is a three story building with a brick exterior and supported by a concrete foundation. The brick pattern is a modified six course common bond. A four-story section is located on the western corner of Building $3025 \mathrm{M}$. The south elevation contains an enclosed walkway, that connects Building 3025M to Building 3025E. The building features windows filled with four-light, horizontal metal sashes and concrete sills (Figure 110). The entries of Building $3025 \mathrm{M}$ are filled with single-light doors.

\section{NATIONAL REGISTER EVALUATION}

Building $3025 \mathrm{M}$ was constructed in 1950 and is adjacent to $3025 \mathrm{E}$. It historically housed the Solid State Offices and Laboratories and was part of the outgrowth of the Aircraft Nuclear Propulsion Project. Research into radiation damage studies and related solid-state investigations were performed in the building (Carver and Slater 1994: 111). Building 3025M was previously surveyed in 1994, 2004, and 2015 and recommended as a contributing resource to the ORNL Historic District (Carver and Slater 1994; Thomason and Associates 2004 and 2015). The building retains a majority of its historic materials, as well as its form and massing. As a research/laboratory facility, Building 3025M housed work that furthered ORNL's mission in nuclear science during the Cold War era. However, the building is not the single location most importantly associated with a scientific achievement, scientist, or other event or person of historic significance to merit individual listing in the NRHP under Criterion A or B. Furthermore, the building lacks notable architectural elements that would warrant individual listing in the NRHP under Criterion C. Instead, the significance of Building 3025M is best understood within the broader context of the body of work advanced by researchers in the ORNL Historic District during the Cold War era. As such, Building 3025M does not warrant individual listing in the NRHP under Criterion A, B, or C; however, the building is a contributing resource to the ORNL Historic District. 


\section{$3026 C$}

\section{BUILDING NAME}

Radioisotope Development Laboratory B

\section{DATE OF CONSTRUCTION}

1943

DOE OFFICE RESPONSIBLE

EM (UCOR)

NRHP ELIGIBILITY

Demolished - N/A

\section{DESCRIPTION}

Field survey confirmed Building $3026 \mathrm{C}$ is no longer extant.

\section{NATIONAL REGISTER EVALUATION}

Building 3026C was constructed in 1943 and historically served as laboratory for radioisotope development. The resource was previously surveyed in 1994 and 2004 and recommended as contributing to the ORNL Historic District (Carver and Slater 1994; Thomason and Associates 2004). Prior to its demolition, in 2009 DOE submitted documentation of Building $3026 \mathrm{C}$ to the SHPO, as required by the PA, along with documentation for several other facilities (DOE-ORO 2009). In 2015, the resource was recorded in the process of being demolished (Thomason and Associates 2015). During the current survey, CRA confirmed that the resource is no longer extant and as such, no longer retains its integrity of location, design, setting, materials, workmanship, feeling, and association. Thus, Building $3026 \mathrm{C}$ is not individually eligible for listing in the NRHP under Criterion $\mathrm{A}, \mathrm{B}$, or $\mathrm{C}$, nor is it contributing to the ORNL Historic District. 


\section{D}

\section{BUILDING NAME}

Dismantling \& Examination Hot Cells

\section{DATE OF CONSTRUCTION}

1944

DOE OFFICE RESPONSIBLE

EM (UCOR)

NRHP ELIGIBILITY

Demolished - N/A

\section{DESCRIPTION}

Field survey confirmed Building $3026 \mathrm{D}$ is no longer extant.

\section{NATIONAL REGISTER EVALUATION}

Building 3026D was constructed in 1945 and historically served as a facility containing examination areas and hot cells; the building was affixed to Building 3026C. The resource was previously surveyed in 1994 and 2004 and recommended as contributing to the ORNL Historic District (Carver and Slater 1994; Thomason and Associates 2004). Prior to its demolition, in 2009 DOE submitted documentation of Building 3026D to the SHPO, as required by the PA, along with documentation for several other facilities (DOE-ORO 2009). In 2015, the resource was recorded in the process of being demolished (Thomason and Associates 2015). During the current survey, CRA confirmed that the resource is no longer extant and as such, no longer retains its integrity of location, design, setting, materials, workmanship, feeling, and association. Thus, Building 3026D is not individually eligible for listing in the NRHP under Criterion A, B, or C, nor is it contributing to the ORNL Historic District. 


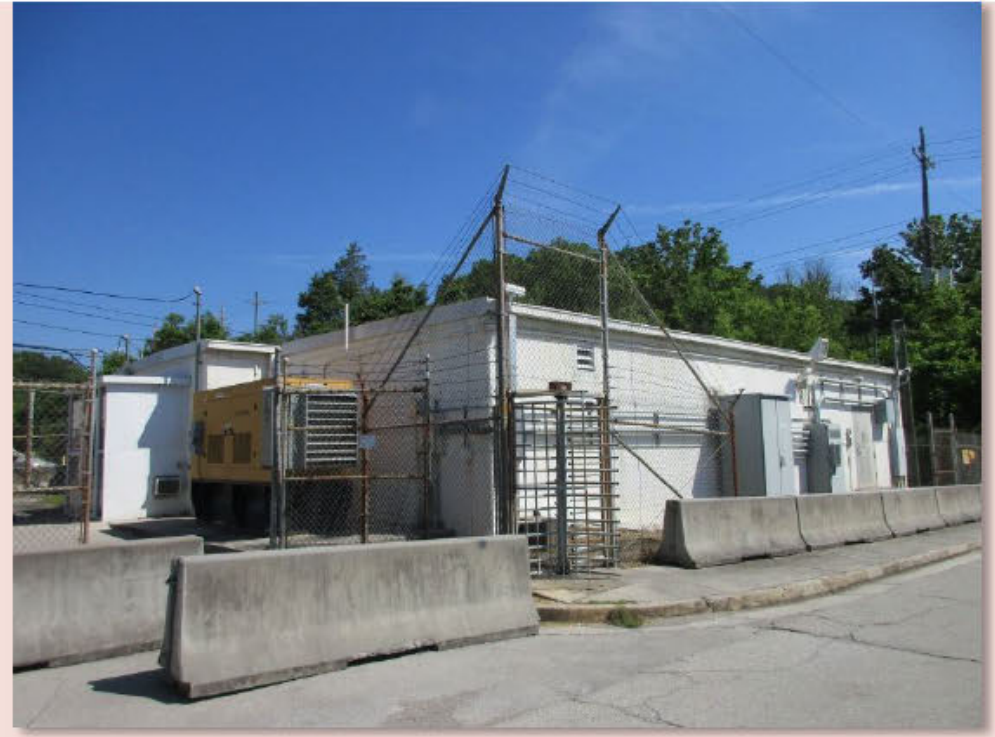

Figure 111. Overview of west and south elevations of Building 3027.

SC

NRHP ELIGIBILITY

Contributing to ORNL Historic District

\section{DESCRIPTION}

Building 3027 is located near the intersection of Hillside Avenue and Fifth Street. Building 3027 is a one-story, flat-roof, concrete structure supported by a concrete foundation (Figures 111 and 112). A flat-roof, steel and glass entrance/vestibule addition is located on the west elevation. No other fenestration is present on the building. A fence encompasses the building.

\section{NATIONAL REGISTER EVALUATION}

Building 3027 was constructed in 1955 as a vault to house nuclear materials; in more recent times it has served as a dispatch center. The building was previously surveyed in 1994, 2004, and 2015 and recommended as a contributing resource to the ORNL Historic District (Carver and Slater 1994; Thomason and Associates 2004 and 2015). The building retains a majority of its historic materials, as well as its form and massing. As a storage facility, Building 3027 supported work that furthered ORNL's mission in nuclear science during the Cold War era. However, the building is not the single location most importantly associated with a scientific achievement, scientist, or other event or person of historic significance to merit individual listing in the NRHP under Criterion A or B. Furthermore, the building lacks notable architectural elements that would warrant individual listing in the NRHP under Criterion C. Instead, the significance of Building 3027 is best understood as a support resource necessary to the functioning of research and processing facilities in the ORNL Historic District during the Cold War era. As such, Building 3027 does not warrant individual listing in the NRHP under Criterion A, B, or C; however, the building is a contributing resource to the ORNL Historic District. 


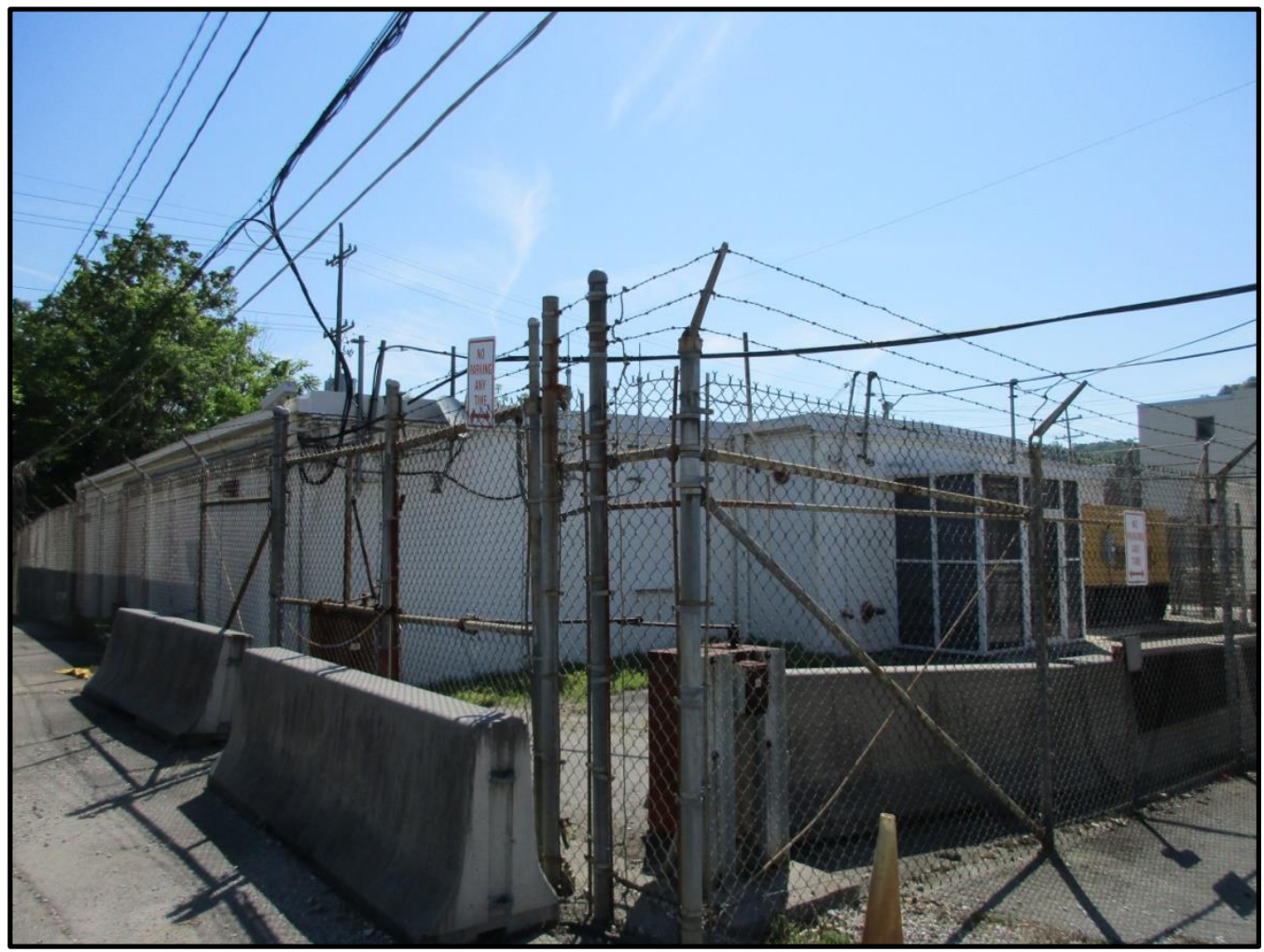

Figure 112.Overview of north and west elevations of Building 3027. 


\section{BUILDING NAME}

Radioisotope Production Laboratory - A

DATE OF CONSTRUCTION

1951

\section{DOE OFFICE RESPONSIBLE}

EM (UCOR)

\section{NRHP ELIGIBILITY}

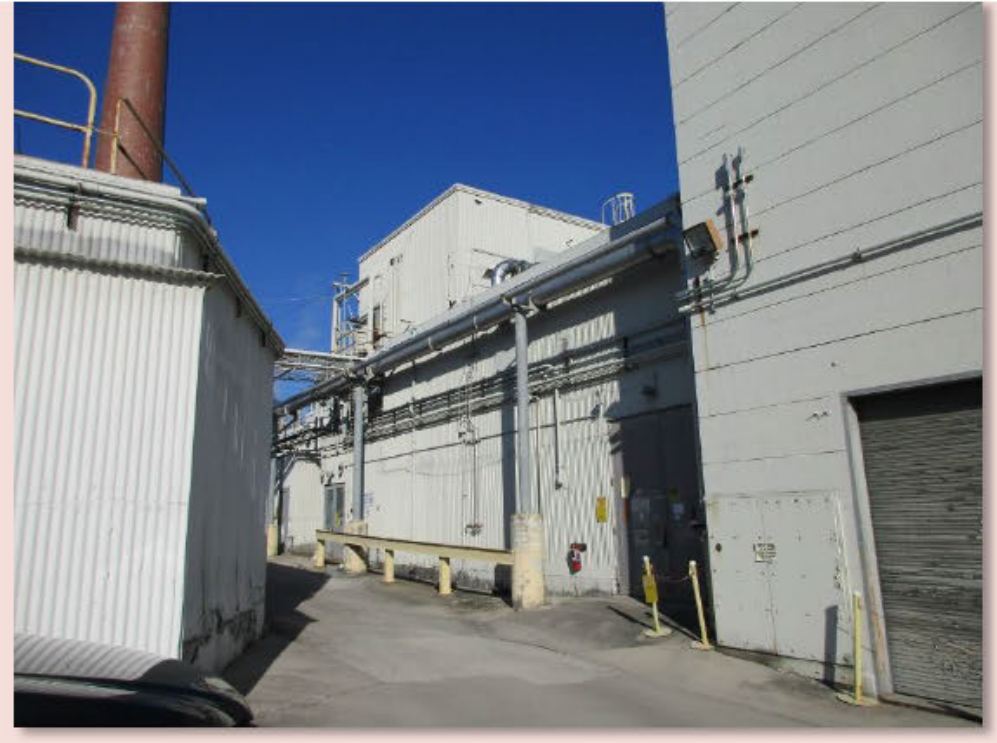

Contributing to ORNL Historic District

Figure 113. Overview of south elevation of Building 3028.

\section{DESCRIPTION}

Building 3028 is located south of Hillside Avenue. The architectural resource is a multi-story, flat-roof, steel frame structure situated on a concrete foundation (Figures 113 and 114). Metal coping extends along the roof's edge. The exterior of Building 3028 is clad with corrugated metal siding. Single and double-leaf entries are filled with single-light and solid metal doors. The building contains no visible window openings.

\section{NATIONAL REGISTER EVALUATION}

Building 3028 was constructed in 1951 and is one of ten buildings that comprise the Isotope Complex, known as Isotope Circle, that were constructed for the processing of isotopes. Following World War II, efforts were refocused to the development and production of radioisotopes. Radioisotopes are utilized for biological, medical, and industrial research, including cancer research. The construction of the Isotope Complex illustrates ORNL's transition from wartime production to a national laboratory largely focused on the peaceful applications of nuclear science (Thomason 2015: 257). Building 3028 was previously surveyed in 1994, 2004, and 2015 and recommended as a contributing resource to the ORNL Historic District (Carver and Slater 1994; Thomason and Associates 2004 and 2015). The building retains a majority of its historic materials, as well as its form and massing. As a research/laboratory facility, Building 3028 housed work that furthered ORNL's mission in nuclear science during the Cold War era. However, the building is not the single location most importantly associated with a scientific achievement, scientist, or other event or person of historic significance to merit individual listing in the NRHP under Criterion A or B. Furthermore, the building lacks notable architectural elements that would warrant individual listing in the NRHP under Criterion C. Instead, the significance of Building 3028 is best understood within the broader context of the body of work advanced by researchers in the ORNL Historic District during the Cold War era. As such, Building 3028 does not warrant individual listing in the NRHP under Criterion $\mathrm{A}, \mathrm{B}$, or $\mathrm{C}$; however, the building is a contributing resource to the ORNL Historic District. 


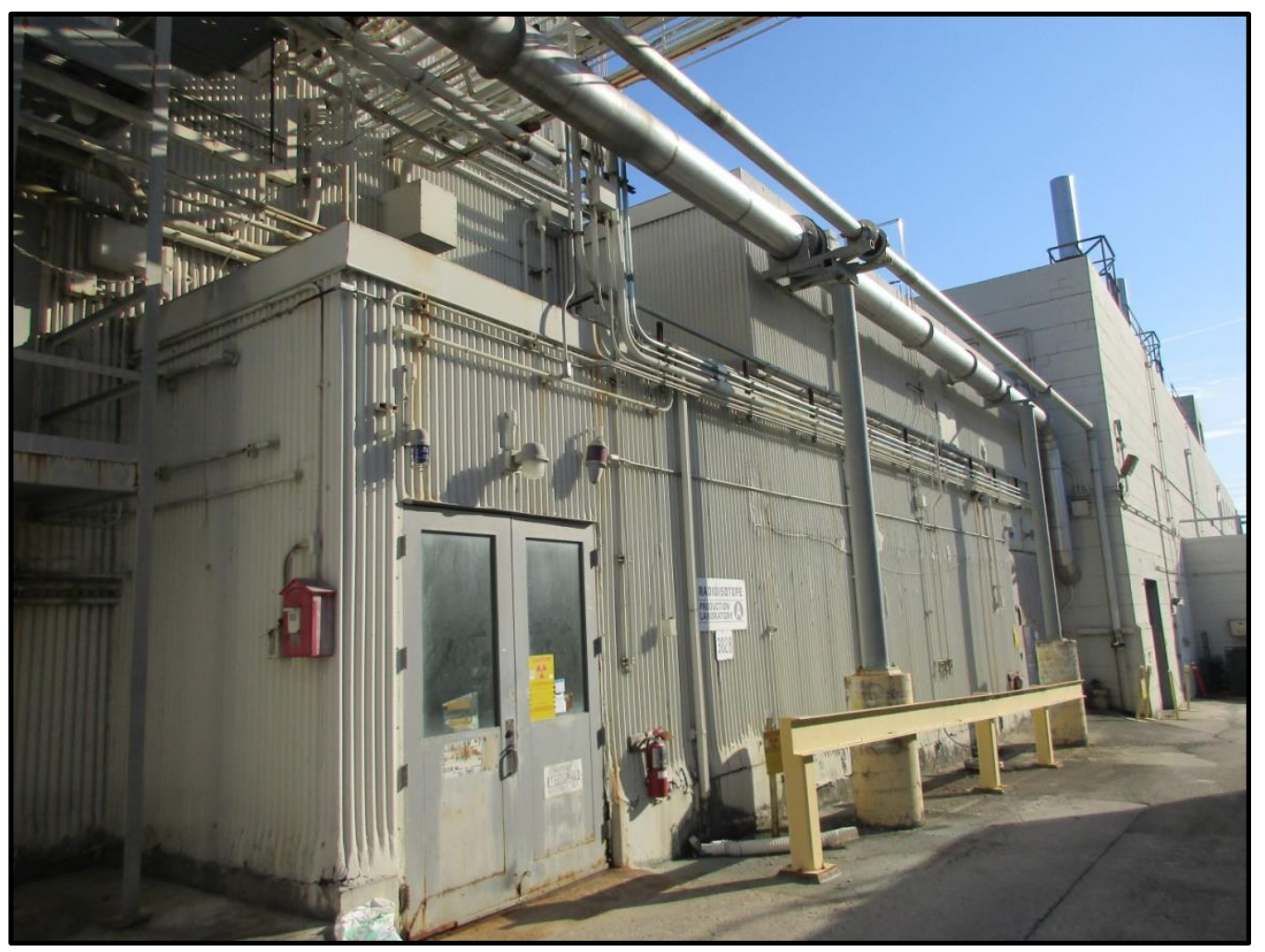

Figure 114. Overview of south elevation and partial west elevation of Building 3028. 


\section{9}

\section{BUILDING NAME}

Radioisotope Production Laboratory - B

DATE OF CONSTRUCTION

1951

\section{DOE OFFICE RESPONSIBLE}

EM (UCOR)

NRHP ELIGIBILITY

Figure 115. Overview of west elevation and partial south elevation of Building 3029 .

Contributing to ORNL Historic District

\section{DESCRIPTION}

Building 3029 is located south of Hillside Avenue. The architectural resource is a multi-story, steel-frame, flatroof structure and is supported by a concrete foundation (Figures 115 and 116). Metal coping extends along the roof's edge. The exterior of Building 3029 is clad in corrugated metal siding. An exterior stair leads to a portion of the first floor's roof where a metal railing encloses the roof.

\section{NATIONAL REGISTER EVALUATION}

Building 3029 was constructed in 1951 and is one of ten buildings that comprise the Isotope Complex, known as Isotope Circle, that were constructed for the processing of isotopes. Following World War II, efforts were refocused to the development and production of radioisotopes. Radioisotopes are utilized for biological, medical, and industrial research, including cancer research. The construction of the Isotope Complex illustrates ORNL's transition from wartime production to a national laboratory largely focused on the peaceful applications of nuclear science (Thomason 2015: 258). Building 3029 was previously surveyed in 1994, 2004, and 2015 and recommended as a contributing resource to the ORNL Historic District (Carver and Slater 1994; Thomason and Associates 2004 and 2015). The building retains a majority of its historic materials, as well as its form and massing. As a research/laboratory facility, Building 3029 housed work that furthered ORNL's mission in nuclear science during the Cold War era. However, the building is not the single location most importantly associated with a scientific achievement, scientist, or other event or person of historic significance to merit individual listing in the NRHP under Criterion A or B. Furthermore, the building lacks notable architectural elements that would warrant individual listing in the NRHP under Criterion C. Instead, the significance of Building 3029 is best understood within the broader context of the body of work advanced by researchers in the ORNL Historic District during the Cold War era. As such, Building 3029 does not warrant individual listing in the NRHP under Criterion $\mathrm{A}, \mathrm{B}$, or $\mathrm{C}$; however, the building is a contributing resource to the ORNL Historic District. 


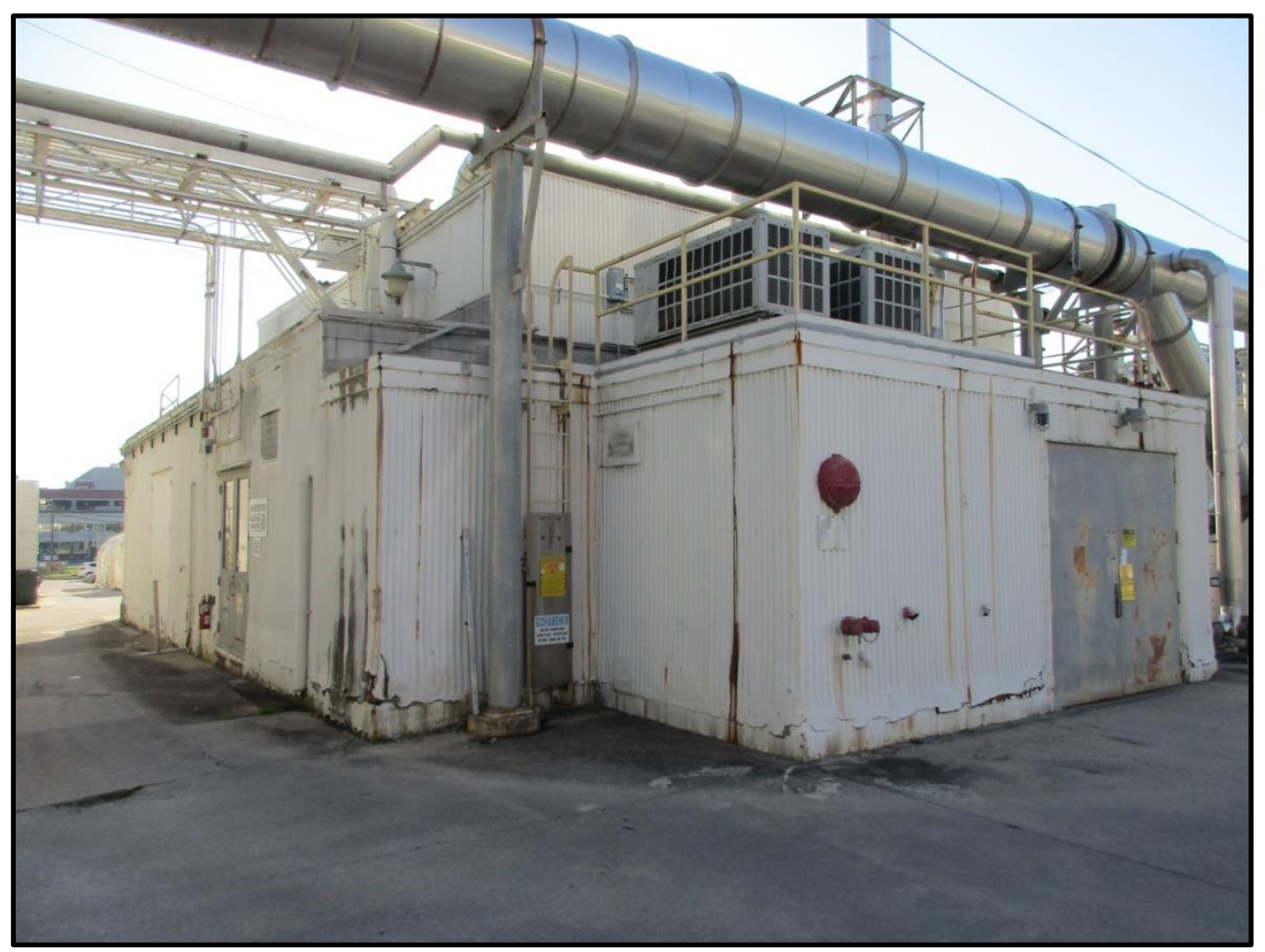

Figure 116. Overview of north and west elevations of Building 3029. 


\section{0}

\section{BUILDING NAME}

Radioisotope Production Laboratory - C

DATE OF CONSTRUCTION

1951

\section{DOE OFFICE RESPONSIBLE}

EM (UCOR)

\section{NRHP ELIGIBILITY}

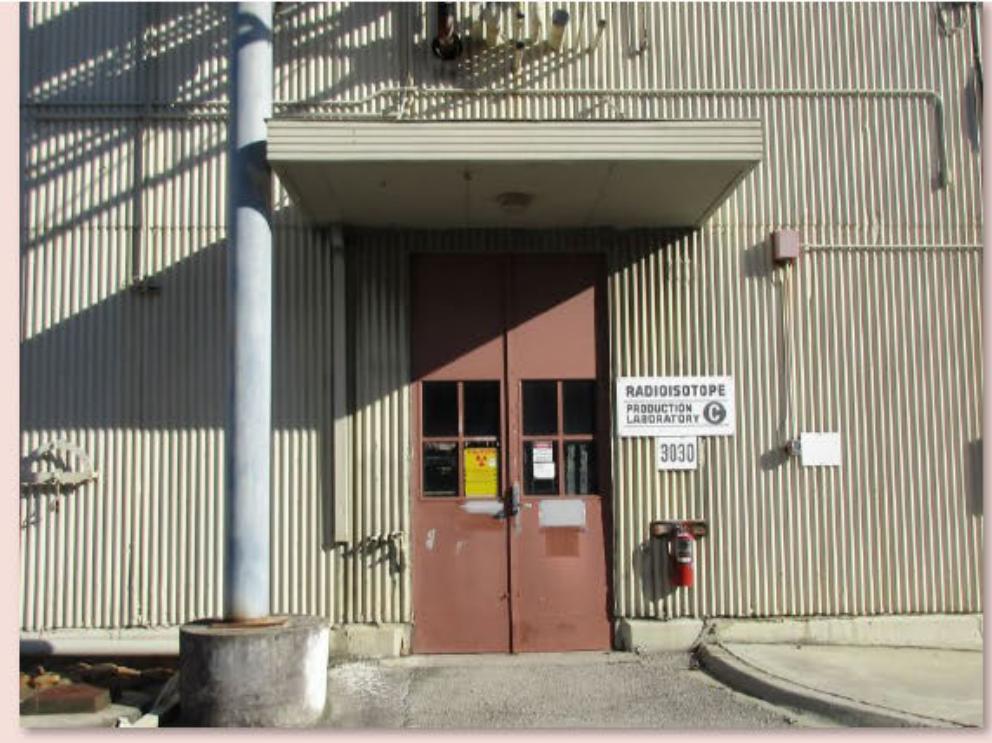

Contributing to ORNL Historic District

\section{DESCRIPTION}

Building 3030 is situated between Hillside and Central Avenues, near Fifth Street. Adjacent to Building 3118, Building 3030 is the first of a long row of buildings exhibiting similar materials and construction. The row includes Buildings $3030,3031,3032,3033,3033 \mathrm{~A}, 3034,3036$, and 3118 . Building 3030 is a one-story, flatroof, steel structure supported by a concrete foundation (Figures 117 and 118). The building's exterior is clad with corrugated metal siding. A double-leaf entry filled by a pair of four-light metal doors and covered by a flat metal awning is found on the facade (south) elevation. A single-leaf entry filled with a four-light metal door is located on the rear (north) elevation.

\section{NATIONAL REGISTER EVALUATION}

Building 3030 was constructed in 1951 and is one of ten buildings that comprise the Isotope Complex, known as Isotope Circle, that were constructed for the processing of isotopes. Following World War II, efforts were refocused to the development and production of radioisotopes. Radioisotopes are utilized for biological, medical, and industrial research, including cancer research. The construction of the Isotope Complex illustrates ORNL's transition from wartime production to a national laboratory largely focused on the peaceful applications of nuclear science (Thomason 2015: 261). Building 3030 was previously surveyed in 1994, 2004, and 2015 and recommended as a contributing resource to the ORNL Historic District (Carver and Slater 1994; Thomason and Associates 2004 and 2015). The building retains a majority of its historic materials, as well as its form and massing. As a research/laboratory facility, Building 3030 housed work that furthered ORNL's mission in nuclear science during the Cold War era. However, the building is not the single location most importantly associated with a scientific achievement, scientist, or other event or person of historic significance to merit individual listing in the NRHP under Criterion A or B. Furthermore, the building lacks notable architectural elements that would warrant individual listing in the NRHP under Criterion C. Instead, the significance of Building 3030 is best understood within the broader context of the body of work advanced by researchers in the ORNL Historic District during the Cold War era. As such, Building 3030 does not warrant individual listing in the NRHP under Criterion A, B, or C; however, the building is a contributing resource to the ORNL Historic District. 


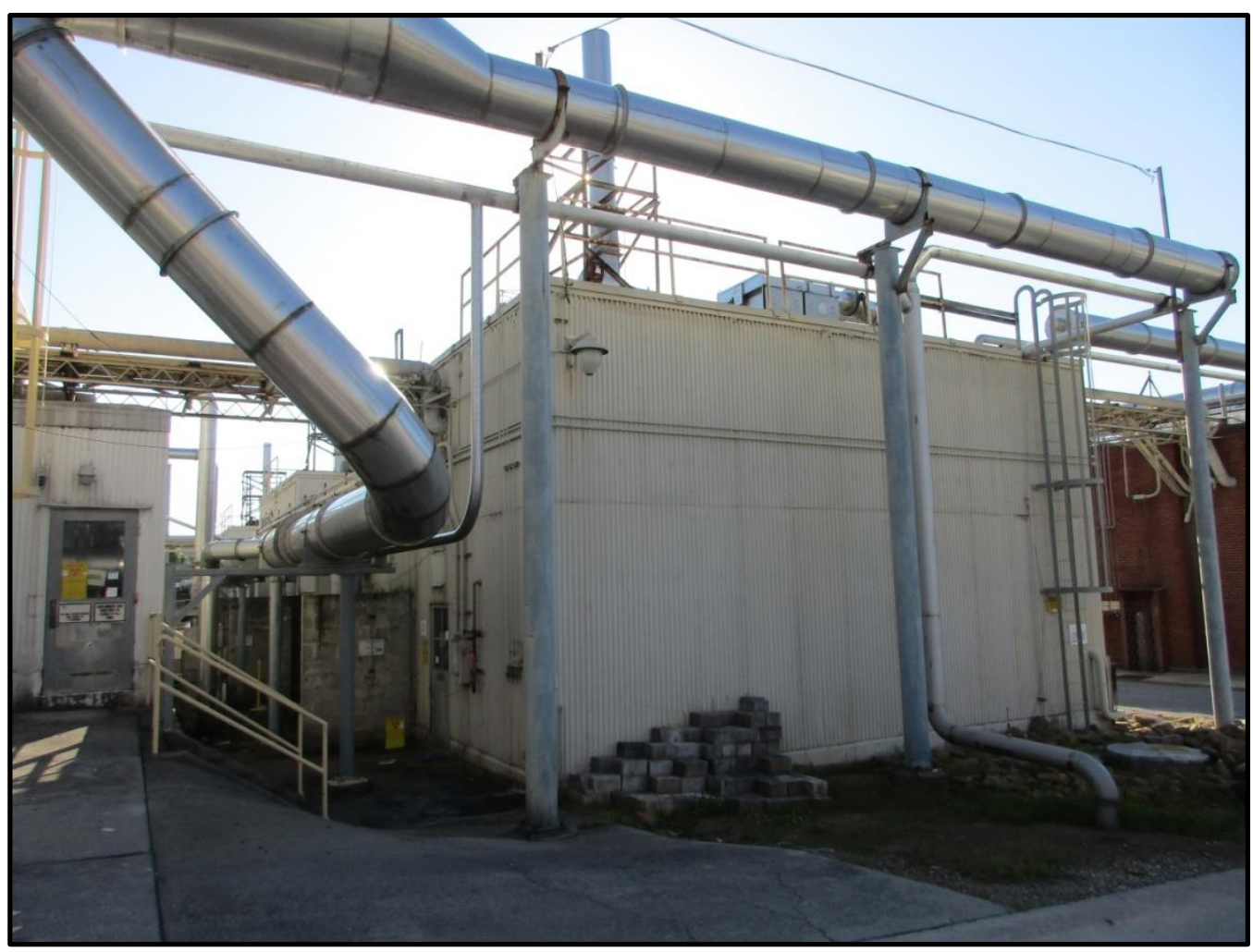

Figure 118. Overview of north and west elevations of Building 3030. 


\section{1}

\section{BUILDING NAME}

Radioisotope Production Laboratory - D

DATE OF CONSTRUCTION

1951

DOE OFFICE RESPONSIBLE

EM (UCOR)

NRHP ELIGIBILITY

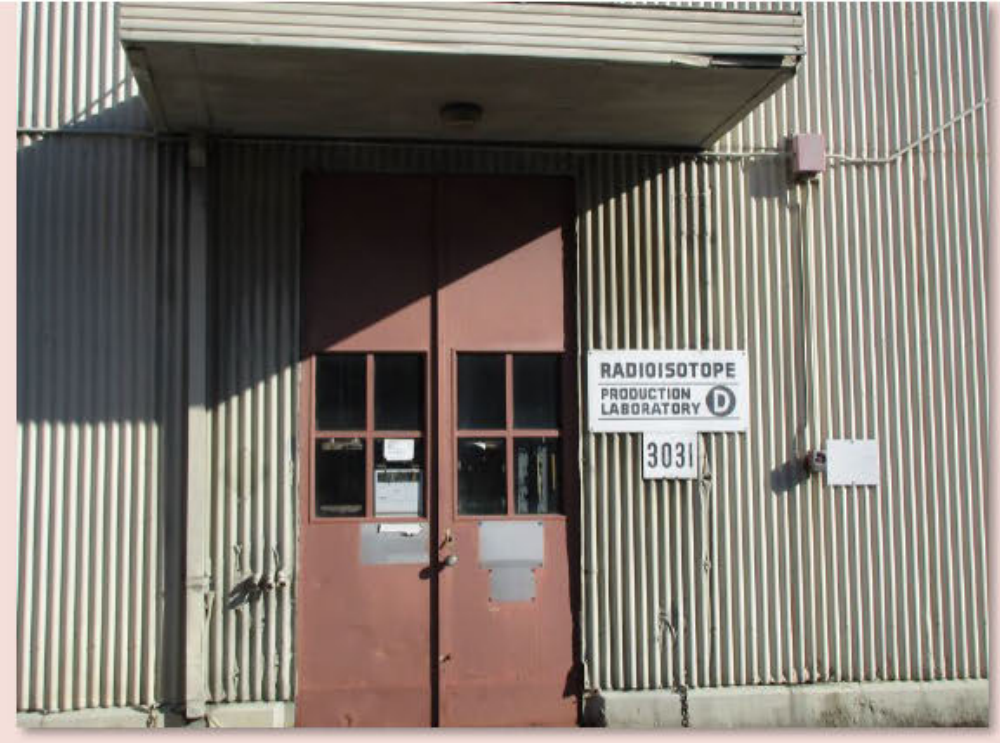

Contributing to ORNL Historic District

Figure 119. Overview of south elevation of Building 3031.

\section{DESCRIPTION}

Building 3031 is situated between Buildings 3030 and 3031 . Building 3031 is a one-story, flat-roof, steel structure resting on a concrete foundation (Figures 119 and 120). The building's roof is encompassed by metal coping. The exterior is clad with corrugated metal siding. The façade (south) elevation of Building 3031 features a double-leaf entry filled with a pair of four-light metal doors sheltered by a flat-roof metal awning.

\section{NATIONAL REGISTER EVALUATION}

Building 3031 was constructed in 1951 and is one of ten buildings that comprise the Isotope Complex, known as Isotope Circle that were constructed for the processing of isotopes. Following World War II, efforts were refocused to the development and production of radioisotopes. Radioisotopes are utilized for biological, medical, and industrial research, including cancer research. The construction of the Isotope Complex illustrates ORNL's transition from wartime production to a national laboratory largely focused on the peaceful applications of nuclear science (Thomason 2015: 263). Building 3031 was previously surveyed in 1994, 2004, and 2015 and recommended as a contributing resource to the ORNL Historic District (Carver and Slater 1994; Thomason and Associates 2004 and 2015). The building retains a majority of its historic materials, as well as its form and massing. As a research/laboratory facility, Building 3031 housed work that furthered ORNL's mission in nuclear science during the Cold War era. However, the building is not the single location most importantly associated with a scientific achievement, scientist, or other event or person of historic significance to merit individual listing in the NRHP under Criterion A or B. Furthermore, the building lacks notable architectural elements that would warrant individual listing in the NRHP under Criterion C. Instead, the significance of Building 3031 is best understood within the broader context of the body of work advanced by researchers in the ORNL Historic District during the Cold War era. As such, Building 3031 does not warrant individual listing in the NRHP under Criterion $\mathrm{A}, \mathrm{B}$, or $\mathrm{C}$; however, the building is a contributing resource to the ORNL Historic District. 


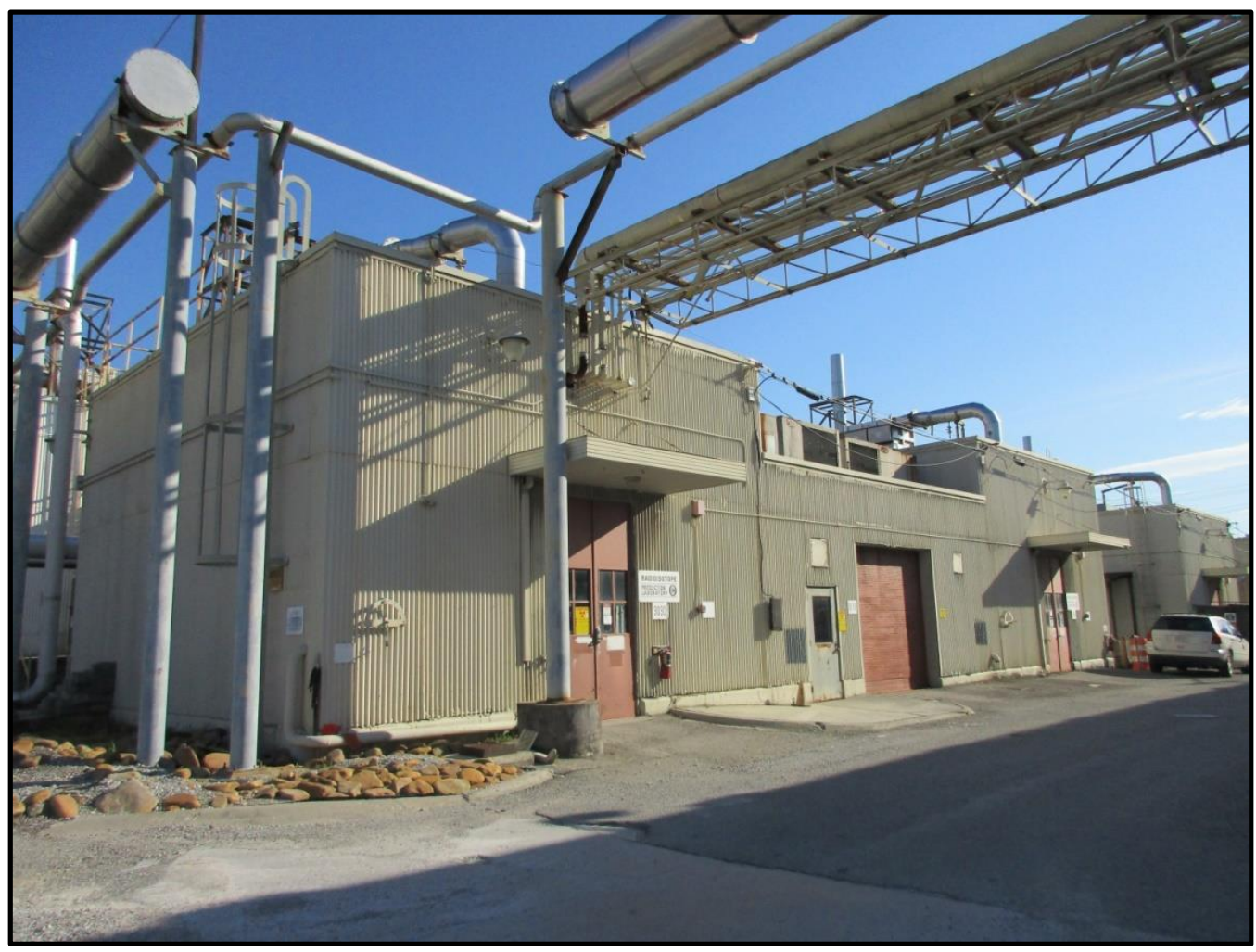

Figure 120. Overview of west and south elevations of Building 3031. 


\section{BUILDING NAME}

Radioisotope Production Laboratory - E

DATE OF CONSTRUCTION

1951

\section{DOE OFFICE RESPONSIBLE}

EM (UCOR)

\section{NRHP ELIGIBILITY}

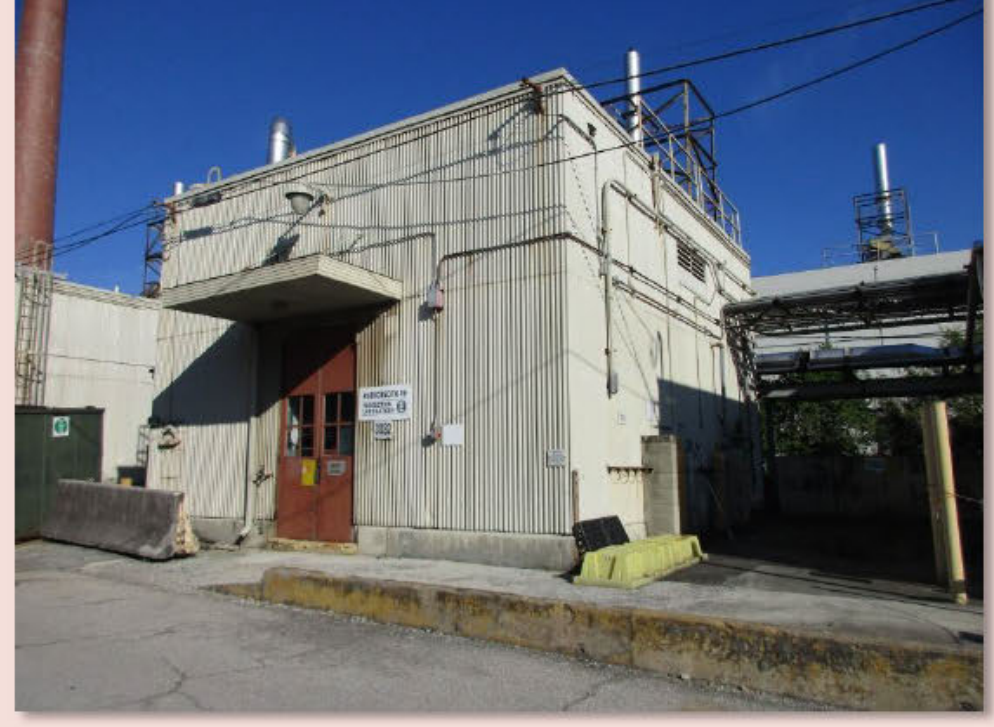

Contributing to ORNL Historic District

\section{DESCRIPTION}

Building 3032 situated between Buildings 3031 and 3033. Oriented to the south, Building 3032 is a one-story, single-bay, flat-roof, metal frame detached structure supported by a concrete foundation (Figures 121 and 122). Metal coping extends along the edge of the roof. The exterior is clad with corrugated metal siding. The building's façade (south) elevation features a central double-leaf entry filled with paired four-light metal doors and sheltered by a flat metal awning.

\section{NATIONAL REGISTER EVALUATION}

Building 3032 was constructed in 1951 and is one of ten buildings that comprise the Isotope Complex, known as Isotope Circle, that were constructed for the processing of isotopes. Following World War II, efforts were refocused to the development and production of radioisotopes. Radioisotopes are utilized for biological, medical, and industrial research, including cancer research. The construction of the Isotope Complex illustrates ORNL's transition from wartime production to a national laboratory largely focused on the peaceful applications of nuclear science (Thomason 2015: 265). Building 3032 was previously surveyed in 1994, 2004, and 2015 and recommended as a contributing resource to the ORNL Historic District (Carver and Slater 1994; Thomason and Associates 2004 and 2015). The building retains a majority of its historic materials, as well as its form and massing. As a research/laboratory facility, Building 3032 housed work that furthered ORNL's mission in nuclear science during the Cold War era. However, the building is not the single location most importantly associated with a scientific achievement, scientist, or other event or person of historic significance to merit individual listing in the NRHP under Criterion A or B. Furthermore, the building lacks notable architectural elements that would warrant individual listing in the NRHP under Criterion C. Instead, the significance of Building 3032 is best understood within the broader context of the body of work advanced by researchers in the ORNL Historic District during the Cold War era. As such, Building 3032 does not warrant individual listing in the NRHP under Criterion A, B, or C; however, the building is a contributing resource to the ORNL Historic District. 


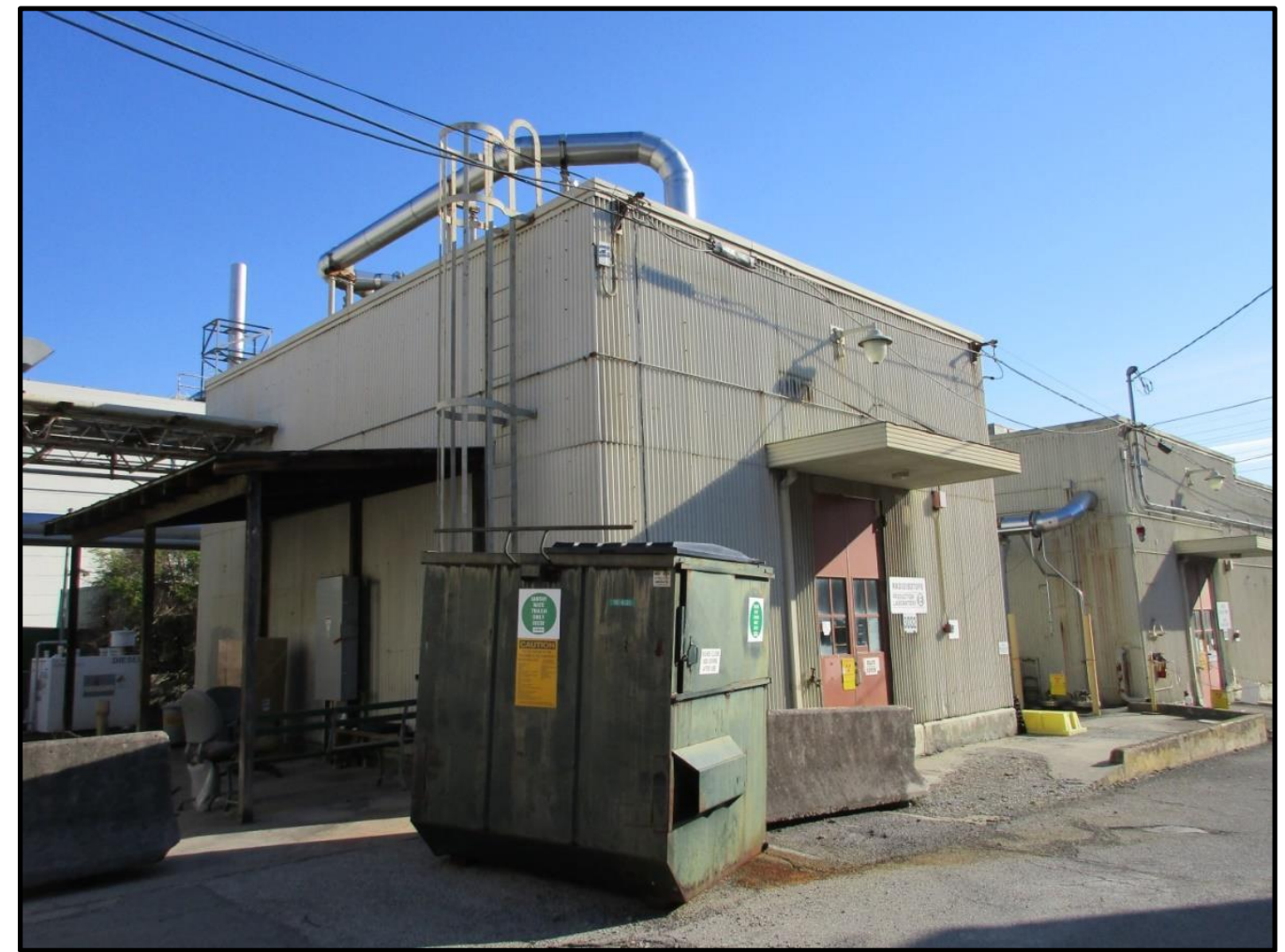

Figure 122. Overview of west and south elevations of Building 3032. 


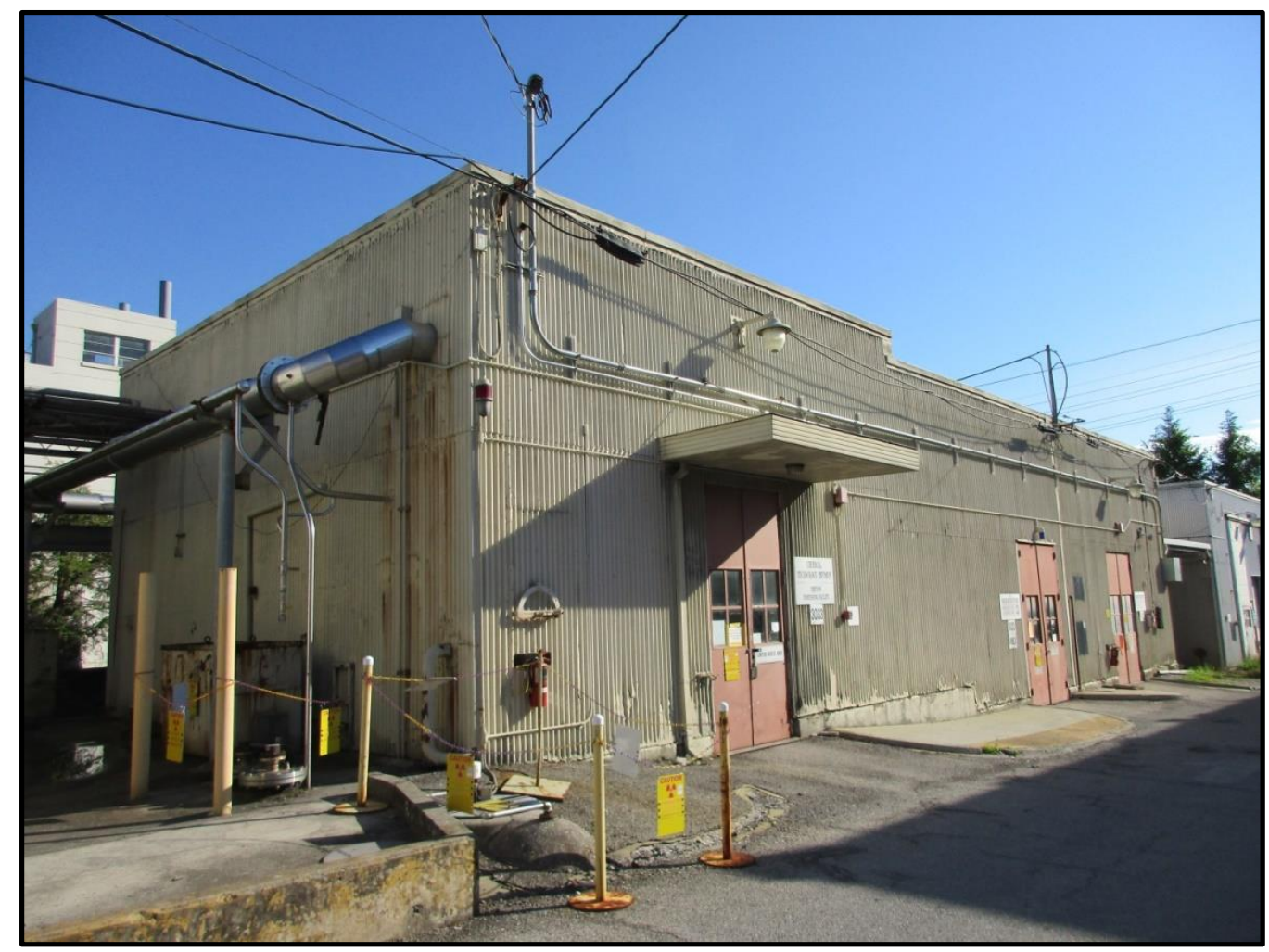

Figure 124. Overview of west and south elevations of Building 3033. 
in the NRHP under Criterion $A, B$, or $C$; however, the building is a contributing resource to the ORNL Historic District.

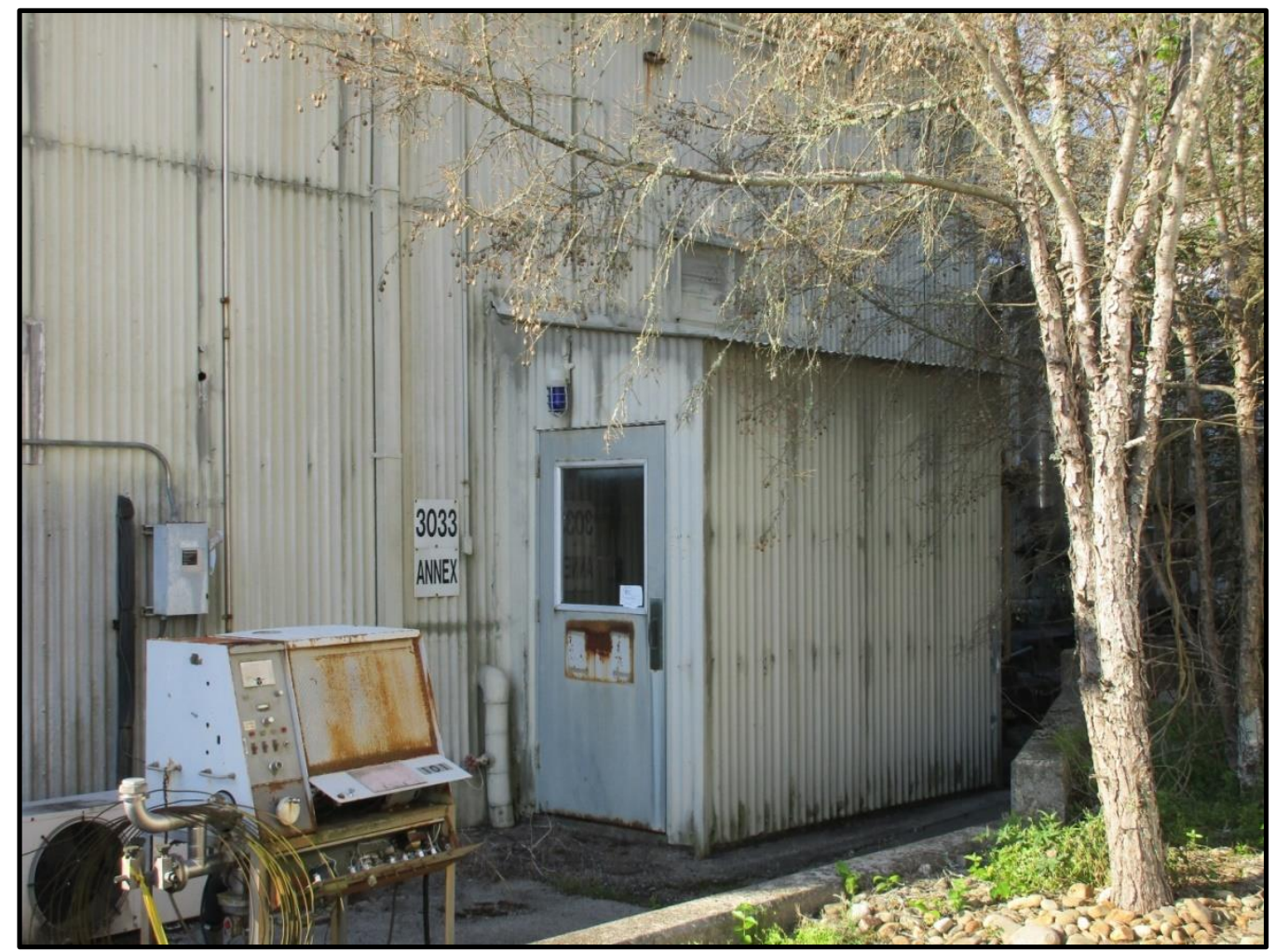

Figure 126. Overview of north elevation of Building 3033A. 
3034

\section{BUILDING NAME}

Radioisotope Area Services

DATE OF CONSTRUCTION

1951

DOE OFFICE RESPONSIBLE

SC

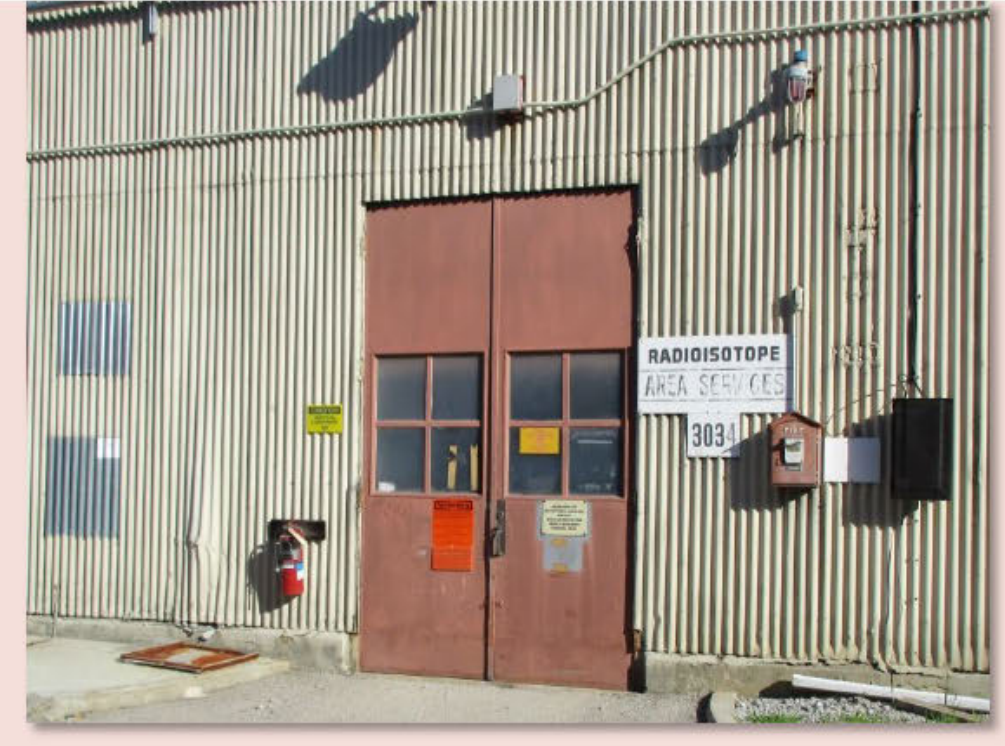

NRHP ELIGIBILITY

Figure 127. Overview of south elevation of Building 3034.

Contributing to ORNL Historic District

\section{DESCRIPTION}

Building 3034 is adjacent to Building $3033 \mathrm{~A}$ and is attached to Building 3036 by an overhang. Oriented to the south, Building 3034 is a one-story, single-bay, flat-roof structure clad in corrugated metal panels and supported by a concrete foundation (Figures 127 and 128). Metal coping extends along the roof's edge. The façade (south) elevation features a double-leaf entry filled with a pair of four-light metal pedestrian doors. The rear (north) elevation has a single-leaf entry filled with a four-light metal pedestrian door.

\section{NATIONAL REGISTER EVALUATION}

Building 3034 was constructed in 1951 and is one of the buildings that comprise the Isotope Complex. Building 3034 historically functioned as a field shop for the Plant and Equipment Division and supported isotope production; however, no isotopes were ever produced in the building. It currently functions as the central electrical distribution station for the Isotope Complex area (Thomason and Associates 2015: 269). Building 3034 was previously surveyed in 1994, 2004, and 2015 and recommended as a contributing resource to the ORNL Historic District (Carver and Slater 1994; Thomason and Associates 2004 and 2015). The building retains a majority of its historic materials, as well as its form and massing. As a utility/maintenance facility, Building 3034 provided utilitarian support services for work that furthered ORNL's mission in nuclear science during the Cold War era. However, the building is not the single location most importantly associated with a scientific achievement, scientist, or other event or person of historic significance to merit individual listing in the NRHP under Criterion A or B. Furthermore, the building lacks notable architectural elements that would warrant individual listing in the NRHP under Criterion C. Instead, the significance of Building 3034 is best understood as an integral support resource necessary to the functioning of research and processing facilities in the ORNL Historic District during the Cold War era. As such, Building 3034 does not warrant individual listing in the NRHP under Criterion A, B, or C; however, the building is a contributing resource to the ORNL Historic District. 


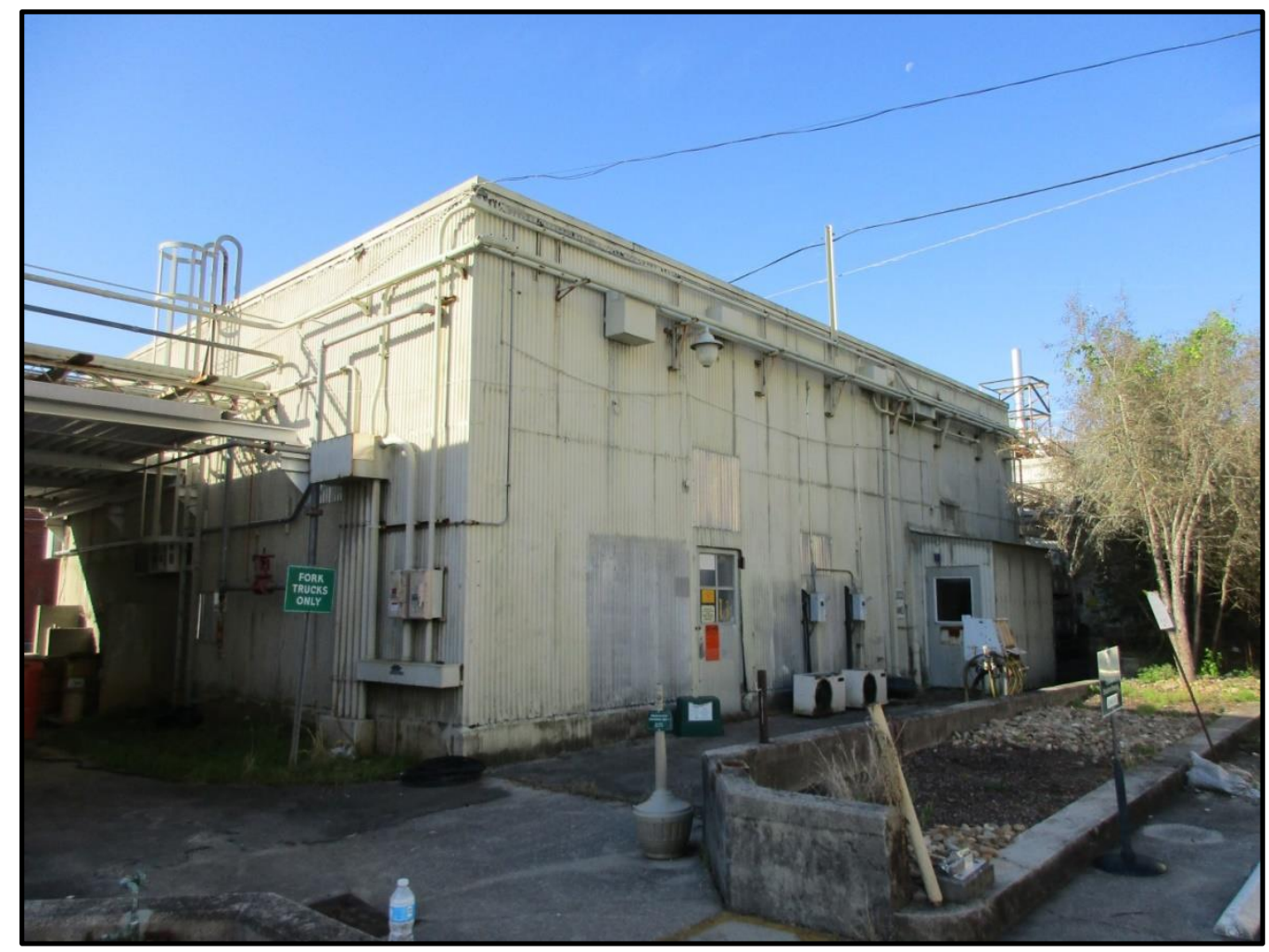

Figure 128. Overview of north and west elevations of Building 3034. 


\section{BUILDING NAME}

Isotope Area Storage \& Services Building

DATE OF CONSTRUCTION

1951

\section{DOE OFFICE RESPONSIBLE}

SC

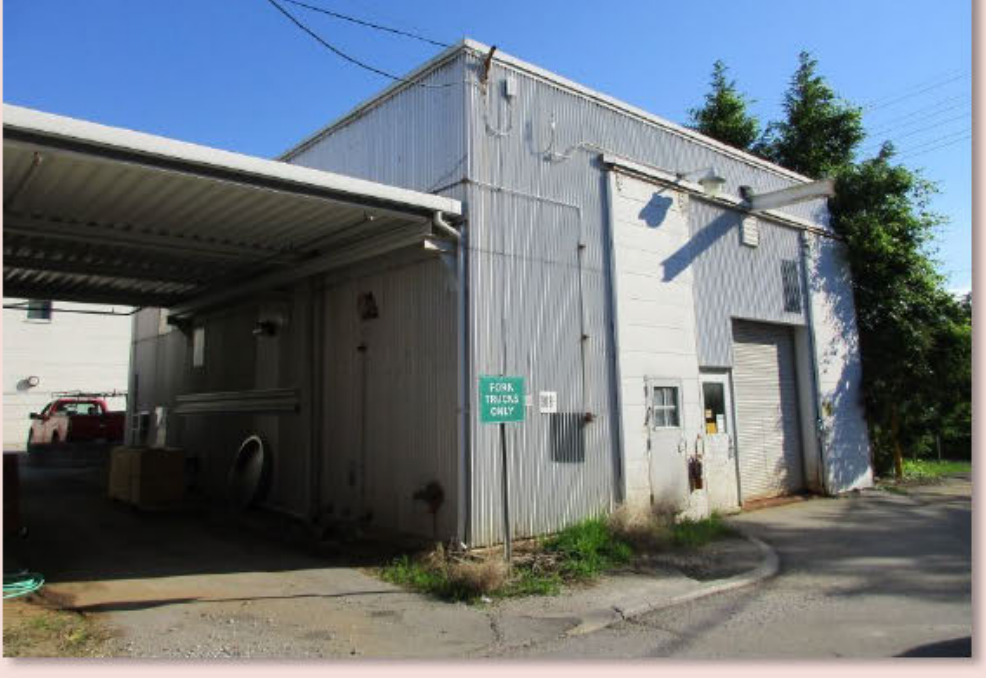

NRHP ELIGIBILITY

Figure 129. Overview of west and south elevations of Building 3036.

Contributing to ORNL Historic District

\section{DESCRIPTION}

Building 3036 is attached to Building 3034 to the west by a metal overhang between the buildings. The building, oriented to the south, is a one-story, three-bay, flat-roof, metal frame structure clad in corrugated metal siding and resting on a concrete foundation (Figures 129 and 130). Metal coping extends along the roof's edge. The façade (south) elevation features three entries including: a large metal sliding door on a metal track with a fourlight pedestrian door set in of the horizontal sliding door; a single-leaf entry filled with a single-light pedestrian door; and a vehicular entry filled with a metal overhead garage door. A small window filled with vinyl or metal six-over-six, double-hung sashes is located on the west elevation near the rear (north) elevation. A single-leaf pedestrian entry filled with a solid metal door is located on the rear (north) elevation.

\section{NATIONAL REGISTER EVALUATION}

Building 3036 was constructed in 1951 as a storage and service facility in the Isotope Complex. The building was previously surveyed in 1994, 2004, and 2015 and recommended as a contributing resource to the ORNL Historic District (Carver and Slater 1994; Thomason and Associates 2004 and 2015). The building retains a majority of its historic materials, as well as its form and massing. As a storage facility, Building 3036 supported work that furthered ORNL's mission in nuclear science during the Cold War era. However, the building is not the single location most importantly associated with a scientific achievement, scientist, or other event or person of historic significance to merit individual listing in the NRHP under Criterion A or B. Furthermore, the building lacks notable architectural elements that would warrant individual listing in the NRHP under Criterion C. Instead, the significance of Building 3036 is best understood as a support resource necessary to the functioning of research and processing facilities in the ORNL Historic District during the Cold War era. As such, Building 3036 does not warrant individual listing in the NRHP under Criterion A, B, or C; however, the building is a contributing resource to the ORNL Historic District. 


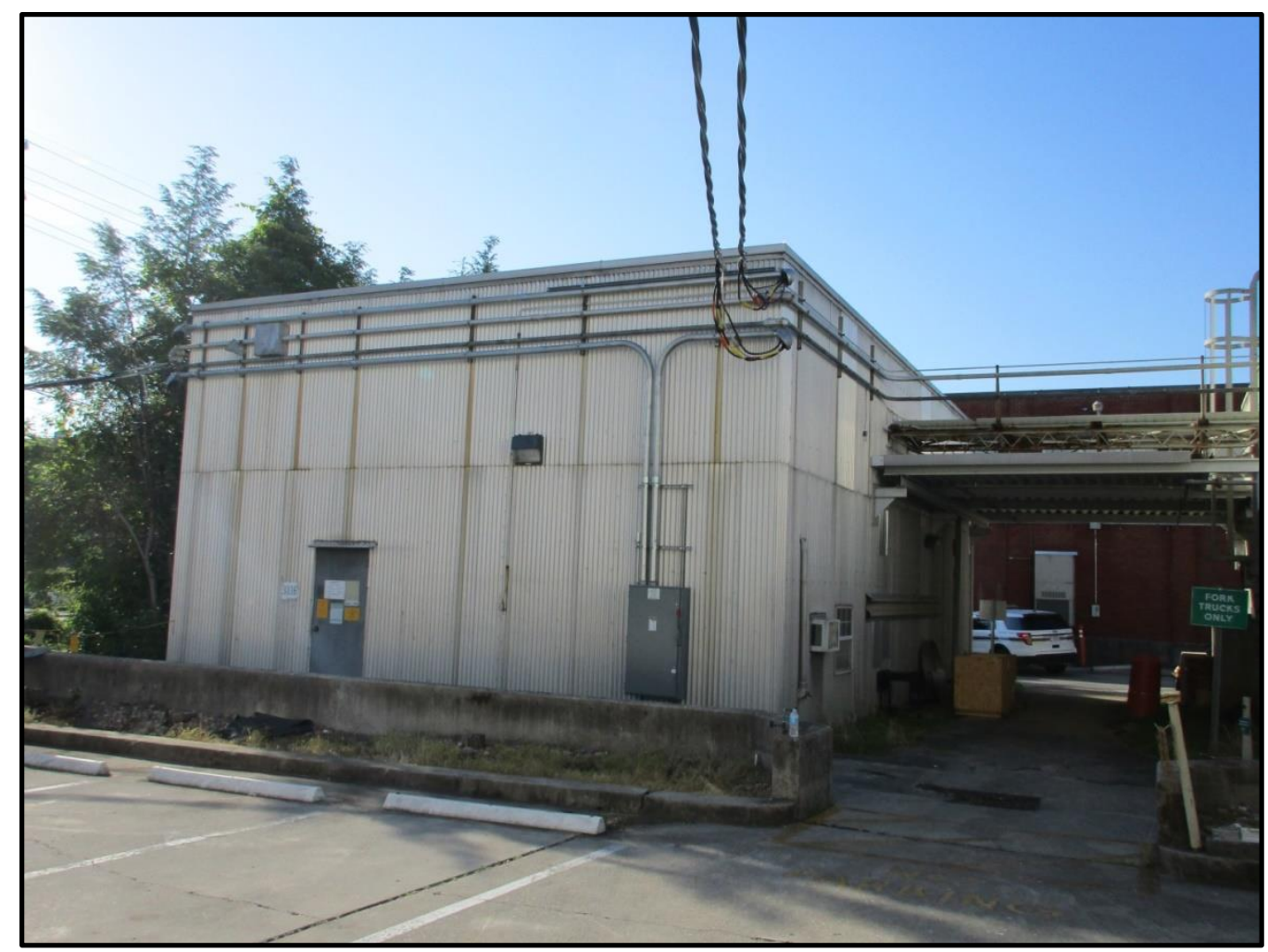

Figure 130. Overview of north and west elevations of Building 3036. 


\section{BUILDING NAME}

Operations Division Office,

Chemical Technical Offices

\section{DATE OF CONSTRUCTION}

1951

\section{DOE OFFICE RESPONSIBLE}

SC

Figure 131. East and north elevations of Building 3037.

\section{NRHP ELIGIBILITY}

Contributing to ORNL Historic District

\section{DESCRIPTION}

Building 3037 was one of 15 resources selected for intensive survey by UT-B as a part of survey planning. It is located within Isotope Circle near the intersection of Central Avenue and Fifth Street on the main campus of ORNL.

Exterior: Building 3037 is a two-story masonry building that features running bond brick veneer with brick pilasters that create distinctive bays on all four elevations of the building (Figures 131 and 132). The rectangular building features a flat roof with concrete coping and is situated on a continuous poured concrete foundation. All elevations are treated similarly without a clearly-differentiated façade, although the primary entrance is located on the east elevation. Windows throughout the building feature one-over-one-light, double-hung vinyl replacement sashes with concrete sills (Figure 133). The building currently features no windows on the first floor; small window openings on the first floor of the south elevation have been enclosed or retrofitted with metal louvered vents. The north, west, and south elevations feature banks of three windows, set within the bays created by brick pilasters. The east elevation features single windows; the northernmost bay on this elevation has been enclosed with brick. Except for two original doors on the west elevation, exterior doors throughout Building 3037 have been replaced with circa 2010 single-leaf, single-light steel doors. An exterior entry on the north elevation is sheltered by a flat-roof metal awning, similar to those found on Building 3038 (Figure 134). Awnings shelter the primary entry on the first floor of the east elevation and the exterior structural steel staircase to the second floor of the west elevation.

Interior: The interior of Building 3037 features a simple plan with a central hallway on each floor. The first floor hallway features original 9-in square commercial grade tile, glazed concrete block walls, and original interior solid steel doors with louvered vents; it provides access to offices, a renovated gym and breakroom, and original change rooms (Figures 135 and 136). The change rooms feature many original details, including original benches, showers, and sections of original lockers (Figures 137, 138, and 139). An interior staircase with original tile and steel treads, a curving original stainless steel handrail, and an original modern light fixture, provides access to the second floor (Figure 140). The second floor features a central hallway with original 9-in tile and original single-light and solid steel doors with louvered vents (Figure 141). The second floor hallway 
provides access to a renovated classroom/briefing room with walls clad in acoustic tile, renovated offices, and a renovated change room (Figures 142, 143, and 144).

\section{NATIONAL REGISTER EVALUATION}

Located within what became known as Isotope Circle, Building 3037 was originally constructed as the Radioisotope Area Office Building. According to previous surveys, Building 3037 is one of ten buildings constructed at ORNL in 1951 to house the Isotope Program during the Program H building expansion. The Isotope Program developed as Clinton Laboratories (now known as ORNL) sought to find a new purpose as a permanent facility, following the end of World War II. The production of radioisotopes emerged as one of ORNL's most significant contributions to the field of science. This radioisotope production was "the most publicized activity at Clinton Labs [ORNL] in the post war years" (Johnson and Schaffer 1992:37; Carver and Slater 1994; Thomason 2015).

Produced in reactors, isotopes are extracted by chemical processes in order to be used for biological, medical, and industrial research. Radioisotopes used for cancer research were produced in the Graphite Reactor (in Building 3001), as early as 1946. In 1947 the Isotopes Section was formed and by 1950 ORNL was distributing over 50 radioisotopes all over the world. Cobalt-60, used in cancer research, was most widely-distributed among the isotopes produced at ORNL. By the late 1940s, production of radioisotopes and the success of other programs led to the stability and permanency of ORNL. Union Carbide, manager of ORNL, began the Program $\mathrm{H}$ expansion to provide permanent buildings to replace temporary structures erected during war-time efforts. The development and construction of a $\$ 2$ million complex of ten buildings and an exhaust stack (Building 3039) "designed to process, package, and ship the Laboratory's most valuable material exports" as a radioisotope complex was a major component of the Program H expansion (Johnson and Schaffer 1992:60). Through this expansion, the Isotope Program became one of the most successful and influential projects at ORNL, gaining the facility international attention and respect. The Isotope Division was disbanded and reassigned to other sections in 1957. It was reorganized and isotope programs were assigned to the Chemical Technology Division in the 1980s (Carver and Slater 1994; Thomason 2015).

Building 3037 was recommended as a contributing resource of the ORNL Historic District in 1994, 2004, and 2015 under Criterion A for its association with the research and production of isotopes. As an office building that supported the work of the Isotope Program in associated laboratories and reactors, Building 3037 does not possess specific individual associations with significant events or people in history to merit individual listing in the NRHP under Criterion A or B. Additionally, it does not possess significant associations for its architectural or engineering design that would warrant individual listing under Criterion $C$. Thus, CRA recommends that it is not eligible for individual listing under Criterion A, B, or C. Rather, the significance of Building 3037 is reflected in its role within the larger group of buildings that comprise Isotope Circle, an important component of the post-World War II mission of ORNL and as part of a collection of purpose-designed scientific processing and research facilities engineered to meet the specific needs of the advanced research occurring within their walls. Despite minor interior alterations and exterior changes including the replacement of windows and doors, Building 3037 retains integrity to support its inclusion within the ORNL Historic District. Therefore, CRA concurs with Thomason's 2015 recommendation that Building 3037 is a contributing resource of the ORNL Historic District under Criterion A for its association with the post-World War II development of government-sponsored scientific 
laboratories, ORNL's evolution as a national laboratory, and early nuclear development and under Criterion C as a purpose-designed scientific research facility within the district.

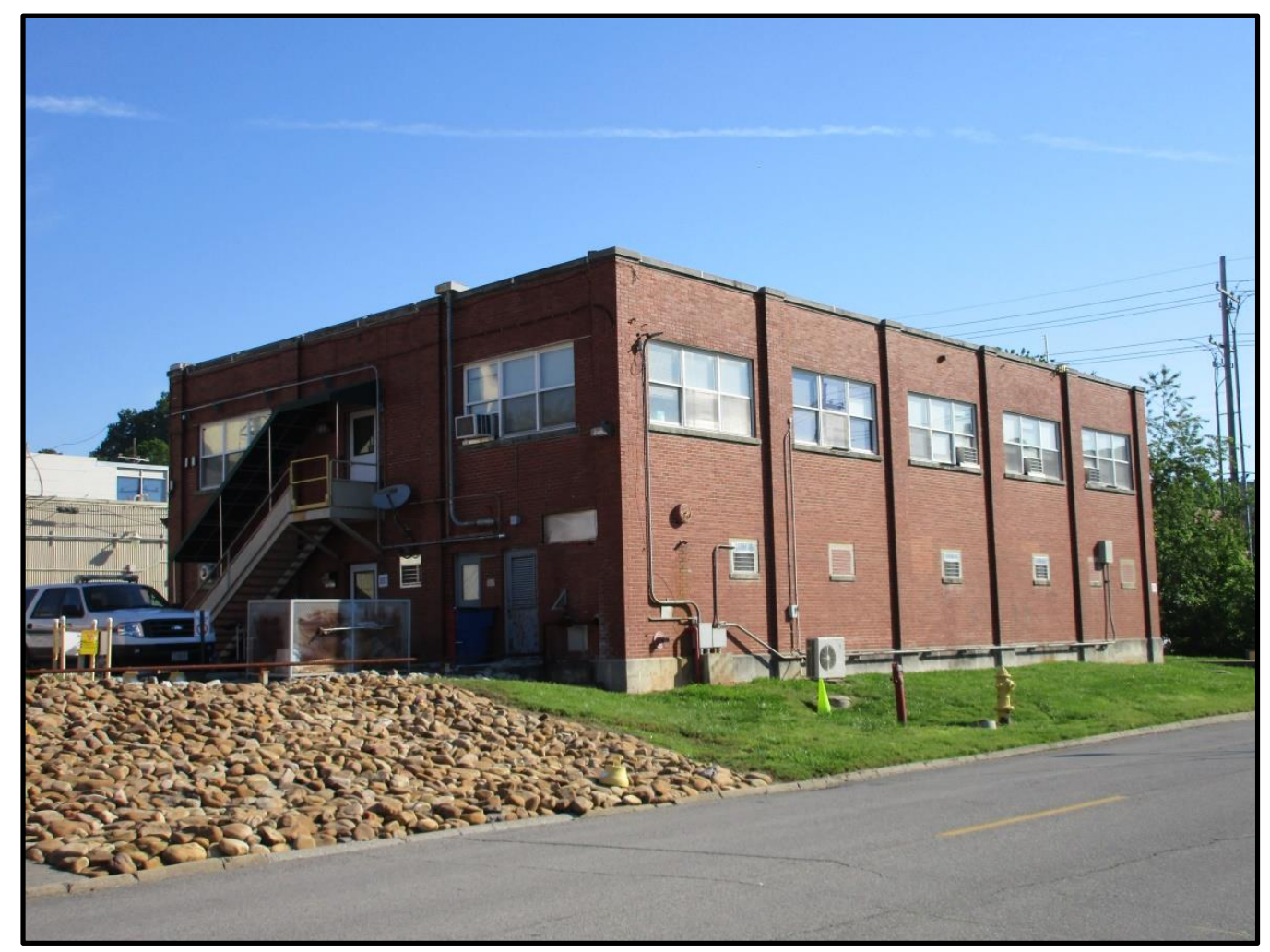

Figure 132. West and south elevations of Building 3037. 


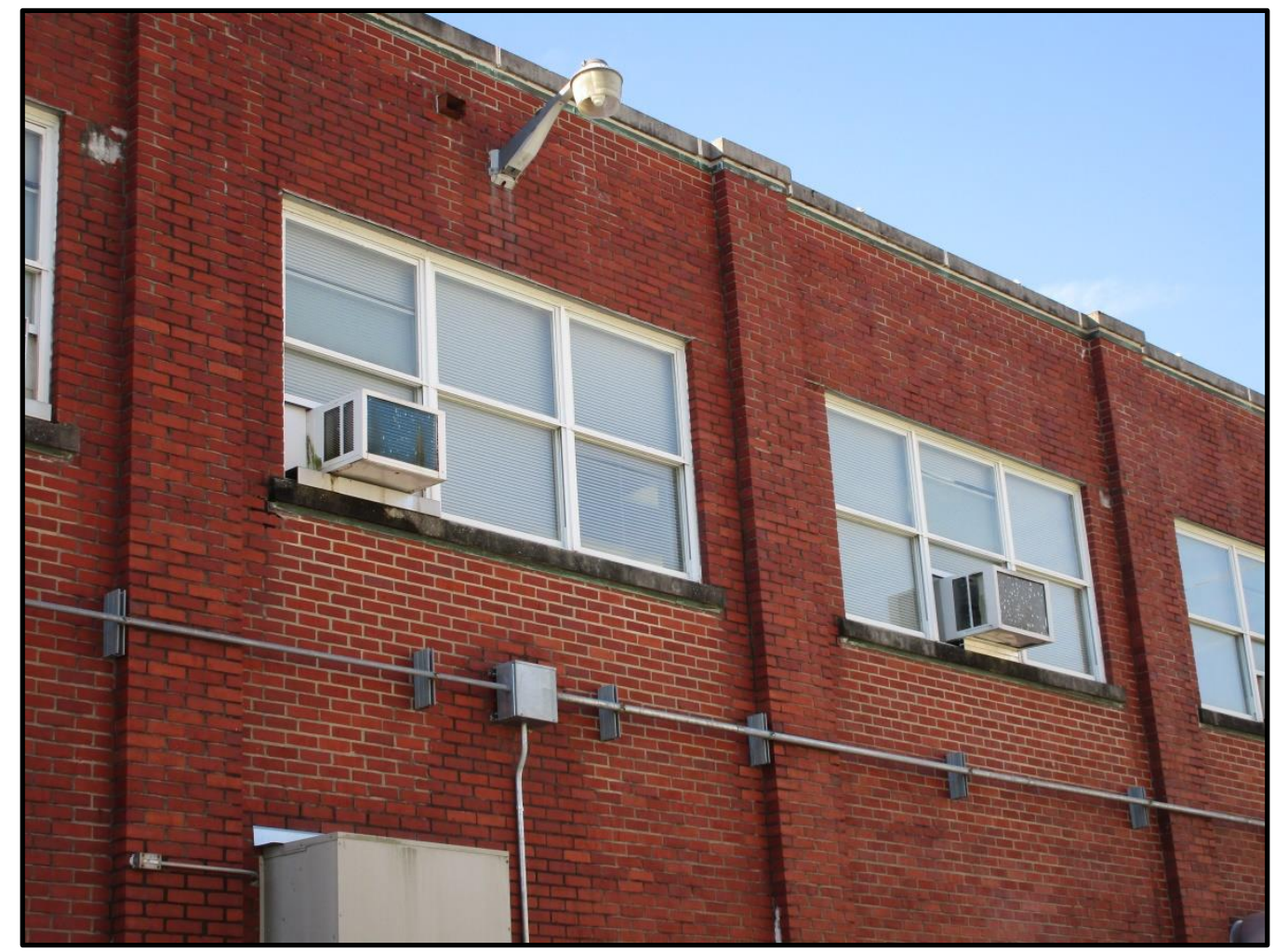

Figure 133. Detail of windows on second story of Building 3037.

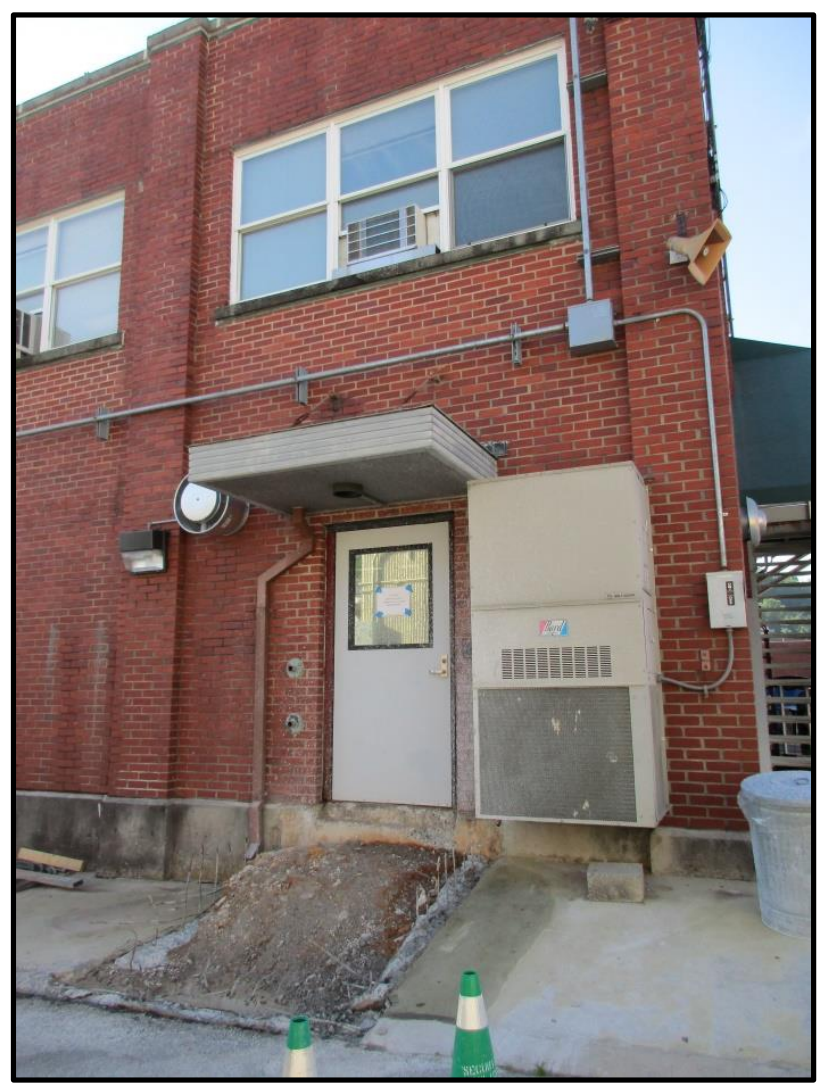

Figure 134. Door and window detail on north elevation of Building 3037. 


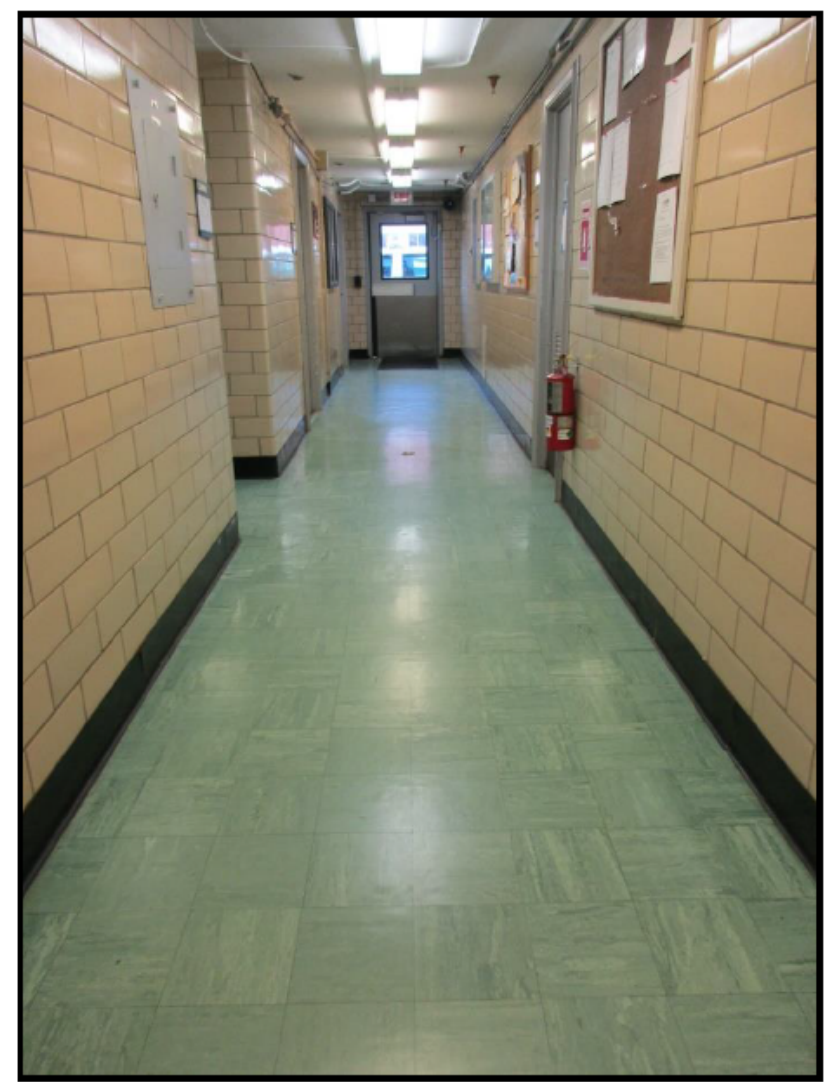

Figure 135. Hallway on first floor of Building 3037.

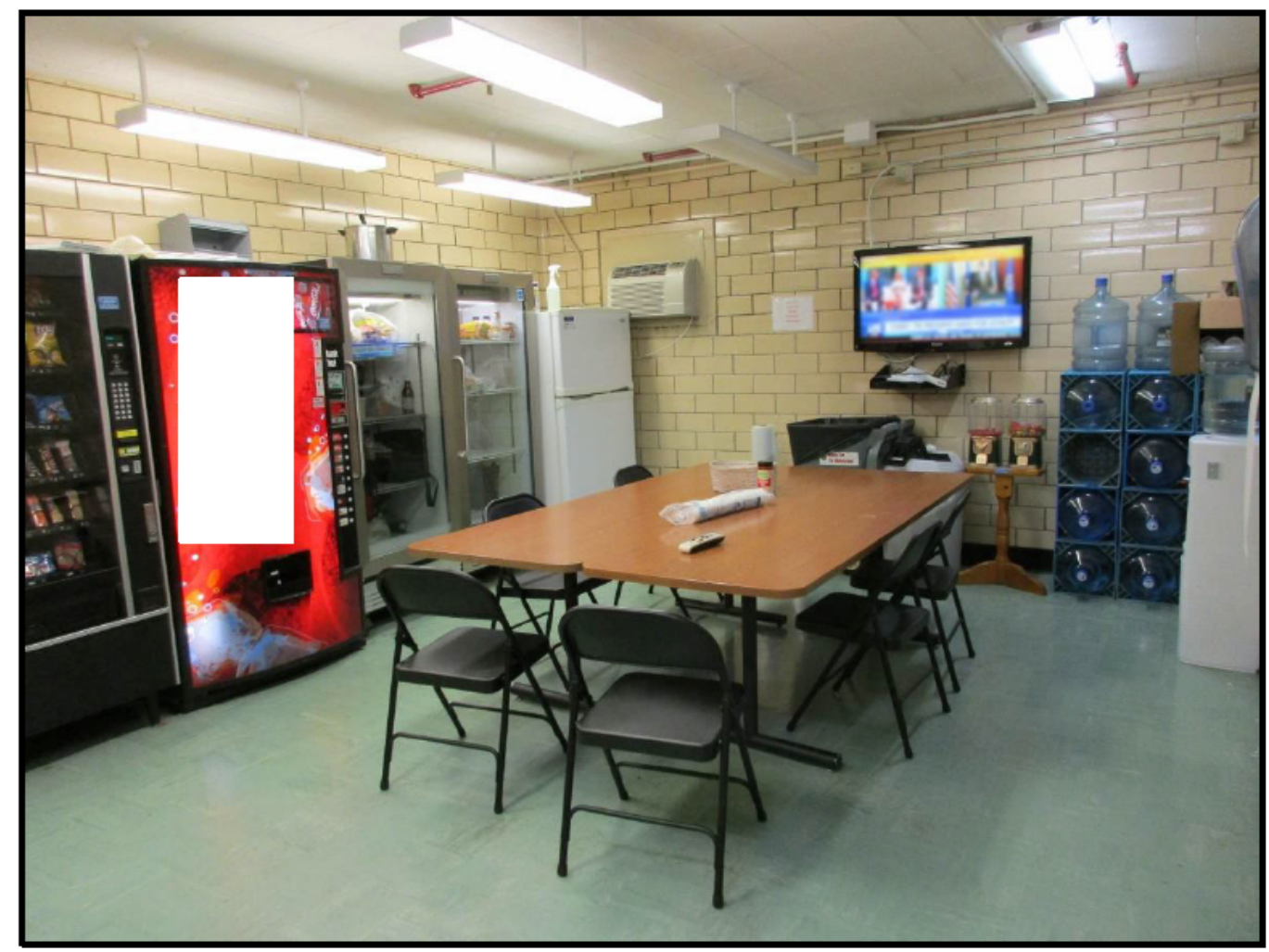

Figure 136. Renovated break room on first floor of Building 3037. 


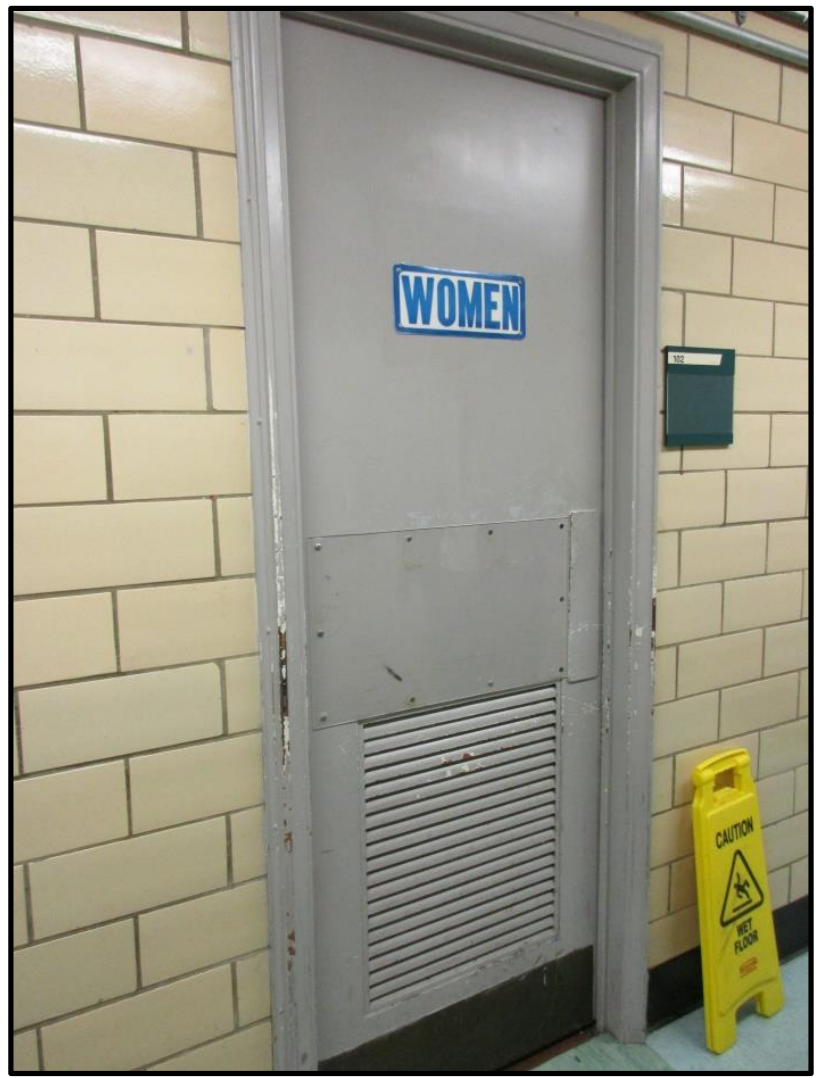

Figure 137. Original door on Women's Change Room on first floor of Building 3037.

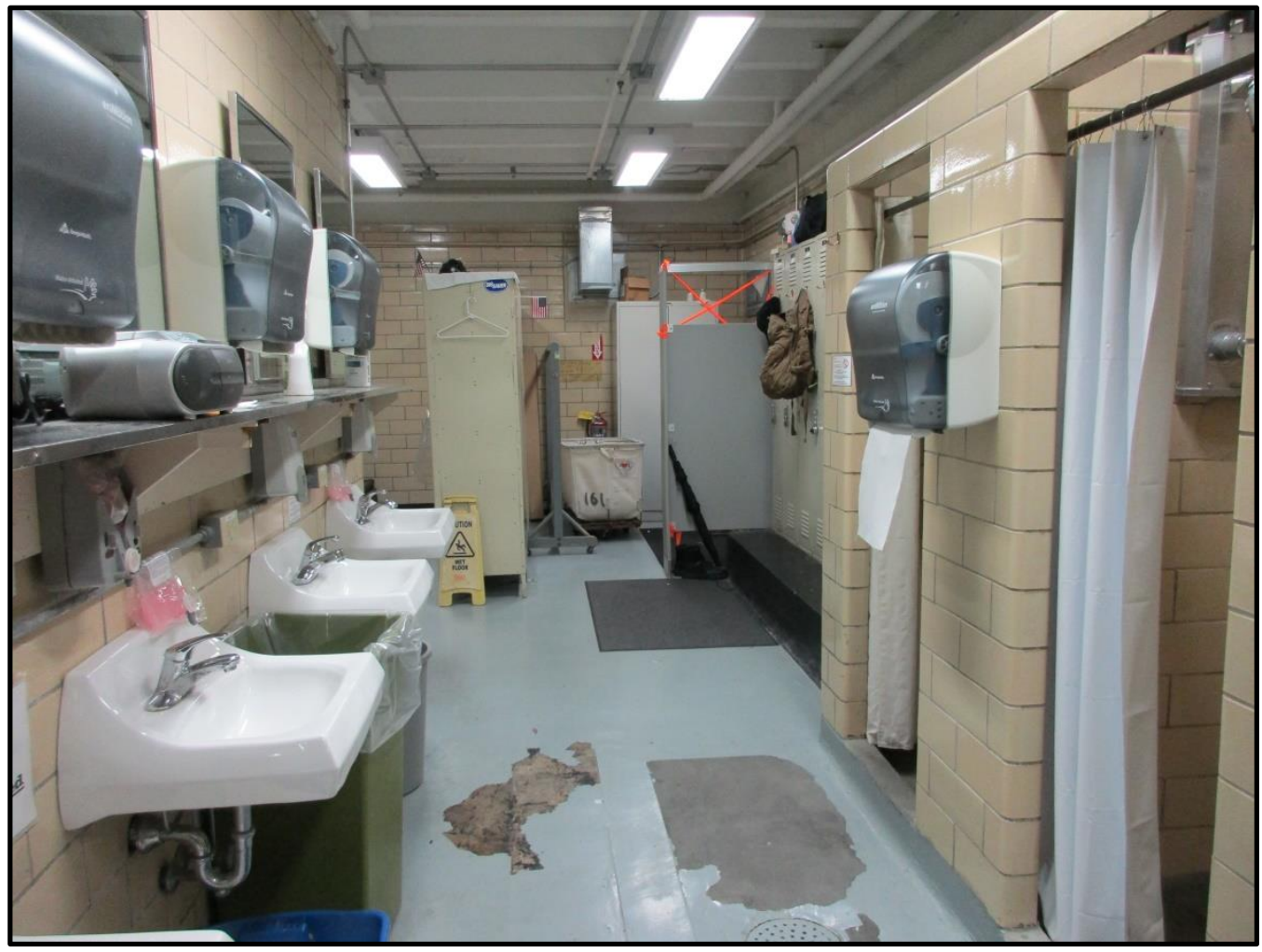

Figure 138. Men's Change Room on first floor of Building 3037. 


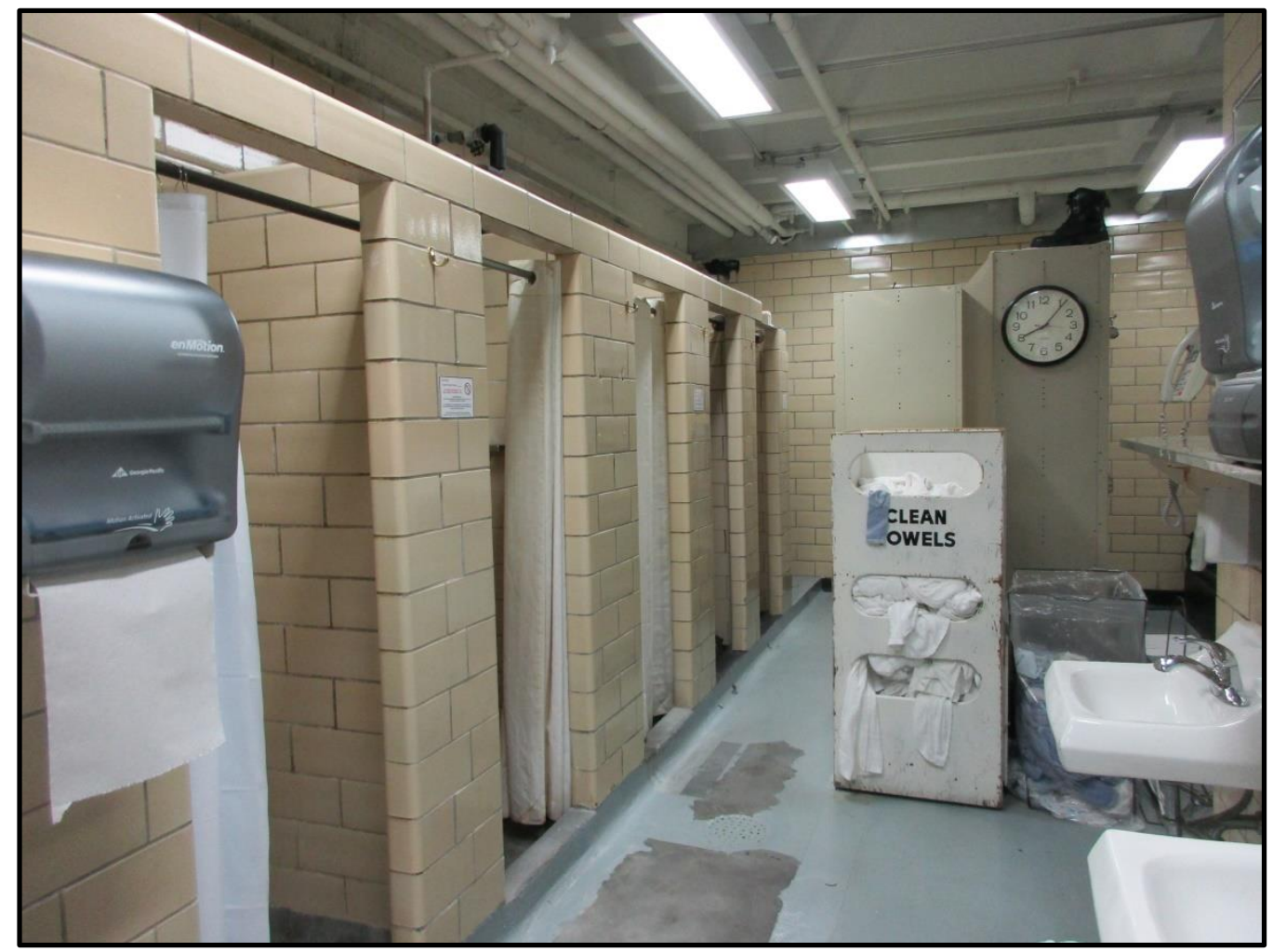

Figure 139. Showers in Men's Change Room on first floor of Building 3037.

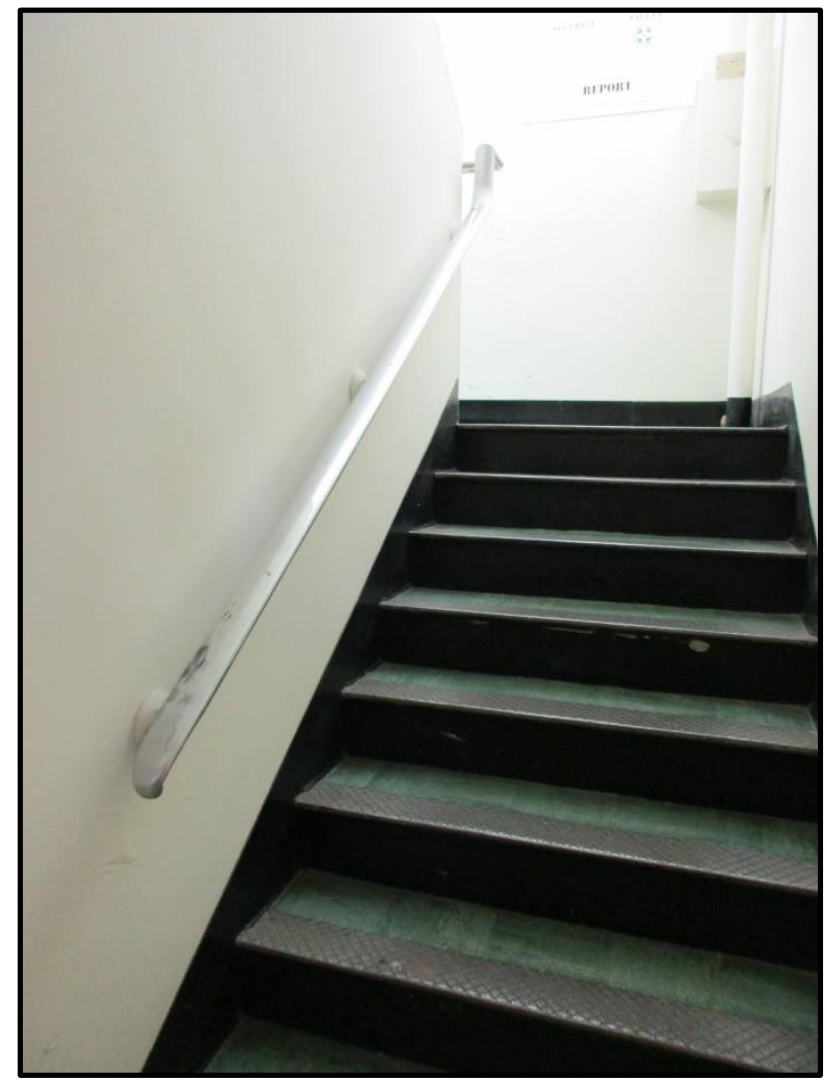

Figure 140. Stairwell and rail to second floor of Building 3037. 


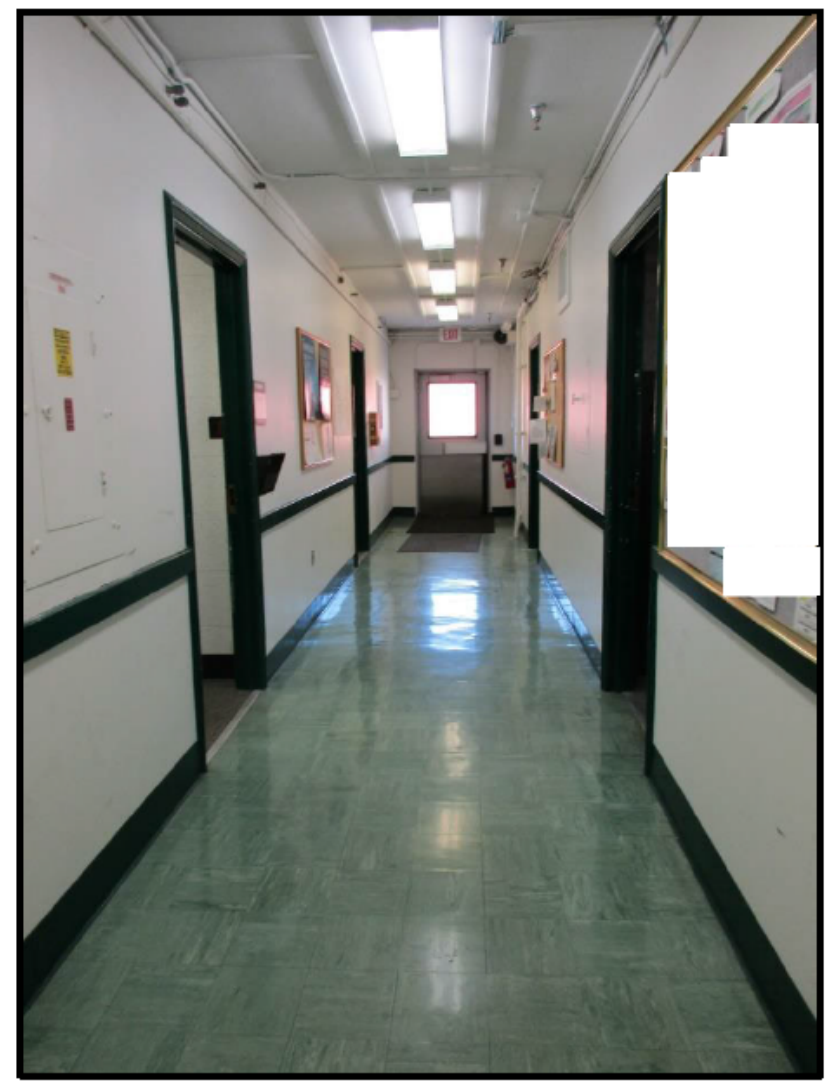

Figure 141. Hallway on second floor of Building 3037

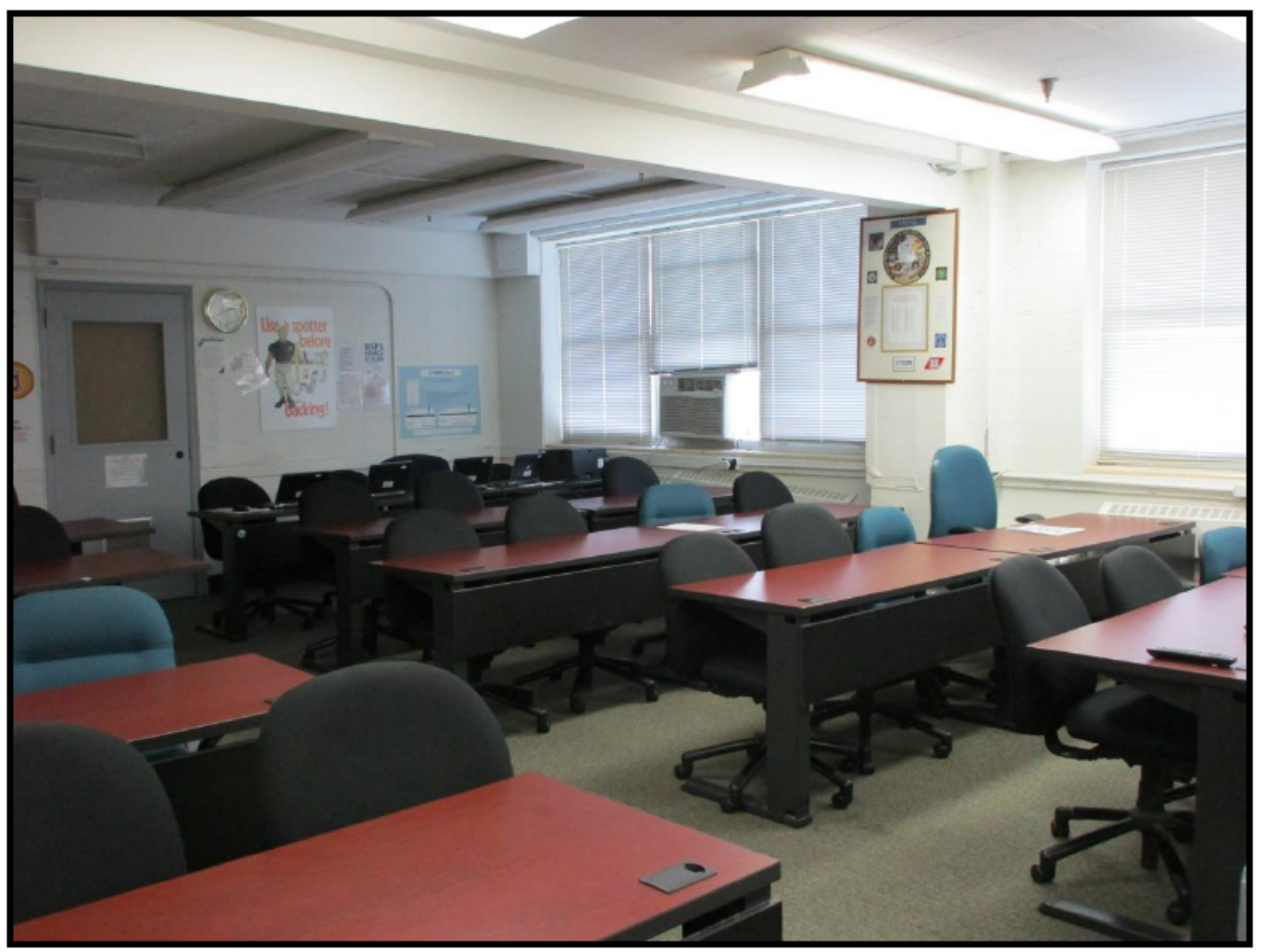

Figure 142. Classroom/Briefing Room on second floor of Building 3037. 


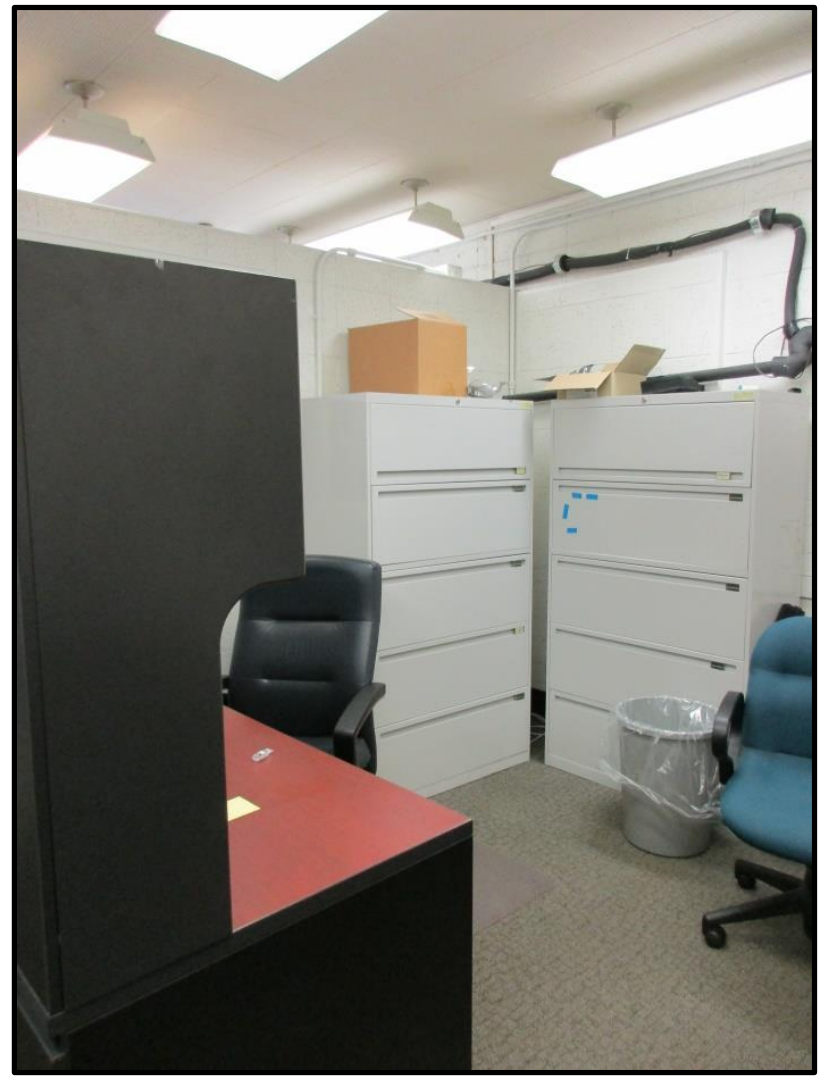

Figure 143. Renovated office on second floor of Building 3037.

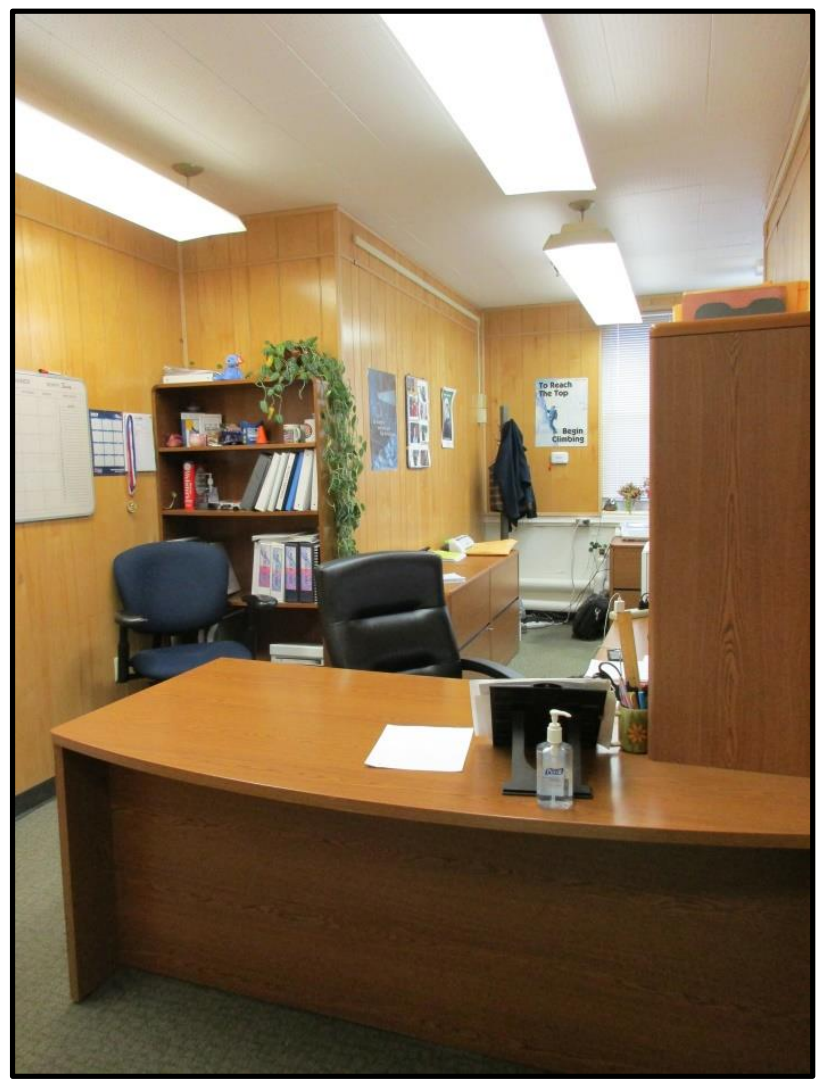

Figure 144. Office on second floor of Building 3037. 


\section{BUILDING NAME}

Radioisotope Laboratory

\section{DATE OF CONSTRUCTION}

1951

\section{DOE OFFICE RESPONSIBLE}

EM (UCOR)

\section{NRHP ELIGIBILITY}

Figure 145. Overview of east and south elevations of Building 3038.

Contributing to ORNL Historic District

\section{DESCRIPTION}

Building 3038 is located on the north side of Central Avenue west of its intersection with Fifth Street. Building 3038 , oriented to the north, is a one-story, five-bay, flat-roof building with an exterior of brick and supported by a concrete foundation (Figures 145 and 146). The brick pattern is laid in a running bond. Brick pilasters form distinctive bays along the building's exterior. The building exhibits concrete coping along the roof's edge. Building 3038 features double- and single-leaf entries along its façade (north) elevation filled with single- and four-light metal pedestrian doors, four sheltered by flat metal awnings. One of the façade entries is filled with larger, hinged six-light industrial doors. Similar entries to those on the façade are found on the west and rear (south) elevations. The east end of the building has a small, flat-roof projection with a single-leaf pedestrian entry on its north elevation and a double-leaf loading dock entry on its east elevation. There are no windows present on this building.

\section{NATIONAL REGISTER EVALUATION}

Building 3038 was constructed in 1951 and is one of the buildings that comprise the Isotope Complex. Building 3038 was historically constructed as a radioisotope laboratory. Building 3038 was previously surveyed in 1994, 2004, and 2015 and recommended as a contributing resource to the ORNL Historic District (Carver and Slater 1994; Thomason and Associates 2004 and 2015). The building retains a majority of its historic materials, as well as its form and massing. As a research/laboratory facility, Building 3038 housed work that furthered ORNL's mission in nuclear science during the Cold War era. However, the building is not the single location most importantly associated with a scientific achievement, scientist, or other event or person of historic significance to merit individual listing in the NRHP under Criterion A or B. Furthermore, the building lacks notable architectural elements that would warrant individual listing in the NRHP under Criterion C. Instead, the significance of Building 3038 is best understood within the broader context of the body of work advanced by researchers in the ORNL Historic District during the Cold War era. As such, Building 3038 does not warrant individual listing in the NRHP under Criterion A, B, or C; however, the building is a contributing resource to the ORNL Historic District. 


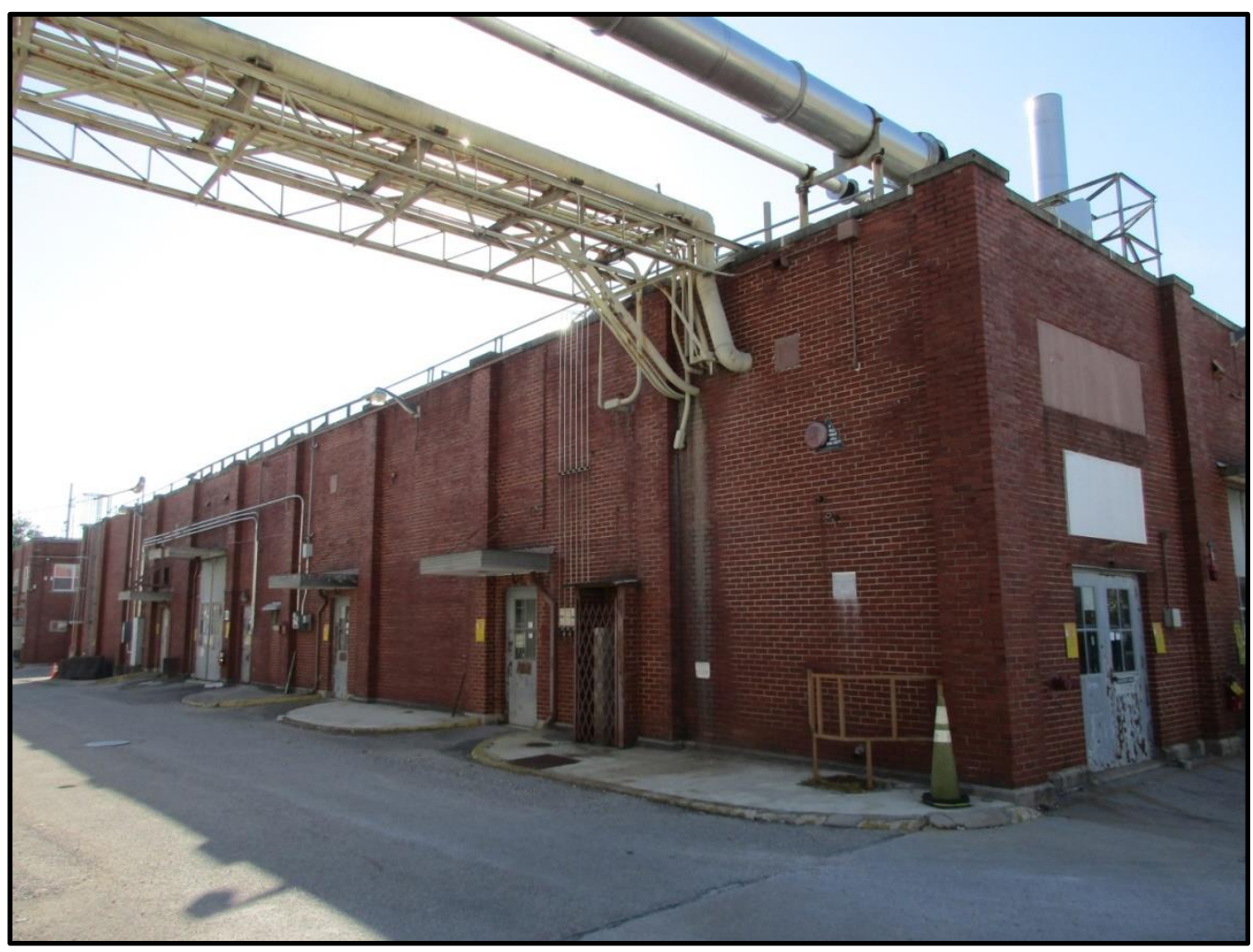

Figure 146. Overview of north and west elevations of Building 3038. 


\section{9}

\section{BUILDING NAME}

Central Radioactive Off-Gas Disposal Facility

DATE OF CONSTRUCTION

1951

DOE OFFICE RESPONSIBLE

EM (UCOR)

NRHP ELIGIBILITY

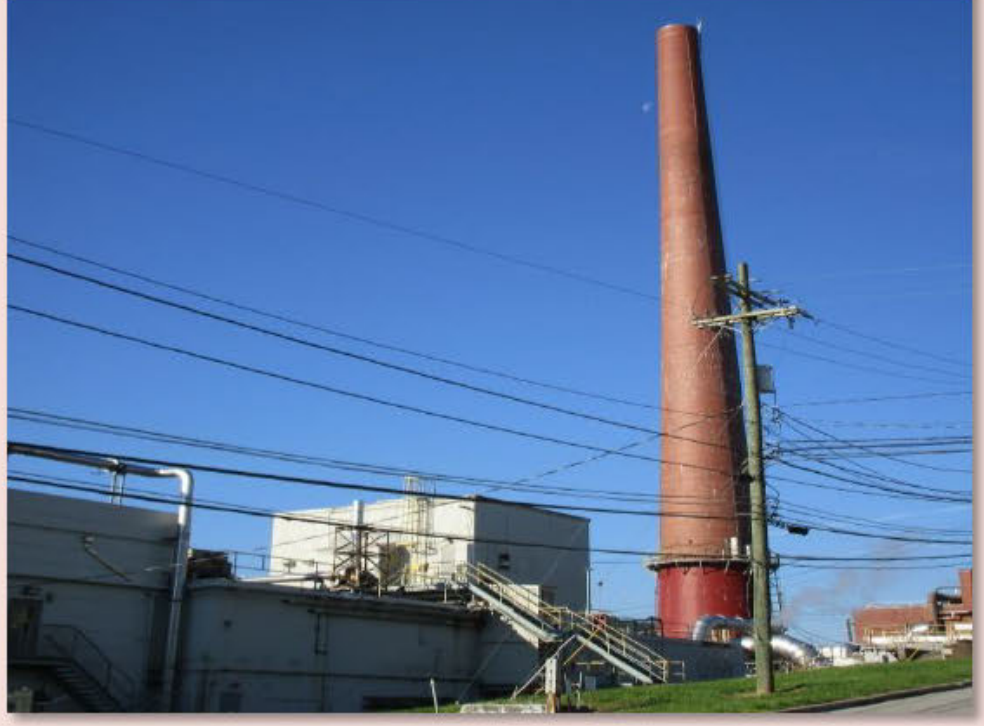

Figure 147. Overview of east elevation of Building 3039.

Contributing to ORNL Historic District

\section{DESCRIPTION}

Building 3039 is located between Hillside Avenue and Central Avenue. Building 3039 is a tall exhaust stack comprised of brick masonry construction (Figures 147 and 148). The exhaust stack displays a tapered design.

\section{NATIONAL REGISTER EVALUATION}

Building 3039 was constructed in 1951 and historically functioned as an exhaust stack. It was previously surveyed in 1994 and 2004 and recommended as a contributing resource to the ORNL Historic District (Carver and Slater 1994; Thomason and Associates 2004). The structure was noted as demolished in 2015 (Thomason and Associates 2015); however, during the current survey, the survey team noted that the building is still extant. Building 3039 retains its historic materials, form, and massing. As a utility/maintenance facility, Building 3039 provided utilitarian support services for work that furthered ORNL's mission in nuclear science during the Cold War era. However, the building is not the single location most importantly associated with a scientific achievement, scientist, or other event or person of historic significance to merit individual listing in the NRHP under Criterion A or B. Furthermore, the building lacks notable architectural elements that would warrant individual listing in the NRHP under Criterion C. Instead, the significance of Building 3039 is best understood as an integral support resource necessary to the functioning of research and processing facilities in the ORNL Historic District during the Cold War era. As such, Building 3039 does not warrant individual listing in the NRHP under Criterion A, B, or C; however, the building is a contributing resource to the ORNL Historic District. 


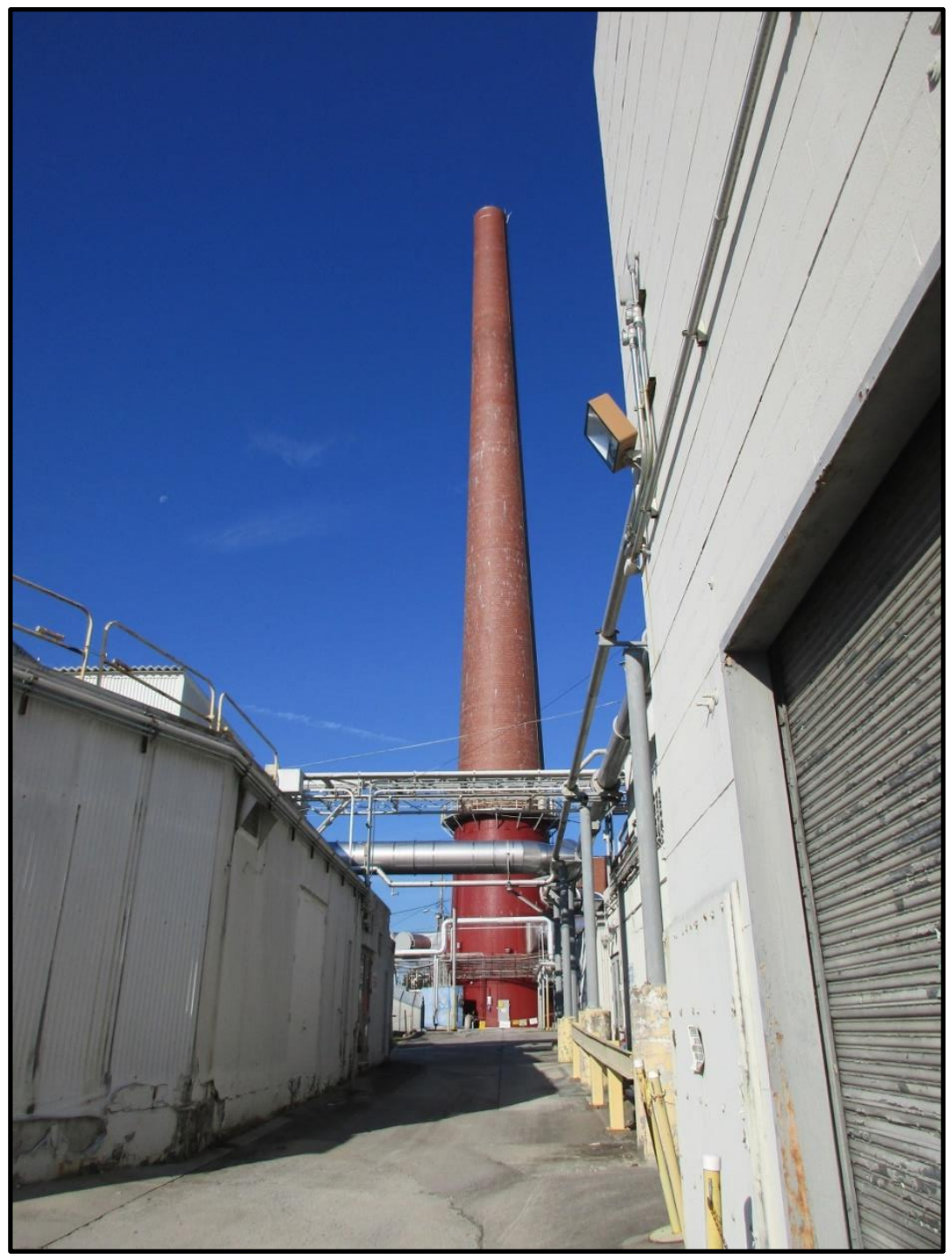

Figure 148. Overview of east elevation of Building 3039. 


\section{BUILDING NAME}

Oak Ridge Research Reactor

DATE OF CONSTRUCTION

1955

DOE OFFICE RESPONSIBLE

EM (UCOR)

NRHP ELIGIBILITY

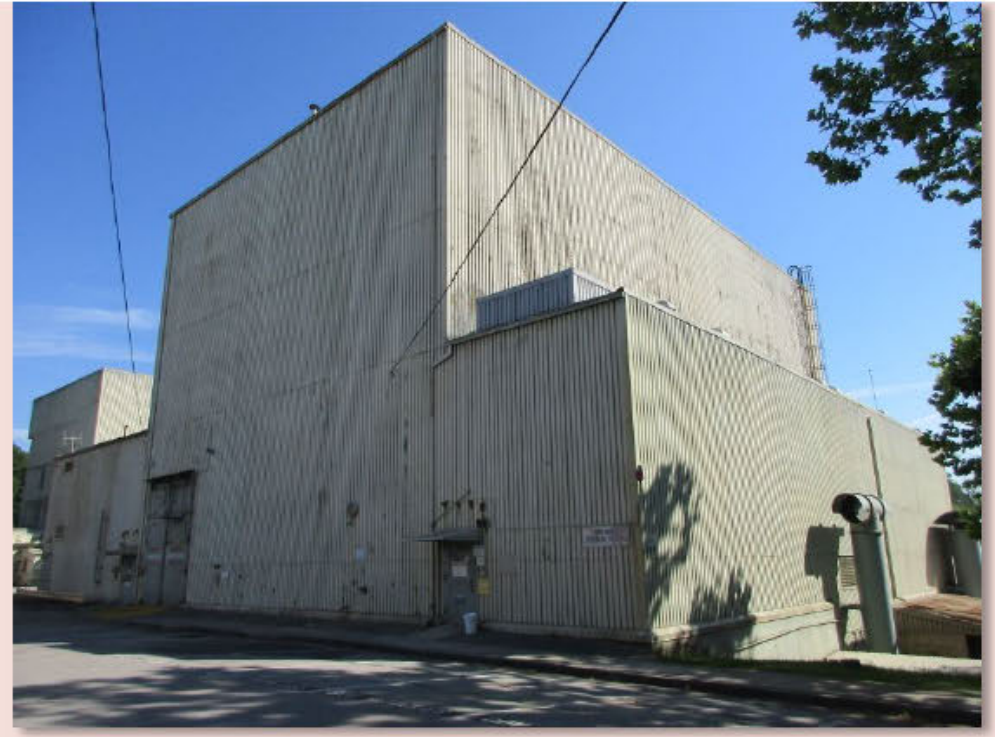

Figure 149. Overview of west and south elevations of Building 3042.

Contributing to ORNL Historic District

\section{DESCRIPTION}

Building 3042 is located along the north side of Hillside Avenue between Third and Fifth Streets. The architectural resource is a multi-story, flat roof, steel frame structure clad with corrugated metal panels and supported by a concrete foundation (Figures 149 and 150). The central section of the building is three stories, with wings to the north and south that are one or two stories in height. Exterior metal stairs are located on the east elevation providing access to the upper story of both wings. The building features large solid metal doors and single-light metal pedestrian doors. Several of the doors are covered by metal awnings. Building 3042 exhibits no window openings.

\section{NATIONAL REGISTER EVALUATION}

Building 3042 was constructed in 1955 as a high performance and general purpose reactor that produced a majority of the isotopes at ORNL, supporting numerous scientific advances. It was shut down in 1987 (Thomason and Associates 2015: 277). Building 3042 was previously surveyed in 1994, 2004, and 2015 and recommended as a contributing resource to the ORNL Historic District in all previous surveys (Carver and Slater 1994; Thomason and Associates 2004 and 2015). The building's integrity remains intact as it retains a majority of its historic materials, form, and massing. As a processing facility, Building 3042 served as an important structure, contributing to major fields of science during the Cold War era. However, the building is not the single location most importantly associated with a scientific achievement, scientist, or other event or person of historic significance to merit listing in the NRHP under Criterion A or B. Furthermore, the building lacks notable architectural elements that would warrant individual listing in the NRHP under Criterion C. Instead, the significance of Building 3042 is best understood within the broader context of the body of work advanced by researchers in the ORNL Historic District during the Cold War era. As such, Building 3042 does not warrant individual listing in the NRHP under Criterion A, B, or C; however, the building is a contributing resource to the ORNL Historic District. 


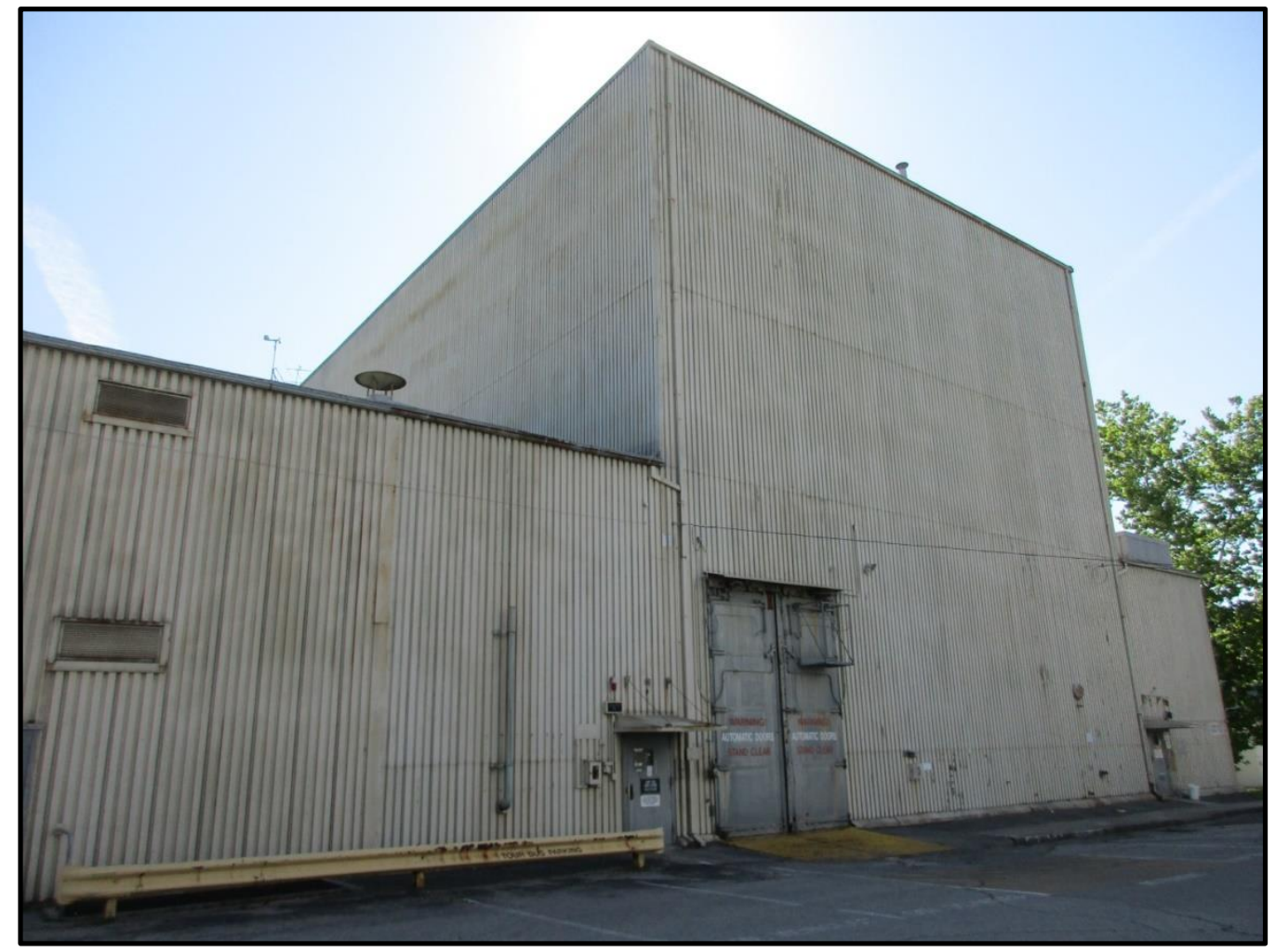

Figure 150. Overview of west elevation and partial north elevation of Building 3042. 


\section{4}

\section{BUILDING NAME}

West Complex Field Shop

DATE OF CONSTRUCTION

1955

DOE OFFICE RESPONSIBLE

SC

NRHP ELIGIBILITY

Demolished - N/A

\section{DESCRIPTION}

Field survey confirmed Building 3044 is no longer extant.

\section{NATIONAL REGISTER EVALUATION}

Building 3044 was constructed in 1955 and historically served as machine shop under the Plant and Equipment Division. The resource was previously surveyed in 1994 and 2004 and recommended as contributing to the ORNL Historic District (Carver and Slater 1994; Thomason and Associates 2004). Prior to its demolition, in 2009 DOE submitted documentation of Building 3044 to the SHPO, as required by the PA, along with documentation for several other facilities (UTB 2009). SHPO accepted the documentation and offered no objection to the proposed demolition (McIntyre 2009). In 2015, the resource was recorded as demolished (Thomason and Associates 2015). During the current survey, CRA confirmed that the resource is no longer extant and as such, no longer retains its integrity of location, design, setting, materials, workmanship, feeling, and association. Thus, Building 3044 is not individually eligible for listing in the NRHP under Criterion A, B, or C, nor is it contributing to the ORNL Historic District. 


\section{BUILDING NAME}

Isotope Technology Building

DATE OF CONSTRUCTION

1962

\section{DOE OFFICE RESPONSIBLE}

NE

\section{NRHP ELIGIBILITY}

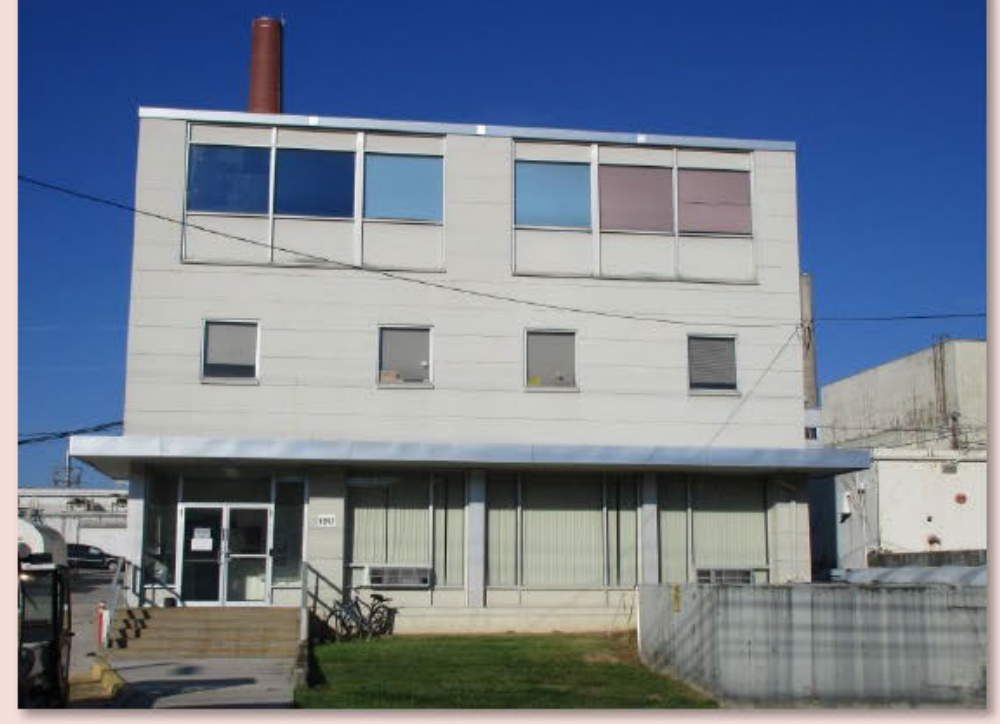

Contributing to ORNL Historic District

Figure 151. Overview of east elevation of Building 3047.

\section{DESCRIPTION}

Building 3047 is located west of Fifth Street and south of Hillside Avenue to the west of the intersection of the two streets. Building 3047 is a three-story, four-bay, flat-roof, concrete block structure resting on a concrete foundation (Figures 151, 152, and 153). Building 3047, oriented to the east, is a long, rectangular building. The façade (east) elevation features a flat-roof metal overhang extending the width of the building sheltering the first floor entry and windows. A double-leaf entry filled with aluminum frame commercial glass doors fills the south façade bay; the remaining three first floor bays are filled with three-light fixed commercial plate glass windows with aluminum mullions. The windows on the façade's second floor include single-light fixed sashes with concrete sills and two large window openings on the third floor each filled with a ribbon of three windows with a larger pane over a slightly smaller panel. The south elevation features three loading bays with metal roll-up doors and a pedestrian entry with a single-light metal door. Windows on the second and third floors of the side (south and north) elevations are primarily filled with single-light fixed sashes. The north elevation includes a one-story addition (Building 3127) and pedestrian entries to all three floors with the upper two stories accessed by metal exterior stairs.

\section{NATIONAL REGISTER EVALUATION}

Building 3047 was constructed in 1962 as a radioisotopes development laboratory. Historically, the facility was used to conduct research and development to produce radioisotopes. The building is currently vacant and no longer used. Building 3047 was previously surveyed in 1994 and recommended as a non-contributing resource to the ORNL Historic District as it was less than 50 years old at the time of the survey (Carver and Slater 1994). The building was surveyed again in 2015 and was recommended as a contributing resource to the ORNL Historic District (Thomason and Associates 2015). Building 3047 has undergone moderate modifications since it was erected, which include window opening alterations and replacement windows. However, these modifications are minor, and overall the building's integrity remains intact. As a research/laboratory facility, Building 3047 housed work that furthered ORNL's mission in nuclear science during the Cold War era. However, the building is not the single location most importantly associated with a scientific achievement, scientist, or other event or person of historic significance to merit individual listing in the NRHP under Criterion A 
or B. Furthermore, the building lacks notable architectural elements that would warrant individual listing in the NRHP under Criterion C. Instead, the significance of Building 3047 is best understood within the broader context of the body of work advanced by researchers in the ORNL Historic District during the Cold War era. As such, Building 3047 does not warrant individual listing in the NRHP under Criterion A, B, or C; however, the building is a contributing resource to the ORNL Historic District.

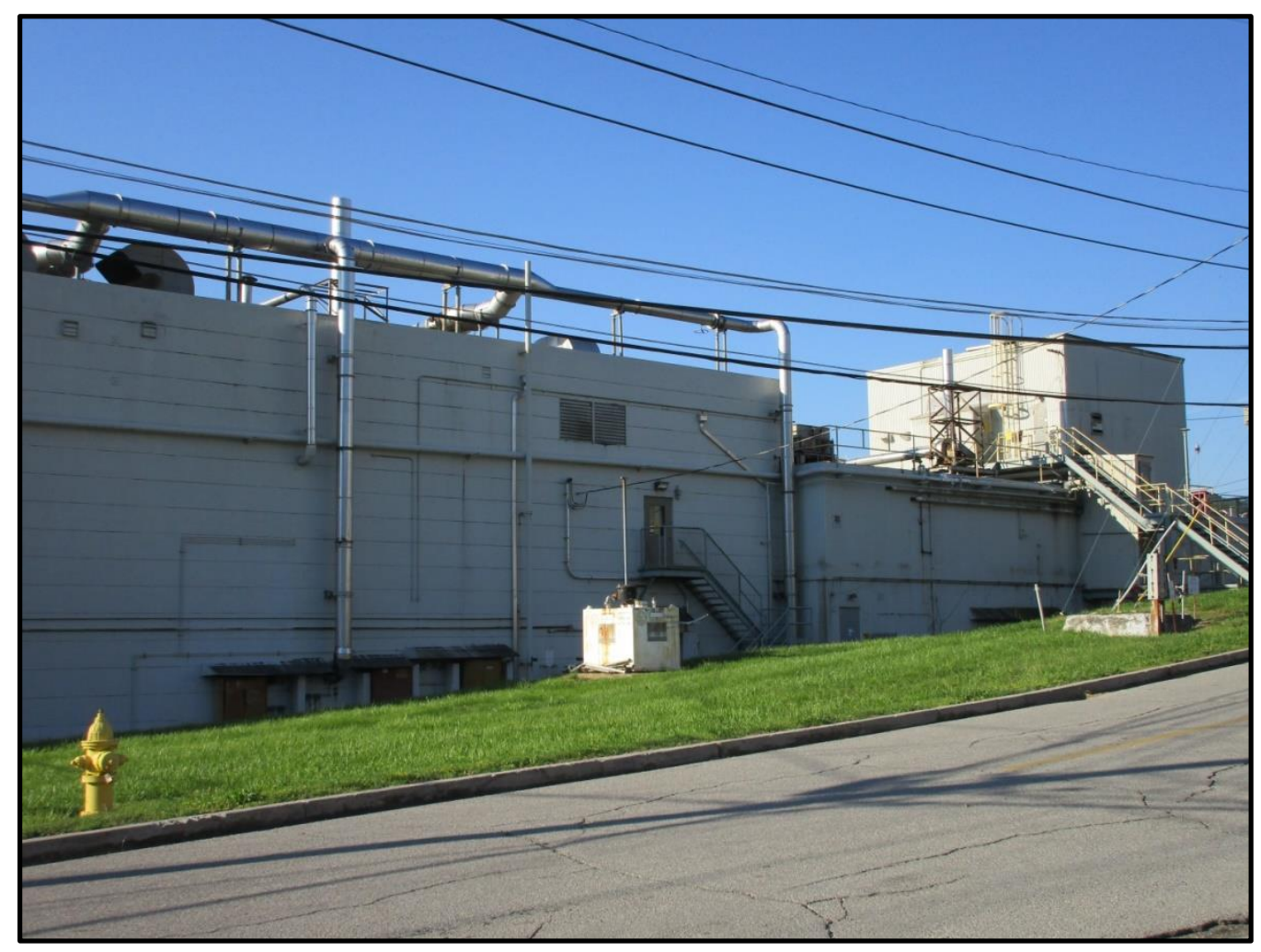

Figure 152. Overview of partial north elevation of Building 3047. 


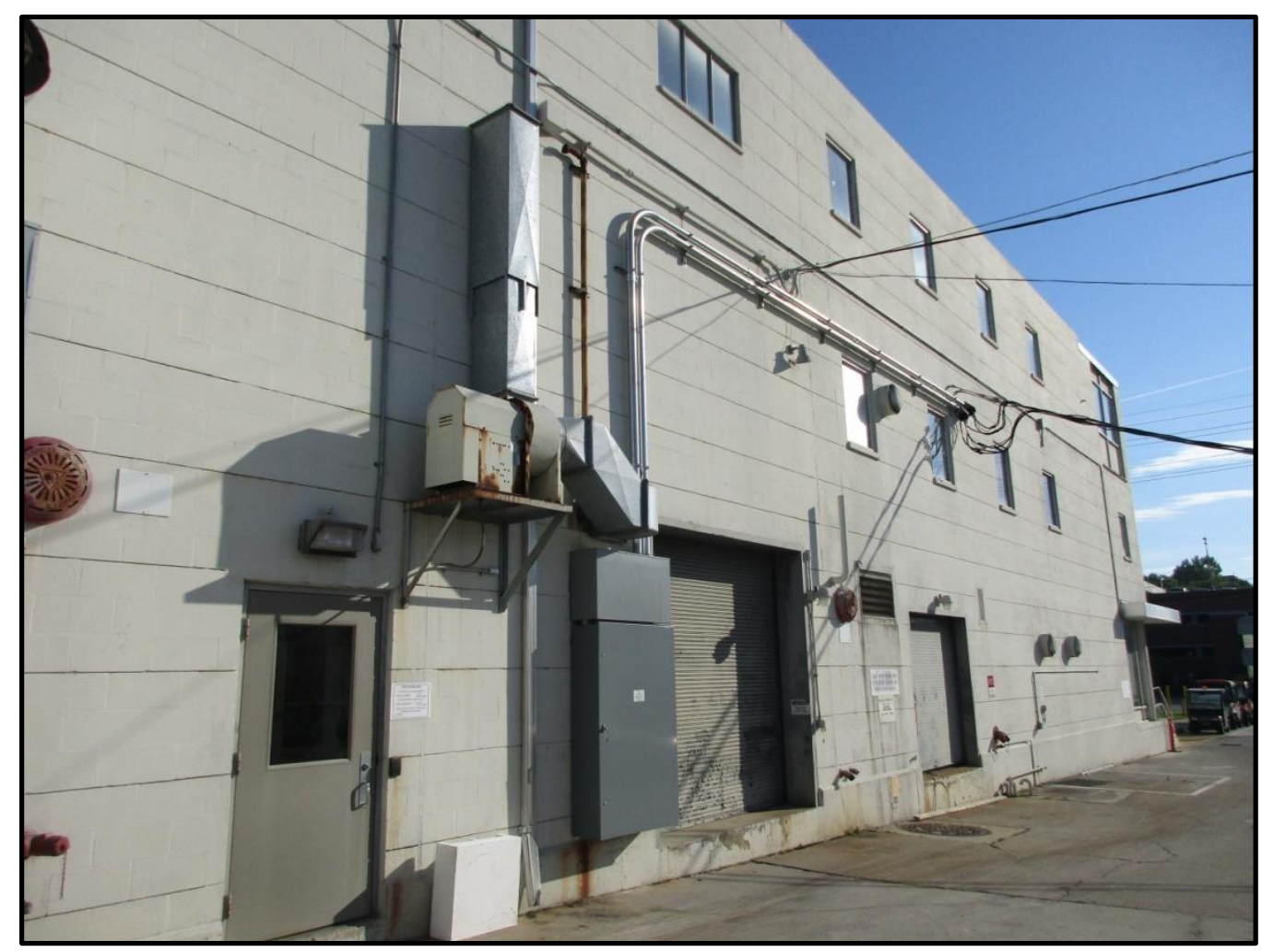

Figure 153. Overview of partial south elevation of Building 3047. 


\section{4}

\section{BUILDING NAME}

Interim Manipulator Repair Facility

\section{DATE OF CONSTRUCTION}

1951

DOE OFFICE RESPONSIBLE

SC

NRHP ELIGIBILITY

Demolished - N/A

\section{DESCRIPTION}

Field survey confirmed Building 3074 is no longer extant.

\section{NATIONAL REGISTER EVALUATION}

Building 3074 was constructed in 1951 and historically served as a maintenance shop. The resource was previously surveyed in 1994 and 2004 and recommended as contributing to the ORNL Historic District (Carver and Slater 1994; Thomason and Associates 2004). Prior to its demolition, in 2009 DOE submitted documentation of Building 3074 to the SHPO, as required by the PA, along with documentation for several other facilities (DOE-ORO 2009). In 2015, the resource was recorded as demolished (Thomason and Associates 2015). During the current survey, CRA confirmed that the resource is no longer extant and as such, no longer retains its integrity of location, design, setting, materials, workmanship, feeling, and association. Thus, Building 3074 is not individually eligible for listing in the NRHP under Criterion A, B, or C, nor is it contributing to the ORNL Historic District. 


\section{0}

\section{BUILDING NAME}

Reactor Experiment Control Room

DATE OF CONSTRUCTION

1953

DOE OFFICE RESPONSIBLE

SC

NRHP ELIGIBILITY

Figure 154. Overview of north and west elevations of Building 3080.

Contributing to ORNL Historic District

\section{DESCRIPTION}

Located at the southern terminus of North Access Road, Building 3080 is a one-story, gable-roof, steel structure supported by a concrete foundation. The building sits adjacent to and west of Building 3010 . The exterior of Building 3080 is clad with corrugated metal siding. The roof features three roof vents along the ridgeline (Figures 154 and 155). The building exhibits single-leaf entries along its north and south gable ends along with two similar entries along its west elevation. These entries are filled with single-light or two-light metal pedestrian doors with a few doorways covered by shed metal awnings. Windows filled with twelve-light metal awning sashes that have been painted over are found on the west and south elevations of Building 3080 .

\section{NATIONAL REGISTER EVALUATION}

Building 3080 was constructed in 1953 as a storage facility for BSR (Building 3010). Historically, the building was used as a control house for BSR experiments. The building was shut down in 2016. It was previously surveyed in 1994, 2004, and 2015 and recommended as a contributing resource to the ORNL Historic District (Carver and Slater 1994; Thomason and Associates 2004 and 2015). The building retains a majority of its historic materials, as well as its form and massing. As a utility/maintenance facility, Building 3080 provided utilitarian support services for work that furthered ORNL's mission in nuclear science during the Cold War era. However, the building is not the single location most importantly associated with a scientific achievement, scientist, or other event or person of historic significance to merit individual listing in the NRHP under Criterion A or B. Furthermore, the building lacks notable architectural elements that would warrant individual listing in the NRHP under Criterion C. Instead, the significance of Building 3080 is best understood as an integral support resource necessary to the functioning of research and processing facilities in the ORNL Historic District during the Cold War era. As such, Building 3080 does not warrant individual listing in the NRHP under Criterion A, B, or C; however, the building is a contributing resource to the ORNL Historic District. 


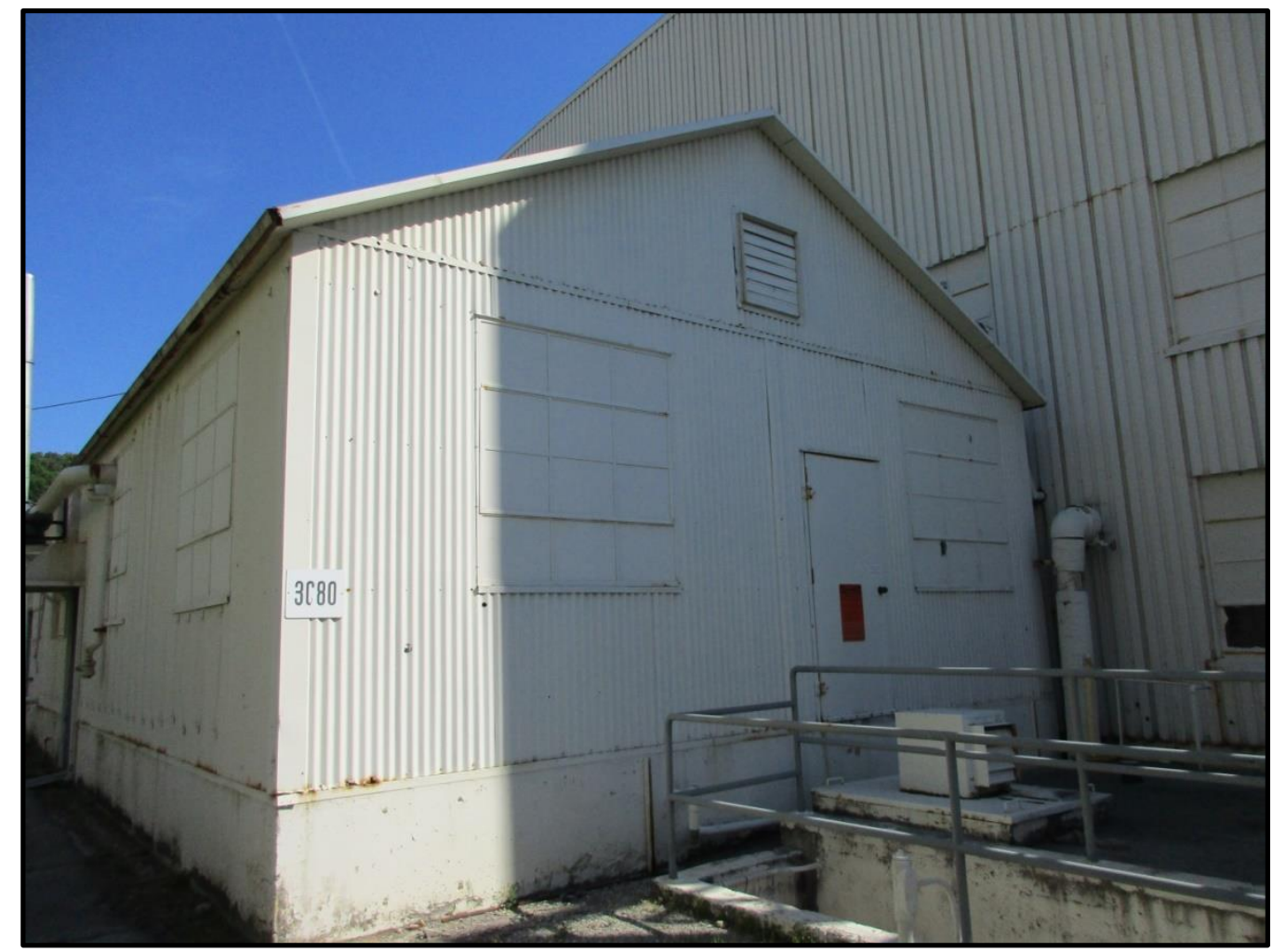

Figure 155. Overview of south elevation and partial west elevation of Building 3080. 


\section{1}

\section{BUILDING NAME}

Filters for Building 3019

\section{DATE OF CONSTRUCTION}

1943

\section{DOE OFFICE RESPONSIBLE}

EM (Isotek)

\section{NRHP ELIGIBILITY}

Contributing to ORNL Historic District

\section{DESCRIPTION}

Due to security concerns, Building 3091 was not fully studied during this survey. The following description is based on previous surveys and the photographs available of the building. In previous surveys, the building was described as "602 square-foot, off gas filter house," which contained filtering and exhaust equipment. The building is located adjacent to Building 3019A. In the 2015 survey by Thomason and Associates, Building 3091 was notated as "demolished."

\section{NATIONAL REGISTER EVALUATION}

Building 3091 was constructed in 1943 and served as filters for cell and hood exhausts for Building 3019 . It was previously surveyed in 1994 and 2004 and recommended as a contributing resource to the ORNL Historic District (Carver and Slater 1994; Thomason and Associates 2004). In 2015, the building was recorded as demolished (Thomason and Associates 2015); however, during the current survey, the survey team noted the building to be extant. While the building was inaccessible and photographs were not allowed, it was noted that very little change had occurred to the building since the 2004 survey. The building retains a majority of its historic materials, as well as its form and massing. As a utility/maintenance facility, Building 3091 provided utilitarian support services for work that furthered ORNL's mission in nuclear science during the Manhattan Project and Cold War era. However, the building is not the single location most importantly associated with a scientific achievement, scientist, or other event or person of historic significance to merit individual listing in the NRHP under Criterion A or B. Furthermore, the building lacks notable architectural elements that would warrant individual listing in the NRHP under Criterion C. Instead, the significance of Building 3091 is best understood as an integral support resource necessary to the functioning of research and processing facilities in the ORNL Historic District during the Manhattan Project and Cold War era. As such, Building 3091 does not warrant individual listing in the NRHP under Criterion A, B, or C; however, the building is a contributing resource to the ORNL Historic District. 


\section{BUILDING NAME}

Off-gas Scrubber Facility

\section{DATE OF CONSTRUCTION}

1956

\section{DOE OFFICE RESPONSIBLE}

EM (UCOR)

\section{NRHP ELIGIBILITY}

Contributing to ORNL Historic District

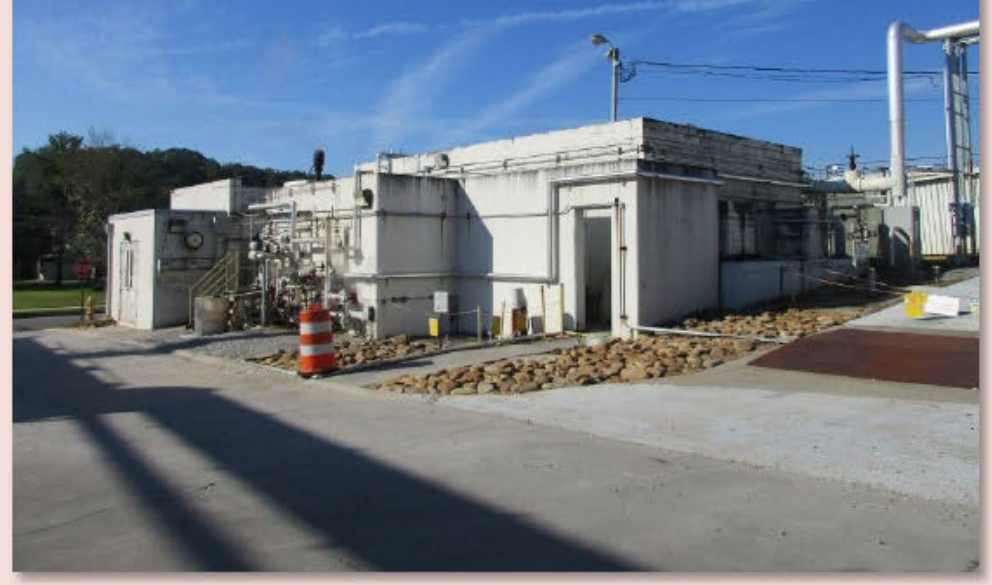

Figure 156. Overview of north and east elevations of Building 3092.

\section{DESCRIPTION}

Building 3092 is located along the northern side of Central Avenue between Third and Fifth Streets. Building 3092 is a one-story, flat-roof, concrete block structure with an irregular plan (Figures 156 and 157). Portions of the building may also be comprised of poured concrete. Building 3092 is supported by a concrete foundation. A double-leaf entry on the east elevation of the building is filled with single-light metal pedestrian doors. The 1994 survey mentions a steel frame structure clad in metal panels within the concrete block masonry structure.

\section{NATIONAL REGISTER EVALUATION}

Building 3092 was constructed in 1956 as an off-gas facility. It was previously surveyed in 1994 and 2004 and recommended as a contributing resource to the ORNL Historic District (Carver and Slater 1994; Thomason and Associates 2004). In 2015, the building was recorded as demolished (Thomason and Associates 2015). During the current survey, the survey team noted that the building is extant; however, a small, steel-frame portion has been demolished. The building no longer retains a small portion of its structure, which diminishes its integrity; however the majority of the historic materials that comprise the overall building, including the concrete block frame and metal pipes remain intact. These components of the building are most important for conveying its meaning as a utilitarian structure that functions as an off-gas facility. As a utility/maintenance facility, Building 3092 provided utilitarian support services for work that furthered ORNL's mission in nuclear science during the Cold War era. However, the building is not the single location most importantly associated with a scientific achievement, scientist, or other event or person of historic significance to merit individual listing in the NRHP under Criterion A or B. Furthermore, the building lacks notable architectural elements that would warrant individual listing in the NRHP under Criterion C. Instead, the significance of Building 3092 is best understood as an integral support resource necessary to the functioning of research and processing facilities in the ORNL Historic District during the Cold War era. As such, Building 3092 does not warrant individual listing in the NRHP under Criterion A, B, or C; however, the building is a contributing resource to the ORNL Historic District. 


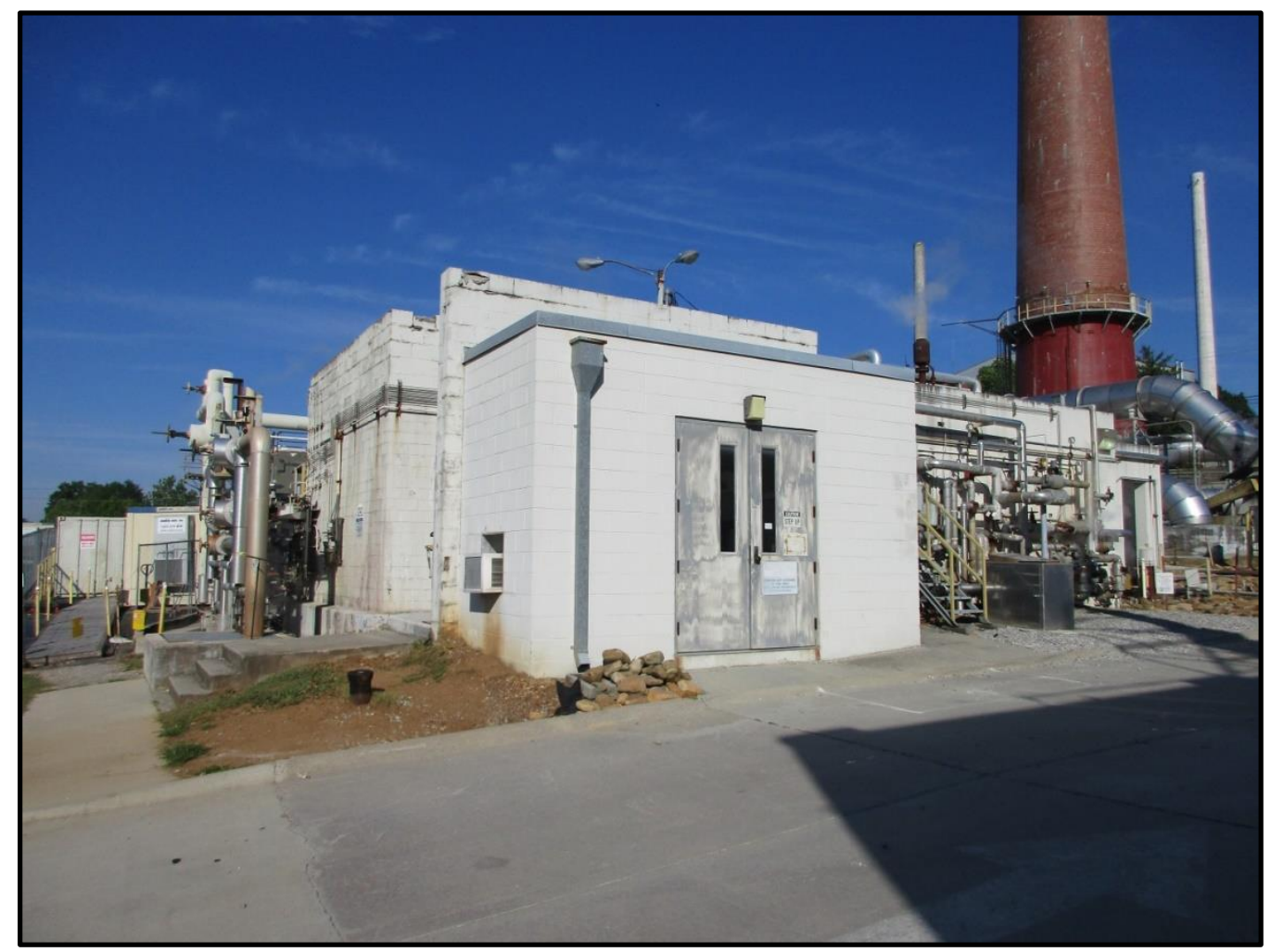

Figure 157. Overview of east and south elevations of Building 3092. 


\section{0}

\section{BUILDING NAME}

Source and Special Materials Vault

\section{DATE OF CONSTRUCTION}

1960

\section{DOE OFFICE RESPONSIBLE}

EM (Isotek)

NRHP ELIGIBILITY

Contributing to ORNL Historic District

\section{DESCRIPTION}

Building 3100 is located within the barricaded portion of the 3000 Area. Access to this high-security area of the 3000 Area is limited; therefore, no photographs of the building were taken at this time. According to previous surveys, Building 3100 is a concrete block masonry building with a low-pitched gable roof. The total square footage of this rectangular building is $1,231 \mathrm{sq}$ ft. The building is adjacent to Building $3019 \mathrm{~A}$ on the north elevation.

\section{NATIONAL REGISTER EVALUATION}

Building 3100 was constructed in 1960 and historically served as a storage vault. The resource was previously surveyed in 1994 and recommended as non-contributing to the ORNL Historic District as it did not fall within the period of significance established at that point (Carver and Slater 1994). The resource was surveyed again in 2015 and recommended as contributing to the ORNL Historic District (Thomason and Associates 2015). As a storage facility, Building 3100 provided support for work that furthered ORNL's mission in nuclear science during the Cold War era. However, the building is not the single location most importantly associated with a scientific achievement, scientist, or other event or person of historic significance to merit individual listing in the NRHP under Criterion $\mathrm{A}$ or $\mathrm{B}$. Furthermore, the building lacks notable architectural elements that would warrant individual listing in the NRHP under Criterion C. Although a minor support structure, Building 3100 was utilized in support of the overall mission of ORNL during the Cold War era, and as such, contributes to the ORNL Historic District. 
individual listing in the NRHP under Criterion A, B, or C; however, the building is a contributing resource to the ORNL Historic District.

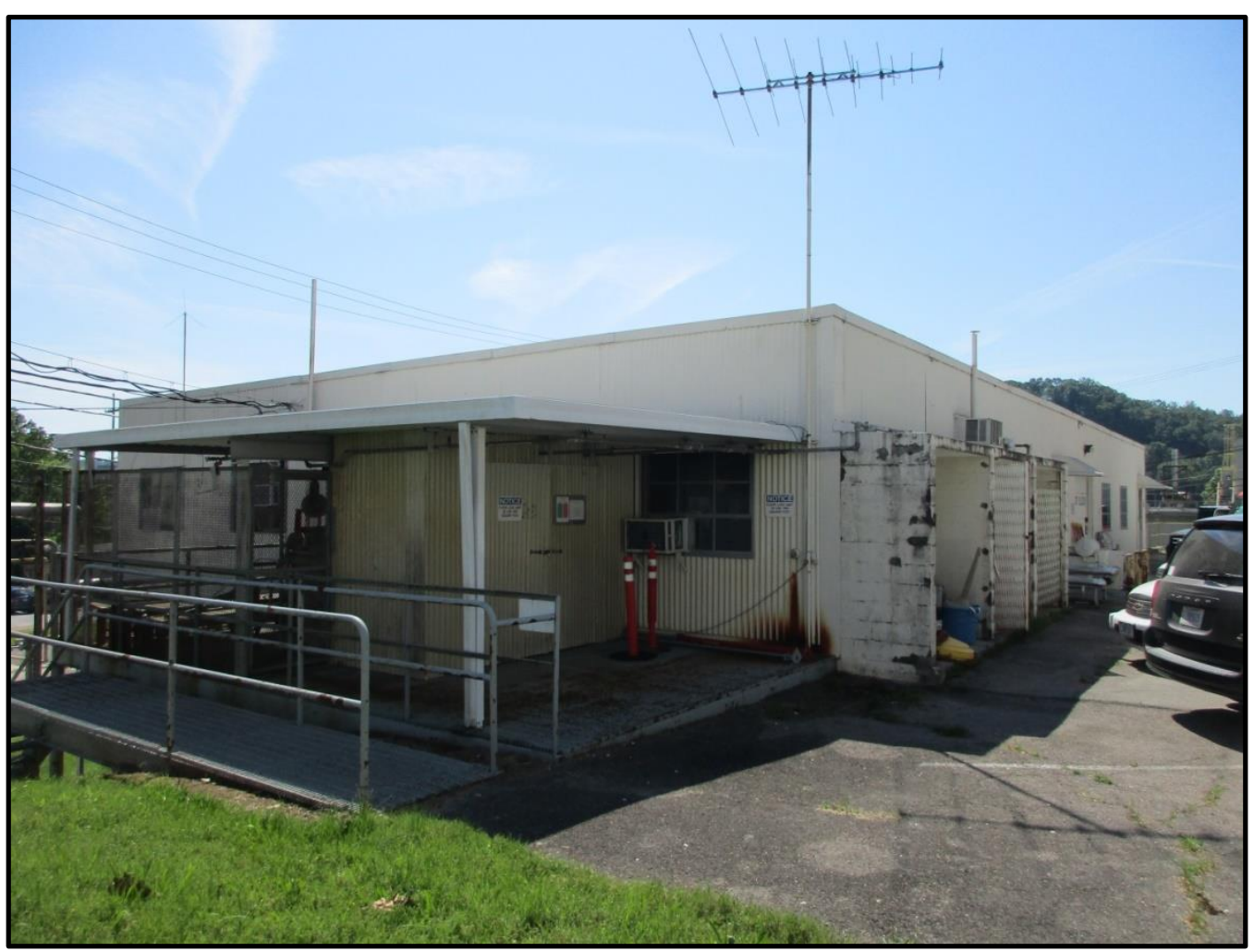

Figure 160. Overview of north elevation and partial west elevation of Building 3104. 


\section{BUILDING NAME}

25 Meter Target House

\section{DATE OF CONSTRUCTION}

1960

\section{DOE OFFICE RESPONSIBLE}

EM (UCOR)

\section{NRHP ELIGIBILITY}

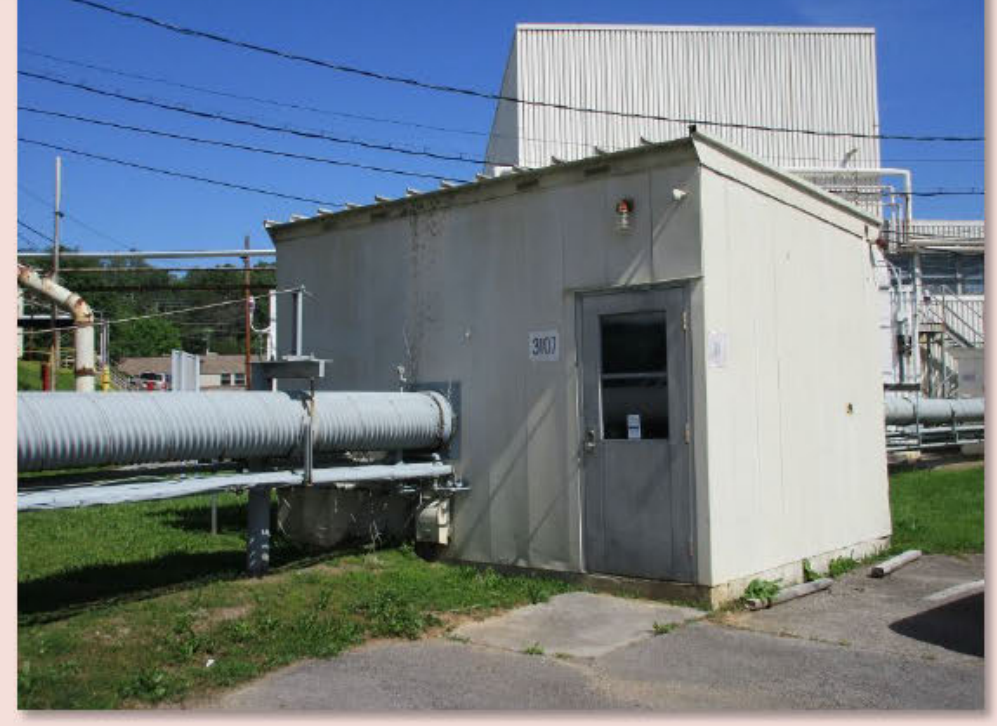

Contributing to ORNL Historic District

\section{DESCRIPTION}

Building 3107 is located north of Building 3104 and south of Building 3010 . Oriented to the west, Building 3107 is a one-story, single-bay, shed-roof, metal-clad structure resting on a concrete foundation (Figures 161 and 162). The building's exterior is clad with vertical metal panels and the roof is also clad in metal. A corrugated metal pipe pierces the façade (west) and rear (east) elevations of Building 3107. A single-leaf entry, located in the southern portion of the façade, is filled with a two-light metal pedestrian door. A window filled with a fourlight metal sash is located on the building's north elevation.

\section{NATIONAL REGISTER EVALUATION}

Building 3107 was constructed in 1960 as a 25 Meter Target House and stands adjacent to Building 3005 . The resource was previously surveyed in 1994 and recommended as non-contributing to the ORNL Historic District as it did not fall within the period of significance established at that time (Carver and Slater 1994). Building 3107 retains a majority of its historic materials, as well as its form and massing. As a utilitarian/maintenance facility, Building 3107 provided utilitarian support services for work that furthered ORNL's mission in nuclear science during the Cold War era. However, the building is not the single location most importantly associated with a scientific achievement, scientist, or other event or person of historic significance to merit individual listing in the NRHP under Criterion A or B. Furthermore, the building lacks notable architectural elements that would warrant individual listing in the NRHP under Criterion C. Although a minor support structure, Building 3107 was utilized in support of the overall mission of ORNL during the Cold War era, and as such, contributes to the ORNL Historic District. 


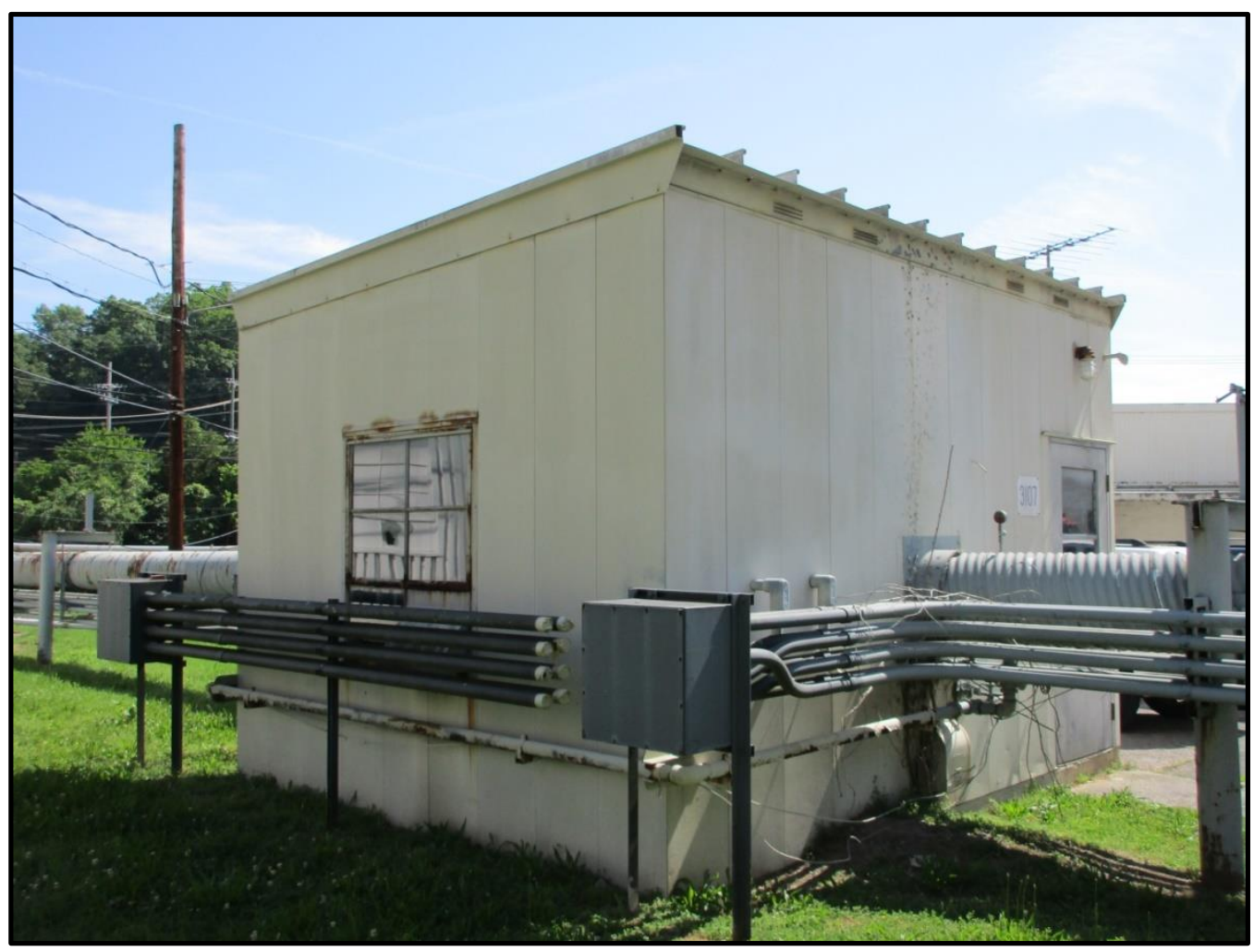

Figure 162. Overview of west and north elevations of Building 3107. 


\section{4}

\section{BUILDING NAME}

Distributed Energy Comm. \& Control Lab

DATE OF CONSTRUCTION

1963

DOE OFFICE RESPONSIBLE

SC

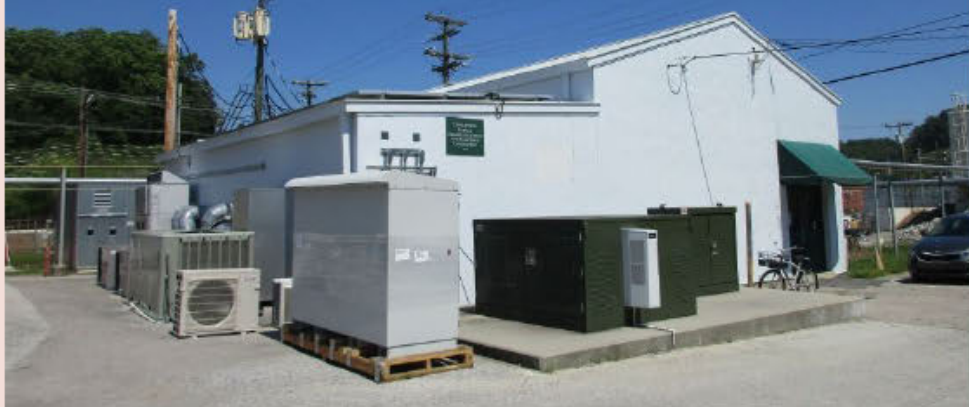

NRHP ELIGIBILITY

Figure 163. Overview of west and north elevations of Building 3114.

Not Eligible

\section{DESCRIPTION}

Building 3114 , oriented to the west, is located along the east side of North Access Road. Building 3114 is comprised of a one-story, single-bay, front-gable section with a shed-roof side section on the north elevation of the building. The steel frame structure has a concrete block foundation (Figures 163 and 164). The exterior is clad with vertical metal panels, and the roof is also clad in metal panels. Two sections of the roof are also covered in solar panels. Double-leaf entries filled with pairs of single-light metal doors and sheltered by fabric awnings are located on the facade (west) and north elevations of Building 3114. There are no windows present on the building.

\section{NATIONAL REGISTER EVALUATION}

Building 3114 was constructed in 1963 for the purpose of cooling, heating, and reactor power laboratory. The building was previously surveyed in 2015 and recommended not eligible due to loss of integrity (Thomason and Associates 2015). Building 3114 has undergone significant alterations, including additions, replacement siding, and the enclosure of bays. As such, the building's integrity of design, materials, and workmanship has been compromised. As a utility/maintenance facility, Building 3114 provided utilitarian support services for work that furthered ORNL's mission in nuclear science during the Cold War era. However, the building is not the single location most importantly associated with a scientific achievement, scientist, or other events or persons of historic significance to merit individual listing in the NRHP under Criterion A or B. Furthermore, the building lacks notable architectural elements that would warrant individual listing in the NRHP under Criterion C. It is located outside the ORNL Historic District boundary. As such, Building 3114 is not eligible for listing in the NRHP under Criterion A, B, or C. 


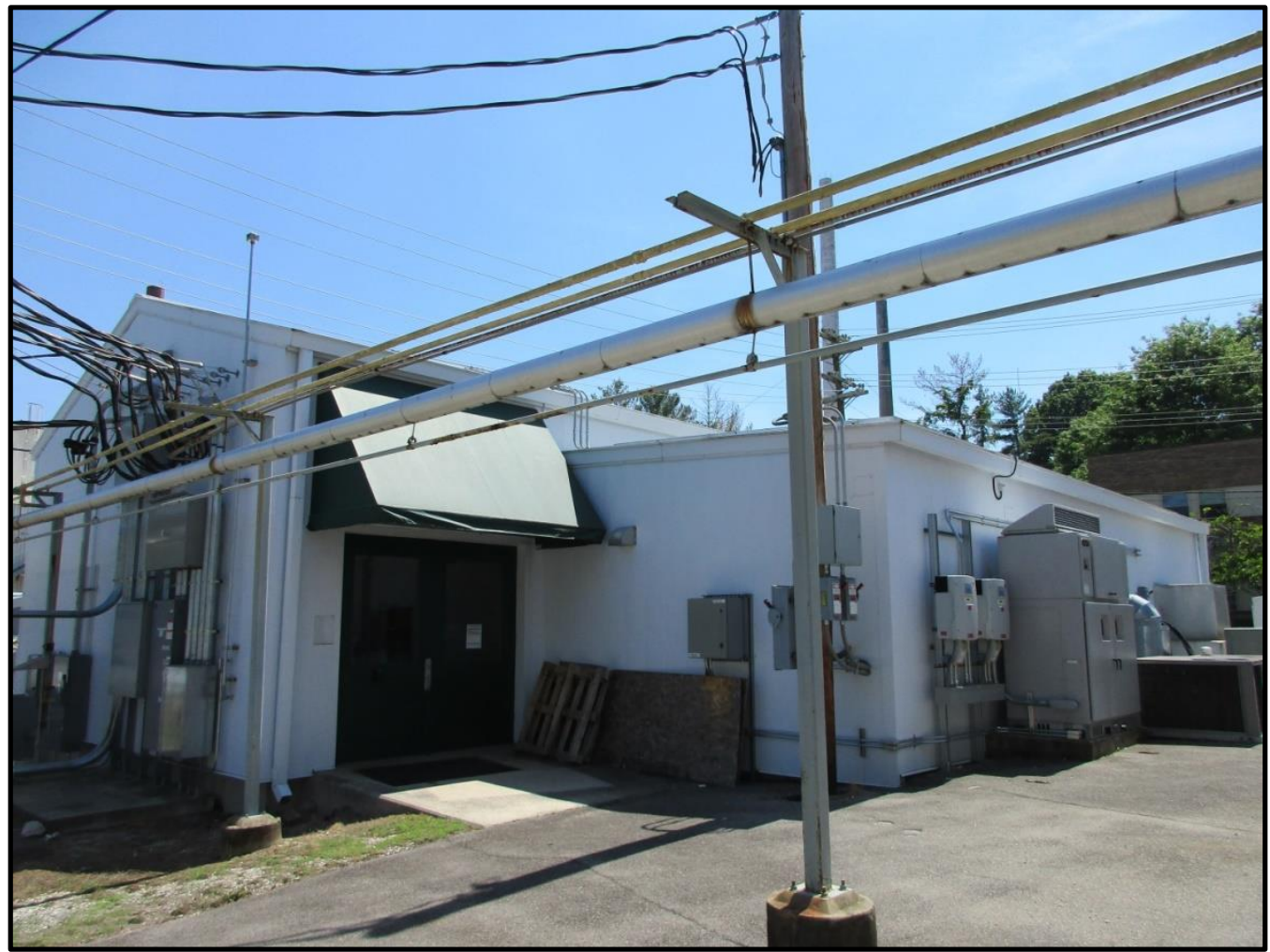

Figure 164. Overview of east elevation and partial north elevation of Building 3114. 


\section{BUILDING NAME}

Radioisotope Production Laboratory - $\mathrm{H}$

DATE OF CONSTRUCTION

1965

\section{DOE OFFICE RESPONSIBLE}

EM (UCOR)

\section{NRHP ELIGIBILITY}

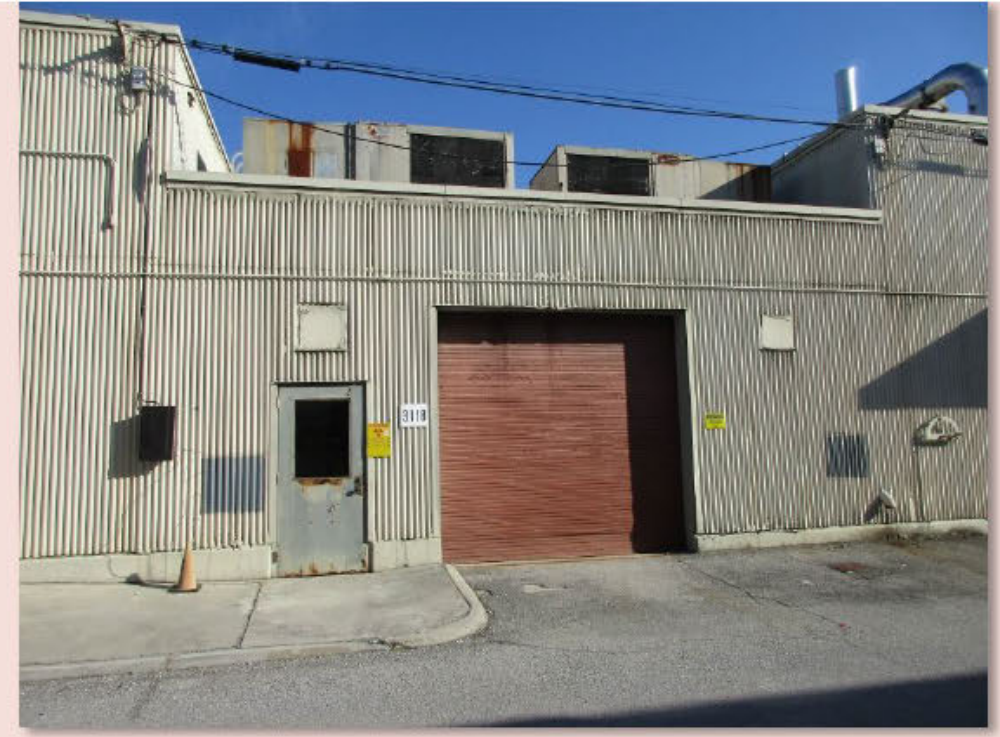

Figure 165. Overview of south elevation of Building 3118.

Contributing to ORNL Historic District

\section{DESCRIPTION}

Building 3118 is situated between Building 3030 and Building 3031 in a line of buildings situated north of Central Avenue. Building 3118 is a one-story, two-bay, flat-roof, steel frame structure with a concrete foundation and is clad with corrugated metal siding (Figure 165). The building, oriented to the south, has metal coping along the roof's edge. The building's facade features a single-leaf entry filled by a single-light metal pedestrian door and a large entry filled with a roll-up garage door.

\section{NATIONAL REGISTER EVALUATION}

Building 3118 was constructed in 1965 and historically functioned as a radioisotope production laboratory. The building was previously surveyed in 2015 and recommended as a contributing resource to the ORNL Historic District (Thomason and Associates 2015). The building retains a majority of its historic materials, as well as its form and massing. As a research/laboratory facility, Building 3118 housed work that furthered ORNL's mission in nuclear science during the Cold War era. However, the building is not the single location most importantly associated with a scientific achievement, scientist, or other event or person of historic significance to merit individual listing in the NRHP under Criterion A or B. Furthermore, the building lacks notable architectural elements that would warrant individual listing in the NRHP under Criterion C. Instead, the significance of Building 3118 is best understood within the broader context of the body of work advanced by researchers in the ORNL Historic District during the Cold War era. As such, Building 3118 does not warrant individual listing in the NRHP under Criterion A, B, or C; however, the building is a contributing resource to the ORNL Historic District. 


\section{BUILDING NAME}

LGWO Documentation Management Storage

\section{DATE OF CONSTRUCTION}

1976

\section{DOE OFFICE RESPONSIBLE}

EM (UCOR)

\section{NRHP ELIGIBILITY}

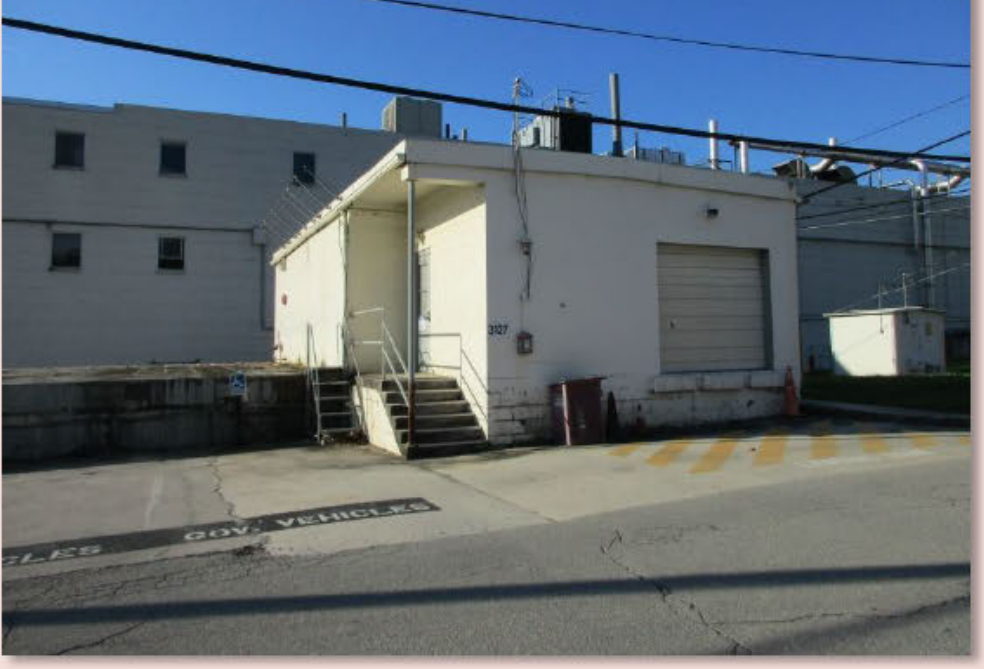

Non-Contributing to ORNL Historic District

\section{DESCRIPTION}

Building 3127 is located along the south side of Hillside Avenue, just west of its intersection with Fifth Street. Building 3127 a one-story, single-bay, flat-roof, concrete block masonry building supported by a concrete foundation (Figures 166 and 167). Oriented to the north, the south (rear) elevation of Building 3127 is attached to Building 3047. The façade (north) elevation features a loading bay filled with an industrial roll-up garage door. Concrete stairs on the east corner of the façade lead to a recessed single-leaf entry along the east elevation, filled with a two-light metal pedestrian door.

\section{NATIONAL REGISTER EVALUATION}

Building 3127 was constructed in 1976 as the Non-Nuclear Research Materials Vault and functions today as a structure for LGWO Documentation Management Storage. The building was previously surveyed in 1994 and recommended as non-contributing to the ORNL Historic District as it did not fall within the period of significance established at that time (Carver and Slater 1994). While the building retains the majority of its historic materials, as well as its form and massing, it still has yet to reach the 50 -year mark and falls outside the recommended period of significance for the ORNL Historic District. The building lacks the necessary significance to warrant listing in the NRHP, individually or as a contributing resource to the district. As a storage facility, Building 3127 provided support for work that furthered ORNL's mission in nuclear science during the Cold War era. However, the building is not the single location most importantly associated with a scientific achievement, scientist, or other event or person of historic significance to merit individual listing in the NRHP under Criterion A or B. Furthermore, the building lacks notable architectural elements that would warrant individual listing in the NRHP under Criterion $\mathrm{C}$. In addition, it is not an integral support resource necessary to the functioning of research and processing facilities in the ORNL Historic District during the Cold War era. Thus, Building 3127 is not individually eligible for listing in the NRHP under Criterion A, B, or C, nor is it contributing to the ORNL Historic District. 


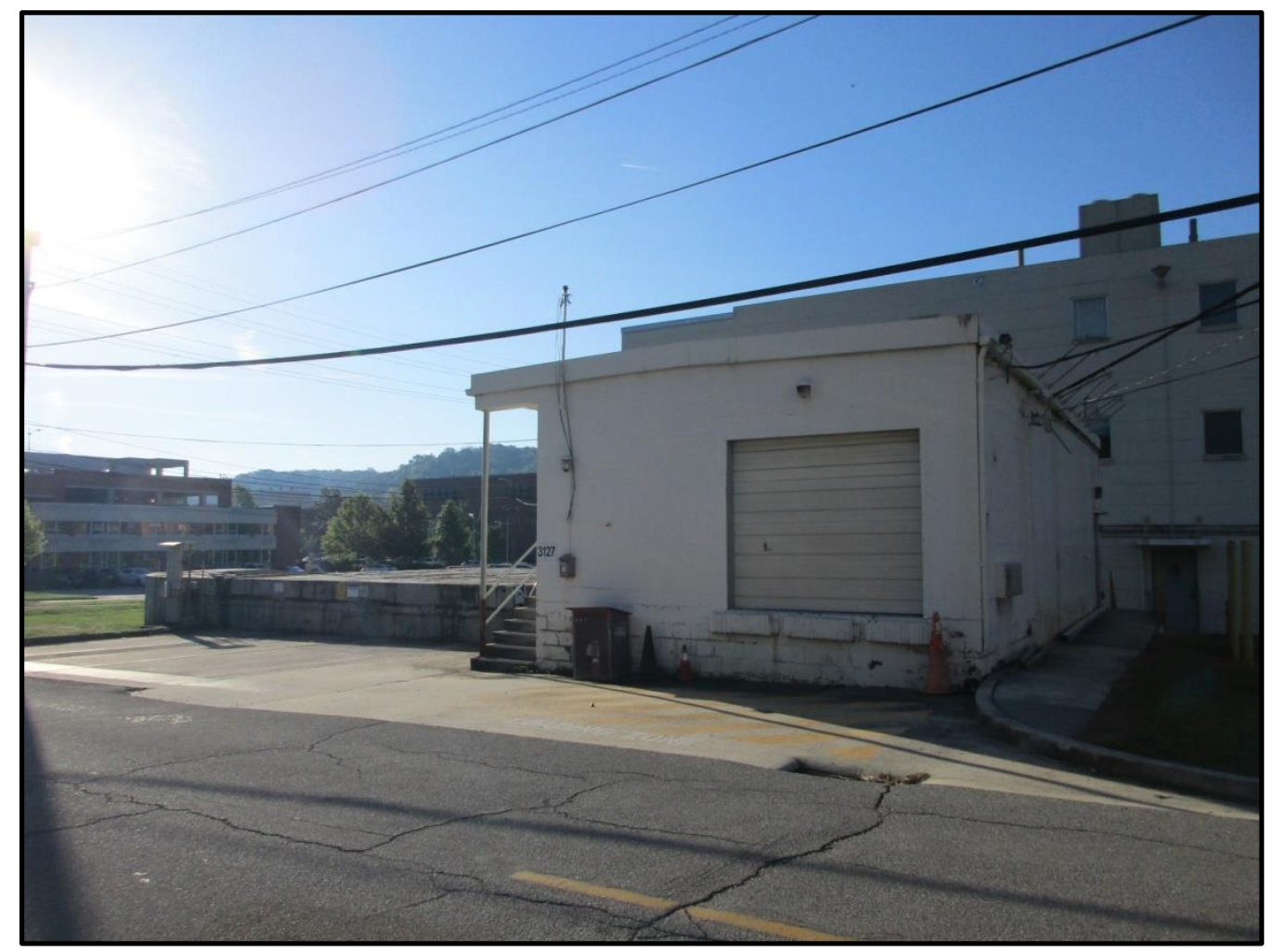

Figure 167. Overview of north and west elevations of Building 3127. 


\section{BUILDING NAME}

DECC Annex for Building 3114

\section{DATE OF CONSTRUCTION}

1976

\section{DOE OFFICE RESPONSIBLE}

SC

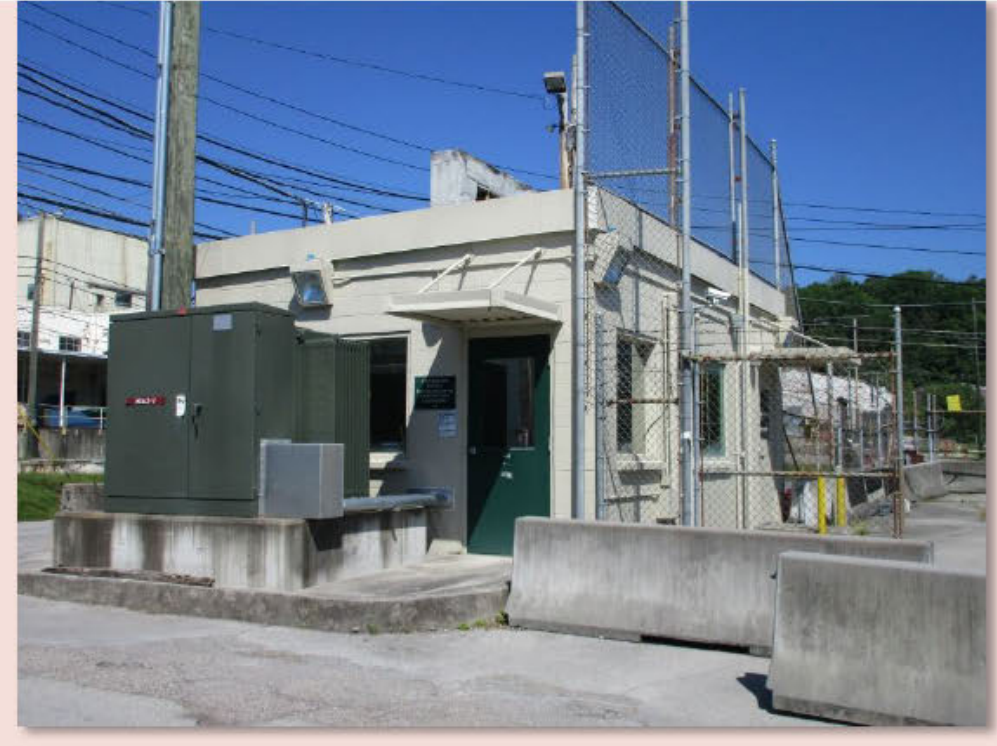

\section{NRHP ELIGIBILITY}

Figure 168. Overview of south and east elevations of Building 3129.

Non-Contributing to ORNL Historic District

\section{DESCRIPTION}

Building 3129 is located along the north side of Hillside Avenue, west of its intersection with Fifth Street. Oriented to the south, Building 3129 a small one-story, two-bay, flat-roof, concrete block masonry building with a concrete foundation (Figures 168 and 169). Metal coping runs along the roof's edge. The façade features a single-leaf entry near the east elevation filled with a single-light pedestrian door sheltered by a flat-roof metal awning. Another pedestrian entry is located on the rear (north) elevation. The building features windows with single-light fixed sashes and concrete sills on all elevations.

\section{NATIONAL REGISTER EVALUATION}

Building 3129 was constructed in 1976 as a personal monitoring station, and at some point after 1994 it was used as on office annex for Building 3114. The building was previously surveyed in in 1994 and recommended as non-contributing to the ORNL Historic District as it fell outside the period of significance established at that time (Carver and Slater 1994). While the building retains the majority of its historic materials, as well as its form and massing, it still has yet to reach the 50-year mark and falls outside of the period of significance for the ORNL Historic District. The building lacks exceptional significance to warrant listing in the NRHP, individually or as a contributing resource to the district. As a utility/maintenance facility, Building 3129 provided utilitarian support services for work that furthered ORNL's mission in nuclear science during the Cold War era. However, the building is not the single location most importantly associated with a scientific achievement, scientist, or other event or person of historic significance to merit individual listing in the NRHP under Criterion A or B. Furthermore, the building lacks notable architectural elements that would warrant individual listing in the NRHP under Criterion C. Also, Building 3129 is not an integral support resource necessary to the functioning of research and processing facilities in the ORNL Historic District during the Cold War era, and it now functions as an office building. As such, Building 3129 does not warrant individual listing in the NRHP under Criterion A, B, or $\mathrm{C}$, nor is it a contributing resource to the ORNL Historic District. 


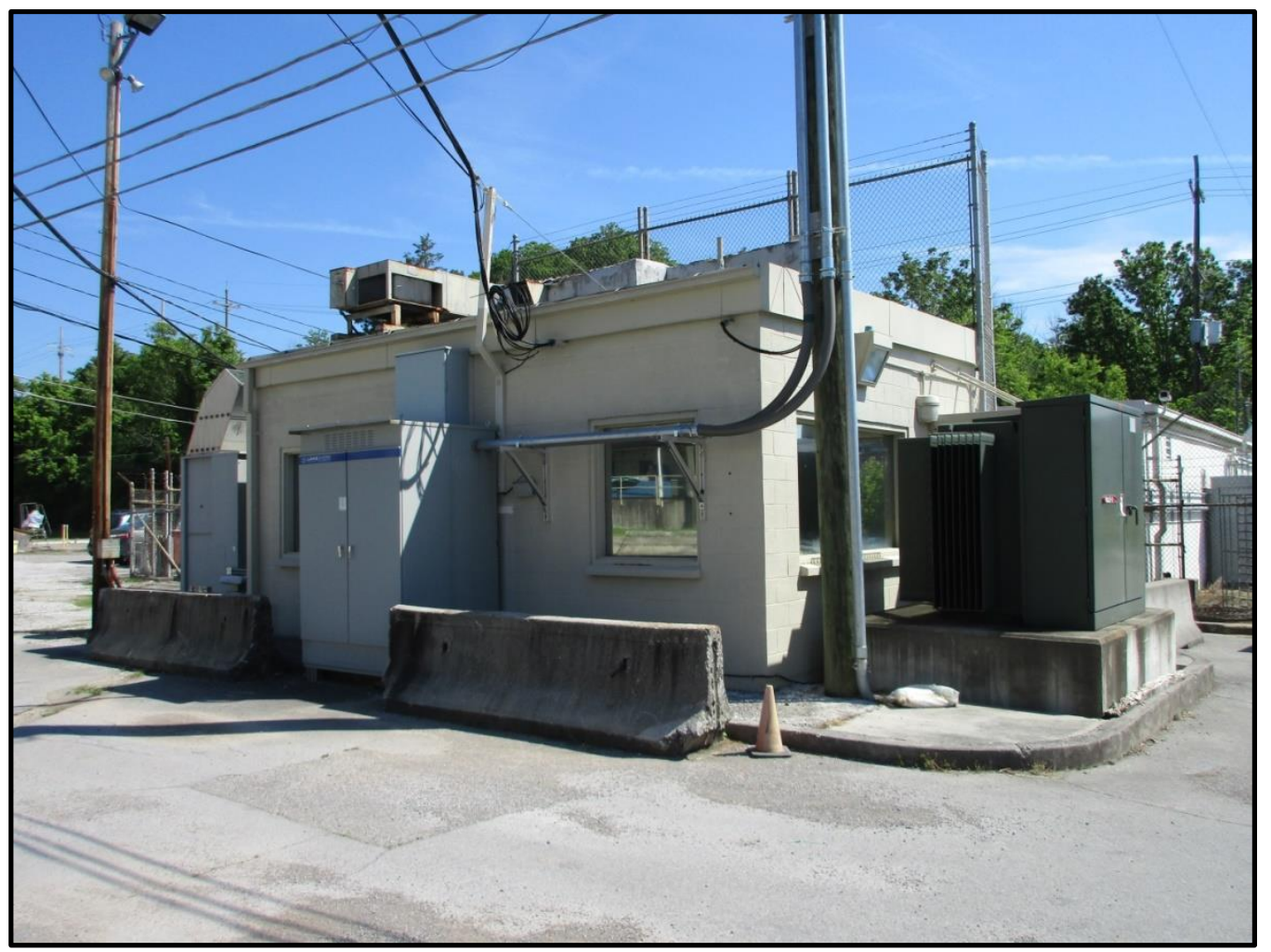

Figure 169. Overview of west and south elevations of Building 3129. 


\section{5}

\section{BUILDING NAME}

Sentry Post-8D

\section{DATE OF CONSTRUCTION}

1968

\section{DOE OFFICE RESPONSIBLE}

EM (Isotek)

\section{NRHP ELIGIBILITY}

Non-Contributing to ORNL Historic District

\section{DESCRIPTION}

Building 3135 is located within the barricaded portion of the 3000 Area along the east side of Third Street. Access to this high-security area of the 3000 Area is restricted; therefore, photographs of the building's exterior were not allowed. The building is a one-story concrete building, totaling at $408 \mathrm{sq} \mathrm{ft}$. The building is sheltered by a flat roof and features windows with fixed single-light sashes. The structure sits adjacent to Building 3019B.

\section{NATIONAL REGISTER EVALUATION}

Building 3135 was constructed in 1968 to serve as a Sentry Post. The building was previously surveyed in 1994 and recommended non-contributing to the ORNL Historic District due to its age (Carver and Slater 1994). Building 3135 was surveyed again in 2015 and recommended contributing to the ORNL Historic District. However, due to the building's construction date, it still does not meet the 50-year mark and falls outside the currently-recommended period of significance for the ORNL Historic District. The building lacks the necessary significance to warrant listing in the NRHP, individually or as a contributing resource to the district. As a utility/maintenance facility, Building 3135 provided utilitarian support services for work that furthered ORNL's mission in nuclear science during the Cold War era. However, the building is not the single location most importantly associated with a scientific achievement, scientist, or other event or person of historic significance to merit individual listing in the NRHP under Criterion A or B. Furthermore, the building lacks notable architectural elements that would warrant individual listing in the NRHP under Criterion C. In addition, Building 3135 is not an integral support resource necessary to the functioning of research and processing facilities in the ORNL Historic District during the Cold War era. As such, Building 3135 does not warrant individual listing in the NRHP under Criterion $\mathrm{A}, \mathrm{B}$, or $\mathrm{C}$, nor is it a contributing resource to the ORNL Historic District. 


\section{BUILDING NAME}

Instrumentation Research Facility;

Instrumentation \& Controls Division Offices

and Research Facility

\section{DATE OF CONSTRUCTION}

1951

DOE OFFICE RESPONSIBLE

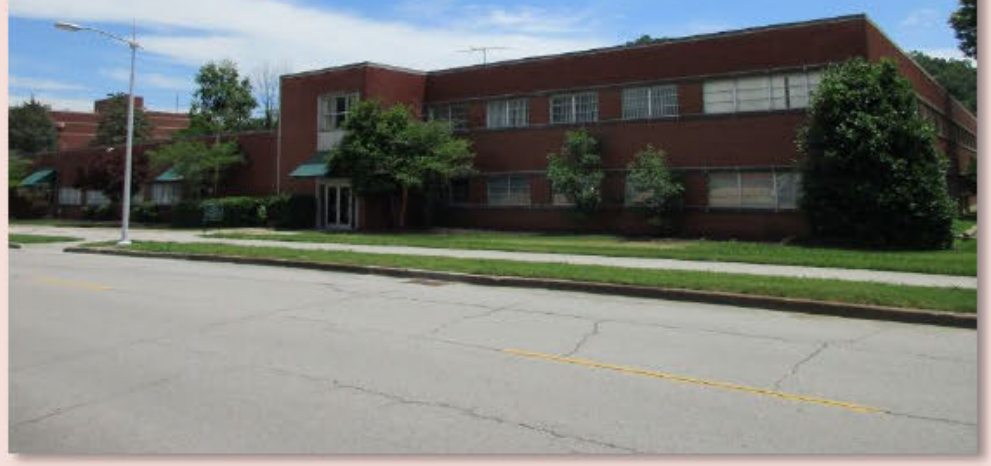

SC

\section{NRHP ELIGIBILITY}

Contributing to ORNL Historic District

\section{DESCRIPTION}

Building 3500 was one of 15 resources selected for intensive survey by UT-B as a part of survey planning. It is located immediately south of Isotope Circle, near the intersection of Central Avenue and Fifth Street on the main campus of ORNL. Building 3500 is comprised of two sections: a one-story rectangular brick section built in 1951 and a two-story rectangular brick section with a high bay built in 1960 (Figure 170). The two sections of the buildings are connected by a single door in a central corridor with a fire door between the two portions of the building.

Exterior: The original section of the building is a one-story rectangular block that features a variant of common bond with five courses of stretchers followed by a course of alternating headers and stretchers, similar to Flemish bond. Set upon a continuous poured concrete foundation, Building 3500 is sheltered by a flat roof of built-up tar and gravel with cast concrete coping. The façade, or north elevation, features two double-leaf entries that each feature double-leaf, full-light circa 1990 steel doors sheltered by a fabric awning (Figures 171 and 172). Cast concrete blocks, set into the brick of the façade, surround the entry and connect with bands of cast concrete that extend above and below a bank of windows that extends between the two façade entries (Figure 173). The windows, comprised of four sets of three windows divided by brick, feature three-light aluminum sashes with a two-light awning sash set above a stationary light. The east elevation features two single-leaf entries that have been enclosed with steel; it is devoid of window openings (Figure 174). The rear, or south, elevation of the one-story section of Building 3500 features a similar arrangement to the façade, however it is slightly elevated, so the rear entries open to a concrete porch and a concrete loading dock (Figure 175). The porch and loading dock feature tubular steel handrails. A one-story corrugated metal shed with a corrugated shed roof is situated on a portion of the loading dock. The windows on the rear elevation feature replacement glazing that is somewhat reflective; however, the windows retain original sashes (Figure 176).

The two-story addition to Building 3500 reflects a compatible design and also features a variant of common bond brick construction with five courses of stretchers followed by a course of alternating headers and stretchers, similar to Flemish bond. It is also situated on a continuous poured concrete foundation and is 
sheltered by a flat built-up tar and gravel roof with cast concrete coping. The primary façade entry of the building is located on a small, two-story projection that is flush with the original portion of the façade; the remainder of the façade of the two-story section is recessed behind the depth of the lobby (Figure 170). The façade entry features double-leaf circa 1990 full-light aluminum doors flanked by full sidelights and is sheltered by a fabric awning (Figure 177). Six square stationary windows, centered above the façade entry, and the façade entry are set off by cast concrete blocks and panels. The building features three-light metal awning windows throughout. Similar to the one-story section, banks of windows in pairs and groups of four extend along the first and second floors of the two-story section of Building 3500. Bands of cast concrete extend above and below both of these banks of windows. The west, or side, elevation features single and paired windows also set off by cast concrete on both the first and second floors (Figure 178). Two single-leaf entries on the first floor feature single-light steel doors that are sheltered by fabric awnings. The southern end of the two-story section of Building 3500 features a high-bay, a two-story open area. A structural steel stair provides access to a rear entry with a single-light steel door on the high bay (Figure 179). Flat metal awnings supported by steel cables extend over this entry as well as a section of the loading dock below. A concrete stairwell provides access to the basement of Building 3500 . The south, or side, elevation of the high bay features a large, two-story, segmented garage door that opens to a loading dock (Figure 180). A secondary entry with a single-light steel door opens to a second loading dock located to the right of the high bay door that is sheltered by a flat metal roof. The south elevation of the second story section extends above the one-story section. Paired two-light metal awning windows set above a cast concrete band extend along this elevation.

Interior: The interior of Building 3500 features a combination of laboratories, offices, conference rooms, and a high bay. The first floor section of the building is comprised of offices, conference rooms, restrooms, and laboratories aligned along two primary hallways that run the length of the building (north to south) and two smaller hallways that run the width of the building (east to west). A fifth hallway, Corridor $\mathrm{J1}$, connects the original section to the two-story addition. Except outside of a large renovated conference room located in the southern corner, the interior walls of the original section are constructed of concrete block or metal interlocking panels (Figure 181). The floors of the hallways and updated breakrooms feature replacement $1 \mathrm{ft}$ square commercial grade tile. The majority of interior entries retain original single-light steel doors with copper hardware and kick plates. Restrooms in the original section feature glazed concrete block walls, original sinks, replacement commercial grade tile, and replacement stall dividers. Many of the offices have been renovated and feature sheet-rock walls and carpeted floors. Some of the labs retain original 9-in floor tile, however, many of the labs have been updated with vinyl flooring (Figure 182). The majority of cabinetry in the lab spaces has been replaced and updated through renovations.

A thick fire door signals the entry into the 1960 addition to Building 3500 from the original section (Figure 183). The two-story addition to the building features two long corridors that run the length of the addition (north to south), two short corridors that run the width of the addition (east to west), and the short corridor that connects the two parts of the building. Each hallway features replacement commercial grade tile, sheetrock walls, and drop ceilings and provides access to laboratory and office space (Figure 184). The majority of interior doors are original single-light steel doors with louvered vents and copper hardware (Figure 185). Doors that have been replaced feature a similar design and are metal with louvered vents. Restrooms feature 9-in commercial grade floor tile and glazed concrete block walls. A freight elevator and two sets of stairs provide access between the first and second floors and basement (Figure 186). The high bay, located at the rear of the addition, features a full two-story open space for storage and research use (Figure 187). The stairwell near the rear of the building, which provides basement access, features concrete steps with landings clad in original 9 -in tile. The lobby of the 
addition, which extends from the first floor to the second floor, has been renovated and features slate tile and rubberized flooring on the steps (Figures 188 and 189). It retains the original steel bannister with wooden handrails. The basement is comprised of mechanical space.

\section{NATIONAL REGISTER EVALUATION}

Constructed in 1951, the original 16,000 sq ft portion of Building 3500, known as the Instrumentation and Controls Division Offices and Research Facility, was the first permanent office and laboratory facility constructed at ORNL. Constructed at a cost of $\$ 435,000$, it was state-of-the-art and the easternmost facility at ORNL at the time of its construction. It was originally designed as a high technology development facility. The rooms on the perimeter of the building were designed to provide large offices and laboratories for research. The interior spaces of the building were designed for use by support staff and consisted of a drafting room, electronic stores, a machine shop, instrument shops, and administrative offices. The two-story 37,000 sq ft addition was constructed in 1960 (Peden and Mossman 1991; Carver and Slater 1994).

Describing the Instrumentation and Controls Division activities in 1963, W. E. Thompson explained that the facility was used for the development and modification of instruments for physics as well as those used for medical diagnostics of isotopes (Carver and Slater 1994; Thomason and Associates 2015).

Previous surveys in 1994 and 2015 recommended that Building 3500 was eligible for listing as a contributing element of the ORNL Historic District under Criterion A, for its historical associations with ORNL (Carver and Slater 1994; Thomason and Associates 2015). As a research/laboratory facility, Building 3500 played an important role in the scientific work that occurred at ORNL in the Cold War period, but research has not indicated that it is individually associated with specific scientific achievements, events, or persons of particular historic significance to merit individual listing in the NRHP under Criterion A or B. Additionally, it does not possess significant associations for its architectural or engineering design that would warrant individual listing under Criterion $C$. Thus, CRA recommends that it is not eligible for individual listing under Criterion $A, B$, or $C$. Rather, the significance of Building 3500 is reflected in its role within the larger context of post-World War II development and research at ORNL and as part of a collection of purpose-designed scientific processing and research facilities engineered to meet the specific needs of the advanced research occurring within their walls. Despite minor interior alterations and exterior changes including the construction of a large addition in 1960, which is itself historic, Building 3500 retains integrity to support its inclusion within the ORNL Historic District. Therefore, CRA concurs with Thomason's 2015 recommendation that Building 3500 is a contributing resource of the ORNL Historic District under Criterion A for its association with the post-World War II development of government-sponsored scientific laboratories, ORNL's evolution as a national laboratory, and early nuclear development and under Criterion $\mathrm{C}$ as a purpose-designed scientific research facility within the district. 


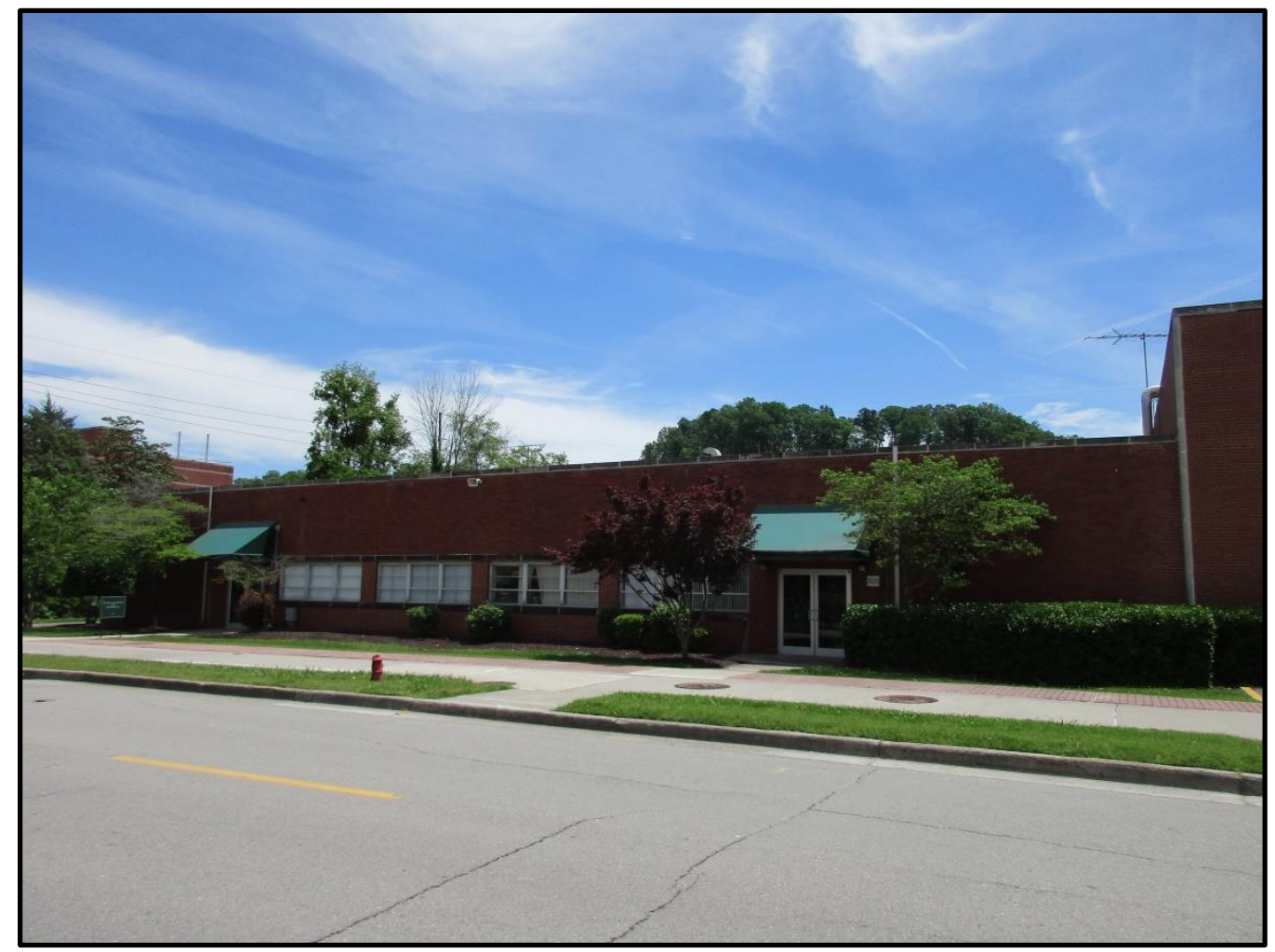

Figure 171. Overview of the façade of the 1-story section of Building 3500.

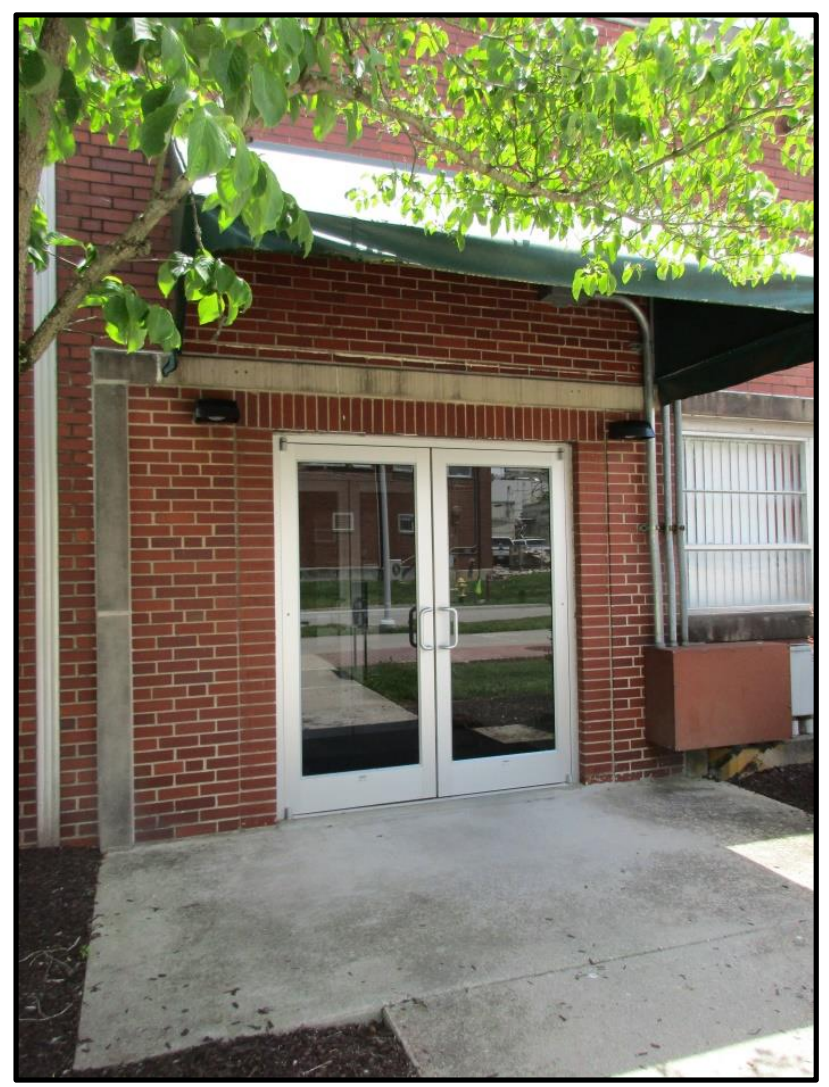

Figure 172. Façade entry with replacement doors on the 1story section of Building 3500 . 


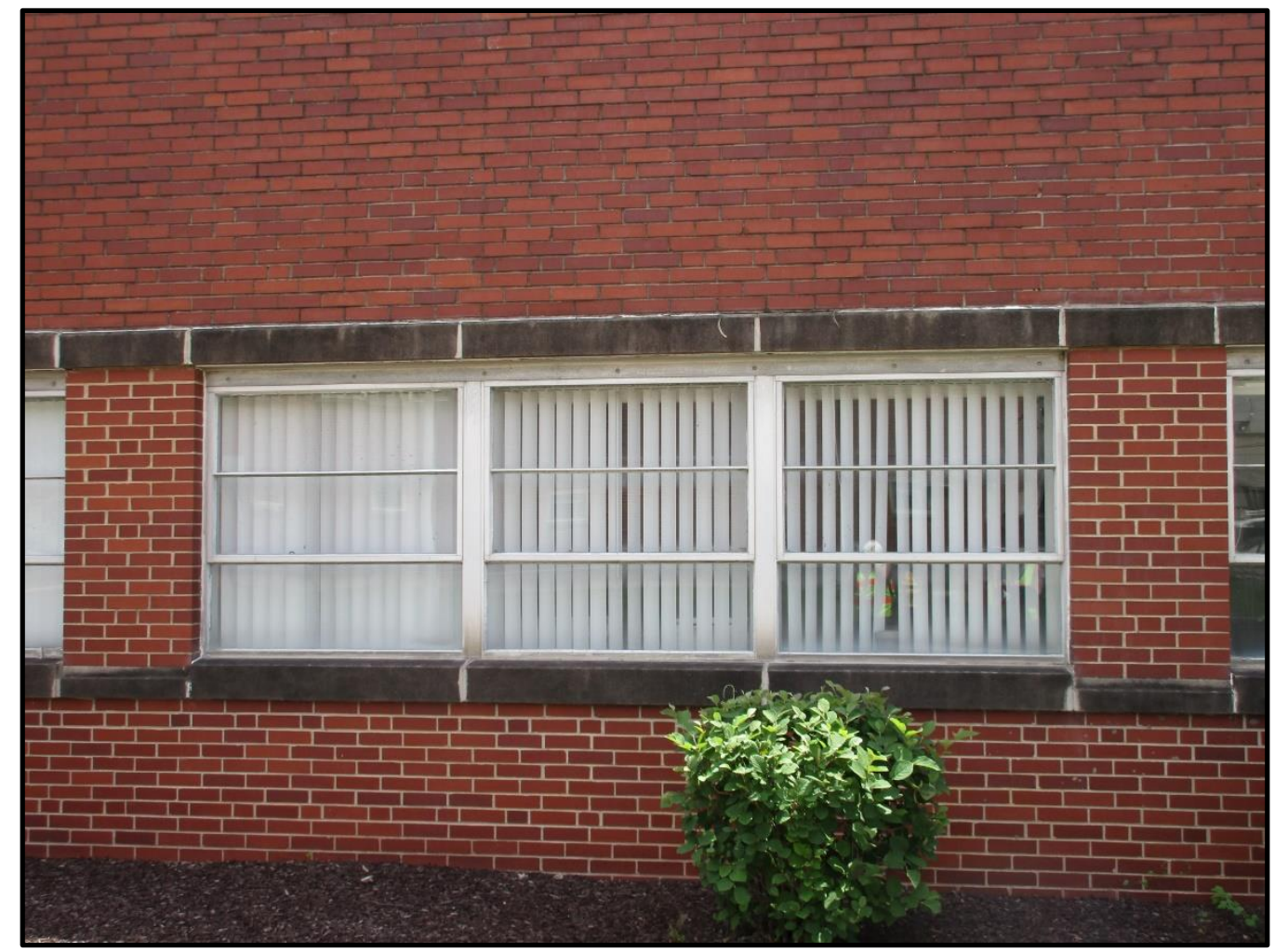

Figure 173. Detail of windows on north (façade) elevation of the 1-story section of Building 3500.

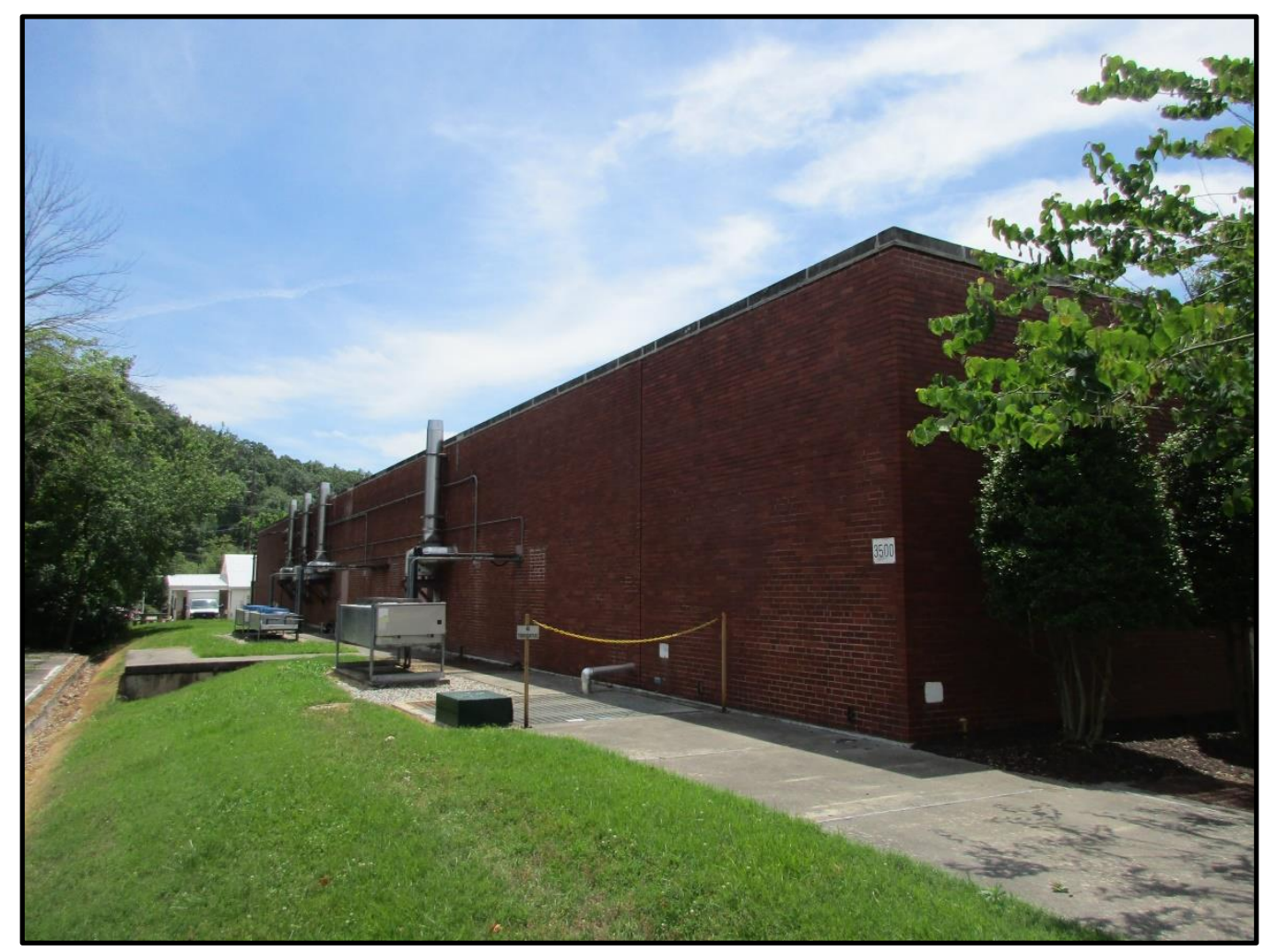

Figure 174. East elevation of the 1-story section of Building 3500. 


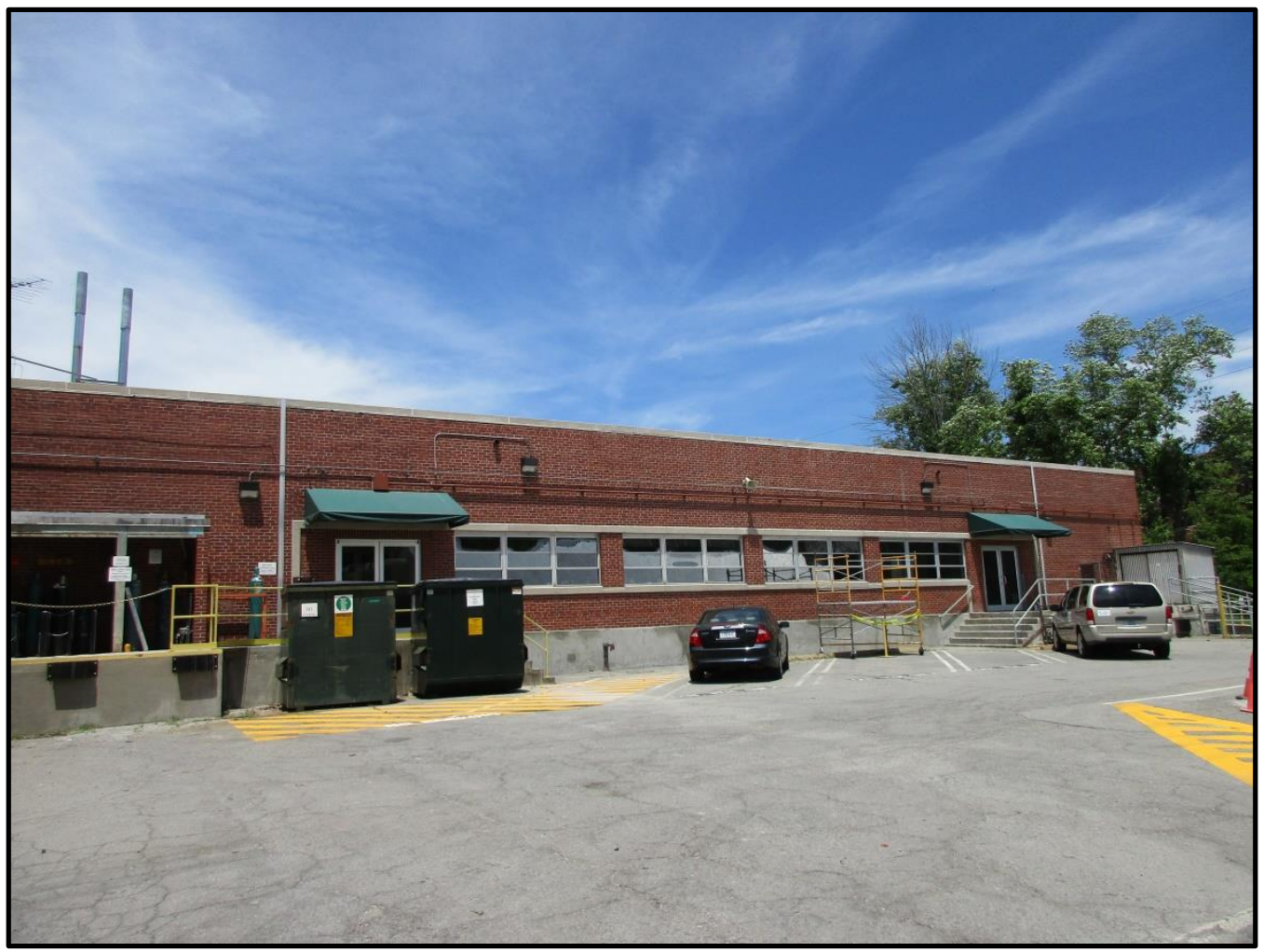

Figure 175. South (rear) elevation of the 1-story section of Building 3500.

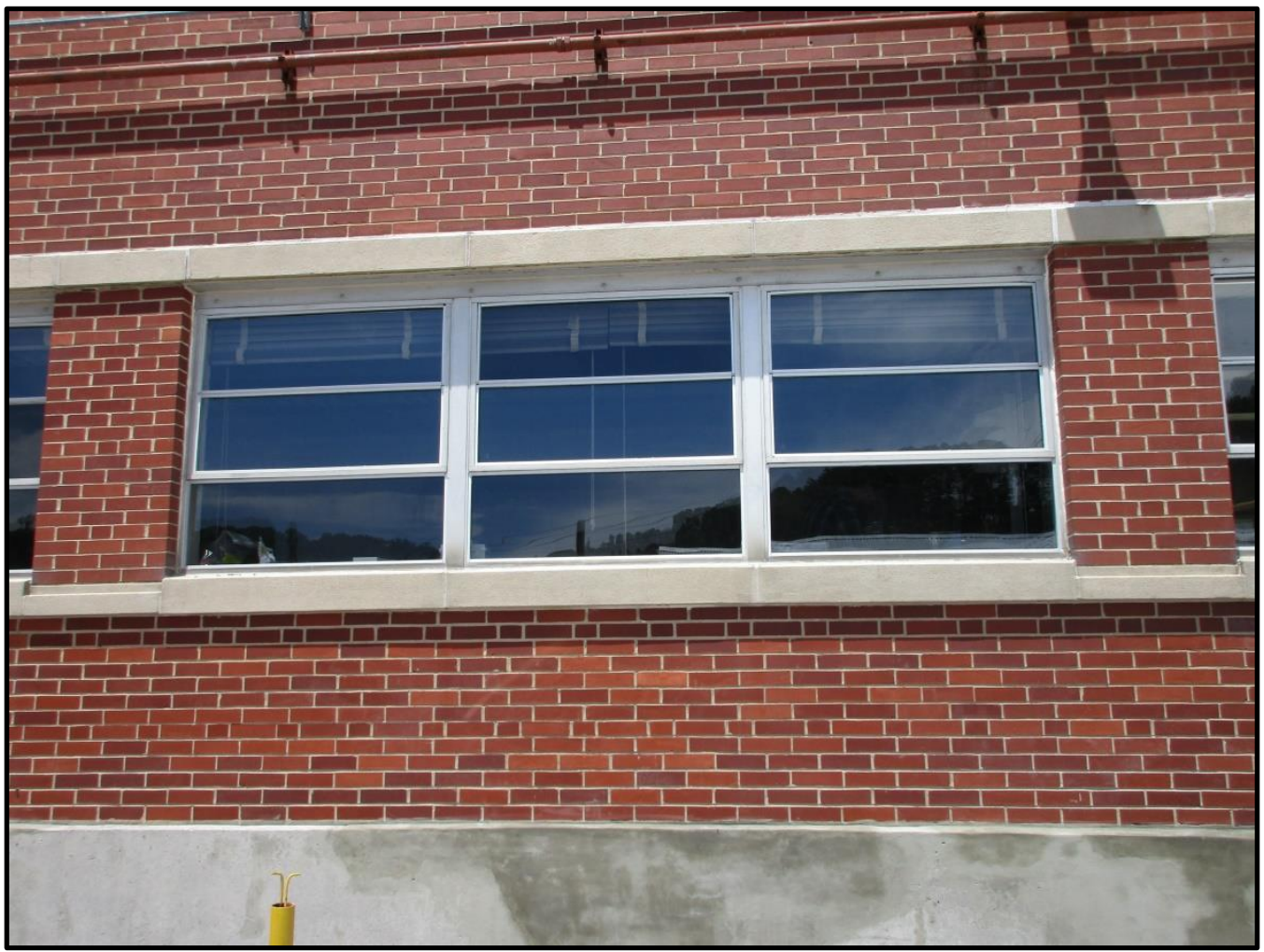

Figure 176. Window detail on south (rear) elevation of the 1-story section of Building 3500. 


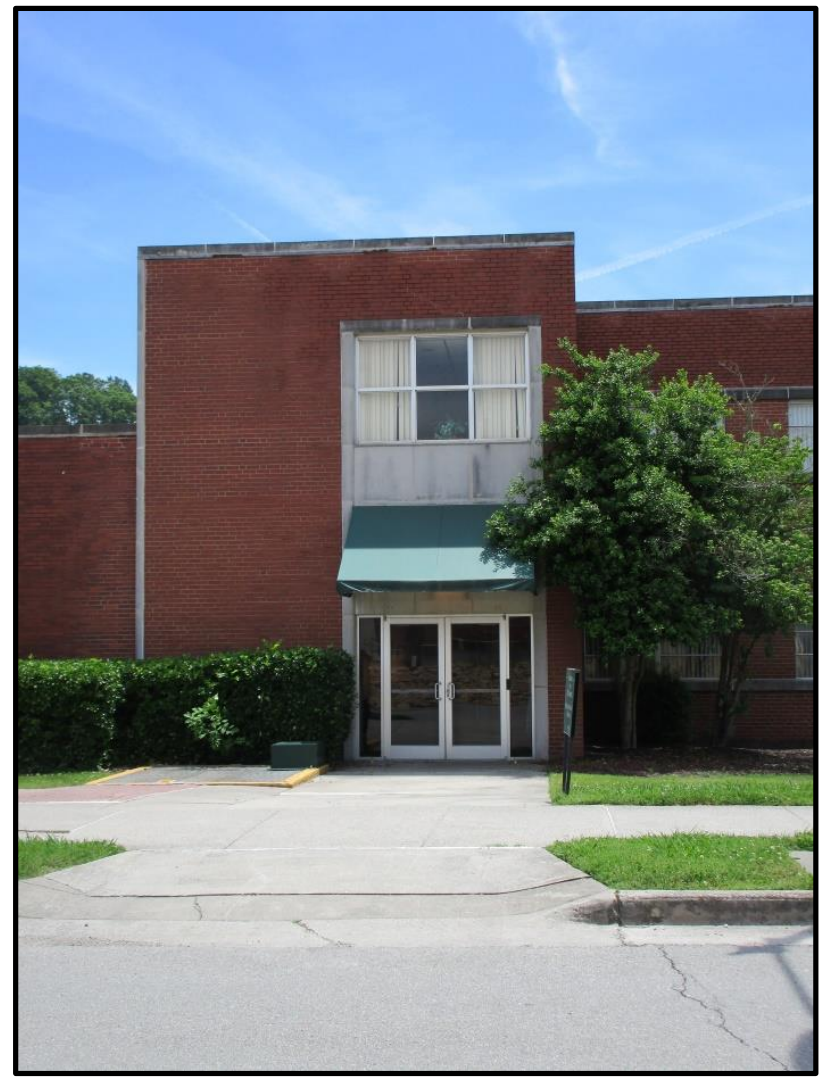

Figure 177. Lobby projection of the 2-story section of Building 3500 .

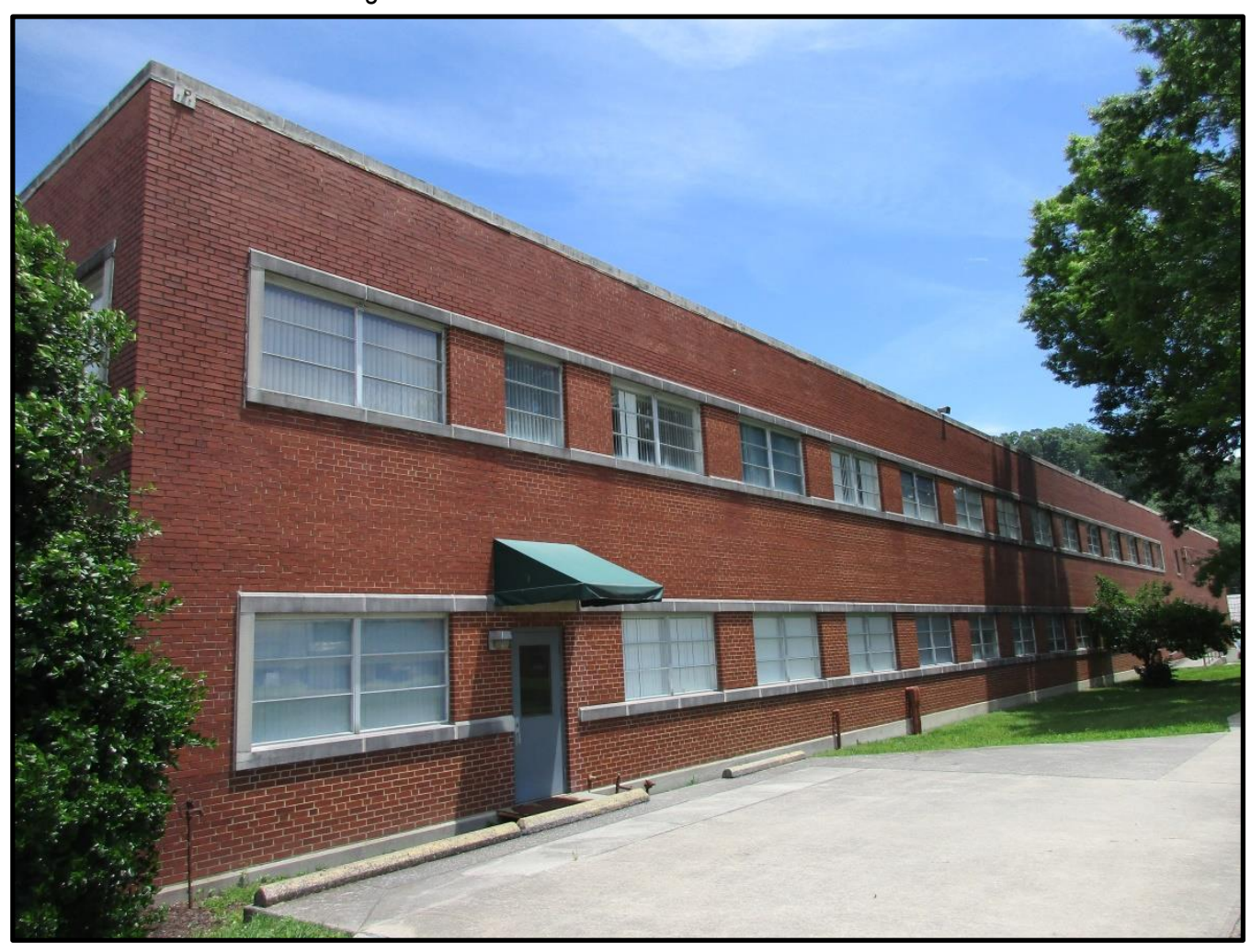

Figure 178. West elevation of the 2-story section of Building 3500. 


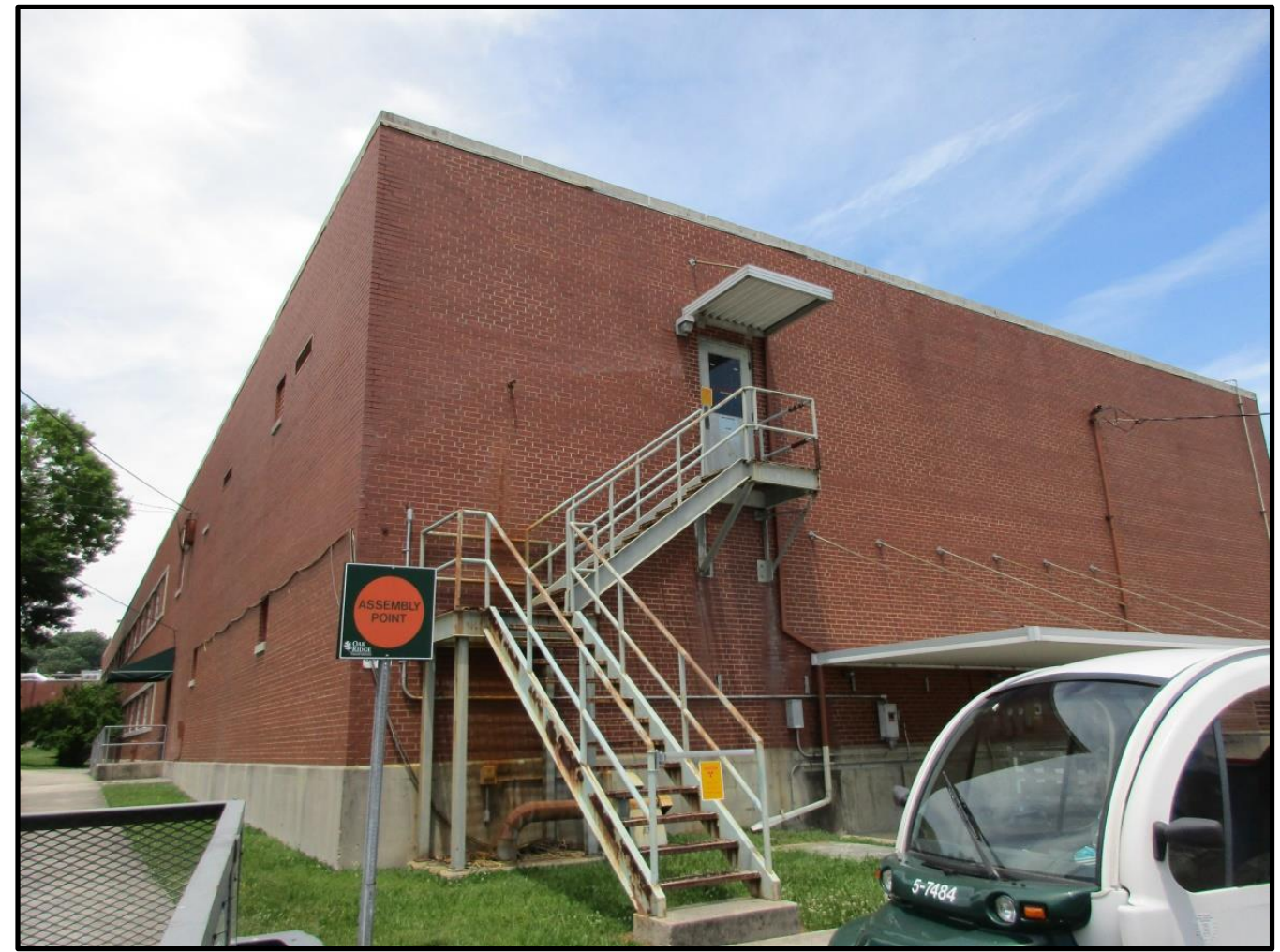

Figure 179. South (rear) elevation of the high bay on the 2-story section of Building 3500.

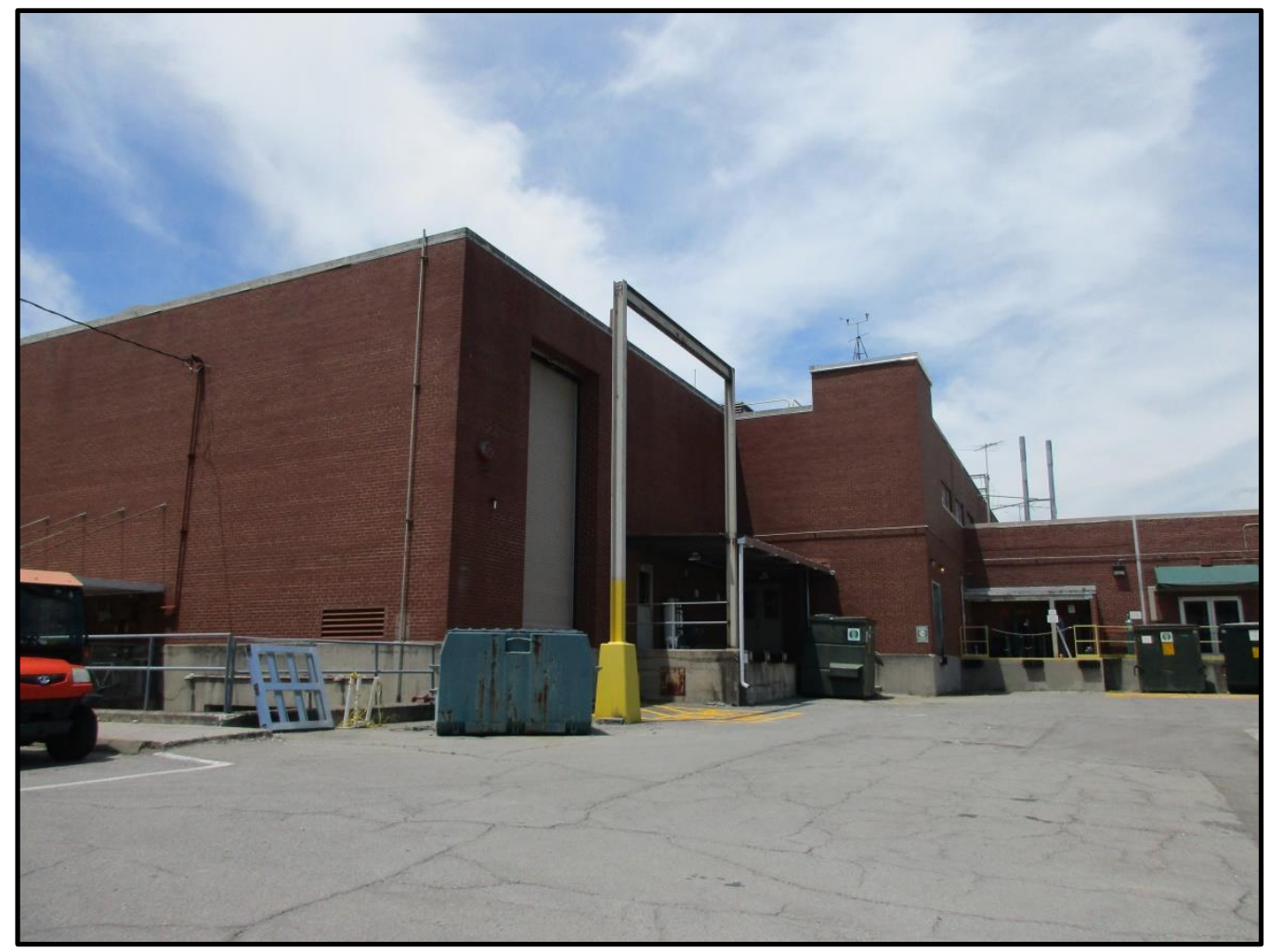

Figure 180. South elevation of the high bay on the 2-story section of Building 3500. 


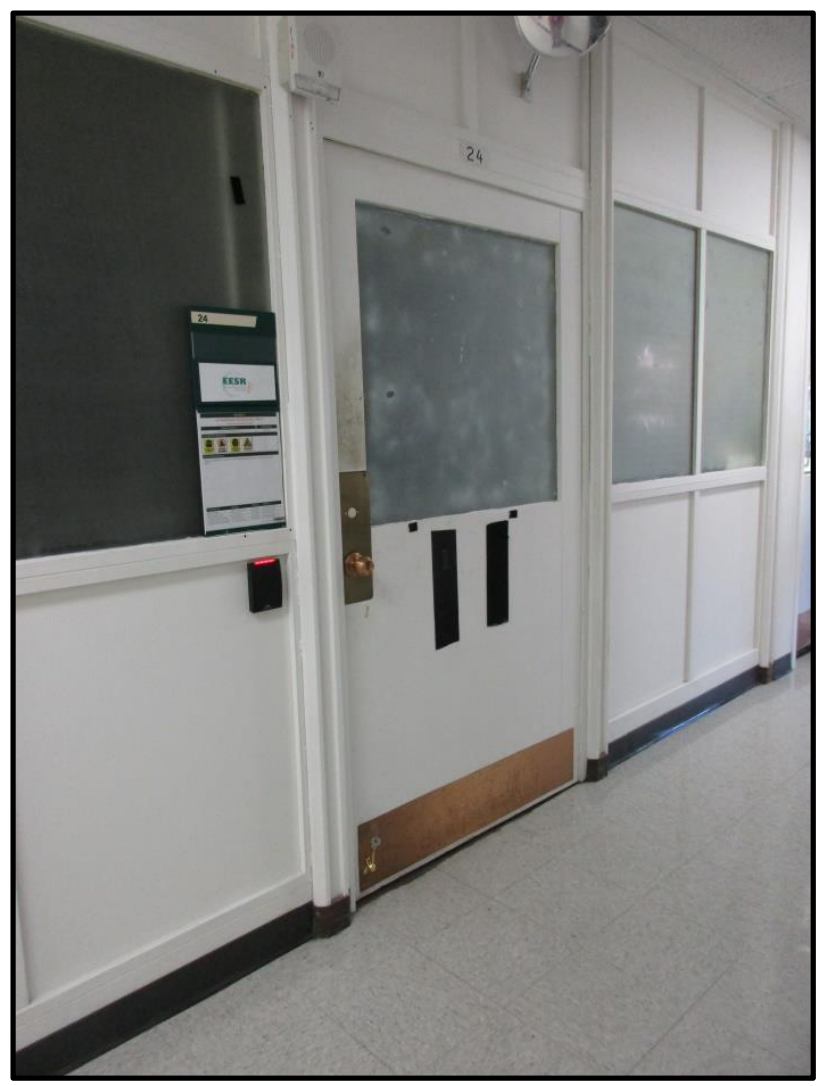

Figure 181. Interlocking metal dividers in 1-story section of Building 3500 .

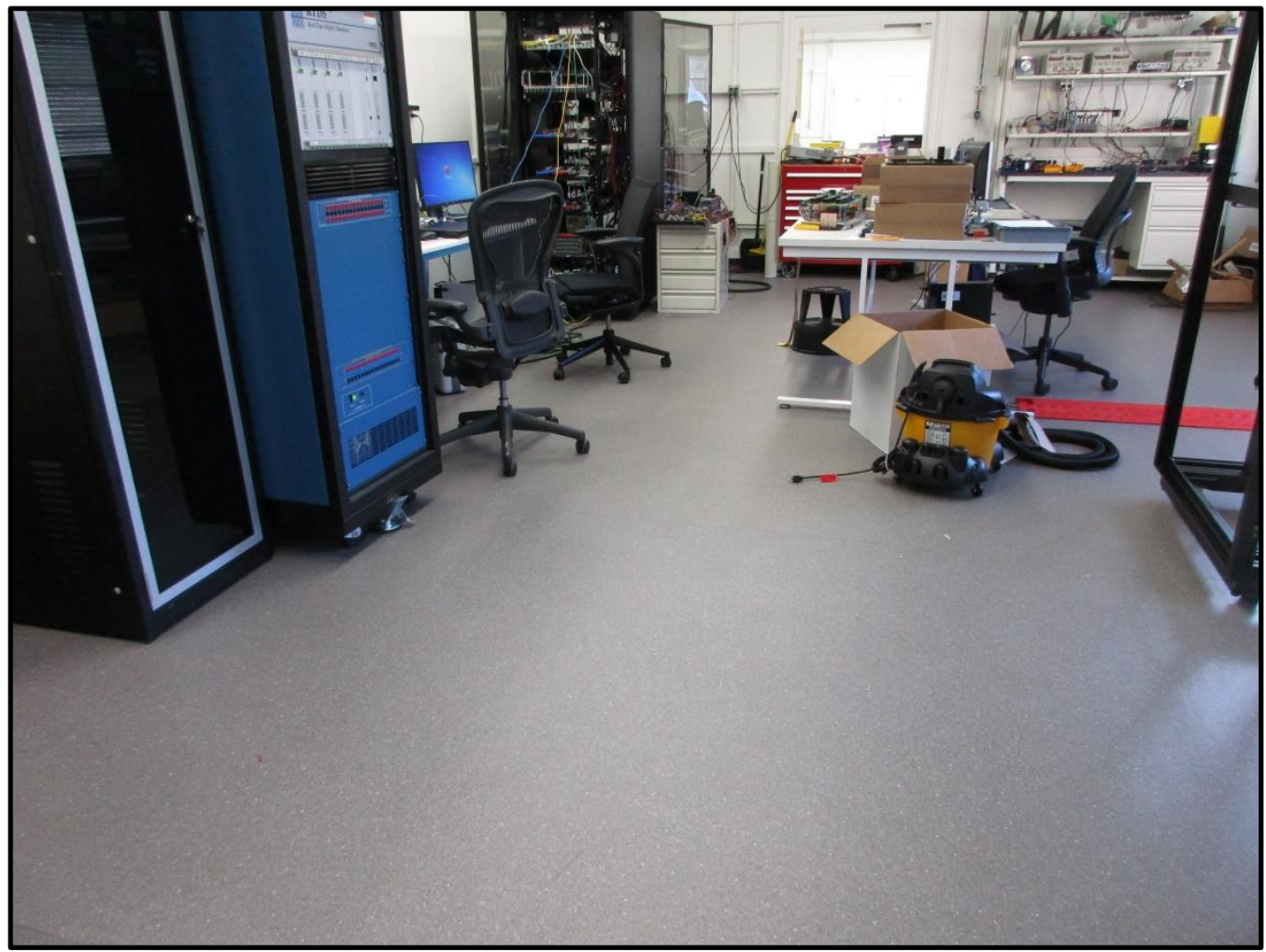

Figure 182. Renovated shop/laboratory space in 1-story section of Building 3500. 


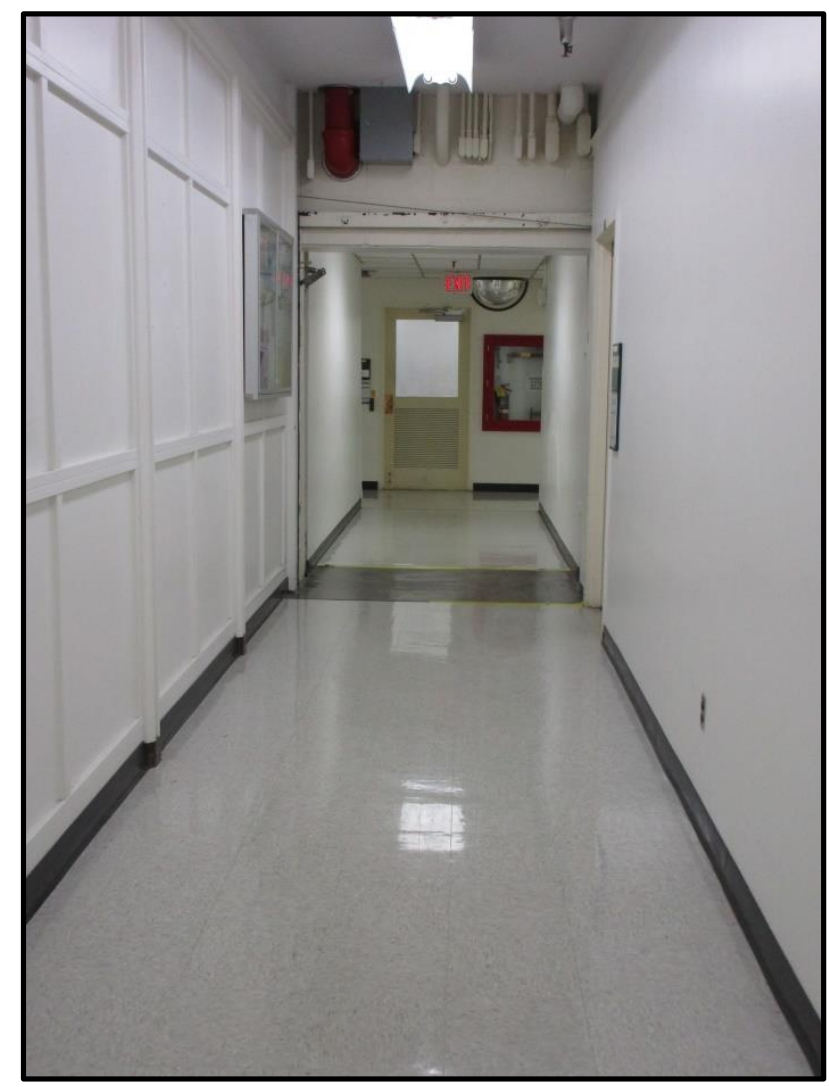

Figure 183. Hallway with fire door connecting original and addition sections of Building 3500 .

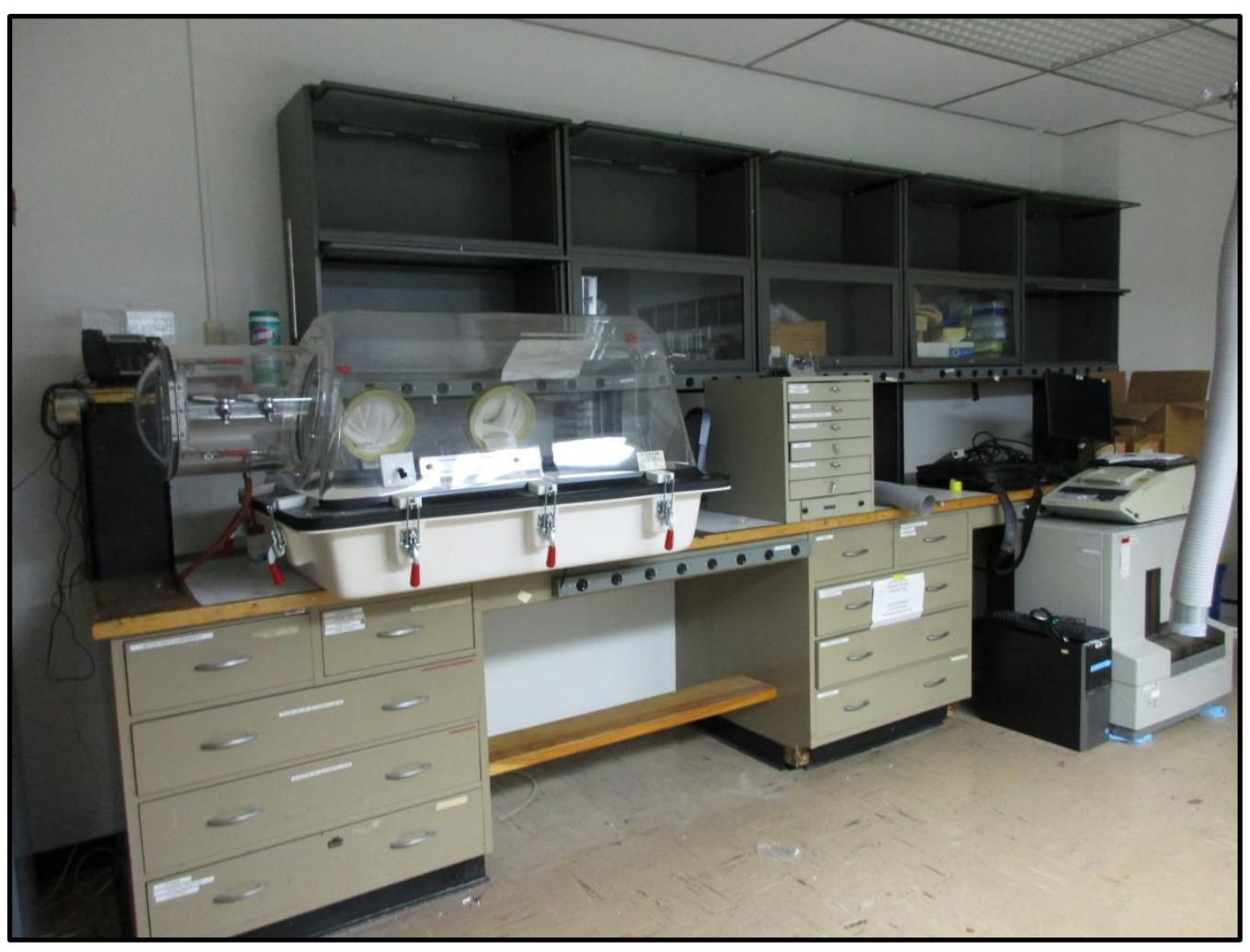

Figure 184. Renovated lab space on second floor of Building 3500. 


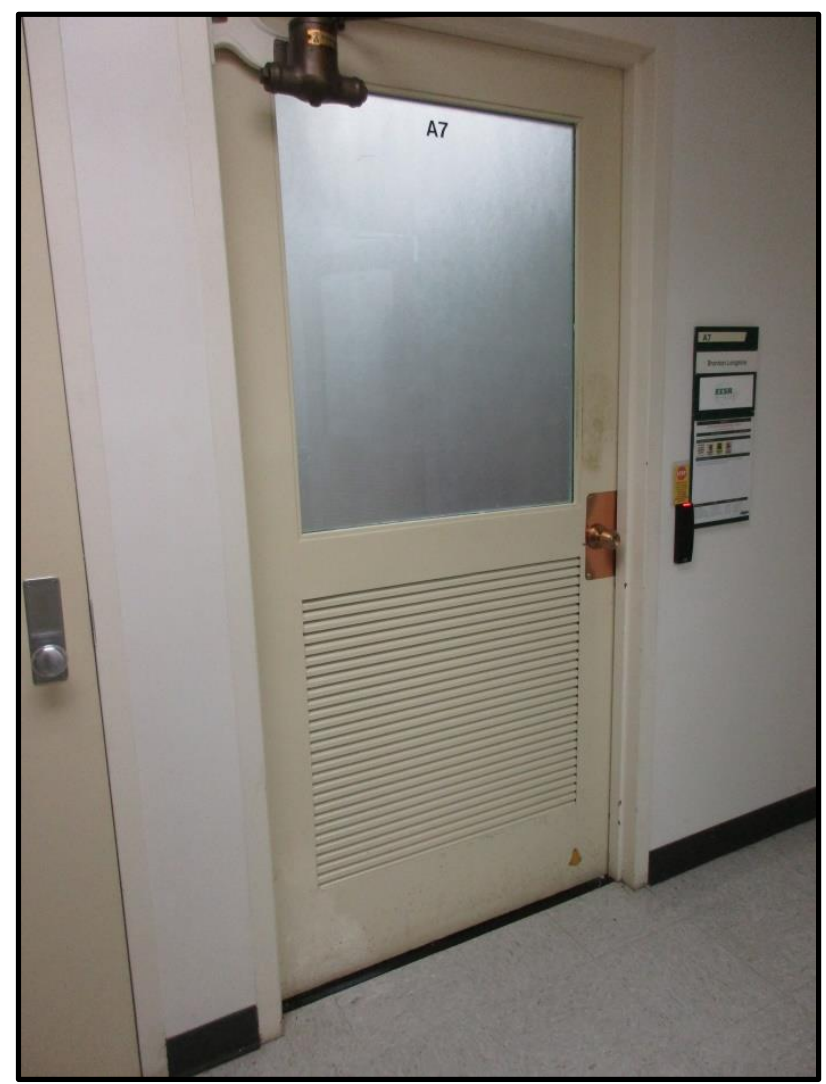

Figure 185. Original door in hallway of 2-story section of Building 3500.

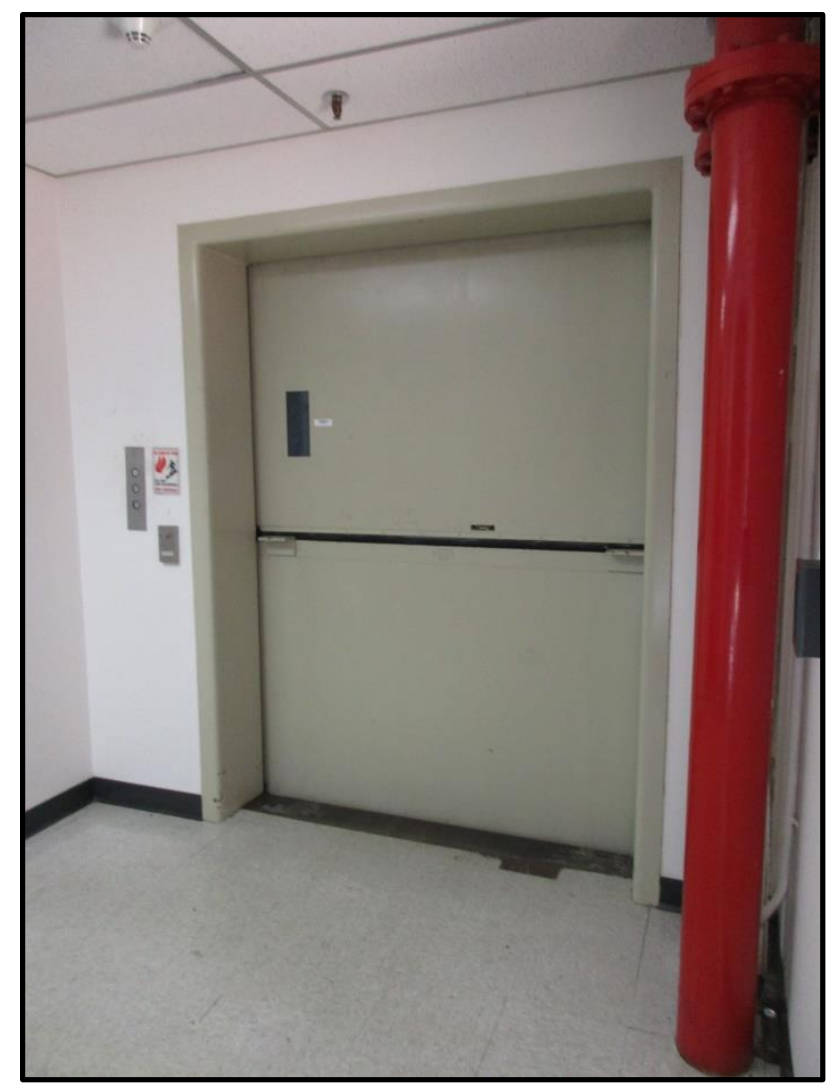

Figure 186. Freight elevator in 2-story section of Building 3500. 


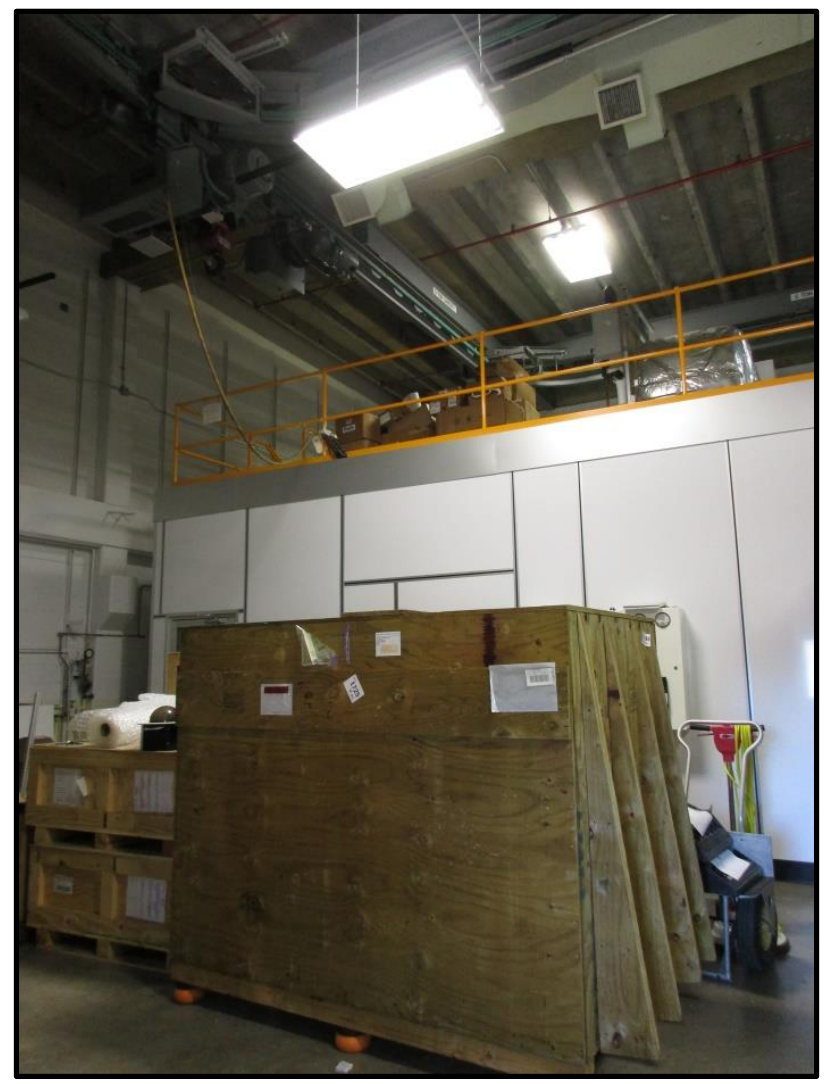

Figure 187. A two-story space for storage within Building 3500.

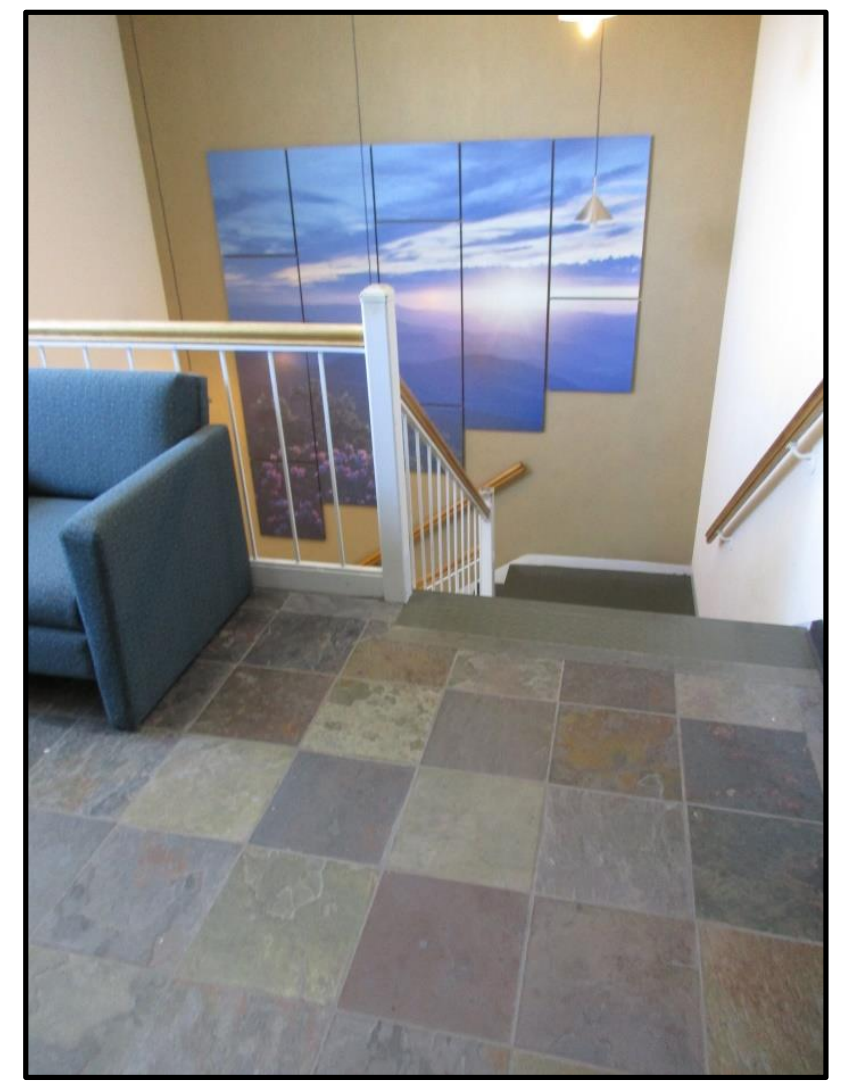

Figure 188. Second floor of lobby of Building 3500. 


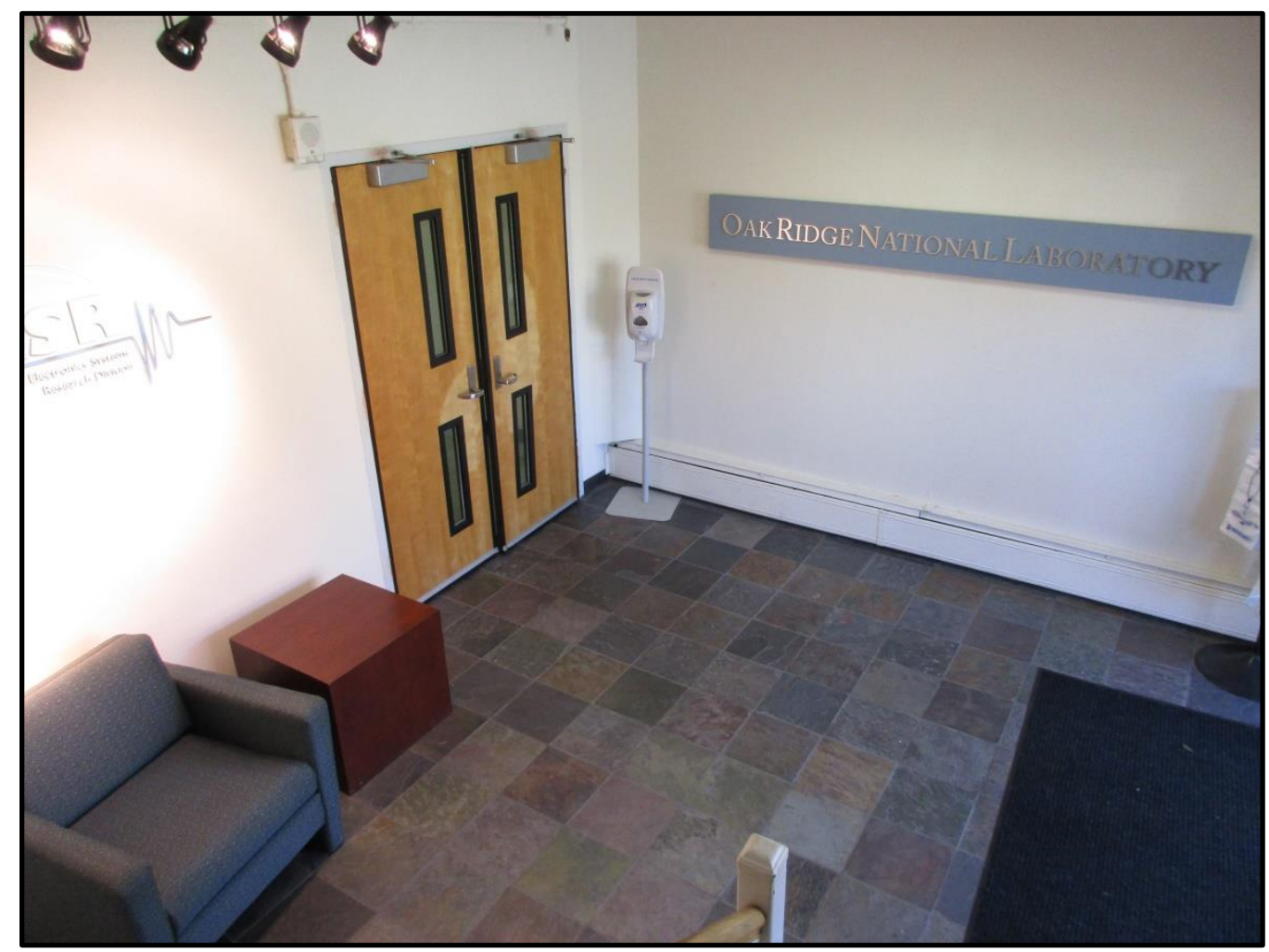

Figure 189. First floor of lobby of Building 3500. 


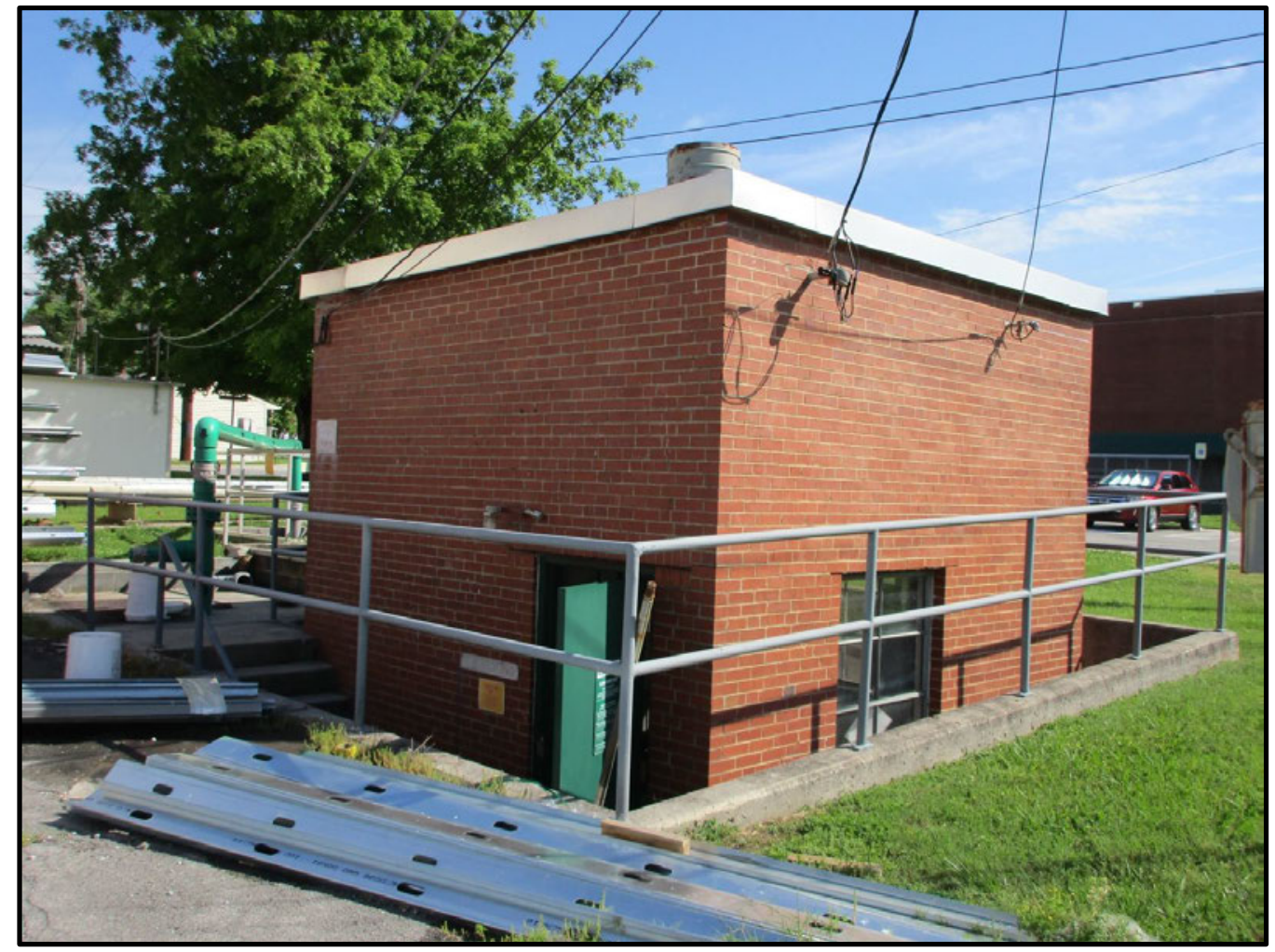

Figure 191. Overview of west and south elevations of Building 3501. 


\section{$3502 / 3502 B$}

\section{BUILDING NAME}

East Research Service Center

DATE OF CONSTRUCTION

1950

\section{DOE OFFICE RESPONSIBLE}

SC/EM (UCOR)

NRHP ELIGIBILITY

Figure 192. Overview of west elevation and partial south elevation of Building 3502 .

Contributing to ORNL Historic District

\section{DESCRIPTION}

Building 3502/3502B is located to the west of Fifth Street and the south side of White Oak Avenue, to the west of the intersection of the two streets. Building 3502 is a multi-story complex of connected sections (Figures 192 and 193). The main eastern section is a two-story, flat-roof, concrete block masonry structure oriented to the north. This two-story section features a single-leaf entry filled by a single-light metal pedestrian door and a vehicular entry filled with a roll-up garage door along the first floor of the façade (north) elevation. The rear (south) elevation has a similar vehicular or unloading entry and a second story single-leaf entry accessed by exterior metal stairs. Windows on the east elevation are filled with one-over-one, double-hung metal or vinyl sashes. A one-story, shed-roof, concrete block section is attached to the southern portion of the west elevation of the two-story section of Building 3502. The shed-roof is sheathed in corrugated metal and a double-leaf entry filled with single-light metal doors is found on the south elevation. Attached to the remainder of the west elevation of the two-story section is a one-story, gable-roof, steel frame section with a rectangular footprint and resting on a concrete foundation. The gable roof is sheathed in corrugated metal panels and the exterior is also clad in metal panels. The west gable end features both a single- and double-leaf entries each filled with multilight metal doors. No windows are located along the north elevation of this section of Building 3502 . Set back from the west gable end wall plane and attached to the gable roof section's south elevation is a one-story, single-bay, shed-roof, concrete block section with a vehicular/unloading entry on its west elevation filled with a metal overhead door. A loading dock is located at the east end of this shed-roof section, providing access to the interior of the gable-roof section. Building 3502B is attached to the rear of the one-story, single-bay, shed-roof concrete block section along the south elevation of Building 3502. Building 3502B is composed of a one-story, flat-roof, concrete block masonry structure oriented to the south (Figure 194). The building features a single-leaf entry filled with a solid metal pedestrian door on its south elevation.

\section{NATIONAL REGISTER EVALUATION}

Building 3502 was constructed in 1950 to serve as the Solvent Operations Office for Building 3503; however, the building was converted to a service center for the Plant and Equipment Division after serving as an office for a period of time. Building 3502 was previously surveyed in 1994, 2004, and 2015 and recommended contributing to the ORNL Historic District (Carver and Slater 1994; Thomason and Associates 2004 and 2015). 
Historically functioning as an office facility, Building 3502 provided administrative and support functions relative to the laboratory and processing facilities and overall operation of ORNL during the Cold War era. However, the building is not the single location most importantly associated with a scientific achievement, scientist, or other event or person of historic significance to merit individual listing in the NRHP under Criterion A or B. Furthermore, the building lacks notable architectural elements that would warrant individual listing in the NRHP under Criterion C. Although a minor support structure, Building 3502 was utilized in support of the overall mission of ORNL during the Cold War era, and as such, contributes to the ORNL Historic District.

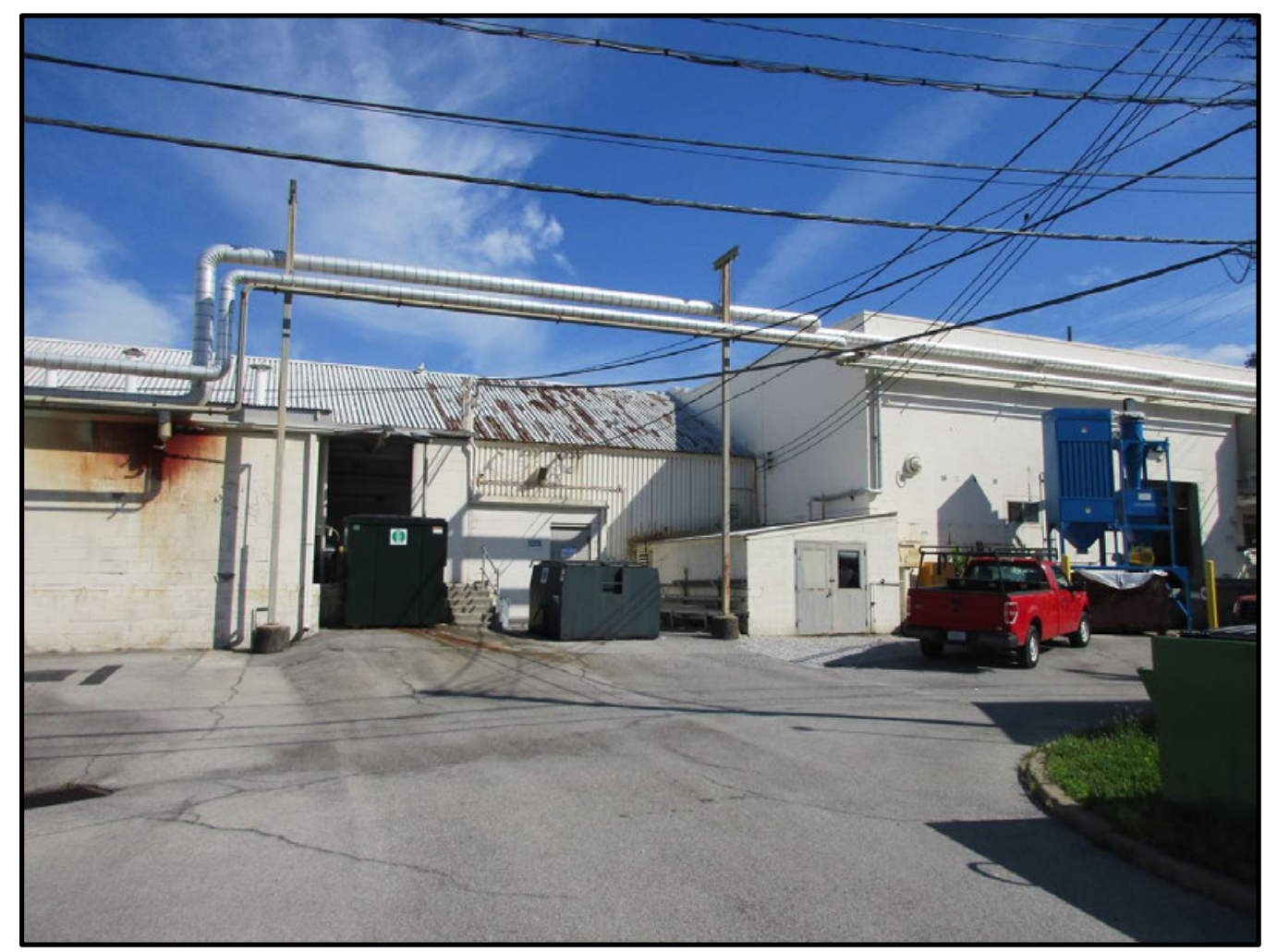

Figure 193. Overview of partial south elevation of Building 3502, showing Building 3502 attached to this elevation. 


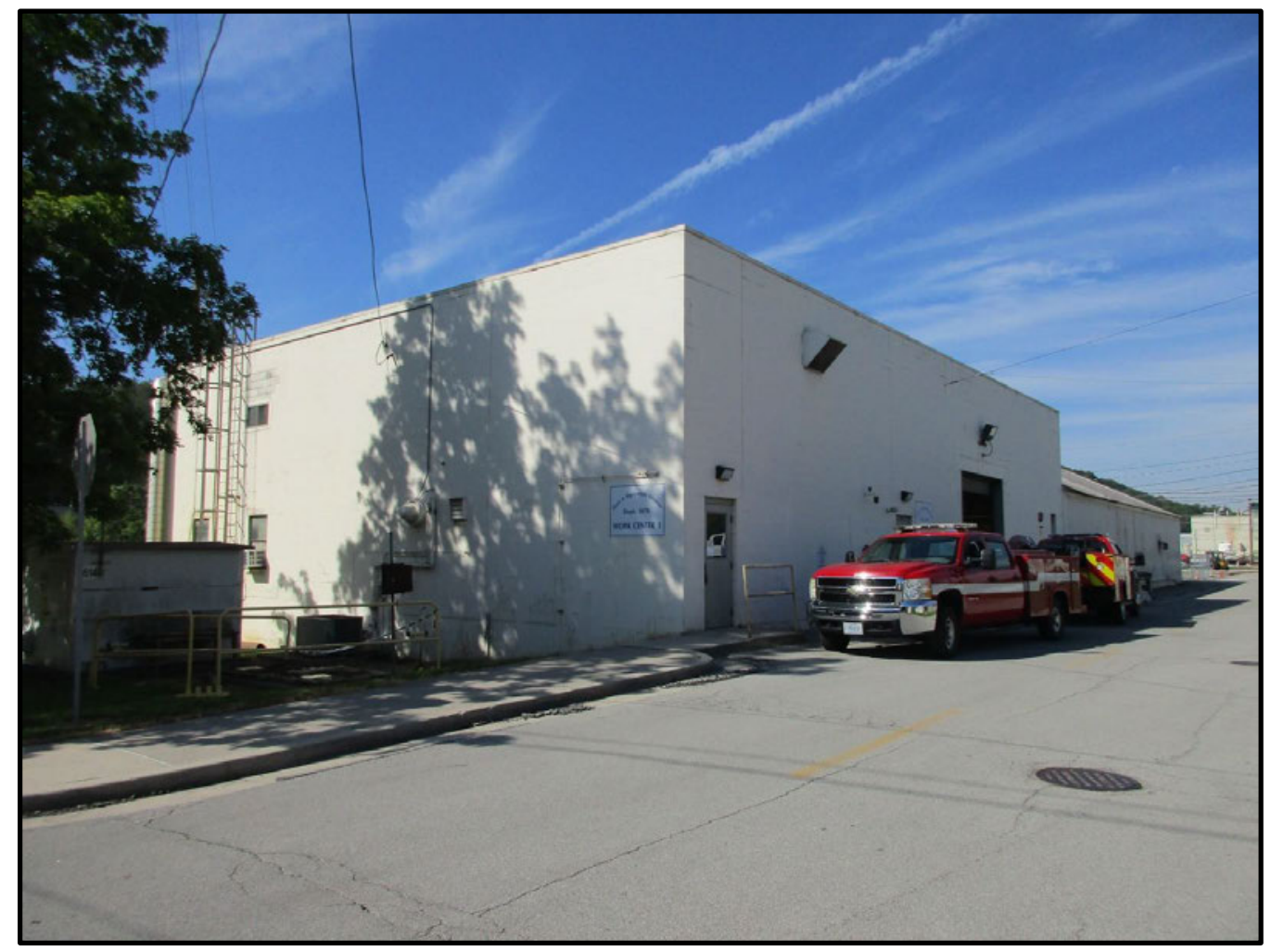

Figure 194. Overview of north and east elevations of Building 3502. 


\section{3}

\section{BUILDING NAME}

High Radiation Level Chemical Engineering

\section{DATE OF CONSTRUCTION}

1948

DOE OFFICE RESPONSIBLE

SC

NRHP ELIGIBILITY

Demolished - N/A

\section{DESCRIPTION}

Field survey confirmed Building 3503 is no longer extant.

\section{NATIONAL REGISTER EVALUATION}

Building 3503 was constructed in 1948 and historically served as a Solvent Operations research facility. The resource was previously surveyed in 1994 and 2004 and recommended as contributing to the ORNL Historic District (Carver and Slater 1994; Thomason and Associates 2004). Prior to its demolition, in 2009 DOE submitted documentation of Building 3503 to the SHPO, as required by the PA, along with documentation for several other facilities (UTB 2009). SHPO accepted the documentation and offered no objection to the proposed demolition (Mclntyre 2009). In 2015, the resource was recorded as demolished (Thomason and Associates 2015). During the current survey, CRA confirmed that the resource is no longer extant and as such, no longer retains its integrity of location, design, setting, materials, workmanship, feeling, and association. Thus, Building 3503 is not individually eligible for listing in the NRHP under Criterion A, B, or C, nor is it contributing to the ORNL Historic District. 


\section{4}

\section{BUILDING NAME}

Geosciences Laboratory

DATE OF CONSTRUCTION

1951

DOE OFFICE RESPONSIBLE

SC

NRHP ELIGIBILITY

Demolished - N/A

\section{DESCRIPTION}

Field survey confirmed Building 3504 is no longer extant.

\section{NATIONAL REGISTER EVALUATION}

Building 3504 was constructed in 1951 and historically served as a Geosciences Laboratory and used for research into health and biological effects of radioactive wastes (Carver and Slater 1994: 243). The resource was previously surveyed in 1994 and 2004 and recommended as contributing to the ORNL Historic District (Carver and Slater 1994; Thomason and Associates 2004). Prior to its demolition, in 2009 DOE submitted documentation of Building 3504 to the SHPO, as required by the PA, along with documentation for several other facilities (UTB 2009). SHPO accepted the documentation and offered no objection to the proposed demolition (Mclntyre 2009). In 2015, the resource was recorded as demolished (Thomason and Associates 2015). During the current survey, CRA confirmed that the resource is no longer extant and as such, no longer retains its integrity of location, design, setting, materials, workmanship, feeling, and association. Thus, Building 3504 is not individually eligible for listing in the NRHP under Criterion A, B, or C, nor is it contributing to the ORNL Historic District. 


\section{7}

\section{BUILDING NAME}

South Tank Farm

\section{DATE OF CONSTRUCTION}

1943

\section{DOE OFFICE RESPONSIBLE}

EM

\section{NRHP ELIGIBILITY}

Non-Contributing to ORNL Historic District

\section{DESCRIPTION}

Building 3507, the South Tank Farm is a collection of six Gunite underground storage tanks constructed in 1943 that were remediated and closed in-situ, rather than demolished. In the 1990s, a DOE-EM contractor constructed temporary aboveground steel platforms which allowed safe access to the highly contaminated tanks through ground-level hatchways using remotely-operated equipment. The tanks were pumped empty and rinsed, and then closed in place by filling with cement. Field survey confirmed that the tanks have been closed and that an asphalt-paved parking lot and gravel current cover the entire surface of the South Tank Farm.

\section{NATIONAL REGISTER EVALUATION}

Building 3507 were comprised of six Gunite tanks that were constructed in 1943 and historically served as storage and transfer of intermediate-liquid chemical waste and liquid uranium waste. The tanks were used until 1978, at which point they were emptied (Carver and Slater 1994: 247). The resource was previously surveyed in 1994 and recommended as contributing to the ORNL Historic District (Carver and Slater 1994). In 2004, Building 3507 was noted as extant, but remediated in place (Thomason and Associates 2004). In 2015, the resource was recorded as demolished (Thomason and Associates 2015). During the current survey, CRA discovered that rather than being demolished, the resource was remediated and closed in-situ. As a storage facility, Building 3507 provided support for work that furthered ORNL's mission in nuclear science during the Manhattan Project and Cold War era. However, the building is not the single location most importantly associated with a scientific achievement, scientist, or other event or person of historic significance to merit individual listing in the NRHP under Criterion A or B. Furthermore, the building lacks notable architectural elements that would warrant individual listing in the NRHP under Criterion C. While a minor support structure, Building 3507 was utilized in support of the overall mission of ORNL during the Manhattan Project and Cold War era; however, alterations, including the closure and filling of the entire resource with concrete and the topping of the entire site with gravel and concrete have diminished the integrity of setting, design, and materials to such a degree that it no longer contributes to the ORNL Historic District. 


\section{8}

\section{BUILDING NAME}

High Level Alpha Radiation Laboratory

\section{DATE OF CONSTRUCTION}

1944

DOE OFFICE RESPONSIBLE

SC

NRHP ELIGIBILITY

Demolished - N/A

\section{DESCRIPTION}

Field survey confirmed Building 3508 is no longer extant.

\section{NATIONAL REGISTER EVALUATION}

Building 3508 was constructed in 1944 and historically served as a laboratory for ORNL's Chemical Technology Division; it focused on work with high-alpha activity isotopes (Carver and Slater 1994: 248). The resource was previously surveyed in 1994 and 2004 and recommended as contributing to the ORNL Historic District (Carver and Slater 1994; Thomason and Associates 2004). Prior to its demolition, in 2009 DOE submitted documentation of Building 3508 to the SHPO, as required by the PA, along with documentation for several other facilities (UTB 2009). SHPO accepted the documentation and offered no objection to the proposed demolition (Mclntyre 2009). In 2015, the resource was recorded as demolished (Thomason and Associates 2015). During the current survey, CRA confirmed that the resource is no longer extant and as such, no longer retains its integrity of location, design, setting, materials, workmanship, feeling, and association. Thus, Building 3508 is not individually eligible for listing in the NRHP under Criterion A, B, or C, nor is it contributing to the ORNL Historic District. 


\section{3}

\section{BUILDING NAME}

Settling Basin

DATE OF CONSTRUCTION

1944

DOE OFFICE RESPONSIBLE

EM

NRHP ELIGIBILITY

Demolished - N/A

\section{DESCRIPTION}

Field survey confirmed Building 3513 is no longer extant.

\section{NATIONAL REGISTER EVALUATION}

Building 3513 was constructed in 1944 and historically served as settling basin for radioactive solids and liquids. The facility was taken out of service in 1976 when a new Process Treatment Plant was constructed (Building 3544) (Carver and Slater 1994: 249). The resource was previously surveyed in 1994 and 2004 and recommended as contributing to the ORNL Historic District (Carver and Slater 1994; Thomason and Associates 2004). In 2015, the resource was recorded as demolished (Thomason and Associates 2015). During the current survey, CRA confirmed that the resource is no longer extant and as such, no longer retains its integrity of location, design, setting, materials, workmanship, feeling, and association. Thus, Building 3513 is not individually eligible for listing in the NRHP under Criterion A, B, or C, nor is it contributing to the ORNL Historic District. 


\section{5}

\section{BUILDING NAME}

Fission Product Laboratory No. 1

DATE OF CONSTRUCTION

1948

DOE OFFICE RESPONSIBLE

EM (UCOR)

NRHP ELIGIBILITY

Figure 195. Overview of west and south elevations of Building 3515.

Contributing to ORNL Historic District

\section{DESCRIPTION}

Building 3515 is located south of Central Avenue and east of Third Street. This architectural resource is a onestory, flat-roof, masonry structure constructed with narrow concrete blocks or large bricks (Figures 195 and 196). The roof is sheathed in metal panels and the building is situated on a concrete foundation. One or two entrances along the façade (west) elevation have been enclosed by concrete blocks. No other fenestration is present on the building.

\section{NATIONAL REGISTER EVALUATION}

Building 3515 was constructed in 1948 and historically operated as a component of ORNL's fission product recovery development program. It was shut down in 1958, but remains extant. The building was previously surveyed in 1994, 2004, and 2015 and recommended as a contributing resource to the ORNL Historic District (Carver and Slater 1994; Thomason and Associates 2004 and 2015). The building retains a majority of its historic materials, as well as its form and massing. As a research/laboratory facility, Building 3515 housed work that furthered ORNL's mission in nuclear science during the Cold War era. However, the building is not the single location most importantly associated with a scientific achievement, scientist, or other event or person of historic significance to merit individual listing in the NRHP under Criterion A or B. Furthermore, the building lacks notable architectural elements that would warrant individual listing in the NRHP under Criterion C. Instead, the significance of Building 3515 is best understood within the broader context of the body of work advanced by researchers in the ORNL Historic District during the Cold War era. As such, Building 3515 does not warrant individual listing in the NRHP under Criterion A, B, or C; however, the building is a contributing resource to the ORNL Historic District. 


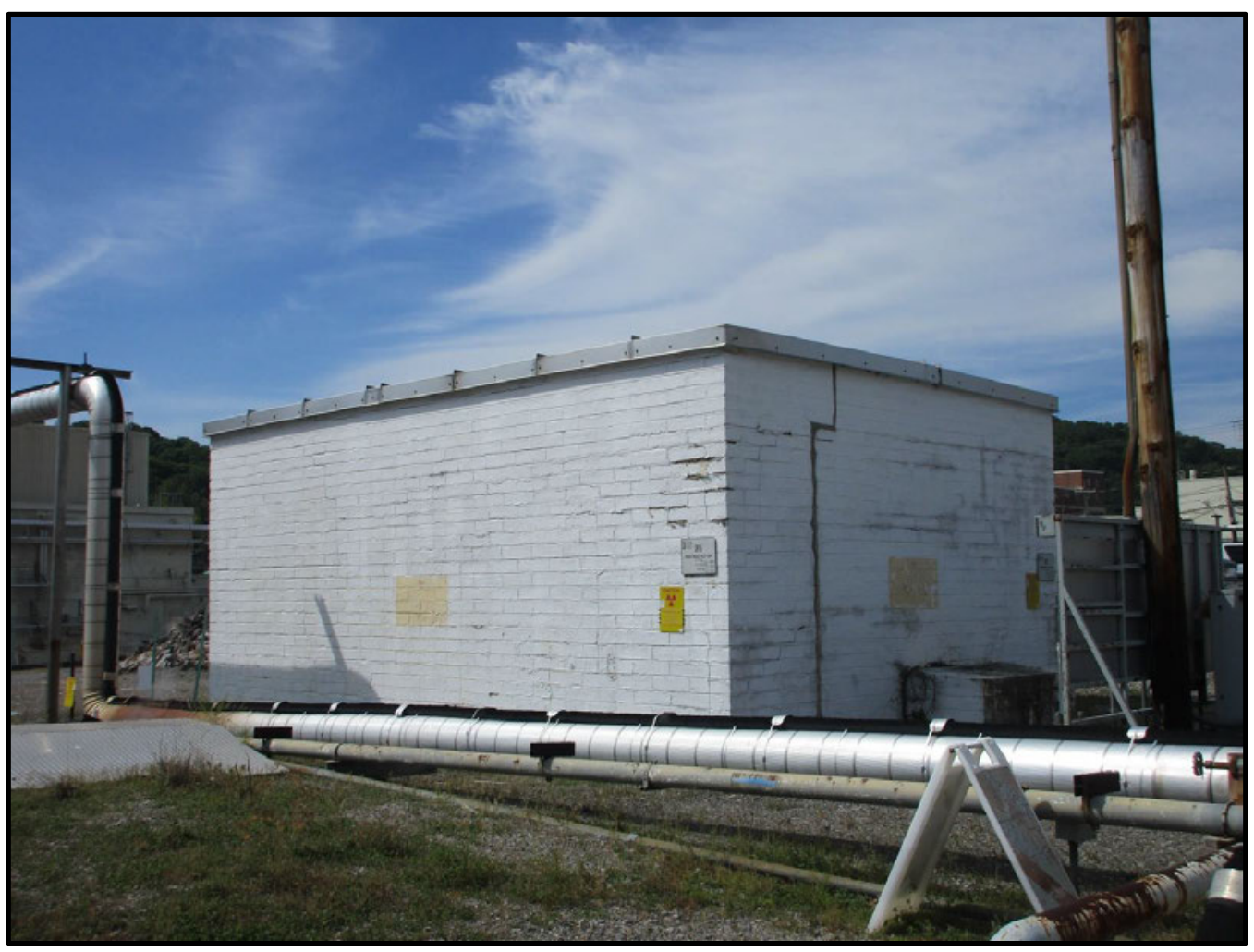

Figure 196. Overview of north and east elevations of Building 3515. 


\section{7}

\section{BUILDING NAME}

Fission Products Development Laboratory

\section{DATE OF CONSTRUCTION}

1958

\section{DOE OFFICE RESPONSIBLE}

EM (UCOR)

\section{NRHP ELIGIBILITY}

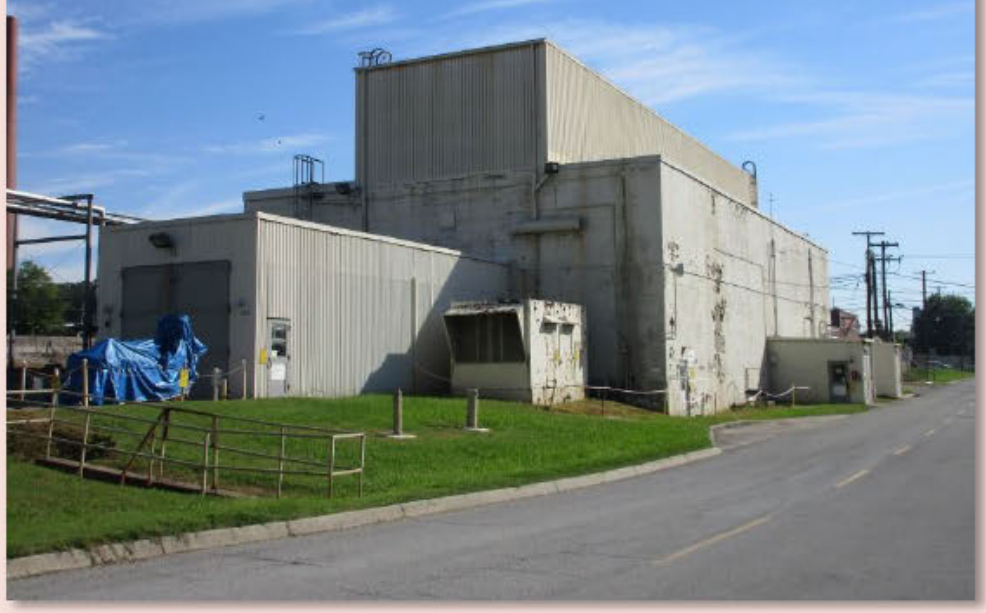

Contributing to ORNL Historic District

\section{DESCRIPTION}

Building 3517 is located on the north side of White Oak Avenue to the west of its intersection with Southside Avenue. Building 3517 is a multi-story, flat-roof structure of concrete block and steel frame construction with a concrete foundation (Figures 197 and 198). The main block of the building is comprised of a large, concrete block section with a steel frame section extending upward from the center of the main block's roof. The steel frame section is clad in metal panels. An exterior metal stairwell is located on the east elevation providing access to a second floor entry to the main block of Building 3517 . The south elevation of the main block has two small single-story, flat-roof projections clad in metal siding; each with double-leaf and single-leaf entries. Another single-leaf entry is located on the south elevation, filled with a four-light metal pedestrian door. Shedand flat-roof projections are also found on the north elevation of the main block. A one-story, narrow, long, flatroof projection clad in corrugated metal panels is located on the west elevation of the main block of the building. This projection has double-leaf entry filled with solid metal doors on its west elevation. No other fenestration is present on the structure.

\section{NATIONAL REGISTER EVALUATION}

Building 3517 was constructed in 1958 and historically operated as ORNL's fission products research and laboratory. The building was previously surveyed in 2015 and recommended to be outside of the proposed boundaries of the ORNL Historic District and thus ineligible for listing in the NRHP (Thomason and Associates 2015). It is, however, within the revised ORNL Historic District boundaries recommended by CRA. The building retains a majority of its historic materials, as well as its form and massing. As a research/laboratory facility, Building 3517 housed work that furthered ORNL's mission in nuclear science during the Cold War era. However, the building is not the single location most importantly associated with a scientific achievement, scientist, or other event or person of historic significance to merit individual listing in the NRHP under Criterion A or B. Furthermore, the building lacks notable architectural elements that would warrant individual listing in the NRHP under Criterion C. Instead, the significance of Building 3517 is best understood within the broader context of the body of work advanced by researchers in the ORNL Historic District during the Cold War era. As 
such, Building 3517 does not warrant individual listing in the NRHP under Criterion A, B, or C; however, the building is a contributing resource to the ORNL Historic District.

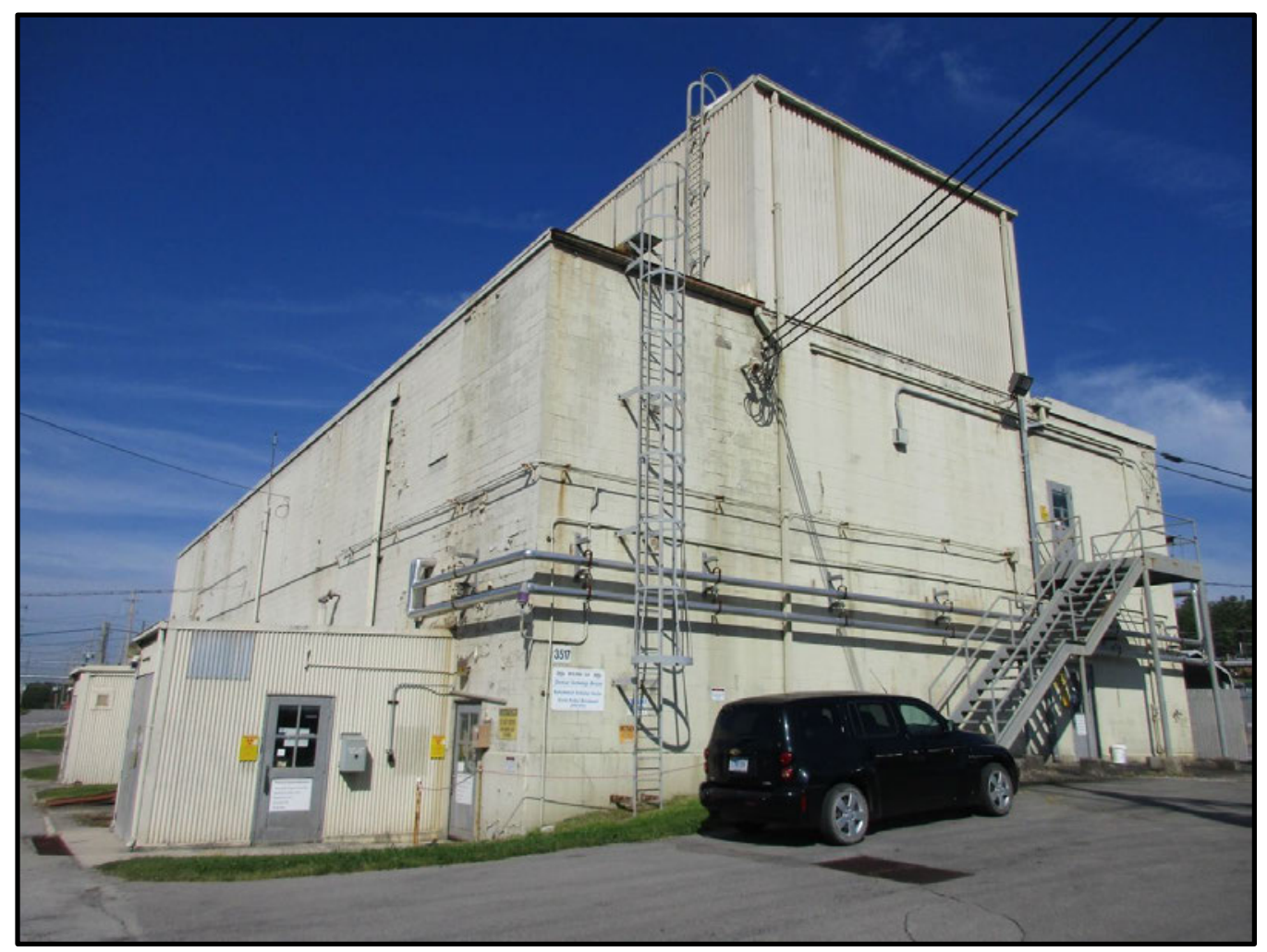

Figure 198. Overview of east and south elevations of Building 3517. 


\section{8}

\section{BUILDING NAME}

Process Wastewater Treatment Plant

DATE OF CONSTRUCTION

1966

DOE OFFICE RESPONSIBLE

EM (UCOR)

NRHP ELIGIBILITY

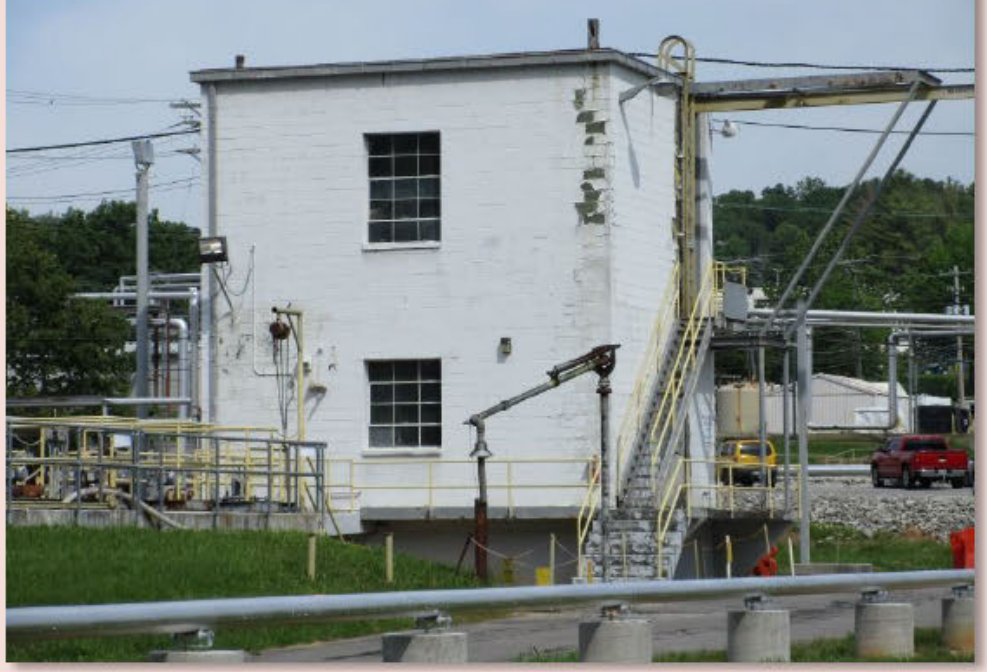

Figure 199. Overview of south and west elevations of Building 3518.

Not Eligible

\section{DESCRIPTION}

Building 3518 is located south of White Oak Avenue, and east of Third Street. This architectural resource is a two-story, flat-roof, concrete block masonry structure on a raised concrete foundation (Figure 199 and 200). Metal coping encompasses the roof's edge. An exterior metal staircase and one or two doors are located on the east elevation of the building. The building features windows on the other three elevations filled with twelve- and fifteen-light metal sashes.

\section{NATIONAL REGISTER EVALUATION}

Building 3518 was constructed in 1966 as a process wastewater treatment plant for the installation and was designed to remove radioactive strontium from large volumes of low level wastes. Building 3518 was previously surveyed in 1994, 2004, and 2015 and recommended contributing to the ORNL Historic District (Carver and Slater 1994; Thomason and Associates 2004 and 2015). Building 3518 retains a majority of its historic materials, form, and massing. However, it is located outside the recommended ORNL Historic District boundary, which is revised to account for demolitions in the vicinity. As a utility/maintenance facility, Building 3518 provided utilitarian support services for work that furthered ORNL's mission in nuclear science during the Cold War era. However, the building is not the single location most importantly associated with a scientific achievement, scientist, or other events or persons of historic significance to merit individual listing in the NRHP under Criterion A or B. Furthermore, the building lacks notable architectural elements that would warrant individual listing in the NRHP under Criterion C. As such, Building 3518 does not warrant individual listing in the NRHP under Criterion A, B, or C. In addition, Building 3518 is no longer eligible as a contributing resource to the ORNL Historic District as it is located outside the recommended district boundaries. 


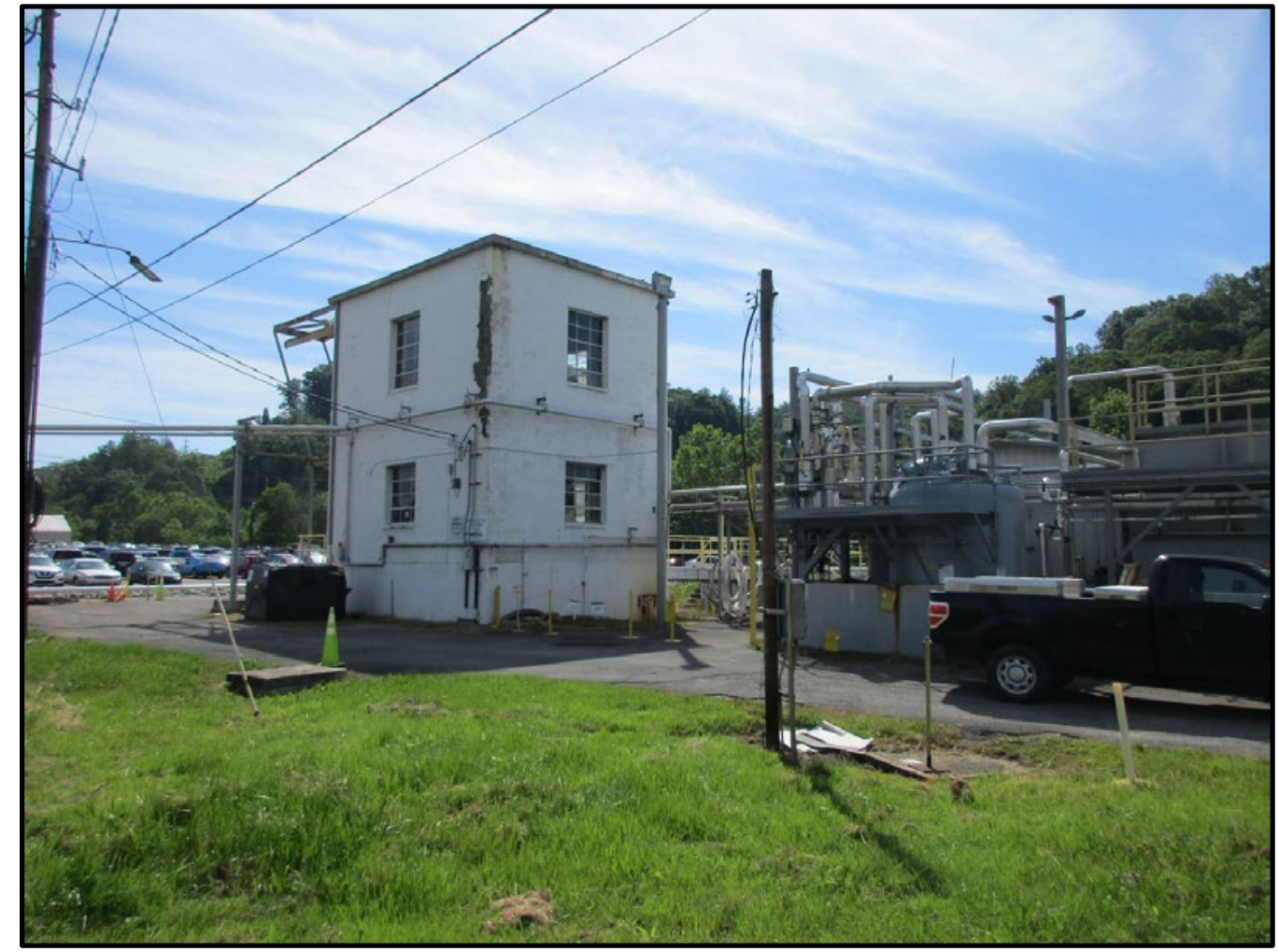

Figure 200. Overview of north and west elevations of Building 3518. 


\section{3}

\section{BUILDING NAME}

Weld Wire Management Facility

\section{DATE OF CONSTRUCTION}

1954

DOE OFFICE RESPONSIBLE

SC

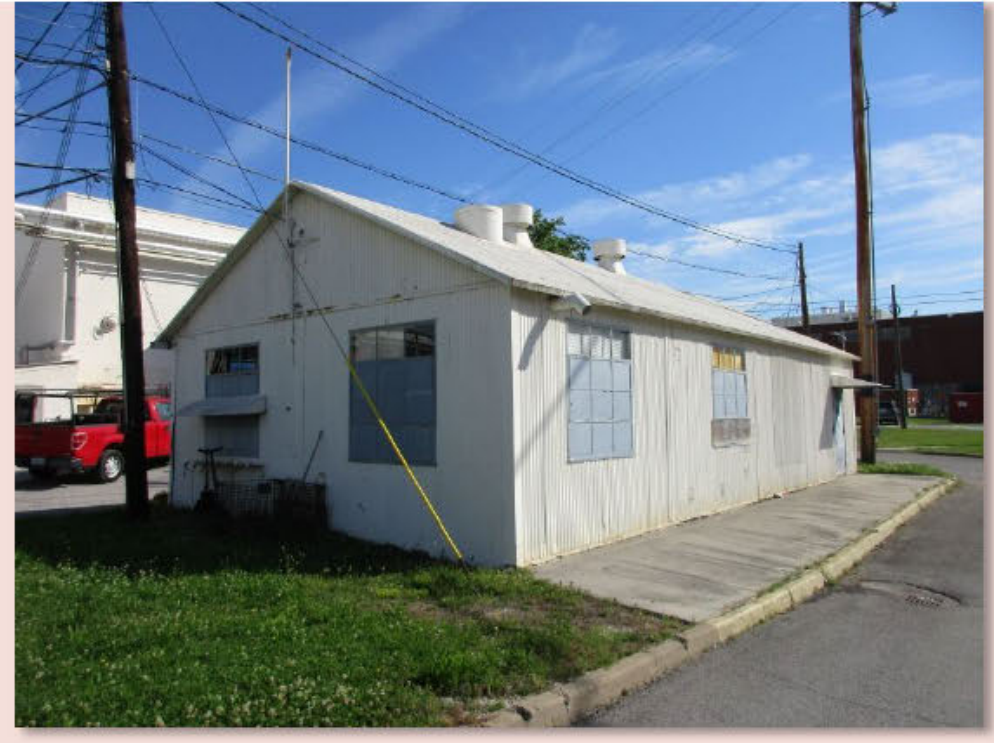

NRHP ELIGIBILITY

Figure 201. Overview of south and west elevations of Building 3523.

Contributing to ORNL Historic District

\section{DESCRIPTION}

Building 3523 is located west of the intersection of Fifth Street and Southside Avenue. Oriented to the north, Building 3523 is a one-story, side-gabled, steel frame structure which is supported by a concrete foundation (Figures 201 and 202). The building's roof and side elevations are clad in corrugated metal. The ridgeline is pierced by two vents and a third vent pierces the south roof slope near the ridgeline. The façade (north) elevation of the building features two single-leaf entries filled with two-light metal pedestrian doors, a double-leaf entry filled with solid metal doors, and two windows. Both gable ends (east and west) feature two windows. A single-leaf entry filled with a one-light metal door and sheltered by a metal awning is located on the south elevation. The building features twelve-light hopper windows, with many of the panes painted over. A "Braden Steel Corporation - Tulsa, Okla" plaque was found on the corrugated metal siding (Figures 203).

\section{NATIONAL REGISTER EVALUATION}

Building 3523 was constructed in 1954 as the Controls Research Laboratory and later converted to a storage facility and electronic fabrication shop. It was previously surveyed in 1994, 2004, and 2015 and recommended as a contributing resource to the ORNL Historic District (Carver and Slater 1994; Thomason and Associates 2004 and 2015). While the building has undergone some minor modifications to its windows and doors that included painted window panes and a replacement door, its integrity of location, design, feeling, and association, those aspects most essential to conveying its identity with nuclear science are intact. As a research/laboratory facility, Building 3523 housed work that furthered ORNL's mission in nuclear science during the Cold War era. However, the building is not the single location most importantly associated with a scientific achievement, scientist, or other event or person of historic significance to merit individual listing in the NRHP under Criterion $\mathrm{A}$ or $\mathrm{B}$. Furthermore, the building lacks notable architectural elements that would warrant individual listing in the NRHP under Criterion C. Instead, the significance of Building 3523 is best understood within the broader context of the body of work advanced by researchers in the ORNL Historic District during the Cold War era. As such, Building 3523 does not warrant individual listing in the NRHP under Criterion A, B, or C; however, the building is a contributing resource to the ORNL Historic District. 


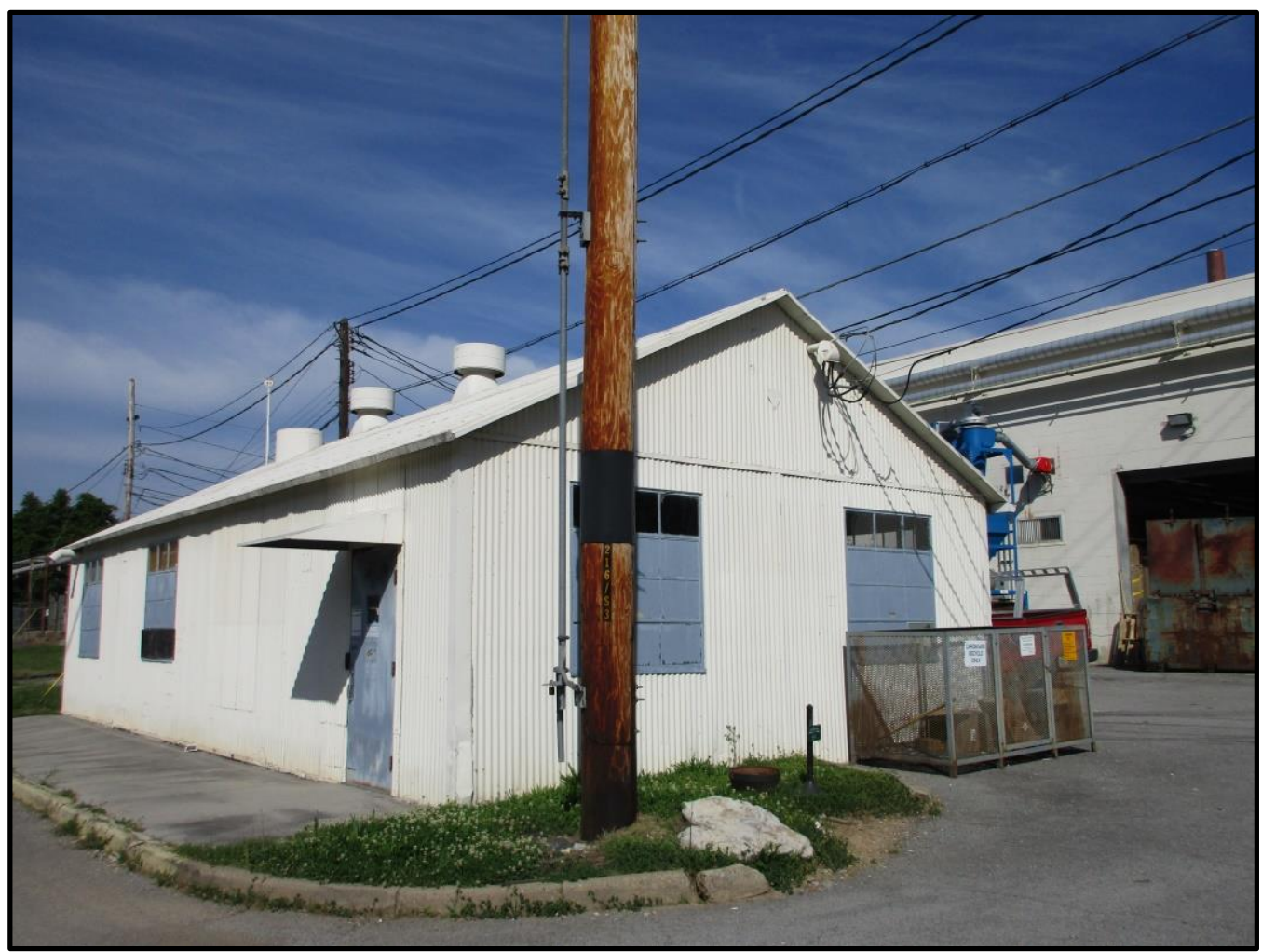

Figure 202. Overview of east and south elevations of Building 3523.

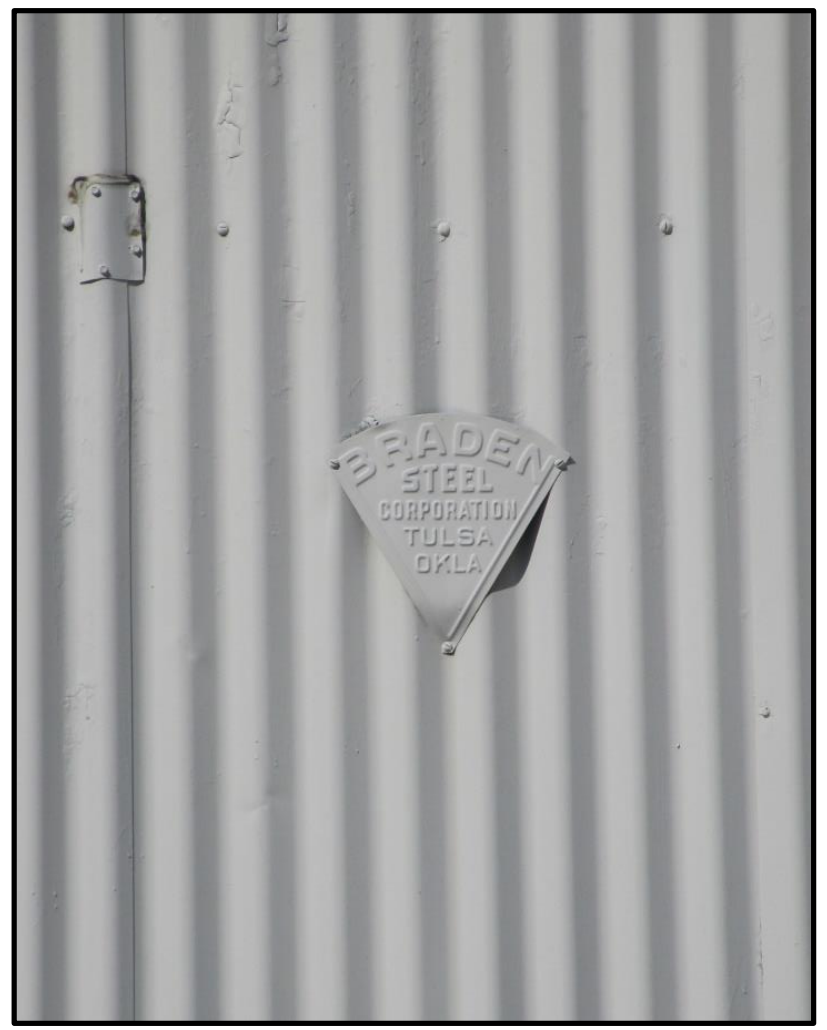

Figure 203. Detail of manufacturing plate found on the corrugated metal siding of Building 3523. 


\section{4}

\section{BUILDING NAME}

Equalization Basin

\section{DATE OF CONSTRUCTION}

1960

DOE OFFICE RESPONSIBLE

EM

NRHP ELIGIBILITY

Demolished - N/A

\section{DESCRIPTION}

Field survey confirmed Building 3524 is no longer extant.

\section{NATIONAL REGISTER EVALUATION}

Building 3524 was constructed in 1960 and historically served as a large pond called the Process Waste System Basin/Equalization Basin; it was once two ponds separated by an earthen divider that merged into two ponds when the divider was removed in 1953-1954. The resource was previously surveyed in 1994 and recommended as contributing to the ORNL Historic District (Carver and Slater 1994). In 2004, the structure was noted as still extant, but remediated in place (Thomason and Associates 2004). In 2015, the resource was recorded as demolished (Thomason and Associates 2015). During the current survey, CRA confirmed that the resource is no longer extant and as such, no longer retains its integrity of location, design, setting, materials, workmanship, feeling, and association. Thus, Building 3524 is not individually eligible for listing in the NRHP under Criterion A, B, or C, nor is it contributing to the ORNL Historic District. 


\section{5}

\section{BUILDING NAME}

High-Rad Level Examination Laboratory

\section{DATE OF CONSTRUCTION}

1963

\section{DOE OFFICE RESPONSIBLE}

EM (UCOR)

\section{NRHP ELIGIBILITY}

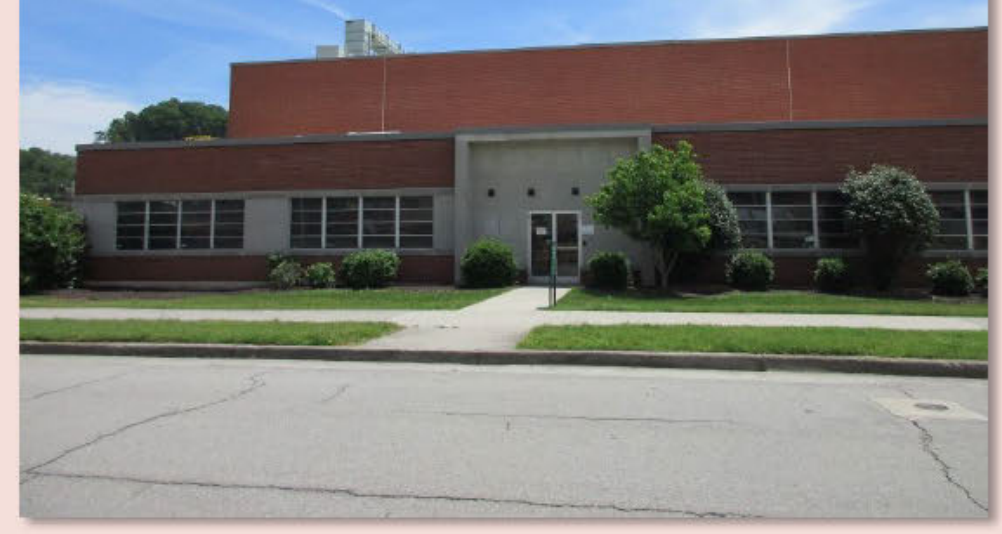

Contributing to ORNL Historic District

\section{DESCRIPTION}

Building 3525 is located along the south side of Central Avenue between Third and Fifth Streets. Oriented to the north, this building is a multi-story, five-bay, flat-roof structure clad in brick and supported by a concrete foundation (Figures 204, 205, and 206). The brick is laid in a modified five course common bond pattern. The building features limestone coping encompassing the roof. A single story wing is located on the façade (north) elevation. The façade features a prominent, central, double-leaf entrance filled by aluminum frame commercial glass doors and framed by concrete panels and a slight concrete panel projection. Flanking the entry are two windows to either side filled by ribbons of four-light metal sashes, possibly awning windows. Concrete panels fill the areas between the façade windows which are framed at the top and bottom by horizontal bands of concrete or stone. The same decorative pattern wraps around to the east elevation of the one-story façade wing, with two windows filled with four-light sashes similar to those of the façade. The larger, main block of Building 3525 has large vents on the east elevation and single-leaf and double-leaf entries filled with metal doors on both side (east and west) elevations. The rear (south) elevation of the main block has a small three-story tower with access to the roof. A single-leaf and large double-leaf entry are also found on the rear (south) elevation of the building's main block.

\section{NATIONAL REGISTER EVALUATION}

Building 3525 was constructed in 1963 and historically operated as a research and laboratory facility. The building was previously surveyed in 1994 and 2015, but recommended as a non-contributing resource to the ORNL Historic District at the time due to its age (Carver and Slater 1994; Thomason and Associates 2015). The building retains a majority of its historic materials, as well as its form and massing. As a research/laboratory facility, Building 3525 housed work that furthered ORNL's mission in nuclear science during the Cold War era. However, the building is not the single location most importantly associated with a scientific achievement, scientist, or other event or person of historic significance to merit individual listing in the NRHP under Criterion A or B. Furthermore, the building lacks notable architectural elements that would warrant individual listing in the NRHP under Criterion C. Instead, the significance of Building 3525 is best understood within the broader context of the body of work advanced by researchers in the ORNL Historic District during the Cold War era. As 
such, Building 3525 does not warrant individual listing in the NRHP under Criterion A, B, or C; however, the building is a contributing resource to the ORNL Historic District.

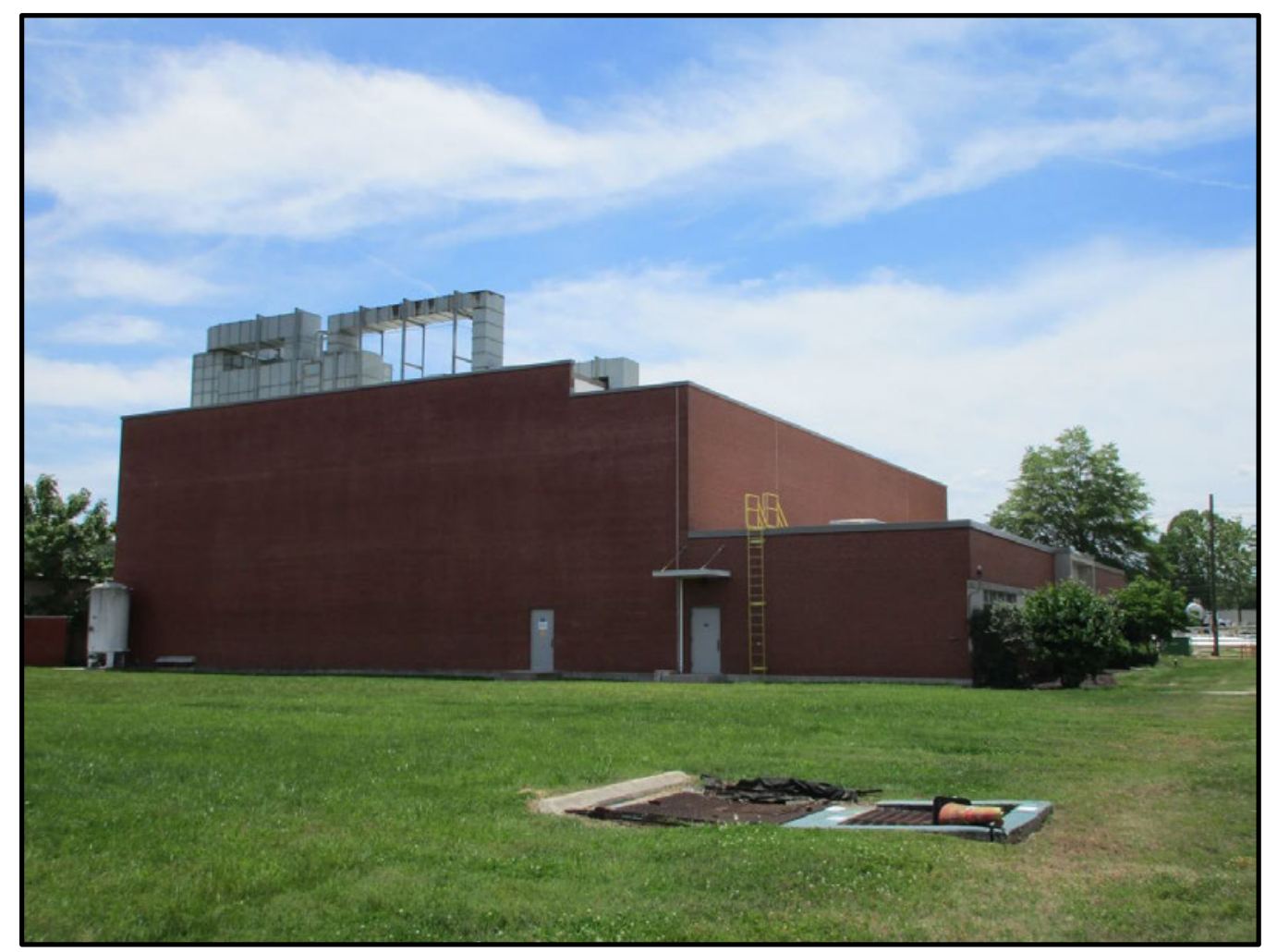

Figure 205. Overview of east and north elevations of Building 3525. 


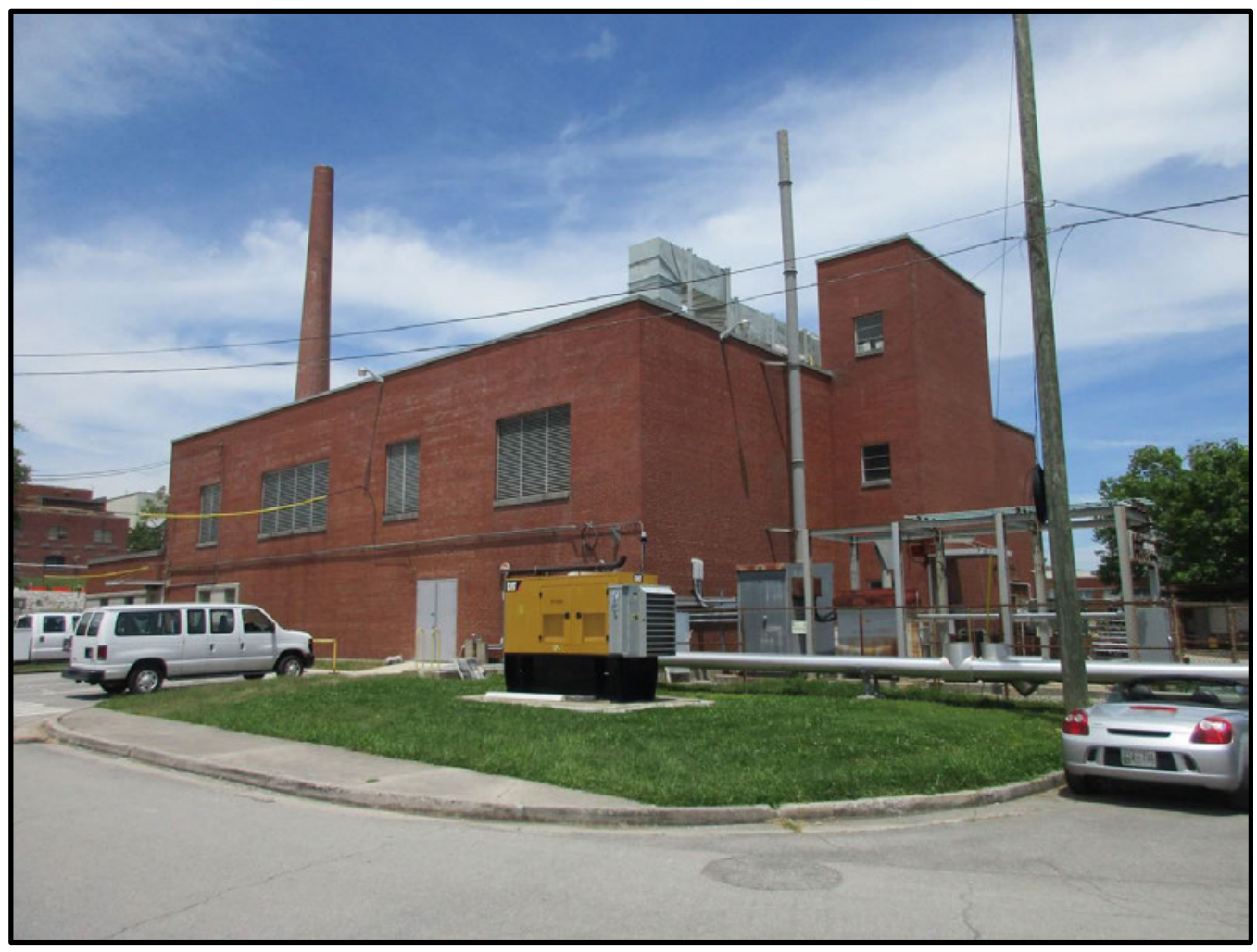

Figure 206. Overview of south and west elevations of Building 3525. 


\section{2}

\section{BUILDING NAME}

Storage Building for 3505 \& 3517

\section{DATE OF CONSTRUCTION}

1965

DOE OFFICE RESPONSIBLE

EM (UCOR)

NRHP ELIGIBILITY

Figure 207. Overview of east and south elevations of Building 3542.

Contributing to ORNL Historic District

\section{DESCRIPTION}

Building 3542 is located east of Third Street near its intersection with White Oak Avenue. Oriented to the east, this building is a one-story, single-bay, side-gable, metal frame structure supported by a concrete foundation (Figures 207 and 208). The building is clad with metal panels and is sheltered by a metal roof. The façade (east) elevation features a single-leaf entry filled with a solid metal door. The structure lacks any other fenestration.

\section{NATIONAL REGISTER EVALUATION}

Building 3542 was constructed in 1965 as storage for Buildings 3505 and 3517 . Building 3542 was previously surveyed in 2015 and recommended as non-contributing to the ORNL Historic District (Thomason and Associates 2015). The building retains a majority of its historic materials, as well as its form and massing. As a storage facility, Building 3542 supported work that furthered ORNL's mission in nuclear science during the Cold War era. However, the building is not the single location most importantly associated with a scientific achievement, scientist, or other event or person of historic significance to merit individual listing in the NRHP under Criterion $\mathrm{A}$ or $\mathrm{B}$. Furthermore, the building lacks notable architectural elements that would warrant individual listing in the NRHP under Criterion C. Although a minor support structure, Building 3542 was utilized in support of the overall mission of ORNL during the Cold War era, and as such, contributes to the ORNL Historic District. 


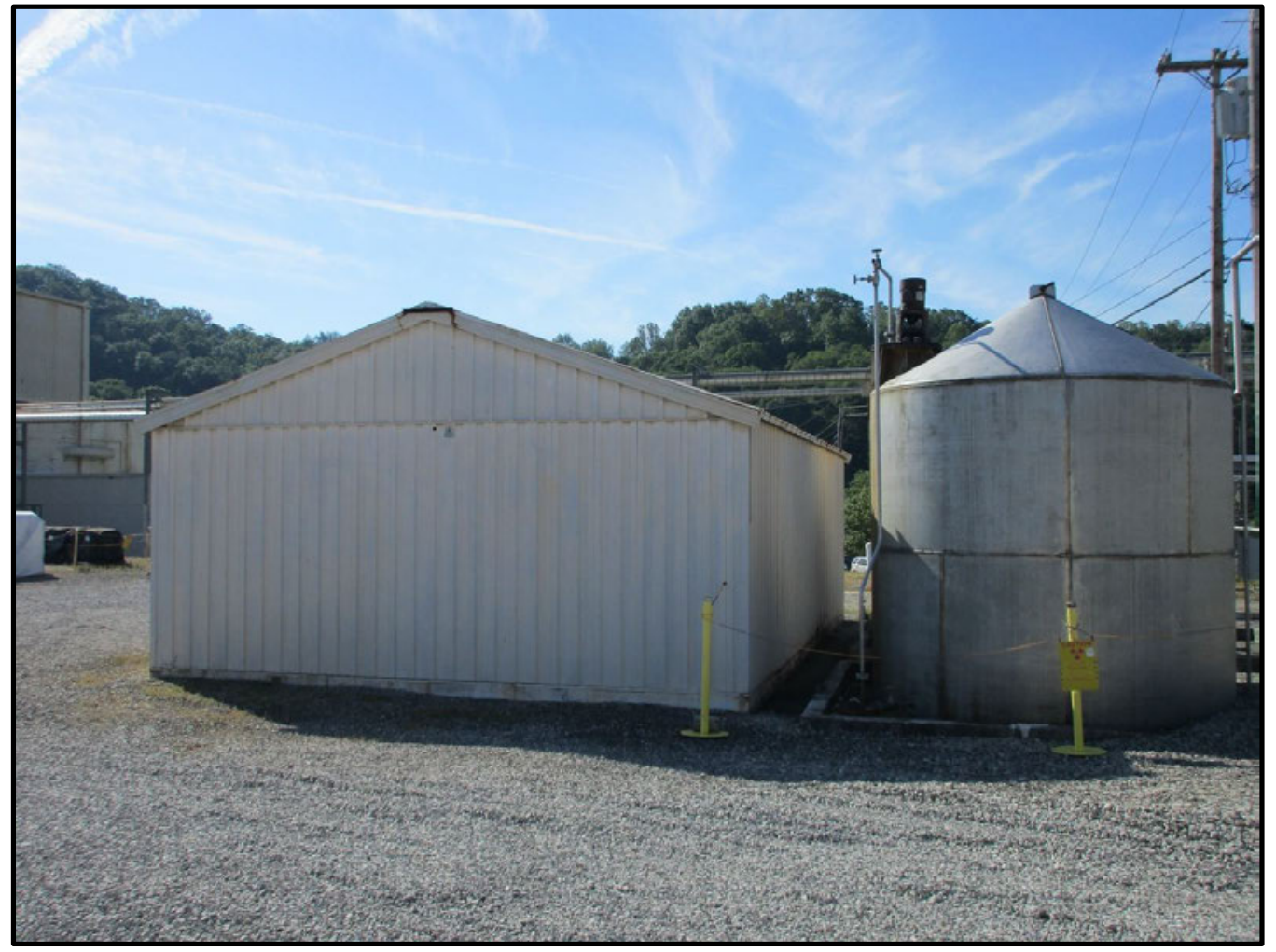

Figure 208. Overview of north and west elevations of Building 3542. 


\section{4}

\section{BUILDING NAME}

Process Waste Treatment Plant

DATE OF CONSTRUCTION

1976

\section{DOE OFFICE RESPONSIBLE}

EM (UCOR)

NRHP ELIGIBILITY

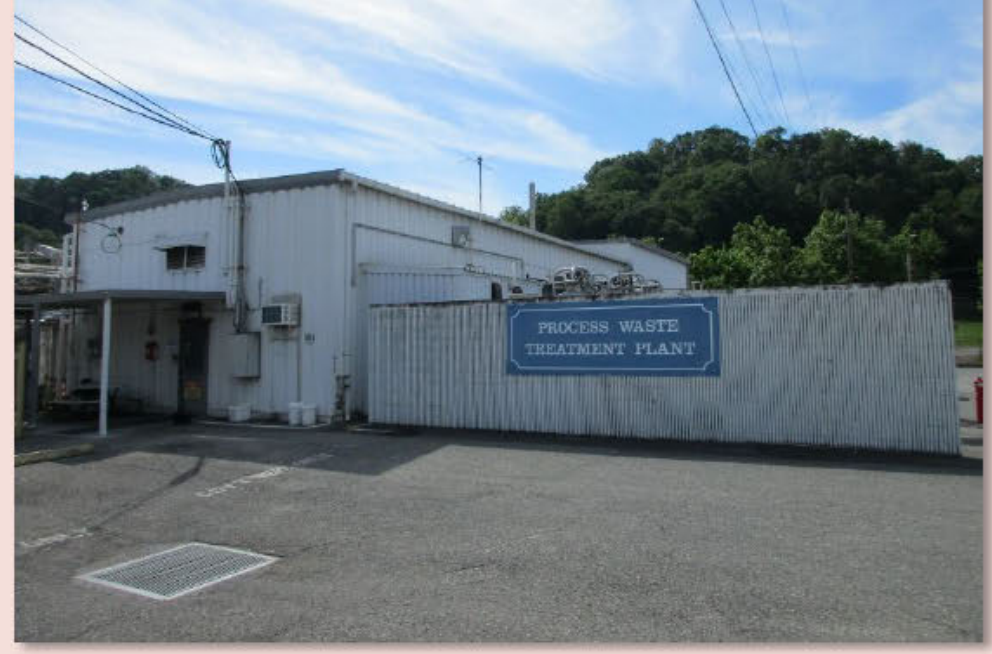

Figure 209. Overview of north and west elevations of Building 3544.

Not Eligible

\section{DESCRIPTION}

Building 3544 located on the east side of Third Street, south of White Oak Avenue. This building is a one-story, single-bay, steel structure comprised of two sections (Figures 209 and 210). The façade is located in the northern section, oriented to the north, and is clad with metal panels and features a low-pitched roof of metal panels. The façade has a central single-leaf entry filled with a two-light metal pedestrian door that is sheltered by a flat-roof porch supported by metal posts. The west elevation of the lower, façade section of Building 3544 has a single-leaf entry similar to the façade and a vehicular entry filled with a large roll-up garage door. The taller section of Building 3544, situated to the rear (south), is clad with metal panels on the exterior and also features a low pitched roof. No fenestration is present on the south section of the building.

\section{NATIONAL REGISTER EVALUATION}

Building 3544 was constructed in 1976 as a Process Wastewater Treatment Plant for the installation and replaced an older plant (Building 3518). Building 3518 was previously surveyed in 1994 and recommended as a non-contributing resource to the ORNL Historic District as fell outside of the period of significance established at that time (Carver and Slater 1994). Building 3544 retains a majority of its historic materials, form, and massing and is located outside the recommended ORNL Historic District boundary, which CRA recommends should be adjusted to account for demolitions and alterations within the district. As a utility/maintenance facility, Building 3544 provided utilitarian support services for work that furthered ORNL's mission in nuclear science during the Cold War era. However, the building is not the single location most importantly associated with a scientific achievement, scientist, or other events or persons of historic significance to merit individual listing in the NRHP under Criterion A or B. Furthermore, the building lacks notable architectural elements that would warrant individual listing in the NRHP under Criterion C. Additionally, it was constructed in 1976, after the end of the period of significance of the ORNL Historic District. As such, Building 3544 does not warrant individual listing in the NRHP under Criterion A, B, or C. Also, Building 3544 is not a contributing resource to the ORNL Historic District as it is located outside the recommended district boundaries. 


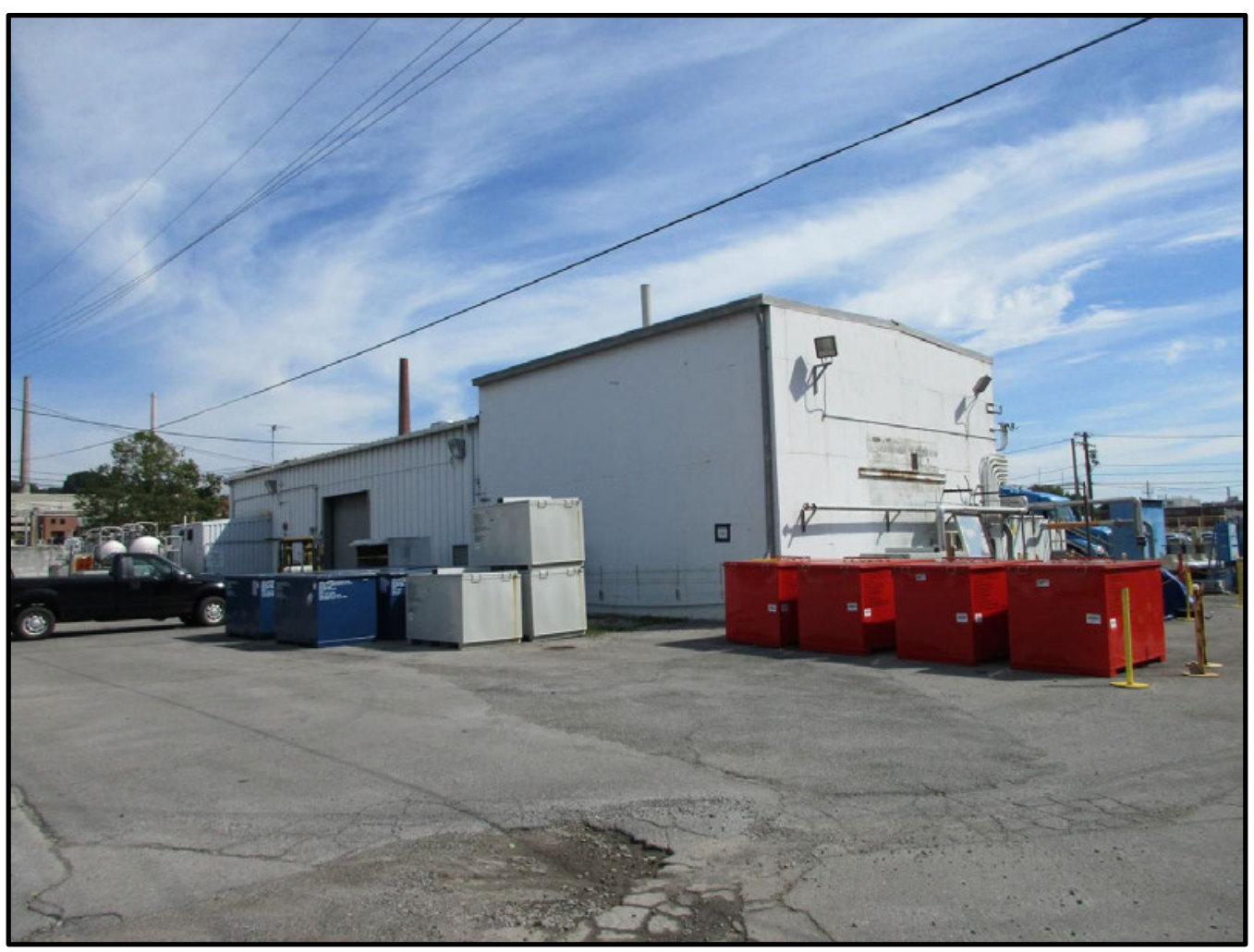

Figure 210. Overview of south and west elevations of Building 3544 . 


\section{4-VB1}

\section{BUILDING NAME}

White Oak Creek Vehicle Bridge

\section{DATE OF CONSTRUCTION}

1958

DOE OFFICE RESPONSIBLE

SC

NRHP ELIGIBILITY

Figure 211. Overview of Building 3544-VB1, a vehicular bridge, looking south along Third Street.

Not Eligible

\section{DESCRIPTION}

Building 3544 -VB1 is a vehicle bridge that crosses White Oak Creek along Third Street just north of its intersection with Incinerator Drive. Access to the bridge from the south is currently blocked. The bridge, extending to the north and south, is composed of poured concrete abutments with an asphalt paved deck (Figures 211 and 212). A metal chain link fence with metal posts serves as the railings.

\section{NATIONAL REGISTER EVALUATION}

Building 3544-VB1 was constructed in 1958 as a vehicular slab bridge. The structure was previously unrecorded. Building 3544 retains a majority of its historic materials, form, and massing and is located outside the current ORNL Historic District boundary. The bridge has no historic associations with significant events or persons, such as a particular designer or fabricator, which would warrant eligibility in the NRHP under Criterion A or B. Furthermore, the structure is a common bridge design that lacks notable architectural and engineering elements that would warrant individual listing in the NRHP under Criterion C. As such, Building 3544-VB1 does not warrant individual listing in the NRHP under Criterion $A, B$, or $C$, nor is it a contributing resource to the ORNL Historic District as it is located outside the current district boundaries. 


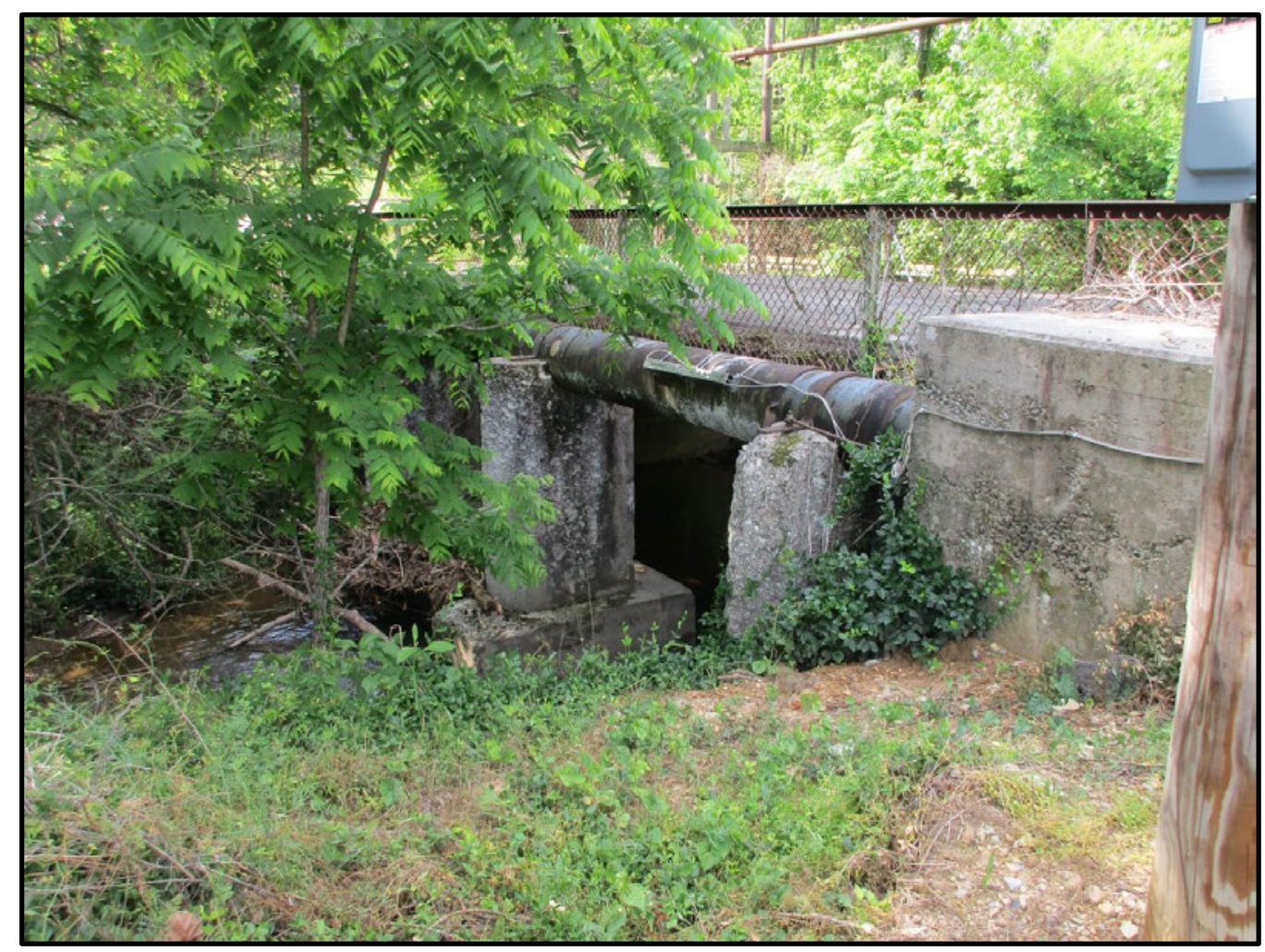

Figure 212. View of vehicular bridge (Building 3544-VB1) and its structure supporting the roadway. 


\section{7}

\section{BUILDING NAME}

Mail Services Building

\section{DATE OF CONSTRUCTION}

1950

\section{DOE OFFICE RESPONSIBLE}

SC

Figure 213. Overview of east and south elevations of Building 3587.

\section{NRHP ELIGIBILITY}

Contributing to ORNL Historic District

\section{DESCRIPTION}

Building 3587 is located north of the intersection of White Oak Avenue and Fifth Street in the 3000 Area. Building 3587 is a one-story, cross-gabled, steel structure with a concrete foundation and an overall "L"-shape (Figures 213 and 214). The roof and exterior of the building are clad in corrugated metal. The main entrance is located at the east end of the north elevation; it contains two entries sheltered by a nearly flat-roof porch. Entries throughout the building are filled with single-light metal pedestrian doors. The building features windows filled with twelve-light metal hopper sashes with the top row of panes painted over.

\section{NATIONAL REGISTER EVALUATION}

Building 3587 was constructed in 1950 as a field service shop. It was later converted in the Mail Services Building. It was previously surveyed in 1994, 2004, and 2015 and recommended as a contributing resource to the ORNL Historic District (Carver and Slater 1994; Thomason and Associates 2004 and 2015). The building has undergone slight modifications that include enclosures of some former bays; however, overall the building retains a majority of its historic materials, as well as its form and massing. As a utility/maintenance facility, Building 3587 provided utilitarian support services for work that furthered ORNL's mission in nuclear science during the Cold War era. However, the building is not the single location most importantly associated with a scientific achievement, scientist, or other event or person of historic significance to merit individual listing in the NRHP under Criterion A or B. Furthermore, the building lacks notable architectural elements that would warrant individual listing in the NRHP under Criterion C. Instead, the significance of Building 3587 is best understood as an integral support resource necessary to the functioning of research and processing facilities in the ORNL Historic District during the Cold War era. As such, Building 3587 does not warrant individual listing in the NRHP under Criterion A, B, or C; however, the building is a contributing resource to the ORNL Historic District. 


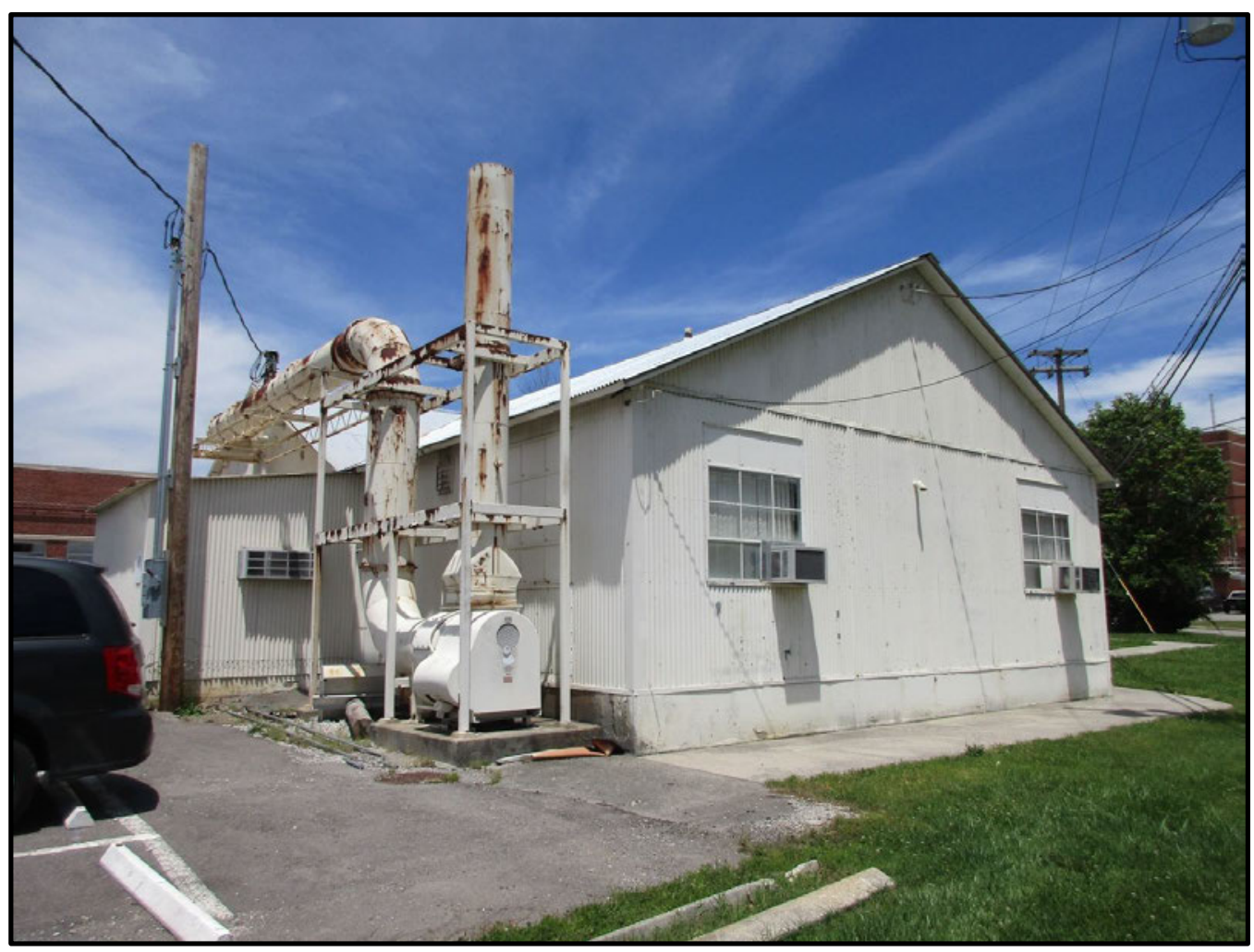

Figure 214. Overview of south and west elevations of Building 3587. 


\section{2}

\section{BUILDING NAME}

Coal Conversion Facility

DATE OF CONSTRUCTION

1952

DOE OFFICE RESPONSIBLE

SC

NRHP ELIGIBILITY

Demolished - N/A

\section{DESCRIPTION}

Field survey confirmed Building 3592 is no longer extant.

\section{NATIONAL REGISTER EVALUATION}

Building 3592 was constructed in 1952 and historically served as processing facility. The resource was previously surveyed in 1994 and 2004 and recommended as contributing to the ORNL Historic District (Carver and Slater 1994; Thomason and Associates 2004). Prior to its demolition, in 2009 DOE submitted documentation of Building 3592 to the SHPO, as required by the PA, along with documentation for several other facilities (UTB 2009). SHPO accepted the documentation and offered no objection to the proposed demolition (Mclntyre 2009). In 2015, the resource was recorded as demolished (Thomason and Associates 2015). During the current survey, CRA confirmed that the resource is no longer extant and as such, no longer retains its integrity of location, design, setting, materials, workmanship, feeling, and association. Thus, Building 3592 is not individually eligible for listing in the NRHP under Criterion A, B, or C, nor is it contributing to the ORNL Historic District. 


\section{4}

\section{BUILDING NAME}

Waste Management Storage Building

DATE OF CONSTRUCTION

1976

DOE OFFICE RESPONSIBLE

EM (UCOR)

NRHP ELIGIBILITY

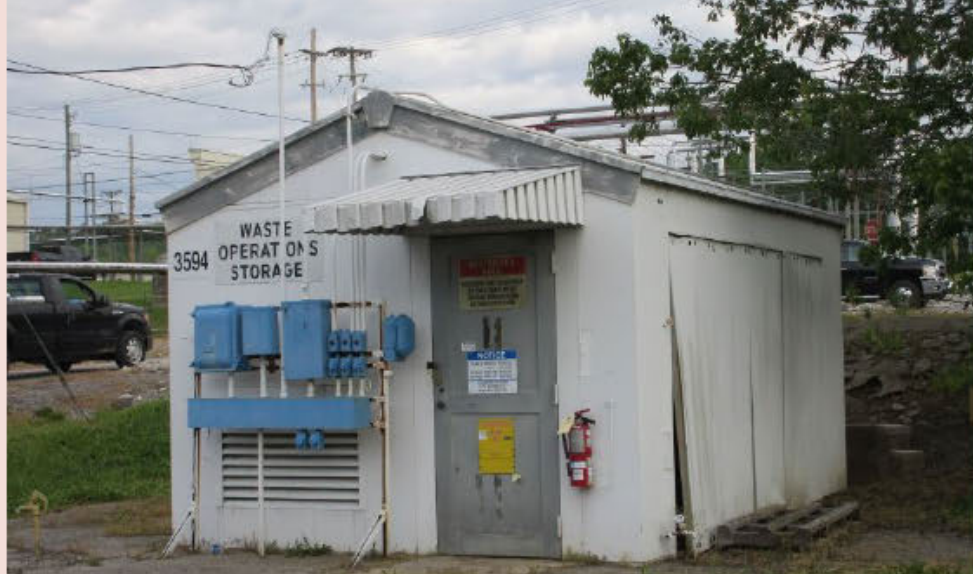

Not Eligible

\section{DESCRIPTION}

Building 3594 is located east of Third Street, south of its intersection with White Oak Avenue. The building, oriented to the south, is a one-story, single-bay, front-gable, metal frame structure with a concrete foundation (Figures 215 and 216). Building 3594 is clad in vertical metal panels. An off-center single-leaf entry on the façade (south) elevation is filled with a solid metal door sheltered by a metal awning. A large opening is located on its east (side) elevation although this is currently enclosed.

\section{NATIONAL REGISTER EVALUATION}

Building 3594 was constructed in 1976 as the Waste Management Storage Building for the ORNL installation. Building 3594 was previously surveyed in 1994 and recommended as a non-contributing resource to the ORNL Historic District due to its age (Carver and Slater 1994). It was surveyed again in 2015 and recommended as a contributing resource to the district (Thomason and Associates 2015); however, it is located outside the recommended district boundary. Building 3594 retains a majority of its historic materials, form, and massing. As a storage facility, Building 3594 provided support for work that furthered ORNL's mission in nuclear science during the Cold War era. However, the building is not the single location most importantly associated with a scientific achievement, scientist, or other event or person of historic significance to merit individual listing in the NRHP under Criterion A or B. Furthermore, the building lacks notable architectural elements that would warrant individual listing in the NRHP under Criterion $\mathrm{C}$, and it was constructed after the end of the period of significance of the ORNL Historic District. As such, Building 3594 does not warrant individual listing in the NRHP under Criterion $A, B$, or $C$, nor is it a contributing resource to the ORNL Historic District as it is located outside the recommended district boundaries. 


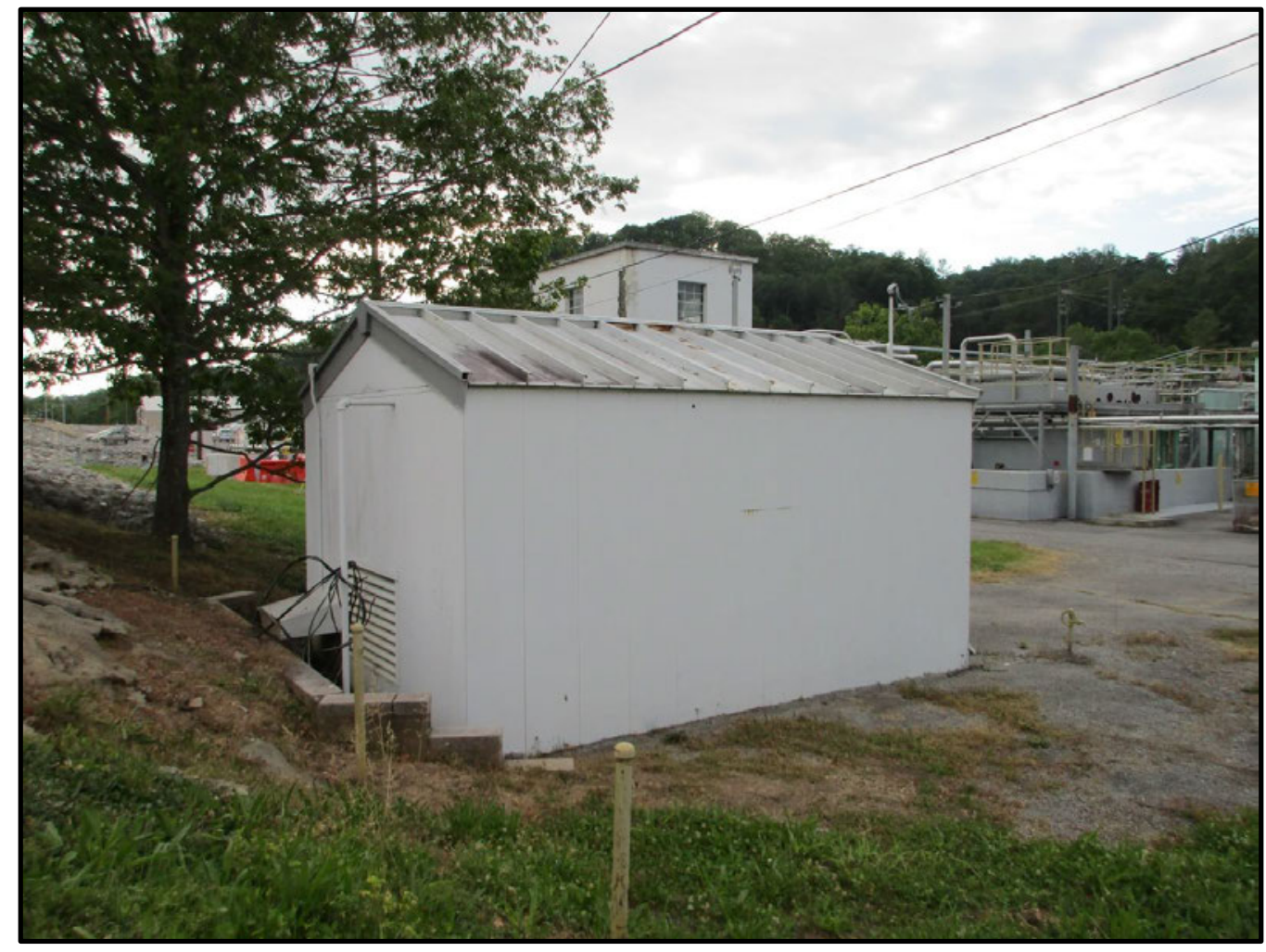

Figure 216. Overview of north and west elevations of Building 3594. 


\section{8}

\section{BUILDING NAME}

WC-10 Tank Farm Pumping Station

\section{DATE OF CONSTRUCTION}

1952

DOE OFFICE RESPONSIBLE

EM (UCOR)

\section{NRHP ELIGIBILITY}

Non-Contributing to ORNL Historic District

\section{DESCRIPTION}

Building 3618 is located immediately north of the intersection of White Oak Avenue and Fifth Street. Building 3618 is a one-story, single-bay, front-gable structure resting on a concrete foundation (Figures 217 and 218). The building is sheltered by a roof of asphalt shingles and clad with vinyl siding. The façade (south) elevation features an off-center single-leaf entry filled with a single-light metal pedestrian door. The side (east and west) elevations of the building feature windows filled with six-light, double-hung replacement vinyl sashes.

\section{NATIONAL REGISTER EVALUATION}

Building 3618 was constructed in 1952 as a pumping station. The building was previously unrecorded. As a utility/maintenance facility, Building 3618 provided utilitarian support services for work that furthered ORNL's mission in nuclear science during the Cold War era. However, the building is not the single location most importantly associated with a scientific achievement, scientist, or other event or person of historic significance to merit individual listing in the NRHP under Criterion A or B. In addition, the building lacks notable architectural elements that would warrant individual listing in the NRHP under Criterion C. Furthermore, Building 3618 exhibits replacement materials including vinyl siding, windows, as well as replacement metal doors. Thus, the building no longer retains integrity of design, materials, or workmanship. Due to compromised integrity, Building 3501 does not warrant individual listing in the NRHP under Criterion A, B, or C, nor is it a contributing resource to the ORNL Historic District. 


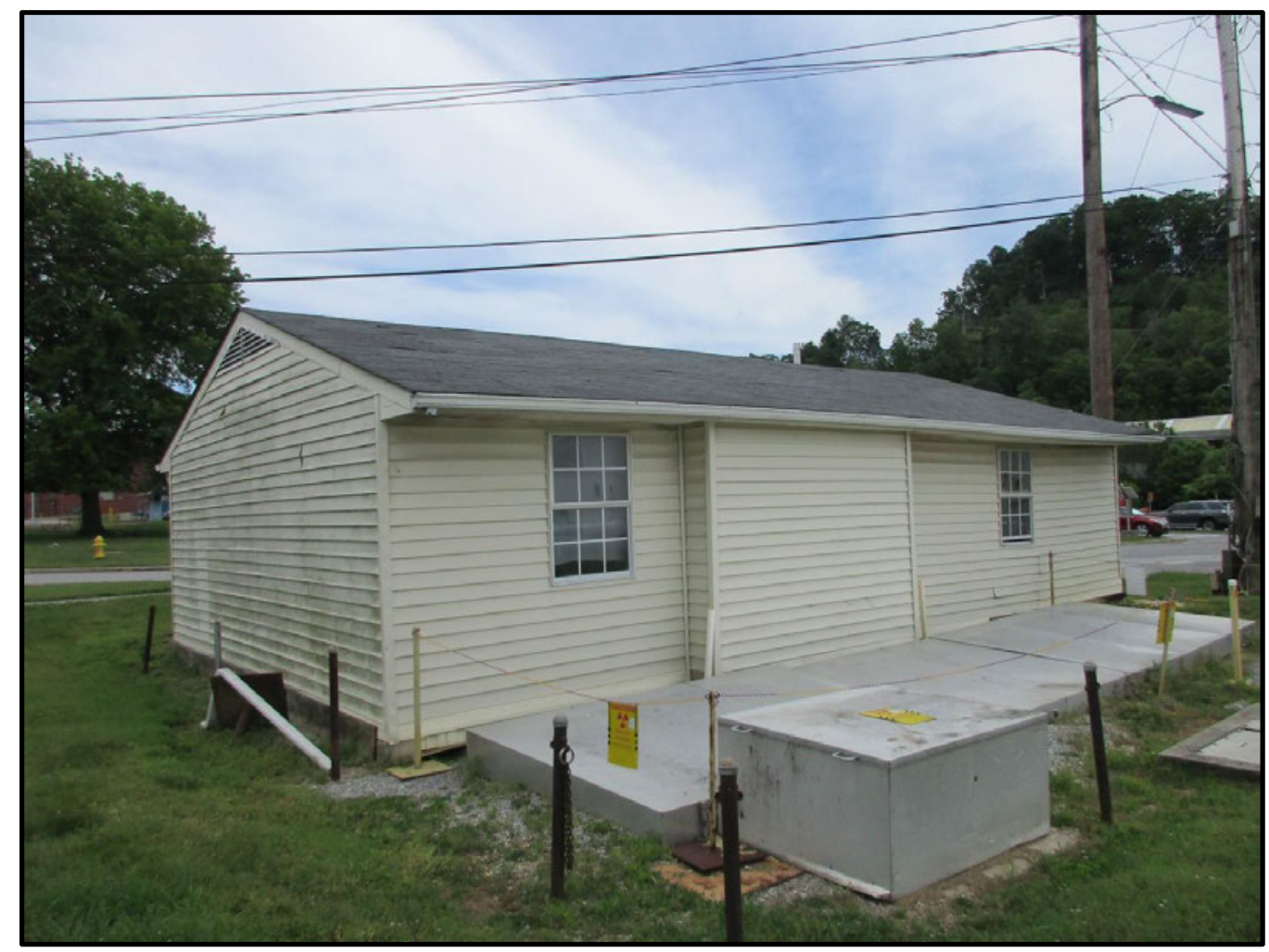

Figure 218. Overview of north and west elevations of Building 3618. 


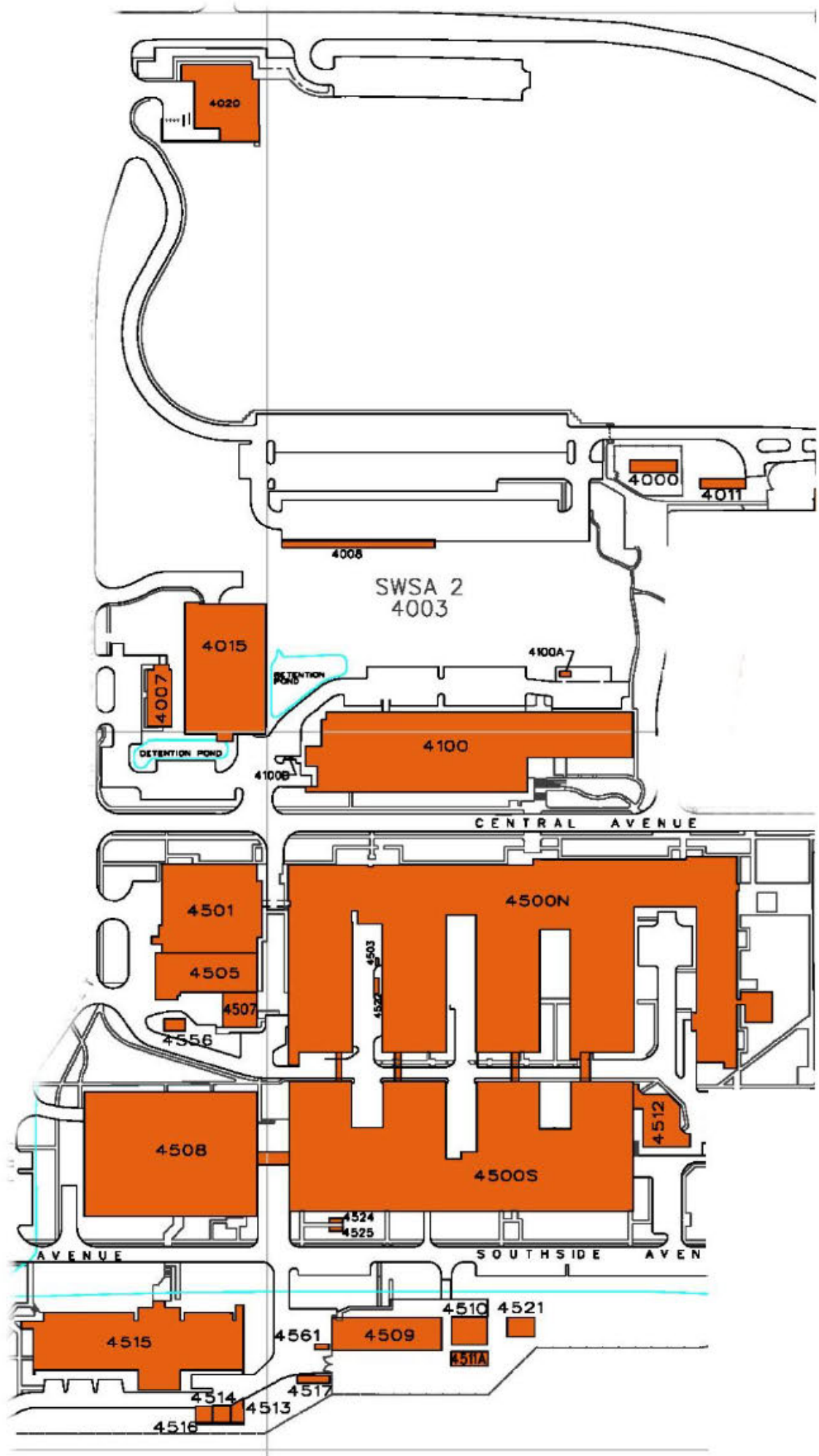

\section{AREA}

CONTRIBUTING TO ORNL HISTORIC DISTRICT

Building $4500 N^{*}$

Building 4500S

Building 4501

Building 4505

Building 4507

Building 4508

NOT ELIGIBLE

Building 4509-VB1

*Also individually

NRHP-eligible

Figure 219. Plan View of 4000 Area. 
This page intentionally left blank 


\section{AREA}

\section{DISTRICT NAME}

4000 Area of ORNL

\section{DATE OF CONSTRUCTION}

1951-2012

\section{NRHP ELIGIBILITY}

Part Contributes to ORNL Historic District

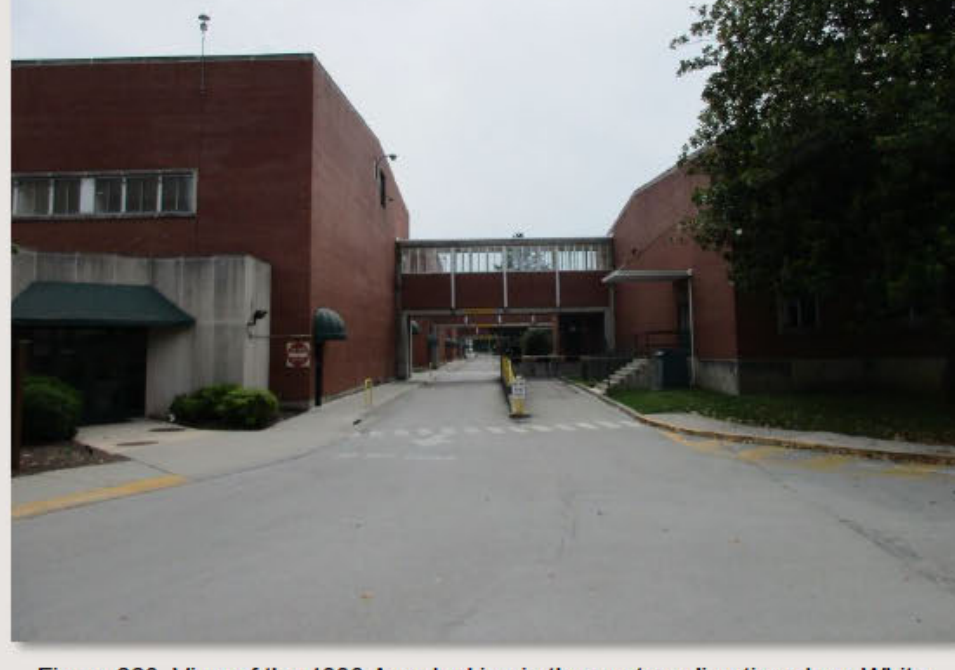

Figure 220. View of the 4000 Area looking in the western direction along White Oak Avenue towards Buildings $4500 \mathrm{~N}$ (right) and $4500 \mathrm{~S}$ (left)

\section{DESCRIPTION}

The 4000 Area is located in the central portion of the main campus of ORNL. It is roughly bounded by Fifth Street, White Oak Creek, Sixth Street, and Bethel Valley Road. A small section of 4000 buildings are located on the south side of White Oak Creek. Central Avenue, White Oak Avenue, and Southside Avenue serve as the primary thoroughfares within the 4000 Area. Twenty-nine buildings and one bridge, Building 4509-VB1, are located within the 4000 Area. Only six of these were constructed before 1980, and were thus included in this survey. The northern section of the 4000 Area is comprised of primarily modern buildings that represent recent expansion of the ORNL campus under UT-B management. The majority of the buildings included in the survey are located between Central Avenue and Southside Avenue. Enclosed concrete pedestrian bridges are a key characteristic of the 4000 Area. These walkways connect Building $4500 \mathrm{~N}$ and Building $4500 \mathrm{~S}$, spanning a portion of White Oak Avenue known as the "Canyon" (Figure 220). An additional enclosed concrete walkway connects Building 4508 to Building 4500S. Green space within the 4000 Area is centered along Central Avenue and in courtyards between wings of Buildings $4500 \mathrm{~N}$ and $4500 \mathrm{~S}$ (Figure 221).

\section{NATIONAL REGISTER EVALUATION}

The 4000 Area was generally constructed in two periods. The majority of resources in the central, historic core-bounded by Fifth Street, Central Avenue, Sixth Street, and Southside Avenue-were constructed between 1951-1962, while most of the resources of the 4000 Area north of Central Avenue and south of Southside Avenue were constructed since 2008 . This area has not been individually evaluated as a whole through past surveys (Carver and Slater 1992; Thomason and Associates 2004 and 2011). Recent construction to the north and south of the historic core of the 4000 Area has diminished the integrity of the entire area to such a degree that the area as a whole is no longer a cohesive entity. Rather, the historic core represents a contributing portion of the larger NRHP-eligible ORNL Historic District, while the portion containing new construction is outside the recommended district boundaries. The contributing portion of the 4000 Area retains integrity to convey clear associations to the central areas of significance of ORNL during the post-World War II development of a national laboratory as a government-owned, contractor-operated, leading scientific research facility that made significant contributions in advancing both defensive and peacetime applications of nuclear science and other fields of scientific inquiry during the Cold War. 


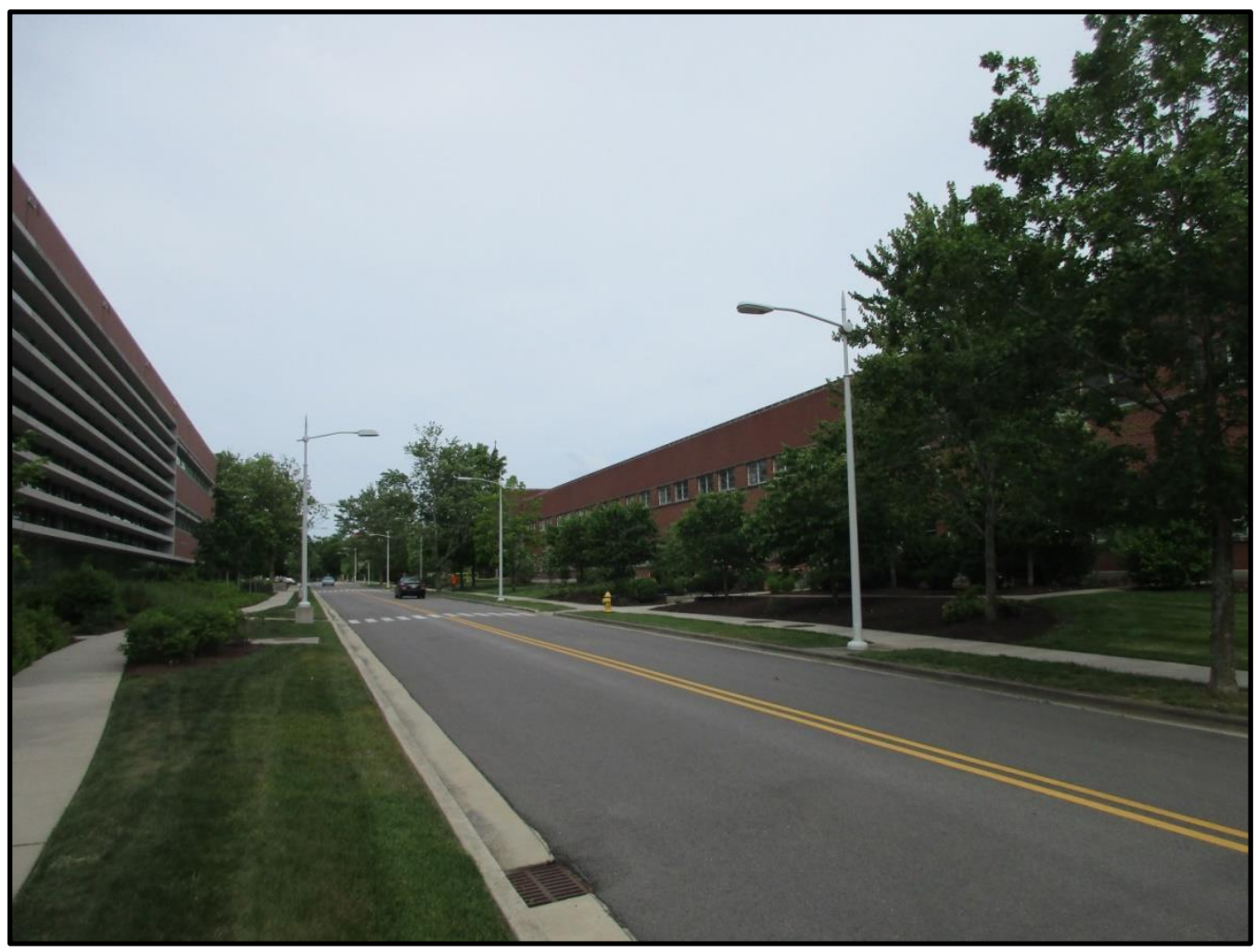

Figure 221. View of the 4000 Area looking in the east direction along Central Avenue towards Buildings $4500 \mathrm{~N}$ (right) and 4100 (left). 


\section{$4500 \mathrm{~N}$}

\section{BUILDING NAME}

Central Research \& Administration North

DATE OF CONSTRUCTION

1952

DOE OFFICE RESPONSIBLE

SC

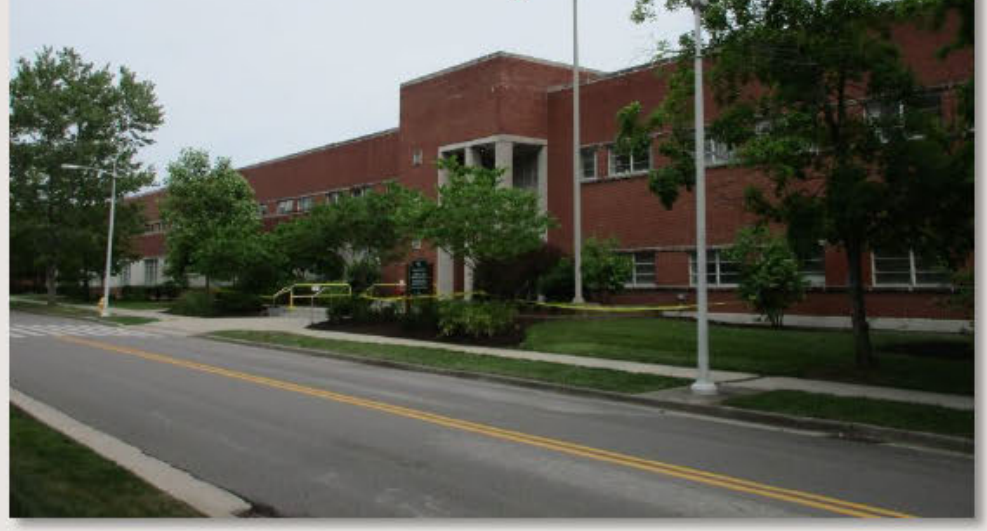

NRHP ELIGIBILITY

Figure 222. North (façade) elevation of Building 4500N.

Eligible; Contributing to ORNL Historic District

\section{DESCRIPTION}

Building $4500 \mathrm{~N}$ was one of 15 resources selected for intensive survey by UT-B as a part of survey planning. In February 2017, UT-B completed and submitted Section 106 documentation to the SHPO (THC) for Building $4500 \mathrm{~N}$ as a part of consultation for renovation and repurposing of the building. SHPO consultation for the proposed project is currently underway. The following description is adapted from the recordation completed as a part of that effort, supplemented with photographs taken in May and June of 2017 by CRA (UT-Battelle, LLC 2017:5-8).

Exterior: Building $4500 \mathrm{~N}$ is a two-story, brick, concrete, and steel building constructed in two phases. The original building was constructed in 1952 at a cost of $\$ 4,966,000$. This structure included a main office section known as the "Head House" and four "ells" or rear wings containing offices and research laboratories. In 1960 the building was extended to the east with the addition of a fifth rear ell wing, added at a cost of $\$ 1,577,000$. Building $4500 \mathrm{~N}$ was originally built with the east and west wings one story in height in the head house block. A second story was added to the head house at the location of these wings in 1960 when Wing 5 was added to the building. Both the 1952 and 1960 buildings were constructed of concrete and steel with an exterior veneer of five-course common bond brick. The building retains original aluminum windows, which are fixed two-light, fixed five-light, and fixed three-light design. Many of the windows are set within rectangular window banks with continuous stone sills and lintels (Figure 222). Windows are located on each elevation of the building except the south elevation of the rear ell wings. The south elevations display two entrances on the ground floor of each wing, and each wing has an attached pedestrian bridge of brick and concrete on the second floor connecting Building 4500N with Building 4500S.

The north elevation of Building $4500 \mathrm{~N}$ consists of the original 1952 construction, while the east elevation was completed in 1960 (Figure 223). The historic main entrance to the building is on the north elevation and is set within a corner two-story portico on a two-story projection extending from the main block of the building. The portico has original rectangular concrete columns and circa 1980 aluminum and glass doors (Figure 224). The projecting entrance bay also contains original structural glass block windows that provide illumination into the interior stairwell. This entrance is decorated with landscaped planter boxes and a metal flagpole. The north elevation has two secondary entrances. The west bay secondary entrance is original to the building and has 
aluminum and glass double doors. The east bay secondary entrance on the north elevation dates from the east wing construction of 1960 . This entrance has original paired aluminum and glass doors, and the entrance is sheltered by a concrete canopy resting on concrete columns (Figure 225).

On the west elevation of the building is a loading dock on the first floor with stairs leading to a pedestrian entrance and to a garage bay entrance in the basement level (Figure 226). There are also two sets of circa 1980 double doors of steel and glass on the first floor of the west elevation that lead to the concrete loading dock. At the south corner of the building is an original one-story brick mechanical room with two doors reinforced with steel plate (Figure 227). The south elevations of the $4500 \mathrm{~N}$ rear laboratory wings have paired circa 2000 single-light steel and glass doors at the southern end of each wing (Figure 228). These entrances lead to corridors that extend the full length of the laboratory wings. The entrances are located on the first floor but are reached by concrete stairs and landings.

Between each of the rear wings are "courtyards," some of which consist of paved parking areas and sidewalks and others of a grass surface (Figure 229). Between Wings One and Two is a paved parking area and sidewalk. At the rear of the head house block is a loading dock bay with a concrete platform and paired circa 1980 steel and glass double doors. Within this courtyard are also added freestanding electrical units and mechanical systems. The south elevation of Wing Two has two entrances, one of which is located under the second floor bridge to 4500S, the other under a circa 2000 metal awning. Concrete stairs with metal railings lead to both entrances. The courtyard between Wings Two and Three has a paved parking area and concrete sidewalk. At the south elevation of the head house block within this courtyard is a loading dock bay with a concrete platform and circa 1980 metal canopy. Leading to this loading dock platform is an original steel and glass pedestrian door and paneled metal garage door. Windows in the east and west elevations of Wing Three were replaced in 2013 and are of fixed single-light, aluminum and glass design (Figure 230). Also on the west elevation of Wing Three is a 2013 handicapped access ramp of concrete with a metal railing. The south elevation of Wing Three has two pedestrian entrances with circa 2013 steel and glass doors (Figure 231). Adjacent to the west bay entrance was a garage bay door that was infilled with brick and a single-light glass and aluminum window. The courtyard between Wings Three and Four contains a sidewalk and a landscaped area with a grass surface. Windows on the east elevation of Wing Three are also circa 2013 single-light glass and aluminum design. The south elevation of Wing Four has two pedestrian entrances with circa 1980 steel and glass doors. The area between Wings Four and Five has a concrete sidewalk, a paved driveway and parking areas, and a landscaped area with two trees and a grass surface. Windows on the east elevation of Wing Four are of the original singlelight glass and aluminum design. At the south elevation is a one-story brick mechanical room with a circa 2000 steel door.

Wing Five is part of the building addition completed in 1960. Wing Five retains original two-light aluminum and glass windows on the east and west elevations (Figure 232). The pedestrian entrances on this elevation have original single-light steel and glass doors. The south elevation of the head house block does not have a loading dock bay and instead features bands of windows on both the first and second floors. On the west elevation of Wing Five is an original, one-story aluminum and glass-enclosed vestibule designed as an ambulance dock enclosure.

The east elevation of Building $4500 \mathrm{~N}$ has original windows and a primary entrance at the north corner (Figure 233). This entrance has circa 1990 aluminum and glass doors similar to the original in design and flanking aluminum and glass full-height windows. Sheltering the entrance is a canopy with damaged support columns 
that were rewrapped in 2007 in an attempt to match the original columns at this location. Attached to a portion of the east elevation of the building is a one-story brick and concrete medical records wing that was added in 1994. The records wing lacks fenestration on the south, east, and north elevations.

Many windows in the building are original aluminum and single-pane glass design that would require updating in order to meet current DOE mandated energy conservation standards. As a stopgap measure for energy conservation most of the windows have added single-light interior aluminum storm windows or exterior aluminum storm windows. Most of the doors leading into the building were replaced from the 1980s to the present with doors of single-light steel and glass design. Some exterior entrances retain original single-light steel and glass doors that have inset lower panels under the glass light.

Interior: The interior of Building $4500 \mathrm{~N}$ was designed for specific uses in the head house block and the laboratory wings. The head house block was designed to contain various offices on both the first and second floors. These offices are divided by two corridors that extend in an east-west direction. Some interior walls are composed of interlocking metal panels while others are of concrete and plaster.

In addition to the office spaces, the first floor of the head house was designed with a large library and a lecture hall now called the Weinberg Auditorium located in Wing Five. The Weinberg Auditorium, named for physicist Alvin Weinberg, was originally remodeled in 1979. The library was expanded and again remodeled within the past decade with new floor carpeting, seating, and acoustic tile ceilings. On the second floor of the head house block is the Wigner Auditorium (Figure 234). This was originally designed to be one of the main lecture spaces in the building and was known as "Lecture Room A" before being renamed in honor of physicist Eugene Wigner. It was substantially remodeled in 1988 with new wall, floor, and ceiling finishes and seats. The back of the auditorium is accessed by two small terrazzo stairs with aluminum handrails.

The laboratory wings were designed with two corridors extending the length of each wing. Between the corridors in the middle of the wings are laboratory spaces separated by metal panel walls (Figure 235). On the outer sides of the corridors are a series of office rooms that also have metal panel walls. These interlocking metal panels walls were an early version of de-mountable partition walls and allowed flexibility in enlarging the office and laboratory spaces as needed. The concrete floors were originally covered with linoleum and asbestos cement tiles, but many of these surfaces have been removed and replaced with non-original linoleum and/or covered with carpet. The ceilings were originally designed with metal acoustic tiles which remain in place in many parts of the building (Figure 236). Many sections of metal tiles have been covered or replaced with acoustic tile of mineral fiber and other materials.

The interior of Building $4500 \mathrm{~N}$ has both original features and modifications added over the past six decades. The original floor plan is largely intact except in the library space and in Wing Three. The floor plan in Wing Three was remodeled extensively in 2013 for office use, and no laboratories remain. Prior to the start of renovations, DOE submitted documentation and project descriptions to the SHPO and received concurrence.

The office and laboratory doors within the building were originally single-light glass and aluminum design (Figure 237). Some doors were designed with clear glass and others with opaque glass. Most of the office and laboratory spaces retain these original doors, but some laboratory doors have been replaced with solid steel doors or doors with safety glass. 
The main lobby in the building off the north entrance retains its original terrazzo floor but has a lowered acoustic tile ceiling and added wall surfaces. The lobby originally had a curved information desk, but this desk was removed and a new curved wall with signage and informative displays was added in 1969 and remodeled with slatted wood paneling added to sections of the walls in recent years. Leading from the lobby to the second story is a terrazzo staircase with original aluminum handrails. A similar staircase of terrazzo and aluminum leads from the east entrance lobby to the second floor.

The second story of the laboratory wings contains a mixture of office space and space for mechanical units. The mechanical units include heating and cooling systems, exhaust ports for the laboratories, and electrical systems. These spaces have concrete floors and concrete block walls. In the head house, many of the office spaces on the second floor have been remodeled with added doors and floor carpeting. Ceilings on the second floor of the building retain both original acoustic metal tiles and plaster surfaces. Light fixtures have been replaced throughout the building with modern fluorescent lights or LED fixtures and similar designs.

Restrooms in the building were originally designed with terrazzo floors and walls of glazed hollow core tile (Figure 238). Some of the building's restrooms still feature these details, although many of the restrooms have been remodeled in recent decades. The staircases in the wings have glazed tile walls, concrete stairs with steel treads and risers, steel balusters, and wood handrails.

The original glass shop remains in operation in Building 4500N. This shop produces much of the glass needed for experiments on the ORNL campus. Many of the original hoods and cabinetry remain in place within the glass shop (Figures 239 and 240).

\section{NATIONAL REGISTER EVALUATION}

One of the most distinctive buildings added to the campus of ORNL during the expansion period following World War II, Building 4500N, the Central Research and Administration Building North, quickly became the center of administration and research activities at ORNL. Constructed as part of "Program H," a $\$ 20$ million project to expand and create a permanent national laboratory, Building $4500 \mathrm{~N}$ was designed with a large library and offices within the main "head house" and laboratories in each of the four original wings. In 1960, an additional wing and a second story above the "head house" were added, and Building 4500S was constructed immediately south of Building $4500 \mathrm{~N}$. Previous surveys indicate that research from a variety of divisions was conducted in Building $4500 \mathrm{~N}$, including nuclear research and research for other federal agencies including the National Aeronautics and Space Administration (NASA), the Department of Housing and Urban Development (HUD), the Department of the Interior (DOI), the Department of State (DOS), and the Federal Bureau of Investigation (FBI). The Analytical Chemistry Division, housed in Building 4500N at the time, conducted research on material recovered from FBI investigations following President John F. Kennedy's assassination as well as studies on moon rocks brought back from Apollo missions. The successful use of these research facilities and laboratories led to the expansion of Building 4500N as well as the rest of ORNL (Carver and Slater 1994: 95; Thomason and Associates 2015:136; Lyon and Shults 1990:17).

Building 4500N was previously surveyed in 1994, 2004, and 2015 (Carver and Slater 1994; Thomason and Associates 2004 and 2015). In 1994, it was recommended as a contributing resource of the NRHP-eligible ORNL Historic District and in 2015, it was recommended as individually eligible and as a contributing resource of the ORNL Historic District under Criterion A for its historical association with the post-World War II government-sponsored scientific movement and early nuclear development. 
CRA concurs that Building $4500 \mathrm{~N}$ stands out as the most significant research/laboratory facility constructed at ORNL in the 1950s, thus it is eligible for listing in the NRHP under Criterion A for its significant role as the center of research activity as ORNL emerged as a permanent national laboratory following World War II. Such associations make Building $4500 \mathrm{~N}$ individually eligible for NRHP listing and make it an important contributing building within the ORNL Historic District. Research did not reveal significant associations to individuals or researchers that would rise to a level that would warrant individual listing in the NRHP under Criterion B, nor does not possess significant associations for its architectural or engineering design that would warrant individual listing under Criterion $\mathrm{C}$. While alterations to the building, including the addition of a second story to the "head house" section and an additional wing, and the renovations to Wing Three, Building $4500 \mathrm{~N}$ retains integrity to support its significant associations under Criterion $\mathrm{A}$ both individually and as a contributing resource of the ORNL Historic District. Therefore, CRA recommends that Building 4500N is eligible for listing in the NRHP both individually and as a contributing resource of the ORNL Historic District under Criterion A for its association with the post-World War II development of government-sponsored scientific laboratories, ORNL's evolution as a national laboratory, and early nuclear development, and under Criterion $\mathrm{C}$ as a purpose-designed scientific research facility within the district.

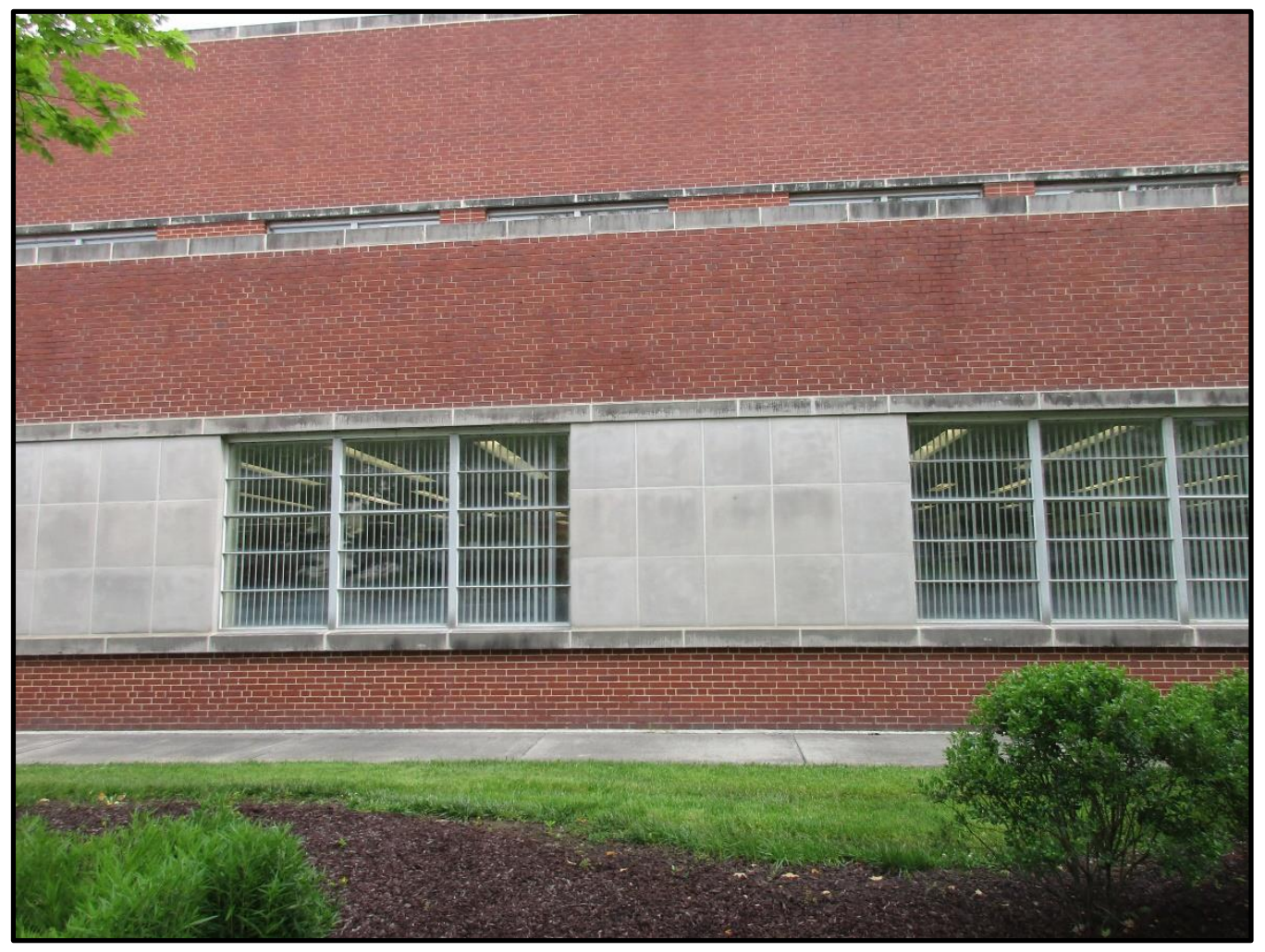

Figure 223. Windows on north (façade) elevation of Building 4500N. 


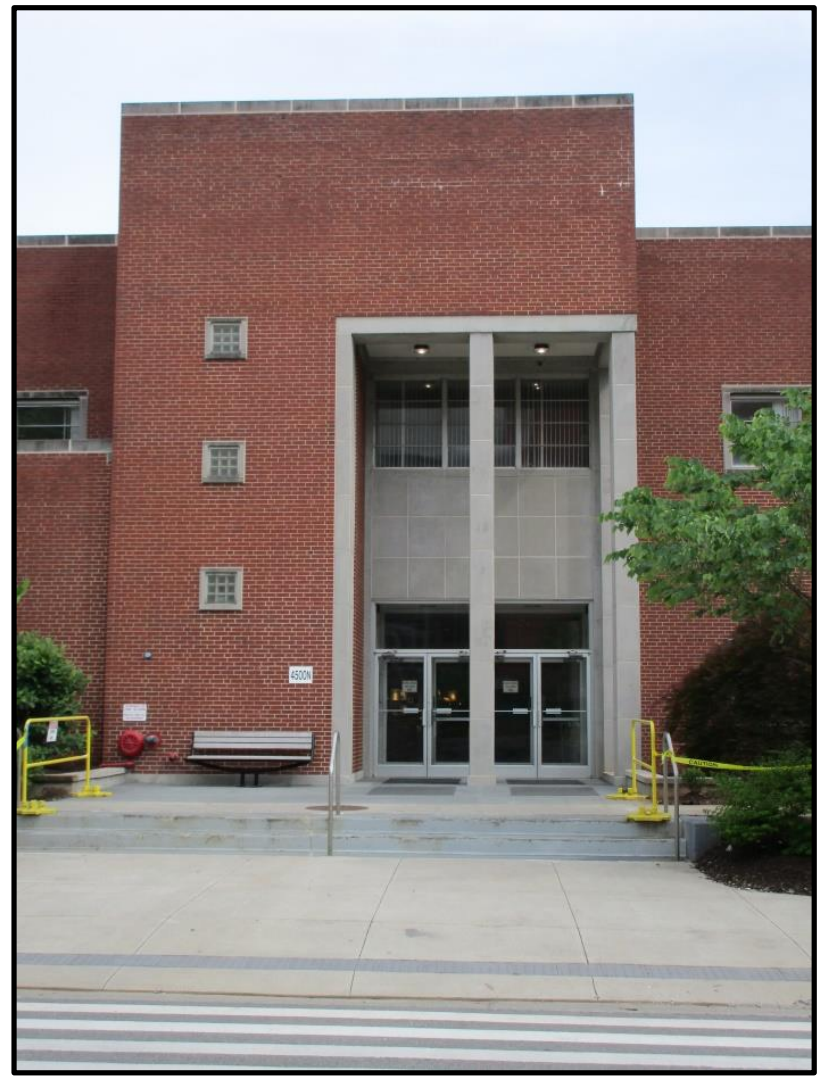

Figure 224. "Flagpole Lobby" entrance on north elevation of Building 4500N.

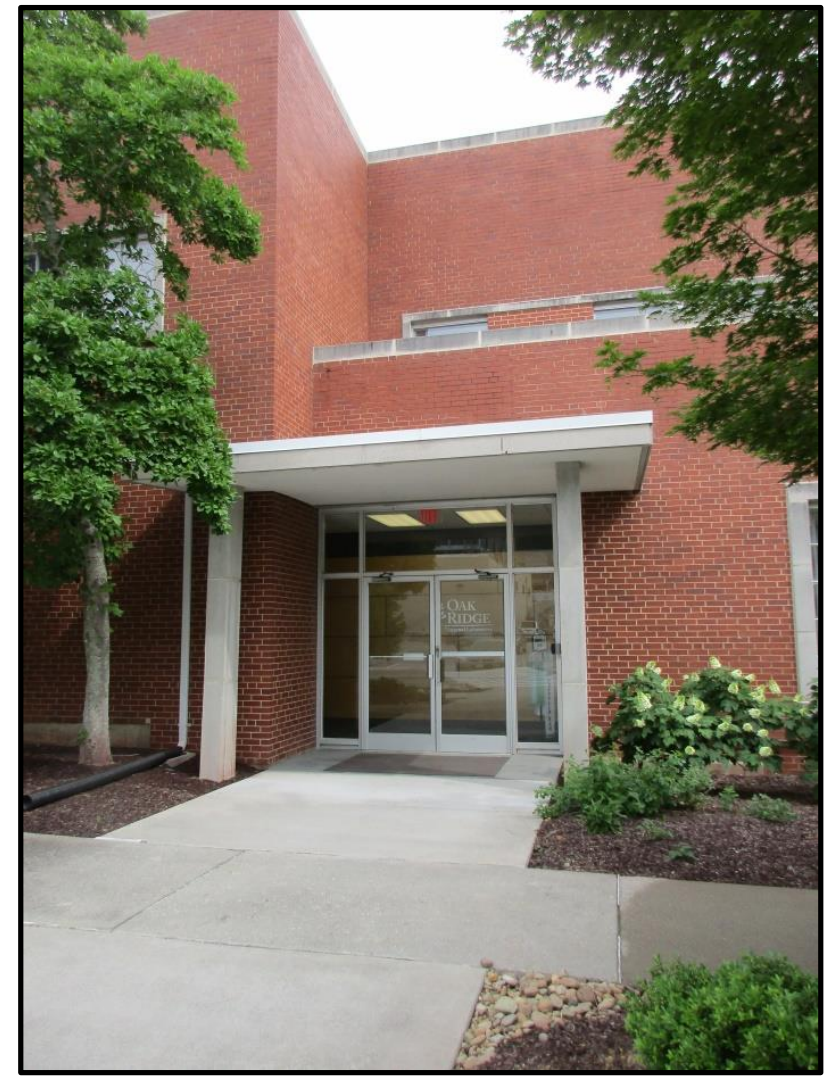

Figure 225. Secondary entry on north elevation of Building $4500 \mathrm{~N}$. 


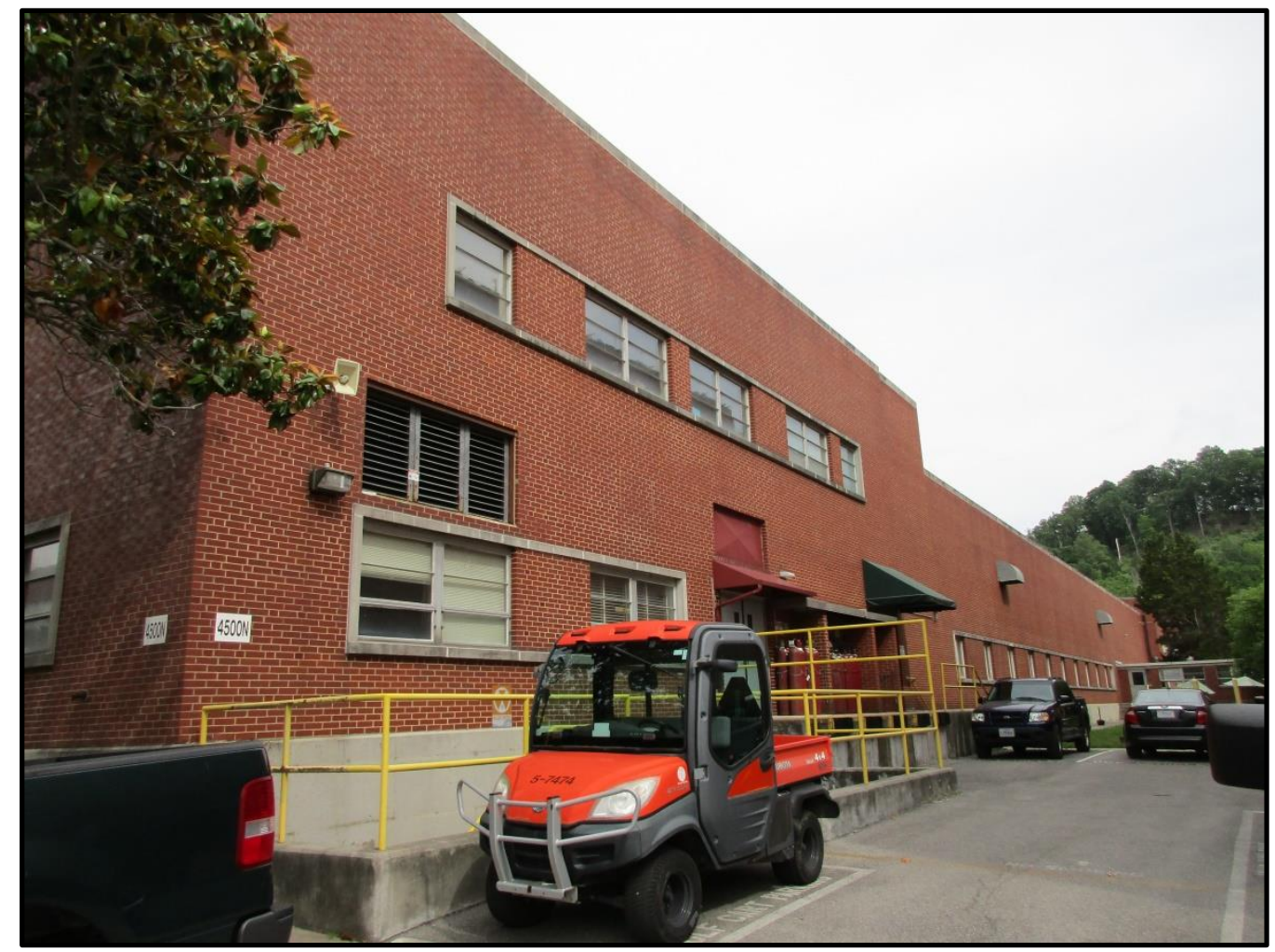

Figure 226. West elevation of Building 4500N.

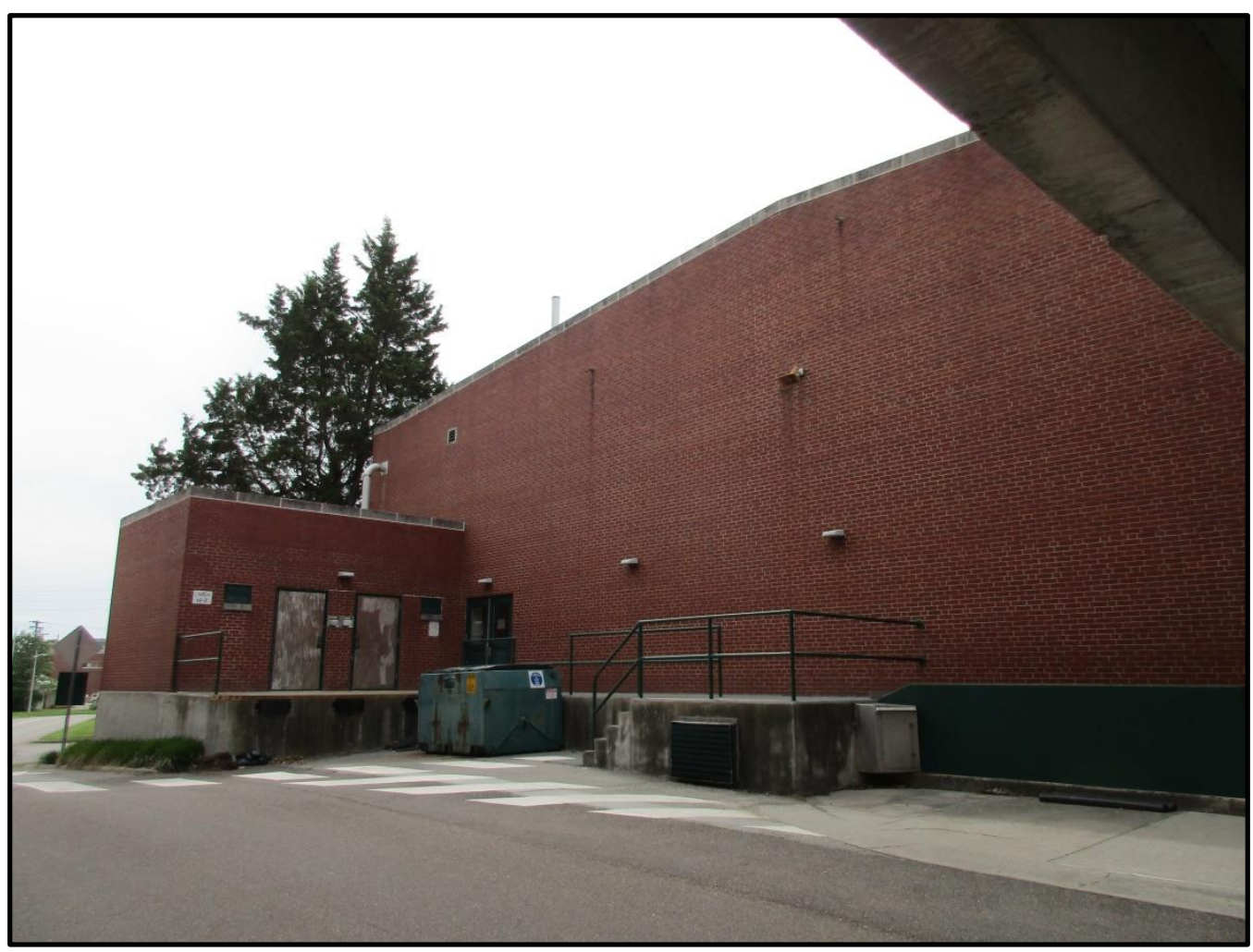

Figure 227. Loading dock at southwest corner of $4500 \mathrm{~N}$, at the "Canyon" between Buildings $4500 \mathrm{~N}$ and $4500 \mathrm{~S}$. 


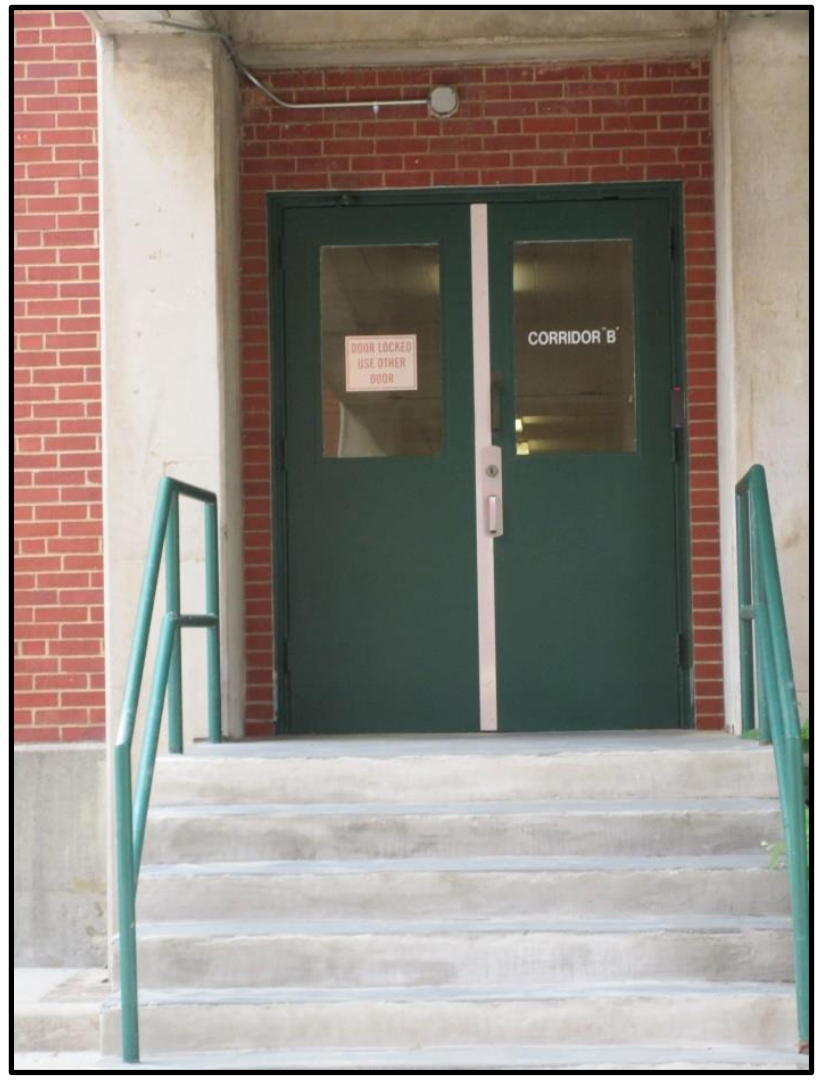

Figure 228. Entry at southern end of Corridor "B" of

Building 4500N.

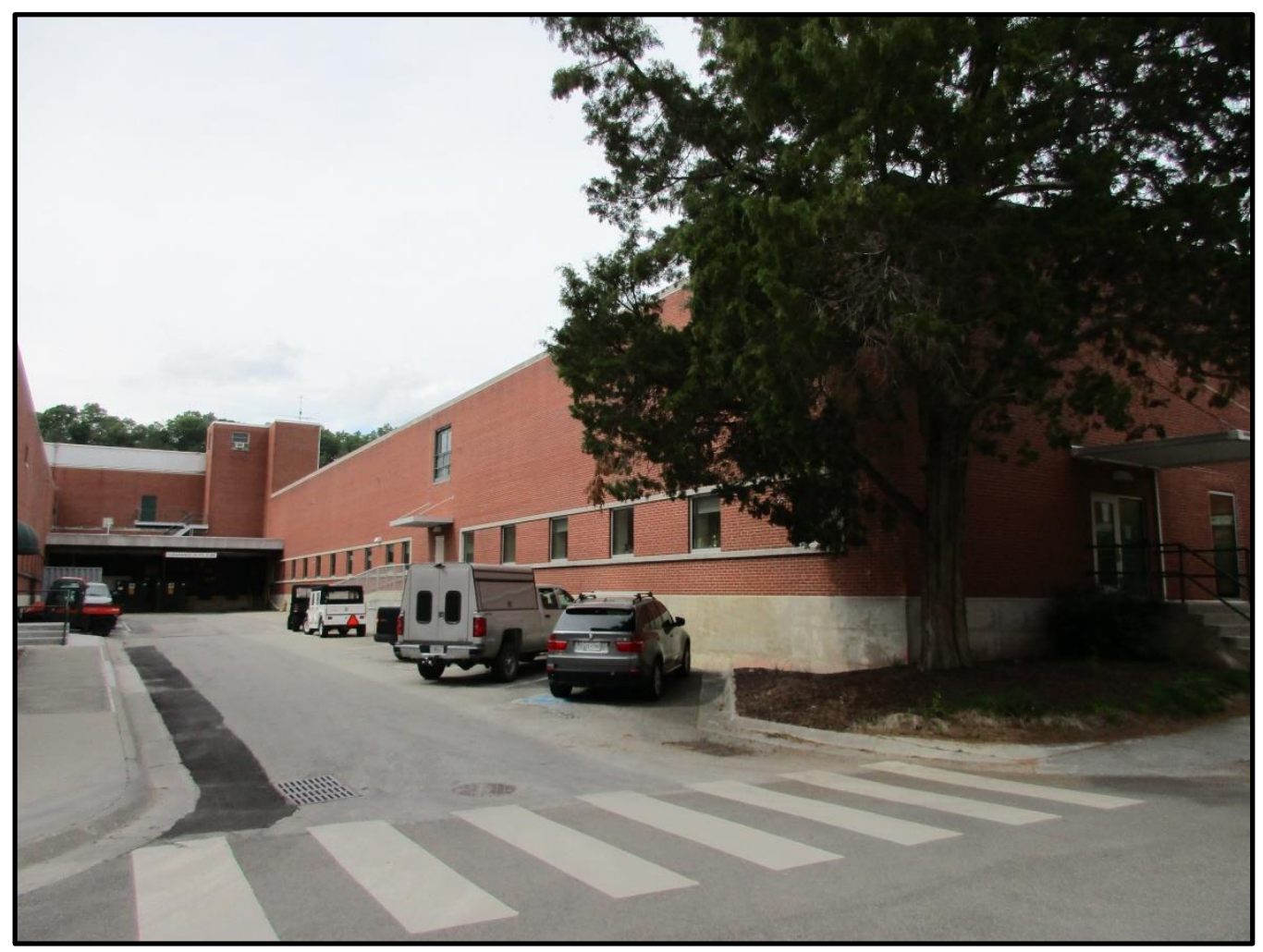

Figure 229. One of four courtyards of Building 4500N. 


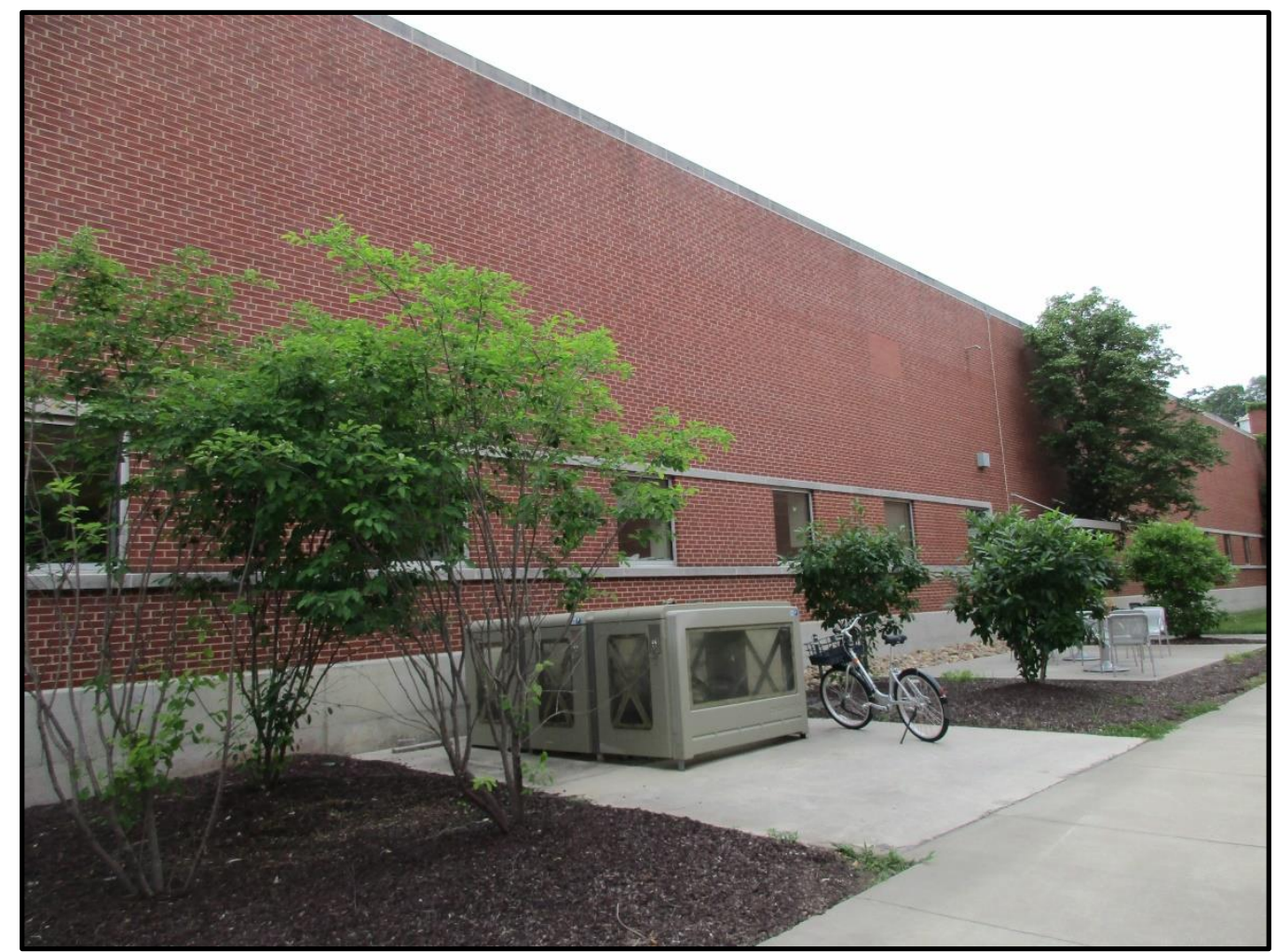

Figure 230. West elevation of Wing Three of Building 4500N.

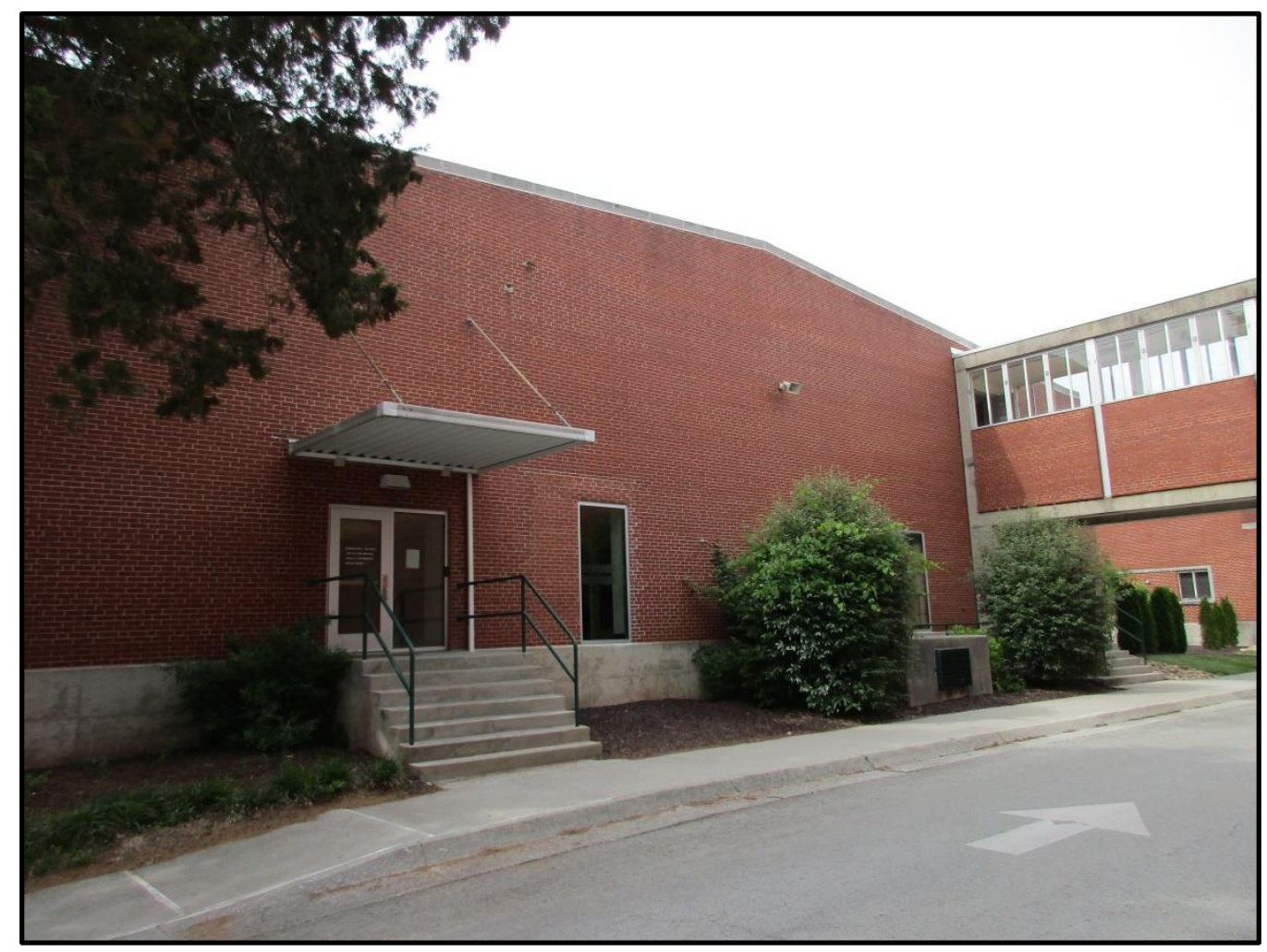

Figure 231. Southern elevation of Wing Three of Building 4500N. 


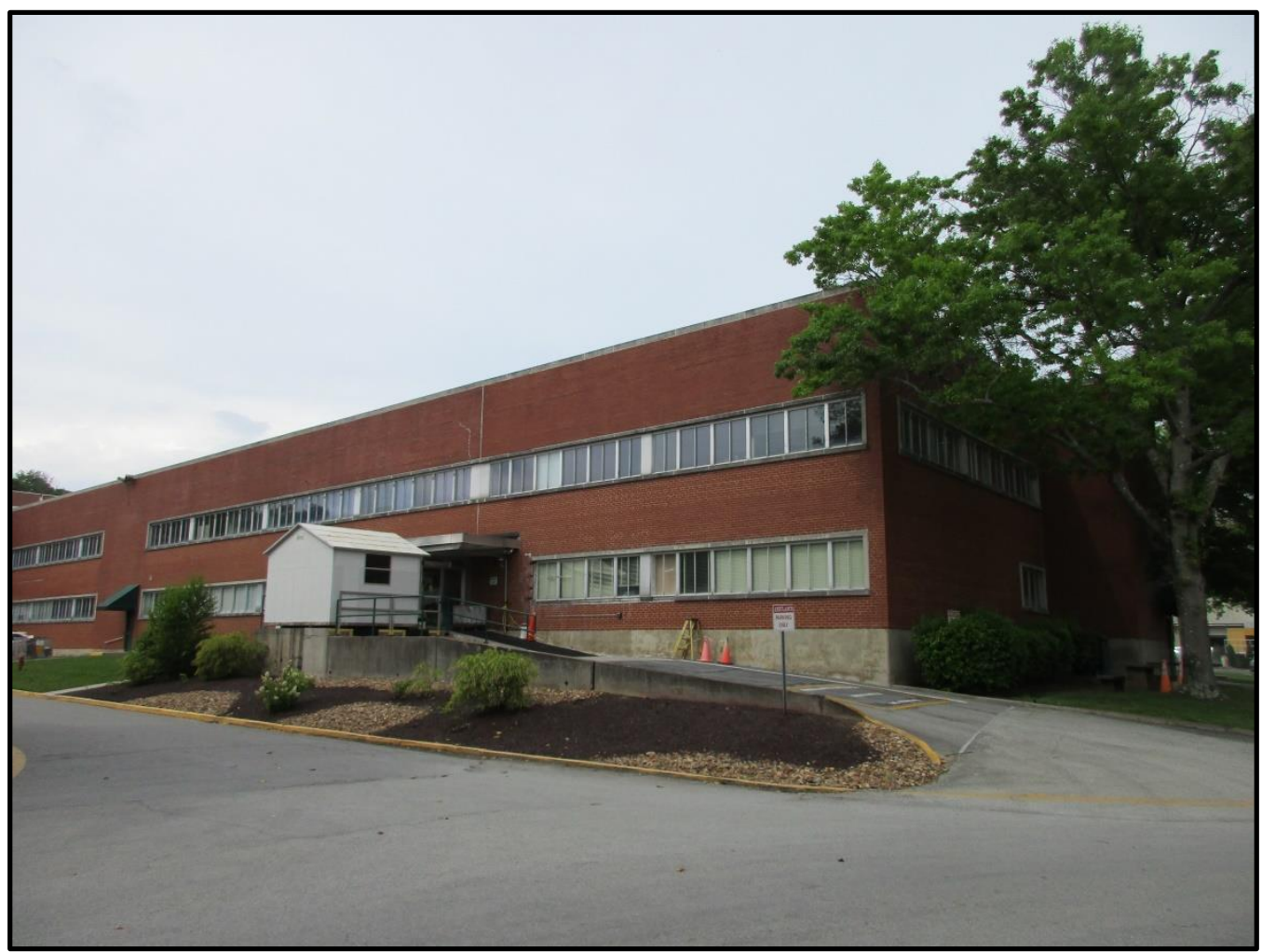

Figure 232. West elevation of Wing Five of Building 4500N.

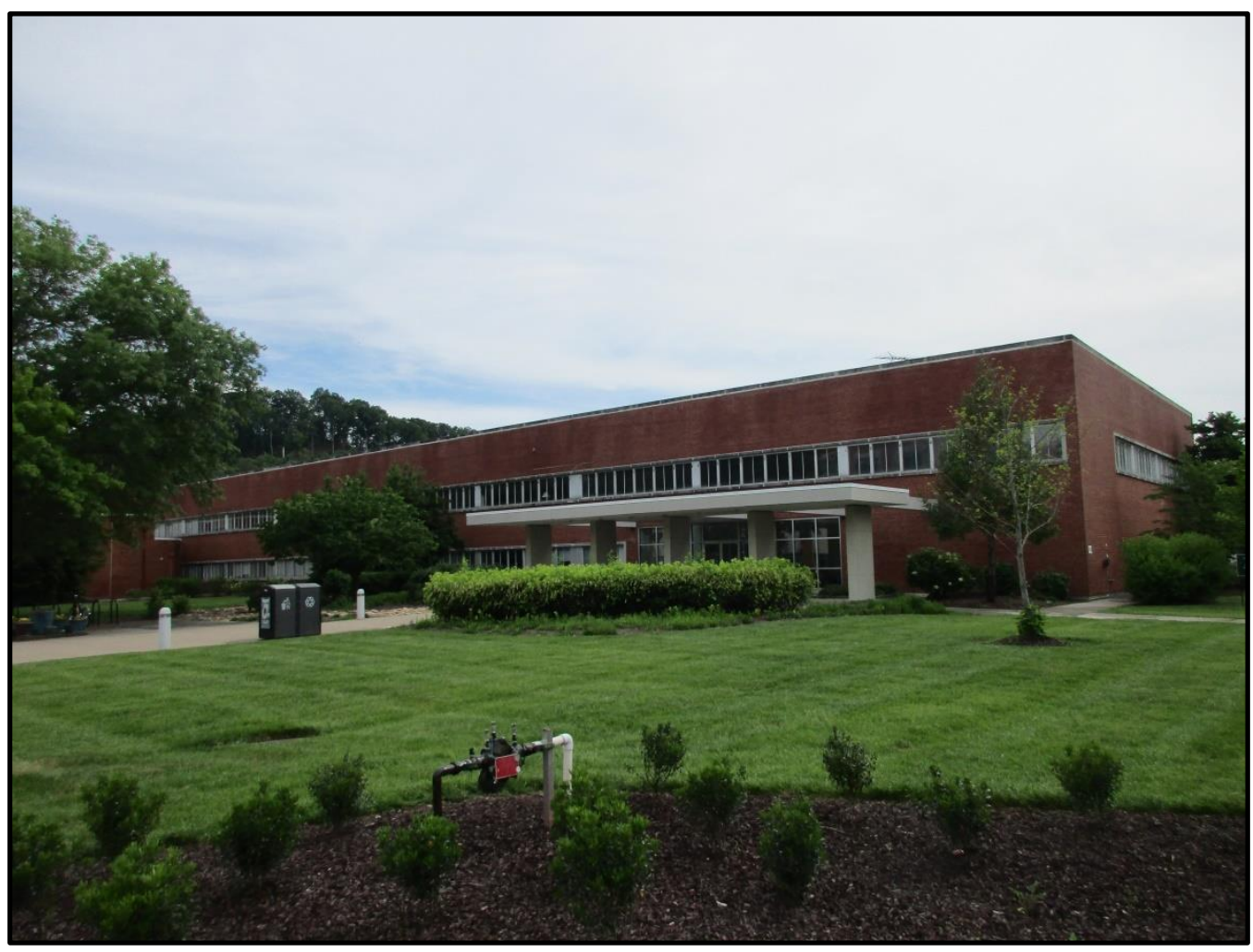

Figure 233. Primary entry on the east elevation of Building $4500 \mathrm{~N}$. 


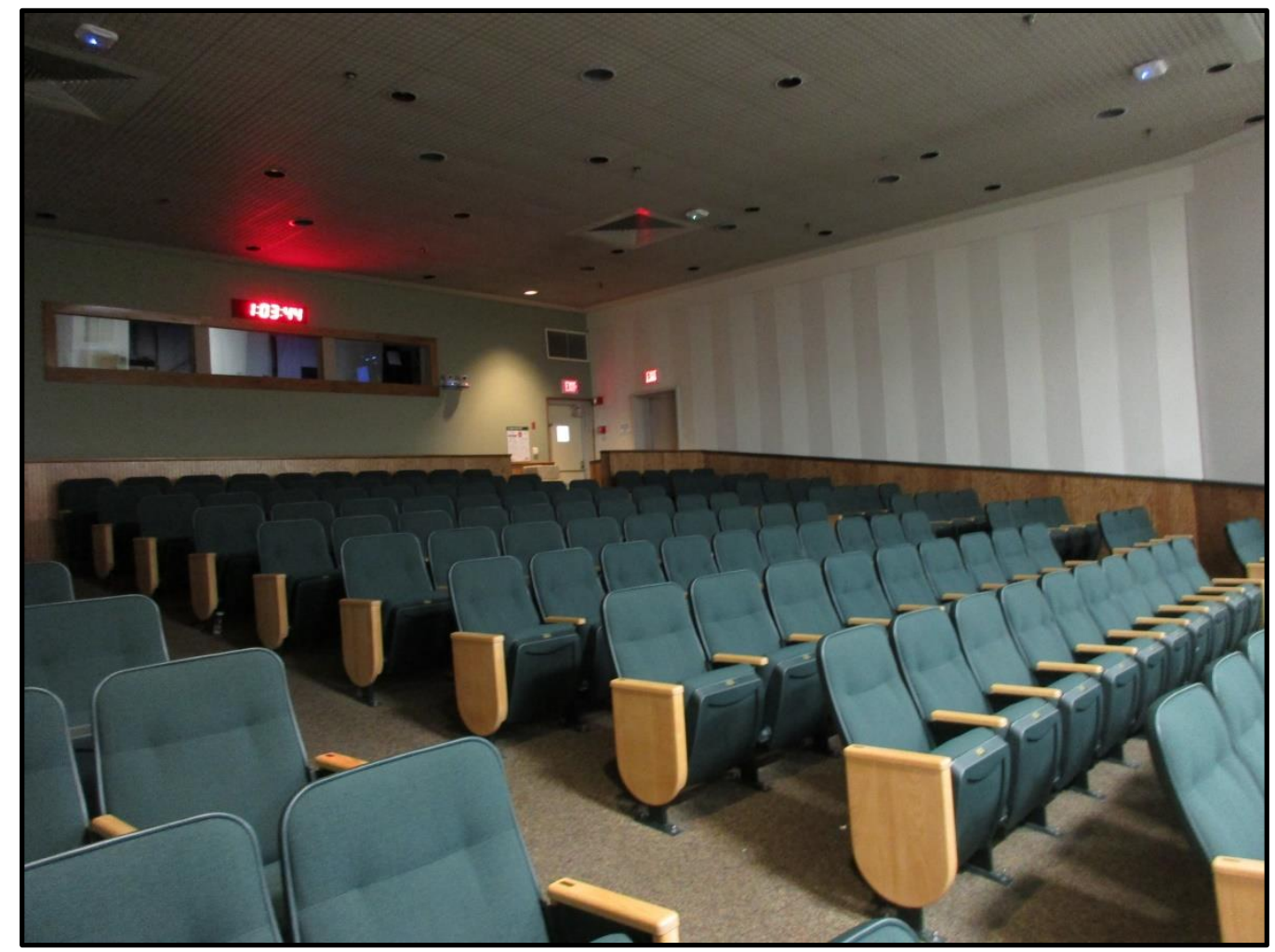

Figure 234. interior of Wigner Auditorium on the second floor of Building 4500N.

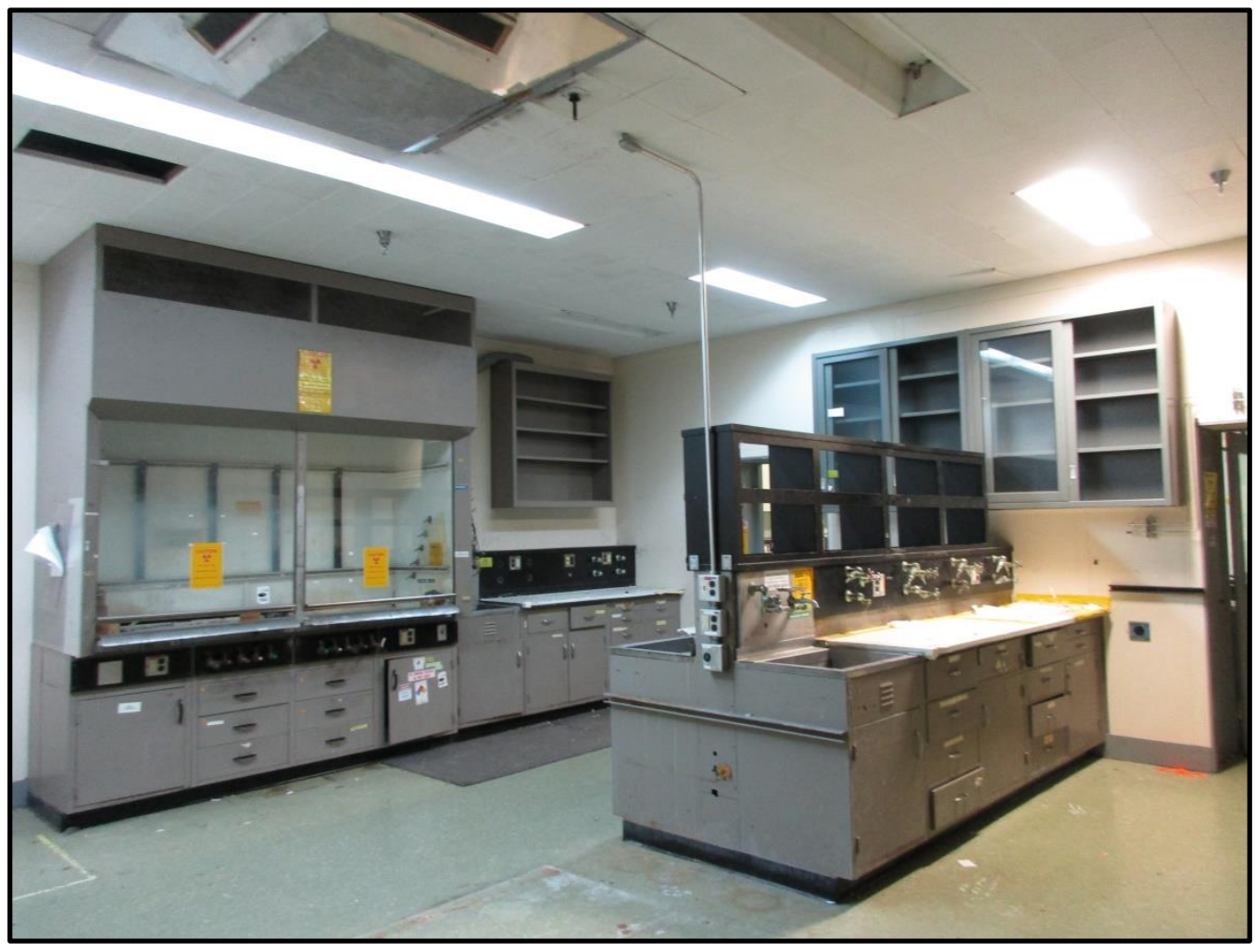

Figure 235. Original laboratory space in Wing 1 of Building $4500 \mathrm{~N}$. 


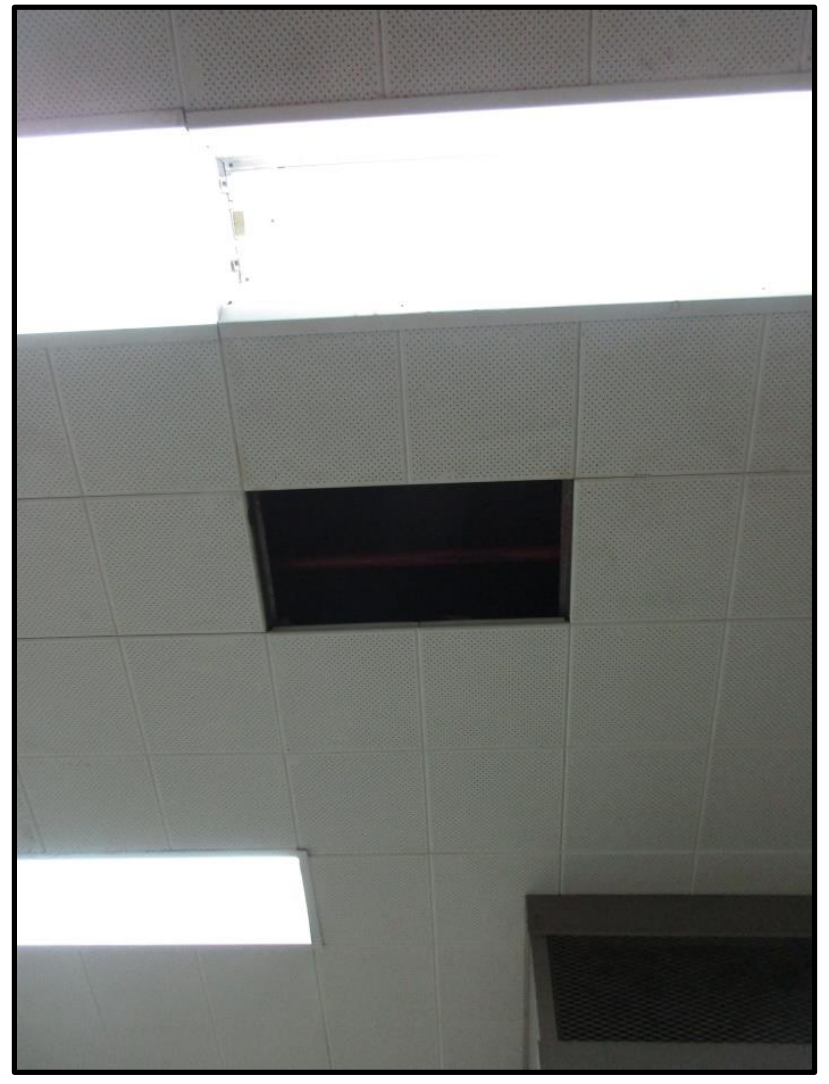

Figure 236. Metal acoustic tiles in a laboratory in Building $4500 \mathrm{~N}$.

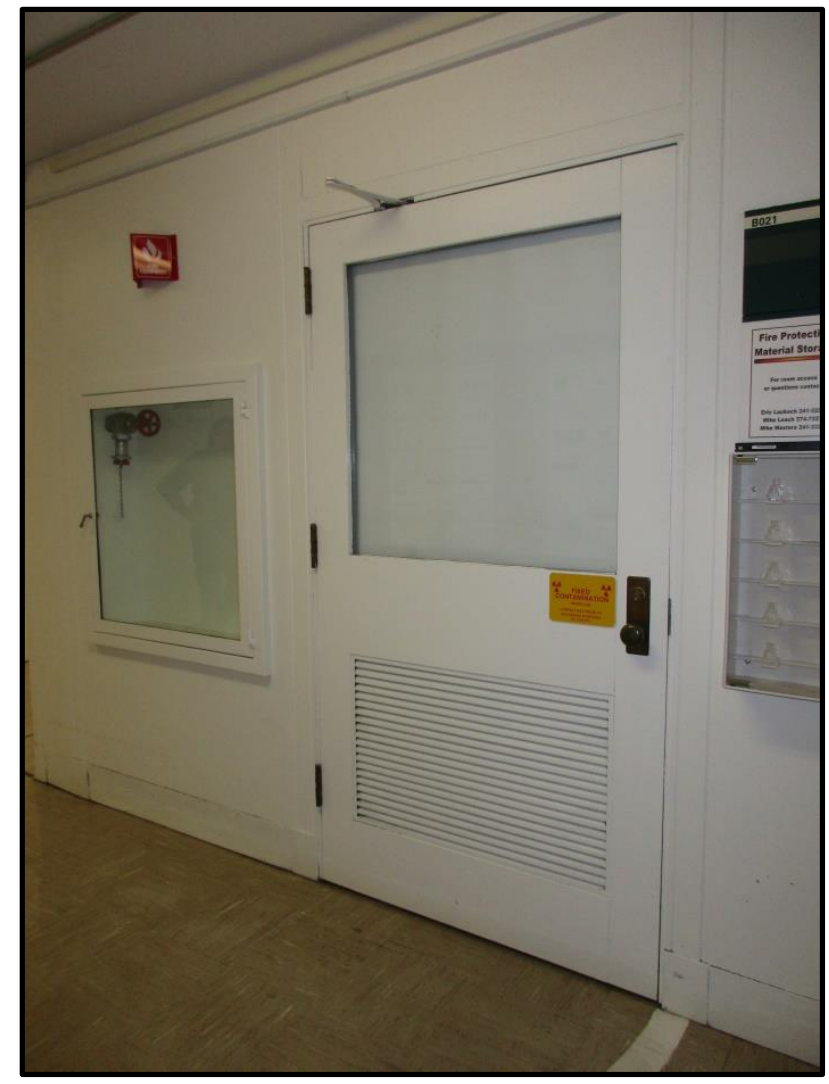

Figure 237. Interlocking metal wall and original door in laboratory wing of Building 4500N. 


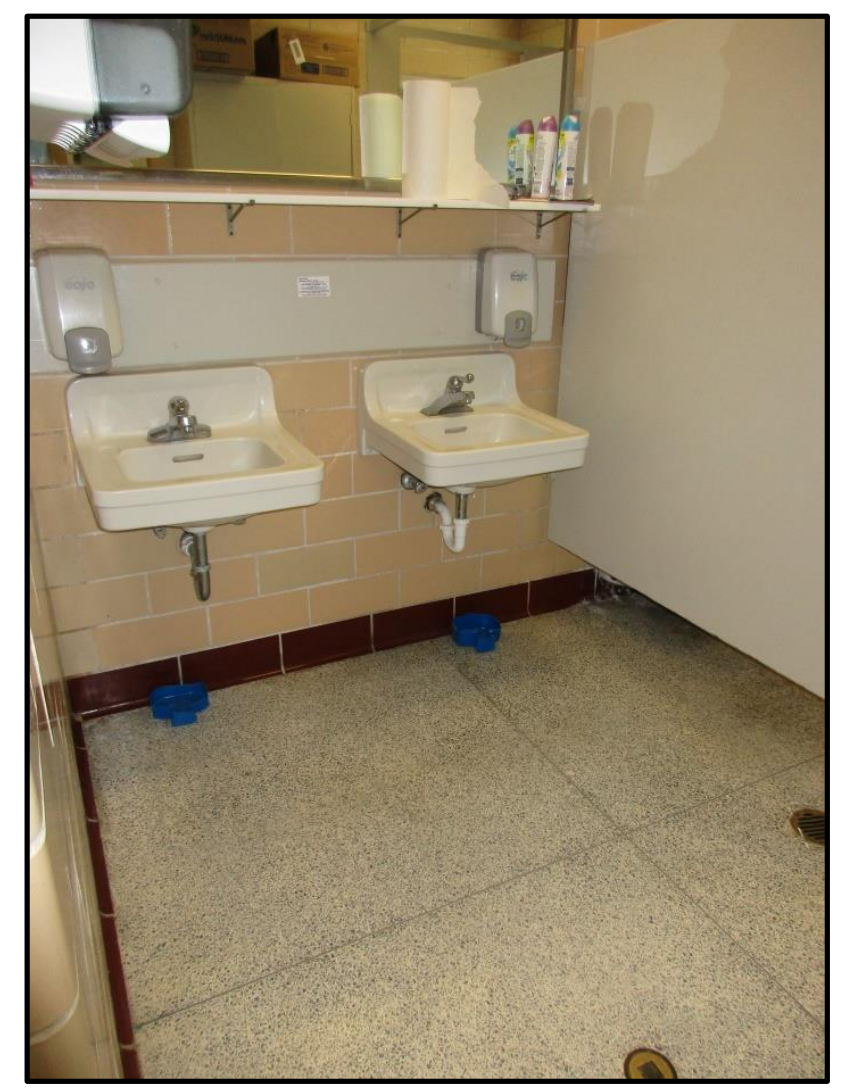

Figure 238. Terrazzo floor and glazed block walls in restroom in Building 4500N.

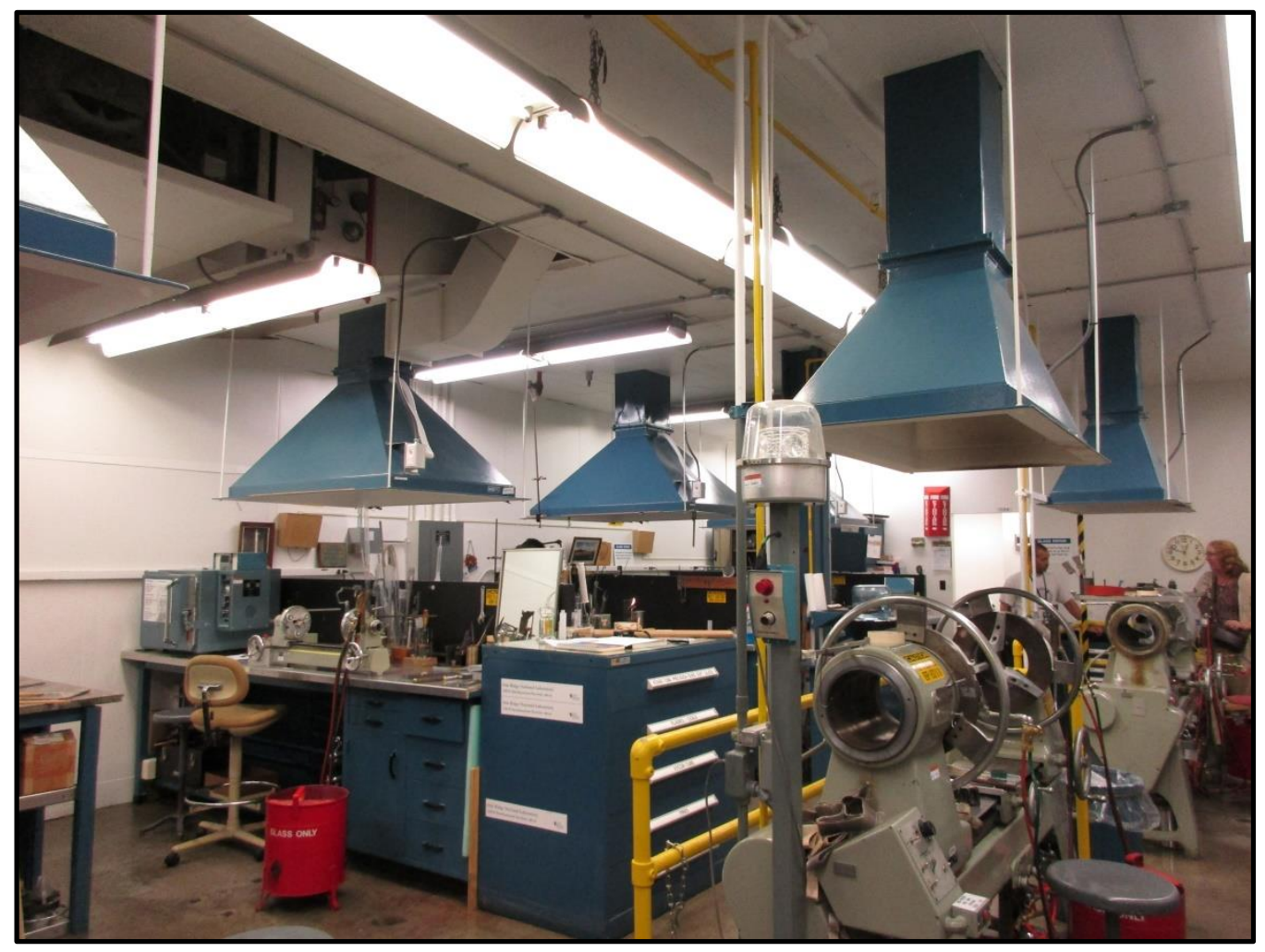

Figure 239. ORNL's Glass Shop is located in Building 4500N. 


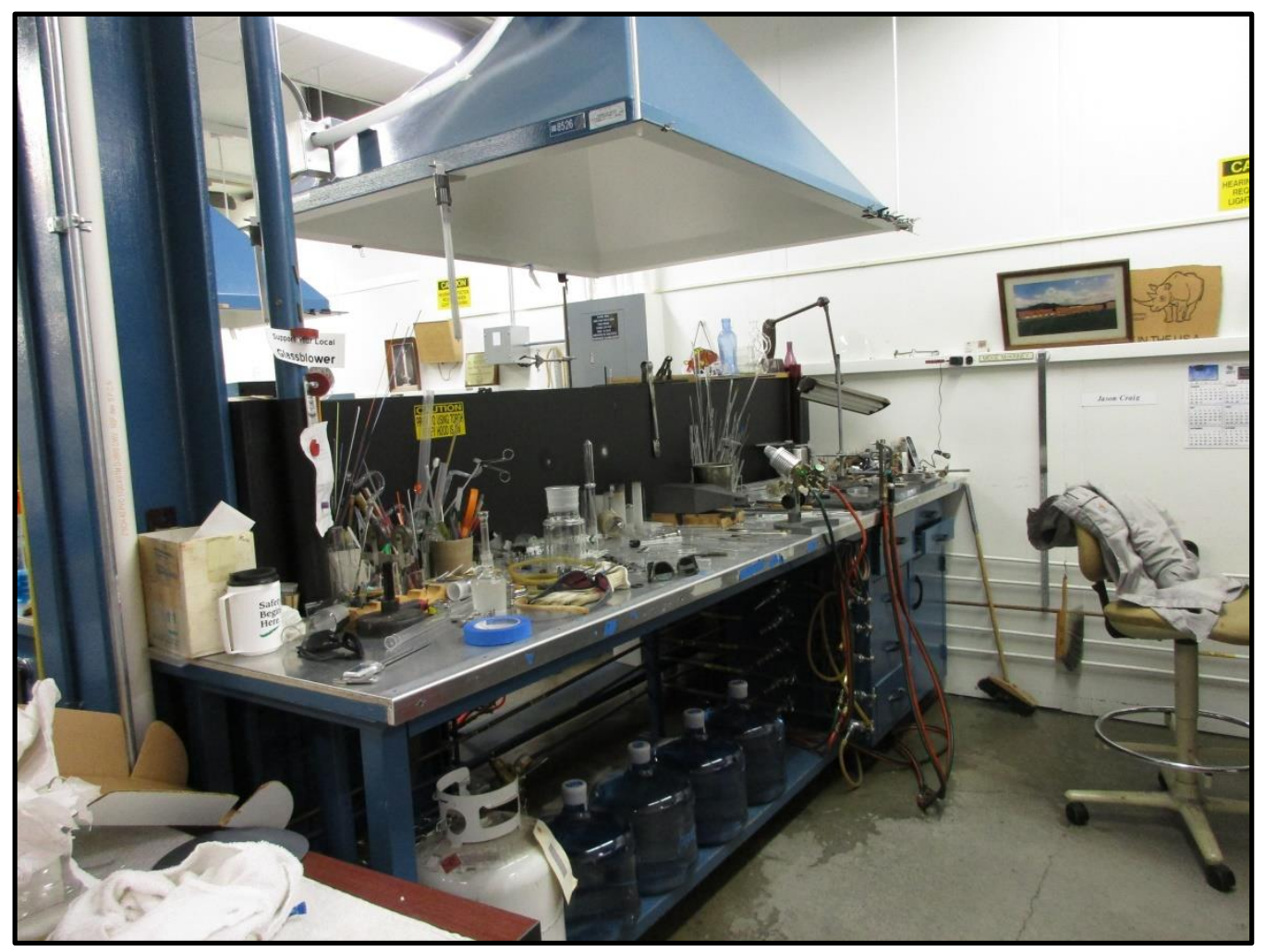

Figure 240. Work Station within the Glass Shop in Building 4500N. 
vents for the building's heating and cooling units. The two upper floors on the south elevation have large horizontal banks of original aluminum and glass windows. These windows are set within a rectangular surround of stone that forms a continuous sill and lintel line.

The east elevation of the building has a loading dock bay in the basement level with original aluminum and glass pedestrian doors (Figure 244). Over this entrance is a circa 2000 metal canopy. On the upper two floors of this elevation are banks of two-light fixed windows similar to those on the other elevations. At the west elevation of the building is a connecting concrete bridge, similar to the ones connecting 4500 North and South, that leads to Building 4508, which was constructed in 1962 (Figure 245). On the upper floors of the laboratory wings there is no fenestration with the exception of an aluminum louvered ventilation panel and a service bay entrance into the attic story of each wing for the addition and removal of mechanical equipment. These entrances have original solid steel paneled doors.

The courtyard between Building 4500S Wings Three and Four contains a paved parking area, grass covered lawn, and the built-up concrete roof of one of the basement laboratories (Figure 246). The north elevation of the head house block has circa 1990 single-light steel and glass pedestrian doors and an added metal fire escape. Windows on the upper floors of Wings Three and Four and the north elevation of the head house block are original, two-light fixed aluminum design. The courtyard between Building 4500S Wings Two and Three has a large paved parking area and an original loading dock bay on the north elevation of the head house block. Leading to the loading dock bay are circa 1990 solid steel and steel and glass replacement doors. In the corner of the loading dock bay is an elevator shaft accessed by a metal elevator door. On the second floor of the head house block is an original exterior stairwell that was enclosed by aluminum and glass panels, circa 1965. Windows on the upper floors of Wings Two and Three and the north elevation of the head house block are all original, two-light fixed aluminum design with stone lintels and sills. Between Wings One and Two is a paved parking area, and at the north elevation of the head house block is a loading dock. This loading dock has a concrete platform, and an original enclosed brick section of the loading dock was remodeled in recent years for the addition of mechanical units. Windows on the upper floors of Wings One and Two are original two-light fixed aluminum design with stone lintels and sills.

The west elevation of the building has original two-light fixed windows on the two upper levels (Figures 247 and 248). The basement level has an original garage bay entrance and a pedestrian entrance with original double doors of single-light glass and steel design. There are no exterior doors on the first floor of this elevation; instead there is a door and an elevated pedestrian bridge that extends west to connect with Building 4508. The head house block has a gable roof, and in the gable field on the west elevation are a series of louvered vents for HVAC exhaust.

Interior: The interior of Building 4500S also mirrors the overall configuration of Building 4500N. The head house block contains two east-west corridors that extend the horizontal length of the building with office spaces on either side. The four laboratory wings have two corridors that extend the vertical length of each wing. Between the two corridors are laboratory and research spaces, and on the outer sides of the corridors are offices. The corridors have asbestos tile floors, some having been replaced with linoleum, dropped acoustic tile ceilings, and plaster walls (Figure 249). The laboratory spaces were originally divided by interlocking panel walls; however, a number of these have been replaced with modern drywall materials.

Many of the offices retain their original single-light glass and metal doors (Figure 250). Some doors have clear glass lights, and others have opaque glass. Most of the laboratory spaces have asbestos tile floors, acoustic tile 
ceilings, and plaster walls (Figure 251). Many of the doors into the laboratory spaces have replacement steel and glass doors. Many of the original metal cabinets, sinks, and shelves remain extant in the laboratories (Figure 252). Of these, many are contaminated with mercury and radioisotopes. Most of the restrooms in the building have original quarry tile floors and glazed block walls (Figure 253).

Office and common spaces throughout the building have been remodeled in recent decades with added carpeting, new vinyl composition tile, wall surfaces, and new acoustic tile ceilings (Figures 254 and 255). The stairwells in the building have terrazzo treads and risers, steel newel posts and railings, and wood handrails (Figure 256).

\section{NATIONAL REGISTER EVALUATION}

Building 4500S was constructed in 1961 as an extension of the research, laboratory, and administrative needs of Building 4500N. Previous survey in 2015 indicated that Building 4500S housed sections of the Chemistry, Analytical Chemistry, and Chemical Technology Divisions as well as Health Physics, Metallurgy, and Reactor Chemistry Divisions. The research and development that occurred in Building 4500S supported advancements in nuclear energy, physics, and related fields.

Previous survey in 2015 recommended that Building 4500S was eligible for listing in the NRHP under Criterion A as a contributing element to the recommended expanded boundary of the NRHP-eligible ORNL Historic District, for its historical associations with ORNL (Thomason and Associates 2015). While important scientific work occurred here, as a research/laboratory facility that was constructed at a later date as an expansion of Building $4500 \mathrm{~N}$, it lacks individual associations to events or people of historic significance and it does not rise to the same level of significance within the broader context of ORNL as Building $4500 \mathrm{~N}$ to merit individual listing in the NRHP under Criterion A or B. Additionally, it does not possess significant associations for its architectural or engineering design that would warrant individual listing under Criterion $C$. Thus, CRA recommends that it is not eligible for individual listing under Criterion A, B, or C. Rather, the significance of Building 4500S is reflected in its role within the larger context of Cold War-era development and research at ORNL and as part of a collection of purpose-designed scientific processing and research facilities engineered to meet the specific needs of the advanced research occurring within their walls. Despite minor interior alterations and exterior changes Building 4500S retains integrity to support its inclusion as a contributing resource of the ORNL Historic District, within the recommended boundary extension. Therefore, CRA concurs with Thomason's 2015 recommendation that Building 4500S is a contributing resource of the ORNL Historic District under Criterion A for its association with the post-World War II development of government-sponsored scientific laboratories, ORNL's evolution as a national laboratory, and early nuclear development and under Criterion $\mathrm{C}$ as a purposedesigned scientific research facility within the district. 


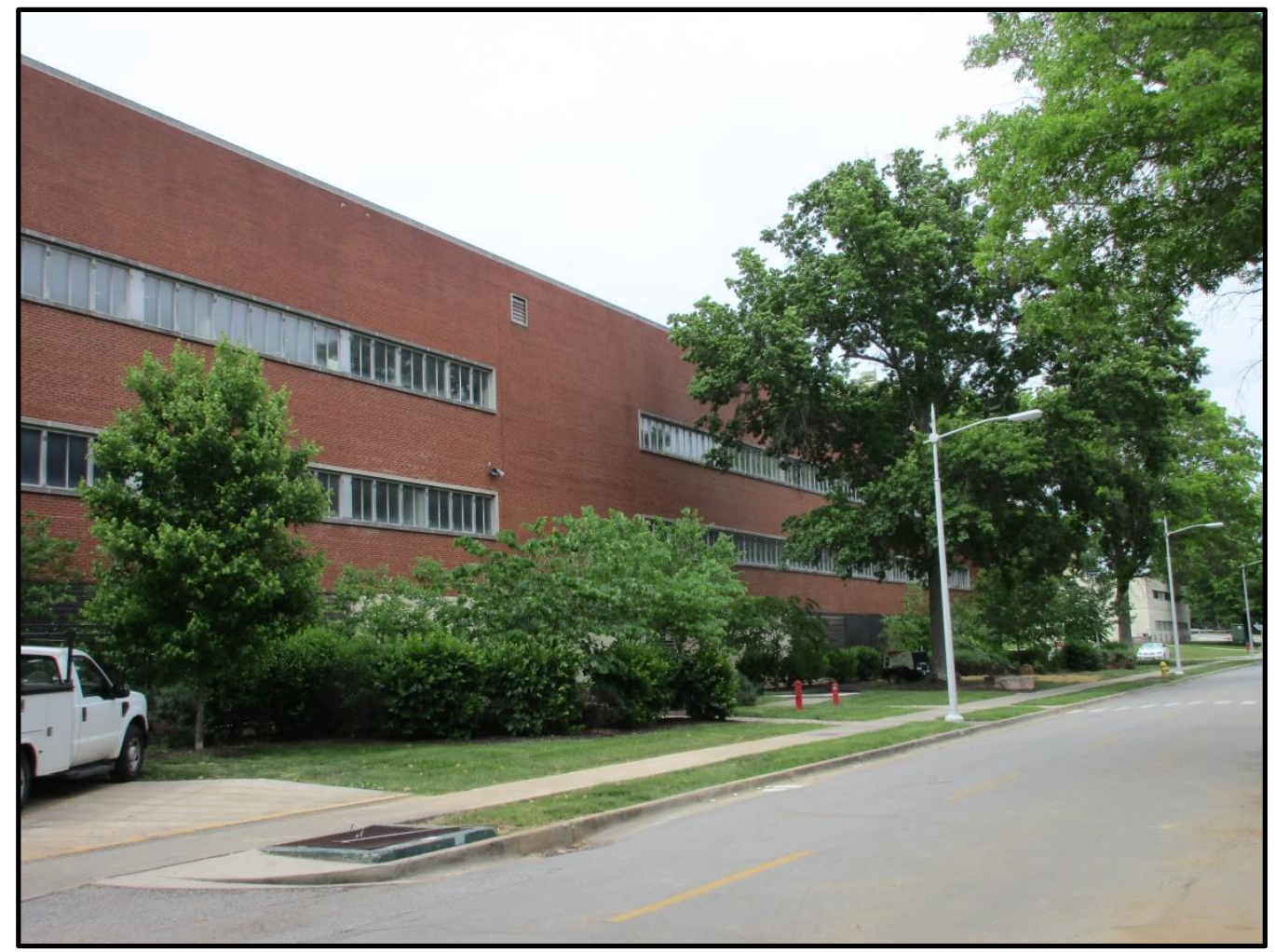

Figure 242. South elevation of Building 4500S.

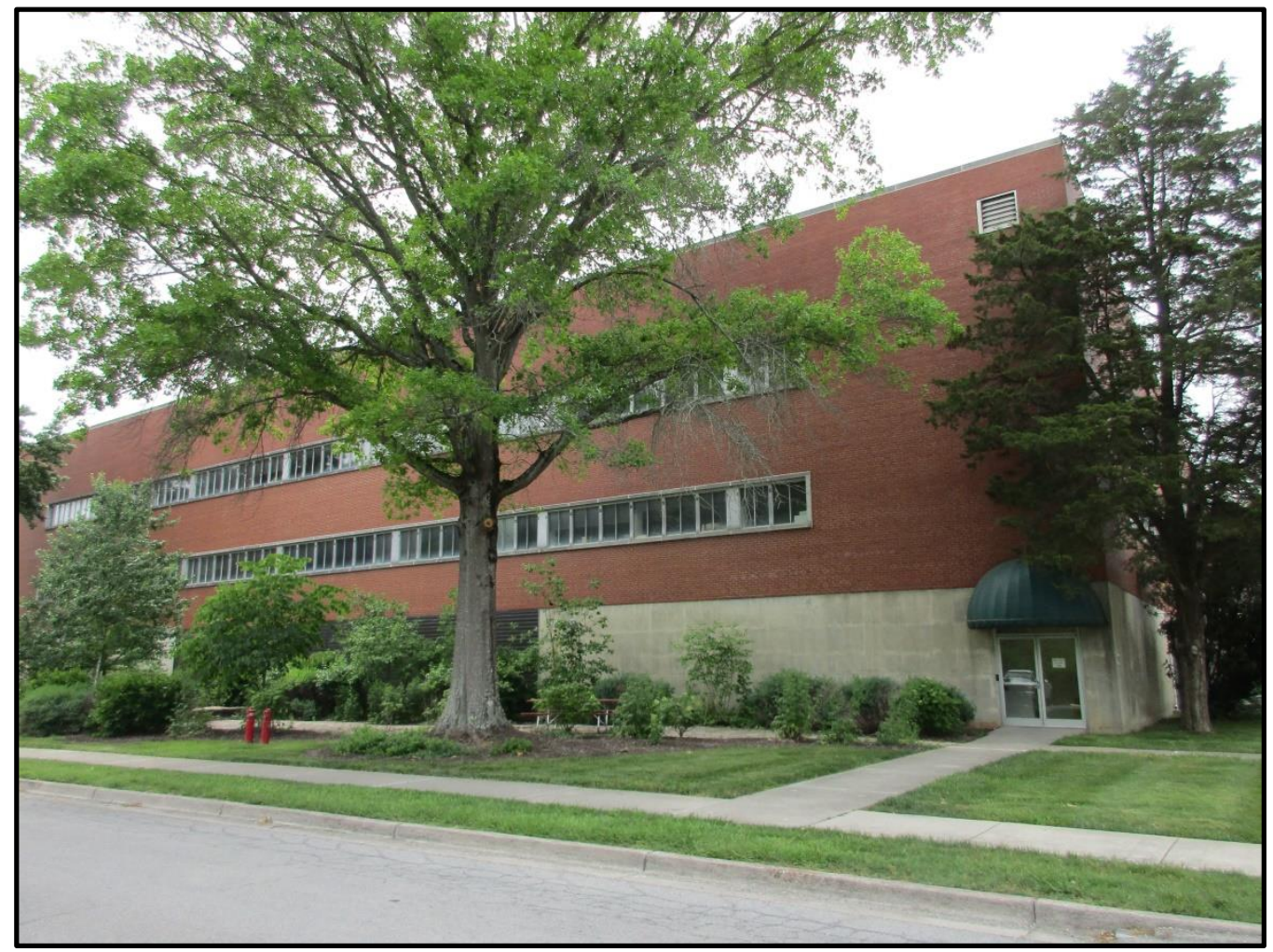

Figure 243. South elevation of Building 4500S. 


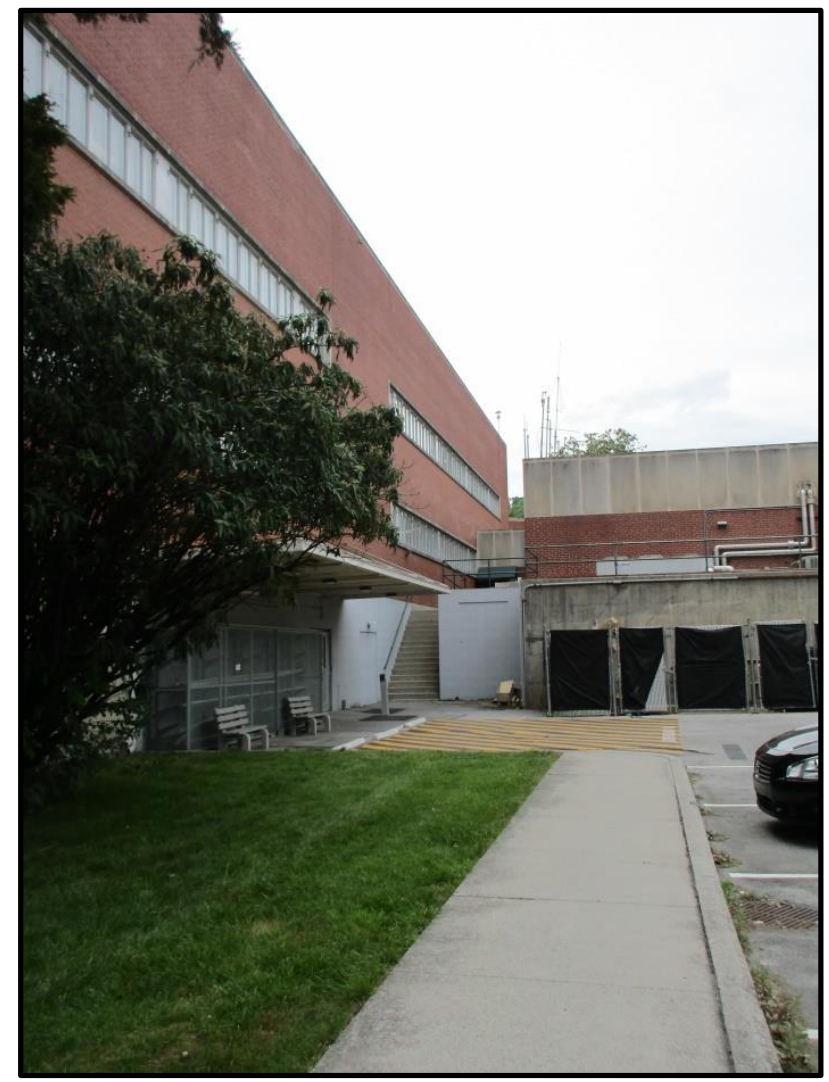

Figure 244. East elevation of Building 4500S.

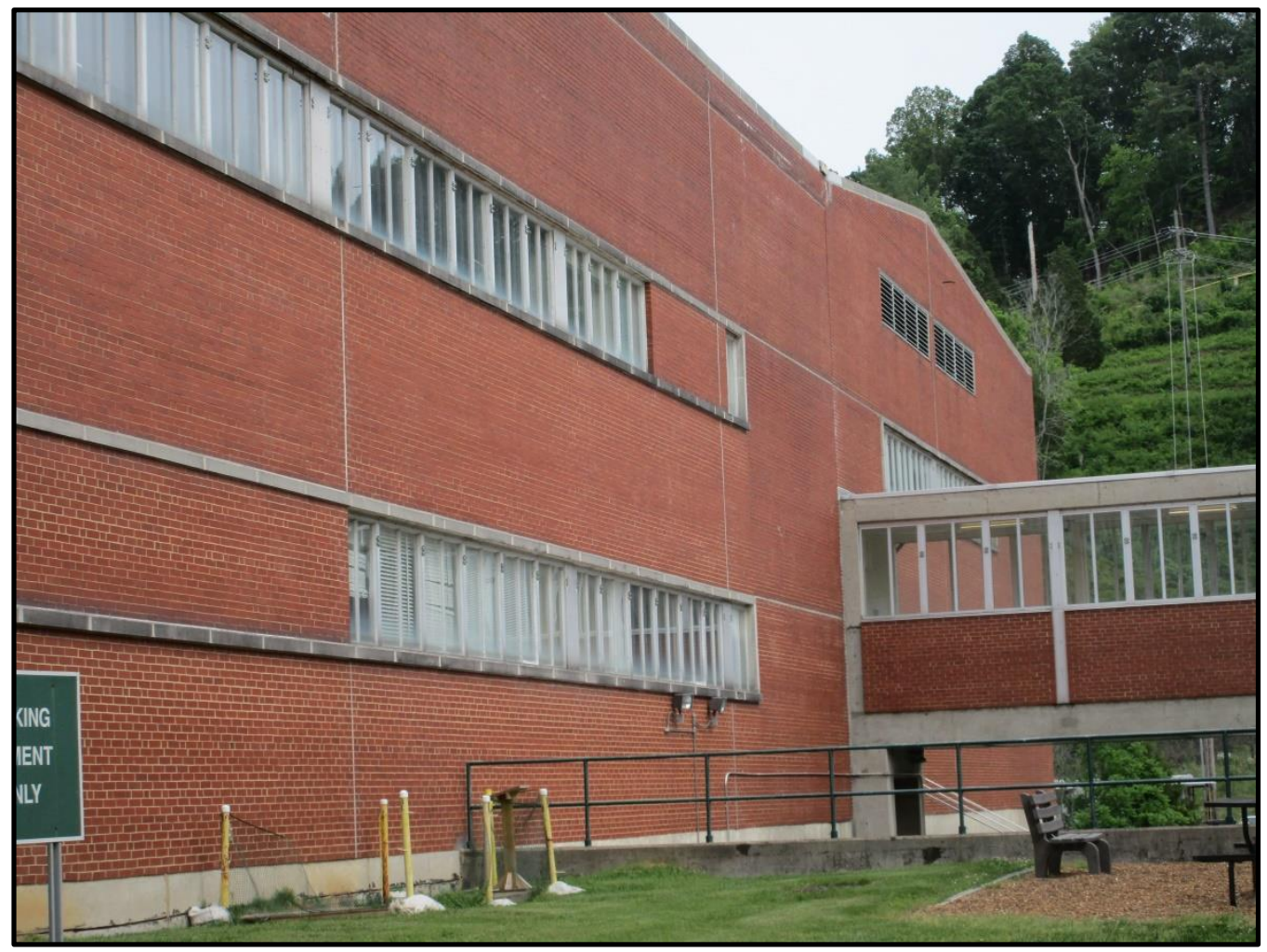

Figure 245. West elevation of Building 4500S. 


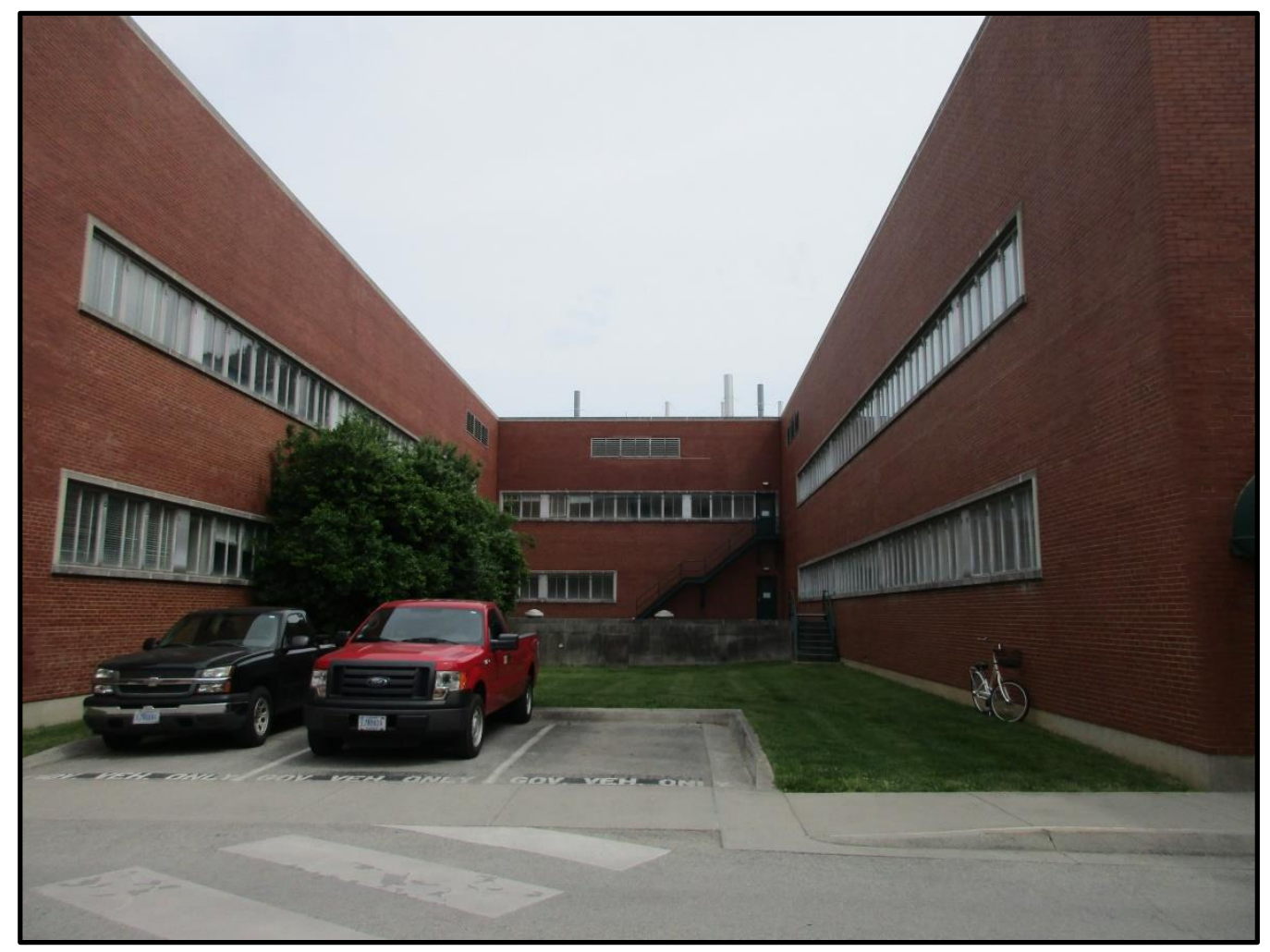

Figure 246. Courtyard between Wing Three and Wing Four of Building $4500 S$.

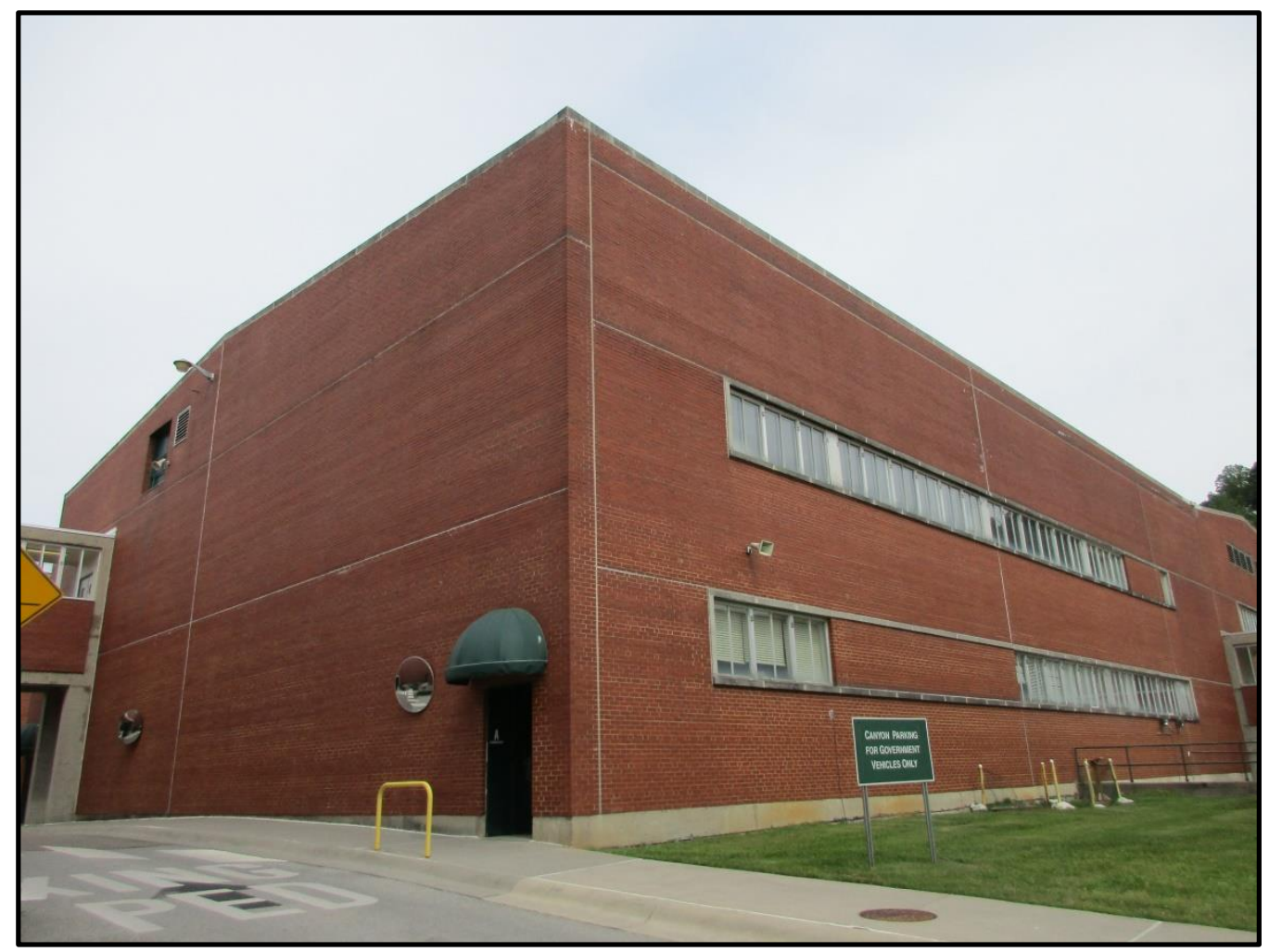

Figure 247. North and west elevations of Building 4500S. 


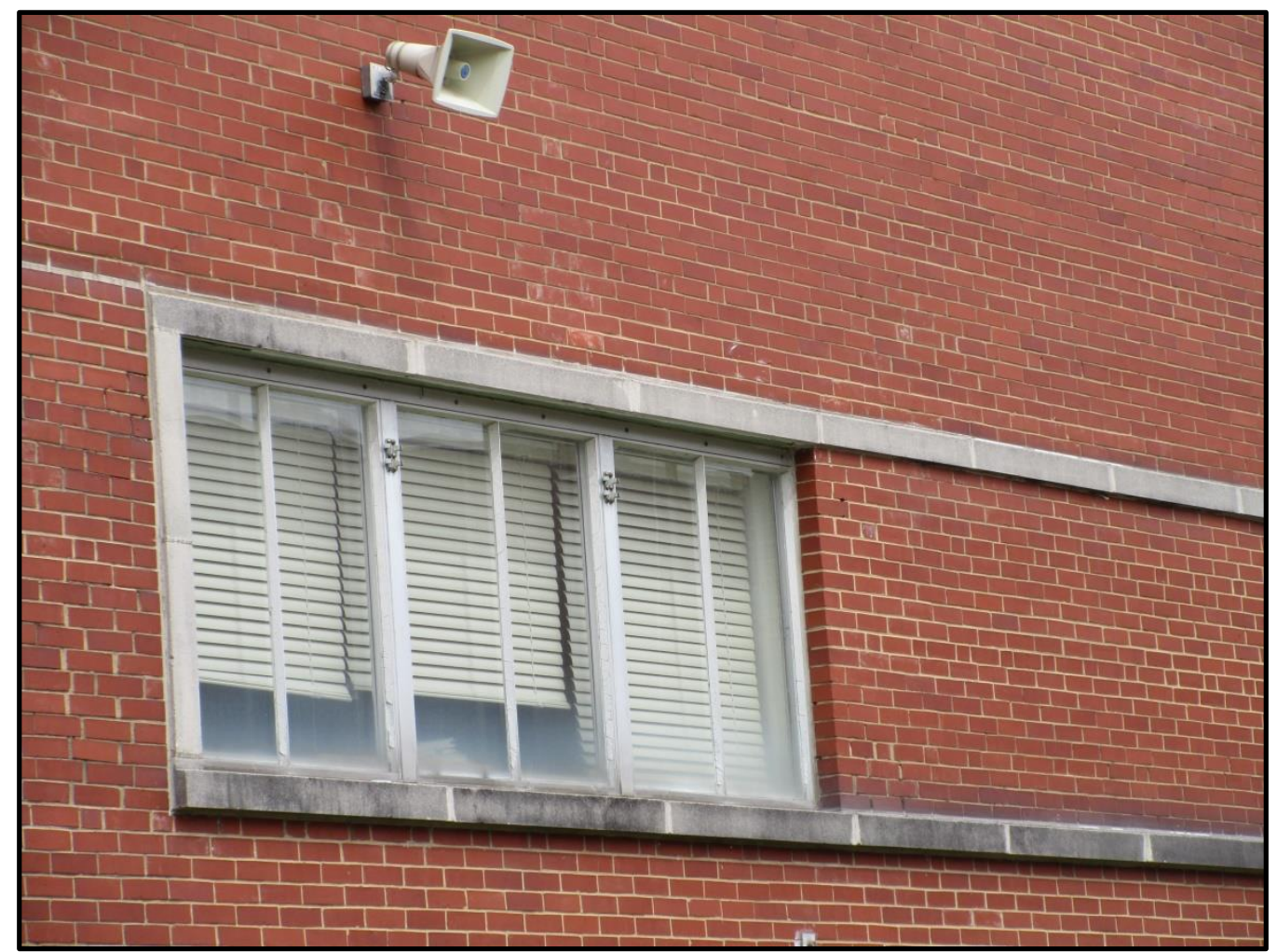

Figure 248. Window detail on west elevation of Building $4500 \mathrm{~S}$.

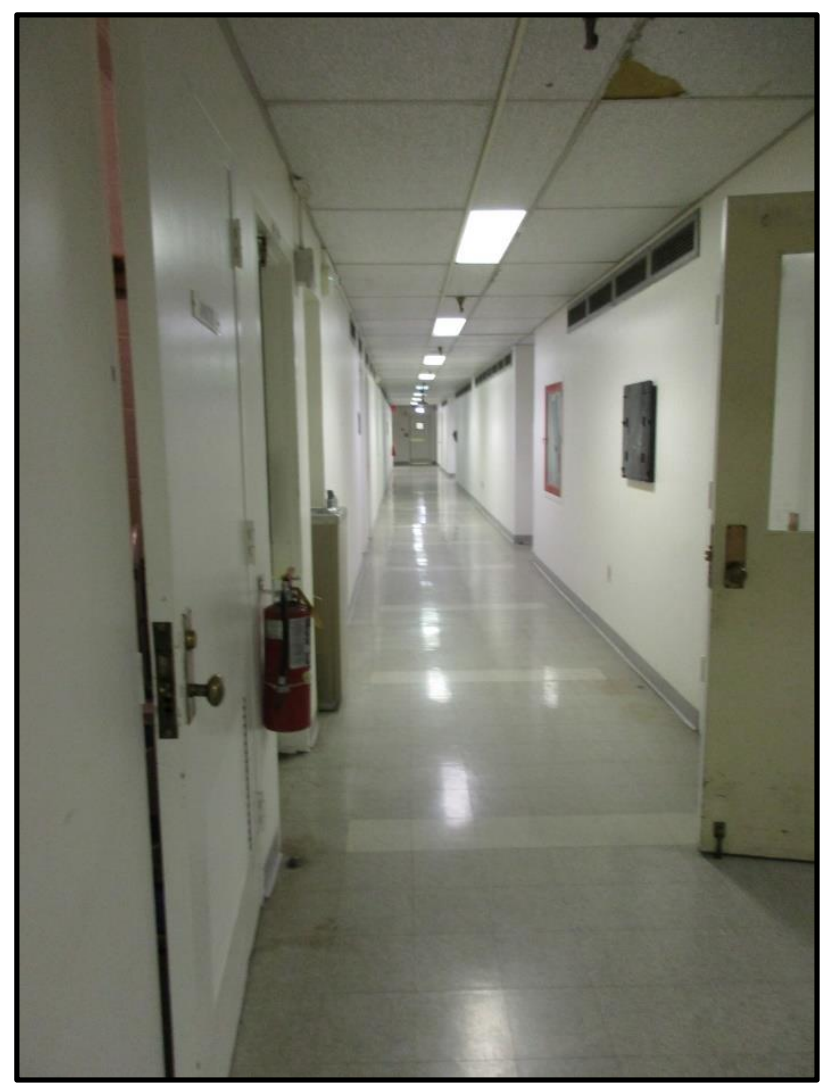

Figure 249. Corridor $E$ on the second floor of Building $4500 \mathrm{~S}$. 


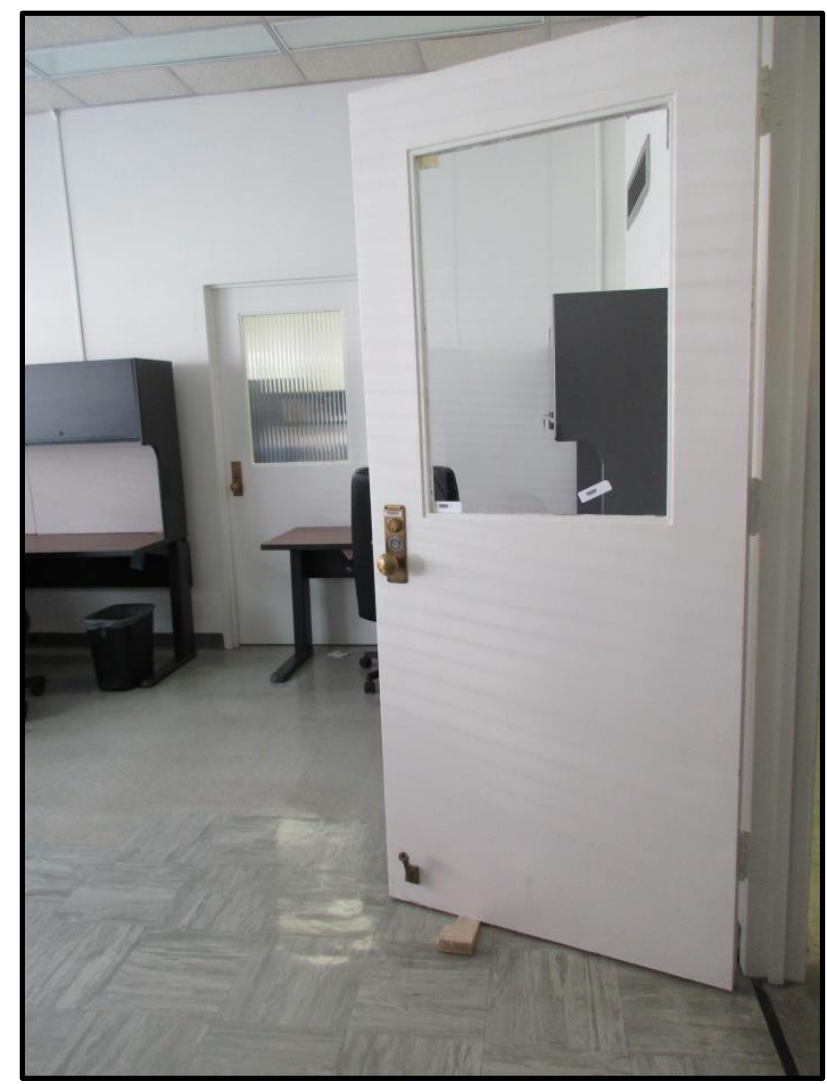

Figure 250. Original door to an office on the first floor of Building 4500S.

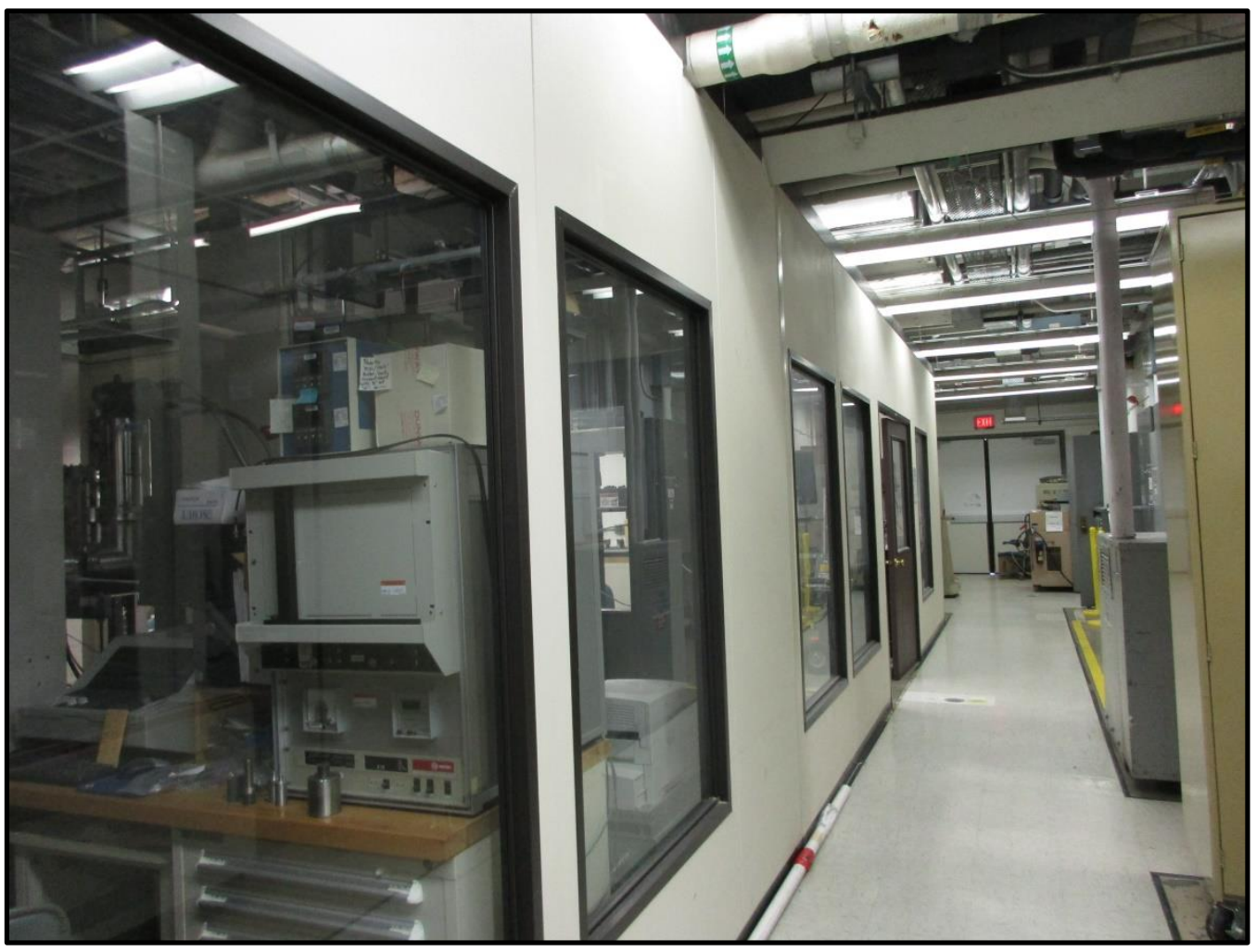

Figure 251. The CREEP lab is located on the ground floor of Building $4500 S$. 


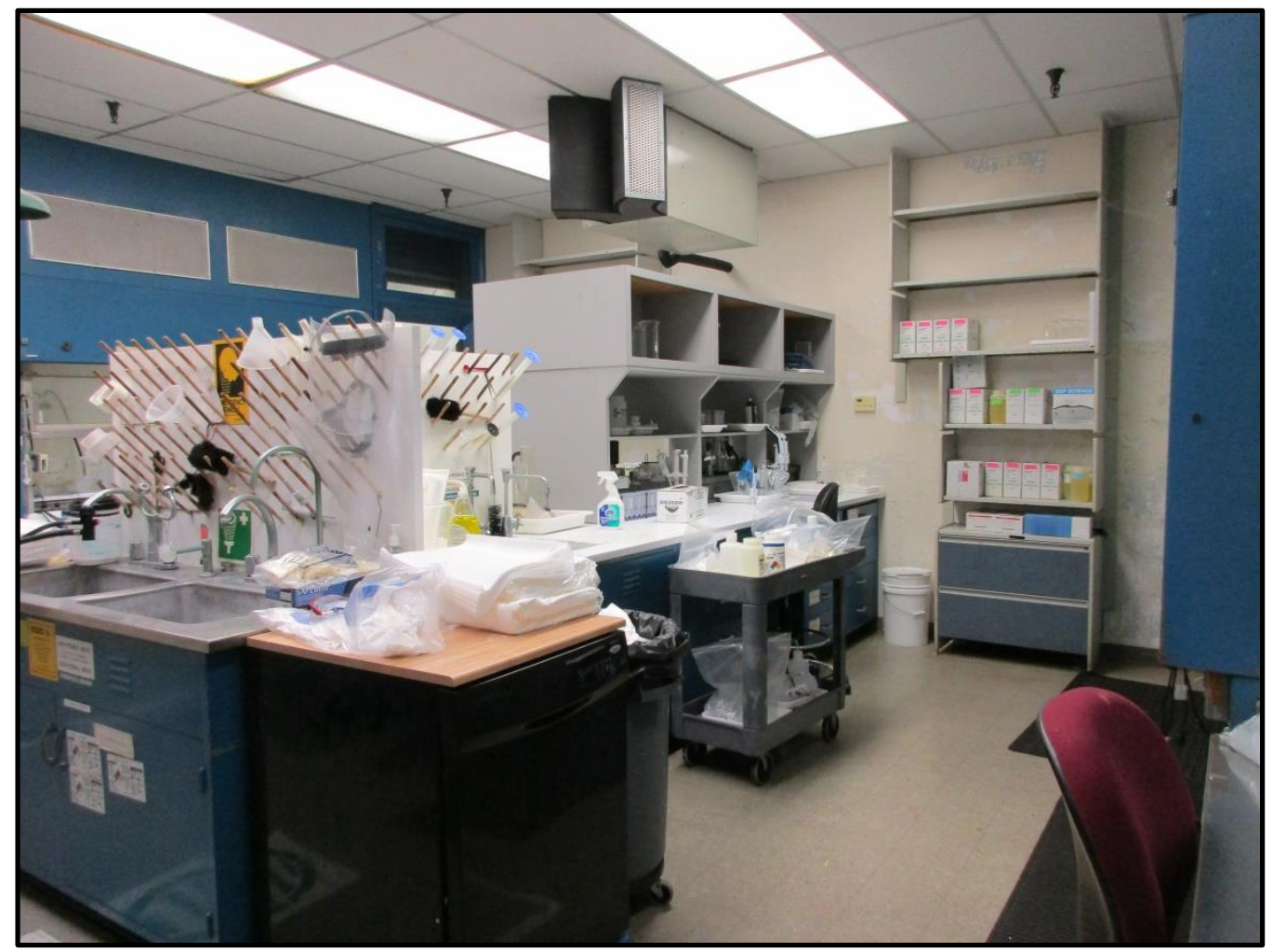

Figure 252. Laboratory space on the second floor of Building 4500S.

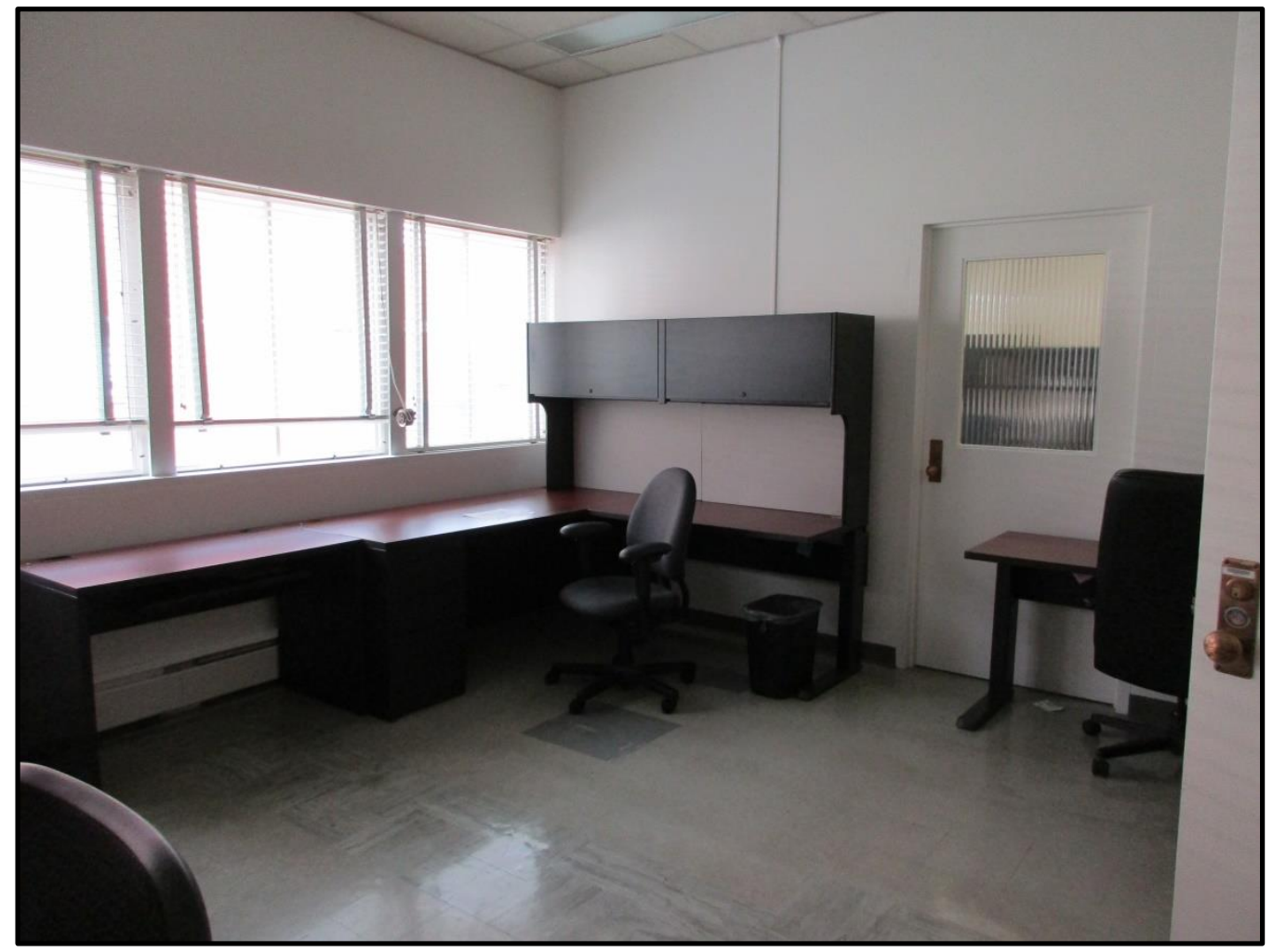

Figure 253. Renovated office space on the first floor of Building 4500S. 


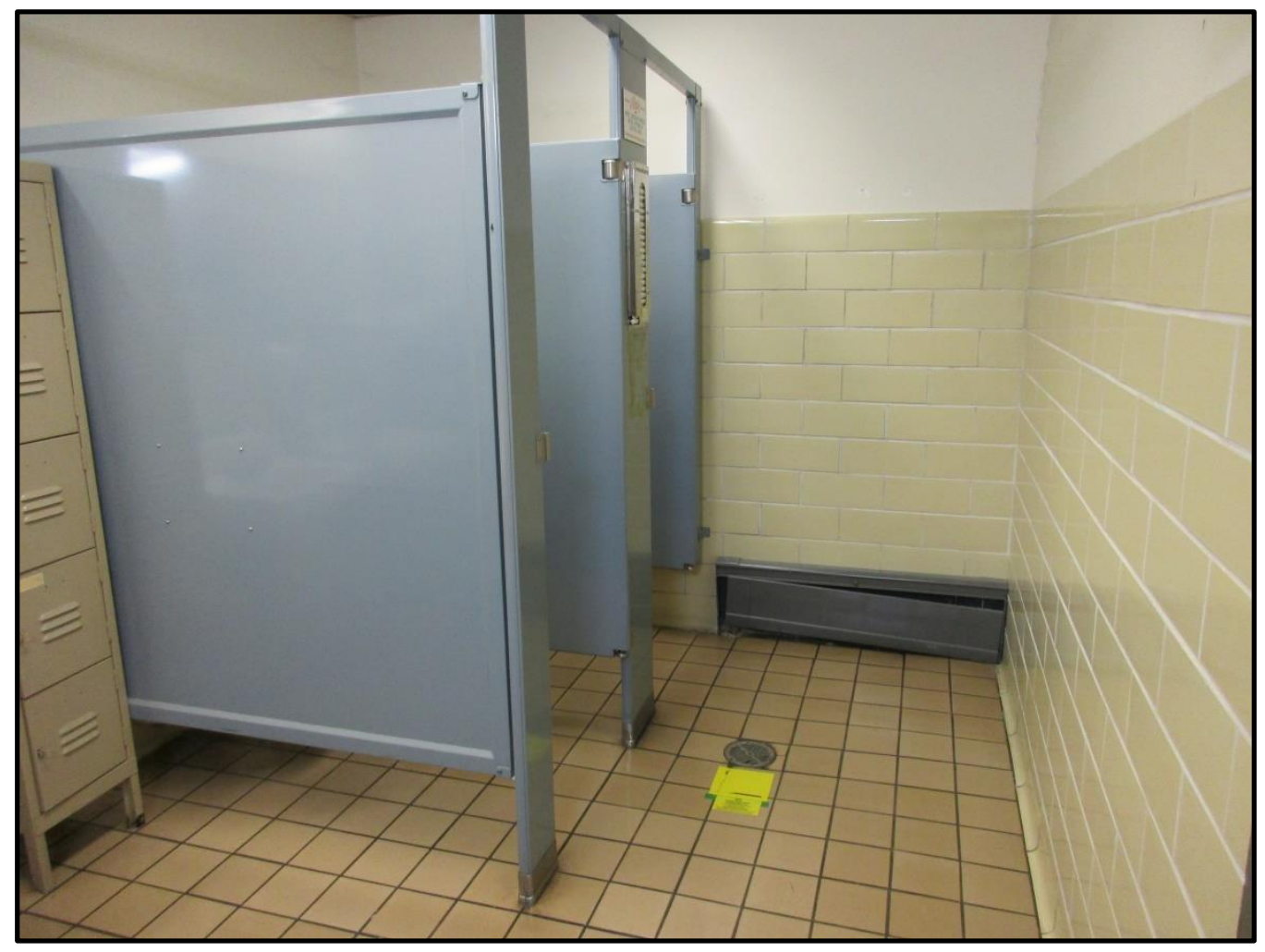

Figure 254. Tiled restroom in Building 4500S.

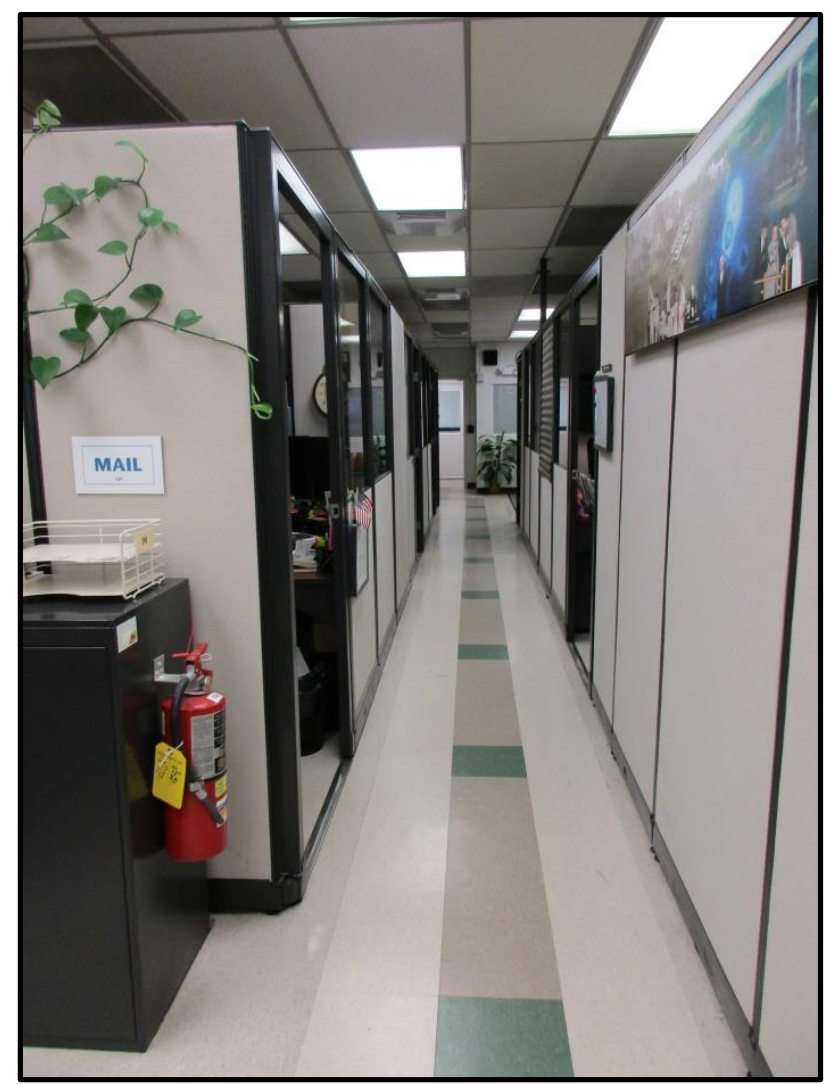

Figure 255. Renovated office space on the ground floor of Building 4500S. 


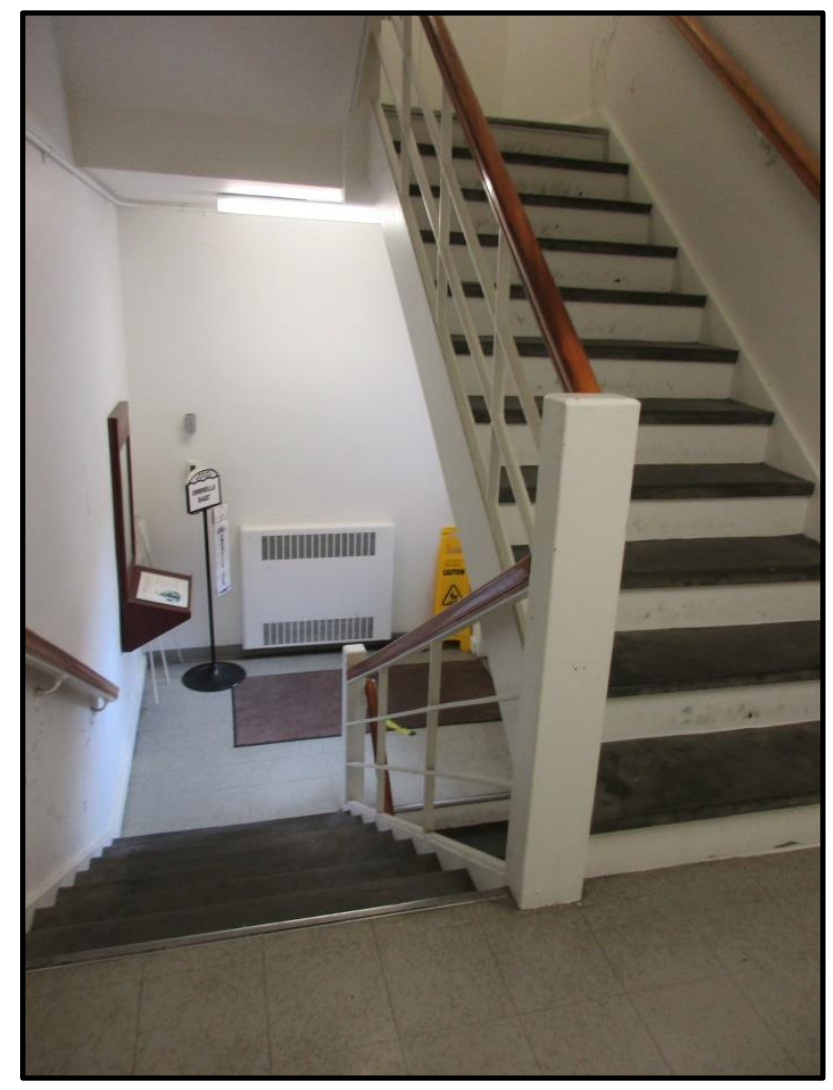

Figure 256. Original staircase in Building 4500S. 


\section{BUILDING NAME}

Radiochemistry Laboratory

DATE OF CONSTRUCTION

1951

\section{DOE OFFICE RESPONSIBLE}

SC

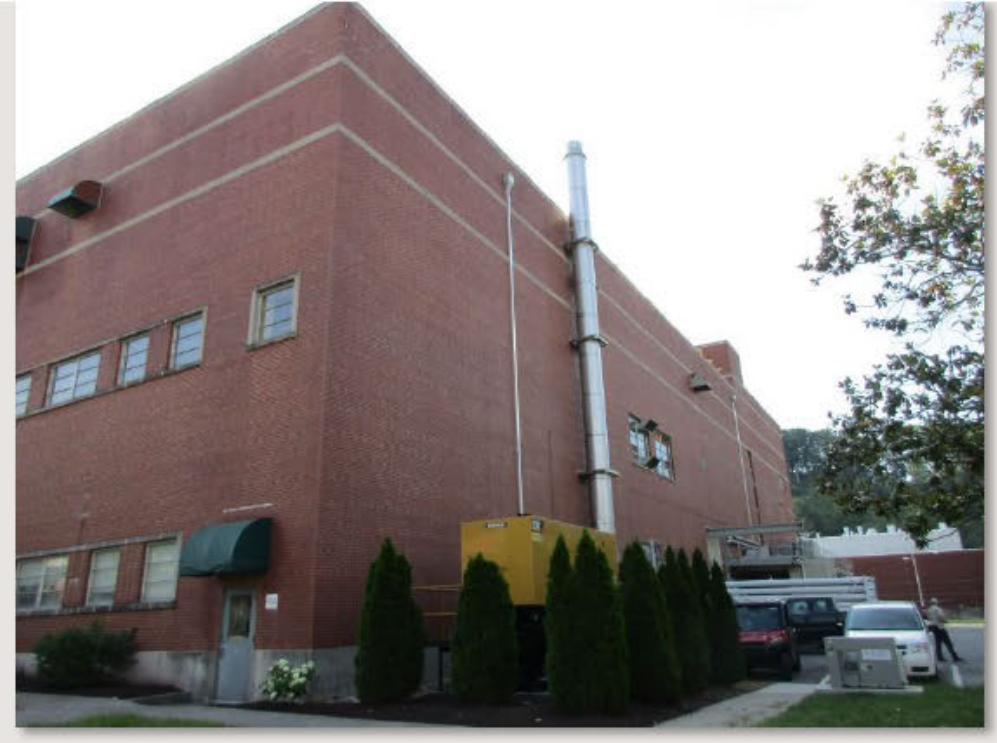

NRHP ELIGIBILITY

Figure 257. West elevation of Building 4501.

Contributing to ORNL Historic District

\section{DESCRIPTION}

Building 4501 was one of 15 resources selected for intensive survey by UT-B as a part of survey planning. In July 2016, DOE completed Section 106 documentation for Buildings 4501 and 4505 in anticipation of consultation for renovation. The following description is adapted from the recordation completed as a part of that effort, supplemented with photographs taken in May and June of 2017 by CRA (Thomason and Associates 2016:6).

Exterior: Buildings 4501 and 4505 are interconnected and are located on the south side of Central Avenue and east of Fifth Street. These two buildings share a common wall at the south end of Building 4501 but are considered two separate buildings.

Building 4501 is a three-story concrete and brick building with a concrete foundation, flat roof of gravel and tar, and an exterior of six-course common bond brick. Along with its basement the building has an area of $74,790 \mathrm{sq}$ $\mathrm{ft}$. All elevations are treated similarly without a clearly-differentiated façade, although the primary entrance is located on the east elevation. On the west elevation is a pedestrian entrance with an original, single-light glass and steel door. This elevation also has a garage bay with original, paired, four-light hinged, steel-panel doors (Figures 257 and 258). Windows on the west elevation are original, five-light, aluminum, fixed design. The north elevation has an entrance at the north corner with an original, single-light glass and steel door (Figure 259). Windows on the north elevation are original, three-light, horizontal, fixed design and are set within concrete surrounds, and the window bays are divided by panels of stacked stretcher-course brick (Figure 260). The upper floor has a series of louvered exhaust vents with metal canopies (Figure 261). Below the roofline are two concrete belt courses and two soldier-course brick courses. At the roofline is concrete coping. The east elevation has an entrance on the first floor with an original, single-light glass and steel door and a concretepanel surround (Figure 262). It also has a metal canopy supported by a round, steel column. This bank has original, two- and three-light horizontal, aluminum, awning windows with concrete sills. Between the windows are spandrels of stacked stretcher bond brick.

Interior: The interior of Building 4501 is divided into three floors. The first two floors feature four corridors that access offices and laboratory space around the exterior and within an interior core of the building. A fifth corridor 
extends across the interior core of the building. The first floor corridors in Building 4501 have linoleum tile floors, metal partition walls, and metal acoustic tile ceiling (Figures 263, 264, and 265). The doors are a mixture of original and replacement designs. The original doors are steel and glass with lower panels of louvered vents (Figure 266). Four radiological "hot" cells are located on the first floor (Figure 267). The laboratory spaces on the second floor have linoleum floors, concrete block walls, and metal acoustic tiles (Figure 268). The second floor corridors feature tile floors, interlocking metal partition walls, and interlocking metal ceilings (Figure 269). A high-bay area, commonly referred to as the KALC Tower, is centrally located at the west end of the building and is open from the first floor to the building roof. The name KALC refers to the "Krypton absorption in liquid carbon dioxide method of separating krypton from CO2 in high-temperature gas-cooled reactor fuel reprocessing" (L.M Toth et.al 1976:21). The KALC Tower footprint is approximately 1,300 square feet and is separated from other building areas by masonry construction. A second high-bay area with a footprint of approximately 2,800 square feet is centrally located on the second floor of the building and is open to the building roof. Restrooms and stairwells feature original glazed block walls (Figures 270 and 271).

\section{NATIONAL REGISTER EVALUATION}

According to previous surveys and documentation, Building 4501 was constructed in 1951 at a cost of $\$ 3,070,000$. Buildings 4501 and 4505 were originally a single unit, known collectively as the High Level Radiation Laboratory. Originally designed to provide support to the Graphite Reactor, Building 4501 later became associated with ORNL's isotope program, one of the most prominent of ORNL's post-World War II period (Thomason and Associates 2015: 140).

Several types of research have been conducted in Buildings 4501/4505 since its construction in 1951. The process for lithium isotope separation through OREX (organic exchange) became a key project of ORNL's Chemical Technology Division (Chem Tech) within Building 4501/4505 in 1953. While OREX research was conducted within Building 4501/4505, Chem Tech staff were scattered in various buildings across the ORNL campus. Beginning in 1955, a small team of scientists began conducting early fission product release testing in Building 4501/4505; this research included early tests on nuclear fuels. All of these studies contributed to safety information at materials testing reactors (MTRs) and light-water reactors (LWRs) at other national laboratory sites across the country. The AEC reactor safety analysis, produced in 1961 as a result of tests within Building 4501, became the basis for AEC Regulatory Guides for power reactor design requirements. During the early 1970s, the staff and mission of Building 4501 changed and the nuclear reactor safety research group and facilities became part of the newly formed Chemical Development Section in the Chemical Technology Division.

As recently as 2011, Building 4501/4505 was the site of experimentation based on previous research. Mercury contamination at ORNL is a major concern, and the water from Sump 1 at Building 4501/4505 historically accounts for $80 \%$ of the site's contamination as a result of OREX research in the 1950s. Scientists hope to ascertain from these data new information regarding mercury removal efficiency, resin-change-out frequency, and disposal costs of the treatment. Today, the ORNL divisions responsible for most of the operational activities in the two buildings include the Nuclear Security and Isotope Technology Division (NSITD) and Chemical Sciences Division. Activities in the buildings involve both radio-chemistry and non-radioactive research and development in multiple areas including nuclear medicine, waste handling, and energy research (Thomason and Associates 2016:30-33).

In 2015, Thomason and Associates recommended that Building 4501/4505 is eligible for inclusion in the NRHP under Criterion A for its historical association with ORNL's evolution as a national laboratory, the post-World 
War II government-sponsored scientific movement, and early nuclear research as a contributing property in the NRHP-eligible ORNL Historic District. The work conducted in the building from 1951 to the mid-1960s included experimentation with lithium isotope separation and nuclear safety procedures (Thomason and Associates 2015).

As a research/laboratory facility, Building 4501 was associated with important scientific research at ORNL in the Cold War era, but it is not the individual building most directly associated with any specific accomplishment or person that rises to the level of significance for individual listing in the NRHP under Criterion A or B. Additionally, it does not possess significant associations for its architectural or engineering design that would warrant individual listing under Criterion $C$. Thus, CRA recommends that it is not eligible for individual listing under Criterion $A, B$, or $C$. Rather, the significance of Building 4501 is reflected in its contributing role within the larger context of Cold War-era development and research at ORNL and as part of a collection of purpose-designed scientific processing and research facilities engineered to meet the specific needs of the advanced research occurring within their walls. Despite alterations to the interior, including the replacement of interior doors and the renovation of laboratories, Building 4501 retains integrity to support its inclusion as a contributing resource of the ORNL Historic District, within the recommended boundary extension. Therefore, CRA concurs with Thomason's 2015 recommendation that Building 4501 is a contributing resource of the ORNL Historic District under Criterion A for its association with the post-World War II development of government-sponsored scientific laboratories, ORNL's evolution as a national laboratory, and early nuclear development, and under Criterion C as a purpose-designed scientific research facility within the district. 


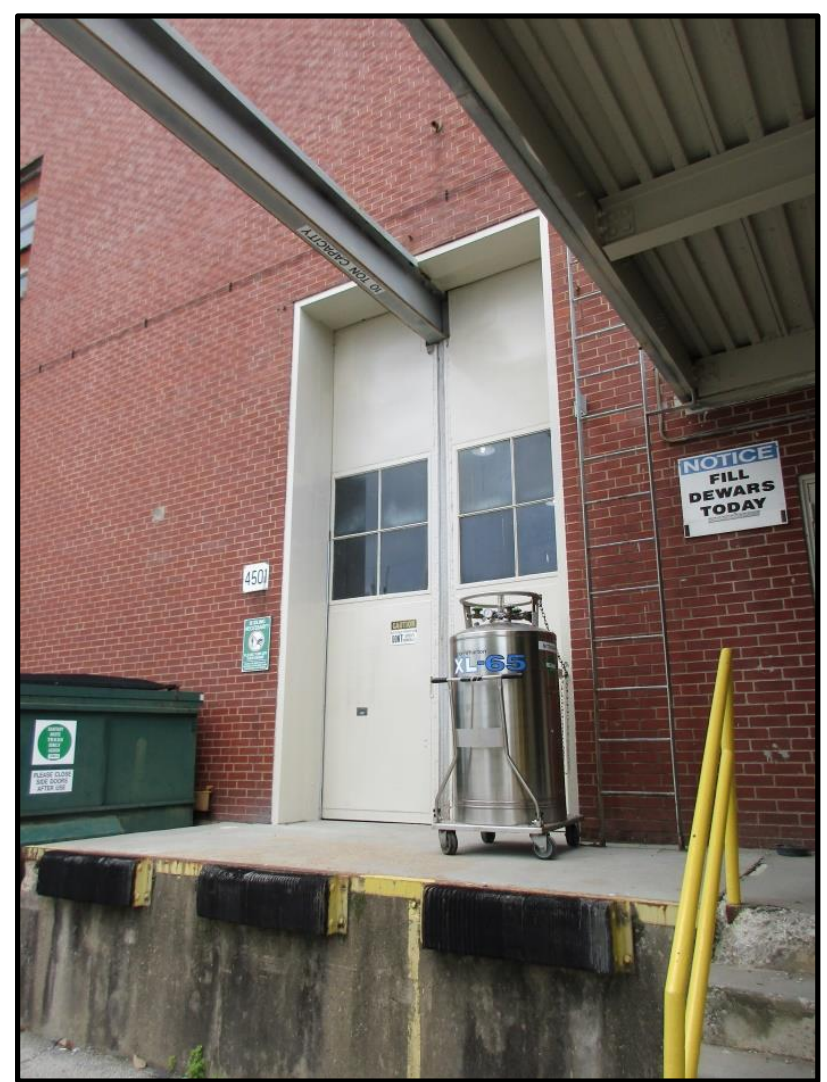

Figure 258. Original doors to high bay entry on west elevation of Building 4501.

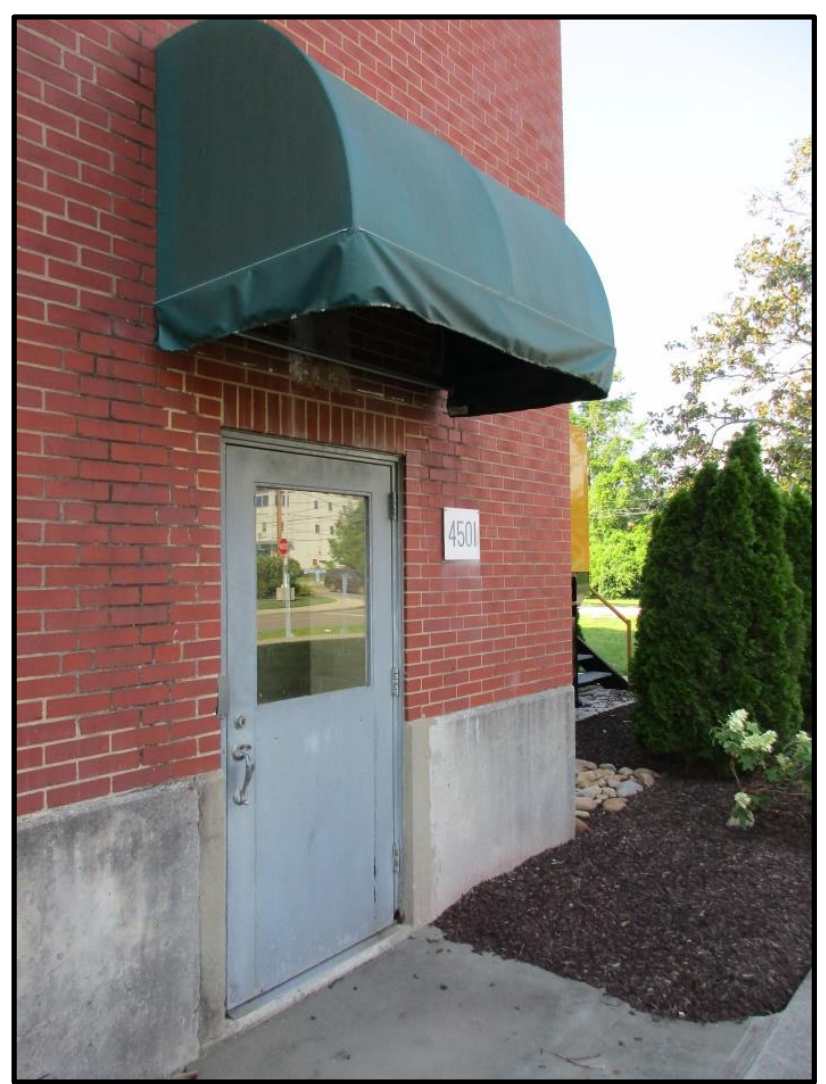

Figure 259. Secondary entry on the north elevation of Building 4501. 


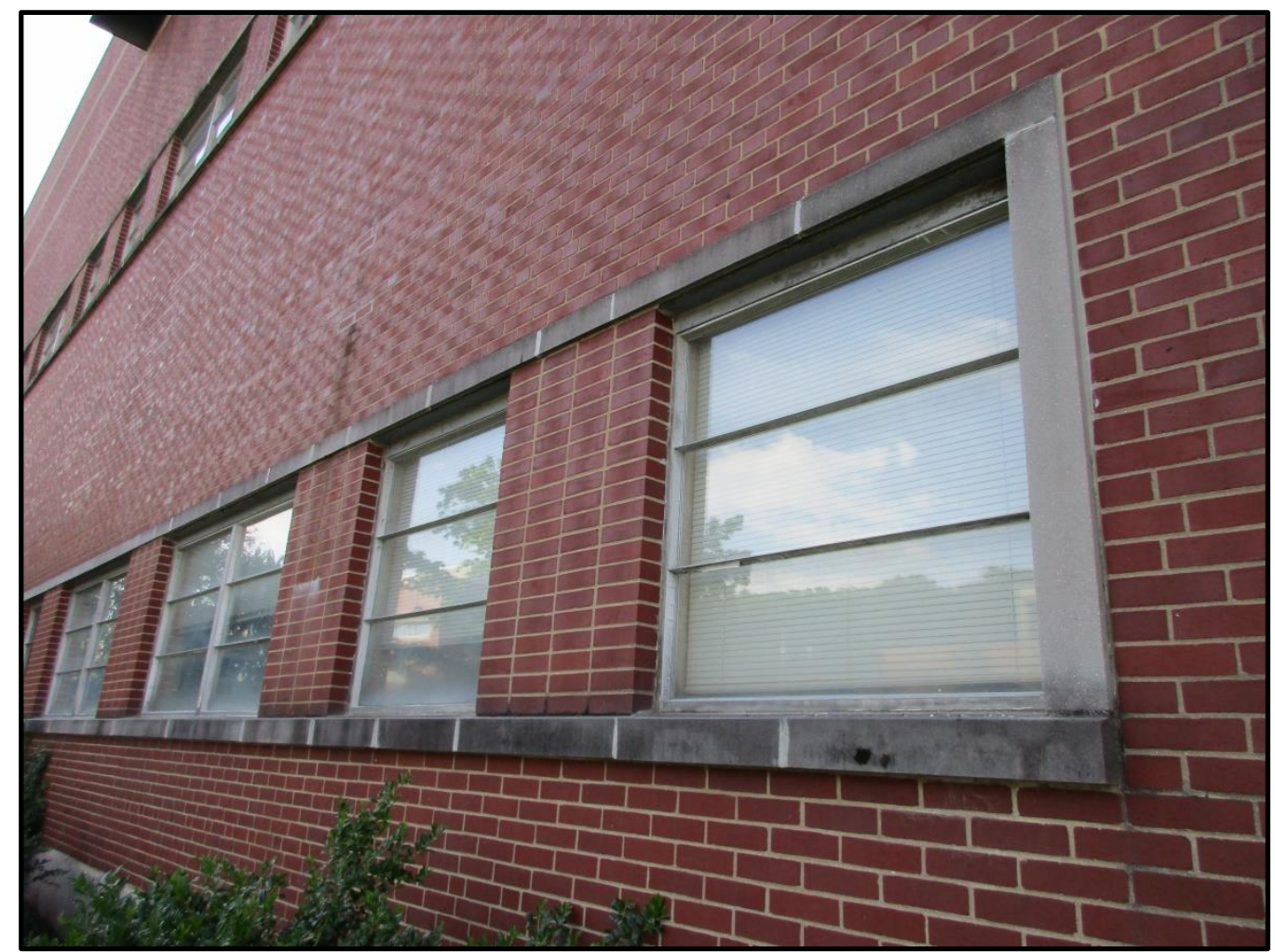

Figure 260. Bank of original windows on north elevation of Building 4501.

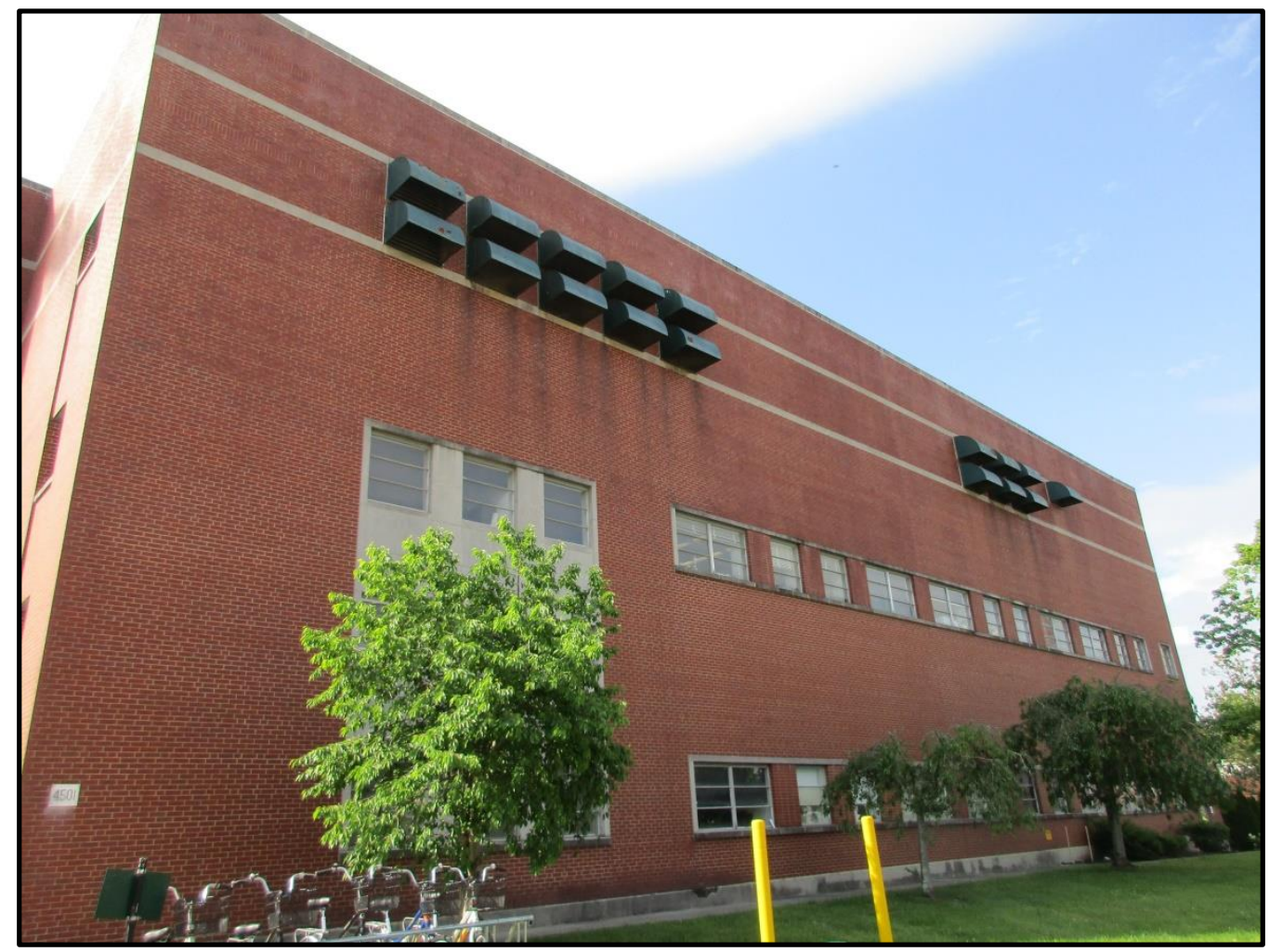

Figure 261. North elevation of Building 4501. 


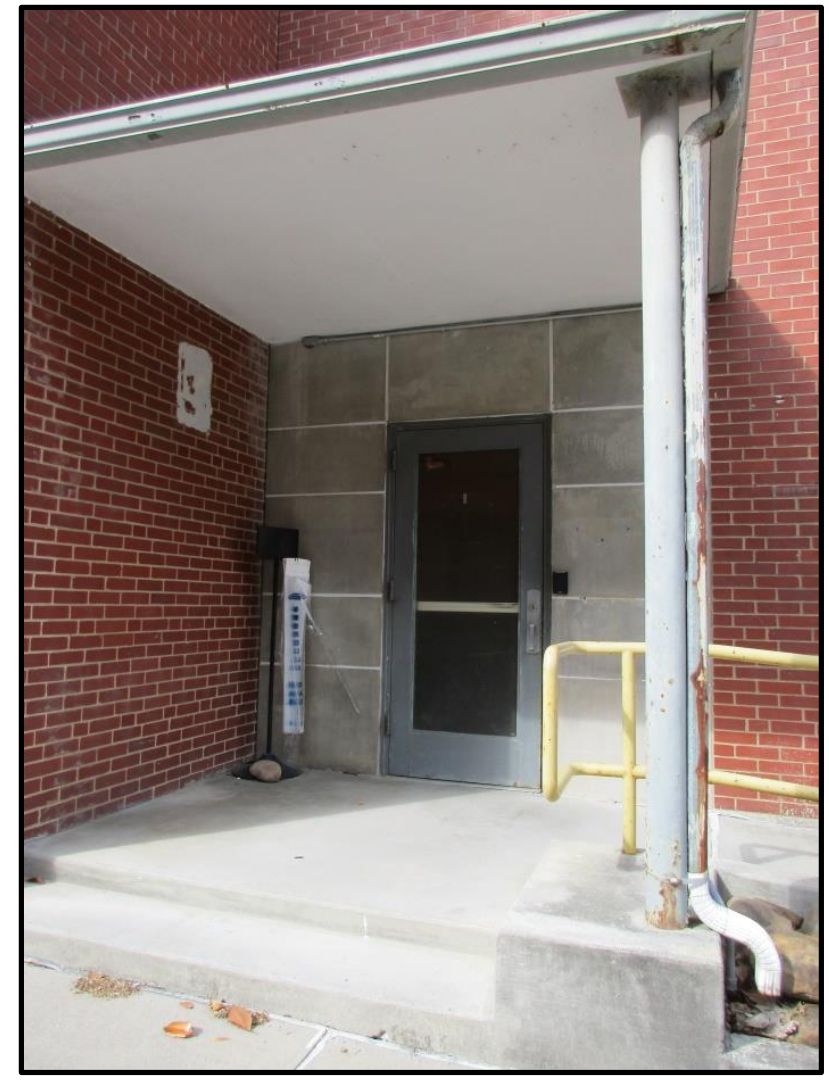

Figure 262. Primary entry on east elevation of Building 4501.

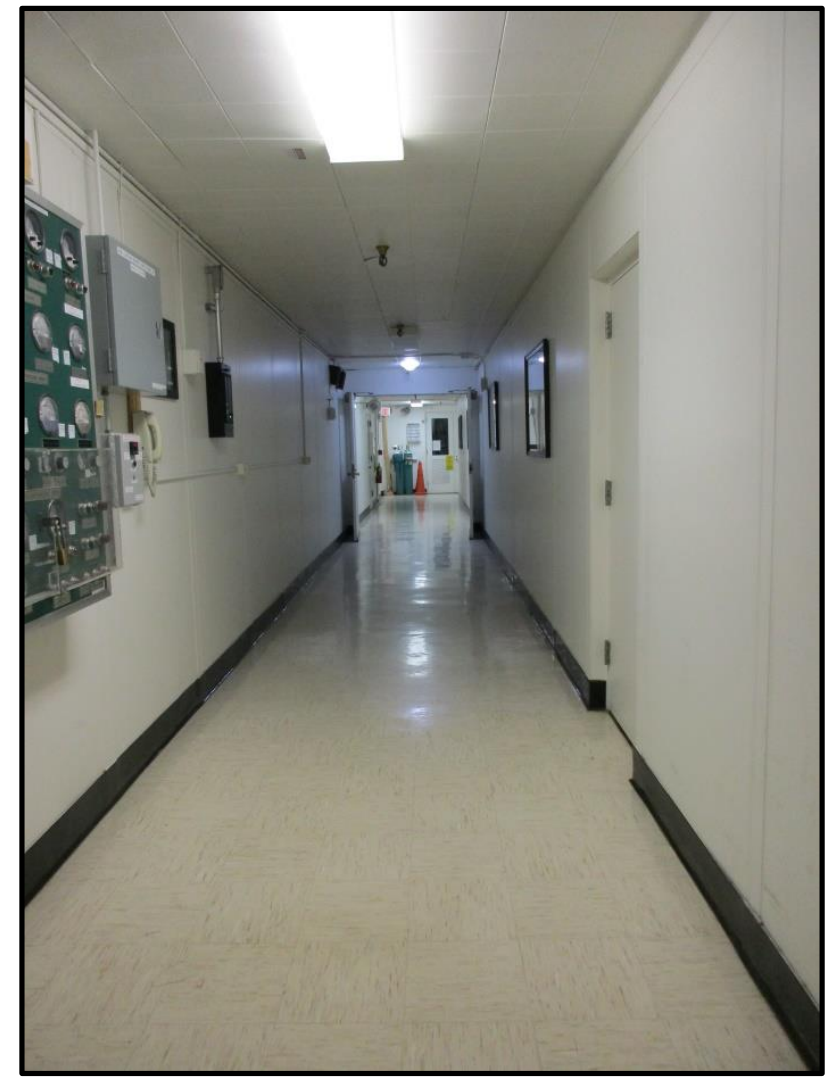

Figure 263. Corridor on first floor of Building 4501. 


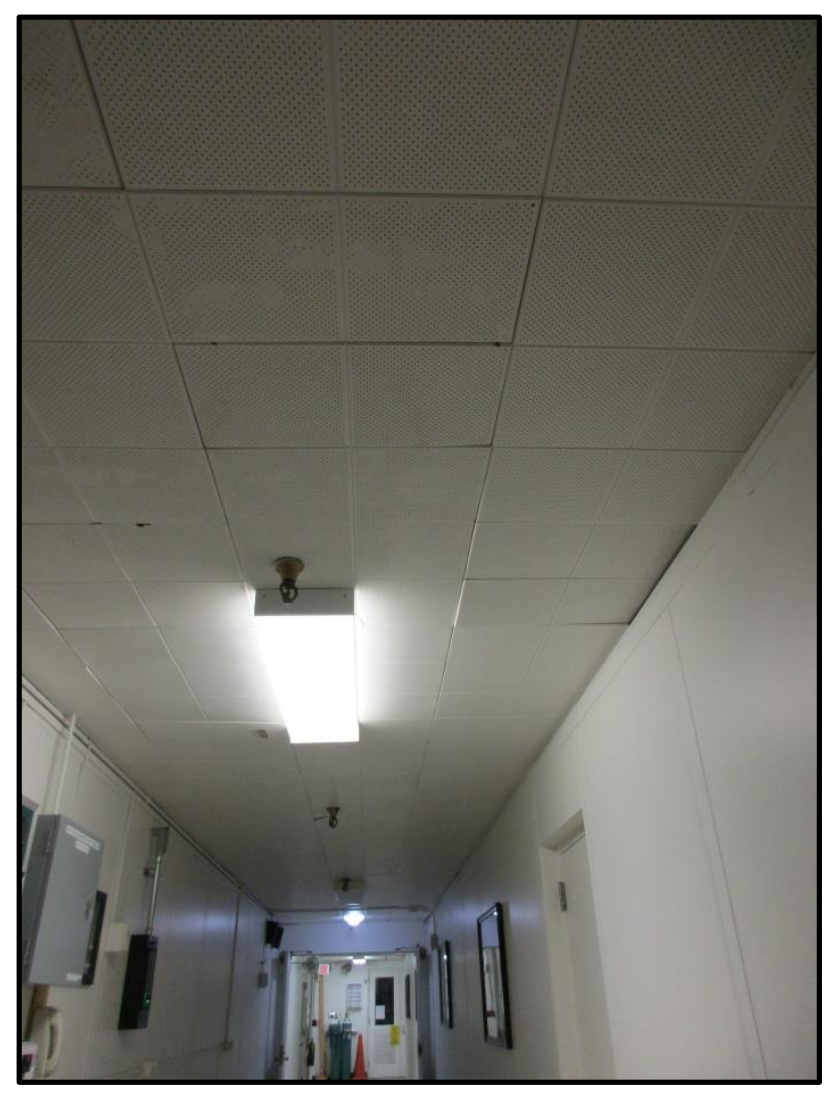

Figure 264. Metal ceiling tile in corridor on first floor of Building 4501.

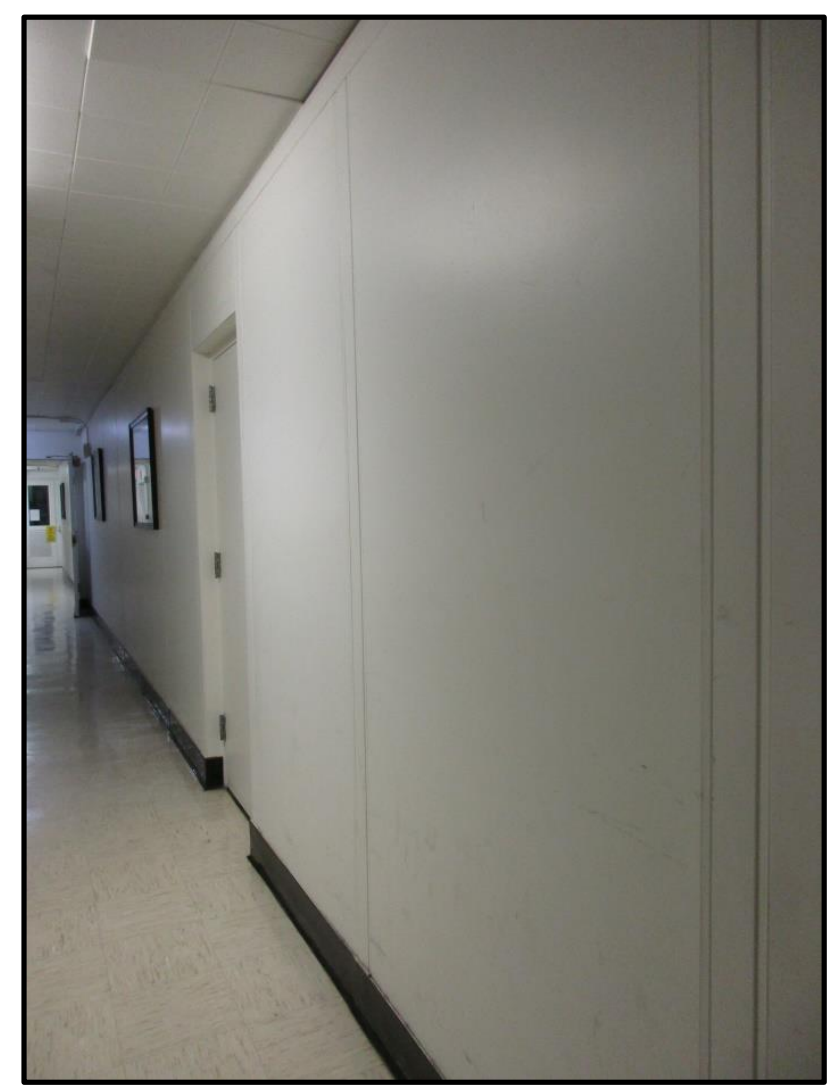

Figure 265. Interlocking metal panel dividing walls on first floor of Building 4501. 


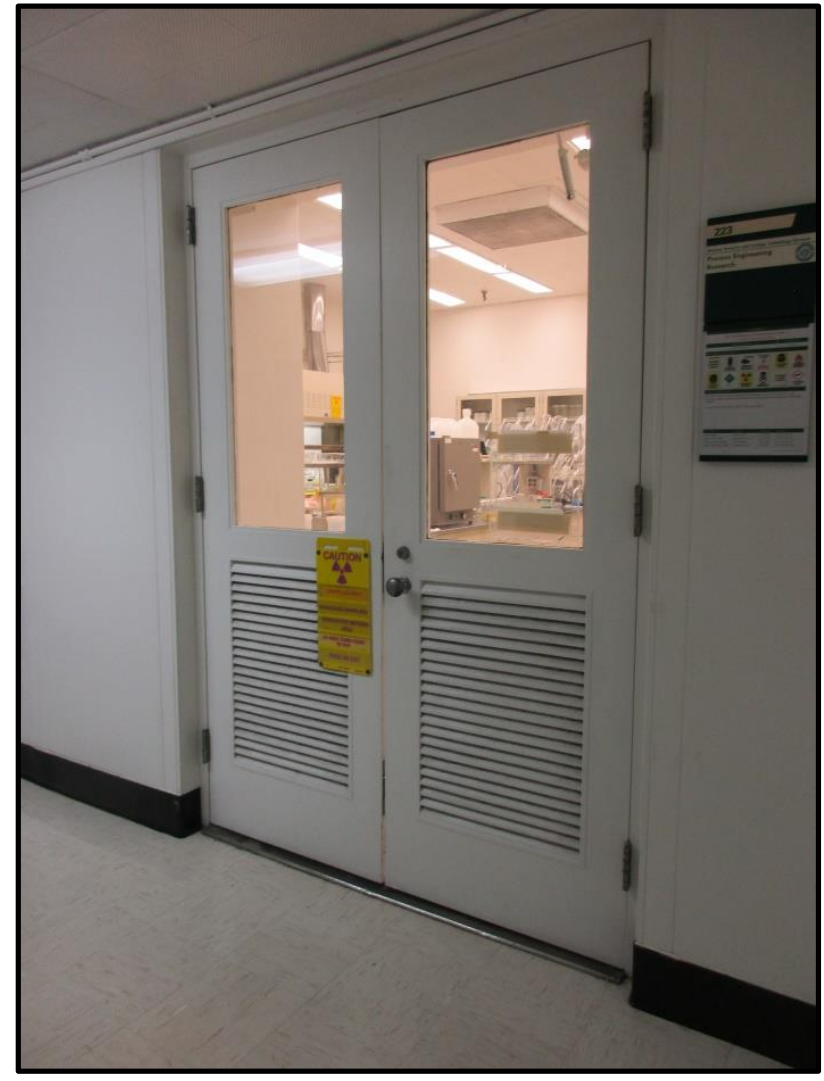

Figure 266. Original doors to a laboratory space on the second floor of Building 4501.

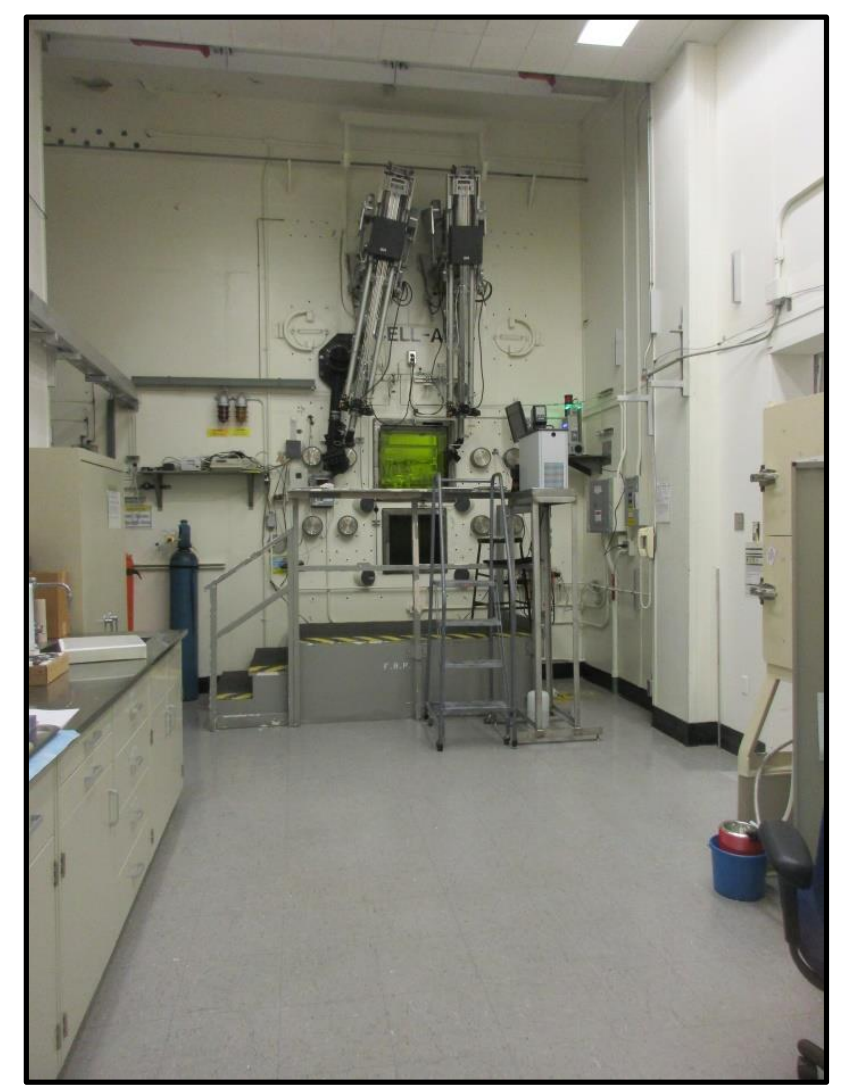

Figure 267. Operational hot cell in laboratory on first floor of Building 4501. 


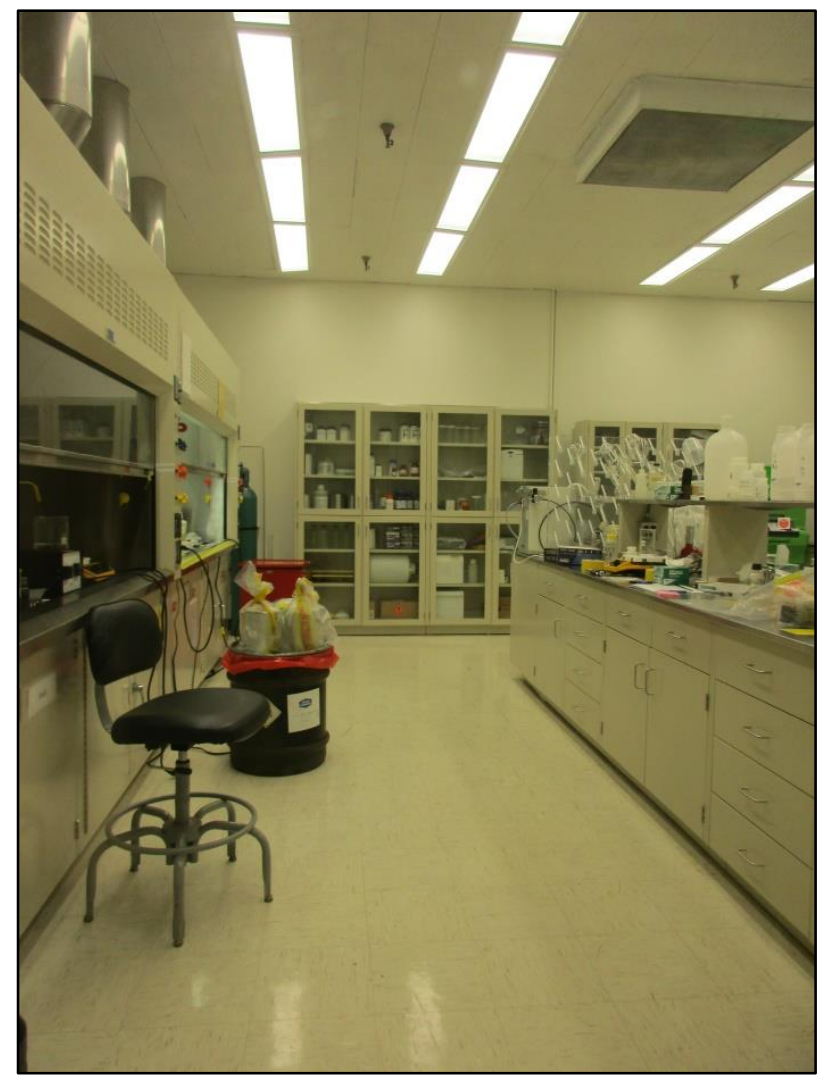

Figure 268. interior of laboratory space on the second floor of Building 4501.

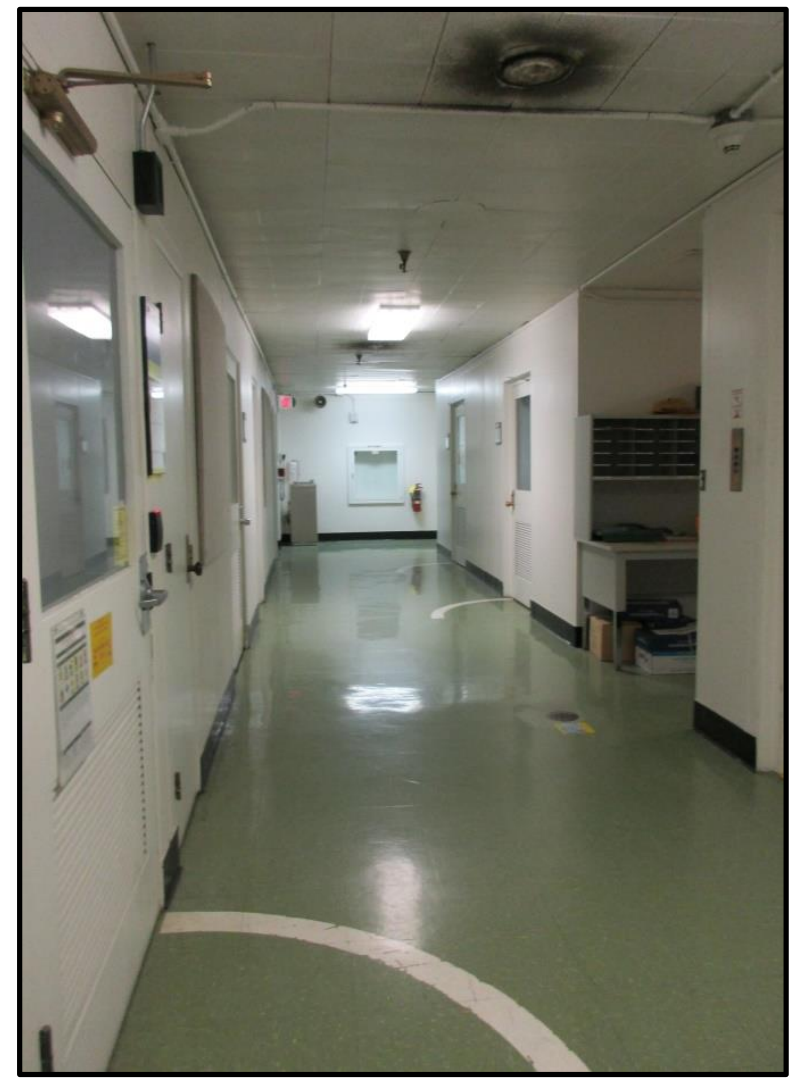

Figure 269. Corridor on second floor of Building 4501. 


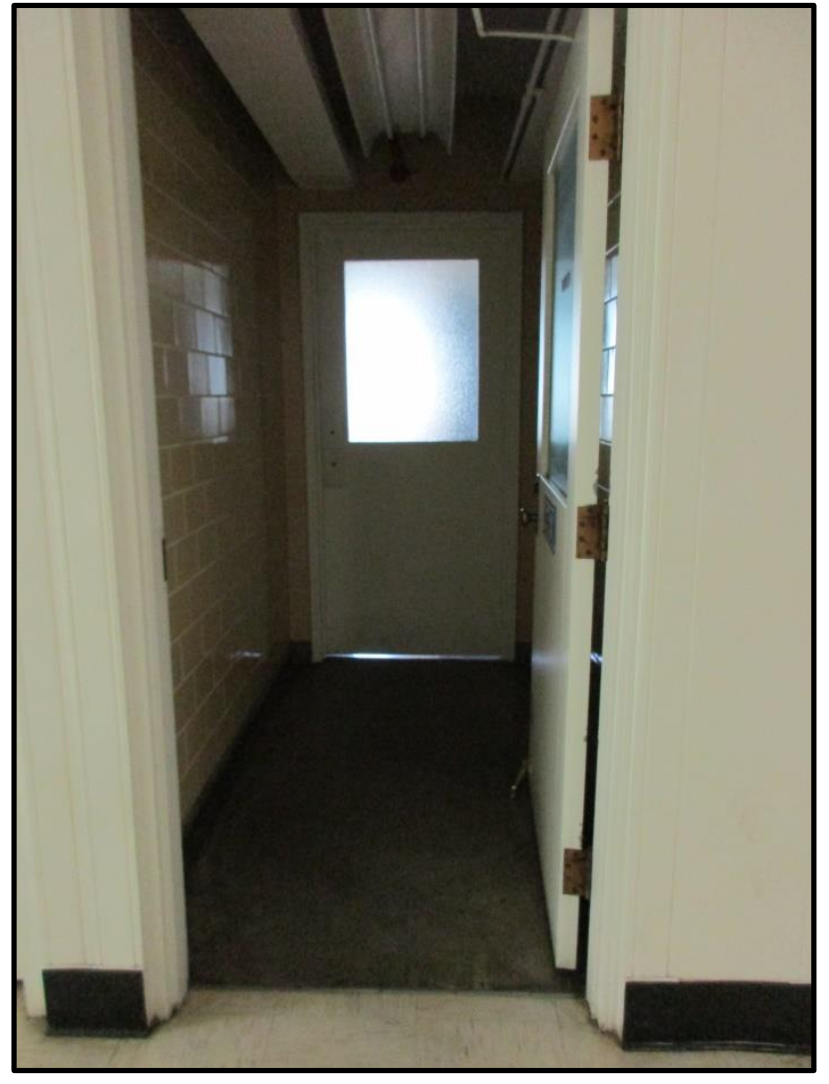

Figure 270. Restroom entry on first floor of Building 4501.

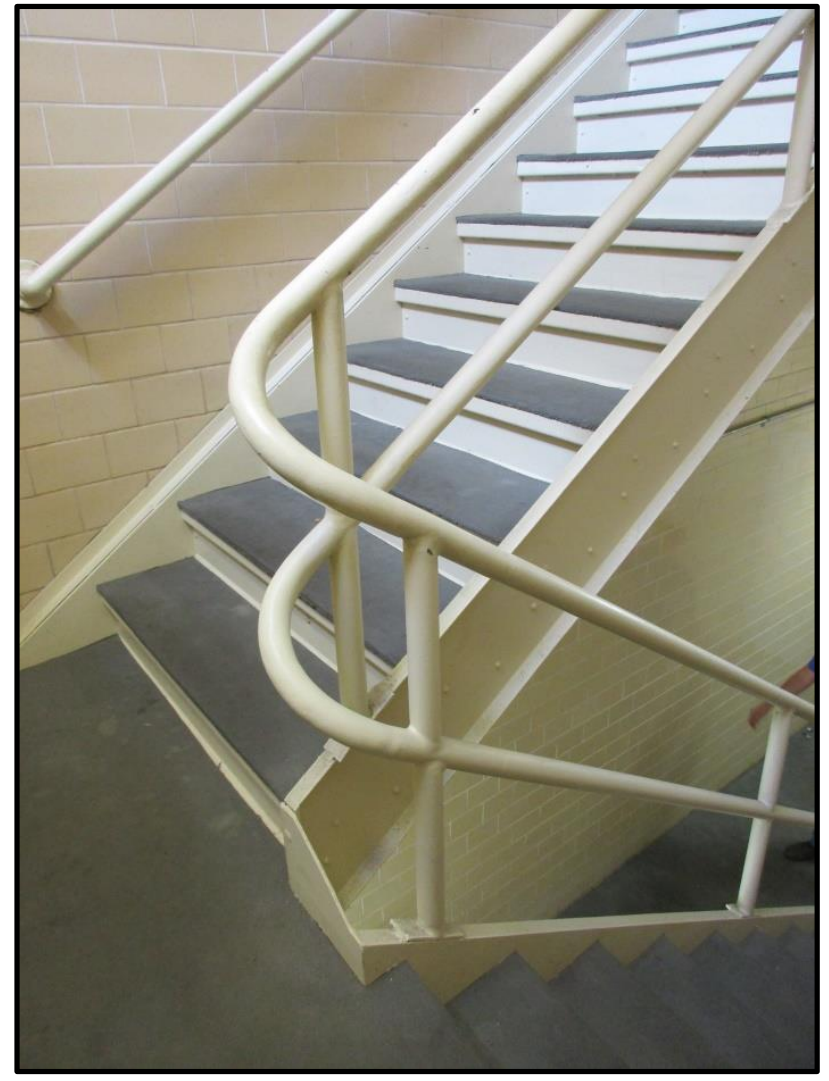

Figure 271. Stairwell of Building 4501 with glazed tile walls and original hand rails. 


\section{5}

\section{BUILDING NAME}

Experimental Engineering

\section{DATE OF CONSTRUCTION}

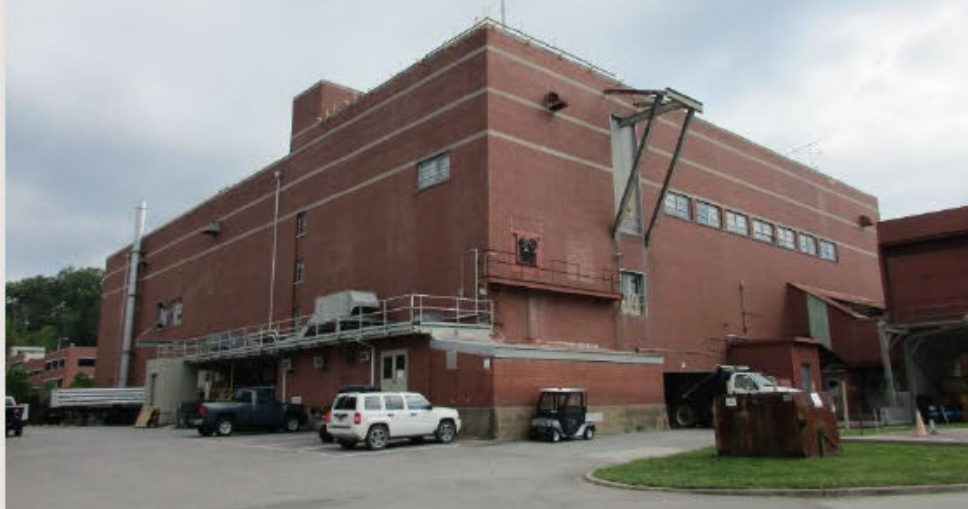

1951

DOE OFFICE RESPONSIBLE

SC

Figure 272. West and south elevation of Building 4505 .

\section{NRHP ELIGIBILITY}

Contributing to ORNL Historic District

\section{DESCRIPTION}

Building 4501 was one of 15 resources selected for intensive survey by UT-B as a part of survey planning. In July 2016, DOE completed Section 106 documentation for Buildings 4501 and 4505 in anticipation of consultation for renovation. The following description is adapted from the recordation completed as a part of that effort, supplemented with photographs taken in May and June of 2017 by CRA (Thomason and Associates 2017:6-7).

Exterior: Buildings 4501 and 4505 are interconnected and are located on the south side of Central Avenue and east of Fifth Street. These two buildings share a common wall but are considered two separate buildings. Building 4507, the High Level Chemical Development Lab, is attached to the south corner of Building 4505.

The south side of Building 4501 attaches to the north side of Building 4505 (Figure 272). Building 4505 is four stories in height. The south elevation has loading dock bays on the second and third floors (Figures 273). The second-story entrance has original, paired, single-light glass and steel doors. The third story has hinged, steel doors (Figure 274). Windows are original, three- light, horizontal, aluminum, awning design (Figure 275). Above the windows on the third floor are several concrete belt courses and soldier-course brick courses. At the roofline is concrete coping. The west elevation has a projecting, one-story wing with a loading dock bay and a series of pedestrian doors. Most doors are original, single-light glass and steel design. Windows on the upper façade are two-light, horizontal, aluminum, awning design. The east elevation has two entrances on the first floor with original, single-light glass and steel doors (Figure 276). In the upper floor are three-light, aluminum, fixed windows. On the second floor is an entrance with a single-light glass and steel door accessed by an exterior, concrete walkway from Building 4501.

Interior: The interior of Building 4505 is divided into four floors of offices and laboratory space. The first two floors feature two primary corridors that form an $L$ that provide access to most of the laboratory and office space along the exterior of the building; a secondary corridor accesses the remaining spaces. The first floor of Building 4505 has linoleum floors and concrete block walls in the laboratory spaces and dry wall partitions in some office spaces (Figure 277). Some doors have been replaced but most doors are original and are glass and steel with single-light and steel louvered vents on the lower section (Figure 278). Ceilings in corridors are metal acoustic 
tile, some office spaces have new dropped acoustic tile ceiling with recessed fluorescent lights and added floor carpeting. The stairwell has original tan glazed tile walls with original steel stairs and handrails (Figure 279). Four radiological "hot" cells are centrally located on the first floor.

On the second floor of Building 4505 wood partition walls have been added to divide office spaces and these rooms have linoleum floors. The conference room on the second floor has added floor carpeting, dry wall, and dropped acoustic tile ceilings (Figure 280). Bathrooms have concrete floors and glazed tile walls (Figure 281). The Bioengineering Labs on the second floor have metal cabinets, linoleum floors, and concrete block walls (Figure 282). The east-west corridors have linoleum floors, concrete block walls, and modern dropped acoustic ceilings and fixtures. Offices on the second floor have concrete block walls and modern acoustic dropped tile ceilings. A high bay, Hot Cell Platform, is located on the second floor containing a 2.5 ton crane (Figure 283). In this open area, the floor is covered with linoleum, the walls are concrete block, and the ceiling is steel. Portions of the third and fourth floors are open to floors below.

\section{NATIONAL REGISTER EVALUATION}

According to previous surveys and documentation, Building 4501 was constructed in 1951 at a cost of $\$ 3,070,000$. Buildings 4501 and 4505 were originally a single unit, known collectively as the High Level Radiation Laboratory. Building 4501 is associated with ORNL's isotope program, one of the most prominent of ORNL's post-World War II period (Thomason and Associates 2015: 140). For a detailed history of Buildings 4501/4505, see previous discussion of Building 4501.

In 2015, Thomason and Associates recommended that Building 4501/4505 is eligible for inclusion in the NRHP under Criterion A for its historical association with ORNL's evolution as a national laboratory, the post-World War II government-sponsored scientific movement, and early nuclear research as a contributing property in the NRHP-eligible ORNL Historic District (Thomason and Associates 2015). The work conducted in the building from 1951 to the mid-1960s included experimentation with lithium isotope separation and nuclear safety procedures.

As a research/laboratory facility, Building 4505 was associated with important scientific research at ORNL in the Cold War era, but it is not the individual building most directly associated with any specific accomplishment or person that rises to the level of significance for individual listing in the NRHP under Criterion A or B. Additionally, it does not possess significant associations for its architectural or engineering design that would warrant individual listing under Criterion $C$. Thus, $C R A$ recommends that it is not eligible for individual listing under Criterion A, B, or C. Rather, the significance of Building 4505 is reflected in its contributing role within the larger context of Cold War-era development and research at ORNL and as part of a collection of purpose-designed scientific processing and research facilities engineered to meet the specific needs of the advanced research occurring within their walls. Despite alterations to the interior, including the replacement of interior doors and the renovation of laboratories, Building 4505 retains integrity to support its inclusion as a contributing resource of the ORNL Historic District, within the recommended boundary extension. Therefore, CRA concurs with Thomason's 2015 recommendation that it is a contributing resource of the ORNL Historic District under Criterion A for its association with the post-World War II development of government-sponsored scientific laboratories, ORNL's evolution as a national laboratory, and early nuclear development and under Criterion $\mathrm{C}$ as a purposedesigned scientific research facility within the district. 


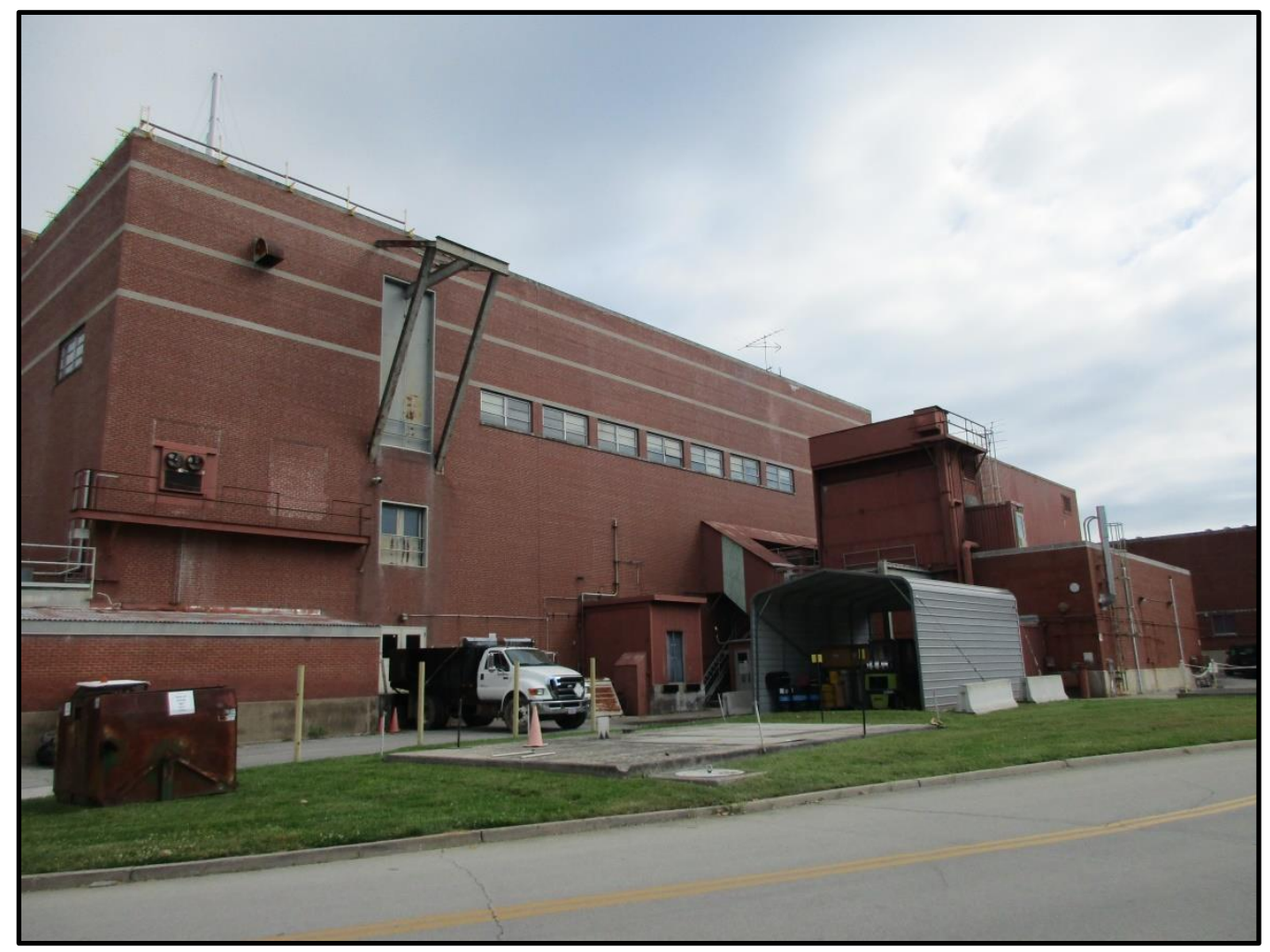

Figure 273. South elevation of Building 4505.

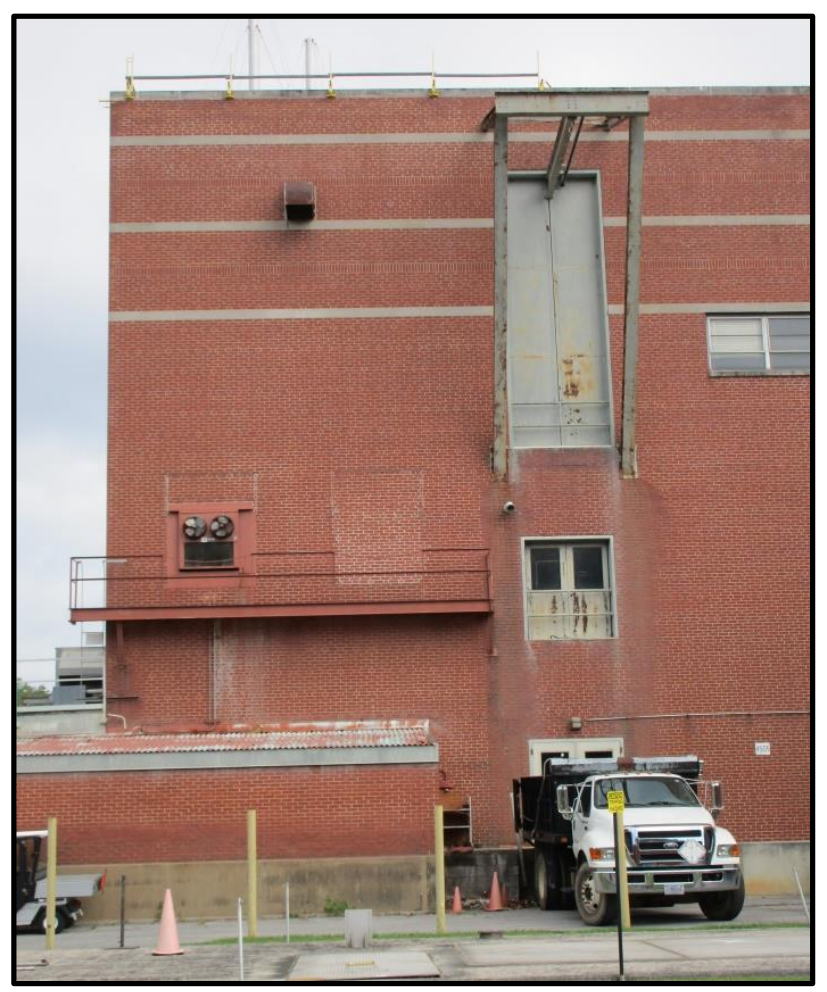

Figure 274. High bay entries on south elevation of Building 4505. 


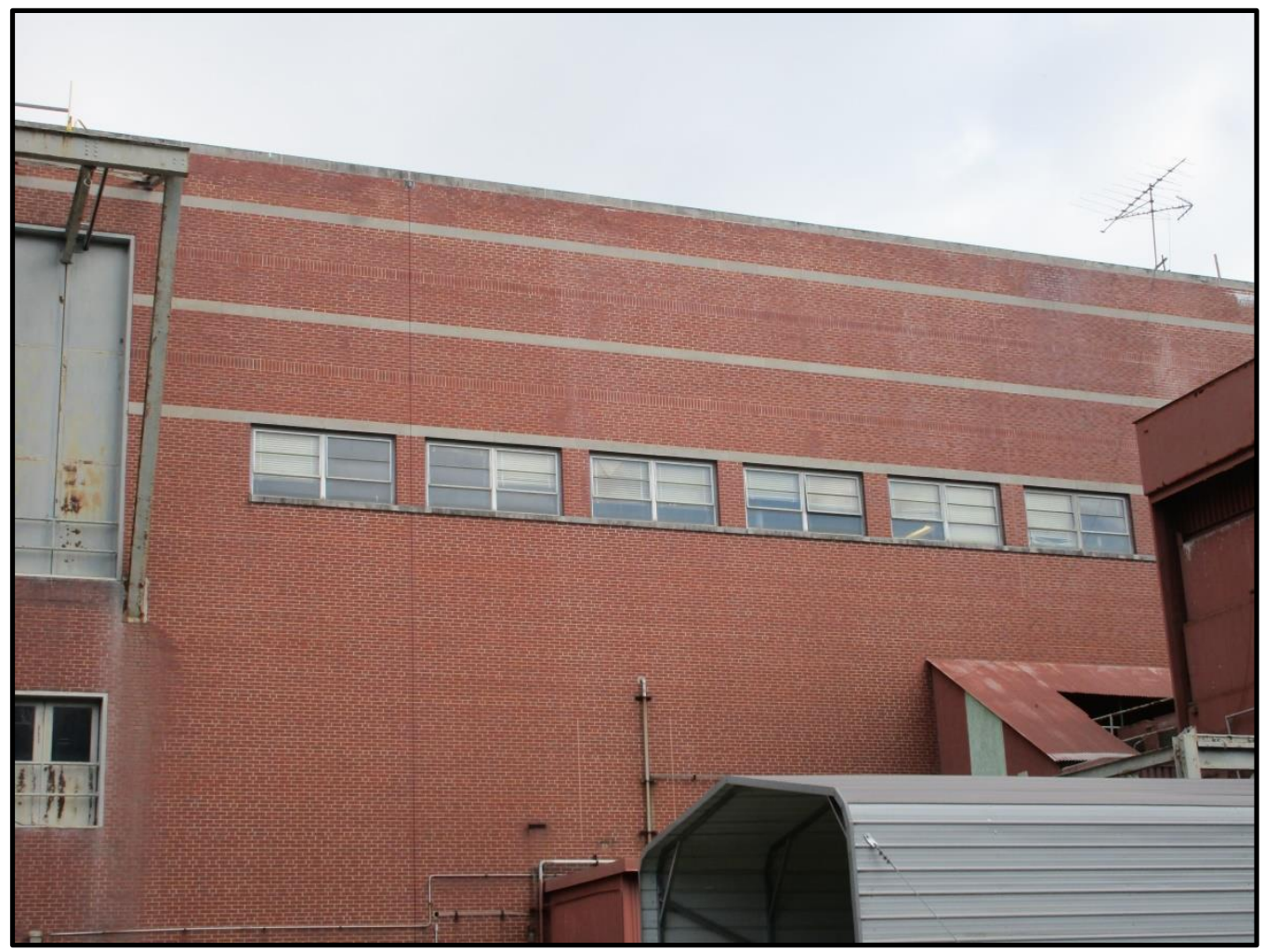

Figure 275. Windows on the south elevation of Building 4505.

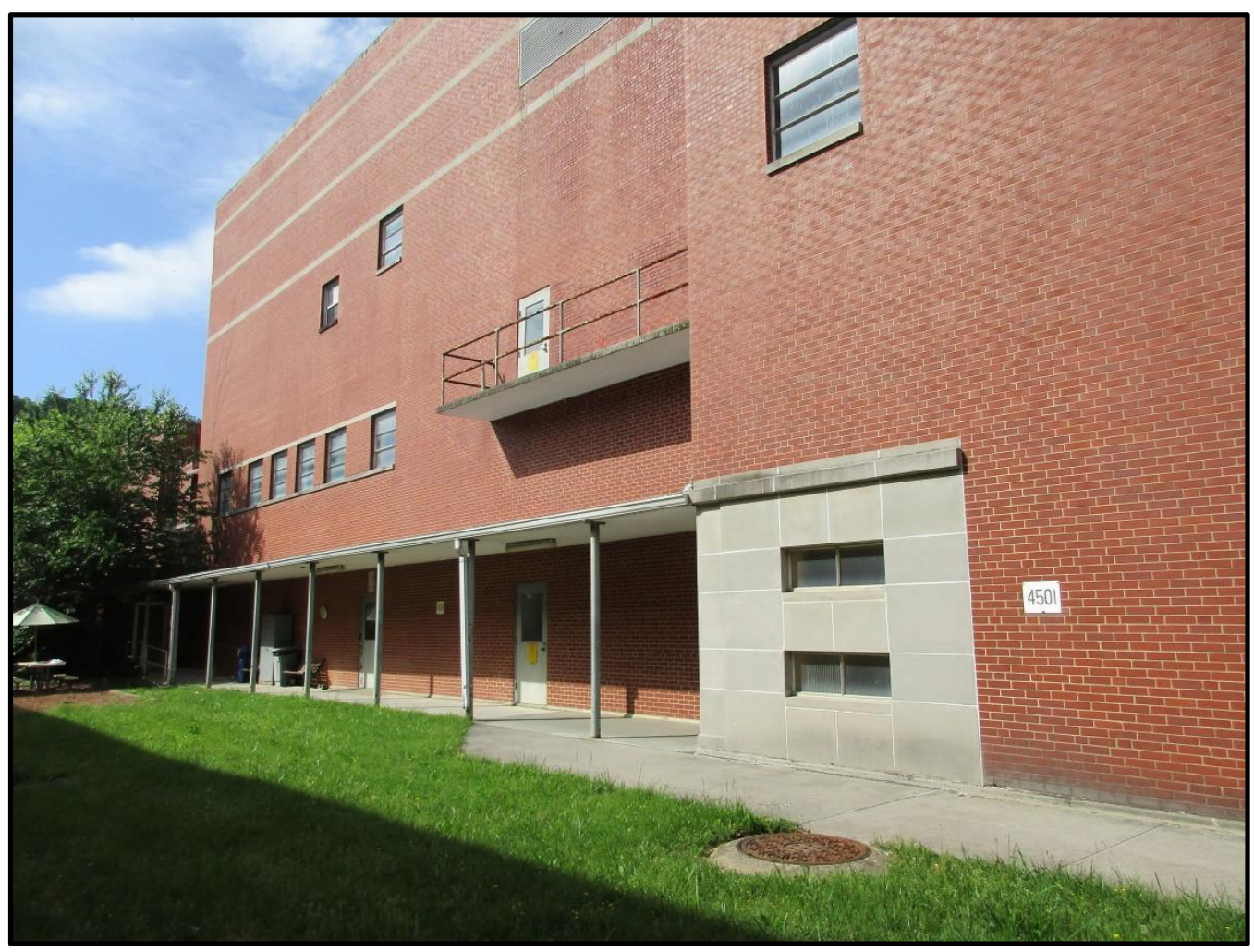

Figure 276. East elevation of Building 4505. 


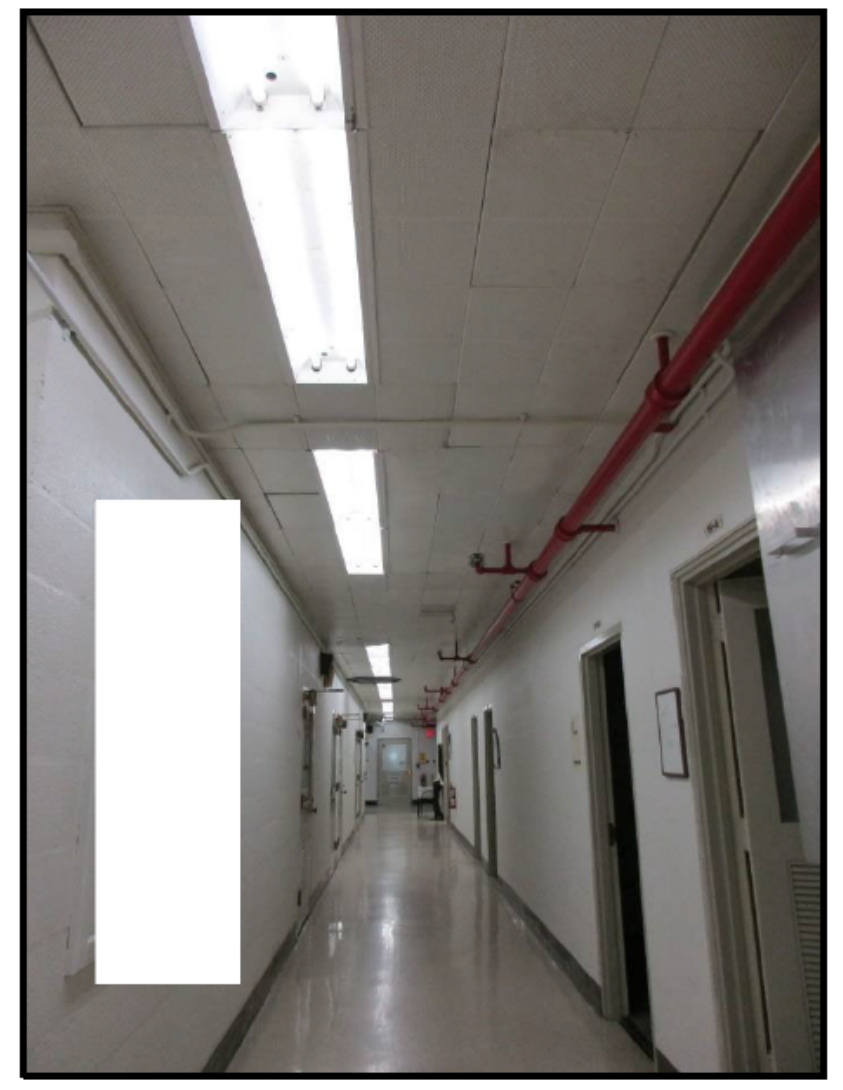

Figure 277. First floor corridor in Building 4505.

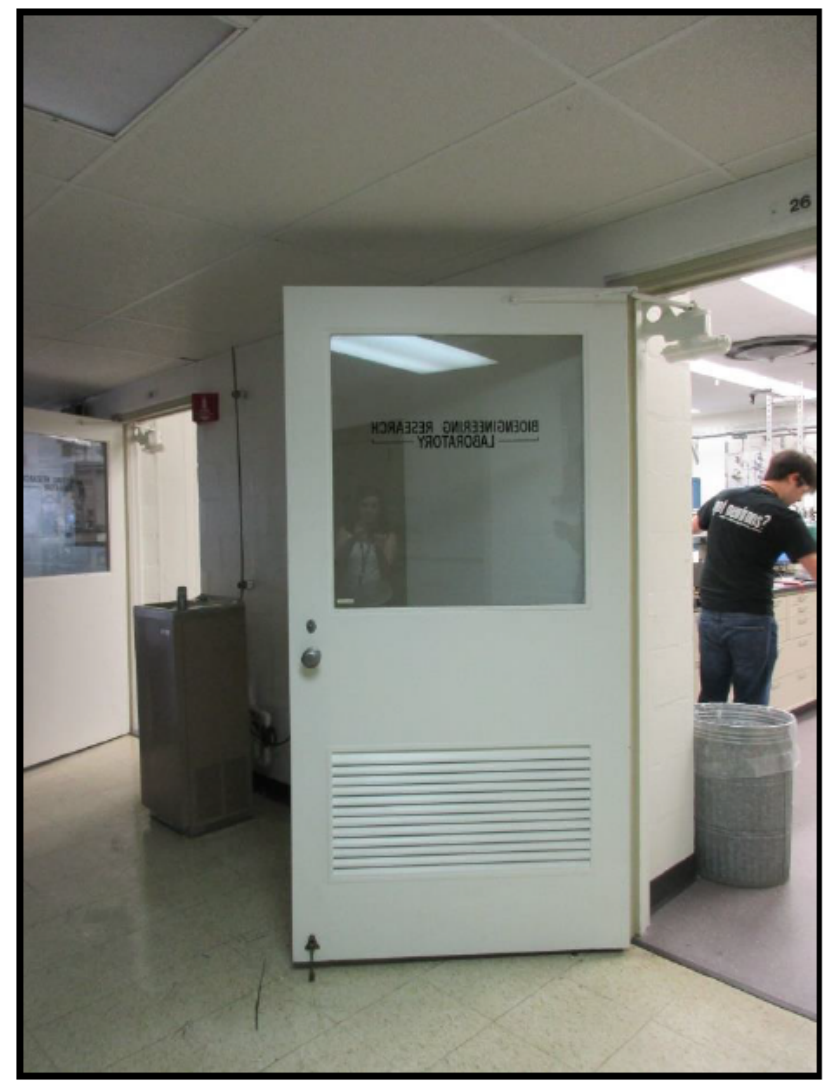

Figure 278. Original door to Bioengineering Research Laboratory on second floor of Building 4505 . 


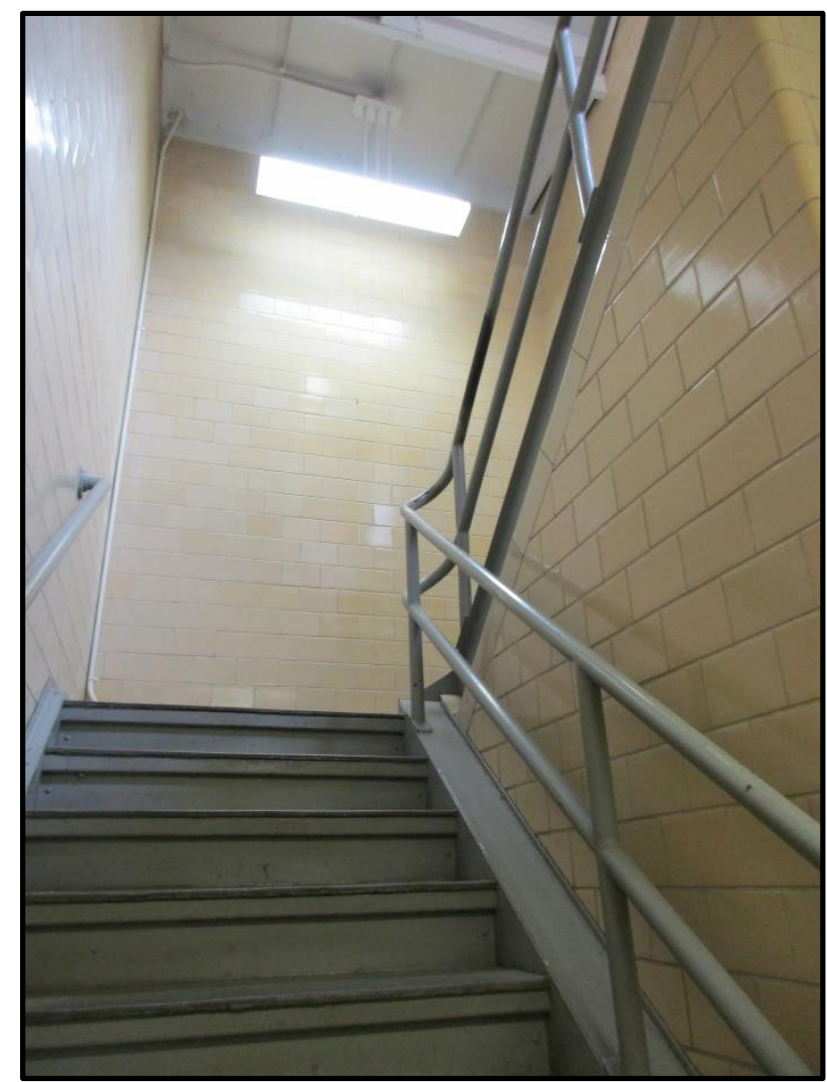

Figure 279. Stairwell in Building 4505.

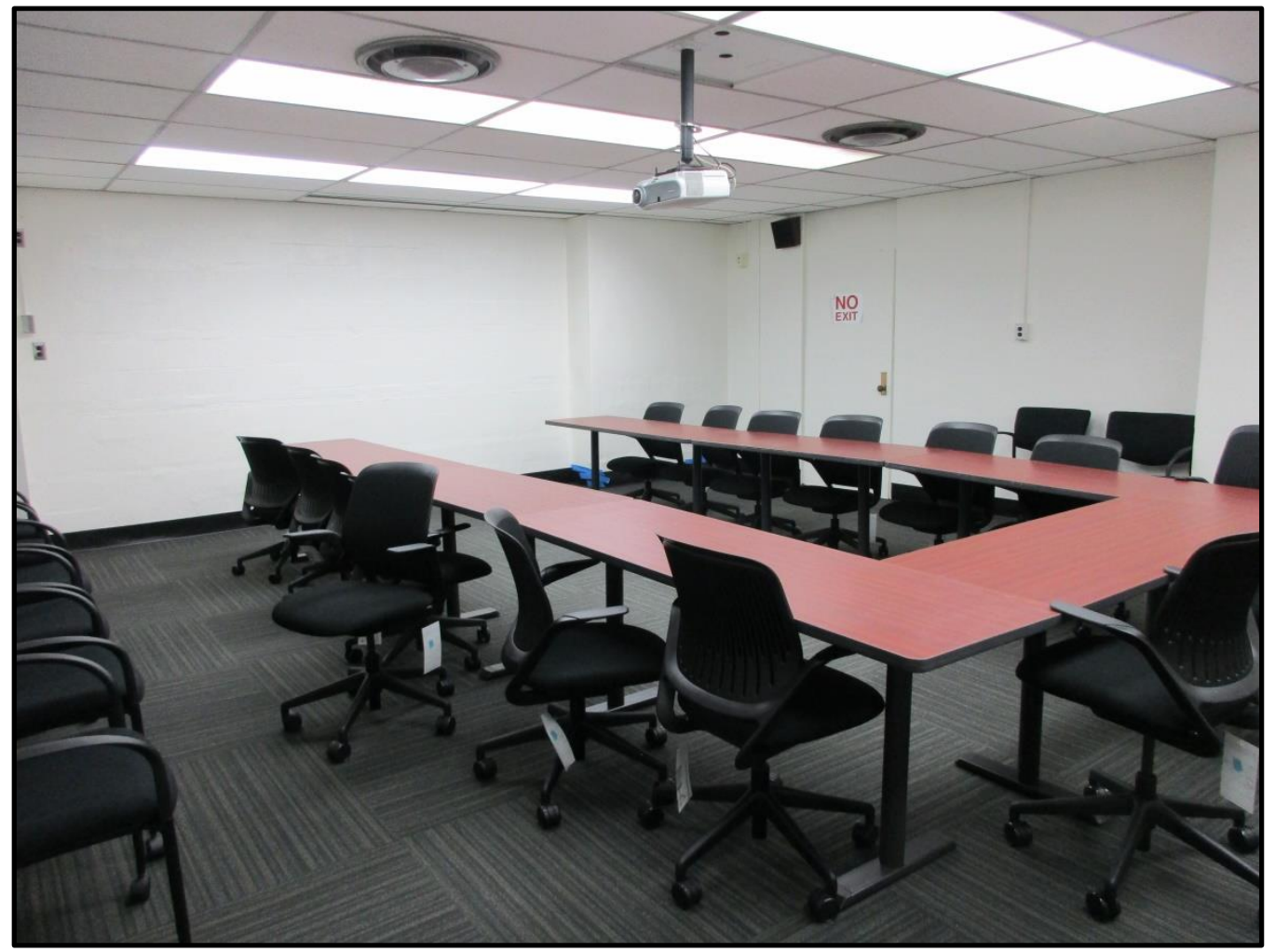

Figure 280. Renovated conference room in Building 4505. 


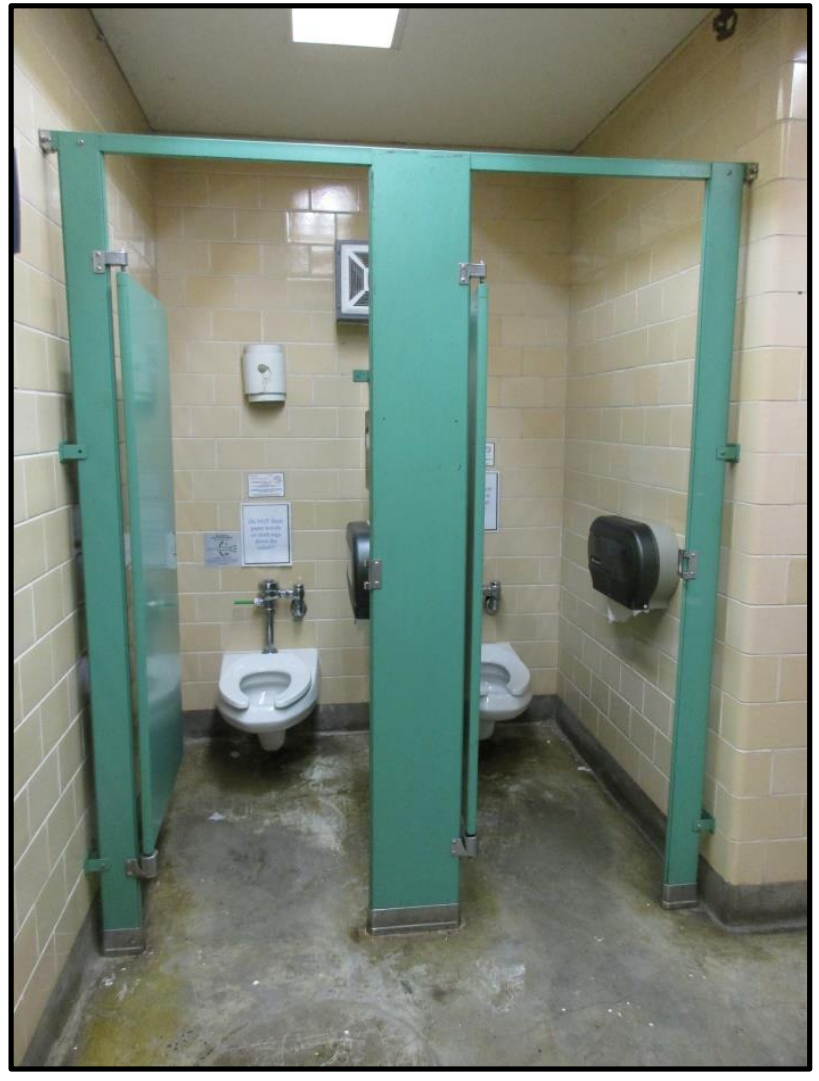

Figure 281. Restroom in Building 4505.

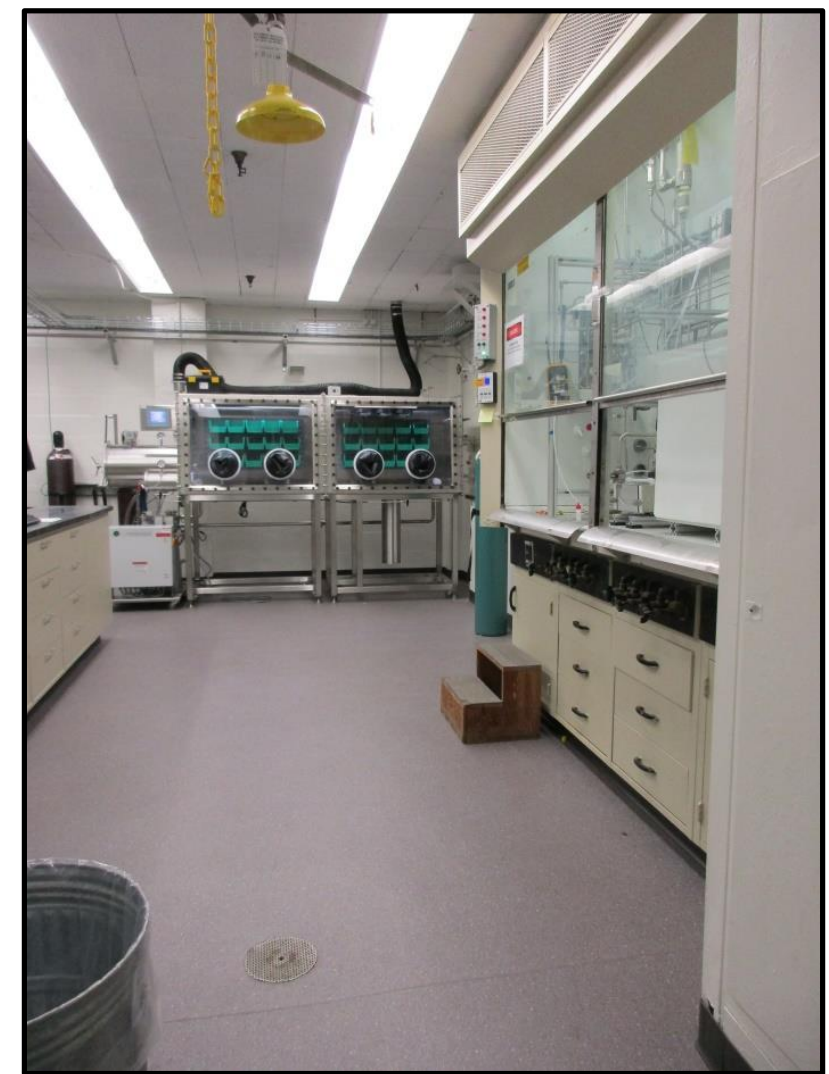

Figure 282. Renovated Bioengineering Research Laboratory on second floor of Building 4505. 


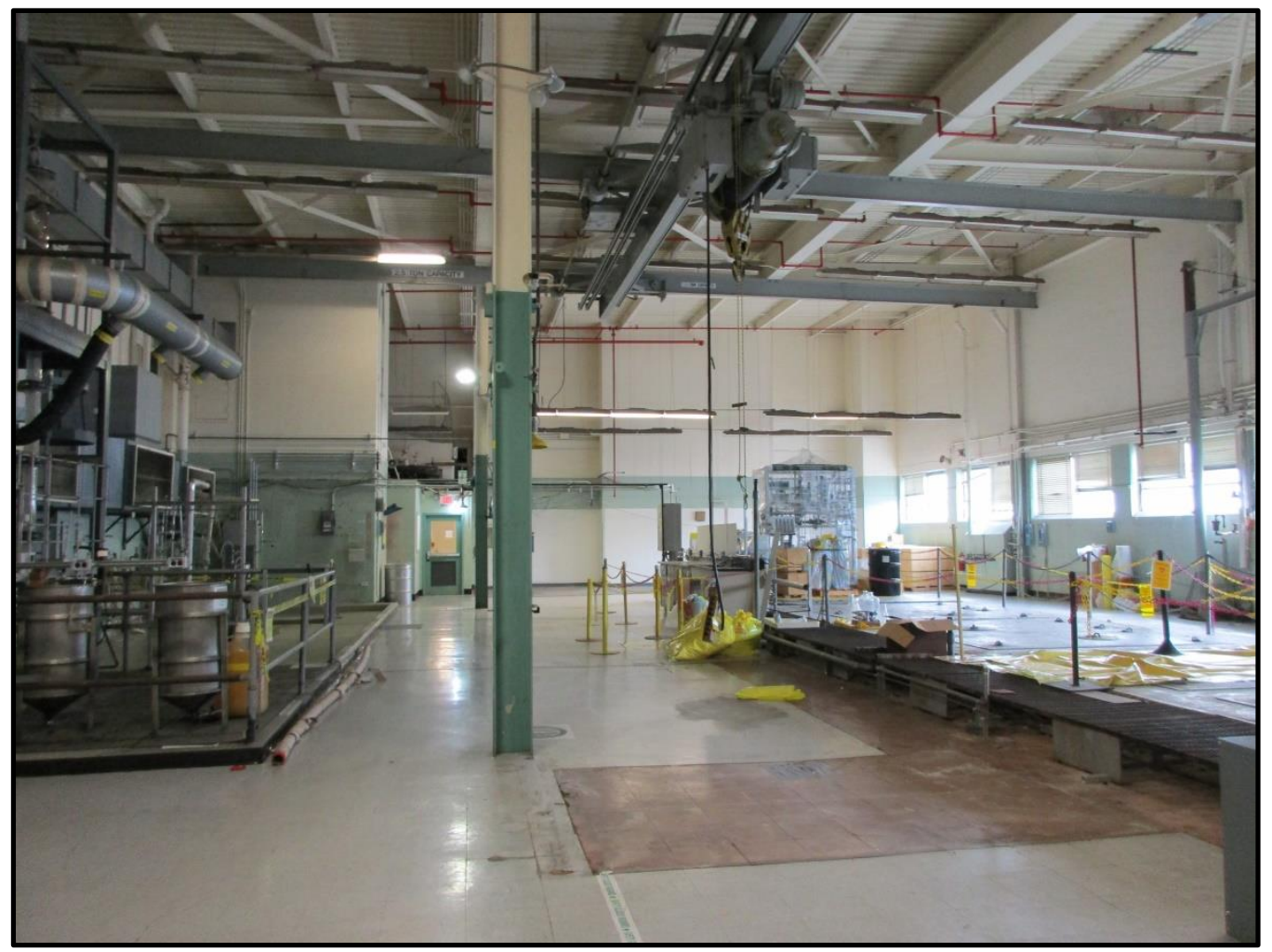

Figure 283. High bay area on third floor of Building 4505. 


\section{7}

\section{BUILDING NAME}

High Level Chemical Development Laboratory

\section{DATE OF CONSTRUCTION}

1952

\section{DOE OFFICE RESPONSIBLE}

EM (UCOR)

\section{NRHP ELIGIBILITY}

Figure 284. Overview of west and south elevations of Building 4507.

Contributing to ORNL Historic District

\section{DESCRIPTION}

Building 4507 is located north of White Oak Avenue and east of its intersection with Fifth Street. Building 4507 is attached to the south elevation of Building 4505 . Building 4507 is a multi-story structure constructed of brick masonry and steel with a concrete foundation (Figures 284 and 285). The brick pattern featured on the building is a variant of common bond with six courses of stretchers followed by a course of alternating headers and stretchers, similar to Flemish bond. The building is sheltered by a flat roof. One-story sections with brick exteriors are located on the east and west elevations that feature single-light metal pedestrian doors. The upper sections of the building are constructed of steel and are clad with corrugated metal siding. On the first floor, a wing on the east elevation of Building 4507 is attached to the west elevation of $4500 \mathrm{~N}$.

\section{NATIONAL REGISTER EVALUATION}

Building 4507 was constructed in 1952 as a High Radiation Level Chemical Laboratory and is associated with the Chemical Technology Division. Initially, the building was used for development studies for reactor fuel reprocessing and included a laboratory and small scale pilot plant. In the 1950s, research focused on the Fluoride Volatility Processing Program. The purpose of the program was the development of alternative methods for recovering uranium from spent nuclear fuel. This method had many advantages over previous methods including high concentration of waste and increased nuclear safety. Molten Salt Fluoride Volatility Process was emphasized at ORNL at that time. The process was developed and tested in Building $4500 \mathrm{~N}$ before being taken to the hot cell level in Building 4507. After the hot cell level, full-scale production would be installed in Building 3019 (Carver and Slater 1994:265).

Building 4507 was first surveyed by Duvall \& Associates in 1994. They concluded that the building was eligible for listing in the NRHP as a contributing building in the ORNL Historic District (Carver and Slater 1994). The 2004 and 2015 surveys conducted by Thomason and Associates also concurred with the previous assessment, citing the building's association with ORNL's evolution as a national laboratory, the post-World War II government sponsored scientific movement, and early nuclear research (Thomason and Associates 2004 and 2015). As a research/laboratory facility, Building 4507 housed work that furthered ORNL's mission in nuclear 
science during the Cold War era. However, the building is not the single location most importantly associated with a scientific achievement, scientist, or other event or person of historic significance to merit individual listing in the NRHP under Criterion A or B. Furthermore, the building lacks notable architectural elements that would warrant individual listing in the NRHP under Criterion C. Instead, the significance of Building 4507 is best understood within the broader context of the body of work advanced by researchers in the ORNL Historic District during the Cold War era. As such, Building 4507 does not warrant individual listing in the NRHP under Criterion A, B, or C; however, the building is a contributing resource to the ORNL Historic District.

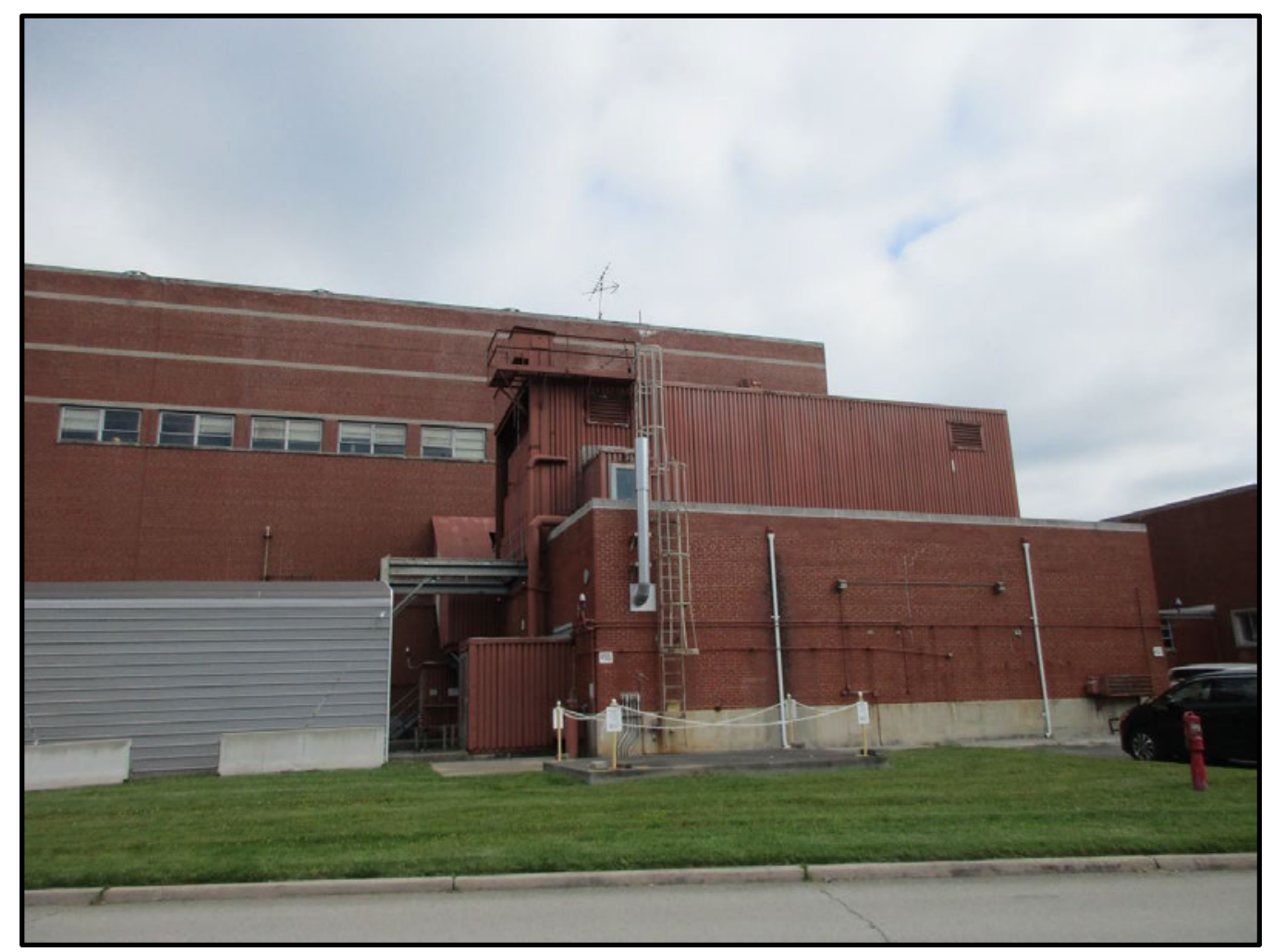

Figure 285. Overview of west and south elevations of Building 4507. 


\section{8}

\section{BUILDING NAME}

Metals \& Ceramics Laboratory

\section{DATE OF CONSTRUCTION}

1962

\section{DOE OFFICE RESPONSIBLE}

SC

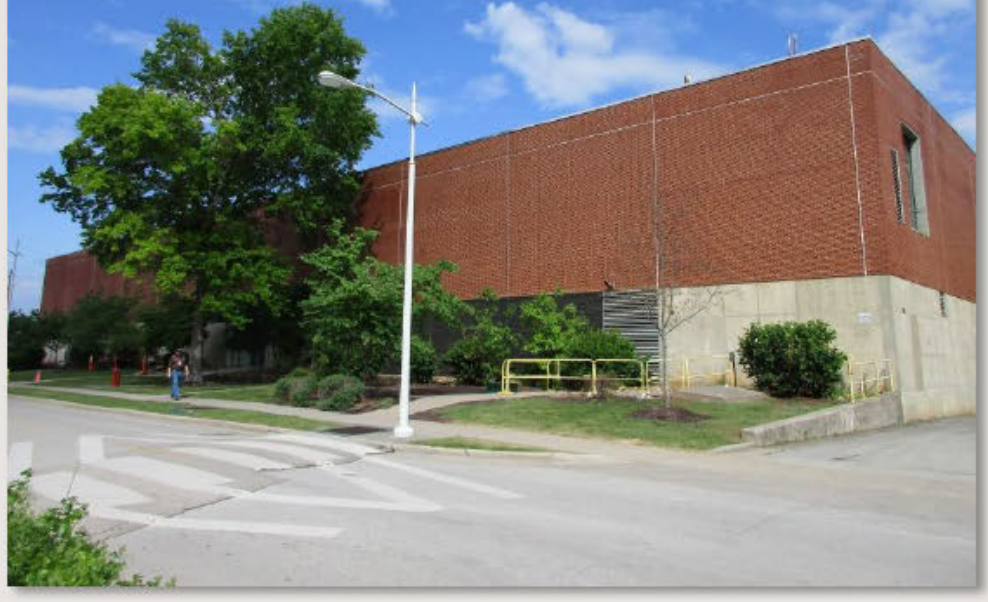

NRHP ELIGIBILITY

Figure 286. South elevation of Building 4508 .

Contributing to ORNL Historic District

\section{DESCRIPTION}

Building 4508 was one of 15 resources selected for intensive survey by UT-B as a part of survey planning. It is located north of the intersection of Fifth Street and Southside Avenue, within the main campus of ORNL.

Exterior: Building 4508 is a two-story rectangular block that features a variant of common bond with five courses of stretchers followed by a course of alternating headers and stretchers, similar to Flemish bond. Set upon a continuous poured concrete foundation, the building features a flat roof with metal coping. All exterior elevations of Building 4508 are devoid of windows, except at entries. The south elevation features two entries: a primary entry and a secondary entry (Figure 286). The primary entry, which originally featured two sets of double doors with transoms, has been modified to feature two fixed lights and a transom in the left entry and full-length singlelight steel doors with a transom on the right entry (Figure 287). A fabric awning extends over this entry and the other entries on all elevations. The second entry on the south elevation features a single-leaf solid steel door (Figure 288). The east elevation, connected to Building $4500 \mathrm{~S}$ by an enclosed elevated walkway, features loading docks and entries on the first floor and a tall garage bay on the second floor (Figures 289 and 290). The north elevation is devoid of windows and doors (Figure 291) and the west elevation features two garage bays and two single-leaf secondary entries with solid steel doors (Figure 292).

Interior: The interior of Building 4508 is comprised of two stories and a penthouse area in the attic for mechanical equipment. Throughout the first and second floors, Building 4508 retains many original interior doors (Figures 293, 294, and 295). Renovated offices and conference rooms feature new drop ceilings, concrete block and sheetrock walls, and original and replacement commercial floor tile (Figure 296). Laboratories feature a variety of original and replacement casework, counters, and floors (Figures 297 and 298).

The first floor plan is complex, with a series of corridors that wind through the first floor providing access to large lab spaces and smaller offices and conference rooms. The majority of the corridors feature replacement commercial tile, drop ceilings with acoustic tile, and sheetrock walls (Figure 299). The western corner of the building features a high bay area that is open to the second floor (Figure 300).

A freight elevator and three stairwells provide access between the floors of Building 4508 (Figures 301 and 302). The second floor of Building 4508 features a more simple floor plan with a series of corridors that provide 
access to laboratory and office spaces around the exterior of the building and in an interior block, near the center of the building. Corridors on the second floor feature a combination of original and replacement commercial tile, drop ceilings with acoustic tiles, and permanent sheetrock walls dividing spaces (Figures 303 and 304). Restrooms feature a variety of interior finishes that feature original and replacement floor tile and concrete block and glazed concrete block walls (Figures 305 and 306).

\section{NATIONAL REGISTER EVALUATION}

Constructed in 1962, Building 4508 was constructed to serve as a research facility for metals and ceramics. Previous survey records indicate that the first floor of Building 4508 houses the Interim Plutonium Laboratory $(\mathrm{IPL})$, a part of the Ceramics Laboratory. Location of the IPL in this building is due to its secondary containment design, as it was equipped with a purge system that provided its gloveboxes with working inert atmospheres of very low oxygen and water, needed to work with plutonium and uranium nitrides. The gloveboxes as a part of this lab were equipped to synthesize, press, and sinter (or press powder into a solid form) pellets of plutonium and uranium nitrides. Another key facility housed within Building 4508 was the Fuel Cycle Alpha Facility (FCAF), which fabricated plutonium oxide and plutonium-uranium oxide fuel pellets and developed and fabricated special target materials for the High Flux Isotope Reactor (HFIR, Building 7900). The FCAF has been relocated to the Basement of Building 3019; however, the research with target materials for HFIR and vibratory compaction and slug injection fuel-rod-loading techniques proved valuable to the success of nuclear research and the continued operation of the HFIR today (Thomason and Associates 2015:154).

In 1994, Duvall \& Associates' survey of ORNL recommended that Building 4508 was not included in the boundary of the ORNL Historic District due to its age (Carver and Slater 1994). In 2015, Thomason and Associates recommended Building 4508 was an important component of ORNL's role as a national laboratory and held significance under Criterion A as a part of the ORNL Historic District for its associated with ORNL's evolution as a national laboratory, the post-World War II government-sponsored scientific movement, and early nuclear research.

As a research/laboratory facility, Building 4508 was associated with important scientific research at ORNL in the Cold War era, but it is not the individual building most directly associated with any specific accomplishment or person that rises to the level of significance for individual listing in the NRHP under Criterion A or B. Additionally, it does not possess significant associations for its architectural or engineering design that would warrant individual listing under Criterion $C$. Thus, CRA recommends that it is not eligible for individual listing under Criterion $A, B$, or $C$. Rather, the significance of Building 4508 is reflected in its contributing role within the larger context of Cold War-era development and research at ORNL and as part of a collection of purpose-designed scientific processing and research facilities engineered to meet the specific needs of the advanced research occurring within their walls. Despite alterations to the interior, including the reorganization and renovation of office and laboratory spaces, Building 4508 retains integrity to support its inclusion as a contributing resource of the ORNL Historic District, within the recommended boundary extension. Therefore, CRA concurs with Thomason's 2015 recommendation that Building 4508 is a contributing resource of the ORNL Historic District under Criterion A for its association with the post-World War II development of government-sponsored scientific laboratories, ORNL's evolution as a national laboratory, and early nuclear development and under Criterion C as a purpose-designed scientific research facility within the district. 


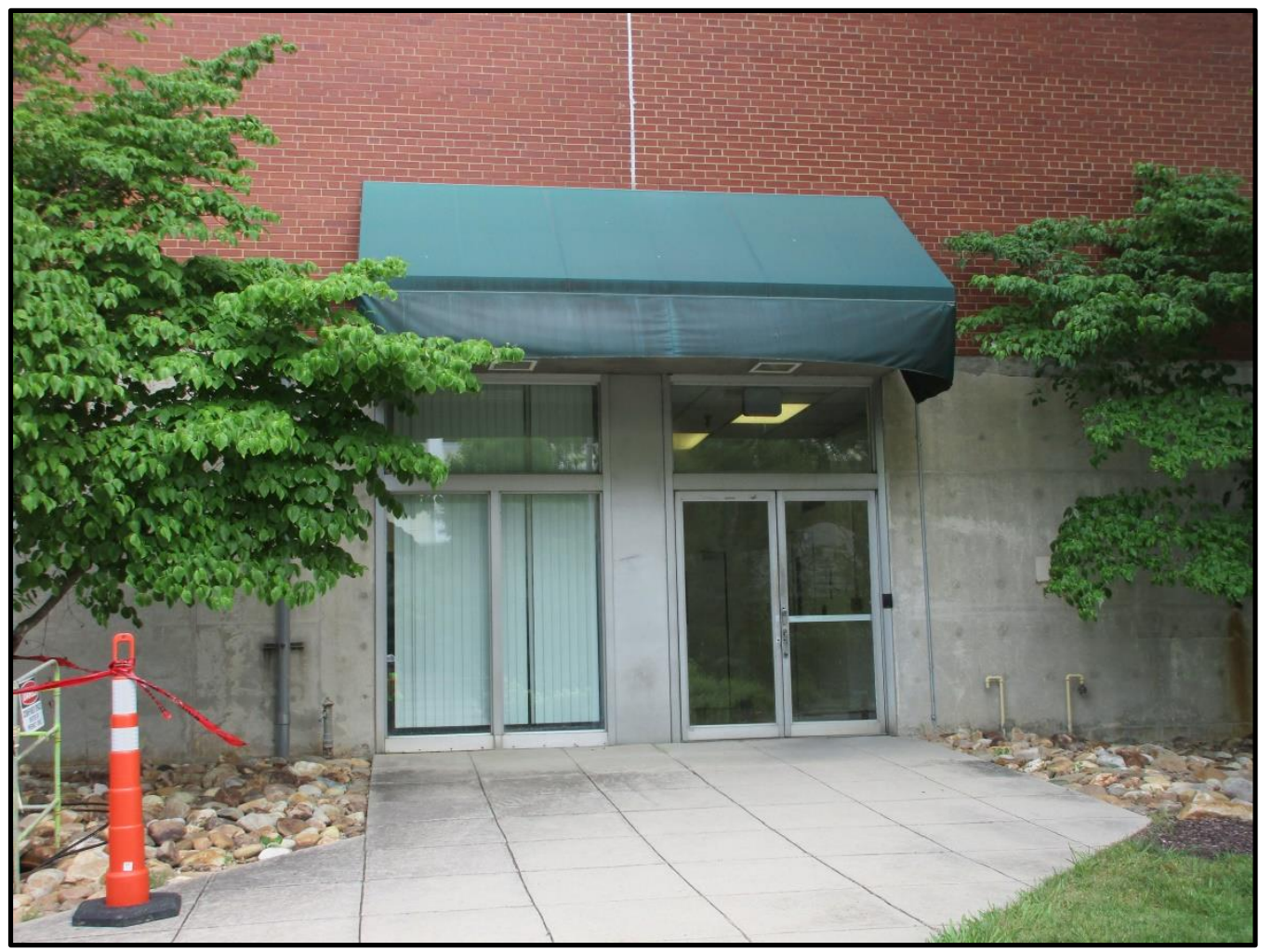

Figure 287. Primary entry on south elevation of Building 4508.

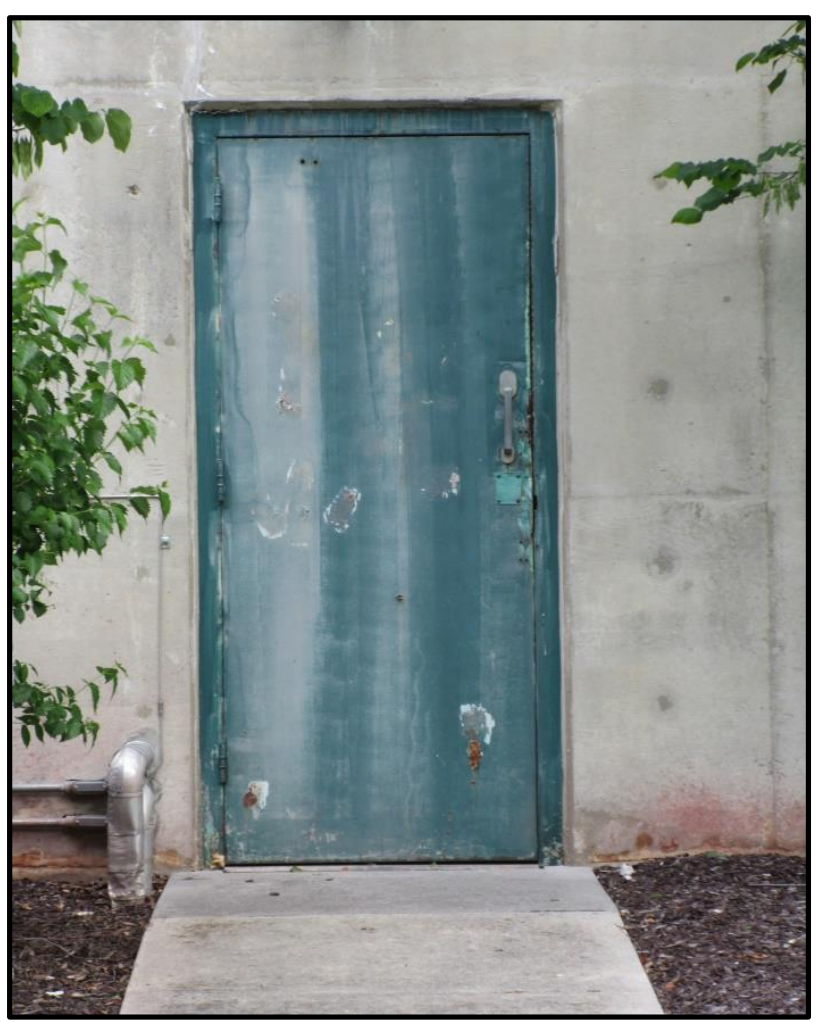

Figure 288. Secondary entry on south elevation of Building 4508. 


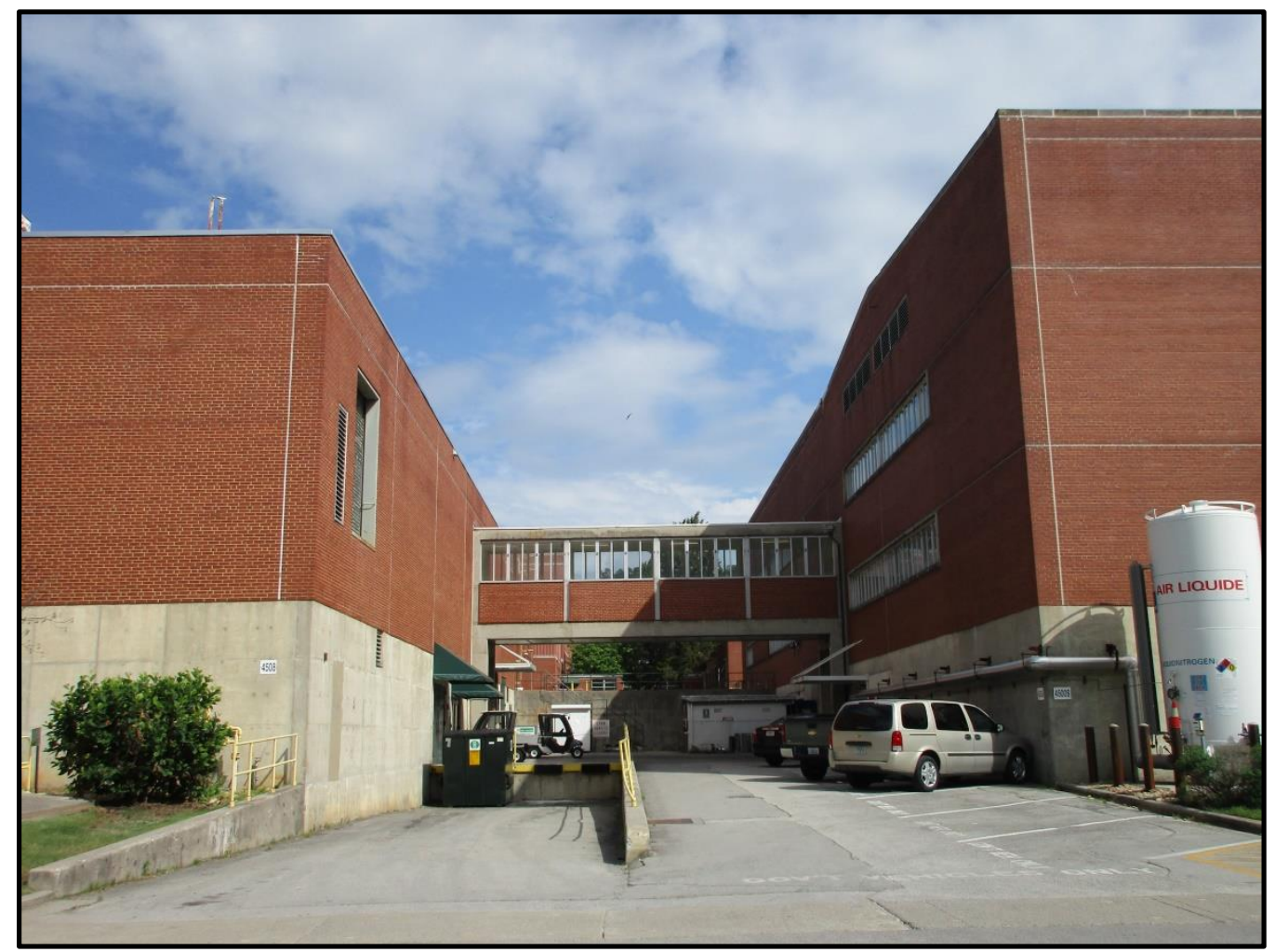

Figure 289. East elevation of Building 4508 and the corridor connecting it to Building $4500 S$.

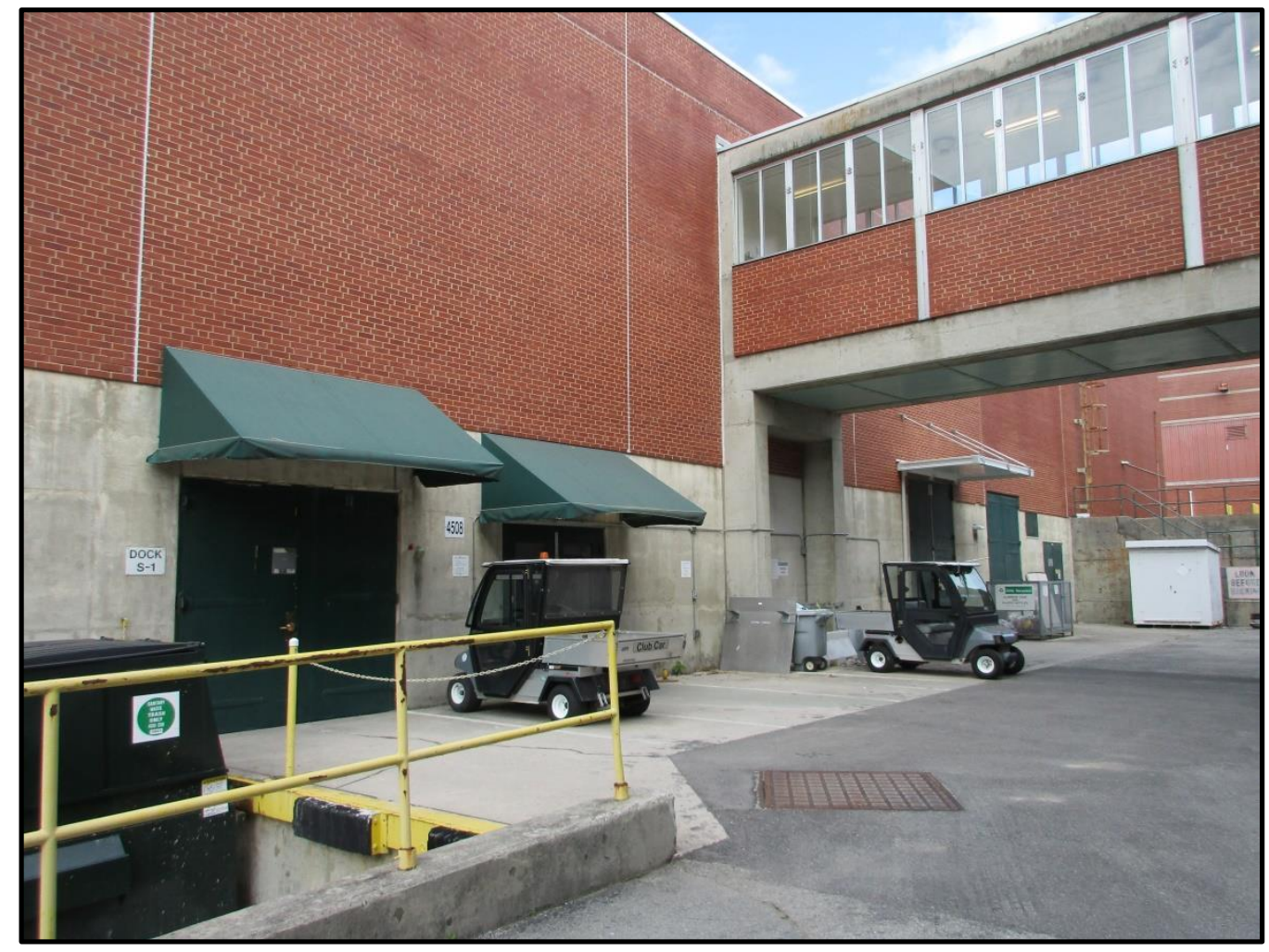

Figure 290. Loading dock and entries of the east elevation of Building 4508. 


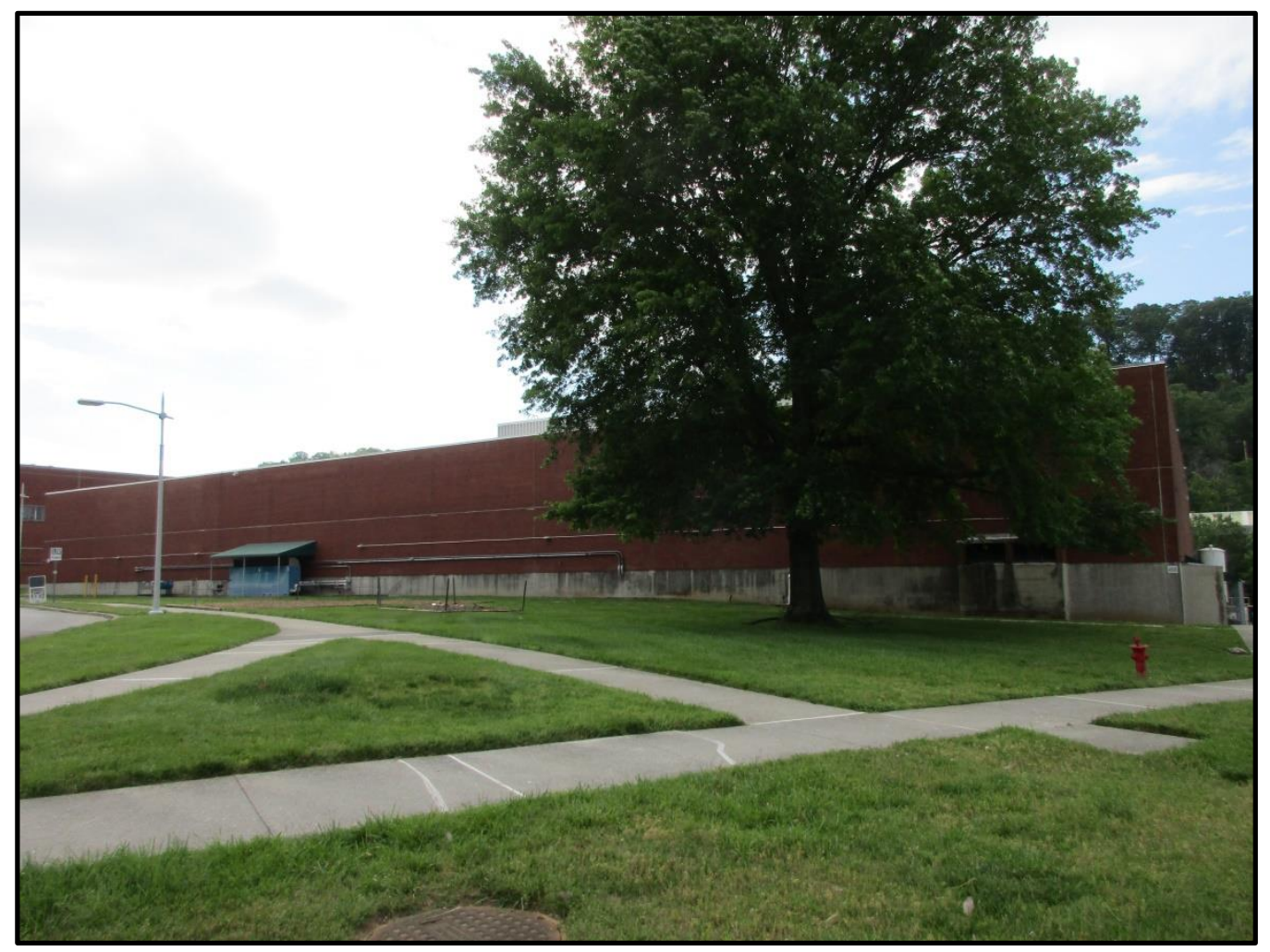

Figure 291. North elevation of Building 4508.

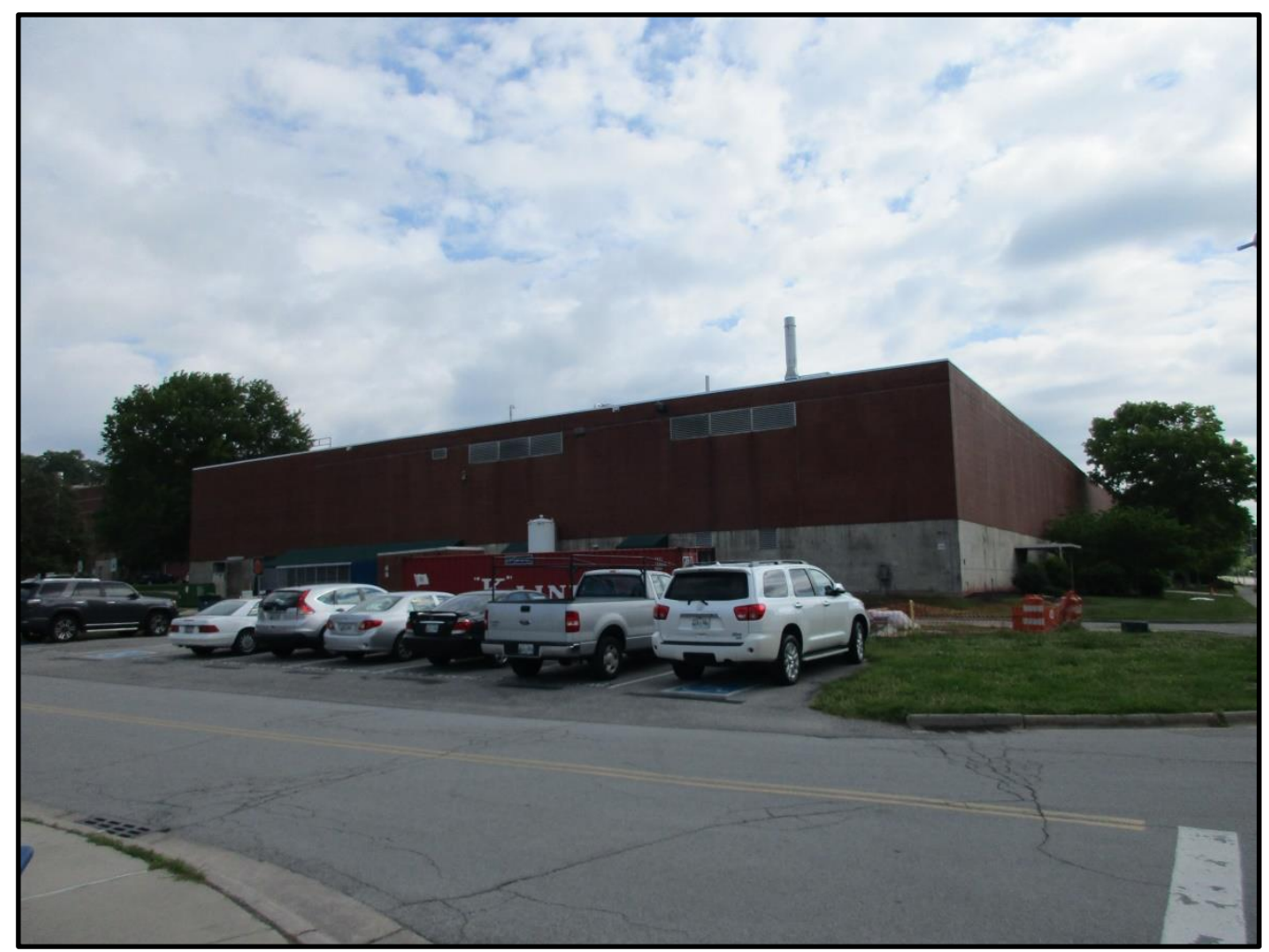

Figure 292. West elevation of Building 4508. 


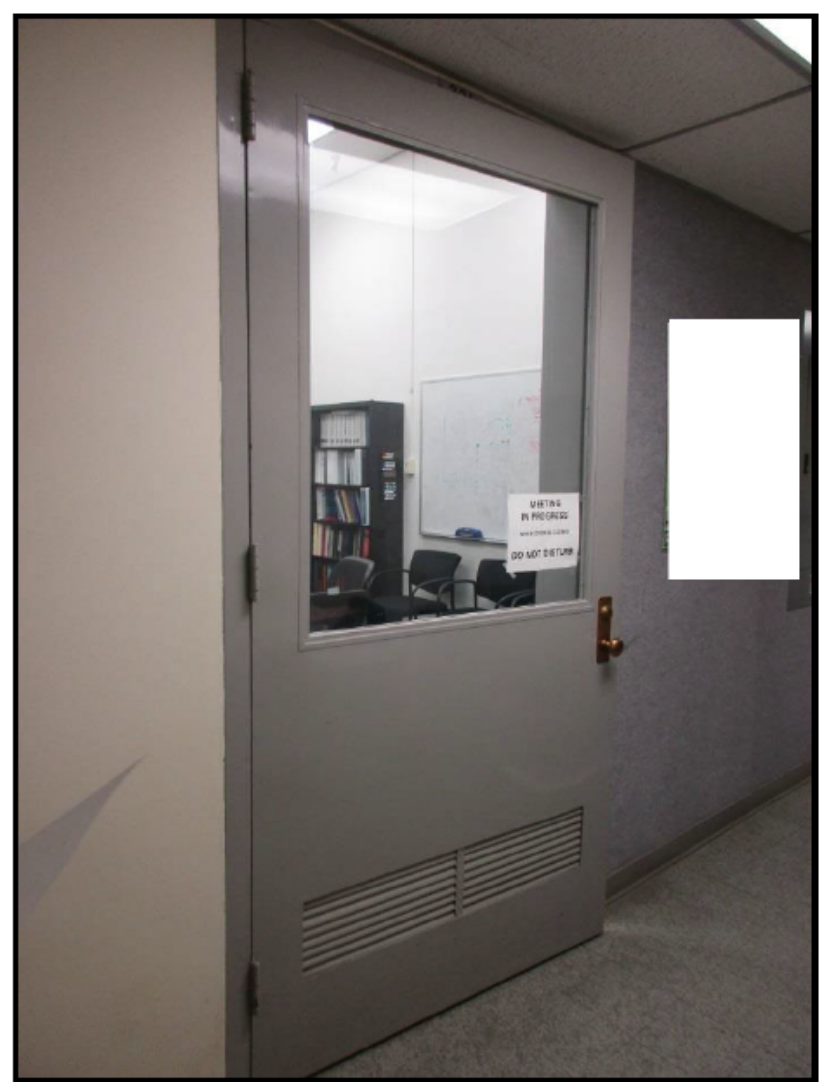

Figure 293. Original door on the second floor of Building 4508.

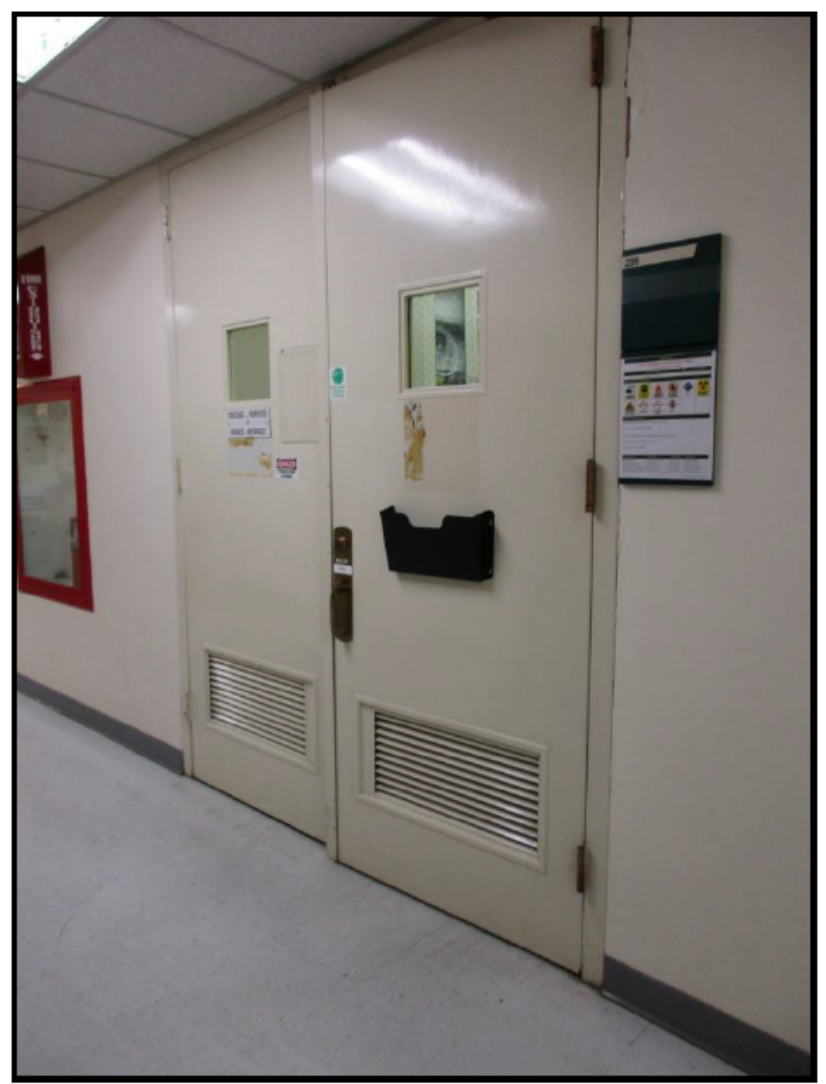

Figure 294. Original doors on the second floor of Building 4508. 


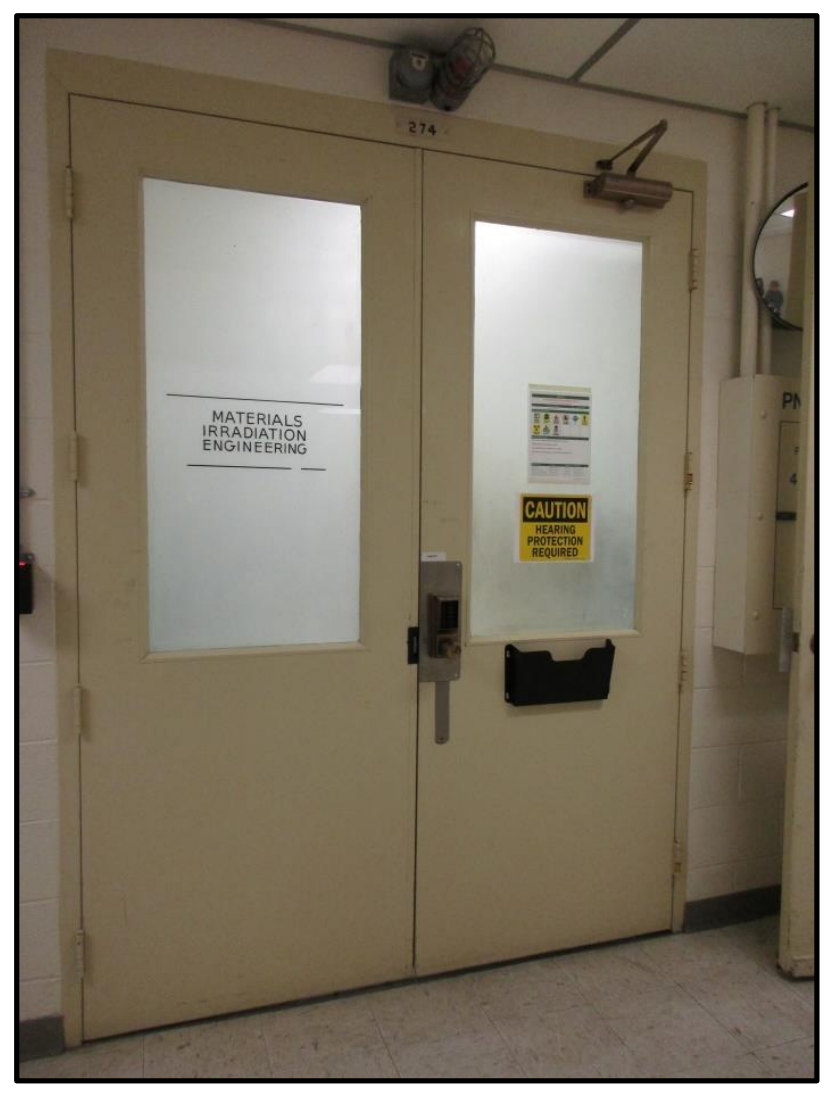

Figure 295. Original doors to the Materials Irradiation Engineering Lab on the second floor of Building 4508.

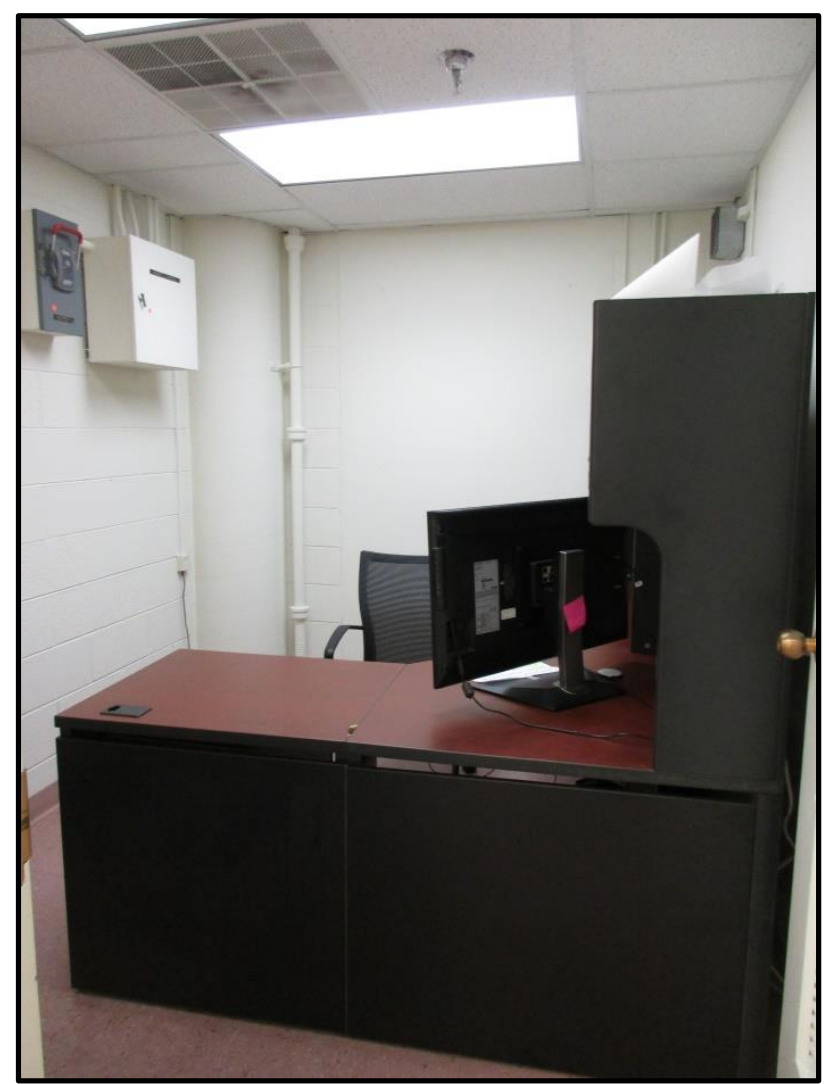

Figure 296. Renovated office space on the second floor of Building 4508. 


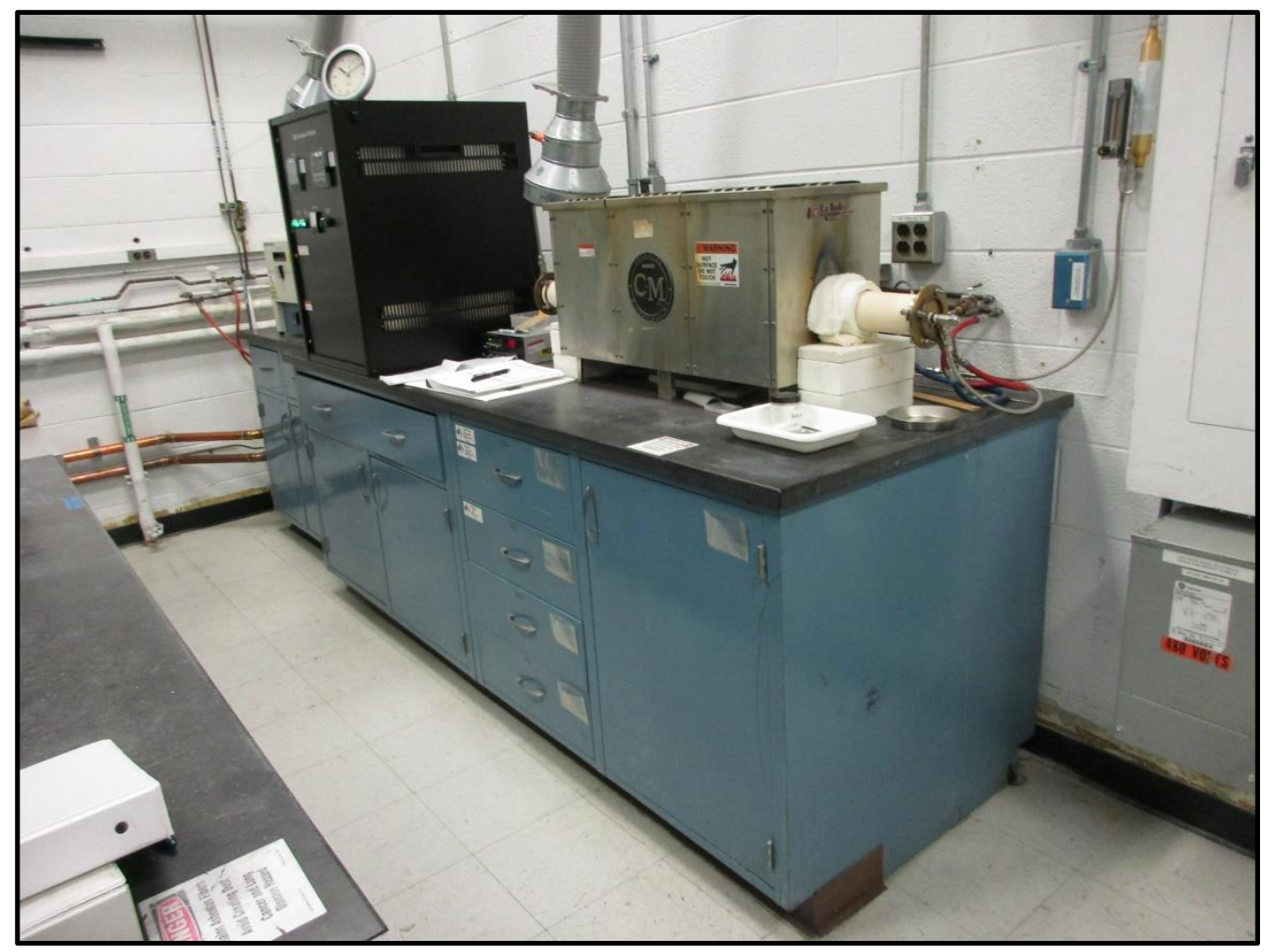

Figure 297. Original casework in a laboratory on the second floor of Building 4508.

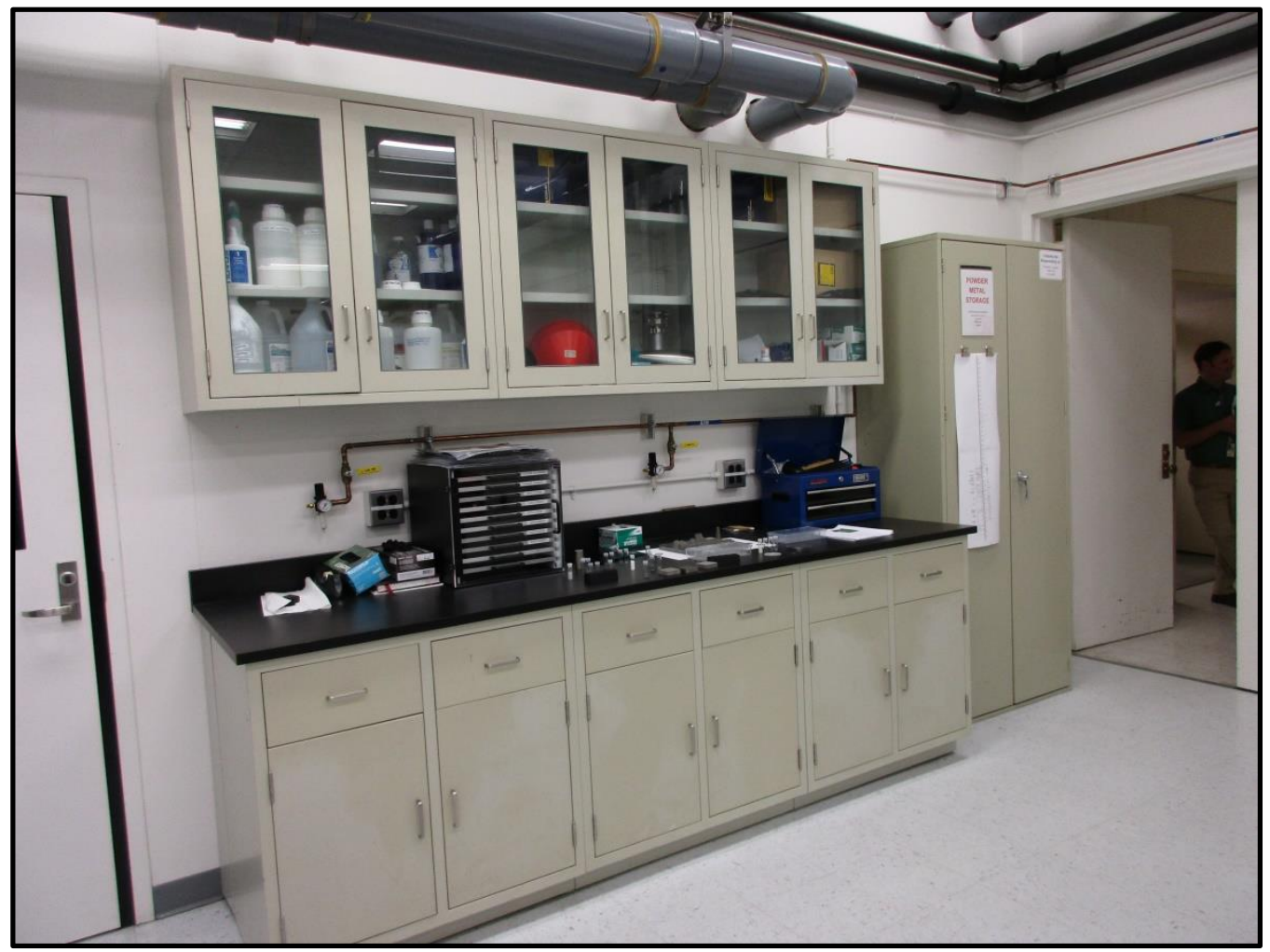

Figure 298. Recently replaced casework in laboratory space on the second floor of Building 4508. 


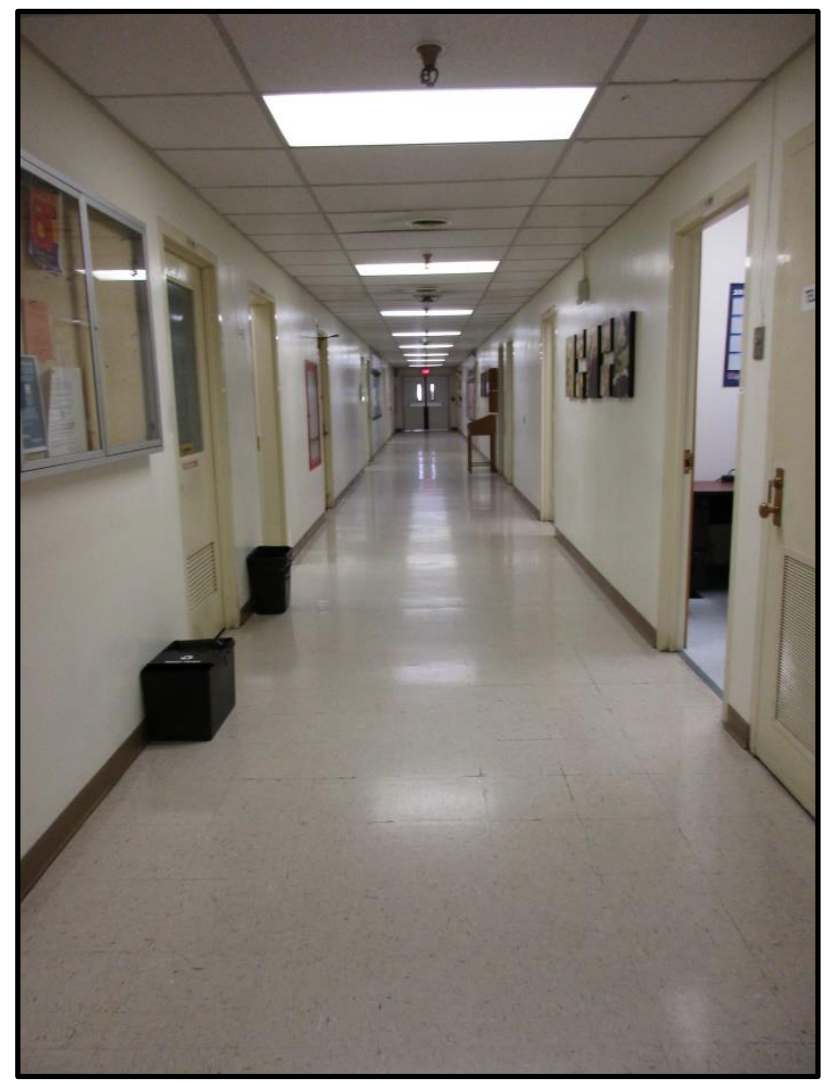

Figure 299. Corridor on the first floor of Building 4508.

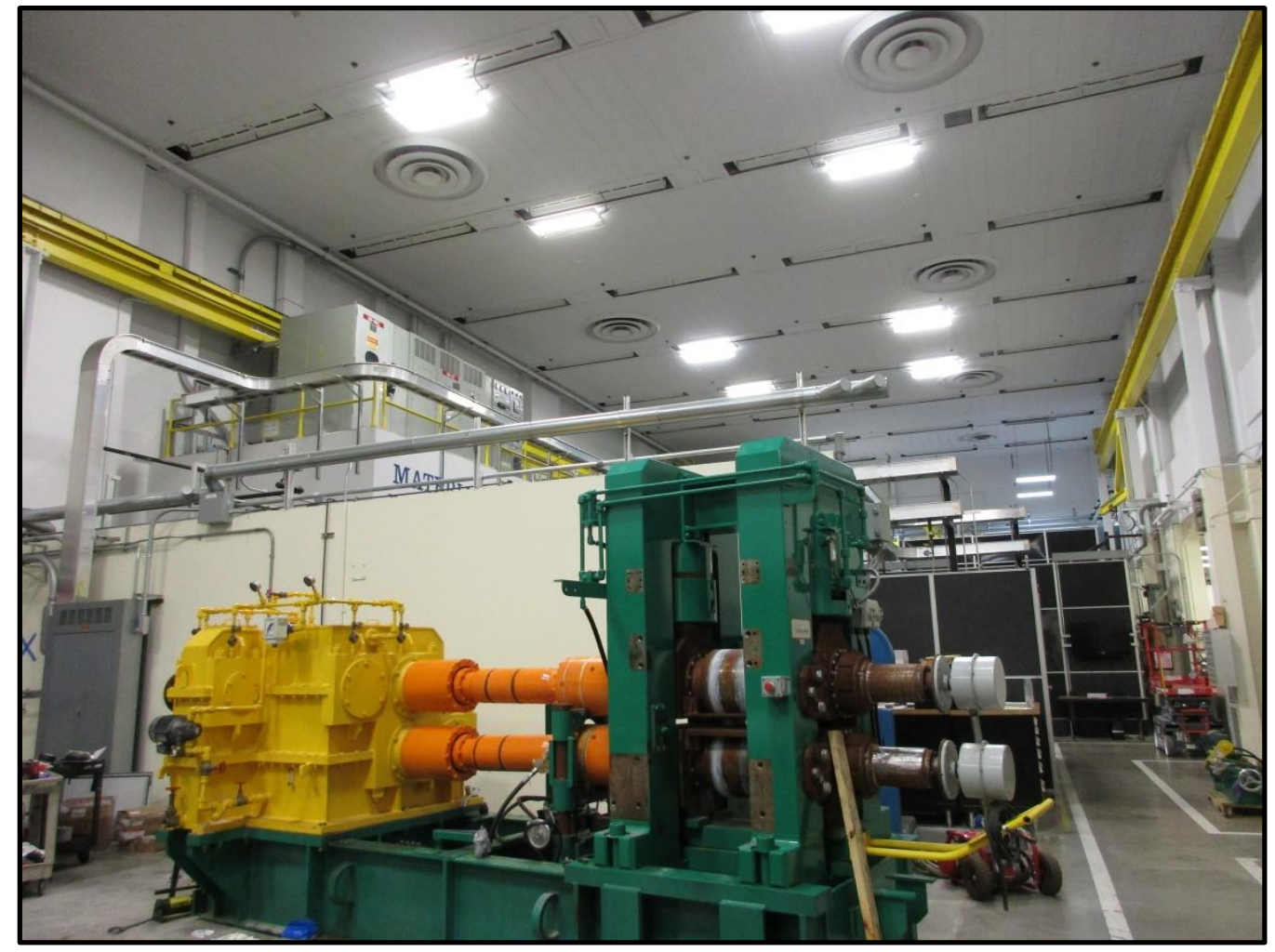

Figure 300. High bay area of Building 4508. 


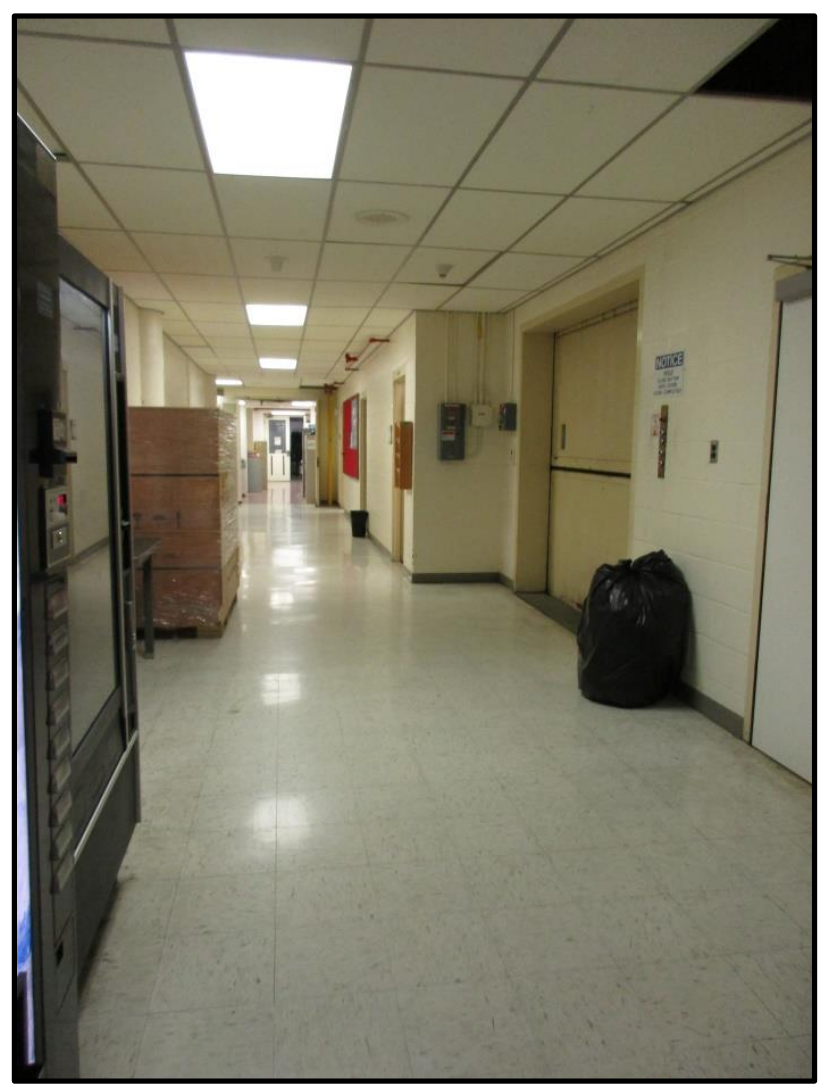

Figure 301. Corridor and freight elevator on second floor of Building 4508.

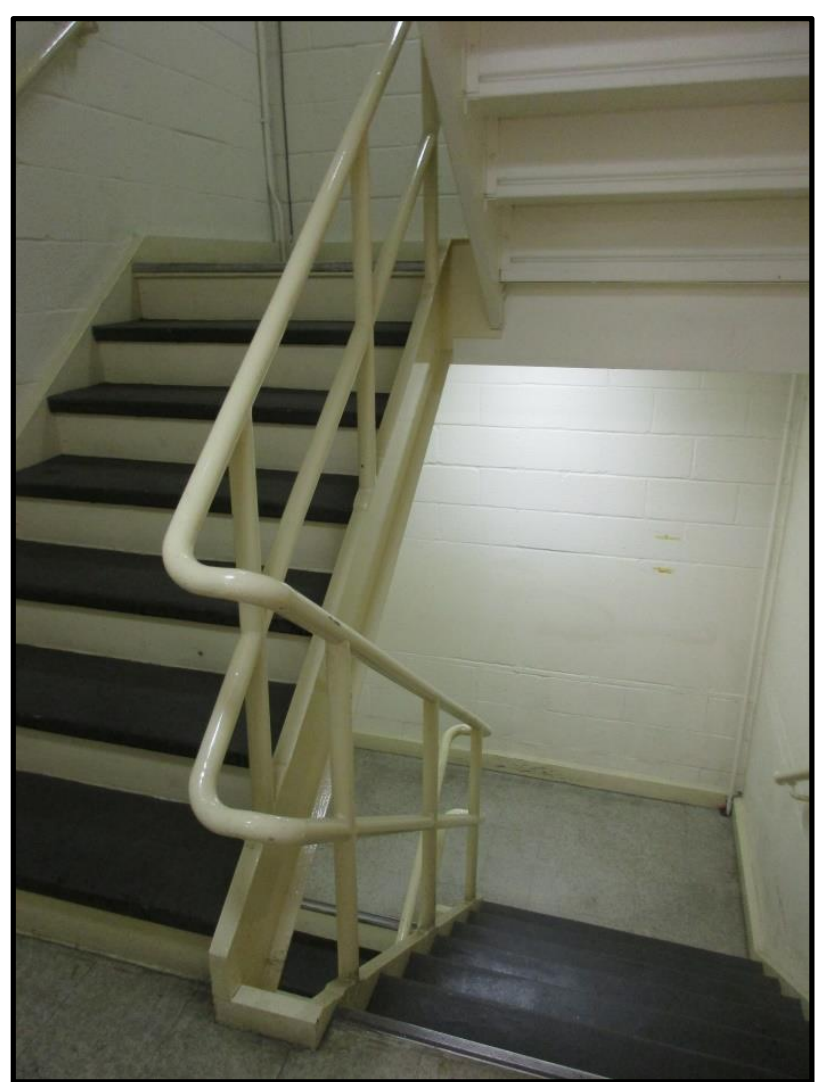

Figure 302. Stairwell in Building 4508. 


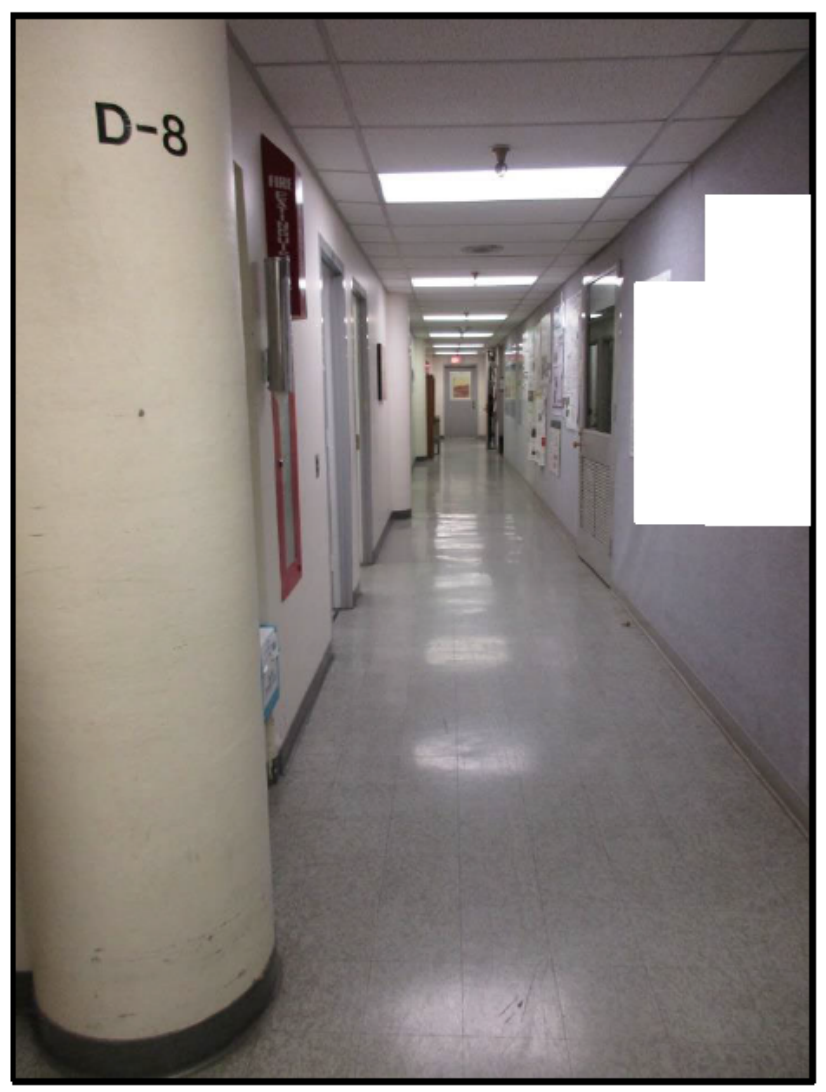

Figure 303. Interior corridor on second floor of Building 4508.

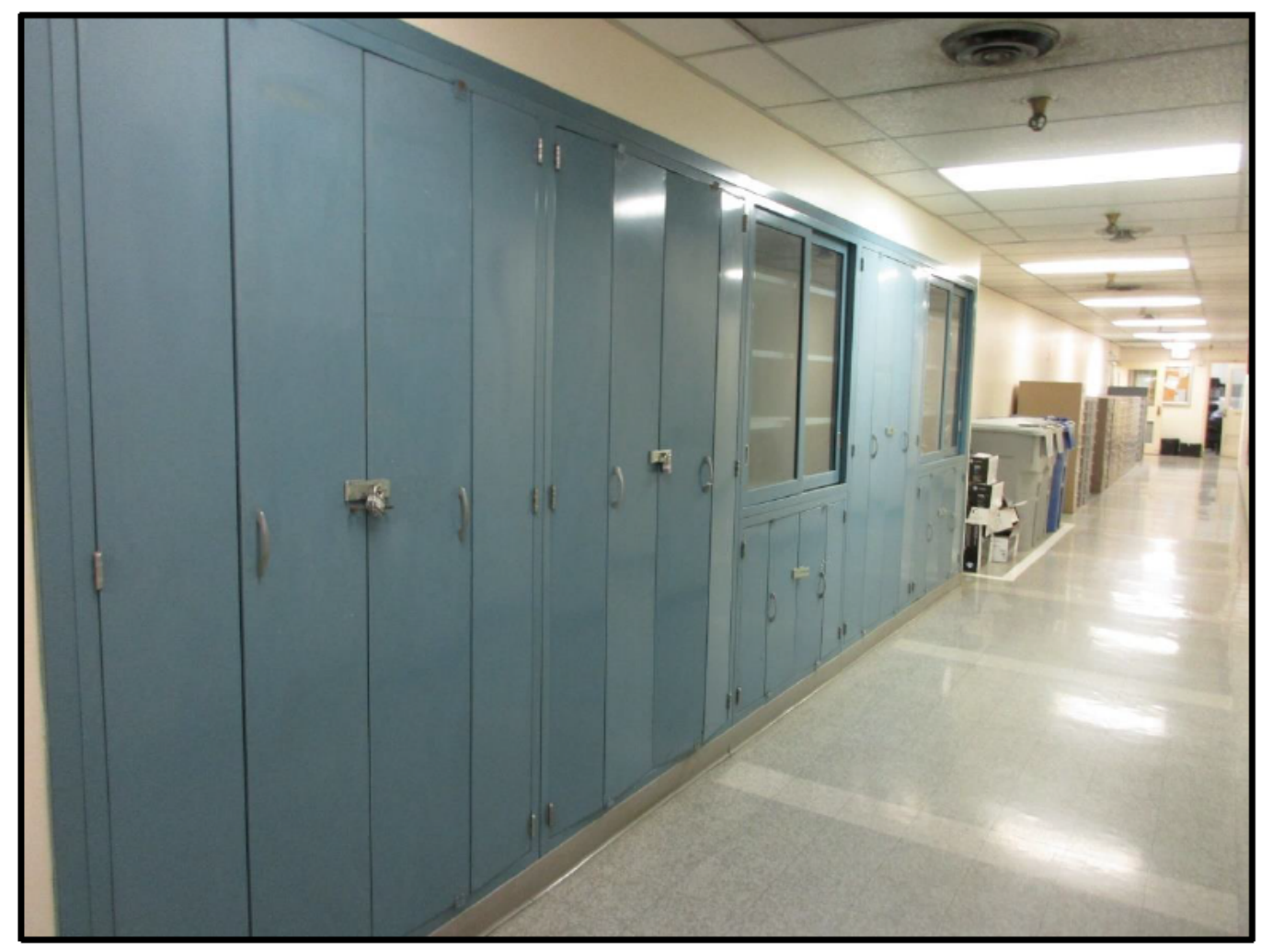

Figure 304. Original built-in casework on the second floor of Building 4508 . 


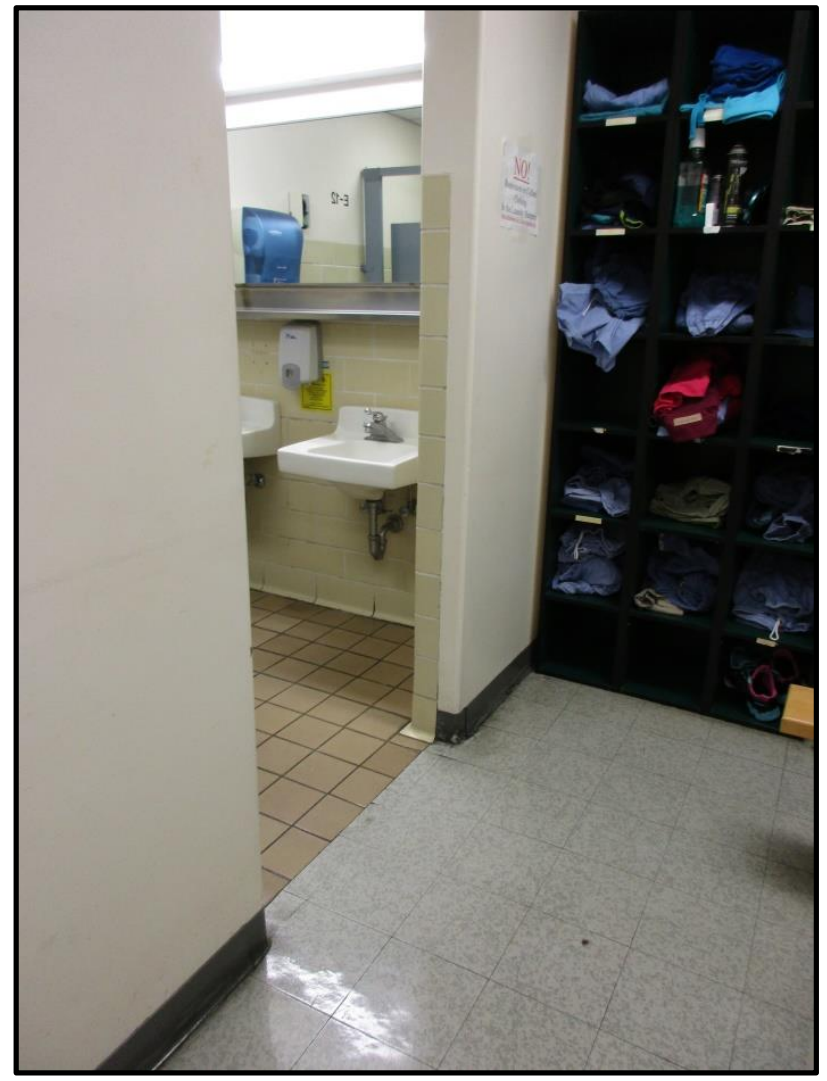

Figure 305. Men's restroom on second floor of Building 4508.

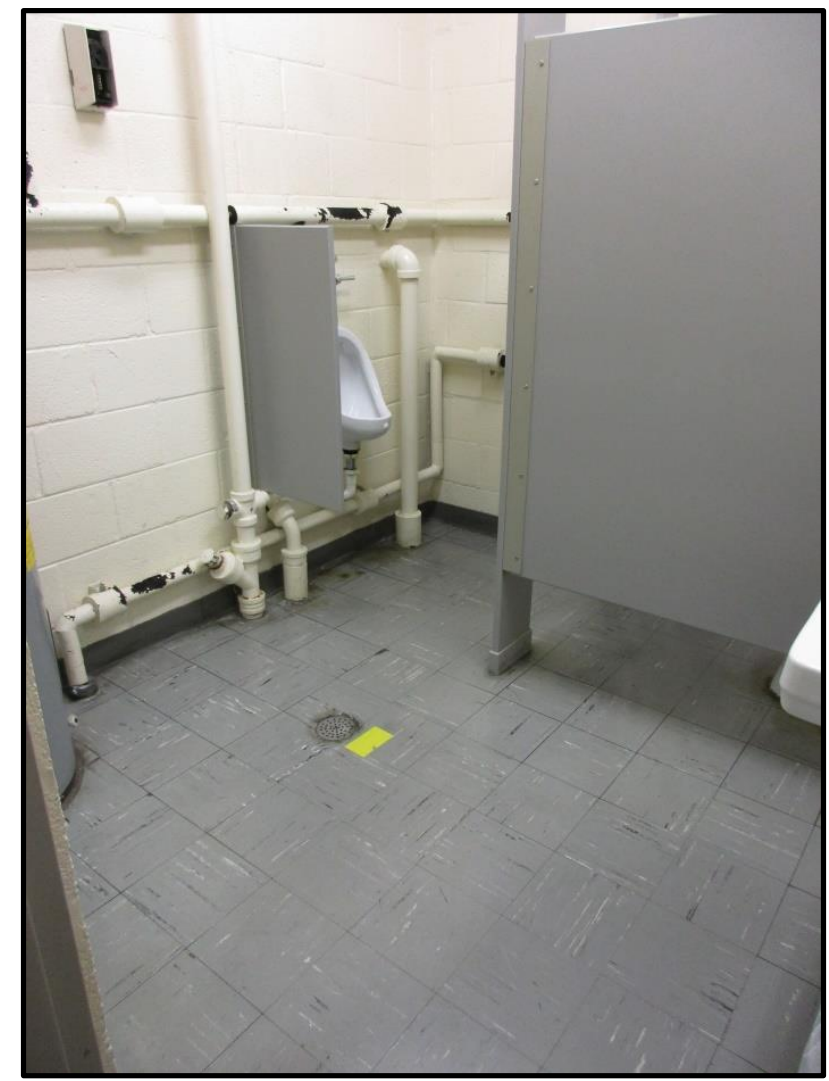

Figure 306. Women's restroom on second floor of Building 4508. 


\section{9-VB1}

\section{BUILDING NAME}

4509 White Oak Creek Vehicle Bridge

DATE OF CONSTRUCTION

1962

DOE OFFICE RESPONSIBLE

SC

NRHP ELIGIBILITY

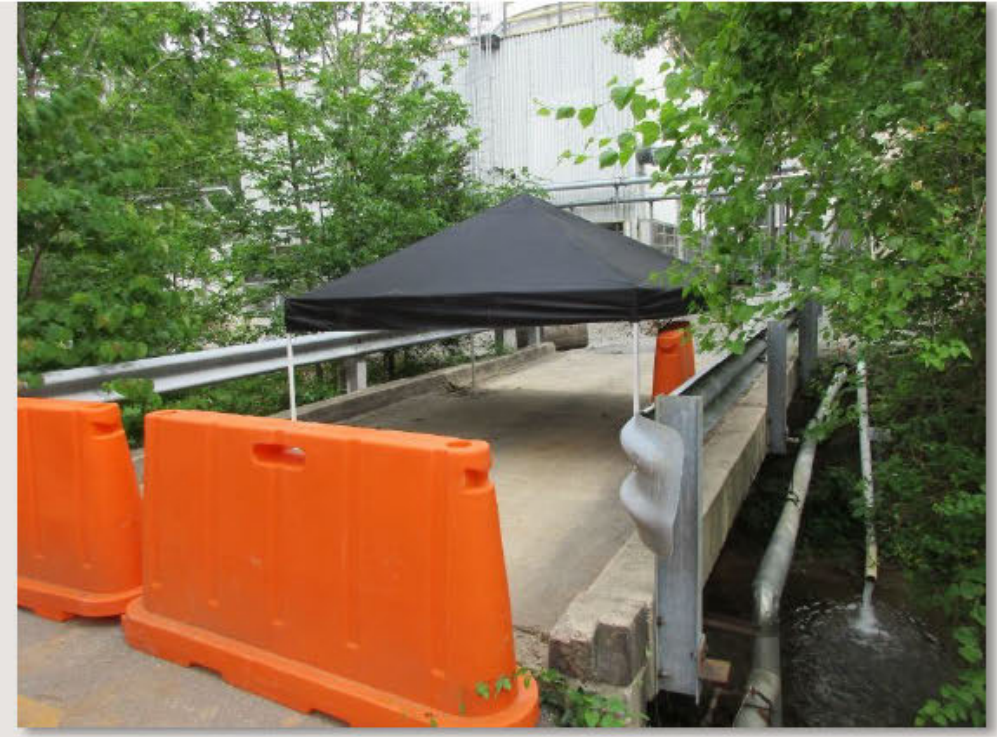

Figure 307. Overview of Building 4509-VB1, a vehicular bridge, looking from Southside Avenue to the south.

Not Eligible

\section{DESCRIPTION}

Building 4509-VB1 is a vehicular bridge that crosses White Oak Creek near Building 4509 and Building $4500 S$. The bridge, located south of Southside Avenue, was closed temporarily for repairs at the time of the survey efforts. The single-span structure is composed of concrete abutments and steel beams (Figures 307 and 308). A concrete surface makes up the roadway. Metal guardrails extend along the edges of the bridge's deck.

\section{NATIONAL REGISTER EVALUATION}

Building 4509-VBI was constructed in 1962 as a vehicular bridge. The bridge connects a small section of 4000 Area buildings to the larger 4000 Area. The vehicular bridge, Building 4509-VB1 has not been previously recorded or surveyed. As a vehicular bridge, the structure is not associated with any specific events or people at ORNL to merit listing under Criterion A or B. Nor does Building 4509-VB1 qualify for listing under Criterion C since it does not represent a distinctive form, type, or method of construction. Additionally, it is located outside of the recommended boundaries of the NRHP-eligible ORNL Historic District, thus it is not a contributing element of the district. Thus, CRA recommends the vehicular bridge Building 4509-VB1 not eligible for listing under Criterion $\mathrm{A}, \mathrm{B}$, or $\mathrm{C}$. 


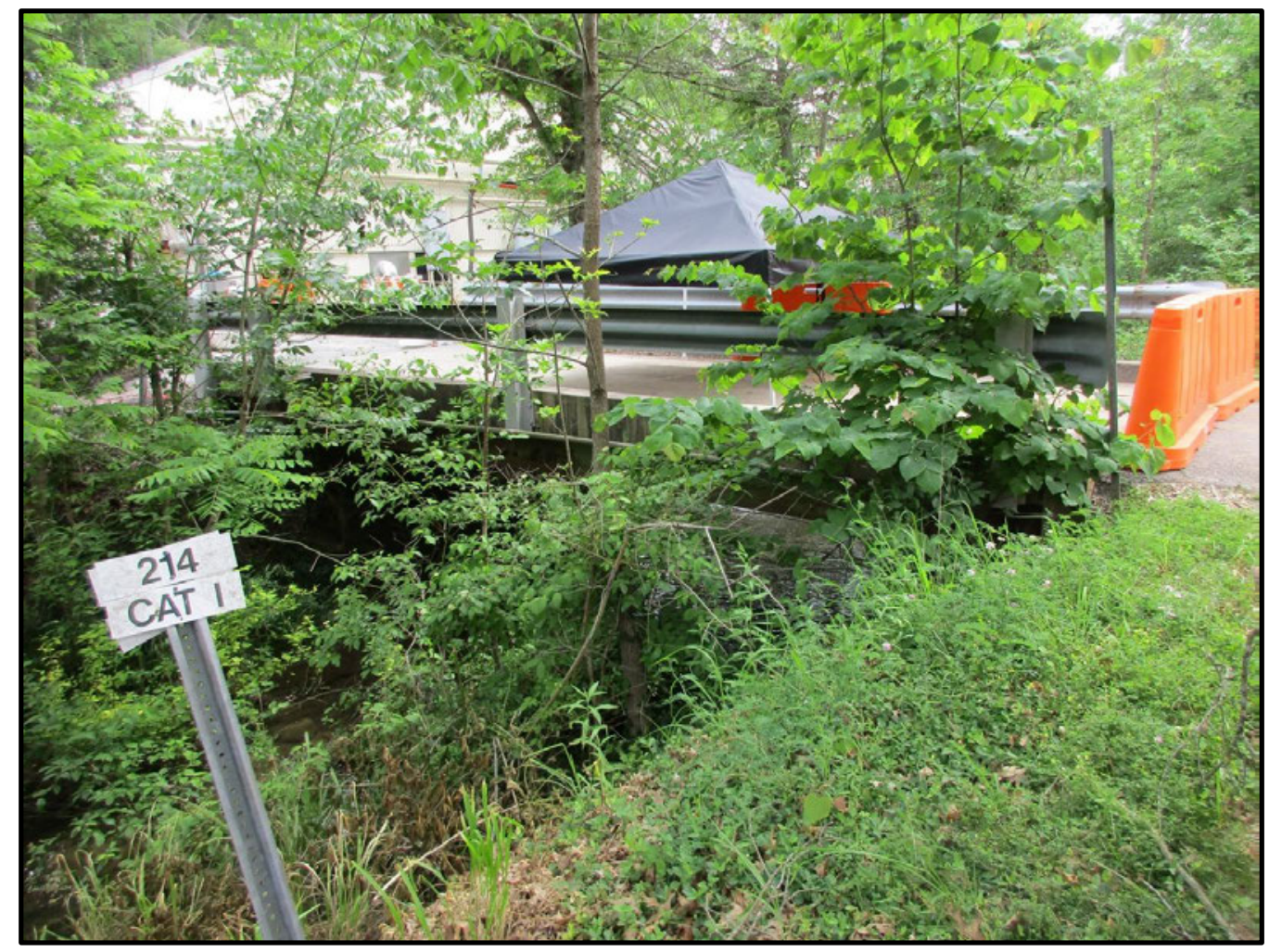

Figure 308. Looking east, a view of the west elevation of vehicular bridge, Building 4509-VB1. 
This page intentionally left blank 


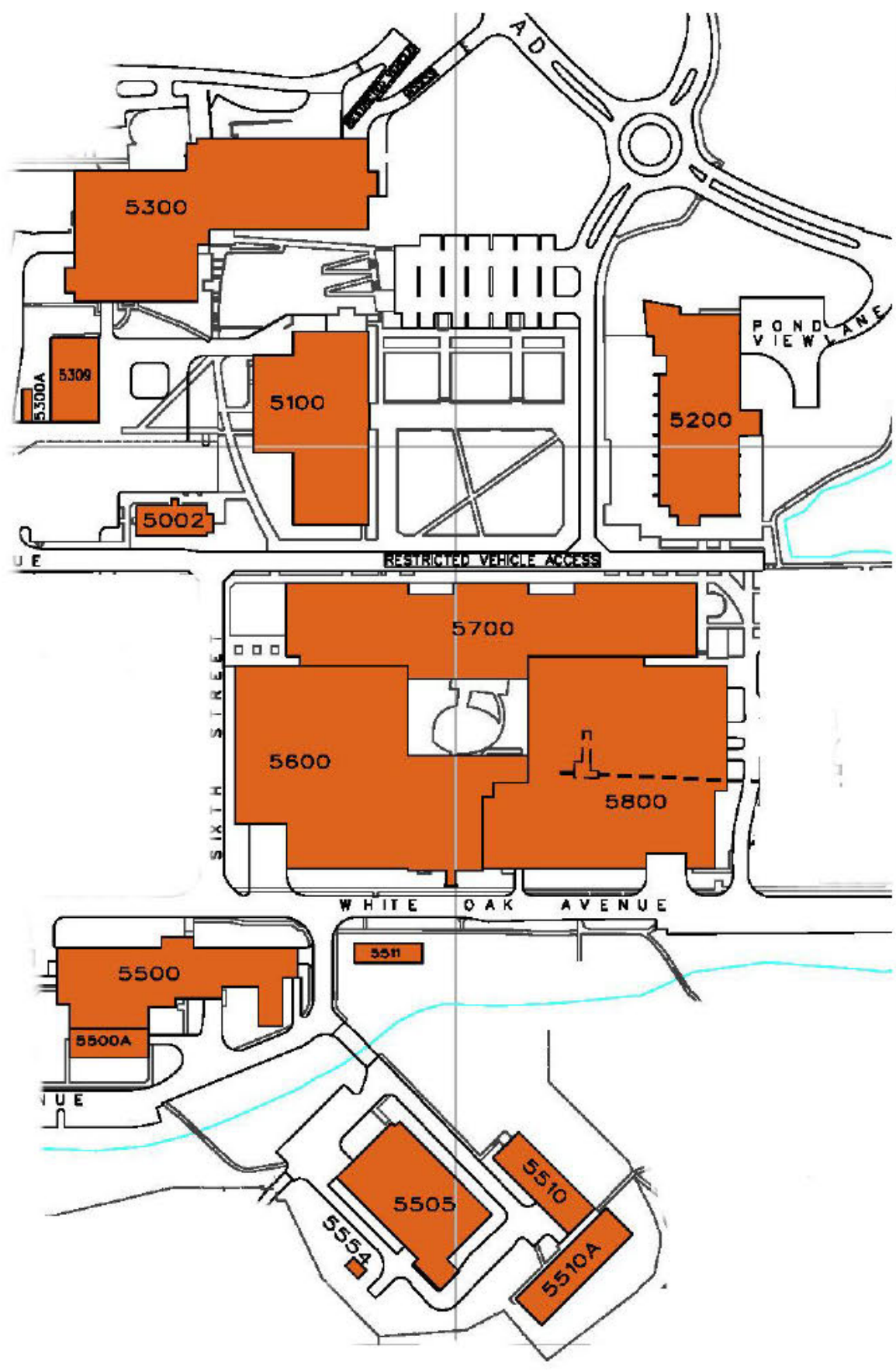

\section{AREA}

CONTRIBUTING TO ORNL HISTORIC DISTRICT

Building 5500

Building 5500A

NOT ELIGIBLE

Building 5505

Building 5505-VB1

Building 5507

Figure 309. Plan View of 5000 Area. 
This page intentionally left blank 


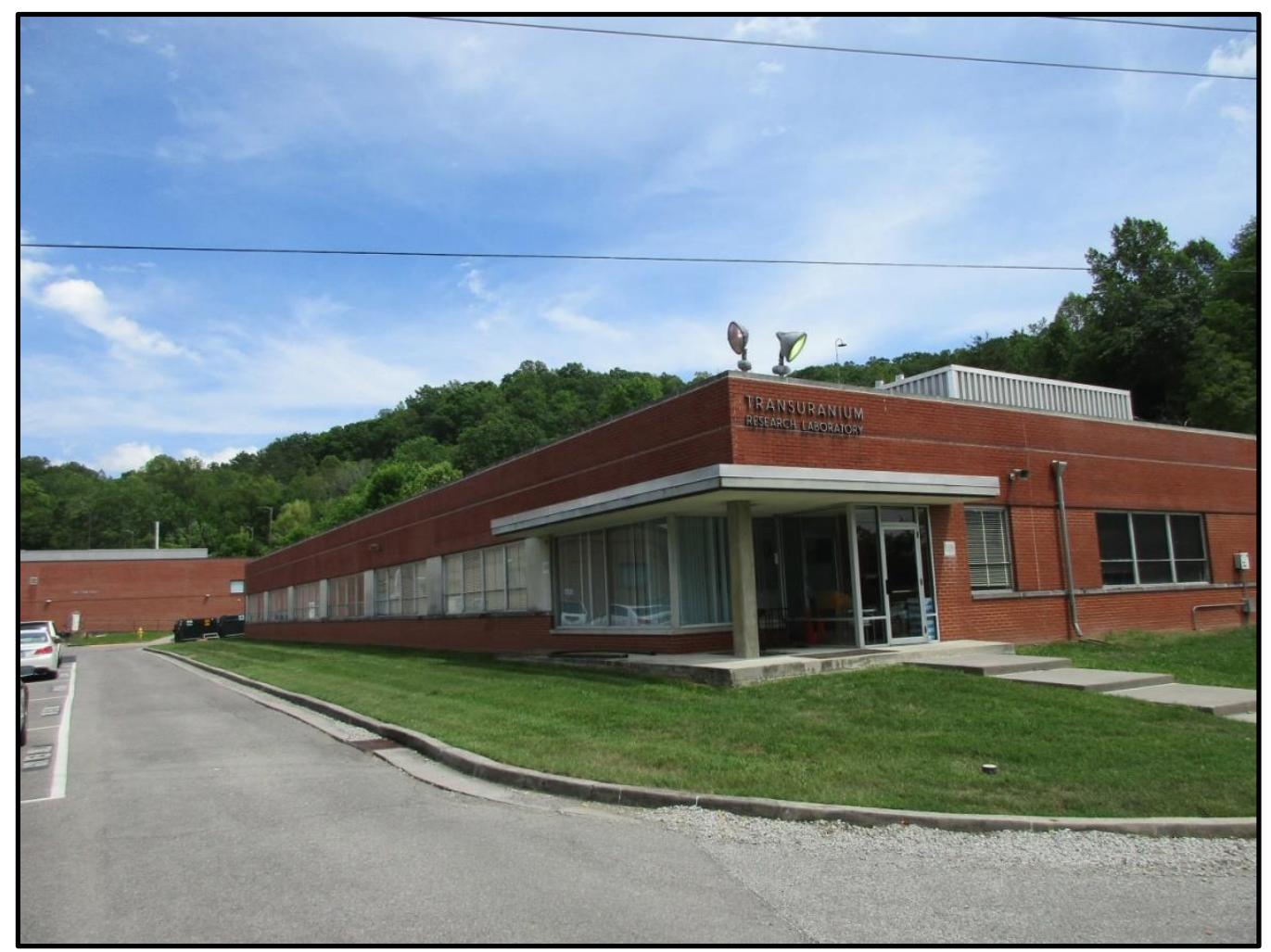

Figure 311. View of the 5000 Area looking towards Buildings 5505 and $5510 \mathrm{~A}$ from near the entrance of 5505-VB1. 


\section{$5500 / 5500 A$}

\section{BUILDING NAME}

High Voltage Acceleratory Laboratory

\section{DATE OF CONSTRUCTION}

1952

\section{DOE OFFICE RESPONSIBLE}

SC

\section{NRHP ELIGIBILITY}

Figure 312. Façade (north) elevation of Building 5500.

Contributing to ORNL Historic District

\section{DESCRIPTION}

Building 5500/5500A was one of 15 resources selected for intensive survey by UT-B as a part of survey planning. Building 5500 is located on the east side of the main campus of ORNL, near the intersection of White Oak Avenue and Southside Avenue. It is comprised of four sections: the circa 1952 west end, the circa 1962 east end, a circa 1976 rear addition, and a circa 1978 annex, identified as Building 5500A.

Exterior: Building 5500 features two stories and an irregular plan comprised of rectangular sections and a tall high-bay area that extends above the roof of the original section of the building. The circa 1952 and 1962 sections of Building 5500 feature a variant of common bond with six courses of stretchers followed by a course of alternating headers and stretchers, similar to Flemish bond. Set upon a continuous poured concrete foundation, the building features a flat roof with concrete coping.

The façade, or north elevation, of Building 5500 , is comprised of the length of the original circa 1952 and circa 1962 sections of Building 5500 (Figure 312). The façade entry is located on the circa 1962 section, immediately adjacent to the circa 1952 section of the building. The façade entry features a double-leaf entry with full-light steel and glass doors that open to a glass-enclosed portion of a concrete and brick entry porch (Figure 313). Sheltered by a flat concrete roof with metal coping supported by square concrete posts, the porch features structural steel railing. A series of nine stacked brick veneer pilasters bordered by a band of concrete extends from the foundation to the roof behind the façade entry. The circa 1952 section of the building features bands of original, three-light aluminum windows with a two-light awning window over a stationary light surrounded by bands of cast concrete (Figures 314 and 315). The circa 1962 section of the building is devoid of windows on all elevations. The west elevation the two-story Building 5500 features a secondary entry on the first floor with a single-light steel replacement door sheltered by a flat, metal roof supported by thin, metal posts. The entirety of the high-bay and the circa 1976 rear addition to Building 5500 are clad in corrugated metal panels (Figure 316). The west elevation of Building 5500A features a single-leaf recessed entry (Figure 317). The south, or rear elevation, of Building 5500A features banks of single-light stationary windows (Figure 318). A single band of three-light metal awning windows extends along the south elevation of the high-bay of Building 5500 . A singleleaf entry with a single-light steel door opens to a structural steel staircase that extends to the roof of the circa 1976 metal-clad addition (Figure 319). Building 5500A features recessed entries on both the first and second 
floors of the east elevation. A series of several small one- and two-story metal-clad additions extend from the rear, or south, elevation of the circa 1962 section of Building 5500 (Figure 320). A concrete loading dock, sheltered by a flat metal roof, extends from the eastern end of the circa 1962 section of the building (Figure 321). The east elevation, or end, elevation of this section features only a single garage bay with an overhead segmented garage door.

Interior: The interior of Building 5500 is characterized by long corridors that provide access to a series of laboratories, office space, and high bay research areas. Corridors on the first floor of the circa 1952 section of the building feature original interlocking metal panel walls, original doors, and sections of original and replacement commercial-grade tile (Figure 322). The majority of interior doors in both the circa 1952 and 1962 sections of the building retain original doors (Figure 323). Laboratories on the first floor feature original casework, replacement flooring, and interlocking drop ceilings (Figure 324). The first floor of the building provides access to the high-bay area in the circa 1976 addition (Figure 325). Corridors on the first floor of the circa 1962 section feature replacement commercial grade tile, concrete block walls, original single-light doors, and a modern replacement drop ceiling (Figure 326).

A freight elevator and stairwells with glazed concrete block and original steel handrails provide access to the second floor of Building 5500. The second floor of the circa 1962 section of Building 5500 features corridors with original floor tile, concrete block walls, and a drop ceiling (Figure 327). Corridors in the circa 1952 section feature replacement tile and original single-light steel doors that provide access to laboratory space (Figure 328). The laboratories provide varying degrees of renovation with replacement casework, flooring, and drop ceilings. Restrooms in the circa 1952 section feature glazed concrete block walls, replacement floor tiles, and original dividers and fixtures (Figure 329).

The freight elevator and stairs also provide access to the third floor of the circa 1952 section of Building 5500 that features a large high bay research area (Figure 330) and the basement of the circa 1952, circa 1962, and circa 1976 sections of Building 5500. The circa 1952 and 1962 sections of the basement feature corridors that provide access to additional offices and laboratories. These corridors feature many original doors, including a thick door to the eastern end of the circa 1962 section (Figures 331 and 332).

\section{NATIONAL REGISTER EVALUATION}

Following the End of World War II, ORNL sought to establish an expanded accelerator program. The U.S. Air Force agreed to purchase a 5-MW Van de Graaff Accelerator, on the condition that ORNL would construct a building to house the equipment. Originally installed at $\mathrm{Y}-12$, the accelerator was acquired by the Metal and Ceramics Division and moved to the High Voltage Accelerator Laboratory, Building 5500, upon its completion in 1952 at a cost of $\$ 1,044,000$. Expansions to the building in 1962 housed an additional Van De Graaff accelerator and offices (Carver and Slater 1994:110; Thomason and Associates 2015:148). The High Voltage Accelerator Laboratory Wing, Building 5500A, was added to the complex in 1976 (Carver and Slater 1994:267; Thomason and Associates 2015).

A second .04-MV Van de Graaff accelerator was added Building 5500 in the mid- to late-1970s. This allowed the researchers of the Metals and Ceramics Division to complete dual-ion irradiations in which the smaller machine would inject helium and the larger machine was used for metallic self-ions of the specimen material. This capability helped scientists at ORNL to better understand neutron radiation effects in both fission and fusion reactor materials. A third, a 2.5-MW Van de Graaff, accelerator was added in the 1980s to allow triple-ion 
irradiations. This configuration of three accelerators, called the Triple Ion Irradiation Facility, allowed the capability to study fusion reactor insulator materials and complete ion beam treatment research (Craig 1997:118). The accelerators in Building 5500 were formally shutdown on August 22, 2016. The building currently houses offices and laboratories involved with high energy physics, which is the study of subatomic particles smaller than neutron, electrons, and protons (Carver and Slater 1994: 267; Thomason and Associates 2015).

In 1994, Duvall \& Associates' survey of ORNL recommended that Building 5500 was eligible for listing in the NRHP, as a contributing resource to the NRHP-eligible ORNL Historic District (Carver and Slater 1994). Thomason and Associates also recommended that Building 5500 was eligible for inclusion in the NRHP under Criterion A for its historical association with ORNL's evolution as a national laboratory, the post-World War II government-sponsored scientific movement, and early nuclear research, as a contributing resource to the ORNL Historic District in both 2004 and 2015 assessments. Thomason and Associates also recommended that Building 5500A was eligible as a contributing element to the ORNL Historic District in 2015 (Thomason and Associates 2004; 2015).

As the building that housed ORNL's first accelerator, Building 5500 is categorized as a processing facility. However, the accelerators contained in Building 5500 were standard purchased models, where as many of ORNL's other processing facilities contained one-of-a-kind or custom-built reactors and accelerators. Buildings 5500 and $5500 \mathrm{~A}$ also contained laboratory and office space, and their significance is more comparable to that of other such facilities at ORNL. Buildings 5500 and 5500A were associated with important scientific research at ORNL in the Cold War era, but they are not the individual buildings most directly associated with any specific accomplishment or person that rises to the level of significance for individual listing in the NRHP under Criterion A or B. Additionally, the buildings' architectural design is typical of laboratories constructed in the 1950s and 1960s and does not exhibit architectural significance for listing in the NRHP under Criterion C. As such, CRA recommends that Buildings 5500 and $5500 \mathrm{~A}$ are not eligible for individual listing under Criterion $\mathrm{A}$, B, or $\mathrm{C}$. Rather, the significance of the buildings is reflected in their contributing role within the larger context of Cold War-era development and research at ORNL and as part of a collection of purpose-designed scientific processing and research facilities engineered to meet the specific needs of the advanced research occurring within their walls. Thus, despite minor alterations to the interior, including the reorganization and renovation of office and laboratory spaces, Building 5500 retains integrity to support its inclusion as a contributing resource to the ORNL Historic District, within the recommended boundary extension. Building 5500A, however, was constructed in 1976, after the period of significance of the ORNL Historic District, which begins in 1943 and ends in 1965. Therefore, CRA recommends that Building 5500 is a contributing resource to the ORNL Historic District under Criterion A for its association with the post-World War II development of government-sponsored scientific laboratories, ORNL's evolution as a national laboratory, and early nuclear development and under Criterion $\mathrm{C}$ as a purpose-designed scientific research facility within the district; Building $5500 \mathrm{~A}$ is a noncontributing resource to the ORNL Historic District, as it was constructed after the period of significance of the district. 


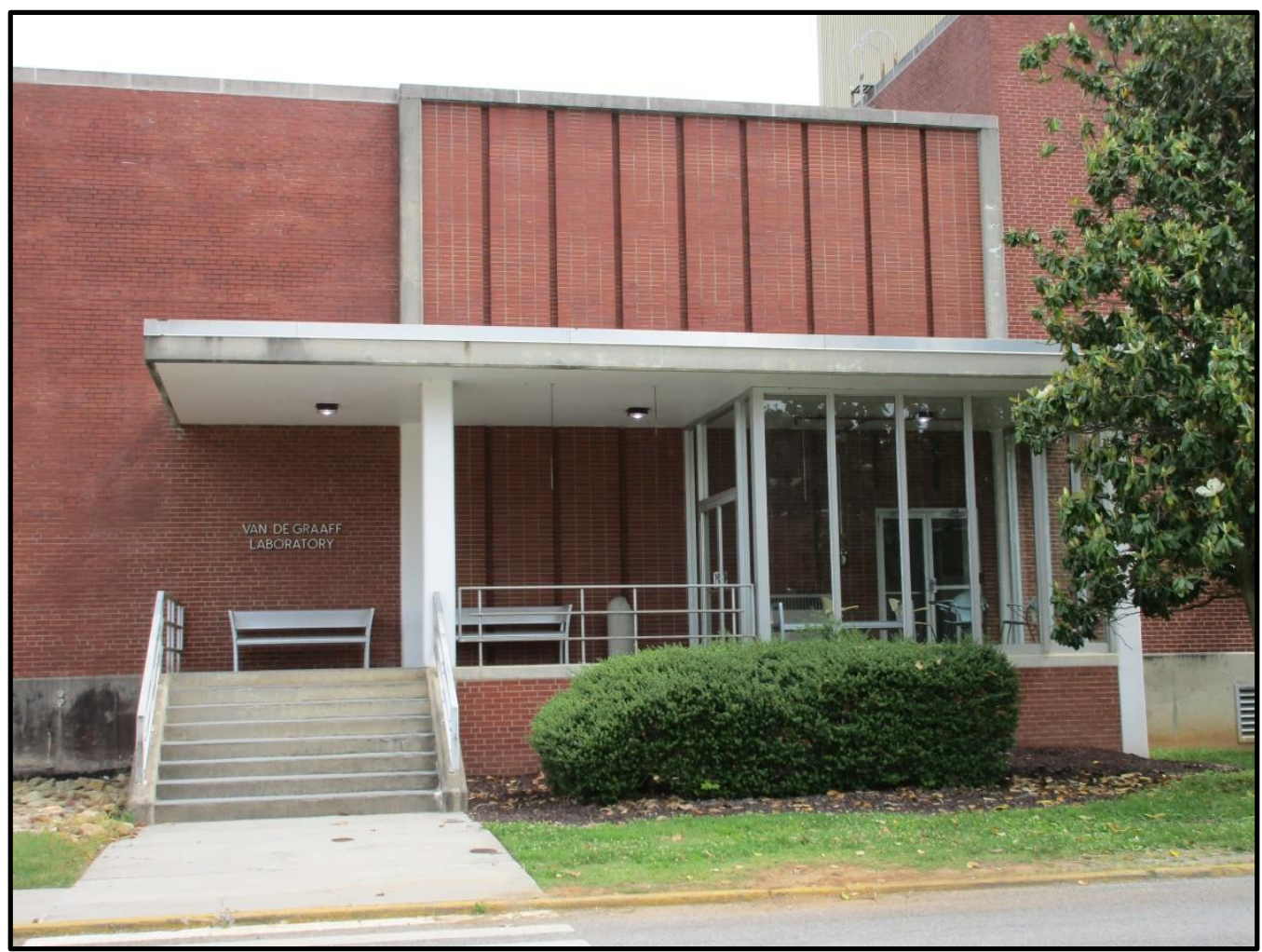

Figure 313. Façade entry on north elevation of Building 5500.

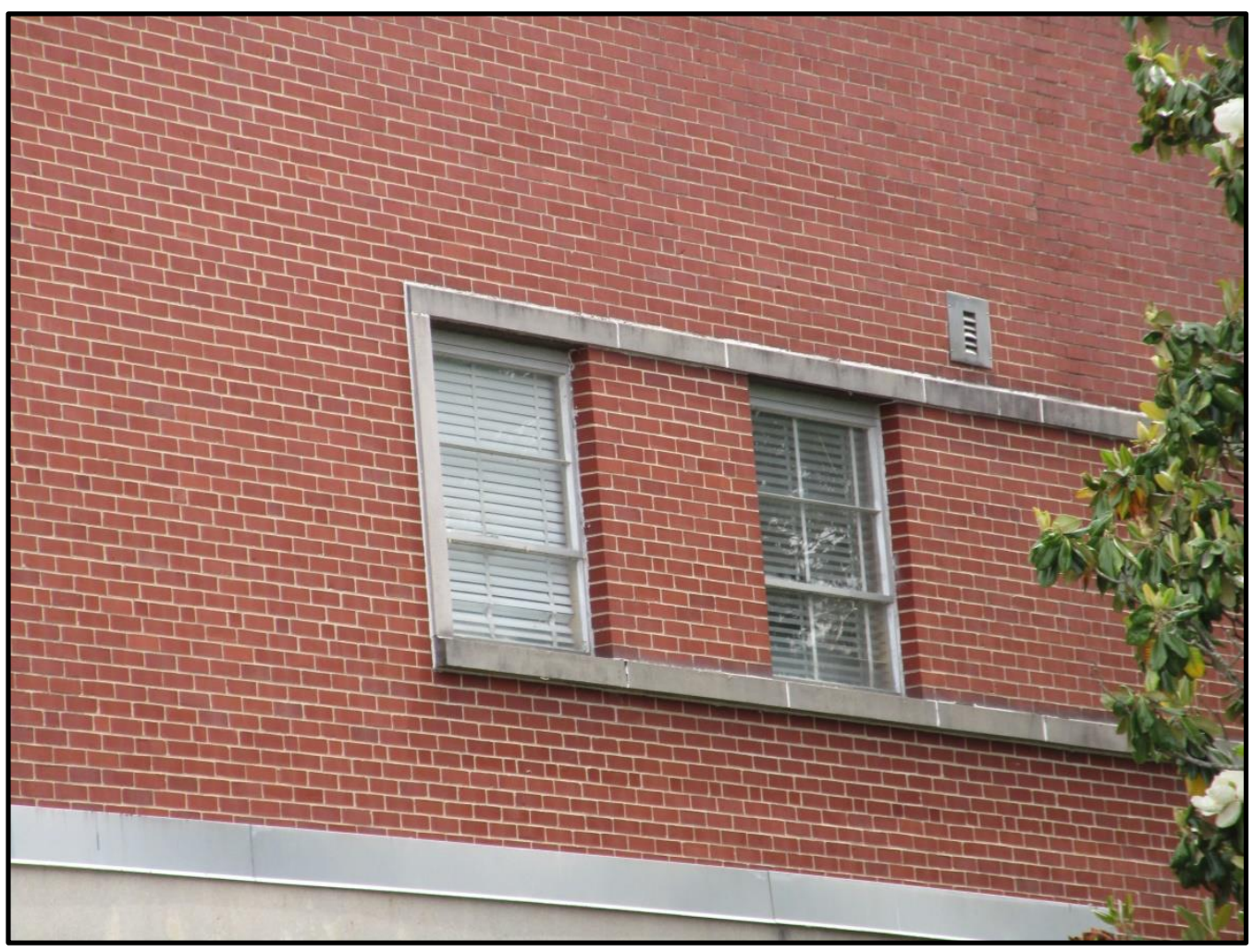

Figure 314. Window detail on north, façade, elevation of Building 5500. 


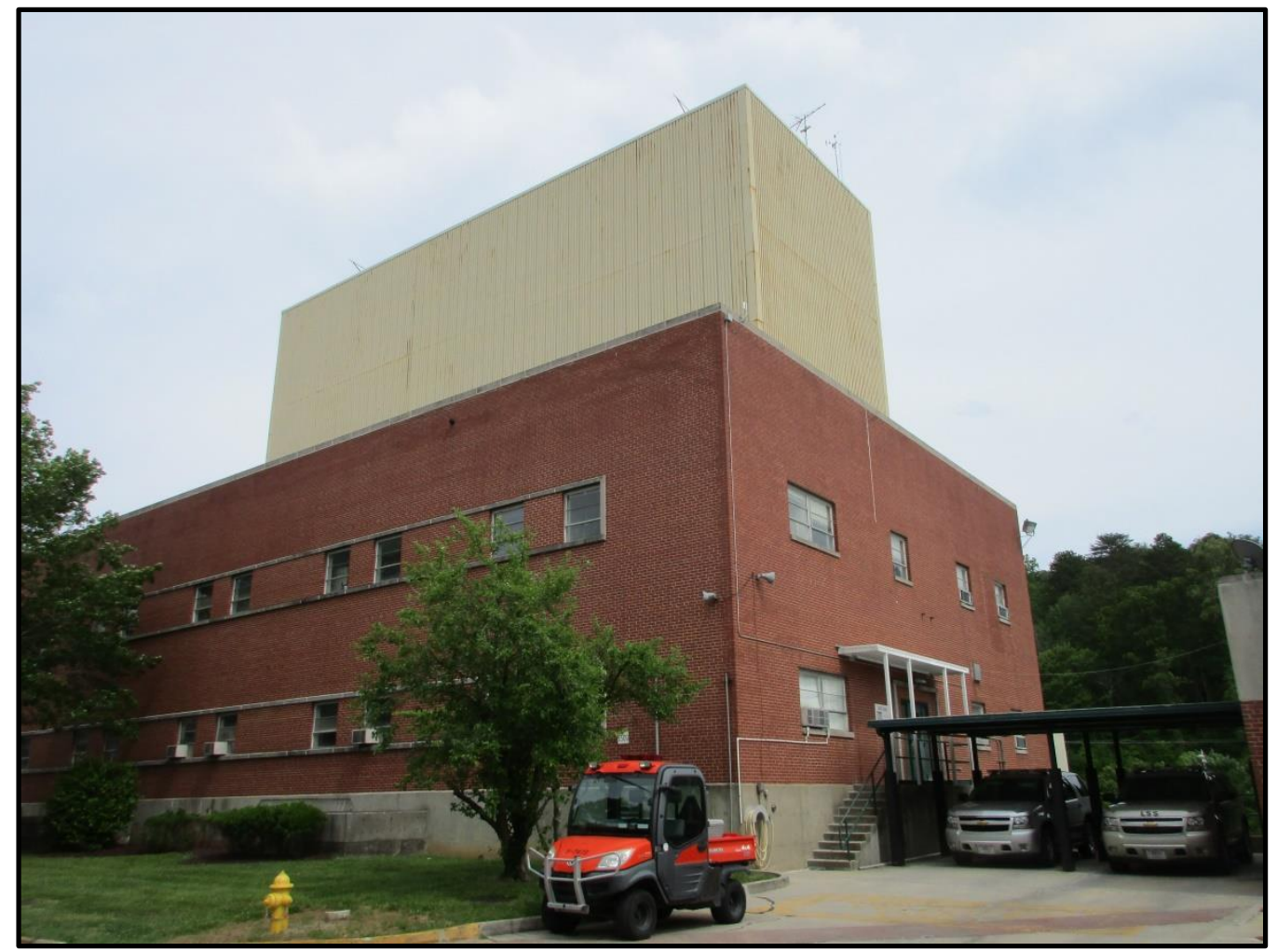

Figure 315. Façade (north) and west elevations of Building 5500.

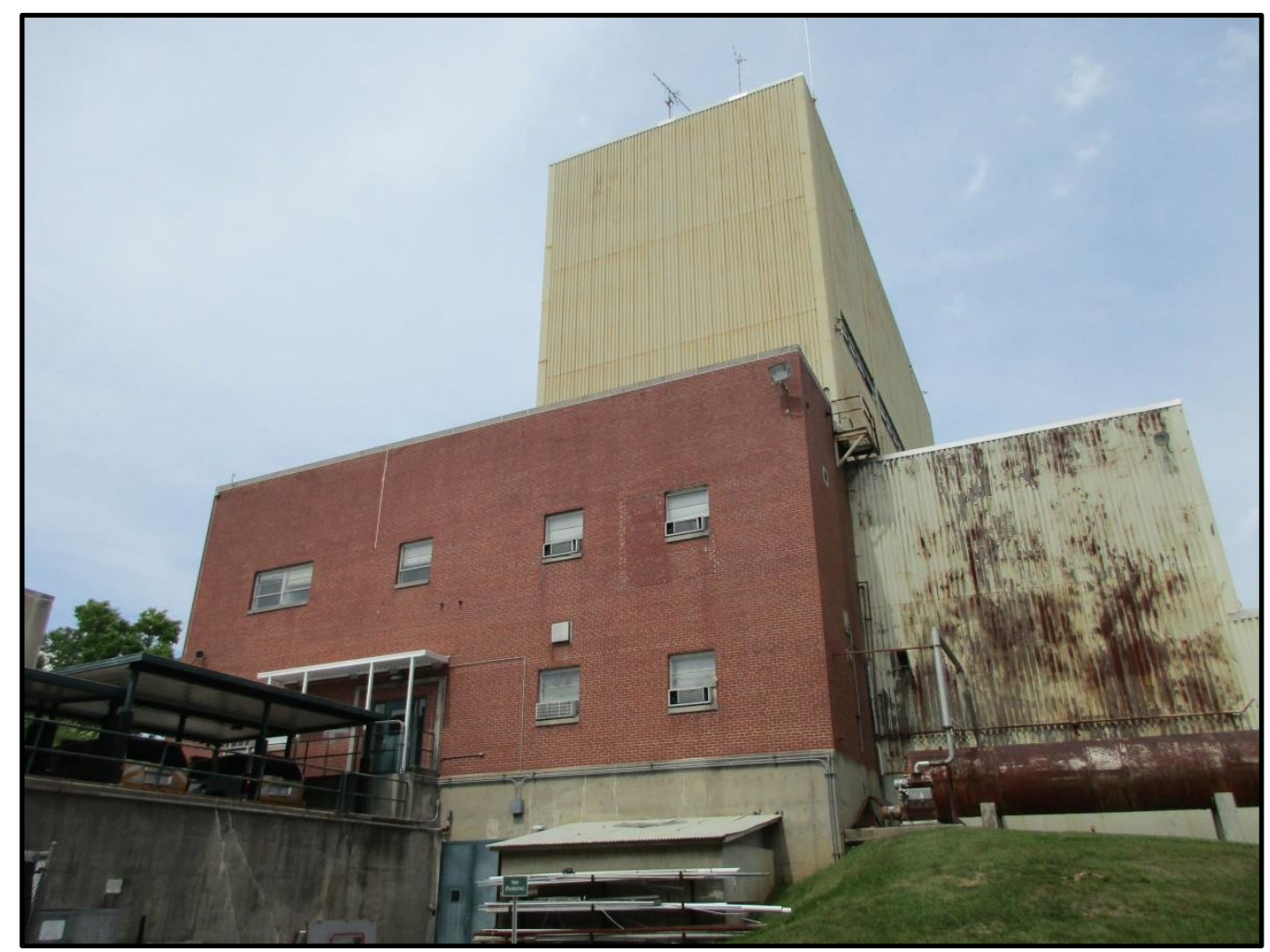

Figure 316. West elevation of Building 5500. 


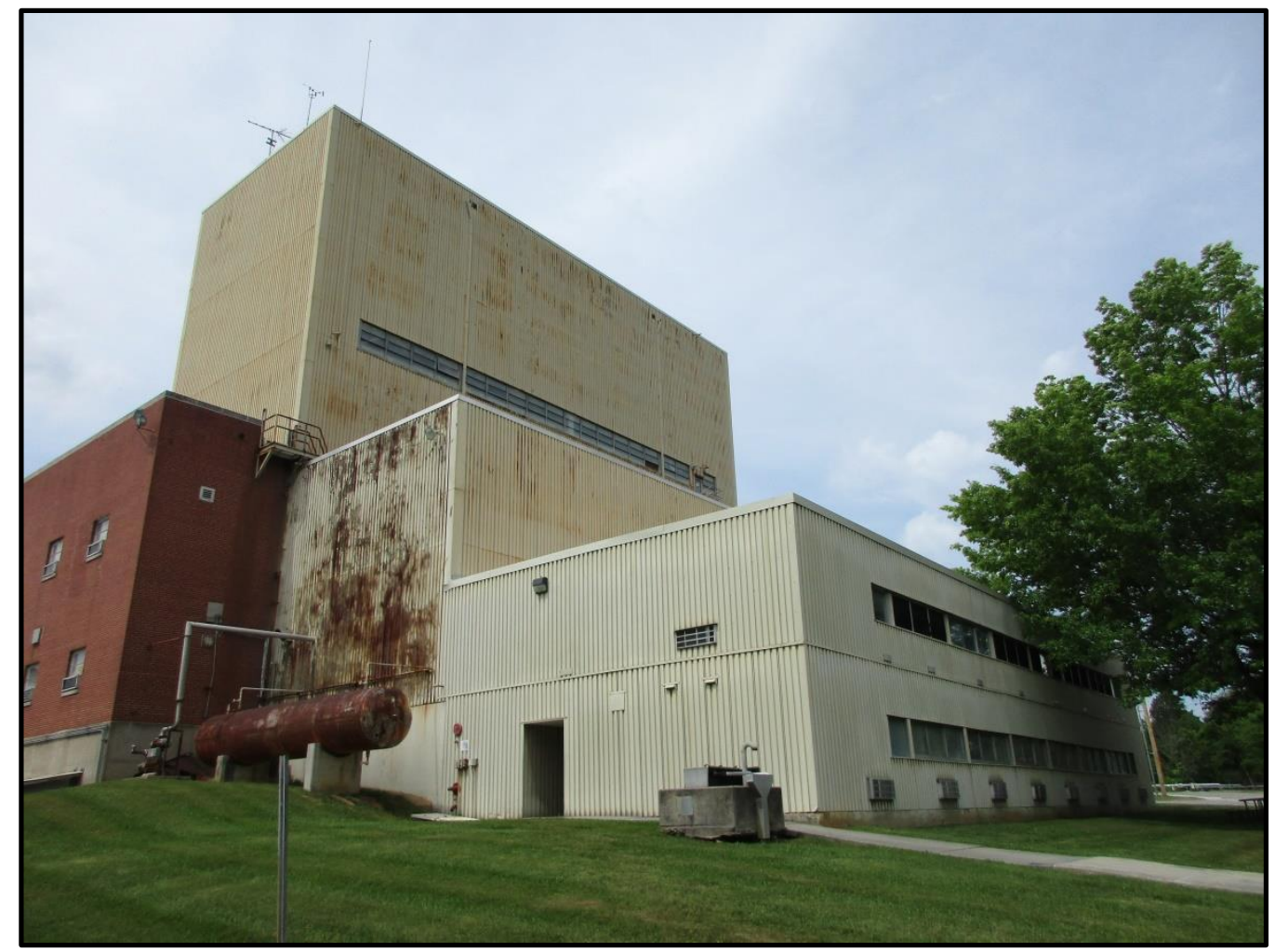

Figure 317. West and south elevations of Buildings 5500 and $5500 \mathrm{~A}$.

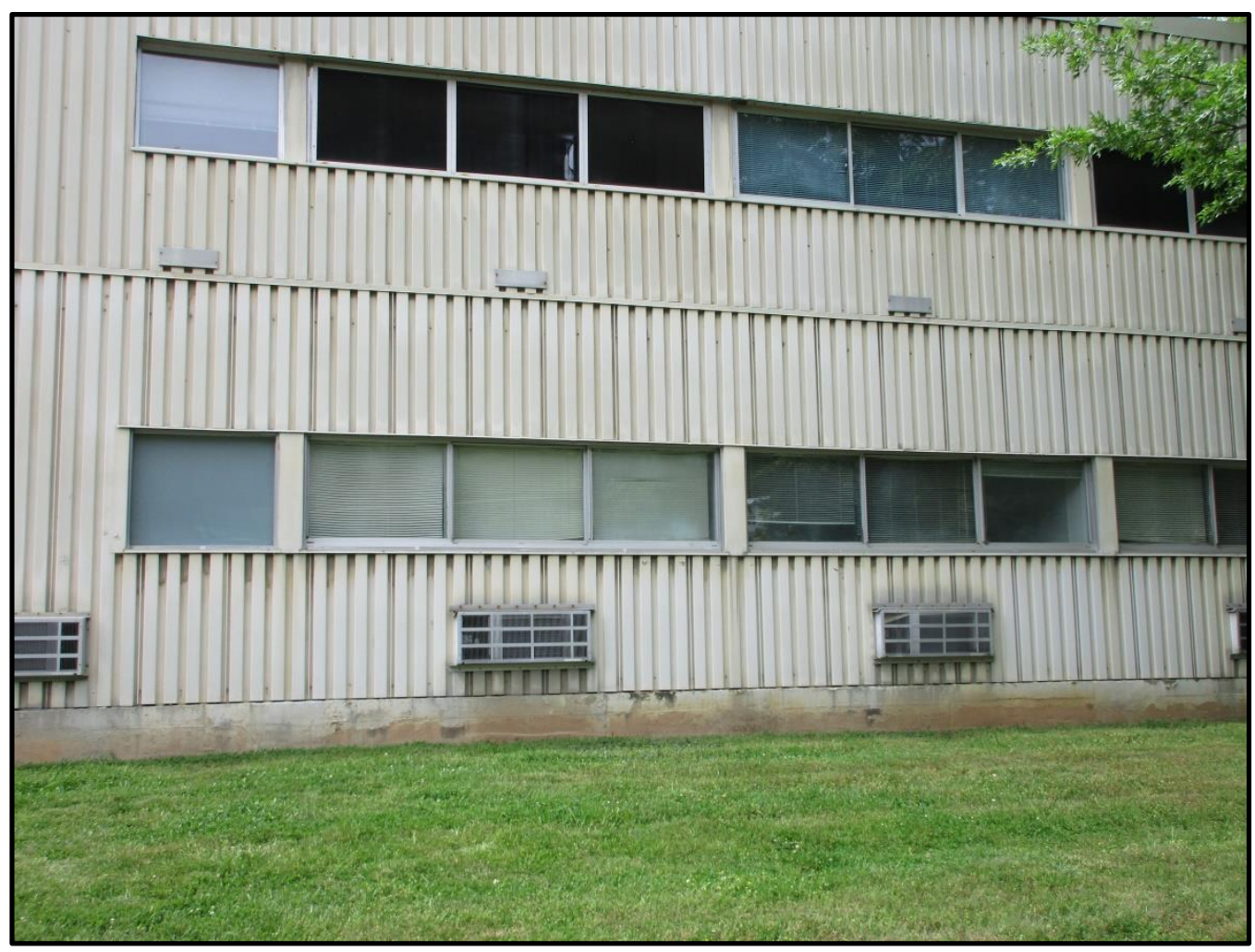

Figure 318. Window detail on south elevation of Building 5500A. 


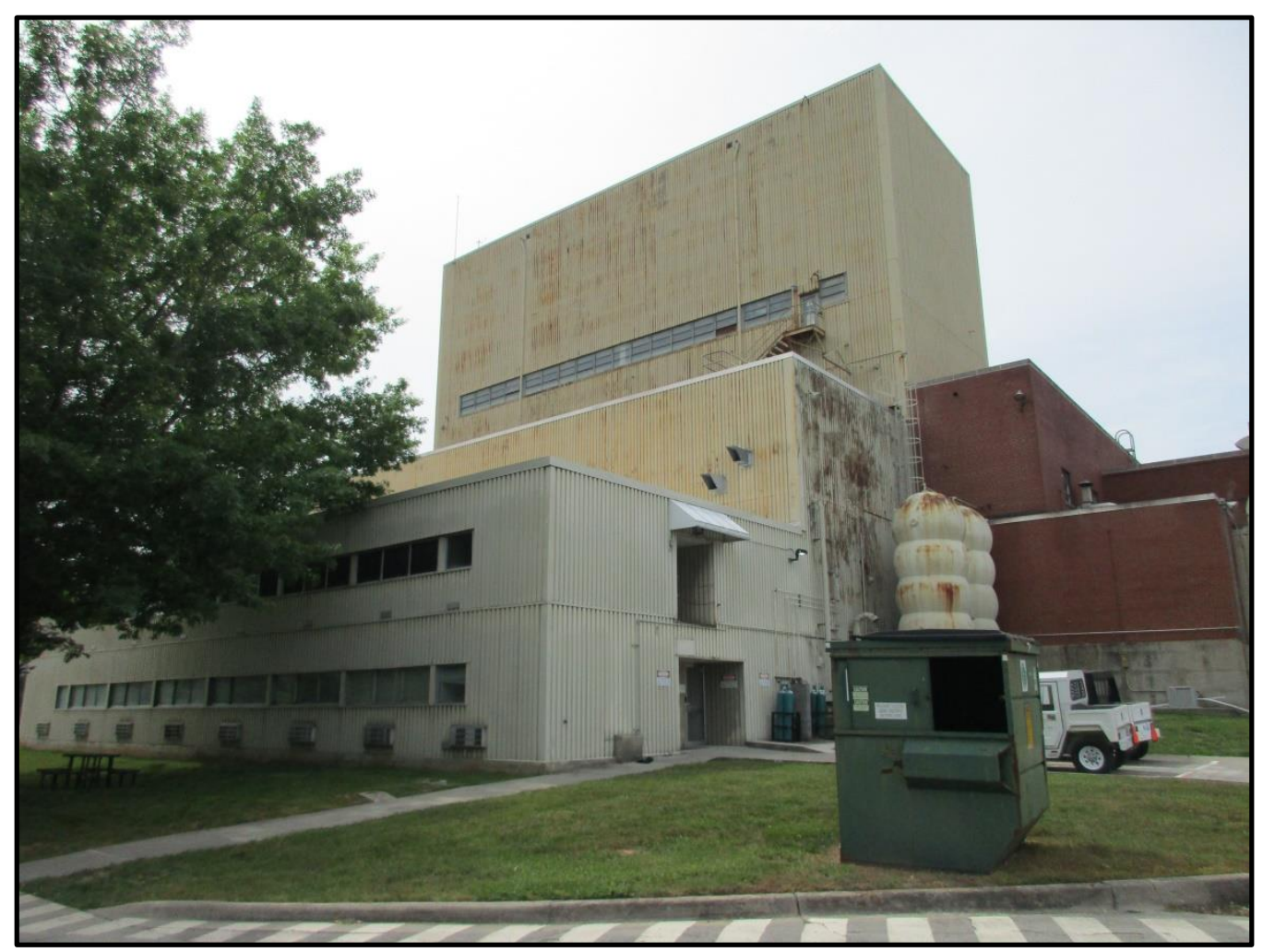

Figure 319. South and east elevations of Buildings 5500 and 5500A.

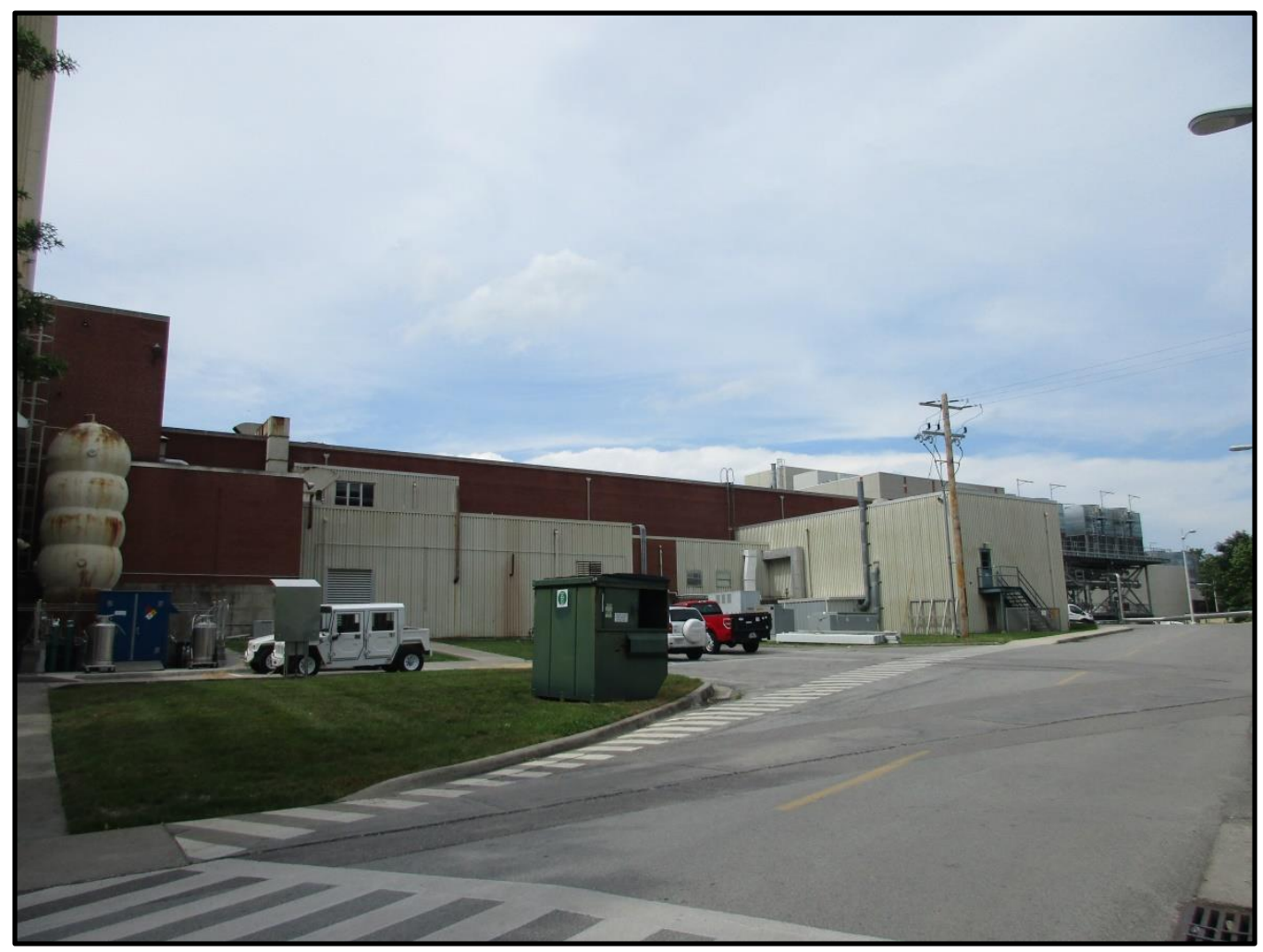

Figure 320. South elevation of c.1962 east end of Building 5500. 


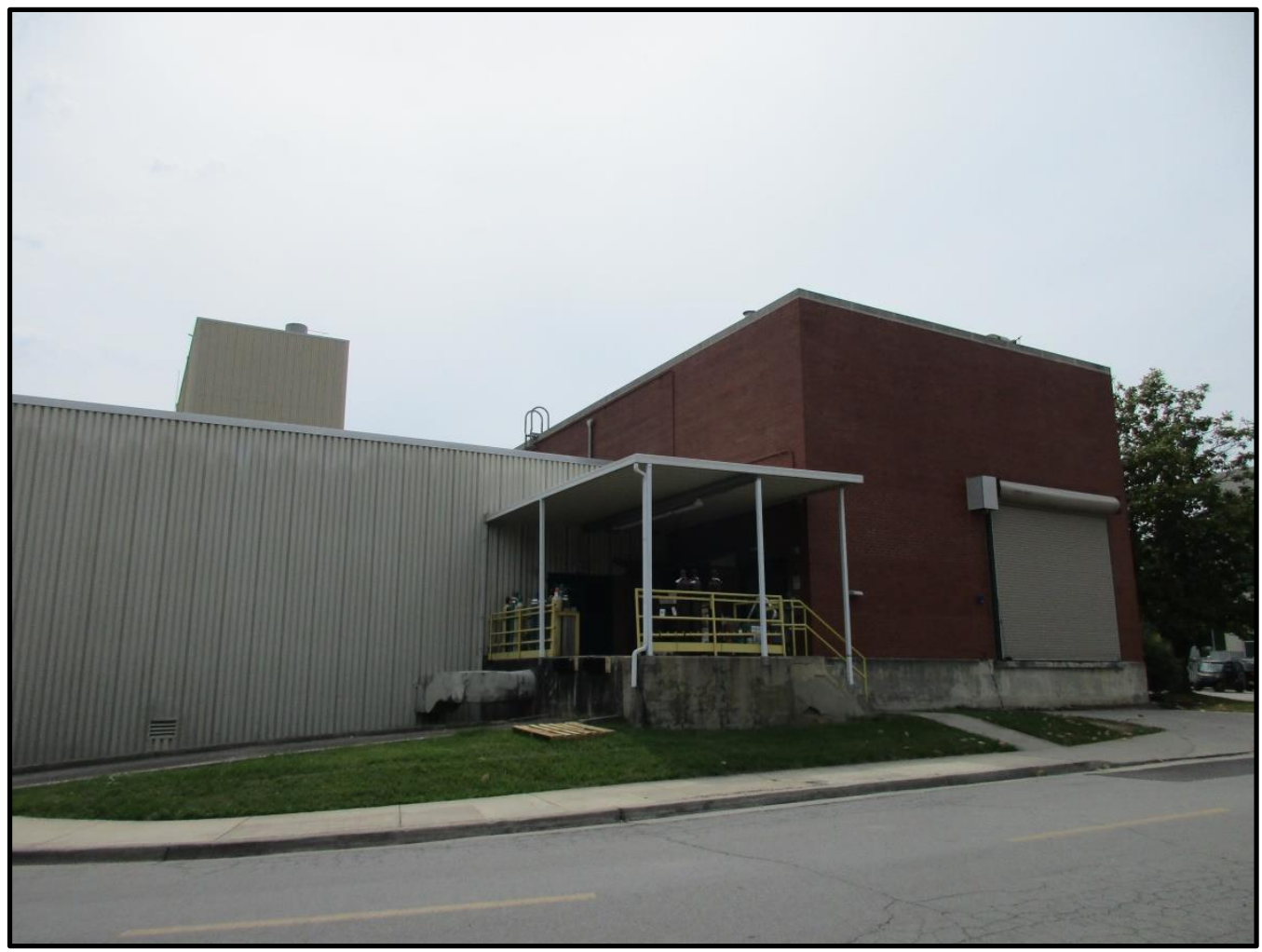

Figure 321. Loading dock on south elevation of Building 5500.

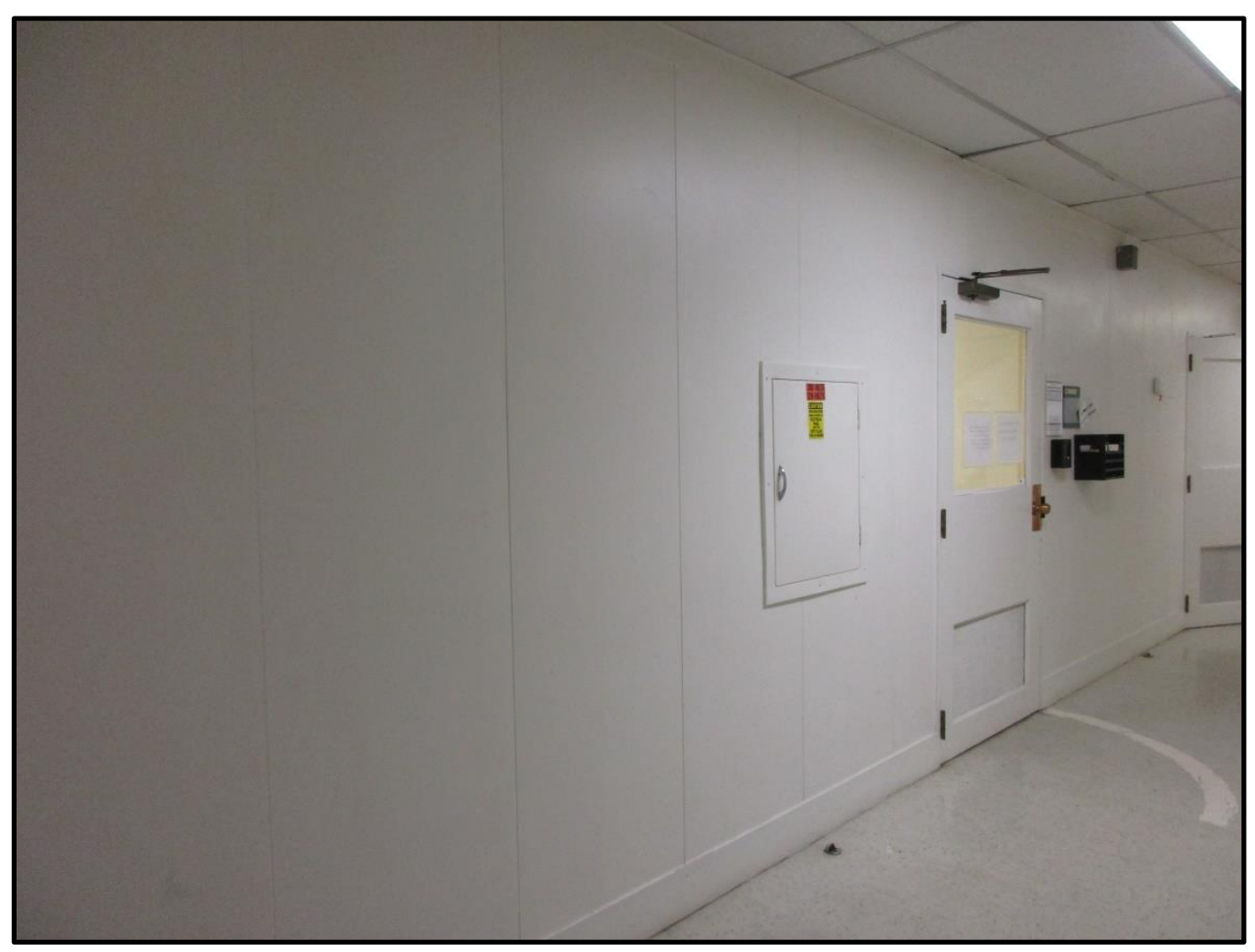

Figure 322. Original interlocking metal panels on the first floor corridor of the c. 1952 section of Building 5500. 


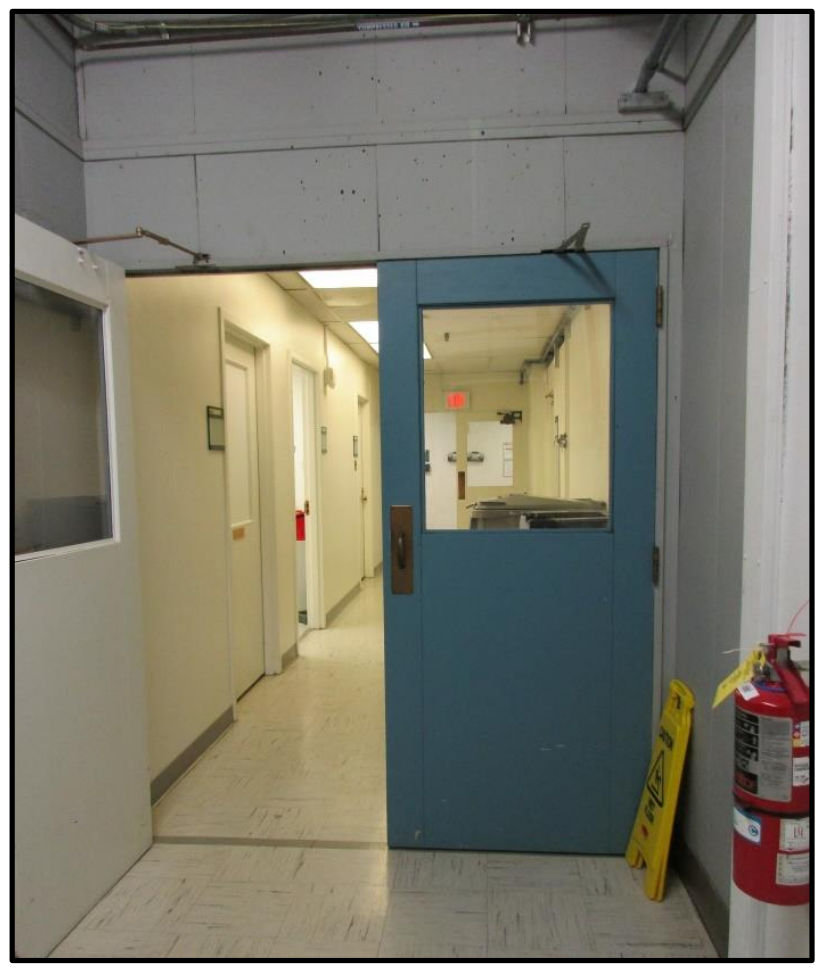

Figure 323. Original interior doors to c. 1976 section of Building 5500 .

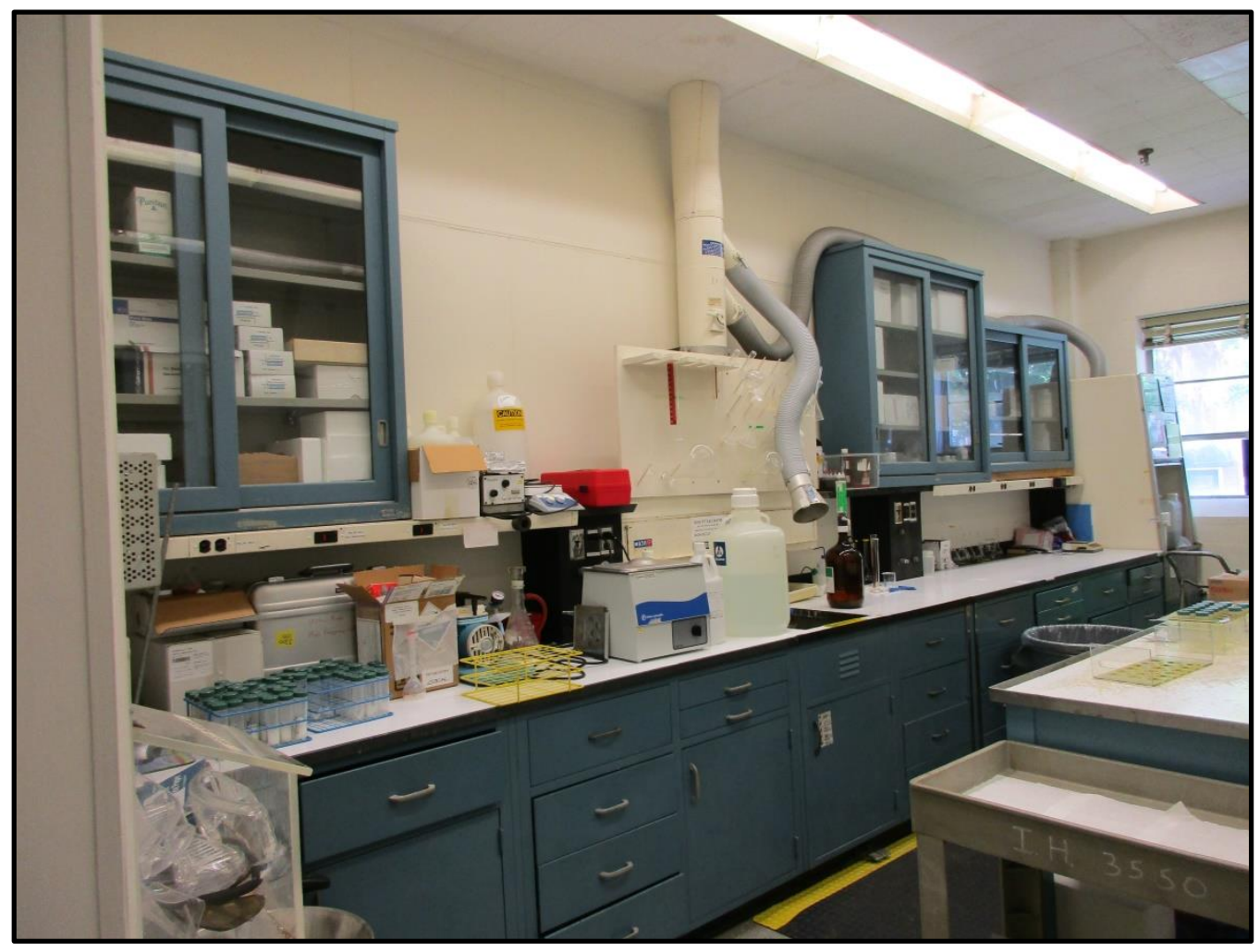

Figure 324. Laboratories on the first floor feature original casework in Building 5500. 


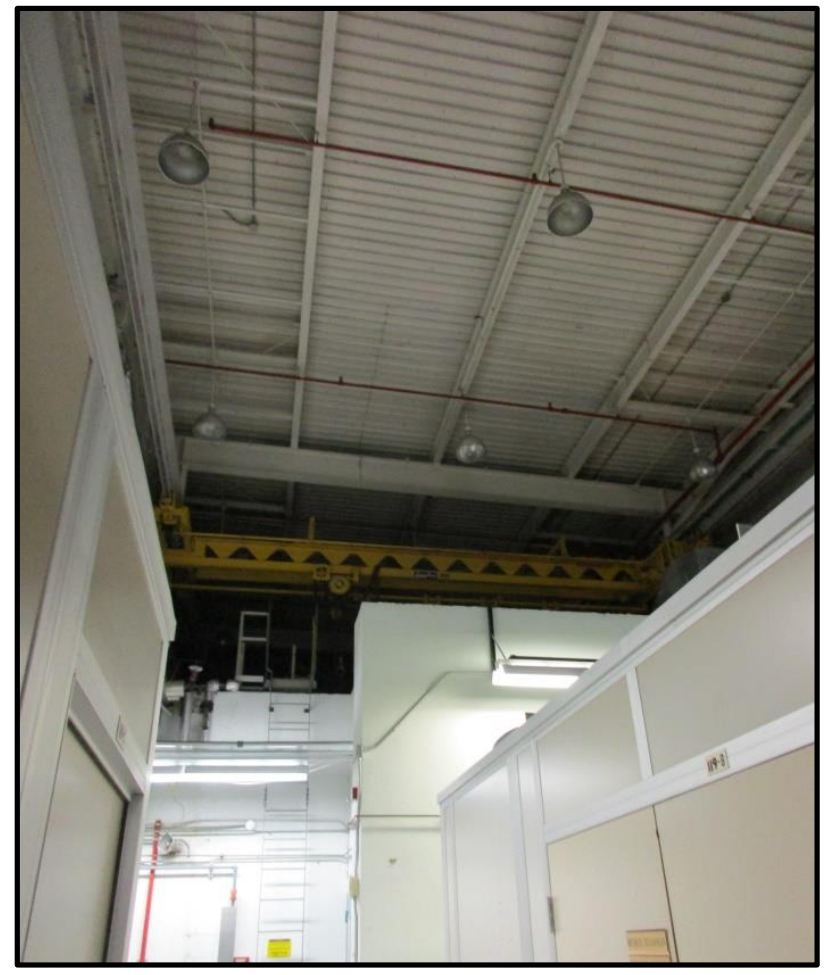

Figure 325. interior of high bay area in c. 1976 section of

Building 5500 .

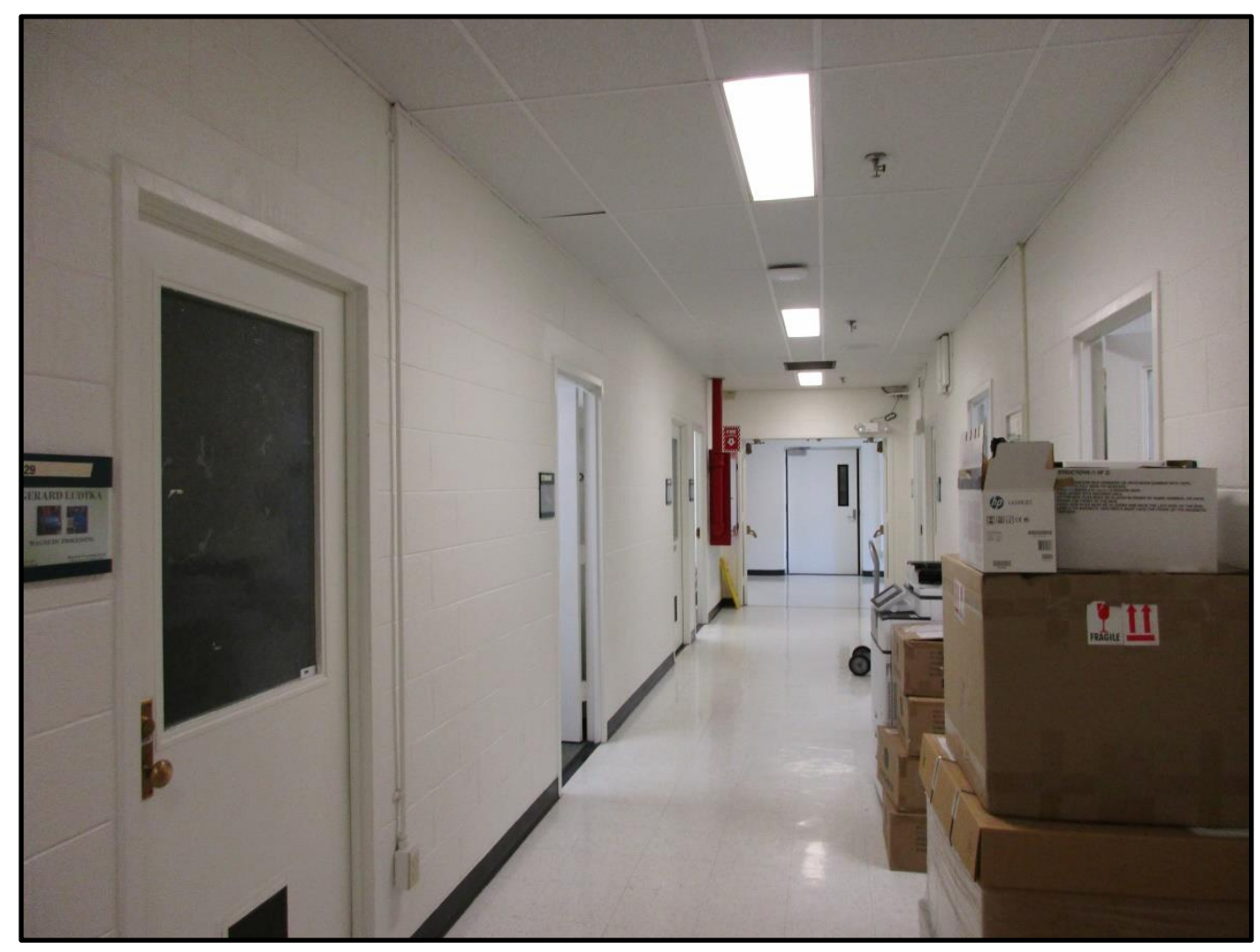

Figure 326. Corridor on first floor of c. 1962 section of Building 5500. 


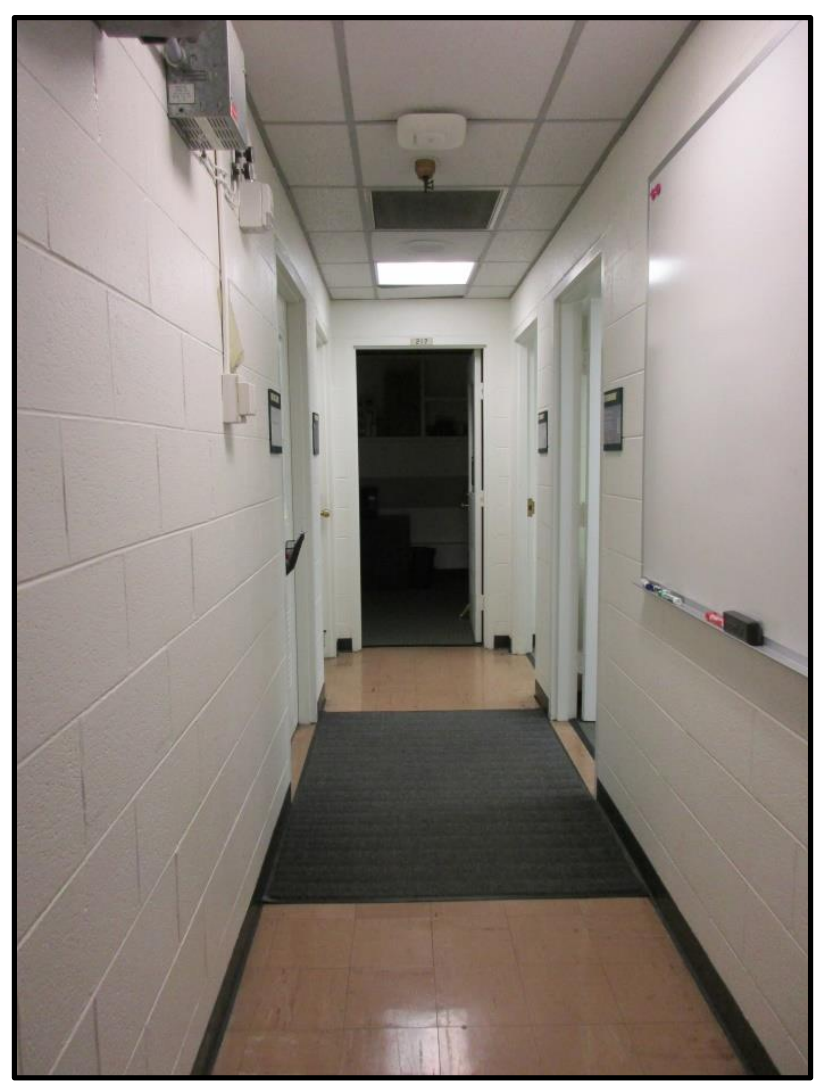

Figure 327. Corridor on second floor of c. 1962 section of Building 5500 .

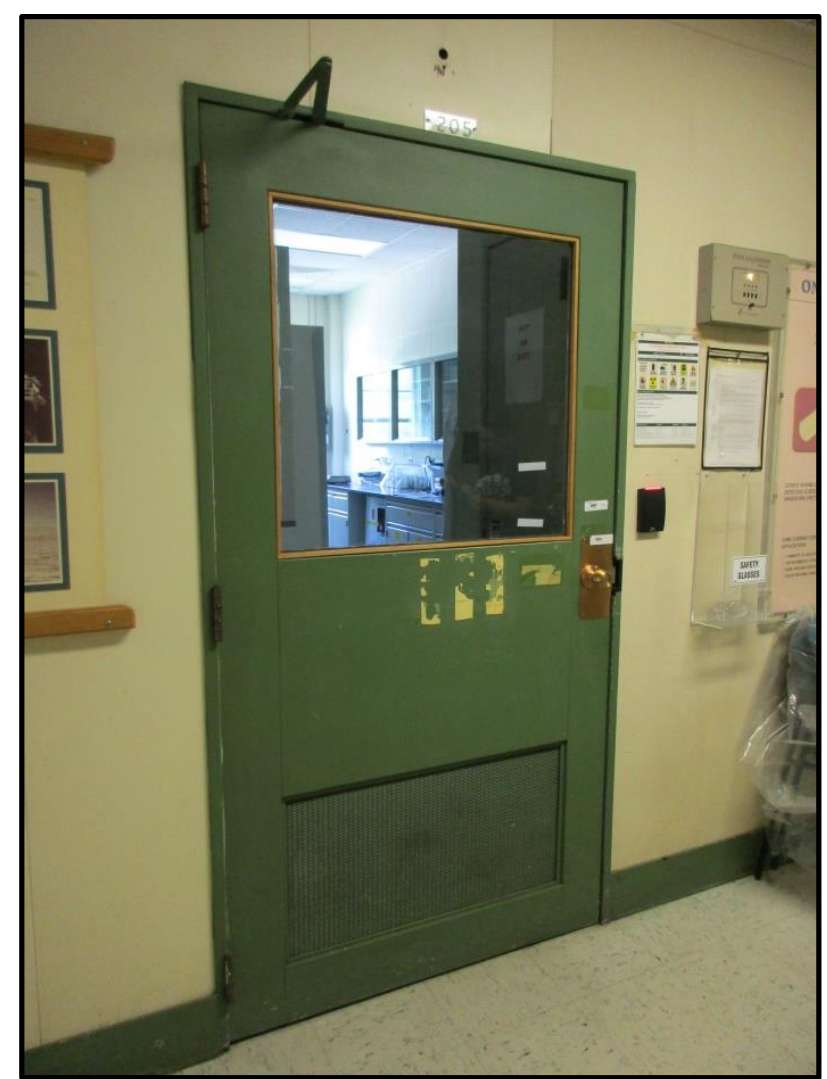

Figure 328. Original interior door to laboratory on second floor of c. 1952 section of Building 5500. 


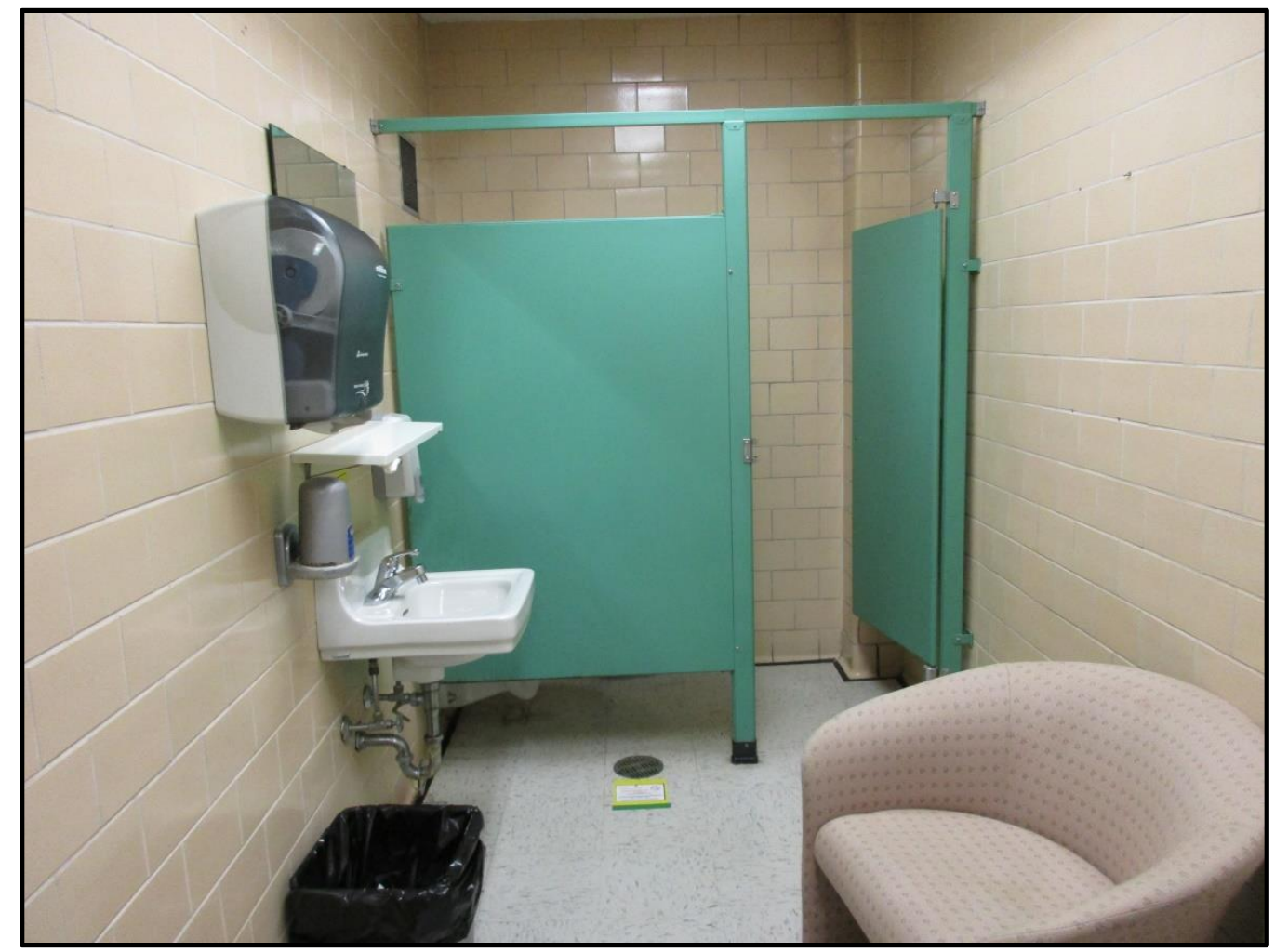

Figure 329. Restroom on second floor of the c. 1952 section of Building 5500.

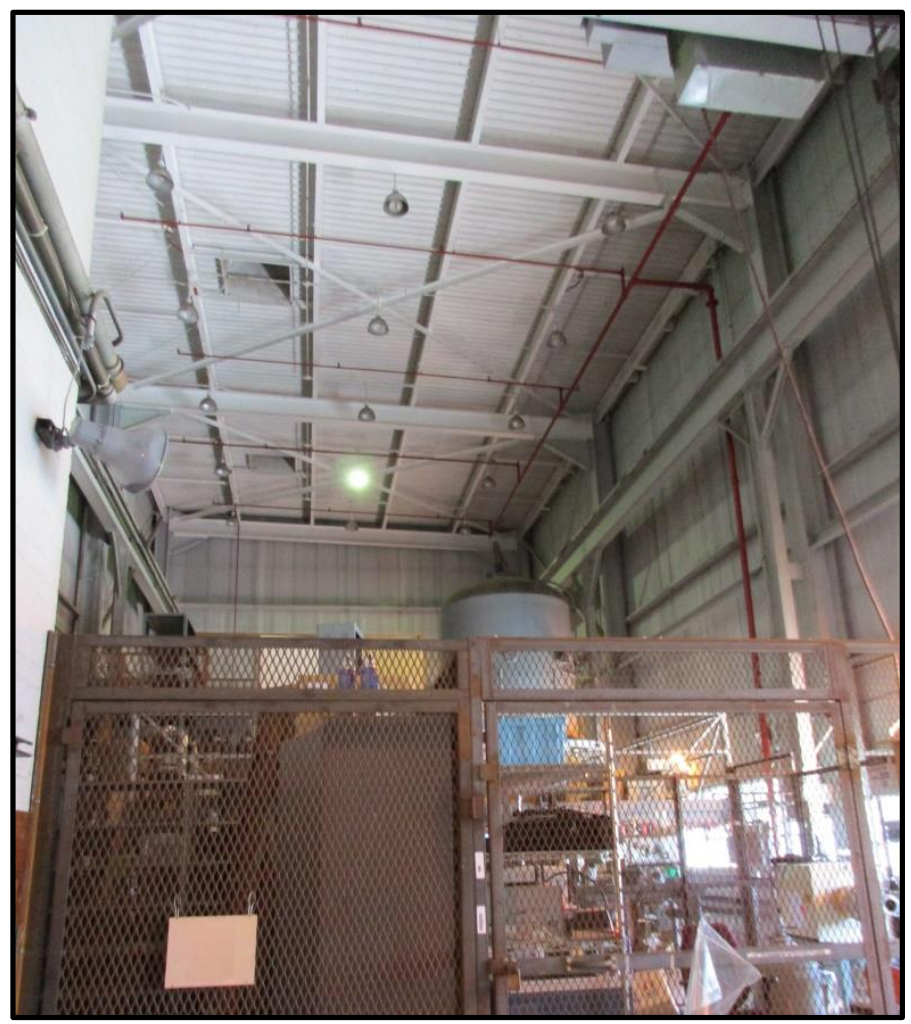

Figure 330. High bay area on third floor of the c. 1952 section of Building 5500 . 


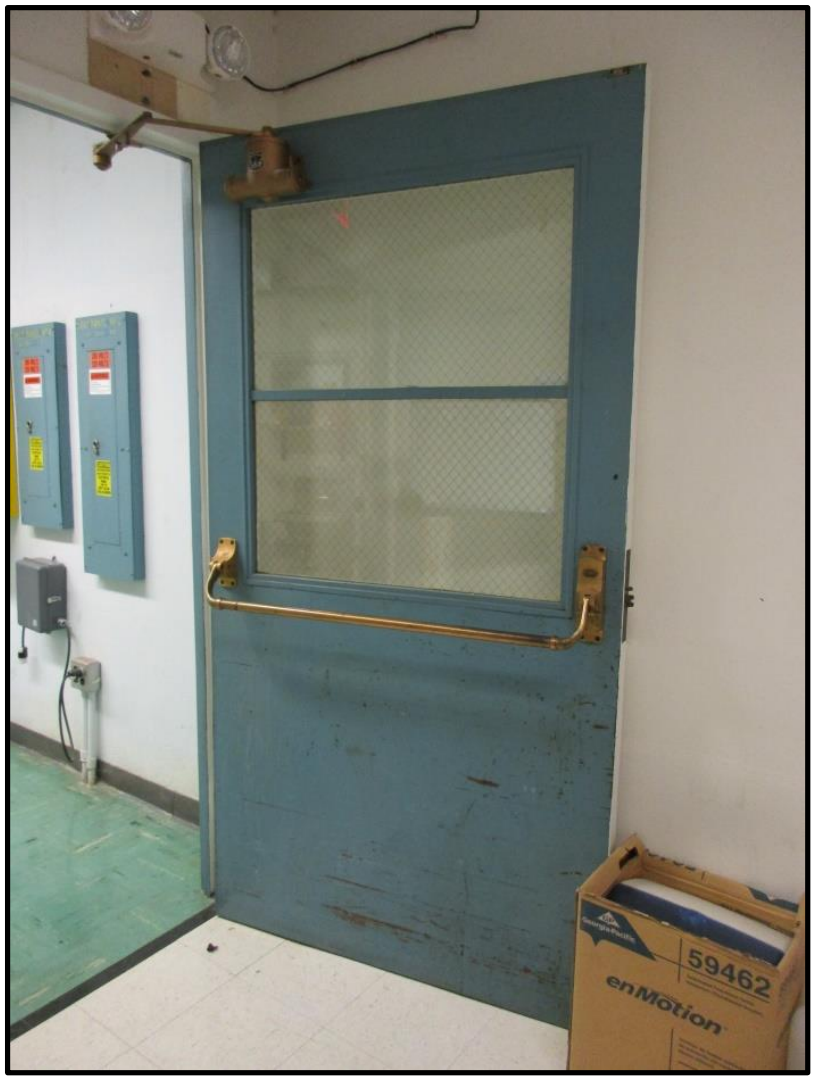

Figure 331. Original interior door in basement of the c. 1962 section of Building 5500.

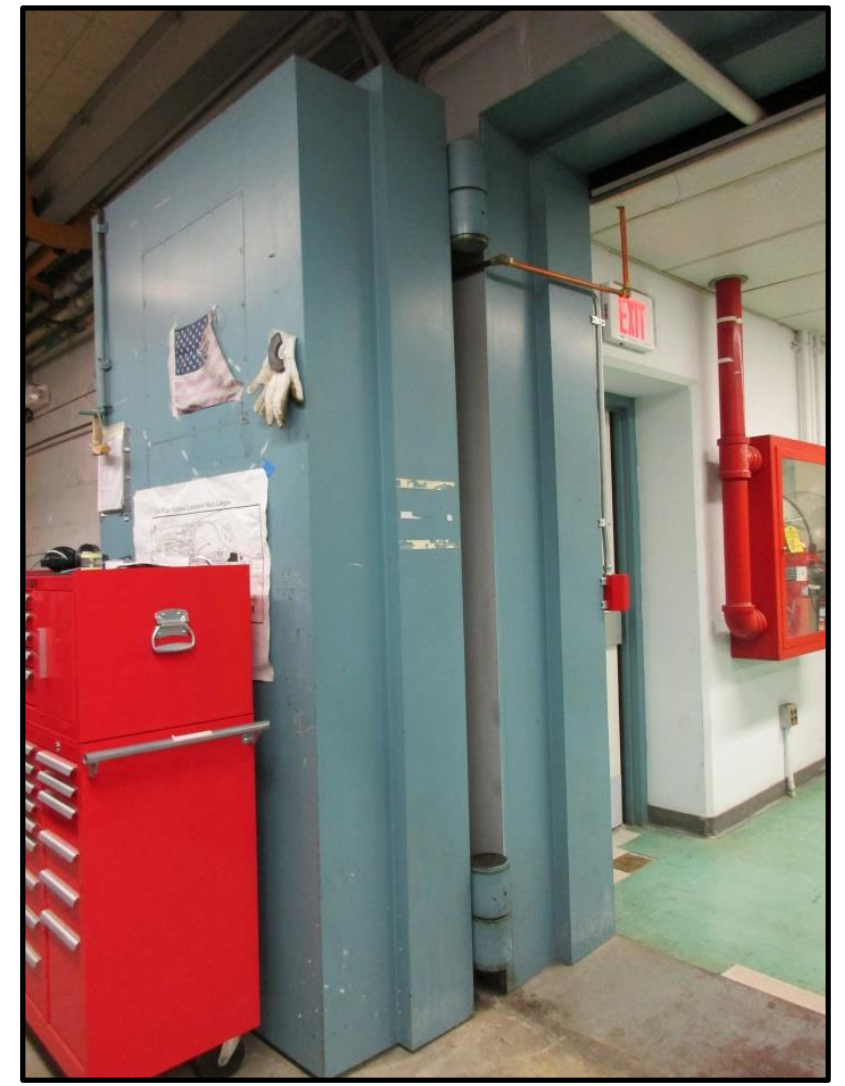

Figure 332. Thick doors to Valve Test Shop in the basement of the c. 1962 section of Building 5500. 


\section{BUILDING NAME}

Transuranium Research Lab

\section{DATE OF CONSTRUCTION}

1967

\section{DOE OFFICE RESPONSIBLE}

SC

\section{NRHP ELIGIBILITY}

Not Eligible

\section{DESCRIPTION}

Building 5505 is a one-story concrete block masonry building clad in running bond brick veneer, situated into a hill, allowing access to the structure on the roof (Figures 333, 334 and 335). The building has a concrete foundation and is sheltered by a flat roof. The north corner is accentuated with a large concrete canopy with metal coping and supported by a square concrete column. The entrance, recessed below the canopy and located on the facade, is a glass door with large transom and side lights surrounding it. The building features two-light fixed aluminum windows with concrete sills. A loading dock with single-light metal doors is located on the south elevation. Two single-light metal doors with metal awnings are located on the east elevation. A smaller one-story structure is located on the roof of the building. This structure is composed of steel and clad with metal panels.

\section{NATIONAL REGISTER EVALUATION}

Building 5505 was built as a Transuranium Research Laboratory (TRL) in 1967. Research conducted in this building included chemistry, physics, and material science of actinides and their compounds. Also, the facility provided fundamental and technological information and a platform for the development of analytical instrumentation. A series of office air supply systems, laboratory exhaust systems, and glovebox exhaust system within in the building allowed the facility to maintain negative pressure (Thomason and Associates 2015:150). Building 5505 was first surveyed in 2015 by Thomason and Associates. The building was recommended at that time to be added to the ORNL Historic District as contributing building even though the building had not yet reached the 50-year mark (Thomason and Associates 2015). CRA disagrees with this recommendation, given that Building 5505 is located on the south side of White Oak Creek, and is therefore not a cohesive continuation of ORNL's main campus that is included within the recommended boundaries for the ORNL Historic District. As a research/laboratory facility, Building 5505 housed work that furthered ORNL's mission in nuclear science during the Cold War era. However, the building is not the single location most importantly associated with a scientific achievement, scientist, or other event or person of historic significance to merit individual listing in the NRHP under Criterion A or B. Furthermore, the building lacks notable architectural elements that would warrant individual listing in the NRHP under Criterion C. In addition, the building is located 
outside of the original and recommended boundaries of the ORNL Historic District, and therefore not a contributing building to the district. As such, Building 5505 does not warrant listing in the NRHP.

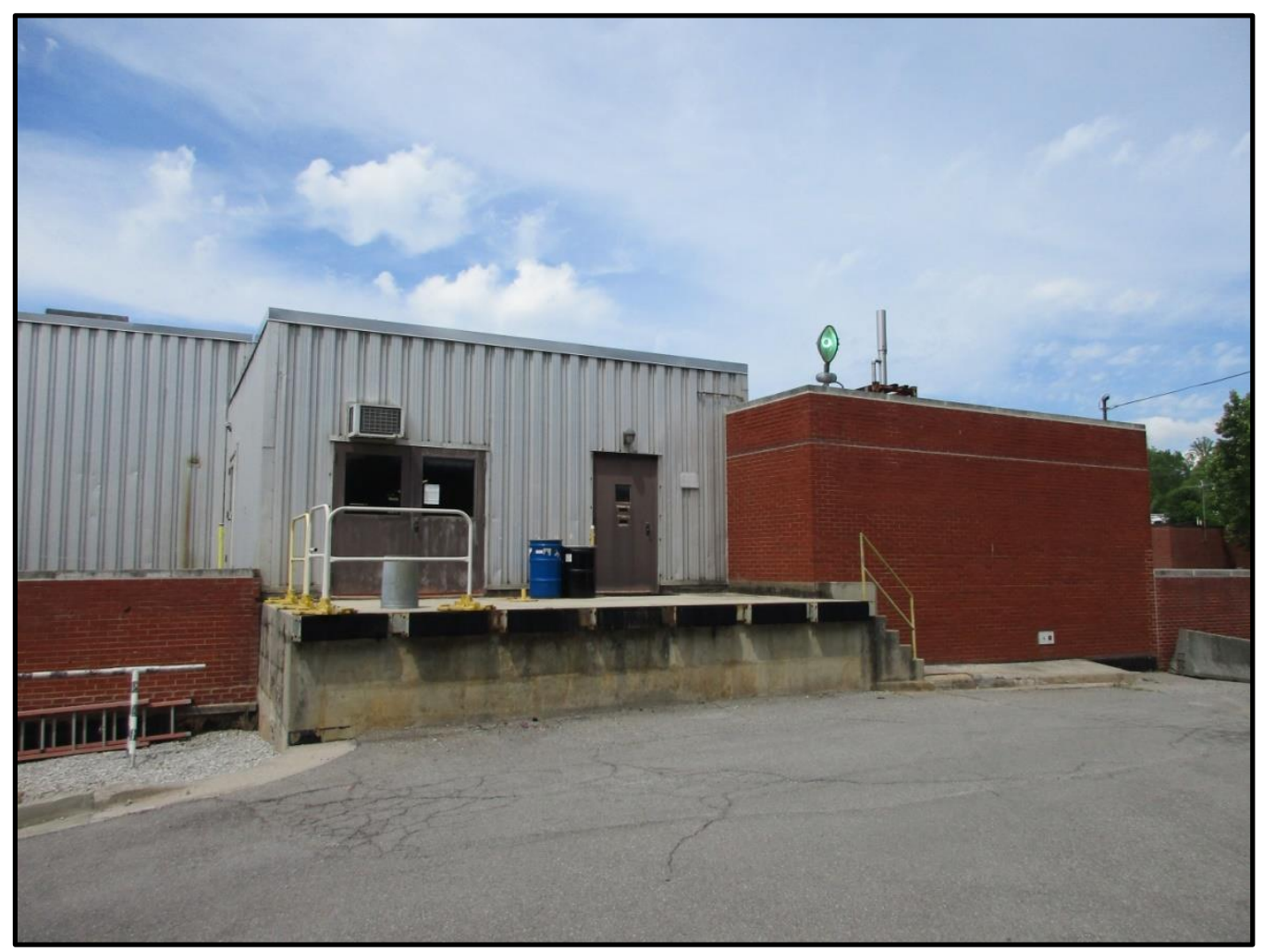

Figure 334. Overview of south elevation of Building 5505. 


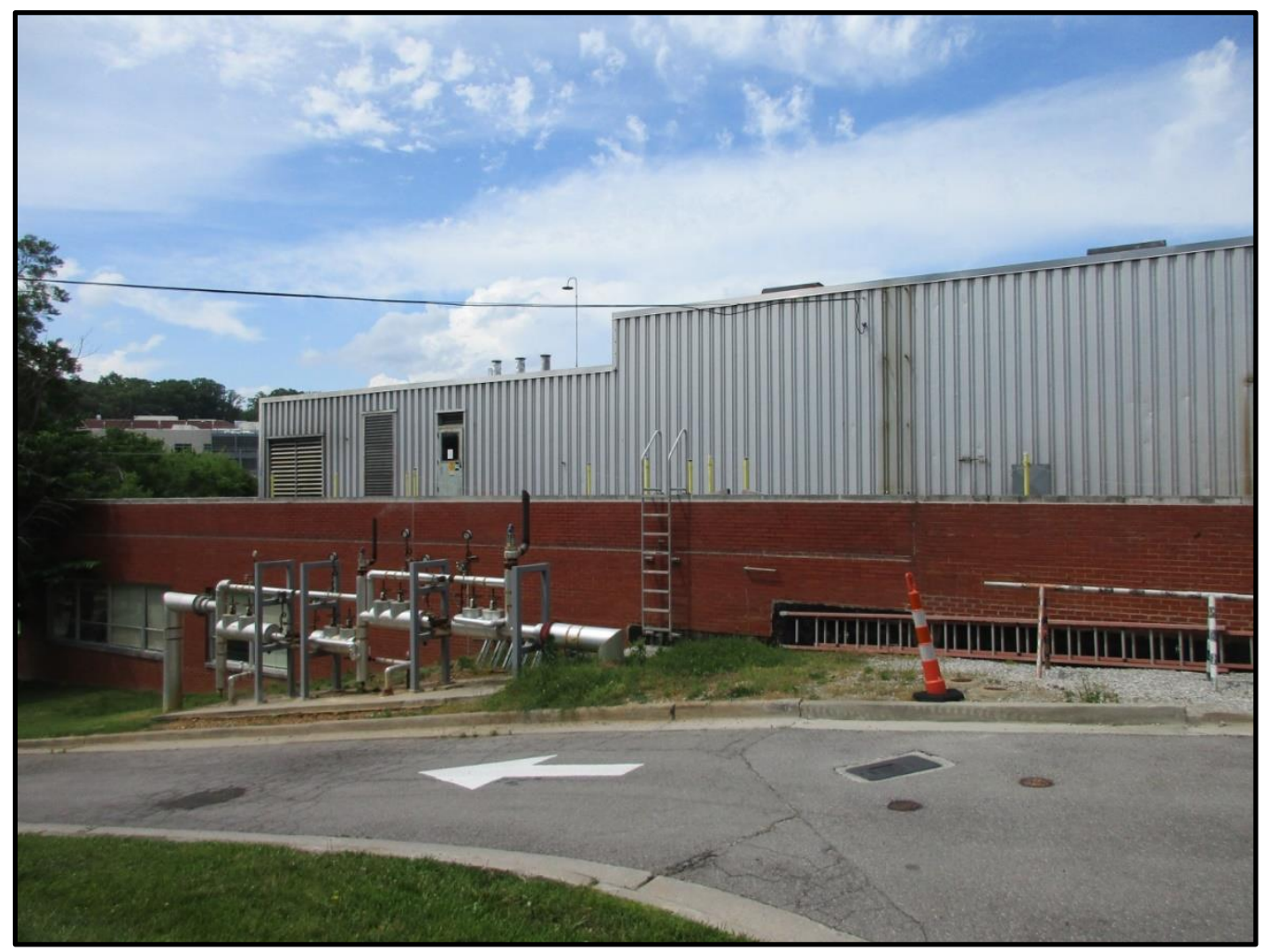

Figure 335. Overview of west elevation of Building 5505. 


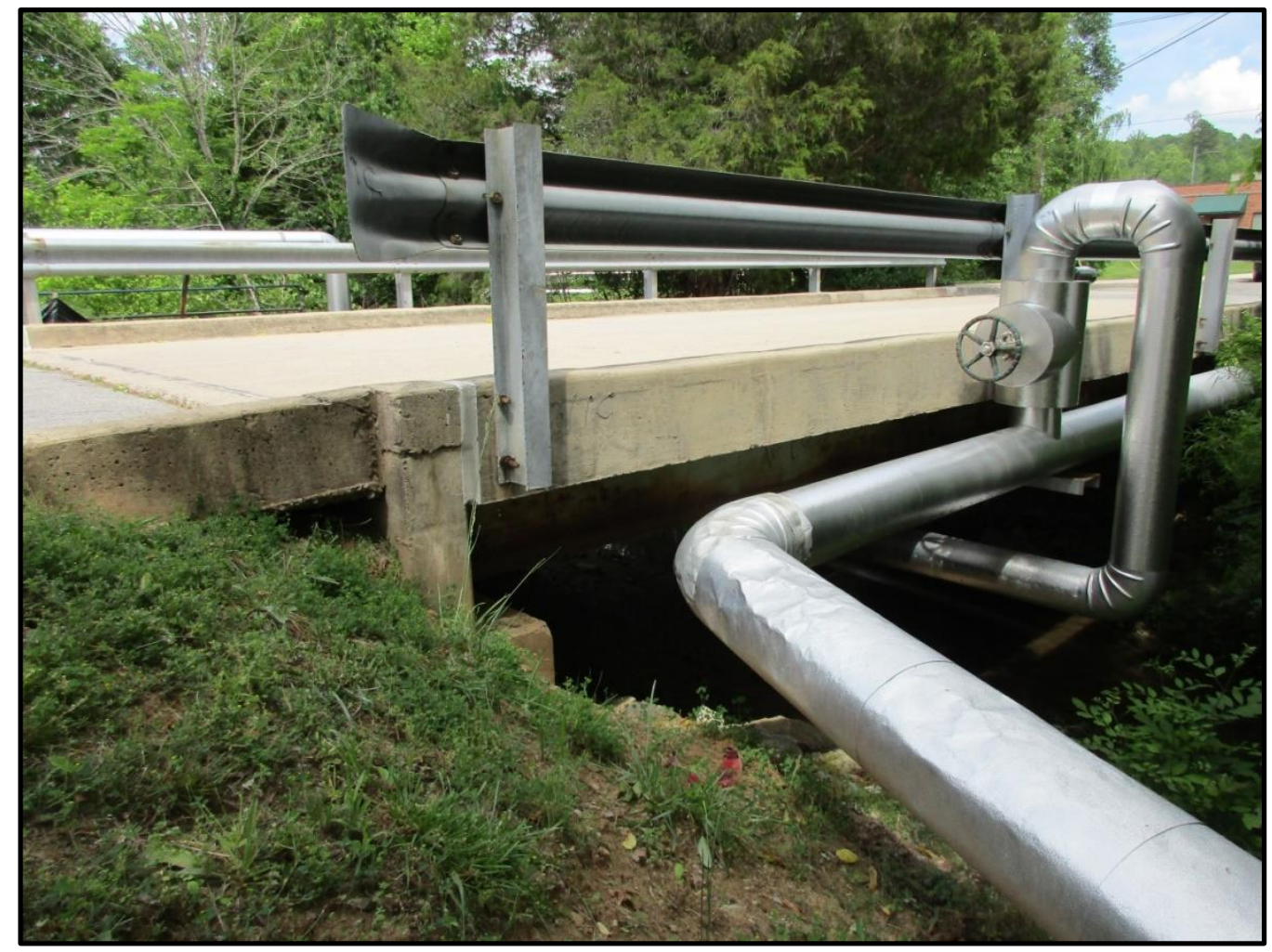

Figure 337. Looking in an eastern direction, a view of the west elevation of vehicular bridge, Building 5505-VB1. 


\section{7}

\section{BUILDING NAME}

Miscellaneous Material Storage

DATE OF CONSTRUCTION

1969

DOE OFFICE RESPONSIBLE

SC

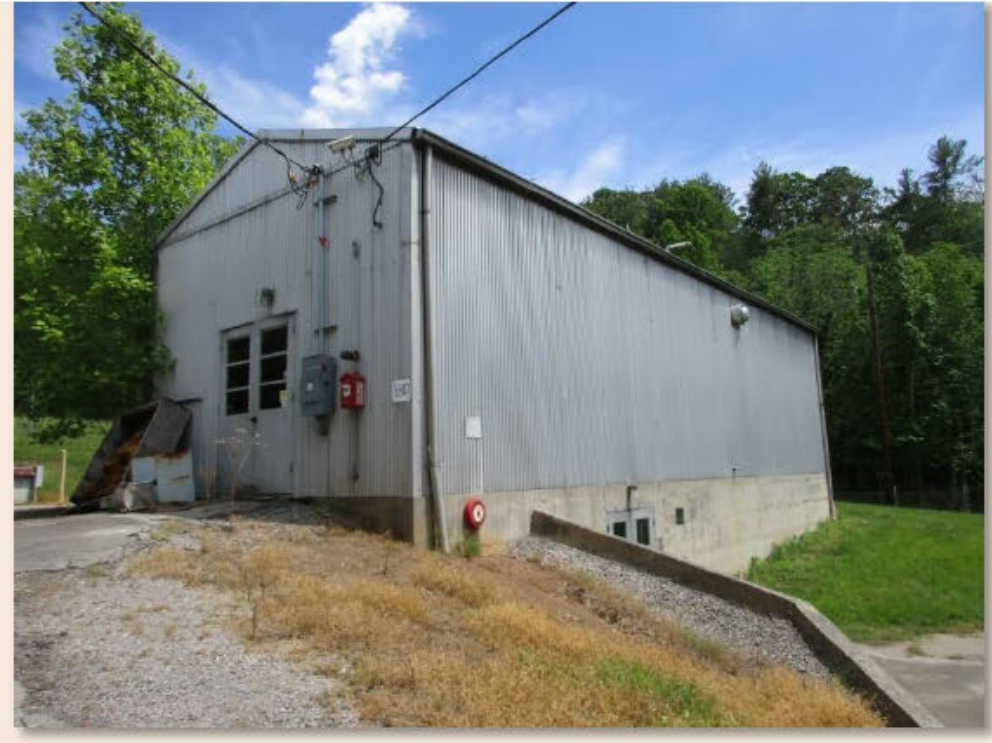

NRHP ELIGIBILITY

Figure 338. Overview of north and west elevations of Building 5507.

Not Eligible

\section{DESCRIPTION}

Building 5507 is a one-story, front-gabled metal frame building with a poured concrete basement. The building is built into the hill, revealing a basement level on the west elevation. The exterior walls and roof are clad with corrugated metal. The building features a pair of three-light metal doors on the north elevation. Two-light metal pedestrian doors are located on the east elevation and a pair of two-light metal pedestrian doors is located on the basement level on the west elevation.

\section{NATIONAL REGISTER EVALUATION}

Building 5507 was constructed as the Electro Spectrometer Facility in 1969. Its present use is a storage facility. Building 5507 was first surveyed in 2015 by Thomason and Associates and considered not eligible for listing in the NRHP (Thomason and Associates 2015). As a storage facility, Building 5505 supported ORNL's mission in nuclear science during the Cold War era. However, the building is not the single location most importantly associated with a scientific achievement, scientist, or other event or person of historic significance to merit listing in the NRHP under Criterion A or B. Furthermore, the building lacks notable architectural elements that would warrant individual listing in the NRHP under Criterion $\mathrm{C}$. In addition, the building is located outside of the original and recommended boundaries of the ORNL Historic District. As such, Building 5507 does not warrant listing in the NRHP under Criterion $A, B$, or C. 


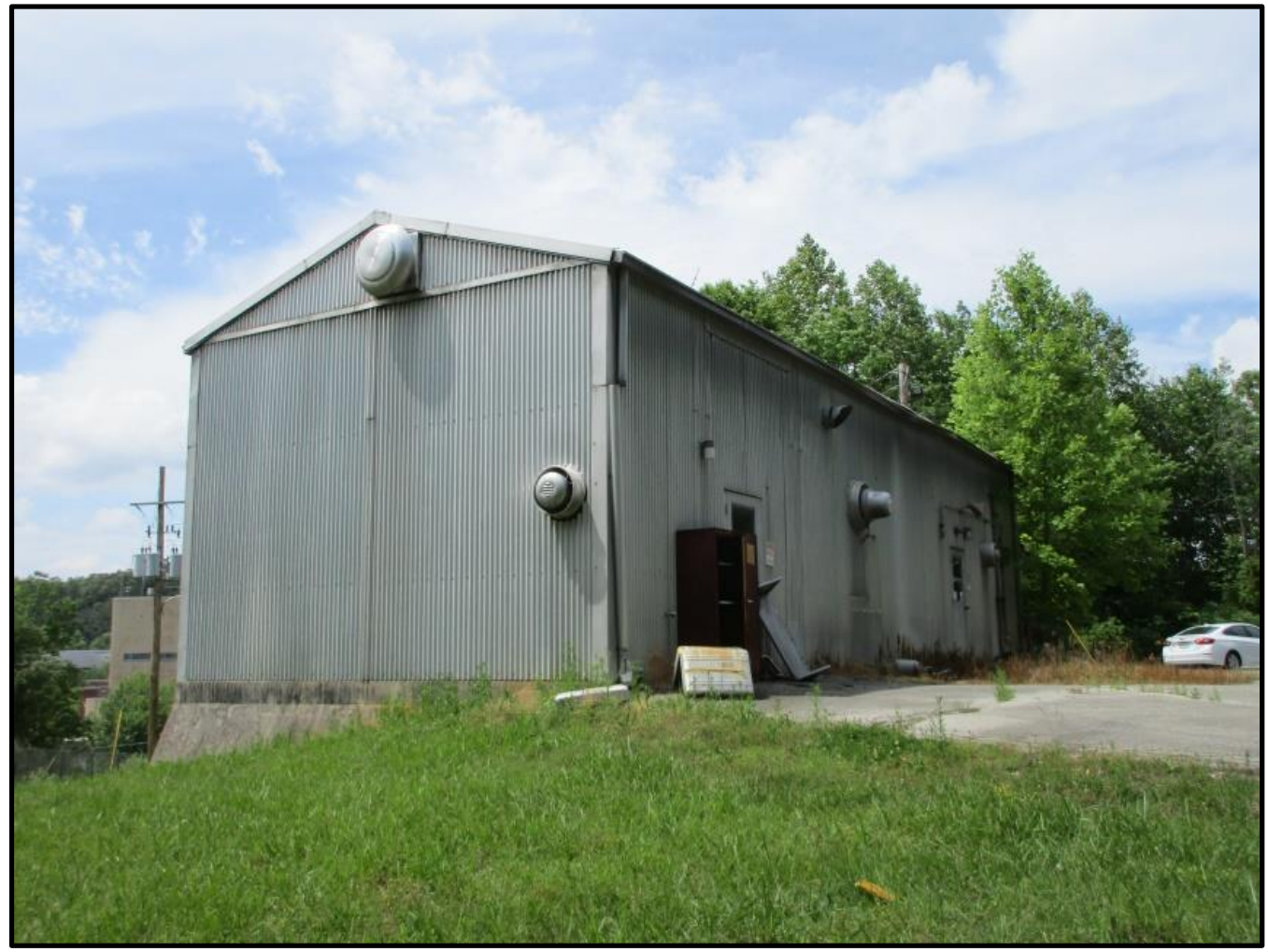

Figure 339. Overview of north and west elevations of Building 5507. 


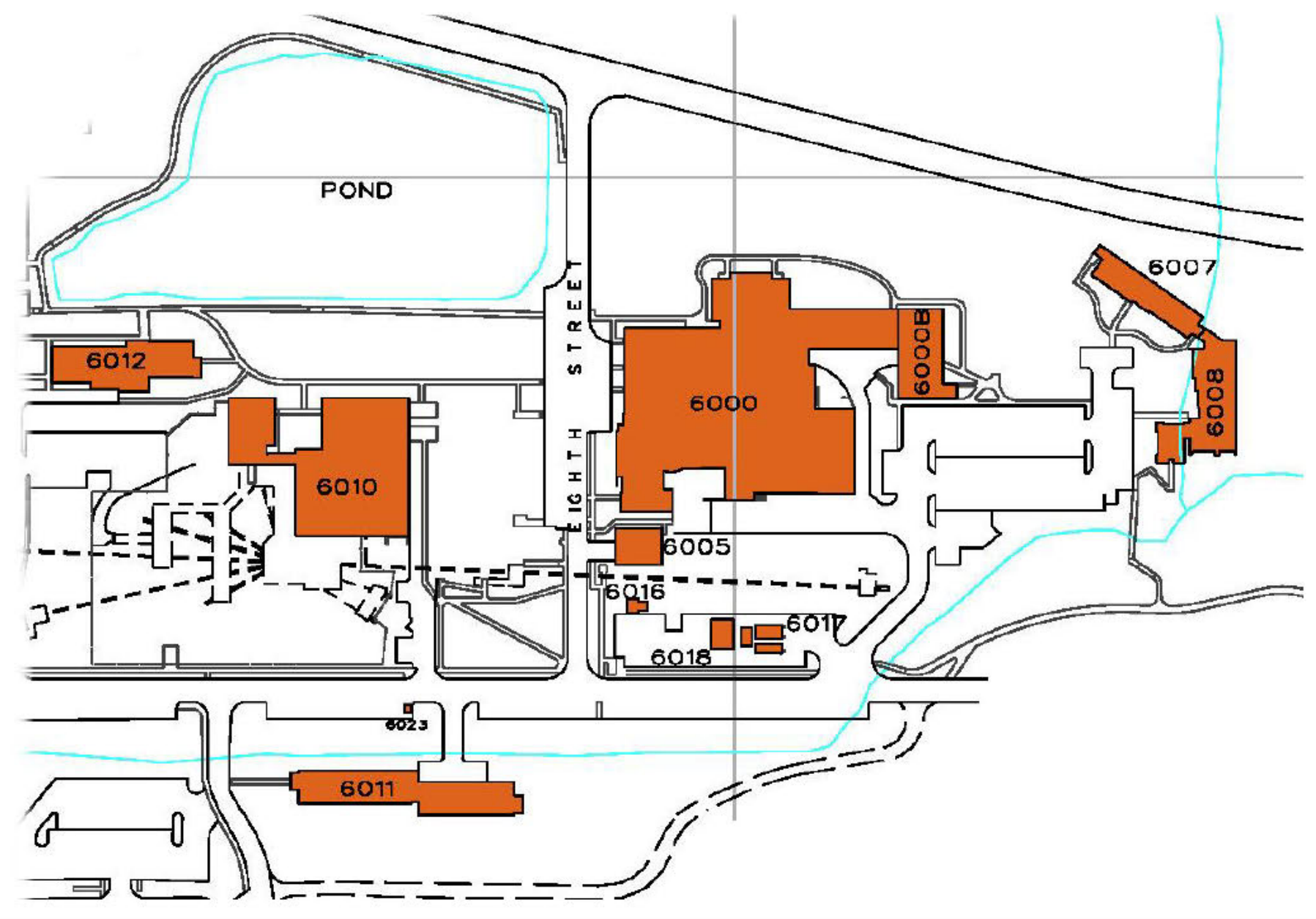

\section{AREA}

Figure 340. Plan View of 6000 Area.

\section{NOT ELIGIBLE}

Building 6000

Building 6010 
This page intentionally left blank 


\section{AREA}

\section{DISTRICT NAME}

6000 Area of ORNL

\section{DATE OF CONSTRUCTION}

1969-2010

NRHP ELIGIBILITY

Not Eligible

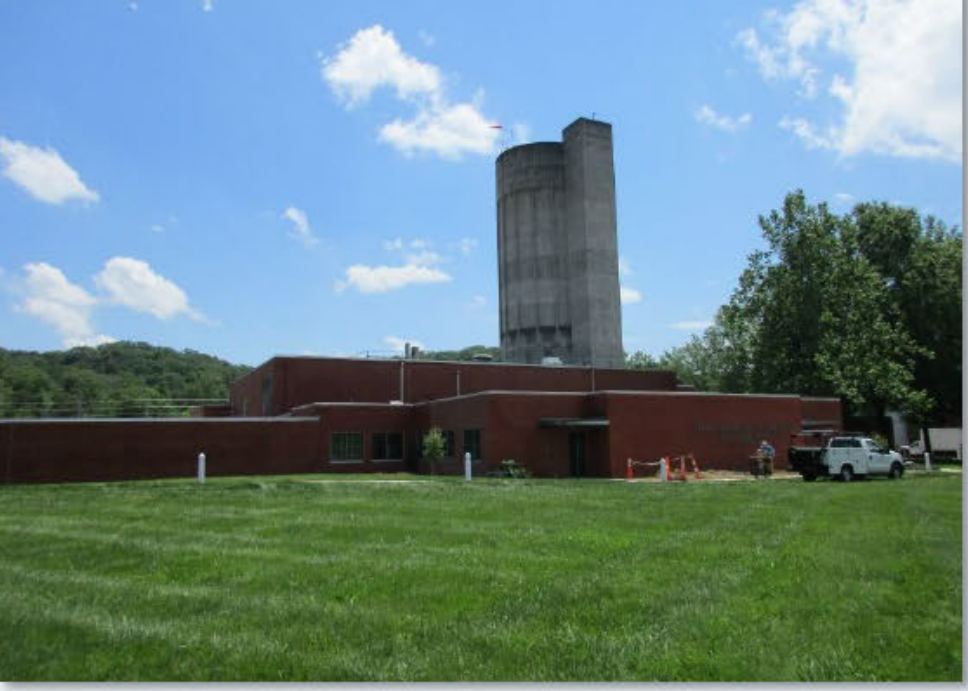

Figure 341. View of the 6000 Area looking towards Building 6000 from Bethel Valley Road.

\section{DESCRIPTION}

The 6000 Area is located immediately east of the main campus of ORNL. The area is bounded by a pond, known as Swan Pond, and Bethel Valley Road on the north and White Oak Avenue on the south. The resources located within the 6000 Area are primarily associated with two processing facilities: the Holifield Radioactive Ion Beam Facility (HRIBF), originally constructed as the Oak Ridge Isochronous Cyclotron (ORIC), in Building 6000 and the Oak Ridge Electron Linear Accelerator (ORELA) in Building 6010. In addition to Building 6000 , Buildings $6005,6007,6008,6016,6017$, and 6018 also are associated with the HRIBF. Eight buildings are located within the 6000 Area, two of which were originally constructed before 1980 and thus included in this survey. Access roads from White Oak Avenue and Eighth Street provide access to the 6000 Area.

\section{NATIONAL REGISTER EVALUATION}

The 6000 Area is comprised of two facilities, the HRIBF and the ORELA; however, the area was initially developed as the ORIC in 1961. The ORIC, which started operation in 1962, was one of the world's first cyclotrons to research azimuthally varying field focusing. The ORIC was intentionally located in an area east of the security area surrounding ORNL, so that easier access could be provided to outside users, including nonUS citizens (Thomason and Associates 2013:12). The Oak Ridge Electron Linear Accelerator (ORELA) was constructed in 1969 as an expansion of the ORIC complex in Building 6000 (Johnson and Schaffer:155 and 158). An additional facility, Building 6025, was constructed in 1967 to house the Neutron Physics Office and Laboratory and to support the ORELA, which was under construction (Thomason and Associates 2015: 158). In 1994, Duvall \& Associates' survey of ORNL recommended that there was "insufficient historical perspective to assess the significance of facilities in the 6000 Area" and recommended reevaluating the facility when it became 50 years old (Carver and Slater 1994:278). The area was not assessed as a district and Building 6010 was not included in Thomason and Associates' 2004 survey update (Thomason and Associates 2004). In 2013, Thomason and Associates completed an extensive documentation of the 6000 Area; however, it was not assessed for NRHP eligibility as a part of that review (Thomason and Associates 2013). The 2015 survey update completed by Thomason and Associates also did not evaluate the 6000 Area as a whole. In addition to not having reached 50 years of age, Thomason and Associates determined there was not enough information regarding Building 6010's role in research and analysis in nuclear physics to determine if it possessed 
exceptional significance under Criteria Consideration $\mathrm{G}$ and recommended it not eligible under Criterion $\mathrm{A}, \mathrm{B}$, or $C$ (Thomason and Associates 2015:156). While the majority of the 6000 Area is currently associated with the $\mathrm{HRIBF}$, only two buildings that represent the original development of the area remain extant, following the demolition of Building 6025 in January 2017. The 6000 Area retains at its core research and processing facilities where key scientific advancements occurred in Buildings 6000 and 6010; however, alterations to both buildings through renovations and reconfigurations and the demolition of Building 6025 has diminished the integrity of the 6000 Area. As such, it does not represent a distinct, cohesive portion of the ORNL campus. Therefore, CRA recommends that the 6000 Area is not eligible for listing as a historic district.

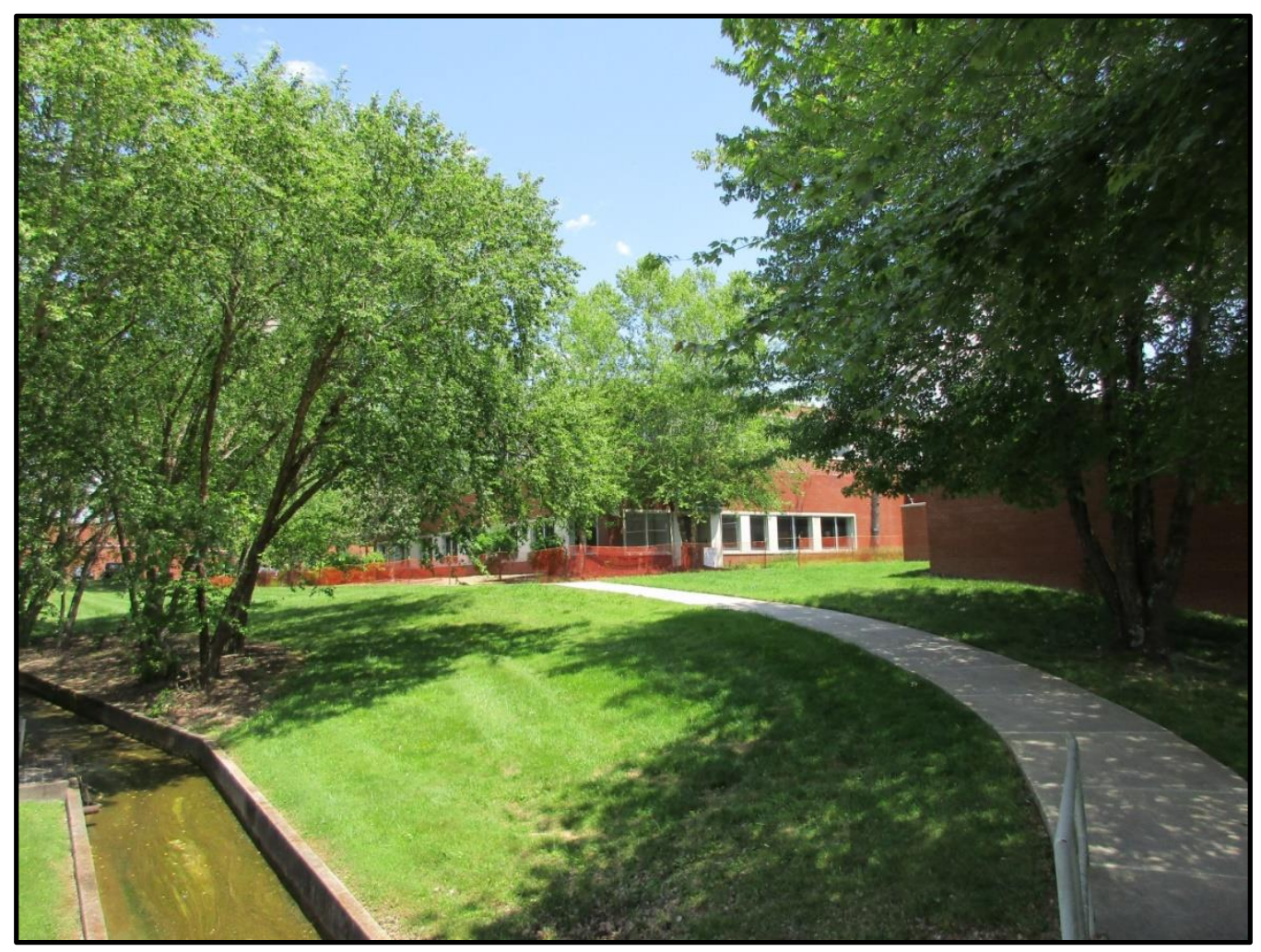

Figure 342. View of the 6000 Area looking towards Building 6010. 


\section{BUILDING NAME}

Holifield Radioactive lon Beam Facility

\section{DATE OF CONSTRUCTION}

1961

\section{DOE OFFICE RESPONSIBLE}

SC

\section{NRHP ELIGIBILITY}

Figure 343. North (façade) elevation of Building 6000.

Not Eligible

\section{DESCRIPTION}

Building 6000 was one of 15 resources selected for intensive survey by UT-B as a part of survey planning. In September 2013, Thomason and Associates completed Section 106 documentation for the Holifield Radioactive Ion Beam Facility (HRIBF), Building 6000, as a part of consultation for the DOE Oak Ridge Site Office (DOEOSO). The following description is based upon the recordation completed as a part of that effort, supplemented with photographs taken in May and June of 2017 by CRA (Thomason and Associates 2013:7-9).

Located on the eastern edge of the main campus, Building 6000 is the largest of seven buildings associated with the HRIBF. It is the primary research facility and offices for the complex. Other associated buildings include housing and research space for visitors and four support buildings (Buildings 6005, 6007, 6008, 6016, 6017, and 6018). Oriented to the north, the complex faces Bethel Valley Road with parking lots to the east and south of Building 6000 .

Building 6000 , a brick, concrete, and steel building, was constructed in several phases. Constructed in 1961, the original section of the building included a two-story office wing (first floor and basement levels) and a three-story laboratory that housed the Oak Ridge Isochronous Cyclotron (ORIC). Additional space for offices and laboratories was added to the east elevation in 1964 and in a wing on the façade (north) elevation in 1967. In 1971 an additional laboratory wing was added to the south elevation. Other additions and modifications to Building 6000 included the construction of an east wing for office space associated with the tandem accelerator in 1979; the distinctive concrete accelerator tower in 1978; a rear annex to the south elevation in 1982; an additional experimental hall to the south corner of the building in 1986; and a concrete wing on the south elevation in 1994 to support the Recoil Mass Spectrometer (RMS). Furthermore, the west end of the annex on the south elevation was modified to form a lightly-shielded instrumentation room as a part of the High Power Target Laboratory (HPTL) project in 2003. Given the multitude of changes to Building 6000 since its initial construction in 1961, the original building contains less than half of the square footage of Building 6000 . The majority of the additions date to the 1970s, 1980s, and 1990s, and are therefore less than 50 years of age (Thomason and Associates 2013:7). 
Exterior: The north elevation, which faces toward Bethel Valley Road, features a portion of the original main block of Building 6000 (Figure 343). Set upon a continuous poured concrete foundation with a full basement, this one-story original section features steel and concrete block construction clad in running bond brick veneer and is sheltered by a flat roof with metal-clad concrete coping. The façade entry to the original main block features original double-leaf, full-light aluminum doors (Figures 344). A large transom and plate glass windows surround the entry, which opens to a concrete apron sheltered by a flat concrete awning. The original block of Building 6000 features banks of single-light fixed aluminum windows with aluminum sills (Figure 345). The original section of the building was enlarged with a projecting central office wing on the façade (north) elevation in 1967. This projecting wing has two original entrances in the corner bays with original two-light steel and glass doors sheltered by flat metal canopies supported by steel posts. Between these two entrances there is no fenestration, but affixed to the face of the buildings are aluminum letters spelling "Holifield Radioactive lon Beam Facility, Oak Ridge National Laboratory, Physics Division." The west elevation of the projecting wing also features a secondary entrance with original double-leaf, single-light glass and steel doors. The north elevation of the east wing has a single-light steel and glass door and a barrel canvas awning (Figure 346).

The east elevation of the east wing lacks fenestration except for single-light steel and glass doors with canvas awnings. Above the doors are solider course lintels. This elevation has a metal louvered enclosure to shield HVAC units (Figure 347). At the south corner of the building is a one-story circa 1979 brick wing which has a single-light steel and glass door and paired hinged steel garage bay doors. This wing lacks fenestration on the south elevation (Figure 348). The east elevation of the building is composed of wings added in 1979. This elevation has a single-light glass and wood door on the second story connected by a structural steel staircase. The first floor features an original single-light steel and glass door and double steel hinged garage bay doors. The south elevation of the east wing has an original two-light steel and glass door and hinged steel garage bay doors (Figure 349).

The south (rear) elevation of the building has a series of wings added in 1982 and 1994 of brick, concrete block, and concrete. The three-story concrete block section on the south elevation and east of the tower has two original solid steel doors which connect to the ground via a structural steel exterior staircase (Figure 350). This elevation also has sliding track steel doors for equipment access on the third floor. The one-story brick wing, known as the South Annex, has an added handicapped ramp leading to an entrance with a circa 2000 aluminum canopy and paired original two-light steel and glass doors (Figure 351). The south elevation also features a one-story concrete wing added in 1994 for the RMS. This wing has two recessed horizontal bands and a solid steel door on the south elevation. An entrance bay on this elevation has been infilled with concrete block. On the east elevation of this wing is a garage bay with a metal roll-up door.

The west elevation of Building 6000 features two original, single-leaf, two-light steel and glass doors with solider course lintels sheltered by added canvas awnings (Figure 353). Two basement entrances with concrete stairs, metal railings, and original two-light steel and glass doors are also located on the west elevation. The two-story section of the elevation has a solid steel door and paired single-light doors on the first story and a single-light door on the second story. This elevation has a circa 2000 metal canopy over the double doors and an original steel staircase leading to the second floor entrance. The second floor also has double steel doors for equipment access. The concrete basement section extends from the main block on the south elevation and at the west corner of the building is a recessed entrance with an original solid steel door. The south elevation of the concrete block wing lacks fenestration. 
The most prominent structure at the facility is the concrete tower which houses the $25 \mathrm{MW}$ tandem electrostatic accelerator, which is no longer in operation at the time of this survey in 2017 (Figure 354). Construction of the tower began in 1976 and it was completed in 1978. It is constructed of poured concrete and measures $167 \mathrm{ft}$ in height and 48 in diameter, and houses a $98 \mathrm{ft}$ tall by $33 \mathrm{ft}$ diameter pressure vessel. The tower was poured in horizontal sections and is accented through vertical bands. At the top of the tower on the south elevation is a rectangular equipment door for access into the tower. On the north elevation of the tower is a rectangular concrete elevator shaft (Thomason and Associates 2013:9).

Interior: The interior of the building is divided into various sections containing office space, laboratories, and equipment rooms housing the ORIC and tandem accelerators and experimental systems. Most interior spaces have concrete floors, with original asbestos and linoleum tile floors in the office areas and hallways, particularly in the original block of the building (Figure 355). Corridors in other sections feature brick and concrete block walls, replacement tile or carpet, and replacement drop ceilings (Figure 356). Wall surfaces are primarily drywall in the office areas and exposed concrete block, poured concrete, or brick in the laboratories and equipment rooms. Ceilings in the office area and hallways are of acoustic tile while those in the laboratories and equipment rooms are of steel or concrete. The lobby off the main entrance has an added floor surface of decorative tile (Figure 357). Within the lobby is a staircase leading to the basement and featuring an original aluminum handrail. The accelerator and experimental equipment areas are typically constructed of poured concrete walls and ceilings, up to $7 \mathrm{ft}$ thick, for radiation shielding (Figure 358). In addition, many of the rooms have steel encased concrete bank-vault-type access doors (Figure 359) (Thomason and Associates 2013:7-9). Restrooms in the original block of Building 6000 feature glazed ceramic tile, concrete floors, and original stall dividers (Figure 360).

\section{NATIONAL REGISTER EVALUATION}

Originally constructed in 1961 at a cost of $\$ 3,718,000$ by the Electronuclear Division that was originally part of Y-12, Building 6000 was designed to house the Oak Ridge Isochronous Cyclotron (ORIC). The ORIC, which started operation in 1962, was one of the world's first cyclotrons to research azimuthally varying field focusing. The ORIC was intentionally located in an area west of the security area surrounding ORNL, so that easier access could be provided to outside users, including non-US citizens (Thomason and Associates 2013:12). The cyclotron produced a wide variety of particle beams used in both chemistry and nuclear physics research and experiments. These included beams of nitrogen, oxygen, neon, and argon that were made available for physics and chemistry research (Johnson and Schaffer 1992:155 and 158).

The Electronuclear Division consolidated with the Physics Division in 1972 under the direction of Joseph Fowler and later Paul Stelson and James Ball (Johnson and Schaffer 1992:155 and 158). The first major reconfiguration to Building 6000, begun in 1975 and completed in 1980, included the addition of a 25-million volt Tandem Electrostatic Accelerator. The reconfiguration shifted the ORIC to serve as a booster accelerator. The new facility was named the Holifield Heavy lon Research Facility (HHIRF), in honor of U.S. Representative Chet Holifield. It was formally dedicated on December 8, 1980 and became a DOE national user facility, providing more than 70 ion species to researchers around the world (Cabage 2016).

The second and most recent major reconfiguration of Building 6000, the Holifield Radioactive lon Beam Facility (HRIBF), opened in 1996 and utilized the ORIC as a driver accelerator to produce radioactive ion species to be injected into and accelerated by the 25-million volt tandem accelerator. The HRIBF utilized world-leading isotope separation developments to provide beams of 200 rare isotopes, 50 of which were produced at world- 
record intensity. The equipment and staff of the HRIBF led to several advancements in the field of nuclear physics, including the "first measurement with a reaccelerated unstable beam in North America, the first acceleration of neutron-rich fission fragments leading to the confirmation of the doubly magic nature of the heavy tin isotope $132 \mathrm{Sn}$, the pioneering experiments on the giant quadupole resonance in nuclei, and dramatic new insights into numerous nuclear reactions that drive the evolution of the cosmos" (Cabage 2016).

After 50 years of operation, the Building 6000 was placed into shutdown status is 2012, though experiments with the tandem accelerator continued until early 2016. Through three major configurations, Building 6000 and its associated facilities, ORIC, the HHIRF, and the HRIBF supported nuclear physics and astrophysics research at ORNL over five decades. In July 2016, the HRIBF was named as an American Physical Society (APS) Historic Physics Site. Upon presenting the distinction, APS President Laura Greene explained that, "in naming the Holifield Radioactive Ion Beam Facility as a Historic Physics Site, the American Physical Society took into consideration the half century of nuclear and atomic physics research performed there, as well as the scores of scientists who performed experiments with its unique capabilities...the Holifield Facility has indeed been an important contributor to the physical sciences history" (Cabage 2016).

In 1994, Duvall \& Associates' survey of ORNL recommended that there was "insufficient historical perspective to assess the significance of facilities in the 6000 Area" and recommended reevaluating the facility when it became 50 years old (Carver and Slater 1994:278). Building 6000 was not included in Thomason and Associates' 2004 survey update (Thomason and Associates 2004). In 2013, Thomason and Associates completed an extensive documentation of the 6000 Area; however, it was not assessed for NRHP eligibility as a part of that review (Thomason and Associates 2013). The 2015 survey update completed by Thomason and Associates recommended that Building 6000 was not eligible for inclusion in the NRHP due to the extent of additions that date to the 1980s and the lack of available literature on the research and analysis in nuclear physics. A reexamination in 2030, when the 1980s-era portions of the building reach 50 years of age, was recommended (Thomason and Associates 2015:154-155).

Throughout its history, Building 6000 has housed three distinct processing facilities, the ORIC, the HHIRF, and the HRIBF, that have played important roles in the research mission of ORNL. However, additions to Building 6000 that occurred as a result of the two major reconfigurations to create the HRIBF represent more than half of the original footprint of the facility, such that Building 6000 no longer retains integrity to reflect its original use as the ORIC, the only use of the building that occurred over 50 years ago. While the significance of Building 6000 dating from its original construction through its final decommissioning in 2016 has been recognized by the physics community, its significance within United States' history more broadly is not yet clear. In its current state, the exterior of the building retains integrity to reflect its use from 1980 to the present, while the most important scientific equipment contained in the building dates to the 1990s, with older equipment repurposed to meet new research needs. Groundbreaking research occurred here between 1980 and 2016, but there is not yet sufficient historic perspective to understand the lasting impact of such research on American society. As such, CRA finds the Building 6000 lacks integrity to the historic period (pre-1967) and that it does not clearly exhibit exceptional significance to qualify for listing in the NRHP based on later uses of the building. CRA concurs with previous recommendations that the building be reevaluated as its circa 1980 additions reach 50 years of age. 


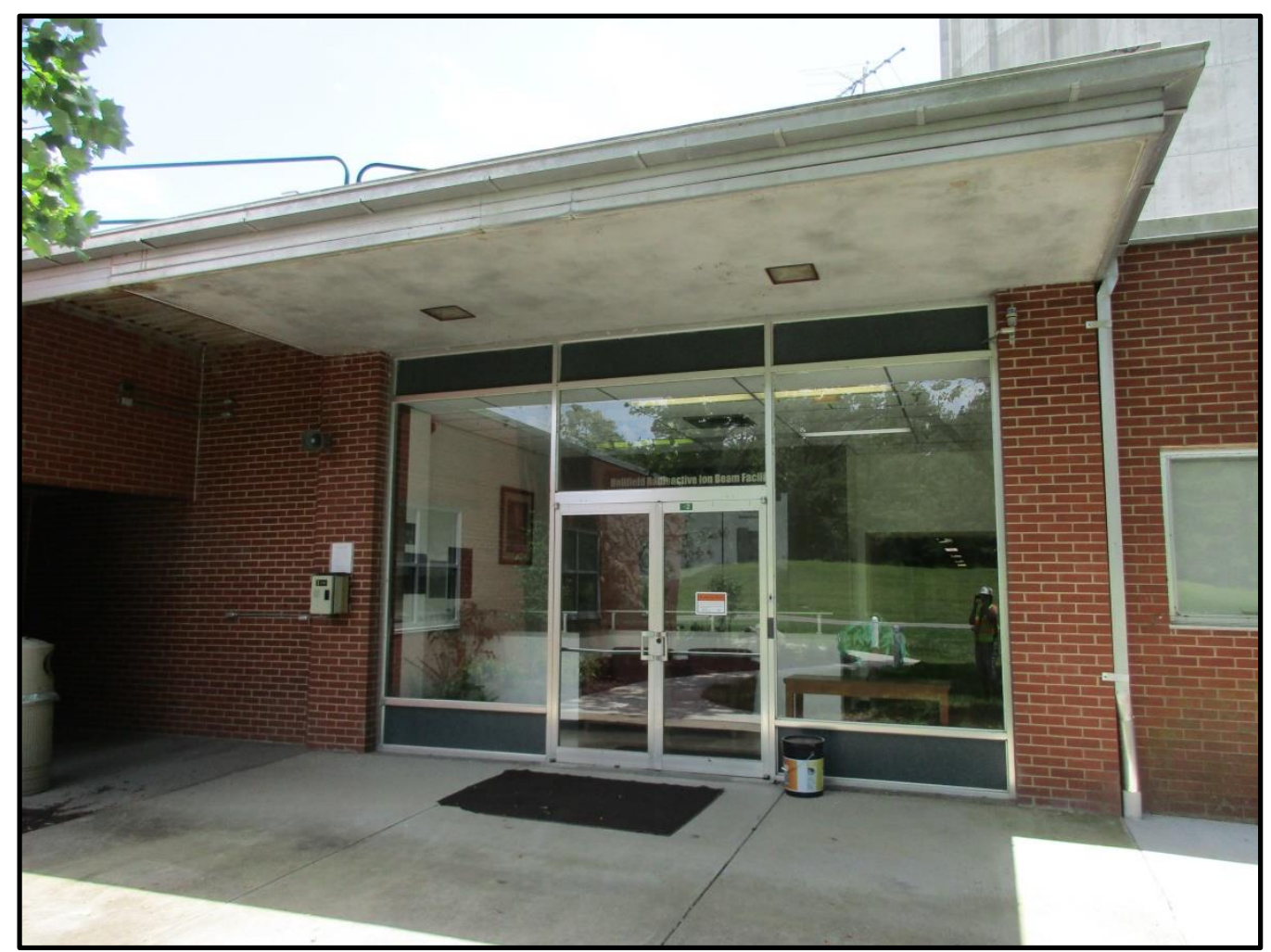

Figure 344. Façade entry on north elevation of original section of Building 6000.

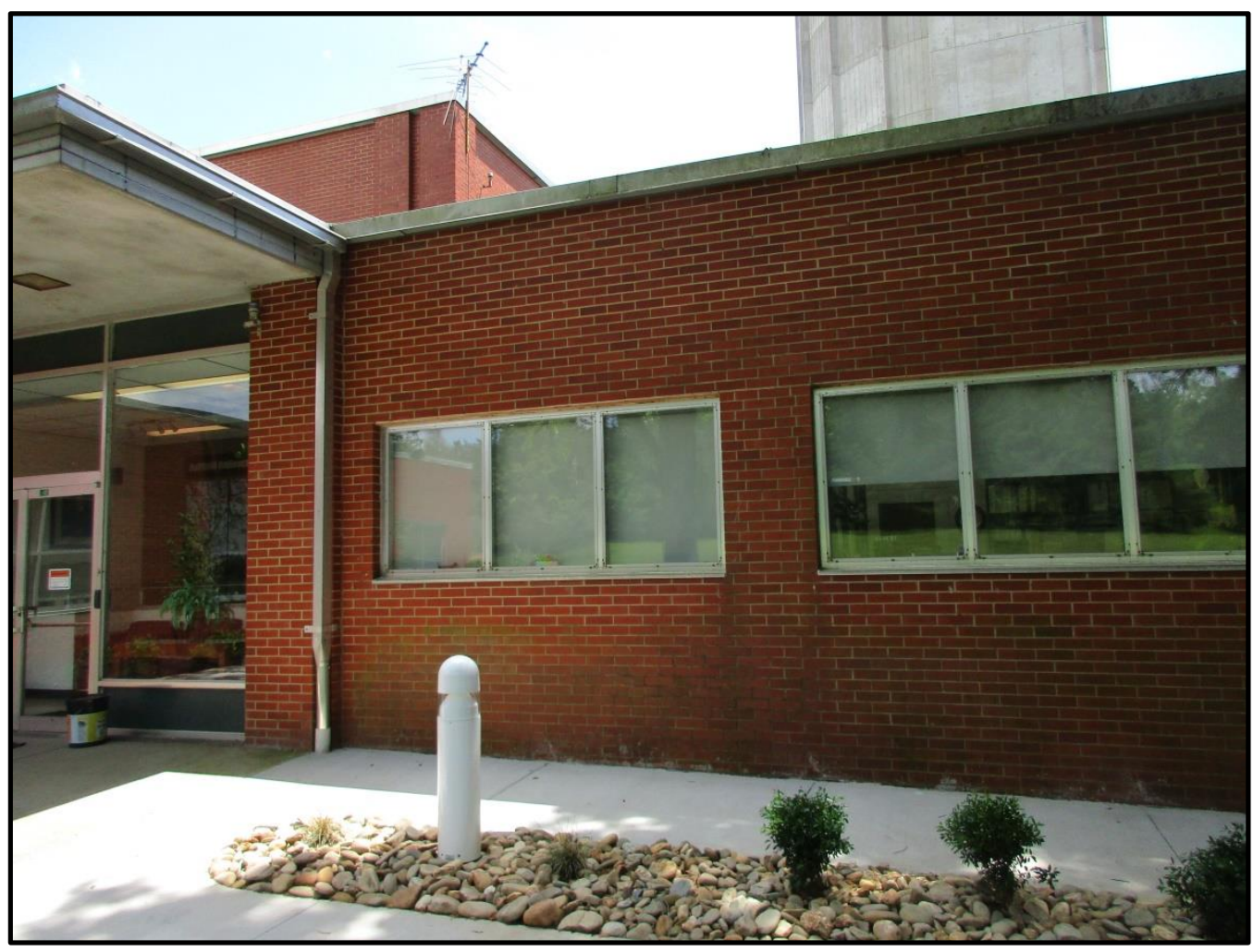

Figure 345. Window detail on the north (façade) elevation of the original section of Building 6000 . 


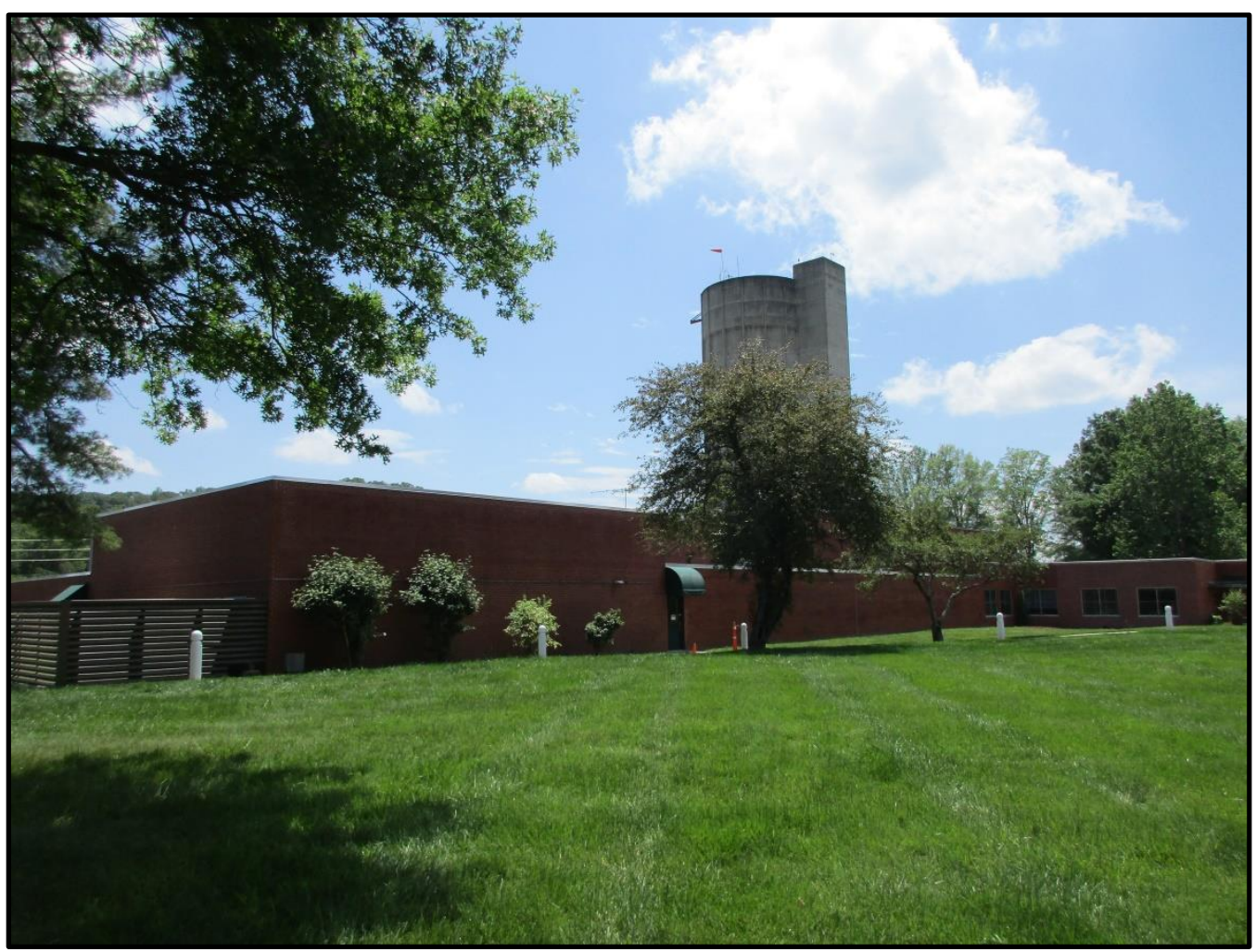

Figure 346. North (façade) and east wing of Building 6000.

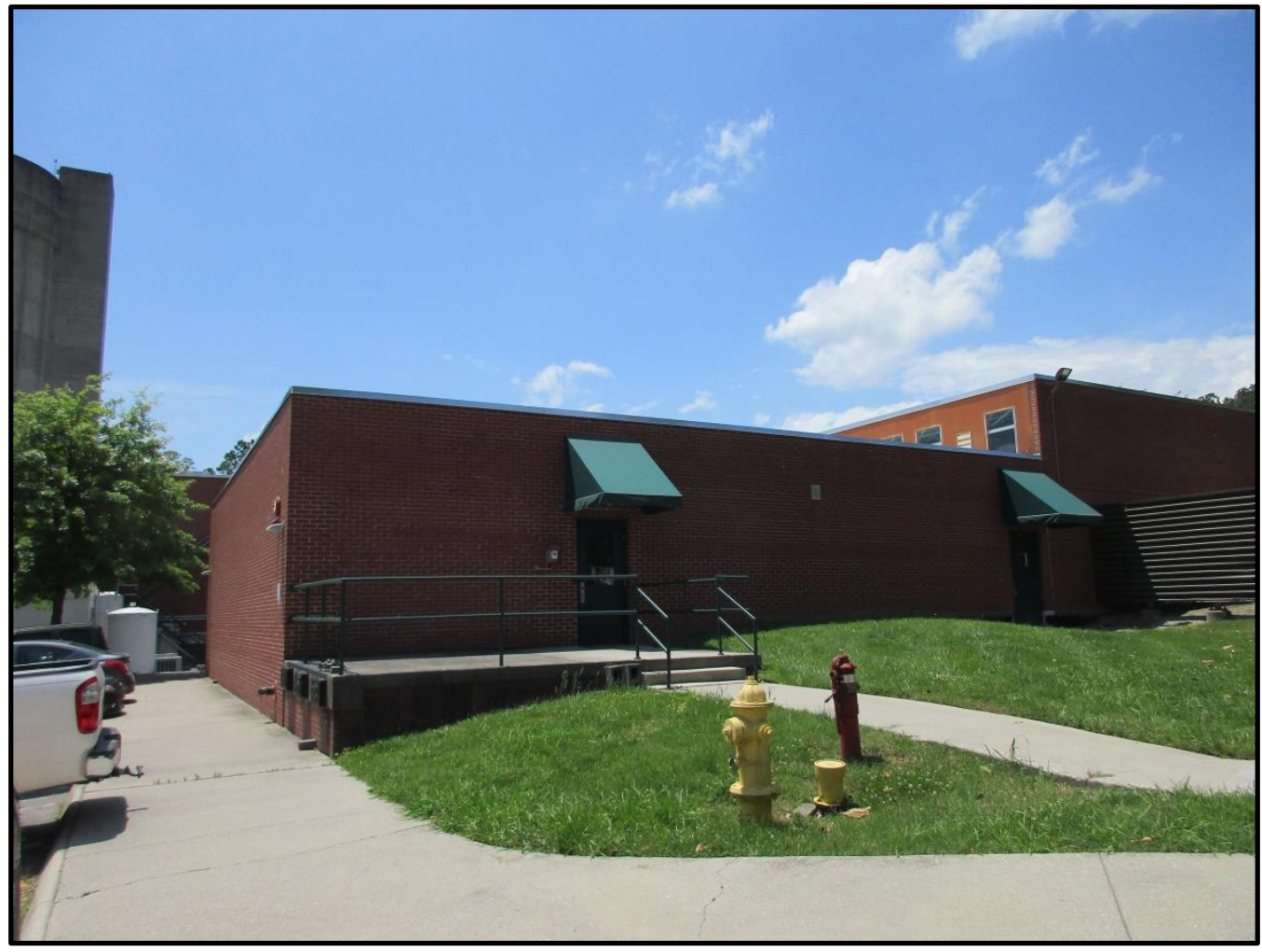

Figure 347. East elevation of the east wing of Building 6000. 


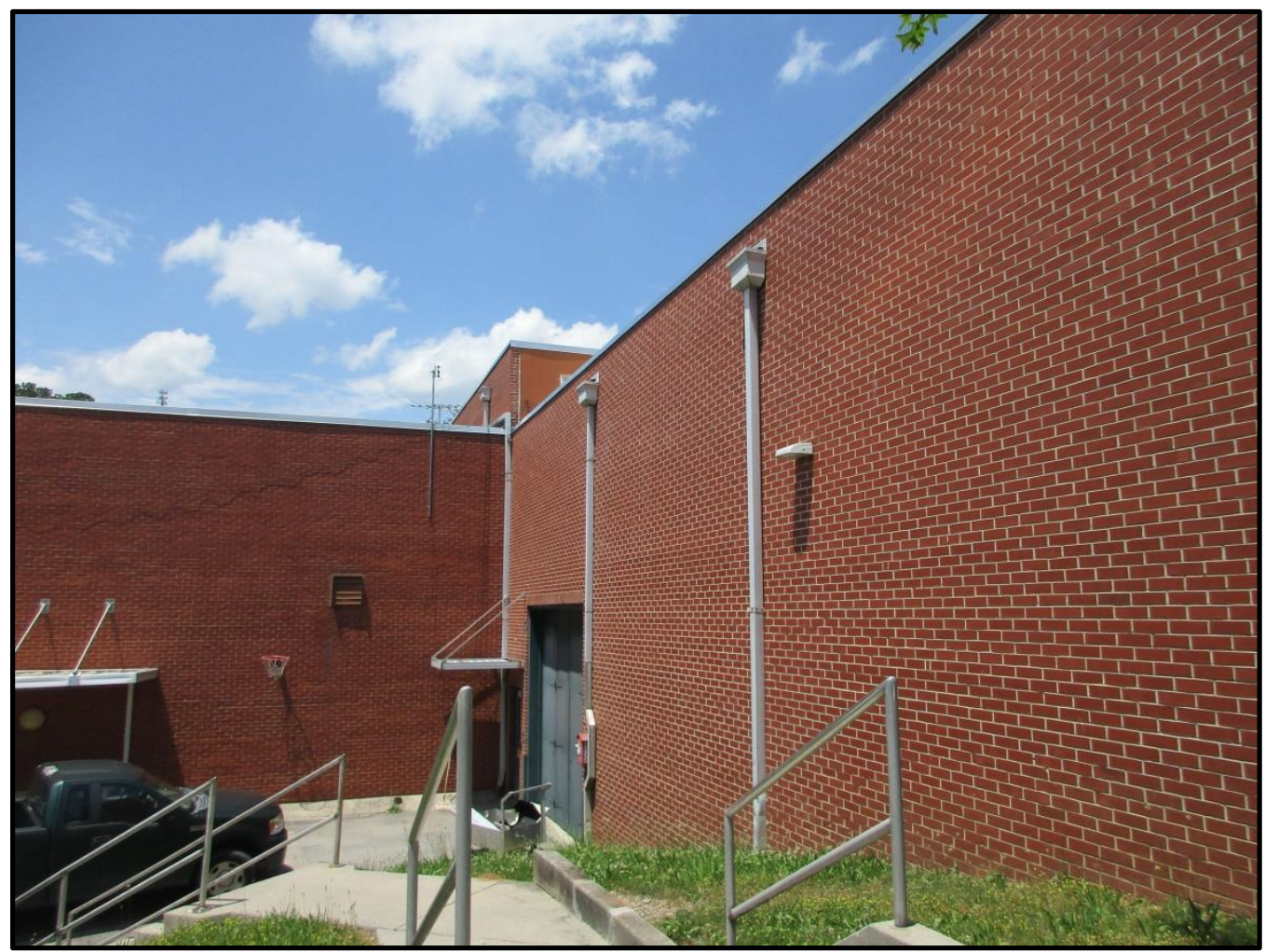

Figure 348. West corner of wing at the south corner of Building 6000 .

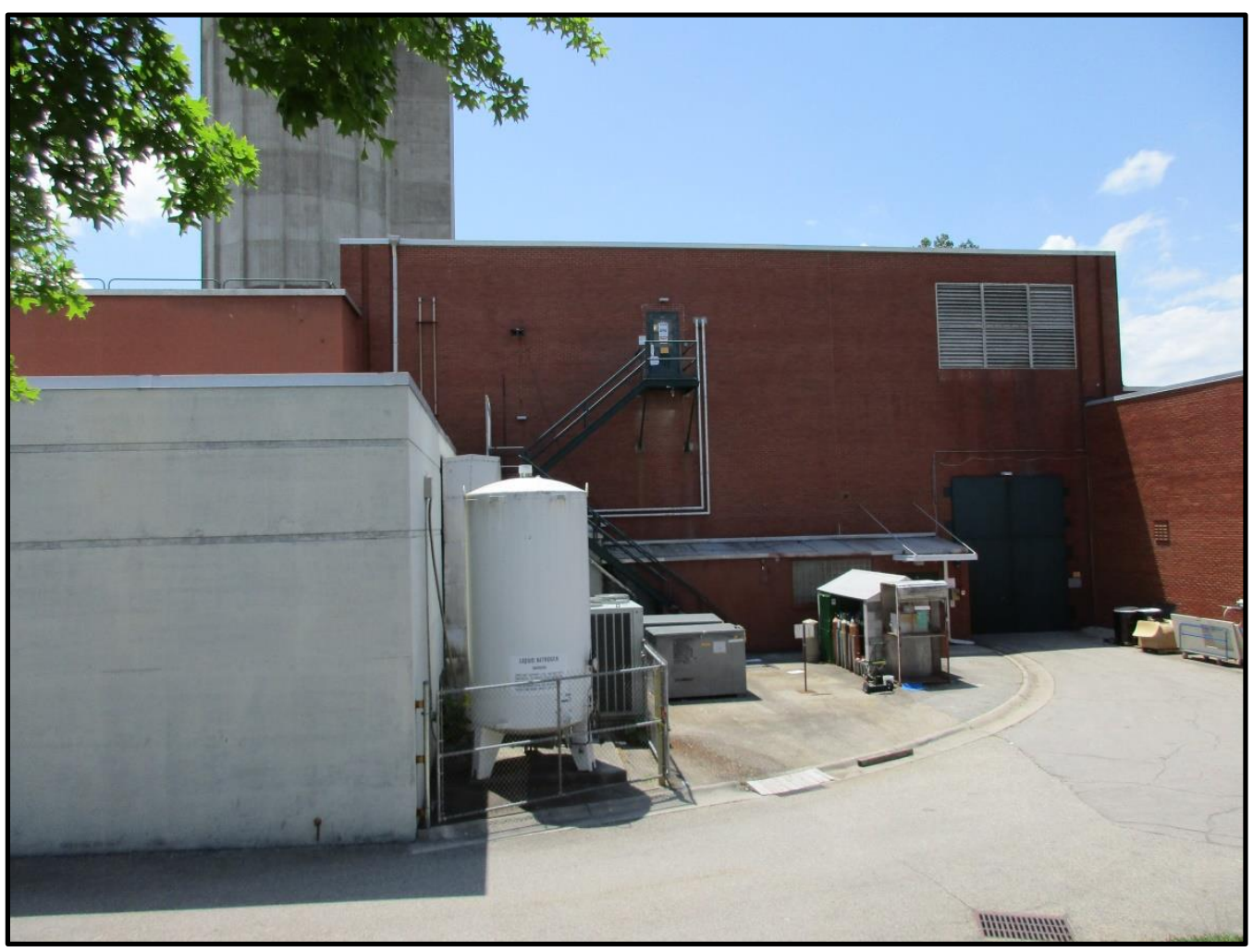

Figure 349. East elevation of the 1979 wings of Building 6000. 


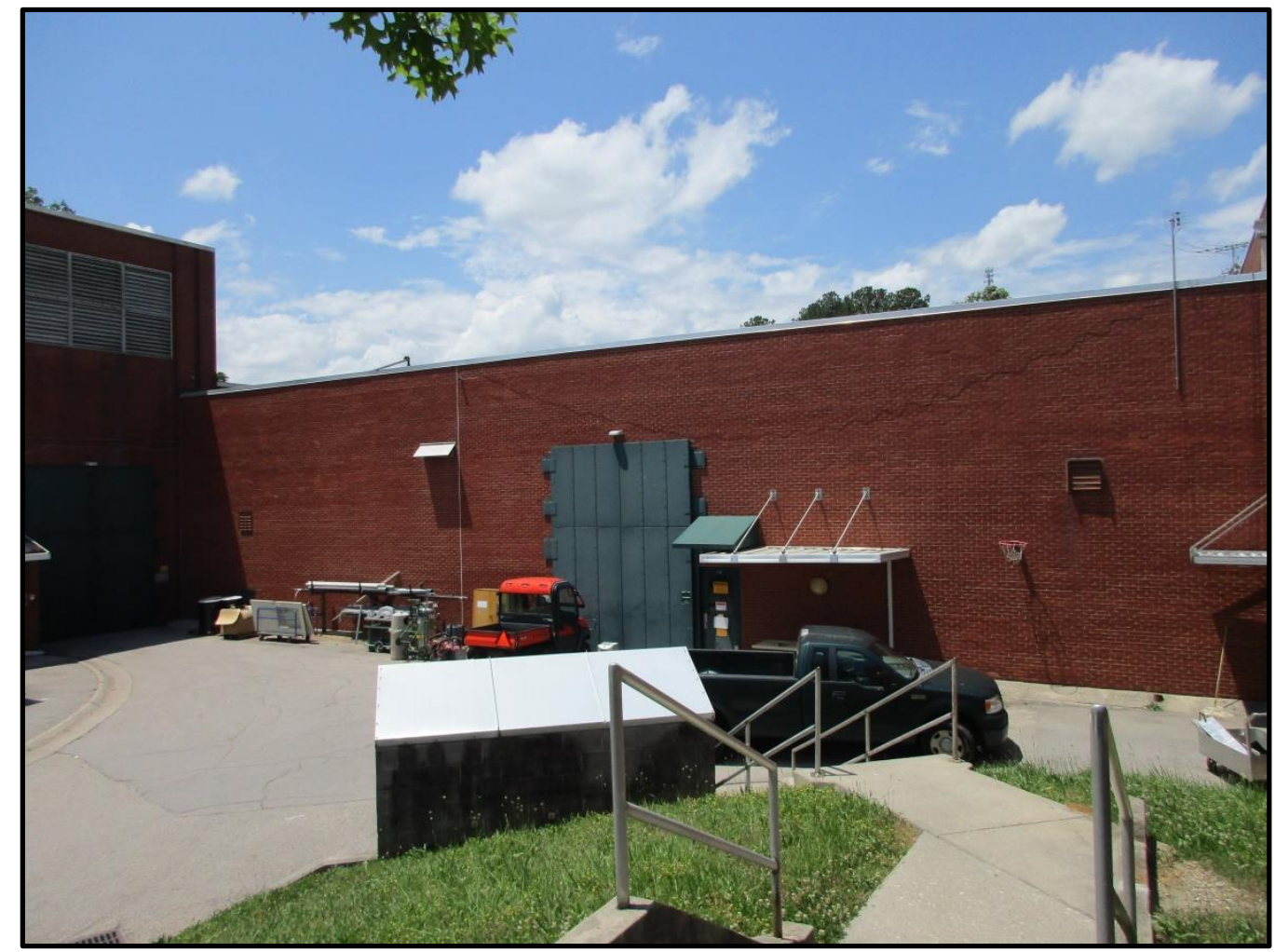

Figure 350. South elevation of the east wing of Building 6000 .

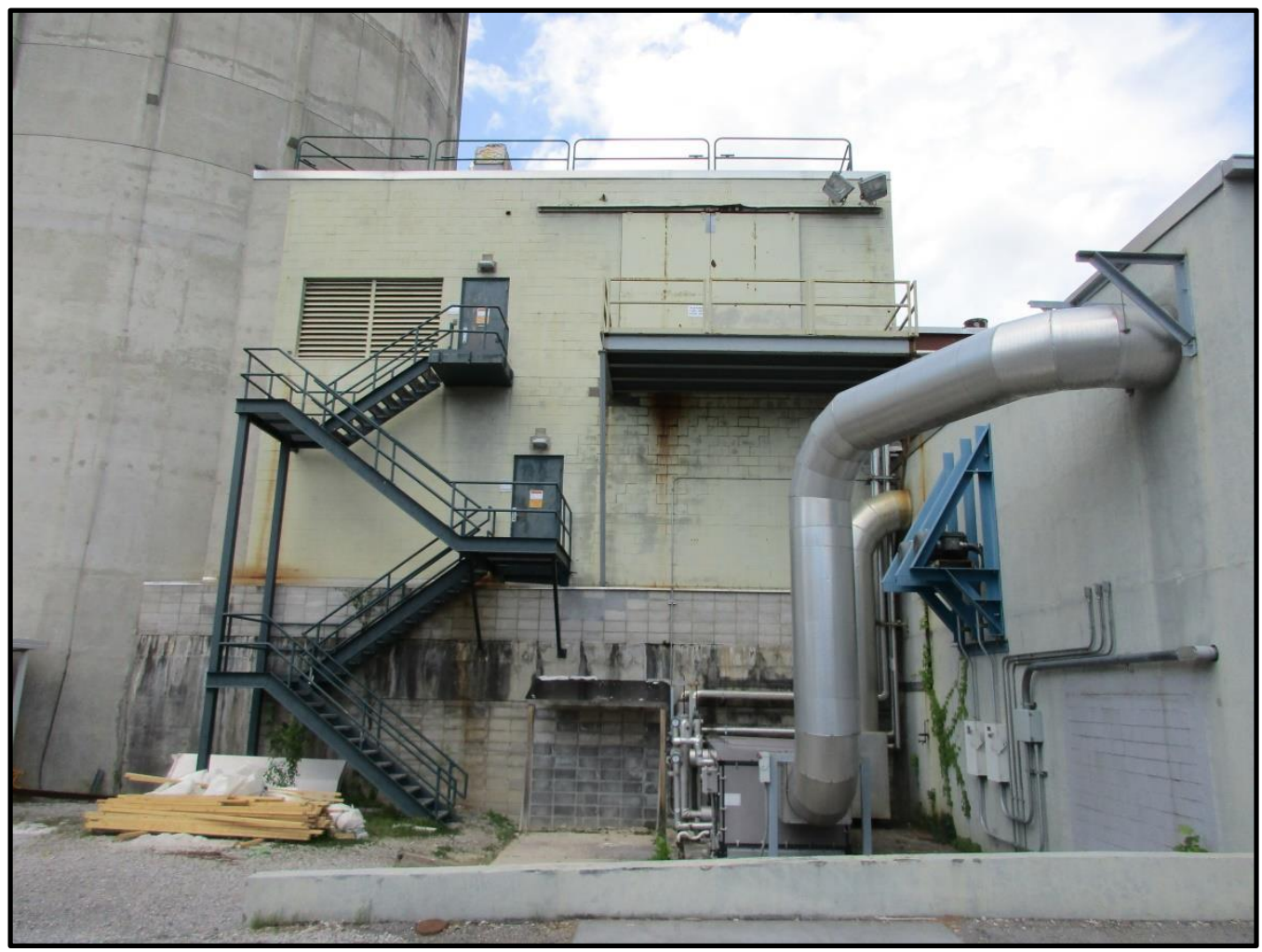

Figure 351. South (rear) elevation of rear additions of Building 6000. 


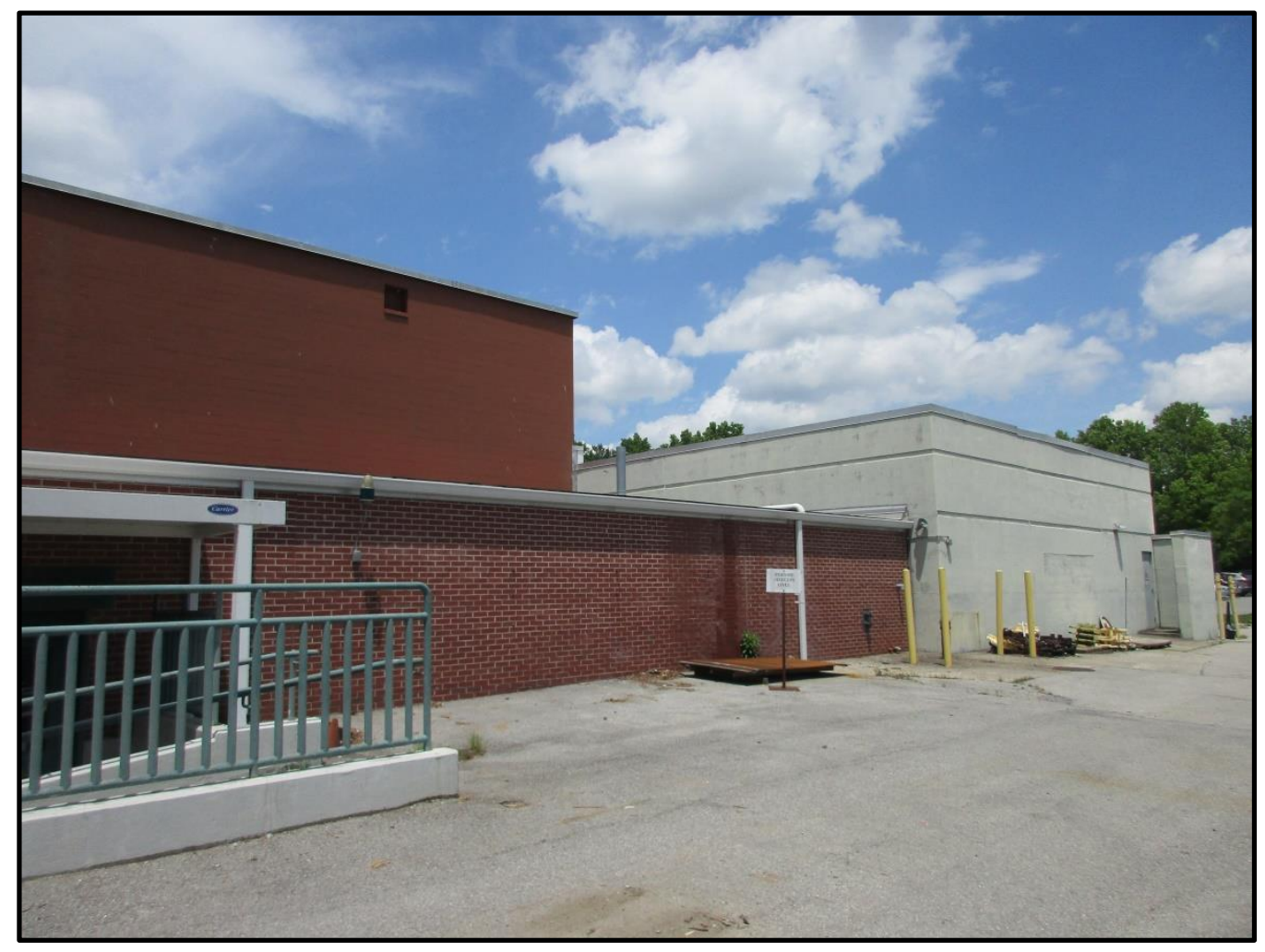

Figure 352. South (rear) elevation of South Annex and 1994 wing of Building 6000.

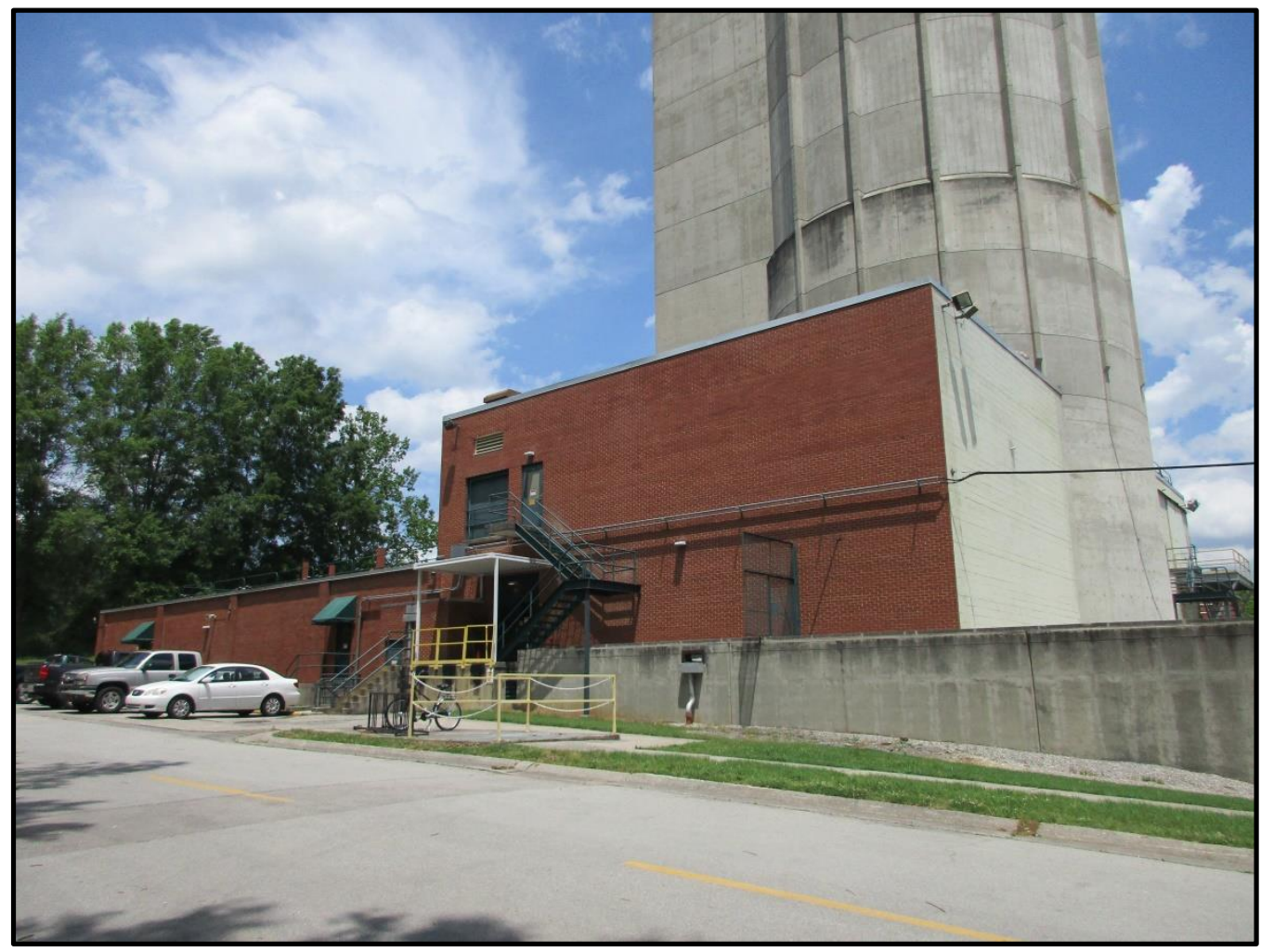

Figure 353. West elevation of Building 6000. 


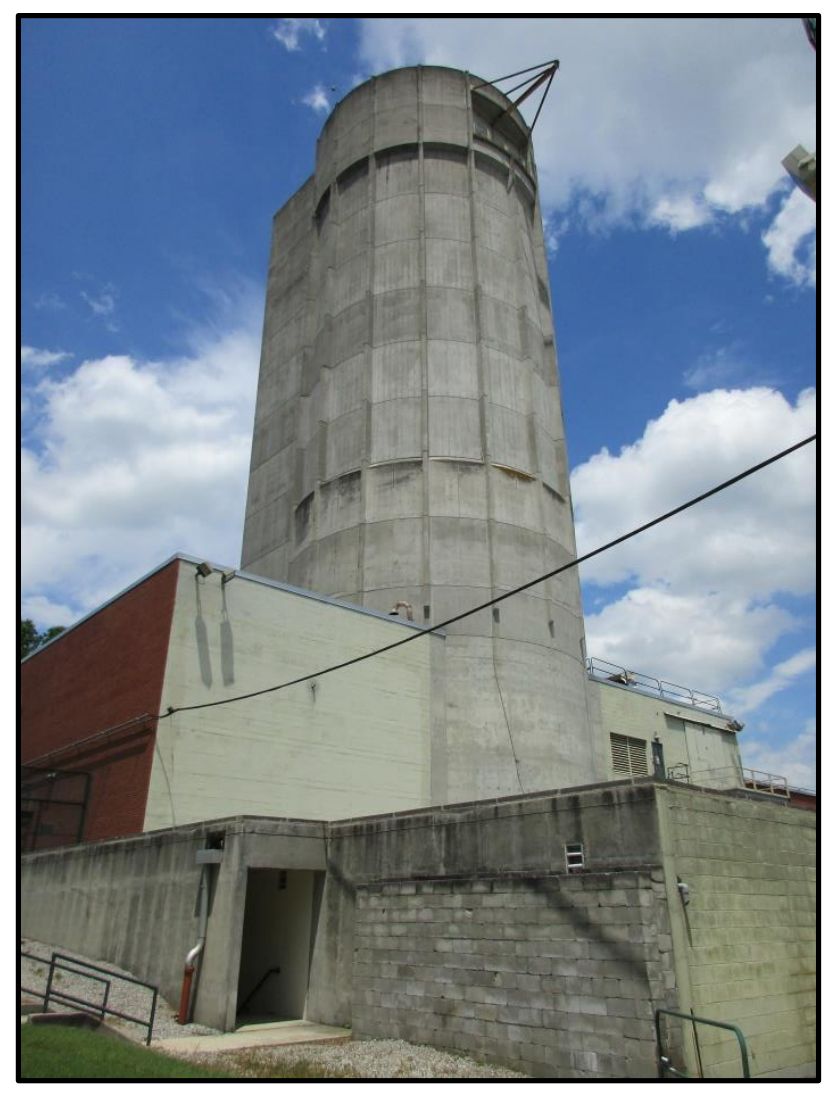

Figure 354. South elevation of concrete tower for accelerator of Building 6000 .

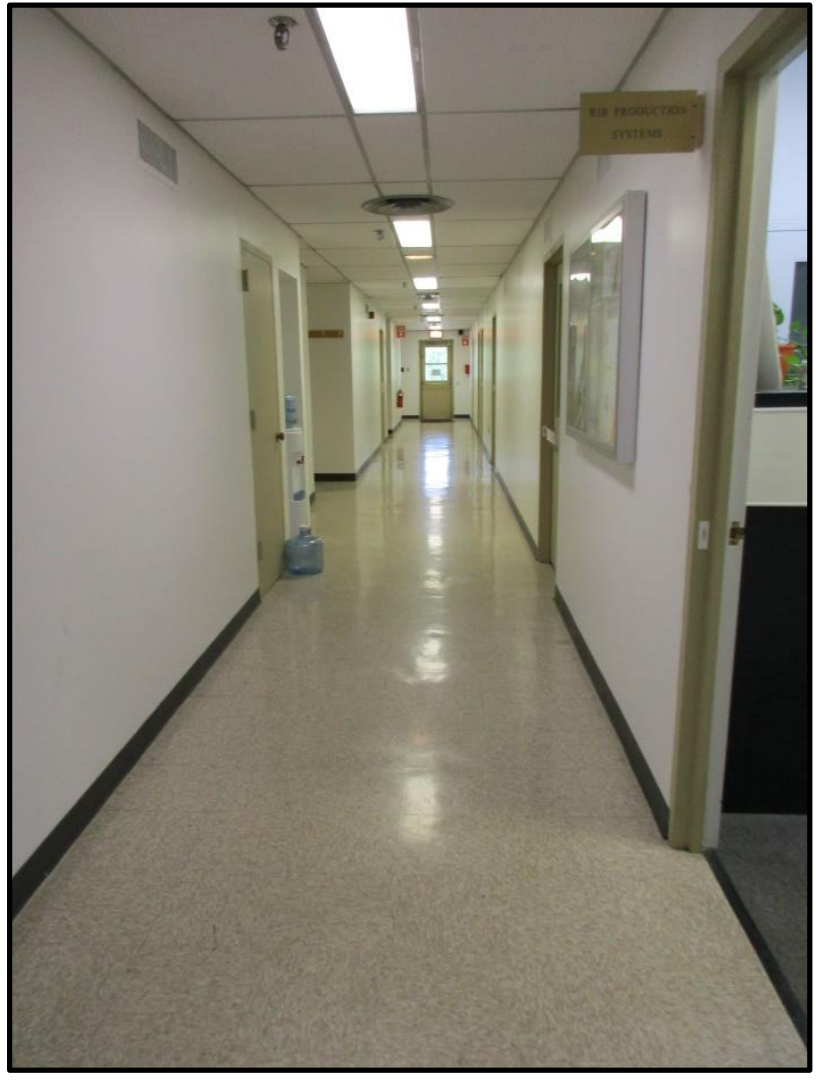

Figure 355. Second floor corridor in original 1960 block of Building 6000 . 


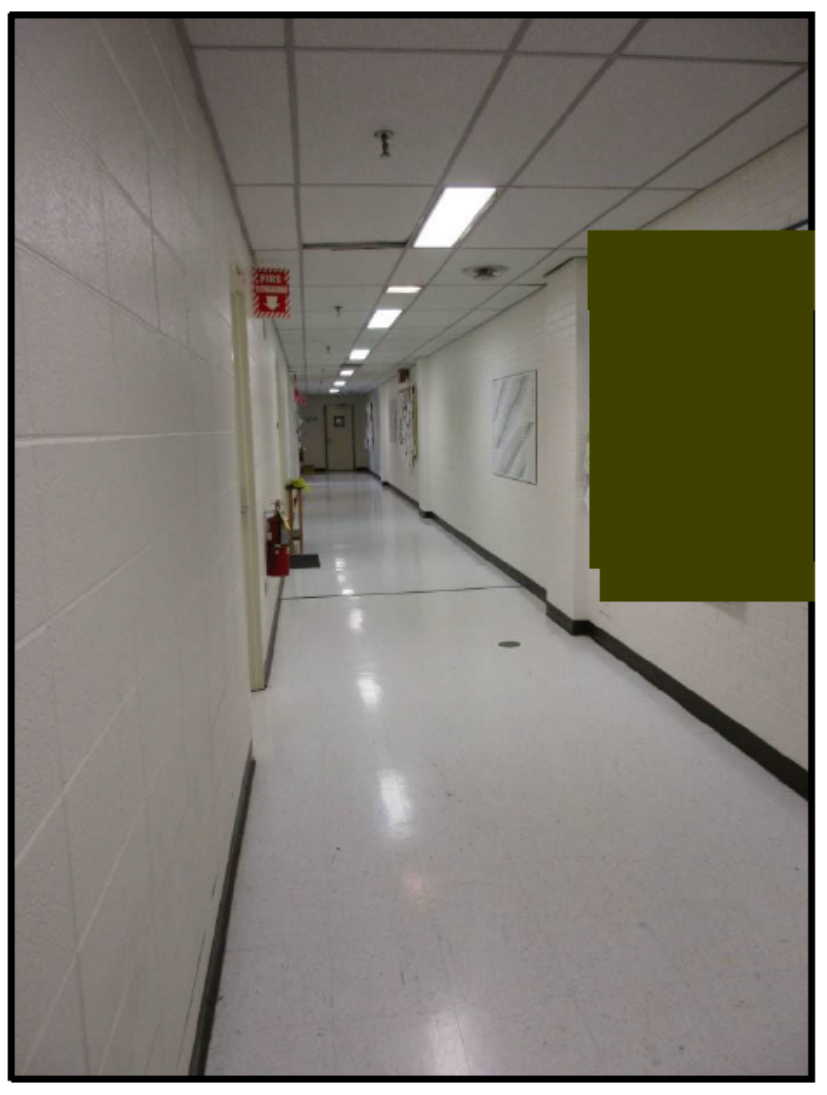

Figure 356. Corridor in South Annex of Building 6000.

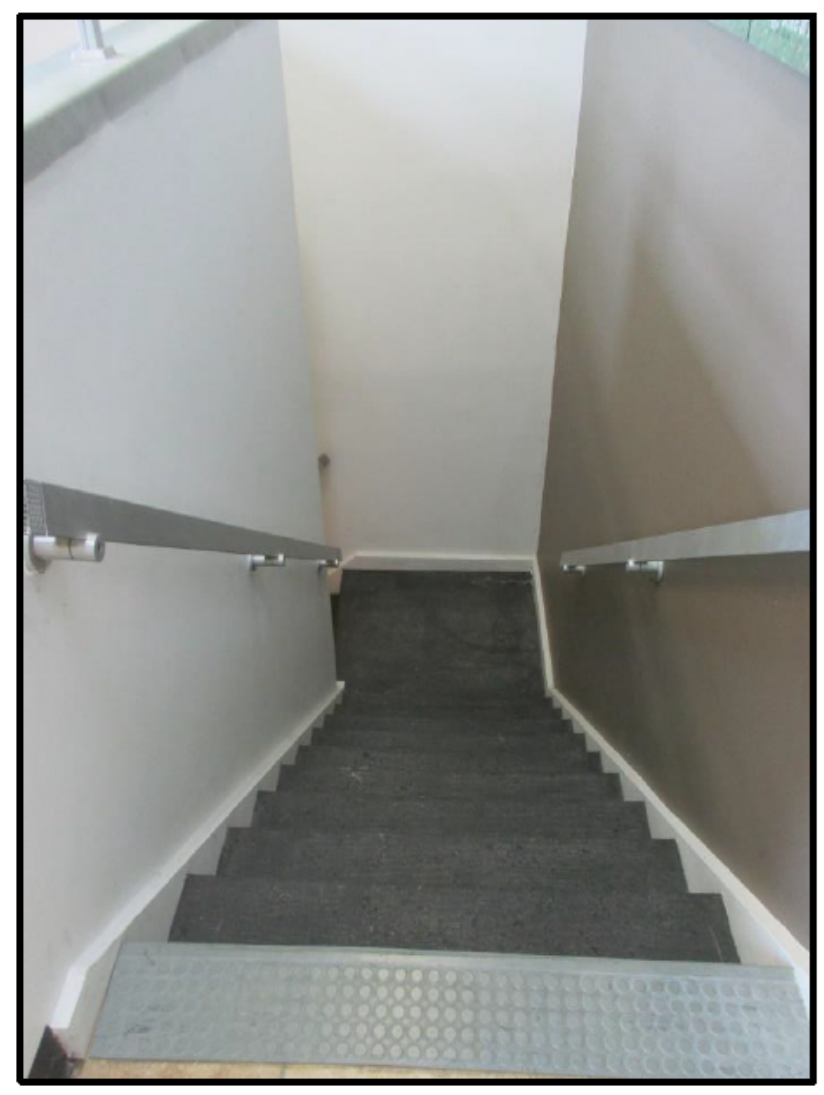

Figure 357. Renovated lobby in original section of Building 6000. 


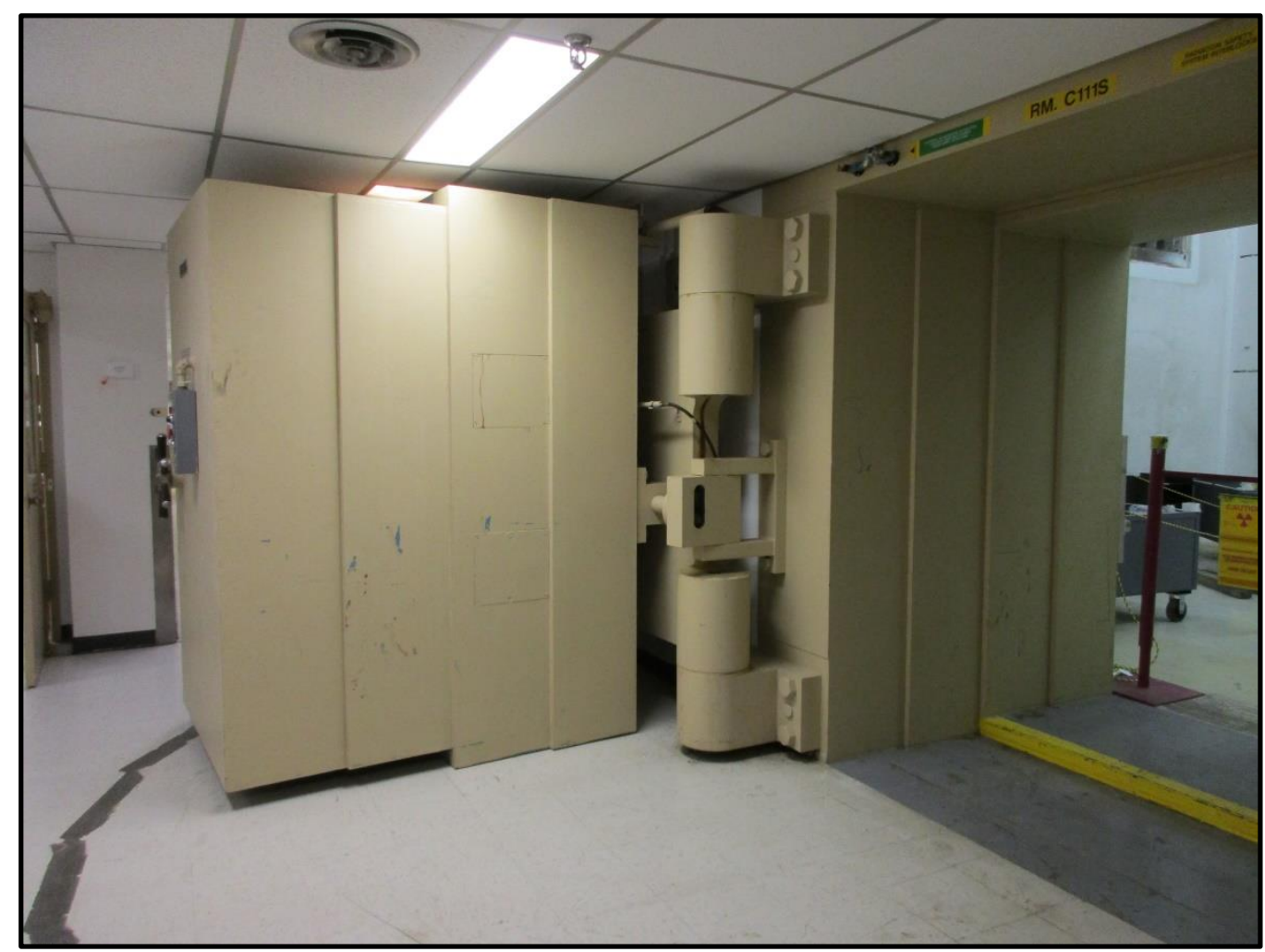

Figure 358. Thick walls in portion of original Building 6000.

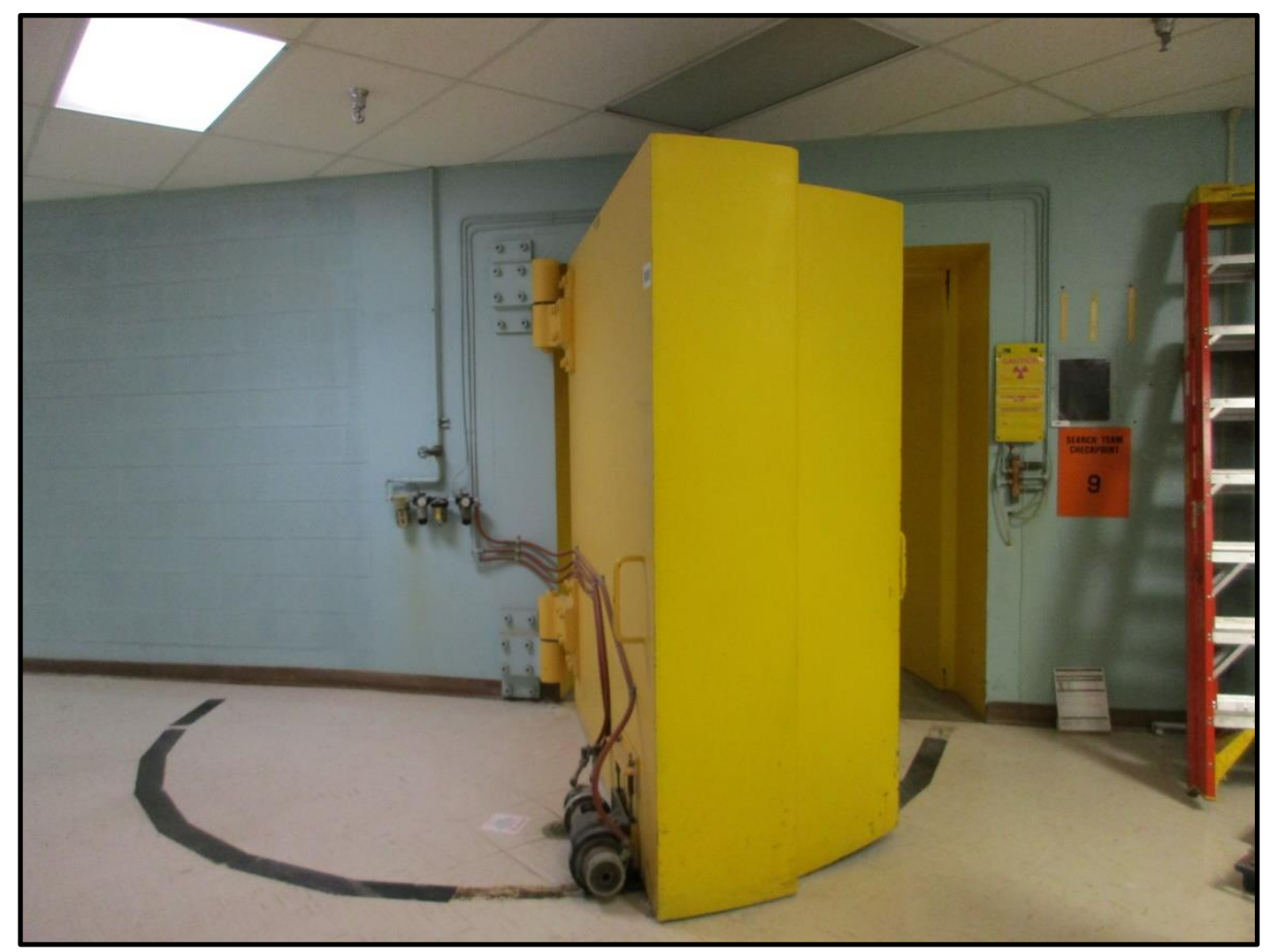

Figure 359. Shielded door on second floor of Building 6000 at the base of the accelerator in Building 6000. 


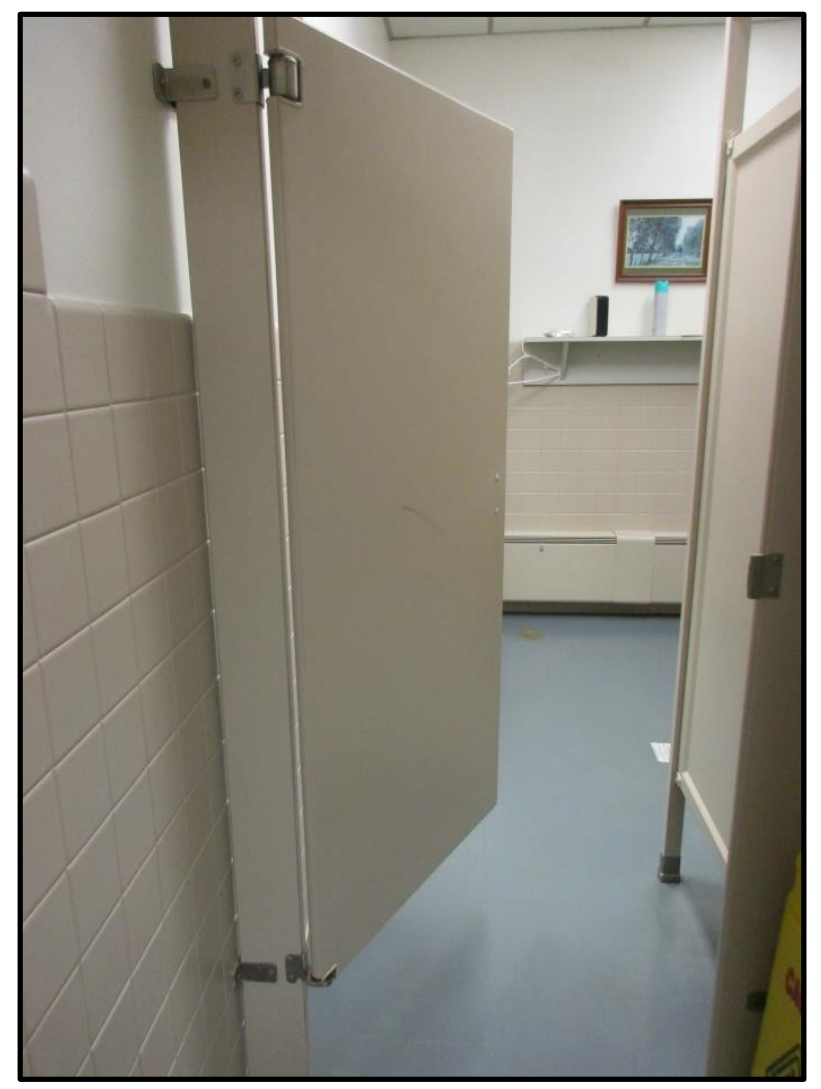

Figure 360. Restroom on second floor of the original section of Building 6000 . 


\section{BUILDING NAME}

Oak Ridge Electron Linear Accelerator

\section{DATE OF CONSTRUCTION}

1969

\section{DOE OFFICE RESPONSIBLE}

SC

\section{NRHP ELIGIBILITY}

Figure 361. North elevation of Building 6010 .

Not Eligible

\section{DESCRIPTION}

Building 6010 was one of 15 resources selected for intensive survey by UT-B as a part of survey planning. It is located just east of the main campus of ORNL and is oriented to the north, toward Bethel Valley Road. While targeted for intensive documentation as a part of this survey, the interior of Building 6010 was inaccessible at the time of survey because renovations to Building 6010 were underway. From beyond the barrier around Building 6010, renovations appeared to include the gutting and reorganization of the interior and the construction of a high bay addition to the east elevation.

Exterior: Building 6010 is a two-story, rectangular building of steel and masonry construction clad running bond brick veneer. Situated upon a continuous poured concrete foundation, Building 6010 is sheltered by a flat roof with metal coping. Variations in the shade of brick and mortar on all elevations indicates the addition of a second story to the building since its original construction in 1969.

The north elevation of Building 6010 features banks of paired single-light fixed aluminum windows along the first and second floors (Figure 361). Panels of concrete divide the paired windows and bands of cast concrete surround each bank of windows.

The east elevation of Building 6010 features a single-leaf entry with a steel and glass door that opens to a portion of a concrete walkway sheltered by a section of a flat concrete roof (Figure 362). This sheltered walkway previously connected Building 6010 to Building 6025; however, Building 6025 was demolished in January 2017. A second entrance on the second floor features a single-leaf entry that is sheltered by a cloth awning and opens to an exterior structural steel staircase. Banks of paired windows, similar to those found on the north elevation, also are located on the northern end of the east elevation. A three-story high bay addition, under construction at the time of survey, projects from the east elevation (Figure 363).

The south elevation of Building 6010 is partially set into an earthen berm (Figure 364). The south elevation of the high bay addition features a garage bay. A second garage bay is located on the east elevation of a onestory addition extending from the south elevation of the main block of Building 6010 . The only other fenestration of the south elevation is an entrance with a single-leaf single-light metal door on the second floor of the main block of the building that opens to the roof of the one-story addition. 
The west elevation of the rear of Building 6010 features a series of one-story, brick-clad, one-story additions, partially set into an earthen berm (Figure 365). The west elevations of the additions feature a garage bay and a single-leaf secondary entry with a single-light steel door sheltered by a cloth awning. The west elevation of the rear of Building 6010 features bands of single and paired aluminum stationary windows, set apart by bands of cast concrete (Figure 366). A single-leaf secondary entry is located on this section of the west elevation. A curved cloth awning shelters this entry, which opens to a concrete sidewalk.

The flight path for the Oak Ridge Electron Linear Accelerator (ORELA), currently inactive, runs beneath Building 6010 and the former location of Building 6025.

\section{NATIONAL REGISTER EVALUATION}

The ORELA was constructed in 1969 as an expansion of the ORIC complex in Building 6000. Comprised of an office and laboratory building (Building 6010) set over an underground accelerator covered by $20 \mathrm{ft}$ of earth shielding, the ORELA extended $75 \mathrm{ft}$ along an accelerator tube to a water-cooled target. This bombardment produced "more than ten times as many neutrons for short pulse operation than any other linear accelerator in the world," (Johnson and Schaffer:155 and 158). ORELA was created as a joint project between the Physics and Neutron Physics Divisions, headed by Jack Harvey and Fred Maienschien. Its primary purpose was to "obtain fast-neutron cross sections for the fast-breeder reactor program-that is, to determine the probability that a given fuel, shielding, or structural material would absorb fast neutrons," (Johnson and Schaffer:158). During its operation, ORELA was used for researching radioisotopes for medical and industrial purposes as well as generating heavy nuclei (Thomason and Associates 2015:156). Research conducted in 1990 with ORELA made a direct contribution to a better understanding of the strength of the force that holds the parts of a neutron together, when intense neutron beams bombarded a lead-208 target (Johnson and Schaffer 1992:155 and 158).

ORELA is no longer functional and the building was undergoing renovation and repurposing at the time of survey in May and June of 2017.

In 1994, Duvall \& Associates' survey of ORNL recommended that there was "insufficient historical perspective to assess the significance of facilities in the 6000 Area" and recommended reevaluating the facility when it became 50 years old (Carver and Slater 1994:278). Building 6010 was not included in Thomason and Associates' 2004 survey updates (Thomason and Associates 2004). In 2013, Thomason and Associates completed an extensive documentation of the 6000 Area; however, it was not assessed for NRHP eligibility as a part of that review (Thomason and Associates 2013). The 2015 survey update completed by Thomason and Associates recommended that Building 6010 was not eligible for inclusion in the NRHP. In addition to not having reached 50 years of age, Thomason and Associates determined there was not enough research regarding Building 6010's role in research and analysis in nuclear physics to determine if it possessed exceptional significance under Criteria Consideration G (Thomason and Associates 2015:156).

As a processing facility, Building 6010 housed the ORELA, a state-of-the-art accelerator that furthered ORNL's mission in nuclear science during the Cold War era and made significant contributions to nuclear science. Although not presently 50 years old, the building is nearing that threshold, and thus it was not evaluated under Criteria Consideration G. However, alterations and renovations as a part of repurposing, including the construction of a rear high-bay addition, and the construction of a second floor on the original building have diminished the design, materials, and workmanship of Building 6010 to such a degree that it no longer reflects its original appearance. As such, CRA recommends that the aboveground portions of Building 6010 lack the 
integrity needed for listing in the NRHP under Criterion A, B, or C. However, CRA did not have access to ORELA or its flight path during fieldwork, and the current survey did not specifically evaluate the NRHP eligibility of the scientific equipment contained within ORNL's research facilities.

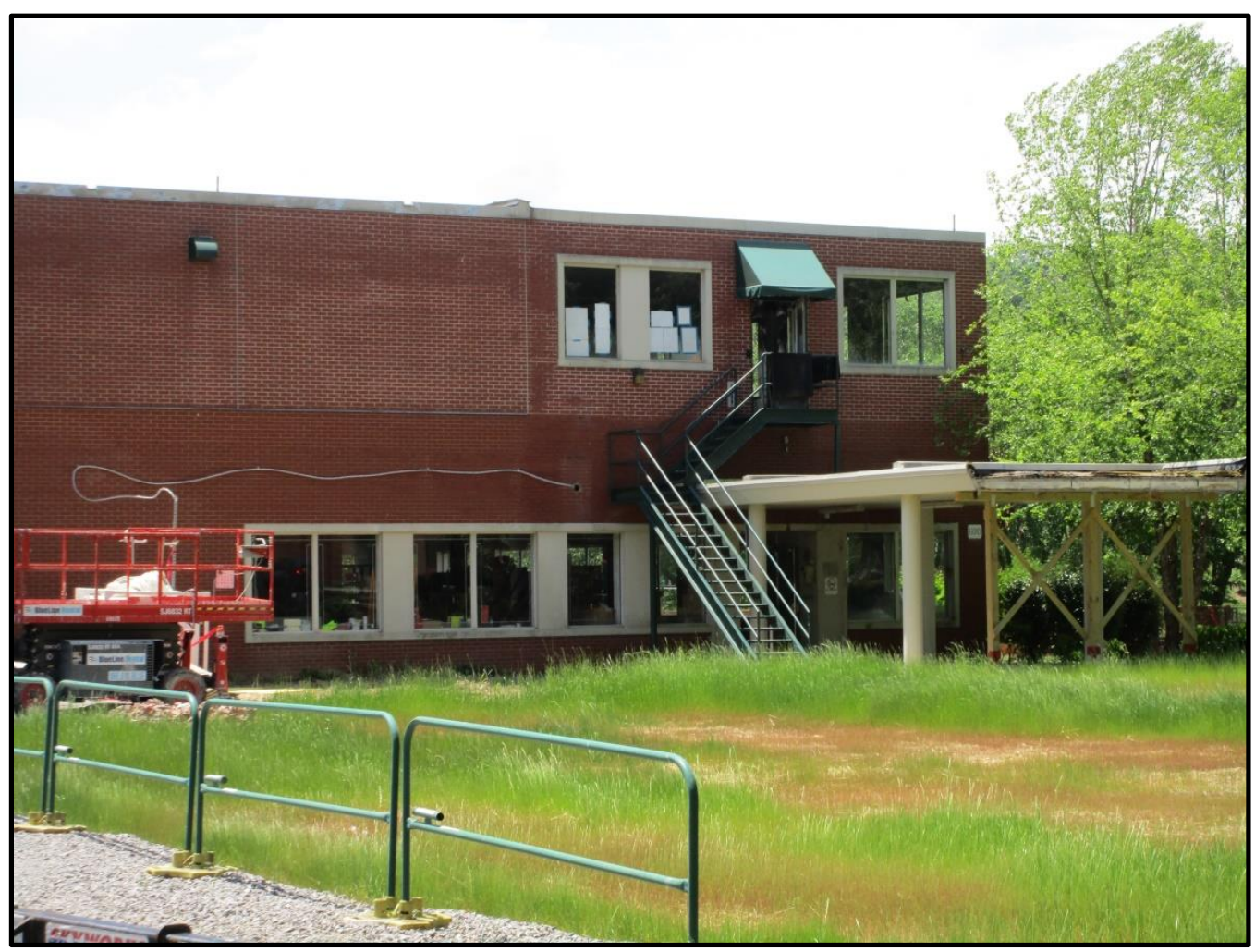

Figure 362. Primary and secondary entries on the east elevation of Building 6010. 


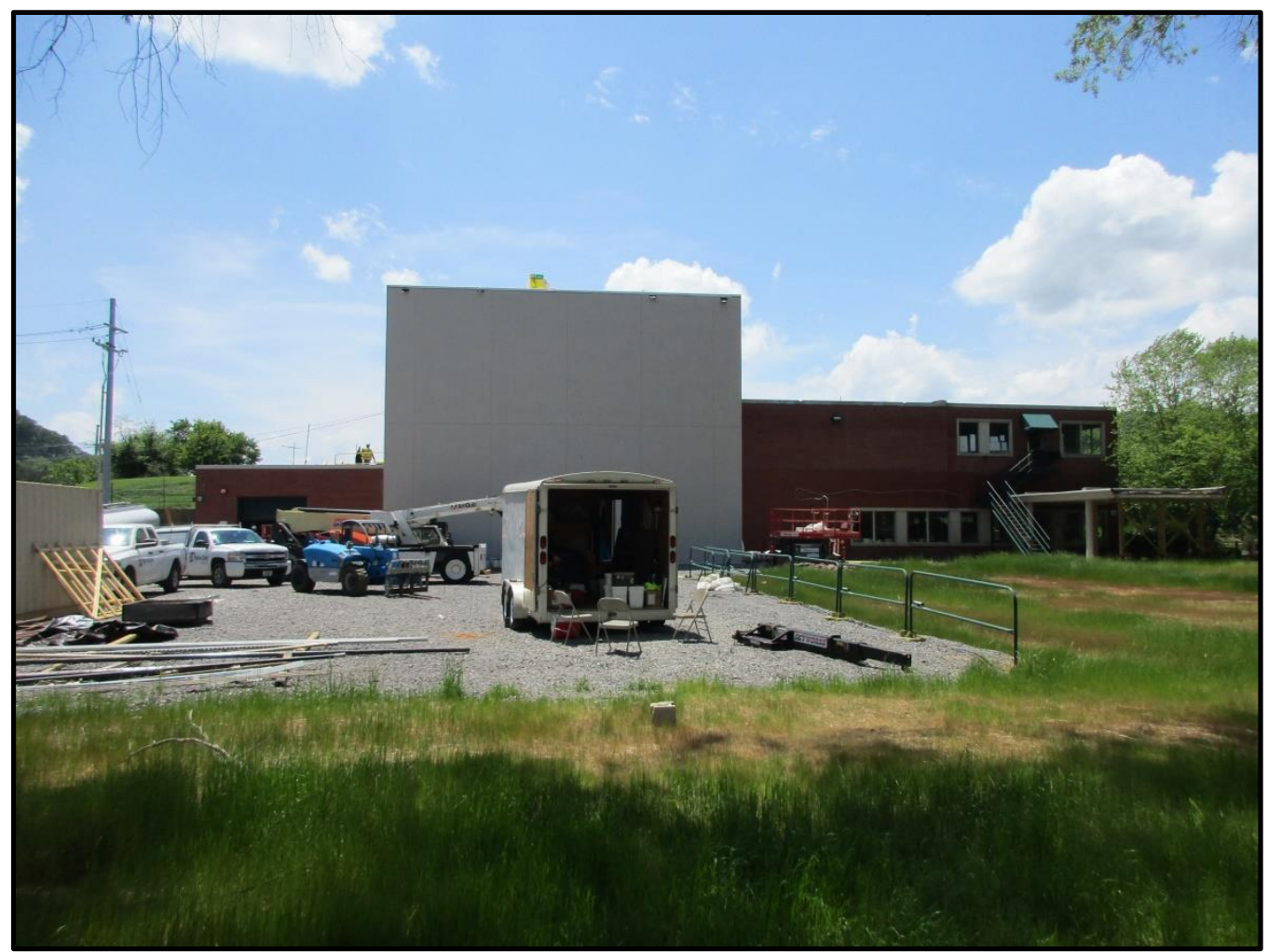

Figure 363. East elevation of Building 6010.

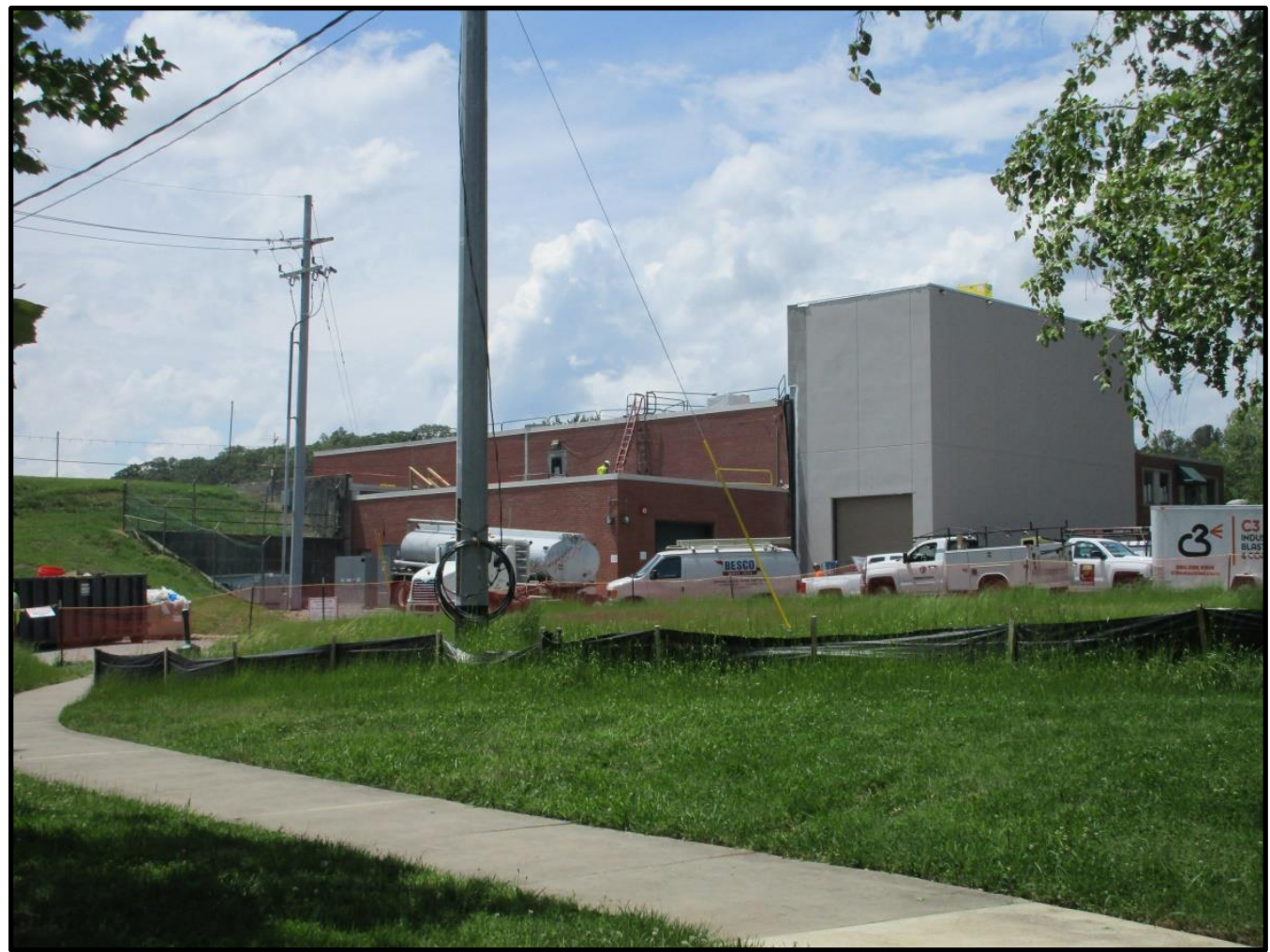

Figure 364. South elevation of Building 6010. 


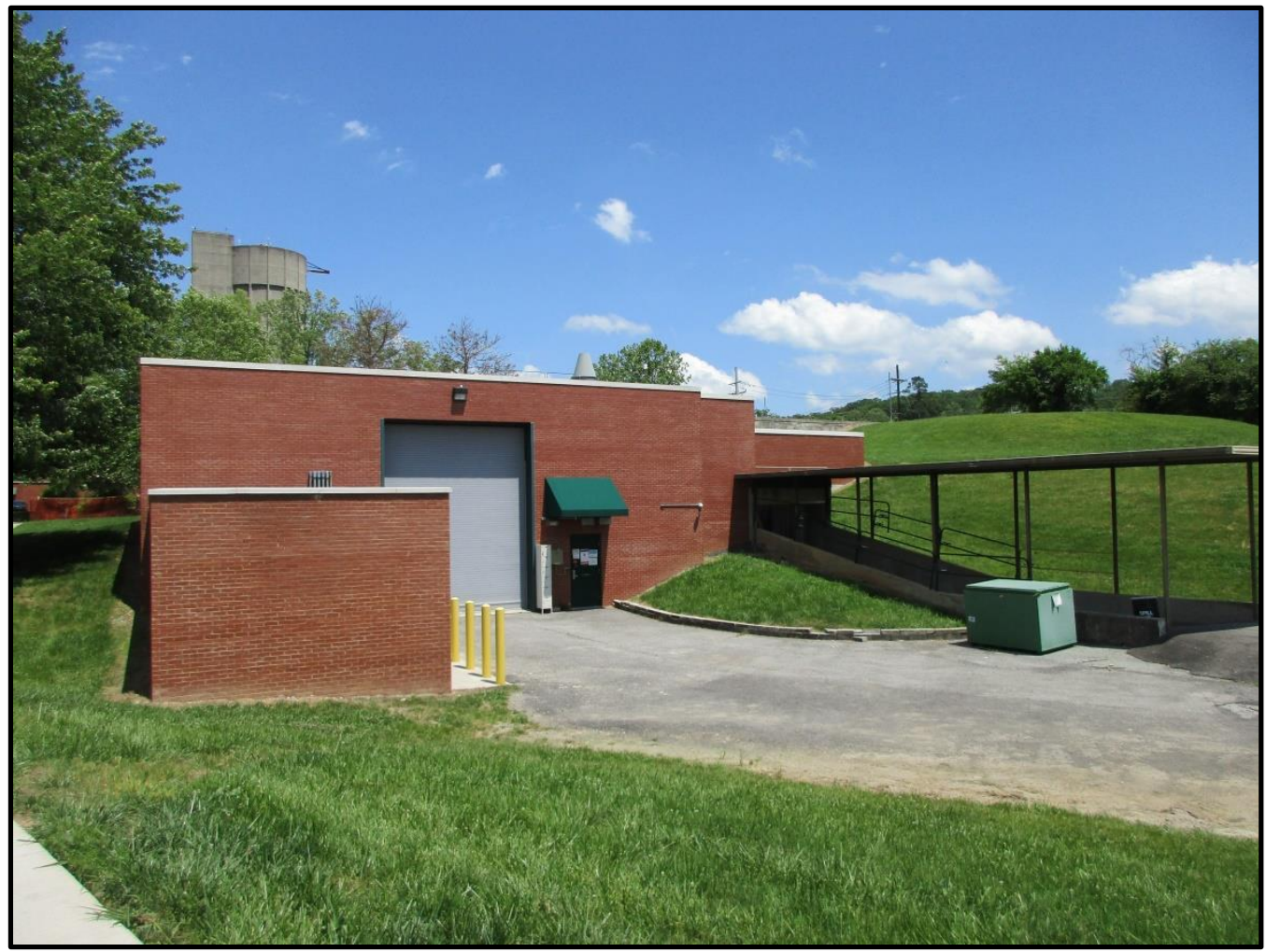

Figure 365. West elevation of the rear additions to Building 6010 .

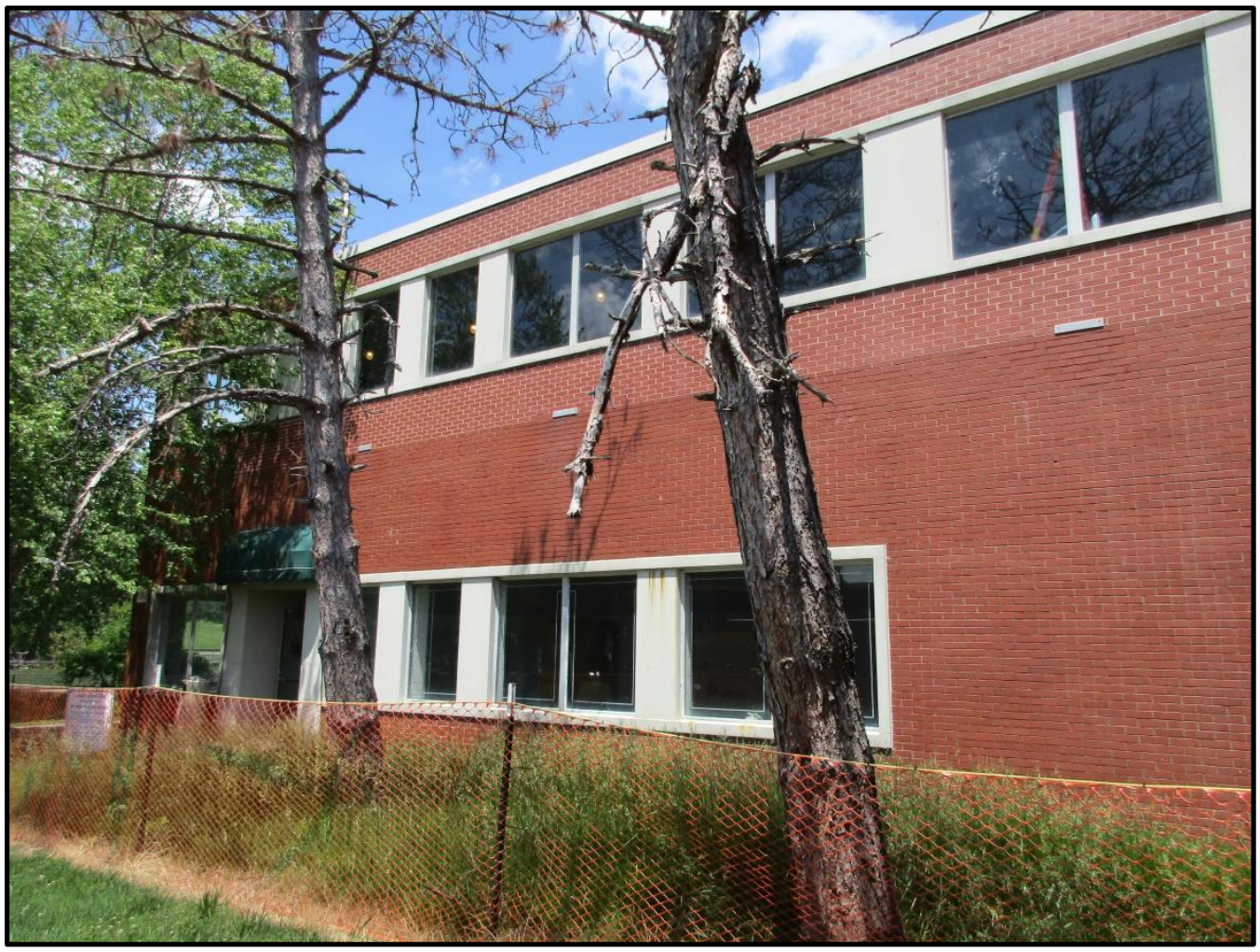

Figure 366. West elevation of the main block of Building 6010 . 
This page intentionally left blank 


\section{AREA}

\section{DISTRICT NAME}

East Support Area; 7000 Area of ORNL

\section{DATE OF CONSTRUCTION}

1947-2013

\section{NRHP ELIGIBILITY}

Not Eligible

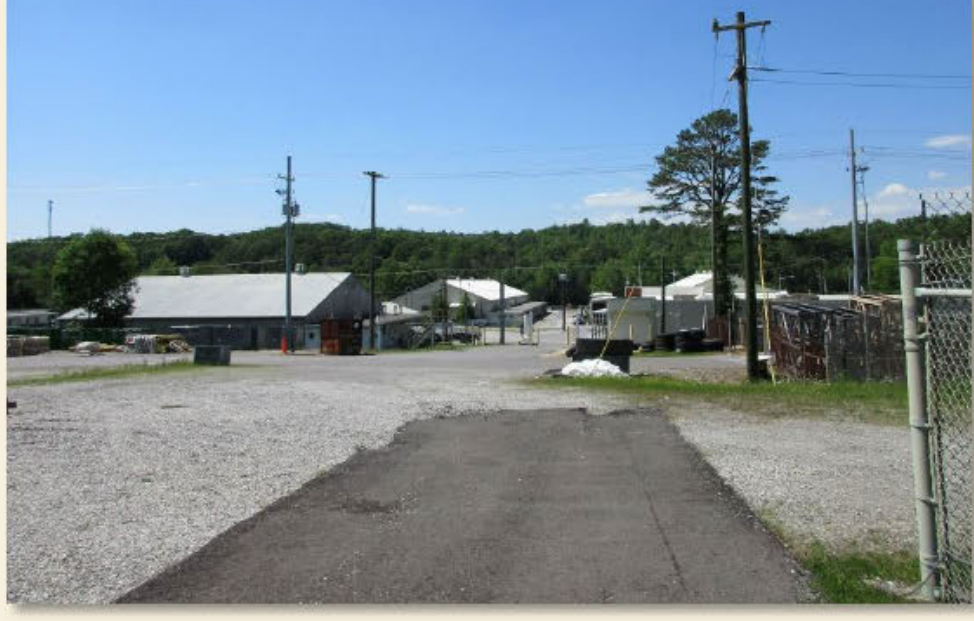

Figure 368. View of the 7000 Area looking toward Buildings 7013 and 7120.

Buildings 7001 and 7015 can be seen in the background.

\section{DESCRIPTION}

The 7000 Area is located east of the main campus of ORNL, south of Bethel Valley Road and east of Melton Valley Access Road. Known as the East Support Area, this cluster of buildings houses the shops and facilities to support the operation of the main campus and research facilities of ORNL (Figures 368 and 369). White Oak Avenue is the primary access road running through the 7000 Area. Much of the landscape surrounding the buildings located in the 7000 Area is gravel and pavement. Other key landscape features within this area include several articulate pathways located near Building 7067 . Fifty-eight total buildings are located within the 7000 Area. Out of the 58 resources, 30 buildings built before 1980 were surveyed in this assessment.

\section{NATIONAL REGISTER EVALUATION}

The 7000 Area is the primary historic and current maintenance and utility area at ORNL. As such, it provided, and continues to provide, vital support services to the rest of the facility, but it lacks the direct and significant ties to pioneering work in nuclear science found in the research areas of the laboratory. Since ORNL as a whole does not qualify for listing in the NRHP as a historic district, and since the 7000 Area is physically distant from those research areas that are eligible, it cannot contribute to part of a larger historic district. On its own, the 7000 Area lacks associations to events or persons of historic significance to merit listing in the NRHP under Criterion A or B. As a group of simple utilitarian structures, it also lacks the significance needed for listing in the NRHP under Criterion C. Further, the integrity of many individual buildings and the area as a whole is compromised by additions and alterations. Thus, CRA recommends that the 7000 Area does not qualify for listing in the NRHP as a historic district. 


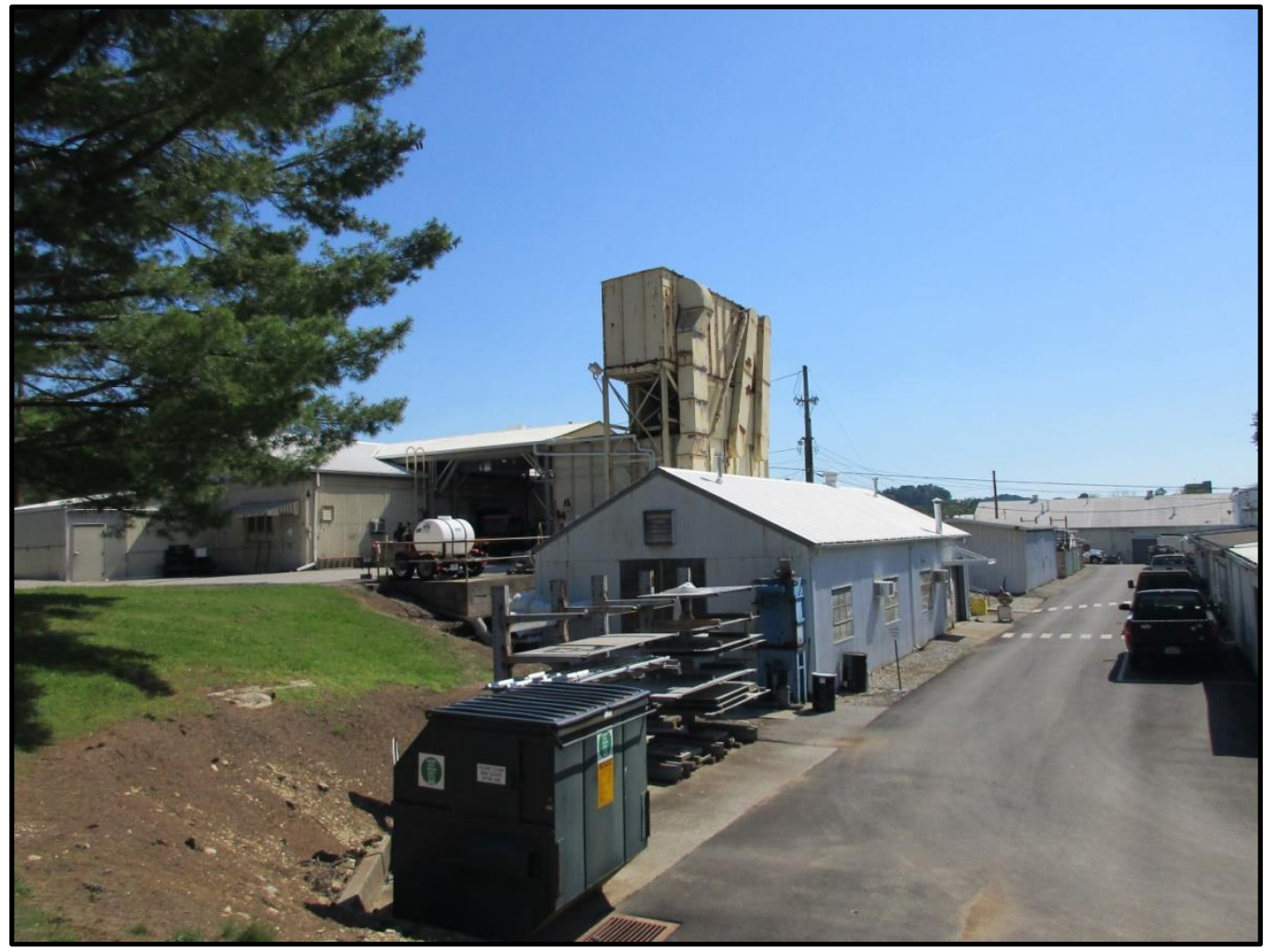

Figure 369. View of the 7000 Area looking toward Buildings 7021, 7031, and 7057. 


\section{A}

\section{BUILDING NAME}

Sewage Pumping Station Equipment Storage

\section{DATE OF CONSTRUCTION}

1948

\section{DOE OFFICE RESPONSIBLE}

SC

\section{NRHP ELIGIBILITY}

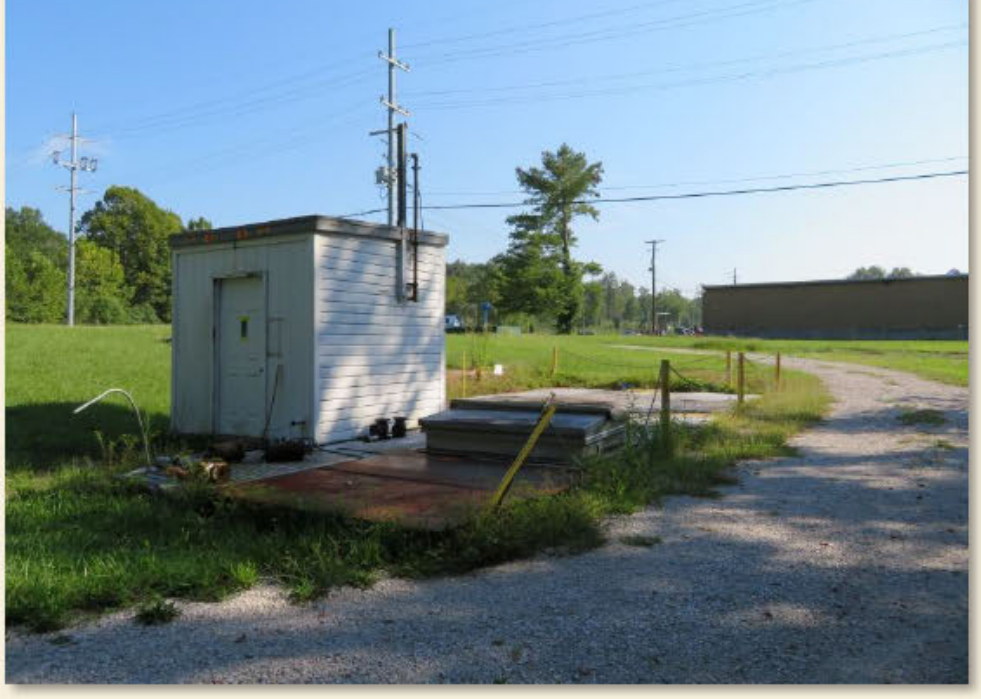

Figure 370. Overview of west and south elevations of Building 7000A.

\section{DESCRIPTION}

Building 7000A is located on a gravel loop south of Bethel Valley Road, east of Melton Valley Access Road, and north of White Oak Avenue. Building 7000A is a one-story, single-bay, shed-roof, wood-frame building and is situated on a large concrete pad foundation (Figures 370 and 371). The building is clad with wood panel siding simulating vertical boards on the east and west elevations and horizontal wood novelty siding on the north and south elevations. The structure has a low-pitch, asphalt-clad shed roof. The façade (west) elevation has a single-leaf entry filled with a six-panel modern door. The remaining elevations are blank. Several utility resources are located near and around the building.

\section{NATIONAL REGISTER EVALUATION}

Building 7000A was constructed in 1948 as a Sewage Pumping Station Equipment Storage facility. Building $7000 \mathrm{~A}$ was first surveyed as Building 7000 in 1994 by Duvall \& Associates and was recommended as not eligible for listing in NRHP (Carver and Slater 1994). It was not included in the 2004 and 2015 surveys of ORNL (Thomason and Associates 2004 and 2015). It was recently documented by CRA in 2017 (Leeds 2017a). At that time, CRA concurred with the 1994 assessment and recommended Building $7000 \mathrm{~A}$ as not eligible for listing in the NRHP. As a utility building, Building $7000 \mathrm{~A}$ is not a primary resource associated with scientific achievements at ORNL, nor is it known to be individually associated with any other events or persons of historic significance, thus it does not qualify for listing in the NRHP under Criterion A or B. Further, the building is a simple utilitarian structure that lacks architectural significance for listing in the NRHP under Criterion $\mathrm{C}$. The building is not located in a NRHP-eligible historic district. Thus, CRA recommends that Building 7000A is not eligible for listing in the NRHP under Criterion A, B, or C. 


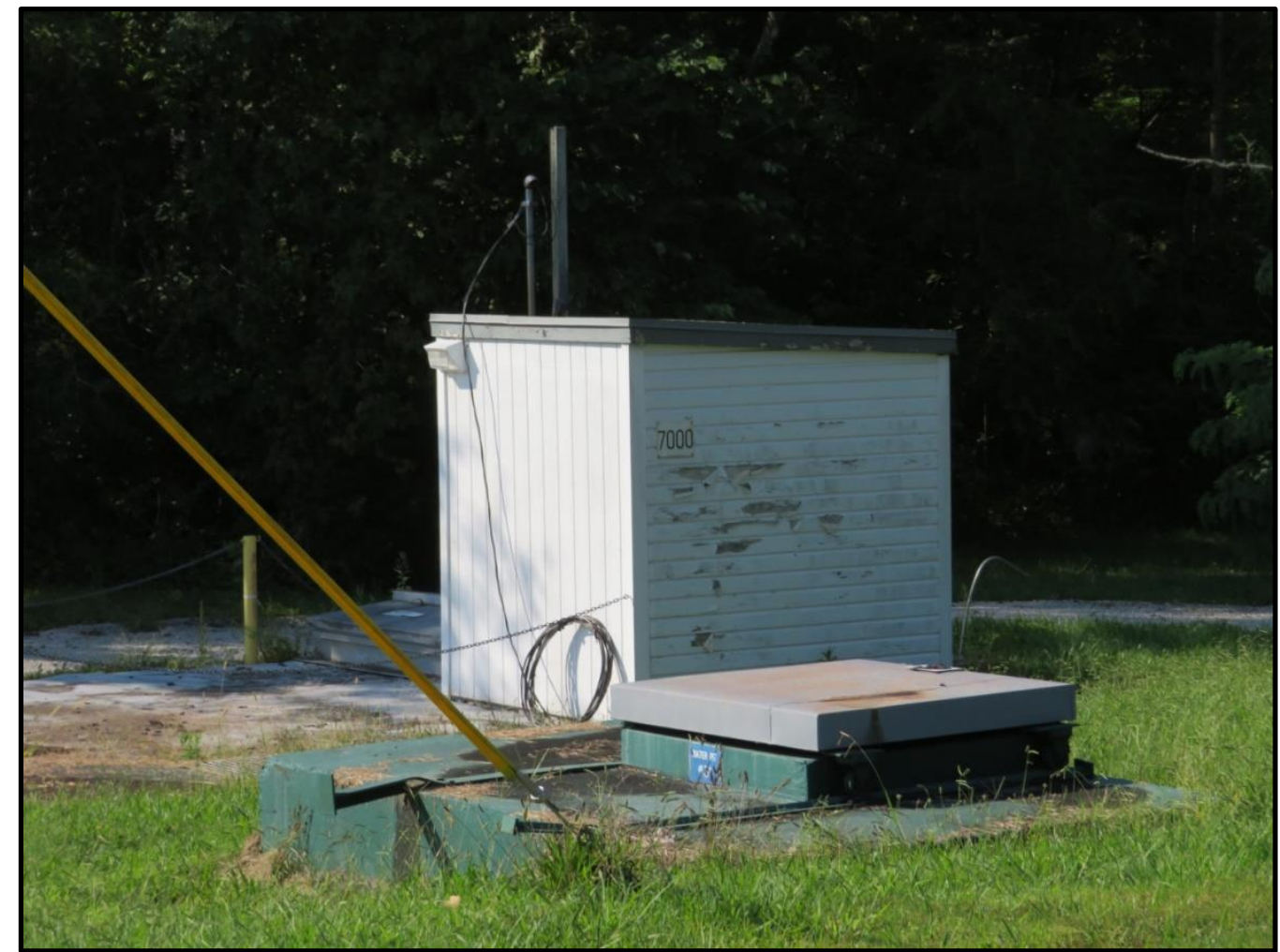

Figure 371. Overview of west and south elevations of Building 7000A, showing concrete foundation. 
7001

\section{BUILDING NAME}

Shipping, Receiving, and General Stores

\section{DATE OF CONSTRUCTION}

1948

\section{DOE OFFICE RESPONSIBLE}

SC

\section{NRHP ELIGIBILITY}

Demolished - N/A

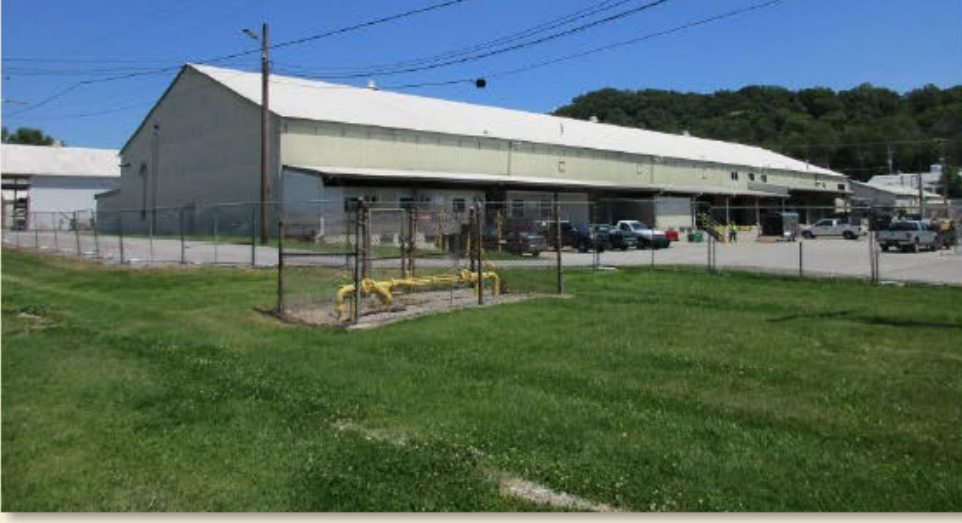

Figure 372. Overview of north and west elevations of Building 7001.

\section{DESCRIPTION}

Situated between White Oak Avenue and Bethel Valley Road, Building 7001 is a large, one-story, multi-bay, side-gable, steel structure (Figures 372 and 373 ). The building, with a rectangular footprint, is clad in corrugated metal including the roof. Several roof vents are located along the ridgeline. A poured concrete foundation supports the building. The structure is comprised of $44,273 \mathrm{sq} \mathrm{ft}$. Two additions are attached along the east and west elevations. The east addition is constructed of concrete block and is partially open in the middle. This addition has a nearly flat roof which is clad with gravel and tar. The west addition has an open shed roof and has a few enclosed sections. The building features two-light windows with horizontal panes and single-light metal pedestrian metal doors. The upper portions of the main block of the building feature single and three-light windows with vertical panes. Large roll-up garage doors are located along the long (east and west) elevations. This building was demolished by August 2017.

\section{NATIONAL REGISTER EVALUATION}

Building 7001 was constructed as a General Stores facility and served as the headquarters for the building contractor, J.A. Jones Construction Company. Section 106 Documentation was completed for Building 7001 by Thomason and Associates in 2013 prior to consultation with SHPO regarding planned demolition (Thomason and Associates 2013b). According to the initial 1994 survey of ORNL, this building, along with Building 7002, is eligible for listing in the NRHP under Criterion A due to their association with the Program $\mathrm{H}$ expansion of ORNL in the early 1950s (Carver and Slater 1994). The surveys conducted by Thomason and Associates in 2004 and 2015 concurred with the previous assessment (Thomason and Associates 2004 and 2015). Since completion of fieldwork for the current survey, Building 7001 has been demolished, so it no longer qualifies for listing in the NRHP. Prior to demolition, documentation of Building 7001, as required by the PA, was submitted to the SHPO. In November of 2013, the SHPO accepted the documentation and offered no objection to the demolition (McIntyre 2013). 


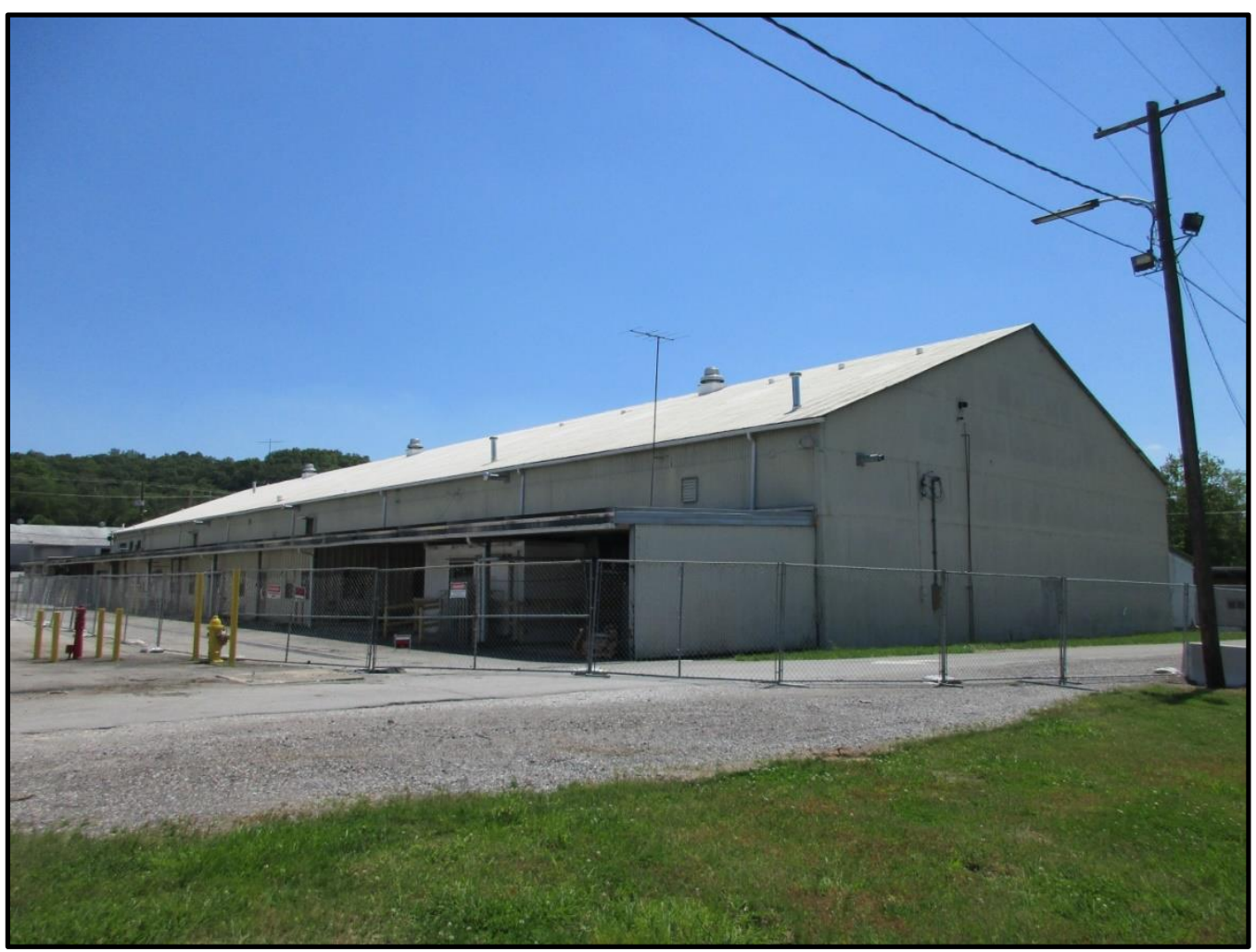

Figure 373. Overview of east and north elevations of Building 7001. 
7002

\section{BUILDING NAME}

Garage and Iron Working Shop

DATE OF CONSTRUCTION

1947

\section{DOE OFFICE RESPONSIBLE}

$\mathrm{SC}$

\section{NRHP ELIGIBILITY}

Figure 374. Overview of north and west elevations of Building 7002.

Eligible

\section{DESCRIPTION}

Located between White Oak Avenue and Bethel Valley Road, Building 7002 is a one-story, side-gable, steel structure with multiple additions and wings attached to the main block (Figures 374 and 375 ). The gable ends of the main block are located on the north and east elevations. The total area of the building is $28,262 \mathrm{sq} f t$. The roof and side elevations of the building are clad in corrugated metal panels. Four roof vents protrude from the ridgeline of the main block. Many of the openings along the long elevations are large vehicular bays filled with roll-up garage doors. The building also features pedestrian entries filled with solid metal and single-light metal doors as well as windows filled with two-light fixed sashes with horizontal panes. A row of single-light windows is located on the north elevation, which have since been painted over. A shed-roof addition is attached along the south elevation and a smaller shed-roof addition is located on the west elevation. A larger addition is located along the east elevation of the main block and is comprised of a gable roof section with a long shed-roof addition. Some of the windows in the gable-roof addition have one-over-one-light, double-hung sashes. Several flat metal awnings sheltering entries are present on both the west and east elevations.

\section{NATIONAL REGISTER EVALUATION}

Similar to Building 7001 , Building 7002 was constructed as a General Store building and served as the headquarters for the building contractor, J.A. Jones Construction Company. Buildings 7001 and 7002 were associated with the Program $\mathrm{H}$ building expansion of ORNL. This program would replace temporary buildings constructed during the Manhattan Project with more permanent structures for the new national laboratory. Building 7002 continues to function as a general storehouse for shipping and receiving, as well as storage. Section 106 Documentation was completed for Building 7002 by Thomason and Associates in 2013 prior to consultation with SHPO regarding planned demolition (Thomason and Associates 2013c). According to the initial 1994 survey of ORNL, Building 7002 is eligible for listing in the NRHP under Criterion A due to its association with the Program H expansion of ORNL in the early 1950s (Carver and Slater 1994). The surveys conducted by Thomason and Associates in 2004 and 2015 concurred with the previous assessment (Thomason and Associates 2004 and 2015). CRA concurs with previous determinations that Building 7002 is eligible for listing in the NRHP under Criterion A for its association with the expansion of ORNL under Project $\mathrm{H}$ and J.A. Jones Construction Company. Despite some additions, the building retains those key aspects of its original form 
and exterior materials to convey such associations. However, Building 7002 does not have specific associations with individuals of historic significance and therefore is not eligible under Criterion B. Additionally, it does not possess significant associations for its architectural and engineering design that would warrant individual listing under Criterion C. Thus, CRA recommends Building 7002 eligible for individual listing in the NRHP under Criterion A. In anticipation of its eventual demolition, documentation of Building 7002, as required by the PA, was submitted to the SHPO. In November of 2013, the SHPO accepted the documentation and offered no objection to the demolition (McIntyre 2013). Thus, no additional review is required prior to demolition.

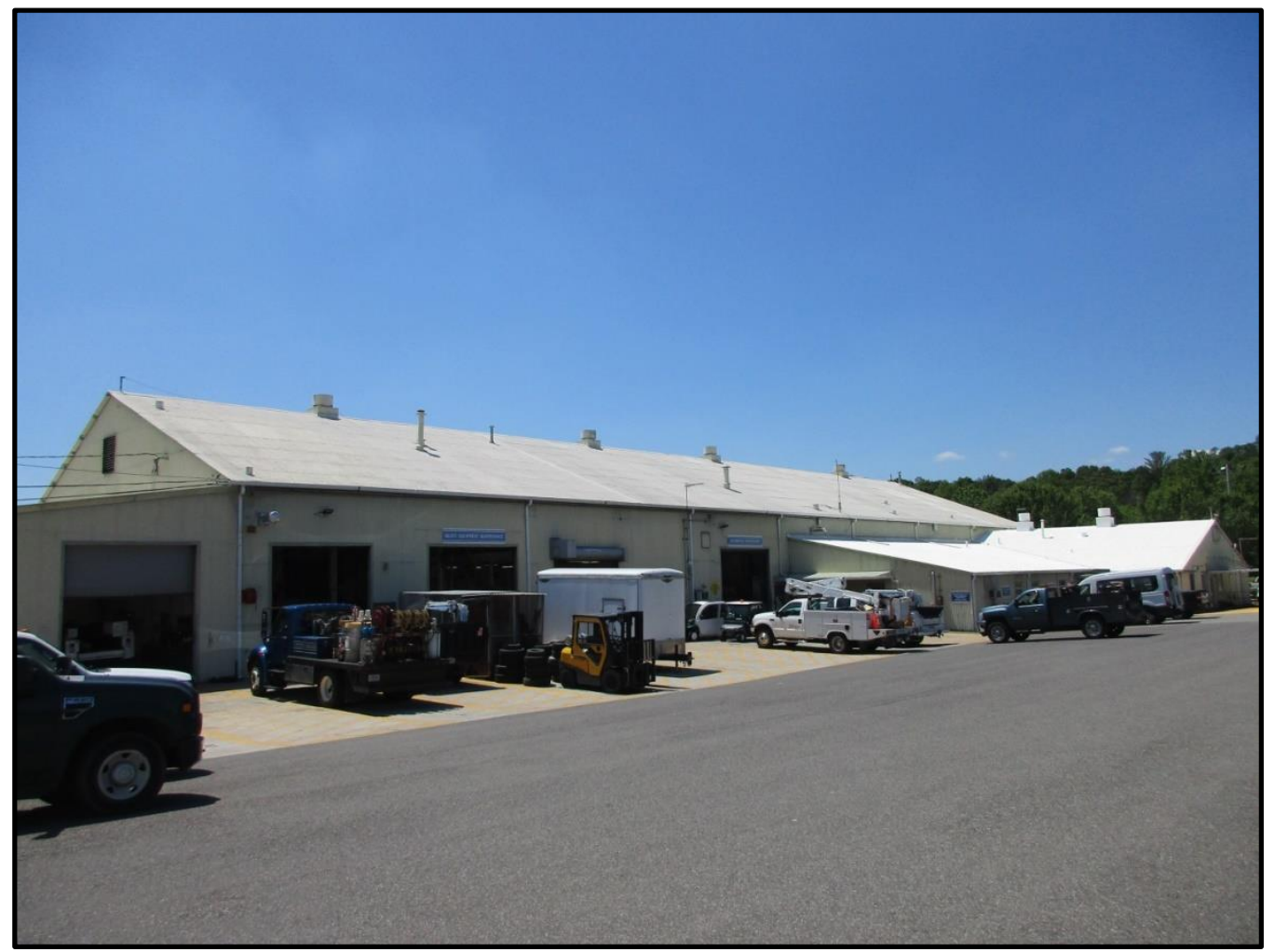

Figure 375. Overview of south and east elevations of Building 7002. 


\section{3}

\section{BUILDING NAME}

Welding and Brazing Shop

\section{DATE OF CONSTRUCTION}

1947

\section{DOE OFFICE RESPONSIBLE}

SC

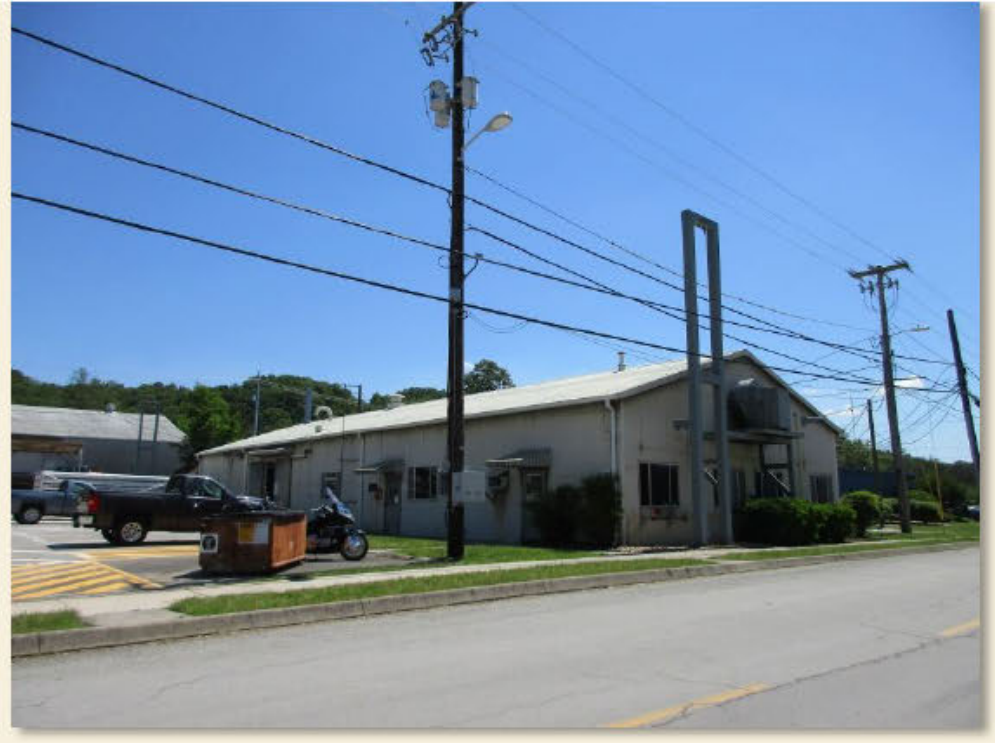

NRHP ELIGIBILITY

Figure 376. Overview of east and north elevations of Building 7003.

Not Eligible

\section{DESCRIPTION}

Located south of White Oak Avenue, Building 7003 is a one-story, five-bay, side-gable, steel frame building clad in corrugated metal siding (Figures 376 and 377). The roof is also clad in corrugated metal panels. The building is oriented to the east. An open shed roof clad with corrugated metal is attached in the rear (south) elevation. The building, built in 1947, features three-light sliding (or fixed) windows with vertical panes and single-light and solid steel doors sheltered by metal awnings. Large metal sliding track doors are located on the façade (east) elevation. A small concrete block masonry addition is attached to the rear of west elevation and features a twolight glass and steel door. The roof of this section is flat and clad with tar and gravel with a band of metal coping along the top.

\section{NATIONAL REGISTER EVALUATION}

Building 7003 was used as a Welding and Brazing Shop in 1948 as well as chemical storage facility in the early 1950s. Building 7003 was first surveyed in 1994 by Duvall \& Associates, and they recommended the building as not eligible for listing in NRHP (Carver and Slater 1994). It was not included in the 2004 survey of ORNL. However, it was assessed in the 2015 survey, and Thomason and Associates concurred with the previous assessment (Thomason and Associates 2004 and 2015). As a maintenance facility, Building 7003 is not a primary resource associated with scientific achievements at ORNL, nor is it known to be individually associated with any other events or persons of historic significance, thus it does not qualify for listing in the NRHP under Criterion A or B. Further, the building is a simple utilitarian structure with alterations including a modern concrete wing on the south elevation that lacks architectural significance and integrity for listing in the NRHP under Criterion $\mathrm{C}$. The building is not located in a NRHP-eligible historic district. Thus, CRA recommends that Building 7003 is not eligible for listing in the NRHP under Criterion A, B, or C. 


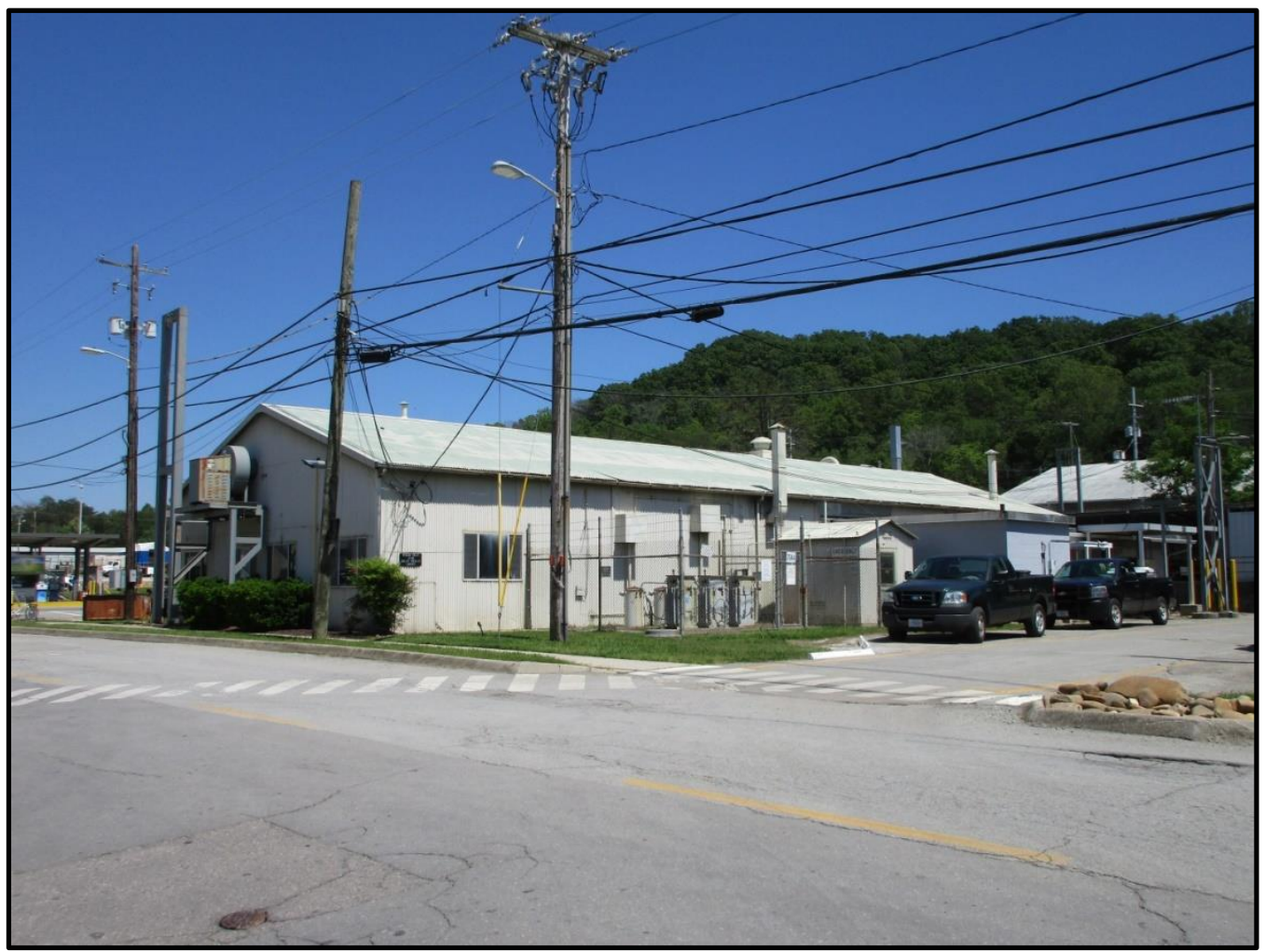

Figure 377. Overview of the north and west elevations of Building 7003. 


\section{BUILDING NAME}

Insulator Shop

\section{DATE OF CONSTRUCTION}

1951

\section{DOE OFFICE RESPONSIBLE}

SC

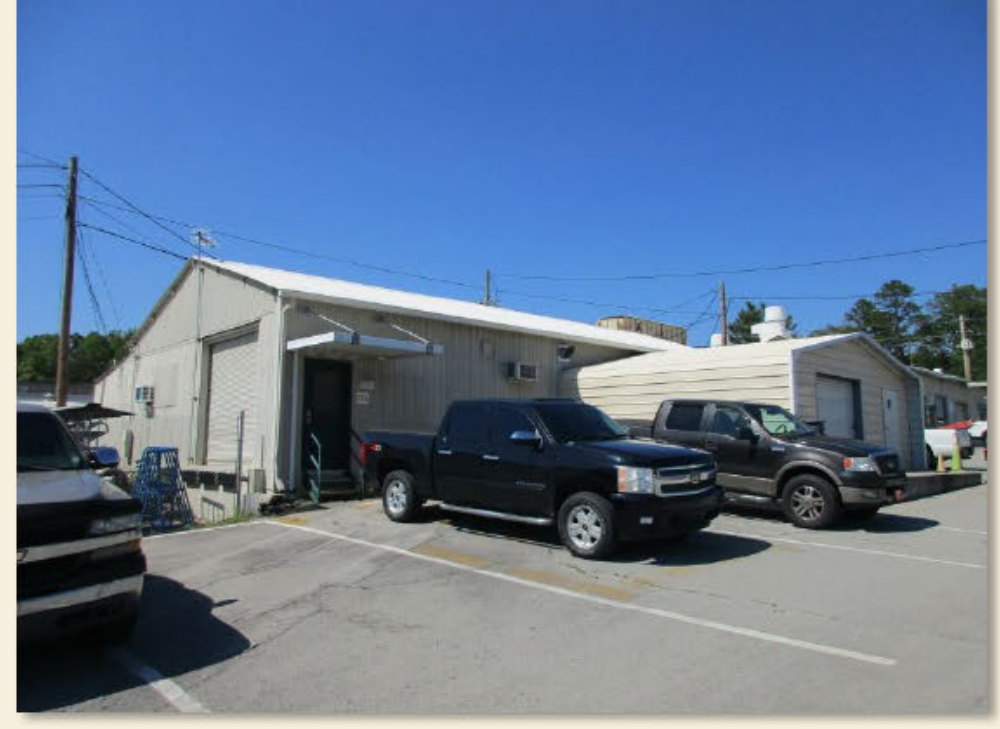

NRHP ELIGIBILITY

Figure 378. Overview of the west and south elevations of Building 7006 .

Not Eligible

\section{DESCRIPTION}

Building 7006 is located on the north side of White Oak Avenue. Building 7006 is a one-story, gable-roof, steel frame building clad with corrugated metal siding (Figures 378 and 379 ). The roof is also clad in corrugated metal panels. The building is comprised of a gable-roof main block with a moderate shed-roof section extending the length of the north elevation. A side-gable metal garage addition is attached to the south elevation of the main block that features a garage opening and pedestrian entry filled with a single-light metal door. Single-light metal double doors fill a double-leaf entry located on the east elevation with a small shed metal awning. The south elevation features a single-leaf entry filled with a single-light metal door sheltered by a flat metal awning. The west elevation features a large roll-up garage door. Several windows on the building are covered with pieces of corrugated metal siding.

\section{NATIONAL REGISTER EVALUATION}

Building 7006 was constructed in 1951 as an Insulator Shop. Building 7006 was first surveyed in 1994 by Duvall \& Associates, and they recommended the building as not eligible for listing in NRHP (Carver and Slater 1994). It was not included in the 2004 survey of ORNL. However, it was assessed in the 2015 survey, and Thomason and Associates concurred with the previous assessment (Thomason and Associates 2004 and 2015). As a maintenance facility, Building 7006 is not a primary resource associated with scientific achievements at ORNL, nor is it known to be individually associated with any other events or persons of historic significance, thus it does not qualify for listing in the NRHP under Criterion A or B. Further, the building is a simple utilitarian structure with replacement windows and doors that lacks architectural significance and integrity for listing in the NRHP under Criterion $\mathrm{C}$. The building is not located in a NRHP-eligible historic district. Thus, CRA recommends that Building 7006 is not eligible for listing in the NRHP under Criterion A, B, or C. 


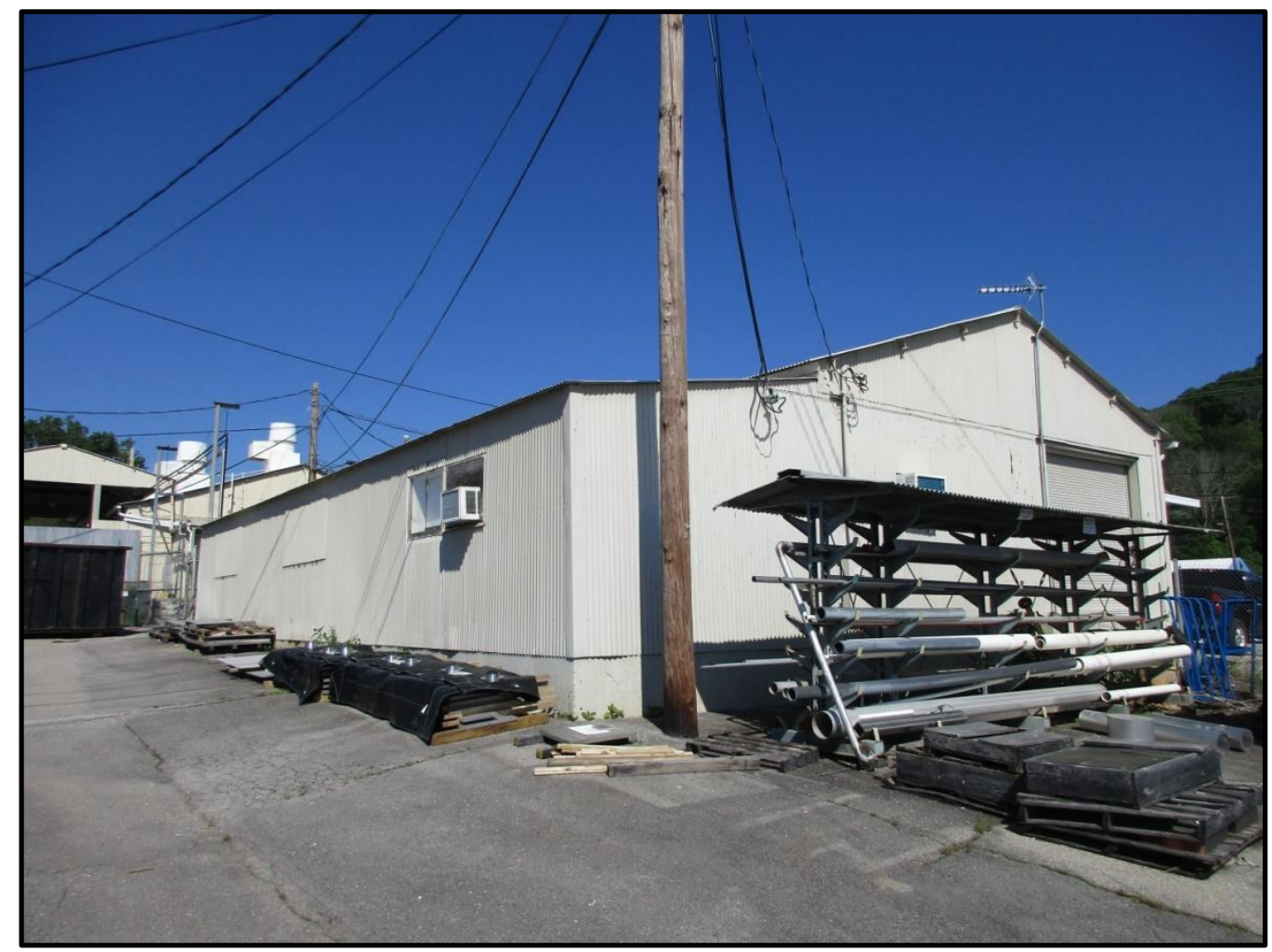

Figure 379. Overview of north and west elevations of Building 7006. 


\section{BUILDING NAME}

Paint Shop

\section{DATE OF CONSTRUCTION}

1947

\section{DOE OFFICE RESPONSIBLE}

SC

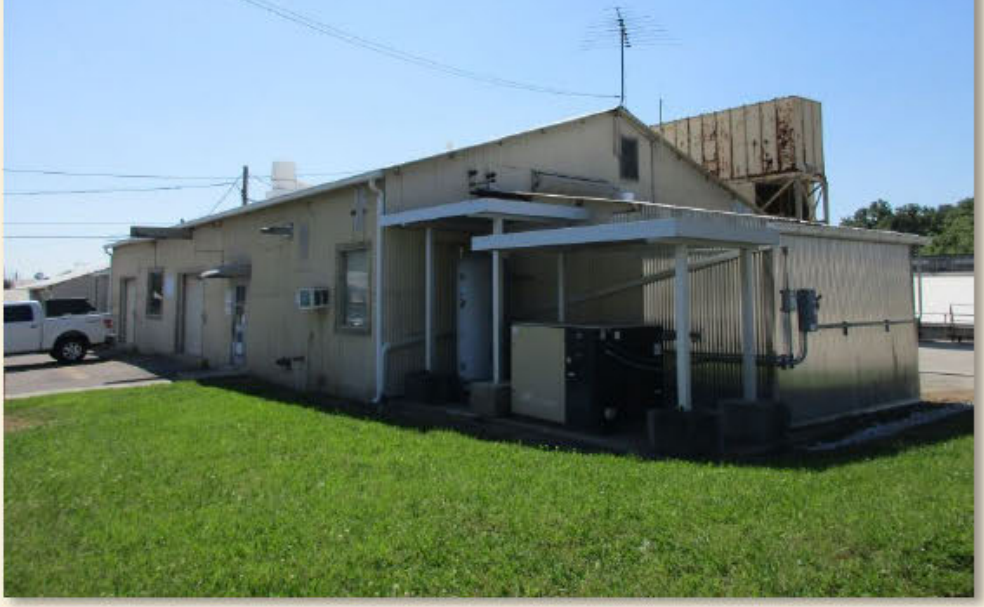

\section{NRHP ELIGIBILITY}

Figure 380. Overview of south and west elevations of Building 7007.

Not Eligible

\section{DESCRIPTION}

Located on the north side of White Oak Avenue, Building 7007 is a one story, side-gable, steel frame building situated on a concrete foundation and clad in corrugated metal siding (Figures 380 and 381). The roof is also clad in corrugated metal panels. A small shed-roof addition that is also clad in corrugated metal is located on the east gable end elevation. An addition on the west gable end has a flat roof of tar and gravel and is supported by steel posts. The building features single-light and multi-light wood windows. It also features pedestrian entries filled with four-light wood doors as well as single-light metal doors. Shed metal awnings cover several of the openings on the building. A gable-roof canopy connects Building 7007 to Building 7057 on the north elevation.

\section{NATIONAL REGISTER EVALUATION}

Building 7007 was constructed as an electric and pipe shop. The building now serves as a paint shop within the maintenance area. Building 7007 was first surveyed in 1994 by Duvall \& Associates, and they recommended the building as not eligible for listing in NRHP (Carver and Slater 1994). It was not included in the 2004 survey of ORNL. However, it was assessed in the 2015 survey, and Thomason and Associates concurred with the previous assessment (Thomason and Associates 2004 and 2015). As a maintenance facility, Building 7007 is not a primary resource associated with scientific achievements at ORNL, nor is it known to be individually associated with any other events or persons of historic significance, thus it does not qualify for listing in the NRHP under Criterion A or B. Further, the building is a simple utilitarian structure with replacement windows and doors and an addition that lacks architectural significance and integrity for listing in the NRHP under Criterion C. The building is not located in a NRHP-eligible historic district. Thus, CRA recommends that Building 7007 is not eligible for listing in the NRHP under Criterion A, B, or C. 


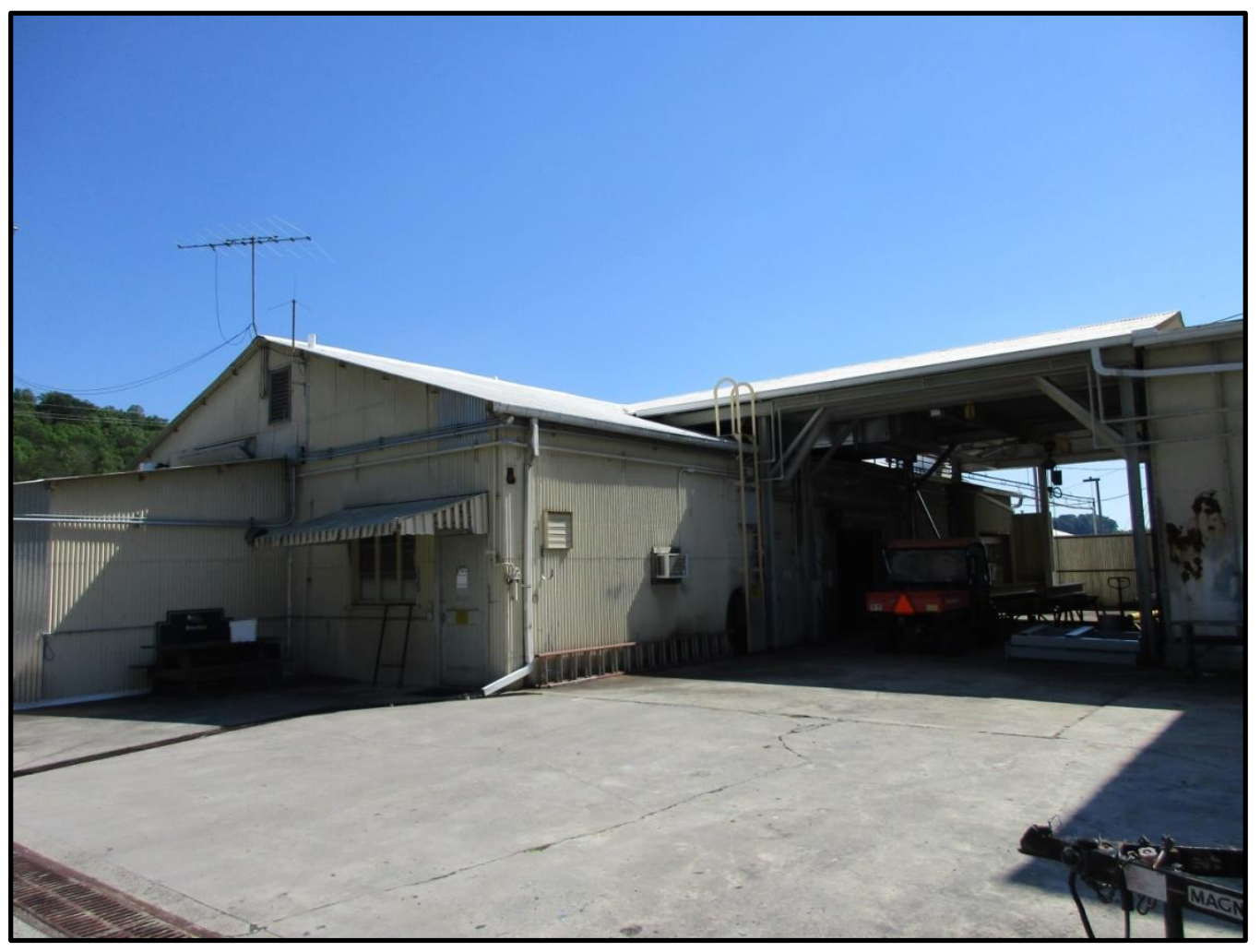

Figure 381. Overview of west and north elevations of Building 7007. 


\section{BUILDING NAME}

Carpenter Shop

\section{DATE OF CONSTRUCTION}

1947

\section{DOE OFFICE RESPONSIBLE}

SC

\section{NRHP ELIGIBILITY}

Not Eligible

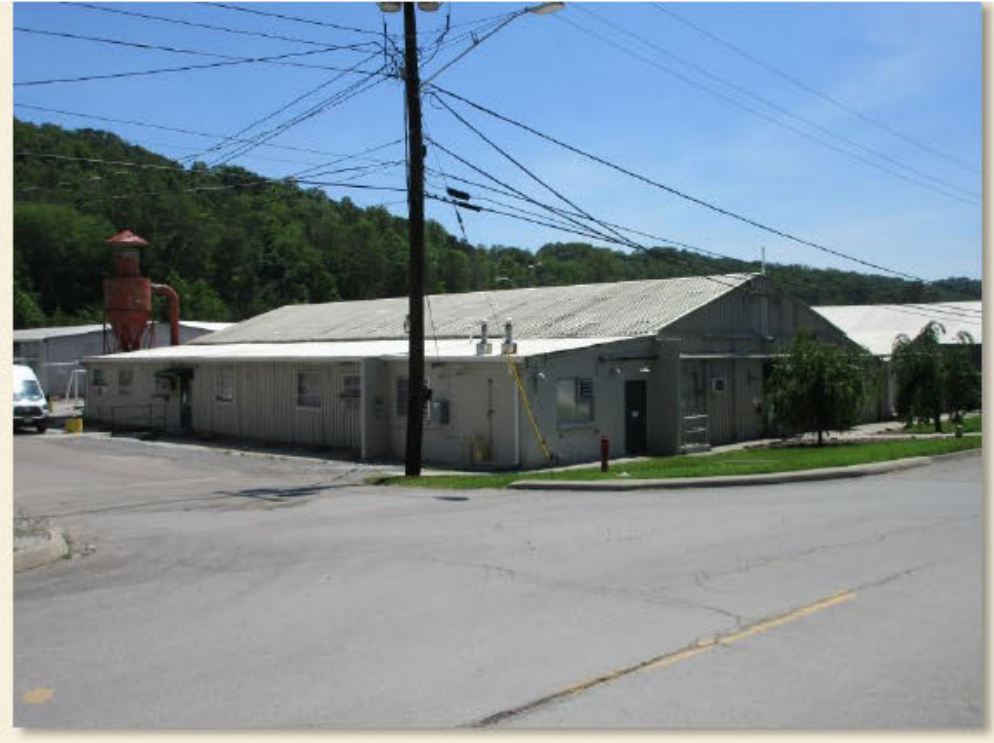

Figure 382. Overview of east and north elevations of Building 7009 .

\section{DESCRIPTION}

Located on the south side of White Oak Avenue, Building 7009 is a one-story, front-gable building clad in corrugated metal siding and situated on a concrete foundation (Figures 382 and 383). A west wing features an additional front-gable section and another wing along the east elevation of the main block features a low-pitch shed roof. All three roofs are clad with corrugated metal. The pedestrian entries are filled with glazed doors composed of wood or steel and have various configurations including single-light and four-light. Many of the doors on the building feature metal shed awnings. On the south elevation, a large roll-up garage door is featured in the center of the main section of the building. The building has three- and nine-light metal awning windows as well as twelve-light steel casement windows.

\section{NATIONAL REGISTER EVALUATION}

Building 7009 was constructed in 1947 as a carpenter shop. Building 7009 was first surveyed in 1994 by Duvall \& Associates, and they recommended the building as not eligible for listing in NRHP (Carver and Slater 1994). It was not included in the 2004 survey of ORNL. However, it was assessed in the 2015 survey, and Thomason and Associates concurred with the previous assessment (Thomason and Associates 2004 and 2015). As a maintenance facility, Building 7009 is not a primary resource associated with scientific achievements at ORNL, nor is it known to be individually associated with any other events or persons of historic significance, thus it does not qualify for listing in the NRHP under Criterion A or B. Further, the building is a simple utilitarian structure with an addition that lacks architectural significance and integrity for listing in the NRHP under Criterion $\mathrm{C}$. The building is not located in a NRHP-eligible historic district. Thus, CRA recommends that Building 7009 is not eligible for listing in the NRHP under Criterion A, B, or C. 


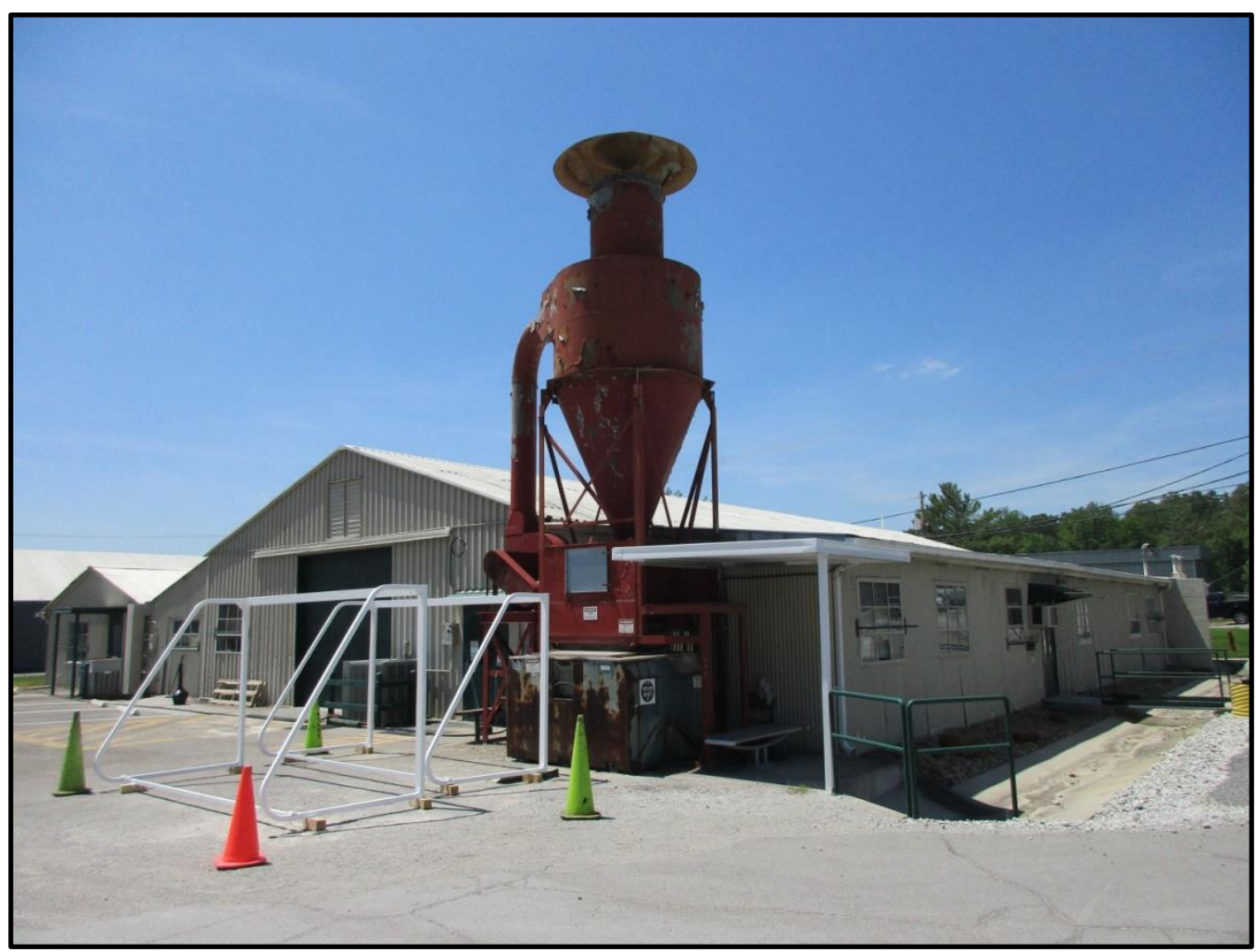

Figure 383. Overview of south and east elevations of Building 7009. 


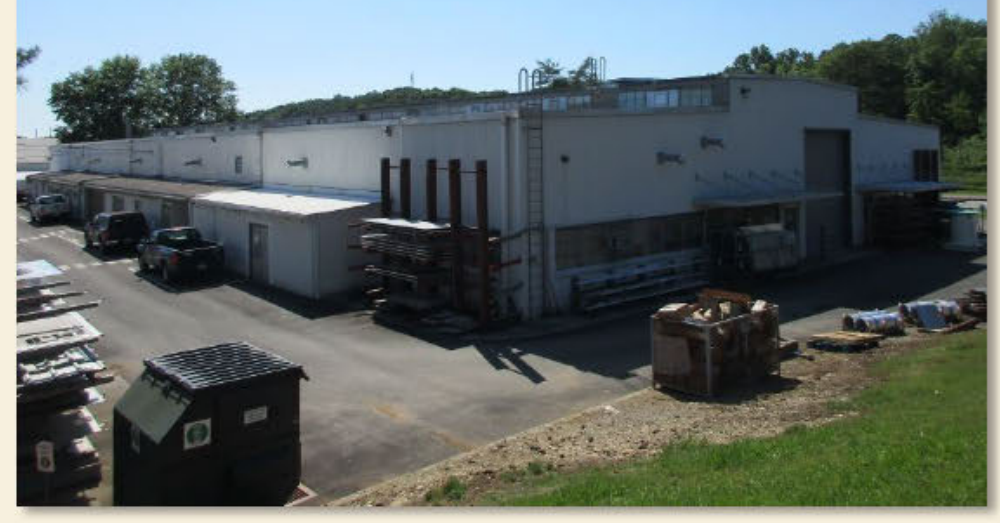

SC

Figure 384. Overview of south and east elevations of Building 7012.

\section{NRHP ELIGIBILITY}

Not Eligible

\section{DESCRIPTION}

Located north of White Oak Avenue and south of Bethel Valley Road, Building 7012 is a one-story building with a rectangular plan that totals $26,864 \mathrm{sq} \mathrm{ft}$ (Figures 384 and 385 ). The building is situated on a poured concrete foundation and sheltered by a roof of corrugated Transite. The lower portion of the exterior of the building is constructed of concrete block while the upper portions of the side elevations are clad with Transite siding. The building features a monitor roof with clerestory windows. The building features ribbons windows with six- and nine-light metal awning sashes. Several shed additions, also clad Transite siding, are located on the north and south elevations. The shed additions also exhibit multi-pane awning windows. Flat metal awnings are located above several openings in the building including windows and single-light metal doors.

\section{NATIONAL REGISTER EVALUATION}

Constructed in 1953, Building 7012 served as a central mechanical shop facility. This building was constructed as part of the Program H building expansion. Building 7012 was first surveyed in 1994 by Duvall \& Associates, and they recommended the building as not eligible for listing in NRHP (Carver and Slater 1994). It was not included in the 2004 survey of ORNL. However, it was assessed in the 2015 survey, and Thomason and Associates concurred with the previous assessment (Thomason and Associates 2004 and 2015). As a maintenance facility, Building 7012 is not a primary resource associated with scientific achievements at ORNL, nor is it known to be individually associated with any other events or persons of historic significance, thus it does not qualify for listing in the NRHP under Criterion A or B. Further, the building is a simple utilitarian structure with additions and altered fenestration that lacks architectural significance and integrity for listing in the NRHP under Criterion $\mathrm{C}$. The building is not located in a NRHP-eligible historic district. Thus, CRA recommends that Building 7012 is not eligible for listing in the NRHP under Criterion A, B, or C. 


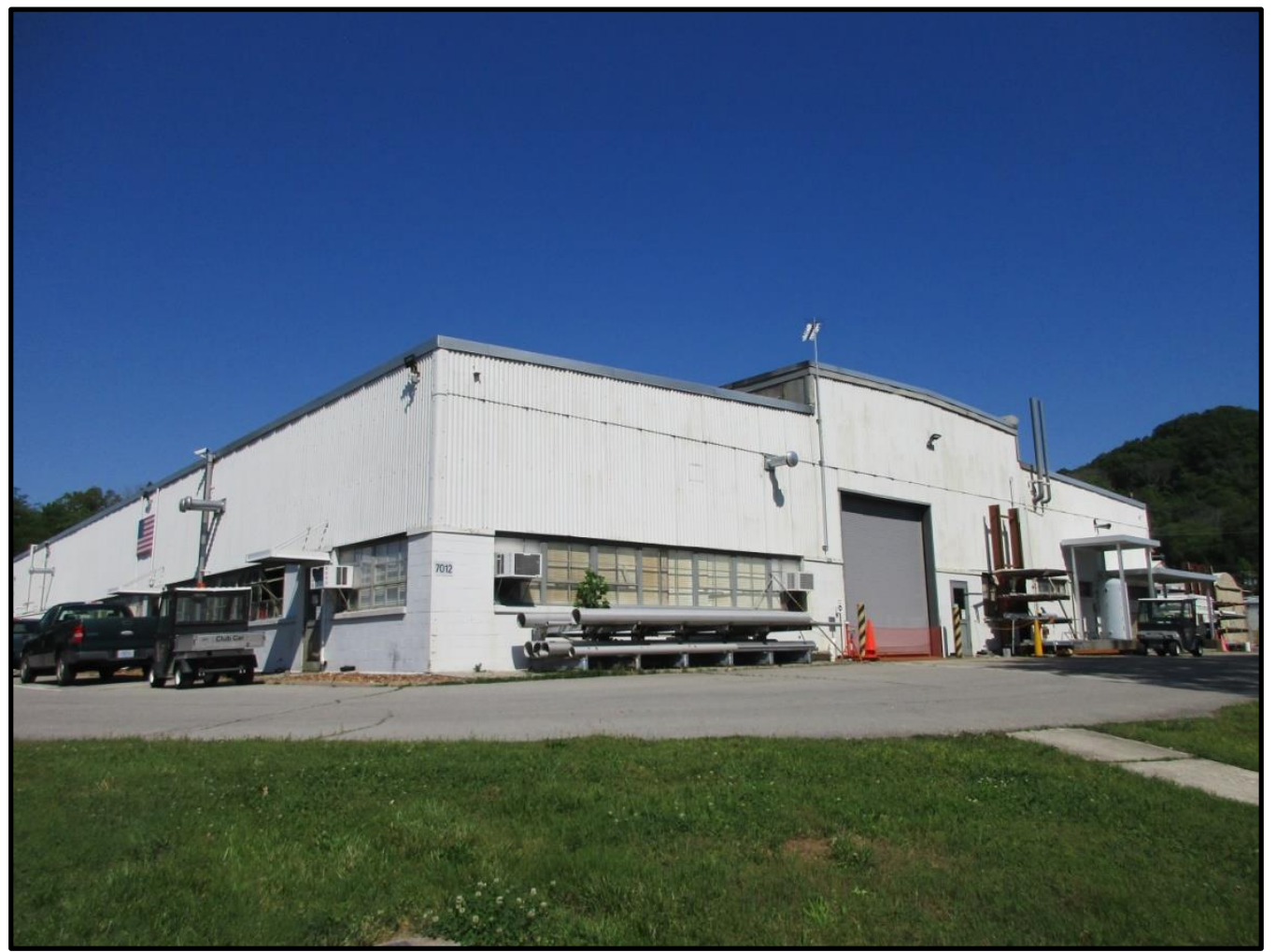

Figure 385. Overview of north and west elevations of Building 7012. 


\section{BUILDING NAME}

Acid Chemical \& Flammable Liquid Storage

\section{DATE OF CONSTRUCTION}

1954

\section{DOE OFFICE RESPONSIBLE}

SC

\section{NRHP ELIGIBILITY}

Figure 386. Overview of north and west elevations of Building 7013.

Not Eligible

\section{DESCRIPTION}

Located south of White Oak Avenue, Building 7013 is a one-story, front-gable building situated on a concrete foundation and clad in corrugated metal siding (Figures 386 and 387). The roof is also clad in corrugated metal and contains two ridgeline vents. The gable ends of the building are oriented to the east and west. The building features large vent openings, metal doors, and several large roll-up garage doors covered by flat metal awnings. A concrete block masonry section can be found on the east (gable) elevation. The roof on this section is flat and clad with gravel and tar. This section features multiple roof vents along the ridgeline and shelters at least four single-leaf entries.

\section{NATIONAL REGISTER EVALUATION}

Building 7013 was constructed as an Acid, Chemical, \& Flammable Liquid Storage facility within the maintenance area. Building 7013 was first surveyed in 1994 by Duvall \& Associates, and they recommended the building as not eligible for listing in NRHP (Carver and Slater 1994). It was not included in the 2004 survey of ORNL. However, it was assessed in the 2015 survey, and Thomason and Associates concurred with the previous assessment (Thomason and Associates 2004 and 2015). As a storage facility, Building 7013 is not a primary resource associated with scientific achievements at ORNL, nor is it known to be individually associated with any other events or persons of historic significance, thus it does not qualify for listing in the NRHP under Criterion A or B. Further, the building is a simple utilitarian structure that lacks architectural significance for listing in the NRHP under Criterion $C$. The building is not located in a NRHP-eligible historic district. Thus, CRA recommends that Building 7013 is not eligible for listing in the NRHP under Criterion A, B, or C. 


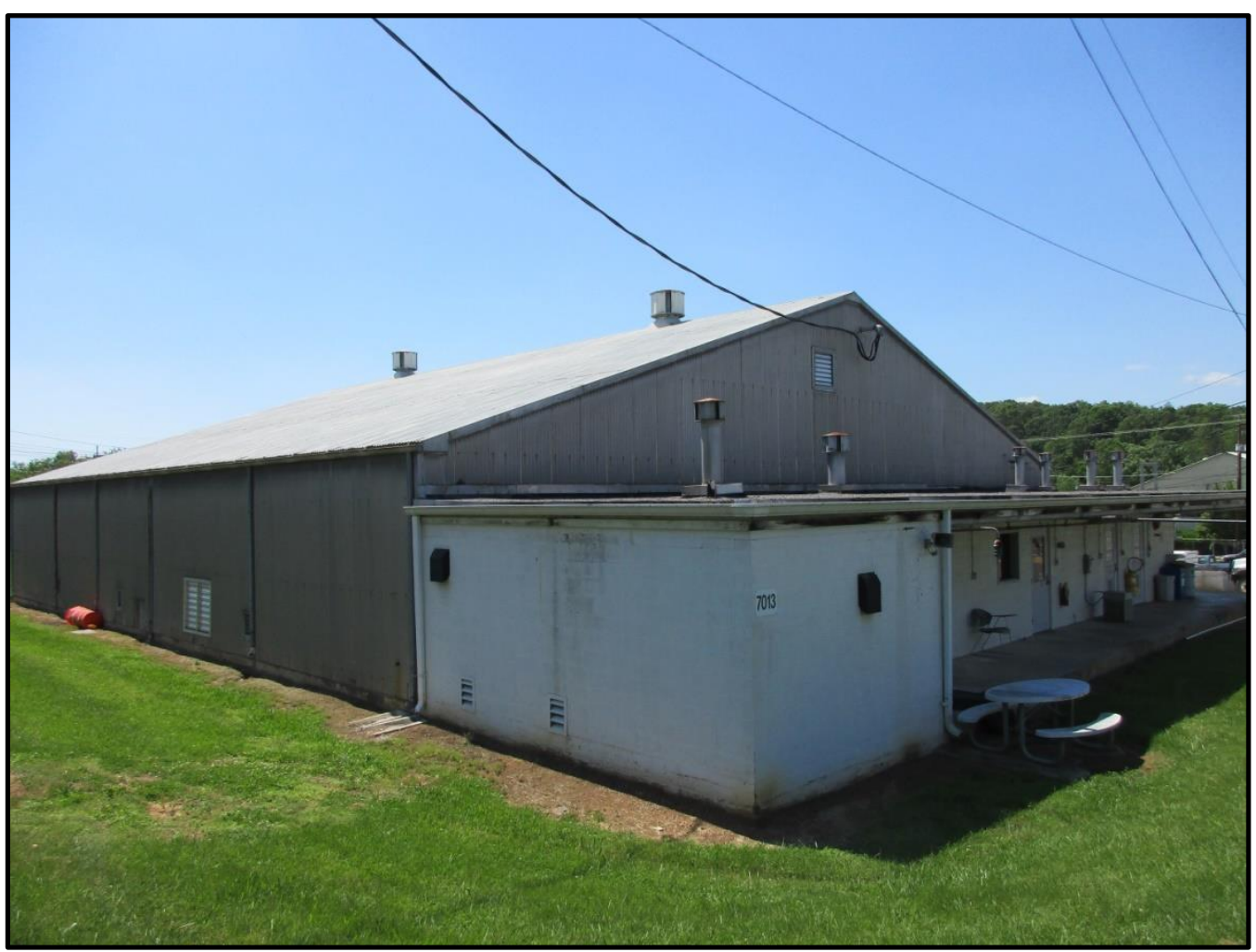

Figure 387. Overview of south and east elevations of Building 7013. 


\section{5}

\section{BUILDING NAME}

Metal Storage \& Cutting Facility

\section{DATE OF CONSTRUCTION}

1955

\section{DOE OFFICE RESPONSIBLE}

$\mathrm{SC}$

\section{NRHP ELIGIBILITY}

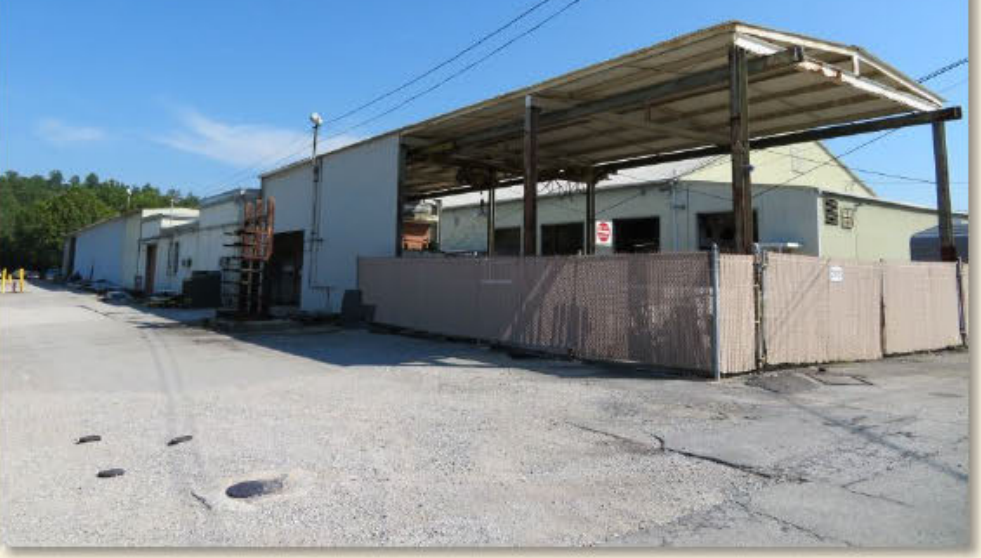

Figure 388. Overview of west and south elevations of Building 7015.

Not Eligible

\section{DESCRIPTION}

Located between White Oak Avenue and Bethel Valley Road, Building 7015 is a one-story linear building that was constructed in several phases and extends to the north and south (Figures 388 and 389). The original building is located in the middle and composed of concrete block masonry. It originally was a rectangular building with two large metal sliding doors and two windows. Two additional wings were constructed later, creating a U-shaped building. These additions also are composed of concrete block masonry. This U-shaped section features a flat roof with a shallow metal parapet and the roof is covered in tar and gravel. The windows on this section are four-light, fixed steel with horizontal panes. Two are located on the façade, which faces east, and one window replaced a sliding door located on the west elevation. A large metal sliding door is featured in the center of the south elevation, which is the one remaining feature of the original building, as none of the other original openings remain. This section also contains two large south facing roll-up garage doors on each of the wings. The concrete block masonry is painted but in some areas the paint is peeling.

Two large additions are located on either side (north and south) of the concrete block masonry section. These additions are steel structures and clad with various types of corrugated metal siding. The additions feature gable roofs with low slopes that are clad with corrugated metal sheets. The north addition is long and narrow while the south addition is shorter in length and matches the width of the concrete block wing. The northern addition is partially enclosed on the north and west elevations with a large opening on the west elevation. The southern addition is open entirely on the east and south elevations. It is partially enclosed on the west elevation with a large garage door opening. This addition is enclosed by a metal fence.

\section{NATIONAL REGISTER EVALUATION}

Building 7015, the Metal Storage and Cutting Facility, was constructed in 1955. The masonry additions were completed in the 1960s and the north and south additions were added by 1990. Building 7015 was first surveyed by Duvall \& Associates, and was recommended as not eligible for listing in the NRHP (Carver and Slater 1994). It was not included in the 2004 and 2015 surveys of ORNL (Thomason and Associates 2004 and 2015). It was recently documented by CRA in 2017 (Leeds 2017b). At that time CRA concurred with the 1994 assessment and recommending Building 7015 as not eligible for listing in the NRHP. As a storage facility, 
Building 7015 is not a primary resource associated with scientific achievements at ORNL, nor is it known to be individually associated with any other events or persons of historic significance, thus it does not qualify for listing in the NRHP under Criterion A or B. Further, the building is a simple utilitarian structure with multiple additions and alterations that lacks architectural significance and integrity for listing in the NRHP under Criterion C. The building is not located in a NRHP-eligible historic district. Thus, CRA recommends that Building 7015 is not eligible for listing in the NRHP under Criterion A, B, or C.

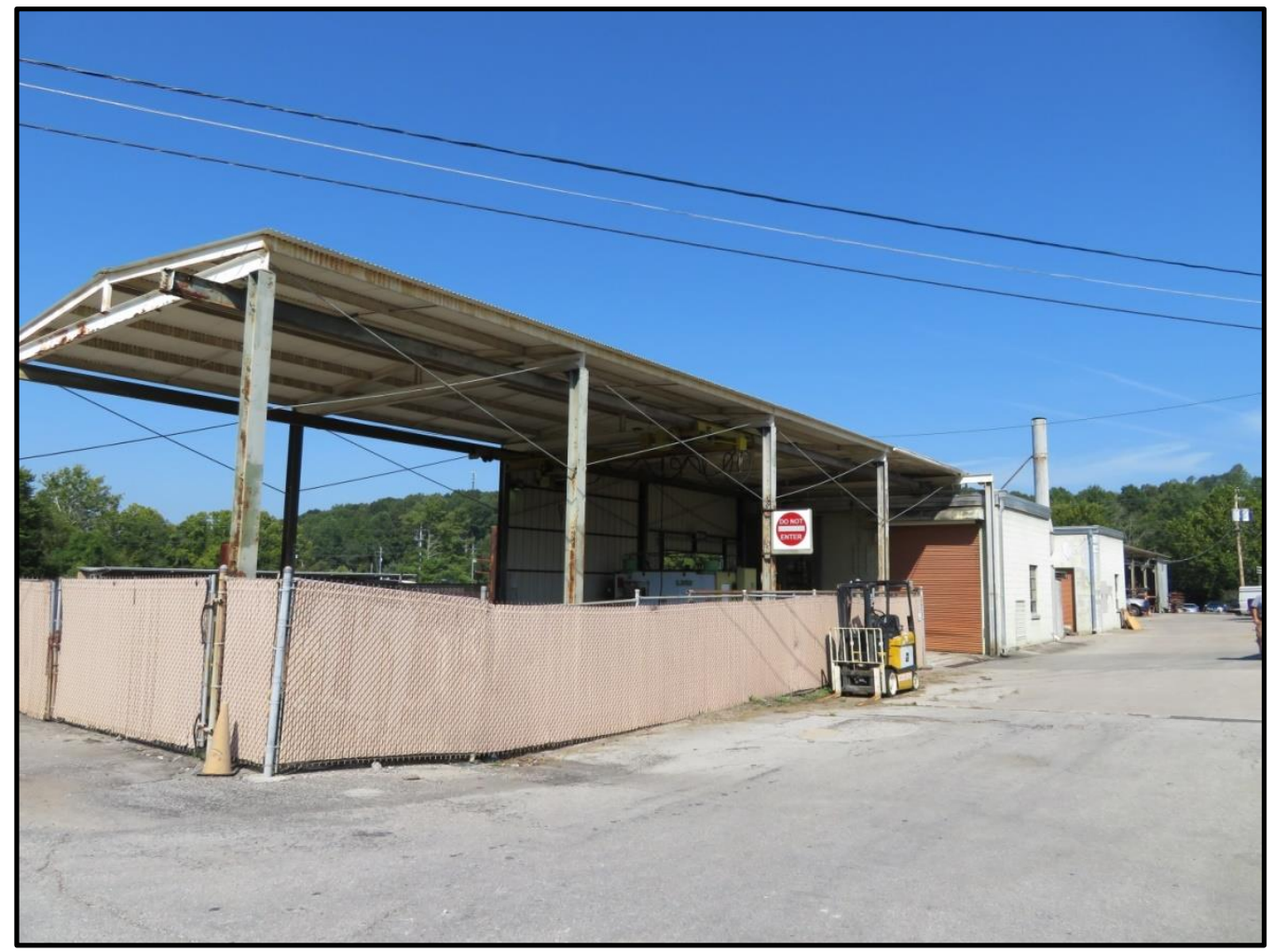

Figure 389. Overview of south and east elevations of Building 7015. 


\section{BUILDING NAME}

Hazardous Materials Storage

\section{DATE OF CONSTRUCTION}

1958

\section{DOE OFFICE RESPONSIBLE}

SC

\section{NRHP ELIGIBILITY}

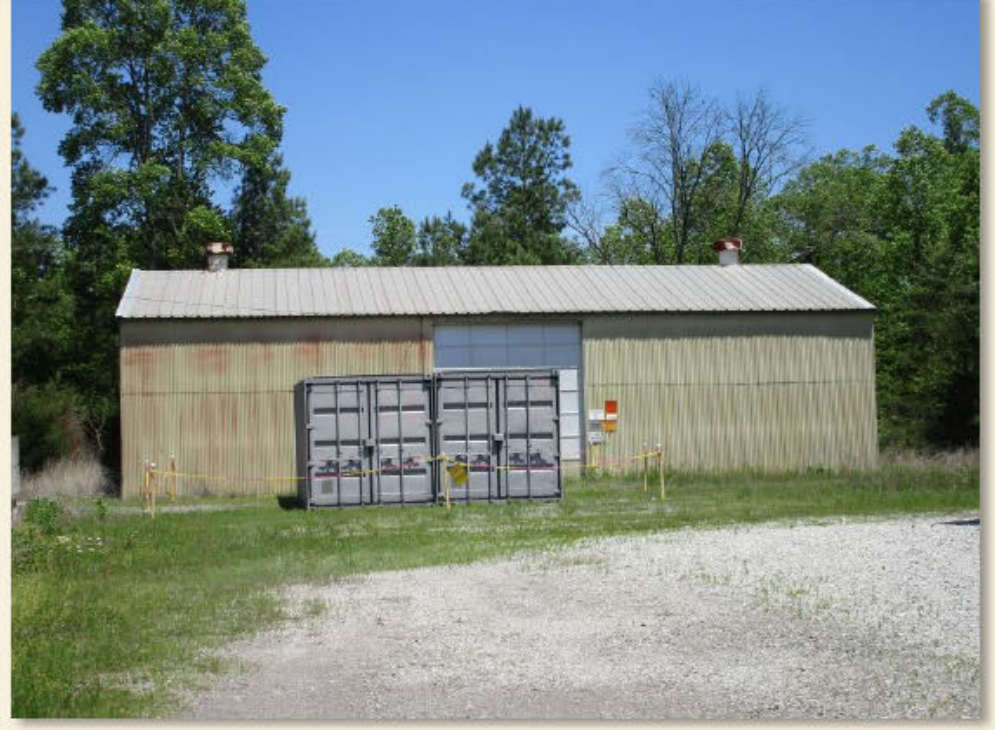

Not Eligible

Figure 390. Overview of west elevation of Building 7019.

\section{DESCRIPTION}

Located in the far eastern end of the 7000 Area, Building 7019 is a Hazardous Materials Storage facility and was surveyed from a distance. A large chain link fence and gate surround the building. Oriented to the west, the one-story structure features a side-gable roof and is clad entirely in corrugated metal (Figures 390 and 391). The roof contains two ridgeline vents. A large modern paneled roll-up garage door is featured on the façade (west) elevation. Nine-light painted steel awning windows are featured on the north and east elevations.

\section{NATIONAL REGISTER EVALUATION}

Building 7019 was constructed as a storage facility for hazardous materials as well as a disposal facility. The building was first surveyed in 1994 by Duvall \& Associates, and they recommended the building as not eligible for listing in NRHP (Carver and Slater 1994). It was not included in the 2004 survey of ORNL. However, it was assessed in the 2015 survey, and Thomason and Associates concurred with the previous assessment (Thomason and Associates 2004 and 2015). As a storage facility, Building 7019 is not a primary resource associated with scientific achievements at ORNL, nor is it known to be individually associated with any other events or persons of historic significance, thus it does not qualify for listing in the NRHP under Criterion A or B. Further, the building is a simple utilitarian structure with a large modern roll-up door that lacks architectural significance and integrity for listing in the NRHP under Criterion $\mathrm{C}$. The building is not located in a NRHP-eligible historic district. Thus, CRA recommends that Building 7019 is not eligible for listing in the NRHP under Criterion $A, B$, or $C$. 


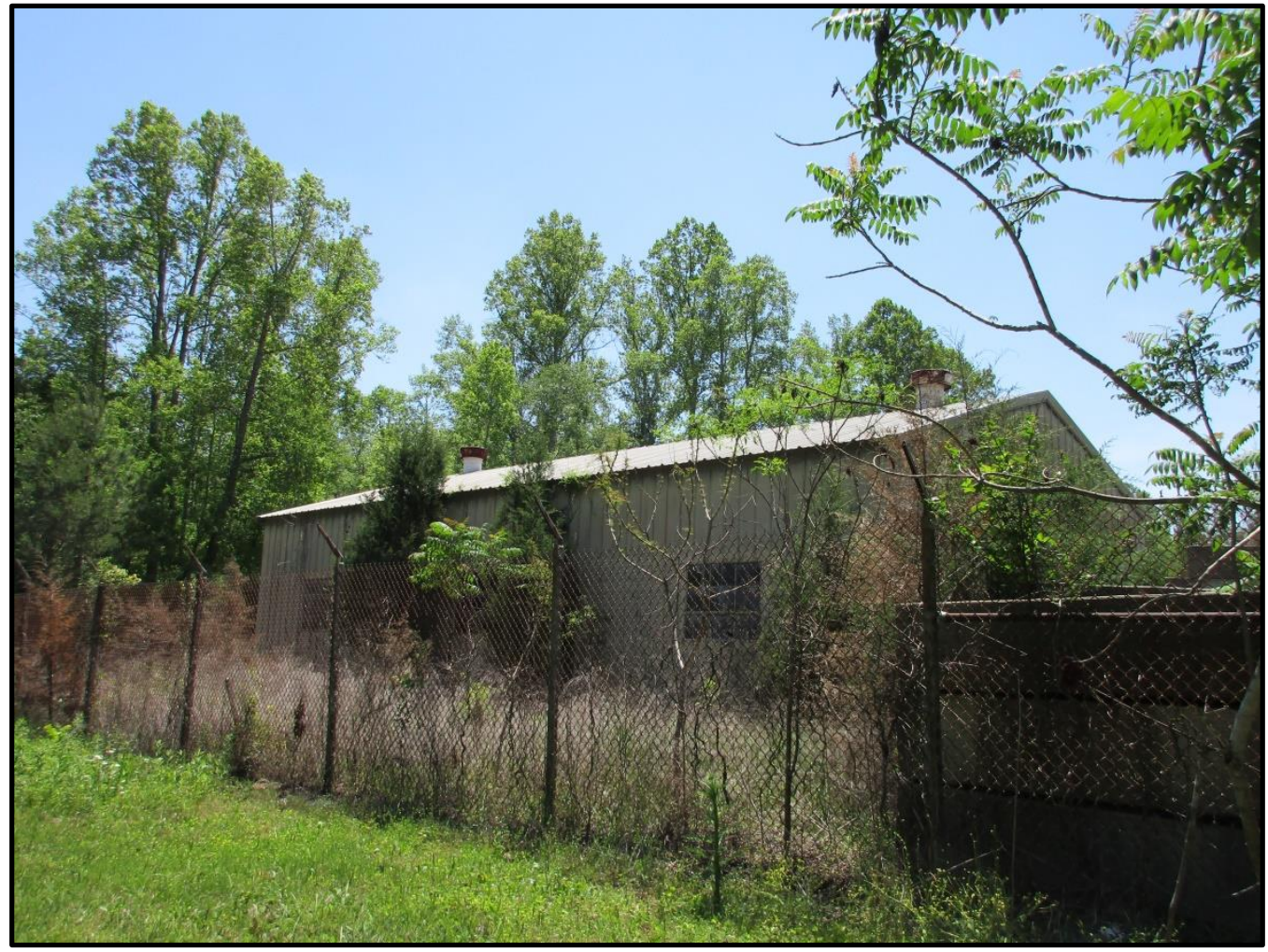

Figure 391. Overview of east and north elevations of Building 7019. 


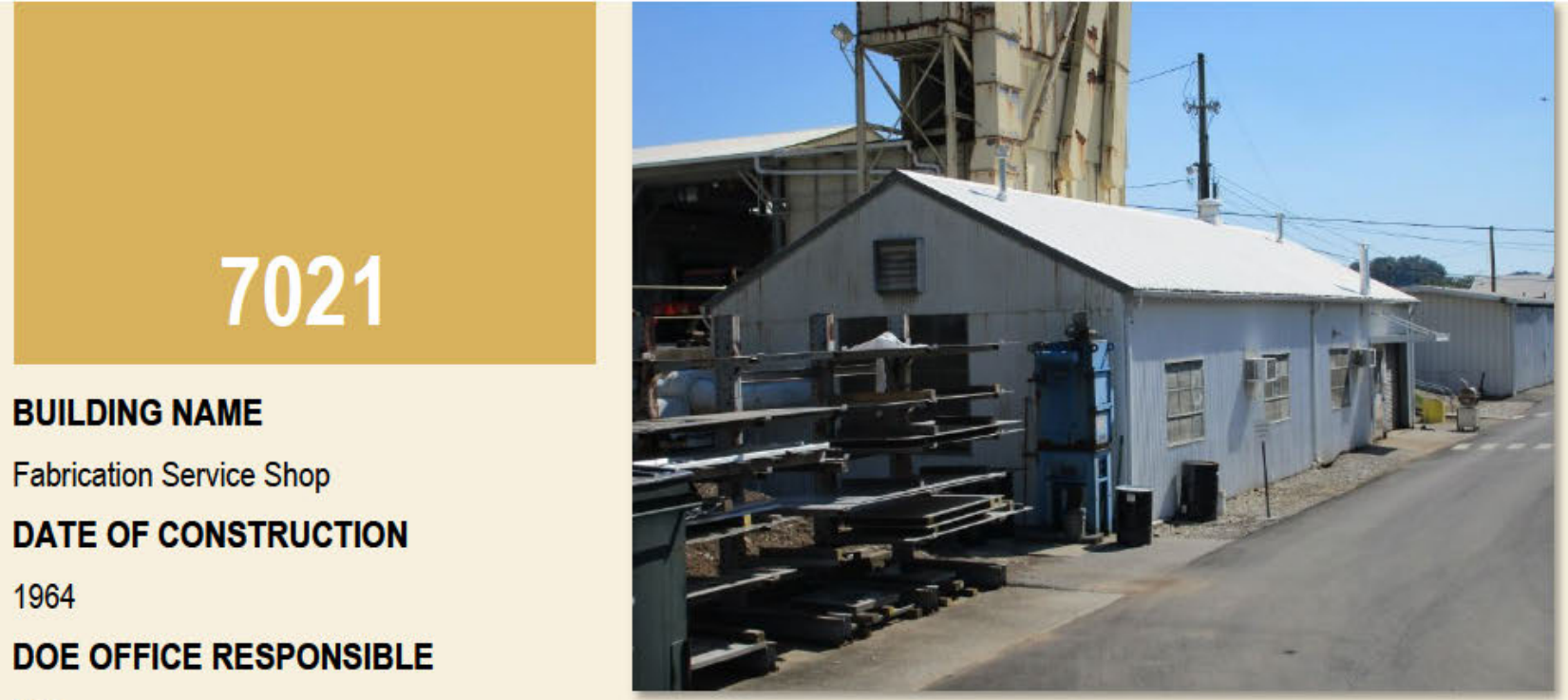

$\mathrm{SC}$

Figure 392. Overview of east and north elevations of Building 7021.

\section{NRHP ELIGIBILITY}

Not Eligible

\section{DESCRIPTION}

Located between White Oak Avenue and Bethel Valley Road, Building 7021 is a one-story, five-bay, side-gable steel structure clad in corrugated metal siding including the roof (Figures 392 and 393). Oriented to the north, the building features nine-light fixed and hopper style windows. Large ten-light awning or hopper windows are located on the gable ends. Small louvered vents are positioned over these windows on the gable ends. A steel and glass door for a pedestrian entry and roll-up garage door are located on the north elevation. The pedestrian entry features a flat metal awning above it.

\section{NATIONAL REGISTER EVALUATION}

Building 7021 was constructed as a fabrication equipment service shop in 1964 within the maintenance area. The building was first surveyed in 1994 by Duvall \& Associates, and they recommended the building as not eligible for listing in NRHP (Carver and Slater 1994). It was not included in the 2004 survey of ORNL. However, it was assessed in the 2015 survey, and Thomason and Associates concurred with the previous assessment (Thomason and Associates 2004 and 2015). As a maintenance facility, Building 7021 is not a primary resource associated with scientific achievements at ORNL, nor is it known to be individually associated with any other events or persons of historic significance, thus it does not qualify for listing in the NRHP under Criterion A or B. Further, the building is a simple utilitarian structure that lacks architectural significance for listing in the NRHP under Criterion $\mathrm{C}$. The building is not located in a NRHP-eligible historic district. Thus, CRA recommends that Building 7021 is not eligible for listing in the NRHP under Criterion A, B, or C. 


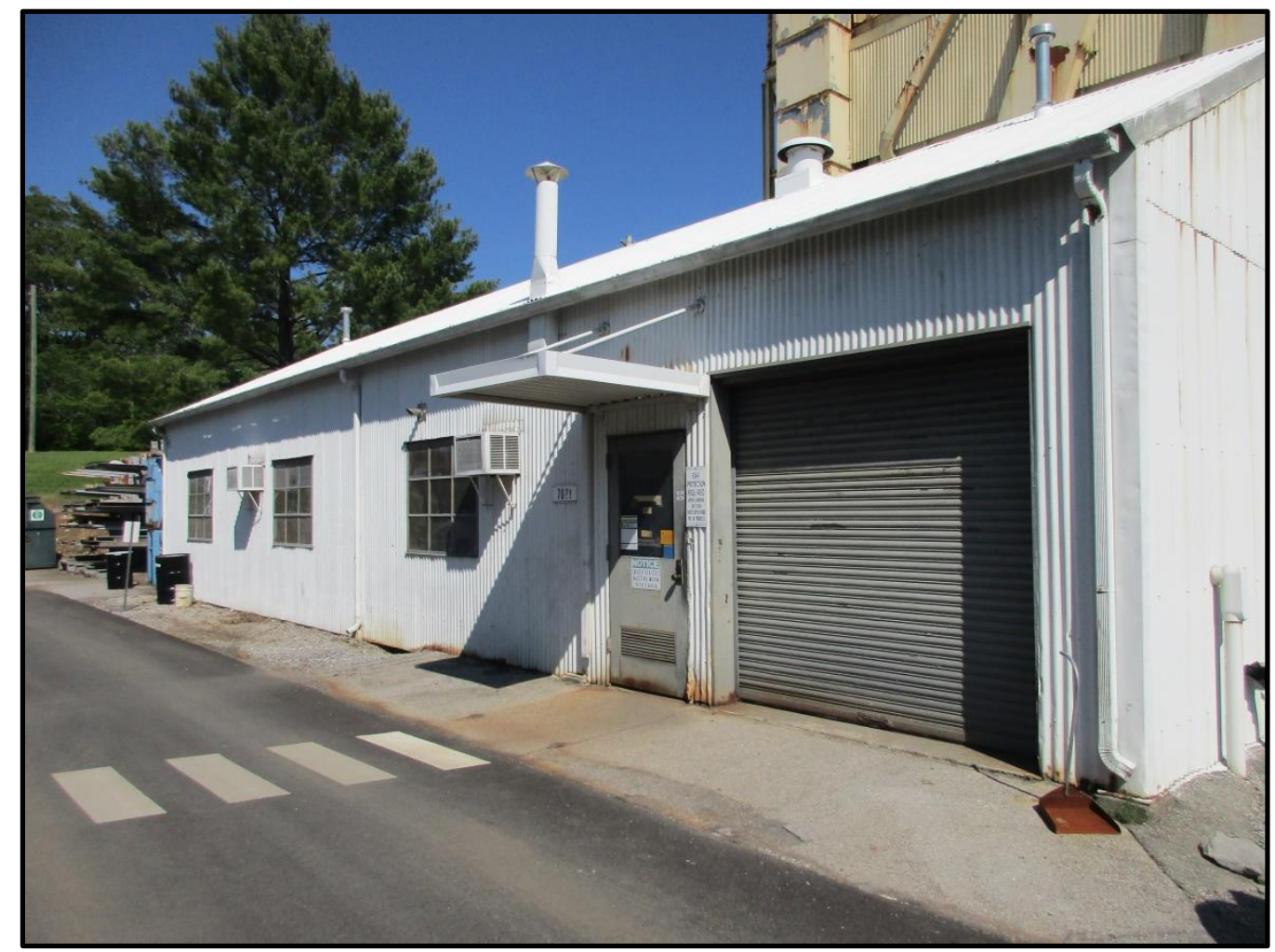

Figure 393. Overview of north elevation of Building 7021. 


\section{BUILDING NAME}

Lamp Recycle Facility

DATE OF CONSTRUCTION

1965

DOE OFFICE RESPONSIBLE

SC

NRHP ELIGIBILITY

Figure 394. Overview of east and north elevations of Building 7022.

Not Eligible

\section{DESCRIPTION}

Located south of White Oak Avenue, Building 7022 is a one-story, shed-roof, steel structure on an elevated concrete foundation (Figures 394 and 395). Oriented to the north, the building features an open air design and is enclosed entirely on the west and south elevations in corrugated metal. The roof is a low-pitch shed that is also clad with corrugated metal. The open elevations are enclosed by a metal railing.

\section{NATIONAL REGISTER EVALUATION}

Building 7022 was constructed as a gas cylinder storage shed. It was also referenced as an electronics recycling facility (Thomason and Associates 2015;164). The building was first surveyed in 1994 by Duvall \& Associates, and they recommended the building as not eligible for listing in NRHP (Carver and Slater 1994). It was not included in the 2004 survey of ORNL. However, it was assessed in the 2015 survey, and Thomason and Associates concurred with the previous assessment (Thomason and Associates 2004 and 2015). As a storage facility, Building 7022 is not a primary resource associated with scientific achievements at ORNL, nor is it known to be individually associated with any other events or persons of historic significance, thus it does not qualify for listing in the NRHP under Criterion A or B. Further, the building is a simple utilitarian structure that lacks architectural significance for listing in the NRHP under Criterion C. The building is not located in a NRHPeligible historic district. Thus, CRA recommends that Building 7022 is not eligible for listing in the NRHP under Criterion $\mathrm{A}, \mathrm{B}$, or $\mathrm{C}$. 


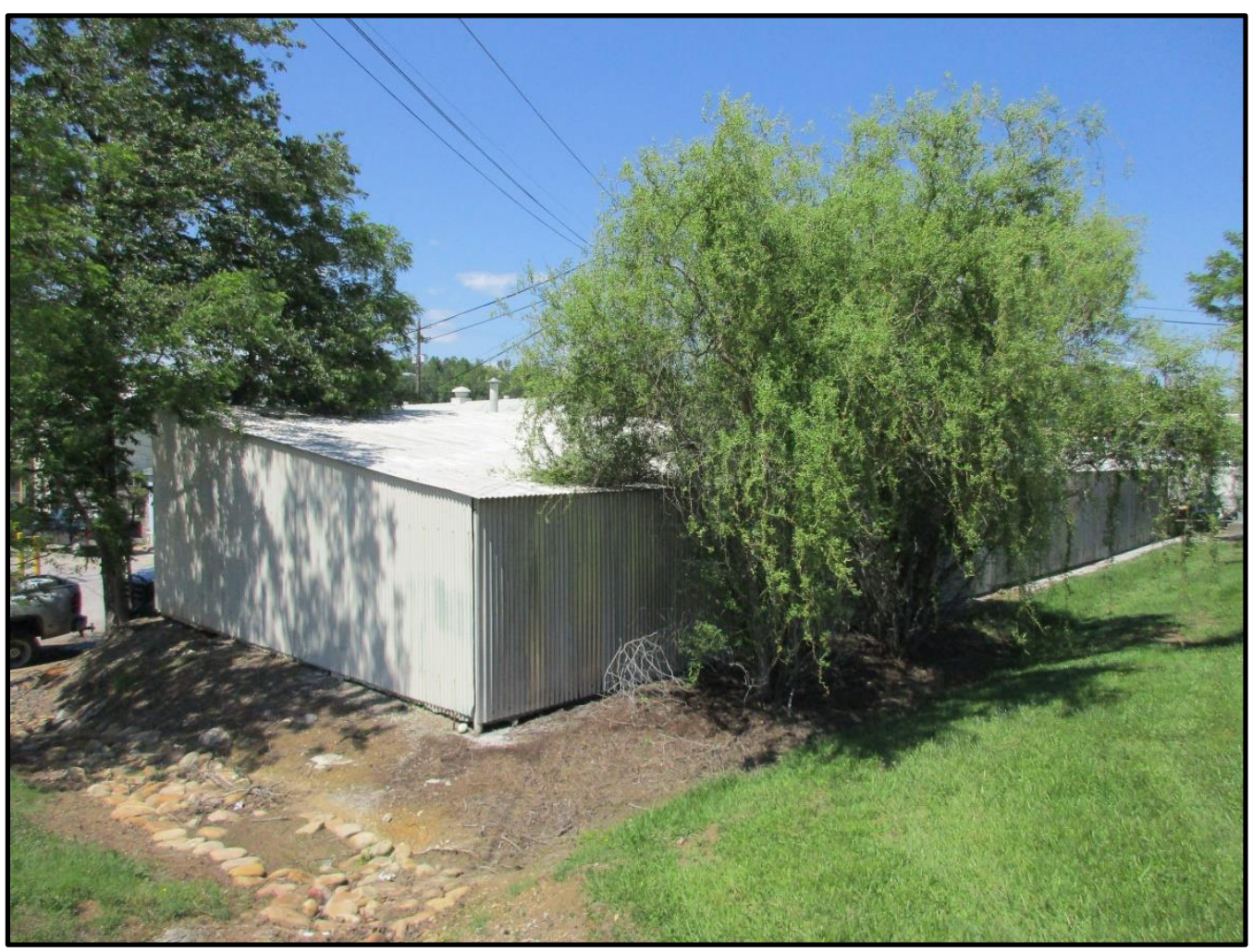

Figure 395. Overview of west and south elevations of Building 7022. 


\section{BUILDING NAME}

Tritium Target Preparation Facility

\section{DATE OF CONSTRUCTION}

1969

\section{DOE OFFICE RESPONSIBLE}

EM (UCOR)

\section{NRHP ELIGIBILITY}

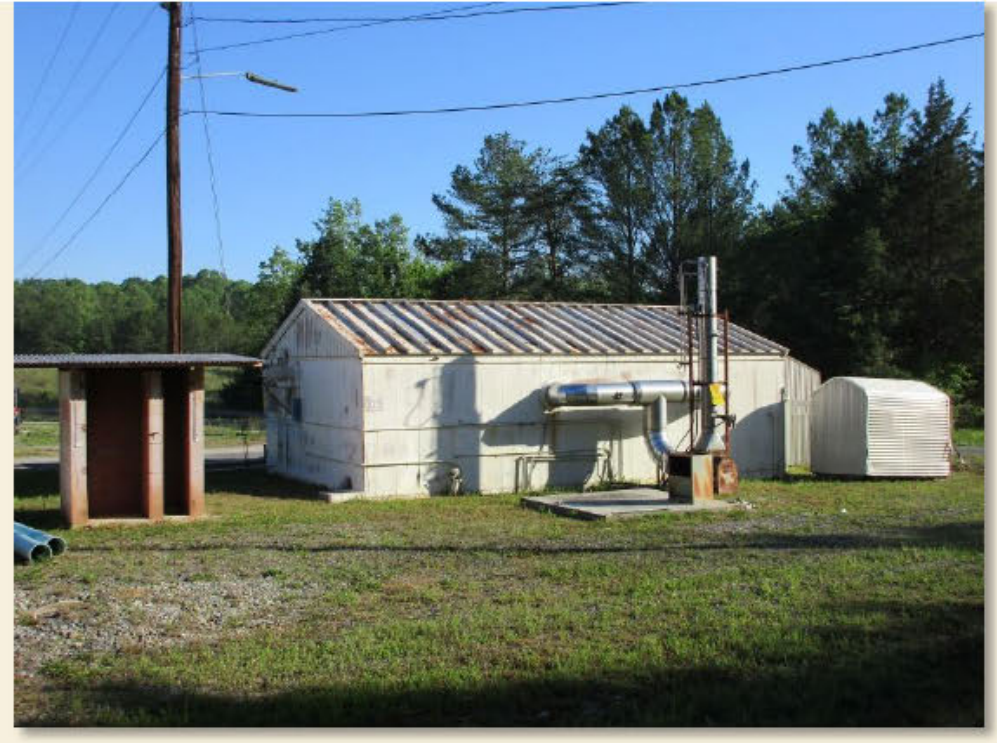

Figure 396. Overview of west and south elevations of Building 7025 .

Not Eligible

\section{DESCRIPTION}

Located near the east corner of the 7000 Area, Building 7025 is a one-story, side-gable, steel structure clad with metal panels, including the roof (Figures 396 and 397). A pedestrian entry filled with a one-light steel door is located on the façade (north) elevation. The entry is enclosed by a metal fence. An addition of the same cladding material is attached to the west portion of the façade and features a flat metal clad roof. Ductwork and other piping systems on located on the rear (south) elevation. Smaller side-gable buildings are adjacent to the building.

\section{NATIONAL REGISTER EVALUATION}

Building 7025 was built in 1969 to serve as Tritium Target Facility. The structure was used to primarily fabricate tritide targets. Other tasks conducted in this building included preparing metallurgical samples for helium embrittlement studies. This was completed by diffusing tritium into the samples and allowing it decay to helium. Also, thin films of ThO2/UO were prepared through vacuum evaporation. In October 1989, all tritium processing activities were terminated and bulk tritium and uranium storage traps were removed. The building was decontaminated and declared surplus. For further reference, see report completed by Lockheed Martin in 1997 on the deactivation of Building 7025 (Thomason and Associates 2015:166). Building 7025 was first surveyed in 1994 by Duvall \& Associates, and they recommended the building as not eligible for listing in NRHP (Carver and Slater 1994). It was not included in the 2004 survey of ORNL. However, it was assessed in the 2015 survey, and Thomason and Associates concurred with the previous assessment (Thomason and Associates 2004 and 2015). Although materials used in scientific research were prepared in Building 7025 , as a utility/maintenance facility it is not a primary resource associated with scientific achievements at ORNL, nor is it known to be individually associated with any other events or persons of historic significance, thus it does not qualify for listing in the NRHP under Criterion A or B. Further, the building is a simple utilitarian structure that lacks architectural significance for listing in the NRHP under Criterion $C$. The building is not located in a NRHP-eligible historic district. Thus, CRA recommends that Building 7025 is not eligible for listing in the NRHP under Criterion A, B, or C. 


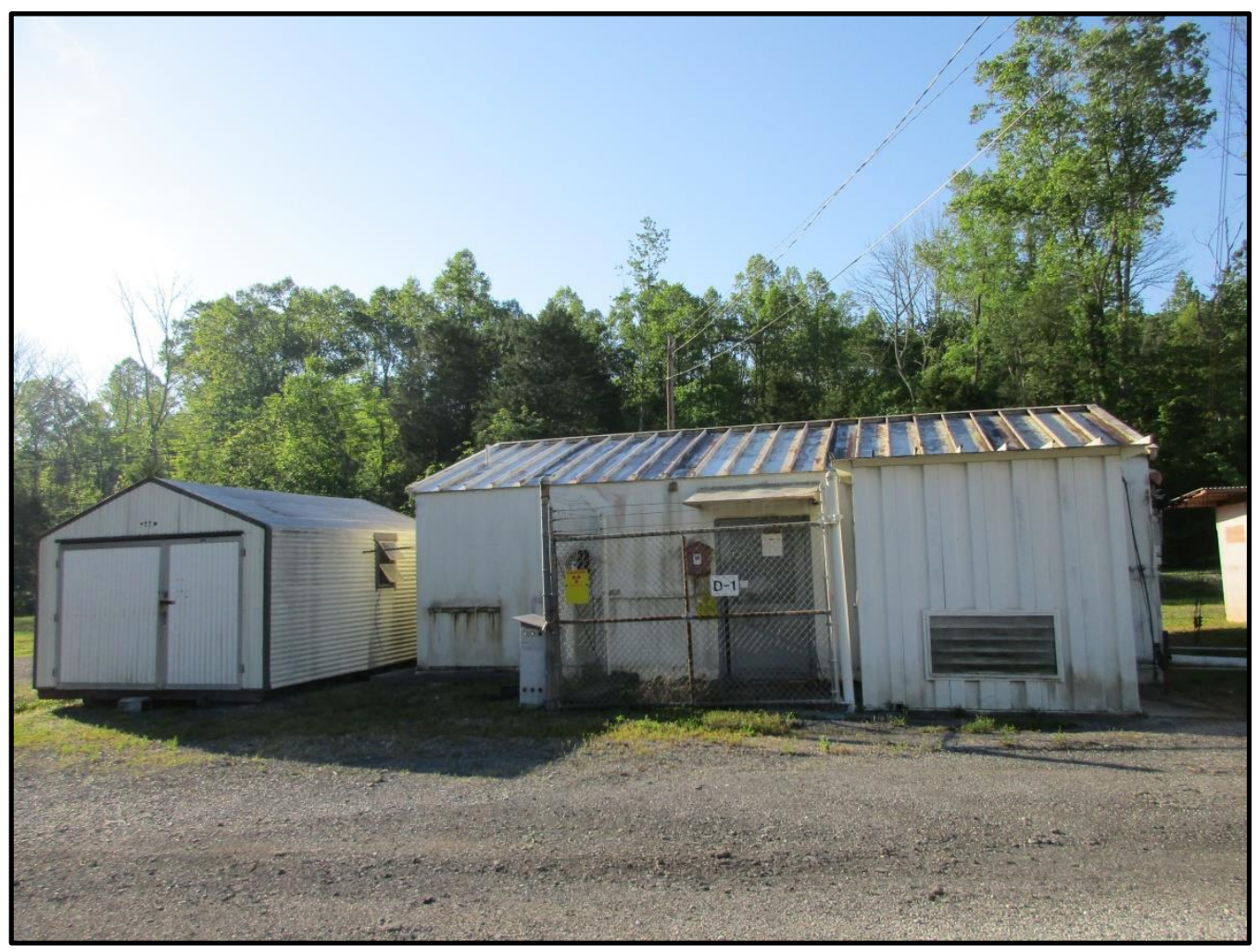

Figure 397. Overview of north elevation of Building 7025. 


\section{BUILDING NAME}

M\&C Storage

DATE OF CONSTRUCTION

1970

DOE OFFICE RESPONSIBLE

$\mathrm{SC}$

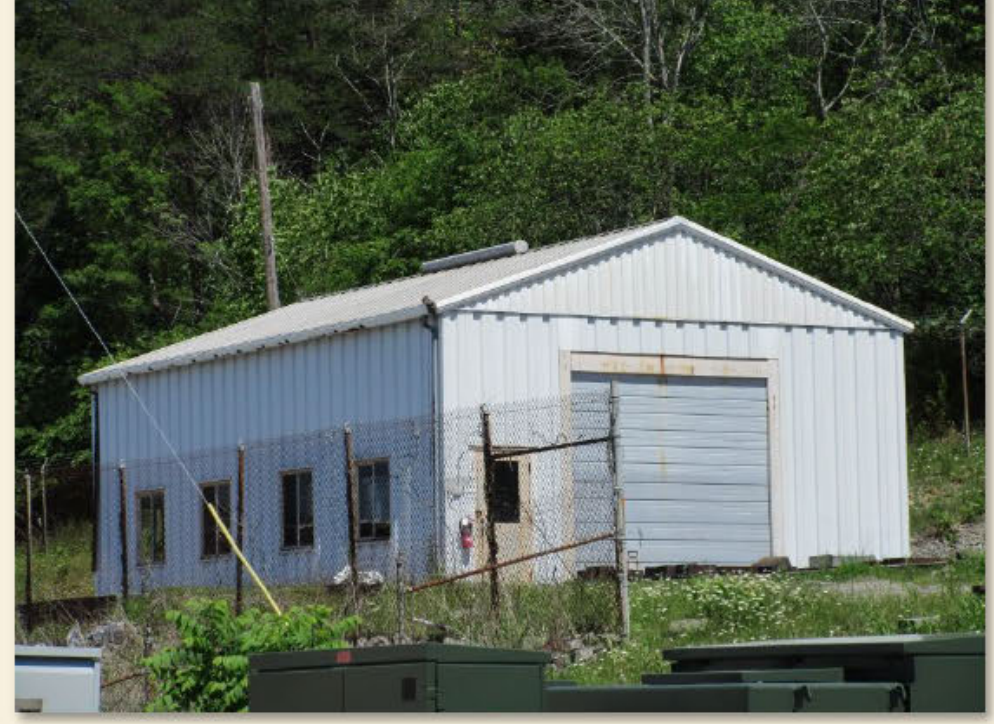

NRHP ELIGIBILITY

Figure 398. Overview of north and west elevations of Building 7026.

Not Eligible

\section{DESCRIPTION}

Located south of White Oak Avenue, Building 7026 is a one-story, front-gable, steel structure with a rectangular plan (Figures 398 and 399). The building is clad and roofed with metal siding and features modern two-light windows with vertical panes. A large industrial garage door is located on the façade (west) elevation as well as a single-light metal pedestrian door.

\section{NATIONAL REGISTER EVALUATION}

Building 7026 was constructed in 1970 as a metals and ceramics storage facility. The building was first surveyed in 1994 by Duvall \& Associates, and they recommended the building as not eligible for listing in NRHP (Carver and Slater 1994). It was not included in the 2004 survey of ORNL. However, it was assessed in the 2015 survey, and Thomason and Associates concurred with the previous assessment (Thomason and Associates 2004 and 2015). As a storage facility, Building 7026 is not a primary resource associated with scientific achievements at ORNL, nor is it known to be individually associated with any other events or persons of historic significance, thus it does not qualify for listing in the NRHP under Criterion A or B. Further, the building is a simple utilitarian structure that lacks architectural significance for listing in the NRHP under Criterion $\mathrm{C}$. The building is not located in a NRHP-eligible historic district. Thus, CRA recommends that Building 7026 is not eligible for listing in the NRHP under Criterion A, B, or C. 


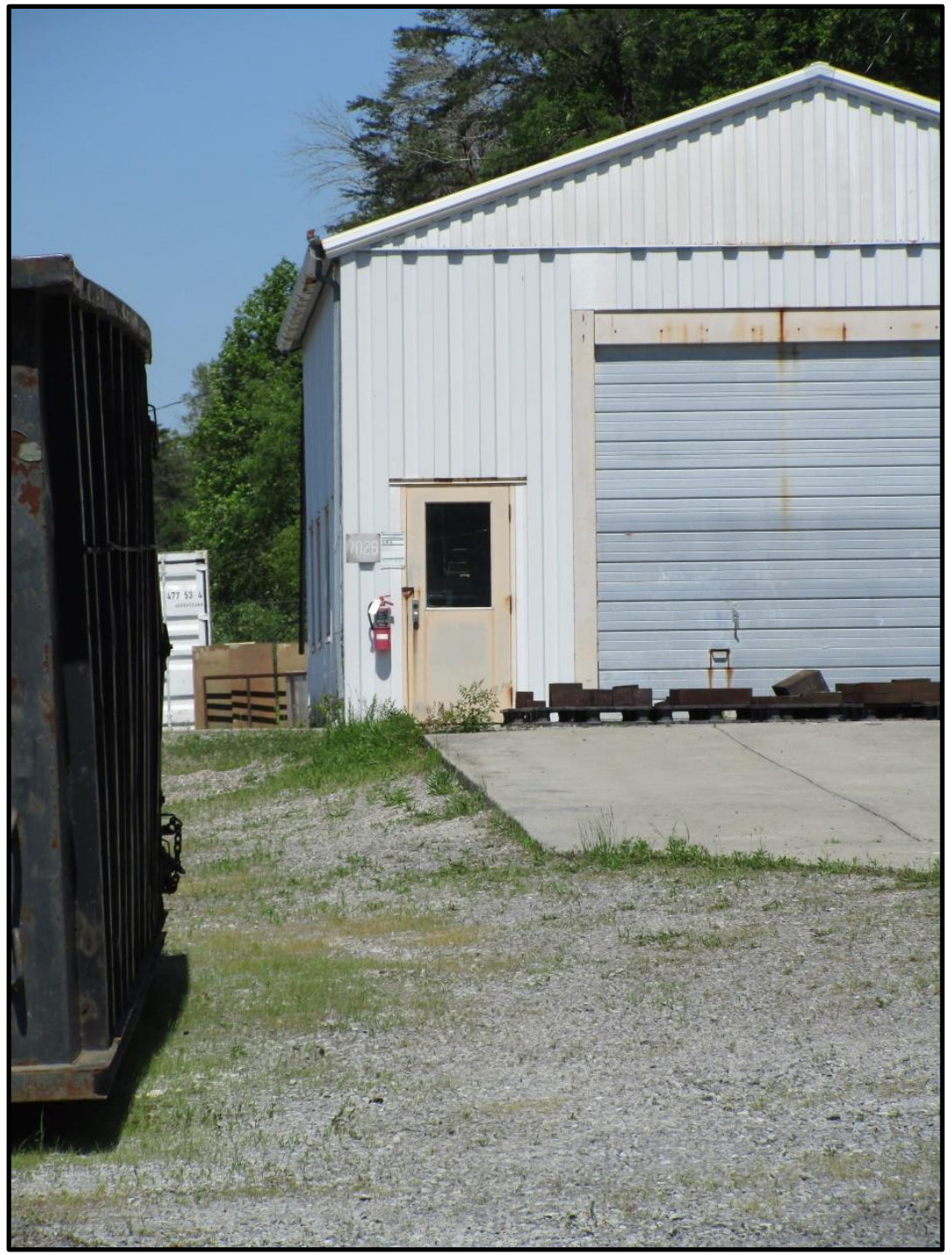

Figure 399. Overview of west elevation of Building 7026. 


\section{BUILDING NAME}

Fabrication Storage Shed

DATE OF CONSTRUCTION

1977

\section{DOE OFFICE RESPONSIBLE}

SC

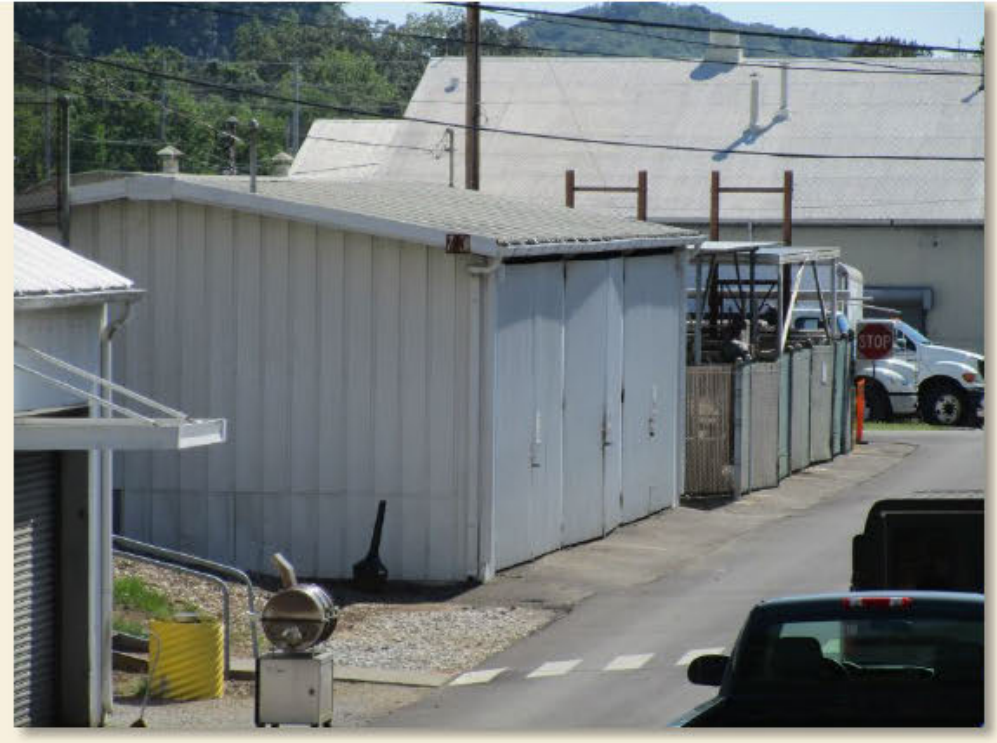

\section{NRHP ELIGIBILITY}

Figure 400. Overview of east and north elevations of Building 7031.

Not Eligible

\section{DESCRIPTION}

Located north of White Oak Avenue, Building 7031 is a one-story, three-bay, side-gable, steel structure with a rectangular plan (Figures 400 and 401). It is situated on a concrete foundation, and the building is clad and roofed with metal panels. Three pairs of hinged, corrugated metal doors are located on the façade (north) elevation.

\section{NATIONAL REGISTER EVALUATION}

Building 3031 was constructed in 1977 as a fabrication storage shed. The building was first surveyed in 1994 by Duvall \& Associates, and they recommended the building as not eligible for listing in NRHP (Carver and Slater 1994). It was not included in the 2004 or 2015 surveys of ORNL (Thomason and Associates 2004 and 2015). As a storage facility, Building 7031 is not a primary resource associated with scientific achievements at ORNL, nor is it known to be individually associated with any other events or persons of historic significance, thus it does not qualify for listing in the NRHP under Criterion A or B. Further, the building is a simple utilitarian structure that lacks architectural significance for listing in the NRHP under Criterion $\mathrm{C}$. The building is not located in a NRHPeligible historic district. Thus, CRA recommends that Building 7031 is not eligible for listing in the NRHP under Criterion $\mathrm{A}, \mathrm{B}$, or $\mathrm{C}$. 


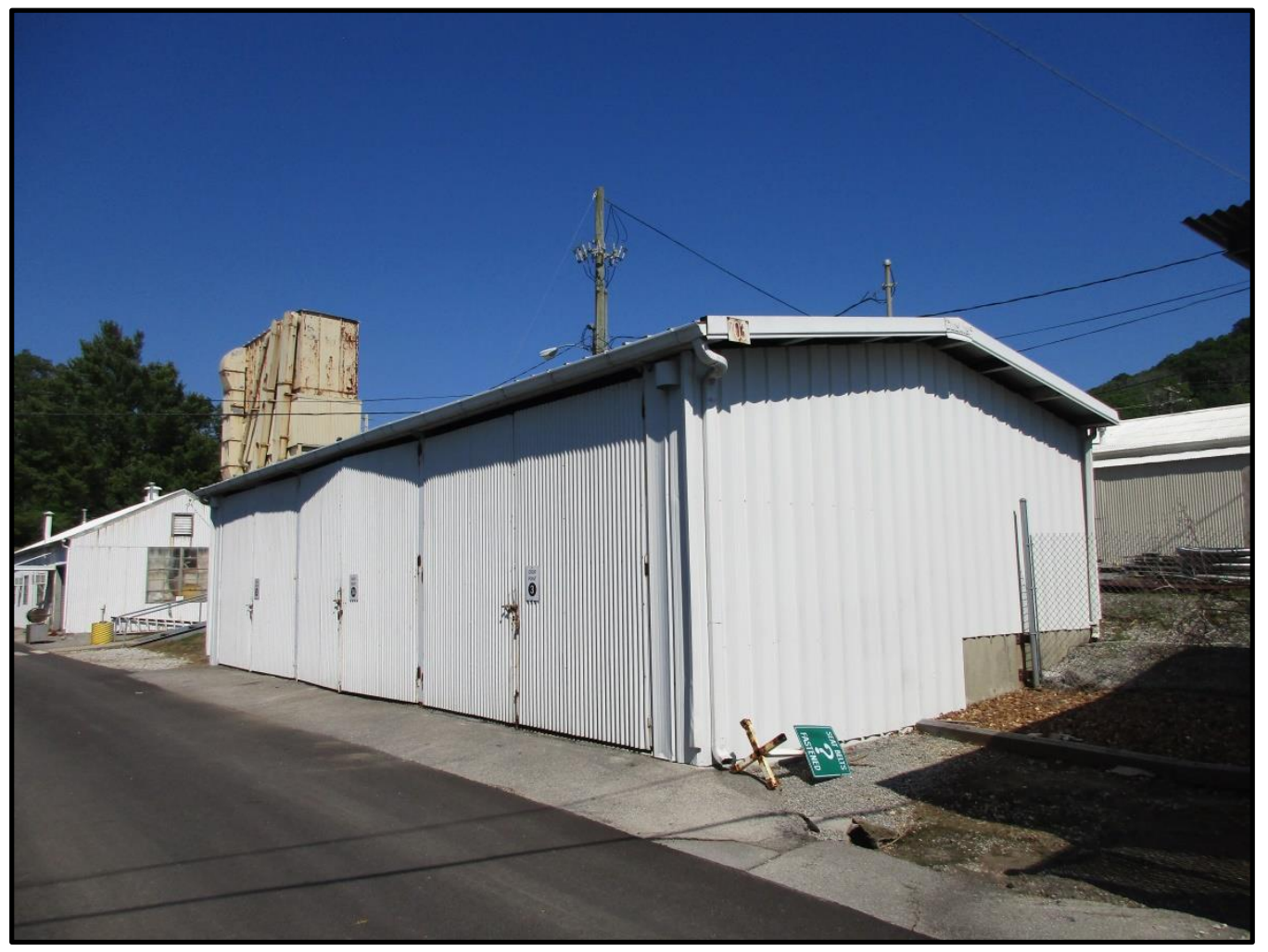

Figure 401. Overview of north and west elevations of Building 7031. 


\section{BUILDING NAME}

Line Crew Facility

\section{DATE OF CONSTRUCTION}

1977

\section{DOE OFFICE RESPONSIBLE}

SC

\section{NRHP ELIGIBILITY}

Figure 402. Overview of east and south elevations of Building 7033.

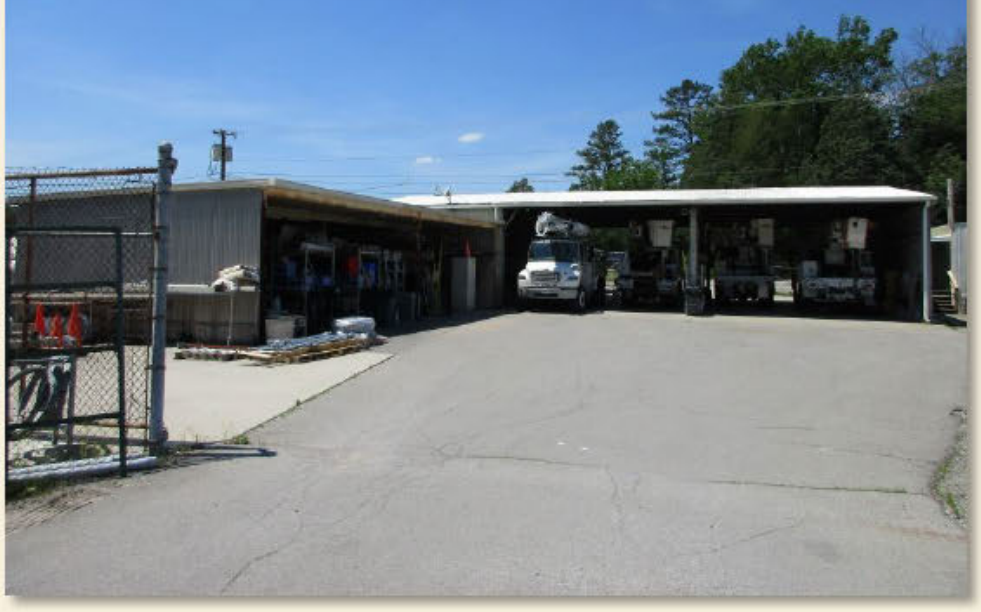

Not Eligible

\section{DESCRIPTION}

Located south of White Oak Avenue, Building 7033 is a one-story, side-gable building and has multiple additions with low-pitch shed roofs (Figures 402 and 403). The building is clad with various types of metal siding and is situated on a concrete foundation. The structure features metal doors, some with single-light openings. The north and south elevations on the main wing of the building are open.

\section{NATIONAL REGISTER EVALUATION}

Building 7033 was constructed in 1977 as an Electrical Material Storage. The structure's current use is a Line Crew Facility. Building 7033 was first surveyed in 1994 by Duvall \& Associates, and they recommended the building as not eligible for listing in NRHP (Carver and Slater 1994). It was not included in the 2004 or 2015 surveys of ORNL (Thomason and Associates 2004 and 2015). Built as a storage facility now used as a maintenance facility, Building 7033 is not a primary resource associated with scientific achievements at ORNL, nor is it known to be individually associated with any other events or persons of historic significance, thus it does not qualify for listing in the NRHP under Criterion A or B. Further, the building is a simple utilitarian structure that lacks architectural significance for listing in the NRHP under Criterion C. The building is not located in a NRHPeligible historic district. Thus, CRA recommends that Building 7033 is not eligible for listing in the NRHP under Criterion $\mathrm{A}, \mathrm{B}$, or $\mathrm{C}$. 


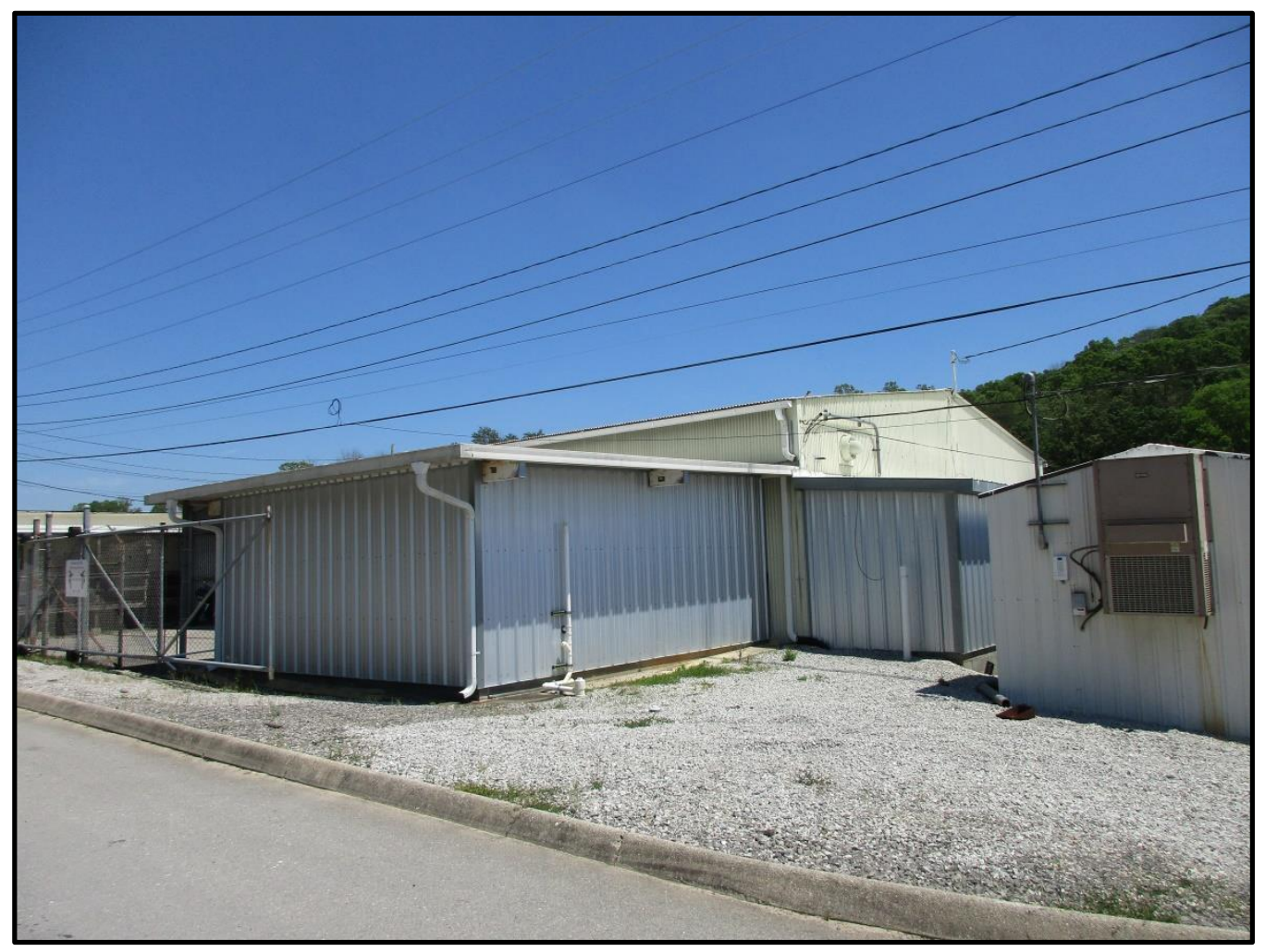

Figure 403. Overview of north and west elevations of Building 7033. 


\section{5/A/B/C/D}

\section{BUILDING NAME}

Paint Mix Building

DATE OF CONSTRUCTION

1977

\section{DOE OFFICE RESPONSIBLE}

SC

NRHP ELIGIBILITY

Figure 404. Overview of west and south elevations of Building 7035A, $7035 \mathrm{~B}$, and $7035 \mathrm{C}$.

Not Eligible

\section{DESCRIPTION}

Located south of White Oak Avenue, Buildings 7035, 7035A, 7035B, and $7035 \mathrm{C}$ are located along a row of similar buildings adjacent to one another. Buildings 7035, 7035A, B and C are one-story, front-gable buildings situated on concrete foundations (Figures 404 and 405). The structures, oriented to the west, feature single-light metal pedestrian doors on their façade (west) elevations. Flat metal awnings are located above the entrances to Buildings $7035,7035 \mathrm{~A}$ and $7035 \mathrm{~B}$. Building $7035 \mathrm{D}$ is a smaller stand-alone building near the row of other buildings (Figure 406). This structure is also clad with corrugated metal siding and features a pair of metal doors on its façade (west) elevation with a metal shed awning located above.

\section{NATIONAL REGISTER EVALUATION}

Buildings 7035, 7035A, 7035B, 7035C, and 7035D were constructed as Material and Equipment Storage buildings within the East Support Area. The buildings were first surveyed in 1994 by Duvall \& Associates, and they recommended the building as not eligible for listing in NRHP (Carver and Slater 1994). They were not included in the 2004 or 2015 surveys of ORNL. (Thomason and Associates 2004 and 2015). As a group of storage and maintenance facilities, Buildings $7035 \mathrm{~A} / \mathrm{B} / \mathrm{C} / \mathrm{D}$ are not primary resources associated with scientific achievements at ORNL, nor are they known to be individually associated with any other events or persons of historic significance, thus they do not qualify for listing in the NRHP under Criterion A or B. Further, the buildings are simple utilitarian structures that lack architectural significance for listing in the NRHP under Criterion $\mathrm{C}$. The buildings are not located in a NRHP-eligible historic district. Thus, CRA recommends that Buildings 7035, 7035A, 7035B, 7035C, and 7035D are not eligible for listing in the NRHP under Criterion A, B, or C. 


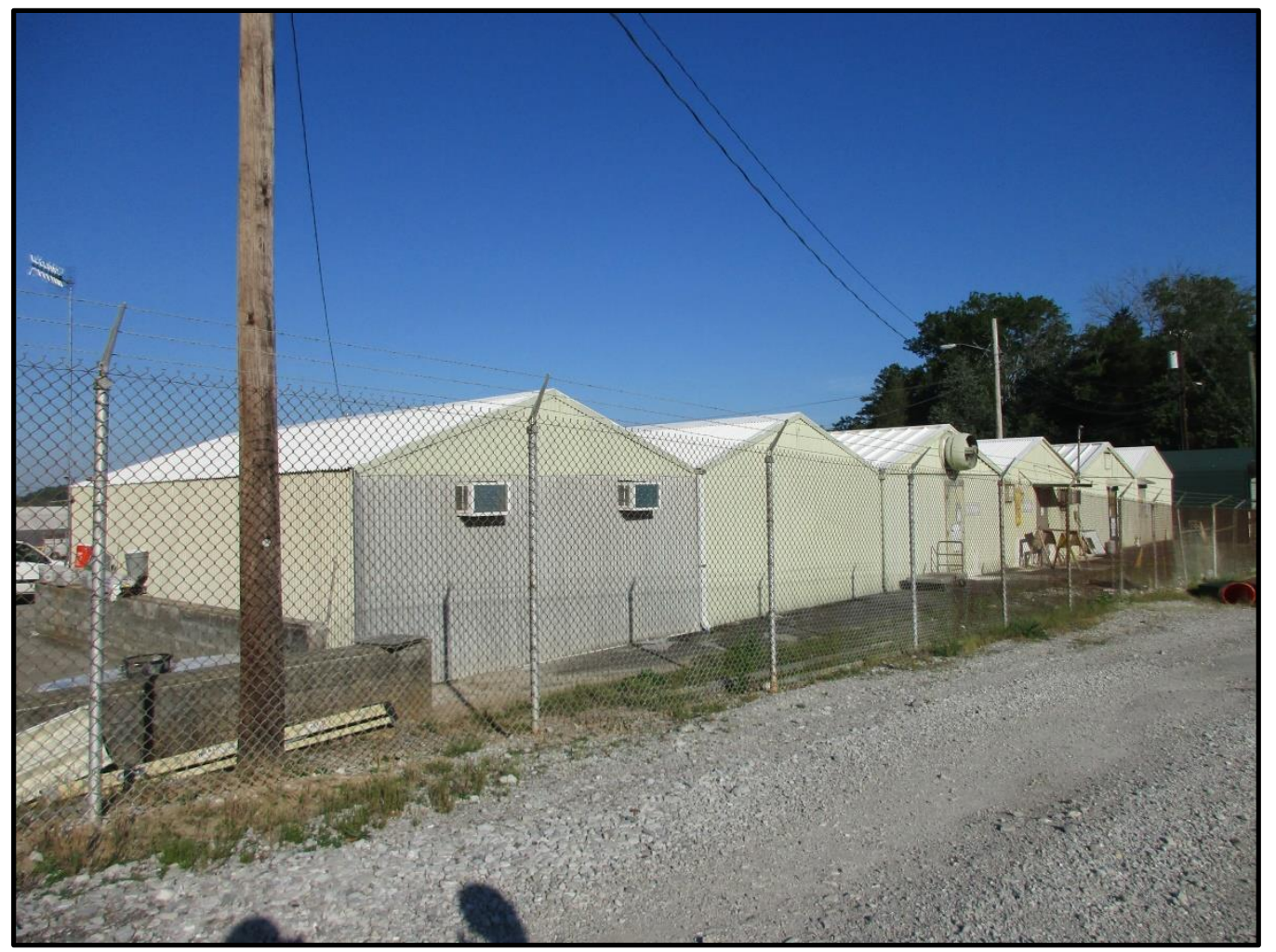

Figure 405. Overview of south and east elevations of Buildings 7035A, 7035B, and 7035C.

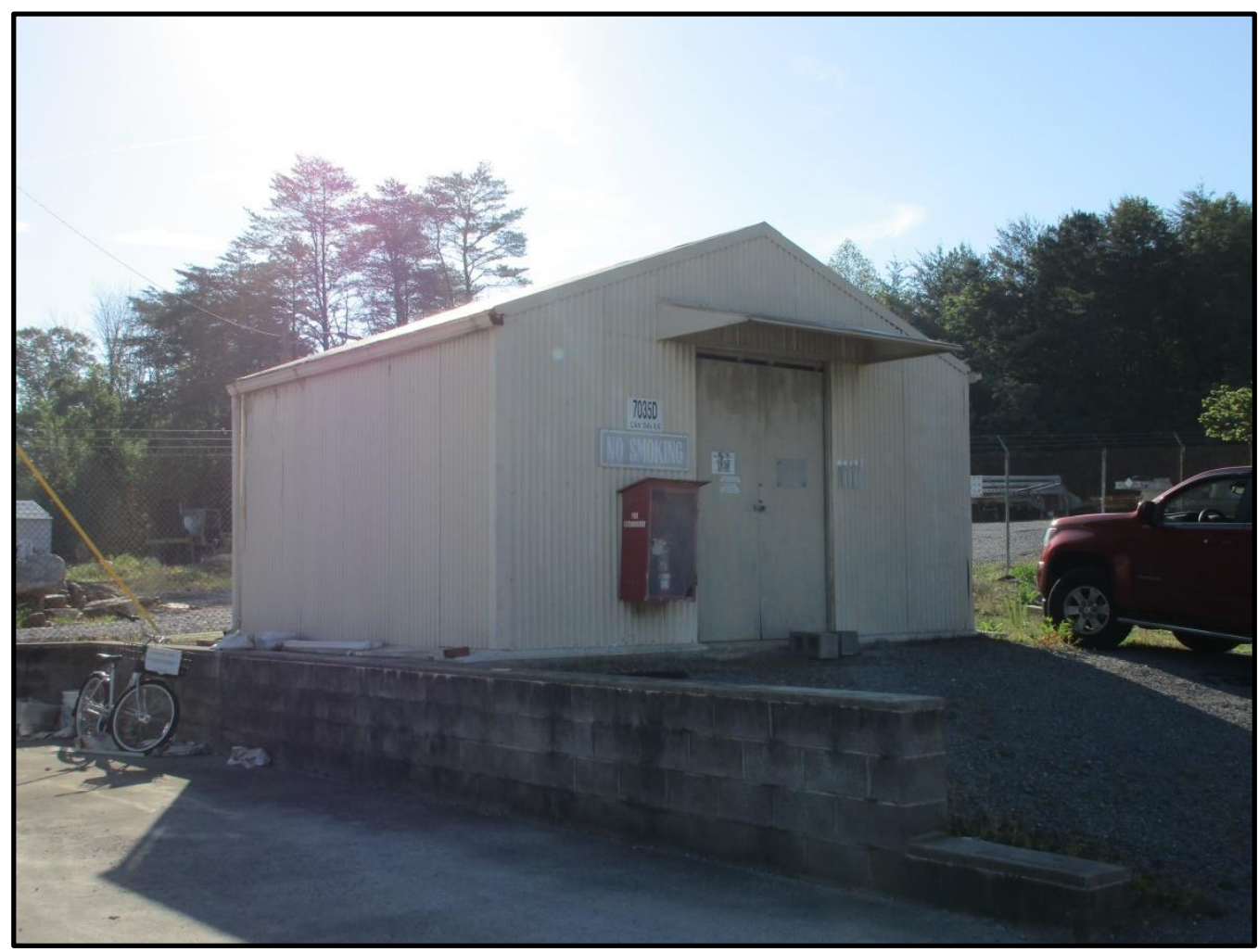

Figure 406. Overview of north and west elevations of standalone Building 7035D. 


\section{BUILDING NAME}

Sandblast Cleaning Facility

DATE OF CONSTRUCTION

1959

DOE OFFICE RESPONSIBLE

$\mathrm{SC}$

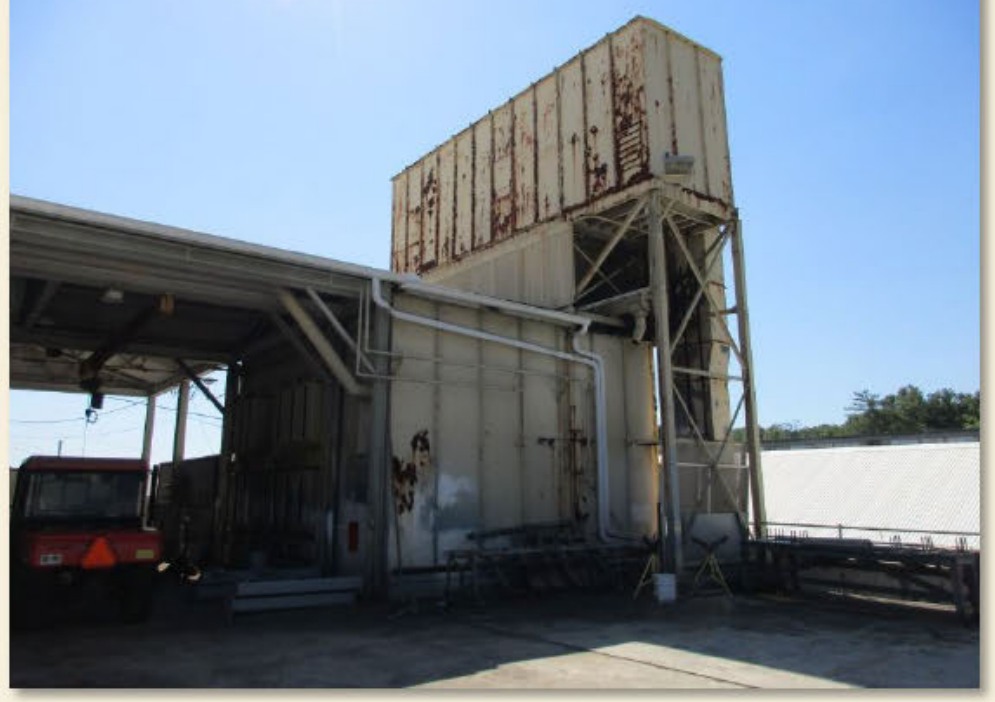

NRHP ELIGIBILITY

Figure 407. Overview of east and south elevations of Building 7057.

Not Eligible

\section{DESCRIPTION}

Located between White Oak Avenue and Bethel Valley Road, Building 7057 sits adjacent to Building 7007 and is connected by a side-gable overhang. The building stands as a steel exhaust tower and is partially clad with corrugated metal while the remainder is clad in vertical metal panels (Figures 407 and 408 ). The structure is situated on a concrete foundation. A series of vents and exhaust systems are located throughout the tower.

\section{NATIONAL REGISTER EVALUATION}

The building was constructed in 1959 as a Sandblasting Cleaning Facility within the maintenance area. This structure has continued to serve this purpose until it was shut down in 2016. Building 7057 was first surveyed in 1994 by Duvall \& Associates, and they recommended the building as not eligible for listing in NRHP (Carver and Slater 1994). It was not included in the 2004 survey of ORNL. However, it was assessed in the 2015 survey, and Thomason and Associates concurred with the previous assessment (Thomason and Associates 2004 and 2015). As a maintenance facility, Building 7057 is not a primary resource associated with scientific achievements at ORNL, nor is it known to be individually associated with any other events or persons of historic significance, thus it does not qualify for listing in the NRHP under Criterion A or B. Further, the building is a simple utilitarian structure that lacks architectural significance for listing in the NRHP under Criterion $\mathrm{C}$. The building is not located in a NRHP-eligible historic district. Thus, CRA recommends that Building 7057 is not eligible for listing in the NRHP under Criterion A, B, or C. 


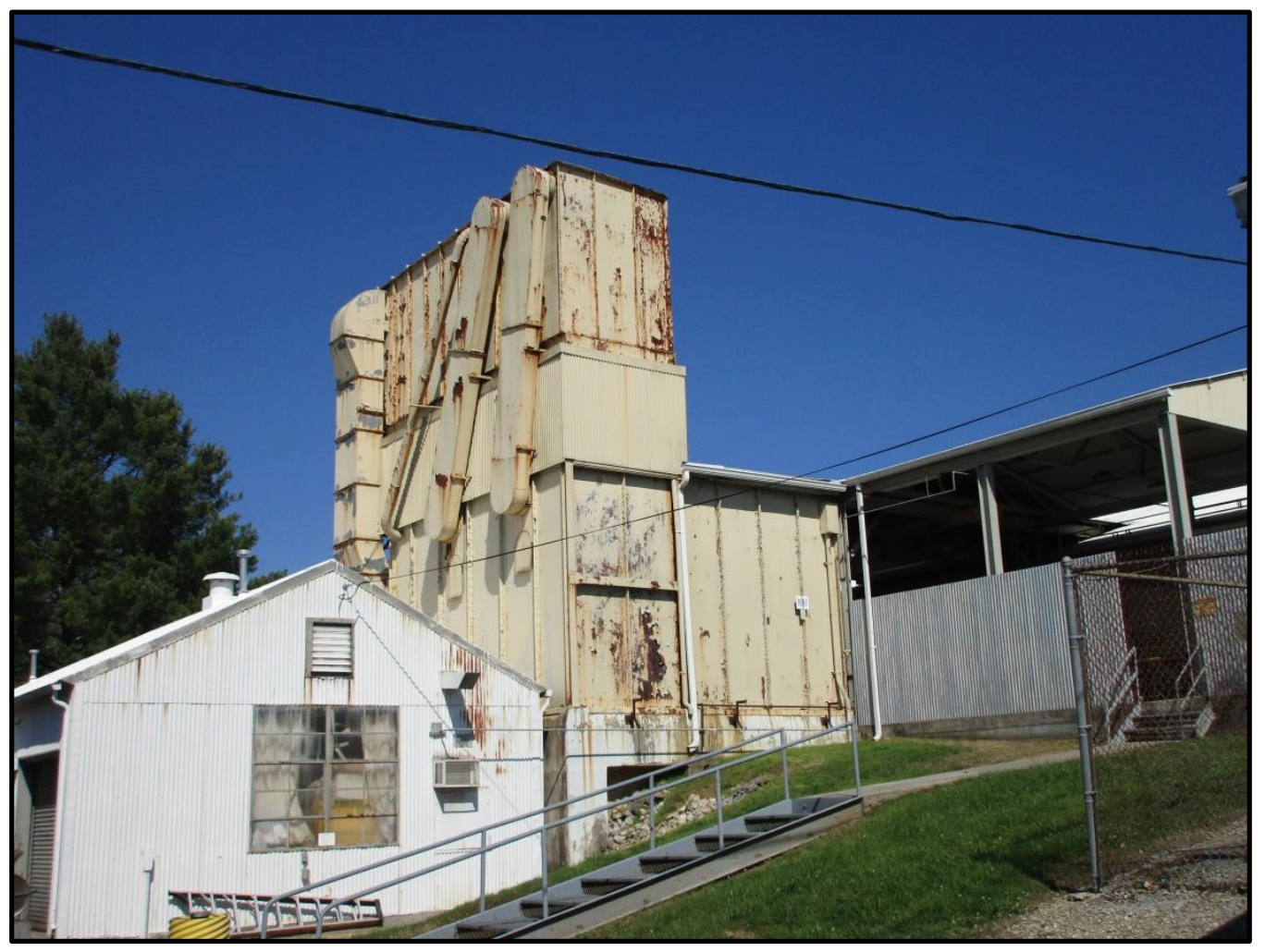

Figure 408. Overview of north and west elevations of Building 7057, the steel exhaust tower. 


\section{BUILDING NAME}

Pipe and Regulator Repair Shop

\section{DATE OF CONSTRUCTION}

1959

\section{DOE OFFICE RESPONSIBLE}

SC

\section{NRHP ELIGIBILITY}

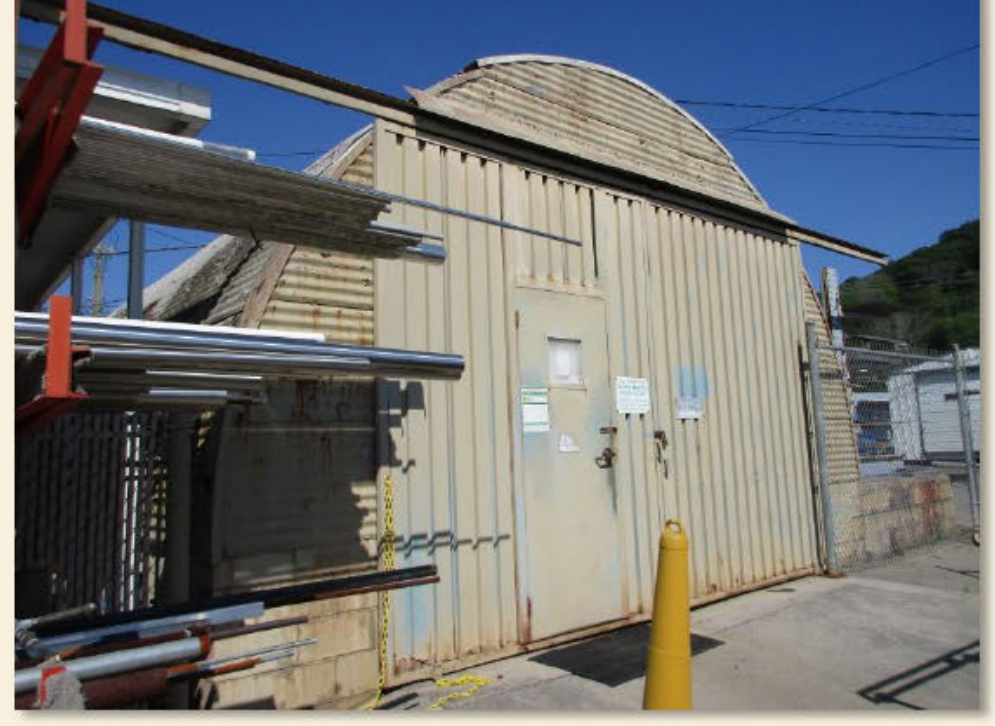

Figure 409. Overview of the west elevation of Building 7058, a Quonset

Not Eligible Hut.

\section{DESCRIPTION}

Located between White Oak Avenue and Bethel Valley Road, Building 7058 is a one-story Quonset Hut facility, which is semicircular in cross section (Figures 409 and 410). Quonset huts are prefabricated with steel and clad with corrugated metal. This particular building features two large sliding-track doors with a smaller inset singlelight pedestrian door on the façade (west). The rear (east) elevation includes a fixed steel ten-light window with an air conditioning unit installed in a portion of it.

\section{NATIONAL REGISTER EVALUATION}

Building 7058 was constructed in 1959 as a machine auxiliaries storage facility. The building now serves a pipe and regulator repair shop within the maintenance area. Building 7058 was first surveyed in 1994 by Duvall \& Associates, and they recommended the building as not eligible for listing in NRHP (Carver and Slater 1994). It was not included in the 2004 survey of ORNL. However, it was assessed in the 2015 survey, and Thomason and Associates concurred with the previous assessment (Thomason and Associates 2004 and 2015). As a storage facility later used as a maintenance facility, Building 7058 is not a primary resource associated with scientific achievements at ORNL, nor is it known to be individually associated with any other events or persons of historic significance, thus it does not qualify for listing in the NRHP under Criterion A or B. Further, the building is a simple utilitarian structure that lacks architectural significance for listing in the NRHP under Criterion $\mathrm{C}$. The building is not located in a NRHP-eligible historic district. Thus, CRA recommends that Building 7058 is not eligible for listing in the NRHP under Criterion A, B, or C. 


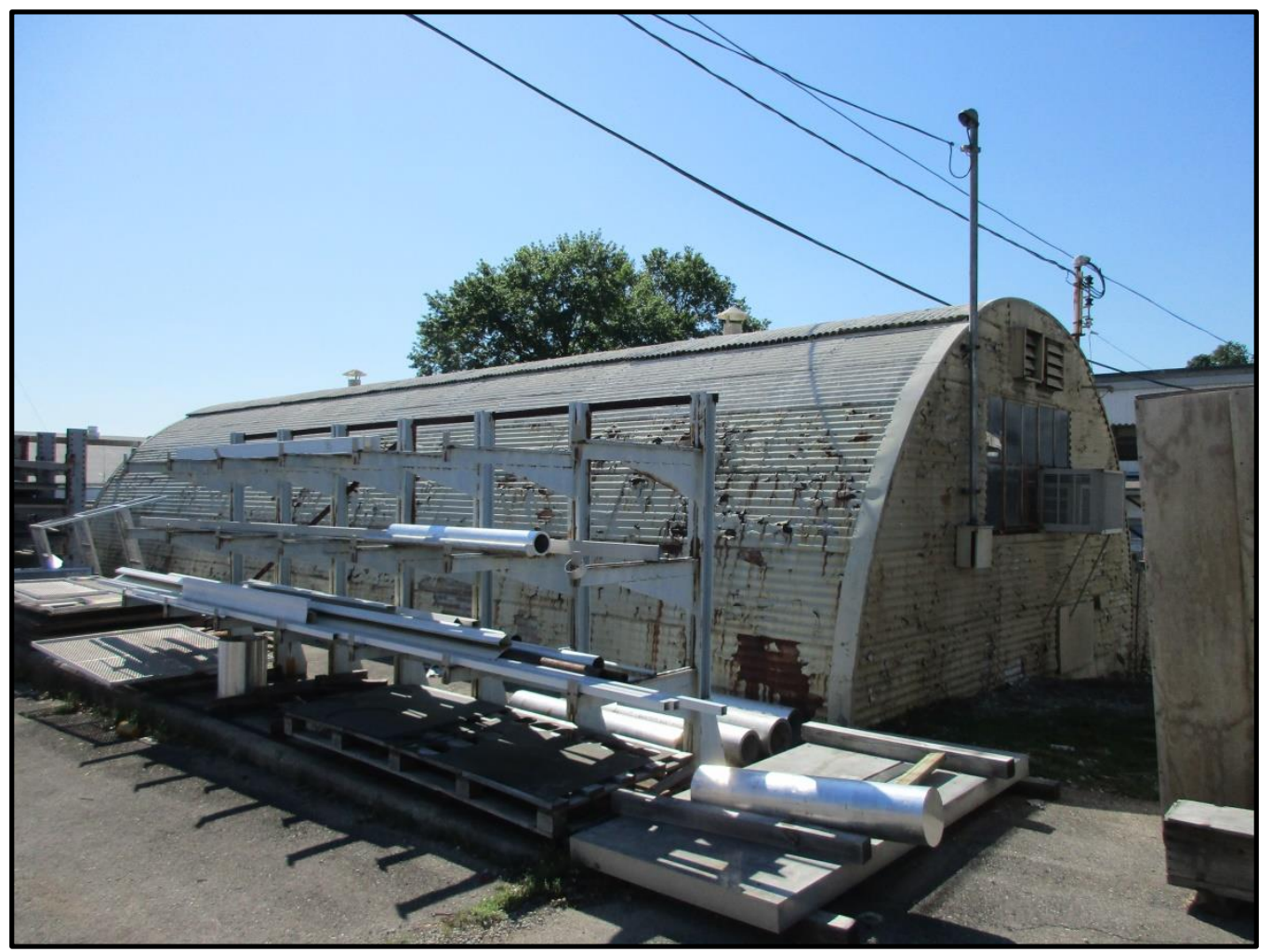

Figure 410. Overview of south and east elevations of Building 7058, a Quonset Hut. 


\section{BUILDING NAME}

Health Physics Environmental Storage

\section{DATE OF CONSTRUCTION}

1957

\section{DOE OFFICE RESPONSIBLE}

SC

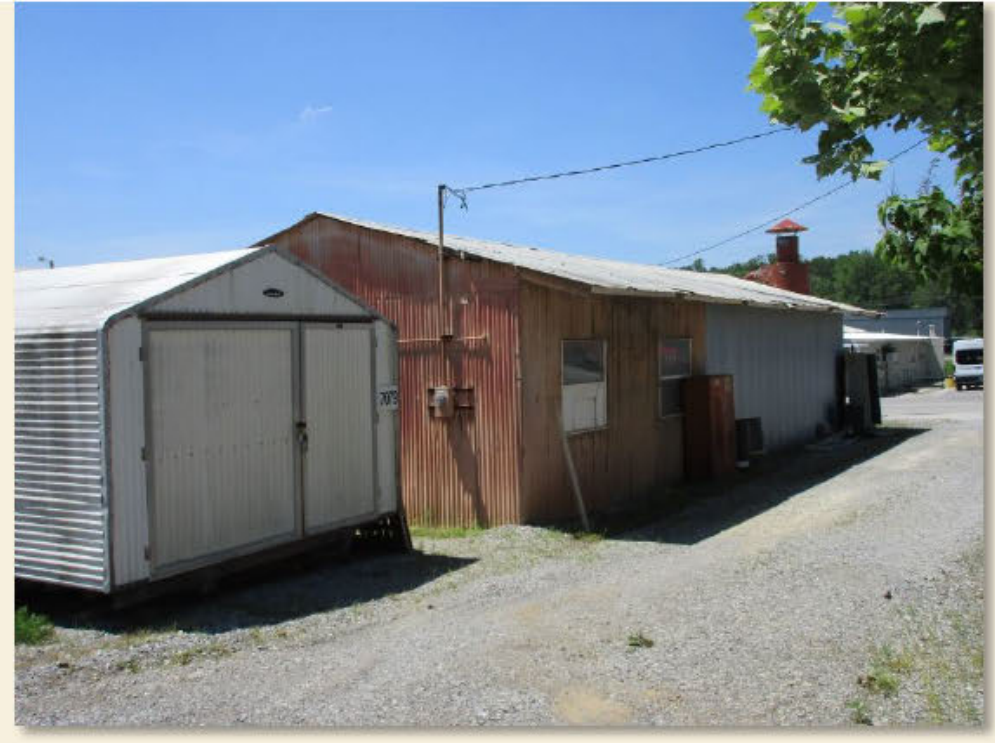

NRHP ELIGIBILITY

Figure 411. Overview of south and east elevations of Building 7061.

Not Eligible

\section{DESCRIPTION}

Located south of White Oak Avenue, Building 7061 is a one-story, front-gable, wood frame structure that is rectangular in plan (Figures 411 and 412). Oriented to the north, Building 7061 is clad in corrugated metal and has deep overhanging eaves and exposed wood rafters. Both the exterior walls and roof are clad in corrugated metal. The façade (north) elevation is open but access is through a chain link gate. The building features twolight metal windows on the side (west and east) elevations. A steel door is located on the south elevation.

\section{NATIONAL REGISTER EVALUATION}

Building 7061 was built in 1957 as an environmental storage building. The building was first surveyed in 1994 by Duvall \& Associates, and they recommended the building as not eligible for listing in NRHP (Carver and Slater 1994). It was not included in the 2004 survey of ORNL. However, it was assessed in the 2015 survey, and Thomason and Associates concurred with the previous assessment (Thomason and Associates 2004 and 2015). As a storage facility, Building 7061 is not a primary resource associated with scientific achievements at ORNL, nor is it known to be individually associated with any other events or persons of historic significance, thus it does not qualify for listing in the NRHP under Criterion A or B. Further, the building is a simple utilitarian structure with alterations that lacks architectural significance and integrity for listing in the NRHP under Criterion C. The building is not located in a NRHP-eligible historic district. Thus, CRA recommends that Building 7061 is not eligible for listing in the NRHP under Criterion A, B, or C. 


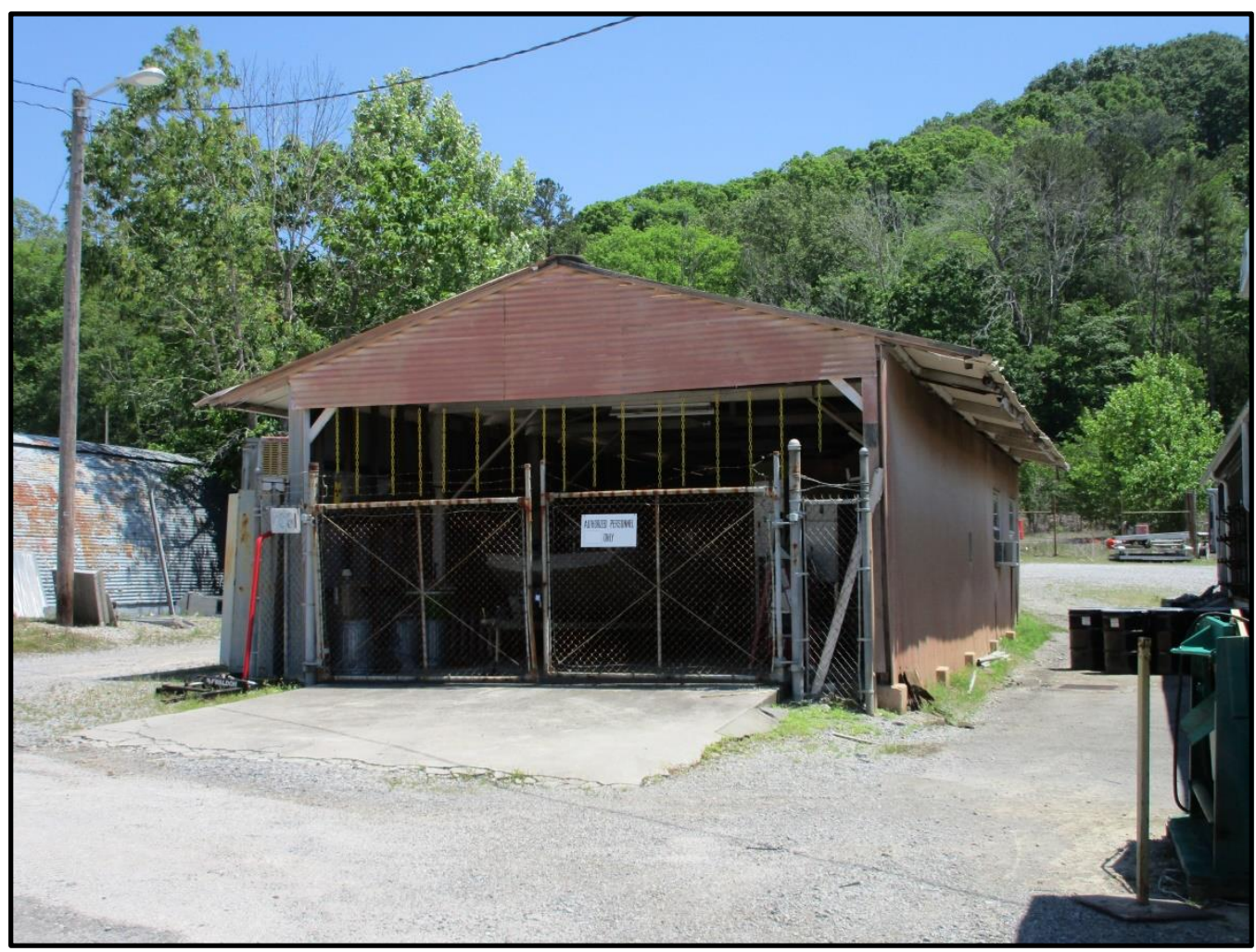

Figure 412. Overview of north and west elevations of Building 7061. 


\section{2}

\section{BUILDING NAME}

Crane Inspection Shop

DATE OF CONSTRUCTION

1961

\section{DOE OFFICE RESPONSIBLE}

SC

\section{NRHP ELIGIBILITY}

Figure 413. Overview of north and west elevations of Building 7062.

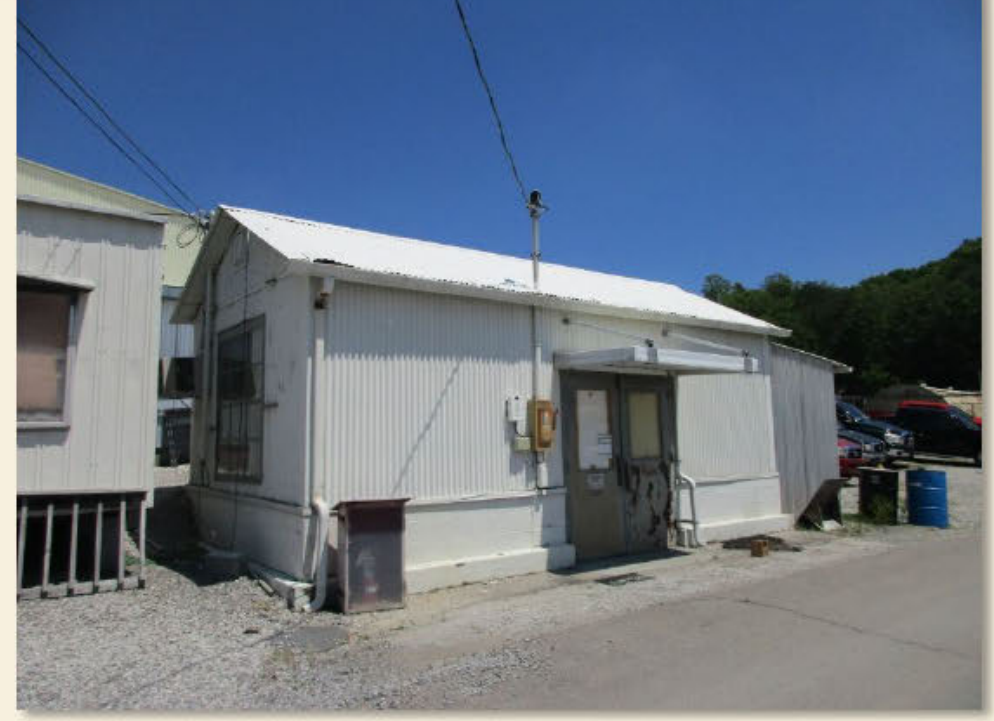

Not Eligible

\section{DESCRIPTION}

Building 7062 is located south of White Oak Avenue west of Building 7033. Building 7062 is a one-story, singlebay, side-gable metal frame building on concrete foundation (Figures 413 and 414). Oriented to the west, the building has a knee wall of concrete block and the remainder of the building's walls are clad in corrugated metal panels. The roof is also covered in corrugated metal. The façade features a double-leaf entry filled with singlelight, metal doors sheltered by a flat metal awning. A twelve-light awning window is located on the north elevation. A shed-roof addition with a single-light steel door is attached to the south elevation of Building 7062. The roof and side elevations of the addition are clad in corrugated metal panels.

\section{NATIONAL REGISTER EVALUATION}

Building 7062 was constructed in 1961 as a storage facility. Today, the structure serves as the crane inspection shop. Located south of White Oak Avenue, Building 7062 was first surveyed in 2015 by Thomason and Associates. It was not included in the 1994 and 2004 surveys of ORNL. Thomason and Associates stated that the building is not eligible for listing in the NRHP (Thomason and Associates 2015). As a storage facility later used as a maintenance facility, Building 7062 is not a primary resource associated with scientific achievements at ORNL, nor is it known to be individually associated with any other events or persons of historic significance, thus it does not qualify for listing in the NRHP under Criterion A or B. Further, the building is a simple utilitarian structure that lacks architectural significance for listing in the NRHP under Criterion C. The building is not located in a NRHP-eligible historic district. Thus, CRA recommends that Building 7062 is not eligible for listing in the NRHP under Criterion A, B, or C. 


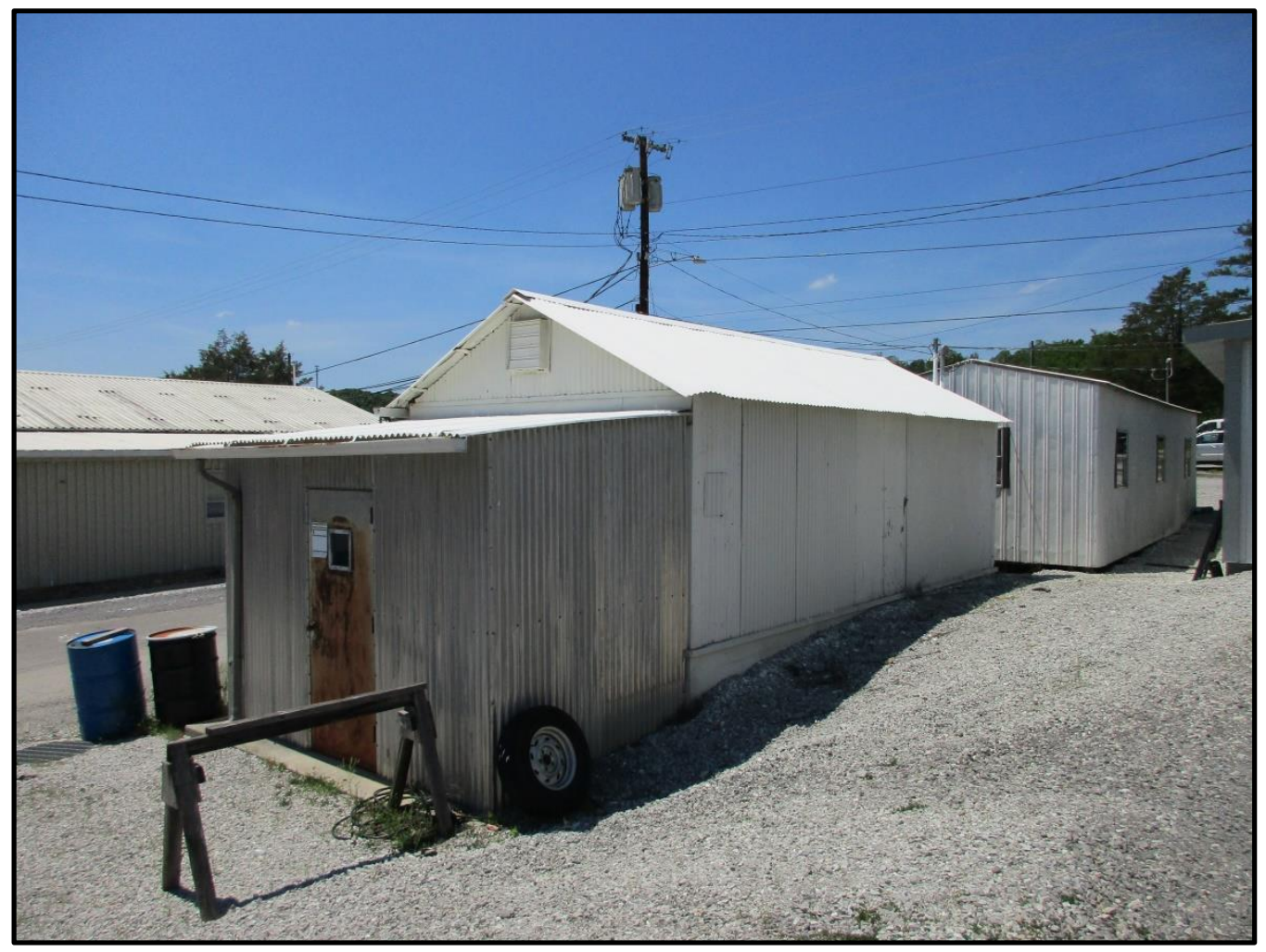

Figure 414. Overview of south and east elevations of Building 7062. 


\section{BUILDING NAME}

Grounds Maintenance Storage

DATE OF CONSTRUCTION

1966

DOE OFFICE RESPONSIBLE

SC

NRHP ELIGIBILITY

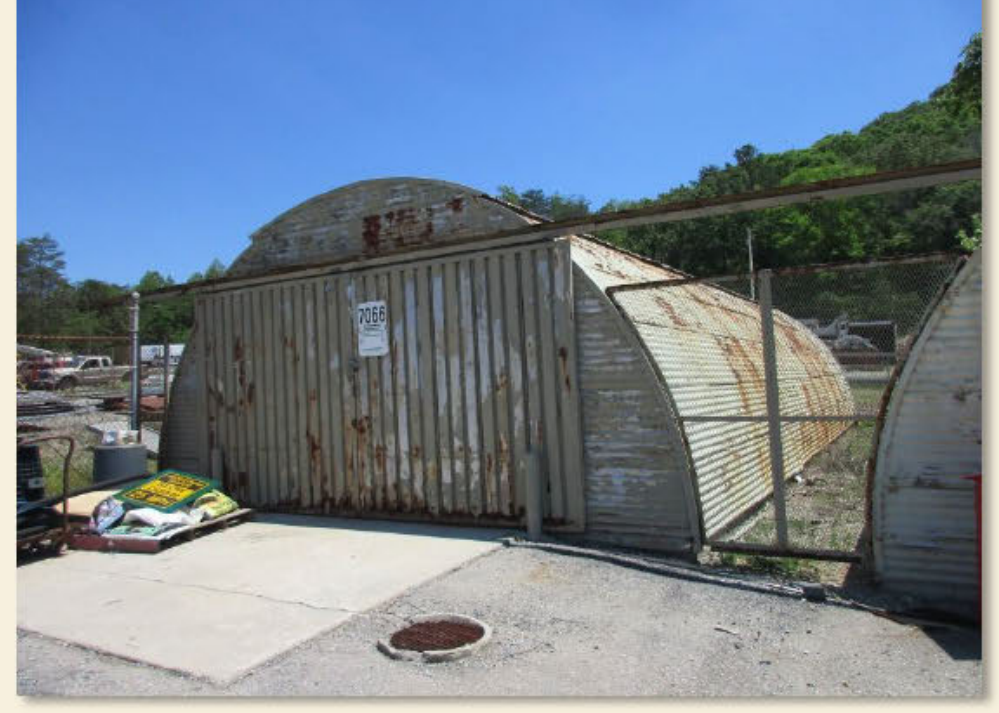

Figure 416. Overview of north and west elevations of Building 7066, a Quonset hut.

Not Eligible

\section{DESCRIPTION}

Similar to Buildings 7058 and 7065 , Building 7066 is a prefabricated Quonset hut structure and is located south of White Oak Avenue. It is adjacent to and immediately east of Building 7065. Rectangular in plan, the building is semicircular in cross section and features a ribbed steel frame clad in corrugated metal (Figures 416 and 417). Building 7065 contains two large sliding track doors on the facade (north) elevation. The rear (south) elevation features a three-light steel awning window with a small louvered vent above.

\section{NATIONAL REGISTER EVALUATION}

Building 7066 was constructed in 1965 and served as grounds maintenance storage facility within the maintenance area. The building continues to provide storage in the ORNL maintenance area. The building was first surveyed in 1994 by Duvall \& Associates, and they recommended the building as not eligible for listing in NRHP (Carver and Slater 1994). It was not included in the 2004 survey of ORNL. However, it was assessed in the 2015 survey, and Thomason and Associates concurred with the previous assessment (Thomason and Associates 2004 and 2015). As a storage facility, Building 7066 is not a primary resource associated with scientific achievements at ORNL, nor is it known to be individually associated with any other events or persons of historic significance, thus it does not qualify for listing in the NRHP under Criterion A or B. Further, the building is a simple utilitarian structure with a common prefabricated form that lacks architectural significance for listing in the NRHP under Criterion $C$. The building is not located in a NRHP-eligible historic district. Thus, CRA recommends that Building 7066 is not eligible for listing in the NRHP under Criterion A, B, or C. 


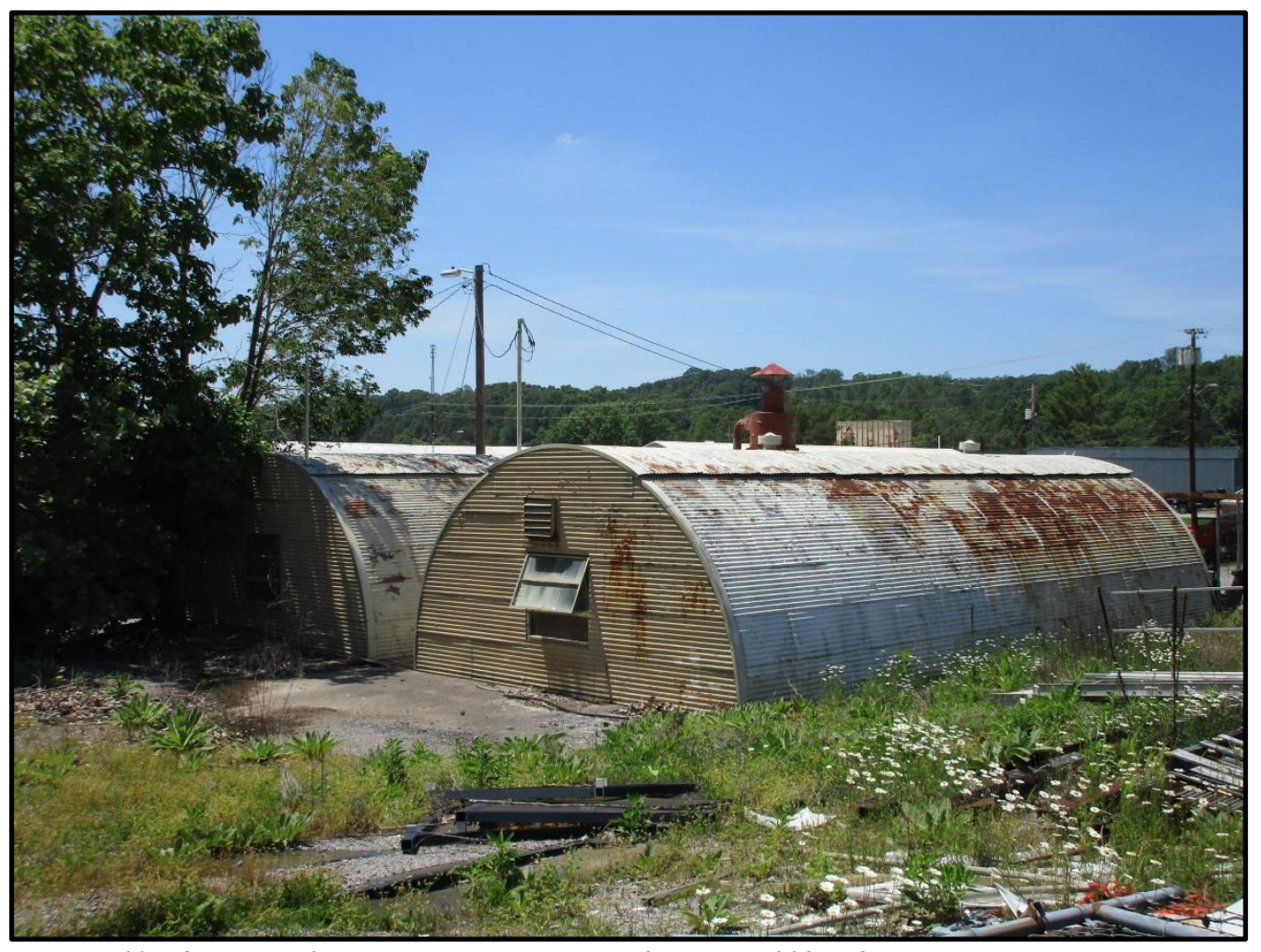

Figure 417. Overview of south and east elevations of Building 7066, a Quonset hut. 


\section{BUILDING NAME}

Facility Surveillance Office

\section{DATE OF CONSTRUCTION}

1965

DOE OFFICE RESPONSIBLE

$\mathrm{SC}$

NRHP ELIGIBILITY

Figure 418. Overview of west and south elevations of Building 7067.

Not Eligible

\section{DESCRIPTION}

Located north of White Oak Avenue, Building 7067 is one-story, concrete block masonry building with a flat roof (Figures 418 and 419). Square in plan, the building features a deep overhangs and exposed concrete rafters. Oriented to the west, Building 7067 exhibits a single-leaf entry on both the façade (west) and north elevations, each filled with single-light metal doors. Windows on the façade (west) and rear (east) elevations are filled with two-over-two horizontal sashes.

\section{NATIONAL REGISTER EVALUATION}

Building 7067 was constructed as an operation and office facility within the maintenance area of ORNL. The building was first surveyed in 1994 by Duvall \& Associates, and they recommended the building as not eligible for listing in NRHP (Carver and Slater 1994). It was not included in the 2004 survey of ORNL. However, it was assessed in the 2015 survey, and Thomason and Associates concurred with the previous assessment (Thomason and Associates 2004 and 2015). As an office for support staff, Building 7067 is not a primary resource associated with scientific achievements at ORNL, nor is it known to be individually associated with any other events or persons of historic significance, thus it does not qualify for listing in the NRHP under Criterion A or $\mathrm{B}$. Further, the building is a simple utilitarian structure that lacks architectural significance for listing in the NRHP under Criterion $C$. The building is not located in a NRHP-eligible historic district. Thus, CRA recommends that Building 7067 is not eligible for listing in the NRHP under Criterion A, B, or C. 


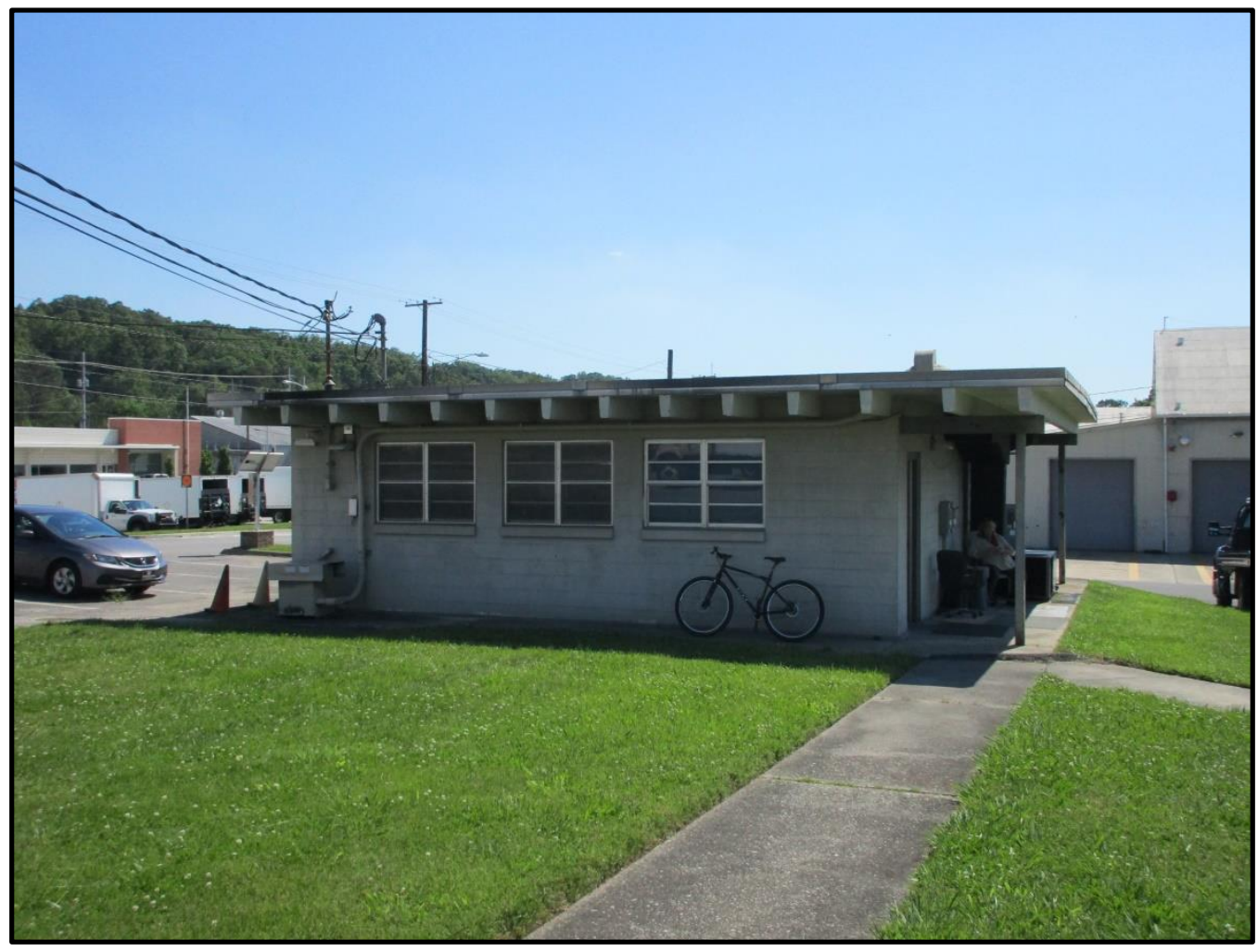

Figure 419. Overview of east and north elevations of Building 7067. 


\section{BUILDING NAME}

Storage Shed

\section{DATE OF CONSTRUCTION}

1969

\section{DOE OFFICE RESPONSIBLE}

SC

\section{NRHP ELIGIBILITY}

Not Eligible

\section{DESCRIPTION}

Located south of White Oak Avenue, Building 7070 is rectangular in plan and is one story in height. The building is a steel structure clad in corrugated metal siding with a side-gable roof also clad in corrugated metal (Figures 420 and 421). The building is entirely enclosed on the north elevation, and the west elevation is enclosed with metal double doors. The remaining elevations feature an open air design with partial enclosure or no enclosure on each elevation. The west elevation features a large rollup industrial garage door. The south elevation is entirely open, exposing the steel truss system, and enclosed by a metal chain link fence.

\section{NATIONAL REGISTER EVALUATION}

Building 7070 was constructed as storage shed in 1969. The building continues to provide storage in the ORNL maintenance area. The building was first surveyed in 1994 by Duvall \& Associates, and they recommended the building as not eligible for listing in NRHP (Carver and Slater 1994). It was not included in the 2004 survey of ORNL. However, it was assessed in the 2015 survey, and Thomason and Associates concurred with the previous assessment (Thomason and Associates 2004 and 2015). As a storage facility, Building 7070 is not a primary resource associated with scientific achievements at ORNL, nor is it known to be individually associated with any other events or persons of historic significance, thus it does not qualify for listing in the NRHP under Criterion $\mathrm{A}$ or $\mathrm{B}$. Further, the building is a simple utilitarian structure that lacks architectural significance for listing in the NRHP under Criterion $C$. The building is not located in a NRHP-eligible historic district. Thus, CRA recommends that Building 7070 is not eligible for listing in the NRHP under Criterion A, B, or C. 


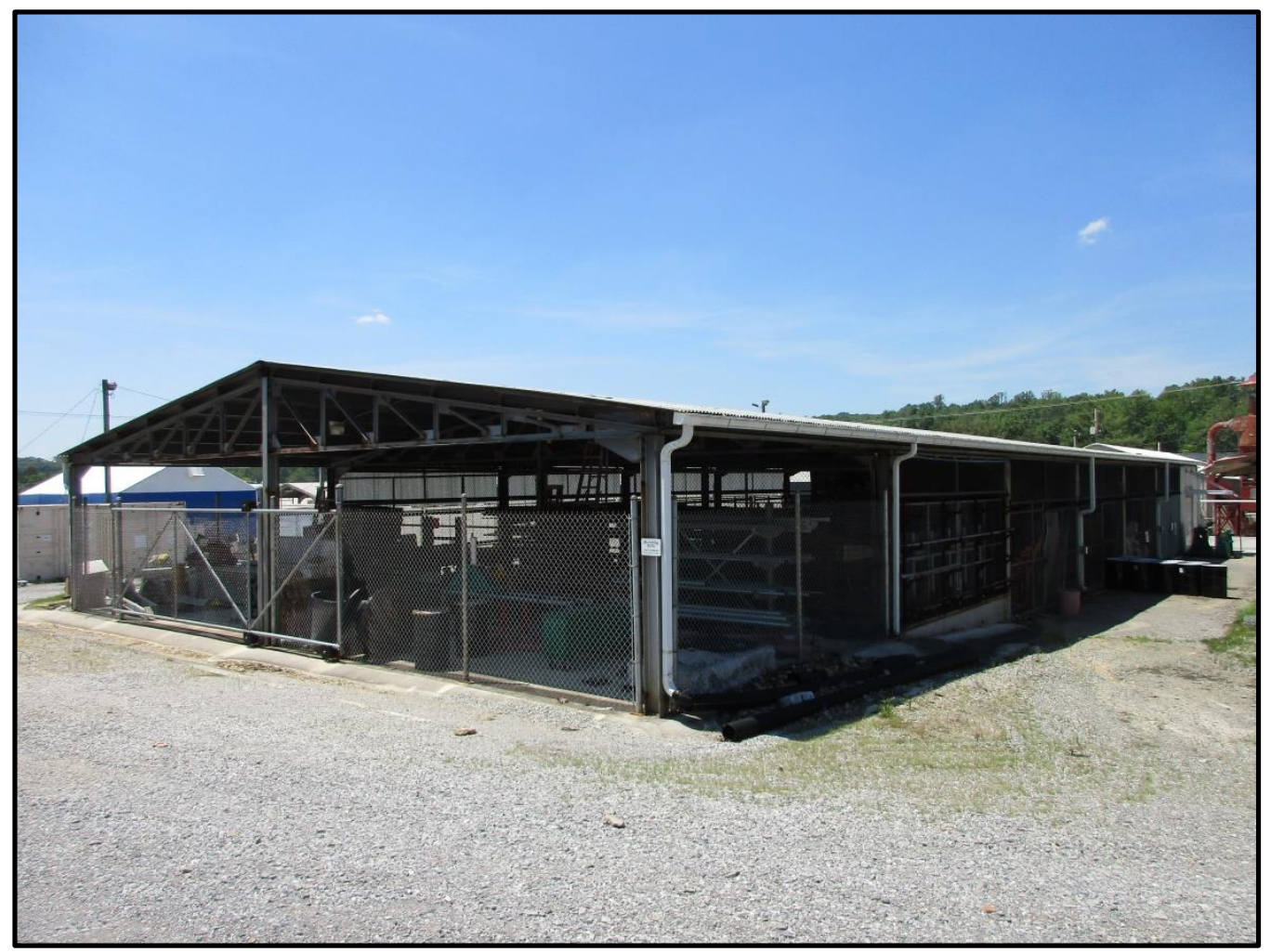

Figure 421. Overview of south and east elevations of Building 7070. 
This page intentionally left blank 


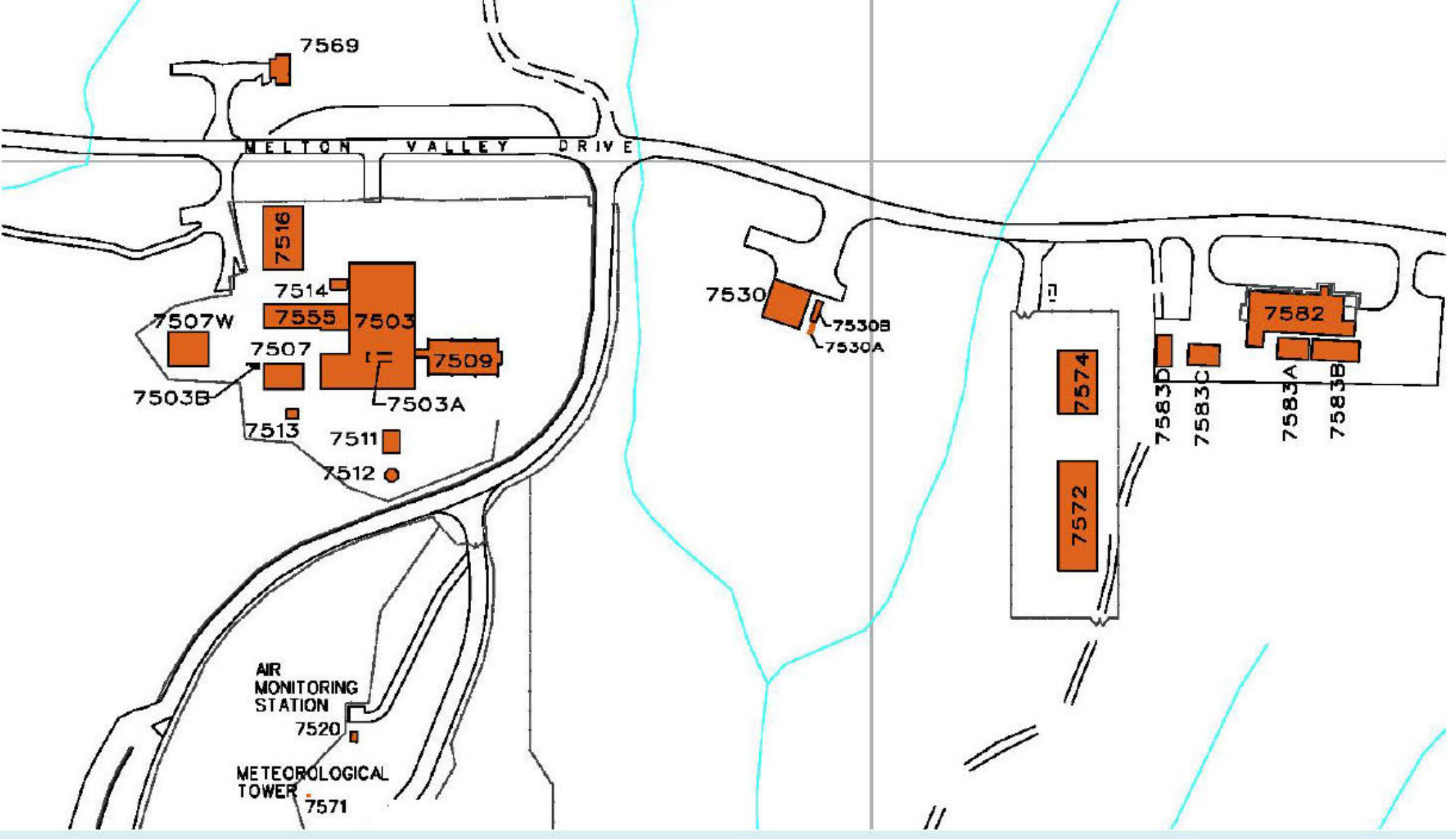

Figure 422. Plan View of 7500 Area.

\section{AREA}

\section{NOT ELIGIBLE}

\section{Building 7500}

Building 7506

Building 7507

Building 7509

Building 7516

Building 7555 
This page intentionally left blank 


\section{AREA}

\section{DISTRICT NAME}

7500 Area of ORNL

\section{DATE OF CONSTRUCTION}

1951-1996

\section{NRHP ELIGIBILITY}

Part Contributes to NRHP-Eligible

ARE/MSRE Facility

Figure 423. View of 7500 Area towards Buildings $7503,7516,7555$, and 7507 from Melton Valley Drive.

\section{DESCRIPTION}

The 7500 Area is located south of the main campus of ORNL. The ten buildings associated with the 7500 Area are clustered into two facilities-the Nuclear Safety Pilot Plant and the Molten Salt Reactor Experiment (MSRE) Facility-south of Melton Valley Drive (Figures 423 and 424). Of the 10 buildings within the area, 7 were constructed before 1980, and were thus included in this survey. Melton Valley Drive provides the only access between these two facilities. Both facility areas include paved parking near Melton Valley Drive. A chain link fence surrounds the MSRE facility.

\section{NATIONAL REGISTER EVALUATION}

The 7500 Area reflects the growth of ORNL in the 1950s and 1960s, particularly as new uses and approaches to nuclear experimentation emerged, as well as the evolution of facilities over time, as the most recent resources date to the 1980s. In 1994, the 7500 Area was evaluated as the 7500 and 7503 Areas. The 7500 Area was determined not eligible for listing due to age; the 7503 Area, which contains the MSRE (Building 7503), was determined eligible under Criterion $A$ and Criteria Consideration $G$ for exceptional significance for the attempted development of a nuclear-powered airplane (Carver and Slater 1994). The 7500 Area was not evaluated in 2004; however, Building 7503 was recommended as eligible under Criterion A (Thomason and Associates 2004). The resources of the 7500 Area were not accessed by Thomason and Associates in 2015; however, based on the documentation from 2004, only Building 7503 was recommended as eligible under Criterion A (Thomason and Associates 2015). Collectively, the two facilities within the 7500 do not represent a cohesive, distinct entity with a singular focus, but rather, they represent two independent facilities. Therefore, CRA recommends that only the portion of the 7500 Area that contains the MSRE is eligible for listing in the NRHP. While Building 7503 is the most significant building in this area, those secondary facilities directly surrounding Building 7503 and associated with the building while the reactor was operational contribute to the NRHP-eligible facility as they provided vital support services to the functioning of the MSRE and to the work of the scientists who conducted research there. 


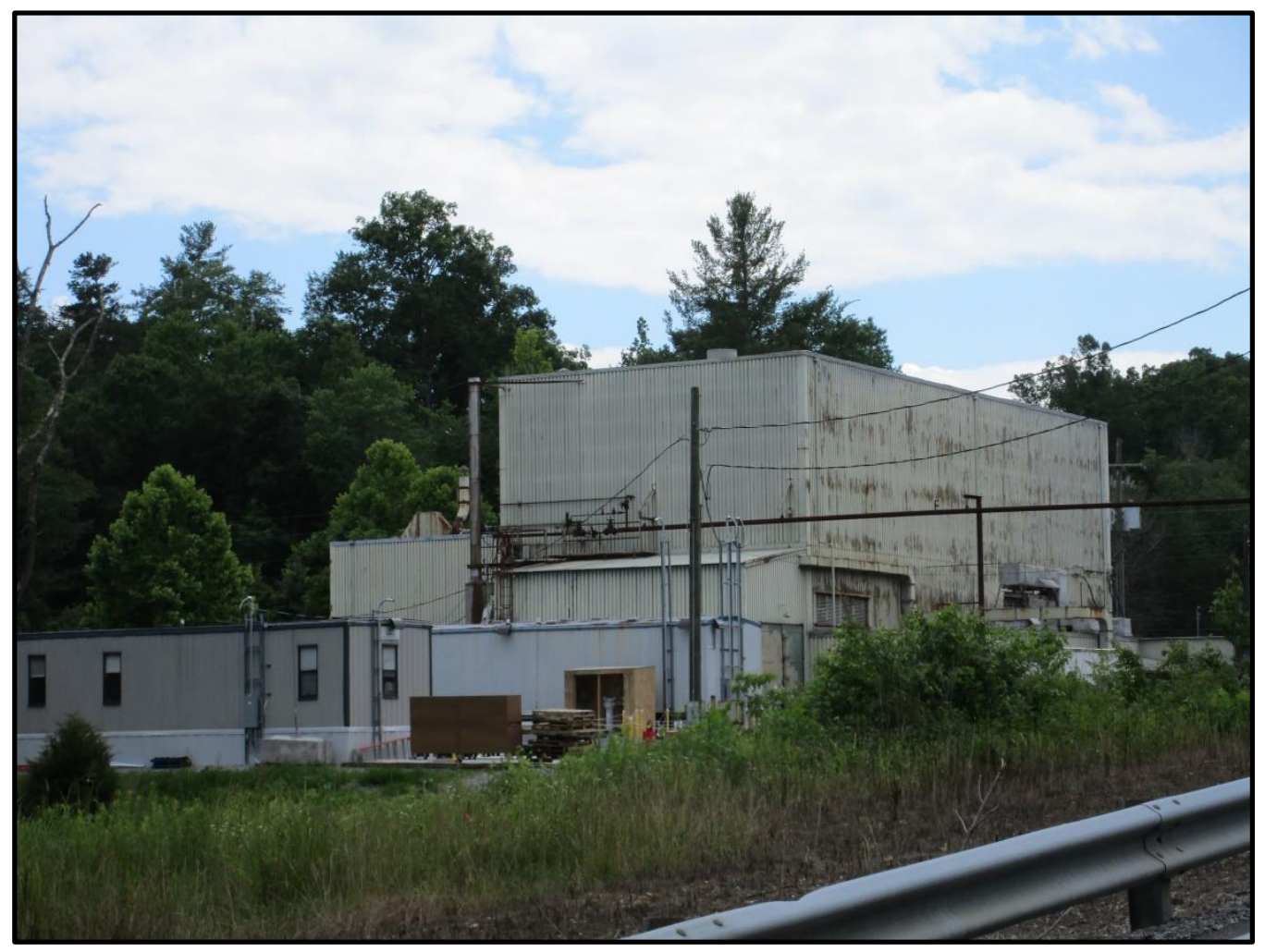

Figure 424. View of 7500 Area in a western direction towards Buildings 7500 from Melton Valley Drive. 


\section{BUILDING NAME}

Nuclear Safety Pilot Plant

\section{DATE OF CONSTRUCTION}

1952

\section{DOE OFFICE RESPONSIBLE}

EM (UCOR)

\section{NRHP ELIGIBILITY}

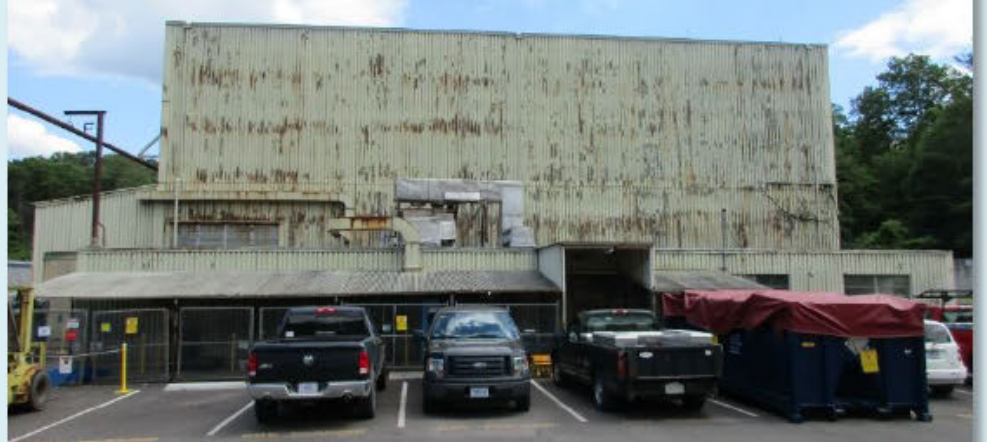

Not Eligible

\section{DESCRIPTION}

Building 7500 is located along Melton Valley Drive, south of the main ORNL campus. The building is a multistory steel structure clad in corrugated metal (Figures 425 and 426). The taller sections of the building have flat roofs. The flat and shed roofs of the one-story sections are clad with corrugated metal. Most of the fenestration on the building is located on the one-story sections, which feature large industrial doors and twelvelight windows. This building was not fully accessible during the survey, and therefore the entire building was not fully photographed or surveyed.

\section{NATIONAL REGISTER EVALUATION}

Building 7500 was constructed as the Homogeneous Reactor Experiment (HRE) facility in 1952. Homogeneous reactors combined fuel, moderator, and coolant in a single solution. Following World War II, chemical engineers were hopeful to develop a liquid-fueled reactor that would dispense costly solid fuel elements, resulting in the production of electrical power. This type of reactor would not be required to be taken off-line in order to dispose of spent fuel since the reactor's fuel and the solution in which it was dissolved was its power source. The Homogeneous Reactor Experiments concluded unsuccessfully in 1960 after a second such reactor began to leak in the late 1950s. In 1961, Building 7500 was converted to a Nuclear Safety Pilot Plant. Experiments involving the production of a range of fission product types to observe behaviors under different conditions and conduct tests of engineering safeguards occurred at the facility (Carver and Slater 1994:290).

Building 7500 was first surveyed in 1994 by Duvall \& Associates and was recommended as not eligible for listing in NRHP due to age (Carver and Slater 1994). It was not included in the 2004 and 2015 surveys of ORNL (Thomason and Associates 2004 and 2015). As a processing facility, Building 7500 housed work that furthered ORNL's mission in nuclear science during the Cold War era. However, the building is not individually associated with scientific work of particular significance or any other events or persons of historic significance, thus it does not qualify for listing in the NRHP under Criterion A or B. Further, the building lacks notable architectural elements that would warrant individual listing in the NRHP under Criterion $\mathrm{C}$. The building is not located in a NRHP-eligible historic district. Thus, CRA recommends that Building 7500 is not eligible for listing in the NRHP under Criterion $\mathrm{A}, \mathrm{B}$, or $\mathrm{C}$. 


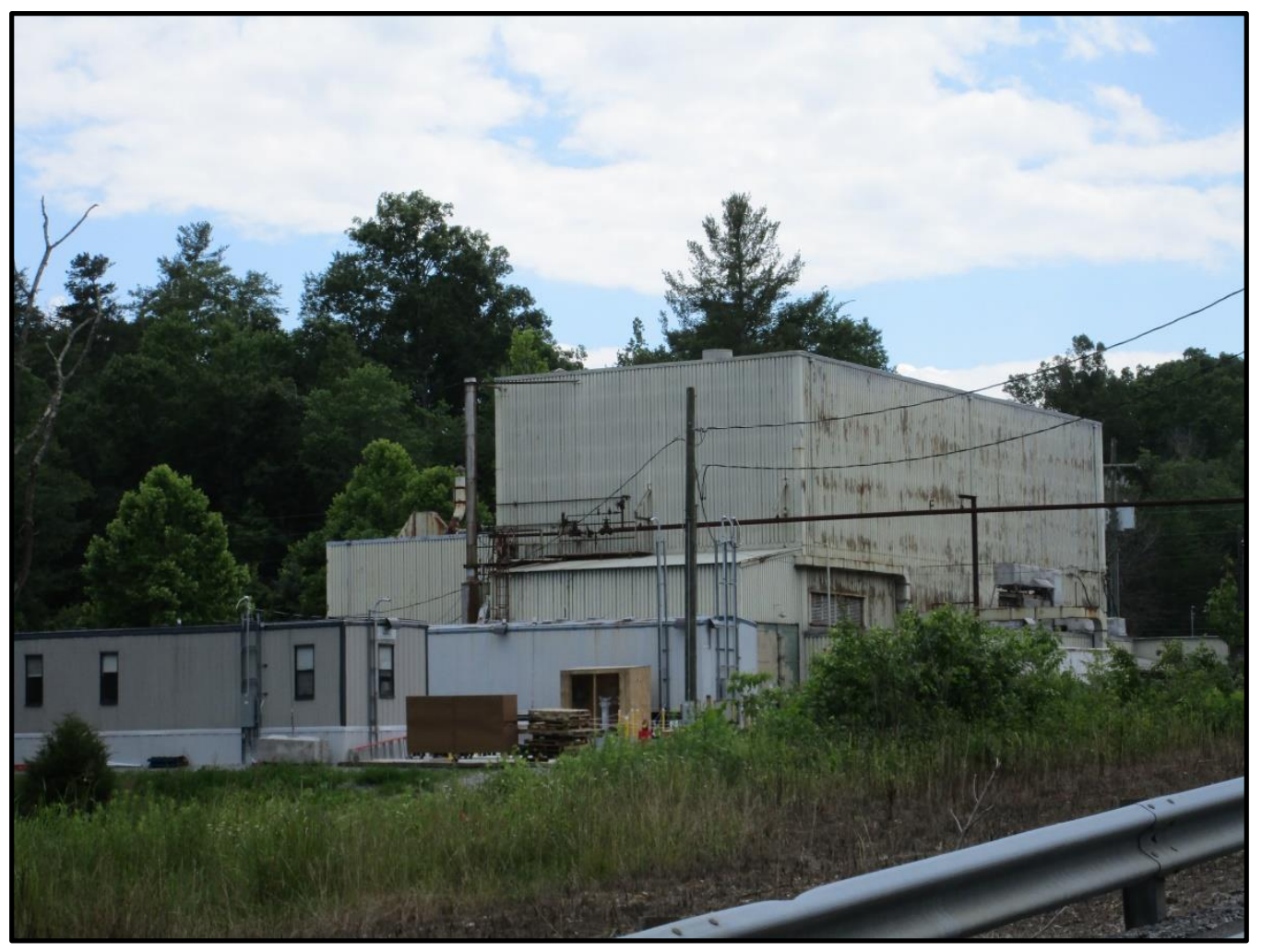

Figure 426. Overview of north and east elevations of Building 7500. 


\section{BUILDING NAME}

Molten Salt Reactor Experiment Building

DATE OF CONSTRUCTION

1951

DOE OFFICE RESPONSIBLE

EM (UCOR)

\section{NRHP ELIGIBILITY}

Contributing to ARE/MSRE Facility

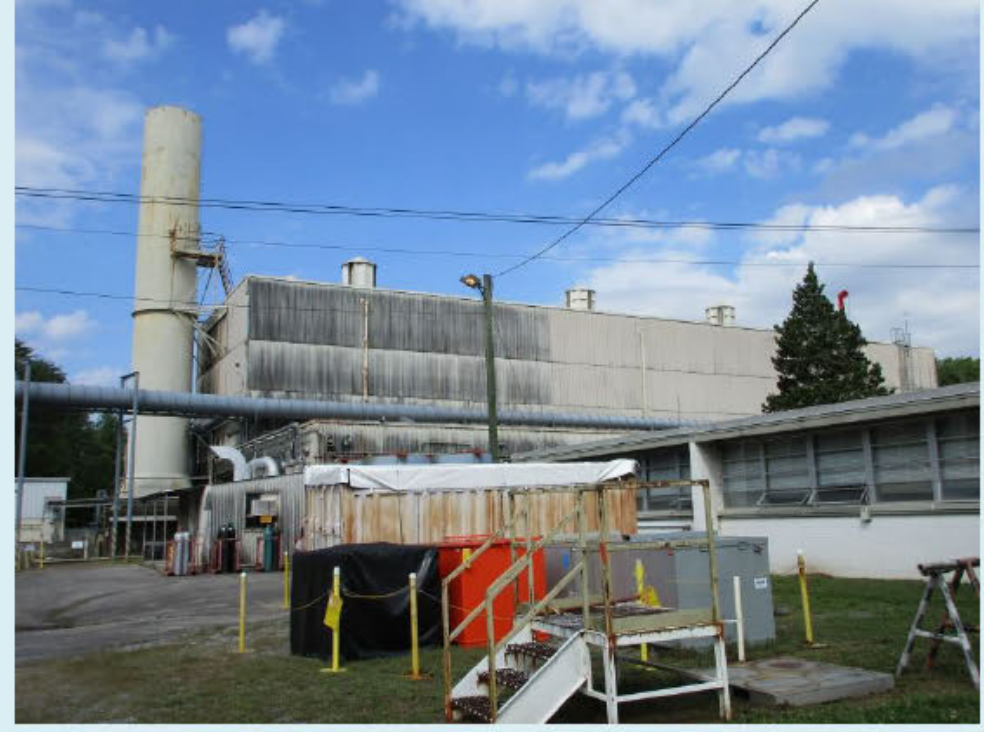

Figure 427. Overview of east and south elevations of Building 7503.

\section{DESCRIPTION}

Building 7503 is a multistory, flat-roof, steel structure clad with corrugated asbestos siding (Figures 427 and 428). Two small, single-story, flat-roof projections are affixed to the core's west elevation. The building's north elevation (façade) is characterized by a large, high bay entry filled with an overhead, rolling, metal door. The building features several windows at the ground level including eight-light and four-light hopper windows. Singlelight metal pedestrian doors are located primarily on the east elevation as well as a large overhead rolling door. Several large roof vents are present along the roofline. There was limited accessibility to this building when the survey was conducted.

\section{NATIONAL REGISTER EVALUATION}

Building 7503 was constructed as a Molten Salt Reactor as a part of the Aircraft Reactor Experiment (ARE), which aimed to develop a reactor system to propel an aircraft. The reactor is said to be the most advanced and innovative reactor developed by the ORNL staff due to the use of molten salt fuel at elevated temperatures. Although successful in advancing technology, the project was discontinued in 1958 due to financial considerations. However, in 1965, a new experiment was conducted in Building 7503 "to further develop the molten salt reactor technology for electric power production" (Carver and Slater 1994: 294). This experiment was referred to as Molten Salt Reactor Experiment (MSRE). The building was shut down in 1969 after several years of production. Building 7503 is the only building associated with both the ARE and MSRE programs; other buildings in the area were built to support the MSRE.

Building 7503 was previously surveyed in 1994, 2004, and 2015 and recommended as individually eligible for listing in the NRHP (Carver and Slater 1994; Thomason and Associates 2004 and 2015). The building retains a majority of its historic materials, as well as its form and massing. As a processing facility, Building 7503 housed work that furthered ORNL's mission in nuclear science during the Cold War era. As a highly innovative reactor associated with the ARE and MSRE experiments, Building 7503 is eligible under Criterion A. However, the building is not associated with a scientist or person of historic significance to merit listing in the NRHP under Criterion $\mathrm{B}$. In addition, the building lacks notable architectural elements that would warrant individual listing in the NRHP under Criterion C. Thus, CRA recommends Building 7503 eligible for individual listing in the NRHP 
under Criterion A. Associated utilities and maintenance facilities and offices that were directly related to the operation of the MSRE facility are contributing buildings within the recommended NRHP boundary (Figures 429 and 430).

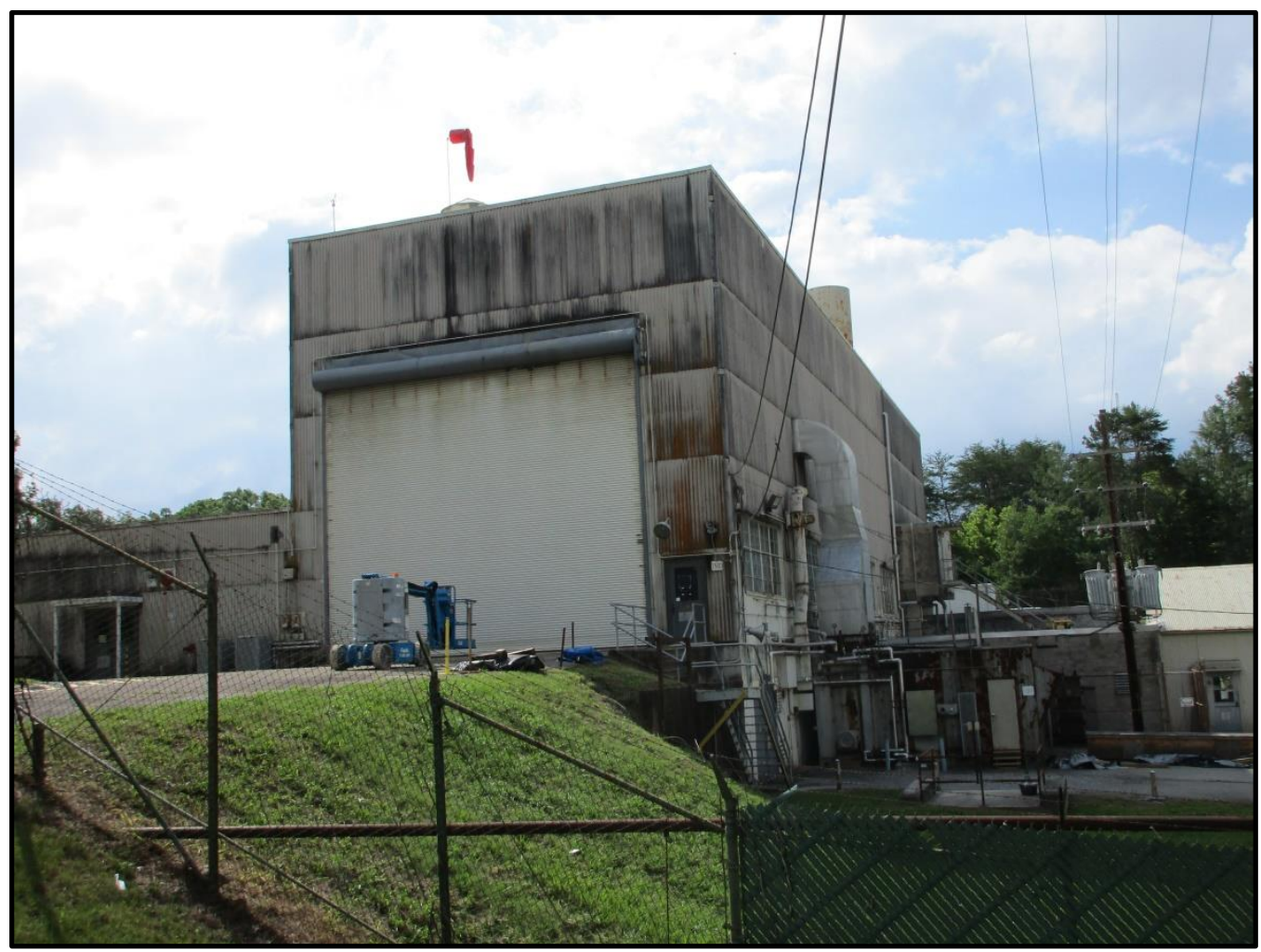

Figure 428. Overview of north and west elevations of Building 7503. 


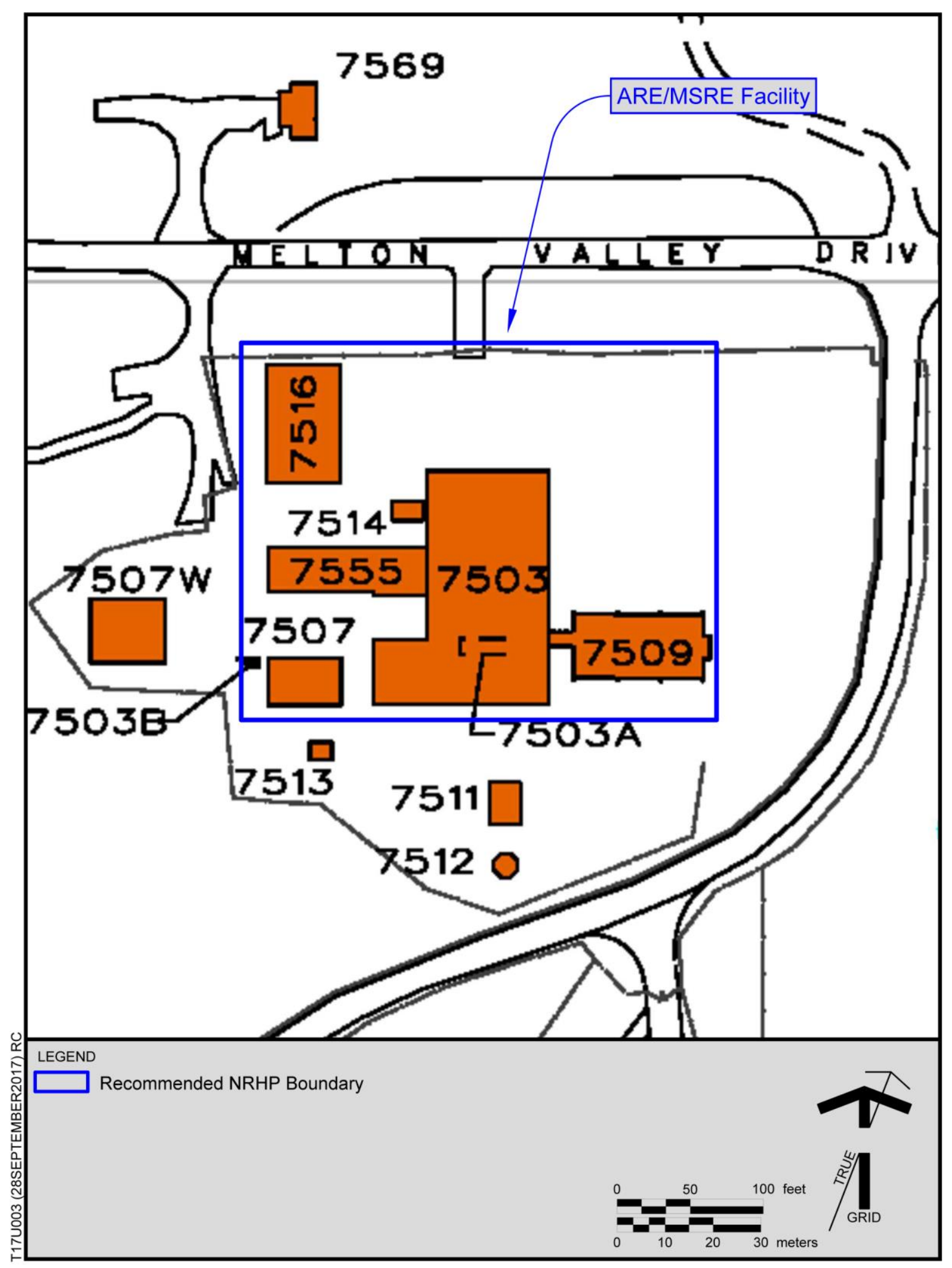

Figure 429. ORNL site plan depicting the recommended NRHP boundary of the ARE/MSRE Facility. 


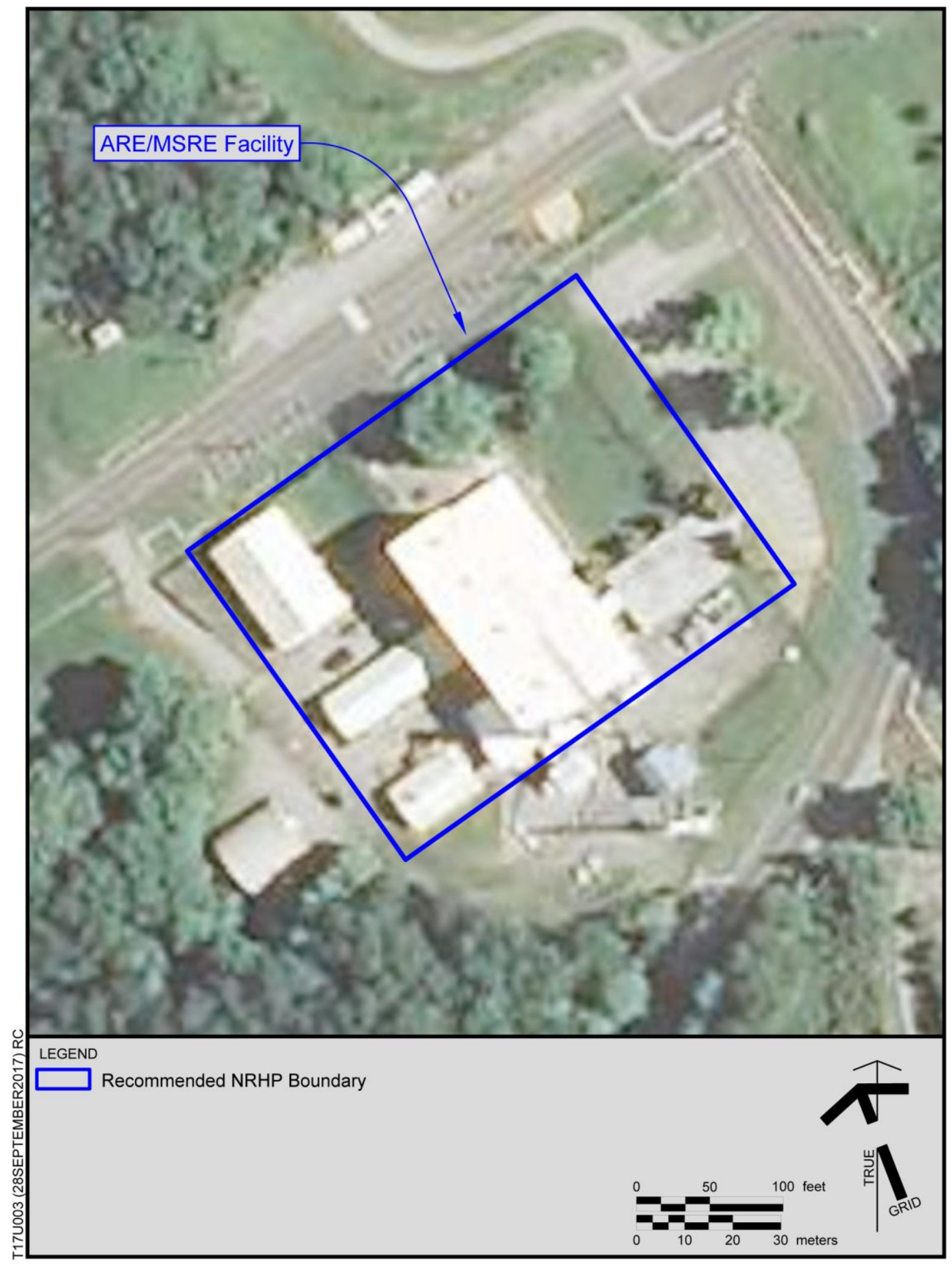

Figure 430. Aerial photographs depicting the recommended NRHP boundary of the ARE/MSRE Facility. 


\section{6}

\section{BUILDING NAME}

LGWOP Maintenance Support Shop

DATE OF CONSTRUCTION

1955

DOE OFFICE RESPONSIBLE

EM (UCOR)

\section{NRHP ELIGIBILITY}

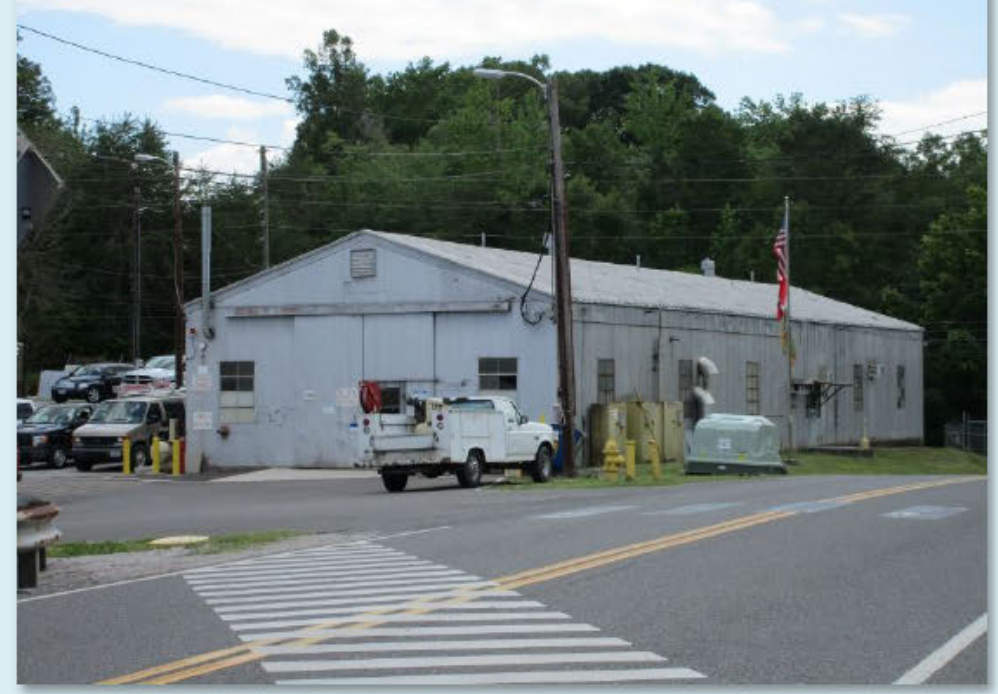

Figure 431. Overview of north and east elevations of Building 7506.

Not Eligible

\section{DESCRIPTION}

Building 7506 is a one-story, gable-roof, steel structure with a shed addition on the south elevation (Figures 431 and 432). The walls and roof of the structure are clad in steel panels. Windows along the structure exhibit eight-light awning metal sashes. The building features two large steel sliding doors on the east elevation; a pedestrian entry has been cut into one of the sliding doors and is filled with a two-light, metal door. Two window bays flank the large entry bay. A two-light metal door is located along the north elevation along with five window bays. A slab metal door and three window bays punctuate the west elevation.

\section{NATIONAL REGISTER EVALUATION}

Building 7506 was constructed in 1955 as the CPAF Contractor Shop. The building was first surveyed in 1994 by Duvall \& Associates and was recommended as not eligible for listing in NRHP (Carver and Slater 1994). It was not included in the 2004 and 2015 surveys of ORNL (Thomason and Associates 2004 and 2015). As a utility and maintenance building, Building 7506 is not a primary resource associated with scientific achievements at ORNL, nor is it known to be individually associated with any other events or persons of historic significance, thus it does not qualify for listing in the NRHP under Criterion A or B. Further, the building is a simple utilitarian structure that lacks architectural significance for listing in the NRHP under Criterion $\mathrm{C}$. The building is not located in a NRHP-eligible historic district. Thus, CRA recommends that Building 7506 is not eligible for listing in the NRHP under Criterion A, B, or C. 


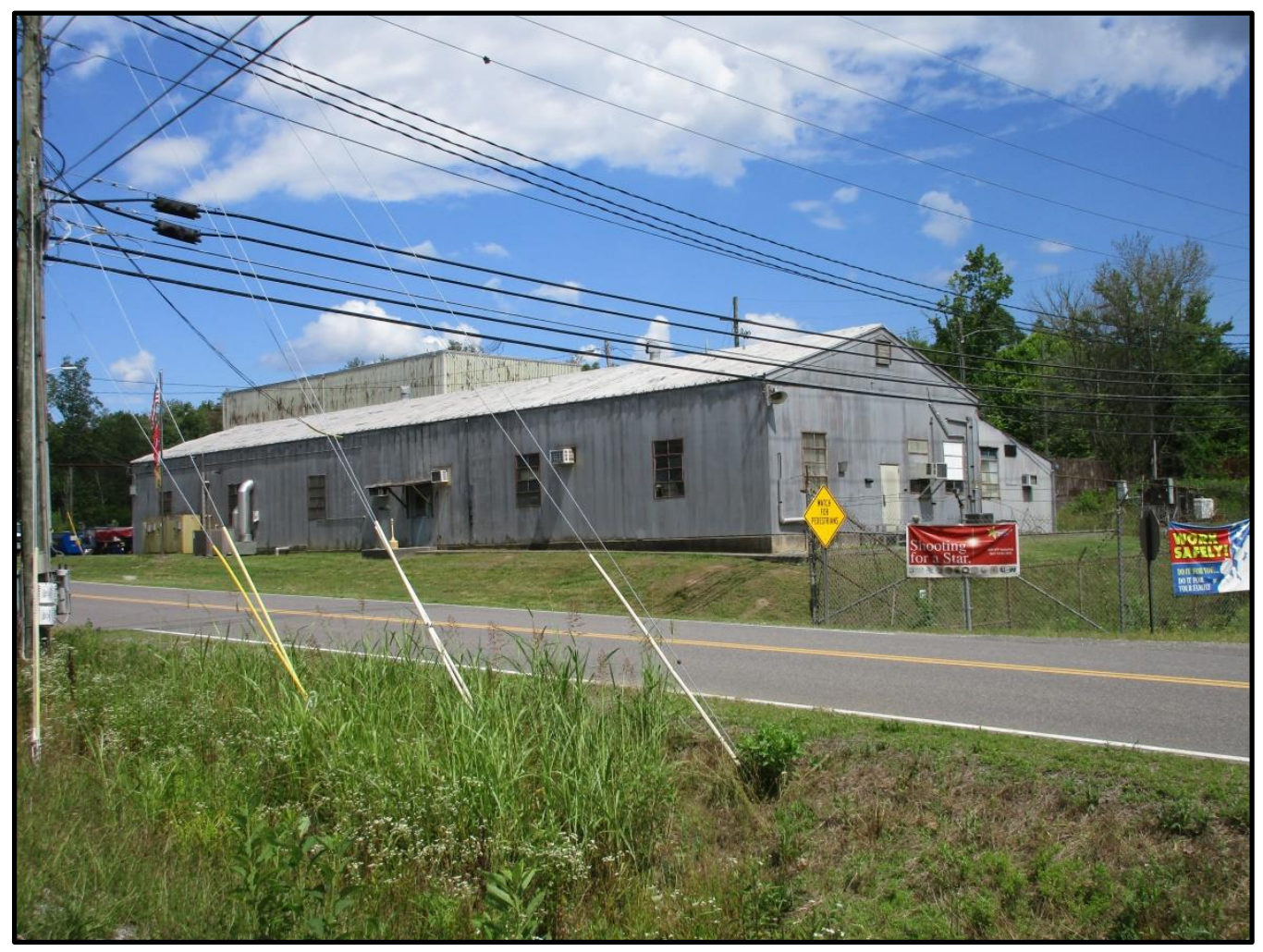

Figure 432. Overview of north and west elevations of Building 7506. 


\section{7}

\section{BUILDING NAME}

Substores

\section{DATE OF CONSTRUCTION}

1961

DOE OFFICE RESPONSIBLE

EM (UCOR)

NRHP ELIGIBILITY

Contributing to ARE/MSRE Facility

\section{DESCRIPTION}

Building 7507 is a one-story, gable-roof, steel structure clad in steel panels with a metal panel roof. The building features nine-light windows. The building was observed from afar so the entire building was not visible during the field survey.

\section{NATIONAL REGISTER EVALUATION}

Building 7507 was constructed in 1961 as a compressor house for Building 7503 . The building was first surveyed in 1994 by Duvall \& Associates and was recommended as not eligible for listing in NRHP; it was not 50 years old at that time (Carver and Slater 1994). It was not included in the 2004 and 2015 surveys of ORNL (Thomason and Associates 2004 and 2015). As a utility building, Building 7507 is not a primary resource associated with scientific achievements at ORNL, nor is it known to be individually associated with any other events or persons of historic significance, thus it does not qualify for individual listing in the NRHP under Criterion A or B. Further, the building is a simple utilitarian structure that lacks architectural significance for listing in the NRHP under Criterion C. Thus, CRA recommends that Building 7507 is not individually eligible for listing in the NRHP under Criterion A, B, or C. However, the building was directly related to the operation of the MSRE (Building 7503) in the 1960s. As such, it is eligible for listing in the NRHP under Criterion A as a contributing component of that facility. 


\section{BUILDING NAME}

MSRE Office Building

DATE OF CONSTRUCTION

1964

DOE OFFICE RESPONSIBLE

EM (UCOR)

\section{NRHP ELIGIBILITY}

Contributing to ARE/MSRE Facility

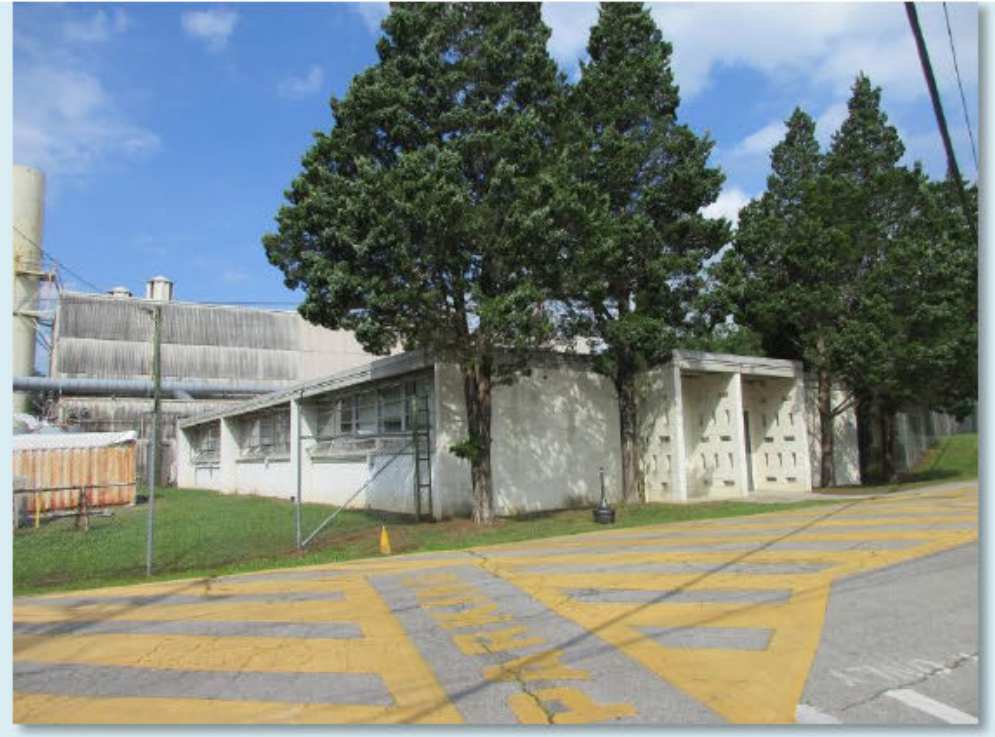

Figure 433. Overview of east and south elevations of Building 7509.

\section{DESCRIPTION}

Building 7509 is a one-story, concrete block masonry structure with a flat roof (Figures 433 and 434). The building is adjacent to Building 7503 and is connected by a small wing attached to the rear. Protruding walls on the east elevation exhibit a pierced block design topped by flat roof and mark the entrance of the building, which contains a steel door with a sidelight set in a wall of square block. The structure features rows of three-light metal hopper windows.

\section{NATIONAL REGISTER EVALUATION}

Building 7509 was constructed in 1961 as an office for MSRE. The building was first surveyed in 1994 by Duvall \& Associates and was recommended as not eligible for listing in NRHP (Carver and Slater 1994). It was not included in the 2004 and 2015 surveys of ORNL (Thomason and Associates 2004 and 2015). As an office building for an outlying facility, Building 7509 it is not known to be individually associated with any events or persons of historic significance, thus it does not qualify for individual listing in the NRHP under Criterion A or B. Further, the building is a simple utilitarian structure that lacks architectural significance for listing in the NRHP under Criterion C. Thus, CRA recommends that Building 7509 is not individually eligible for listing in the NRHP under Criterion $\mathrm{A}, \mathrm{B}$, or $\mathrm{C}$. However, the building was directly related to the operation of the MSRE (Building 7503 ) in the 1960s and is physically attached to that building. As such, it is eligible for listing in the NRHP under Criterion $\mathrm{A}$ as a contributing component of that facility. 


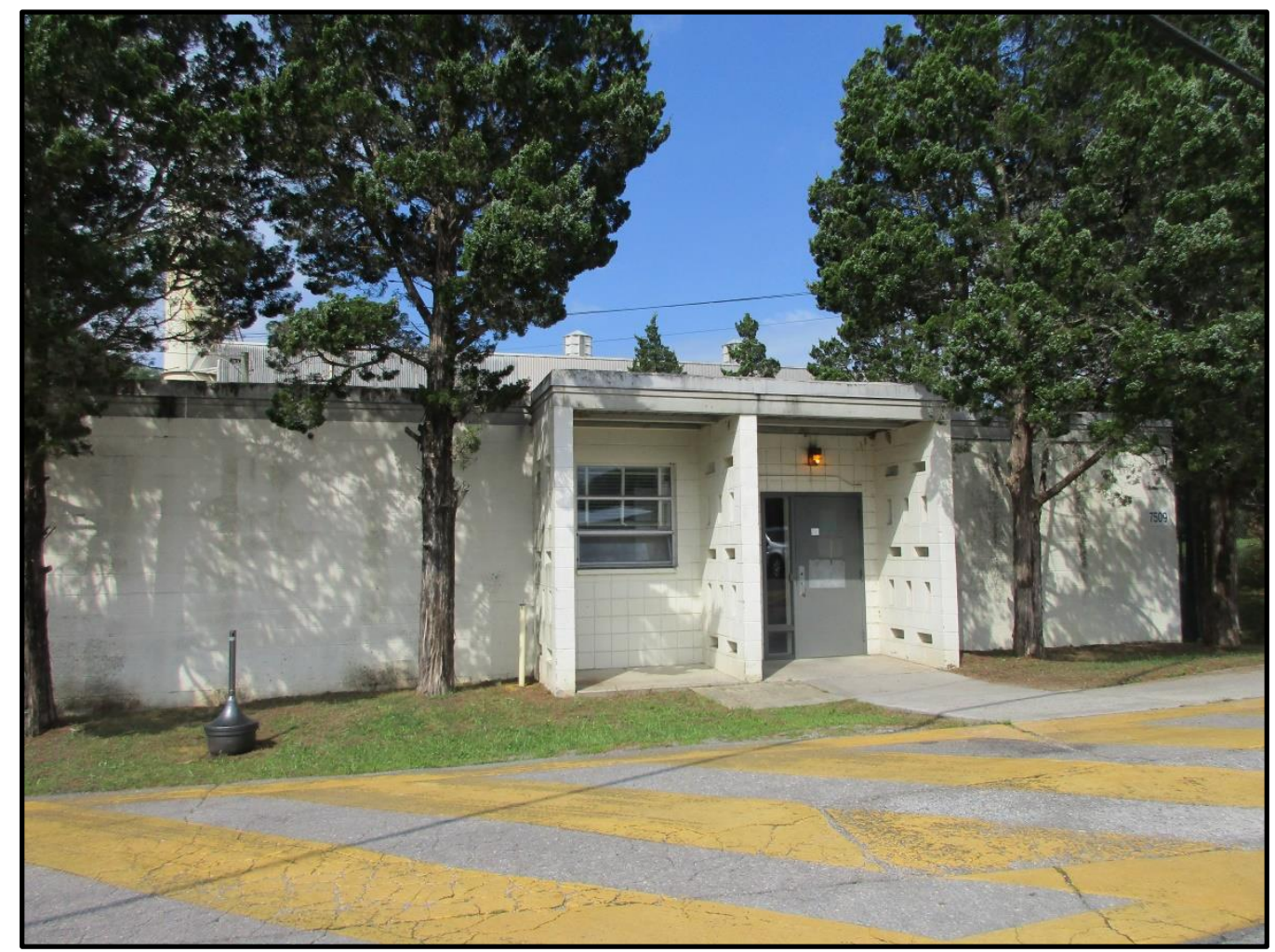

Figure 434. Overview of east elevation of Building 7509. 


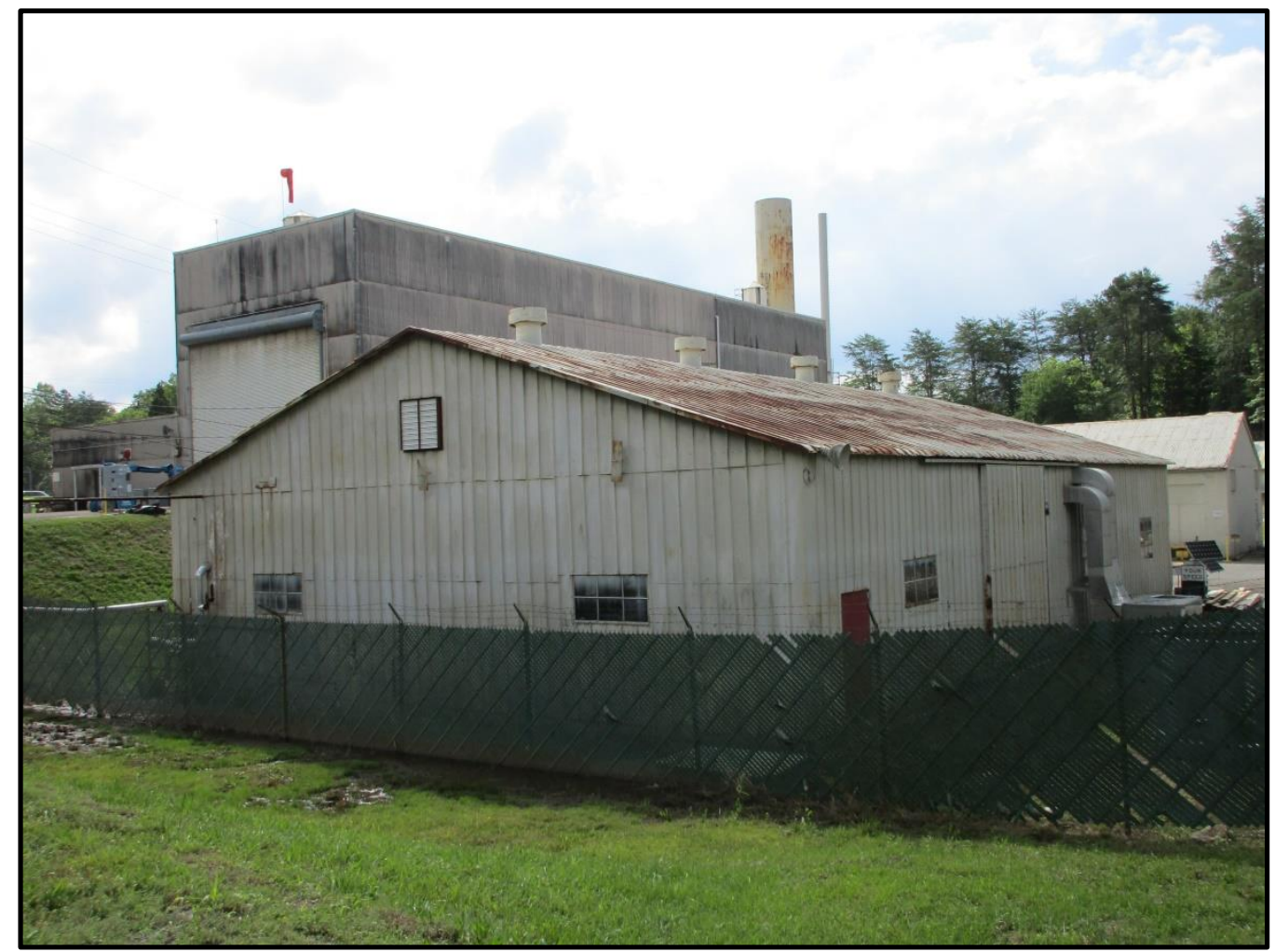

Figure 436. Overview of north and west elevations of Building 7516. 


\section{5}

\section{BUILDING NAME}

Diesel Generator House for 7503

DATE OF CONSTRUCTION

1961

DOE OFFICE RESPONSIBLE

EM (UCOR)

\section{NRHP ELIGIBILITY}

Contributing to ARE/MSRE Facility

\section{DESCRIPTION}

Building 7555 is rectangular in plan and is adjacent to Building 7503 . The building is a one-story, side-gable steel structure (Figures 437 and 438). It is clad in corrugated metal and steel panels. The building features a steel and glass door on the west elevation. A flat-roof, concrete block section connects it to Building 7503 .

\section{NATIONAL REGISTER EVALUATION}

Building 7555 was constructed in 1961 as a Diesel Generator House for 7503 , the Molten Salt Reactor. The building was first surveyed in 1994 by Duvall \& Associates and was recommended as not eligible for listing in NRHP; it was not 50 years old at the time (Carver and Slater 1994). It was not included in the 2004 and 2015 surveys of ORNL (Thomason and Associates 2004 and 2015). As a utility and maintenance building, Building 7555 is not a primary resource associated with scientific achievements at ORNL, nor is it known to be individually associated with any other events or persons of historic significance, thus it does not qualify for individual listing in the NRHP under Criterion A or B. Further, the building is a simple utilitarian structure that lacks architectural significance for listing in the NRHP under Criterion C. Thus, CRA recommends that Building 7555 is not eligible for listing in the NRHP under Criterion A, B, or C. However, the building was directly related to the operation of the MSRE (Building 7503) in the 1960s. As such, it is eligible for listing in the NRHP under Criterion $\mathrm{A}$ as a contributing component of that facility. 


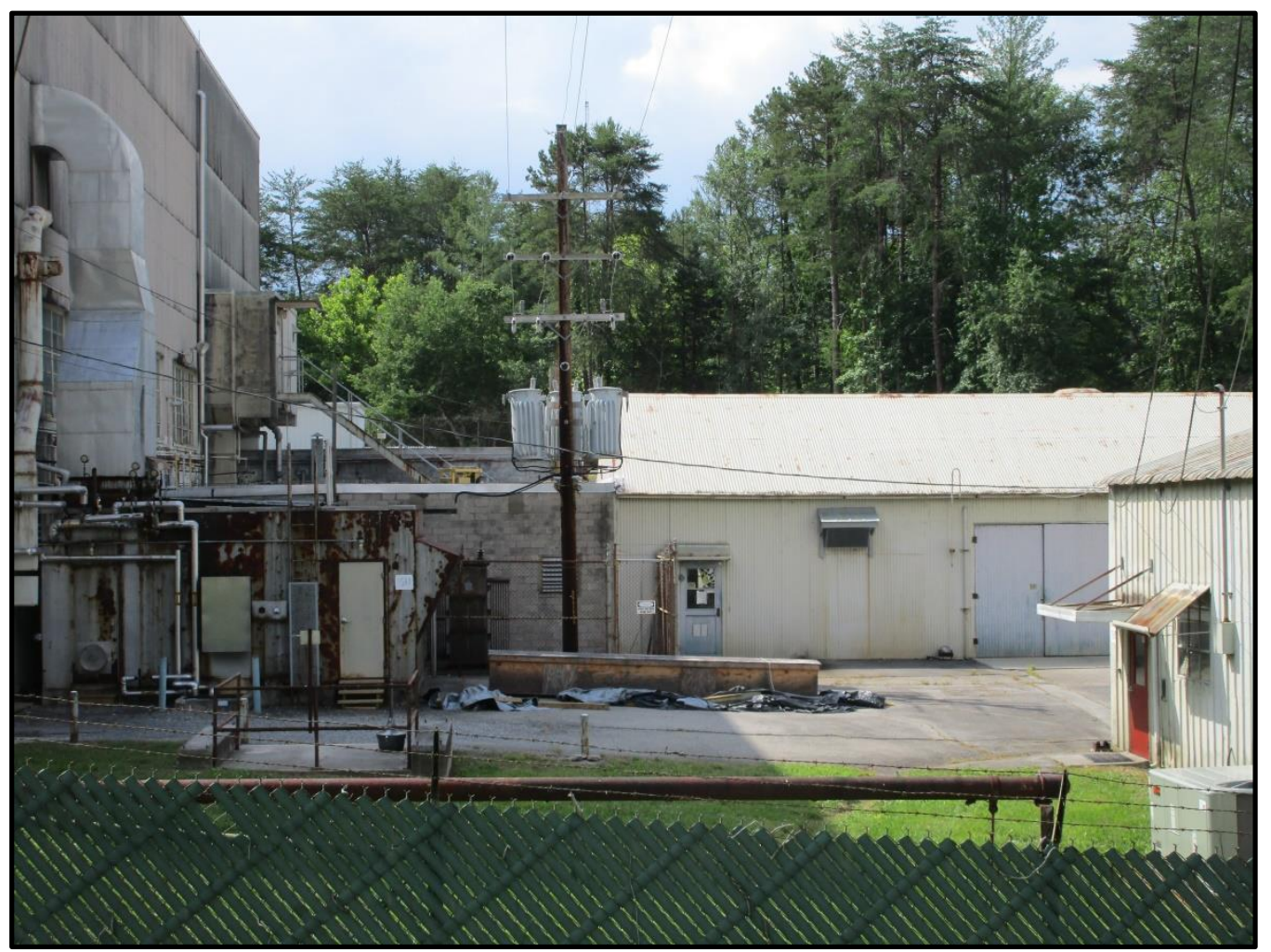

Figure 438. Overview of north elevation of Building 7555. 
This page intentionally left blank 

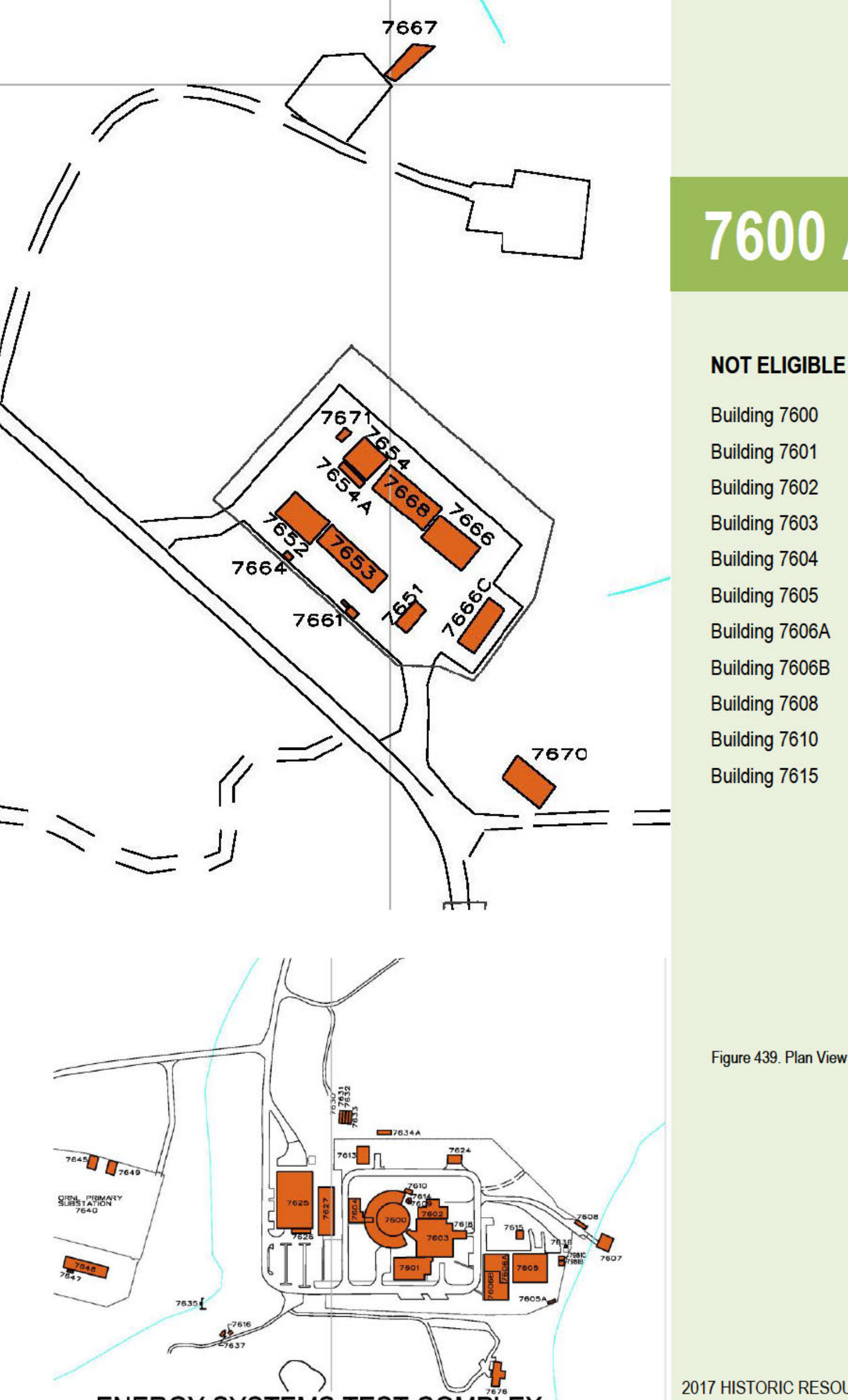

ENERGY SYSTEMS TEST COMPLEX

Figure 439. Plan View of 7600 Area. 
This page intentionally left blank 


\section{AREA}

\section{DISTRICT NAME}

7600 Area of ORNL

\section{DATE OF CONSTRUCTION}

1954-2011

NRHP ELIGIBILITY

Not Eligible

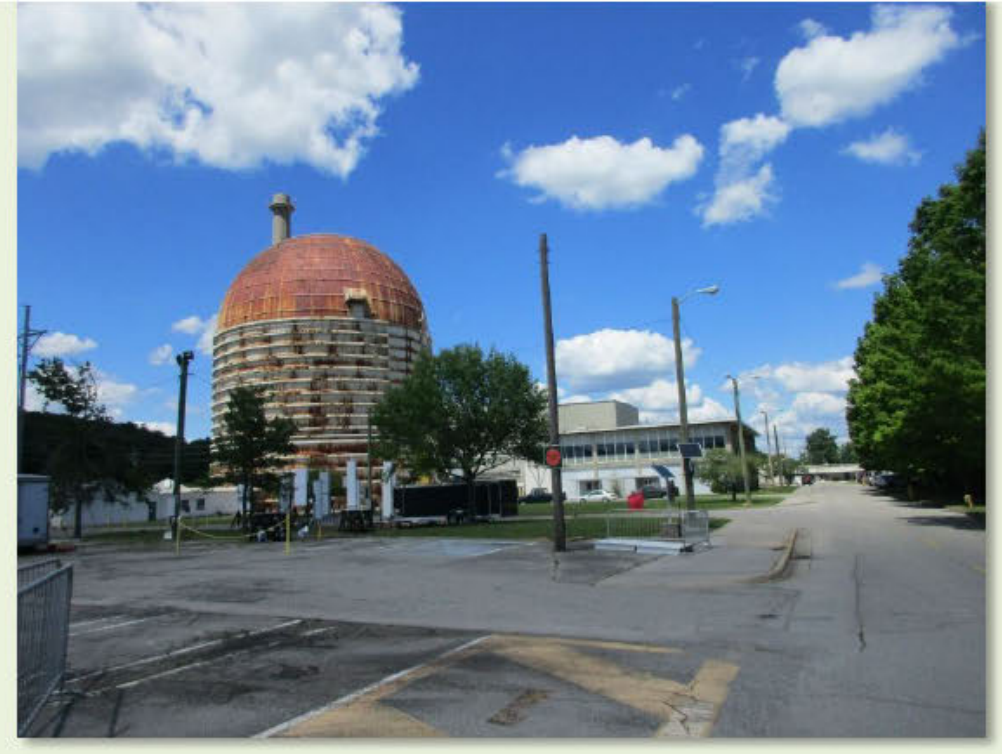

Figure 440. View of the 7600 Area looking towards Buildings 7600 and 7601

from EGCR Access Road.

\section{DESCRIPTION}

The 7600 Area is located approximately 2 mi east of the main portion of the ONRL campus, at the intersection of Ramsey Drive and Experimental Gas-Cooled Reactor Access Road (Figure 439). The facility, also referred to as the Experimental Gas-Cooled Reactor (EGCR) Facility, is located near Melton Hill Lake (Figures 440 and 441). Twenty-nine buildings are located within the 7600 complex, 11 of which were built before 1980 and thus were included in this survey. The central component of the 7600 Area is Building 7600 , a large domed, cylindrical structure which is encompassed and connected to several other structures within this area including Buildings 7603 and 7604 . Other buildings in the complex are located closer to the lake. The buildings located in this area vary in function from a large central processing facility to multiple supporting utility and maintenance facilities. In addition, a large two-story office building is located in this area.

\section{NATIONAL REGISTER EVALUATION}

The Experiment Gas-Cooled Reactor (EGCR) Facility was initiated by the U.S. Atomic Energy Commission (AEC) and with plans that the Tennessee Valley Authority (TVA) would later operate the facility. The reactor was based off technology utilized and studied in Europe. This type of reactor was intended to serve as a power generating prototype. The project was underway in the late 1950s, and, after several delays, the facility was finally completed in 1966. However, due to costs and new technology, the AEC never tested the facility and terminated the program in 1966 before the reactor became radioactive (Rosenthal 2009). The facilities were eventually used in other research efforts on the ORNL campus including the Consolidated Fuel Recycling Program. Today, the structures are used by the Robotics and Process Systems Division (Thomason and Associates 2015). In the 1994 survey, the buildings located in the 7600 Area are considered to be not eligible because the buildings did not fall within the period significance. Other reasons included that the facility "did not develop wholly new technology, did not substantially advance the field of the nuclear sciences, and the reactor was never operational" (Carver and Slater 1994). Thomason and Associates also concurred with the previous assessment (Thomason and Associates 2015). The 7600 Area reflects an area with a processing facility at its core; however that processing facility, the EGCR, never became active. Furthermore, the 7600 Area reflects buildings with diverse functions and associations, and has never collectively supported a single active program or division of ORNL. Therefore, CRA recommends that the 7600 Area is not eligible for listing in the NRHP as a historic district. 


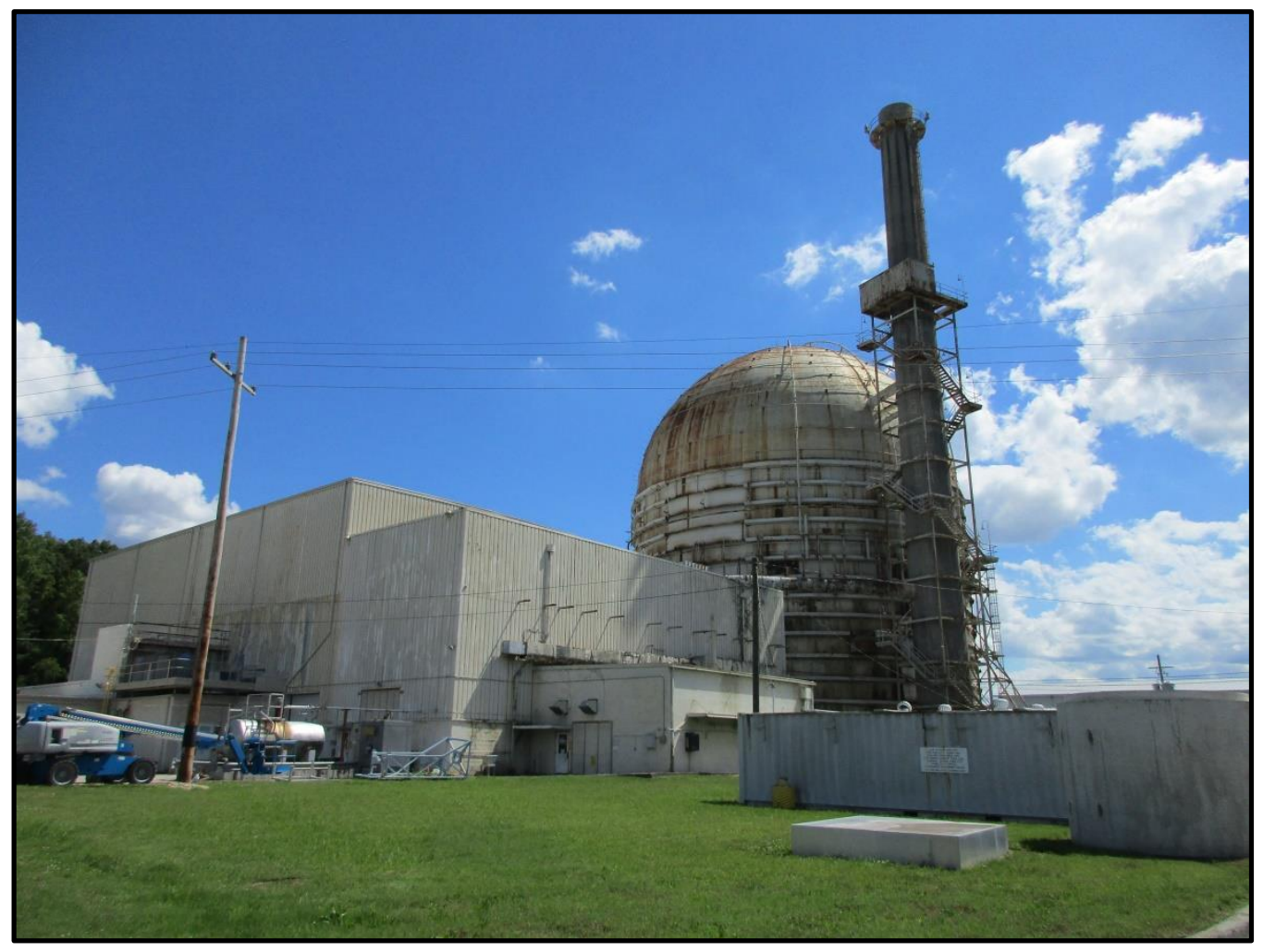

Figure 441 . View of the 7600 Area looking towards Buildings 7600,7602 , and 7603. 


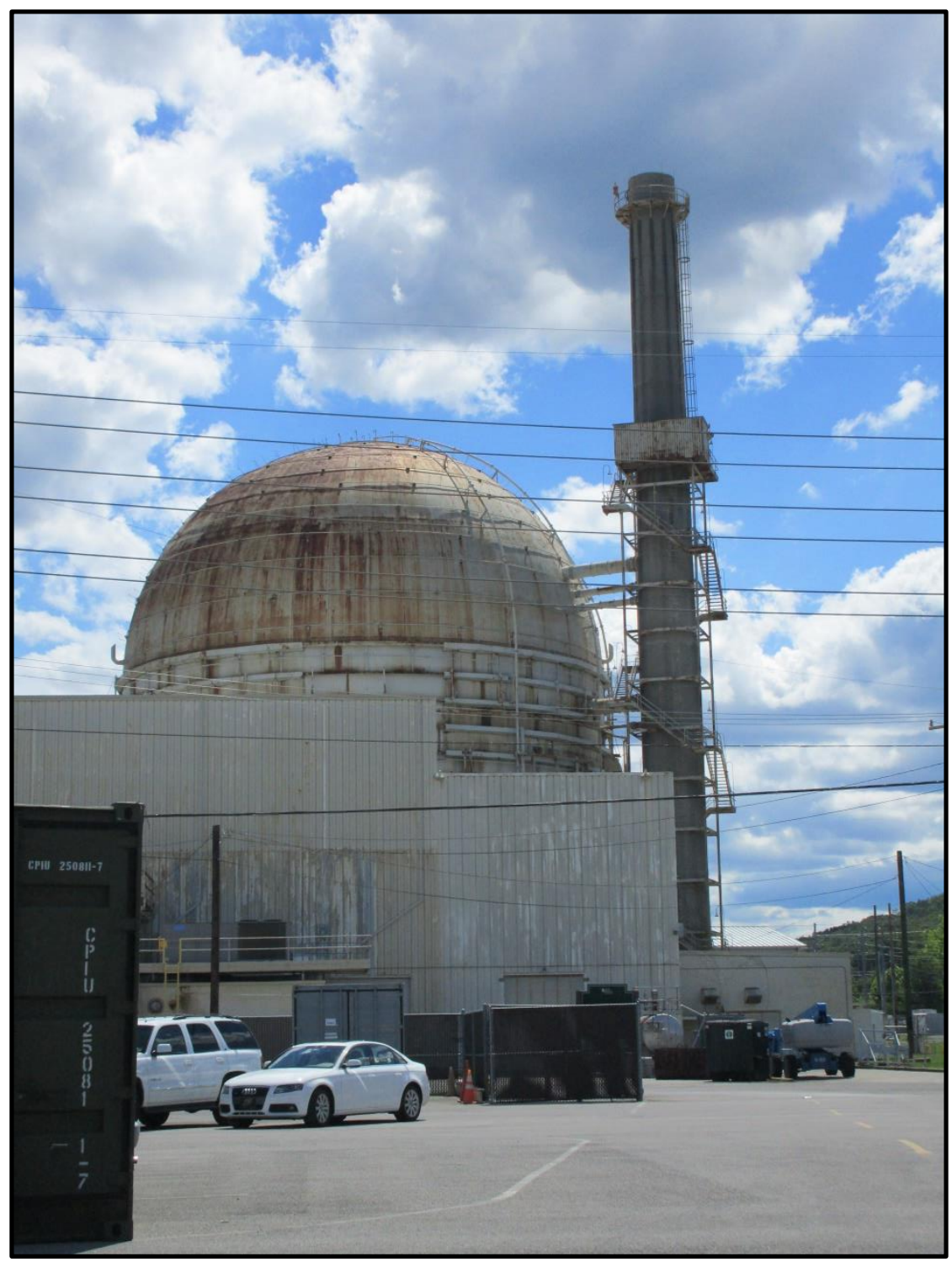

Figure 443. Overview of east elevation of Building 7600. 
building is located outside of the recommended boundaries of a NRHP-eligible historic district. As such, Building 7601 does not warrant listing in the NRHP under Criterion A, B, or C.

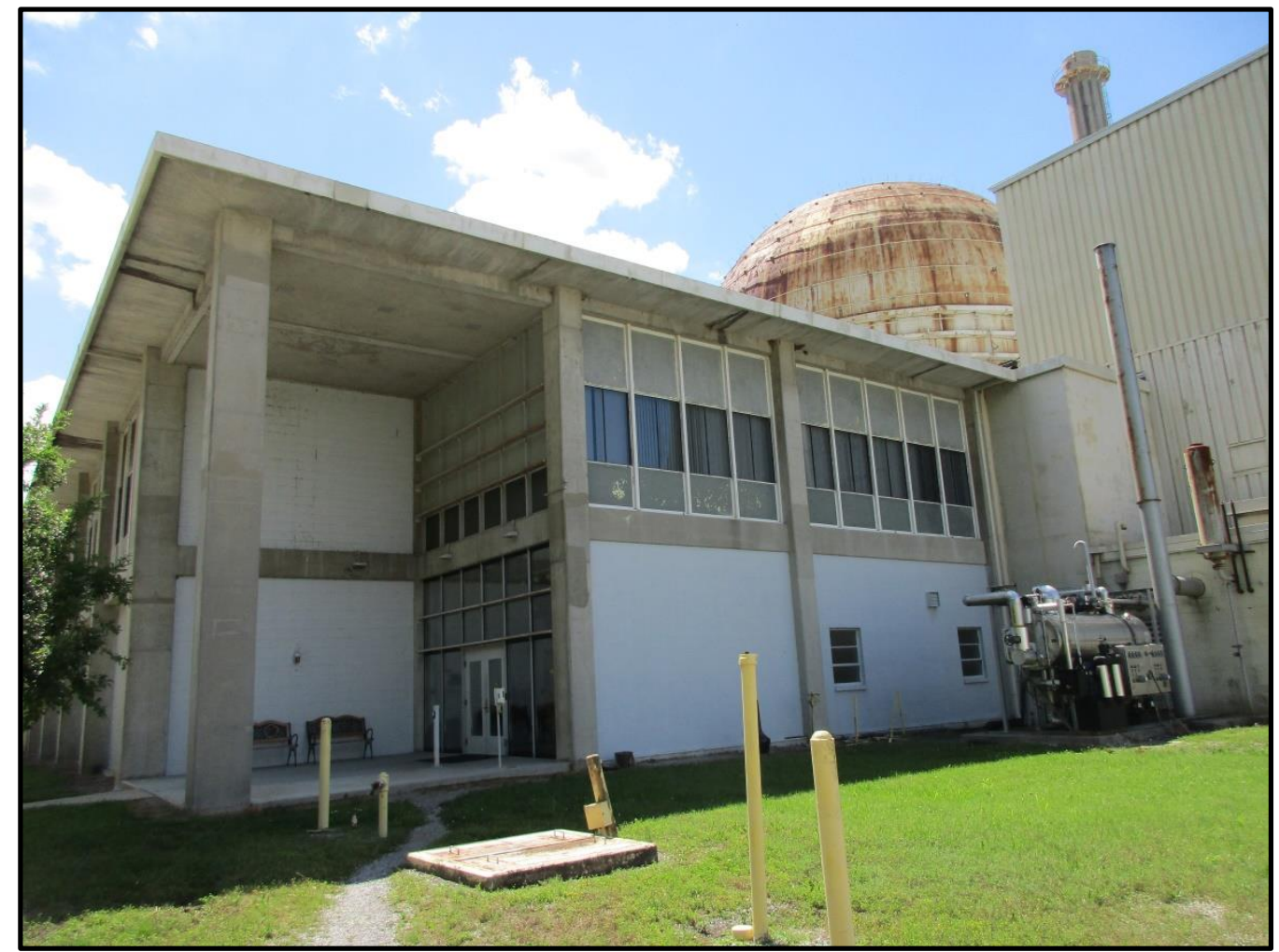

Figure 445. Overview of east elevation and partial south elevation of Building 7601. 


\section{BUILDING NAME}

Integrated Process Demonstration Facility

DATE OF CONSTRUCTION

1965

\section{DOE OFFICE RESPONSIBLE}

EM (UCOR)

NRHP ELIGIBILITY

Figure 446. Overview of east elevation and partial north elevation of Building 7602 .

Not Eligible

\section{DESCRIPTION}

Building 7602 is located east of Building 7600 and is adjacent to the north elevation of Building 7603 . The structure is composed of both concrete block masonry and steel framing. The plan of Building 7602 is rectangular in form with a long multi-story steel frame section (Figures 446 and 447). The lower portion of this main block is composed of concrete block masonry while the upper portions of the exterior walls are clad in steel panels. A smaller one-story concrete block masonry wing is located on the north elevation. Both sections of the building have flat roofs. Fenestration is located on the east elevation of the main block in the form of a single-light steel glazed door and large industrial garage doors.

\section{NATIONAL REGISTER EVALUATION}

Building 7602 was constructed in 1965 as an Integrated Process Demonstration Building as a part of the EGCR Facility. However, this building was never utilized for its original purpose. When the EGCR became obsolete, this building continued to function as a research/laboratory facility for other forms of research including the Consolidated Fuel Recycling Program and the Robotics and Process Systems Division. The building with its high bays are used to house hazardous materials. The building was previously surveyed in 1994 and 2015 and recommended as not eligible for listing in the NRHP (Carver and Slater 1994; Thomason and Associates 2015). The building retains a majority of its historic materials, as well as its form and massing. As a research/laboratory facility, Building 7602 housed work to further ORNL's mission in scientific research during the Cold War era. However, the building is not the single location most importantly associated with a scientific achievement, scientist, or other event or person of historic significance to merit listing in the NRHP under Criterion A or B. Furthermore, the building lacks notable architectural elements that would warrant individual listing in the NRHP under Criterion $\mathrm{C}$. In addition, the building is located outside of the recommended boundaries of a NRHPeligible historic district. As such, Building 7602 does not warrant listing in the NRHP under Criterion A, B, or C. 


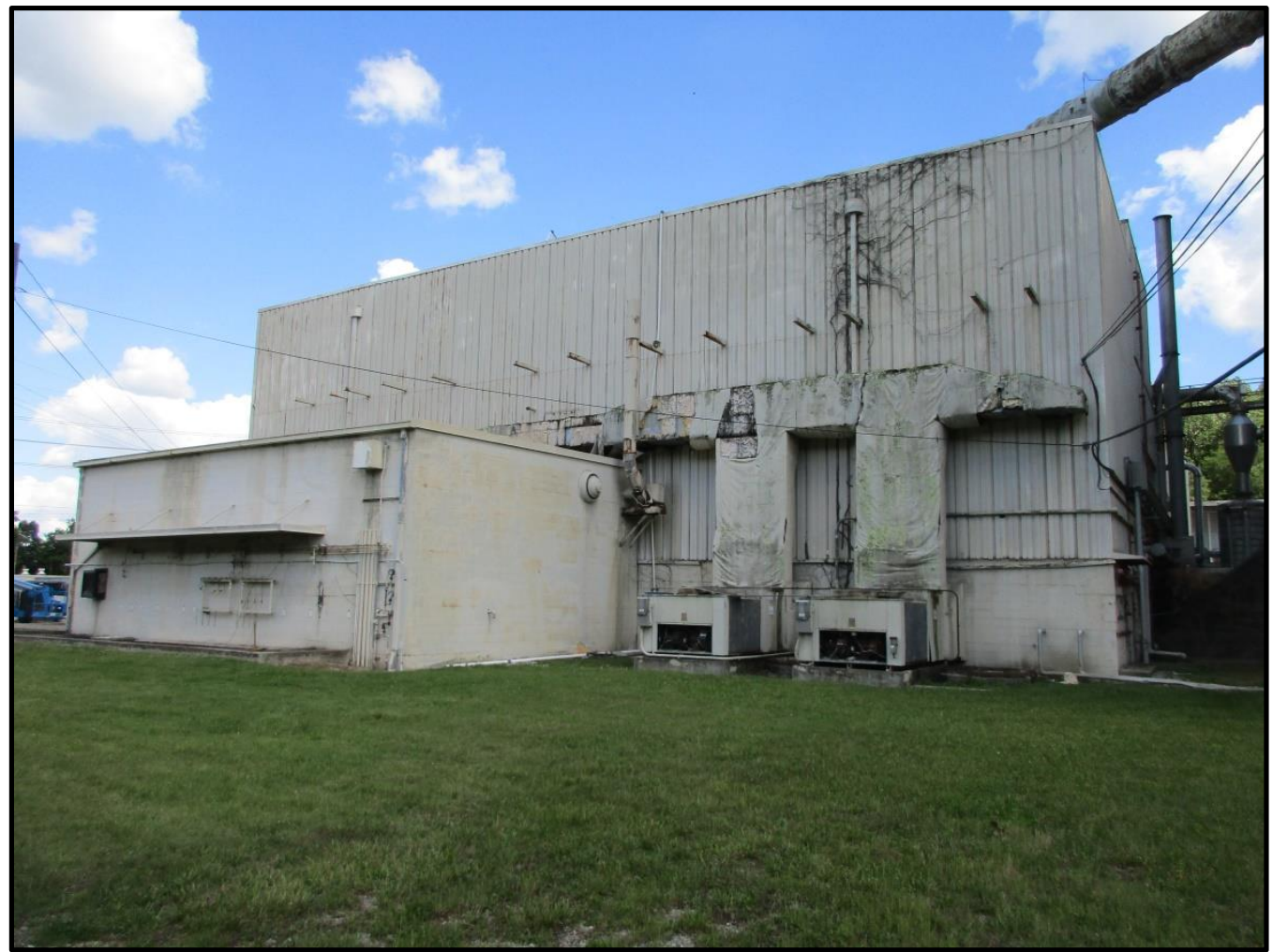

Figure 447. Overview of north elevation and partial west elevation of Building 7602. 


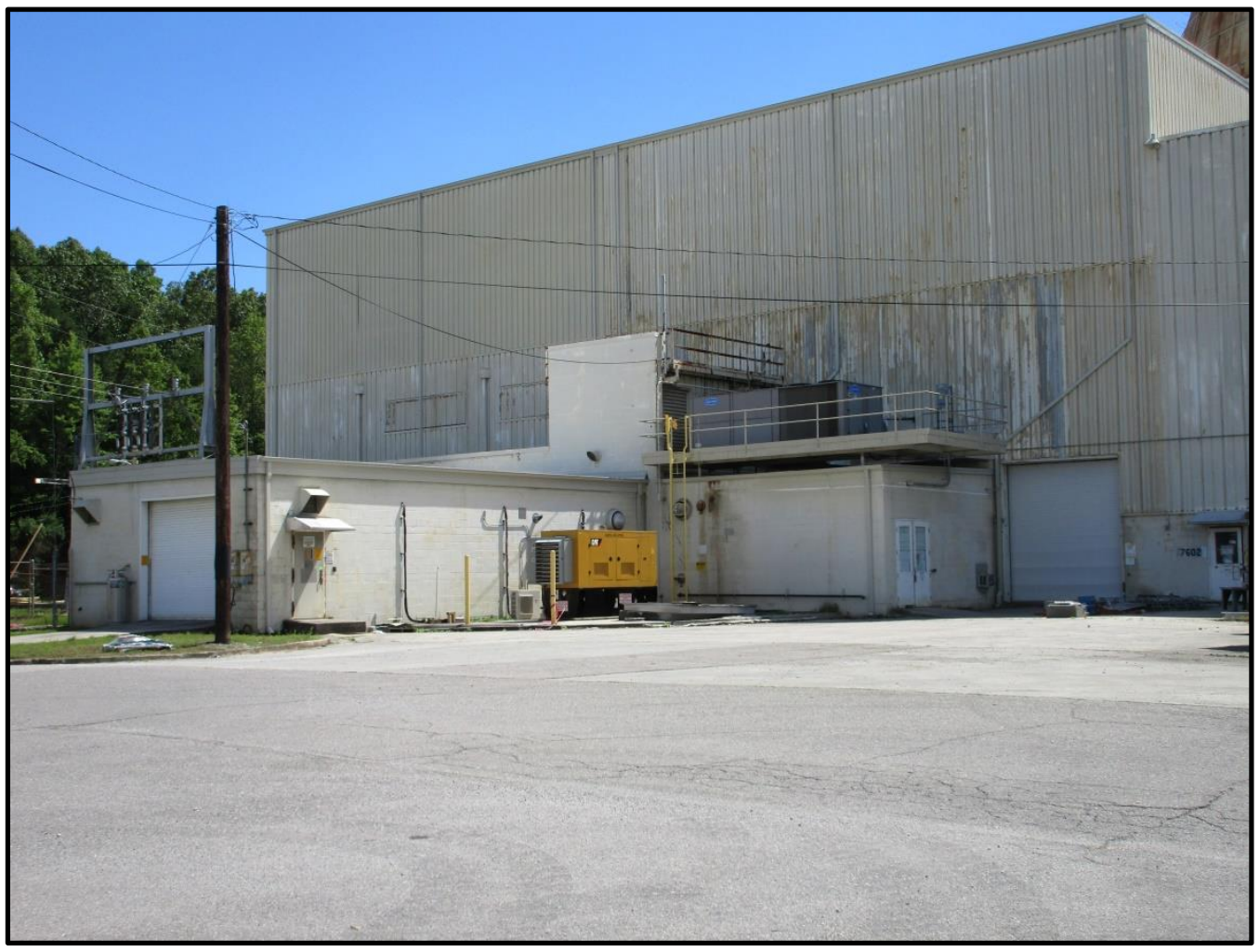

Figure 449. Overview of east elevation of Building 7603. 


\section{BUILDING NAME}

Utility Building

\section{DATE OF CONSTRUCTION}

1965

DOE OFFICE RESPONSIBLE

SC

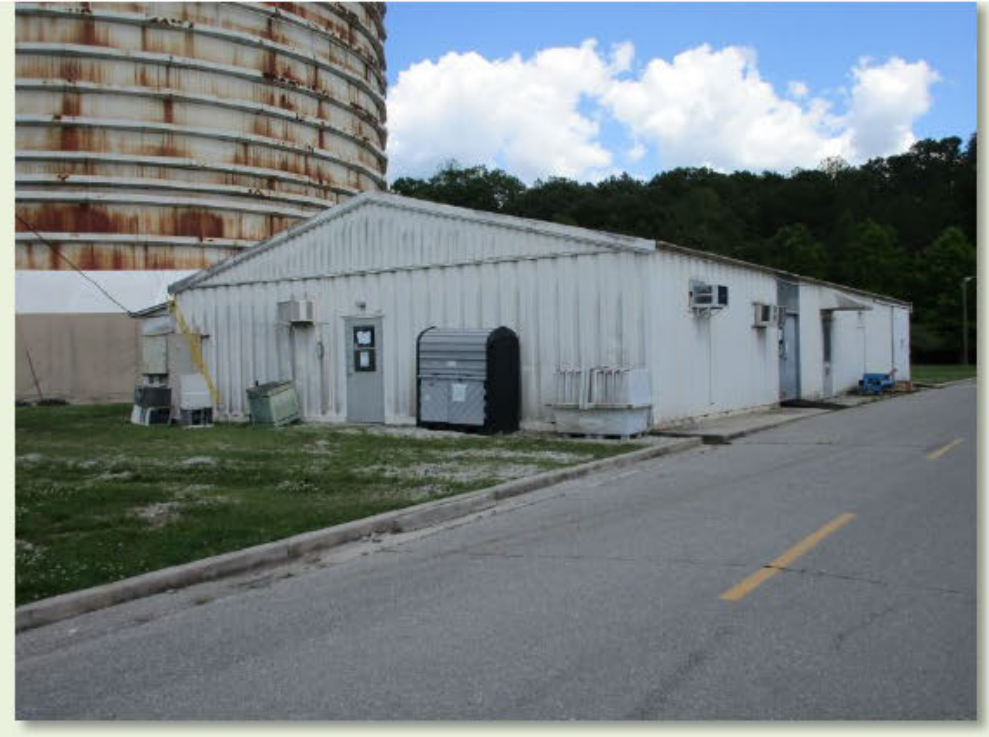

NRHP ELIGIBILITY

Figure 450. Overview of north and west elevations of Building 7604 .

Not Eligible

\section{DESCRIPTION}

Building 7604 is located within the EGCR Access Road loop in the 7600 Area. Building 7604 is a one-story, side-gable steel structure situated on a concrete foundation (Figures 450 and 451 ). The exterior walls are clad with corrugated metal and the roof is covered in metal panels. Oriented to the west, the structure features single-light and two-light metal doors with small metal awnings above. Several additions and wings can be found on the east elevation. A long, narrow, gable-roof steel wing clad in corrugated metal extends from the rear of the building to the east to Building 7600 . This wing features three-light awning windows with horizontal panes. A smaller, shed-roof addition of similar materials is adjacent to the gable-roof wing. An open shed-roof addition can be found on the north portion of the rear (east) elevation. This small addition covers the utilities associated with the building.

\section{NATIONAL REGISTER EVALUATION}

Building 7604 was constructed in 1965 as a utility building for the EGCR Facility. When the EGCR became obsolete, this building continued to function as a utility facility for other forms of research including the Consolidated Fuel Recycling Program and the Robotics and Process Systems Division. The building was previously surveyed in 1994 and 2015 and recommended as not eligible for listing in the NRHP (Carver and Slater 1994; Thomason and Associates 2015). The building retains a majority of its historic materials, as well as its form and massing. As a utility facility, Building 7604 played a secondary role in support of ORNL's mission in scientific research during the Cold War era. However, the building is not the single location most importantly associated with a scientific achievement, scientist, or other event or person of historic significance to merit listing in the NRHP under Criterion A or B. Furthermore, the building lacks notable architectural elements that would warrant individual listing in the NRHP under Criterion C. In addition, the building is located outside of the recommended boundaries of a NRHP-eligible historic district. As such, Building 7604 does not warrant listing in the NRHP under Criterion A, B, or C. 


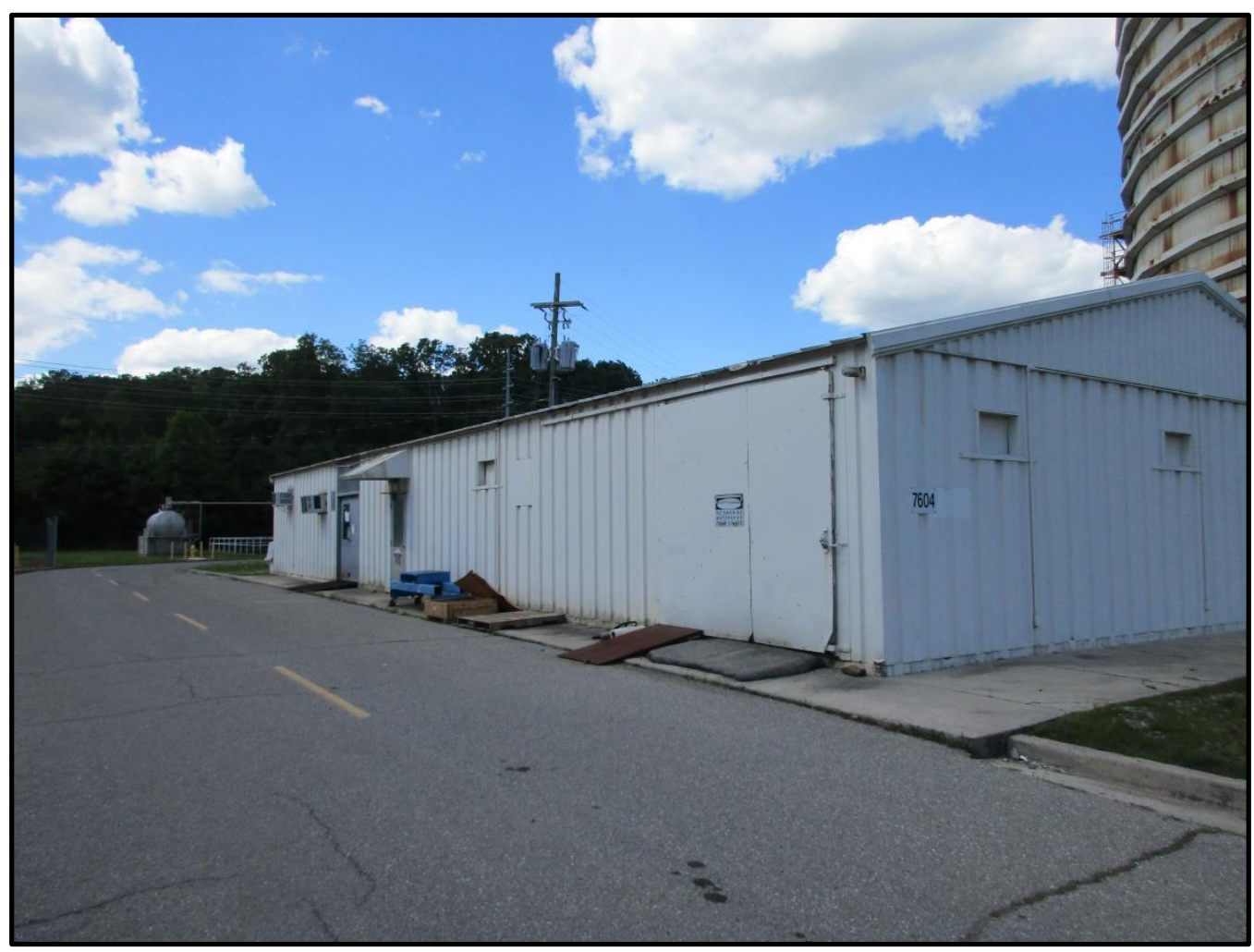

Figure 451. Overview of west elevation and partial south elevation of Building 7604. 


\section{5}

\section{BUILDING NAME}

Storage Building

DATE OF CONSTRUCTION

1954

DOE OFFICE RESPONSIBLE

SC

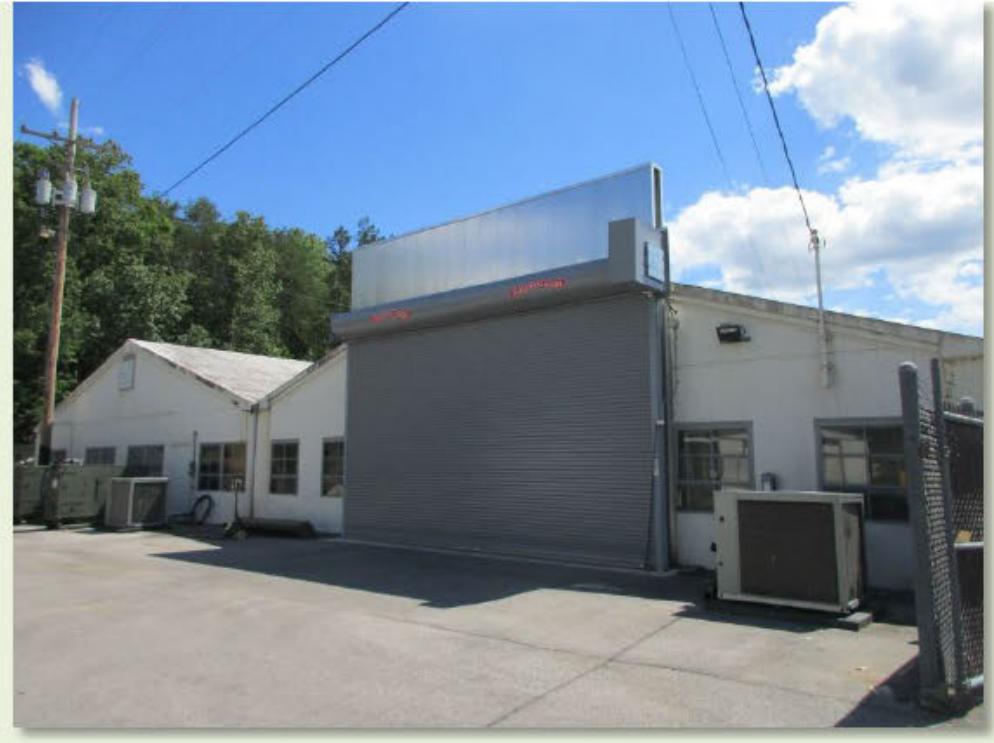

NRHP ELIGIBILITY

Figure 452. Overview of east elevation of Building 7605.

Not Eligible

\section{DESCRIPTION}

Building 7605 is part of the Robotics and Process Systems Complex. Located to the immediate west of Melton Hill Lake, Building 7605 is a one-story, rectangular, steel structure situated on a concrete foundation (Figures 452 and 453). The exterior is clad with vertical steel panels. The structure features a double-gable roof clad with corrugated metal, suggesting two gable-roof structures adjacent to one another. The gable ends of the building are oriented to the east and west. The building's fenestration consists of six-light steel awning windows and thee-light steel glazed doors. Large roll-up garage doors can be found on the north and east elevations, with a loading dock on the north elevation.

\section{NATIONAL REGISTER EVALUATION}

Building 7605 was constructed in 1954 as a storage building. The building was previously surveyed in 1994 and 2015 and recommended as not eligible for listing in the NRHP (Carver and Slater 1994; Thomason and Associates 2015). The building retains a majority of its historic materials, as well as its form and massing. As a storage facility, Building 7605 played a secondary role in support of ORNL's mission in scientific research during the Cold War era. However, the building is not the single location most importantly associated with a scientific achievement, scientist, or other event or person of historic significance to merit listing in the NRHP under Criterion A or B. Furthermore, the building lacks notable architectural elements that would warrant individual listing in the NRHP under Criterion C. In addition, the building is located outside of the recommended boundaries of a NRHP-eligible historic district. As such, Building 7605 does not warrant listing in the NRHP under Criterion $\mathrm{A}, \mathrm{B}$, or $\mathrm{C}$. 


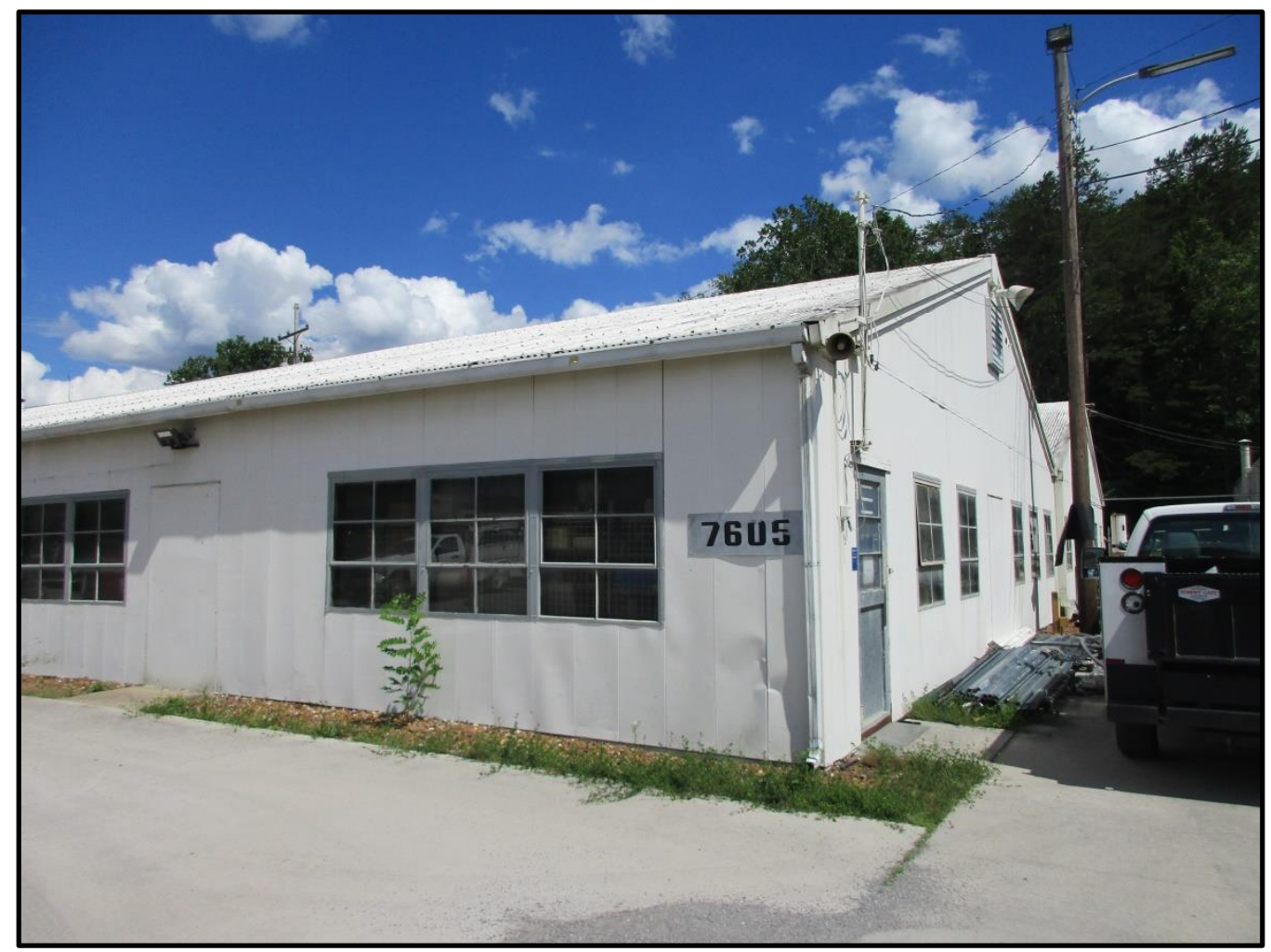

Figure 453. Overview of north and west elevations of Building 7605. 


\section{A}

\section{BUILDING NAME}

Property Management Office

\section{DATE OF CONSTRUCTION}

1962

\section{DOE OFFICE RESPONSIBLE}

SC

NRHP ELIGIBILITY

Figure 454. Overview of west elevation and partial east elevation of Building 7606A.

Not Eligible

\section{DESCRIPTION}

Building $7606 \mathrm{~A}$ is adjacent to and forms the north portion of the larger 7606 Building which includes Building 7606B. The structure is located in the Robotics and Process Systems Complex east of the EGCR Access Road loop. The building is a one-story, concrete block masonry structure with a flat roof (Figures 454 and 455 ). This building features windows filled with one-over-one, double-hung sashes. The north elevation features a roll-up garage door and two single-light steel pedestrian doors on either side. The doors are sheltered by small awnings. The single-leaf entry on the west elevation is filled with an aluminum and glass commercial door with a sidelight. A convex fabric awning is placed above this doorway.

\section{NATIONAL REGISTER EVALUATION}

Building 7606A was constructed in 1962 as an office building. The building was previously surveyed in 1994 and 2015 and recommended as not eligible for listing in the NRHP (Carver and Slater 1994; Thomason and Associates 2015). The building retains a majority of its historic materials on the exterior, as well as its form and massing. However, the interior of the building has been heavily altered. As an office building, Building 7606A supported ORNL's mission in nuclear science during the Cold War era. However, the building is not the single location most importantly associated with a scientific achievement, scientist, or other event or person of historic significance to merit listing in the NRHP under Criterion A or B. Furthermore, the building lacks notable architectural elements that would warrant individual listing in the NRHP under Criterion $\mathrm{C}$. In addition, the building is located outside of the recommended boundaries of a NRHP-eligible historic district. As such, Building $7606 \mathrm{~A}$ does not warrant listing in the NRHP under Criterion A, B, or C. 


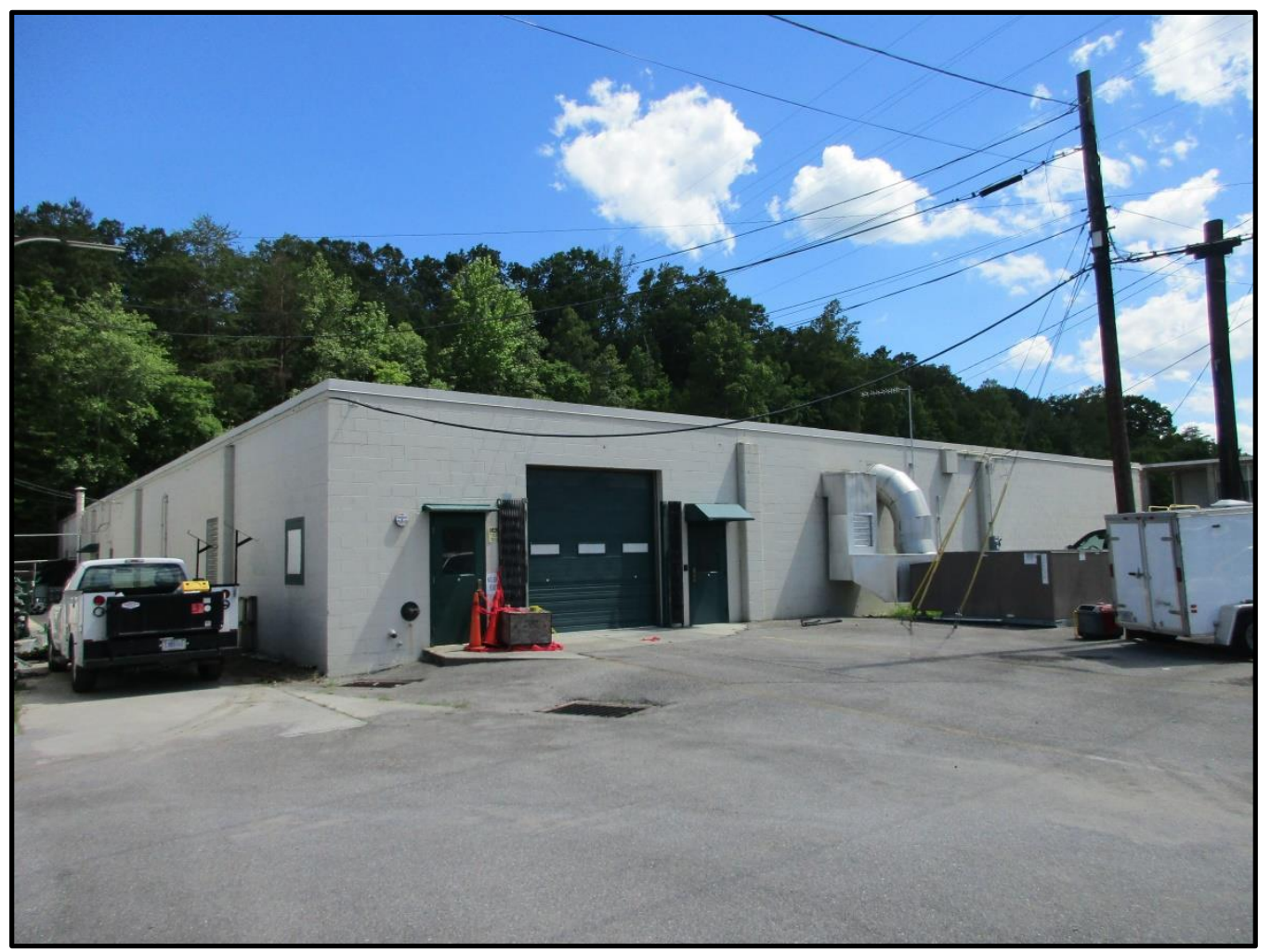

Figure 455. Overview of north and east elevations of Building 7606A. 


\section{$7606 B$}

\section{BUILDING NAME}

General Maintenance Shop

DATE OF CONSTRUCTION

1962

DOE OFFICE RESPONSIBLE

SC

NRHP ELIGIBILITY

Figure 456. Overview of west elevation of Building 7606B, showing the entrance to the building.

Not Eligible

\section{DESCRIPTION}

Building $7606 \mathrm{~B}$ is located adjacent to Building $7606 \mathrm{~A}$ and forms the west portion of the larger 7606 Building which includes Building 7606A. The structure is located in the Robotics and Process Systems Complex east of the EGCR Access Road loop. Similar to Building 7606A, this is a one-story, concrete block masonry building with a flat roof (Figures 456 and 457). This portion of the building features a long, flat metal awning on the west elevation. This elevation also features single-light steel doors and a large roll-up garage door.

\section{NATIONAL REGISTER EVALUATION}

Building 7606B was constructed in 1962 as a maintenance facility for the EGCR Facility. When the EGCR became obsolete, this building continued to function as a maintenance facility for other forms of research including the Consolidated Fuel Recycling Program and the Robotics and Process Systems Division. The building was previously surveyed in 1994 and 2015 and recommended as not eligible for listing in the NRHP (Carver and Slater 1994; Thomason and Associates 2015). The building retains a majority of its historic materials, as well as its form and massing. As a maintenance facility, Building $7606 \mathrm{~B}$ played a secondary role in support of ORNL's mission in scientific research during the Cold War era. However, the building is not the single location most importantly associated with a scientific achievement, scientist, or other event or person of historic significance to merit listing in the NRHP under Criterion A or B. Furthermore, the building lacks notable architectural elements that would warrant individual listing in the NRHP under Criterion C. In addition, the building is located outside of the recommended boundaries of a NRHP-eligible historic district. As such, Building 7606B does not warrant listing in the NRHP under Criterion A, B, or C. 


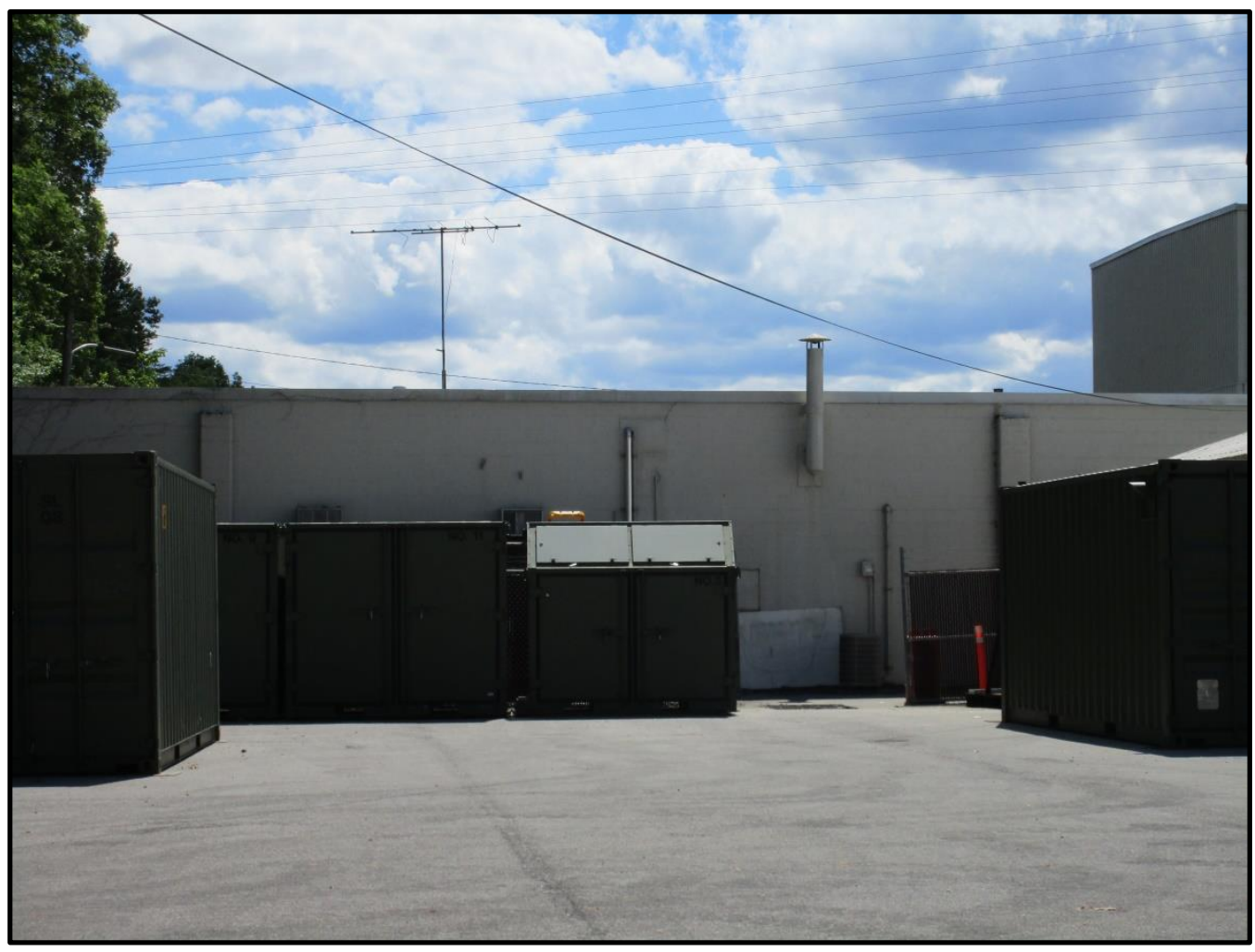

Figure 457. Overview of east elevation of Building 7606B, showing the rear of the building. 


\section{BUILDING NAME}

Component Development - CFRP

DATE OF CONSTRUCTION

1965

\section{DOE OFFICE RESPONSIBLE}

SC

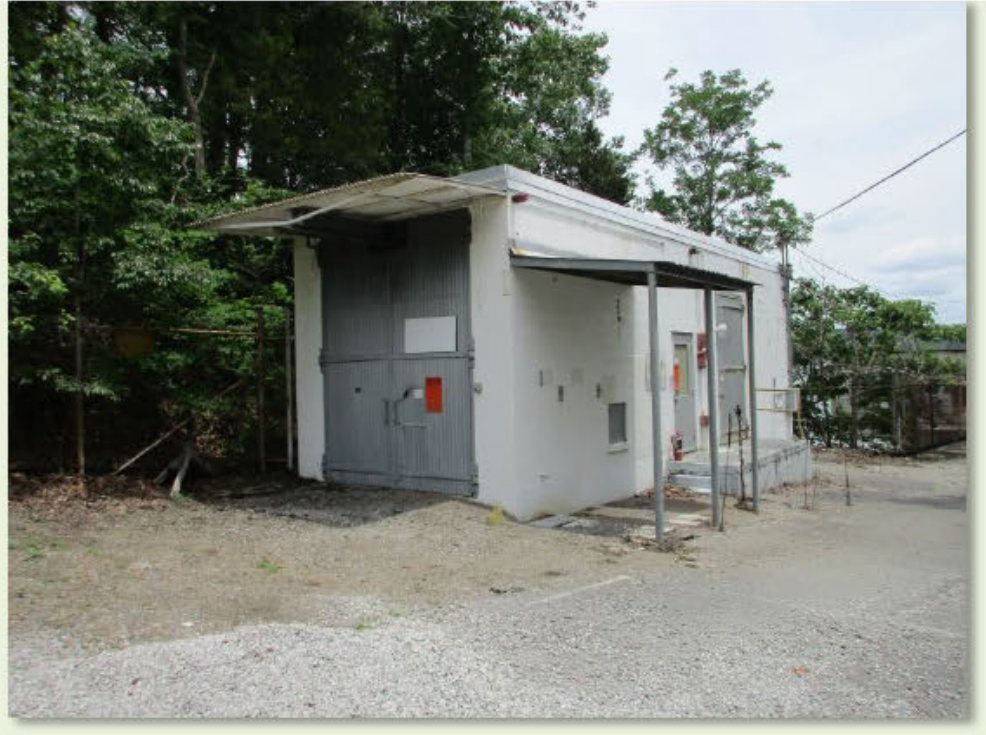

NRHP ELIGIBILITY

Figure 458. Overview of Building 7608.

Not Eligible

\section{DESCRIPTION}

Building 7608 is located in the Robotics and Process Systems Complex. Located to the immediate west of Melton Hill Lake, Building 7608 is a one-story, concrete block masonry building with a flat roof exhibiting metal coping (Figures 458 and 459). Rectangular in form, the west elevation features a double-leaf garage bay filled with paired, hinged corrugated metal doors under a flat corrugated metal awning. Single-leaf entries filled with a single-light steel door and a larger steel equipment access door is located on the building's south elevation. A corrugated metal canopy with steel posts is also located on this elevation.

\section{NATIONAL REGISTER EVALUATION}

Building 7608 was constructed in 1965 as a component development building for the EGCR Facility. When the EGCR became obsolete, this building continued to function as a research/laboratory facility for other forms of research including the Consolidated Fuel Recycling Program and the Robotics and Process Systems Division. The building was previously surveyed in 1994 and 2015 and recommended as not eligible for listing in the NRHP (Carver and Slater 1994; Thomason and Associates 2015). The building retains a majority of its historic materials, as well as its form and massing. As a research/laboratory facility, Building 7608 housed work to further ORNL's mission in scientific research during the Cold War era. However, the building is not the single location most importantly associated with a scientific achievement, scientist, or other event or person of historic significance to merit listing in the NRHP under Criterion A or B. Furthermore, the building lacks notable architectural elements that would warrant individual listing in the NRHP under Criterion C. In addition, the building is located outside of the recommended boundaries of a NRHP-eligible historic district. As such, Building 7608 does not warrant listing in the NRHP under Criterion A, B, or C. 


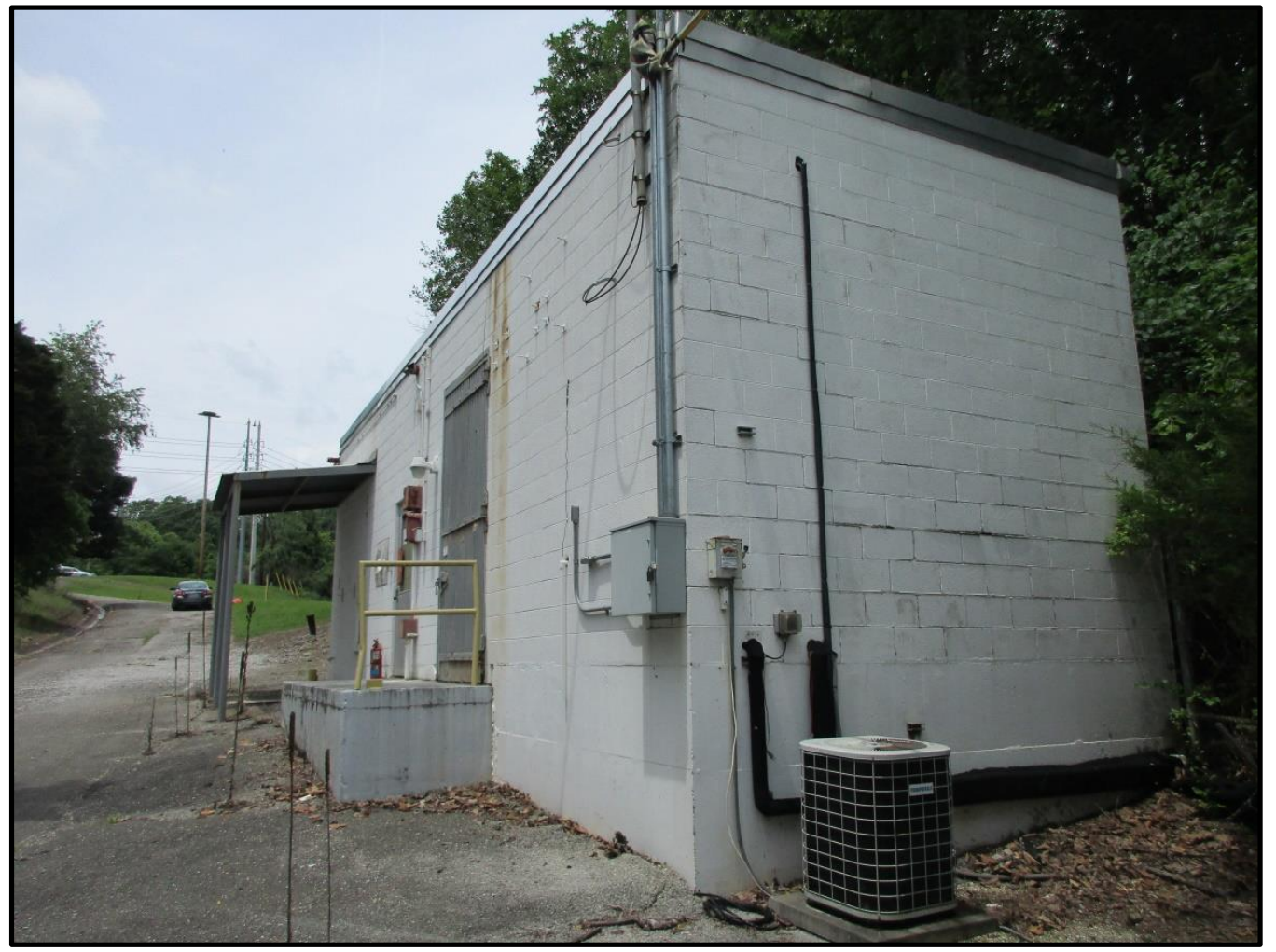

Figure 459. Overview of south and east elevation of Building 7608. 


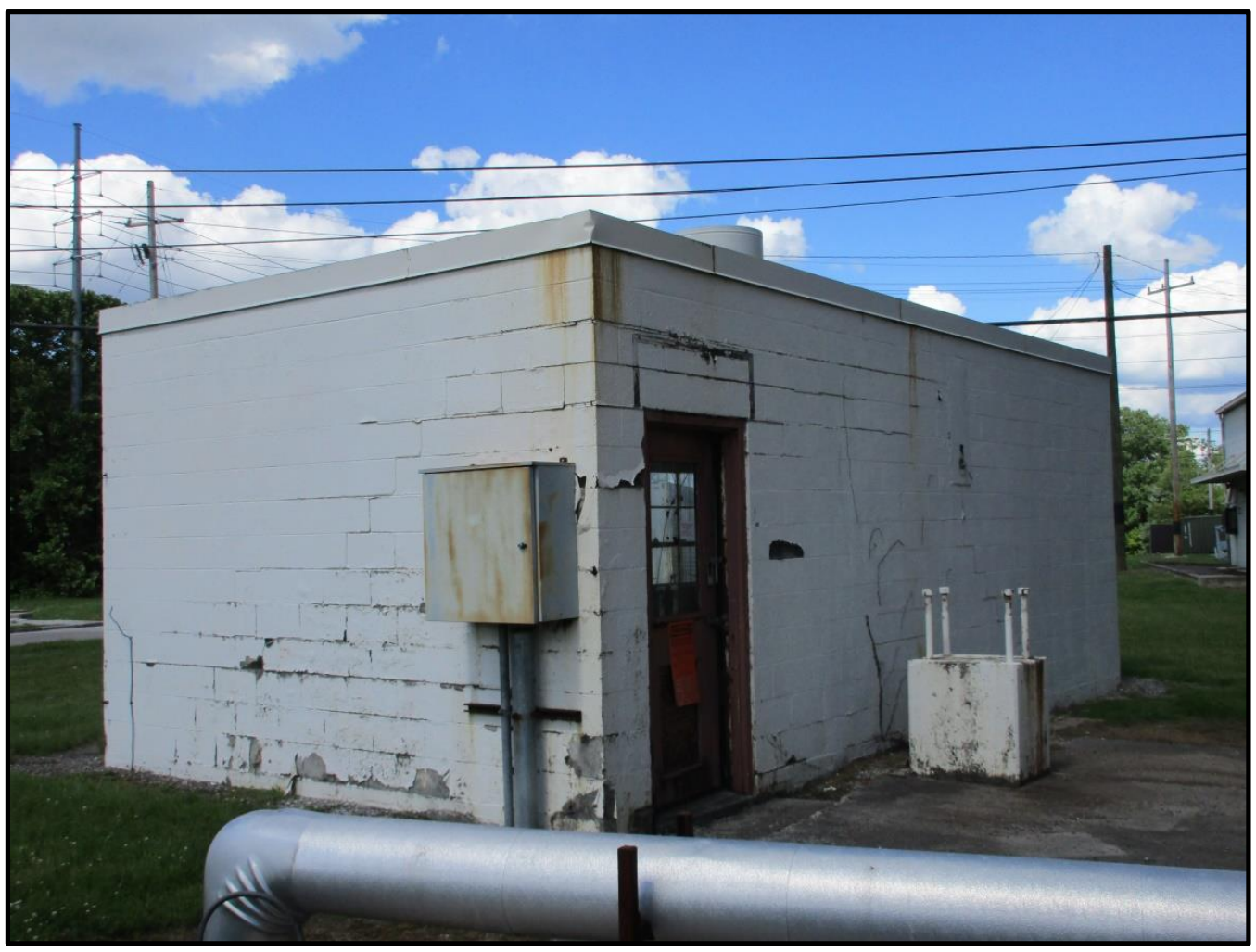

Figure 461. Overview of west and south elevations of Building 7610. 


\section{5}

\section{BUILDING NAME}

Energy Systems Storage

DATE OF CONSTRUCTION

1965

\section{DOE OFFICE RESPONSIBLE}

SC

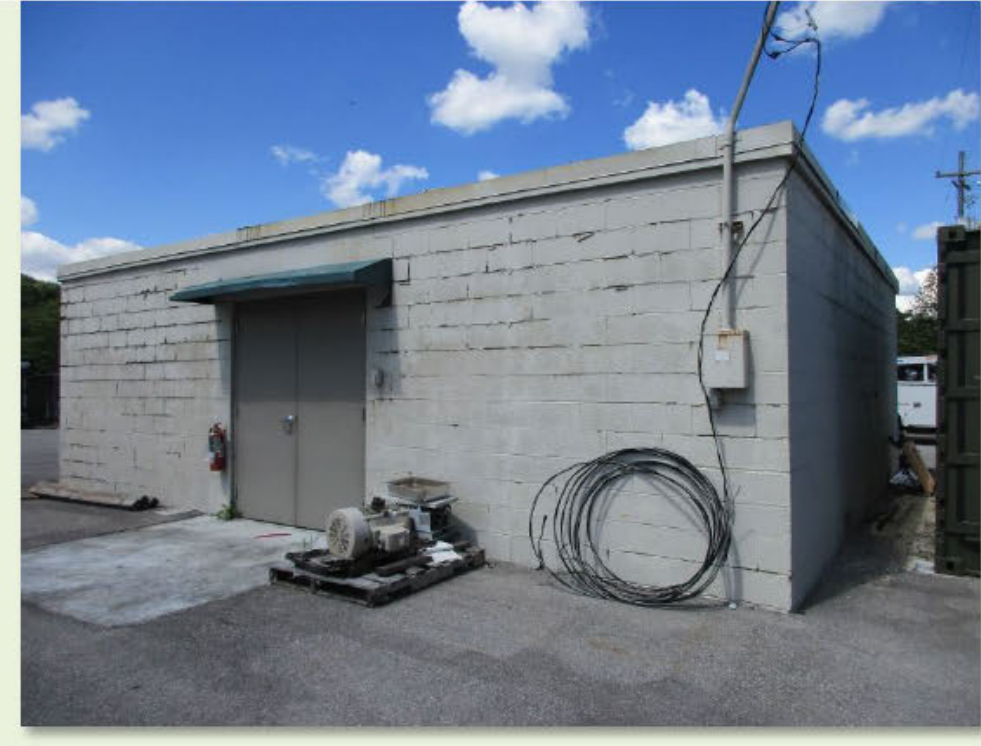

NRHP ELIGIBILITY

Figure 462. Overview of west and south elevations of Building 7615.

Not Eligible

\section{DESCRIPTION}

Building 7615 is located in the 7600 Area east of the EGCR Access Road loop. Building 7615 is a one-story, concrete block masonry building and rectangular in plan (Figures 462 and 463). The roof is flat with two roof vents and metal coping. The building features two double-leaf entries filled with steel double doors on the east and west elevations sheltered by small arched awnings.

\section{NATIONAL REGISTER EVALUATION}

Building 7615 was constructed in 1965 as a storage facility for the EGCR Facility. When the EGCR became obsolete, this building continued to function as a storage facility for other forms of research including the Consolidated Fuel Recycling Program and the Robotics and Process Systems Division. The building was previously surveyed in 1994 and 2015 and recommended as not eligible for listing in the NRHP (Carver and Slater 1994; Thomason and Associates 2015). The building retains a majority of its historic materials, as well as its form and massing. As a storage facility, Building 7615 played a secondary role in support of ORNL's mission in scientific research during the Cold War era. However, the building is not the single location most importantly associated with a scientific achievement, scientist, or other event or person of historic significance to merit listing in the NRHP under Criterion A or B. Furthermore, the building lacks notable architectural elements that would warrant individual listing in the NRHP under Criterion $\mathrm{C}$. In addition, the building is located outside of the recommended boundaries of a NRHP-eligible historic district. As such, Building 7615 does not warrant listing in the NRHP under Criterion A, B, or C. 


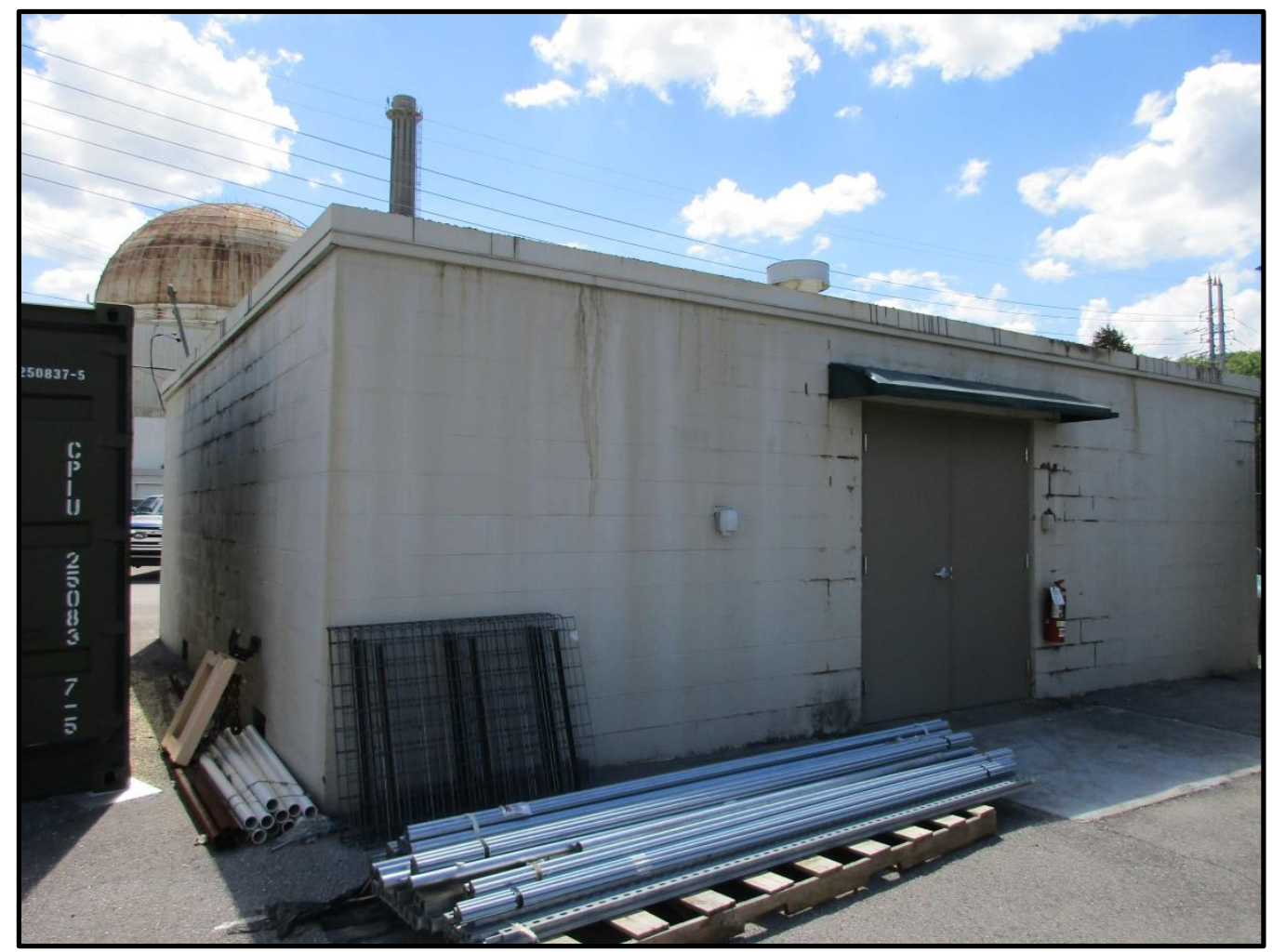

Figure 463. Overview of east and south elevations of Building 7615. 

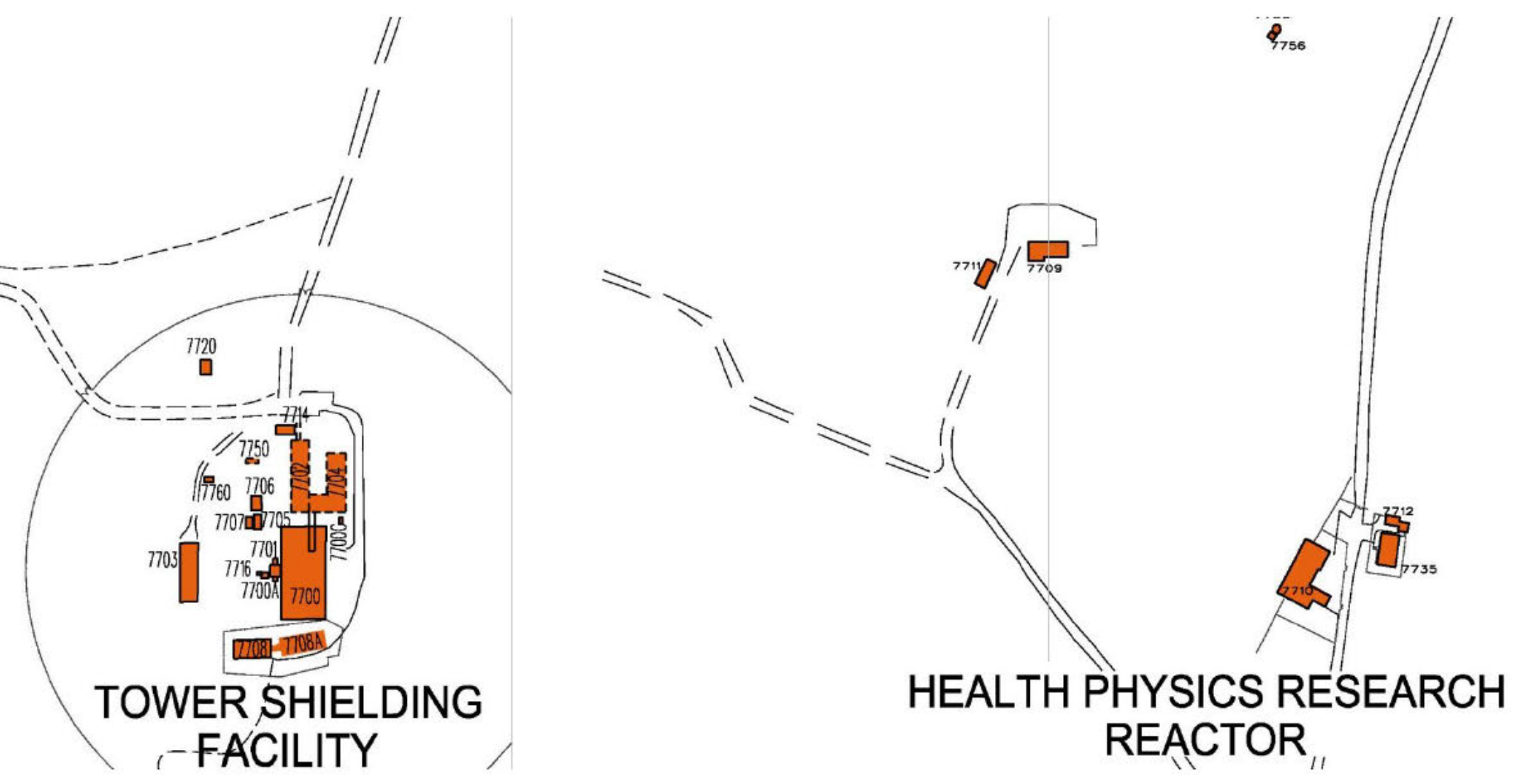

7700 AREA

Figure 464. Plan View of 7700 Area.

NOT EVALUATED/NOT ACCESSED

Building $7700^{*}$

Building $7701^{*}$

Building $7702^{*}$

Building $7703^{*}$

Building 7704 *

Building 7705

Building 7707

Building 7708

Building 7709*

Building $7710^{*}$

Building 7712

Building 7720

Building 7740

Building 7758
*Previously

determined

NRHP-eligible

\section{DEMOLISHED}

Building $7751^{*}$ 
This page intentionally left blank 


\section{AREA}

\section{DISTRICT NAME}

7700 Area of ORNL

\section{DATE OF CONSTRUCTION}

1947-1988

\section{NRHP ELIGIBILITY}

Part Contributes to Tower Shielding Facility

\section{DESCRIPTION}

The 7700 Area is located southeast of the main portion of the ORNL campus and the 7500 and 7900 Areas (Figure 464). The resources located within the 7700 Area are primarily grouped into two facilities-the Tower Shielding Facility (TSF) and the Dosimetry Applications Research (DOSAR) Facility-with additional buildings scattered throughout Melton Valley, south and southeast of the main campus of ORNL. Twenty buildings are located within the 7700 Area, 15 of which were built before 1980 and thus were identified for the survey. A secure access road leads to the facility and a fence forms a circle around the facility. Due to the security of the facility, access was not permitted at the time of survey. Therefore, all descriptions and evaluations for the following buildings are derived from previous assessments based on photography and documentation completed in 2004 (Thomason and Associates 2004).

\section{NATIONAL REGISTER EVALUATION}

Buildings associated with the TSF were constructed between 1952 and 1963 and buildings associated with the DOSAR Facility were constructed between 1960 and 1988. In 1994 the TSF was determined eligible for listing in the NRHP under Criteria $A$ and $C$ as well as Criteria Consideration $G$ for exceptional significance as an innovative facility capable of suspending a reactor in the air (Carver and Slater 1994:307). As the only reactor of this type in the United State, the TSF was "designed and built for radiation-shielding studies in which both the reactor source and shield samples could be raised into the air to provide measurements without ground scattering or other spurious effects" (Murkenthaler 1992:33). The ability to lift the reactor into the air allowed for advancements in the field of shielding research, particularly related to the attempted development of nuclearpowered aircraft, which required a reactor and shielding to be elevated off the ground. In 1994 the DOSAR Facility was determined not eligible due to age (Carver and Slater 1994). In 2004 the TSF was again recommended eligible under Criteria A and C; DOSAR was not evaluated (Thomason and Associates 2004). In 2015 Thomason and Associates used the documentation from 2004 as the basis for their evaluation in 2015 (Thomason and Associates 2015). While the 7700 Area retains at its core research and processing facilities where key scientific advancements occurred, the area does not represent a cohesive, distinct entity with a singular focus. Rather it is a collection of outlying facilities associated with ORNL missions of the 1950s and 1960s. Thus, CRA recommends that the 7700 Area, as a whole, does not represent a NRHP-eligible historic district. However, the buildings within this area were not accessible during the 2017 field survey. While the photographic documentation from the previous survey was used to provide brief descriptions of the facilities, it 
does not allow CRA to assess current conditions. Therefore, CRA recommends that the 7700 Area requires updated documentation and evaluation of individual facilities once accessible. Until such documentation can occur, the current NRHP-status of all buildings in the 7700 Area is undetermined, but the TSF should continue to be treated as an eligible facility based on its previous evaluation, as should the individual resources in the DOSAR facility that were previously recommended eligible. 


\section{0}

\section{BUILDING NAME}

Towers, Tower Shielding Facility

\section{DATE OF CONSTRUCTION}

1953

DOE OFFICE RESPONSIBLE

EM (UCOR)

NRHP ELIGIBILITY

Not Evaluated; Not Accessible

\section{DESCRIPTION}

This building is located in the TSF. Building 7700 is "comprised of four, 315 -foot tall steel towers erected at each corner of a rectangular concrete pad, which is $100^{\prime} \times 200^{\prime}$ in size. Towers at the short sides of the rectangle are connected at the top by a cross steel support; the towers at the northwest side of the rectangle have an additional connector in the center which served as the instrument platform. Guy wires (two-inch plow steel guys) connect to anchors at each corner of the tower. The tower is equipped with a hoist system designed to lift the reactor off the ground. The concrete pad originally contained a pool for storage of the reactor" (Carver and Slater 1994:306).

\section{NATIONAL REGISTER EVALUATION}

Building 7700 was constructed in 1953 as tall towers for the TSF (Carver and Slater 1994:306). In previous assessments, Building 7700 was determined eligible as a contributing resource of the TSF. The 1994 assessment conducted by Duvall \& Associates stated the building was eligible under Criterion A due to its innovation and technological advancements in the fields of shielding and radiation scattering, as this building is a part of the only reactor facility of its kind built in the United States. Thomason and Associates concurred with this assessment in 2004 and used the documentation from 2004 as the basis for his evaluation in 2015 (Thomason and Associates 2004 and 2015). Buildings within this area were not accessible during the survey, so their current condition is unknown. Therefore, CRA recommends that until Building 7700 can be accessed, documented, and reassessed, the building should be treated as eligible for listing in the NRHP as a contributing resource of the TSF. 


\section{1}

\section{BUILDING NAME}

Pool, Tower Shielding Facility

\section{DATE OF CONSTRUCTION}

1953

DOE OFFICE RESPONSIBLE

EM (UCOR)

NRHP ELIGIBILITY

Not Evaluated; Not Accessible

\section{DESCRIPTION}

Building 7701 once served as a pool for Building 7700 . Since its initial construction, the pool has been covered with a 2-ft concrete slab. (Carver and Slater 1994:306)

\section{NATIONAL REGISTER EVALUATION}

Building 7701 was constructed as a pool to store the reactor for the TSF. The pool has since been covered with a 2-ft concrete slab. In previous assessments, Building 7701 was determined eligible as a contributing resource of the TSF. The 1994 assessment conducted by Duvall \& Associates stated the building was eligible under Criterion $A$ due to its innovation and technological advancements in the fields of shielding and radiation scattering, as this building is a part of the only reactor facility of its kind built in the United States. Thomason and Associates concurred with this assessment in 2004 and used the documentation from 2004 as the basis for his evaluation in 2015 (Thomason and Associates 2004 and 2015). Buildings within this area were not accessible during the survey, thus their current condition is unknown. Therefore, CRA recommends that until Building 7701 can be accessed, documented, and reassessed, the building should be treated as eligible for listing in the NRHP as a contributing resource of the TSF. 


\section{2}

\section{BUILDING NAME}

Control House, Tower Shielding Facility

\section{DATE OF CONSTRUCTION}

1954

DOE OFFICE RESPONSIBLE

EM (UCOR)

NRHP ELIGIBILITY

Not Evaluated; Not Accessible

\section{DESCRIPTION}

Building 7702 is a control house and is "an $12,768 \mathrm{sq} \mathrm{ft}$ underground bunker, which was built underneath the concrete pad and tower. An entrance is located on the east side of the elevated tower and a ramp that descends from the concrete pad to a hoist control station is located on the west side. The building contains offices, laboratories, and original control panels" (Carver and Slater 1994:306).

\section{NATIONAL REGISTER EVALUATION}

Building 7702 was constructed in 1954 as a control house and underground bunker for the TSF. The building was determined eligible as a contributing resource of the TSF in the 1994 assessment conducted by Duvall \& Associates. Building 7702 was determined eligible under Criterion A due to its innovation and technological advancements in the fields of shielding and radiation scattering, as this building is a part of the only reactor facility of its kind built in the United States (Carver and Slater 1994). Thomason and Associates concurred with this assessment in 2004 and used the documentation from 2004 as the basis for his evaluation in 2015 (Thomason and Associates 2004 and 2015). Buildings within this area were not accessible during the survey, thus their current condition is unknown. Therefore, CRA recommends that until Building 7702 can be accessed, documented, and reassessed, the building should be treated as eligible for listing in the NRHP as a contributing resource of the TSF. 


\section{3}

\section{BUILDING NAME}

Hoist House, Tower Shielding Facility

\section{DATE OF CONSTRUCTION}

1953

DOE OFFICE RESPONSIBLE

EM (UCOR)

NRHP ELIGIBILITY

Not Evaluated; Not Accessible

\section{DESCRIPTION}

Building 7703 is a one-story building, rectangular in plan, with metal siding and a shed roof. On the northeast elevation, the structure features multi-light windows and "below each window are openings for the cables from the tower to connect to the hoisting mechanism. Between the tower and hoist house are cylinders on concrete pedestals which serve as guides for the cables" (Carver and Slater 1994:306).

\section{NATIONAL REGISTER EVALUATION}

Building 7703 was constructed in 1953 as a hoist house for the TSF. The building was determined eligible as a contributing resource of the TSF in the 1994 assessment conducted by Duvall \& Associates. Building 7703 was determined eligible under Criterion A due to its innovation and technological advancements in the fields of shielding and radiation scattering, as this building is a part of the only reactor facility of its kind built in the United States (Carver and Slater 1994). Thomason and Associates concurred with this assessment in 2004 and used the documentation from 2004 as the basis for his evaluation in 2015 (Thomason and Associates 2004 and 2015). Buildings within this area were not accessible during the survey, thus their current condition is unknown. Therefore, CRA recommends that until Building 7703 can be accessed, documented, and reassessed, the building should be treated as eligible for listing in the NRHP as a contributing resource of the TSF. 


\section{4}

\section{BUILDING NAME}

Control House No. 2, Tower Shielding Facility

\section{DATE OF CONSTRUCTION}

Unknown

DOE OFFICE RESPONSIBLE

EM (UCOR)

\section{NRHP ELIGIBILITY}

Not Evaluated; Not Accessible

\section{DESCRIPTION}

Building 7704 is similar to Building 7702 in that it is an underground bunker. It is smaller in size than Building 7702 at only $2,235 \mathrm{sq} f \mathrm{ft}$ in size. The building is constructed of concrete and connects to Building 7702 by way of a short tunnel, where a ramp leads to the concrete pad (Carver and Slater 1994:306).

\section{NATIONAL REGISTER EVALUATION}

Building 7704 was constructed as a control house and underground bunker for the TSF. The date of construction is unknown. The building was determined eligible as a contributing resource of the TSF in the 1994 assessment conducted by Duvall \& Associates. Building 7704 was determined eligible under Criterion A due to its innovation and technological advancements in the fields of shielding and radiation scattering, as this building is a part of the only reactor facility of its kind built in the United States (Carver and Slater 1994). Thomason and Associates concurred with this assessment in 2004 and used the documentation from 2004 as the basis for his evaluation in 2015 (Thomason and Associates 2004 and 2015). Buildings within this area were not accessible during the survey, thus their current condition is unknown. Therefore, CRA recommends that until Building 7704 can be accessed, documented, and reassessed, the building should be treated as eligible for listing in the NRHP as a contributing resource of the TSF. 


\section{5}

\section{BUILDING NAME}

Pump House, Tower Shielding Facility

\section{DATE OF CONSTRUCTION}

1960

DOE OFFICE RESPONSIBLE

EM (UCOR)

NRHP ELIGIBILITY

Not Evaluated; Not Accessible

\section{DESCRIPTION}

Building 7705 is rectangular in plan and $540 \mathrm{sq} f \mathrm{ft}$ area. It is constructed of concrete masonry block and has a flat roof (Carver and Slater 1994:306).

\section{NATIONAL REGISTER EVALUATION}

Building 7705 was constructed in 1960 as a pump house for the TSF. The building was determined to be a noncontributing resource of the TSF based upon the 1994 assessment conducted by Duvall \& Associates (Carver and Slater 1994). The building was not included in the 2004 and 2015 surveys (Thomason and Associates 2004 and 2015). Buildings within this area were not accessible during the survey, thus their current condition is unknown. Since Building 7705 has turned 50 years of age since it was previously determined ineligible for listing in the NRHP, it should be reassessed to consider if it should now be considered a contributing resource in the TSF. 


\section{7}

\section{BUILDING NAME}

Battery House, Tower Shielding Facility

\section{DATE OF CONSTRUCTION}

1960

DOE OFFICE RESPONSIBLE

EM (UCOR)

NRHP ELIGIBILITY

Not Evaluated; Not Accessible

\section{DESCRIPTION}

Similar to Building 7705 , this structure is constructed with concrete block masonry and contains a flat roof. Building 7707 is rectangular and contains $430 \mathrm{sq} f t$ (Carver and Slater 1994:306).

\section{NATIONAL REGISTER EVALUATION}

Building 7707 was constructed in 1960 as a battery house for the TSF. The building was determined to be a non-contributing resource of the TSF based upon the 1994 assessment conducted by Duvall \& Associates (Carver and Slater 1994). The building was not included in the 2004 and 2015 surveys (Thomason and Associates 2004 and 2015). Buildings within this area were not accessible during the survey, thus their current condition is unknown. Since Building 7707 has turned 50 years of age since it was previously determined ineligible for listing in the NRHP, it should be reassessed to consider if it should now be considered a contributing resource in the TSF. 


\section{8}

\section{BUILDING NAME}

Reactor Shield Storage, Tower Shielding Facility

\section{DATE OF CONSTRUCTION}

1961

DOE OFFICE RESPONSIBLE

EM (UCOR)

NRHP ELIGIBILITY

Not Evaluated; Not Accessible

\section{DESCRIPTION}

Building 7708 is "located to the west of the tower, this $3,277 \mathrm{sq} \mathrm{ft}$ building is of steel frame construction with a gable roof and corrugated metal siding. It has sliding track doors on the gable end: one panel contains a door and other an 18-pane fixed window. Pair of 18-light windows are found to each side of the track doors" (Carver and Slater 1994:307).

\section{NATIONAL REGISTER EVALUATION}

Building 7708 was constructed in 1961 as reactor shield storage building for the TSF (Carver and Slater 1994:307). The building was determined to be a non-contributing resource of the TSF based upon the 1994 assessment conducted by Duvall \& Associates (Carver and Slater 1994). The building was not included in the 2004 and 2015 surveys (Thomason and Associates 2004 and 2015). Buildings within this area were not accessible during the survey, thus their current condition is unknown. Since Building 7708 has turned 50 years of age since it was previously determined ineligible for listing in the NRHP, it should be reassessed to consider if it should now be considered a contributing resource in the TSF. 


\section{9}

\section{BUILDING NAME}

Health Physics Research Reactor

\section{DATE OF CONSTRUCTION}

1962

\section{DOE OFFICE RESPONSIBLE}

SC

\section{NRHP ELIGIBILITY}

Not Evaluated; Not Accessible

\section{DESCRIPTION}

Building 7709 was "a small, unshielded, unmoderated fast reactor" located south of Haw Ridge in Melton Valley. The Health Physics Research Reactor (HPRR) was housed originally in the DOSAR facility, which also included a control and laboratory building (7710) (Thomason and Associates 2015:53). The building is described as "3,004 sq ft, steel-frame, metal-sided, gable-roofed building," which is enclosed by a fence (Carver and Slater 1994:312).

\section{NATIONAL REGISTER EVALUATION}

Building 7709 was completed in 1962 as a "fast burn reactor." The reactor was tested at ORNL prior to being moved to the Nevada Test Site, an outdoor testing ground outside of Las Vegas. At this test site, the reactor was used to collect data on the exposure of radiation from different heights. The reactor operated on a 1500 -ft tower. Eventually, the reactor was returned to Oak Ridge and continued its studies within the DOSAR facility until it was shut down in 1987 (Thomason and Associates 2015). In the 1994 assessment, Building 7709 was determined not individually eligible due to its age (Carver and Slater 1994). However, in their 2004 and 2015 surveys, Thomason and Associates considered the building to be individually eligible for listing in the NRHP (Thomason and Associates 2004 and 2015). Buildings within this area were not accessible during the survey and have not been recorded or assessed since 2004, thus their current condition is unknown. Therefore, CRA recommends that until Building 7709 can be accessed, documented, and reassessed, the building should be treated as eligible for listing in the NRHP. 


\section{0}

\section{BUILDING NAME}

Dosimetry Applications Research Facility

\section{DATE OF CONSTRUCTION}

1962

DOE OFFICE RESPONSIBLE

SC

\section{NRHP ELIGIBILITY}

Not Evaluated; Not Accessible

\section{DESCRIPTION}

This building is described as a "2,574 sq ft, flat-roofed, concrete block structure" (Carver and Slater 1994:312). The building has a large loading bay on its front façade and a series of pipes connects Building 7710 to Building 7709 , the HPRR.

\section{NATIONAL REGISTER EVALUATION}

Building 7710 was completed in 1962 as a facility for the HPRR and research in Dosimetry Applications (Carver and Slater 1994:312). In the 1994 assessment, Building 7710 was determined not individually eligible due to its age (Carver and Slater 1994). However, in their 2004 and 2015 surveys, Thomason and Associates considered the building to be individually eligible in the NRHP under Criterion A for its achievements in science and health/medicine as the research conducted by the Health Physics Division at the DOSAR facility was significant within nuclear studies (Thomason and Associates 2004 and 2015). Buildings within this area were not accessible during the survey and have not been recorded or assessed since 2004, thus their current condition is unknown. Therefore, CRA recommends that until Building 7710 can be accessed, documented, and reassessed, the building should be treated as eligible for listing in the NRHP. 


\section{2}

\section{BUILDING NAME}

DOSAR Low-Energy Accelerator

\section{DATE OF CONSTRUCTION}

1963

DOE OFFICE RESPONSIBLE

SC

\section{NRHP ELIGIBILITY}

Not Evaluated; Not Accessible

\section{DESCRIPTION}

This building is described as a " $1,122 \mathrm{sq} \mathrm{ft}$, steel-frame, metal-sided building" that features a gable roof and a roll-up door located on the gable end (Carver and Slater 1994:312).

\section{NATIONAL REGISTER EVALUATION}

Building 7712 was constructed in 1963 as low energy accelerator for research in Dosimetry Applications (Carver and Slater 1994:312). In the 1994 assessment, Building 7710 was determined not individually eligible due to its age (Carver and Slater 1994). Building 7712 was not included in the 2004 and 2015 surveys (Thomason and Associates 2004 and 2015). Buildings within this area were not accessible during the survey and have not been recorded or assessed since 1994, thus their current condition is unknown. Since Building 7712 has turned 50 years of age since it was previously determined ineligible for listing in the NRHP, it should be reassessed to consider if it should now be considered a contributing resource in the HPRR and DOSAR facility. 


\section{0}

\section{BUILDING NAME}

Tower Shielding Civil Defense Bunker

\section{DATE OF CONSTRUCTION}

1954

DOE OFFICE RESPONSIBLE

EM (UCOR)

NRHP ELIGIBILITY

Not Evaluated; Not Accessible

\section{DESCRIPTION}

The building is located within the TSF. The building was not observed during the current survey and was not included in previous surveys.

\section{NATIONAL REGISTER EVALUATION}

Building 7720 was constructed in 1954 as Tower Shielding Civil Defense Bunker for the TSF. Building 7720 has not been previously surveyed prior to this study (Carver and Slater 1994; Thomason and Associates 2004; Thomason and Associates 2015). The building is located outside of the previously recommended boundaries for the NRHP-eligible TSF. Therefore, CRA recommends that Building 7720 must be accessed, documented, and assessed before a NRHP evaluation can be provided. 


\section{0}

\section{BUILDING NAME}

Melton Hill Radio Transmission Facility

\section{DATE OF CONSTRUCTION}

1964

\section{DOE OFFICE RESPONSIBLE}

SC

\section{NRHP ELIGIBILITY}

Not Evaluated; Not Accessible

\section{DESCRIPTION}

In the 1994 assessment, Building 7740 is described as a radio transmission tower on top of Melton Hill, east of the TSF (Carver and Slater 1994). However, in the 2015 assessment, Building 7740 is described as a small one-story metal structure adjacent to the radio transmissions tower. The building lays on a concrete foundation and features an exterior of vertical metal panels and a flat roof of aluminum (Thomason and Associates 2015).

\section{NATIONAL REGISTER EVALUATION}

The building has been previously surveyed in 1994, 2004, and 2015 and was determined ineligible for listing in the NRHP. (Carver and Slater 1994; Thomason and Associates 2004 and 2015). Buildings within this area were not accessible during the survey and have not been recorded since 2004 as the 2015 assessment relied on earlier documentation, thus their current condition is unknown. The building is located outside of the previously recommended boundaries for the NRHP-eligible TSF facility. Since Building 7740 has turned 50 years of age since it was previously determined ineligible for listing in the NRHP, it should be reassessed to formally establish its current NRHP status. 


\section{1}

\section{BUILDING NAME}

Sentry Post 22, Tower Shielding Facility Exclusion Area

\section{DATE OF CONSTRUCTION}

1947

DOE OFFICE RESPONSIBLE

SC

NRHP ELIGIBILITY

Demolished - N/A

\section{DESCRIPTION}

According to the original historic and architectural resource survey of ORNL in 1994, Building 7751 was a 64 sq $\mathrm{ft}$, wood frame building that featured a hip roof, novelty board siding, and one-over-one-light wood sash frame windows and stood off State Route 95 at the perimeter fence and entrance to the Tower Shielding Facility. It is thought to have been moved there from another location in 1952 (Carver and Slater 1994:307).

\section{NATIONAL REGISTER EVALUATION}

Building 7751 was constructed in 1947 as sentry post for the TSF area (Carver and Slater 1994:307). The building was previously surveyed in 1994, 2004, and 2015 and was determined eligible for listing in the NRHP (Carver and Slater 1994; Thomason and Associates 2004 and 2015). Buildings within this area were not accessible during the survey; however, information provided by ORNL staff confirmed that Building 7751 was documented in 2015 in anticipation of its demolition. DOE submitted this documentation to the SHPO, as required by the PA, and SHPO accepted the documentation and offered no objection to the proposed demolition (McIntyre 2015). The building was demolished in the fall of 2017. 


\section{8}

\section{BUILDING NAME}

High Flux Isotope Reactor Facility

Parts Storage

\section{DATE OF CONSTRUCTION}

1962

\section{DOE OFFICE RESPONSIBLE}

SC

\section{NRHP ELIGIBILITY}

Not Evaluated; Not Accessible

\section{DESCRIPTION}

Building 7758 is a one-story metal building located in Melton Valley and contains $530 \mathrm{sq}$ ft. The building is situated on a concrete foundation and features an exterior of vertical metal panels and a flat roof (Thomason and Associates 2015:209).

\section{NATIONAL REGISTER EVALUATION}

Building 7758 was built in 1962 as a storage facility for the High Flux Isotope Reactor Facility (HFIR) and continues to serve this purpose (Thomason and Associates 2015:209). Building 7758 was first surveyed in 2015 by Thomason and Associates; it was recommended as not eligible for listing in the NRHP (Thomason and Associates 2015). Buildings within this area were not accessible during this survey. As a storage facility it is not the primary site associated with scientific achievements at ORNL, and thus is unlikely to rise to the level of significance needed for individual listing under Criterion A or B. Furthermore, it exhibits simple utilitarian design, lacking notable stylistic elements or innovative design features, precluding it from listing in the NRHP under Criterion $\mathrm{C}$. Additionally, the building is located outside of the recommended boundaries for the NRHP-eligible TSF and HFIR facility, thus it not a contributing building to either of those identified historic district. Since formally assessed in 2015, it is unlikely that its NRHP status has not changed, but updated documentation would be necessary to make a formal recommendation. Therefore, CRA recommends that until Building 7758 can be accessed, documented, and reassessed, the building should be treated as not eligible for listing in the NRHP. 
This page intentionally left blank 

This page intentionally left blank 


\section{AREA}

\section{DISTRICT NAME}

7800 Area of ORNL

\section{DATE OF CONSTRUCTION}

1955-2013

NRHP ELIGIBILITY

Not Eligible

\section{DESCRIPTION}

The 7800 Area, is located southwest of the main portion of the ORNL campus (Figure 465). Clusters of buildings are spread out through the southern and western sections of the property. A large section of the 7800 Area is situated along Evacuation Road. However, many of the buildings listed below stand alone or within a small cluster of 7800 buildings. All the buildings are situated in the southwestern most portion of the ORNL installation; the White Oak Dam and Lake (Buildings 7813 and 7846) are solitary structures that are located just outside ORNL's security gate and bisected by Highway 95 . Buildings 7831 and 7846 are located to the east of the lake and dam off of Melton Valley Drive. Building 7811 was inaccessible to the survey team.

\section{NATIONAL REGISTER EVALUATION}

The small collection of buildings that comprise the 7800 Area consist of storage and utility/maintenance facilities associated with emergency wastewater retention. These support structures are not directly associated with significant research/laboratory or processing facilities that display clear associations to the central areas of significance of ORNL, namely its origins as the Manhattan Project's $X-10$ facility and its subsequent development as ORNL. As a secondary support area, the 7800 Area lacks collective significant associations with events or persons that would warrant for listing in the NRHP under Criterion A or B. Furthermore, the 7800 Area lacks significant architecture that would qualify it as eligible for listing in the NRHP under Criterion $\mathrm{C}$. Thus, the 7800 Area is not eligible for listing in the NRHP as a historic district under Criterion A, B, or C. 


\section{BUILDING NAME}

White Oak Creek Dam and Lake

\section{DATE OF CONSTRUCTION}

1943

\section{DOE OFFICE RESPONSIBLE}

EM (UCOR)

NRHP ELIGIBILITY

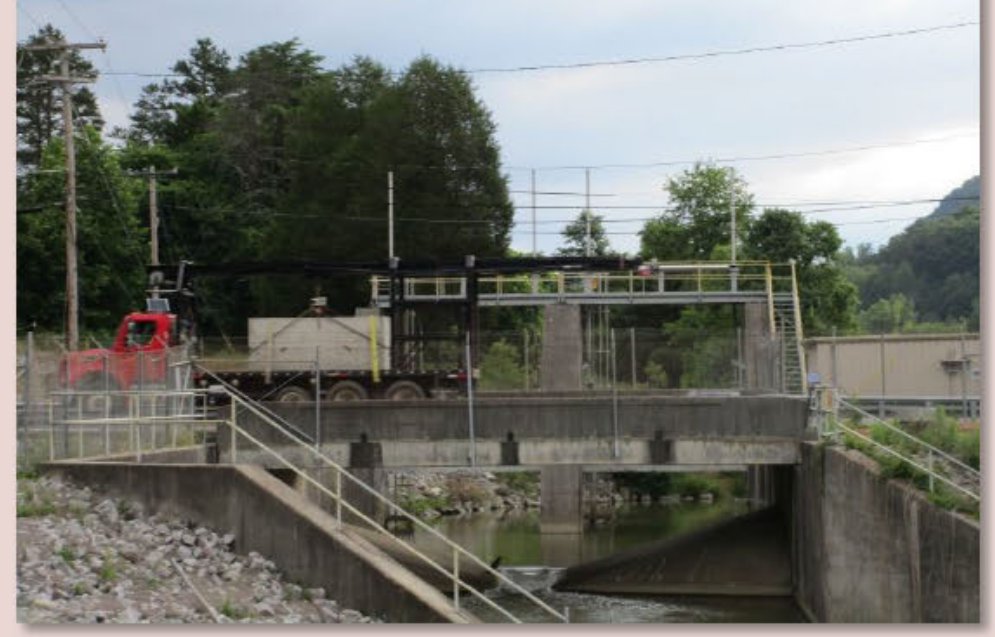

Figure 466. Overview of west elevation of Building 7813, which is White Oak Creek Dam.

Eligible

\section{DESCRIPTION}

White Oak Creek Dam, Building 7813, is comprised of an earthen dam with a poured concrete spillway and sluice gates set in a concrete sluice gate control structure that spans the spillway (Figures 466 and 467 ). The spillway, which features concrete wing walls, is located along the north side of the dam; water flows through the spillway in a westerly direction. The sluice gates, which are typically open, allow for normal water flow, but can be quickly closed if necessary in order to stop water flow. Highway 95, also called White Wing Road, traverses the crest of the dam and a concrete slab bridge carries Highway 95 over the dam's spillway. Riprap covers the dam's sides.

The construction of the dam impounded White Oak Creek, creating White Oak Lake, Building 7846 (Figure 468). The lake lies to the east of the dam and Highway 95. This man-made reservoir is comprised of 25 acres and acts as a settling basin for radioactive materials, allowing for the passage of low-level wastewater into the Clinch River via the dam's spillway.

\section{NATIONAL REGISTER EVALUATION}

White Oak Creek Dam, Building 7813, was originally constructed in 1943 as an earthen dam with a weir to prevent radioactive materials from accidently flowing from White Oak Creek into the Clink River, the creek's natural destination. White Oak Creek flows through ORNL's main facilities complex and ties into the Clinch River to the west. During the WWII era, radioactive waste materials were stored in underground tanks while low level wastes (low in radioactivity) from floor drains, operating areas, and process cooling would pass through settling tanks before being released into the creek. Once constructed, the White Oak Creek Dam provided a means of holding radioactive material that may be released in accidental scenarios and prevent contaminants from reaching the Clinch River. The construction of the dam impounded White Oak Creek, creating White Oak Lake, which allowed radioactive materials to settle to the bottom, permitting lower-level radioactive waste to flow through the dam to the Clinch River. Once the wastewater treatment plant was constructed in the late 1950s, the dam and lake were no longer essential to the ORNL installation; however, the structures remained important as they were backup safety devices to hold contaminated water in the event of an accidental release of radioactive materials and could be used for monitoring and sampling treated water from the treatment plant prior 
to its release into the Clinch River. In later years, the lake and lake bed were utilized for research to study the effects of radioactivity on ecological systems (Carter and Slater 1994: 314).

According to the previous 1994 survey, the dam was modified in 1980 when the earthen dam and weir was replaced with a cofferdam (Carver and Slater 1994); however, the current survey revealed that an earthen dam is still extant. Since cofferdams are temporary structures typically used for construction work below waterlines, a cofferdam may have been constructed temporarily while modifications to the existing structure were made, including the construction of the concrete spillway, sluice control gate structure and gates, removal of the original weir, and the widening of the existing earthen dam. Thus, the original earthen dam remains in place; however, it has undergone a series of modifications since it was first constructed in 1943. The lake has undergone no visible alterations since the previous surveys.

White Oak Dam and Lake, Buildings 7813 and 7846, were previously surveyed in 1994 and recommended individually eligible for listing in the NRHP under Criterion A for their association with early waste management efforts related to nuclear science development (Carver and Slater 1994). Subsequent surveys in 2004 and 2015 concurred with the initial 1994 eligibility recommendation (Thomason and Associates 2004; 2015). The White Oak Creek Dam and Lake, Buildings 7813 and 7846, continue to serve their historic function as an emergency barrier between the ORNL installation and the Clinch River in case of accidental spills and protecting the waterway from radioactive contaminants. The resources are significant for their early waste management efforts that installed protections between ORNL and nearby waterways. Although the dam has undergone significant modifications since 1980, it still functions in the same place and in the same way as it has since it was installed in 1943. As such, the location, setting, feeling, and association of the structure remain intact. These are the aspects most essential to conveying its identity as a barrier between (contaminated) water and clean water sources (the Clinch River). In addition, the resource has undergone no alterations since the previous surveys. Furthermore, the lake has undergone no changes since its installation and as such, retains its integrity of location, design, setting, materials, workmanship, feeling, and association. As such, CRA concurs with the previous studies that the White Oak Creek Dam and Lake, Buildings 7813 and 7846, are individually eligible for listing in the NRHP under Criterion A for their association with early waste management efforts related to nuclear science development. 


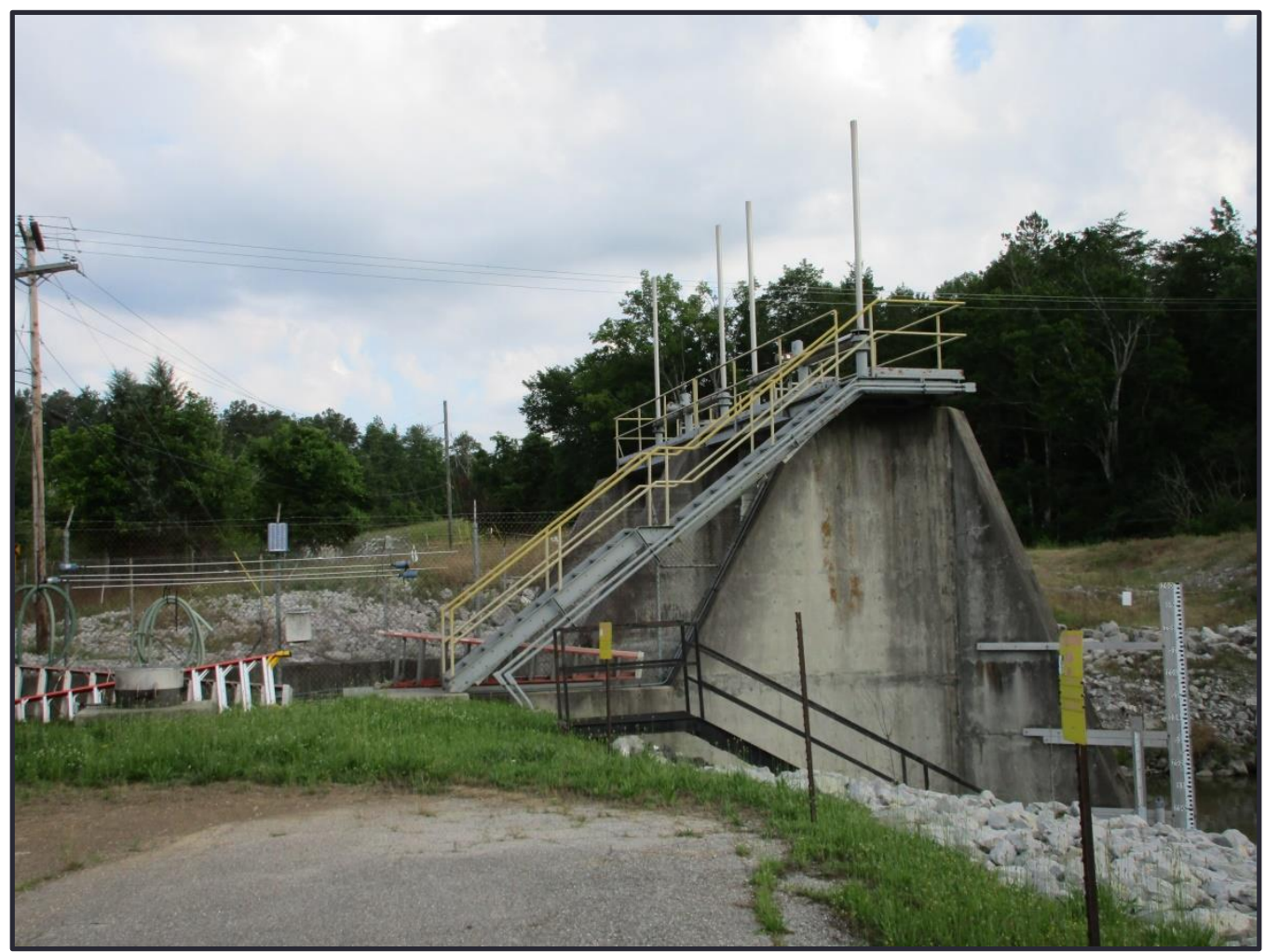

Figure 467. Overview of west and south elevations of Building 7813, which is White Oak Creek Dam.

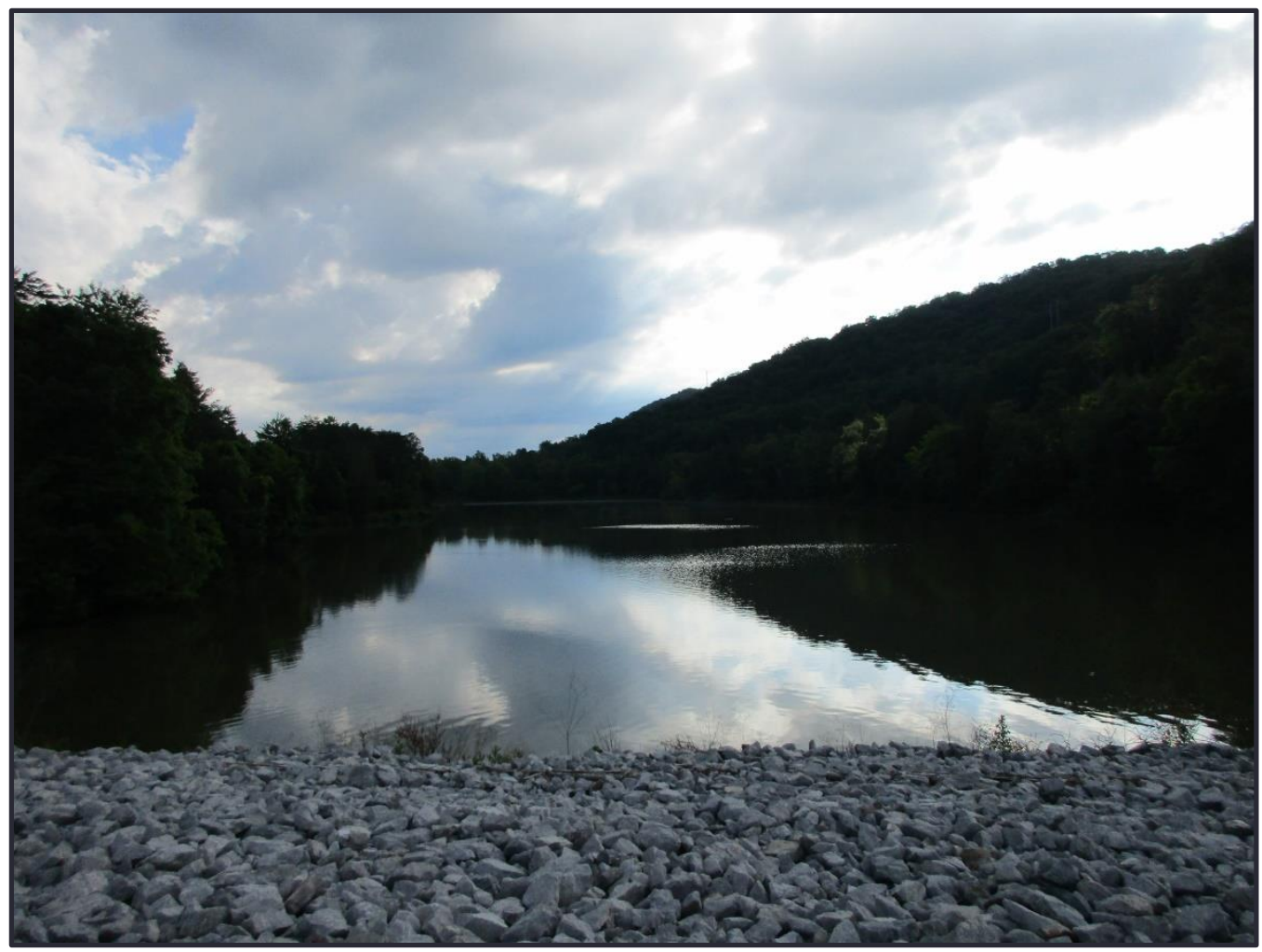

Figure 468. Overview of Building 7846, White Oak Lake, looking south. 


\section{BUILDING NAME}

Radioactive Waste Storage

DATE OF CONSTRUCTION

1975

DOE OFFICE RESPONSIBLE

EM (UCOR)

Figure 469. Overview of Building 7824.

\section{NRHP ELIGIBILITY}

Not Eligible

\section{DESCRIPTION}

Building 7824 is a one-story, front-gable, steel-frame structure clad in corrugated metal. The east elevation features a large roll-up garage door and two single-light metal doors sheltered with flat metal awnings (Figure 469 and 470). The windows on the building feature two-light, sliding sashes. Two window bays punctuate the east elevation and three window bays are located along the south elevation. The north elevation is void of fenestration.

\section{NATIONAL REGISTER EVALUATION}

Building 7824 was constructed in 1975 as a storage facility for radioactive waste. The building was previously surveyed in 1994 and recommended as a not eligible for listing in the NRHP under Criterion A, B, or C (Carver and Slater 1994). The building retains a majority of its historic materials, as well as its form and massing; however, it lacks the necessary significance to warrant listing in the NRHP. As a storage facility, Building 7824 provided support for work that furthered ORNL's mission in nuclear science during the Cold War era. However, the building is not the single location most importantly associated with a scientific achievement, scientist, or other event or person of historic significance to merit listing in the NRHP under Criterion A or B. Furthermore, the building lacks notable architectural elements that would warrant individual listing in the NRHP under Criterion $\mathrm{C}$. In addition, the building lacks exceptional importance that would elevate its significance and qualify it as eligible for listing in the NRHP even though it has yet to reach the 50-year mark for historic resources. The building is not located in a NRHP-eligible historic district. As such, Building 7824 does not warrant listing in the NRHP under Criterion A, B, C, or Criteria Consideration G. 


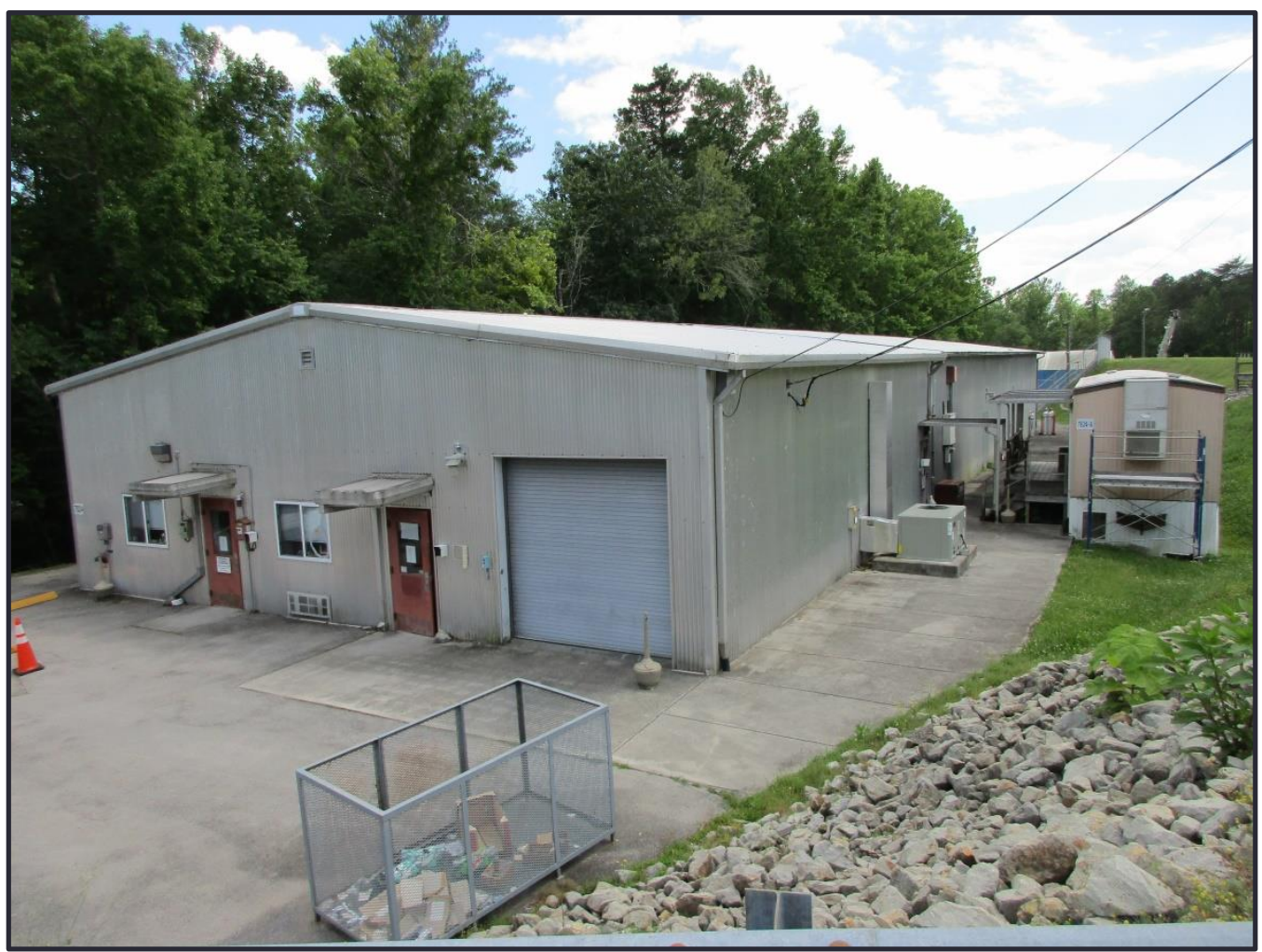

Figure 470. Overview of north and east elevations of Building 7824. 


\section{1}

\section{BUILDING NAME}

Field Office \& Compactor Facility

\section{DATE OF CONSTRUCTION}

1955

\section{DOE OFFICE RESPONSIBLE}

EM (UCOR)

Figure 471. Overview of Building 7831.

\section{NRHP ELIGIBILITY}

Not Eligible

\section{DESCRIPTION}

Building 7831 is a two-story, front-gable, steel-frame structure with a one-story portion. The building is set on a concrete foundation (Figures 471 and 472). The two-story section features a low-pitch, side-gable roof while the one-story portion features a low-pitch shed roof. The roofs are clad in metal panels. Windows along the building exhibit two-light, sliding sashes and pedestrian entries exhibit one-light, metal doors. The building features a wide roll-up garage door along the one-story portion of the east elevation. Located to the right of the garage door, along the first story is a pedestrian entry sheltered by a flat, metal awning and two window bays. An exterior metal staircase leads to a pedestrian entry on the second story of the east elevation. The north elevation is punctuated by a pedestrian entry and window bay along the first story; both bays are sheltered by a partial-width, flat-roof, porch supported with metal posts. A window bay is located along the second story. A small shed awning with steel posts is located on the south elevation; the elevation features no fenestration. The west elevation is void of fenestration.

\section{NATIONAL REGISTER EVALUATION}

Building 7831 was constructed in 1955 as a solid waste compactor facility. The building was previously surveyed in 1994 and recommended as a not eligible for listing in the NRHP under Criterion A, B, or C (Carver and Slater 1994). The building retains a majority of its historic materials, form and massing; however, it lacks the necessary significance to warrant listing in the NRHP. As a utility/maintenance facility, Building 7831 provided utilitarian services in support of ORNL's mission in nuclear science during the Cold War era. However, the building is not the single location most importantly associated with a scientific achievement, scientist, or other event or person of historic significance to merit listing in the NRHP under Criterion A or B. Furthermore, the building lacks notable architectural elements that would warrant individual listing in the NRHP under Criterion $\mathrm{C}$. The building is not located in a NRHP-eligible historic district. As such, Building 7831 does not warrant listing in the NRHP under Criterion $A, B$, or $C$. 


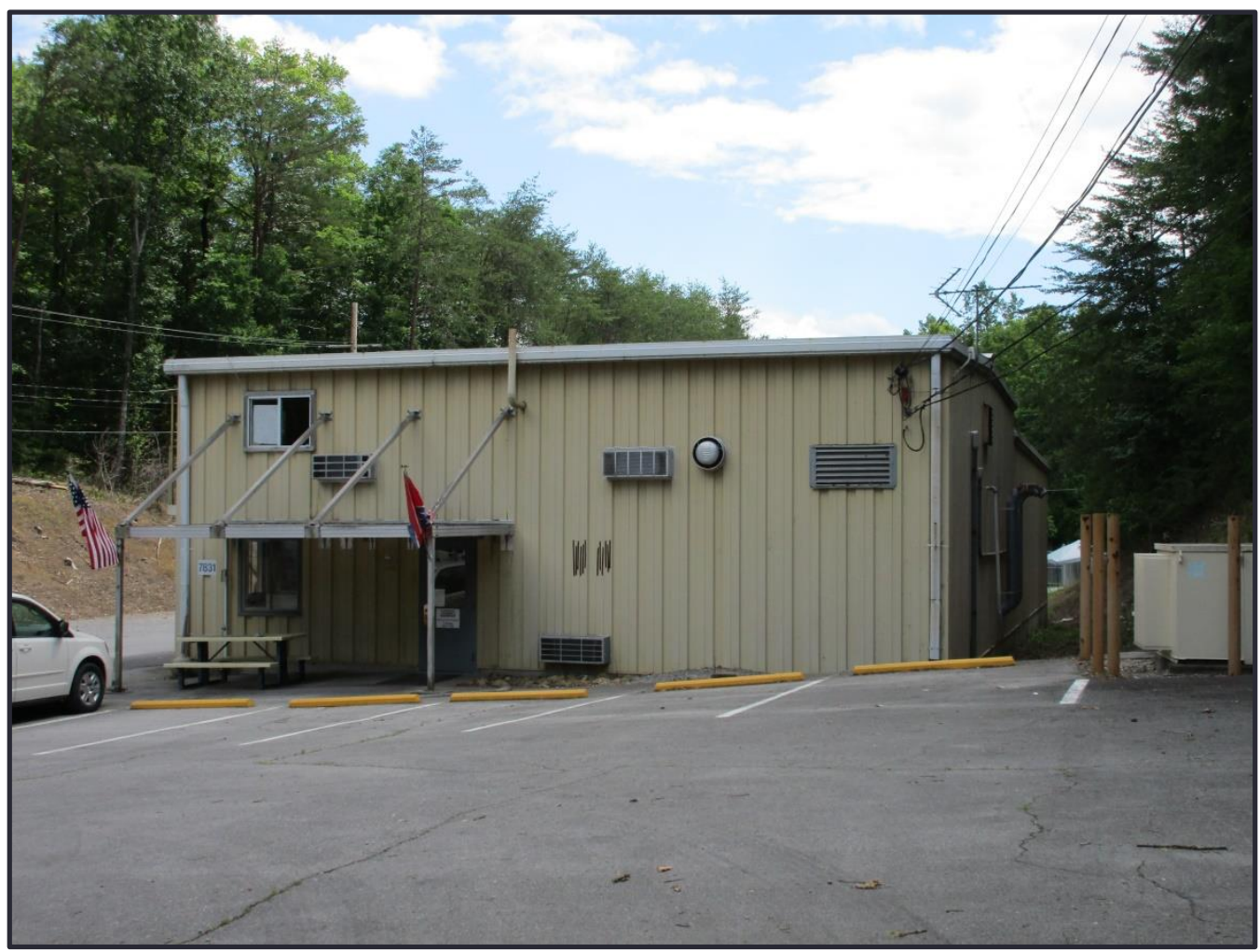

Figure 472. Overview of north and west elevations of Building 7831. 


\section{AREA}

\section{CONTRIBUTING TO HFIR/REDC FACILITY}

Building 7900

Building 7901

Building 7911

Building 7920

Building 7930

\section{NOT ELIGIBLE}

Building 7903

Building 7910

Building 7914

Building 7914A

Building 7915

Building 7916

Figure 473. Plan View of 7900 Area. 
This page intentionally left blank 


\section{AREA}

\section{DISTRICT NAME}

7900 Area of ORNL

\section{DATE OF CONSTRUCTION}

1962-2011

\section{NRHP ELIGIBILITY}

Part Contributes to NRHP-Eligible

HFIR/REDC Facility

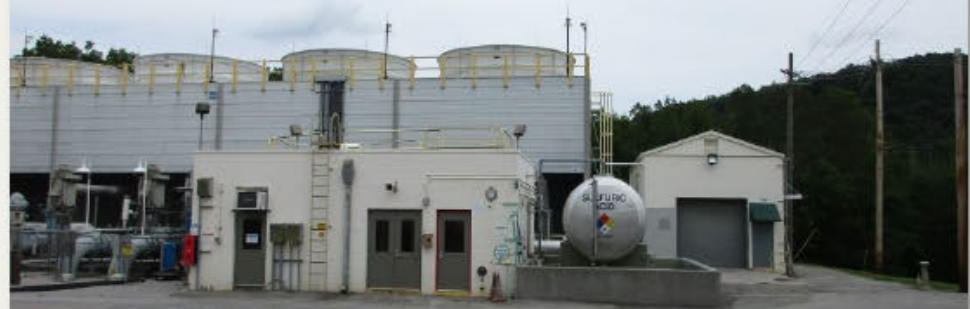

\section{DESCRIPTION}

The 7900 Area, containing the High Flux Isotope Reactor (HFIR), Radiochemical Engineering Development Center (REDC), and associated buildings, is located south of the main portion of the ORNL campus, south of Melton Valley Drive and east of Evacuation Road (Figures 473-475). Access to the HFIR/REDC area is restricted and controlled by a sentry post, Building 7955 , at the entrance to the 7900 Area from HFIR Access Road. Twenty-eight buildings and several modular trailers are located within the 7900 Area. Only 11 of these were constructed before 1980, and thus were included in this survey. Paved access roads and a series of sidewalks provide access within the 7900 Area. The core of the HFIR/REDC facility and the buildings that most closely support it are located in the eastern half of the 7900 Area.

\section{NATIONAL REGISTER EVALUATION}

As the home to the only remaining active reactor at ORNL, the 7900 Area reflects continuous use of the HFIR facility since its original construction in 1965, as well its overlapping missions with the REDC since its development in 1966 and 1968. In 1994, the HFIR was determined to be ineligible for listing in the NRHP due to age and because it was not the first of its kind to be developed in the United States (Carver and Slater 1994:324). Thomason and Associates did not assess the eligibility of the entire 7900 Area in 2004. In 2015 they focused on Buildings 7900,7920 and 7930 , which were recommended eligible as the HFIR complex (Thomason and Associates 2004 and 2015). While these previous assessments have been focused on the operation and support of HFIR, they have not recognized the significance of the REDC. As the national center of production, storage, and distribution of transuranium elements for the DOE's heavy-element research programs, the REDC reflects significant contributions on its own as a part of the Chemical Technology Division and its descendent divisions. The HFIR has remained in operation under the Research Reactors Division and its descendant organizations. Both the HFIR and REDC have their own missions, however, they also support each other's missions and collectively are a significant grouping within the ORNL campus. Therefore, in order to reflect the significant role of the synergistic and inter-dependent relationship between the two facilities, CRA recommends that the buildings most closely related to the operation of HFIR and REDC qualify for listing in the NRHP as a part of the HFIR/REDC facility, which was important in the advancement of ORNL's mission in nuclear science, isotope research, and health and medicine, key fields of study during the Cold War era. While the 7900 Area includes the operation and support of the HFIR and REDC, only five buildings-Buildings 7900, 7901, 7911, 
7920 and 7930-are most closely associated with the HFIR and REDC. Additionally, construction in the 7900 Area in the 1980s through today, including the addition of several modular office buildings (identified as trailers in FIMS) have diminished the integrity of the entire 7900 Area so that it is no longer a cohesive, distinct entity with a singular focus on the operation of HFIR and REDC. Therefore, CRA recommends that only the portion of the 7900 Area that contains the five historic buildings most closely associated with HFIR and REDC contributes to the NRHP-eligible HFIR/REDC facility.

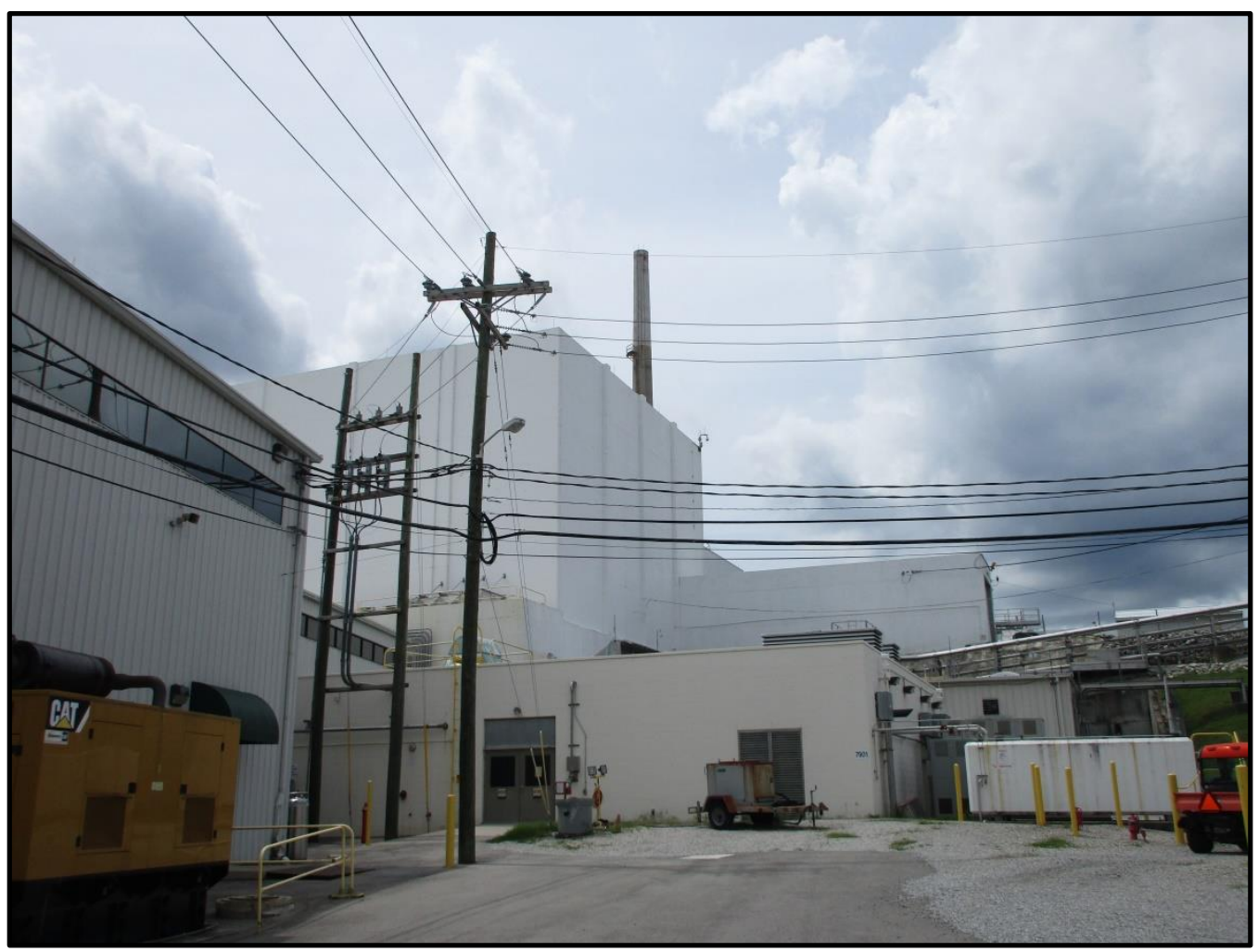

Figure 475. View of the 7900 Area looking towards Buildings 7900 and 7901. 
the south elevation of Building 7900 (Figure 482). This south elevation of this wing features two entries with single-light steel doors sheltered by cloth awnings on the basement. Four two-over-one-light aluminum awning windows are located on the first floor of the southwest elevation of the addition. Building 7970A attaches Buildings 7970 and 7972 to the south elevation of Building 7900 (Figure 483).

Interior: Building 7900 houses the reactor and pools set within a three-story open tower as well as a series of control rooms, offices, and laboratory space. Corridors on the first and second floor feature a combination of concrete and tile floors, concrete block walls, and acoustic tile ceilings.

The first floor of Building 7900 features the reactor and its associated pools (Figures 484 and 485). The remainder of the first floor is comprised of laboratory and research space, including hot cells for radiological research (Figure 486). The Cryogenics Laboratory addition features a central corridor that provides access to various offices; this wing has been extensively renovated (Figure 487). Stairwells with original steel railing and concrete steps and a freight elevator provide access to the levels of Building 7900 (Figure 488 and 489).

A large portion of the second floor is open to the reactor bay below. A corridor on the second floor of Building 7900 provides access to an auxiliary control room (Figure 490). The third floor is also open to the reactor room. A series of canted plate glass windows in the third story corridor provide a view to the reactor room below as well as an exhibit space (Figure 491). The control room is also located on the third floor (Figure 492). Restrooms in the core of Building 7900 reflect a variety of renovations, though at least one restroom retains original ceramic tile and glazed concrete block walls (Figure 493).

\section{NATIONAL REGISTER EVALUATION}

Along with Buildings 7901 and 7911 , Building 7900 represents the operation and support of the HFIR. The HFIR missions frequently overlap with the Radiochemical Engineering Development Center (REDC), comprised of the Transuranic Facility (Building 7920) and the Thorium-Uranium Recycle Facility (Building 7930). Contributing secondary resources associated with the facility include Buildings 7901 and 7911.

Construction began on Building 7900, the HFIR, in 1961, and criticality was reached in August of 1965. This beryllium-reflected, light-water-cooled and moderated, flux trap reactor uses highly enriched U-235, a naturally occurring isotope of Uranium, to produce californium and other superheavy elements (Thomason and Associates 2015:55).

With its debut, the HFIR once again brought the most intense neutron source for research in the world to ORNL. This new intensity, combined with the groundbreaking instrumentation at the four HFIR beam ports, allowed new experiments, and some of the instruments used were among some of the most unique in the world. Given the success of HFIR, by the early 1980s, ORNL and DOE assisted in the establishment of the National Center for Small-Angle Scattering Research with the National Science Foundation (NSF), to design and operate a NSFfunded small-angle scattering (SANS) facility at the HFIR (Johnson and Schaffer 1992:231).

The HFIR continued operation until 1985. In November of 1986, it was shut down for more than three years due to safety and management concerns. The HFIR was restarted in 1989 following retrofits and upgrades (Thomason and Associates 2015: 55). Today, HFIR is a DOE Office of Science User Facility. It remains one of the world's very few sources of the radioisotope californium-252, used in industry and medicine. For five decades, HFIR has provided international researchers with unique irradiation capabilities. Additionally, HFIR was used in the assassination investigation of President John F. Kennedy, helped prove that President Zachary 
Taylor died of natural causes, and most recently, produced the radioisotope berkelium-249, used to discover and confirm the existence of Tennessine, element 117 (ORNL 2014).

In November 2014, the ANS named the HFIR a Nuclear Historic Landmark. At the time of the designation, ORNL Director Thom Mason said, "This designation from the ANS recognized HFIR's role in the history of the nuclear age, but it also speaks to the excellence of its design and operation...HFIR retains one of the world's most capable reactor-based neutron science, radioisotope production, and materials irradiation facilities, and we expect that to continue for many years," (ORNL 2014).

In 1994, Duvall \& Associates' survey of ORNL recommended HFIR was not eligible for listing in the NRHP because it was less than 50 years old and it was the third of its kind developed in the United States, so it was not a new significant technology (Carver and Slater 1994:324). The HFIR facility was not included in Thomason and Associates' 2004 survey updates (Thomason and Associates 2004). The 2015 survey update completed by Thomason and Associates recommended that Building 7900 and its associated laboratory facilities, Buildings 7920 and 7930, met NRHP Criterion A for significance in science and health/medicine as ORNL's only operating reactor and one of the world's most powerful and capable research reactors (Thomason and Associates 2015:55).

As a processing facility, and more specifically as a reactor, HFIR, Building 7900 , and its associated processing facilities and research/laboratory facilities (Buildings 7920 and 7930) and utilities and maintenance facilities (Buildings 7901 and 7911), offer one-of-a-kind capabilities that made scientific contributions of widelyrecognized importance including, but not limited to, the production of californium-252, death investigations of Presidents Kennedy and Taylor and the discovery of Tennessine, the most-recently identified element (ORNL 2014). In addition to these contributions to the broad patterns of American history, materials research conducted at the HFIR also guides energy needs including energy loss, liquid biomass transportation fuels, and energyefficient magnetic refrigerators (Thomason 2015:211) Thus, HFIR and its associated facilities are eligible for listing in the NRHP under Criterion A for contributions in nuclear science and health and medicine (Figures 494 and 495). The HFIR facility is not closely associated with a scientist of truly exceptional importance that would warrant listing under Criterion B. Building 7900, the lynchpin of the HFIR Facility, reflects a the tall, windowless, box form and its was one of three reactors featuring a similar design. Therefore, it lacks notable stylistic elements or innovative design features that would qualify it for listing in the NRHP under Criterion C. Thus, CRA recommends Building 7900 is eligible for listing in the NRHP as a contributing element of the HFIR/REDC facility under Criterion $A$. 


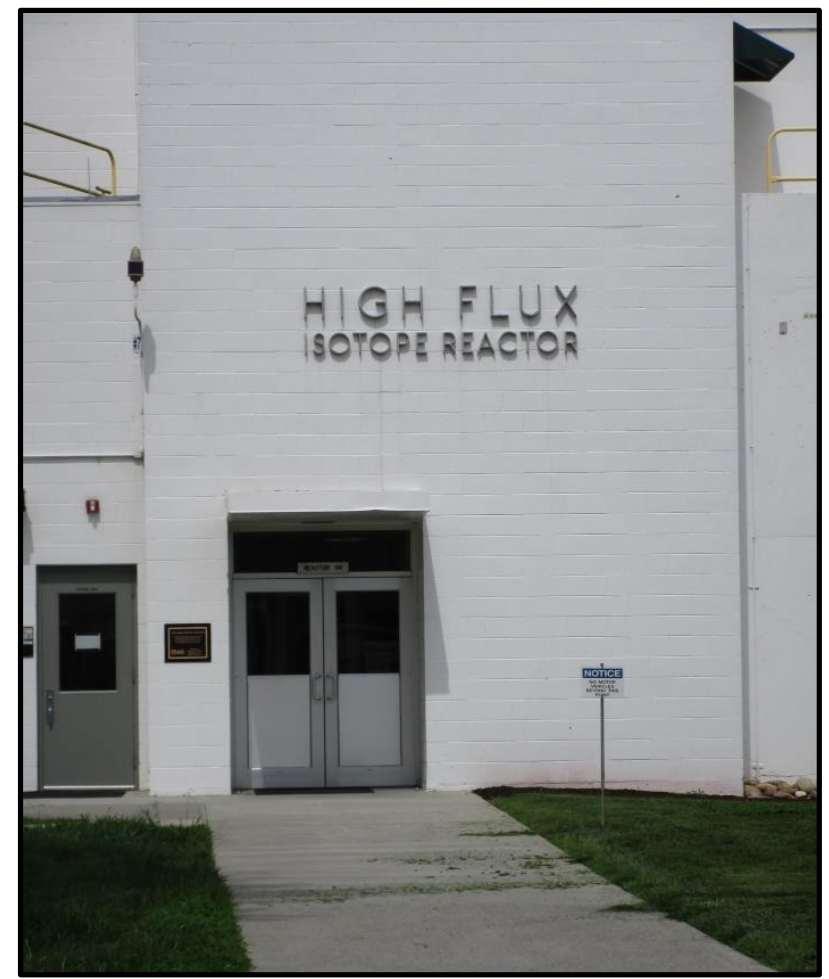

Figure 477. Façade entry on facade, or west elevation, of Building 7900.

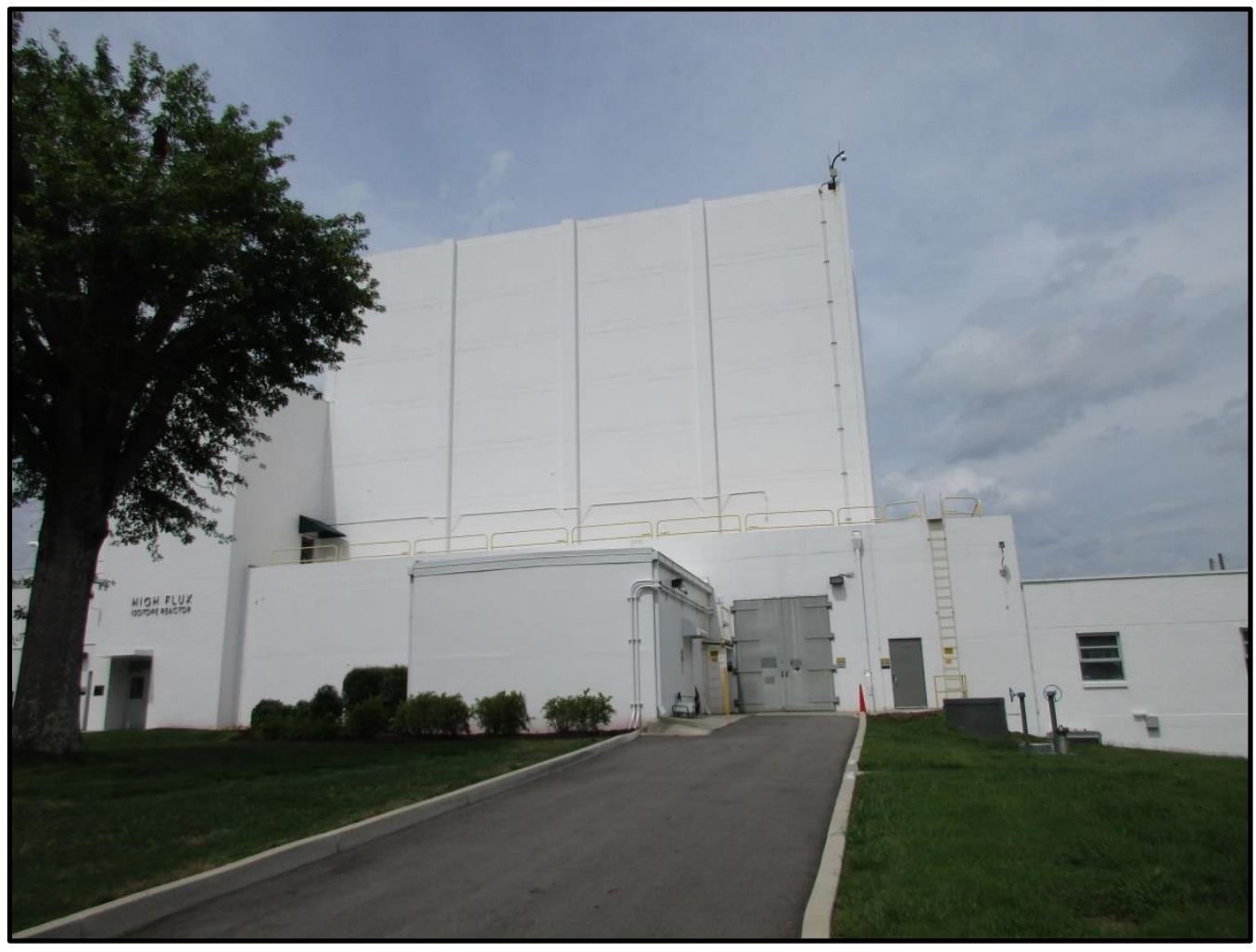

Figure 478. Garage bay on façade, or west, elevation of Building 7900. 


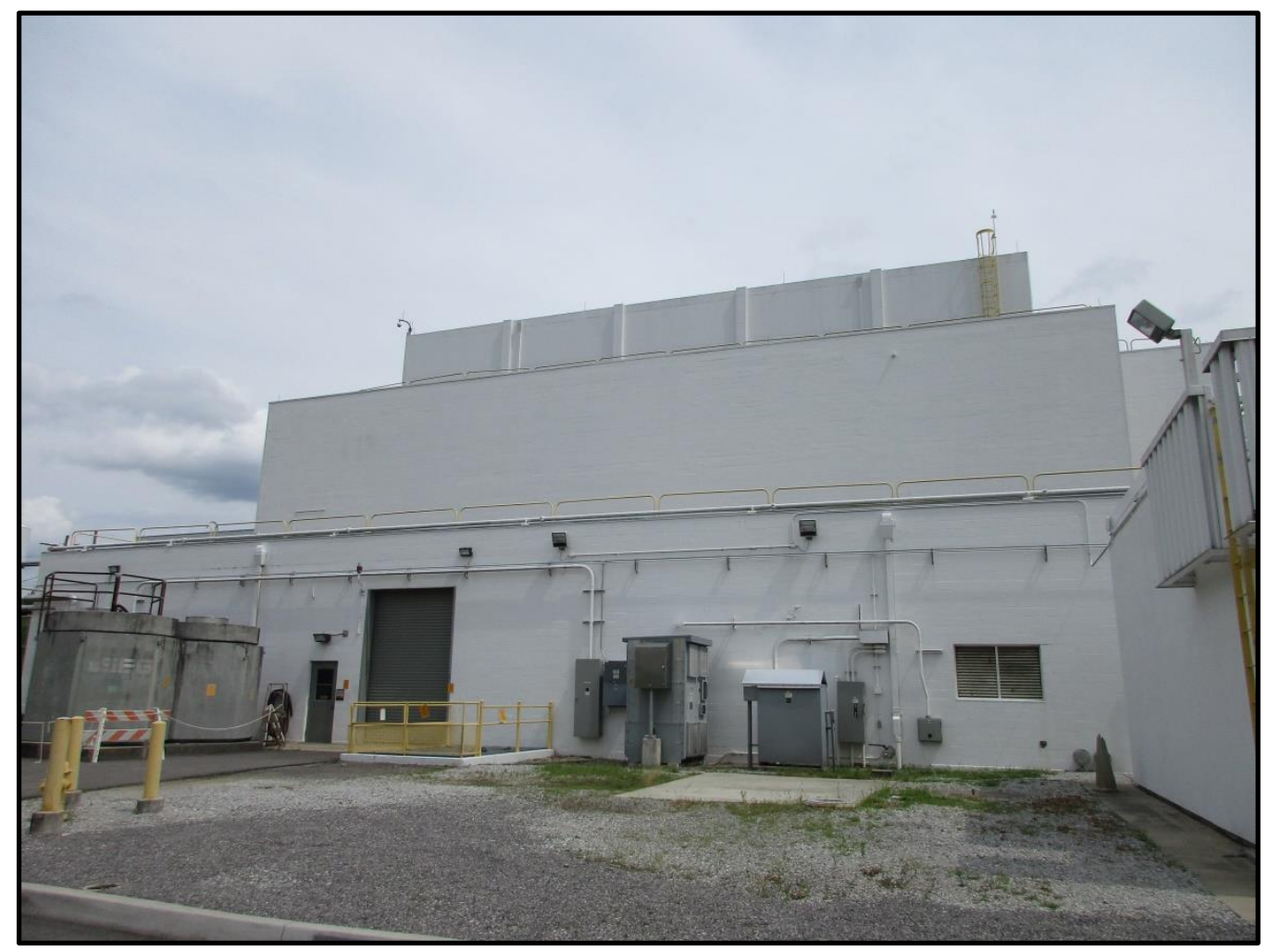

Figure 479. North elevation of Building 7900.

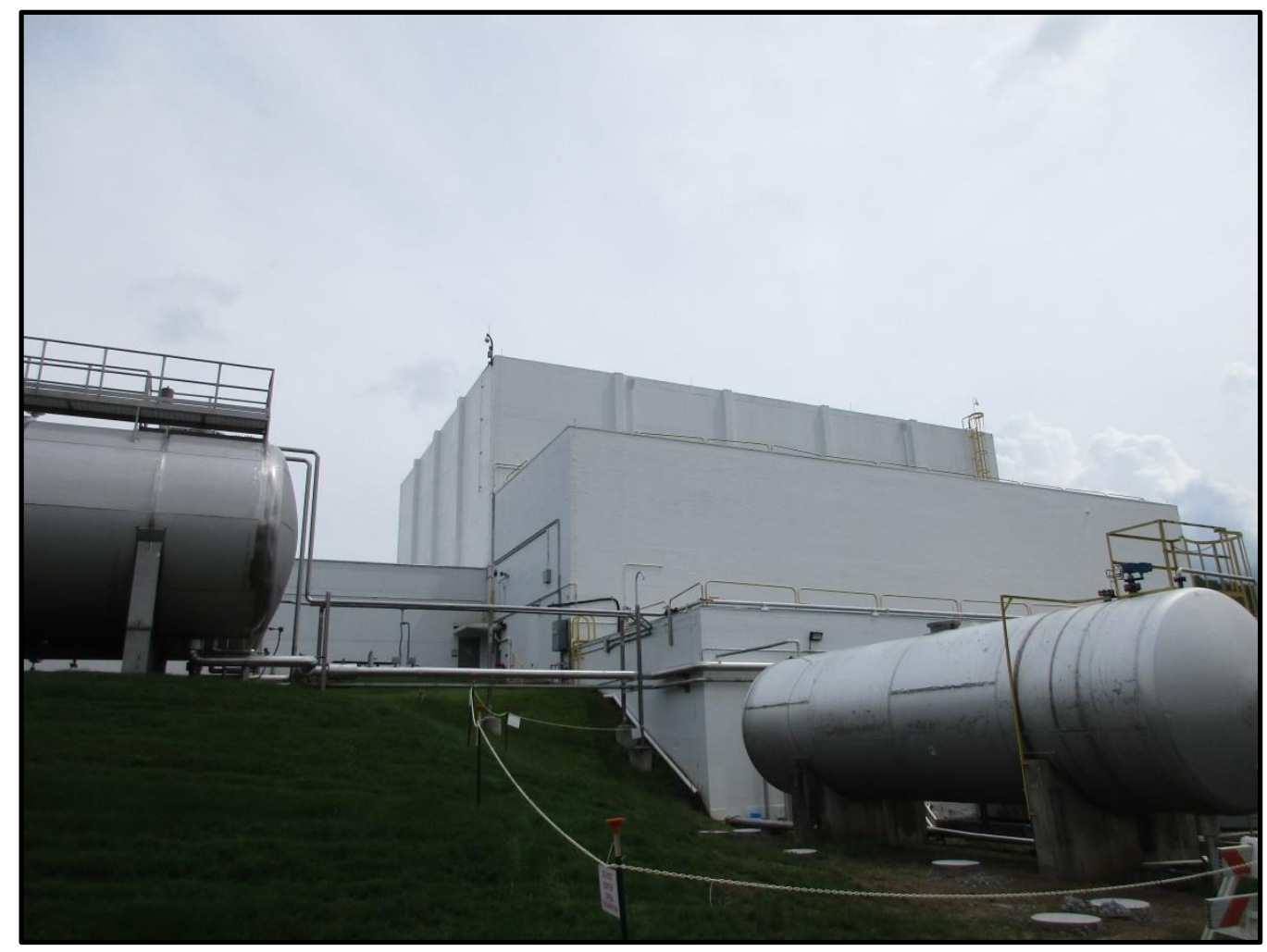

Figure 480. North and east elevations of Building 7900. 


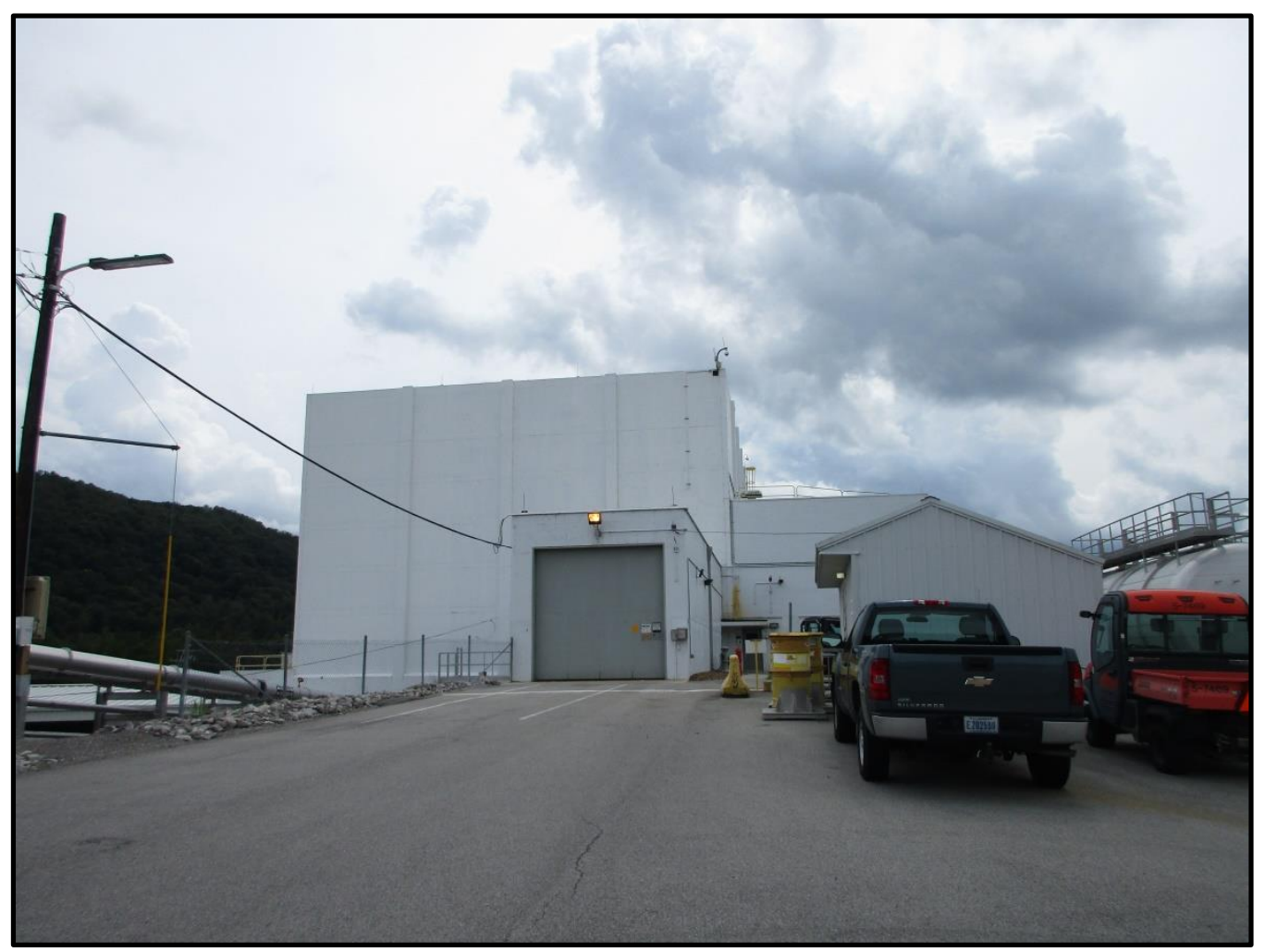

Figure 481. East elevation of Building 7900.

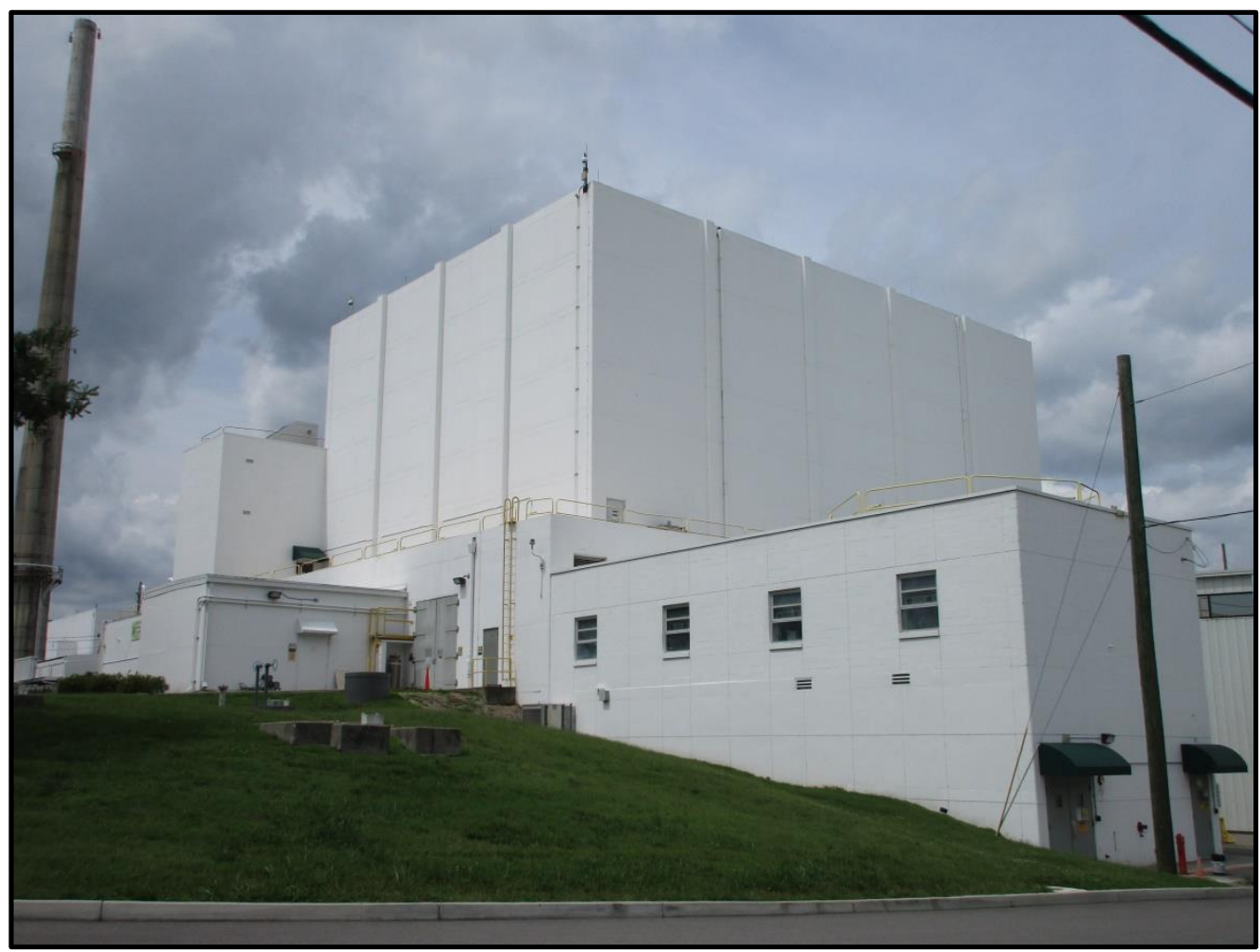

Figure 482. Cryogenics Laboratory addition to Building 7900. 


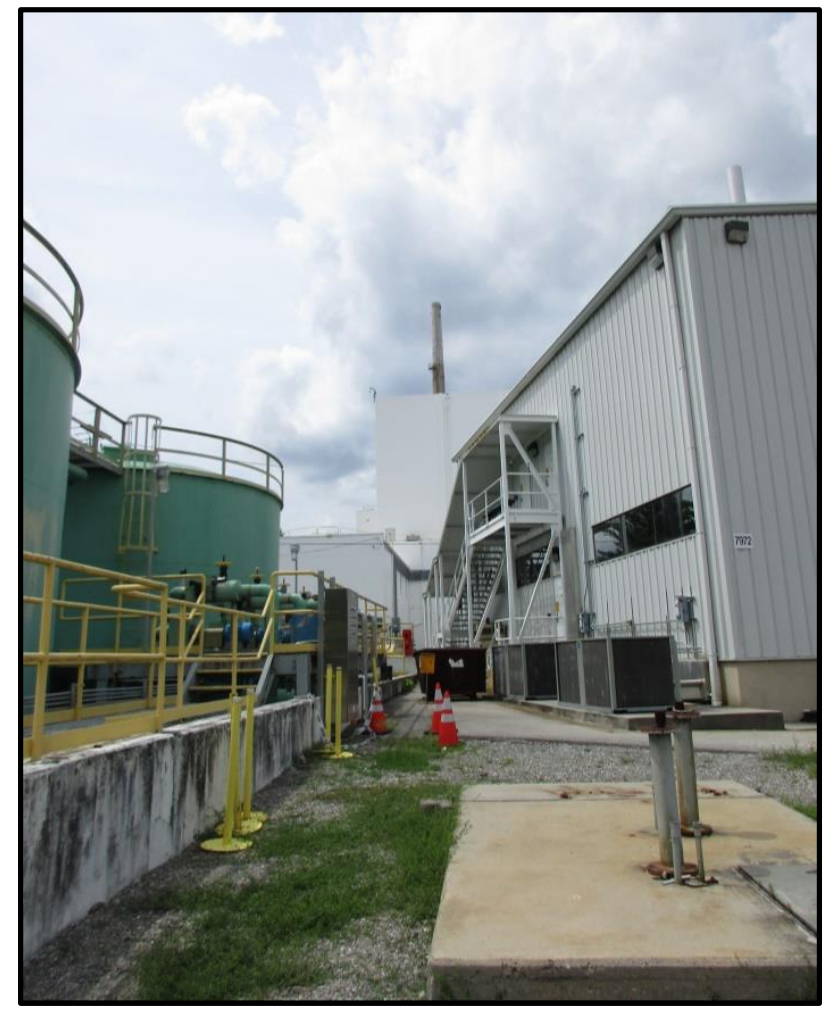

Figure 483. Buildings 7970 and 7972 and the south elevation of Building 7900 .

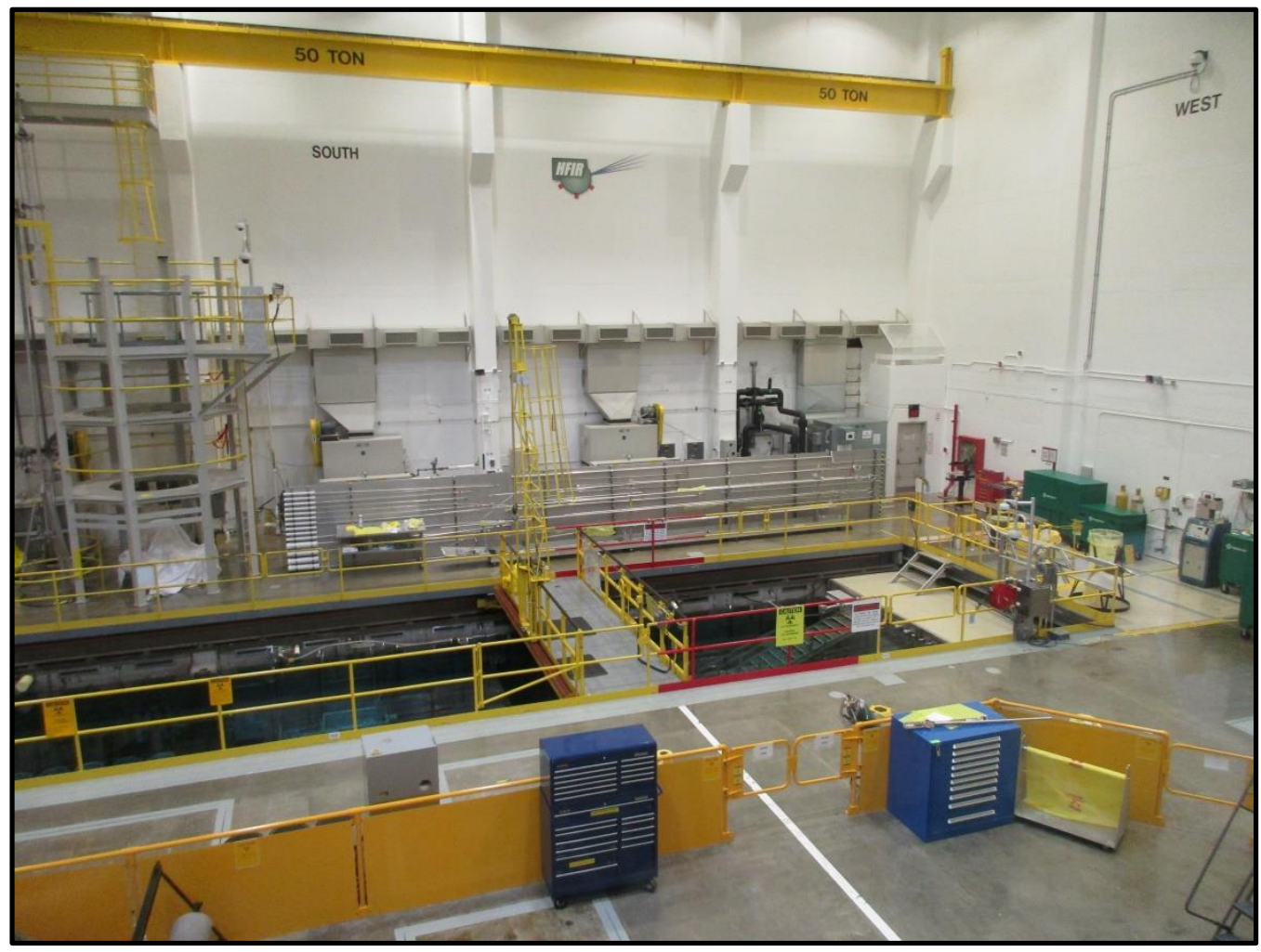

Figure 484. Pools for reactor on first floor of Building 7900. 


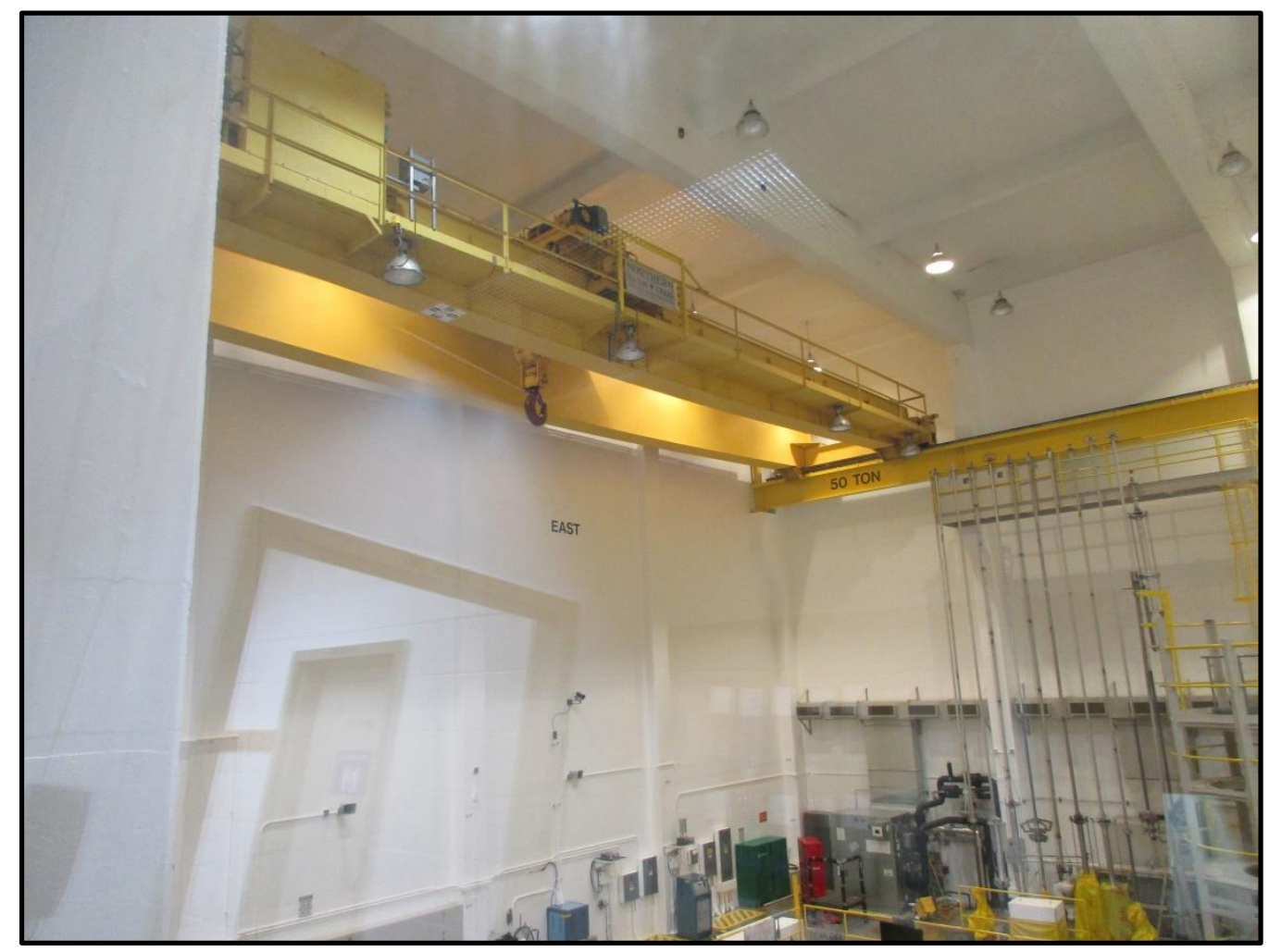

Figure 485. Crane above pools for reactor on first floor of Building 7900.

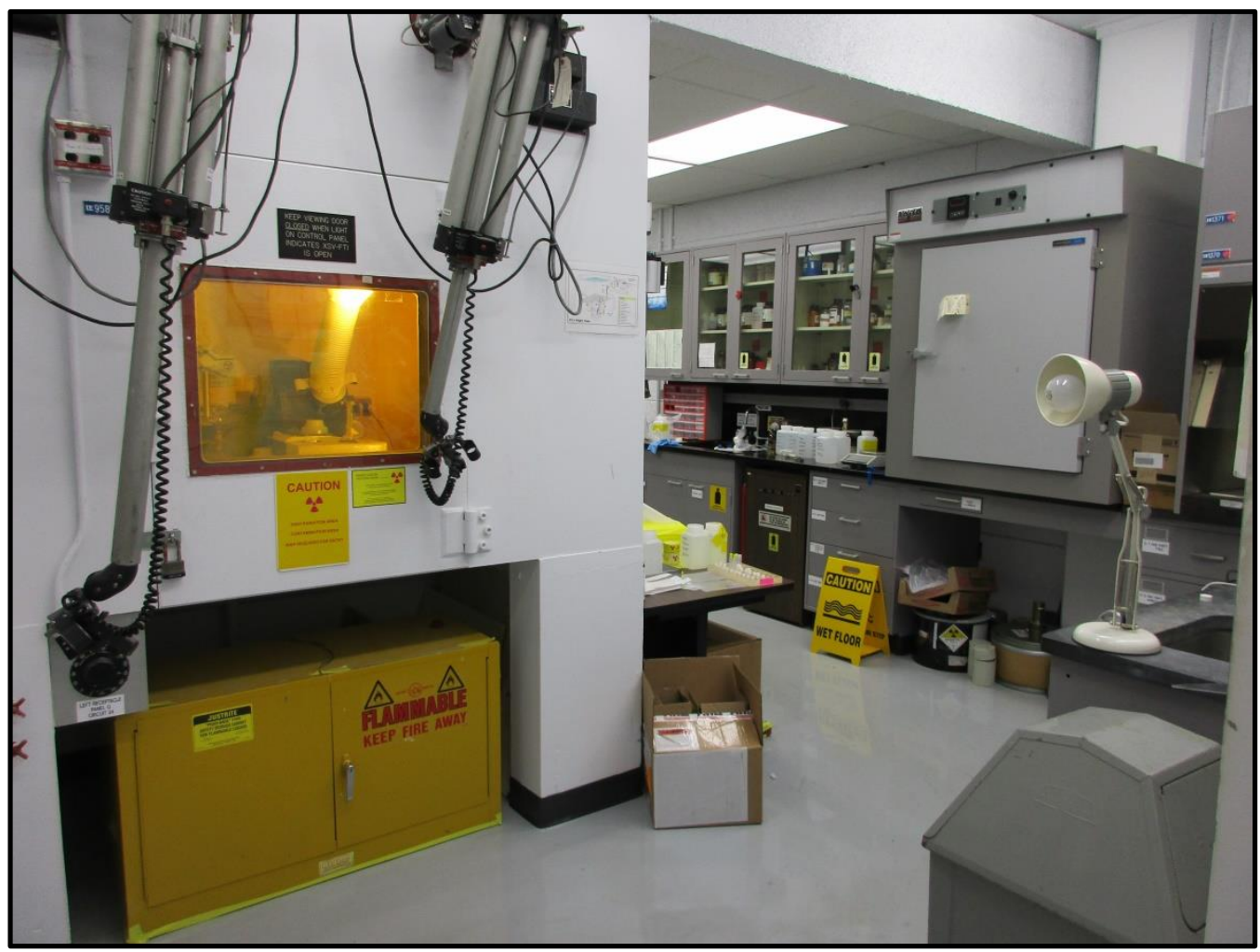

Figure 486. Hot cells on the first floor of Building 7900. 


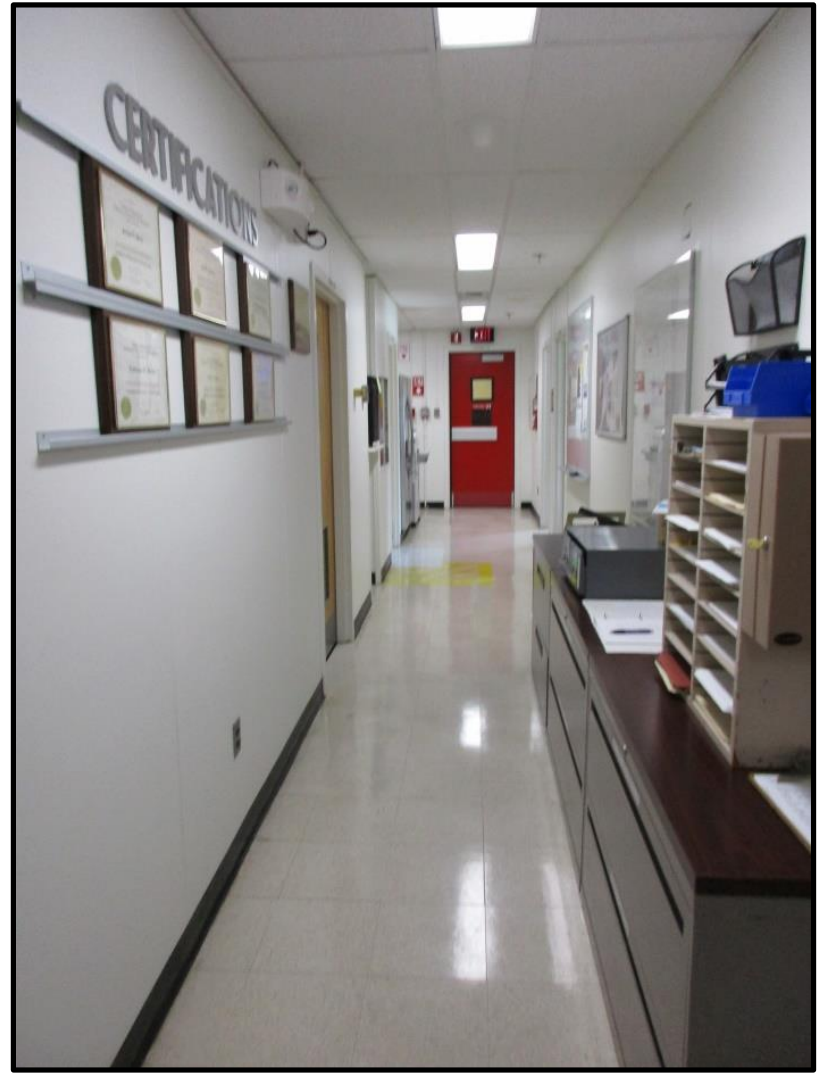

Figure 487. Corridor in Cryogenics Laboratory addition to Building 7900.

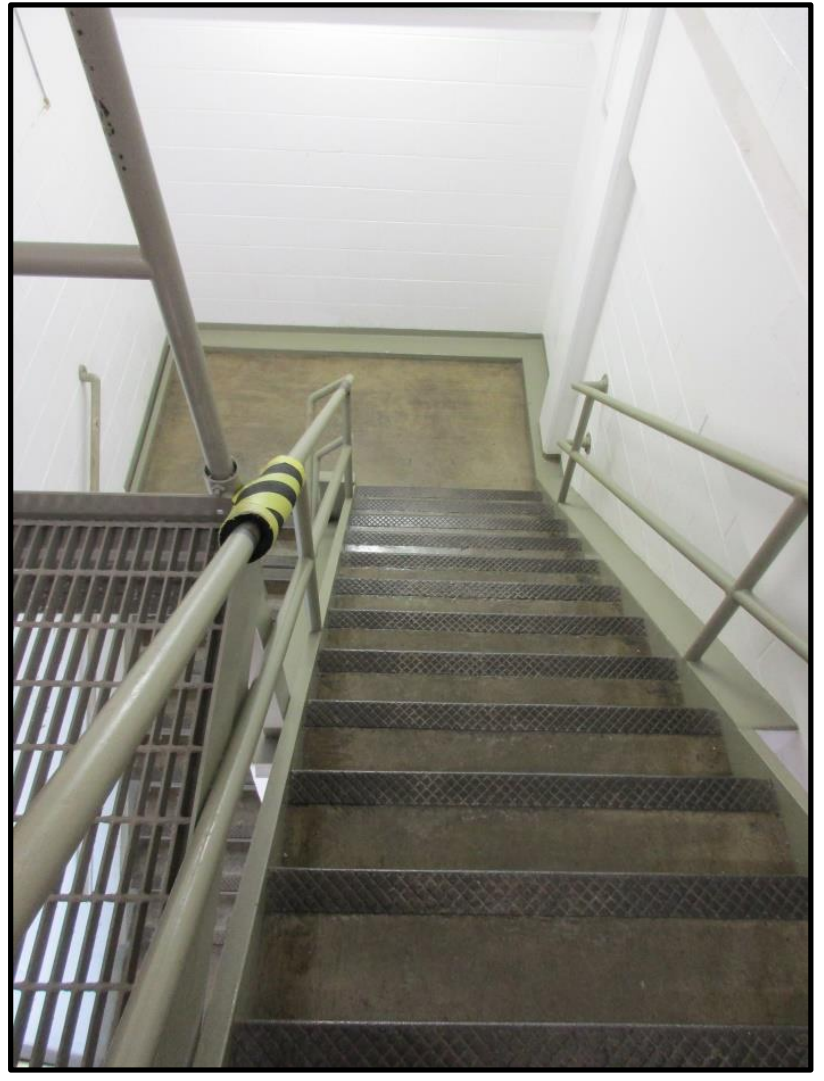

Figure 488. Stairwell in Building 7900. 


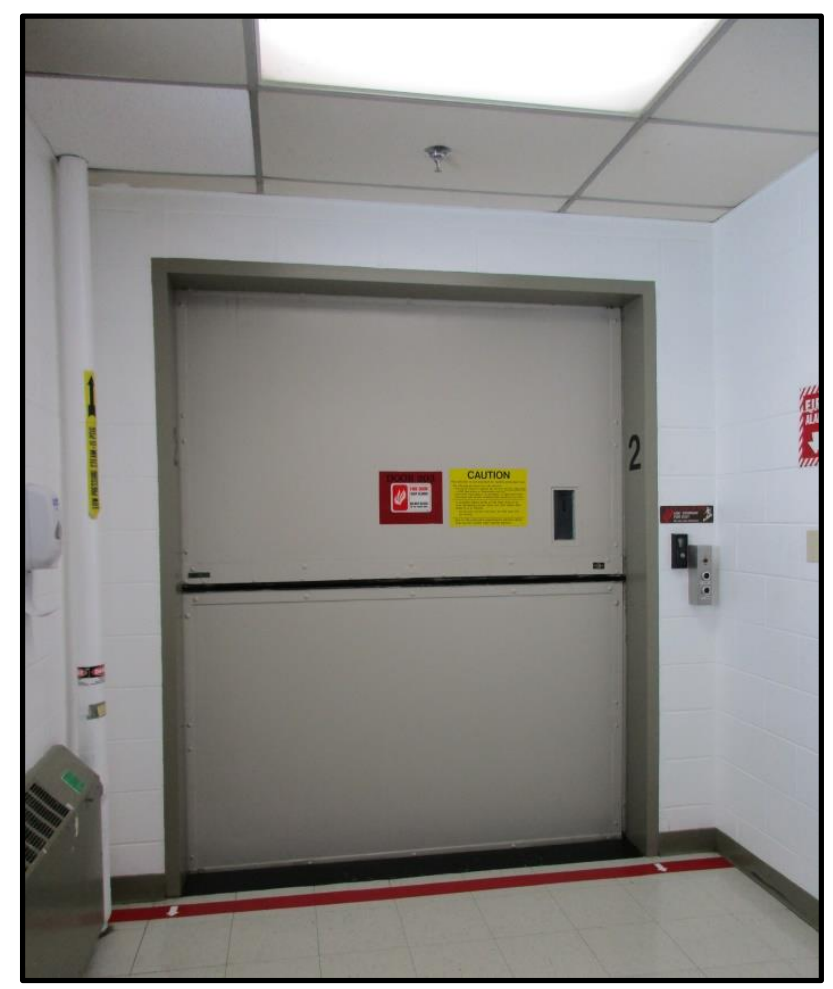

Figure 489. Freight elevator in Building 7900.

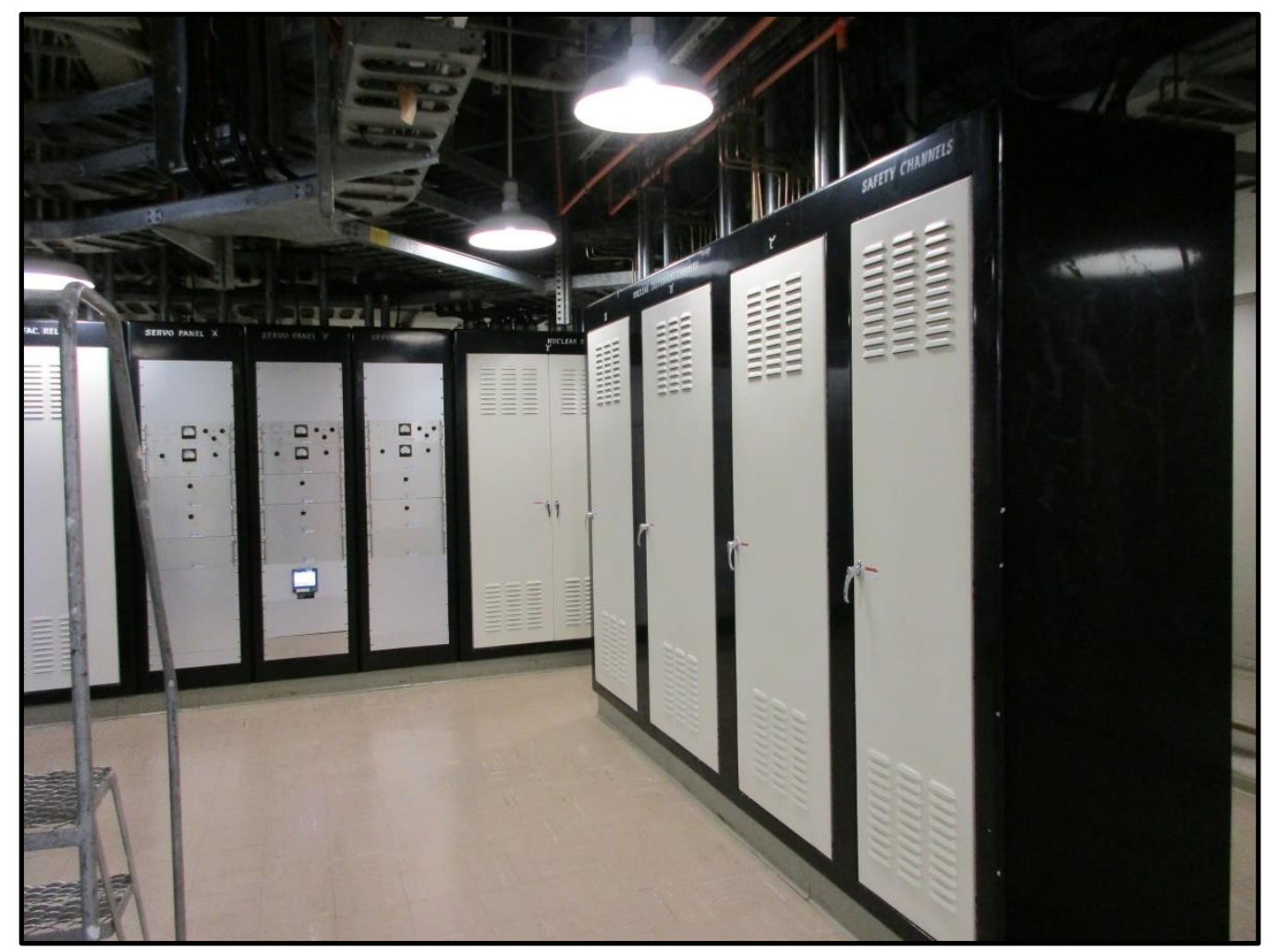

Figure 490. Auxiliary Control Room on second floor of Building 7900. 


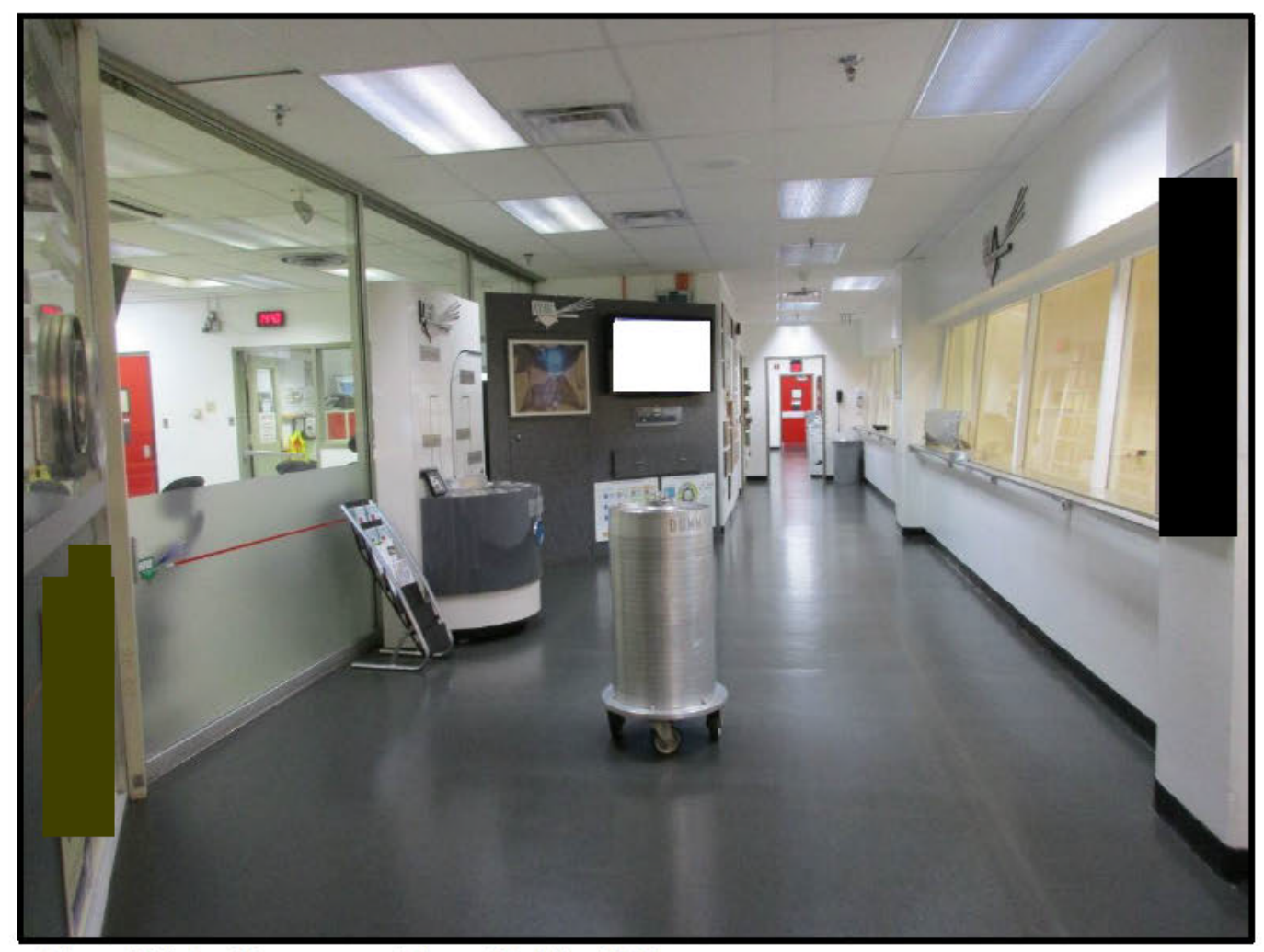

Figure 491. Corridor on second floor of Building 7900

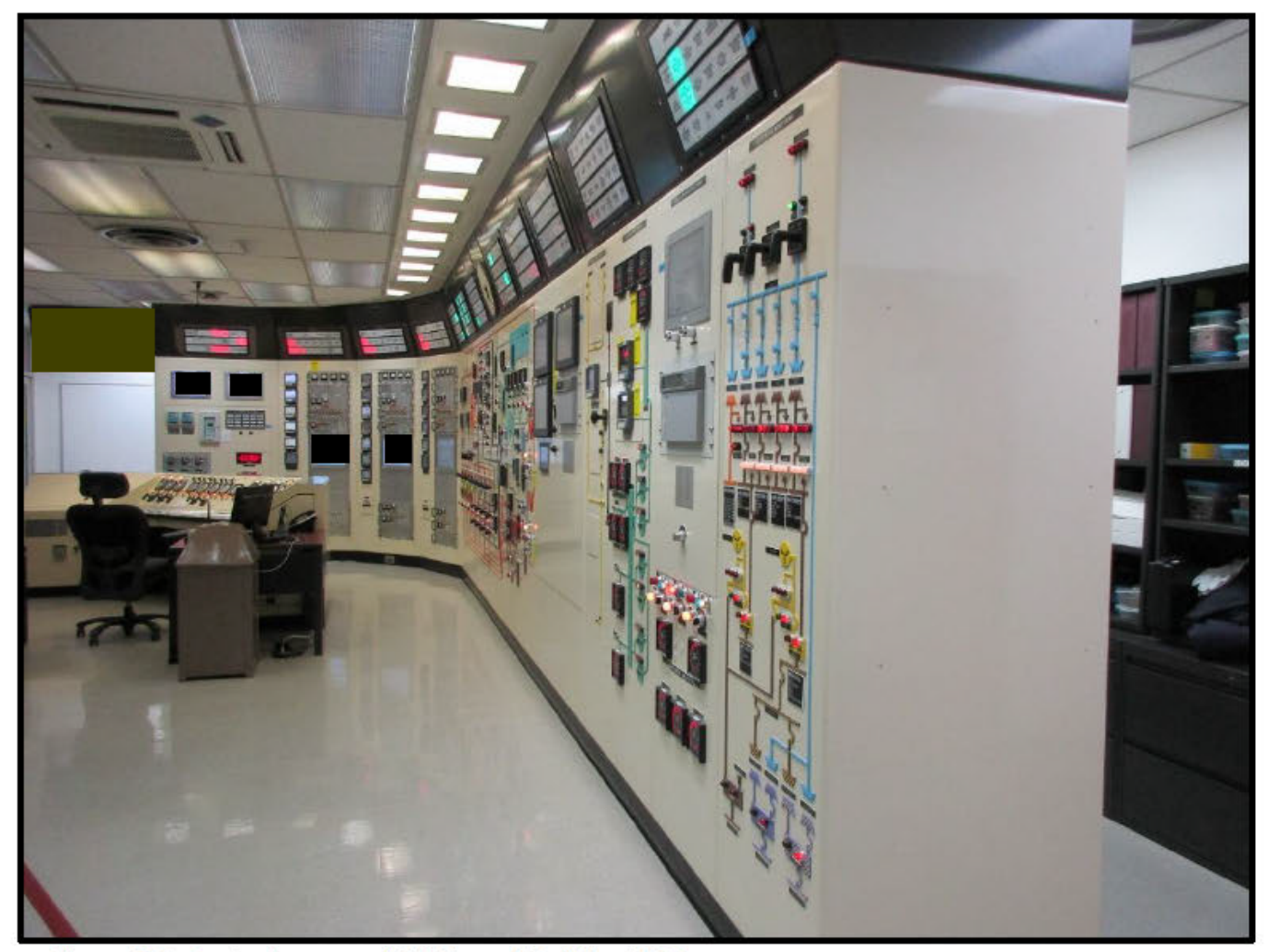

Figure 492. Control room on third floor of Building 7900 . 


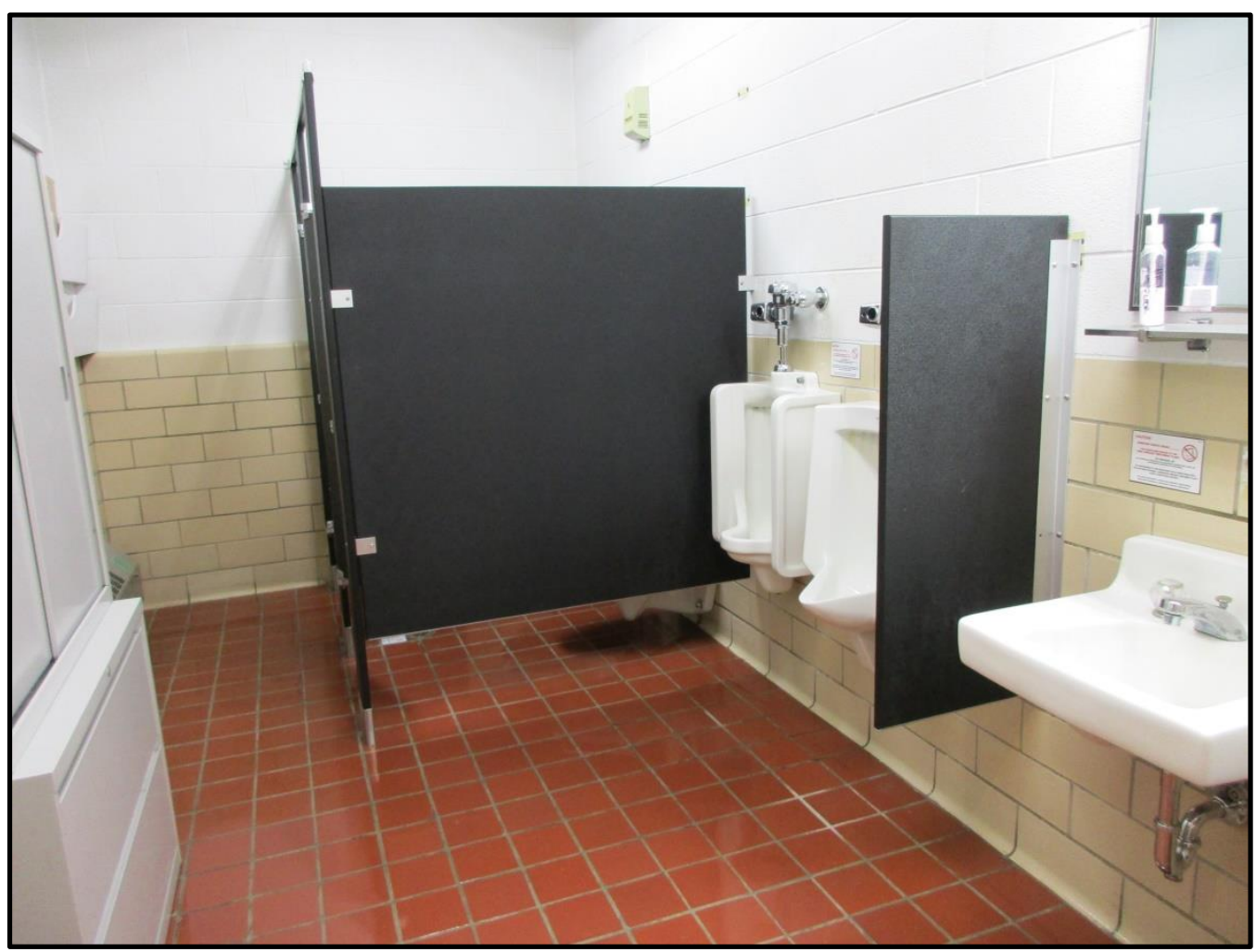

Figure 493. Restroom on second floor of Building 7900. 


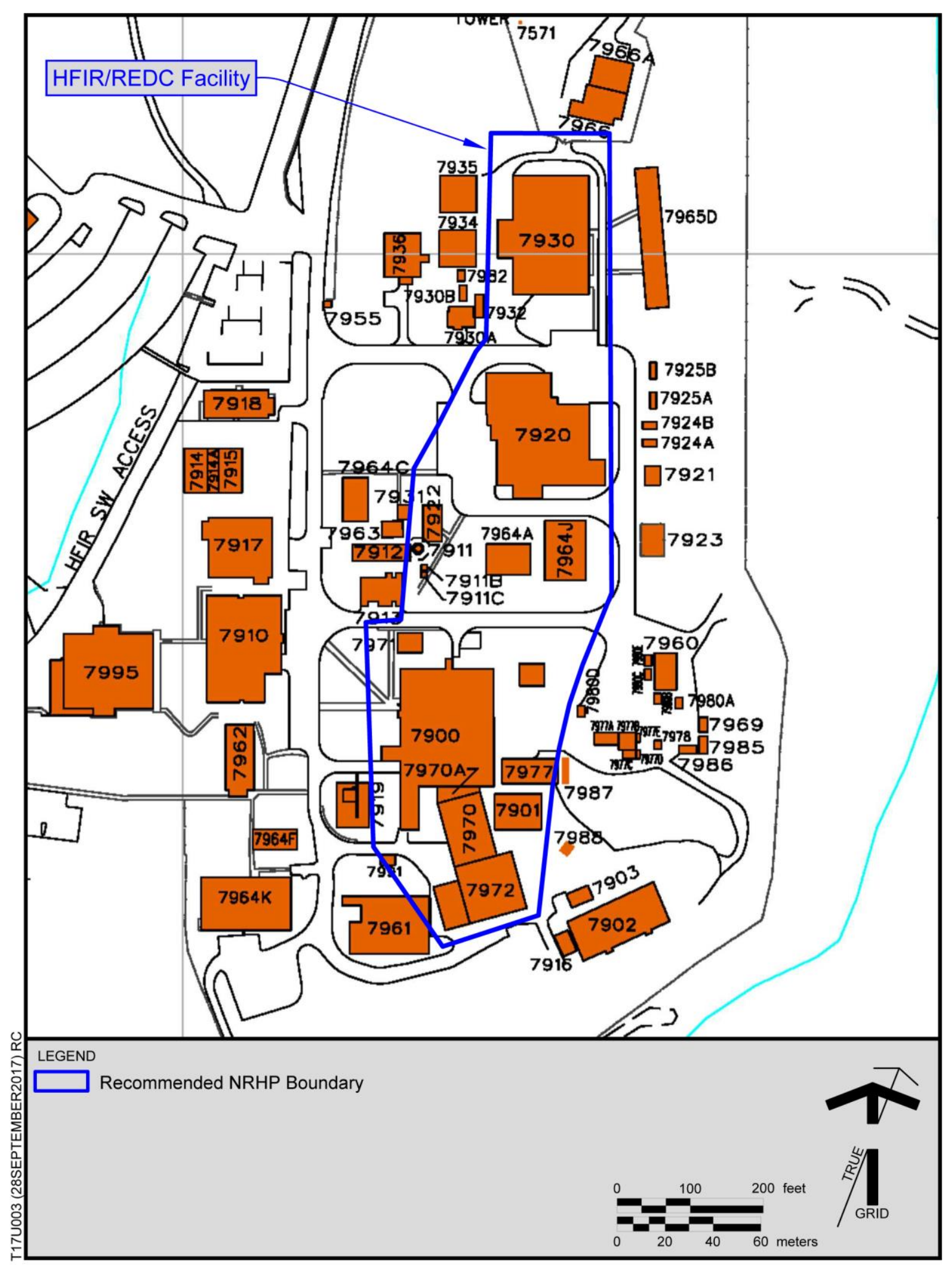

Figure 494. ORNL site plan depicting the recommended NRHP boundary of the HFIR/REDC Facility. 


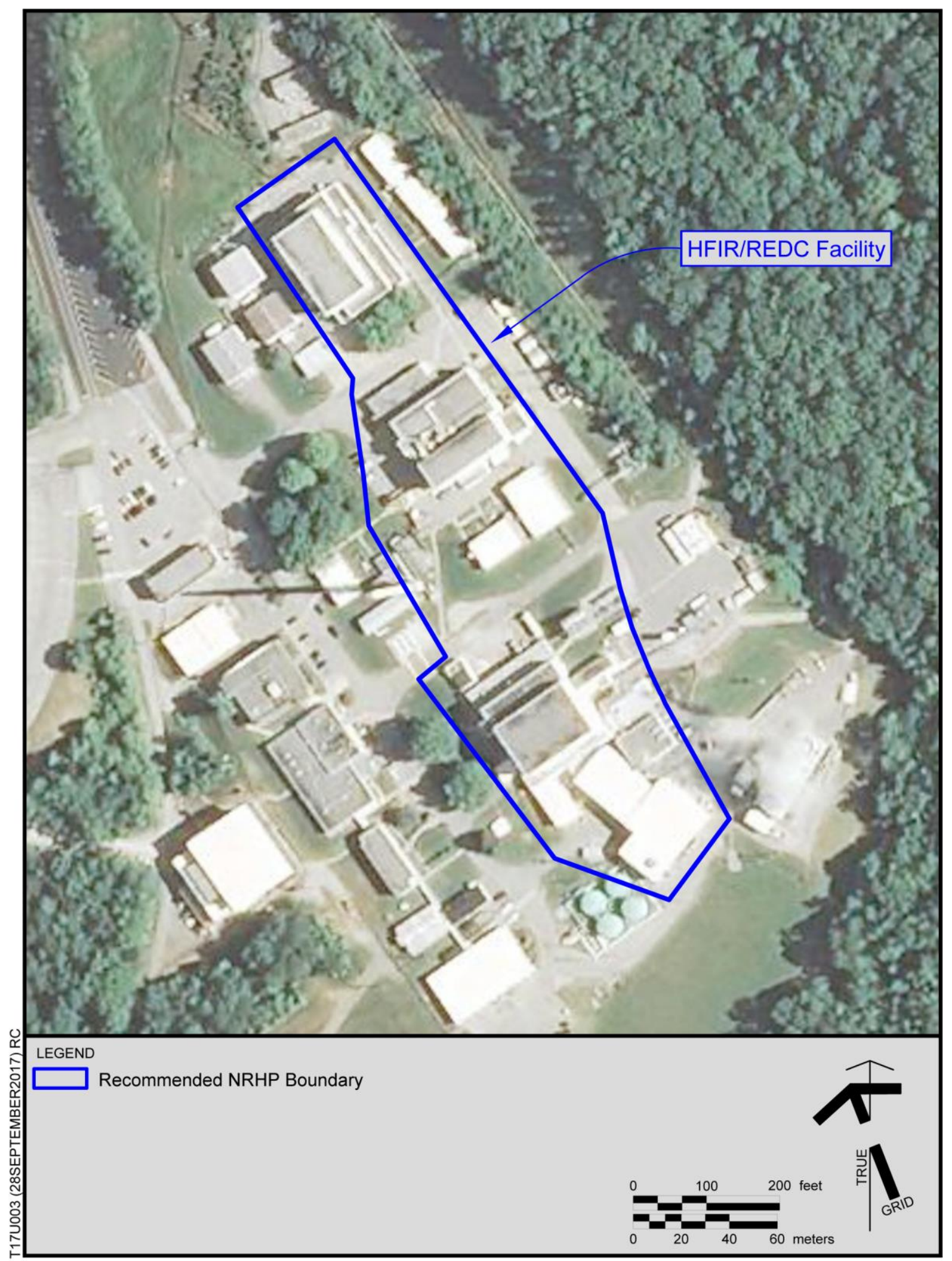

Figure 495. Aerial photographs depicting the recommended NRHP boundary of the HFIR/REDC Facility. 


\section{1}

\section{BUILDING NAME}

Electric Building for 7900

DATE OF CONSTRUCTION

1951

DOE OFFICE RESPONSIBLE

SC

NRHP ELIGIBILITY

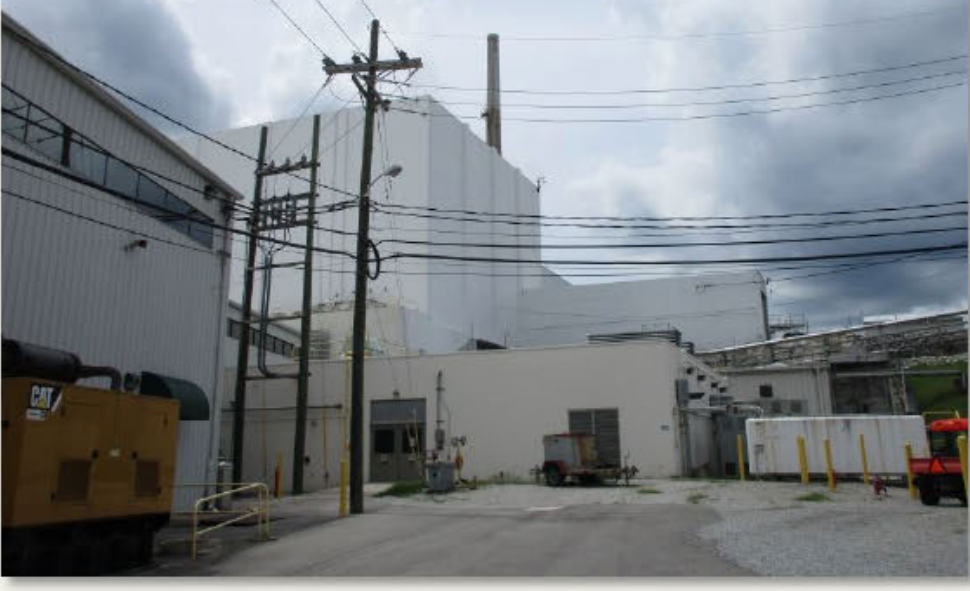

Figure 496. Overview of Buildings 7901 and 7900.

Contributing to HFIR/REDC Facility

\section{DESCRIPTION}

Building 7901 was one of 15 resources selected for intensive survey by UT-B as a part of survey planning. Located in the heart of the Melton Valley Campus, south of the main campus of ORNL, Building 7901 is located immediately east of Building 7900. It supports the operation of Building 7900 (Figure 496).

Exterior: Set up on a continuous poured concrete foundation, this one-story, rectangular, concrete block building is sheltered by flat roof with thin metal coping. The south elevation of Building 7901 features a central doubleleaf entry with single-light steel doors and a steel transom (Figure 497). Two single-leaf entries with steel doors are located on the north elevation (Figure 498). The southwest and east elevations of Building 7901 are devoid of fenestration (Figure 499).

Interior: The interior of Building 7901 is comprised of four rooms. All four rooms feature concrete floors, concrete block walls, and steel ceilings. The largest room contains mechanical equipment related to the electrical powering of Building 7900 , HFIR (Figures 500 and 501). The three smaller rooms contain additional mechanical equipment and batteries for back-up electrical power (Figures 502 and 503).

\section{NATIONAL REGISTER EVALUATION}

Building 7901 was constructed in 1965 as the primary electrical building for the HFIR facility. The HFIR required its own electrical building, given the large amount of electrical power required for its operation (Thomason 2015:56).

In 1994, Duvall \& Associates' survey of ORNL recommended Building 7901, as a part of the HFIR facility in the 7900 Area, was not eligible for listing in the NRHP because it was less than 50 years old (Carver and Slater 1994:324). The HFIR facility was not included in Thomason and Associates' 2004 survey updates (Thomason and Associates 2004). The 2015 survey update completed by Thomason and Associates recommended that Building 7900 and its associated facilities, Buildings 7901, 7920 and 7930, met NRHP Criterion A for significance in science and health/medicine as ORNL's only operating reactor and one of the world's most powerful and capable research reactors (Thomason and Associates 2015:56). 
As a utility and maintenance facility, Building 7901 is not the primary site associated with scientific achievements at ORNL, thus it does not rise to the level of significance needed for individual listing in the NRHP under Criterion A or B. Furthermore, as a utility and maintenance facility, Building 7901 exhibits a utilitarian design, lacking notable stylistic elements or innovative design features that would qualify it for listing in the NRHP under Criterion C. However, because it is integral to the functioning of the research and processing facilities within the HFIR/REDC complex, Building 7901 qualifies for listing in the NRHP under Criterion A for its association with the work of ORNL during the operation of HFIR.

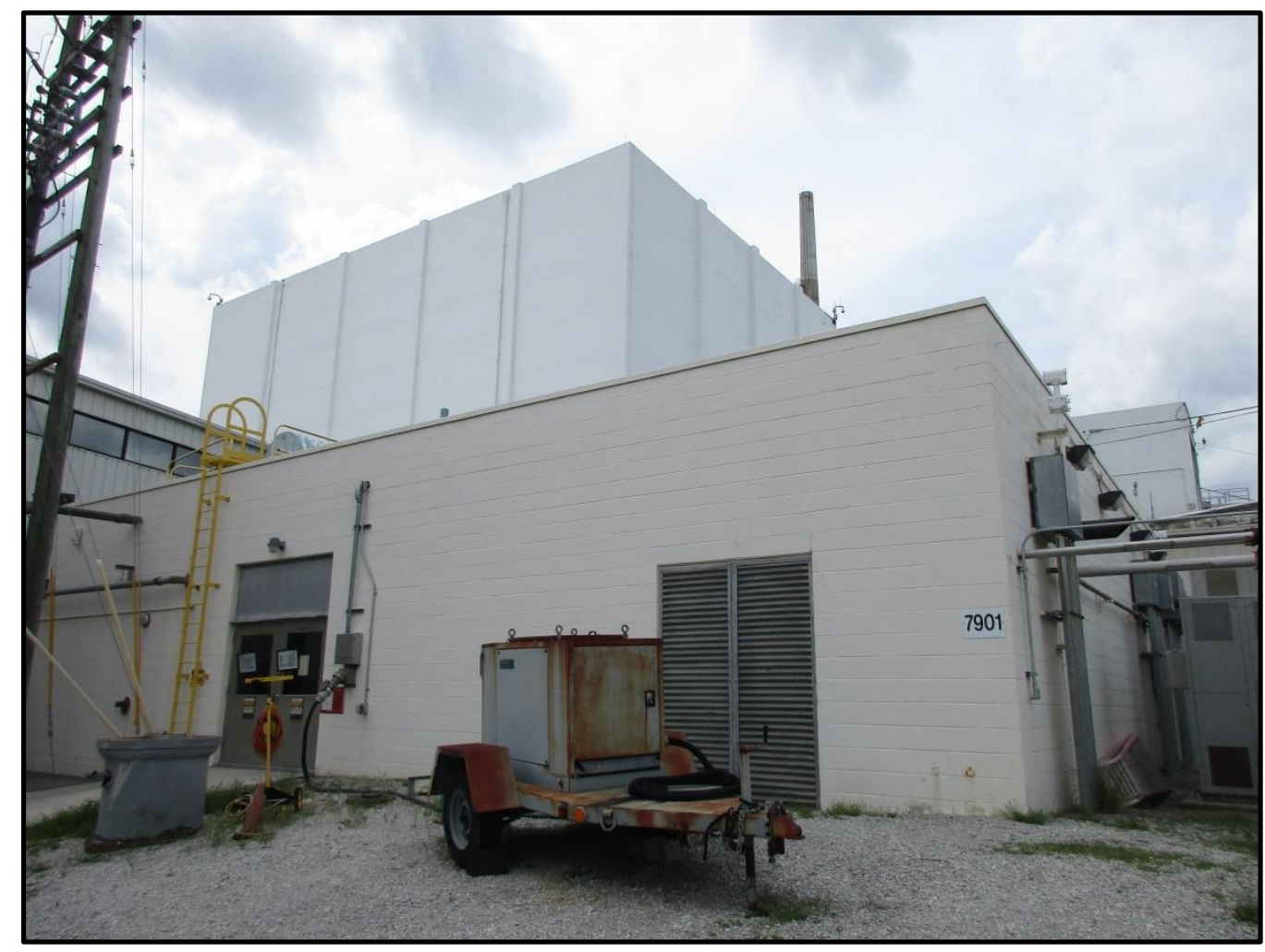

Figure 497. South and east elevations of Building 7901. 


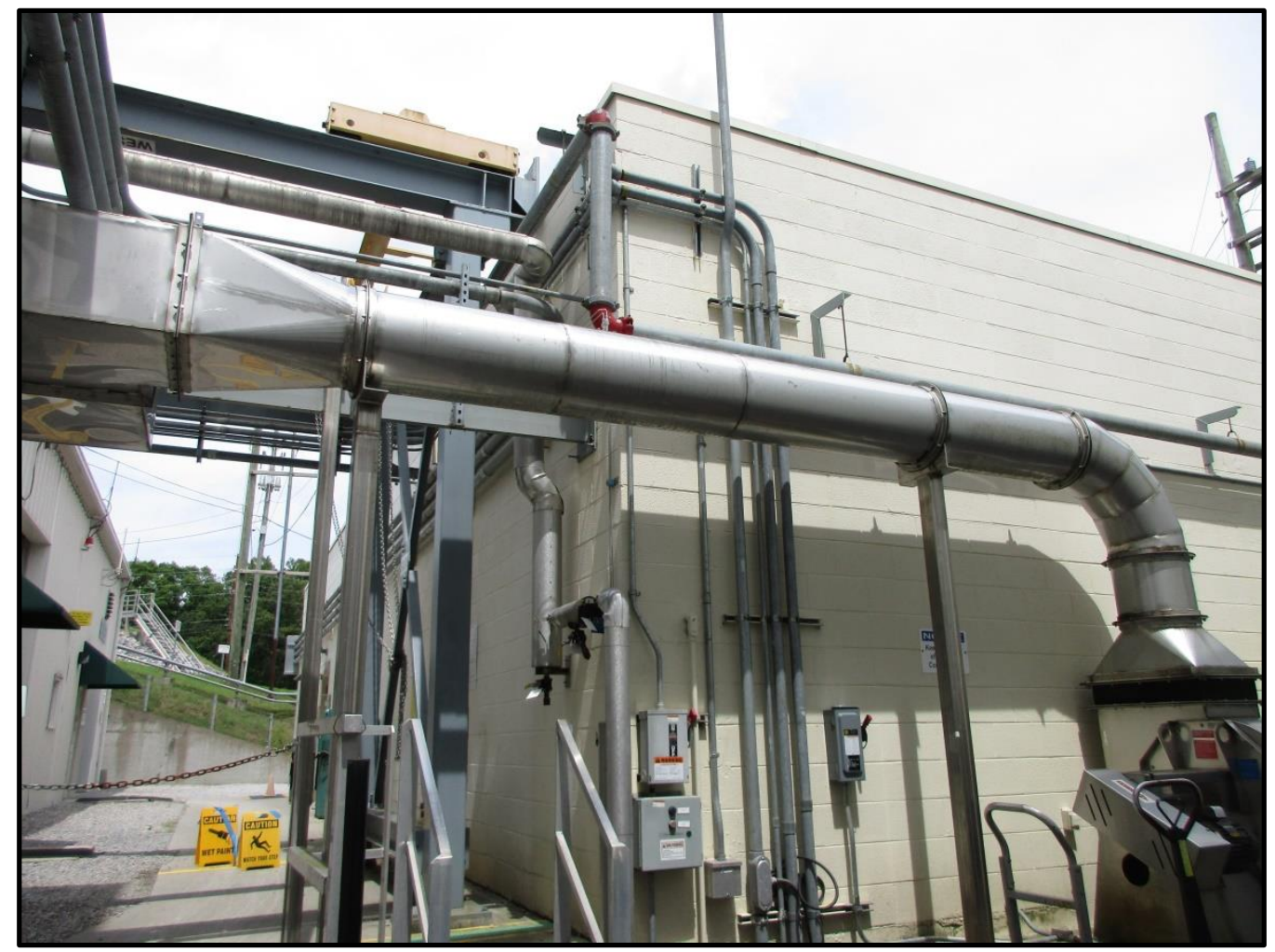

Figure 498. North and west elevations of Building 7901.

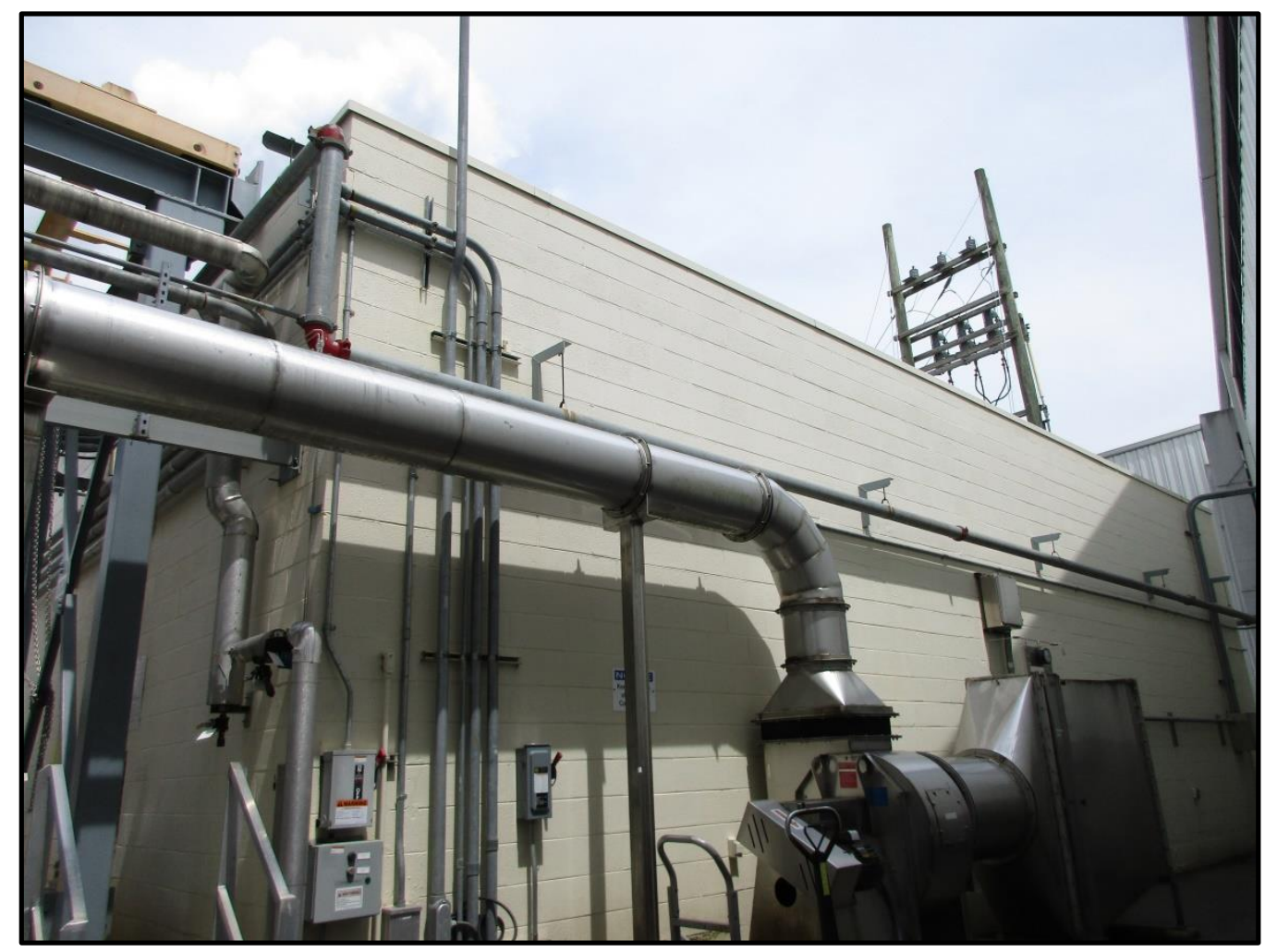

Figure 499. West elevation of Building 7901. 


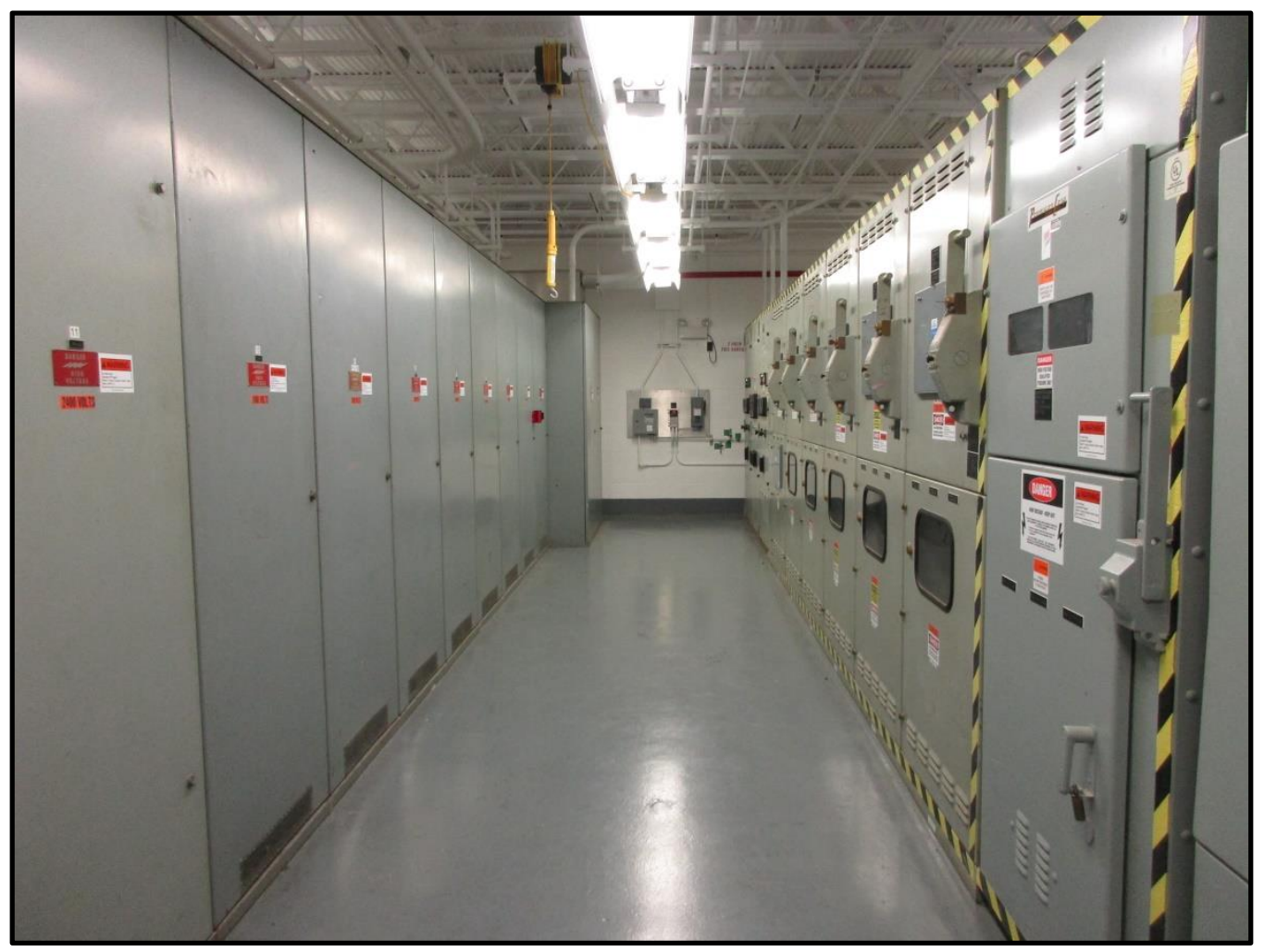

Figure 500. Room 1 of Building 7901.

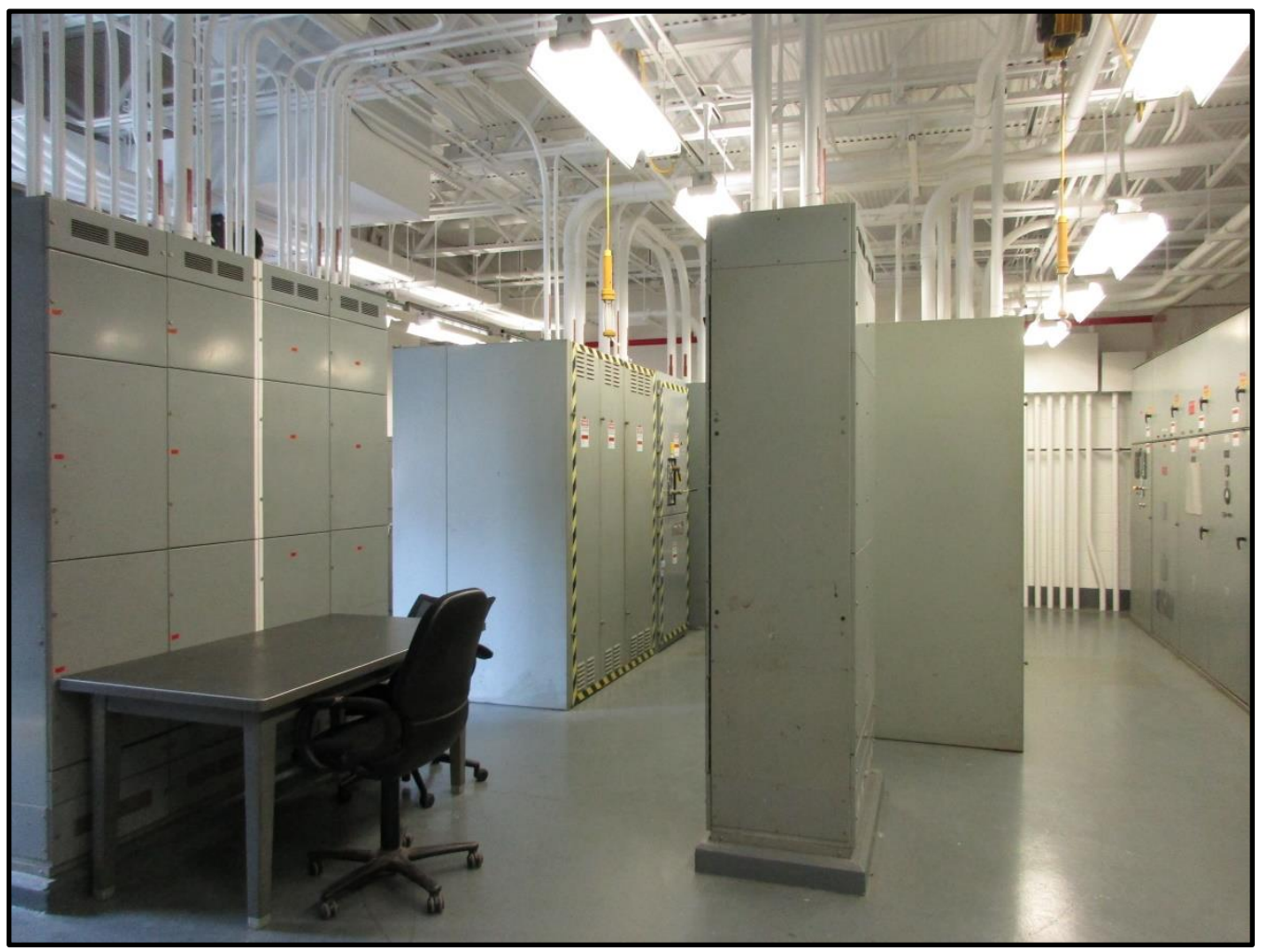

Figure 501. Room 1 of Building 7901. 


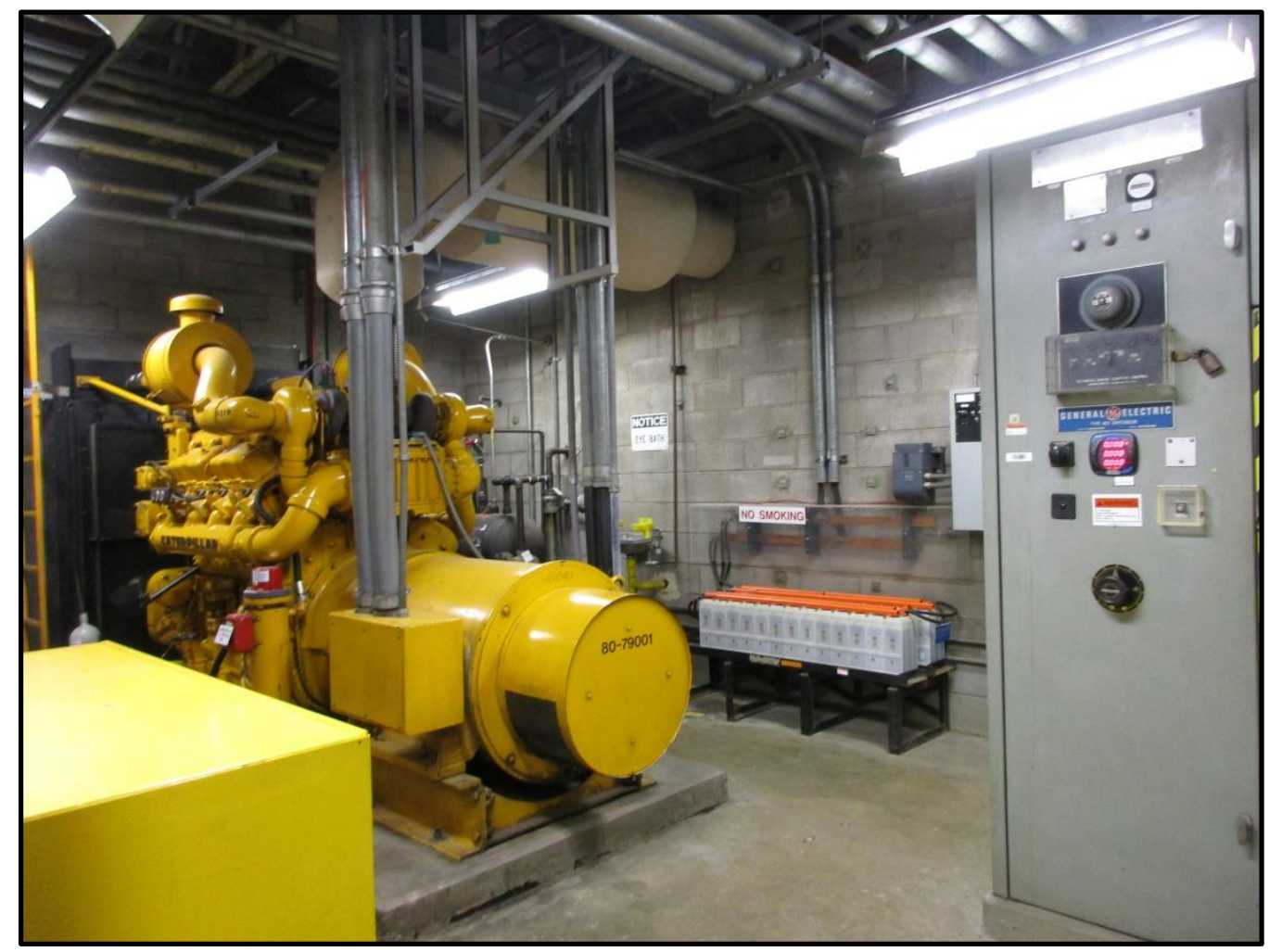

Figure 502. Room 2 of Building 7901.

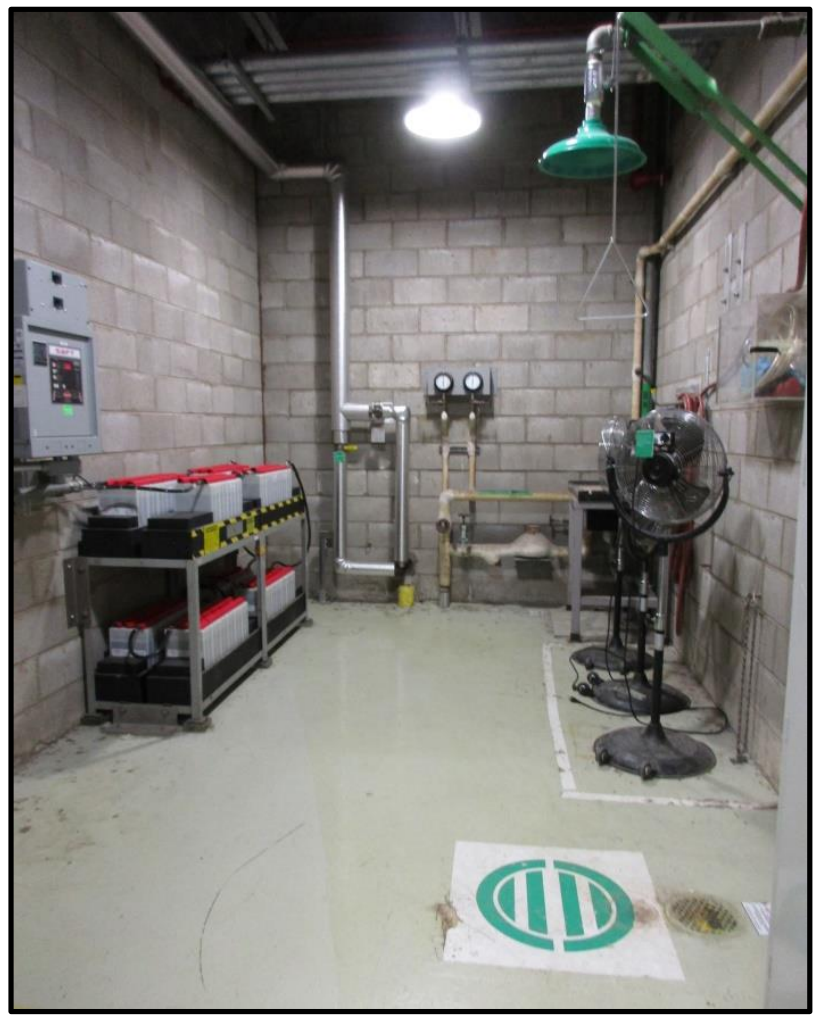

Figure 503. Room 3 of Building 7901. 


\section{3}

\section{BUILDING NAME}

Cooling Tower Equip Facility

DATE OF CONSTRUCTION

1965

DOE OFFICE RESPONSIBLE

SC

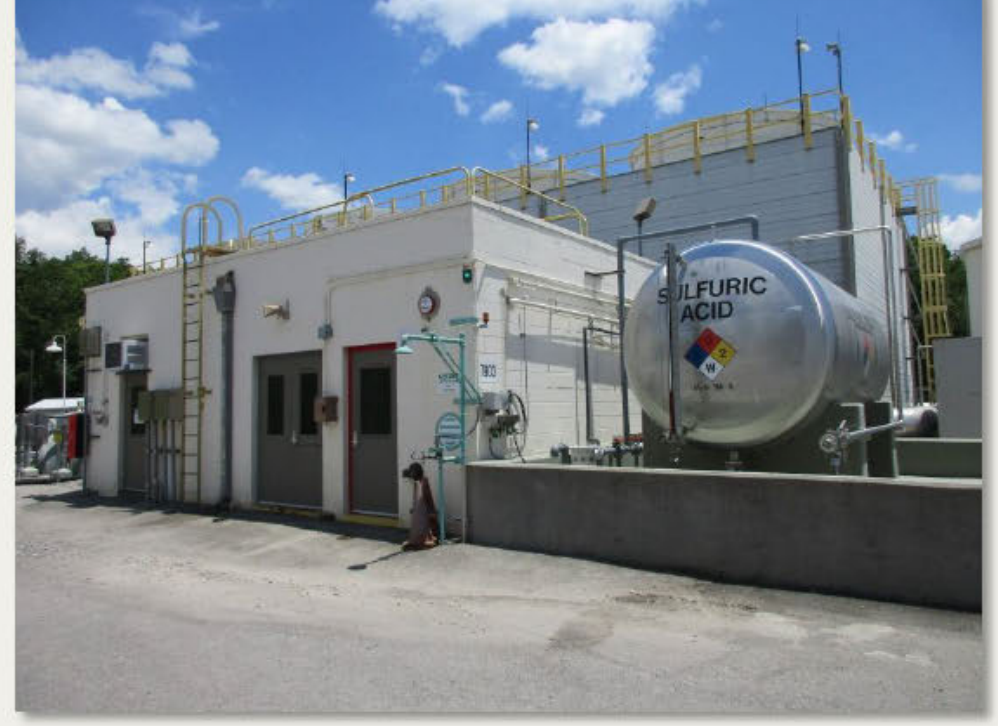

NRHP ELIGIBILITY

Figure 504. Overview of Building 7903.

Not Eligible

\section{DESCRIPTION}

Building 7903 is a one-story, flat-roof structure constructed with concrete block masonry (Figures 504 and 505). The building's north elevation features two single-leaf entrances and one double-leaf entrance, all containing single-light steel doors.

\section{NATIONAL REGISTER EVALUATION}

Building 7903 was constructed in 1965 as a cooling tower equipment facility for the HFIR. The building was first surveyed by Duvall \& Associates in their 1994 assessment, and the HFIR complex, including this building, was considered ineligible for listing in the NRHP due to age (Carver and Slater 1994). The building was not included in the 2004 and 2015 surveys conducted by Thomason and Associates (Thomason and Associates 2004 and 2015). The integrity of the building has been somewhat diminished due to the addition of replacement doors. As a utility facility, Building 7903 is not a primary resource associated with scientific achievements at ORNL, nor is it known to be individually associated with any other events or persons of historic significance, thus it does not qualify for listing in the NRHP under Criterion A or B. Further, the building is a simple utilitarian structure that lacks architectural significance for listing in the NRHP under Criterion C. In addition, the building is located outside of the recommended boundaries for the NRHP-eligible HFIR/REDC facility, as it is outside of the most intact and significant portion of the 7900 Area. Thus, CRA recommends that Building 7903 is not eligible for listing in the NRHP under Criterion A, B, or C. 


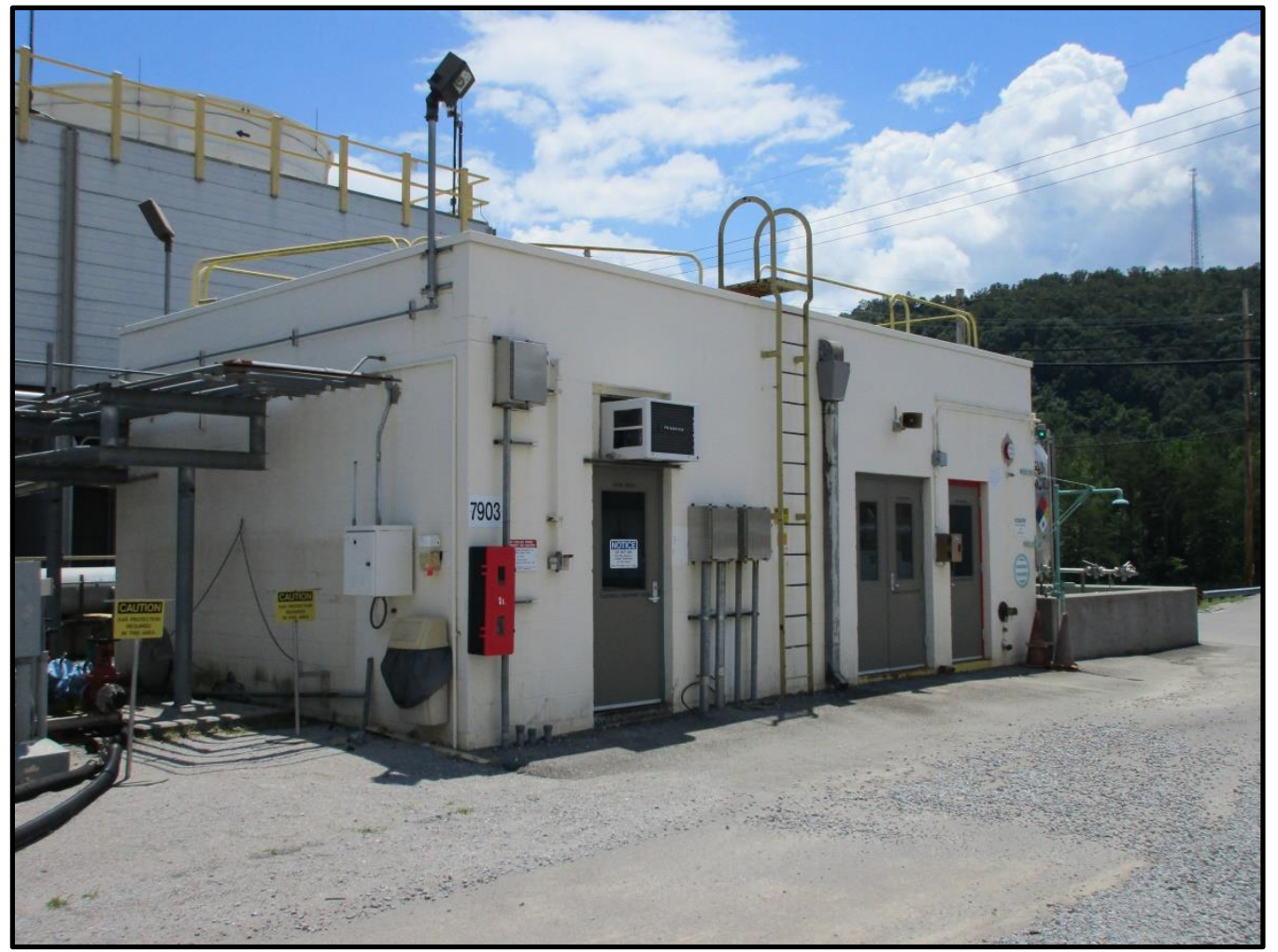

Figure 505. Overview of north and east elevations of Building 7903. 


\section{BUILDING NAME}

Office Building for 7900

DATE OF CONSTRUCTION

1965

DOE OFFICE RESPONSIBLE

SC

\section{NRHP ELIGIBILITY}

Figure 506. Overview of south elevation and partial east elevation of Building 7910.

Not Eligible

\section{DESCRIPTION}

Building 7910 is a one-story, concrete block masonry building with a flat roof featuring metal coping (Figures 506 and 507). There are several changes in roof heights which include a lower portion located above the main entrance on the east facade, a second level on the south section, and a third level, the tallest, is located on the north section. The lower portion of the roof near the main entrance (east façade) is clad with corrugated metal. A secondary entrance is located on the south elevation. The structure features modern multi-light windows and single-light glass and metal doors throughout. Shed awnings are placed above many of the entrances. A roll-up garage door is located on the east elevation. A covered walkway is found on the south elevation, which connects to Building 7962 .

\section{NATIONAL REGISTER EVALUATION}

Building 7910 was constructed in 1965 to serve as an office building for Building 7900 , the HFIR. The building was first surveyed by Duvall \& Associates in their 1994 assessment, and the HFIR area, including this building, was considered ineligible for listing in the NRHP due to age (Carver and Slater 1994). The building was not included in the 2004 conducted by Thomason and Associates. However, the building was included in the 2015 survey by Thomason and Associates, which concurred with the previous assessment (Thomason and Associates 2015). The integrity of the building has been diminished due to the addition of replacement windows and doors during a renovation completed in 2000 . As an office building, Building 7910 is not a primary resource associated with scientific achievements at ORNL, nor is it known to be individually associated with any other events or persons of historic significance, thus it does not qualify for listing in the NRHP under Criterion A or B. Further, the building is a simple utilitarian structure that lacks architectural significance for listing in the NRHP under Criterion $\mathrm{C}$. In addition, the building is located outside of the recommended boundaries for the NRHPeligible HFIR/REDC facility, as it is outside of the most intact and significant portion of the 7900 Area. Thus, CRA recommends that Building 7910 is not eligible for listing in the NRHP under Criterion A, B, or C. 


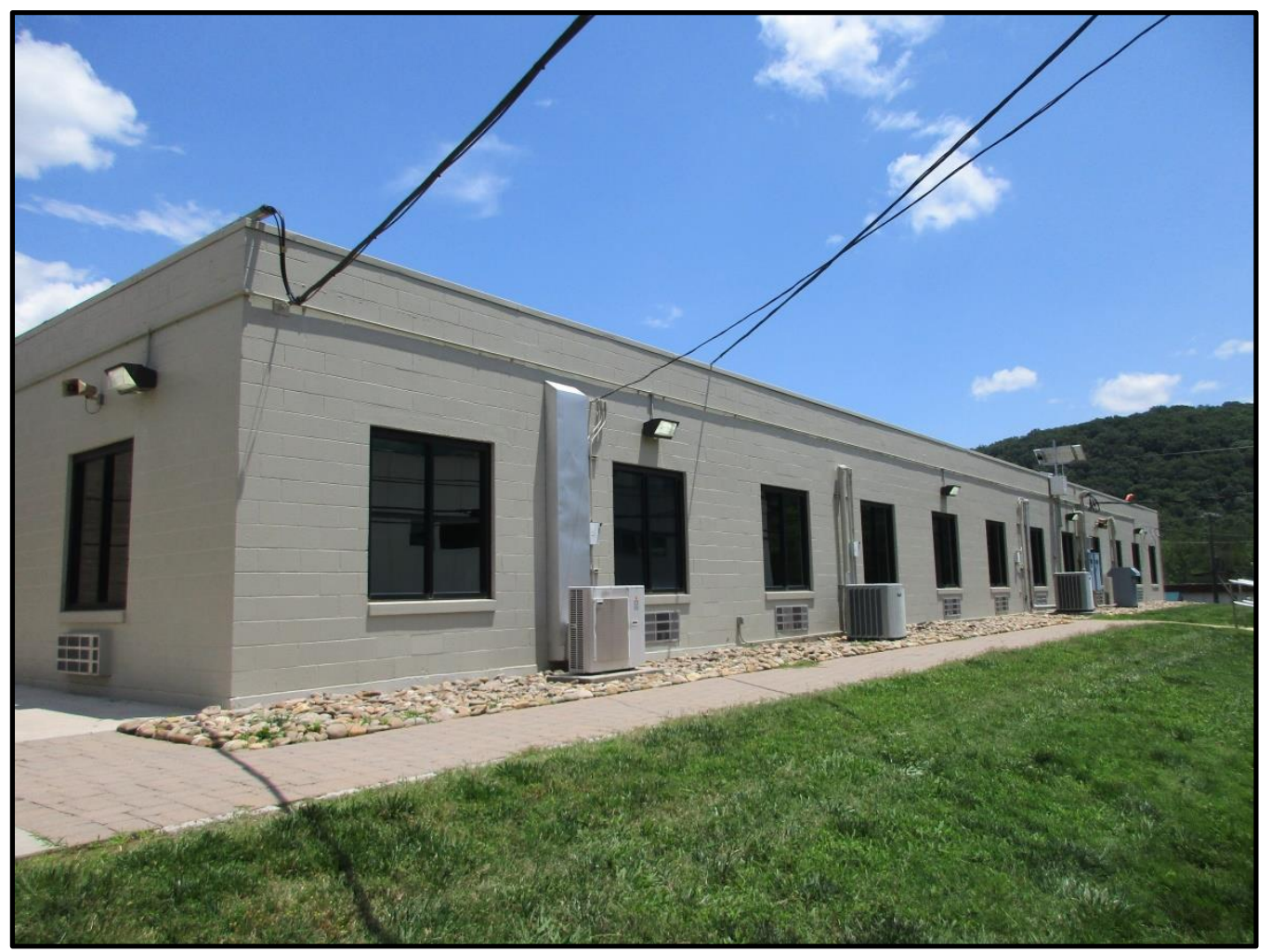

Figure 507. Overview of southwest elevation and partial north elevation of Building 7910. 


\section{1}

\section{BUILDING NAME}

Exhaust Stack for 7900

DATE OF CONSTRUCTION

1965

DOE OFFICE RESPONSIBLE

SC

\section{NRHP ELIGIBILITY}

Contributing to HFIR/REDC Facility

\section{DESCRIPTION}

Building 7911 is a concrete exhaust stack for Building 7900 , and stands north of the reactor. The exhaust stack features a tapered design (Figure 508). Metal ladder rungs set in the concrete ascend to three platforms located at various points along its height.

\section{NATIONAL REGISTER EVALUATION}

Building 7911 was constructed in 1965 and serves an exhaust stack for Building 7900, the HFIR (Carver and Slater 1994:322). The building was first surveyed by Duvall \& Associates in their 1994 assessment, and the HFIR area, including this building, was considered ineligible for listing in the NRHP due to age (Carver and Slater 1994). The building was not included in the 2004 and 2015 surveys (Thomason and Associates 2004 and 2015). The integrity of the exhaust stack has remained intact. As a utility structure, Building 7911 is not a primary resource associated with scientific achievements at ORNL, nor is it known to be individually associated with any other events or persons of historic significance, thus it does not qualify for individual listing in the NRHP under Criterion $\mathrm{A}$ or $\mathrm{B}$. Further, the building is a simple utilitarian structure that lacks architectural significance for listing in the NRHP under Criterion C. As such, Building 7911 does not warrant individual listing in the NRHP under Criterion A, B, or C. Instead, the significance of Building 7911 is best understood within the broader context of HFIR/REDC Facility as it supported the function of the key processing facility at its core, the HFIR (Building 7900). Thus, CRA recommends that Building 7911 is as a contributing resource of the NRHP-eligible HFIR/REDC facility. 


\section{4}

\section{BUILDING NAME}

Equipment \& Parts Storage Building

DATE OF CONSTRUCTION

1962

DOE OFFICE RESPONSIBLE

SC

\section{NRHP ELIGIBILITY}

Not Eligible

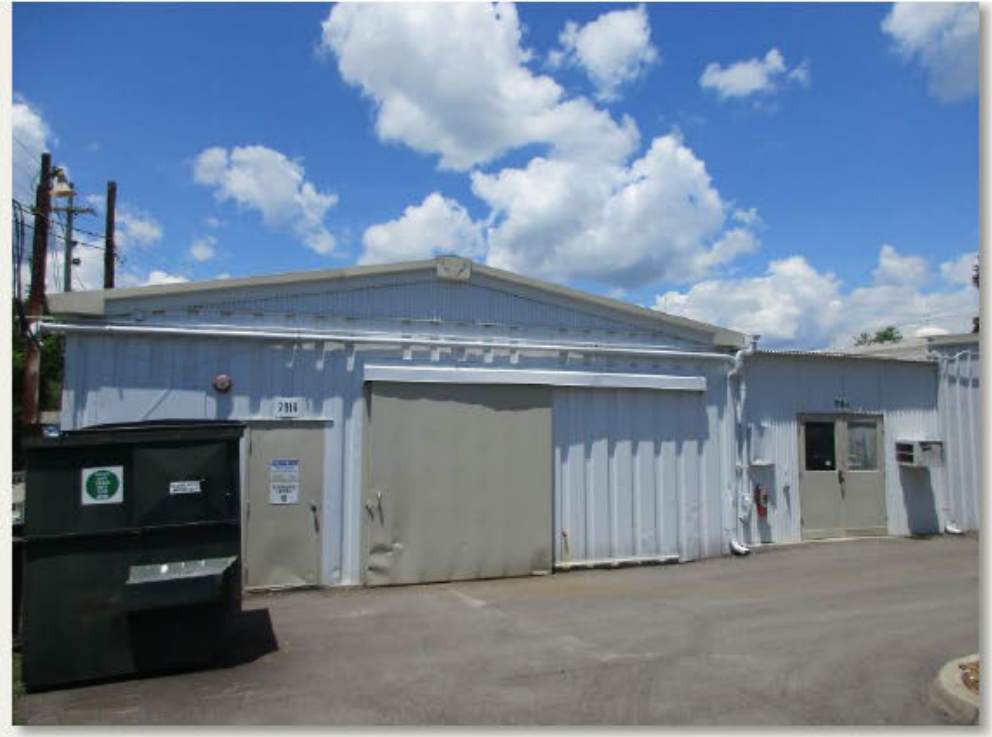

Figure 509. Overview of south elevation of Building 7914.

\section{DESCRIPTION}

The east elevation of Building 7914 connects to its annex, Building 7914A, which in turn connects to Building 7915. The building is a one-story, front-gable structure on a concrete foundation (Figures 509 and 510 ). The building's walls and roof are clad in metal panels, and it is topped by two roof vents. The building features small pedestrian metal doors and large sliding doors on the south and north elevations.

\section{NATIONAL REGISTER EVALUATION}

Building 7914 was constructed in 1962 as a storage facility for equipment and parts in the HFIR area (Carver and Slater:322). The building was first surveyed by Duvall \& Associates in their 1994 assessment, and the HFIR area, including this building, was considered ineligible for listing in the NRHP due to age (Carver and Slater 1994). The building was not included in the 2004 conducted by Thomason and Associates. However, the building was included in the 2015 survey by Thomason and Associates, which concurred with the previous assessment (Thomason and Associates 2015). The building has been altered since its initial construction, including changes made to the exterior and roof, which has diminished the building's integrity. As a storage facility, Building 7914 is not a primary resource associated with scientific achievements at ORNL, nor is it known to be individually associated with any other events or persons of historic significance, thus it does not qualify for listing in the NRHP under Criterion A or B. Further, the building is a simple utilitarian structure that lacks architectural significance for listing in the NRHP under Criterion $\mathrm{C}$. In addition, the building is located outside of the recommended boundaries for the NRHP-eligible HFIR/REDC facility, as it is outside of the most intact and significant portion of the 7900 Area. Thus, CRA recommends that Building 7914 is not eligible for listing in the NRHP under Criterion A, B, or C. 


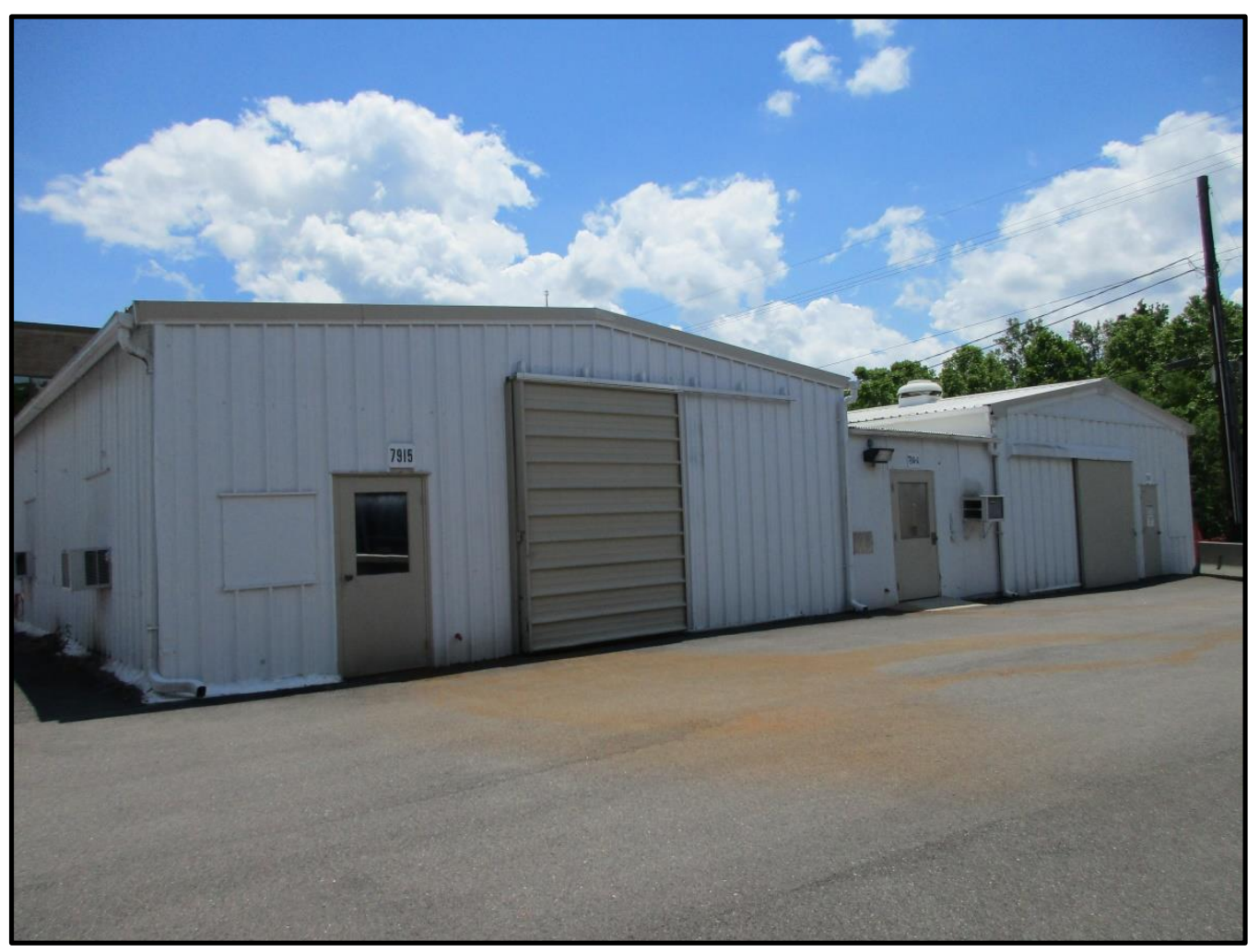

Figure 510. Overview of north of Building 7914, 7914A, and 7915. Building 7914 is located at the far right of the photograph. 


\section{A}

\section{BUILDING NAME}

Equipment Storage

DATE OF CONSTRUCTION

1962

DOE OFFICE RESPONSIBLE

SC

\section{NRHP ELIGIBILITY}

Figure 511. Overview of south elevation of Building 7914A.

\section{DESCRIPTION}

Building 7914A is connected to Building 7914 (to the west) and Building 7915 (to the east) (Figure 511). The walls and flat roof are clad in corrugated metal. Entrances containing double-leaf, single-light metal doors are found on the south and north elevations.

\section{NATIONAL REGISTER EVALUATION}

Building 7914 was constructed in 1962 as a storage facility for equipment in the HFIR area (Carver and Slater 1994:322). The building was first surveyed by Duvall \& Associates in their 1994 assessment, and the HFIR area, including this building, was considered ineligible for listing in the NRHP due to age (Carver and Slater 1994). The building was not included in the 2004 conducted by Thomason and Associates. However, the building was included in the 2015 survey by Thomason and Associates, which concurred with the previous assessment (Thomason and Associates 2015). The building has been altered since its initial construction, including changes made to the exterior and roof, which has diminished the building's integrity. As a storage facility, Building $7914 \mathrm{~A}$ is not a primary resource associated with scientific achievements at ORNL, nor is it known to be individually associated with any other events or persons of historic significance, thus it does not qualify for listing in the NRHP under Criterion A or B. Further, the building is a simple utilitarian structure that lacks architectural significance for listing in the NRHP under Criterion C. In addition, the building is located outside of the recommended boundaries for the NRHP-eligible HFIR/REDC facility, as it is outside of the most intact and significant portion of the 7900 Area. Thus, CRA recommends that Building 7914A is not eligible for listing in the NRHP under Criterion $A, B$, or C. 


\section{5}

\section{BUILDING NAME}

Operations Storage Building

DATE OF CONSTRUCTION

1962

DOE OFFICE RESPONSIBLE

SC

NRHP ELIGIBILITY

Figure 512. Overview of southeast elevation and partial east elevation of Building 7915.

Not Eligible

\section{DESCRIPTION}

The west elevation of Building 7915 connects to Building 7914A, which in turn connects to Building 7914 . The building is a one-story, front-gable structure on a concrete foundation (Figures 512 and 513). The building's walls and roof are clad in metal panels. The building features small pedestrian, single-light metal doors and large sliding doors on the south and north elevations.

\section{NATIONAL REGISTER EVALUATION}

Building 7915 was constructed in 1962 as a storage facility for operations in the HFIR area (Carver and Slater 1994:322). The building was first surveyed by Duvall \& Associates in their 1994 assessment, and the HFIR area, including this building, was considered ineligible for listing in the NRHP due to age (Carver and Slater 1994). The building was not included in the 2004 conducted by Thomason and Associates. However, the building was included in the 2015 survey by Thomason and Associates, which concurred with the previous assessment (Thomason and Associates 2015). The building has been altered since its initial construction, including changes made to the exterior and roof, which has diminished the building's integrity. As a storage facility, Building 7915 is not a primary resource associated with scientific achievements at ORNL, nor is it known to be individually associated with any other events or persons of historic significance, thus it does not qualify for listing in the NRHP under Criterion A or B. Further, the building is a simple utilitarian structure that lacks architectural significance for listing in the NRHP under Criterion C. In addition, the building is located outside of the recommended boundaries for the NRHP-eligible HFIR/REDC facility, as it is outside of the most intact and significant portion of the 7900 Area. Thus, CRA recommends that Building 7915 is not eligible for listing in the NRHP under Criterion A, B, or C. 


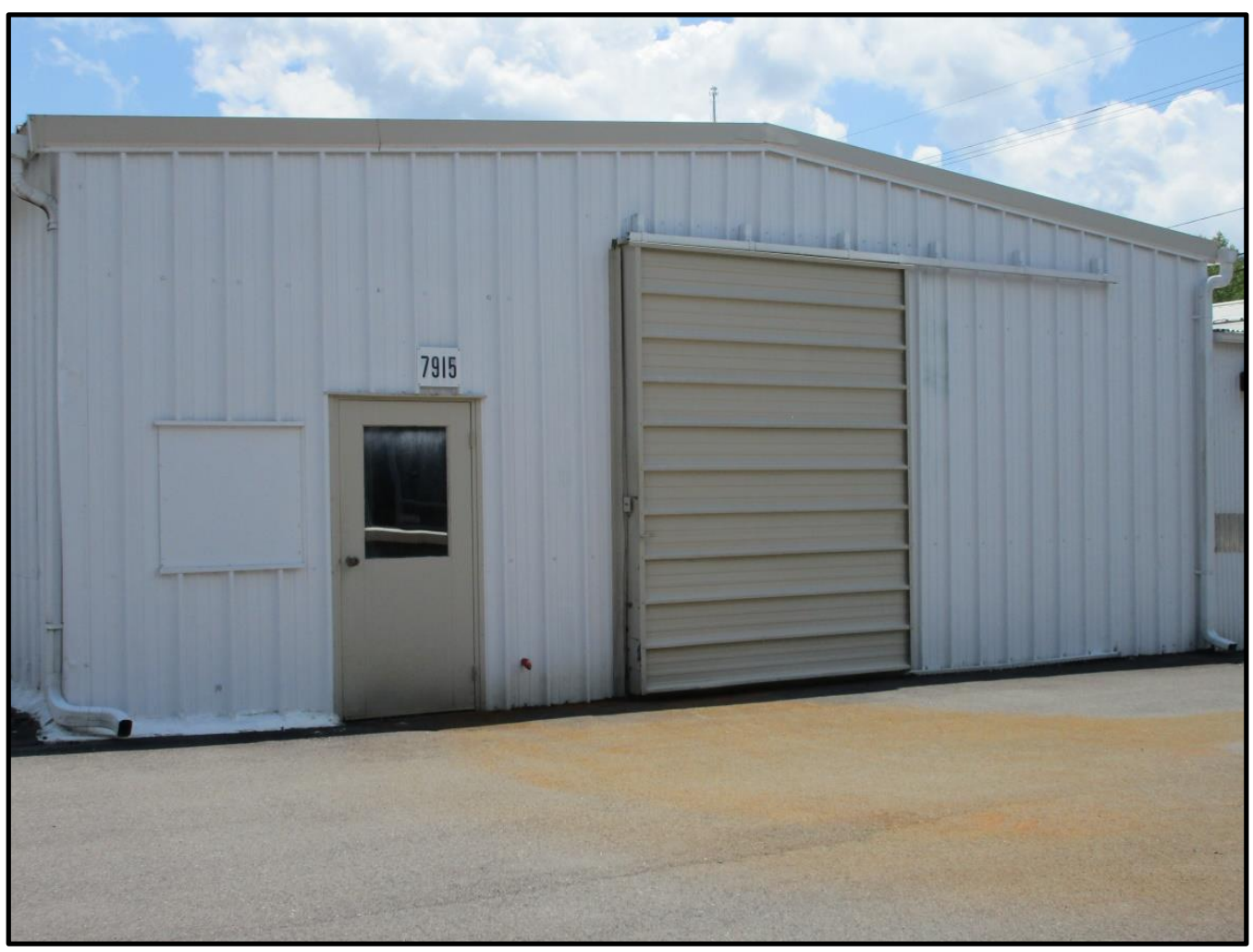

Figure 513. Overview of north elevation of Building 7915. 


\section{BUILDING NAME}

HFIR Electrical Service Shop

\section{DATE OF CONSTRUCTION}

1975

DOE OFFICE RESPONSIBLE

SC

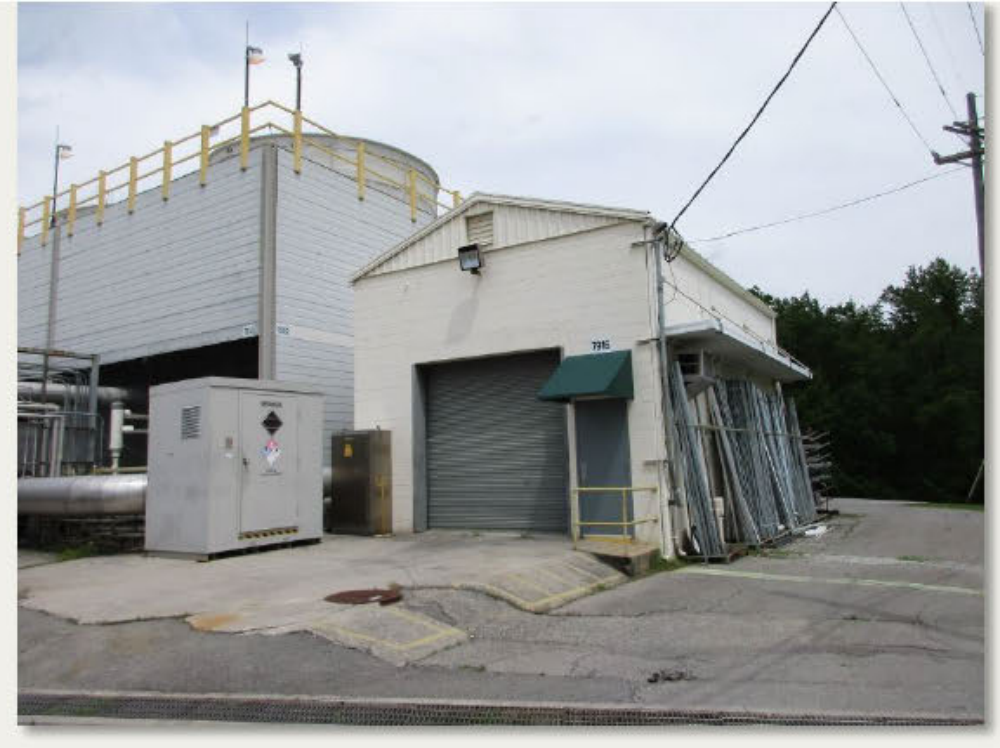

NRHP ELIGIBILITY

Figure 514. Overview of north and west elevations of Building 7916.

Not Eligible

\section{DESCRIPTION}

Building 7916 is a two-story, front-gable, concrete block masonry building (Figure 514 and 515). The upper part of the gable ends is clad in metal panels. The roof is clad with metal seam roof. A large industrial roll-up door is located one the north elevation, along with a steel door with a shed awning. A flat awning runs along the west elevation. A single-light metal door with a shed awning is located on the south elevation, as is a two-light, singlehung window.

\section{NATIONAL REGISTER EVALUATION}

Building 7916 was constructed in 1975 and served as an electrical service shop for the HFIR area (Carver and Slater 1994:322). The building was first surveyed by Duvall \& Associates in their 1994 assessment, and the HFIR area, including this building, was considered ineligible for listing in the NRHP due to age (Carver and Slater 1994). The building was not included in the 2004 and 2015 surveys conducted by Thomason and Associates (Thomason and Associates 2004 and 2015). The integrity of the building has been diminished due to the addition of replacement doors and windows. As a utility facility, Building 7916 is not a primary resource associated with scientific achievements at ORNL, nor is it known to be individually associated with any other events or persons of historic significance, thus it does not qualify for listing in the NRHP under Criterion A or B. Further, the building is a simple utilitarian structure that lacks architectural significance for listing in the NRHP under Criterion $\mathrm{C}$. In addition, the building is located outside of the recommended boundaries for the NRHPeligible HFIR/REDC facility, as it is outside of the most intact and significant portion of the 7900 Area. Thus, CRA recommends that Building 7916 is not eligible for listing in the NRHP under Criterion $A, B$, or $C$. 


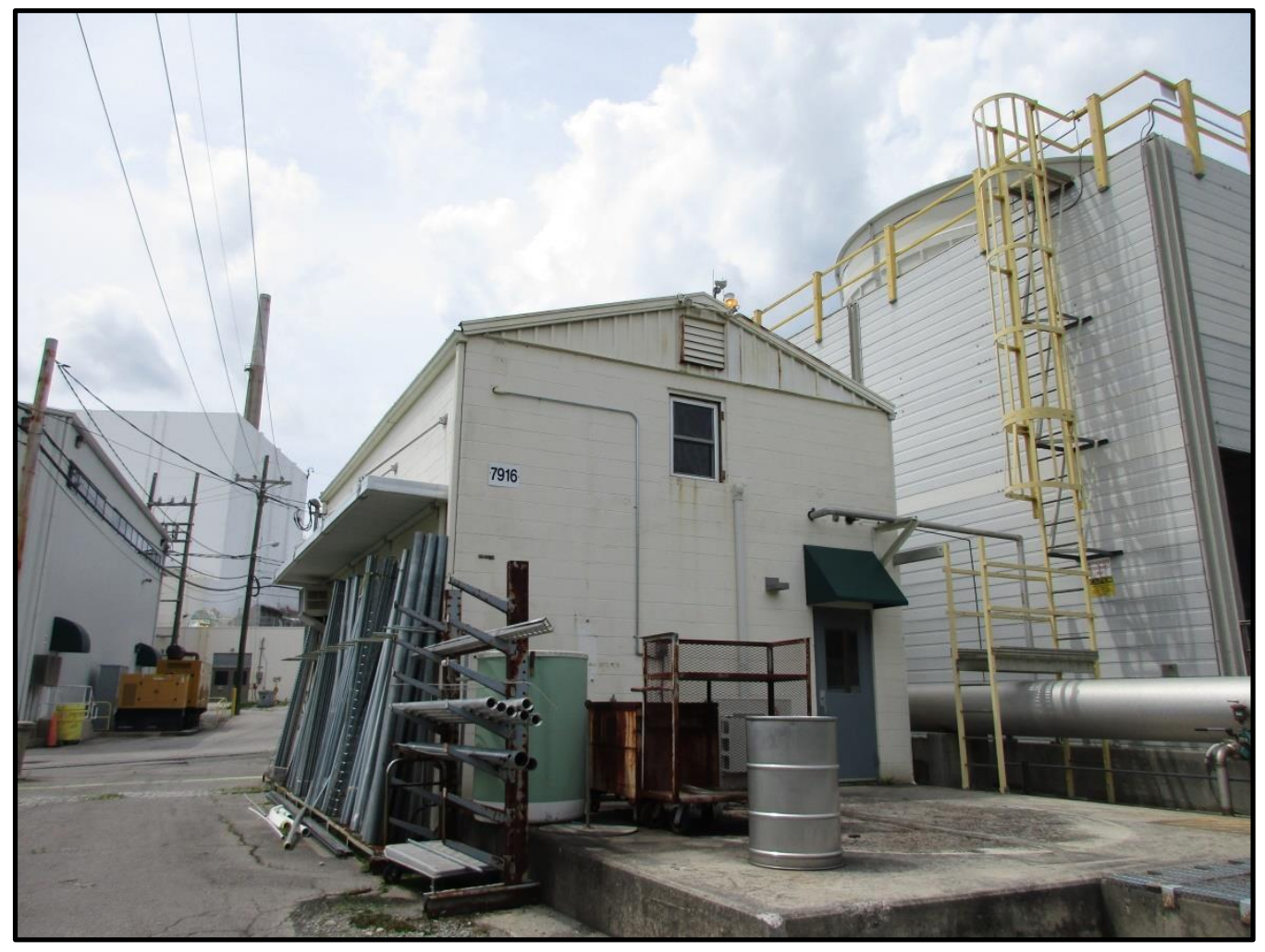

Figure 515. Overview of west and south elevations of Building 7916. 
elevation of is located on this projection (Figure 522). A pair of two-light steel doors opens to a concrete loading dock sheltered by a flat metal roof supported by thin metal posts (Figure 523). Sections of pierced concrete block form screens along portions of the southwest and north elevations of Building 7920. A small, flat-roofed storage area that extends from the north elevation features the same pierced block construction.

Interior: The interior of Building 7920 is comprised of a series of corridors that provide access to offices and laboratory space as well as large, open areas with hot cells for radiological experimentation. The one-story section of Building 7920 features a central corridor. The corridor features large commercial grade floor tile, concrete block walls, and many original wood doors (Figures 524 and 525). Restrooms in this section feature ceramic tile floors and glazed concrete block walls with original fixtures (Figure 526).

The first floor of the two-story section of the building is comprised of a hot cell facility that features 17 hot cells for radiological research. The corridors of the first floor feature replacement floor tile and drywall walls and ceiling (Figure 527). Large rooms on either side of the hot cells on the first floor provide room for monitoring equipment and the robotic arms to manipulate the contents of hot cells (Figure 528). A staircase with structural steel stairs and handrails and a freight elevator provide access to the second floor of Building 7920 (Figures 529 and 530).

The second floor of Building 7920 is partially open to the hot cells below. The remainder of the second floor is comprised of a corridor that provides access to renovated offices (Figures 531 and 532). Laboratory spaces on the second floor feature original commercial floor tile and concrete ceilings (Figures 533 and 534).

\section{NATIONAL REGISTER EVALUATION}

Building 7920 was constructed in 1966 as the Radiochemical Engineering Development Center (REDC). The REDC, comprised of two facilities-the Transuranic Facility (REDC-1, Building 7920) and the Thorium-Uranium Recycle Facility (REDC-2, Building 7930) -was constructed to chemically extract the newly-produced, intensely radioactive heavy elements produced within the HFIR and at other reactor facilities. The REDC serves as the national center of production, storage, and distribution of transuranium elements for the DOE's heavy-element research programs. Building 7920 is the site of target preparation for HFIR as well as the recovery and purification of transuranic elements from targets (Thomason and Associates 2015:57).

In 1994, Duvall \& Associates' survey of ORNL recommended HFIR (the 7900 Area) was not eligible for listing in the NRHP because it was less than 50 years old and it was the third of its kind developed in the United States, so it was not a new significant technology (Carver and Slater 1994:324). The HFIR/REDC facility was not included in Thomason and Associates' 2004 survey updates (Thomason and Associates 2004). The 2015 survey update completed by Thomason and Associates recommended that Building 7900 and its associated facilities, Buildings 7901, 7920 and 7930, met NRHP Criterion A for significance in science and health/medicine as ORNL's only operating reactor and one of the world's most powerful and capable research reactors (Thomason and Associates 2015:56).

As a research/laboratory facility, Building 7920 and its counterpart, Building 7930, are significant contributing resources within the larger HFIR/REDC facility in the 7900 Area. The work of REDC supports the operation of and employs radioisotopes produced by HFIR while also pursing independent missions in chemical engineering. Thus, in order to reflect the significant role of the synergistic and inter-dependent relationship between the two 
facilities, the buildings of REDC qualify for listing in the NRHP as a part of the HFIR/REDC facility, which was important in the advancement of ORNL's mission in nuclear science and isotope research, key fields of study during the Cold War era. Because Building 7920 is not the sole building most closely associated with a scientific breakthrough or a scientist of truly exceptional importance, its significance is most appropriately recognized as a component part of the larger HFIR/REDC facility, and thus does not qualify for individual listing in the NRHP under Criterion A or B. Additionally, Buildings 7920 and 7930 exhibit the simple institutional design that characterized ORNL's Cold War era facilities, lacking notable stylistic elements that would warrant listing under Criterion C.

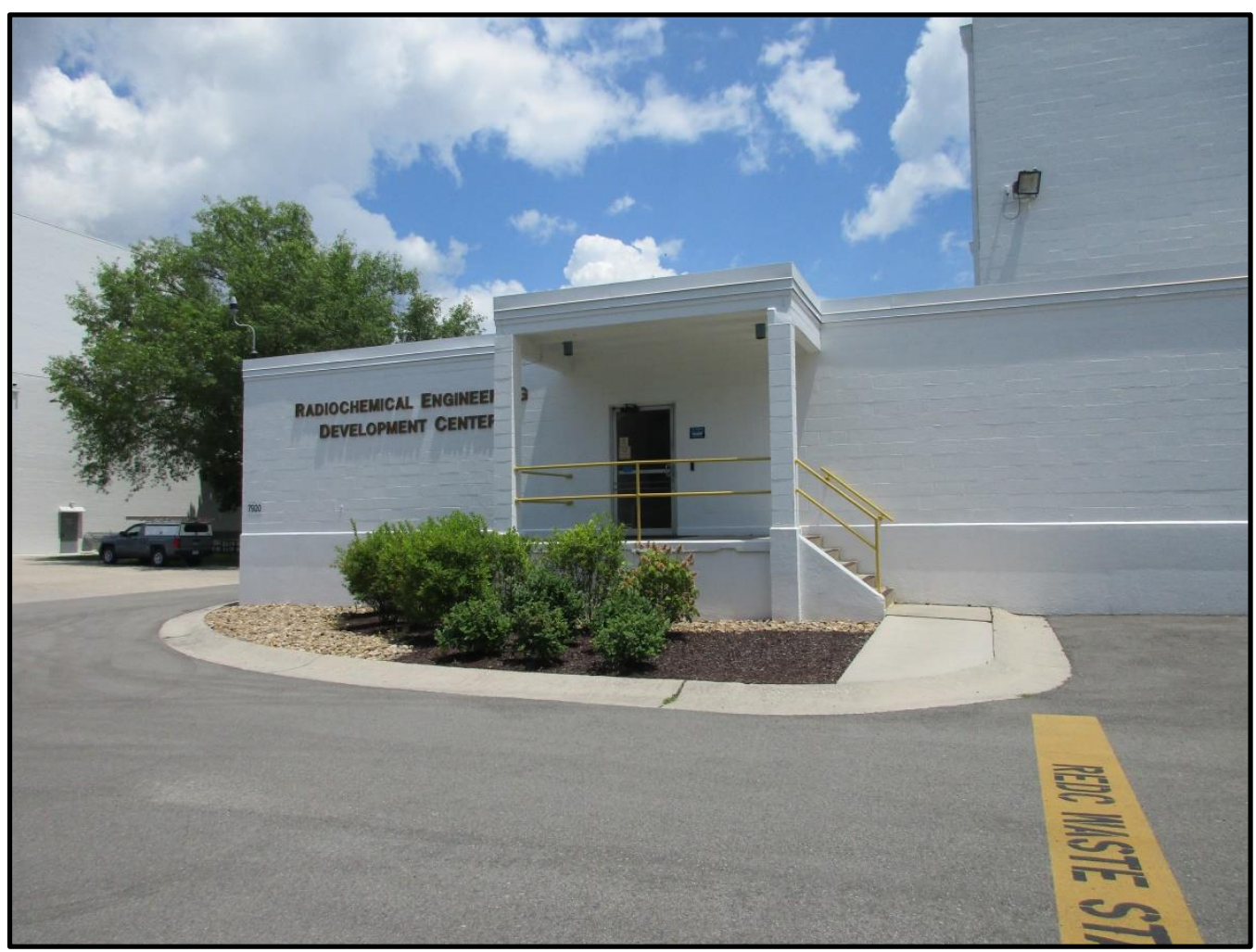

Figure 517. Façade entry of Building 7920. 


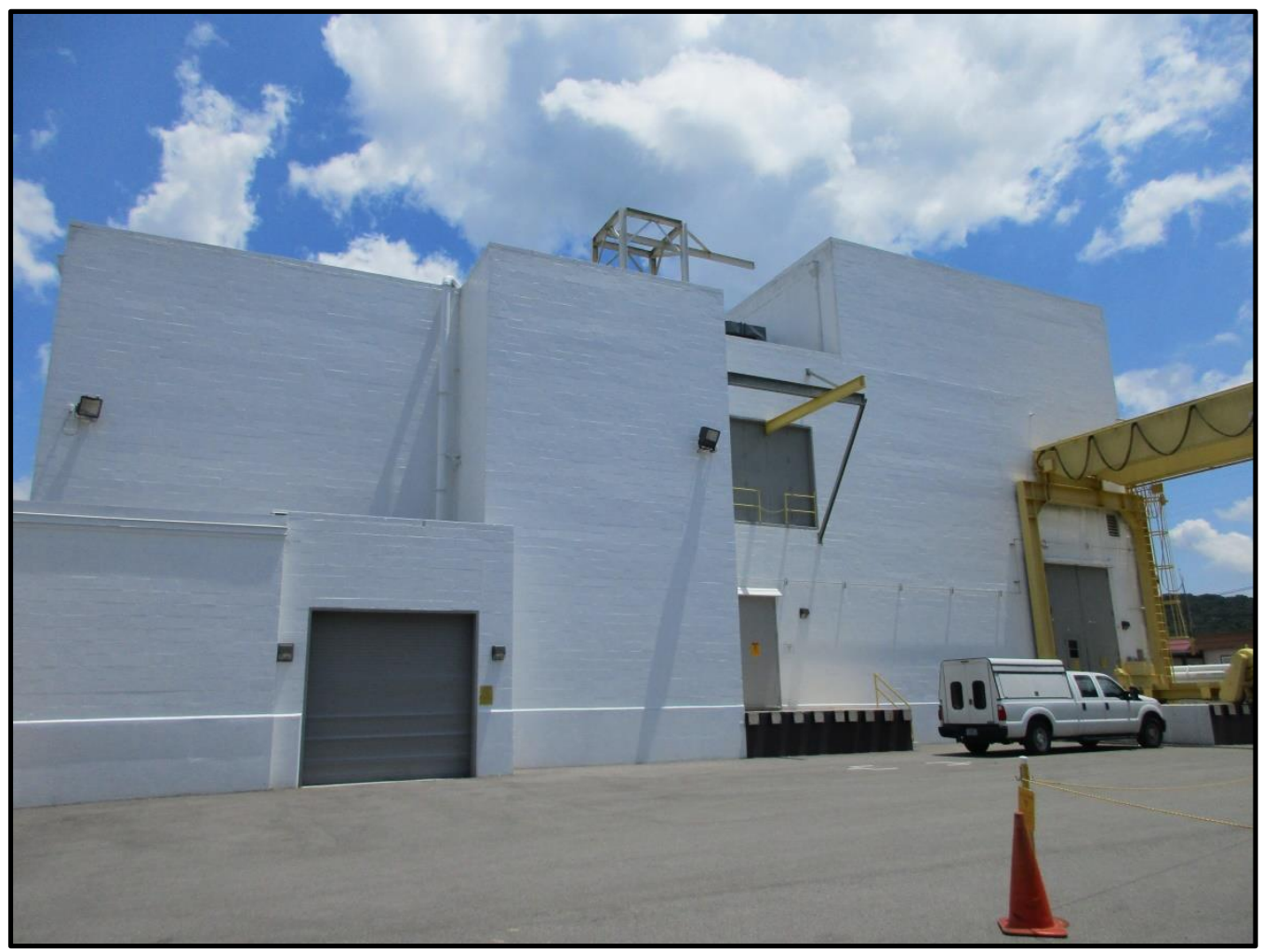

Figure 518. West elevation of Building 7920.

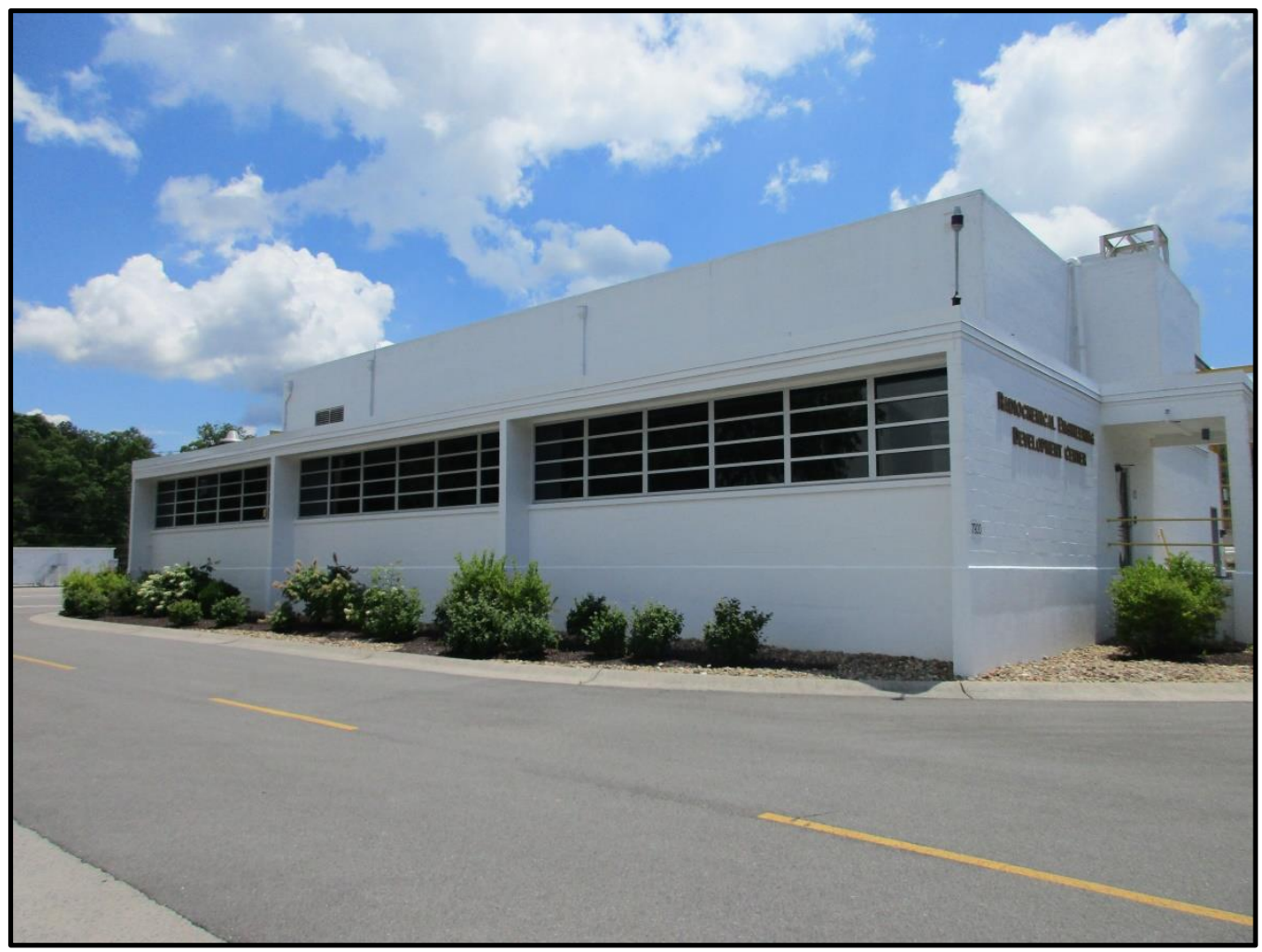

Figure 519. North elevation of Building 7920. 


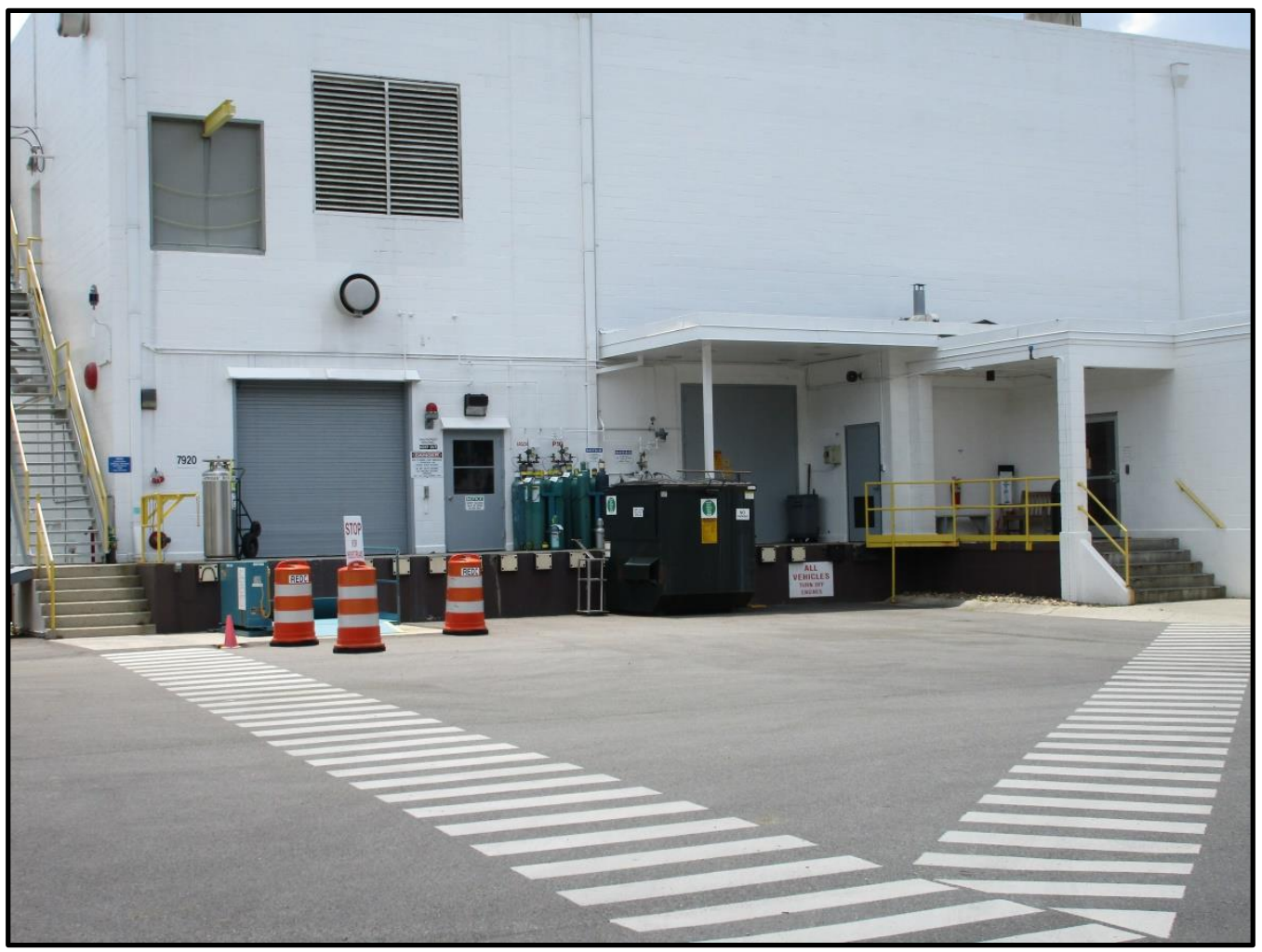

Figure 520. Loading dock on north elevation of Building 7920.

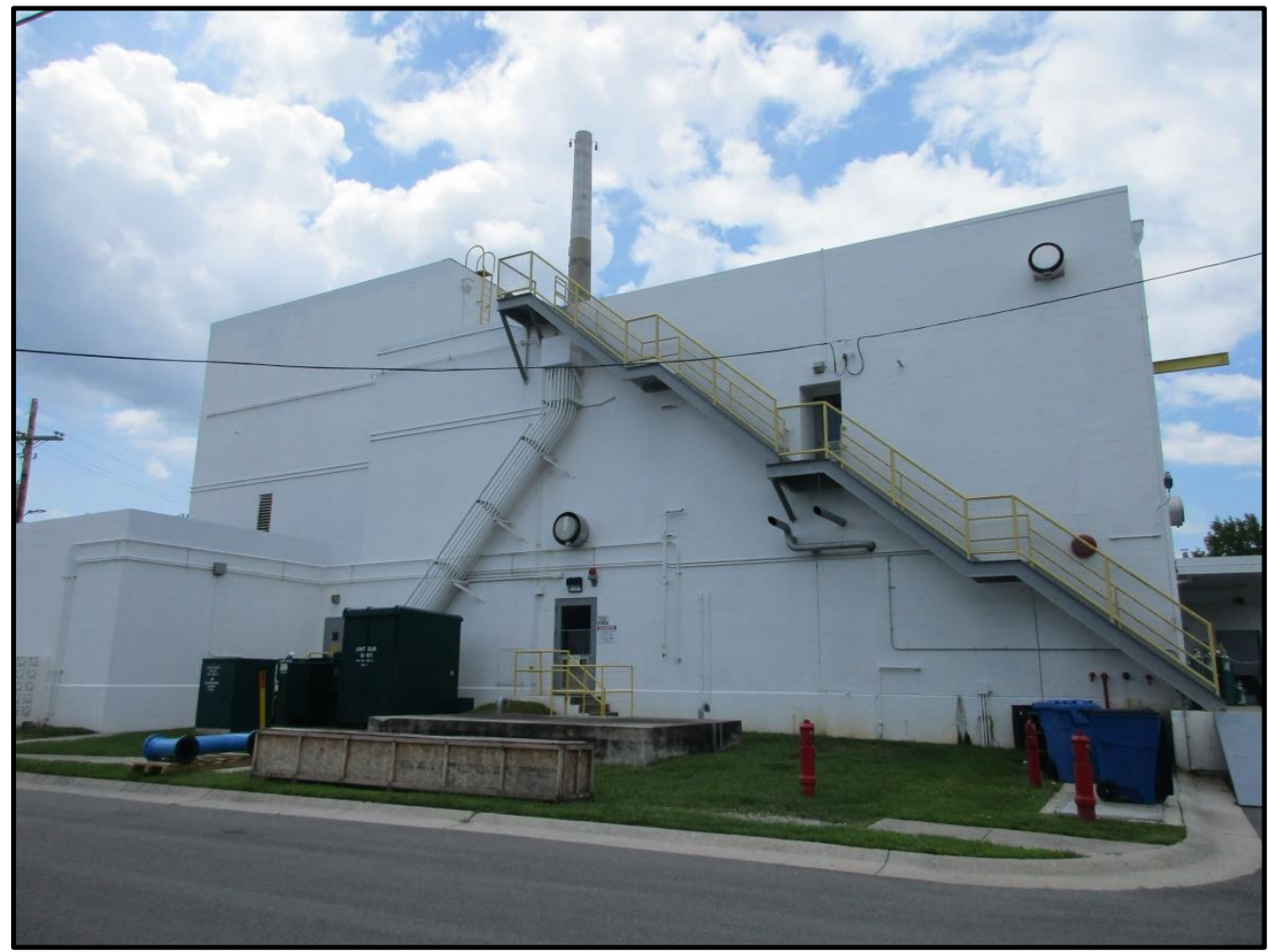

Figure 521. East elevation of Building 7920. 


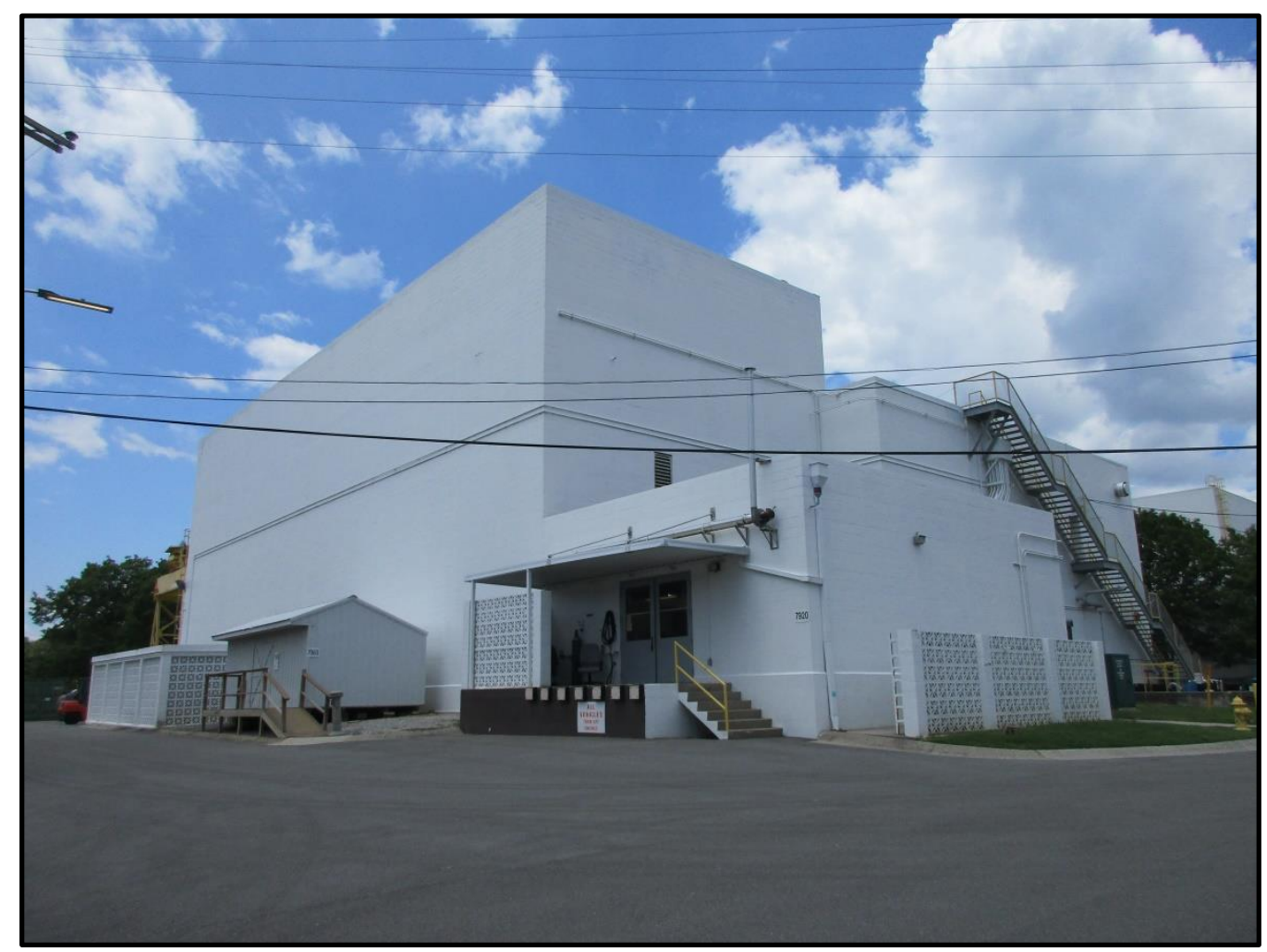

Figure 522. East and southeast elevations of Building 7920.

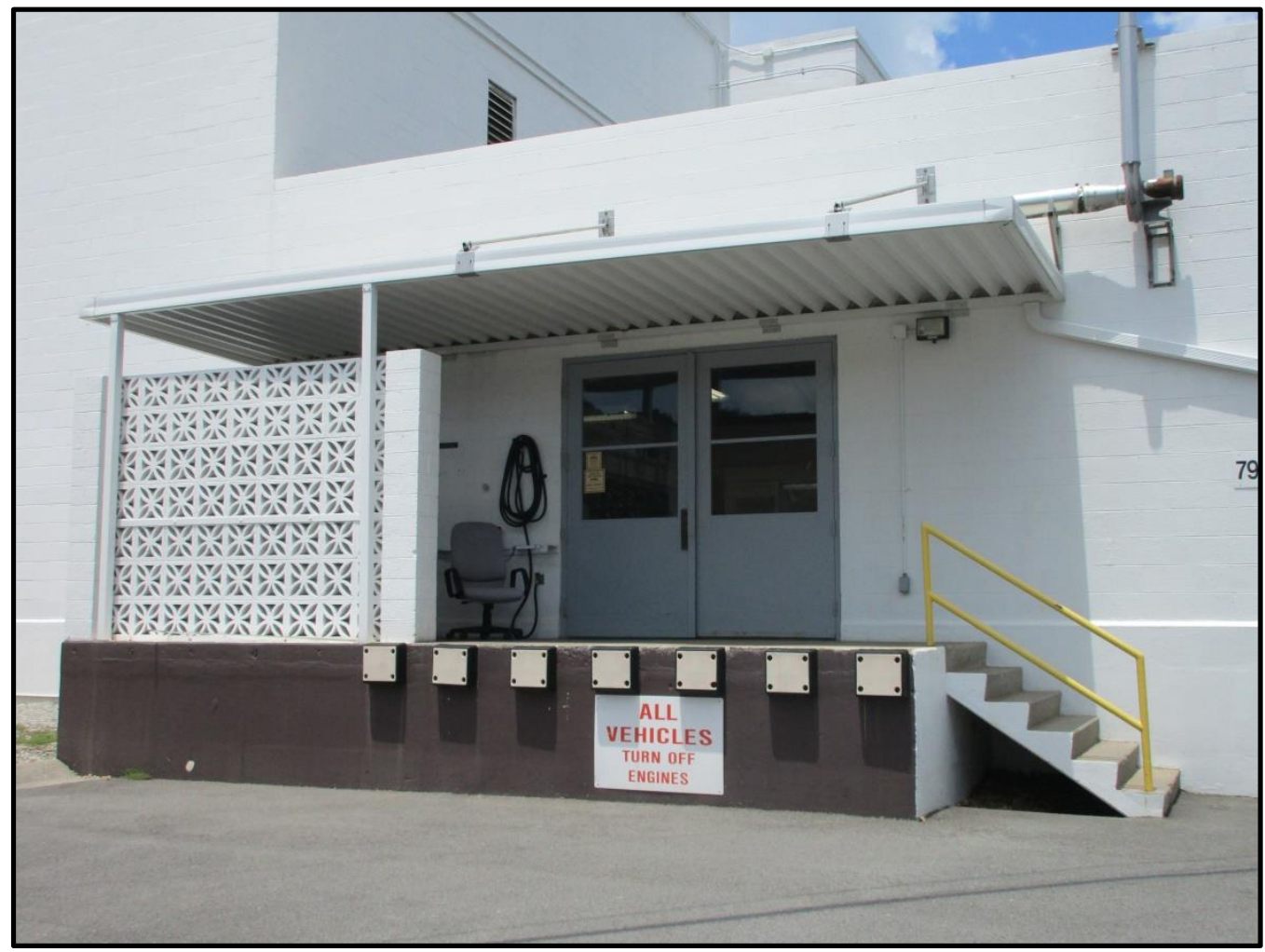

Figure 523. Entry on south elevation of Building 7920. 


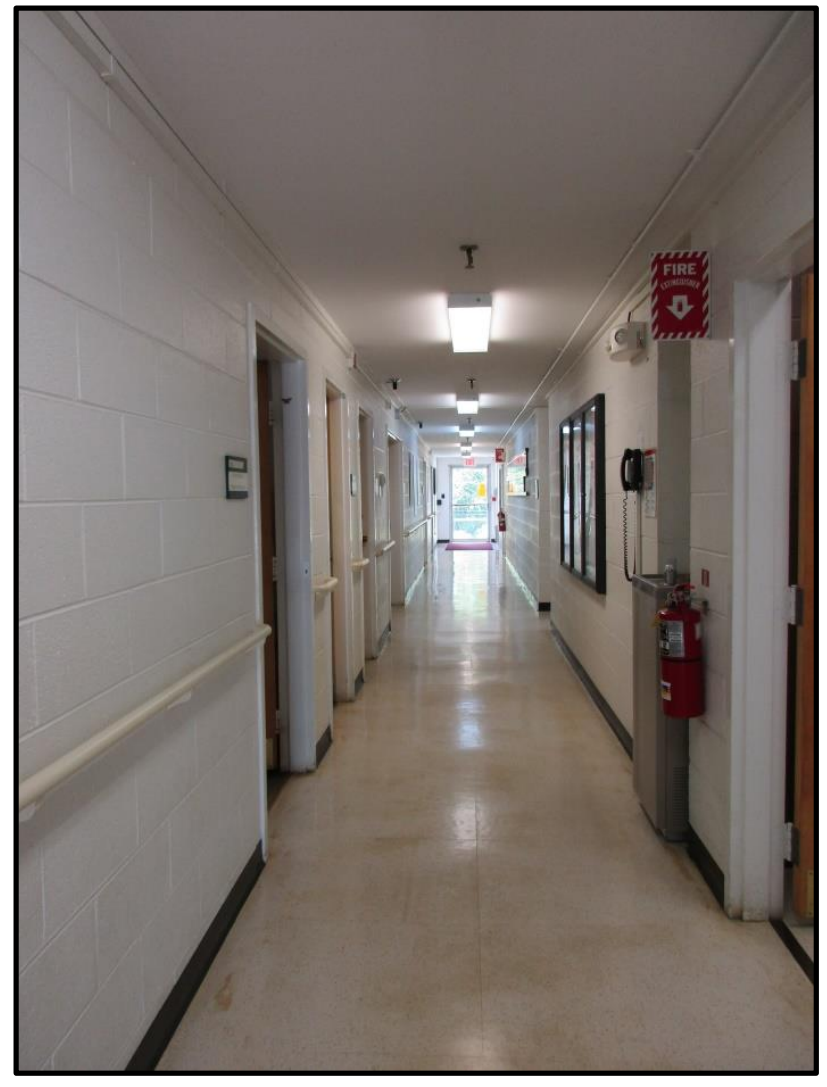

Figure 524. Corridor in one-story section of Building 7920.

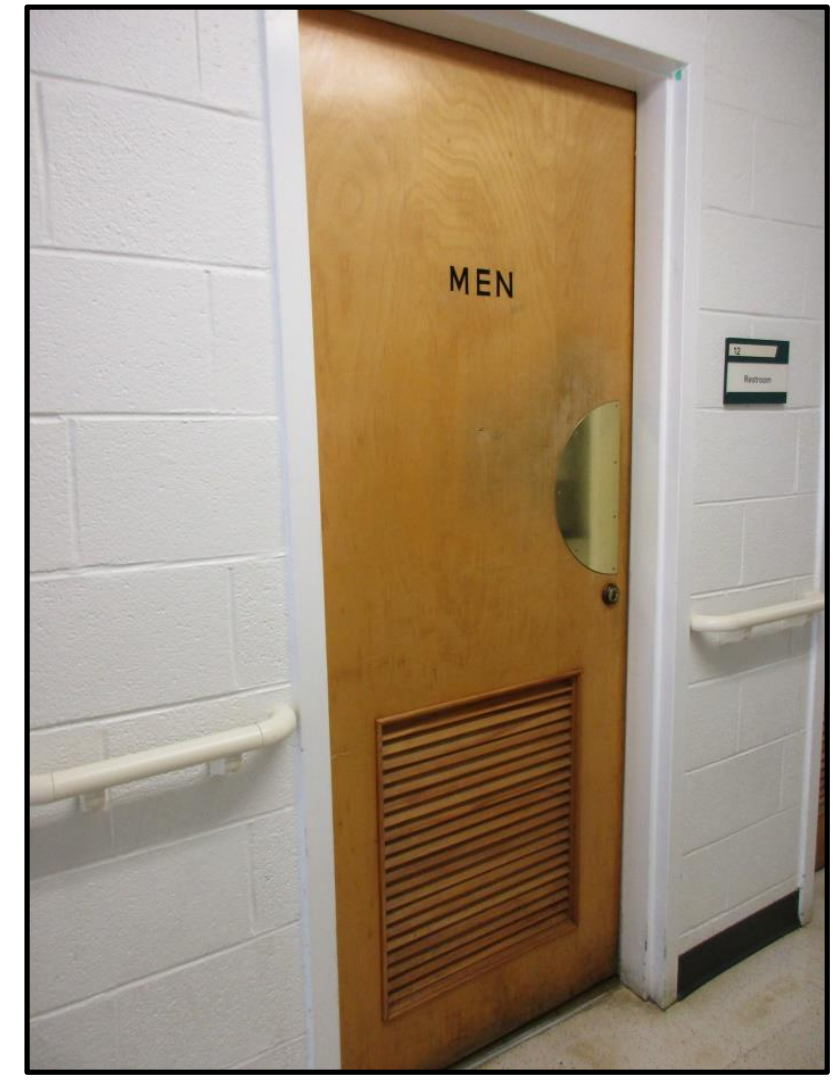

Figure 525. Original wood door with louvered vent on first floor of Building 7920. 


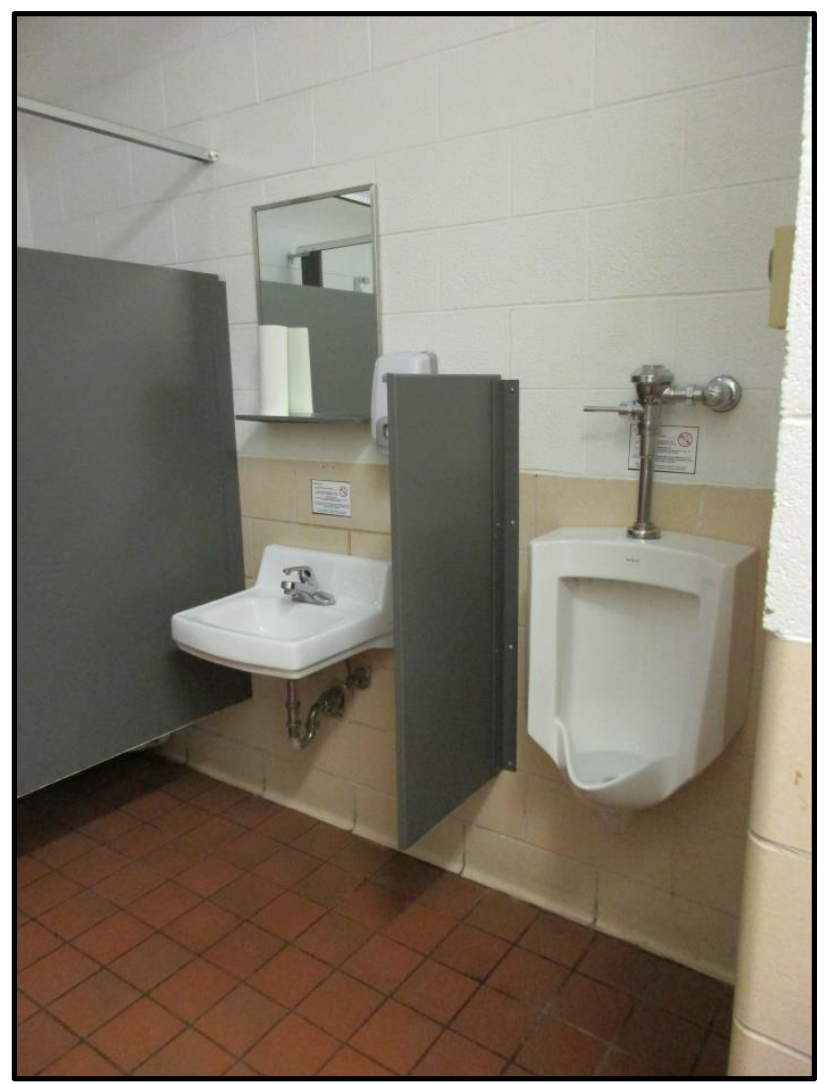

Figure 526. Restroom in one-story section of Building 7920.

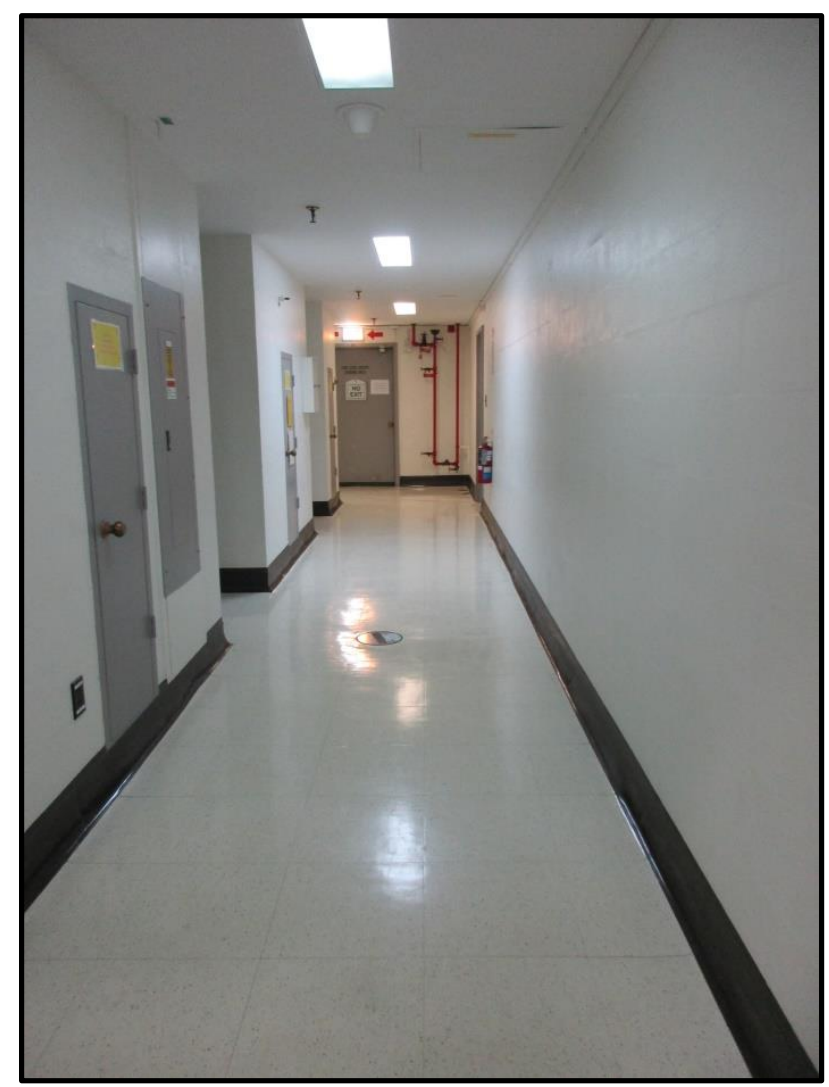

Figure 527. Corridor on first floor of Building 7920. 


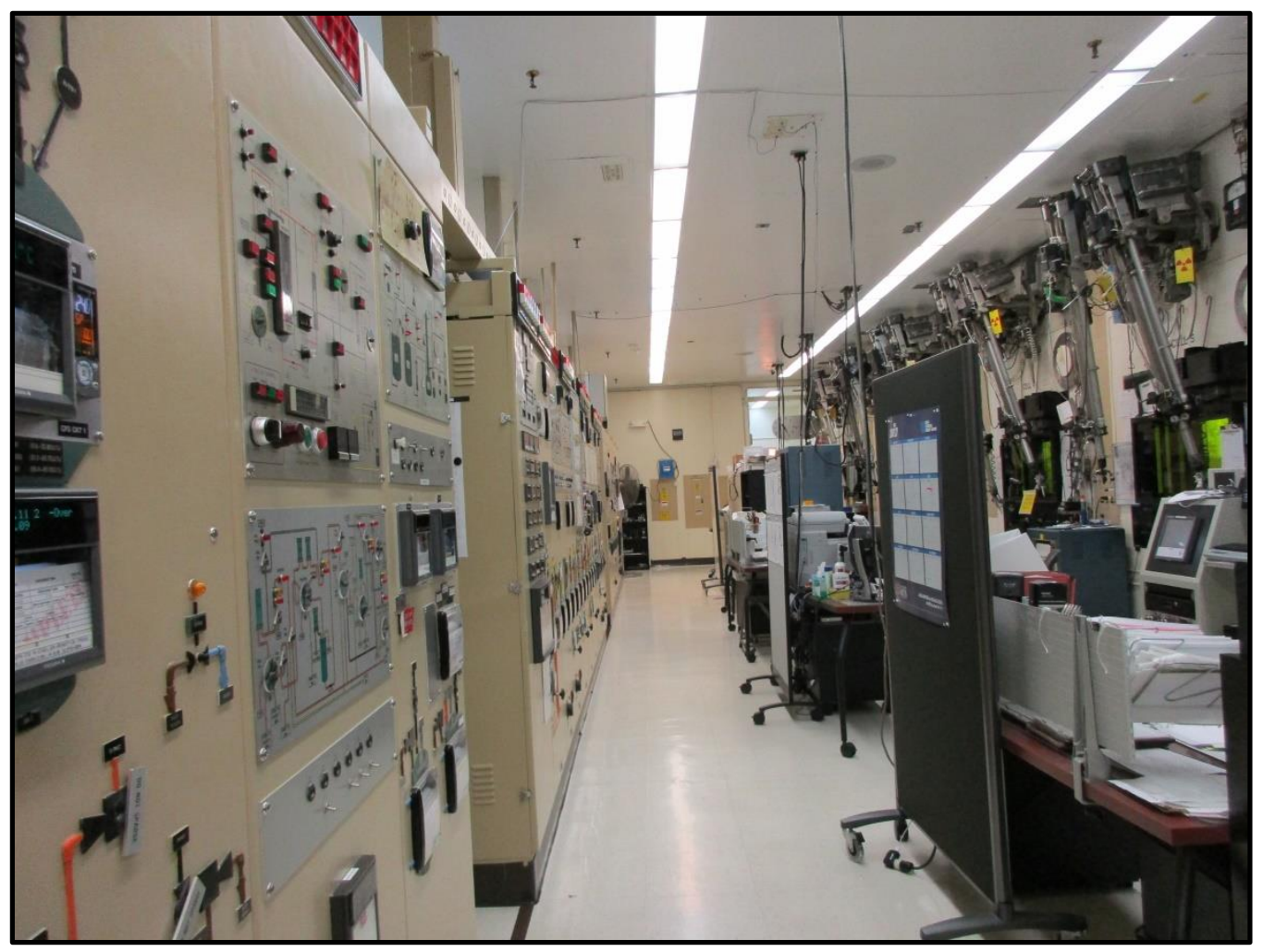

Figure 528. Laboratory space and hot cells on first floor of Building 7920.

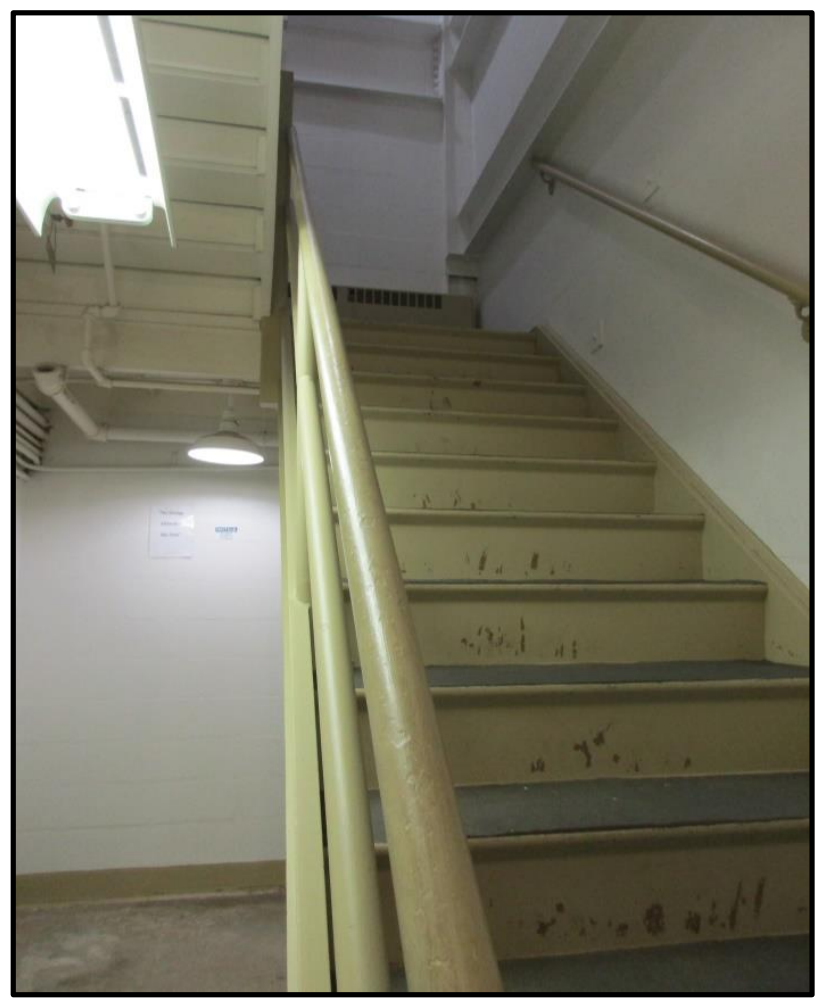

Figure 529. Stairwell in Building 7920. 


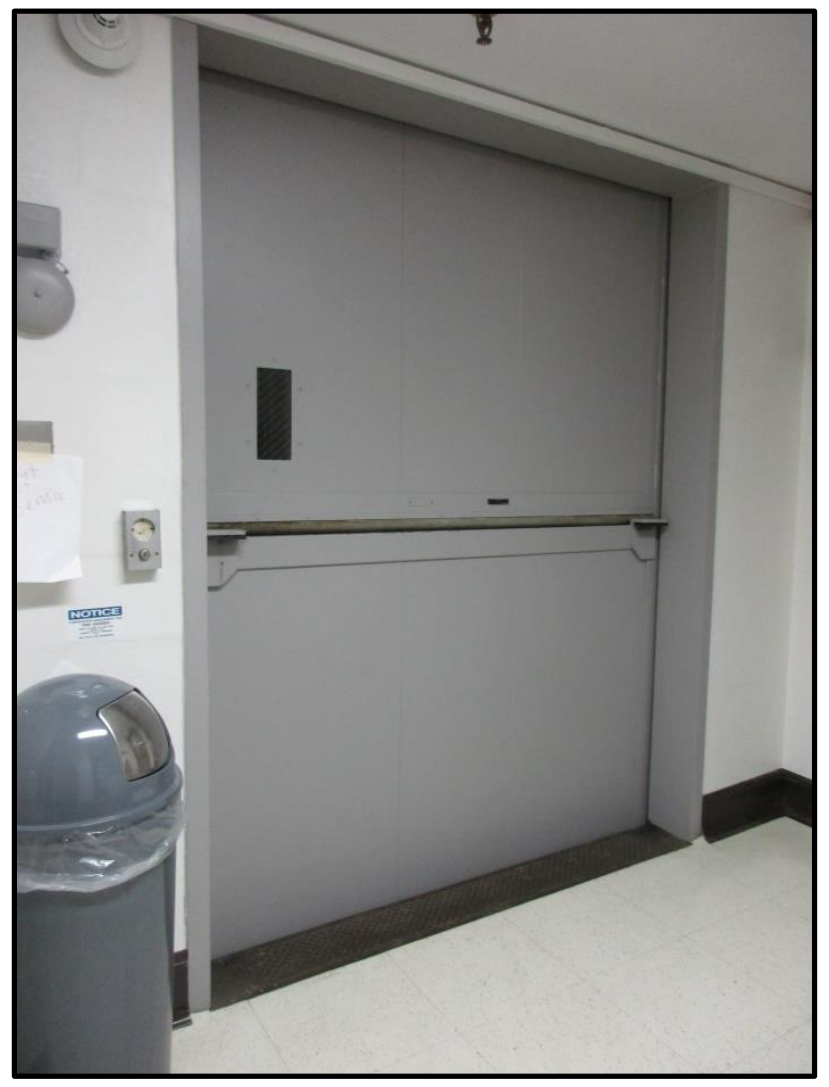

Figure 530. Freight elevator in Building 7920.

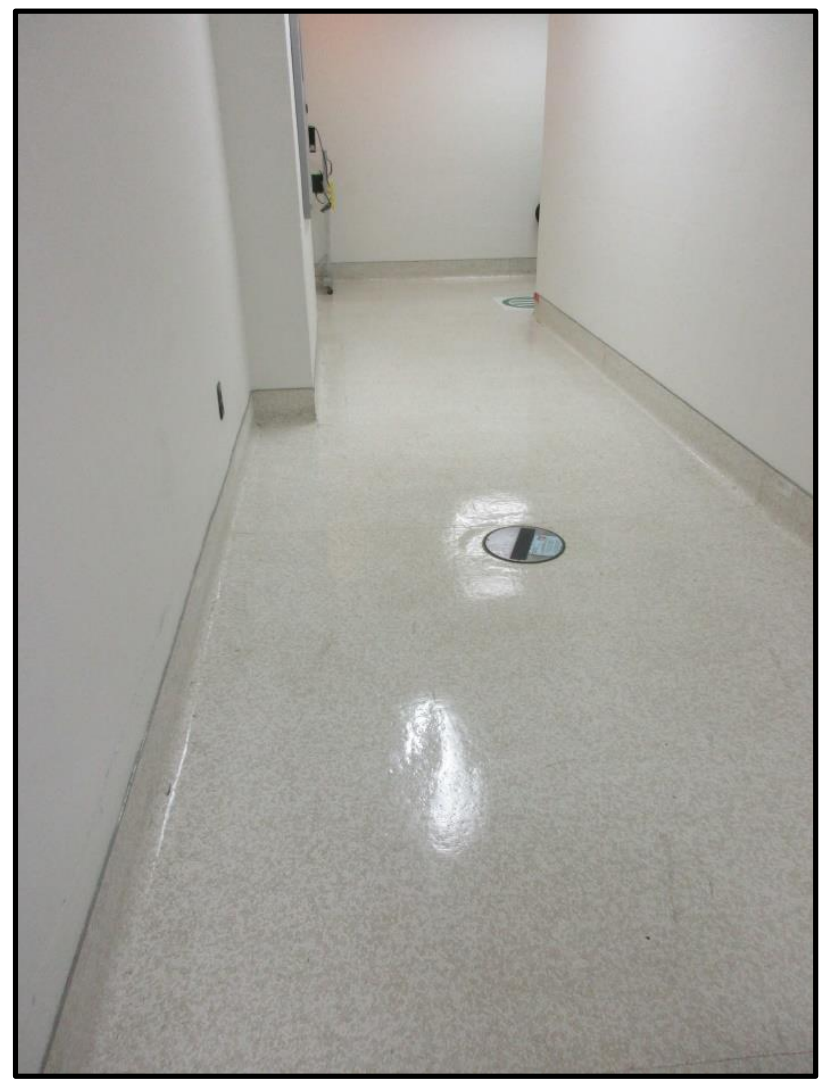

Figure 531. Corridor on second floor of Building 7920. 


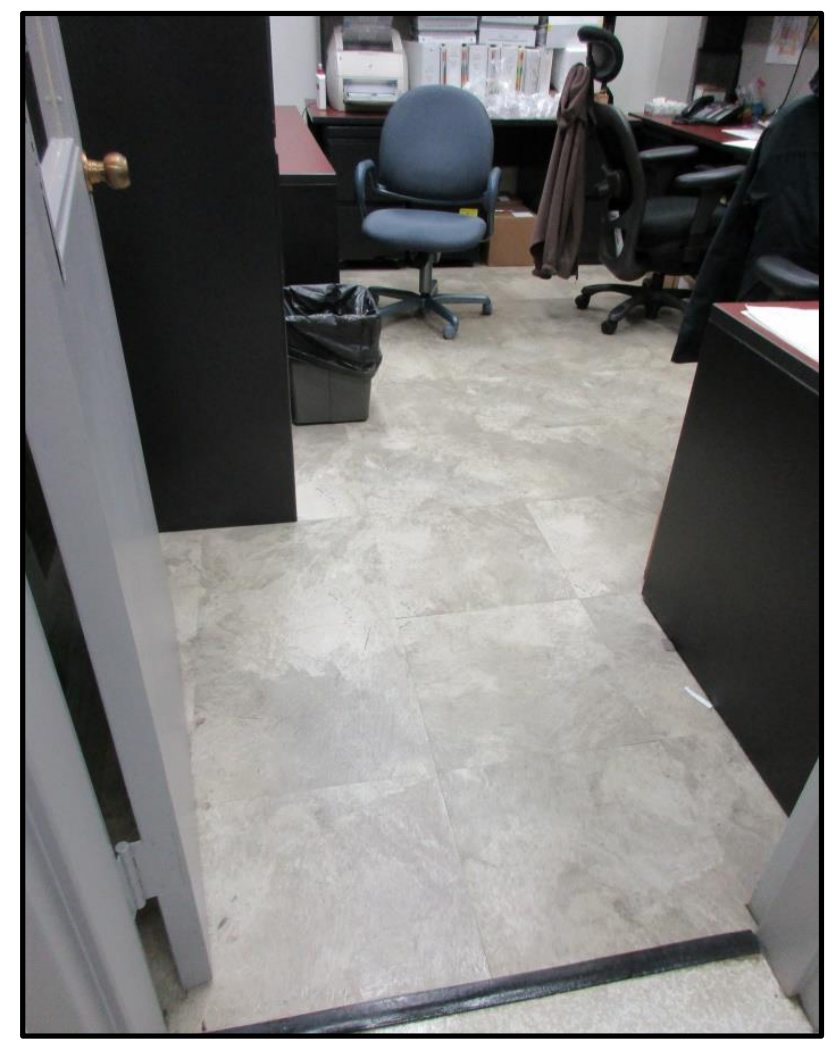

Figure 532. Renovated office space on second floor of Building 7920.

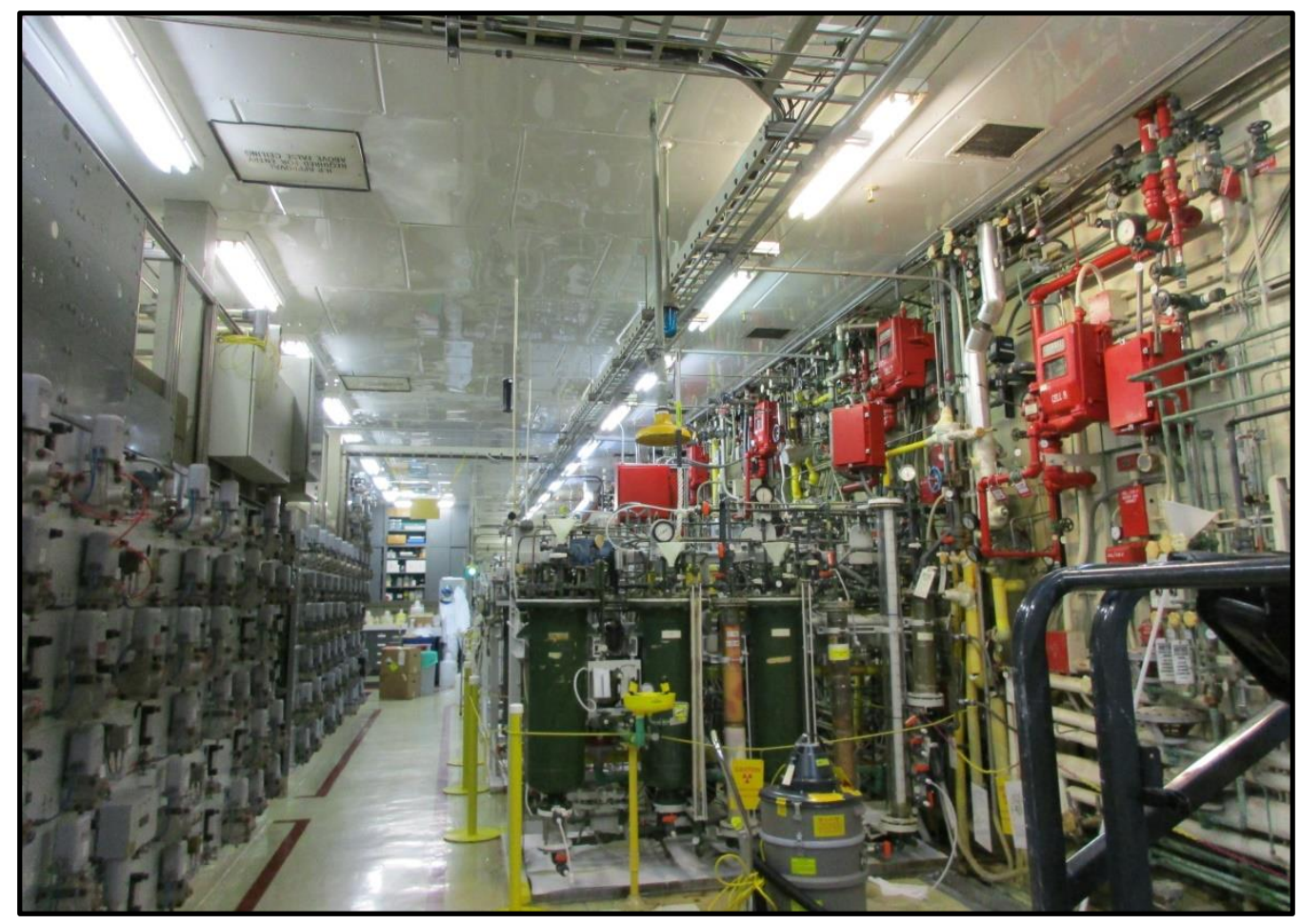

Figure 533. Laboratory space on second floor of Building 7920. 


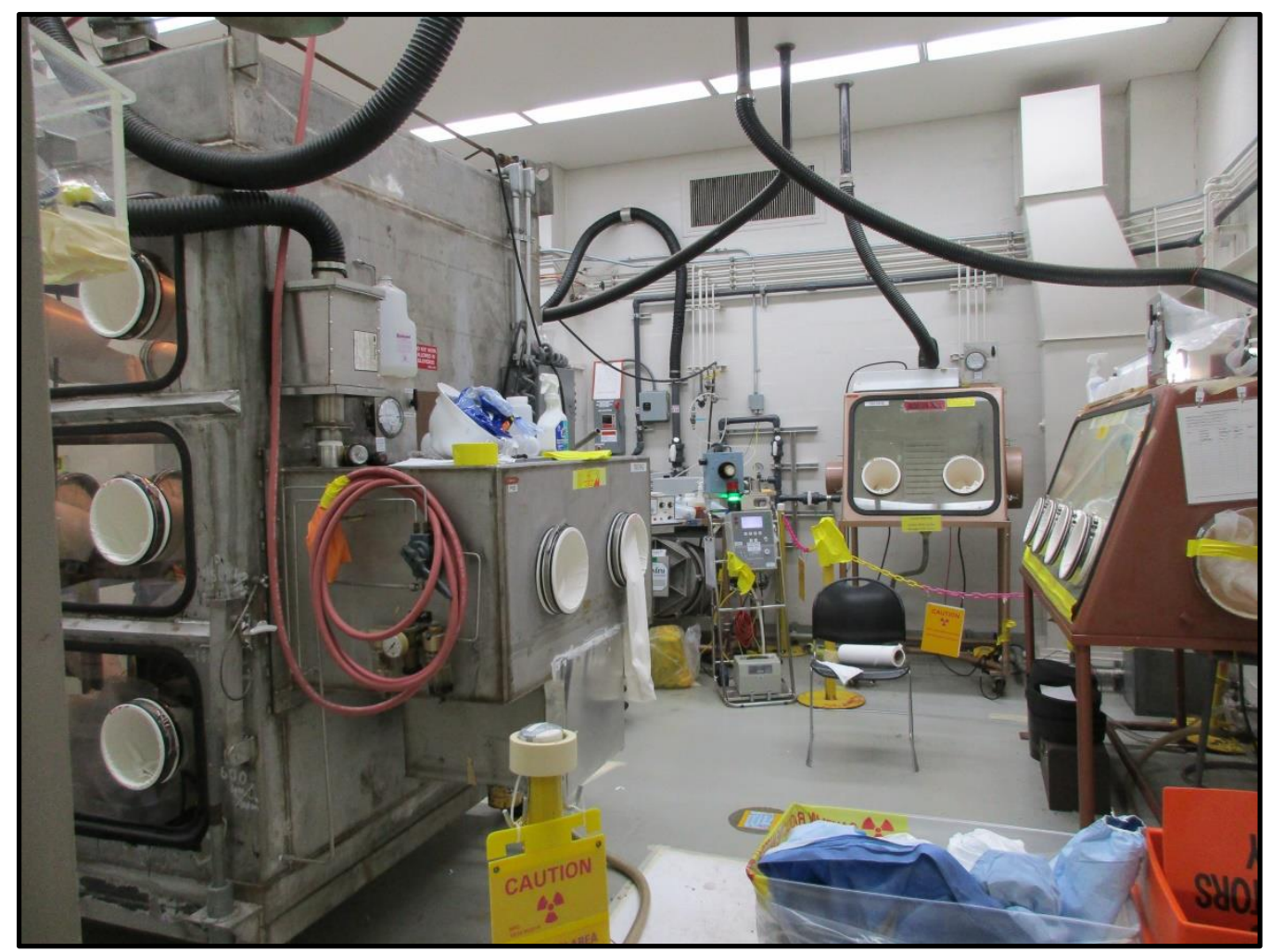

Figure 534. Laboratory space on second floor of Building 7920. 


\section{BUILDING NAME}

Thorium-U Recycle Facility

\section{DATE OF CONSTRUCTION}

1968

\section{DOE OFFICE RESPONSIBLE}

SC

\section{NRHP ELIGIBILITY}

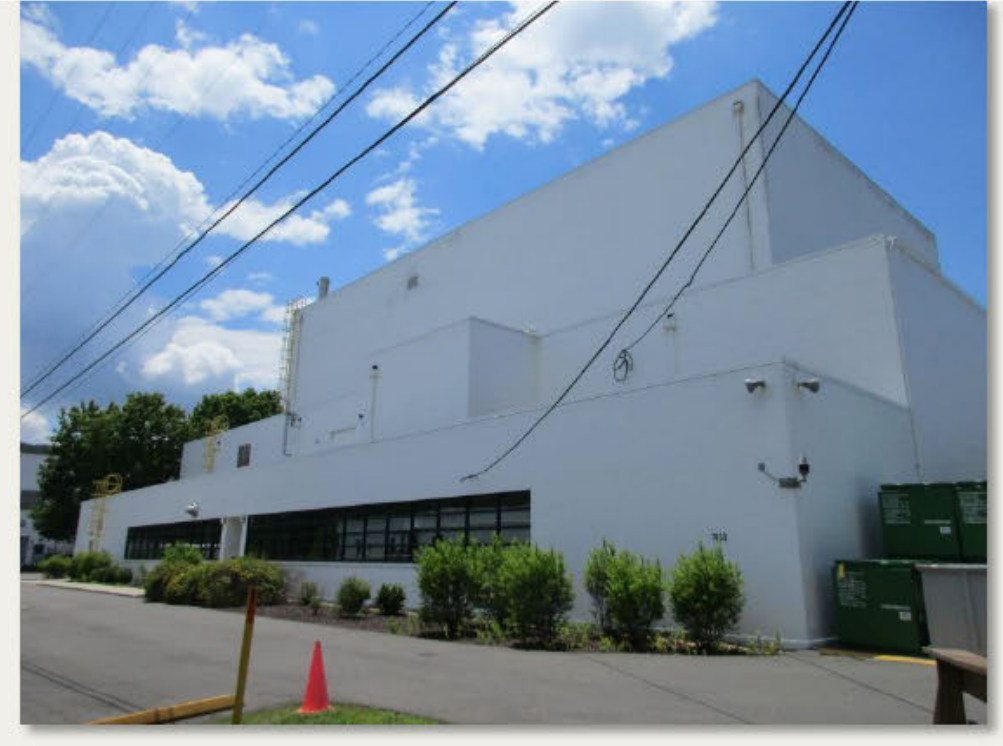

Contributing to HFIR/REDC Facility

\section{DESCRIPTION}

Building 7930 was one of 15 resources selected for intensive survey by UT-B as a part of survey planning. It is located within the Melton Valley Campus. Located generally south of the main campus of ORNL and Melton Valley Road, the Melton Valley Campus is focused upon the operation and support of Building 7900.

Exterior: Building 7930 is a generally rectangular building of steel and concrete block construction that features one-, two, and three-story sections (Figure 535). Situated upon a continuous poured concrete foundation, Building 7930 is sheltered by a flat roof with metal coping. The only windows found on Building 7930 are located on the first floor of the east (façade) elevation.

Centered on the façade, or east elevation, is the recessed façade entry with an original full-light aluminum door and full-light sidelight topped by a transom (Figure 536). Banks of four-light replacement windows flank the recessed façade entry. The glass in these windows is tinted and reflective. The two-story section features a single former entry on the second floor that has been enclosed.

The north, or side, elevation of Building 7930 features two single entries and a stairwell to the basement level; however storage crates and containers blocked the view of these entries at the time of survey (Figure 537 and 538). A two-story rectangular concrete block projection extends from the center of the rear, or southwest, elevation. Two secondary entries are located to the left of the projection (Figure 539). A single secondary entry is located on the projection and another secondary entry is located to the far right of the projection (Figure 540). All of the entries on the southwest elevation of Building 7930 feature single-leaf steel doors (Figure 0801). The south elevation features a one-story section with original double-leaf six-light hinged steel doors (Figure 541). A secondary entry with a single-leaf steel door is located to the right of the hinged doors on a two-story section of Building 7930 .

Interior: The interior of Building 7930 is characterized by research facilities including centrally located hot cells. The first floor plan features access to Hot Cells A, B, C, D, E, and G, a fuel transfer pool, and a corridor that provides access to offices and change rooms along the east side of Building 7930 . The first floor corridor features replacement commercial grade tile, concrete block and drywall walls, and a drop ceiling with acoustic ceiling tiles (Figure 542). Hot cells B, C, D, E, and G are accessed through an operating area that surrounds 
them (Figure 543). The fuel transfer pool is also located on the first floor (Figure 544). Stairwells and a freight elevator provide access to the second floor (Figures 545 and 546).

A portion of the second floor is open to a third floor within a high bay research area (Figure 547). Offices divided by metal interlocking walls have been added to the north end of the second floor (Figure 548). Hot cells C, D, E, $F$, and $G$ extend to the basement level of Building 7930. The basement also contains renovated laboratory space with original doors and replacement casework (Figure 549).

\section{NATIONAL REGISTER EVALUATION}

Building 7930 was constructed in 1968 as part of the Radiochemical Engineering Development Center (REDC). The REDC, comprised of two facilities-the Transuranic Facility (REDC-1, Building 7920) and the ThoriumUranium Recycle Facility (REDC-2, Building 7930)—was constructed to chemically extract the newly-produced, intensely radioactive heavy elements produced within the HFIR. The REDC serves as the national center of production, storage, and distribution of transuranium elements for the DOE's heavy-element research programs. Activities completed within Building 7930 include chemically processing californium, making and preparing neutron sources, recovering $\mathrm{Cm}-248$ from californium, and providing neutron irradiation services (Thomason and Associates 2015:57).

In 1994, Duvall \& Associates' survey of ORNL recommended HFIR (the 7900 Area) was not eligible for listing in the NRHP because it was less than 50 years old and it was the third of its kind developed in the United States, so it was not a new significant technology (Carver and Slater 1994:324). The HFIR facility was not included in Thomason and Associates' 2004 survey updates (Thomason and Associates 2004). The 2015 survey update completed by Thomason and Associates recommended that Building 7900 and its associated facilities, Buildings 7901, 7920 and 7930, met NRHP Criterion A for significance in science and health/medicine as ORNL's only operating reactor and one of the world's most powerful and capable research reactors (Thomason and Associates 2015:56).

As a research/laboratory facility, Building 7930 and its counterpart, Building 7920, are significant contributing resources within the larger HFIR/REDC facility in the 7900 Area. The work of REDC supports the operation of and employs radioisotopes produced by HFIR while also pursing independent missions in chemical engineering. Thus, in order to reflect the significant role of the synergistic and inter-dependent relationship between the two facilities, the buildings of REDC qualify for listing in the NRHP as a part of the HFIR/REDC facility, which was important in the advancement of ORNL's mission in nuclear science and isotope research, key fields of study during the Cold War era. Because Building 7930 is not the sole building most closely associated with a scientific breakthrough or a scientist of truly exceptional importance, its significance is most appropriately recognized as a component part of the larger HFIR/REDC facility, and thus does not qualify for individual listing in the NRHP under Criterion A or B. Additionally, Buildings 7920 and 7930 exhibit the simple institutional design that characterized ORNL's Cold War era facilities, lacking notable stylistic elements that would warrant listing under Criterion C. 


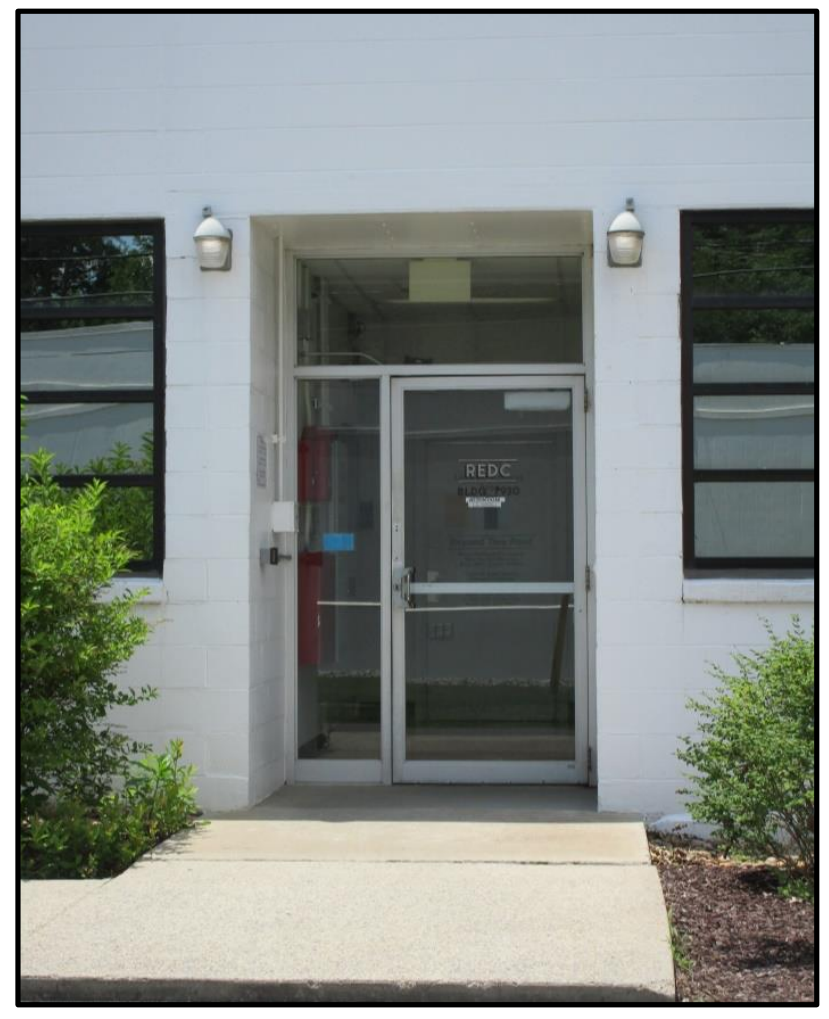

Figure 536. Façade entry of Building 7930.

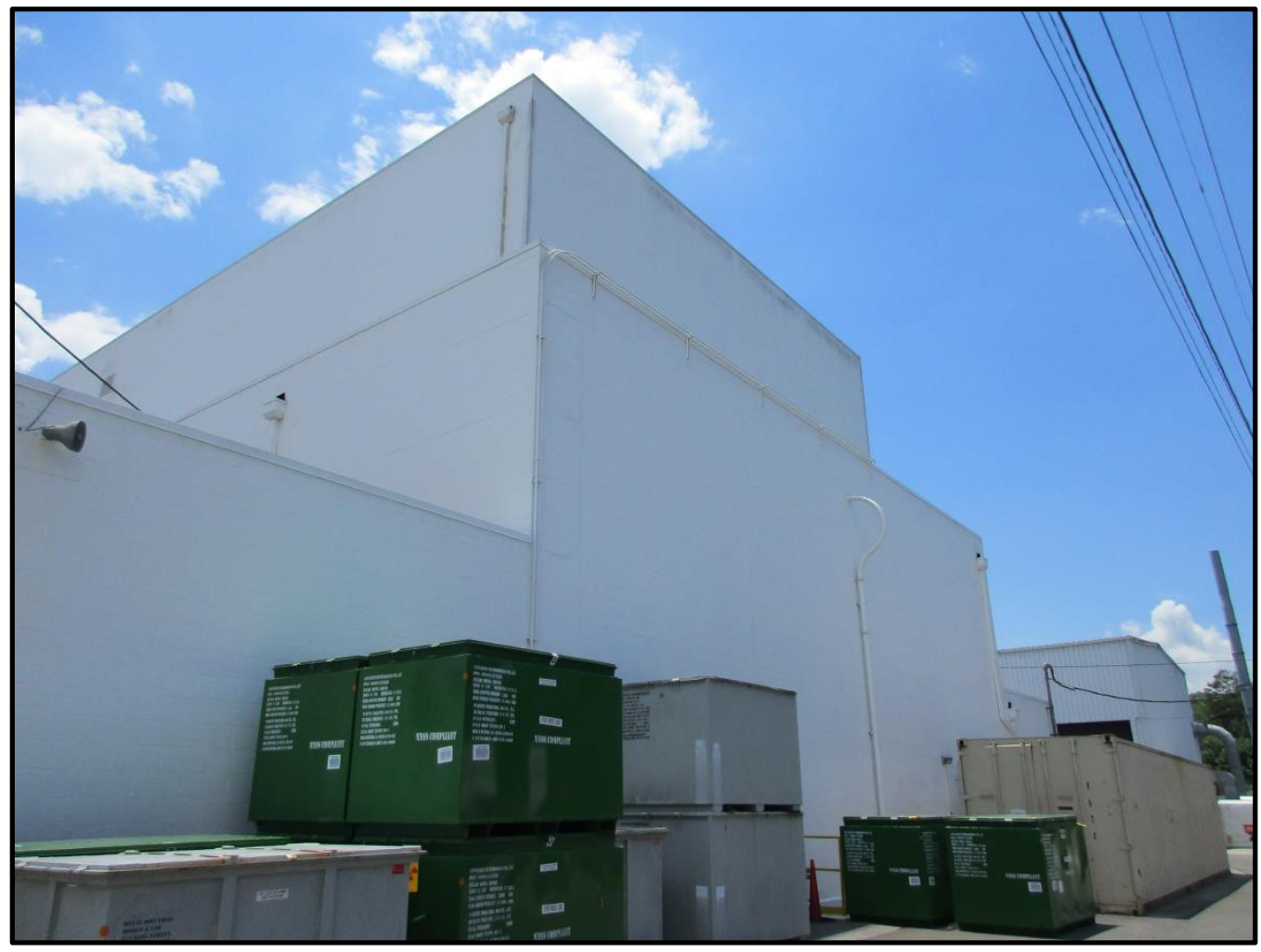

Figure 537. North elevation of Building 7930. 


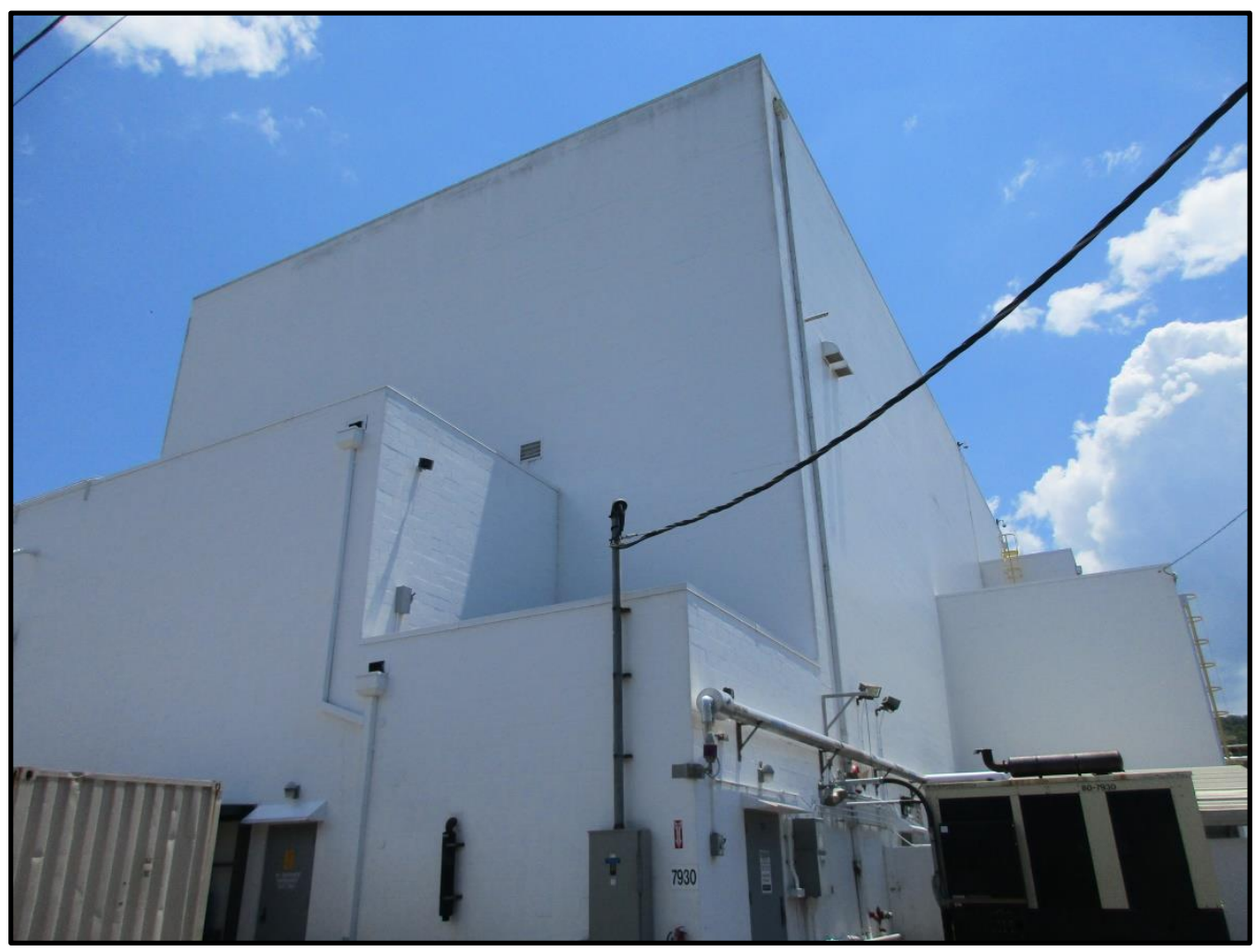

Figure 538. North elevation of Building 7930.

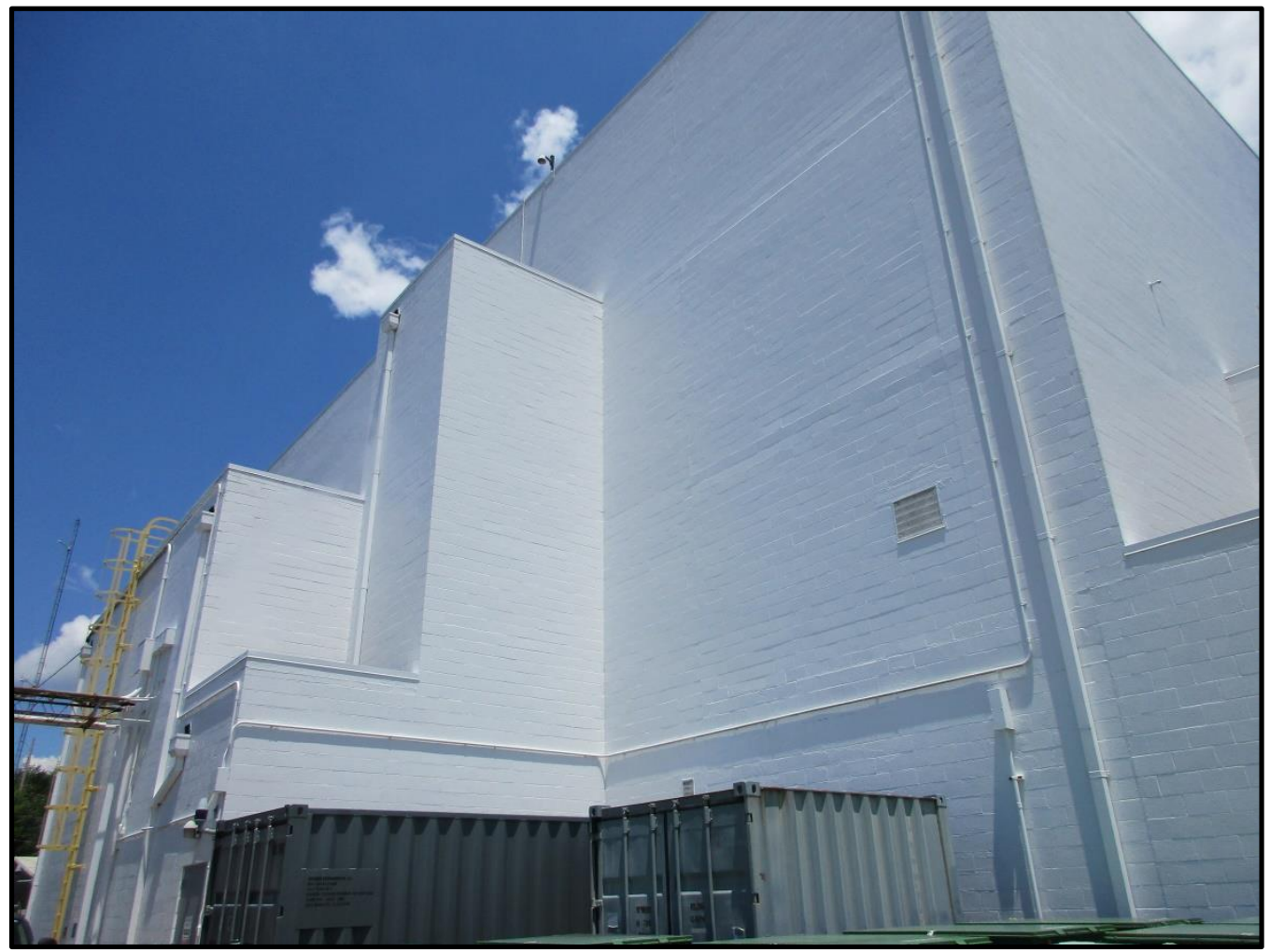

Figure 539. West elevation of Building 7930. 


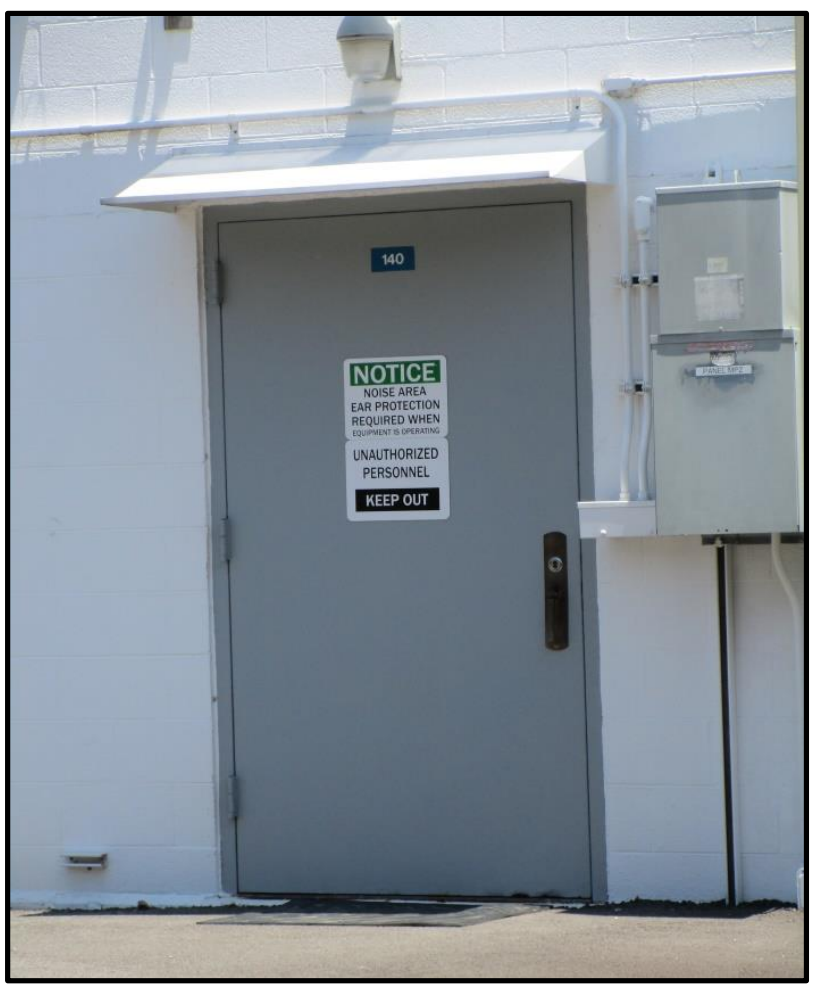

Figure 540. Entry detail on the west elevation of Building 7930.

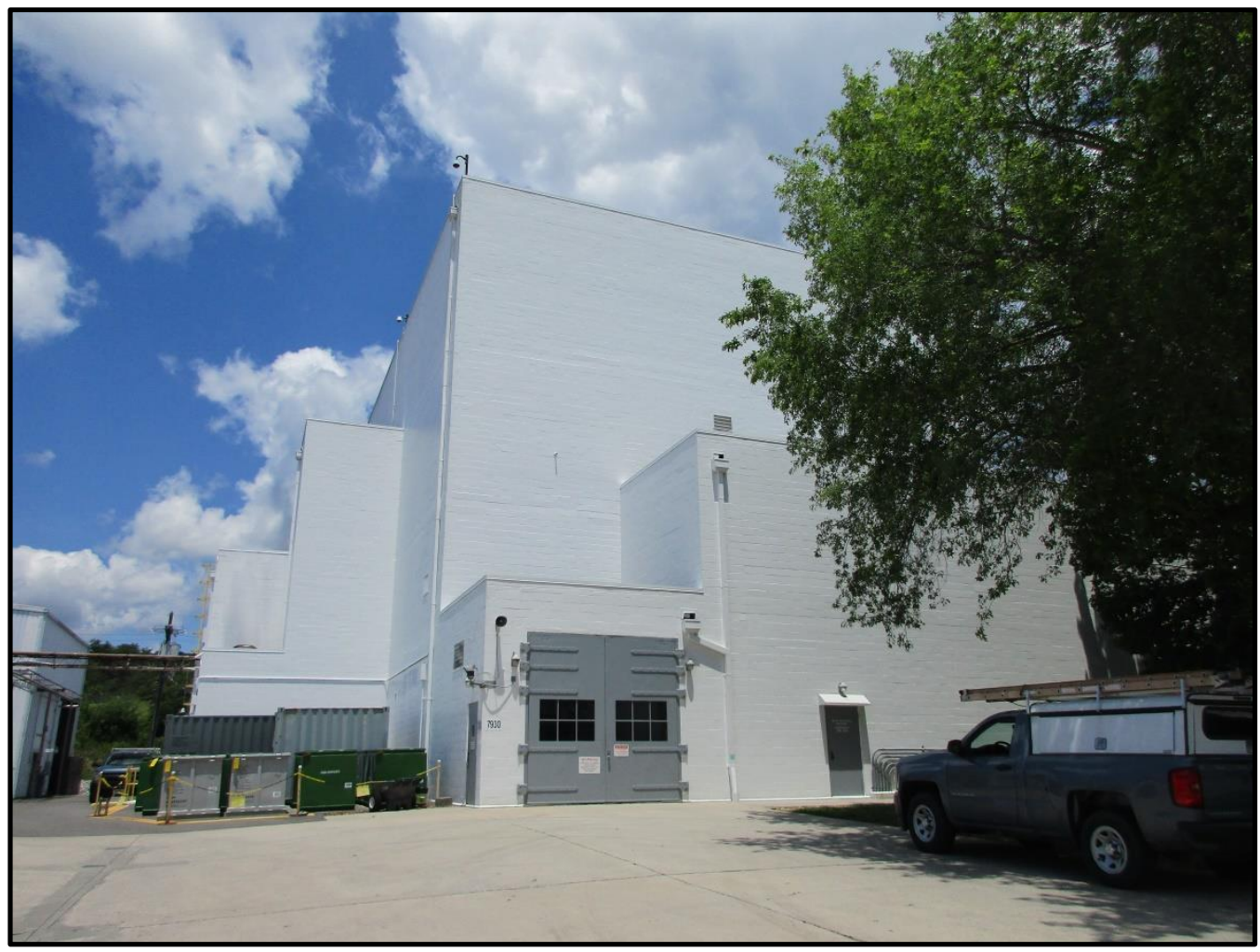

Figure 541. South elevation of Building 7930. 


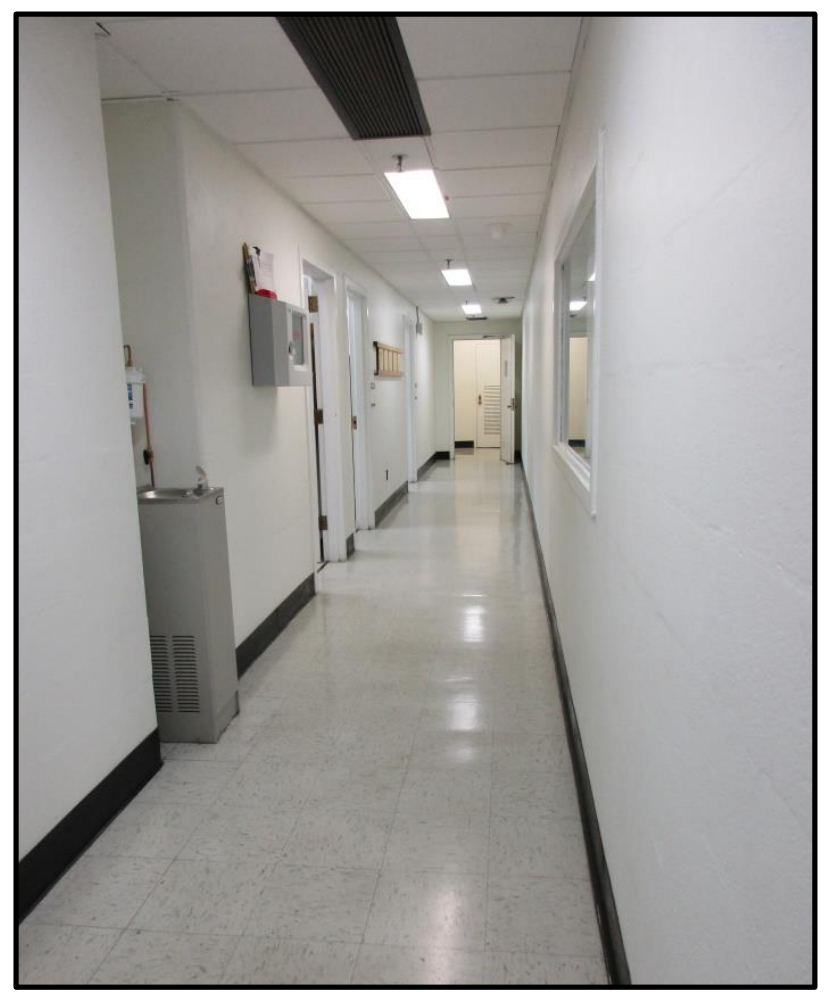

Figure 542. First floor corridor of Building 7930.

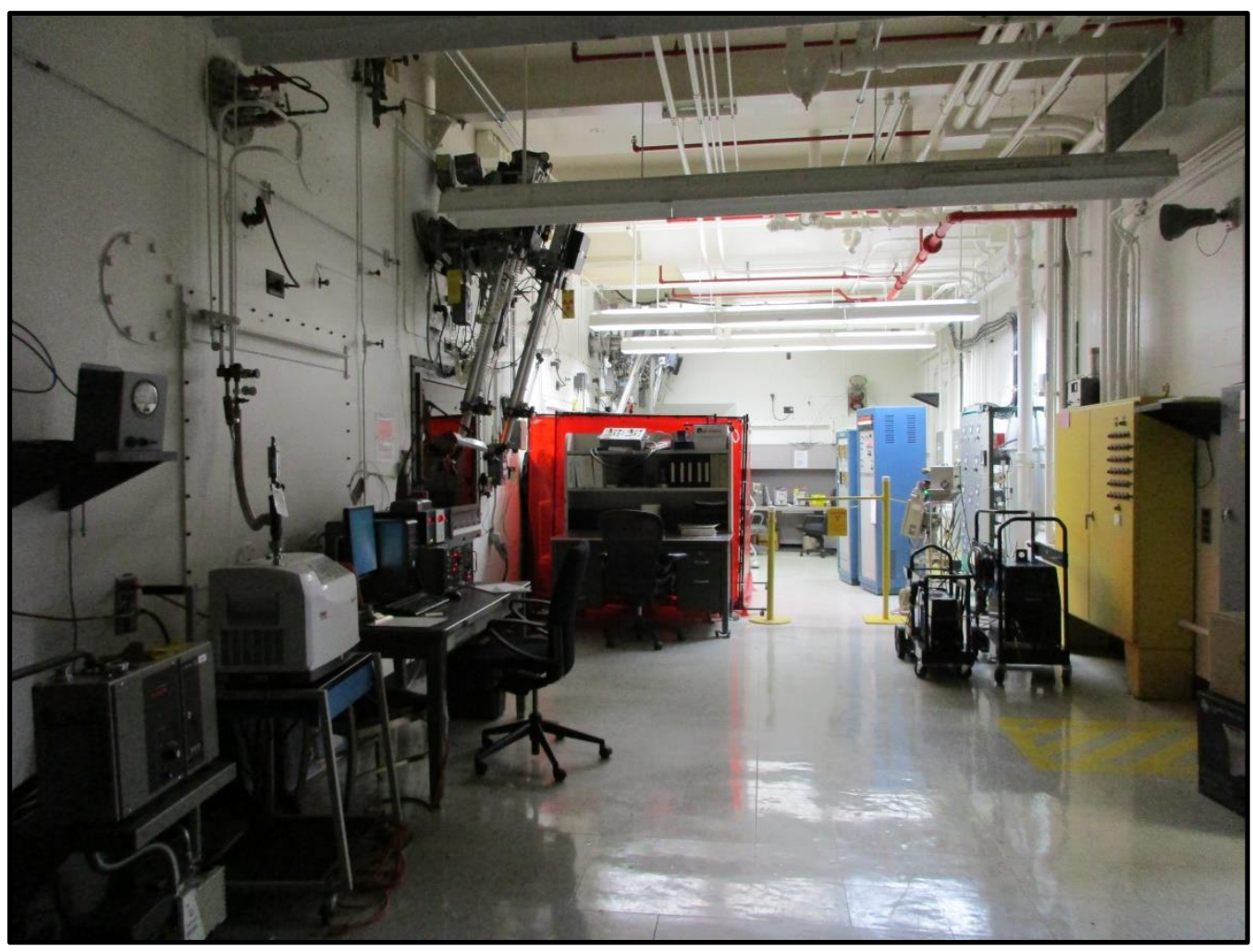

Figure 543. Hot cells on first floor of Building 7930. 


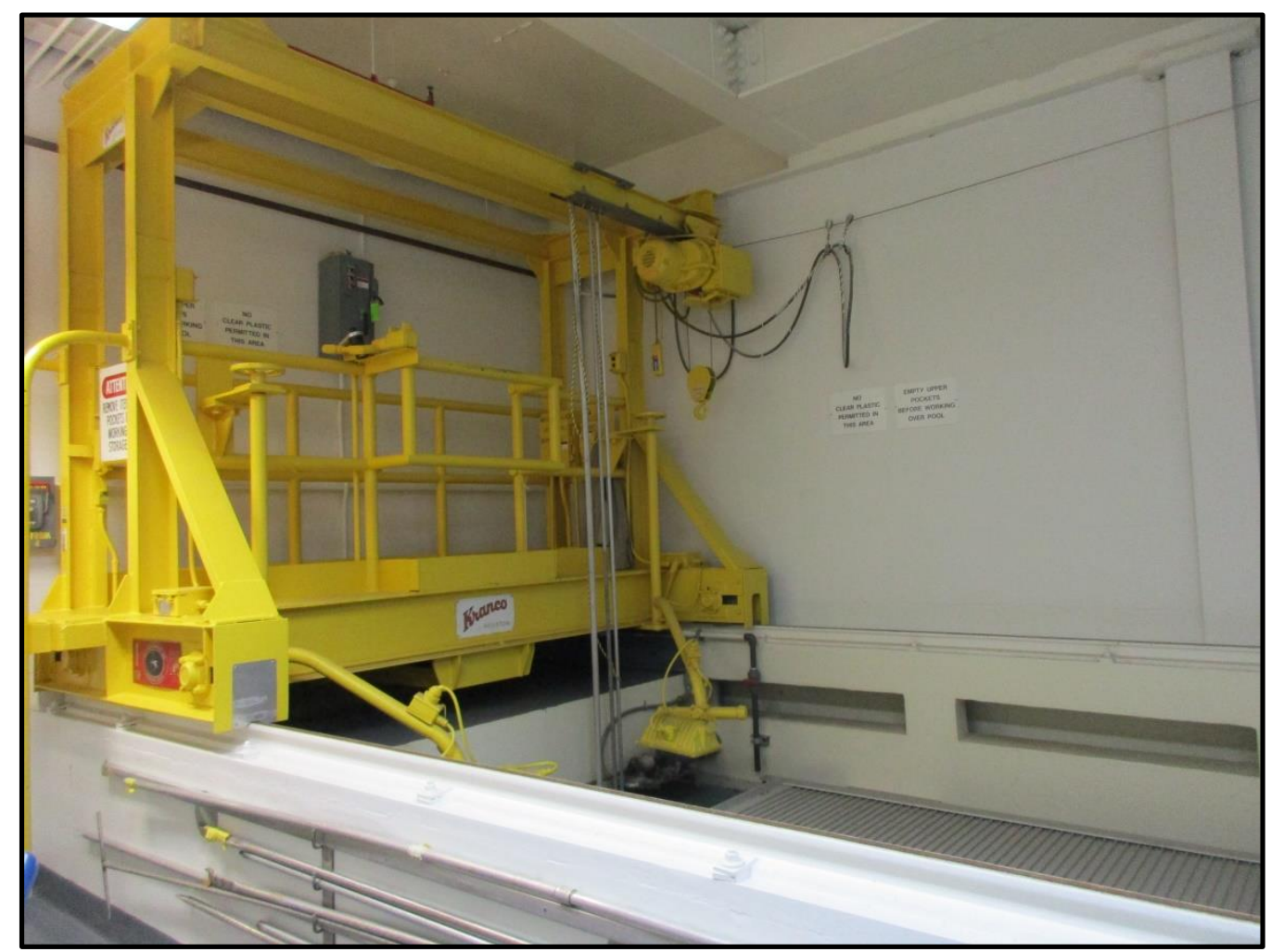

Figure 544. Fuel transfer pool in Building 7930.

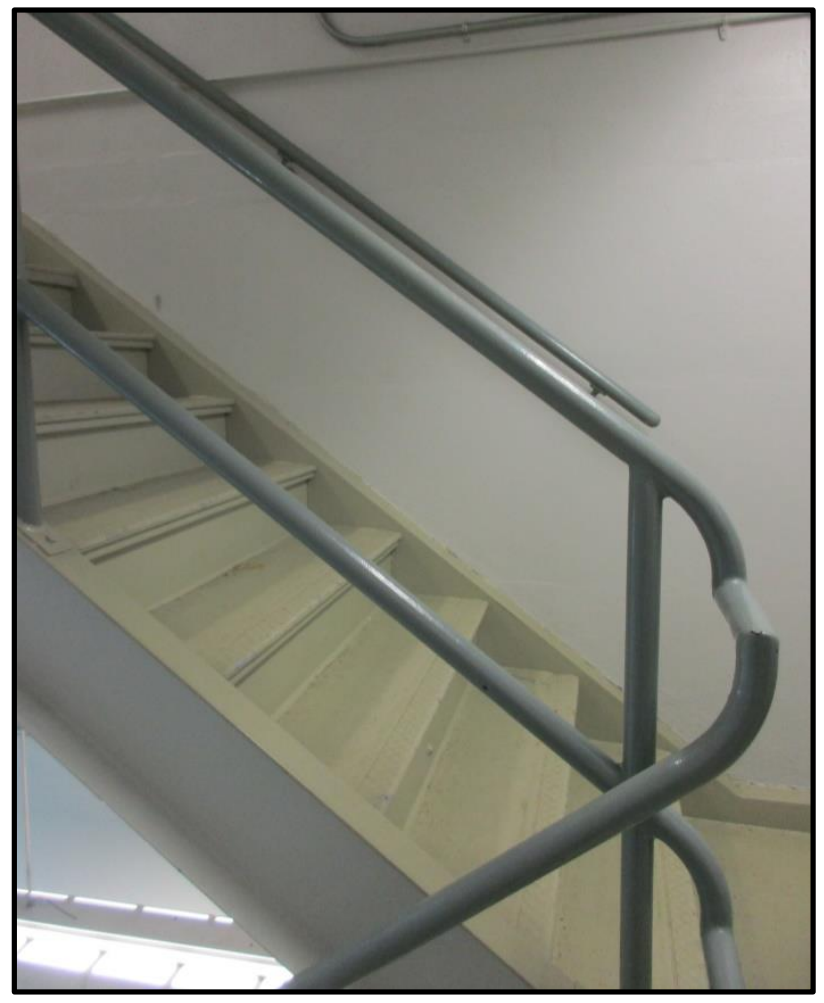

Figure 545. Stairwell in Building 7930. 


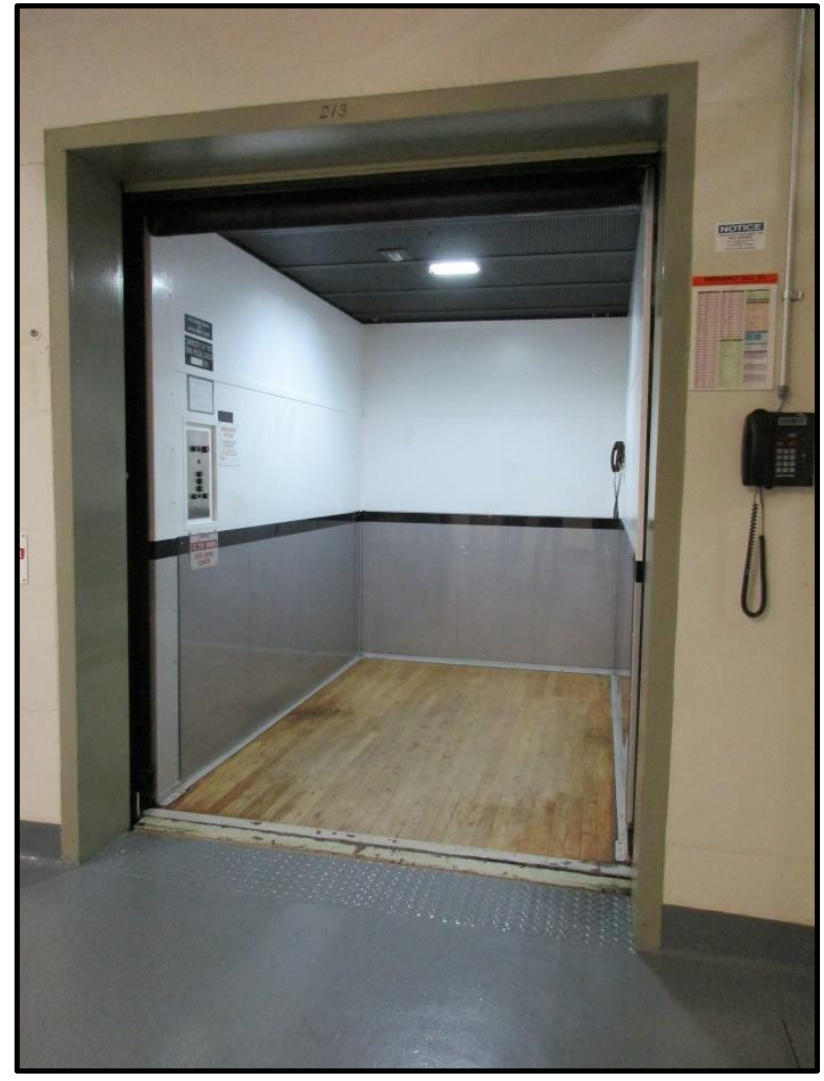

Figure 546. Freight elevator in Building 7930.

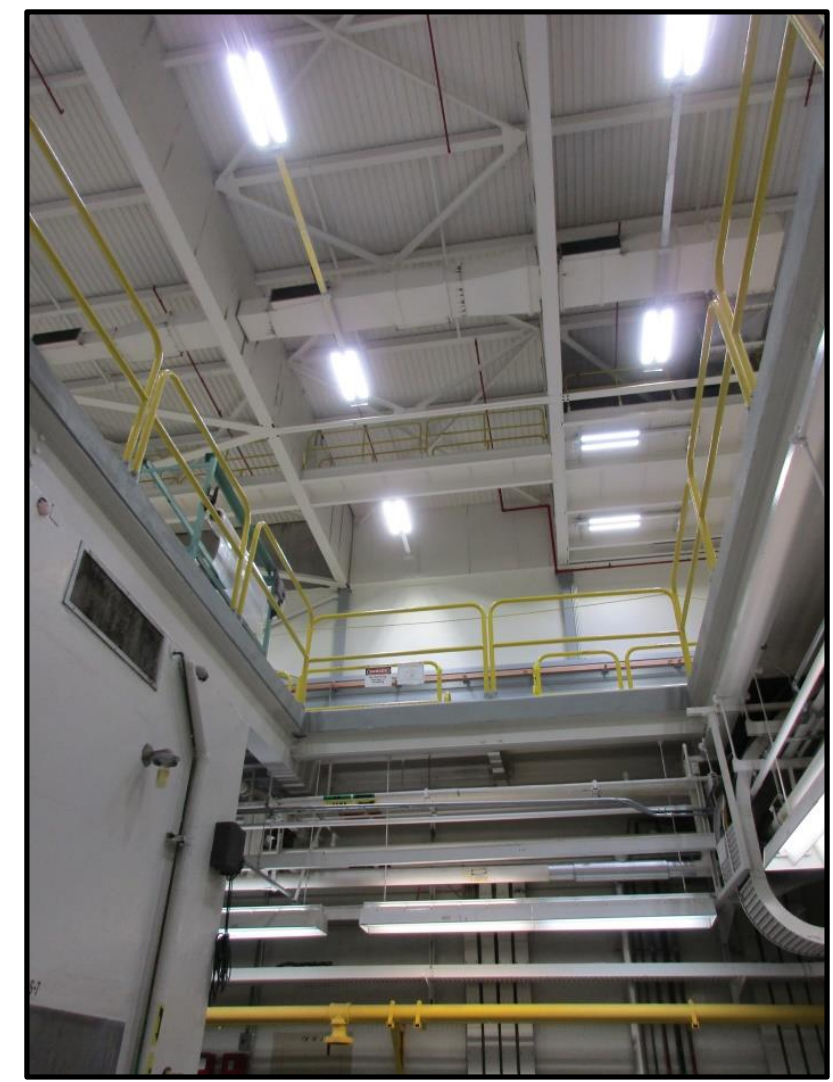

Figure 547 . High bay area from second floor of Building 7930. 


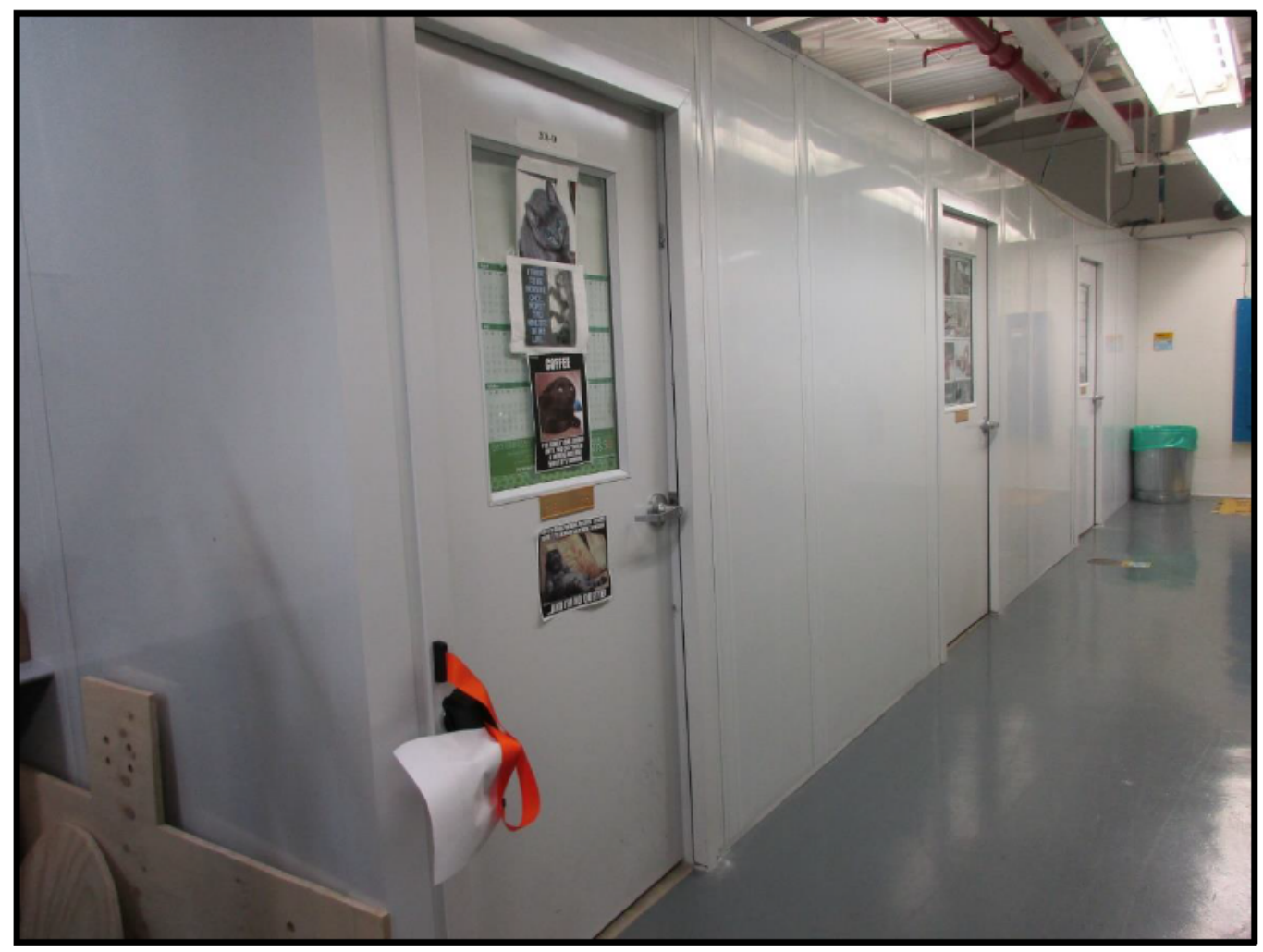

Figure 548. Offices on second floor of Building 7930.

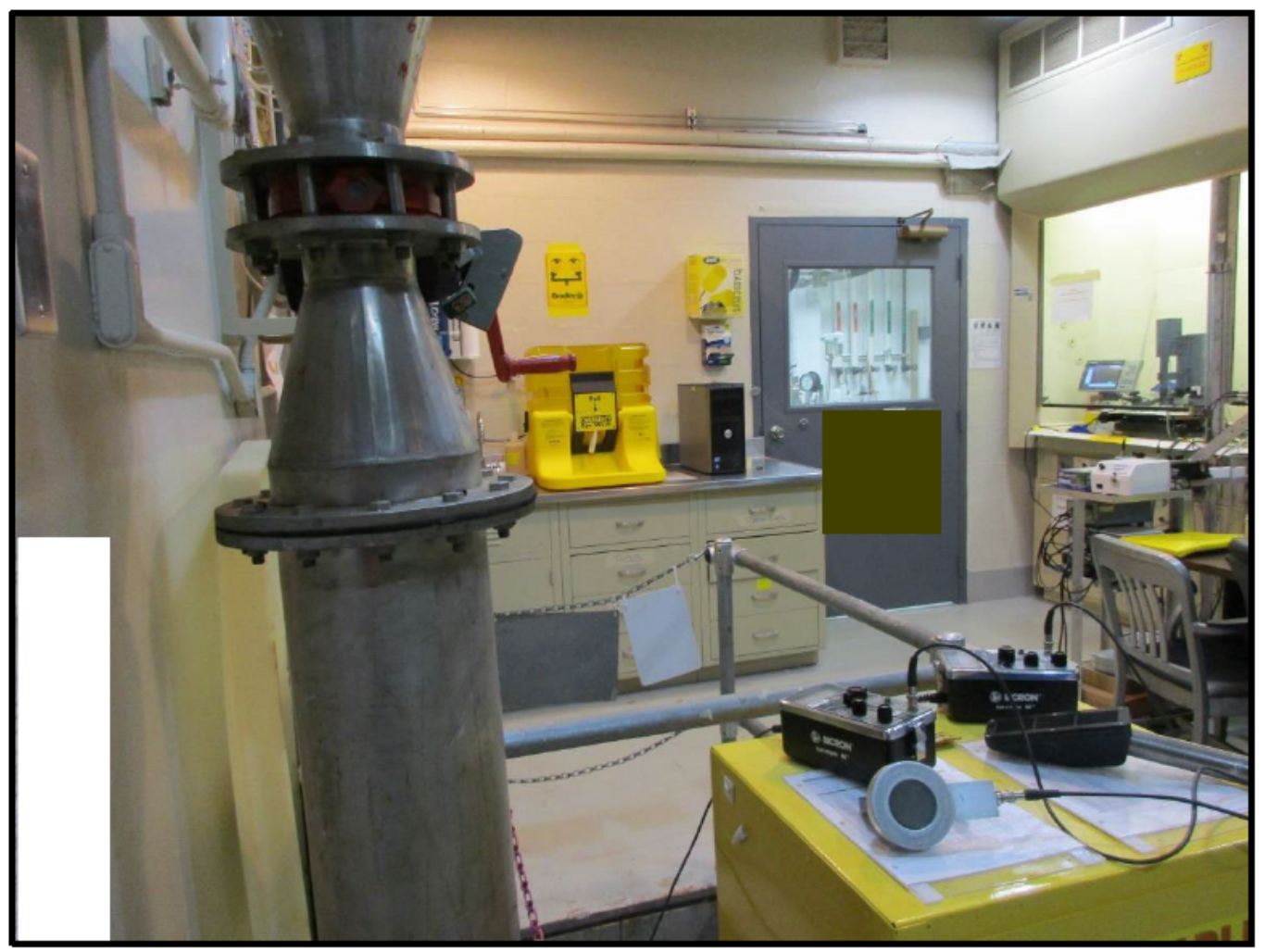

Figure 549. Renovated laboratory space in the basement of Building 7930 


\section{ORNL HISTORIC DISTRICT}

\section{CONTRIBUTING}

\begin{tabular}{|c|c|c|c|c|c|}
\hline Building 3001 & Building 3027 & Building 3047 & Building 3525 & Building 3023 & Building 3008 \\
\hline Building 3002 & Building 3028 & Building 3080 & Building 3542 & Building 3093 & Building 3012 \\
\hline Building 3003 & Building 3029 & Building 3091 & Building 3587 & Building 3127 & Building 3023 \\
\hline Building 3005 & Building 3030 & Building 3092 & Building $4500 \mathrm{~N}$ & Building 3129 & Building $3026 \mathrm{C}$ \\
\hline Building 3009 & Building 3031 & Building 3100 & Building 4500 S & Building 3135 & Building 3026D \\
\hline Building 3010 & Building 3032 & Building 3104 & Building 4501 & Building 3502B & Building 3044 \\
\hline Building $3010 \mathrm{~A}$ & Building 3033 & Building 3107 & Building 4505 & Building 3507 & Building 3074 \\
\hline Building 3017 & Building $3033 \mathrm{~A}$ & Building 3118 & Building 4507 & Building 3618 & \\
\hline Building 3018 & Building 3034 & Building 3500 & Building 4508 & Building 4509-VB1 & \\
\hline Building 3019A & Building 3036 & Building 3501 & Building 5500 & Building $5500 \mathrm{~A}$ & \\
\hline Building 3019B & Building 3037 & Building 3502 & & & \\
\hline Building 3020 & Building 3038 & Building 3515 & & & \\
\hline Building 3025E & Building 3039 & Building 3517 & & & \\
\hline Building $3025 \mathrm{M}$ & Building 3042 & Building 3523 & & & \\
\hline
\end{tabular}

\section{NON-CONTRIBUTING DEMOLISHED}

\section{CONTRIBUTING}


This page intentionally left blank 


\section{ORNL HISTORIC DISTRICT}

\section{DISTRICT NAME}

Oak Ridge National Laboratory Historic District

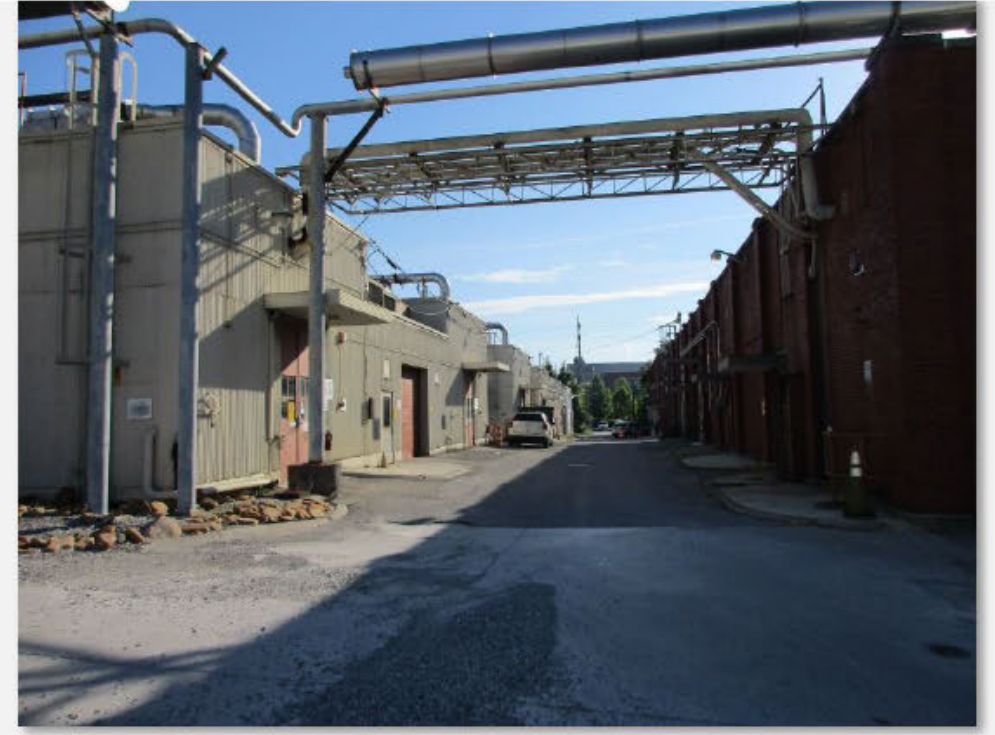

Figure 550. Overview of Isotope Circle within the ORNL Historic District.

\section{DATE OF CONSTRUCTION}

1943-1987

NRHP ELIGIBILITY

Eligible

\section{DESCRIPTION}

The Oak Ridge National Laboratory Historic District is located in the heart of the main campus of ORNL and contains sections of the 3000,4000 , and 5000 Areas (Figures 550-554). This area was developed between 1943 and 1965 and historically served as the core of research facilities on ORNL's main campus. It represents the most intact portion of the original national laboratory as it first developed after World War II, and it retains the only extant Manhattan Project resources at ORNL. It is within this historic core of the ORNL campus that the temporary, frame buildings of the Manhattan Project's X-10 site began to be replaced with brick one- and twostory research/laboratory facilities as ORNL evolved into a permanent, government-sponsored national laboratory.

The original boundary of the NRHP-eligible ORNL Historic District features an irregular shape, roughly bounded by Northside Drive on the north, portions of Fifth Street and Sixth Street on the east, portions of White Oak Avenue and Southside Avenue on the south, and portions of Third Street on the west. Several irregular sections protrude or intrude into the main section of the district, appearing to either include or exclude specific buildings. Given the changes to the ORNL landscape both within and beyond the historic district boundaries since its initial determination of eligibility for listing in the NRHP in 1994, CRA recommends that a more concise, clear boundary with clearly visible divisions would be better suited for the district. The recommended boundary of the ORNL Historic District is roughly bounded by Reactor Drive and Central Avenue on the north, Fifth and Sixth Streets on the east, Southside and White Oak Avenue on the south, and Third Street on the west (Figures C and $\mathrm{D}$ ). The topography within the district is relatively level near the center of the district along Central Avenue, with the northern and southern sections of the district sloped downhill to the south. The northern section of the district is anchored by the Graphite Reactor, Building 3001, and features the highest density of resources within the district; the southern section is anchored by Buildings $4500 \mathrm{~N}$ and $4500 \mathrm{~S}$. The western portion of the district reflects the lowest density of the ORNL Historic District, due in part to the demolition of resources and addition of parking lots within this area. 
Green space within the district is centered along either side of Central Avenue. Sidewalks extend along either side of this main thoroughfare of the district. A series of enclosed concrete walkways connect Buildings $4500 \mathrm{~N}$ and 4500S over White Oak Avenue in "the Canyon" between the two buildings; another enclosed concrete walkway connects Building 4508 to Building 4500S. New construction, reflecting the UT-Battelle expansion of ORNL, is located to the north and east of the southern portion of the district, outside the district boundaries.

The recommended boundaries of the district include a total of 62 resources, which reflect all of the property types found at ORNL (Table 2). The 52 contributing resources to the district include 25 research/laboratory facilities, 7 processing facilities, 3 offices, 4 storage facilities, and 13 utilities and maintenance facilities (see Table 2). Contributing resources were constructed between 1943 and 1965. The majority of contributing resources are two- to three-story, flat-roof research/laboratory facilities and offices with corrugated metal or brick exteriors, sometimes exhibiting simple detailing that includes simple embellishments at their entrances, windows, and rooflines, as well as a very simple modern institutional aesthetic. Most were constructed as a part of Program $\mathrm{H}$, which aimed to shift the facility from its hastily-constructed war-time existence to a more permanent laboratory. This includes Isotope Circle, a grouping of cube-like one-story frame buildings that housed the radioisotope production laboratories. Processing facilities within the district, which include the highest number of reactors within a single area, generally feature metal-clad frame construction and multi-story forms. Resources that are contributing to the district typically retain most, if not all, original exterior doors and windows, and few alterations or additions. Resources with extensive, insensitive additions and extensive remodeling, which often includes installation of replacement doors and windows among other material changes, and those resources constructed after 1965, are considered noncontributing to the district.

Many of the resources, particularly within the 3000 Area of the district, feature exterior pipes and tubing which connect them to other resources; these pipes are often carried over roadways within the district. In addition to the recorded resources, several large pieces of equipment, storage tanks, generators, and mechanical equipment are also located within the historic district. The majority of these resources is not historic and has been replaced or added since the initial construction of the district. Those smaller resources that are historic reflect simple small frame forms and are typically metal-clad shelters over equipment associated with the reactor facilities.

One resource within the historic district, the Graphite Reactor (Building 3001), was designated a National Historic Landmark (NHL) in 1966. According to the NHL nomination form, the facility began operation on November 4, 1943 and continued operation until 1963. Constructed as one of the world's first full-scale nuclear reactors, it was the first to produce measurable amounts of plutonium and large amounts of heat energy. Following World War II, the Graphite Reactor became the first to produce radioactive isotopes for use in medical therapy, as a part of a larger program at ORNL (Rettig 1966).

\section{NATIONAL REGISTER EVALUATION}

In 1994, Duvall \& Associates, in consultation with the TN-SHPO and ORNL and DOE staff, determined that portions of the main campus of ORNL are eligible for listing in the NRHP as a historic district under Criteria A and $\mathrm{C}$. The district was determined eligible under Criterion A for "its historical association with the Manhattan Project, the post-World War II government-sponsored scientific movement, and early nuclear research" and under Criterion $\mathrm{C}$ for the "engineering merits of many of the facilities and for contributions to science and technology" (Carver and Slater 1994:18). Original boundaries were selected to exclude areas with high concentrations of buildings outside of the period of significance or with a high percentage of buildings altered to 
a degree that they were not considered contributing structures within the district. The original boundary included a total of 128 resources, 66 of which were considered contributing to the district. The total resources included small accessory resources, including manhole covers, filters, and generators (Carver and Slater 1994). These small accessory resources were not included in the counts for the current survey.

CRA recommends that the ORNL Historic District, with the recommended boundary revision, is eligible for listing in the NRHP under Criterion A as the original hub of the Manhattan Project's X-10 facility that pioneered the production of plutonium and thus contributed to the creation of the world's first atomic bombs that ended the war with Japan, and its subsequent development as the central core of the Oak Ridge National Laboratory, a government-owned, contractor-operated, leading scientific research facility that made significant contributions in advancing both defensive and peacetime applications of nuclear science, as well as other fields of scientific inquiry, during the Cold War era. Collectively, the resources within the ORNL Historic District are not closely associated with a single scientist or group of scientists of exceptional importance that would qualify it for listing under Criterion B; rather, the collective impact of the many important researchers who worked at ORNL is more appropriately captured under Criterion A. Additionally, the bulk of the contributing resources of the district exhibit the simple institutional or utilitarian design that characterizes ORNL's Cold War era facilities, lacking notable stylistic elements or other noteworthy design features on the exterior. However, as a leader in nuclear science, ORNL also necessarily played a leading role in designing and developing buildings that would appropriately house such facilities, minimize contamination, and ensure the safety of researchers. Many of these facilities reflect the engineering and ingenuity required to house and operate the unique technology contained within them, particularly the reactors and other processing facilities. Thus, CRA concurs with the previous finding that the district is eligible under Criterion $\mathrm{C}$ as a collection of purpose-designed scientific processing and research facilities engineered to meet the specific needs of the advanced research occurring within their walls.

As an eligible historic district, the ORNL Historic District retains at its core research and processing facilities where key scientific advancements occurred. Major reactors and accelerators located within the district include the Graphite Reactor (Building 3001), the Solid State Accelerator Facility (Building 3003), the Low Intensity Test Reactor Facility (Building 3005), the Bulk Shielding Reactor (BSR) Facility (Building 3010), the Oak Ridge Research Reactor (ORR) (Building 3042), and the High Voltage Accelerator Laboratory (Building 5500/5500A) as well as the research/laboratory facilities, offices, storage facilities, and utilities and maintenance facilities that are directly related to the functioning of the area as a research center during the period of significance, which extends from 1943 and the development of the X-10 Graphite Reactor and extends through 1965, when the Program $\mathrm{H}$ expansion of ORNL was complete, ORNL began to diversify its research missions, and most new development at ORNL was focused on the individual facilities located in outlying areas, beyond the main campus.

Based on the results of this survey, CRA recommends a boundary revision to the NRHP-eligible ORNL Historic District (Figures 555 and 556). In the survey update completed in 2004, Thomason and Associates concurred with the previously determined boundaries of the ORNL Historic District (Thomason and Associates 2004:119). While CRA agrees that a revised boundary is appropriate, it is recommended that a revised boundary, roughly bounded by Reactor Drive and Central Avenue on the north, Fifth and Sixth Streets on the east, Southside and White Oak Avenue on the south, and Third Street on the west. This boundary revision excludes resources at the southwest corner of the district, that due to demolition, are no longer clearly associated with the rest of the resources in the district. This recommended boundary will also extend to the corner of Third Street and White Oak Avenue. The recommended boundary would add five additional recommended contributing resources 
(Buildings 3525, 3517, 3542, 4500S, and 4508) and would no longer include four resources (Buildings 2003, 2624,3000 , and 3518) previously-determined as contributing to the district. The recommended boundary revision will create an easily discernable district boundary, based primarily on clear street divisions and natural breaks in the landscape of ORNL's main campus. As based on the guidance provided by the National Park Service (NPS 1997b), this recommended boundary revision encompasses but does not exceed the extent of the significant resources and land areas at ORNL; it excludes buffer zones or acreage not directly contributing to the significance and those peripheral areas that no longer retain integrity due to alterations in physical conditions or setting due to demolition and alterations to resources within the district, all of which was approved by the sitewide Programmatic Agreement; it includes small areas that lack significance or contributing resources when they are completely surrounded by eligible resources; and it is comprised of appropriate natural or cultural features, including many streets that reflect the development of ORNL.

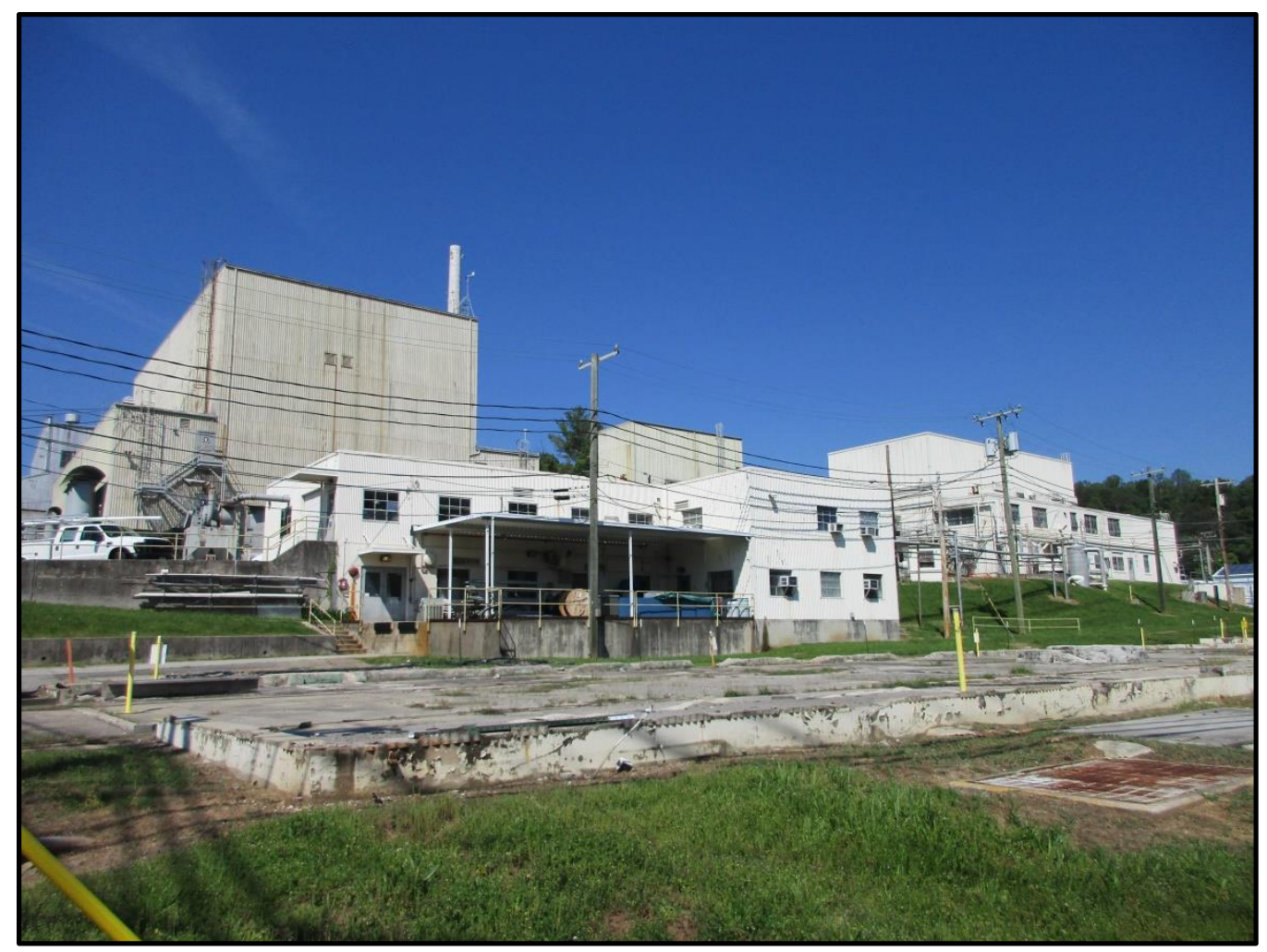

Figure 551. Overview of the 3000 Area within the ORNL Historic District. 


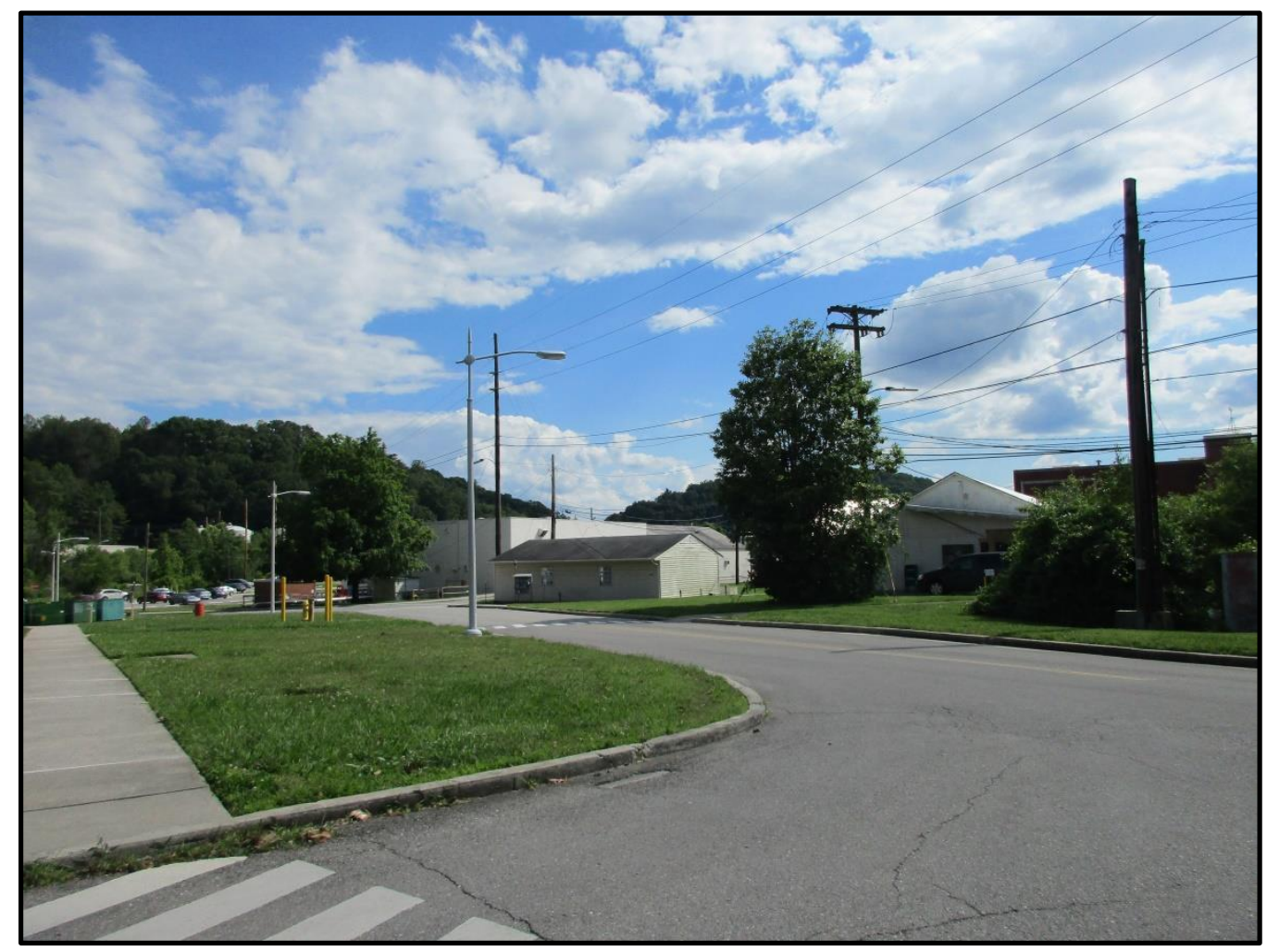

Figure 552. Overview of Fifth Street within the ORNL Historic District.

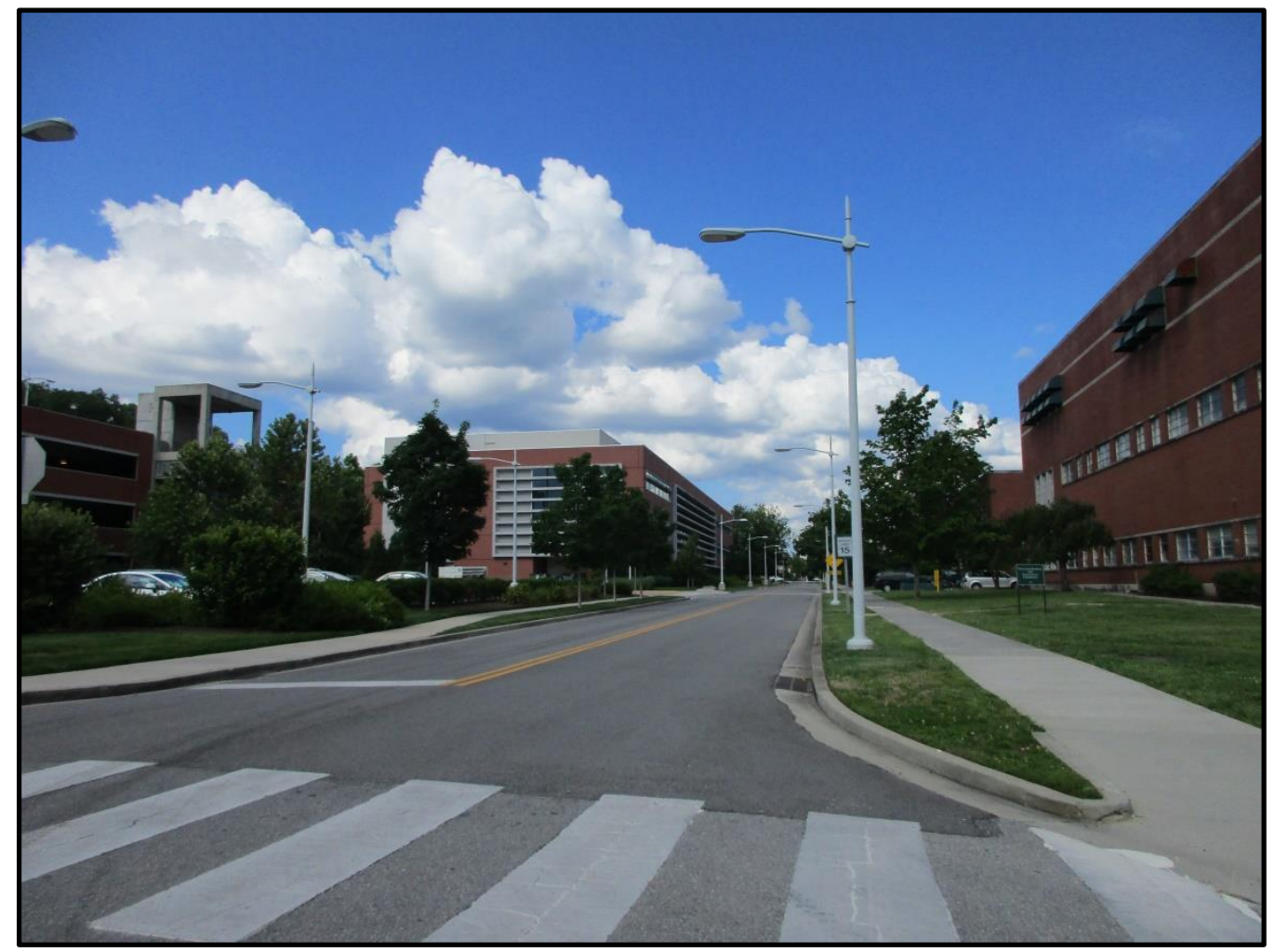

Figure 553. Overview of Central Avenue at the northern boundary of the ORNL Historic District within the 4000 Area. 


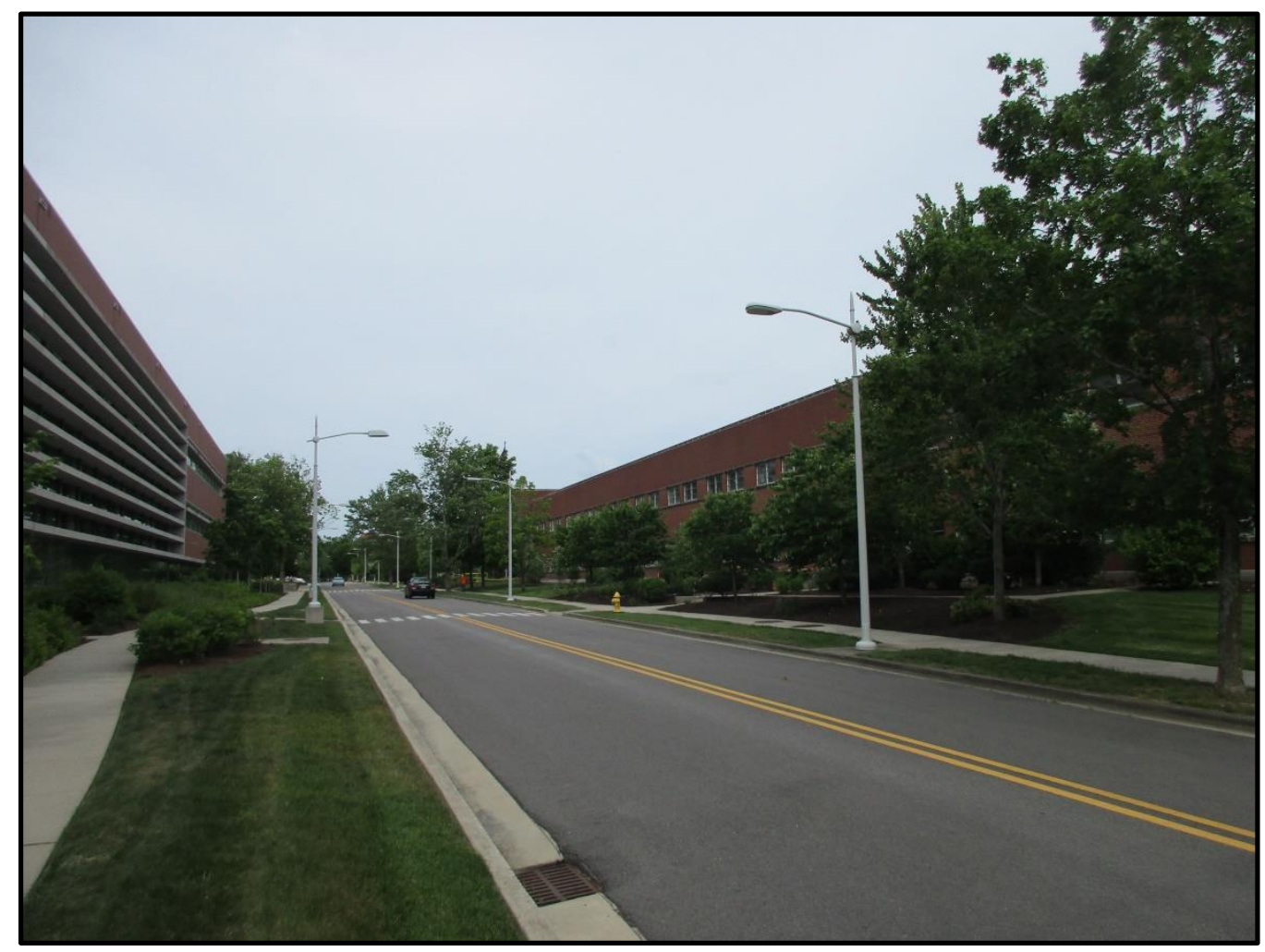

Figure 554. Overview of Building 4500N and Central Avenue within the ORNL Historic District. 


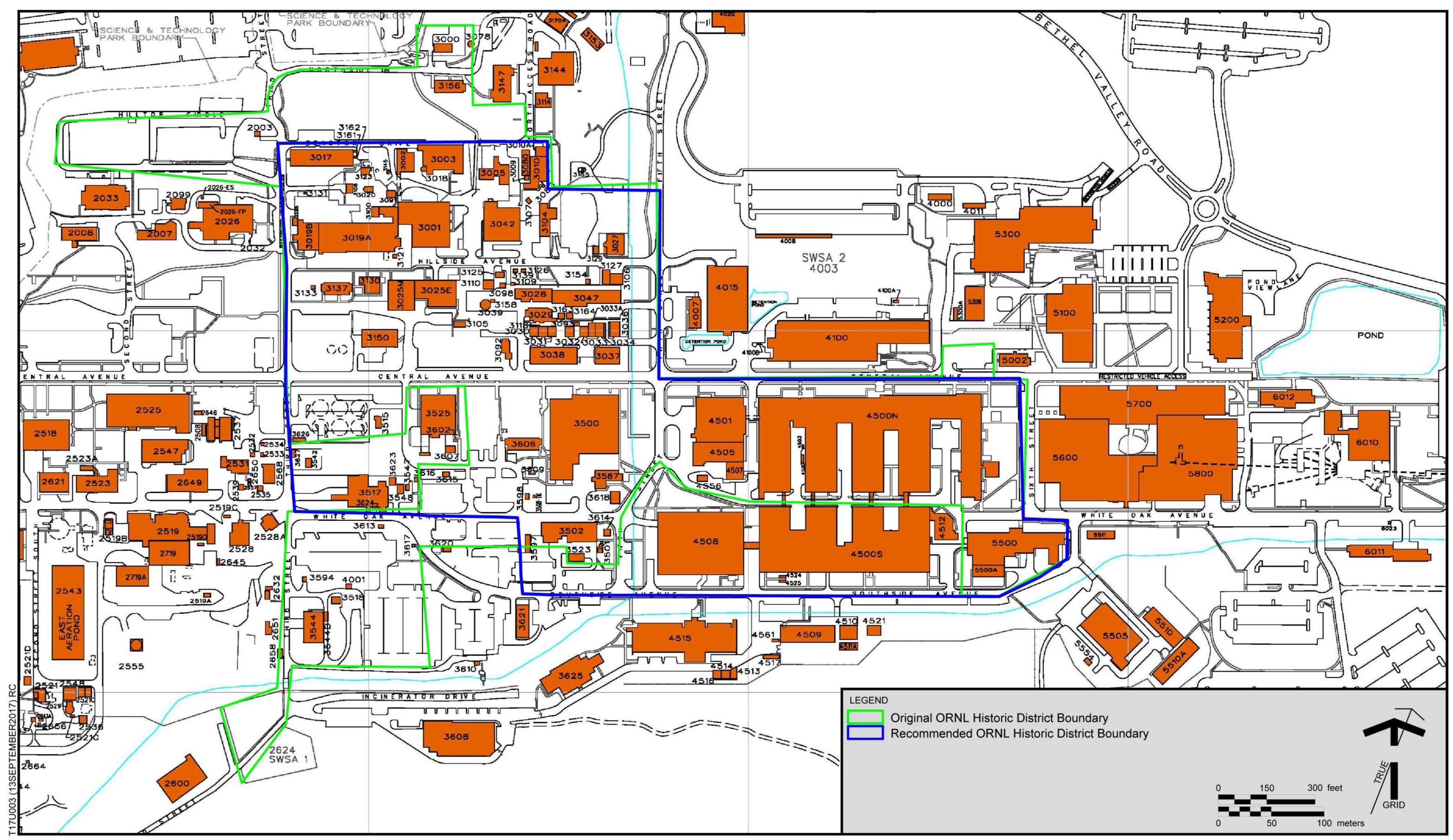

Figure 555. ORNL site plan depicting the recommended NRHP boundary of the ORNL Historic District. 
This page intentionally left blank 


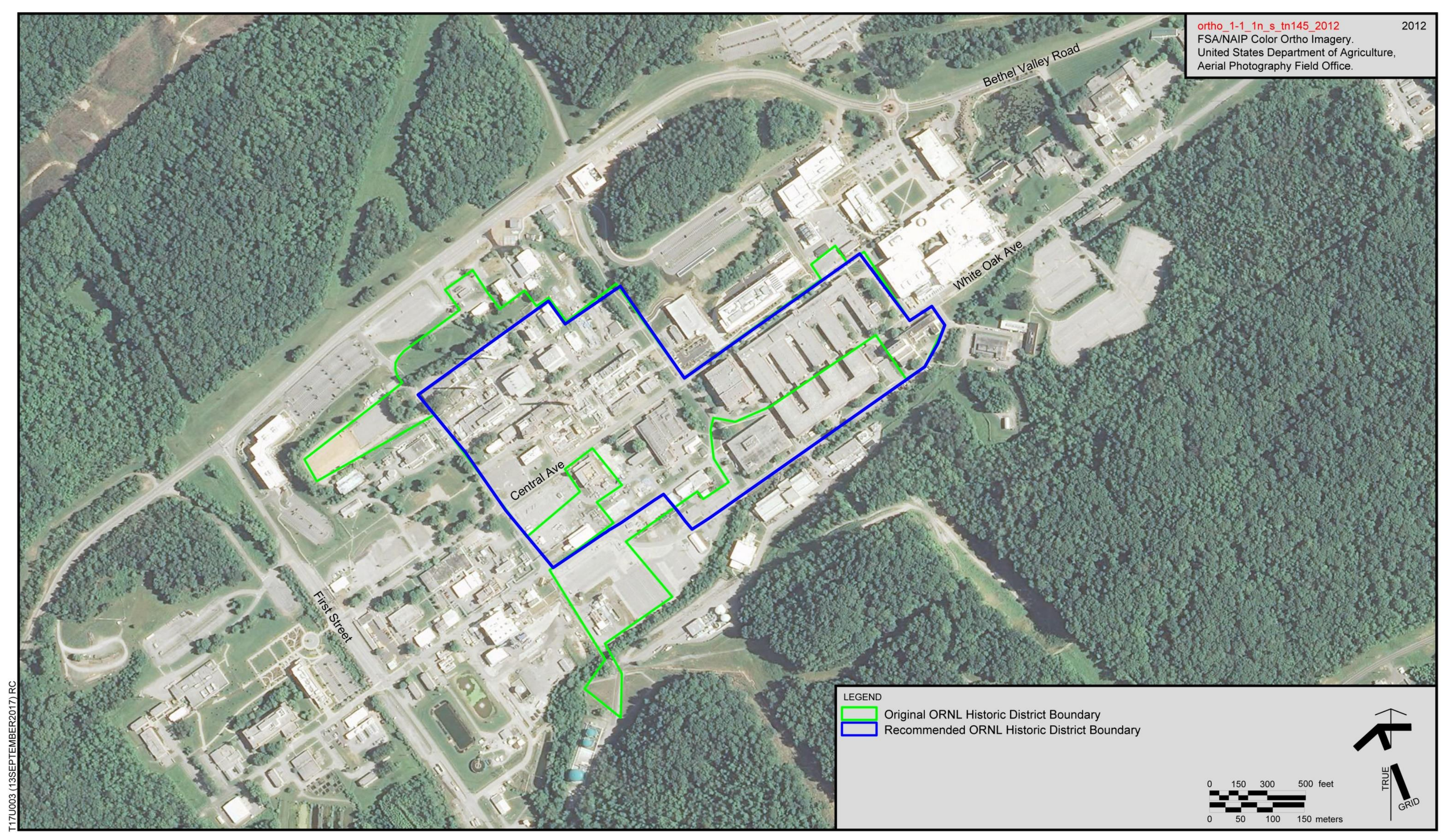

Figure 556. Aerial photographs depicting the recommended NRHP boundary of the ORNL Historic District. 
This page intentionally left blank 
TABLE 2. SURVEYED RESOURCES WITHIN THE ORNL HISTORIC DISTRICT

\begin{tabular}{|c|c|c|c|}
\hline BUILDING \# & $\begin{array}{c}\text { BUILDINGI } \\
\text { FACILITY NAME }\end{array}$ & DATE & NRHP RECOMMENDATION \\
\hline 3001 & Graphite Reactor Building & 1943 & $\begin{array}{l}\text { NRHP-listed as NHL; } \\
\text { Contributing to ORNL } \\
\text { Historic District }\end{array}$ \\
\hline 3002 & $\begin{array}{c}\text { Filter House for Graphite } \\
\text { Reactor - } 3001\end{array}$ & 1948 & $\begin{array}{c}\text { Contributing to ORNL } \\
\text { Historic District }\end{array}$ \\
\hline 3003 & $\begin{array}{c}\text { Solid State Accelerator } \\
\text { Facility }\end{array}$ & 1943 & $\begin{array}{l}\text { Contributing to ORNL } \\
\text { Historic District }\end{array}$ \\
\hline 3005 & $\begin{array}{c}\text { Low Intensity Test Reactor } \\
\text { Facility }\end{array}$ & 1948 & $\begin{array}{l}\text { Individually Eligible; Contributing } \\
\text { to ORNL Historic District }\end{array}$ \\
\hline 3008 & $\begin{array}{c}\text { Source \& Special Material } \\
\text { Vault }\end{array}$ & 1943 & Demolished \\
\hline 3009 & Pump House for Bldg 3010 & 1950 & $\begin{array}{c}\text { Contributing to ORNL Historic } \\
\text { District }\end{array}$ \\
\hline 3010 & $\begin{array}{l}\text { Bulk Shielding Reactor } \\
\text { (BSR) Facility }\end{array}$ & 1950 & $\begin{array}{l}\text { Contributing to ORNL } \\
\text { Historic District }\end{array}$ \\
\hline $3010 \mathrm{~A}$ & $\begin{array}{l}\text { Bulk Shielding Reactor } \\
\text { (BSR) Annex }\end{array}$ & 1954 & $\begin{array}{l}\text { Contributing to ORNL } \\
\text { Historic District }\end{array}$ \\
\hline 3012 & Rolling Mill & 1947 & Demolished \\
\hline 3017 & $\begin{array}{c}\text { Quality Services Division } \\
\text { Building }\end{array}$ & 1952 & $\begin{array}{l}\text { Contributing to ORNL } \\
\text { Historic District }\end{array}$ \\
\hline 3018 & $\begin{array}{l}\text { Cv \& Og Exhaust } \\
\text { Stack-3018 }\end{array}$ & 1943 & $\begin{array}{l}\text { Contributing to ORNL } \\
\text { Historic District }\end{array}$ \\
\hline $3019 A$ & $\begin{array}{c}\text { Radiochemical } \\
\text { Development Facility }\end{array}$ & 1944 & $\begin{array}{l}\text { Contributing to ORNL Historic } \\
\text { District; Interior evaluation may } \\
\text { reveal individual eligibility }\end{array}$ \\
\hline $3019 B$ & $\begin{array}{l}\text { High Level Radiation } \\
\text { Analytical Laboratory }\end{array}$ & 1944 & $\begin{array}{l}\text { Contributing to ORNL Historic } \\
\text { District; Interior evaluation may } \\
\text { reveal individual eligibility }\end{array}$ \\
\hline 3020 & $\begin{array}{l}\text { Cv \& Og Exhaust Stack - } \\
\qquad 3020\end{array}$ & 1943 & $\begin{array}{l}\text { Contributing to ORNL } \\
\text { Historic District }\end{array}$ \\
\hline 3023 & North Tank Farm & 1947 & $\begin{array}{c}\text { Non-Contributing to Historic } \\
\text { District }\end{array}$ \\
\hline $3025 \mathrm{E}$ & IMET Hot Cell Facility & 1950 & $\begin{array}{l}\text { Contributing to ORNL } \\
\text { Historic District }\end{array}$ \\
\hline $3025 \mathrm{M}$ & $\begin{array}{l}\text { Solid State Office \& } \\
\text { Laboratory Building }\end{array}$ & 1950 & $\begin{array}{l}\text { Contributing to ORNL } \\
\text { Historic District }\end{array}$ \\
\hline $3026 C$ & $\begin{array}{c}\text { Radioisotope Development } \\
\text { Laboratory B }\end{array}$ & 1943 & Demolished \\
\hline
\end{tabular}




\begin{tabular}{|c|c|c|c|}
\hline BUILDING \# & $\begin{array}{c}\text { BUILDINGI } \\
\text { FACILITY NAME }\end{array}$ & DATE & NRHP RECOMMENDATION \\
\hline $3026 \mathrm{D}$ & $\begin{array}{c}\text { Dismantling \& Examination } \\
\text { Hot Cells }\end{array}$ & 1944 & Demolished \\
\hline 3027 & $\begin{array}{l}\text { Safeguard Nuclear } \\
\text { Materials Vault/ } \\
\text { Dispatch Center }\end{array}$ & 1955 & $\begin{array}{l}\text { Contributing to ORNL } \\
\text { Historic District }\end{array}$ \\
\hline 3028 & $\begin{array}{l}\text { Radioisotope Production } \\
\text { Laboratory - A }\end{array}$ & 1951 & $\begin{array}{l}\text { Contributing to ORNL } \\
\text { Historic District }\end{array}$ \\
\hline 3029 & $\begin{array}{l}\text { Radioisotope Production } \\
\text { Laboratory - B }\end{array}$ & 1951 & $\begin{array}{l}\text { Contributing to ORNL } \\
\text { Historic District }\end{array}$ \\
\hline 3030 & $\begin{array}{l}\text { Radioisotope Production } \\
\text { Laboratory - C }\end{array}$ & 1951 & $\begin{array}{l}\text { Contributing to ORNL } \\
\text { Historic District }\end{array}$ \\
\hline 3031 & $\begin{array}{l}\text { Radioisotope Production } \\
\text { Laboratory - D }\end{array}$ & 1951 & $\begin{array}{l}\text { Contributing to ORNL } \\
\text { Historic District }\end{array}$ \\
\hline 3032 & $\begin{array}{l}\text { Radioisotope Production } \\
\text { Laboratory - E }\end{array}$ & 1951 & $\begin{array}{l}\text { Contributing to ORNL } \\
\text { Historic District }\end{array}$ \\
\hline 3033 & $\begin{array}{c}\text { Radioisotope Production } \\
\text { Laboratory - F }\end{array}$ & 1951 & $\begin{array}{l}\text { Contributing to ORNL } \\
\text { Historic District }\end{array}$ \\
\hline $3033 \mathrm{~A}$ & $\begin{array}{c}\text { Radioisotope Production } \\
\text { Lab Annex }\end{array}$ & 1951 & $\begin{array}{l}\text { Contributing to ORNL } \\
\text { Historic District }\end{array}$ \\
\hline 3034 & Radioisotope Area Services & 1951 & $\begin{array}{l}\text { Contributing to ORNL } \\
\text { Historic District }\end{array}$ \\
\hline 3036 & $\begin{array}{l}\text { Isotope Area Storage \& } \\
\text { Service Building }\end{array}$ & 1951 & $\begin{array}{l}\text { Contributing to ORNL } \\
\text { Historic District }\end{array}$ \\
\hline 3037 & $\begin{array}{c}\text { Chemical Technology } \\
\text { Offices }\end{array}$ & 1951 & $\begin{array}{l}\text { Contributing to ORNL } \\
\text { Historic District }\end{array}$ \\
\hline 3038 & Radioisotope Laboratory & 1951 & $\begin{array}{l}\text { Contributing to ORNL } \\
\text { Historic District }\end{array}$ \\
\hline 3039 & $\begin{array}{c}\text { Central Radioactive Off-Gas } \\
\text { Disposal Facility }\end{array}$ & 1951 & $\begin{array}{l}\text { Contributing to ORNL } \\
\text { Historic District }\end{array}$ \\
\hline 3042 & $\begin{array}{l}\text { Oak Ridge Research } \\
\text { Reactor (ORRR) }\end{array}$ & 1955 & $\begin{array}{l}\text { Contributing to ORNL } \\
\text { Historic District }\end{array}$ \\
\hline 3044 & West Complex Field Shop & 1955 & Demolished \\
\hline 3047 & Isotope Technology Building & 1962 & $\begin{array}{l}\text { Contributing to ORNL } \\
\text { Historic District }\end{array}$ \\
\hline 3074 & $\begin{array}{l}\text { Interim Manipulator } \\
\text { Repair Facility }\end{array}$ & 1951 & Demolished \\
\hline 3080 & $\begin{array}{l}\text { Reactor Experiment } \\
\text { Control Room }\end{array}$ & 1953 & $\begin{array}{c}\text { Contributing to ORNL } \\
\text { Historic District }\end{array}$ \\
\hline 3091 & Filters for Bldg 3019 & 1943 & $\begin{array}{l}\text { Contributing to ORNL } \\
\text { Historic District }\end{array}$ \\
\hline
\end{tabular}




\begin{tabular}{|c|c|c|c|}
\hline BUILDING \# & $\begin{array}{c}\text { BUILDINGI } \\
\text { FACILITY NAME }\end{array}$ & DATE & NRHP RECOMMENDATION \\
\hline 3092 & Off-gas Scrubber Facility & 1956 & $\begin{array}{l}\text { Contributing to ORNL } \\
\text { Historic District }\end{array}$ \\
\hline 3093 & Storage Cubical for Krypton & 1951 & $\begin{array}{c}\text { Non-Contributing to ORNL } \\
\text { Historic District }\end{array}$ \\
\hline 3100 & $\begin{array}{l}\text { Source and Special } \\
\text { Materials Vault }\end{array}$ & 1960 & $\begin{array}{l}\text { Contributing to ORNL } \\
\text { Historic District }\end{array}$ \\
\hline 3104 & $\begin{array}{c}\text { West Complex Maintenance } \\
\text { Shop }\end{array}$ & 1961 & $\begin{array}{l}\text { Contributing to ORNL } \\
\text { Historic District }\end{array}$ \\
\hline 3107 & 25 Meter Target House & 1960 & $\begin{array}{c}\text { Contributing to ORNL } \\
\text { Historic District }\end{array}$ \\
\hline 3118 & Radioisotope Prod Lab - H & 1965 & $\begin{array}{l}\text { Contributing to ORNL } \\
\text { Historic District }\end{array}$ \\
\hline 3127 & $\begin{array}{l}\text { LGWO Documentation } \\
\text { Management Storage }\end{array}$ & 1976 & $\begin{array}{c}\text { Non-Contributing to ORNL } \\
\text { Historic District }\end{array}$ \\
\hline 3129 & $\begin{array}{c}\text { DECC Annex for Building } \\
3114\end{array}$ & 1976 & $\begin{array}{c}\text { Non-Contributing to ORNL } \\
\text { Historic District }\end{array}$ \\
\hline 3135 & Sentry Post - 8D & 1968 & $\begin{array}{l}\text { Non-Contributing to ORNL } \\
\text { Historic District }\end{array}$ \\
\hline 3500 & $\begin{array}{l}\text { Instrumentation } \\
\text { Research Facility }\end{array}$ & 1951 & $\begin{array}{l}\text { Contributing to ORNL } \\
\text { Historic District }\end{array}$ \\
\hline 3501 & Sewage Pumping Station & 1949 & $\begin{array}{l}\text { Contributing to ORNL } \\
\text { Historic District }\end{array}$ \\
\hline 3502 & $\begin{array}{c}\text { East Research Service } \\
\text { Center }\end{array}$ & 1950 & $\begin{array}{l}\text { Contributing to ORNL } \\
\text { Historic District }\end{array}$ \\
\hline $3502 B$ & $\begin{array}{c}\text { Data Concentrator } 4 \text { WOCC } \\
\text { DAS } 3502\end{array}$ & 1950 & $\begin{array}{c}\text { Non-Contributing to ORNL } \\
\text { Historic District }\end{array}$ \\
\hline 3507 & South Tank Farm & 1943 & $\begin{array}{c}\text { Non-Contributing to ORNL } \\
\text { Historic District }\end{array}$ \\
\hline 3515 & $\begin{array}{l}\text { Fission Product } \\
\text { Laboratory No. } 1\end{array}$ & 1948 & $\begin{array}{c}\text { Contributing to ORNL } \\
\text { Historic District }\end{array}$ \\
\hline 3517 & $\begin{array}{c}\text { Fission Products } \\
\text { Development Laboratory }\end{array}$ & 1958 & $\begin{array}{l}\text { Contributing to ORNL } \\
\text { Historic District }\end{array}$ \\
\hline 3523 & $\begin{array}{c}\text { Weld Wire } \\
\text { Management Facility }\end{array}$ & 1954 & $\begin{array}{l}\text { Contributing to ORNL } \\
\text { Historic District }\end{array}$ \\
\hline 3525 & $\begin{array}{l}\text { High-Rad Level } \\
\text { Examination Laboratory }\end{array}$ & 1963 & $\begin{array}{l}\text { Contributing to ORNL } \\
\text { Historic District }\end{array}$ \\
\hline 3542 & $\begin{array}{l}\text { Storage Building for } \\
3505 \& 3517\end{array}$ & 1965 & $\begin{array}{l}\text { Contributing to ORNL } \\
\text { Historic District }\end{array}$ \\
\hline 3587 & Mail Services Building & 1950 & $\begin{array}{l}\text { Contributing to ORNL } \\
\text { Historic District }\end{array}$ \\
\hline 3618 & $\begin{array}{l}\text { WC-10 Tank Farm } \\
\text { Pumping Station }\end{array}$ & 1952 & $\begin{array}{c}\text { Non-Contributing to ORNL } \\
\text { Historic District }\end{array}$ \\
\hline
\end{tabular}




\begin{tabular}{|c|c|c|c|}
\hline BUILDING \# & $\begin{array}{c}\text { BUILDINGI } \\
\text { FACILITY NAME }\end{array}$ & DATE & NRHP RECOMMENDATION \\
\hline $4500 \mathrm{~N}$ & $\begin{array}{l}\text { Central Research \& } \\
\text { Administration North }\end{array}$ & 1952 & $\begin{array}{c}\text { Individually NRHP-Eligible; } \\
\text { Contributing to ORNL Historic } \\
\text { District }\end{array}$ \\
\hline $4500 \mathrm{~S}$ & $\begin{array}{l}\text { Central Research \& } \\
\text { Administration South }\end{array}$ & 1961 & $\begin{array}{l}\text { Contributing to ORNL } \\
\text { Historic District }\end{array}$ \\
\hline 4501 & Radiochemistry Laboratory & 1951 & $\begin{array}{l}\text { Contributing to ORNL } \\
\text { Historic District }\end{array}$ \\
\hline 4505 & Experimental Engineering & 1951 & $\begin{array}{l}\text { Contributing to ORNL } \\
\text { Historic District }\end{array}$ \\
\hline 4507 & $\begin{array}{l}\text { High Level Chemical } \\
\text { Development Laboratory }\end{array}$ & 1957 & $\begin{array}{l}\text { Contributing to ORNL } \\
\text { Historic District }\end{array}$ \\
\hline 4508 & M\&C Laboratory & 1962 & $\begin{array}{l}\text { Contributing to ORNL } \\
\text { Historic District }\end{array}$ \\
\hline 4509-VB1 & $\begin{array}{l}4509 \text { White Oak Creek } \\
\text { Vehicle Bridge }\end{array}$ & 1962 & $\begin{array}{l}\text { Non-Contributing to ORNL } \\
\text { Historic District }\end{array}$ \\
\hline 5500 & $\begin{array}{l}\text { High Voltage Accelerator } \\
\text { Laboratory }\end{array}$ & 1952 & $\begin{array}{l}\text { Contributing to ORNL } \\
\text { Historic District }\end{array}$ \\
\hline $5500 \mathrm{~A}$ & South Office Building & 1976 & $\begin{array}{l}\text { Non-Contributing to ORNL } \\
\text { Historic District }\end{array}$ \\
\hline
\end{tabular}




\section{RECOMMENDATIONS AND CONCLUSIONS}

The historic significance of the Manhattan Project's X-10 facility in Bethel Valley has been widely recognized for over 50 years. The Graphite Reactor was designated a NHL in 1966, just over 20 years after it was constructed and 3 years after it ceased to operate. The passage of time has only helped to solidify our understanding of the great importance of this building to the creation of the first atomic bomb and development of nuclear science, as evidenced by its recent designation as part of the Manhattan Project National Historical Site. While only a handful of other historic resources associated with the Manhattan Project's use of this property remain extant today, research that occurred here after World War II when the facility became a national laboratory also has significantly impacted American history through the development of peaceful applications of nuclear science in areas such as energy production and medical and biological research. On the whole, Oak Ridge National Laboratory is a significant place.

ORNL's continued importance to the pursuit of advanced scientific research is reflected in changes to the campus that have occurred since 2000, including the creation of a new central hub for the national laboratory in the 5000 Area and the construction of the Spallation Neutron Source (SNS) in a new area north of Bethel Valley Road. While SNS is a world-class research facility, there is not yet adequate perspective to evaluate its historic importance or the importance of the new laboratory and administrative facilities in the center of campus. Along with these new facilities, the addition of buildings between 1970 and 2000 as ORNL's mission diversified, and the demolition of several buildings in the past several decades as obsolete facilities have been removed, have changed the character of the ORNL campus as a whole since the historic period. As such, the entire ORNL campus does not merit consideration as a historic district. Thus, building upon the model established in the first historic resource survey of ORNL completed in 1993-1994 (Carver and Slater 1994), the "Area," which includes resources related by geography and purpose, as well as the individual building, served as appropriate units of evaluation for this study. Within each area, buildings were classified by type based on their function, and guidelines were established for evaluating the significance of individual examples of each property type within the historic context for ORNL to ensure consistent application of the NRHP Criteria for Evaluation.

The findings of this historic resource survey build on the conclusions of the 1994 survey by DuVall \& Associates, Inc., as well as the survey updates completed by Thomason and Associates in 2004 and 2015 in support of the ORNL HPP. Within 12 distinct areas of ORNL, as well as outlying areas, the survey recorded 195 buildings and structures constructed in or before 1980. In consideration of the role and significance of each area and each individual resource within the context of $\mathrm{X}-10$ and $\mathrm{ORNL}$, and in light of their current integrity and condition, CRA recommends the following properties eligible for listing in the NRHP:

- Building 3001, the Graphite Reactor, retains integrity for continued designation as a NHL for its role in the development of the first significant quantities of plutonium that led to the development of the world's first atomic bomb, as well as for its subsequent peacetime use in the development of radioisotopes for medical and biological research. It also serves as a central contributing resource in the ORNL Historic District; 
- The ORNL Historic District, including portions of the 3000, 4000, and 5000 Areas of ORNL, remains eligible for listing in the NRHP as the original hub of the Manhattan Project's X-10 facility and its subsequent development as the central core of the Oak Ridge National Laboratory, a government-owned, contractoroperated, leading scientific research facility that made significant contributions in advancing both defensive and peacetime applications of nuclear science, as well as other fields of scientific inquiry, during the Cold War era. A new boundary is recommended for the NRHP-eligible ORNL Historic District to account for demolitions (which occurred following documentation required by the PA) and current conditions;

- Building 3005, the Low Intensity Reactor Facility, in addition to contributing to the NRHP-eligible ORNL Historic District, is individually eligible for listing in the NRHP for its significant role in ORNL's experimental reactor program during the Cold War era and the subsequent application of the reactor's design as a prototype for commercial and military use, including commercial power plants and reactor propelled naval craft;

- Building 3019A, the Radiochemical Development Facility, and Building 3019B, the High Level Radiation Analytical Laboratory, in addition to contributing to the NRHP-eligible ORNL Historic District, may be individual eligible for listing in the NRHP for their use as a pilot plant for the development of chemical separation processes during the Manhattan Project and subsequent application of such processes in government and commercial facilities around the world; however the facilities were minimally accessed at the time of the current survey, so additional documentation, including of the buildings' interiors, would be necessary to make a final individual determination;

- Building $4500 \mathrm{~N}$, Central Research \& Administration North, in addition to contributing to the NRHP-eligible ORNL Historic District, is individually eligible for listing in the NRHP for its significant role as the center of research activity and facility administration as ORNL emerged as a permanent national laboratory following World War II;

- Building 7002, the Garage and Iron Working Shop, is eligible for listing in the NRHP for its association with Program $\mathrm{H}$, a significant building expansion that shaped ORNL as a modern research facility in the early 1950s;

- The Molten Salt Reactor Experiment (MSRE) facility, including Building 7503 and support Buildings $7507,7509,7516$, and 7555 , is eligible for listing in the NRHP for the initial development of the highly innovative Molten Salt Reactor as part of the Aircraft Reactor Experiment (ARE), which aimed to develop a reactor system 
to propel an aircraft, and subsequent experimentation to develop the molten salt reactor for electric power production;

- The Tower Shielding Facility (TSF), including Buildings 7700, 7701, 7702, 7703, and 7704, was previously recommended eligible for listing in the NRHP as an innovative reactor designed as part of the Aircraft Nuclear Propulsion (ANP) Program to perform radiation shielding studies in midair; however, the TSF was inaccessible at the time of the current survey, thus until reevaluated these structures should continue to be treated as eligible resources;

- Building 7709, the Health Physics Research Reactor (HPRR), and Building 7710, the Dosimetry Applications Research (DOSAR) Facility, were previously recommended eligible for listing in the NRHP for their association with significant research in health physics that established important standards for occupational and public exposure to radiation; however, the facility was inaccessible at the time of the current survey, thus until reevaluated these structures should continue to be treated as eligible resources;

- Buildings 7813 and 7846, White Oak Creek Dam and Lake, are eligible for listing in the NRHP for their association with early waste management efforts related to nuclear science development;

- The High Flux Isotope Reactor (HFIR) / Radiochemical Engineering Development Center (REDC) facility, including Building 7900 and associated Buildings 7901, 7911, 7920, and 7930, is eligible for listing in the NRHP as a part of the HFIR/REDC facility, which was important in the advancement of ORNL's mission in nuclear science, isotope research, and health and medicine, key fields of study during the Cold War era.

- Building 0903, the New Bethel Baptist Church, and Buildings XG1401 and XG1414, Freels Cabin and its associated outbuilding, retain integrity for continued listing in the NRHP under the Historic and Architectural Resources in Oak Ridge MPL for their importance to the pre-ORR history of the area, as well as their use during the Manhattan Project; and

- Building 0969, the Airway Beacon Lighthouse, another pre-ORR resource, is eligible for listing in the NRHP as a rare extant resource associated with the Transcontinental Air Mail Route program of the 1920s.

The recommended NRHP-status of all surveyed resources, including identification of which resources contribute to the NRHP-eligible ORNL Historic District, is included in Appendix A. 
This page intentionally left blank 


\section{REFERENCES}

Allardice, C. and E.R. Trapnell

1974 The Atomic Energy Commission. Praeger Publishers, New York and Washington.

Auerbauch, Stanley I.

1993 A History of the Environmental Sciences Division of Oak Ridge National Laboratory. Prepared by the

Environmental Sciences Division, Oak Ridge National Laboratory, managed by Martin Marietta Energy

Systems, Inc. for the U.S. Department of Energy. Electronic document,

http://technicalreports.ornl.gov/cppr/y2001/rpt/67151.pdf, accessed September 29, 2017.

Business Week

1965 "AEC Unlocks Some Files For Business." Business Week. 2 October 1965.

Cabage, Bill

2016 "American Physical Society names ORNL's Holifield Facility historic physics site." News. Oak Ridge National Laboratory. Electronic document, https://www.ornl.gov/news/american-physical-societynames-ornl-s-holifield-facility-historic-physics-site, accessed September 29, 2017.

Carver, Martha and Margaret Slater

1994 Architectural/Historical Assessment of the Oak Ridge National Laboratory, Oak Ridge Reservation, Anderson and Roane Counties, Tennessee. Prepared for the Oak Ridge National Laboratory, Oak Ridge, Tennessee, managed by Martin Marietta Energy Systems, Inc. for the U.S. Department of Energy. DuVall \& Associates, Inc., Cultural Resources and Environmental Services, Nashville, Tennessee.

Craig, Douglas, F. et.al

1997 Metals and Ceramics Division History 1946-1996. ORNL/M-6589. Oak Ridge National Laboratory, managed and operated by Lockheed Martin Energy Research Corporation for the United States Department of Energy.

U.S. Department of Energy Oak Ridge Office (DOE-ORO) 2009 Section 106 Recordation, Interpretation, and Documentation for Buildings 3074, 3136, 3026-C, and 3026-D at the Oak Ridge National Laboratory. U.S. Department of Energy Oak Ridge Office.

Engineering News-Record 1945 Engineering News-Record, 13 December 1945.

FindAGrave

2017 "New Bethel Baptist Church Cemetery AEC \#16." FindAGrave.com. Electronic document, https://www.findagrave.com/cgibin/fg.cgi? page=cr\&GSsr=1\&GScid=9212\&CRid=9212\&pt=New\%20Bethel\%20Baptist $\% 20$ Church $\% 20 \mathrm{Cem}$ etery\%20AEC\%20\%2316\&, accessed September 1, 2017.

Genung, Richard K. 1994 The ORNL Chemical Technology Division, 1950-1994. Oak Ridge National Laboratory, Oak Ridge.

Greenstreet, W.L. 1992 History of the Engineering Technology Division Oak Ridge National Laboratory 1944-1992. Oak

Ridge, TN: Oak Ridge National Laboratory, 1992. 
Gosling, F.G.

1994 The Manhattan Project: Making the Atomic Bomb. United States Department of Energy, Washington, D.C.

1990 The Manhattan Project: Science in the Second War. U.S. Department of Energy, Washington, D.C.

Hacker, B.C.

1987 The Dragon's Tail. University of California Press, Berkeley.

Hewlett, R.G. and O.E. Anderson

1962 The New World, 1939/1946: Volume I, A History of the United States Atomic Energy Commission.

Pennsylvania State University Press, University Park, Pennsylvania.

Hewlett, R. G. and J. Holl

1989 Atoms for Peace and War, 1953-1961: Volume III, The Eisenhower Administration and the Atomic

Energy Commission. University of California Press, Berkeley.

Johnson, C.W. and C.O. Jackson

1981 City Behind a Fence: Oak Ridge, Tennessee, 1942-1946. University of Tennessee Press, Knoxville.

Johnson, L. and D. Schaffer

1992 The First 50 Years. Oak Ridge National Laboratory REVIEW. Volume 25, Numbers 3 and 4.

Electronic document, https://www.ornl.gov/sites/default/files/ORNL\%20Review\%20v25n3-

4\%201992.pdf, accessed September 29, 2017.

Jones, V.C.

1985 Manhattan: The Army and the Atomic Bomb. Center of Military History, United States Army, Washington, D.C.

Leeds, Jennifer

2017a Building 7000A, Oak Ridge National Laboratory, Oak Ridge, Tennessee. Contract Publication Series 17-347. Prepared for UT-Battelle, LLC. Cultural Resource Analysts, Inc. Knoxville, Tennessee.

2017b Building 7015, Oak Ridge National Laboratory, Oak Ridge, Tennessee. Contract Publication Series 17-353. Prepared for UT-Battelle, LLC. Cultural Resource Analysts, Inc. Knoxville, Tennessee.

Lilienthal, D.

1964 The Journals of David E. Lilienthal. Volume 1, The TVA Years 1939-1945: Including a Selection of Journal Entries from the 1917-1939 Period. Harper \& Row.

Logan, Jonathan.

1996 "The Critical Mass," American Scientist. May-June 1996.

Lyon, W.S. and W. D. Shults

1990 A Brief History, The Analytical Chemistry Division of Oak Ridge National Laboratory, 1950-1990.

Prepared by Oak Ridge National Laboratory, Oak Ridge, Tennessee, operated by Martin Marietta

Energy Systems, Inc. for the U.S. Department of Energy.

Mason, Thomas E.

2013 Thomas E. Mason, Director, Oak Ridge National Laboratory Before the Subcommittee on Energy Committee on Science, Space, and Technology U.S. House of Representatives July 11, 2013: Hearing on Oversight and Management of Department of Energy National Laboratories and Science Activities. Electronic document, http://docs.house.gov/meetings/sy/sy20/20130711/101136/hhrg-113-sy20-wstatemasont-20130711.pdf, accessed September 29, 2017. 
McCullough, David

1992 Truman. Simon and Schuster, New York.

Mclntyre, E. Patrick, Jr.

2015 Re: DOE, ORNL/BLDG. 7751/Demolition, Oak Ridge, Anderson County, letter to Mr. Johnny O. Moore, ORNL Site Office, Oak Ridge, Tennessee.

2013 Re: DOE, ORNL Bldgs 7001/7002, Oak Ridge, Anderson County, letter to Mr. Johnny O. Moore, ORNL Site Office, Oak Ridge, Tennessee.

2009 Re: DOE, ORNL/3008 30123044350335043508 3592, Oak Ridge, Anderson County, letter to Ms. Katatra C. Vasquez, Oak Ridge Operations Office, Oak Ridge,

Tennessee. Murphy, Kimberley A. and Philip Thomason

1991 Historic and Architectural Resources of Oak Ridge, Tennessee. National Register of Historic Places Multiple Documentation Form, U.S. Department of the Interior, National Park Service. Thomason and Associates, Nashville, Tennessee.

National Mining Hall of Fame and Museum

2014 Inductee Database: Steen, Charles Augustus (Charlie). Electronic document, http://www.mininghalloffame.org/inductee/steen, accessed September 29, 2017.

National Park Service (NPS)

1983 Archaeology and Historic Preservation: Secretary of the Interior's Standards and Guidelines. National Park Service, Department of the Interior, Washington, D.C.

1985 National Register Bulletin 24: Guidelines for Local Surveys: A Basis for Preservation Planning. National Park Service, Department of the Interior, Washington, D.C.

1997a National Register Bulletin 15: How to Apply the National Register Criteria for Evaluation. National Park Service, Department of the Interior, Washington, D.C.

1997b National Register Bulletin 21: Defining Boundaries for National Register Properties. National Park Service, Department of the Interior, Washington, D.C.

1998 Guidelines for Evaluating and Nominating Properties that Have Achieved Significance Within the Past Fifty Years. National Park Service, Department of the Interior, Washington, D.C.

Oak Ridge National Laboratory (ORNL)

1992 The First 50 Years. Oak Ridge National Laboratory REVIEW. Volume 25, Numbers 3 and 4. Electronic document, https://www.ornl.gov/sites/default/files/ORNL\%20Review\%20v25n34\%201992.pdf, accessed September 29, 2017.

2003 Oak Ridge National Laboratory REVIEW. Volume 36, Number 1. Electronic document, https://www.ornl.gov/sites/default/files/ORNL\%20Review\%20v36n1\%202003.pdf, accessed September 29, 2017.

2014 "High Flux Isotope Reactor named Nuclear Historic Landmark." News. ORNL, Oak Ridge, Tennessee, managed for DOE by UT-Battelle, LLC. Electronic document, https://ornl.gov/news/highflux-isotope-reactor-named-nuclear-historic-landmark), accessed September 29, 2017.

2017a "Spallation Neutron Source." ORNL, Oak Ridge, Tennessee, managed by UT-Battelle, LLC. Electronic document, http://neutrons.ornl.gov/sns, accessed September 29, 2017.

2017b "Solving Big Problems." ORNL, Oak Ridge, Tennessee, managed by UT-Battelle, LLC. Electronic document, https://www.ornl.gov/sites/default/files/ORNL\%200verview\%20051817.pdf, accessed September 29, 2017. 
Overholt, J. (editor)

1987 "These Are Our Voices, The Story of Oak Ridge 1942-1970." Children's Museum of Oak Ridge, Oak Ridge.

Peden, R.E., Sr., and C.A. Mossman

1991 Utilities and HVAC of the 3500 Complex. Prepared for Instrumentation and Control Division, Oak Ridge National Laboratory, Camman Technologies, Knoxville, Tennessee.

Rettig, Polly M.

1975 X-10 Reactor, Graphite Reactor. National Register of Historic Places Inventory-Nomination Form, U.S. Department of the Interior, National Park Service, Washington, D.C.

Ringholz, Raye C.

2014 "Utah's Uranium Boom." From Beehive History, vol. 16. Salt Lake City: Utah State Historical Society. Electronic document, http://historytogo.utah.gov/utah chapters/utah today/utahsuraniumboom.html, accessed September 29, 2017.

Robinson, G. O.

1950 The Oak Ridge Story. Southern Publisher, Kingsport, Tennessee.

Smyth, H.D.

1945 Atomic Energy for Military Purposes: The Official Report on the Development of the Atomic Bomb Under the Auspices of the United States Government, 1940-1945. Princeton University Press, Princeton.

Thomason and Associates

2004 National Historic Preservation Act Historic Preservation Plan. ORNL/TM-2004/62. Prepared for the Environmental Protection and Waste Services Division, Environmental Protection Services, Oak Ridge National Laboratory, managed by UT-Battelle, LLC for the U.S. Department of Energy. Thomason and Associates, Nashville, Tennessee.

2012 Building 3000, Section 106 Documentation, National Historic Preservation Act as Amended, Oak Ridge National Laboratory, Oak Ridge, Tennessee. Prepared for the Department of Energy Oak Ridge Site Office (DOE-OSO). Thomason and Associates, Nashville, Tennessee.

2013a Holifield Radioactive Ion Beam Facility, Building 6000, Section 106 Documentation, National Historic Preservation Act as Amended, Oak Ridge National Laboratory, Oak Ridge, Tennessee. Prepared for the Department of Energy Oak Ridge Site Office (DOE-OSO). Thomason and Associates, Nashville, Tennessee.

2013b Building 7001, Section 106 Documentation, National Historic Preservation Act as Amended, Oak Ridge National Laboratory, Oak Ridge, Tennessee. Prepared for the Department of Energy Oak Ridge Site Office (DOE-OSO). Thomason and Associates, Nashville, Tennessee.

2013c Building 7002, Section 106 Documentation, National Historic Preservation Act as Amended, Oak Ridge National Laboratory, Oak Ridge, Tennessee. Prepared for the Department of Energy Oak Ridge Site Office (DOE-OSO). Thomason and Associates, Nashville, Tennessee.

2015 National Historic Preservation Act Historic Preservation Plan 2015, Oak Ridge National Laboratory, Oak Ridge, Tennessee. Prepared for UT-Battelle, LLC. Thomason and Associates, Nashville, Tennessee.

2016 Building 4501/4505, Oak Ridge National Laboratory, Oak Ridge, Tennessee, Historic Building Analysis. Prepared for the Department of Energy Oak Ridge Site Office (DOE-OSO). Thomason and Associates, Nashville, Tennessee. 
Thompson, W.E.

1963 History of the Oak Ridge National Laboratory 1943-1963. Oak Ridge: Oak Ridge National Laboratory.

Tichy, Charles R. and James A. Hall

2007 Architectural/Historical Assessment of the Airway Beacon Lighthouse, Oak Ridge Reservation.

ORNL/TM-2008/080. Oak Ridge National Laboratory, Oak Ridge National Laboratory, managed by UT-

Battelle, LLC for the U.S. Department of Energy.

Toth, L.M; S.R. Buxton, J.T. Bell, H.A. Freidman, D.W. Fuller, and M.R. Billings

1976 Chemistry of the KALC Process. The $\mathrm{CO}_{2}-\mathrm{I}_{2}-\mathrm{CH}_{3} \mathrm{l}-\mathrm{H}_{2} \mathrm{O}$ System. Chemistry Division, Thorium Utilization Program, Reprocessing Development. Oak Ridge National Laboratory, Oak Ridge, Tennessee, operated by Union Carbide Corporation for the Energy Research and Development Administration. Electronic document, https://www.osti.gov/scitech/servlets/purl/7327384, accessed September 29, 2017.

UT-Battelle, LLC (UTB)

2017 Buildings 4500N and 4500S Oak Ridge National Laboratory, Oak Ridge, Tennessee, Section 106 Documentation, National Historic Preservation Act as Amended. UT-Battelle, Modernization Project Office. Prepared for Oak Ridge National Laboratory, Oak Ridge, Tennessee managed by UT-Battelle, LLC for the US Department of Energy.

2009 Section 106: Recordation, Interpretation, and Documentation for the Demolition of Buildings 3008, 3012, 3044, 3503, 3504, 3509, and 3592 at the Oak Ridge National Laboratory, Oak Ridge, Tennessee. Prepared by Environmental Protection and Waste Services Division, Environmental Protection Services, Oak Ridge National Laboratory.

Vasquez, Katatra $\mathrm{C}$.

2016 National Historic Preservation Act, Section 106 Compliance, Proposed Undertaking to Demolish and Replace an elevated walkway at the Irradiated Materials Examination and Testing Facility, Building 3025E, Oak Ridge National Laboratory (ORNL), Oak Ridge, Tennessee. Letter to Joseph Y. Garrison, Tennessee Historical Commission Department of Environment and Conservation, on behalf of Department of Energy Oak Ridge Office, June 16, 2016.

Young, J.A.

N.D. An Historical View of Oak Ridge: The Pre-Oak Ridge Communities and Katy's Kitchen. Oak Ridge Public Library, Oak Ridge Room. 
This page intentionally left blank 
APPENDIXA 
This page intentionally left blank 


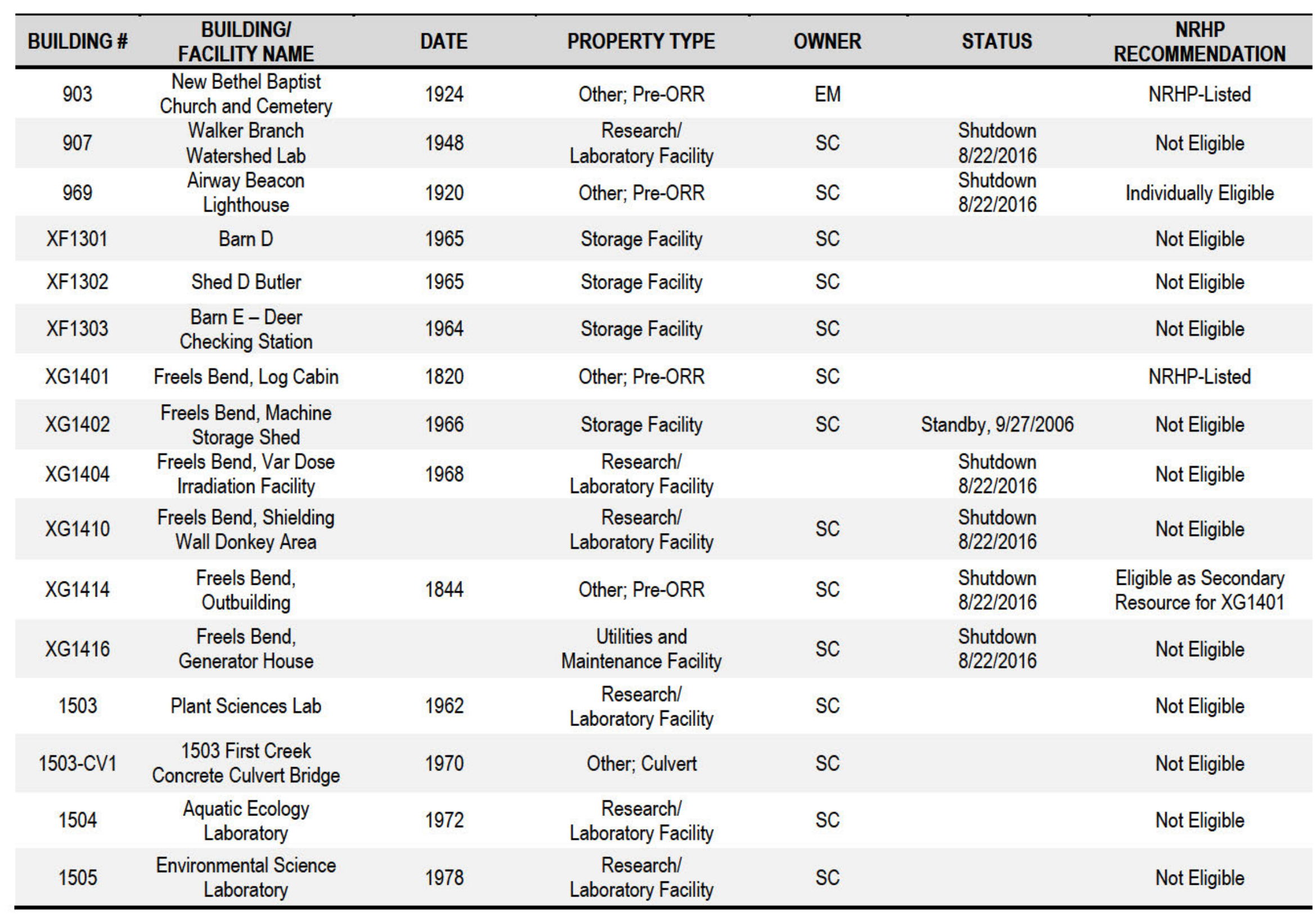




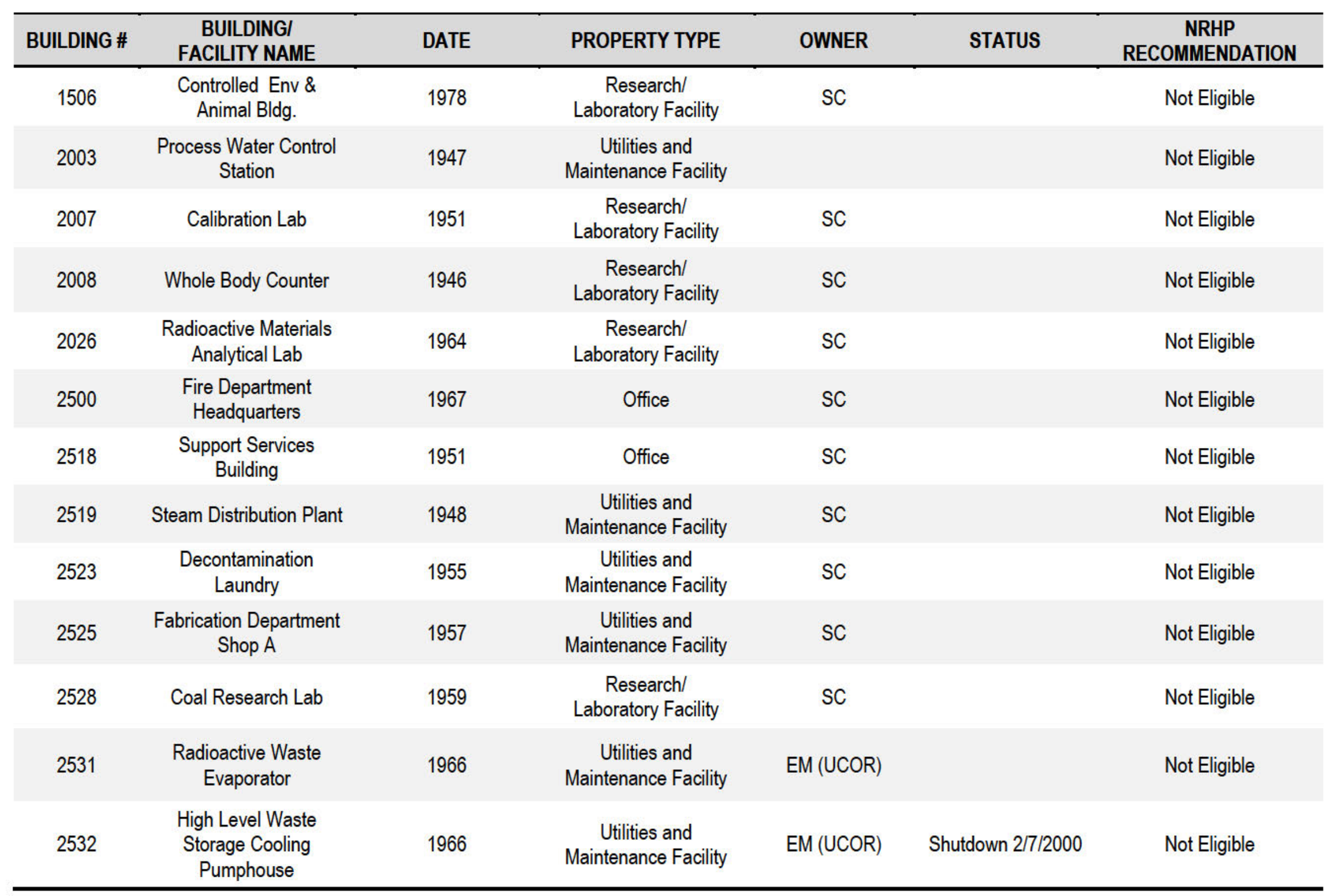




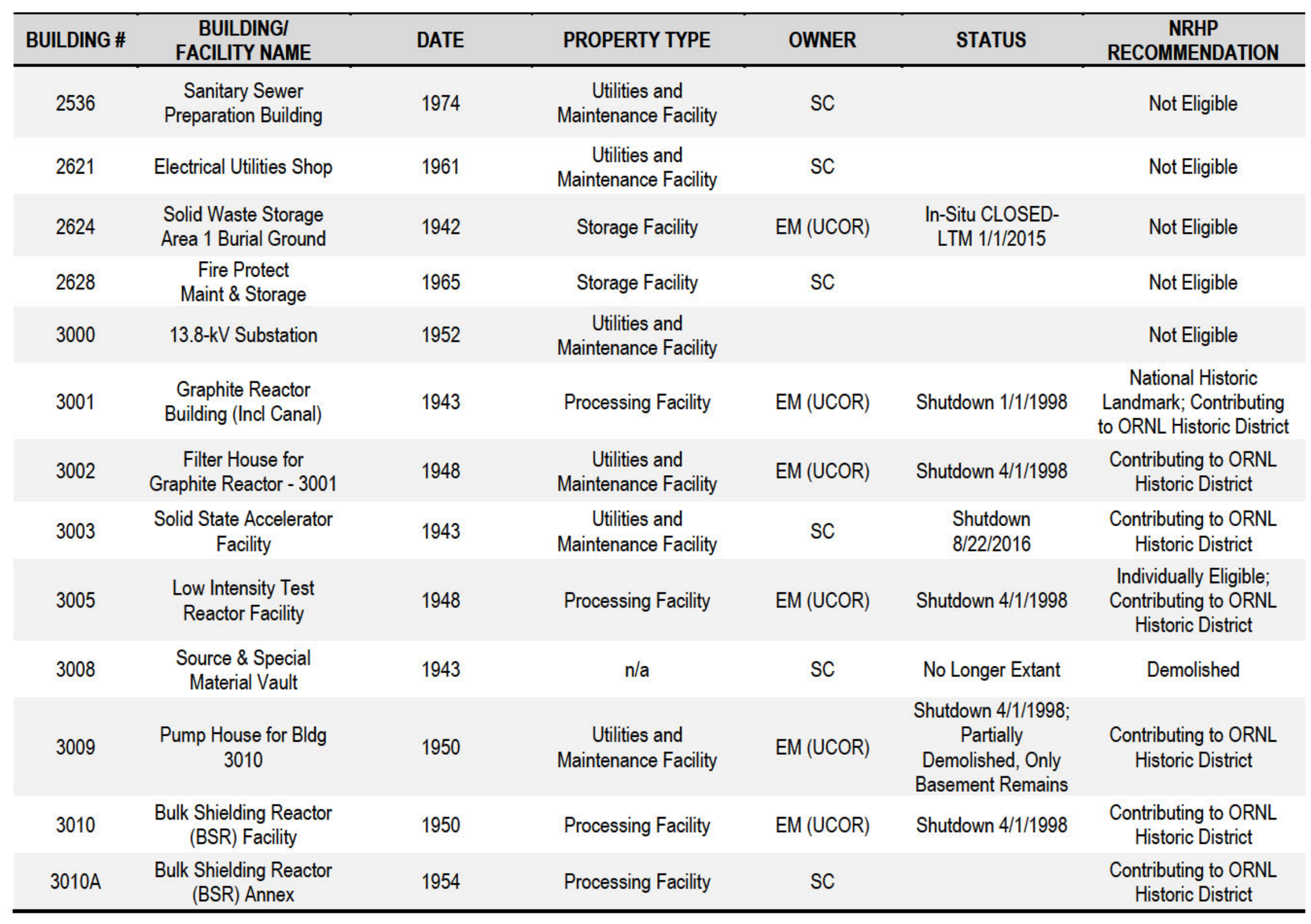




\begin{tabular}{|c|c|c|c|c|c|c|}
\hline BUILDING \# & $\begin{array}{c}\text { BUILDINGI } \\
\text { FACILITY NAME } \\
\end{array}$ & DATE & PROPERTY TYPE & OWNER & STATUS & $\begin{array}{c}\text { NRHP } \\
\text { RECOMMENDATION } \\
\end{array}$ \\
\hline 3012 & Rolling Mill & 1947 & $\mathrm{n} / \mathrm{a}$ & & No Longer Extant & Demolished \\
\hline 3017 & $\begin{array}{l}\text { Quality Services } \\
\text { Division Building }\end{array}$ & 1952 & $\begin{array}{c}\text { Research/ } \\
\text { Laboratory Facility }\end{array}$ & EM (Isotek) & & $\begin{array}{l}\text { Contributing to ORNL } \\
\text { Historic District }\end{array}$ \\
\hline 3018 & $\begin{array}{c}\text { Cv \& Og Exhaust Stack- } \\
3018\end{array}$ & 1943 & $\begin{array}{c}\text { Utilities and } \\
\text { Maintenance Facility }\end{array}$ & EM (UCOR) & Shutdown 5/1/2005 & $\begin{array}{c}\text { Contributing to ORNL } \\
\text { Historic District }\end{array}$ \\
\hline $3019 A$ & $\begin{array}{c}\text { Radiochemical } \\
\text { Development Facility }\end{array}$ & 1944 & Processing Facility & EM (Isotek) & & $\begin{array}{c}\text { Contributing to ORNL } \\
\text { Historic District }\end{array}$ \\
\hline $3019 B$ & $\begin{array}{l}\text { High Level Radiation } \\
\text { Analytical Laboratory }\end{array}$ & 1944 & $\begin{array}{l}\text { Research/ } \\
\text { Laboratory Facility }\end{array}$ & EM (Isotek) & & $\begin{array}{c}\text { Contributing to ORNL } \\
\text { Historic District }\end{array}$ \\
\hline 3023 & North Tank Farm & 1947 & $\mathrm{n} / \mathrm{a}$ & EM & $\begin{array}{l}\text { In-Situ CLOSED- } \\
\text { LTM 11/17/2016 }\end{array}$ & $\begin{array}{l}\text { Non-Contributing to } \\
\text { ORNL Historic Distric }\end{array}$ \\
\hline $3025 E$ & IMET Hot Cell Facility & 1950 & $\begin{array}{c}\text { Research/ } \\
\text { Laboratory Facility }\end{array}$ & SC & & $\begin{array}{c}\text { Contributing to ORNL } \\
\text { Historic District }\end{array}$ \\
\hline $3025 \mathrm{M}$ & $\begin{array}{l}\text { Solid State Office \& } \\
\text { Laboratory Building }\end{array}$ & 1950 & $\begin{array}{c}\text { Research/ } \\
\text { Laboratory Facility }\end{array}$ & SC & & $\begin{array}{c}\text { Contributing to ORNL } \\
\text { Historic District }\end{array}$ \\
\hline $3026 \mathrm{C}$ & $\begin{array}{l}\text { Radioisotope } \\
\text { Development } \\
\text { Laboratory B }\end{array}$ & 1943 & $\begin{array}{c}\text { Research/ } \\
\text { Laboratory Facility }\end{array}$ & EM (UCOR) & $\begin{array}{l}\text { Undergoing } \\
\text { Stabilization/ } \\
\text { Deactivation } \\
\text { 11/4/2014; No } \\
\text { Longer Extant }\end{array}$ & Demolished \\
\hline
\end{tabular}




\begin{tabular}{|c|c|c|c|c|c|c|}
\hline BUILDING \# & $\begin{array}{c}\text { BUILDINGI } \\
\text { FACILITY NAME } \\
\end{array}$ & DATE & PROPERTY TYPE & OWNER & STATUS & $\begin{array}{c}\text { NRHP } \\
\text { RECOMMENDATION } \\
\end{array}$ \\
\hline $3026 \mathrm{D}$ & $\begin{array}{c}\text { Dismantling \& } \\
\text { Examination Hot Cells }\end{array}$ & 1944 & $\begin{array}{c}\text { Research/ } \\
\text { Laboratory Facility }\end{array}$ & EM (UCOR) & $\begin{array}{c}\text { Undergoing } \\
\text { Stabilization/ } \\
\text { Deactivation } \\
11 / 4 / 2014 ; \text { On } \\
\text { ORNL Facility } \\
\text { Demolition List; No } \\
\text { Longer Extant }\end{array}$ & Demolished \\
\hline 3028 & $\begin{array}{l}\text { Radioisotope Production } \\
\text { Laboratory - A }\end{array}$ & 1951 & $\begin{array}{l}\text { Research/Laboratory } \\
\text { Facility }\end{array}$ & EM (UCOR) & Shutdown 4/1/1998 & $\begin{array}{c}\text { Contributing to ORNL } \\
\text { Historic District }\end{array}$ \\
\hline 3029 & $\begin{array}{l}\text { Radioisotope Production } \\
\text { Laboratory - B }\end{array}$ & 1951 & $\begin{array}{l}\text { Research/Laboratory } \\
\text { Facility }\end{array}$ & EM (UCOR) & Shutdown 4/1/1998 & $\begin{array}{l}\text { Contributing to ORNL } \\
\text { Historic District }\end{array}$ \\
\hline 3032 & $\begin{array}{l}\text { Radioisotope Production } \\
\text { Laboratory - E }\end{array}$ & 1951 & $\begin{array}{l}\text { Research/Laboratory } \\
\text { Facility }\end{array}$ & EM (UCOR) & Shutdown 4/1/1998 & $\begin{array}{c}\text { Contributing to ORNL } \\
\text { Historic District }\end{array}$ \\
\hline 3033 & $\begin{array}{l}\text { Radioisotope Production } \\
\text { Laboratory - F }\end{array}$ & 1951 & $\begin{array}{l}\text { Research/Laboratory } \\
\text { Facility }\end{array}$ & EM (UCOR) & Shutdown 4/1/1998 & $\begin{array}{c}\text { Contributing to ORNL } \\
\text { Historic District }\end{array}$ \\
\hline $3033 A$ & $\begin{array}{l}\text { Radioisotope Production } \\
\text { Lab Annex }\end{array}$ & 1951 & $\begin{array}{c}\text { Research/Laboratory } \\
\text { Facility }\end{array}$ & EM (UCOR) & Shutdown 4/1/1998 & $\begin{array}{c}\text { Contributing to ORNL } \\
\text { Historic District }\end{array}$ \\
\hline 3034 & $\begin{array}{l}\text { Radioisotope Area } \\
\text { Services }\end{array}$ & 1951 & $\begin{array}{c}\text { Utilities and } \\
\text { Maintenance Facility }\end{array}$ & SC & $\begin{array}{l}\text { Shutdown } \\
8 / 22 / 2016\end{array}$ & $\begin{array}{c}\text { Contributing to ORNL } \\
\text { Historic District }\end{array}$ \\
\hline 3036 & $\begin{array}{l}\text { Isotope Area Storage \& } \\
\text { Service Building }\end{array}$ & 1951 & Storage Facility & SC & & $\begin{array}{c}\text { Contributing to ORNL } \\
\text { Historic District }\end{array}$ \\
\hline
\end{tabular}




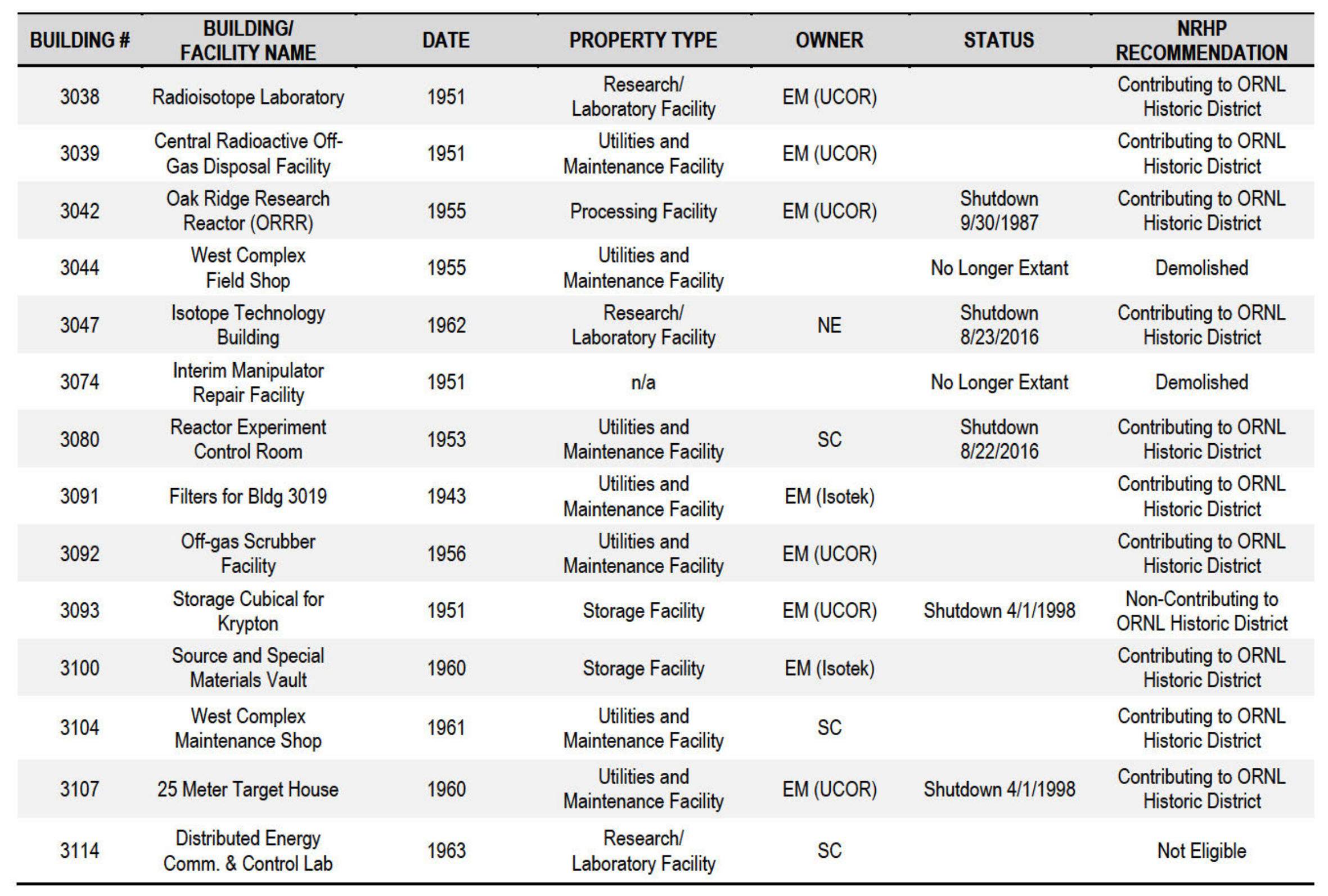




\begin{tabular}{|c|c|c|c|c|c|c|}
\hline BUILDING \# & $\begin{array}{c}\text { BUILDINGI } \\
\text { FACILITY NAME }\end{array}$ & DATE & PROPERTY TYPE & OWNER & STATUS & $\begin{array}{c}\text { NRHP } \\
\text { RECOMMENDATION }\end{array}$ \\
\hline 3118 & $\begin{array}{c}\text { Radioisotope Prod } \\
\text { Lab-H }\end{array}$ & 1965 & $\begin{array}{c}\text { Research/ } \\
\text { Laboratory Facility }\end{array}$ & EM (UCOR) & Shutdown 4/1/1998 & $\begin{array}{c}\text { Contributing to ORNL } \\
\text { Historic District }\end{array}$ \\
\hline 3129 & $\begin{array}{l}\text { DECC Annex for } \\
\text { Building } 3114\end{array}$ & 1976 & $\begin{array}{c}\text { Utilities and } \\
\text { Maintenance Facility }\end{array}$ & SC & & $\begin{array}{l}\text { Non-Contributing to } \\
\text { ORNL Historic Distric }\end{array}$ \\
\hline 3500 & $\begin{array}{l}\text { Instrumentation } \\
\text { Research Facility }\end{array}$ & 1951 & $\begin{array}{c}\text { Research/ } \\
\text { Laboratory Facility }\end{array}$ & SC & & $\begin{array}{c}\text { Contributing to ORNL } \\
\text { Historic District }\end{array}$ \\
\hline 3501 & $\begin{array}{l}\text { Sewage Pumping } \\
\text { Station }\end{array}$ & 1949 & $\begin{array}{c}\text { Utilities and } \\
\text { Maintenance Facility }\end{array}$ & & & $\begin{array}{c}\text { Contributing to ORNL } \\
\text { Historic District }\end{array}$ \\
\hline 3502 & $\begin{array}{c}\text { East Research Service } \\
\text { Center }\end{array}$ & 1950 & Office & SC & & $\begin{array}{c}\text { Contributing to ORNL } \\
\text { Historic District }\end{array}$ \\
\hline 3503 & $\begin{array}{l}\text { High Radiation Level } \\
\text { Chemical Engineering }\end{array}$ & 1948 & $\mathrm{n} / \mathrm{a}$ & & No Longer Extant & Demolished \\
\hline 3504 & Geosciences Laboratory & 1951 & $\mathrm{n} / \mathrm{a}$ & & No Longer Extant & Demolished \\
\hline 3507 & South Tank Farm & 1943 & $\mathrm{n} / \mathrm{a}$ & EM & $\begin{array}{c}\text { Undergoing } \\
\text { Stabilization/ } \\
\text { Deactivation } \\
5 / 1 / 2005\end{array}$ & $\begin{array}{l}\text { Non-Contributing to } \\
\text { ORNL Historic Distric }\end{array}$ \\
\hline 3508 & $\begin{array}{l}\text { High Level Alpha } \\
\text { Radiation Laboratory }\end{array}$ & 1944 & $\mathrm{n} / \mathrm{a}$ & & No Longer Extant & Demolished \\
\hline 3513 & Settling Basin 3513 & 1944 & $\mathrm{n} / \mathrm{a}$ & EM & $\begin{array}{c}\text { In-Situ Closed } \\
3 / 24 / 2016 ; \text { No } \\
\text { Above-Ground } \\
\text { Elements }\end{array}$ & Demolished \\
\hline
\end{tabular}




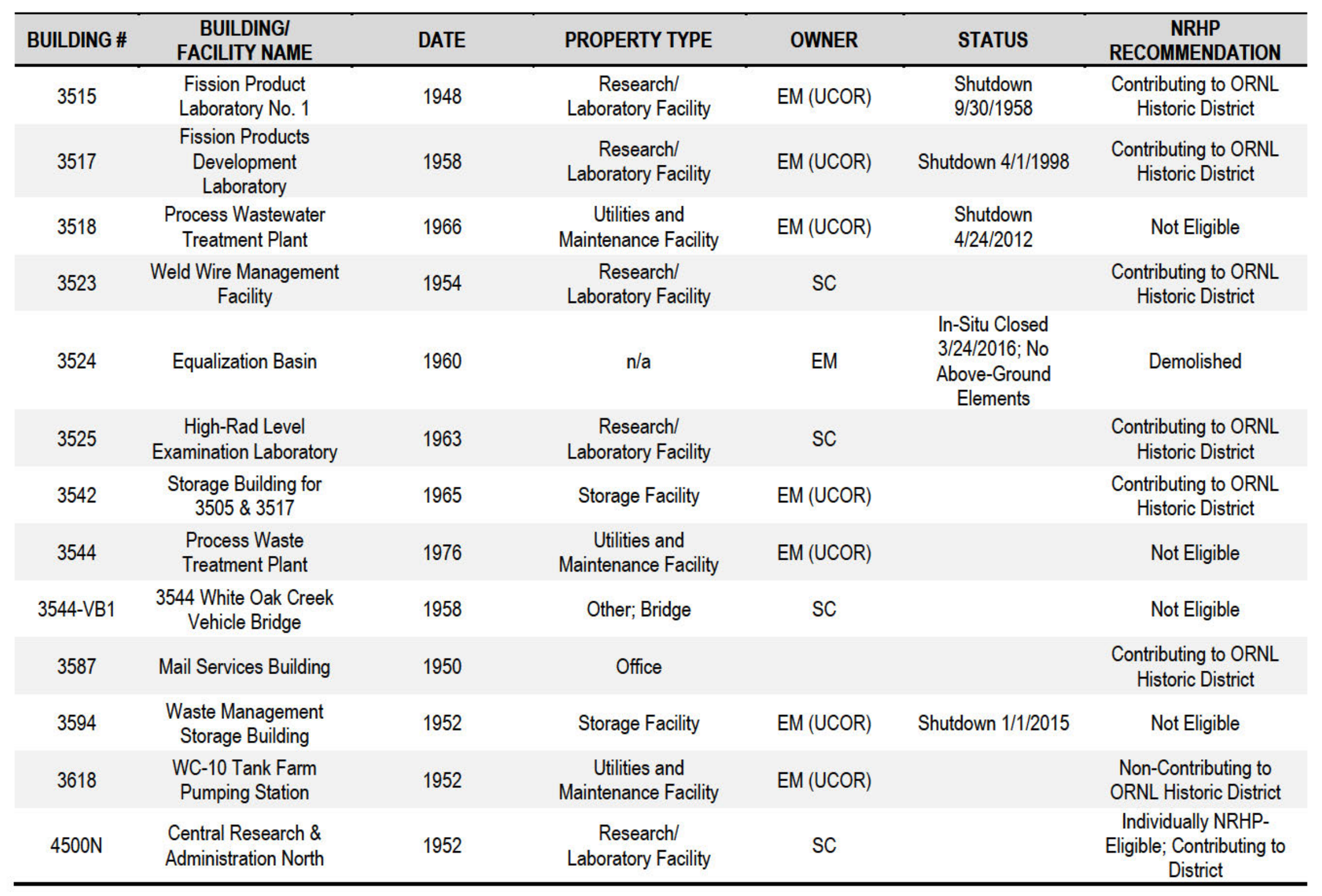




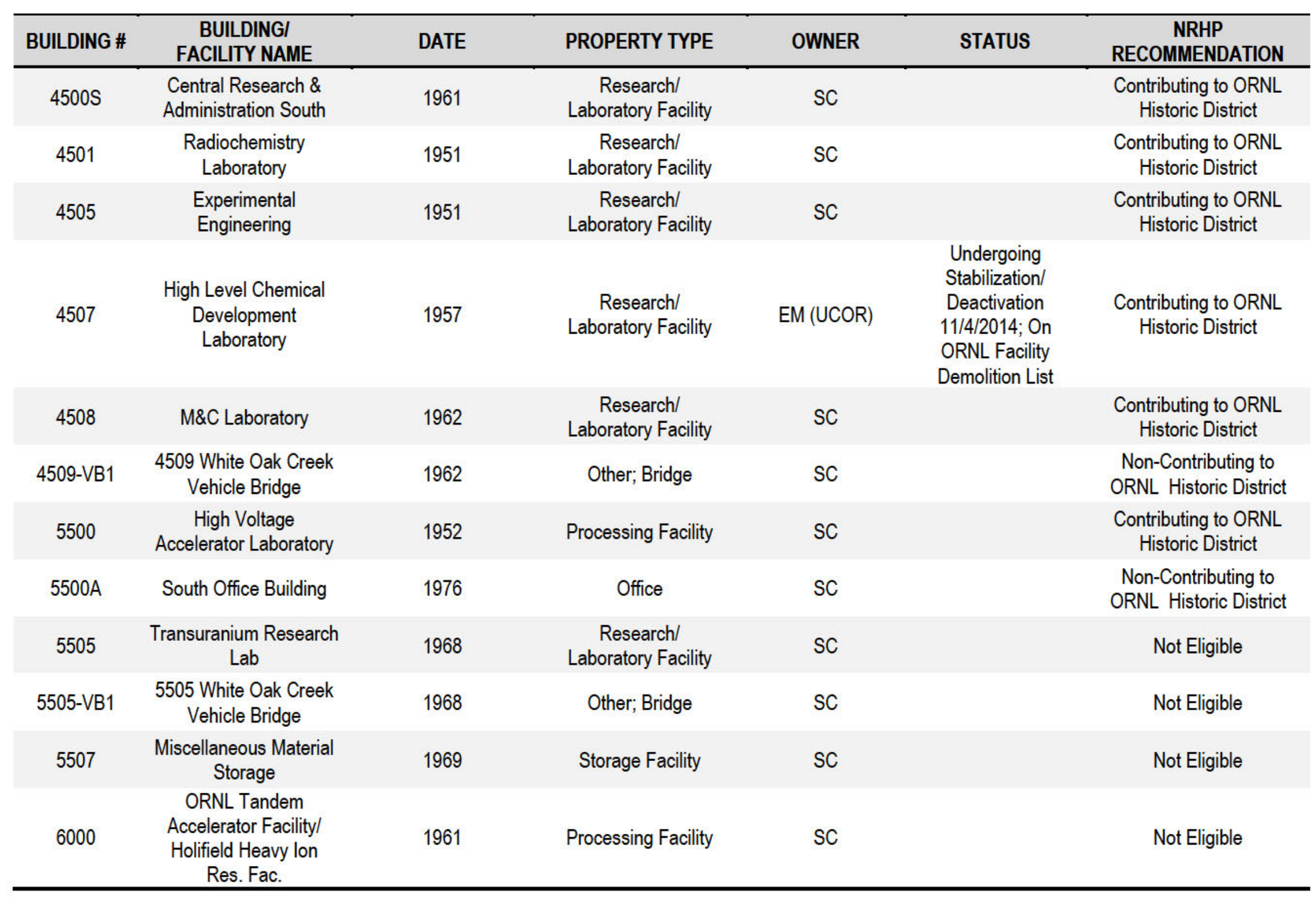




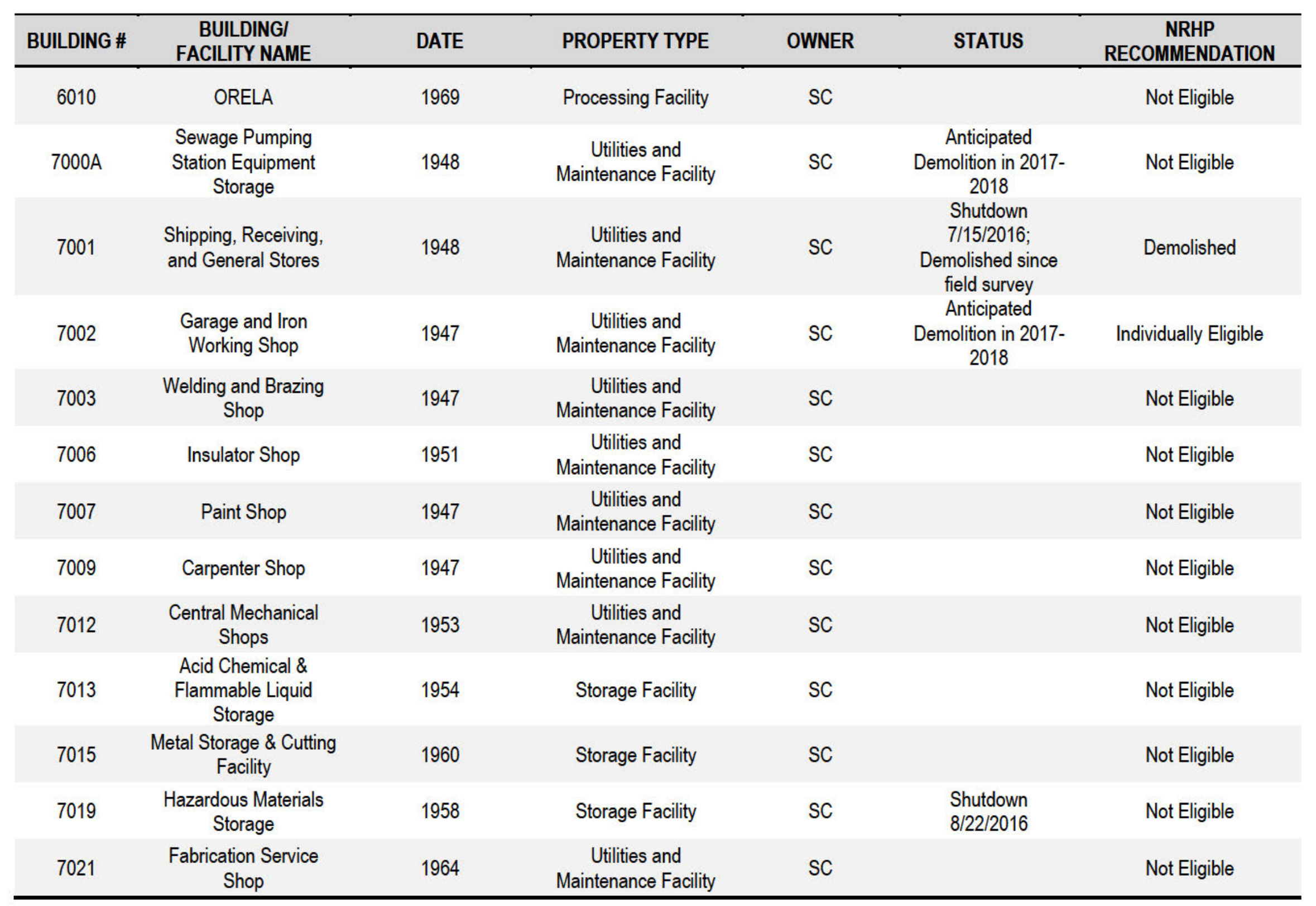




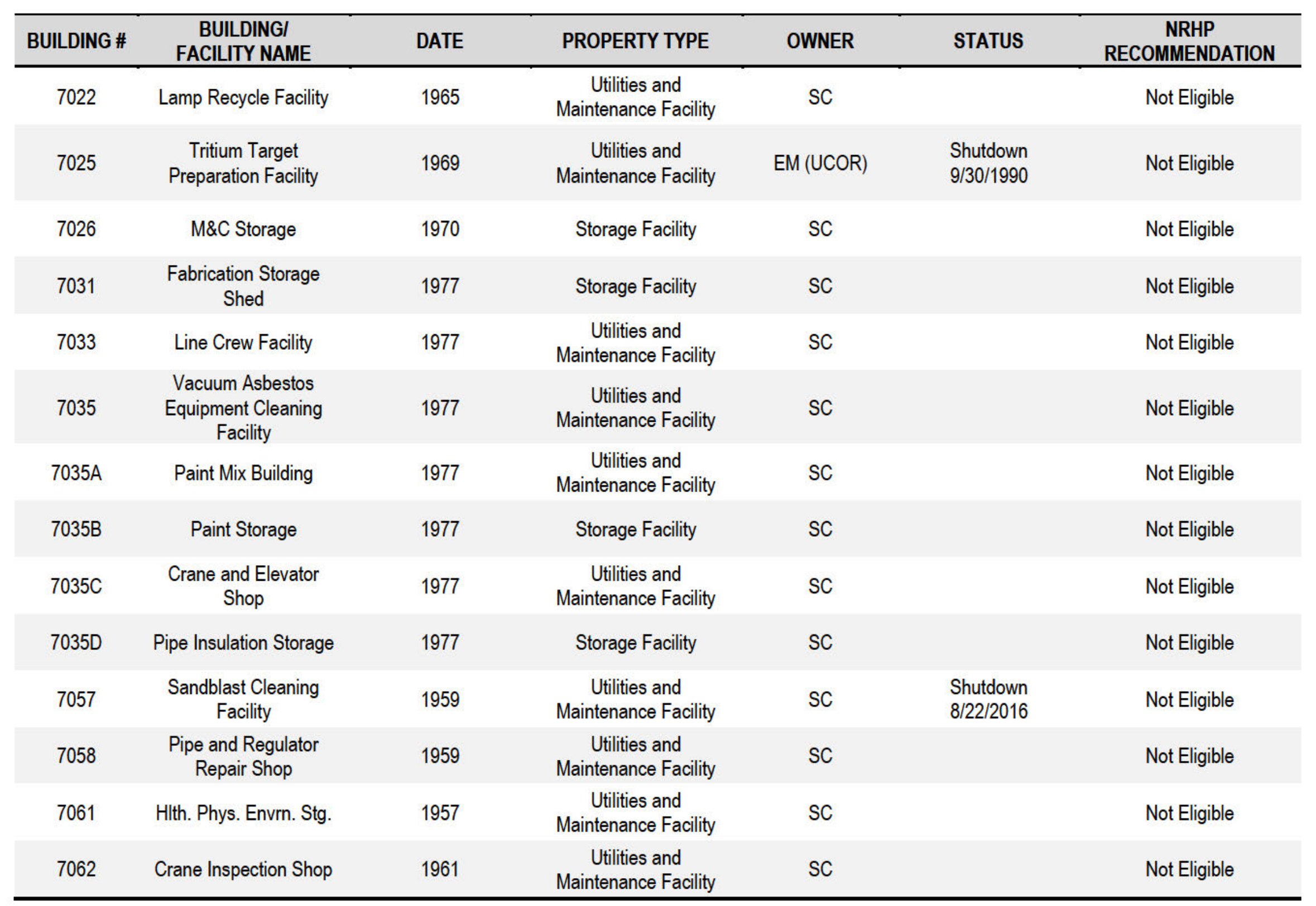




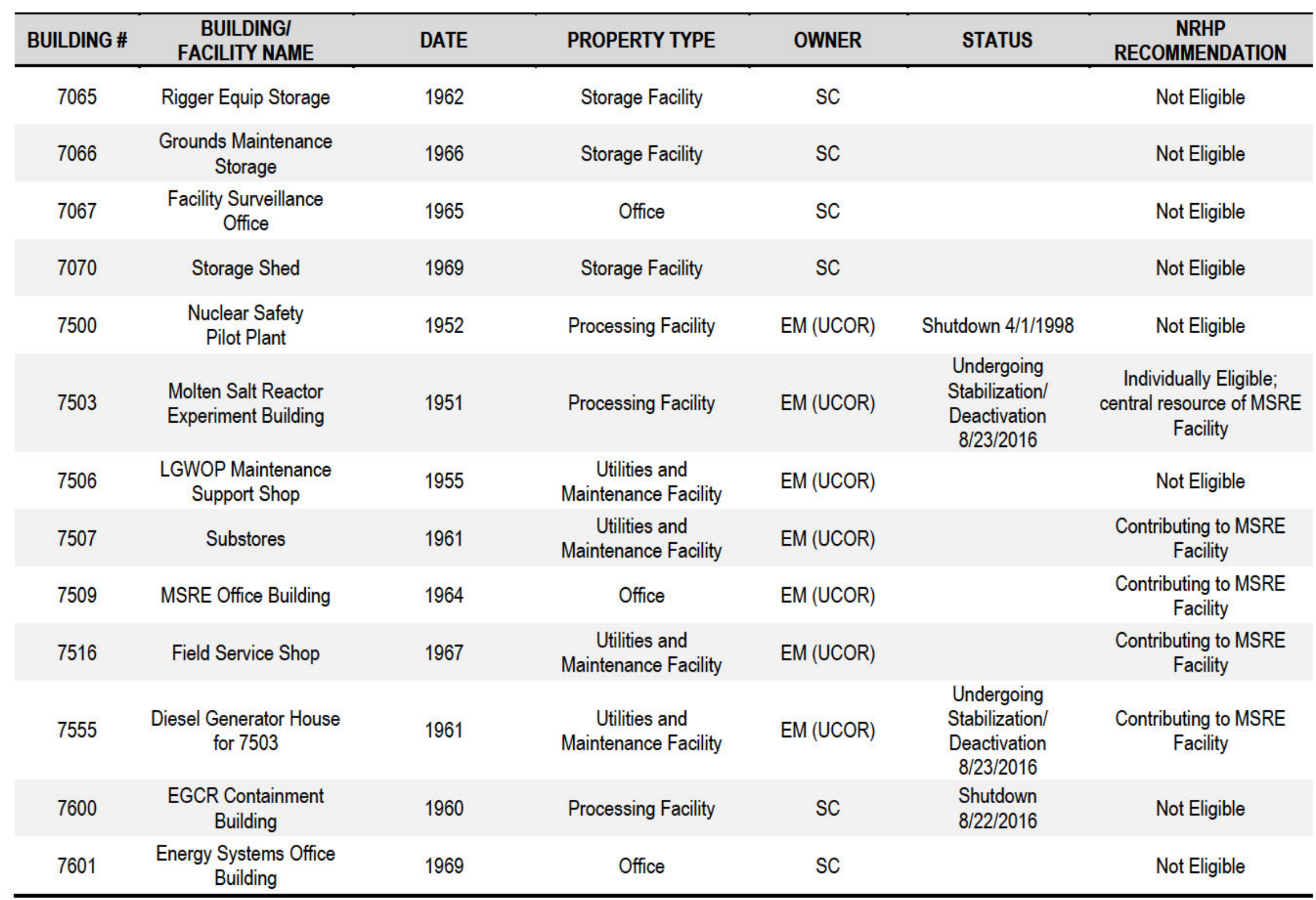




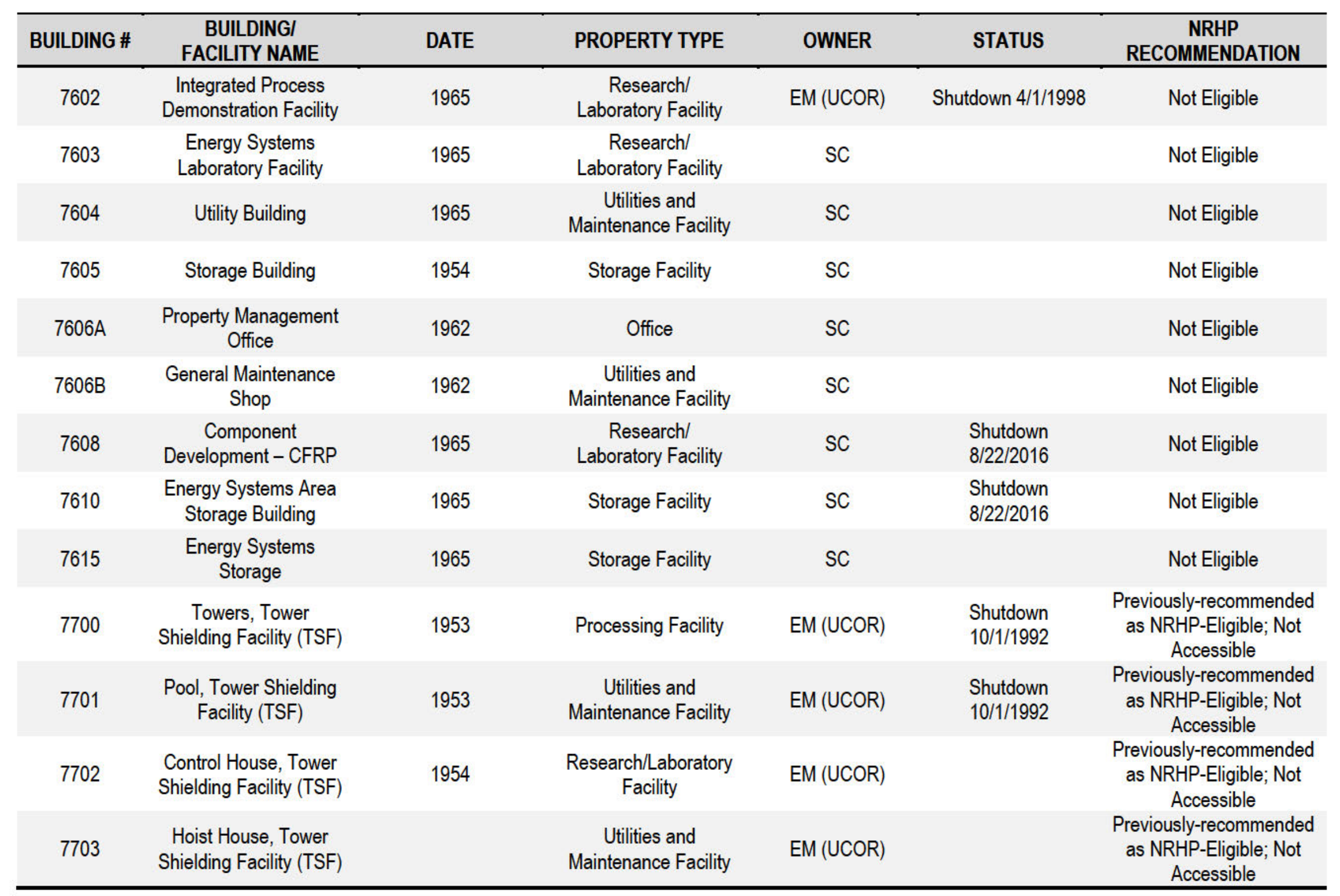




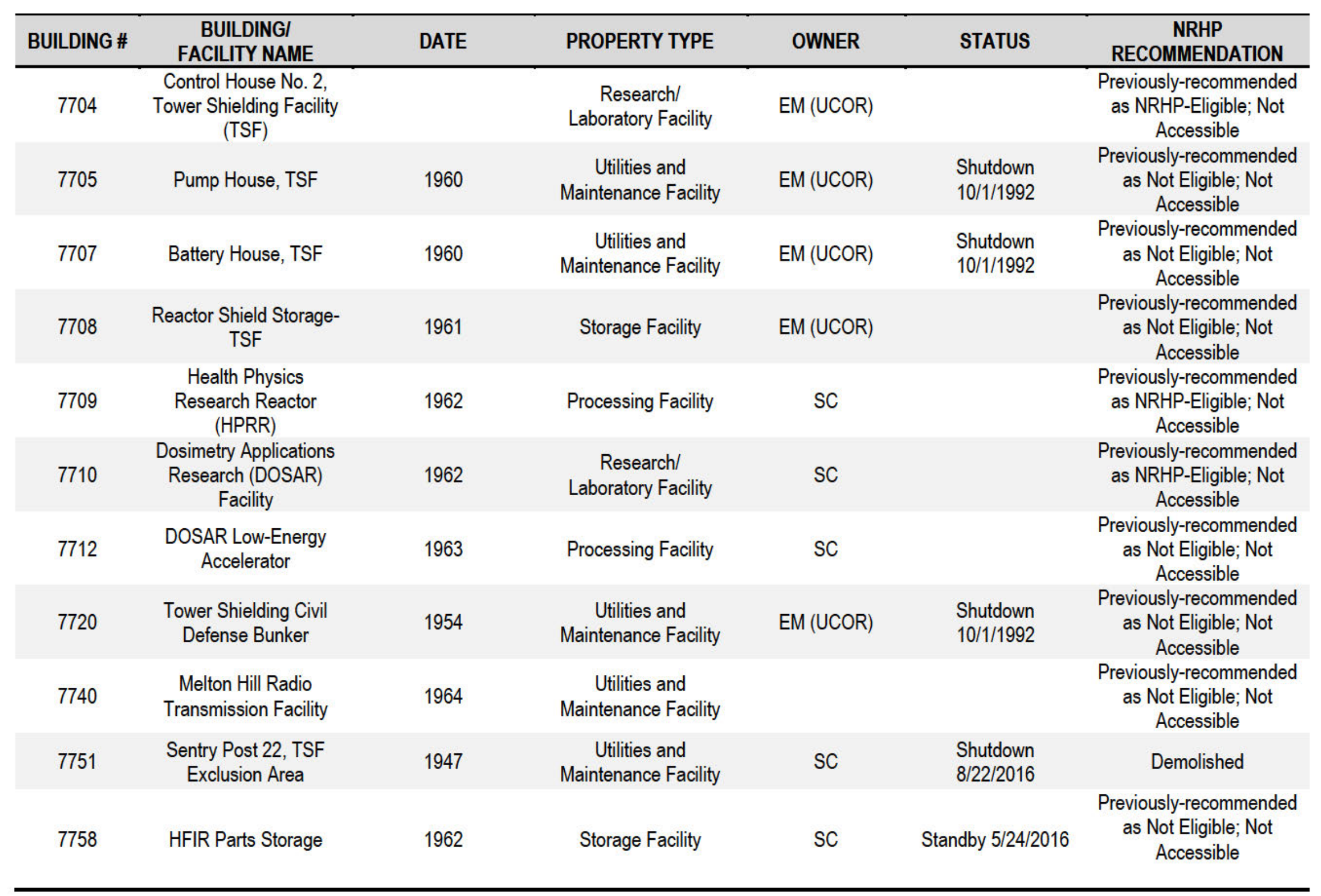




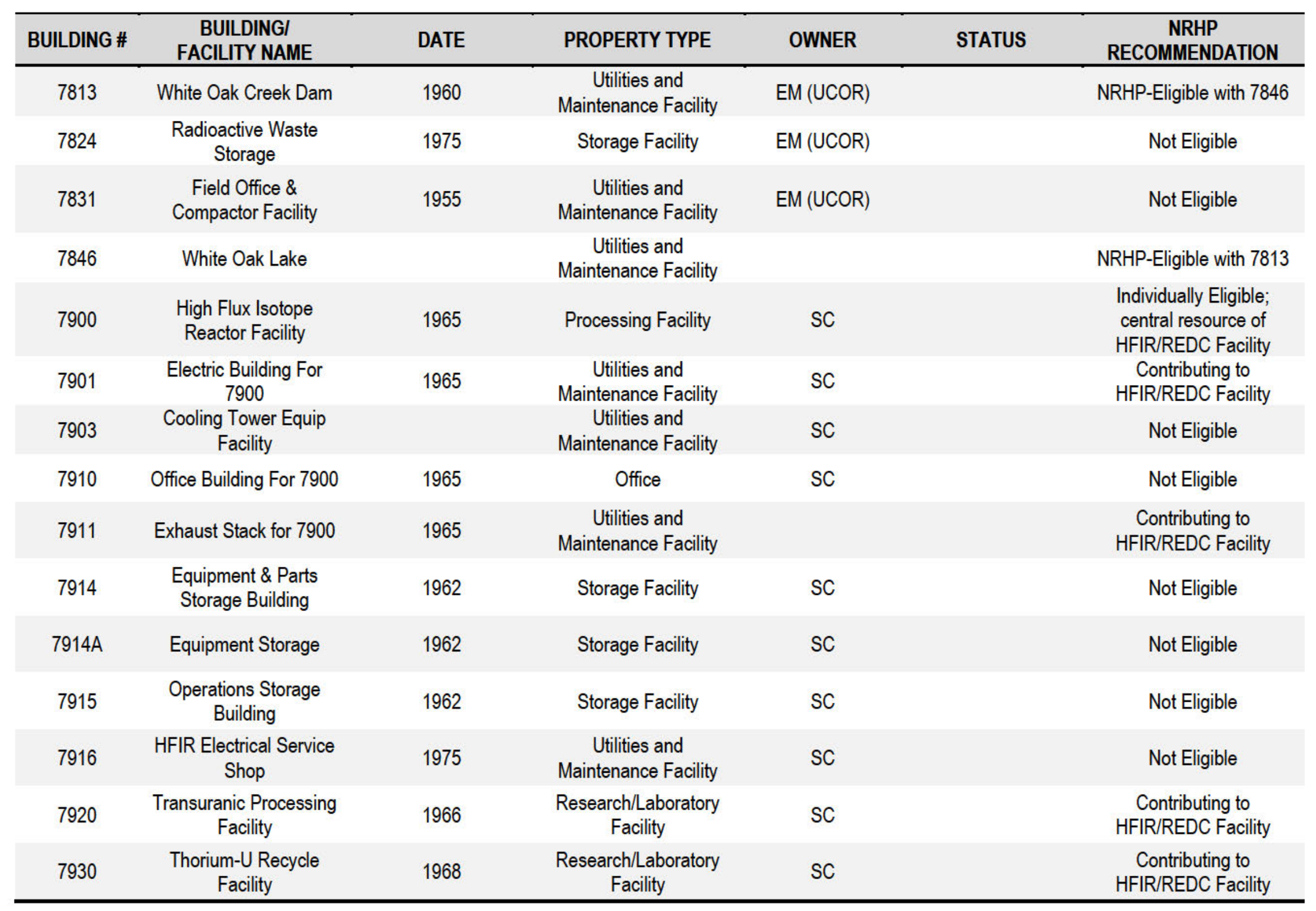

